\title{
ENVIRONMENTAL RESTORATION OF CONCRETE FLOOD-CONTROL CHANNELS
}

By

\begin{abstract}
Celia Wai-Man Fan
Master of Applied Science in Civil Engineering, Ryerson University, Toronto, Ontario, Canada (June 2004)

Bachelor of Engineering in Civil Engineering, Ryerson University, Toronto, Ontario, Canada (June 2002)
\end{abstract}

A dissertation

presented to Ryerson University

in partial fulfillment of the

requirements for the degree of

Doctor of Philosophy

in the Program of

Civil Engineering

Toronto, Ontario, Canada, 2012

(C) Celia Wai-Man Fan 2012 


\section{DECLARATION OF AUTHORSHIP}

I hereby declare that I am the sole author of this dissertation. This is a true copy of the dissertation, including any required final revisions, as accepted by my examiners.

I authorize Ryerson University to lend this dissertation to other institutions or individuals for the purpose of scholarly research.

I further authorize Ryerson University to reproduce this dissertation by photocopying or by other means, in total or in part, at the request of other institutions or individuals for the purpose of scholarly research.

I understand that my dissertation may be made electronically available to the public. 


\section{Environmental Restoration of Concrete Flood-Control Channels Doctor of Philosophy in the Program of Civil Engineering (2012) Celia Fan Ryerson University}

\section{ABSTRACT}

Many rivers and streams throughout the world in the past century were severely affected by human activities including water extraction, watershed land use changes, power generation, dam and levee construction. In highly urbanized cities, engineering practices advocate straightening, enlarging, and converting the natural rivers and streams into concrete channels to minimize flooding and erosion problems. These engineering design approaches destroy the natural equilibrium of the fluvial systems and eliminate the aquatic and riparian species in the watercourse. The objective of this research is to develop a general stream restoration design approach for flood control concrete channels in highly urbanized areas. The restoration goals are: 1) to create a natural and selfsustainable river system in order to re-establish the aquatic species on the flood control channel; 2) to provide appropriate in-stream covers, pools and riffles features for fish spawning and rearing; and 3) to maintain the flood control function after stream restoration.

There are four phrases involved in the design methodology of flood channels restoration: 1) identification of restoration goals, 2) stream assessment on the existing condition; 3) modification and verification of the low-flow channel design based on stream assessment findings; and 4) confirmation of the original flood control function. Yuen Long Nullah in Hong Kong will be used as a pilot site study 
to demonstrate the design framework. Meanders and deflectors will be applied to the low-flow channel modification design. A physical model representing an actual 2-metre wide meander channel section of the low-flow channel was constructed and experimented at The Hong Kong Polytechnic University's Hydraulics Laboratory. A numerical sediment transport model using the CCHE2D program was used to adjust the modification design and verify the flood control function. The pilot site has been tentatively demonstrated the restoration design approach developed in this research where deflectors are a major factor on pools creation. Moreover, a single deflector located along the inner curvature of the meander section with $1 / 3$ contraction ratio is proved to be the best design using the physical model. The numerical model using the CCHE2D program showed that the 7-block system can be used to model a deflector with porosity of $40 \%$. Numerical results also demonstrated that the bed material will not be totally flushed out after a severe thunder storm. 


\section{ACKNOWLEDGEMENTS}

The author would like to thank Dr. James Li and Dr. Grace Luk of Ryerson University, and Dr. Onyx Wai of The Hong Kong Polytechnic University for providing his encouragement, support and expertise throughout this dissertation.

Appreciation is extended to Hing Ge, technician of The Hong Kong Polytechnic University Hydraulic Laboratory, Chun-Ping Wu, Michael Yeung, Sherlock Au, Wan-Rong Liang, Yu Zheng, Honest Cheng, Ming-Liang Zhang, Jin-Shui Sun, Alen Chen and the support of The Hong Kong Polytechnic University Concrete Laboratory for the construction of the physical model and deflector, sediment collection, and the crushed concrete material support for the deflector.

The author would like to thank the funding support by Natural Science and Engineering Research Council. 


\section{DEDICATION}

This dissertation is dedicated to all my family and friends who have supported and encouraged me throughout my life . . . . Thank you very much everyone! 


\section{TABLE OF CONTENTS}

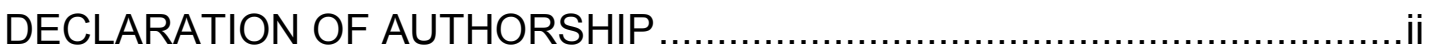

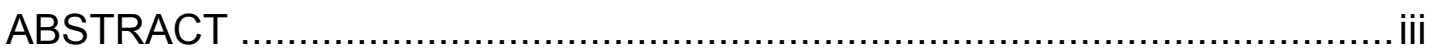

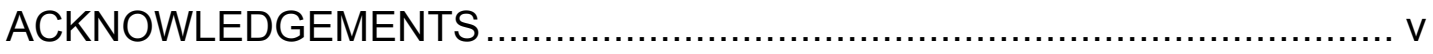

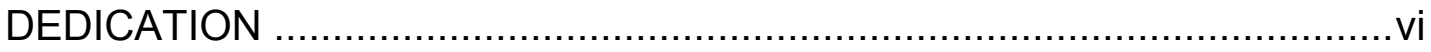

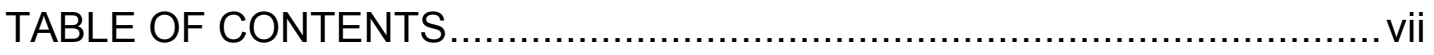

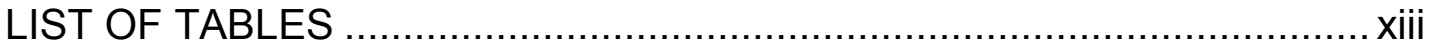

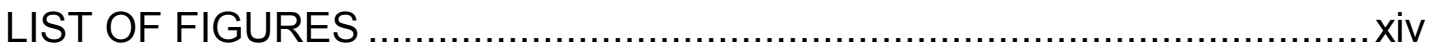

CHAPTER 1 INTRODUCTION ...................................................... 1

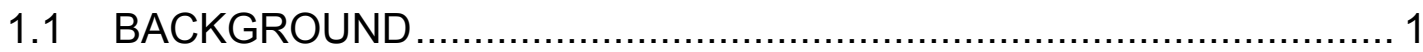

1.2 OVERVIEW OF PAST RIVER RESTORATION PROJECTS .............. 3

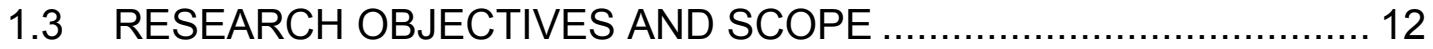

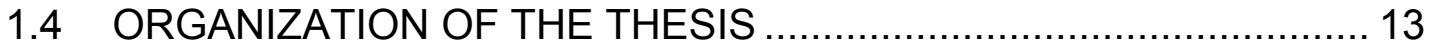

CHAPTER 2 LITERATURE REVIEW............................................... 14

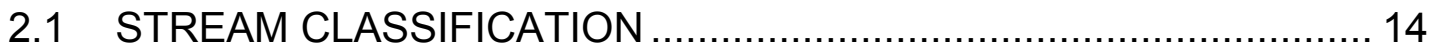

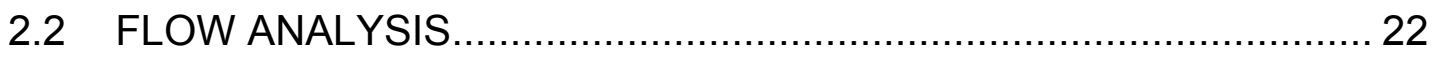

2.2.1 Flow Duration and Frequency ..................................... 22

2.2.2 Channel-Forming Discharge ...................................... 23

2.2.2.1 Bankfull Discharge ...................................... 24

2.2.2.2 Determination of Channel-Forming Discharge Using Specific Discharge Recurrence Interval......... 25

2.2.2.3 Effective Discharge .................................. 26

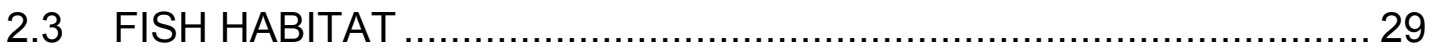

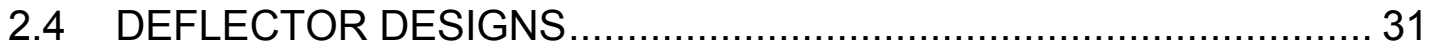

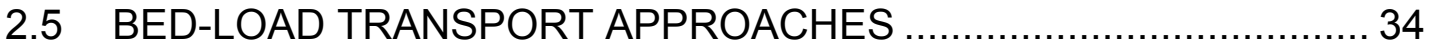


2.6 LOCAL SCOUR EVALUATION USING ABUTMENT

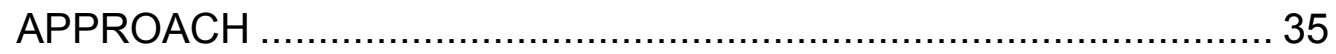

2.6.1 Basic Concepts of Scour Formation at Abutments ................ 35

2.6.1.1 Aggradation and Degradation ................................ 36

2.6.1.2 General Scour ................................................. 36

2.6.1.3 Local Scour............................................................... 36

2.6.1.4 Lateral Stream Migration ..................................... 37

2.6.2 Overview of Common Abutment Scour Equations ................. 38

2.6.3 Froehlich's or HIRE Abutment Scour Equations .................... 39

2.6.4 Maryland SHA Abutment Scour Evaluation Method .............. 42

2.7 NUMERICAL SOFTWARE INVESTIGATION ............................... 45

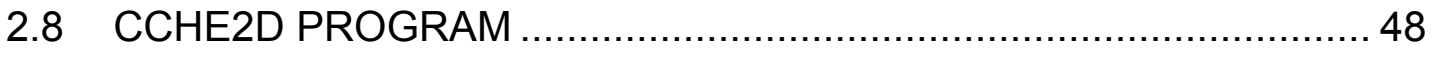

2.8.1 Mesh Generation ......................................................... 48

2.8.1.1 Algebraic Mesh Generation .................................. 49

2.8.1.2 Mesh Smoothness .............................................. 51

2.8.2 Hydrodynamic Governing Equations ................................. 52

2.8.2.1 Two-Dimensional $k-\varepsilon$ Model .................................. 53

2.8.3 Sediment Transport Governing Equations............................ 55

2.8.3.1 Non-Equilibrium Bed Load Transport Model............ 59

2.8.3.2 Channel Morphological Change ……....................... 62

2.8.3.3 Total-Load Transport Modelling Approaches........... 63

2.8.3.4 Non-Cohesive Sediment Transport Capacity........... 64

2.8.3.5 Bed Material Sorting ….......................................... 65

2.8.3.6 Boundary Conditions and Initial Conditions ............. 67

CHAPTER 3 RESTORATION APPROACH FOR CONCRETE FLOOD CONTROL CHANNELS..................................................... 69 
3.1 FRAMEWORK OF THE ENVIRONMENTAL RESTORATION

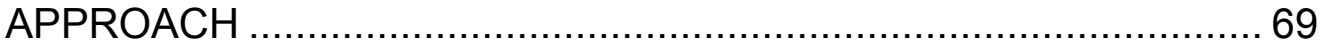

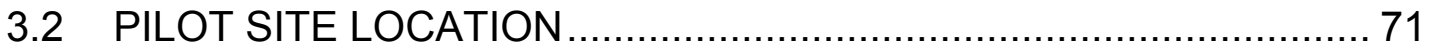

3.3 IDENTIFICATION OF RESTORATION GOALS ............................... 74

3.4 BACKGROUND INFORMATION COLLECTION ............................. 75

3.4.1 Sediment Sampling …...................................................... 75

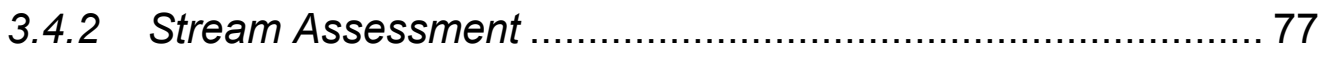

3.4.3 Aquatic Species Investigation............................................ 79

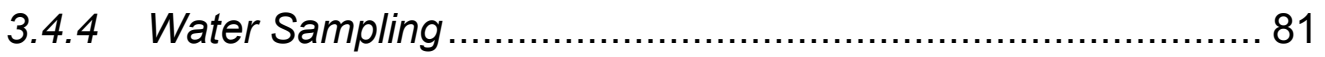

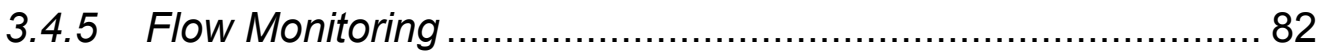

3.5 DISCUSSION OF STREAM ASSESSMENT ….............................. 83

CHAPTER 4 PHYSICAL MODEL EXPERIMENTS ............................... 84

4.1 DESIGN OPTIONS OF THE PHYSICAL MODEL …........................ 84

4.2 ESTIMATION OF WATER DEPTH IN DRY WEATHER

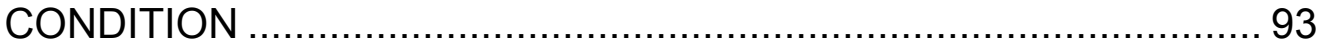

4.3 ESTIMATION OF FLOW RATES UNDER WET WEATHER

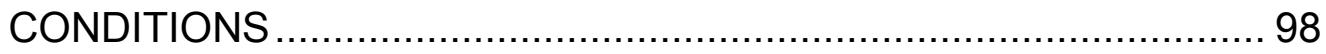

4.4 CONSTRUCTION OF THE PHYSICAL MODEL ….......................... 98

4.5 MODIFICATION OF THE PHYSICAL MODEL ............................... 106

4.6 DESIGN OF THE PHYSICAL EXPERIMENTS ............................. 110

4.6.1 Dry Weather Condition .................................................. 110

4.6.2 Wet Weather Condition Without Incoming Sediment............ 112

4.6.3 Wet Weather Condition With Incoming Sediment................. 121

4.7 PREPARATION OF THE PHYSICAL EXPERIMENTS ................... 122

4.7.1 Sediment Collection and Preparation ............................... 122

4.7.2 Estimation of Inception Velocity...................................... 124 
4.7.3 Porosity in the Deflector 126

4.7.4 Measuring Devices Involved in the Physical Experiments 127

4.8 PROCEDURES OF THE PHYSICAL EXPERIMENTS .................... 131

4.9 DISCUSSION OF THE PHYSICAL EXPERIMENTS …................... 135

4.9.1 Experimental Results on Dry Weather Conditions................ 135

4.9.2 Experimental Results on Wet Weather Condition without Incoming Sediment-Single Deflector. 136

4.9.3 Experimental Results on Wet Weather Condition without Incoming Sediment-Double Deflectors 143

4.9.4 Experimental Results for Wet Weather Conditions with Incoming Sediment-Single Deflector....

4.10 UNCERTAINTIES IN THE PHYSICAL EXPERIMENTS .................. 148

CHAPTER 5 NUMERICAL MODEL EXPERIMENTS 151

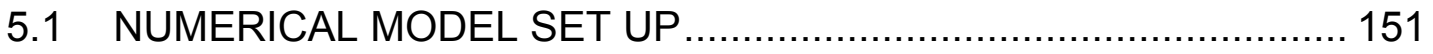

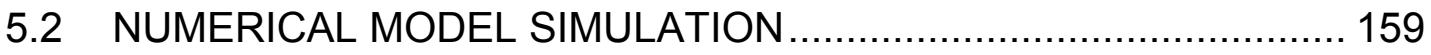

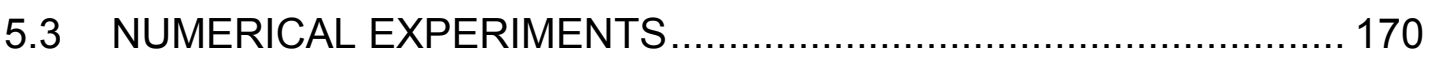

5.3.1 Low-Flow Channel Modification Design.............................. 170

5.3.2 Numerical Experiments Set Up ..................................... 176

5.4 RESULTS AND ANALYSIS OF THE NUMERICAL

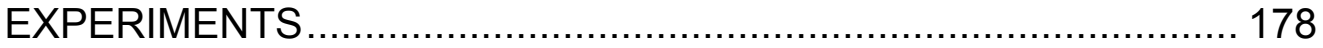

5.5 DISCUSSION ON THE NUMERICAL EXPERIMENTS ................... 187

CHAPTER 6 VALIDATION OF FLOOD CONTROL FUNCTIONS ....... 191

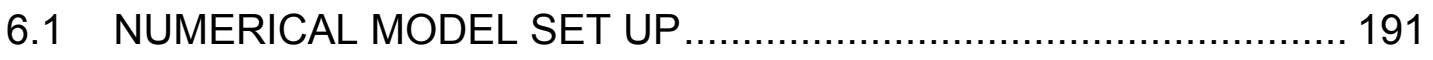

6.1.1 Modification of the Numerical Model ................................. 195

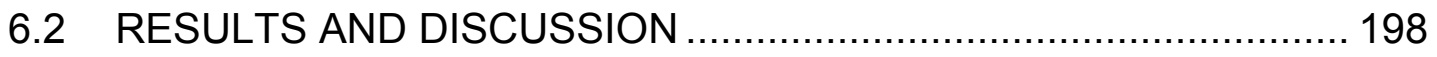

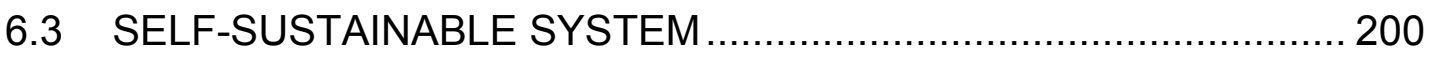


CHAPTER 7

CONCLUSION

7.1 CONCLUSION

202

7.2 FUTURE WORKS

204

REFERENCES

APPENDIX A Particle Size Distribution Analysis of Soil Samples Collected at the Pilot Site

APPENDIX B British Standards BS 1377-2: 1990 (clause 9.2 \& 9.3)

APPENDIX C Site Assessment on January 16 of 2008

APPENDIX D Calibration Between Propeller Velocity Flow Meter and Acoustic Doppler Velocimetry (ADV)

APPENDIX E Determination of Suspended Particles Concentration

APPENDIX F Metal Analysis on Water Samples

APPENDIX G Hong Kong Water Pollution Control Ordinance Cap 358

Section 21 "Technical Memorandum Standards for Effluents Discharged into Drainage and Sewerage Systems, Inland and Coastal Waters"

APPENDIX H Selective Sections of Black \& Veatch's Flow Monitoring Report

APPENDIX J Determination of Longitudinal Slope on the Upstream Section of Yuen Long Nullah

APPENDIX K Specific Gravities of Common Plastic Materials

APPENDIX L Guides from FHWA of Selecting Manning's $\boldsymbol{n}$ for Natural Channels and Floodplains

APPENDIX M Determination of the Porosity of the Deflectors

APPENDIX N Bed Load Estimation 
APPENDIX P Experimental Results of Single Deflector Scenarios for Wet Weather Conditions Without Incoming Sediment

APPENDIX Q Experimental Results of Double Deflector Scenarios for Wet Weather Conditions Without Incoming Sediment

APPENDIX $\mathbf{R}$ Experimental Results for Wet Weather Conditions With Incoming Sediment

APPENDIX S Abutment Calculation

APPENDIX T Numerical Results (without Incoming Sediment)

APPENDIX U Numerical Results (with Incoming Sediment)

APPENDIX V Abutment Scour Depth Estimation at Water Depth $=\mathbf{4 0}$ cm of Low-Flow Channel

APPENDIX W Numerical Software Review 


\section{LIST OF TABLES}

$\underline{\text { Table }} \underline{\text { Title }}$

Page

1 Abutment shape coefficients (Richardson and Davis, 2001).

2 Overview of 2D sediment transport models (Papanicolaou et. al. 2008; Garcia, 2008).

3 Applications for selected models in Table 2 (Garcia, 2008).

$4 \quad$ Average particle size distribution of the soil samples data on Nov 20, 2007.

5 Average particle size distribution of the proposed PVC flexible balls.

6 Values of Manning's roughness coefficients (Chow, 1959).

7 Estimation of water level at dry weather condition after low-flow channel restoration.

8 Estimation of flow rates at different water levels after low-flow channel restoration.

9 Physical Experiments for Dry Weather Condition.

10 Physical experiments for wet weather condition without incoming sediment.

11 Estimation of inception velocity. 125

12 Experimental results of single deflector scenario (Experiment \#B1, \#B3, \#B5, and \#B7).

13 Parameters involved in the CCHE-GUI program 155

14 Inlet flow rates input to the numerical model at various water depths within the low-flow channel (LFC).....

15 Numerical results for no incoming sediment scenario. 185

16 Numerical results for incoming sediment scenario. 185

17 Numerical results for deflector and bed material design scenario at $5 \mathrm{~cm}$ below bankfull of LFC condition.

18 Inlet flow rates input to the numerical model at various water depths in the flood channel (FC). 


\section{LIST OF FIGURES}

\section{Figure $\underline{\text { Title }}$}

1 Structure applied in the late 1980's to straighten a section of the natural stream in Mississauga, Ontario, Canada.

2 Close-up on Figure 1. Structure is severely undermined due to erosion problems and will likely collapse in the future.

3 Concrete trapezoidal channel in Colonial Creek, Waterloo, Ontario, Canada before the restoration project (Harrington, 2003).

$4 \quad$ Photo taken at a similar spot to Figure 3, showing the end products, the natural channel and flood plain, of the restoration project (Harrington, 2003).

5 Plan of river restoration project of the River Cole in Coleshill, Buckinghamshire, England (Burns, 2002).

6 The new meandering river course and the restored meander in the mill leat (Burns, 2002)

7 Cheonggyecheon Stream was covered by roads and elevated highway before restoration project ${ }^{2}$.

8 Removal of the elevated highway and dewatering the Cheonggyecheon Stream during reconstruction ${ }^{2}$.

9 Meanders created by concrete banks in Cheonggyecheon Stream after the completion of the restoration ${ }^{2}$.

10 Photo taken upstream of Figure 11, applying armor stones along the banks ${ }^{2}$.

11 Applied Armour stones on nick point to slow down flow velocity ${ }^{2}$.....10

12 Design approach for flood channel restoration. ................................13

13 Stream ordering in a drainage network (USDA, 2001)....................15

14 Schumm's stream classification system (Schumm, 1977) ...............17

15 Montgomery and Buffington's stream classification system (Montgomery and Buffington, 1993). .......................................18

16 Rosgen's Stream assessment framework (Rosgen, 1996)...............19

17 Rosgen's stream classification system (Rosgen, 1996)..................20

18 Definition of stream pattern (Doll et al., 2003)................................20 
$\underline{\text { Figure }} \underline{\text { Title }} \quad \underline{\text { Page }}$

19 Soar and Thorne's geomorphic appraisal (USDA, 2001) ................21

20 Effective discharge determination (Wolman and Miller, 1960) ..........27

21 Deflector design in Thompson (2002) studies.................................31

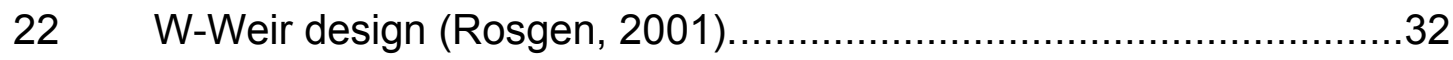

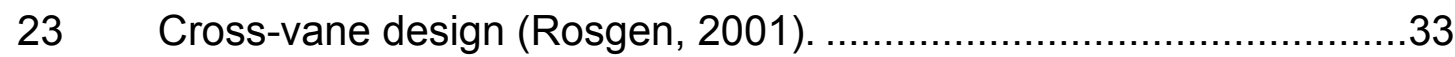

$24 \quad$ J-Hook vane design (Rosgen, 2001). ..........................................33

$25 \quad$ Abutment shapes (Richardson and Davis, 2001)............................40

26 Orientation of embankment angles, $\theta$, to the Flow (Richardson

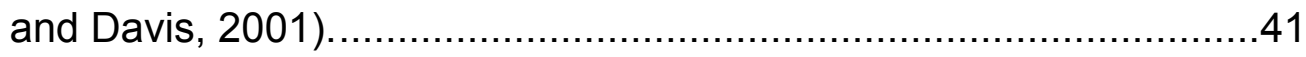

27 Definition sketches for scour predictions (Richardson and Davis,

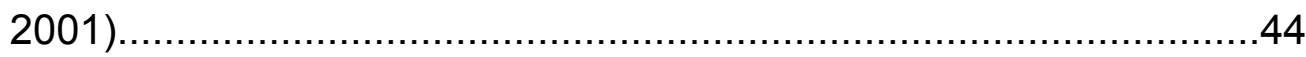

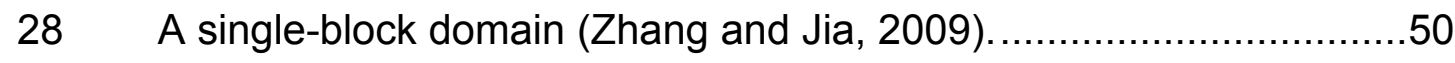

29 Vertical schematization of the sediment-processes domain

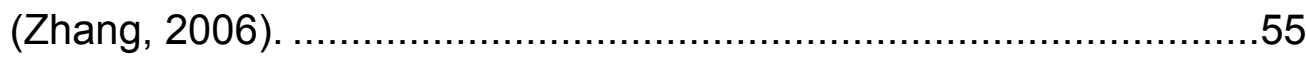

30 Multiple-Layer Sorting Model for Bed Material Gradation (Zhang,

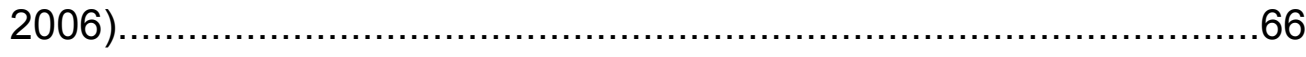

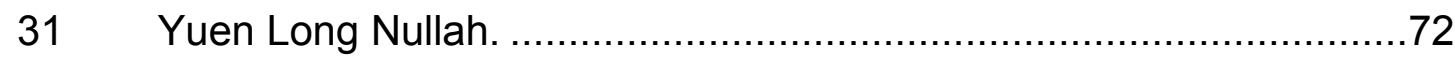

32 Close shot on the upstream of Yuen Long Nullah...........................73

33 Locations of soil samples collection............................................

34 Particle size distribution of soil samples collected on Nov 20 of

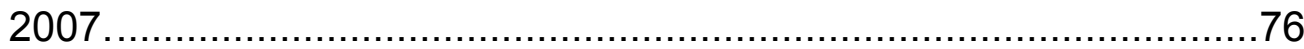

35 Radius of curvature of the stream in the natural area.....................78

36 Closed view of the low-flow channel of Yuen Long Nullah.................79

37 Fish habitat found (red circle) in the natural area near the upstream section of Yuen Long Nullah during preliminary site

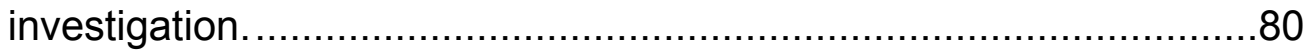

38 Malaysian trumpet snails found during the site assessment.............81

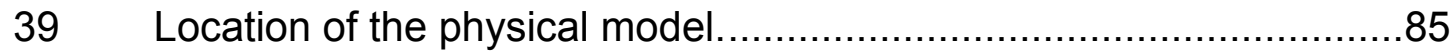

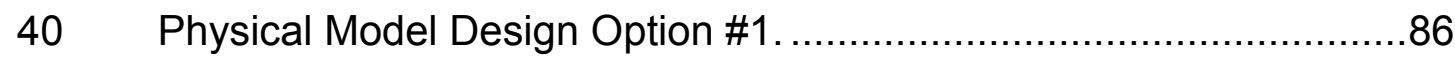

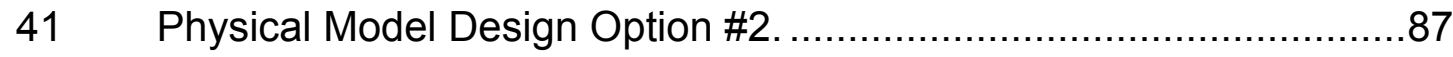

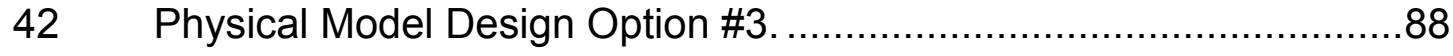


$\underline{\text { Figure Title }} \quad$ Page

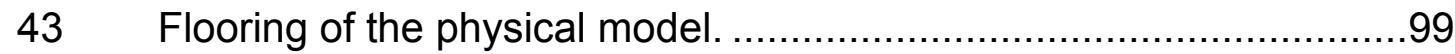

$44 \quad$ Construction process (1) of the physical model. ...............................99

$45 \quad$ Construction process (2) of the physical model. .............................100

$46 \quad$ Construction process (3) of the physical model. ...........................100

47 Rectangular adjustable weir at the outlet of the physical model. .....101

$48 \quad$ Sediment bed preparation ramp. ..........................................102

49 Deflector design with intended vegetation establishment. ...............103

$50 \quad$ Deflector of the physical experiments........................................104

51 Incoming sediment feeder Design Option \#1 ...............................105

52 Incoming sediment feeder Design Option \#2.................................105

53 General flow pattern during the trial experiment. .........................107

54 Flow pattern near the bank at the right-side (facing upstream) during the trial experiment. .....................................................107

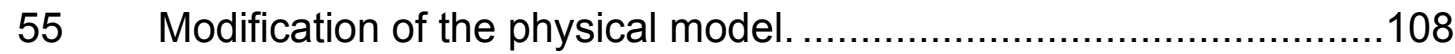

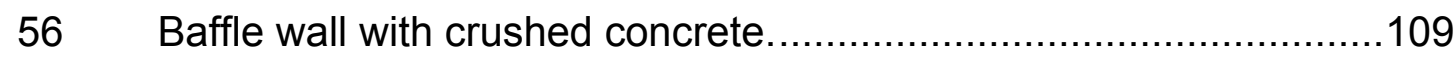

$57 \quad$ Baffle wall with rounded pebble stones........................................109

58 Deflector configurations for physical experiments \#B1 to \#B8 .........114

59 Deflector configurations for physical experiments \#B9 to \#B10.......116

60 Deflector configurations for physical experiments \#B11 to \#B12 ....118

61 Deflector configurations for physical experiments \#B13 to \#B14 ....119

62 Deflector configurations for physical experiments \#B15 to \#B16 .....120

63 Sediment collection at the natural area of the pilot site...................122

64 Preliminary screening of the sediment.......................................123

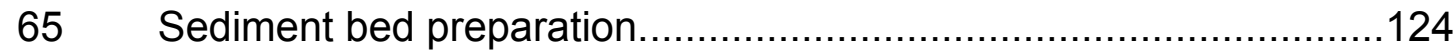

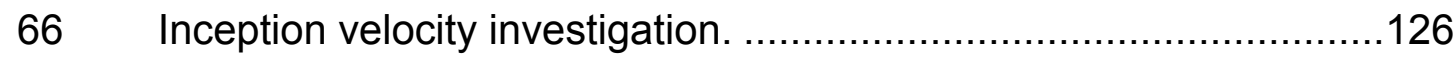

67 Flow meter with sensor connected to the inlet pipe of the holding

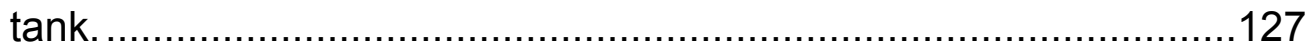

68 Flow meter connected to the discharge pipe of the pump...............128

69 Four-port ADV used for the velocity profile measurement. ..............129

70 Sediment profile measurement using a height gauge .....................130 
$\underline{\text { Figure Title }} \quad$ Page

$71 \quad$ Filling water to the physical model from the outlet drop.................132

72 Bed profile for Experiment \#B7 after 21-hour run. .........................137

73 Scour formation at different time periods for Experiment \#B7 and \#B5.

74 Scour formation at different time periods for Experiment \#B3 and \#B1.

75 Sketch of the physical model in the AutoCAD LDD program...........153

76 Preparation of channel block and deflector block in CCHE-MESH program.

77 Mesh generation in CCHE-MESH program. ...............................154

78 Bed profile for the solid deflector calibration scenario at time $\approx$ 24-hr.

79 Bed profile for the 3-blocks deflector calibration scenario at time $\approx 24-h r$.

80 Bed profile for the 7-blocks deflector calibration scenario at time $\approx 24-h r$.

81 Bed change for the solid deflector calibration scenario at time $\approx 24-\mathrm{hr}$.

82 Bed change for the 3-blocks deflector calibration scenario at time $\approx 24-$ hr.

83 Bed change for the 7-blocks deflector calibration scenario at time $\approx 24-\mathrm{hr}$.

84 Velocity profile of the solid deflector calibration scenario at time $\approx 24-\mathrm{hr}$.

85 Velocity profile of the 3-blocks deflector calibration scenario at time $\approx 24-h r$.

86 Velocity profile of the 7-blocks deflector calibration scenario at time $\approx 24-\mathrm{hr}$.

87 Preliminary design of the low-flow channel modificationoption (1). 
88 Preliminary design of the low-flow channel modification-

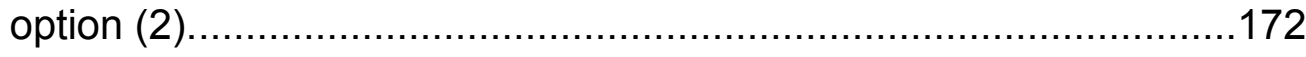

Figure Title

Page

89 Final design of the low-flow channel modification. ...........................173

90 The setup of the elongated block in the CCHE2D program. ............175

91 Boundary setup for the flood condition in CCHE2D program...........194

92 Bed elevation input parameter set up in Approach \#3. ...................197

93 Plants grew along the inner curvature while conducting the

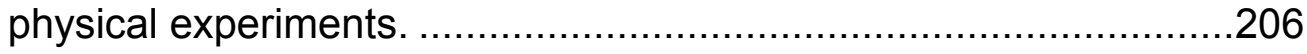




\section{CHAPTER 1 INTRODUCTION}

\subsection{BACKGROUND}

In the past century, many rivers and streams throughout the world have been severely affected by human activities including water extraction, watershed land use changes, navigation, power generation, dam and levee construction, etc. Past engineering practices advocated straightening, hardening, and enlarging natural rivers and streams to minimize flooding and erosion problems. In highly urban areas, many natural rivers and streams have been converted into concrete channels in order to maximize the efficiency of conveying the floodwaters away from populated areas. However, these engineering design approaches tend to disrupt the natural equilibrium of the fluvial systems, resulting in a number of negative impacts such as bed aggradation, erosion, and frequent flooding problems (Figure 1 and Figure 2). Past research suggests that the geomorphology of stream channels is defined by the balance among erosion, transport and deposition of sediment, which is an inherent property of natural fluvial systems. Additionally, spatial and temporal heterogeneity in rivers and streams are collectively known as channels for macro-invertebrates and fish species. With a growing awareness of the value of natural ecosystems, a move has been started from manipulation and control of rivers to restoration and conservation (Biron et al., 2005; Bockelmann et al., 2004; Ness and Joy, 2002; MTO, 1997). 


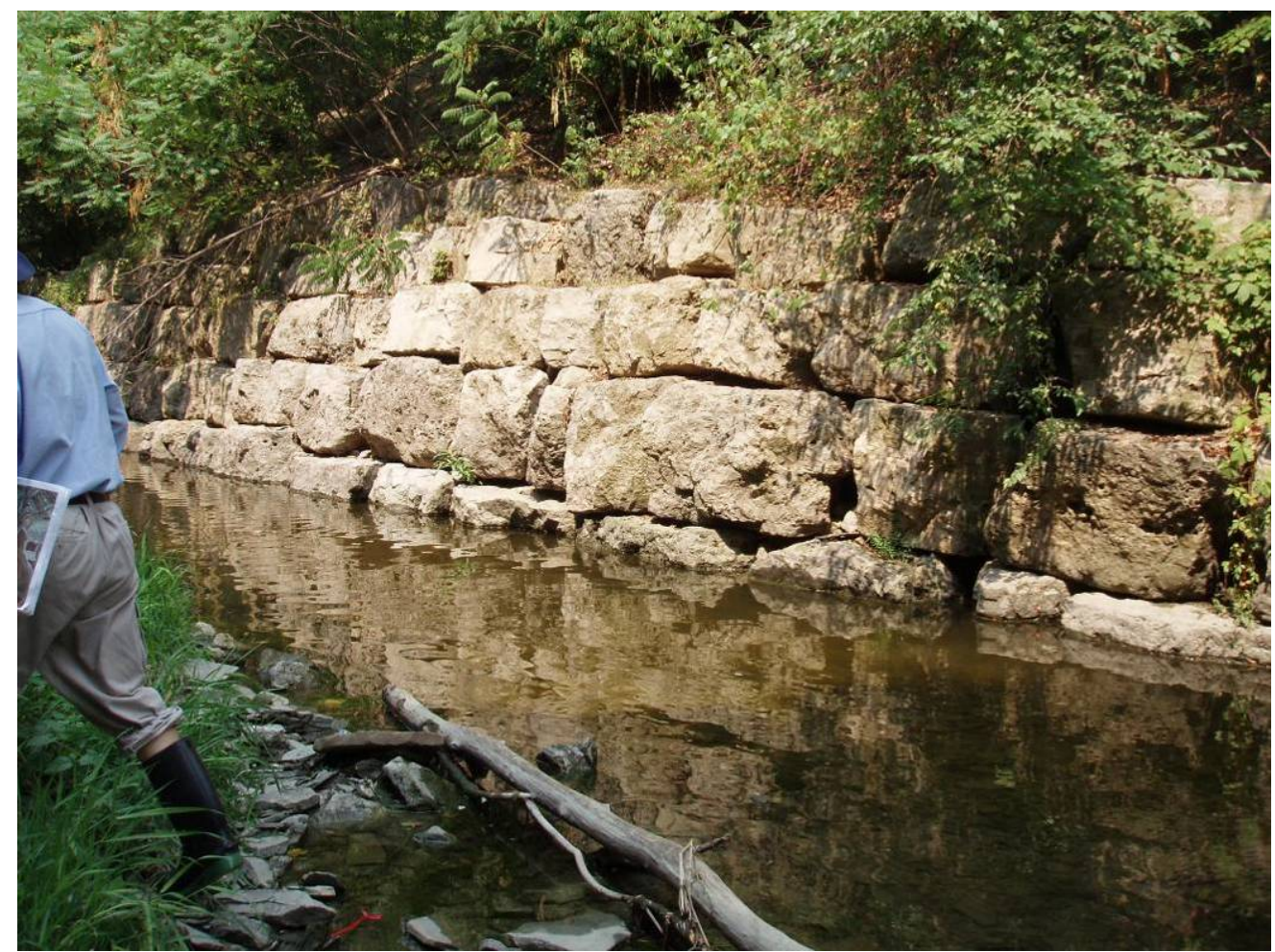

Figure 1: Structure applied in the late 1980's to straighten a section of the natural stream in Mississauga, Ontario, Canada.

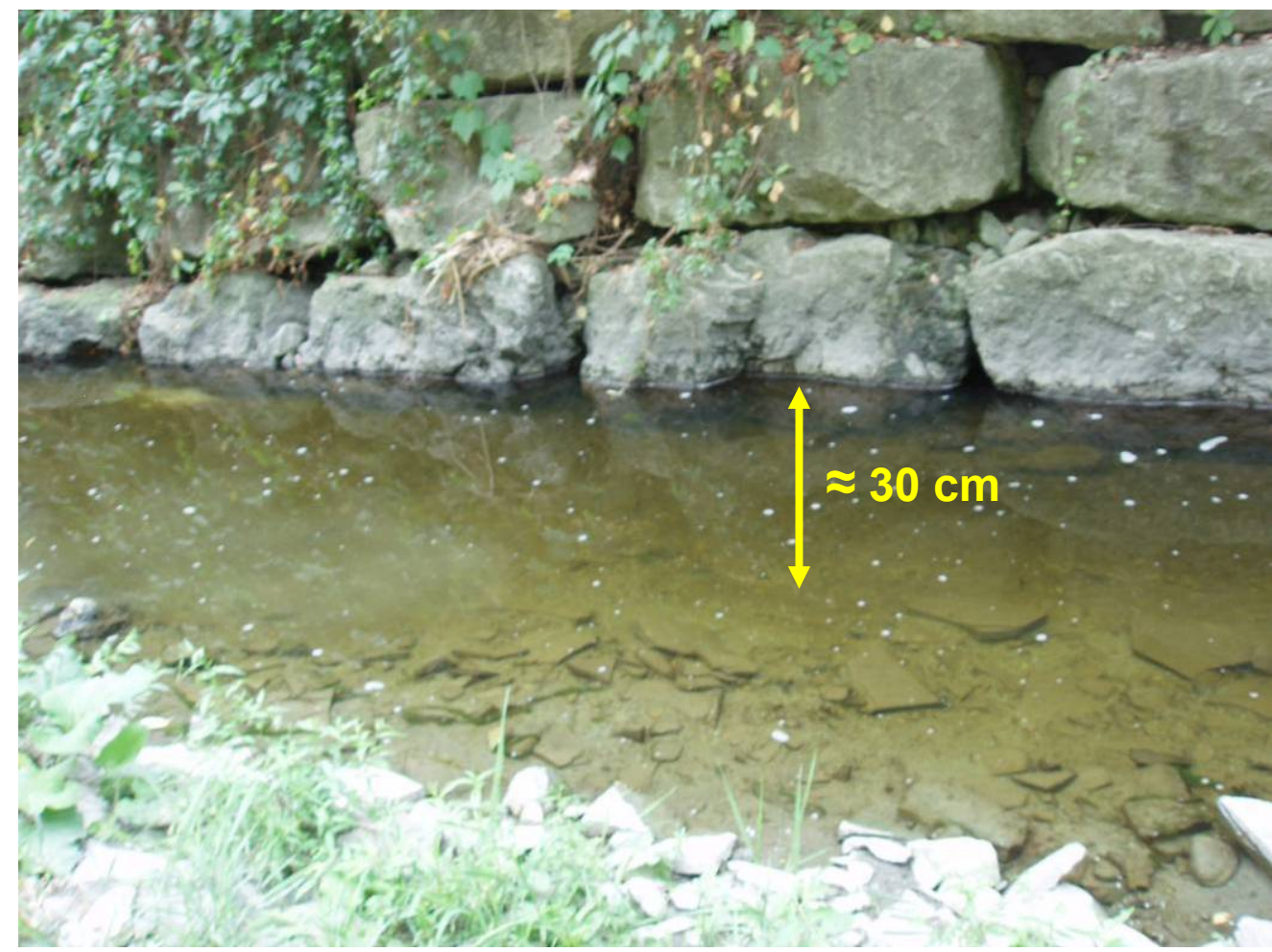

Figure 2: Close-up on Figure 1. Structure is severely undermined due to erosion problems and will likely collapse in the future. 
Fluvial geomorphology is the study of rivers' materials, forms and processes to produce designs that are in balance with natural processes and sustainable in the long term. This natural channel design approach, which involves realignment of rivers and streams with forms that emulate the natural watercourses, has been increasingly applied throughout the world over the past decade for the restoration of degraded streams, particularly in urban areas. The purpose of this practice is to achieve a self-regulating stability of form that characterizes natural rivers and streams in order to reduce damage to property and infrastructure and improve the aesthetic value and ecosystem function of the watercourse (Ness and Joy, 2002; Rosgen, 1994; Doll et al., 2003).

The following section provides an overview of various stream and river restoration projects around the world in the past decade.

\subsection{OVERVIEW OF PAST RIVER RESTORATION PROJECTS}

\section{Colonial Creek in Waterloo, Ontario}

Colonial Creek in Waterloo, Ontario, Canada was the first project in Ontario that involved the removal of a concrete trapezoidal channel and the restoration of a natural channel and flood plain (Figure 3 and Figure 4). Waterloo is a largely suburban city, with a population of approximately 97500 , located in southern

Ontario. The creek flows through an older, developed section of the city with some upstream stormwater quantity controls. The restoration project was 
initiated by the Upper Thames River Conservation Authority involving with the excavation of flood plain and the creation of a meandering ' $C$ ' channel from Rosgen's Natural Channel Design Method (Rosgen, 1994, 2006, 2006a) with a balanced pool-riffle sequence. Fascines, brush mattresses and river stone bed material were used to stabilize the channel and the flood plain. This restoration project is an early example of how a concrete channel can become a candidate for naturalization. It was successful due to the available space along the concrete channel corridors (Figure 3). Flood plain connection (Figure 4) is the key for this project to enable the stream to capture the remaining runoff when the natural channel exceeds the bankfull discharge conditions. Unfortunately, biological or water quality monitoring was not available at this site to aloe calculation of support the improvement of the fluvial system (Harrington, 2003).

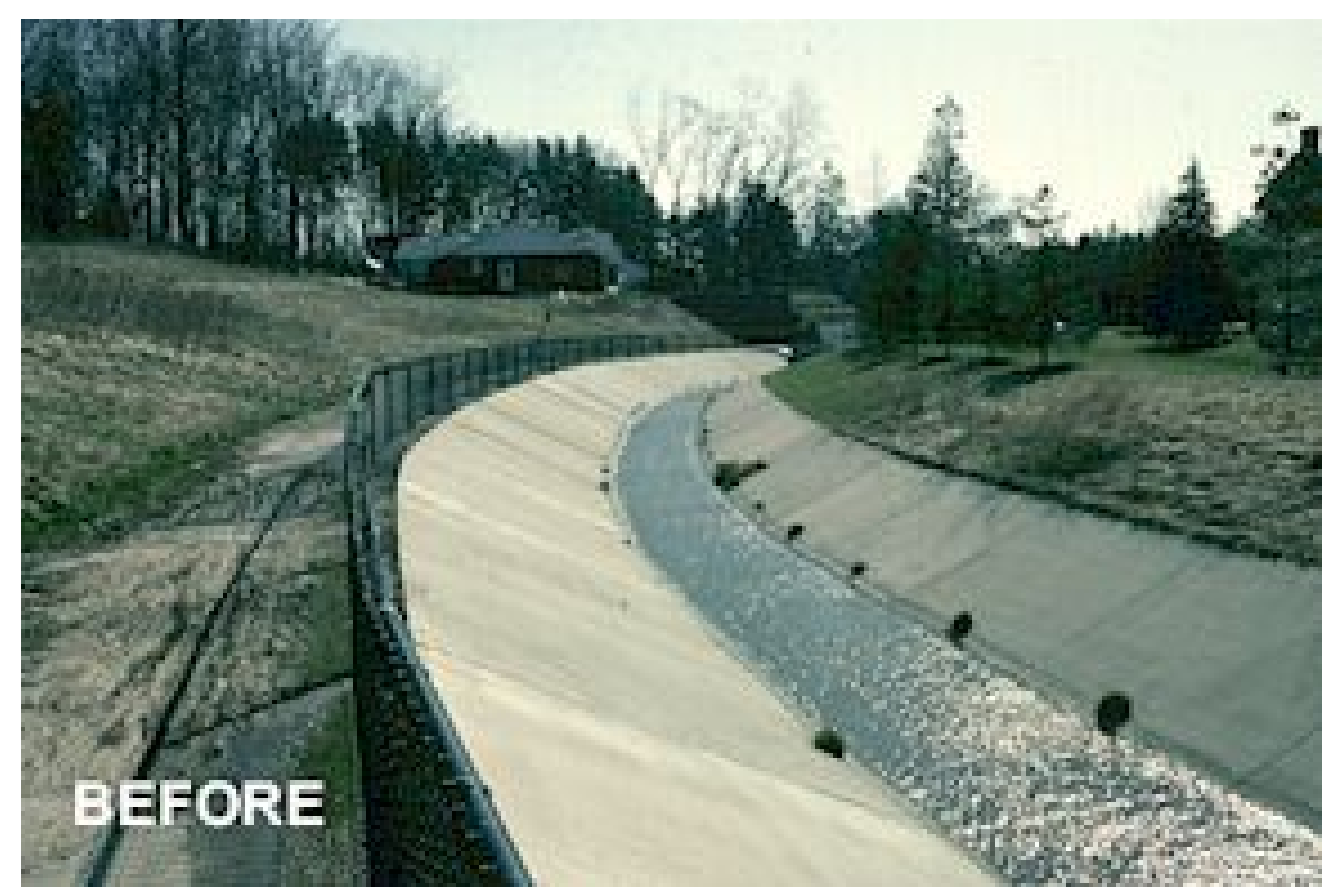

Figure 3: Concrete trapezoidal channel in Colonial Creek, Waterloo, Ontario, Canada before the restoration project (Harrington, 2003). 


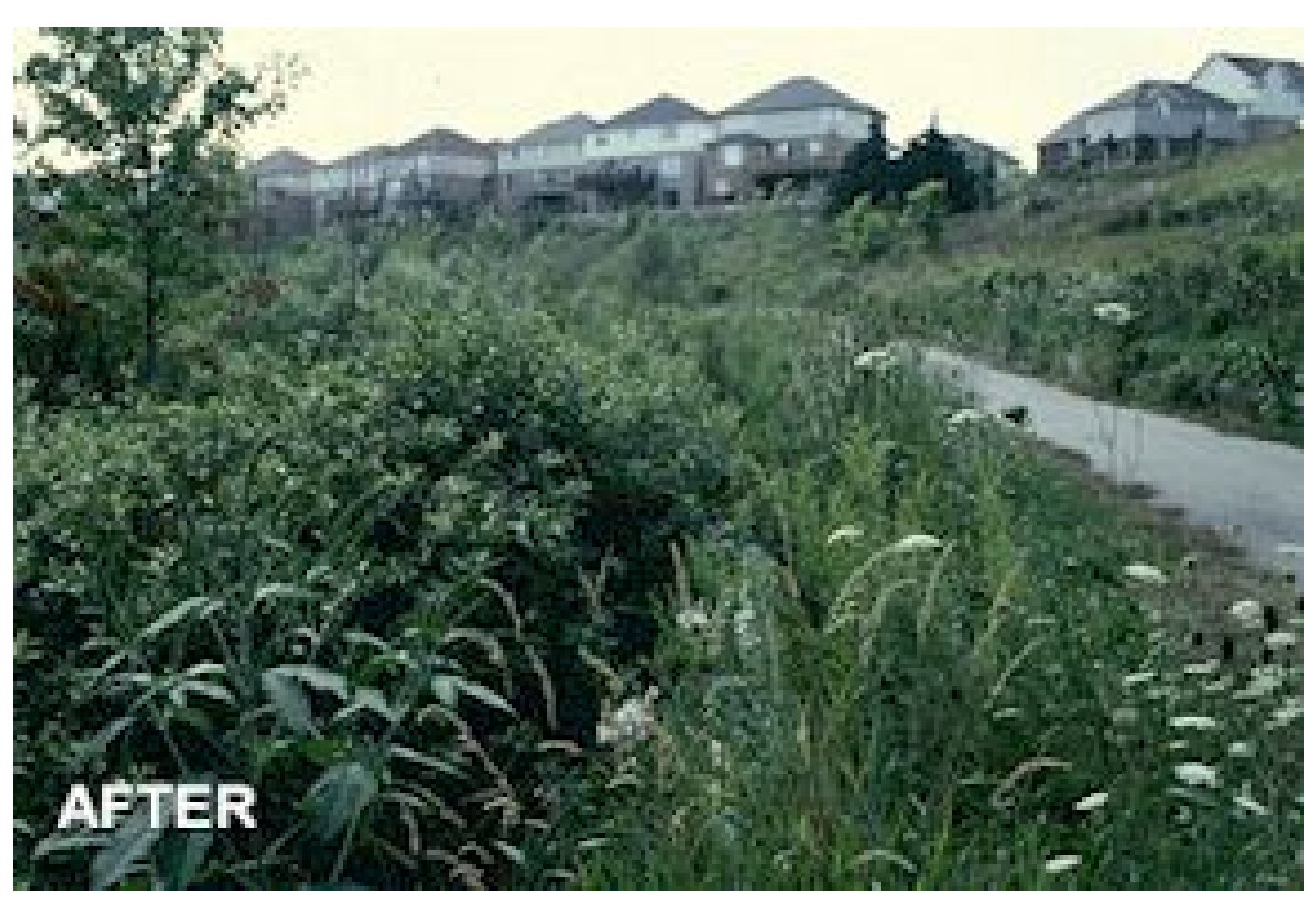

Figure 4: Photo taken at a similar spot to Figure 3, showing the end products, the natural channel and flood plain, of the restoration project (Harrington, 2003).

\section{The River Cole in Coleshill, Buckinghamshire, England}

The River Cole is a tributary of the River Thames located in the upper part of the Cole catchment. The Cole catchment is rural and is $130 \mathrm{~km}^{2}$ in area comprising clay, sand, limestone, and chalk geology. Sediments in the lower reaches, where the river is most modified, are confined to silts and muds. Land use along the River Cole corridors is mixed arable and intensive grassland. The restoration site is located within $6 \mathrm{~km}$ of the River Cole at the village of Coleshill where the floodplain is up to $400 \mathrm{~m}$ wide and graded at about 1 in 1300 . In the early 19 th century, the river was straightened for milling purposes. In the 1970s, the river was further deepened and widened to reduce flooding of arable land. The 
principle achievement of the restoration project is the creation a new $2 \mathrm{~km}$ long meandering river course that is much smaller in size than the previously enlarged channel (Figure 5 and Figure 6). The goal of this design was to restore more frequent seasonal flooding to adjacent flood plains. The existing mill by-pass channel remained in operation and was incorporated into the new design by extending it as far upstream as practical to create the additional meandering channel that was required. This restoration project is an example to demonstrate a restoration design approach that is commonly used in European countries when space is available (Burns, 2002).

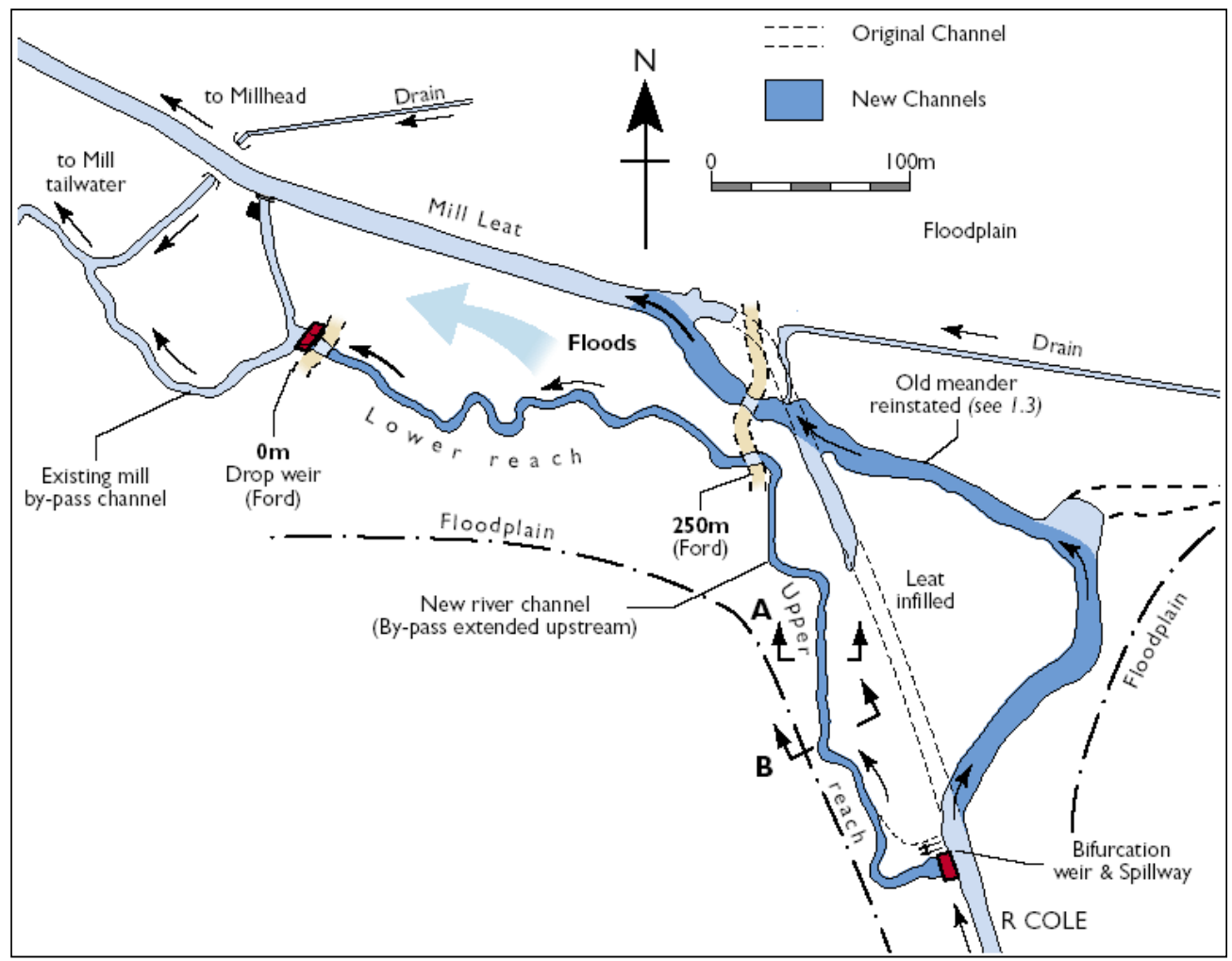

Figure 5: Plan of river restoration project of the River Cole in Coleshill, Buckinghamshire, England (Burns, 2002). 


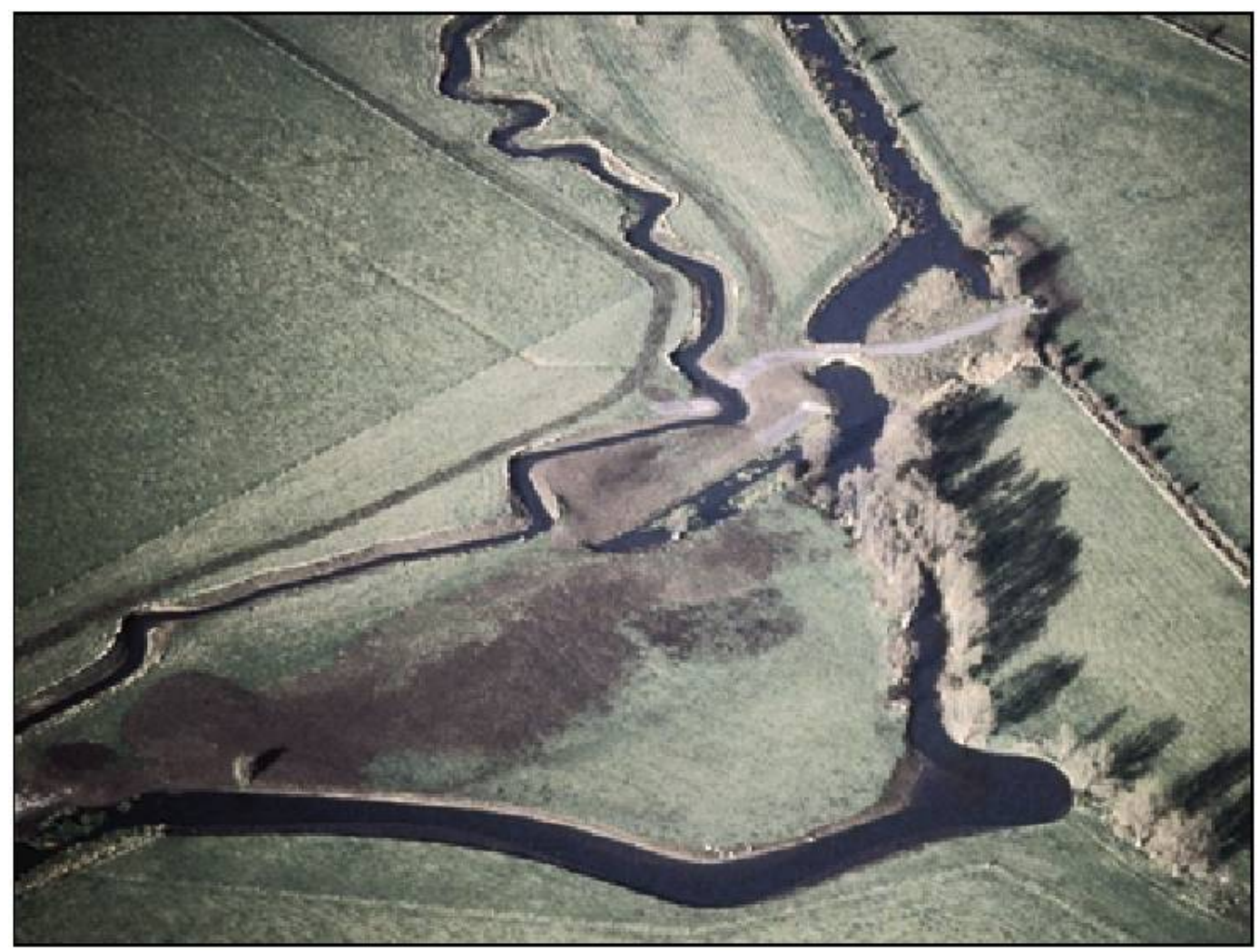

Figure 6: The new meandering river course and the restored meander in the mill leat (Burns, 2002).

\section{Cheonggyecheon Stream, Seoul, South Korea}

Cheonggyecheon Stream is approximately $5.8 \mathrm{~km}$ long flowing through downtown Seoul, the capital city of South Korea. The stream then meets the Jungnangcheon Stream, which in turn empties into the Han River. In the mid-20 ${ }^{\text {th }}$ century, Cheonggyecheon Stream was covered over with concrete construction of a road. In 1968, an elevated highway was built over it (Figure 7). In July 2003, a huge restoration project was initiated to uncover the stream. It was a major undertaking as not only did the highway have to be removed, but years of neglect and development had left the stream nearly totally dry and 120 million litres of water had to be pumped out every day (Figure 8). The bed material was fully 
glued on the concrete channel to avoid erosion problems (Prof. Wai, personal communication, 2008). The cost of the project was about $\$ 900$ million US dollars. The stream was re-opened to the public in September 2005 and lauded as a major success in urban renewal and beautification (Figure 9 to Figure 11). This project is a good example to demonstrate how to apply river restoration techniques on a concrete channel in highly urbanized areas. However, the entire design, such as the immovable bed and all the features associated with the concrete channel, is closer to an artificial approach rather than naturalization and self-sustainable approach (Shin, 2004; SMFM, 2009). The re-establishment of the living environment (i.e. spawning) for the fish habitat after the construction works is questionable.

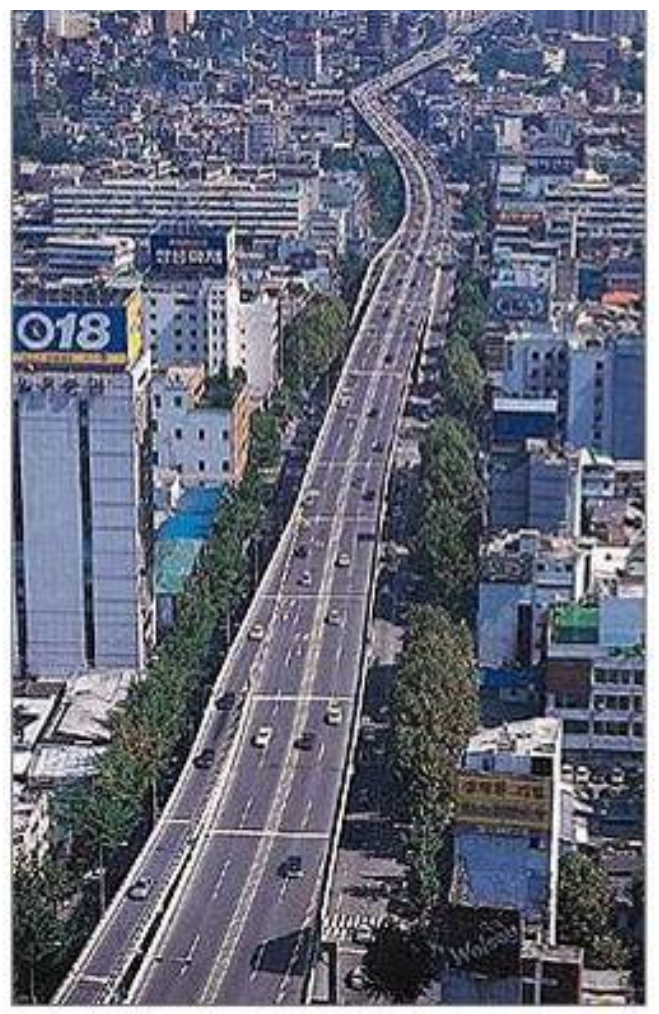

Figure 7: Cheonggyecheon Stream was covered by roads and elevated highway before restoration project ${ }^{2}$. 


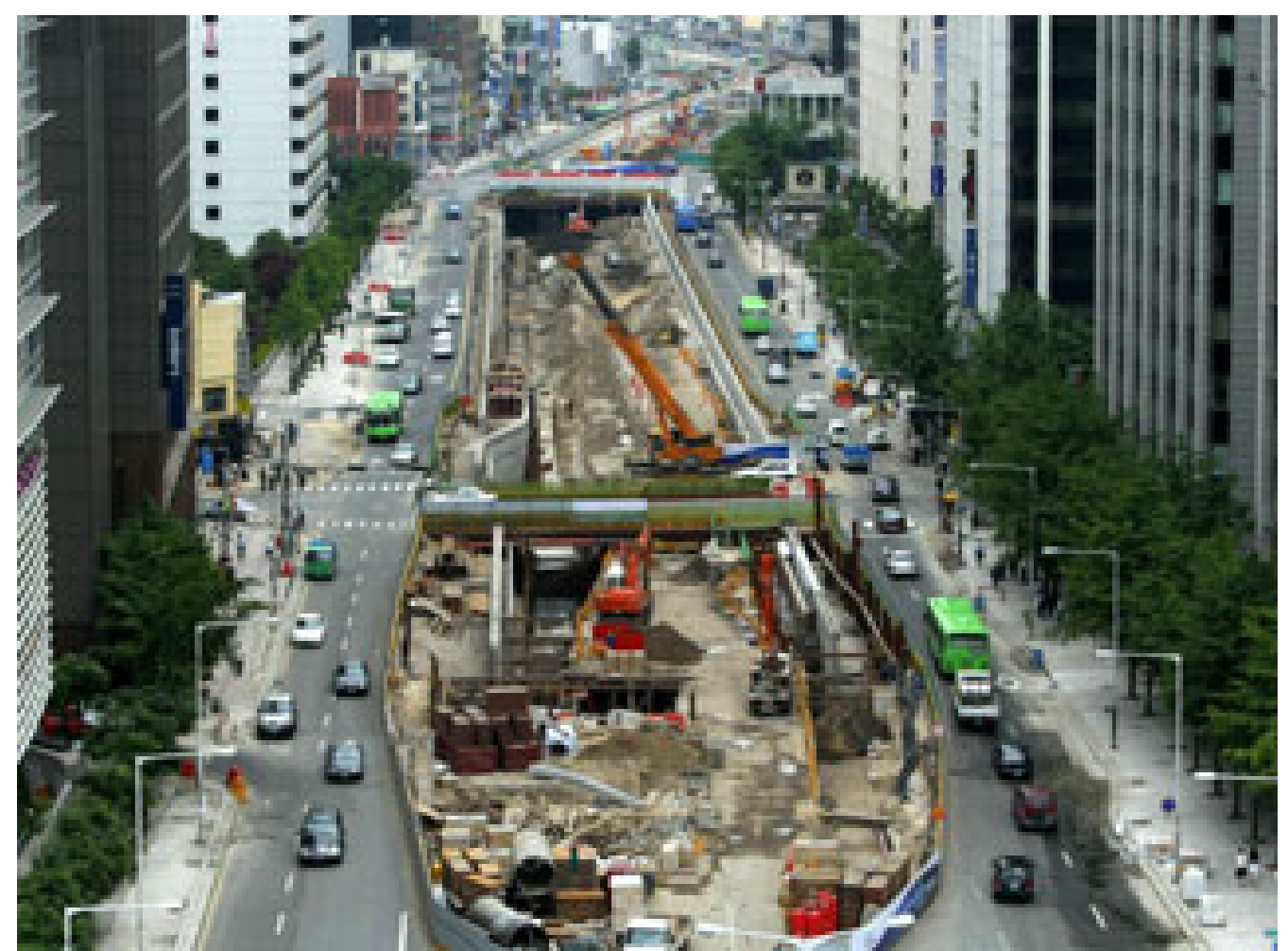

Figure 8: Removal of the elevated highway and dewatering the Cheonggyecheon Stream during reconstruction ${ }^{2}$.

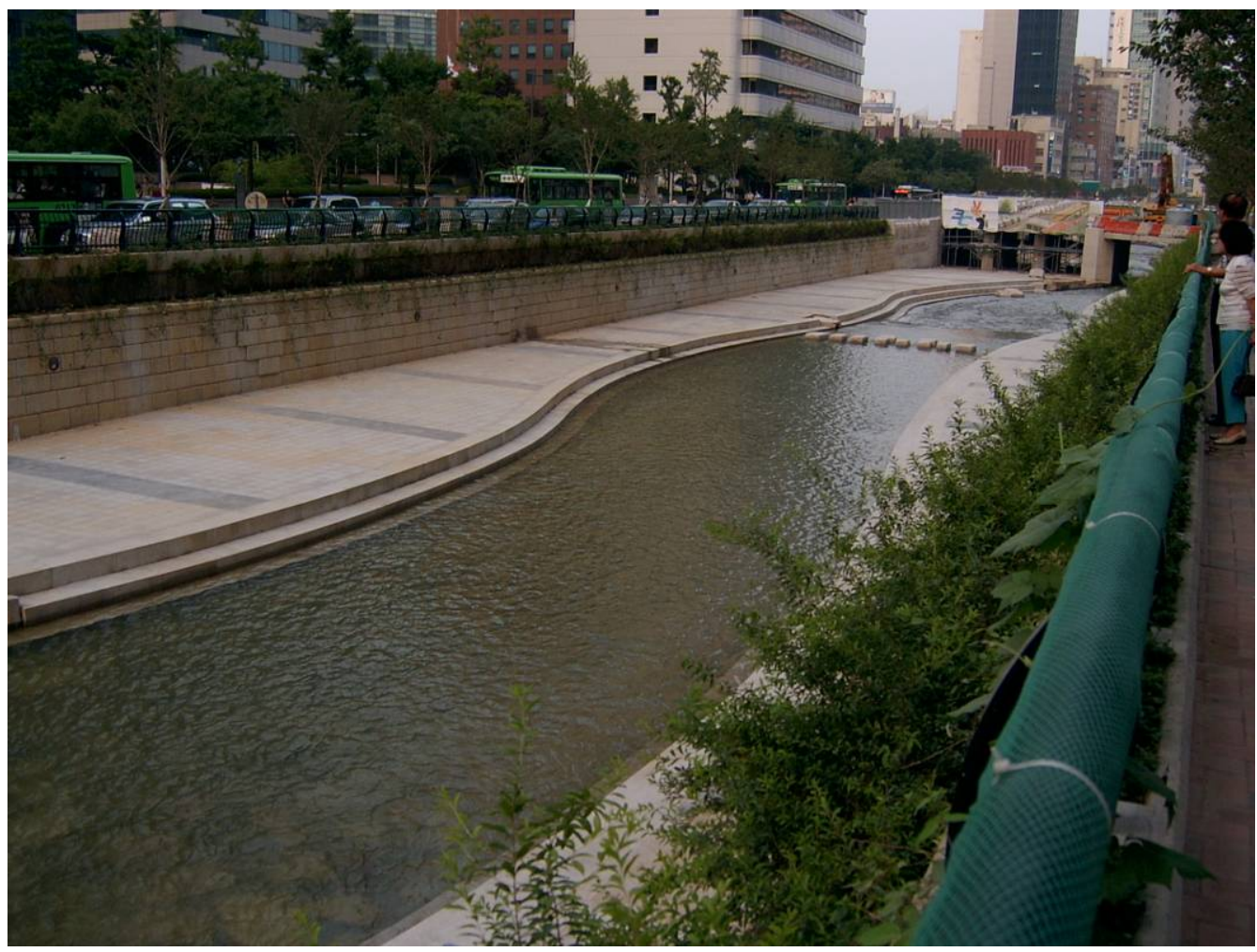

Figure 9: Meanders created by concrete banks in Cheonggyecheon Stream after the completion of the restoration ${ }^{2}$. 


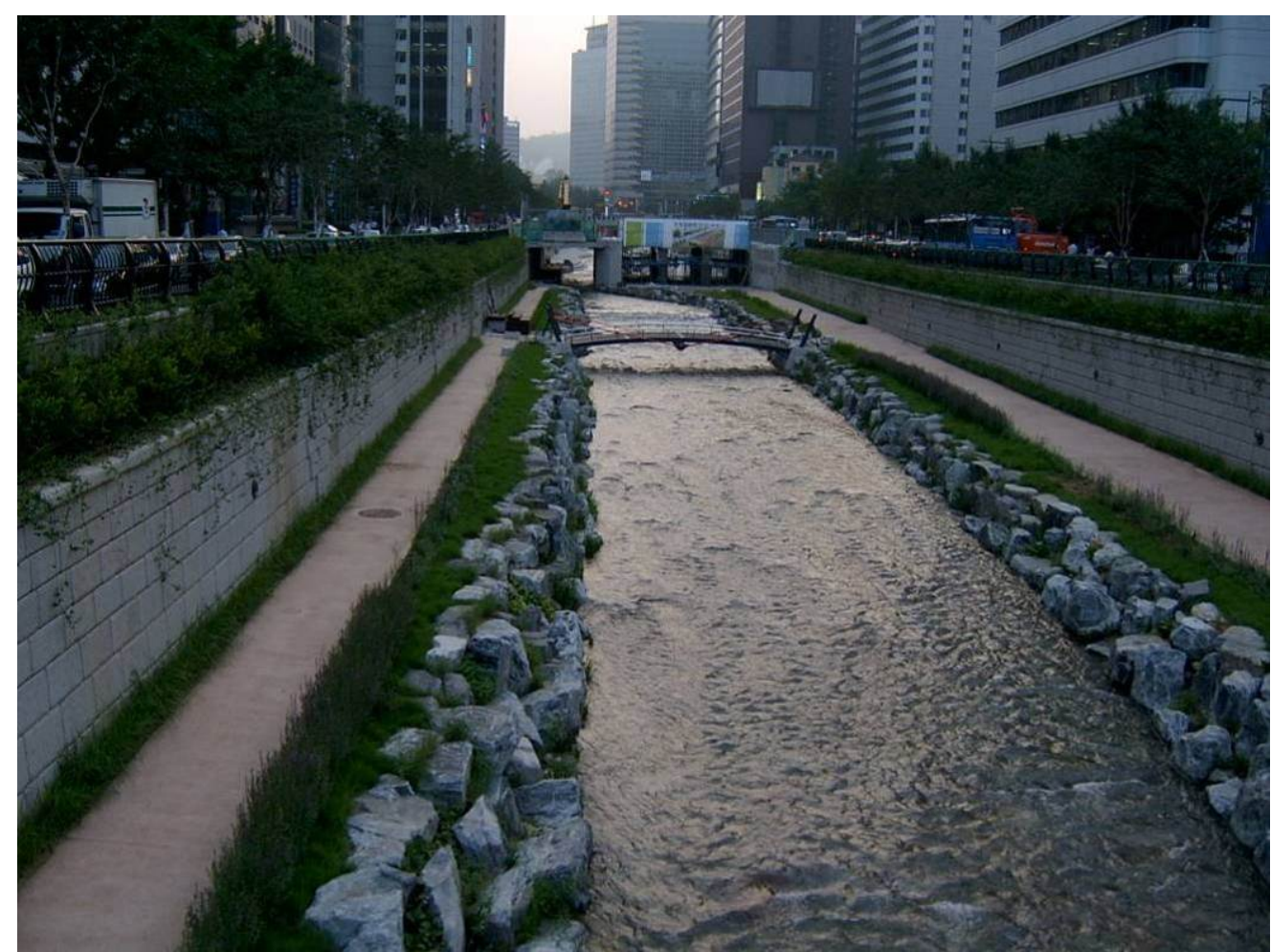

Figure 10: Photo taken upstream of Figure 11, applying armor stones along the banks ${ }^{2}$.

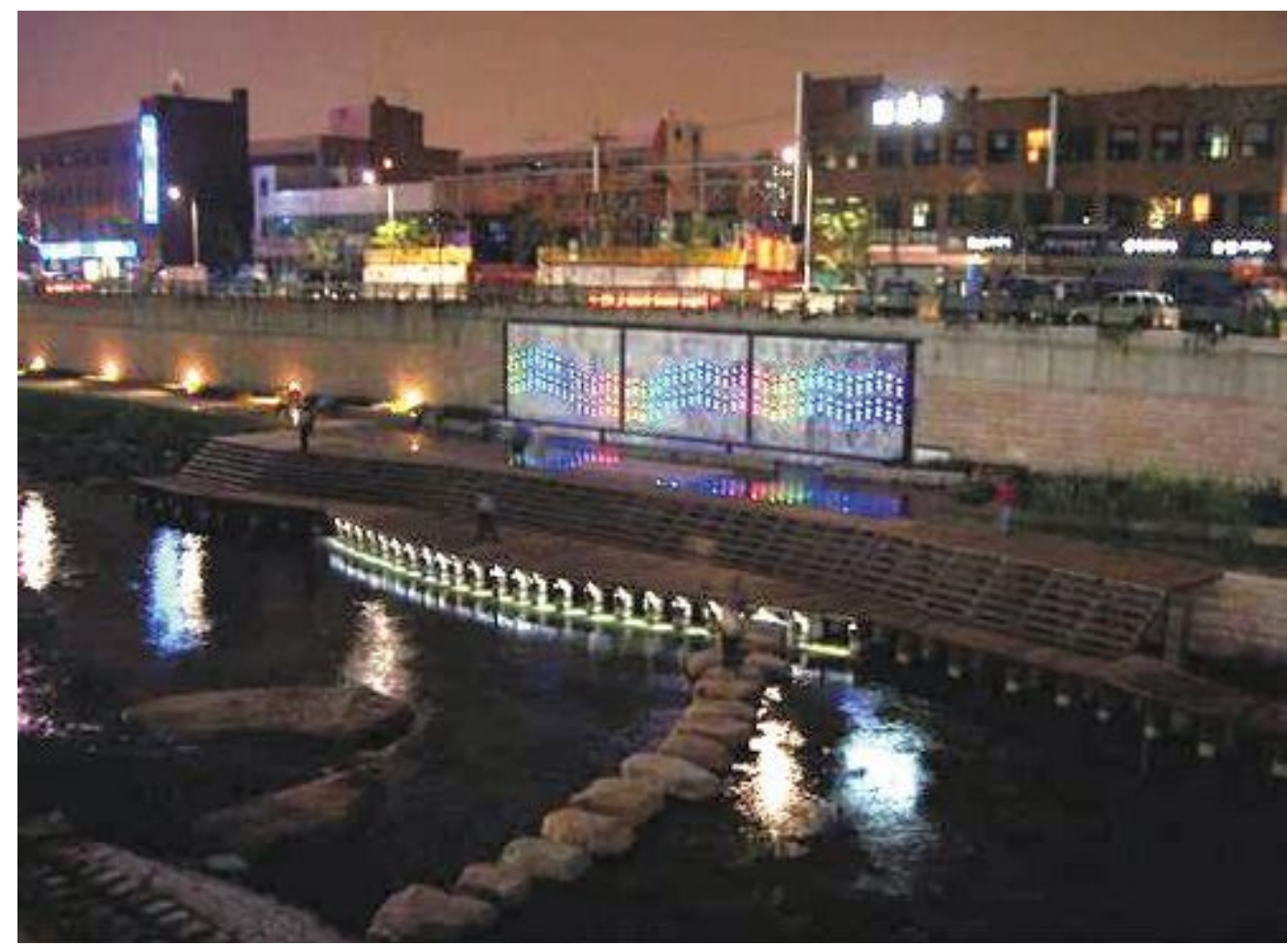

Figure 11: Applied Armour stones on nick point to slow down flow velocity ${ }^{2}$.

2 Photo source: http://www.skyscrapercity.com/showthread.php?t=243093 on September 28, 2007. 
The above discussion has provided a general background review on various significant river and stream restoration projects around the world. Based on the existing applications, it is noticed that stream and river restoration has been taking place under a variety of geographical situations. For instance, stream and river restoration approaches commonly applied in North America and European countries may not be fully adaptable to highly urbanized areas due to the limited space along the channel corridors and their placement on concrete flood control channels in areas whether monsoon conditions create much higher and more prolonged flood conditions. In North America, especially in Ontario, concrete channels were widely adopted on different sections of a stream for flood control, erosion control and bank protection. Current stream restoration practices in North America tend to restore the natural channel and reconnect the floodplain area to the stream if conditions are allowed. These practices are almost impossible to apply to flood control concrete channels in highly urbanized areas due to space limitations and the large quantity of runoff during heavy thunderstorm events. Thus, stream restoration practices in highly urbanized areas must be applied directly on the concrete channels while maintaining the flood control function. Currently, there is no formal documentation and limited research on a general approach to stream restoration for concrete flood control channels in highly urbanized areas. The recent concrete channel restoration project on the Cheonggyecheon Stream in Seoul was based upon an artificial design approach in which the improvement of the marginal fish habitat after the restoration works is questionable. This proposed research will address the research needs and 
focus on the development of a general stream restoration approach for concrete flood control channels in highly urbanized areas. The restoration goals for this approach are to: 1) provide a natural and self-sustainable river system, 2) establish appropriate pools and riffles and in-stream covers which support fish spawning and rearing; and 3) maintain flood control function.

\subsection{RESEARCH OBJECTIVES AND SCOPE}

The objective of this research is to develop a design methodology (Figure 12) for environmental restoration of flood control channels in highly urbanized areas. The framework consists of four phases: 1) identification of restoration goals, 2) stream assessment of existing conditions; 3) modification and verification of lowflow channel designs based on stream assessment findings; and 4) confirmation of the original flood control function. In phase \#3, meanders and deflectors were applied to the low-flow channel for pools and riffles creation and vegetation establishment. Physical and numerical models were the tools used for verification of the modified low-flow channel design. Physical model experiments were conducted at The Hong Kong Polytechnic University's Hydraulic Laboratory to validate the numerical model. Yuen Long Nullah in Hong Kong was used as a pilot site to demonstrate the design framework. 


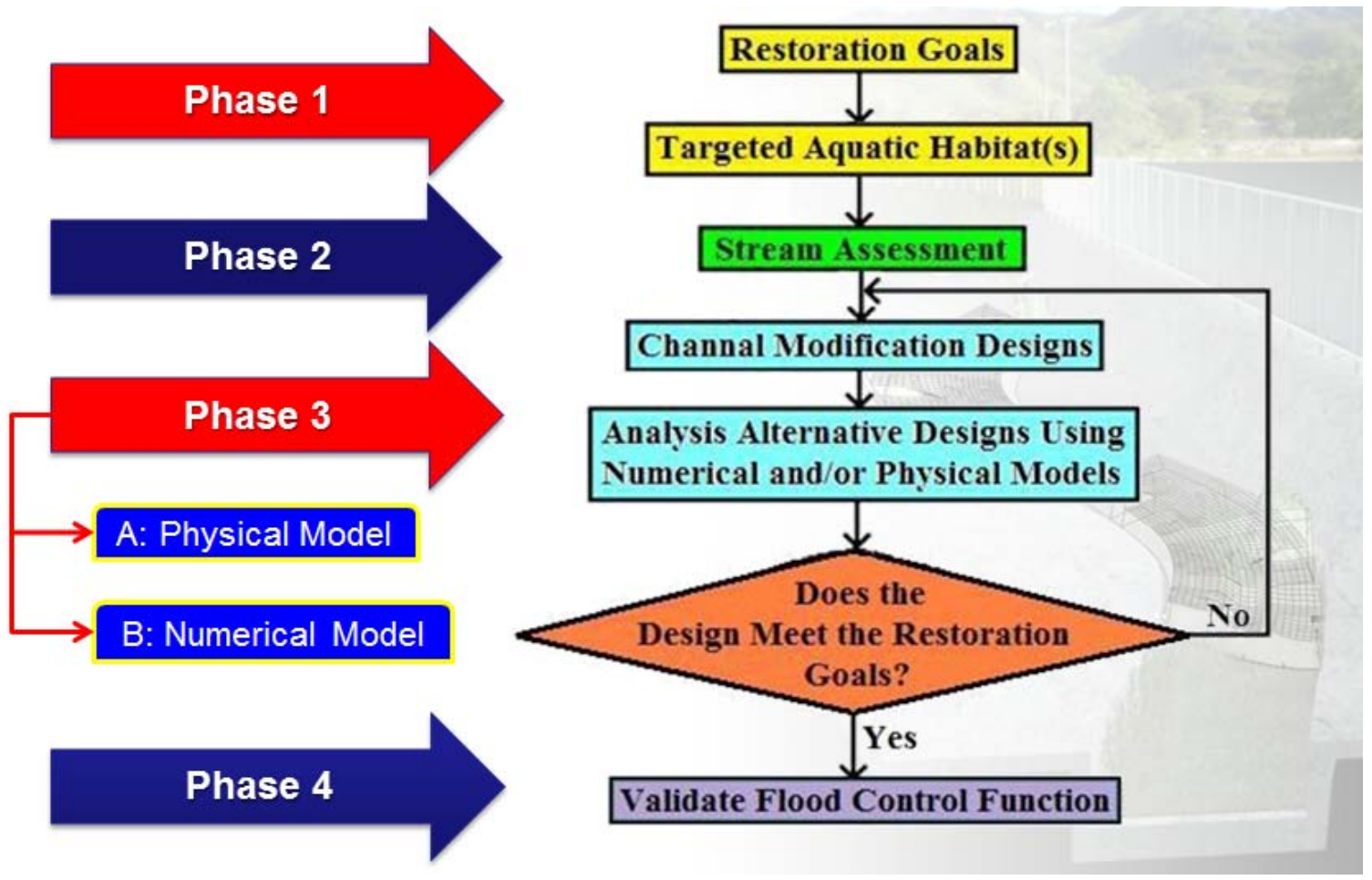

Figure 12: Design approach for flood channel restoration.

\subsection{ORGANIZATION OF THE THESIS}

This thesis is organized in the following manner. Chapter 2 contains the literature review of all the issues involved in the development of the flood channels restoration approach. Chapters 3 and 4 present the stream assessment of the pilot site, the design of the physical model, the physical experiments and results. Chapter 5 presents the design of the numerical model, the numerical experiments and results. In Chapter 6, the uncertainties, potential errors and limitations on the design methodology for concrete flood control channels restoration are discussed. Finally, Chapter 7 concludes the research with recommendations and future study. 


\section{CHAPTER 2 LITERATURE REVIEW}

This chapter reviews stream classification, flow analysis, bed-load estimation, and abutment scour determination techniques; studies the influence factors on fish habitats; and conducts a general overview on the existing hydrodynamic and sediment transport programs.

\subsection{STREAM CLASSIFICATION}

There have been many studies and cookbook-type guidance manuals developed over the past decade to encourage qualified practitioners in stream restoration planning, design, and implementation (USDA, 2001; Doll et al., 2003; Soar and Thorne, 2001; Copeland and McComas, 2001). This section focuses on the geomorphic perspective and discusses the stream analysis techniques that should be involved prior the flood channel restoration design. The purpose in preparing this section is to determine whether there are any methodologies that can facilitate the re-design of the low-flow channels.

Stream assessment is an essential step to any restoration design. It forms the foundation of analysis through data collection and field investigations, and provides the process-based framework to define past and present watershed dynamics, develop integrated solutions, and assess the consequences of restoration activities. One use of stream classification systems is to simplify the complex relationships between streams and watersheds. It also helps the 
restoration practitioner consider the landscape context and determine the expected range of variability for parameters related to channel size, shape, meander pattern, bed materials, etc. Horton (1945) developed some basic empirical stream morphology relations and discovered that the relationships between stream order, average stream length, and slope are straight lines on semi-log paper. Strahler (1957) developed the "stream order" classification system (Figure 13) according to the hierarchy of natural channels within a watershed as depicted on standard topographic maps. This method is dependent on the scale of the maps used to identify the orders of the streams and may be difficult to make direct comparisons of different river basins if the topographic maps are in different scales (Strahler, 1957; USDA, 2001; Doll et al., 2003).

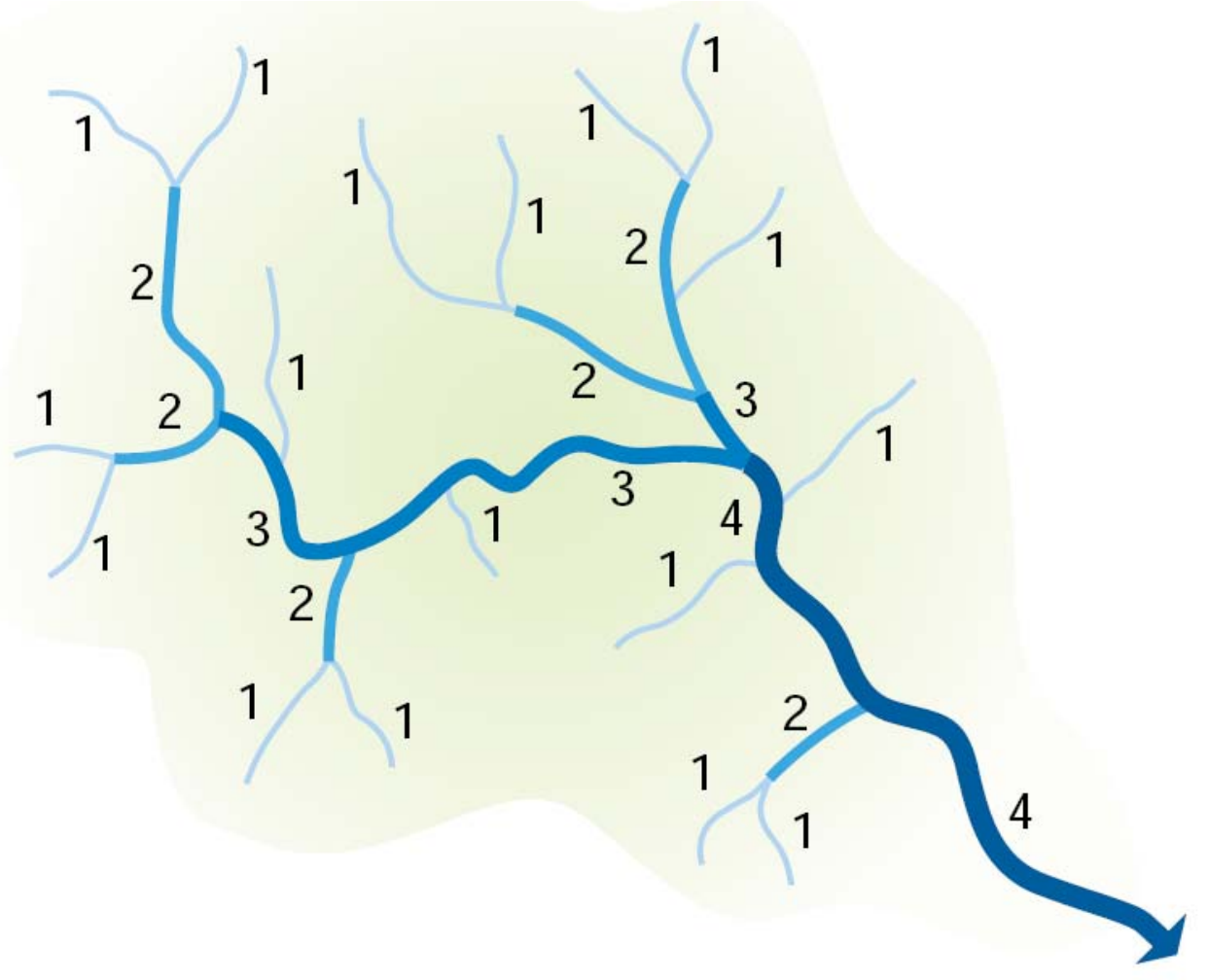

Figure 13: Stream ordering in a drainage network (USDA, 2001). 
To address the limitations of Strahler's method, Yang (1971) derived a theory of average stream fall based on the analogy with thermodynamic principles and were supported by data from fourteen river basins in the United States. The theory states that the ratio of average fall, the change in bed elevation, between any two stream orders in a given river basin is unity. Schumm (1977) combined morphological criteria with dominant modes of sediment transport and related straight, meandering, and braided channels to channel pattern and stability to modes of sediment transport (Figure 14). These were derived from flume experiments wherein fluvial processes were not impeded by highly resistant bed and bank materials, i.e. materials were generally mobile in the fluvial environment. Vannote et al. (1980) adapted stream order in the river continuum concept to distinguish different levels of biological activity. However, this method did not consider restoration of hydrologic and geomorphic functions to stream corridors. (FISRWG, 1998). 


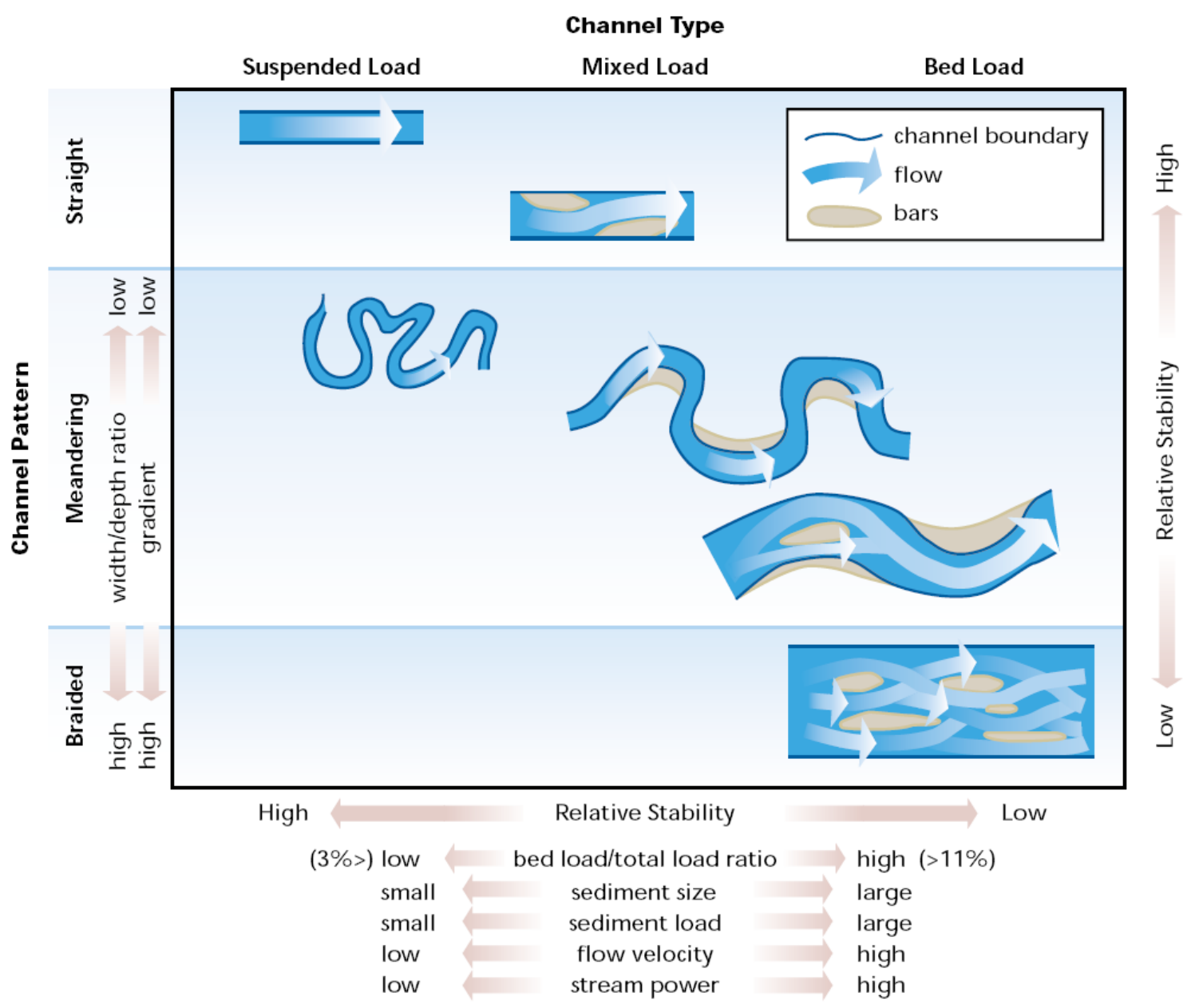

Figure 14: Schumm's stream classification system (Schumm, 1977).

Montgomery and Buffington (1993) proposed a similar classification system of Schumm's method for alluvial, colluvial, and bedrock streams in the Pacific Northwest that addresses channel response to sediment inputs throughout the drainage network (Figure 15). 


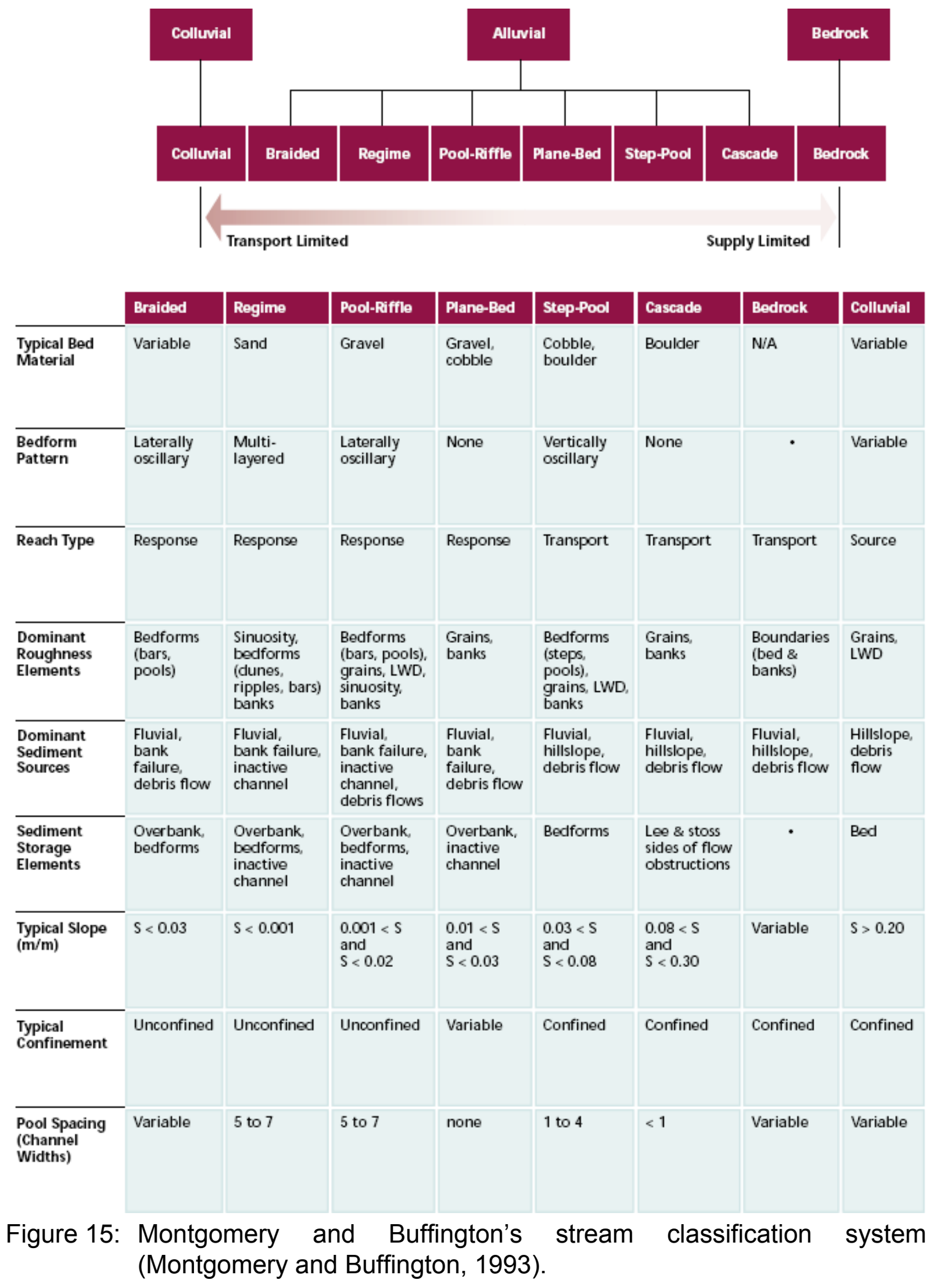


Rosgen (1994) developed a comprehensive stream classification system (Figure 16 and Figure 17) which uses six morphological measurements-stream pattern (including sinuosity, meander wavelength, radius of curvature, belt width), number of channels, slope, bed material particle size, entrenchment, and width/depth ratio, to classify a stream reach (Figure 18). The first four parameters are straightforward measurements, where entrenchment and width/depth ratio depend on a determination of bankfull depth.

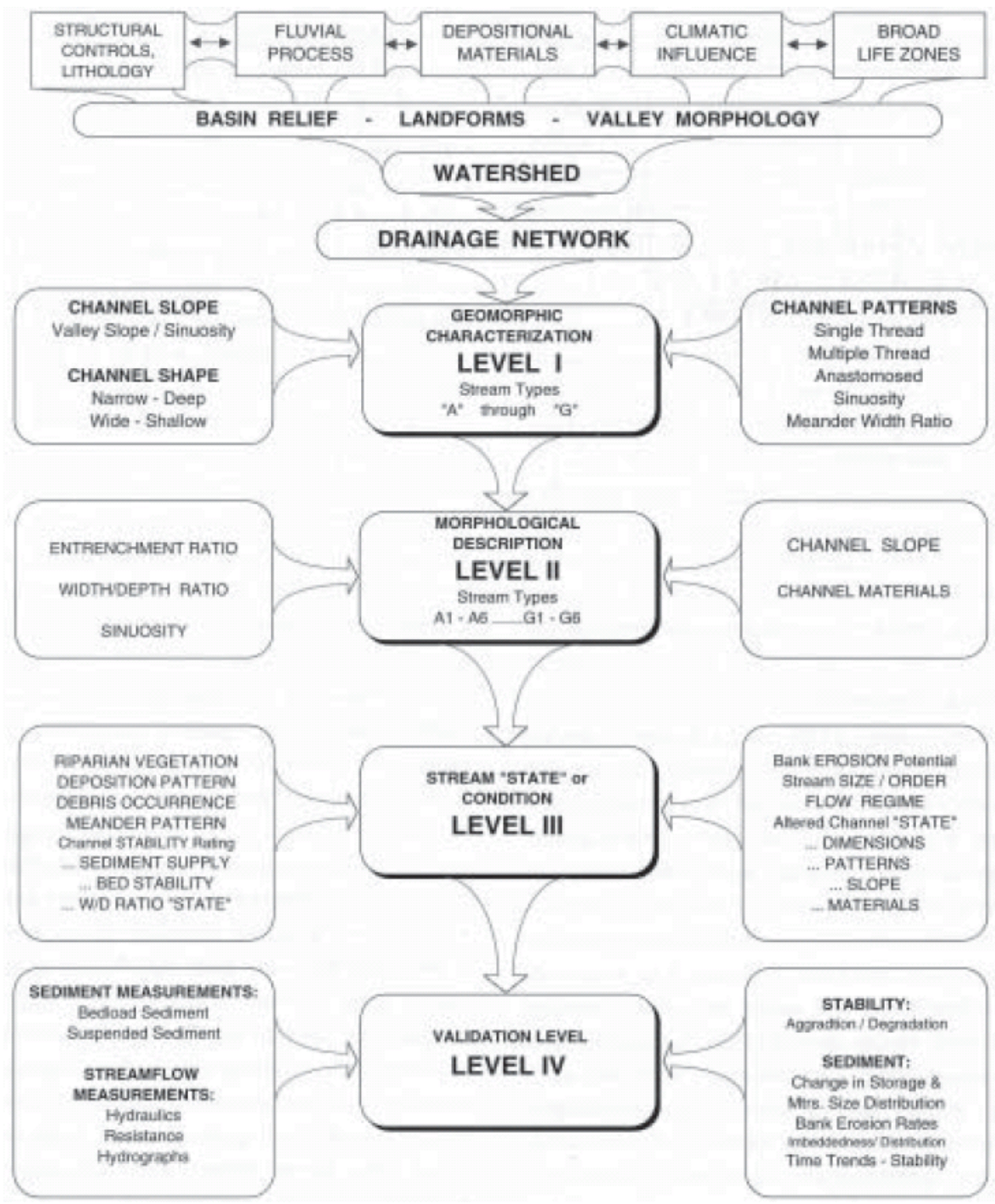

Figure 16: Rosgen's Stream assessment framework (Rosgen, 1996). 


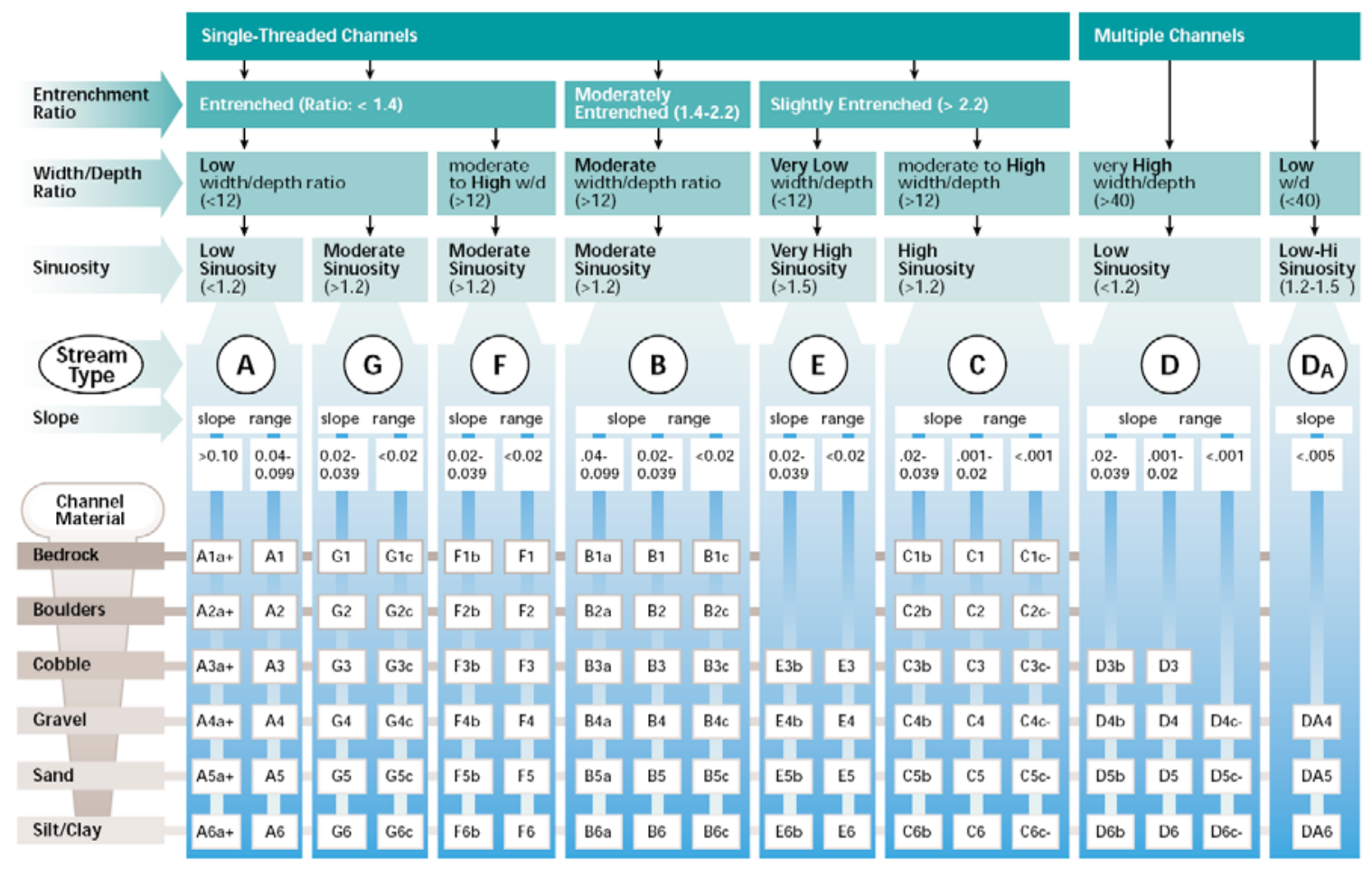

Figure 17: Rosgen's stream classification system (Rosgen, 1996).
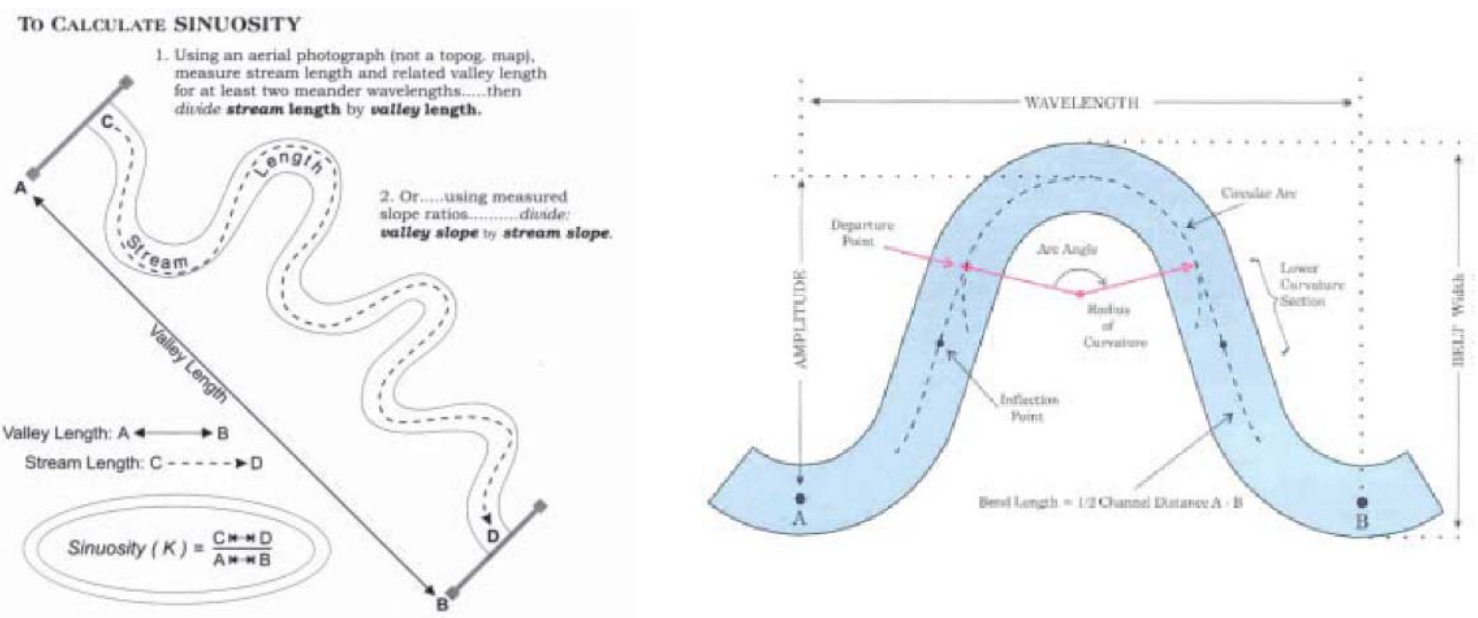

Figure 18: Definition of stream pattern (Doll et al., 2003). 
Furthermore, Soar and Thorne (2001) developed a holistic geomorphic appraisal for the restoration design of a stable channel (Figure 19). Their simplistic onedimensional approach proposed that the design variables pertaining to the characteristic of flow and sediment regimes should be defined from the upstream reference reach.

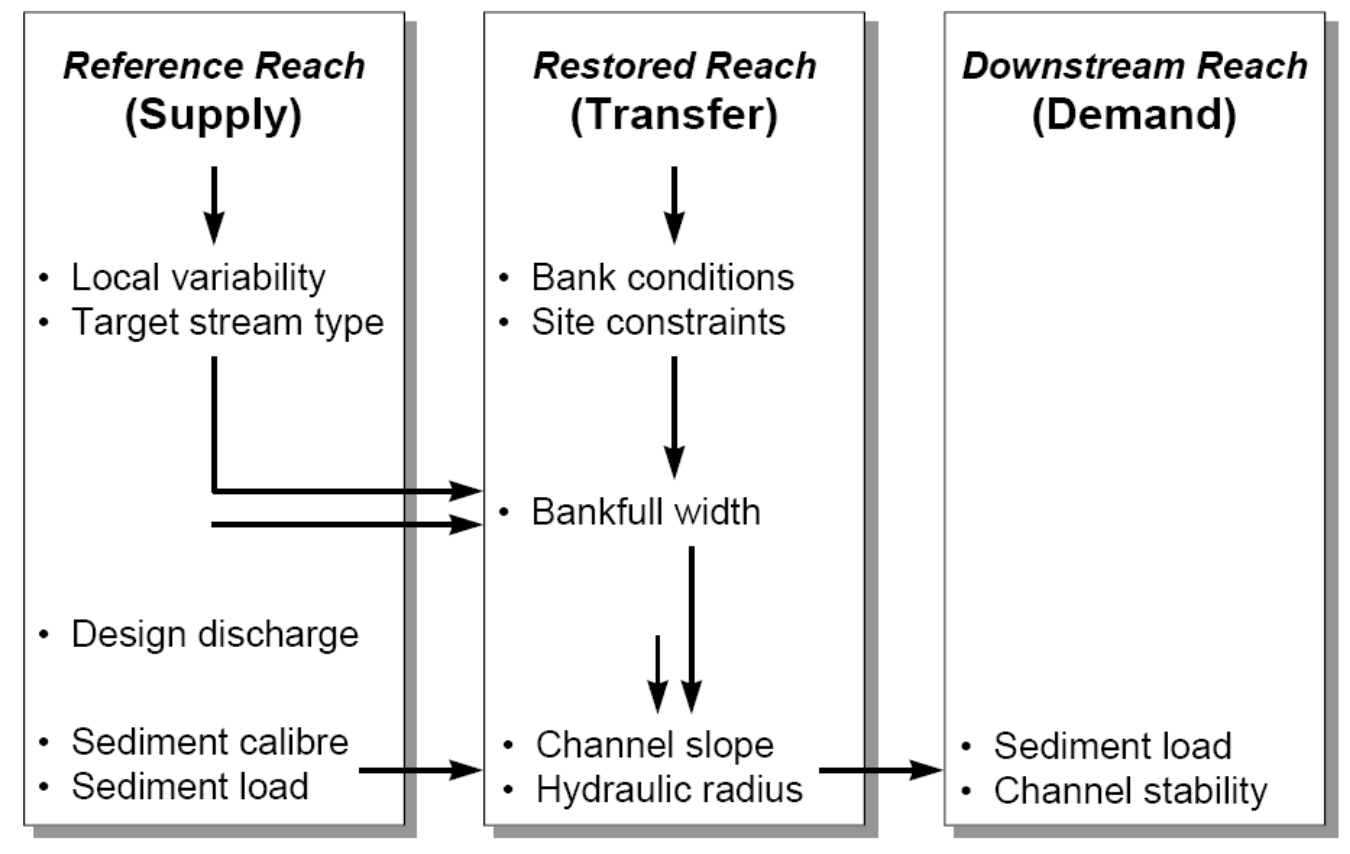

Figure 19: Soar and Thorne's geomorphic appraisal (USDA, 2001).

Some of the existing methods on natural stream classification and stream pattern identification can be applied to the information gathering in Phase 2 of the design approach (Figure 12) and assist the channel modification design in Phase 3 (Figure 12). The stream classification system using morphological measurements as a base developed by Rosgen (1994) is a potential methodology on developing meander patterns suitable for concrete flood control channels. 


\subsection{FLOW ANALYSIS}

The natural spectrum and sequence of flow events have major influences on channel stability over time and moulding the channel forms dynamically through sediment erosion, transportation and deposition. Thus, understanding the flow characteristics of the study area including the relative contributions of baseflow and stormflow in an annual runoff, source of streamflow (whether it is derived primarily from rainfall, snowmelt, etc.), relative frequency and duration of extreme high and low flows (i.e. frequency analysis), duration of certain stream flow levels (i.e. flow duration curves), and the channel-forming or dominant discharge, are essential prior to stream restoration (USDA, 2001; Soar and Thorne, 2001).

\subsubsection{Flow Duration and Frequency}

Stream corridor restoration usually initiates in the lack of systematic stream gauge data. Hence, flow duration and frequency of extreme high and low flows are usually estimated by indirect methods from regional hydrologic analysis. Currently, there are more indirect estimation methods for predicting mean annual flow and flood characteristics for low flows and flow duration characteristics. In Canada, guidelines for determining the flood frequency are usually documented by Environment Canada and local authorities, whereas in United States, USGS and USACE usually take care of the flood frequency analysis. Wharton (1995) reviewed a set of regression equations which were developed using flood frequency estimates from USGS gauging stations and correlated with certain 
channel geometry characteristics. However, the standard errors of these estimates might be large (Wharton, 1995; USDA, 2001; Soar and Thorne, 2001).

Searcy (1959) developed the flow duration curves concept which the percentage of time streamflow equalled or exceeded a given flow level over a period of time. For low-flow frequency analysis, guidelines are not as standardized as for flood frequency since no single frequency distribution or curve-fitting method has been widely accepted (USDA, 2001). Vogel and Kroll (1989) provided a summary of the limited number of studies that have been evaluated for frequency distribution and fitting methods of low flows. Hutchison (1975) and Lumb et al. (1990) developed computer software to perform low-flow analyses using a record of daily mean flows. Fennessey and Vogel (1990) reviewed 23 rivers in Massachusetts, USA, and concluded that the 7-day, 10-year low flow was approximately equal to the $99^{\text {th }}$ flow duration percentile. Zalants (1991), Telis (1991), Atkins and Pearman (1994) published low-flow estimates routinely using USGS gauged sites.

\subsubsection{Channel-Forming Discharge}

The channel-forming or dominant discharge theory stipulates that if there is a unique flow maintained in an alluvial river over a long period of time, it would produce the same bankfull morphology that is shaped by the natural sequence of flows. Even this concept is not an universally accepted method, most practitioners agree that this is applicable in perennial and ephemeral rivers 
(Blench, 1952; Ackers and Charlton, 1970; Bray, 1975; Biedenharn et al., 2000; USDA, 2001; Soar and Thorne, 2001).

Researchers have used various discharge levels to represent the channelforming discharge: 1) bankfull discharge, 2) a specific discharge recurrence interval from the annual peak or partial duration frequency curves, and 3) effective discharge. These approaches frequently produce good approximation of the channel-formed discharge in many situations. However, many practitioners also use specific approaches to determine channel-forming discharge and the response of streams (USDA, 2001; Soar and Thorne, 2001).

\subsubsection{Bankfull Discharge}

The bankfull discharge is generally defined as the flow that fills a stable alluvial channel up to the elevation of the active floodplain. Inglis (1947) probably was the first person who considered that flows at or near the bankfull stage might approximate the dominant discharge. Wolman (1955), and Pickup and Warner (1976) suggested that the bankfull stage is usually the elevation at which the width/depth ratio becomes a minimum. Nixon (1959) defined the bankfull stage as the highest elevation of a river that can be contained within the channel without spilling to the floodplain or washlands, and Woodyer (1968) defined it as the elevation of the middle bench of rivers having several over-flow surfaces (USDA, 2001; Soar and Thorne, 2001). 
Other experts have defined bankfull stage using morphologic factors. Schumm (1960) defined bankfull stage as the height of the lower limit of perennial vegetation. Wolman and Leopold (1957) considered bankfull stage as the average elevation of the highest surface of the channel bars. Leopold (1994) stated that bankfull stage is indicated by a change in vegetation such as herbs, grasses, and shrubs. William (1978) pointed out that field identification of bankfull elevation might be difficult due to the discontinuity in nature of the channel banks such as a change in its sedimentary or vegetative characteristics. Knighton (1984) stated that field identification of bankfull stage indicators should be performed in stable and alluvial stream reaches (USDA, 2001; Soar and Thorne, 2001).

\subsubsection{Determination of Channel-Forming Discharge Using Specific Discharge Recurrence Interval}

Some researchers have assumed the channel-forming discharge as a specific recurrence interval discharge to avoid problems related to field determination of bankfull stage. Wolman and Leopold (1957) suggested that the channel-forming discharge has a recurrence interval of 1 to 2 years. Dury (1973) concluded that the channel-forming discharge is approximately 97 percent of the 1.58-year discharge or the most probable annual flood. Hey and Thorne (1975) used three gravel-bed rivers in British as an example to demonstrate that the 1.5-year flow in an annual maximum series passed through the scatter of bankfull discharges measured along the course of the rivers. Pickup and Warner (1976) determined the bankfull recurrence intervals ranged from 4 to 10 years on the annual series. 
Richards (1982) showed that bankfull discharge equals to the most probable annual flood with 1-year return period using a partial duration series. Leopold (1994) commented that most investigations have concluded that the bankfull discharge recurrence intervals ranged from 1.0 to 2.5 years (USDA, 2001; Soar and Thorne, 2001).

\subsubsection{Effective Discharge}

The effective discharge is defined as the increment of discharge that transports the largest fraction of the sediment load over a long period of time (Andrews, 1980). It incorporates the principle that the channel-forming discharge is a function of both the magnitude of the event and its frequency of occurrence (Wolman and Miller, 1960). The advantage of using the effective discharge is that it is a calculation-based rather than subjective field-determined value. The basic components required for calculating the effective discharge are the flow-duration curve and the sediment-transport rating curve (Figure 20). The peak in curve C (Figure 20) marks the single flow increment that is most effective in transporting sediment and forming the channel. However, there is a range of flows on either side of the effective discharge that also carries a significant portion of the total annual sediment load (Andrews, 1980; Wolman and Miller, 1960; USDA, 2001; Soar and Thorne, 2001). 


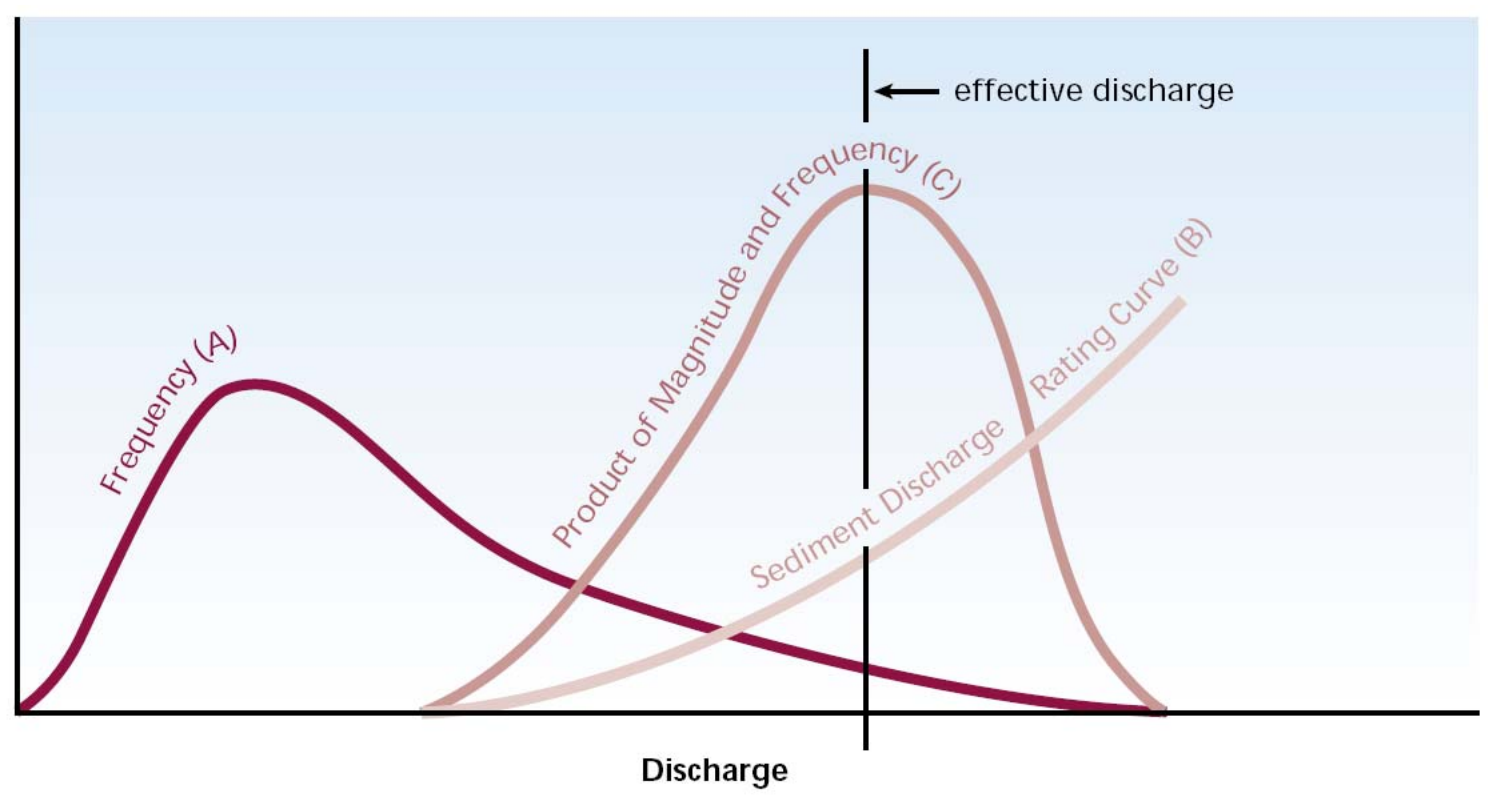

Figure 20: Effective discharge determination (Wolman and Miller, 1960).

If monitoring data are unavailable to calculate the effective discharge or if field determination of bankfull discharge is not permitted, indirect methods based on regional hydrologic analysis may be used (Ponce, 1989). Brookes (1987), Madej (1982), Newbury and Gaboury (1993) used watershed areas as surrogates for bankfull discharge. Dunne and Leopold (1978), and Leopold (1994) developed average curves relating bankfull discharge to drainage area for widely separated regions of the United States (USDA, 2001; Soar and Thorne, 2001; Doll et al., 2003).

The above discussion on the various flow characteristics provides some thoughts for the channel modification design in Phase 3 (Figure 12). As discussed in Chapter 1 , one of the restoration goals for concrete flood control channels 
restoration is to provide a natural and self-sustainable river system. If a natural bed material is applied to the modified flood control channel in order to achieve the restoration goal, the effective discharge (Andrews, 1980), occur in wet weather condition will be a major factor on bed formation. Conversely, low flow occurs in dry weather condition may not have any effects on the bed formation at all. 


\subsection{FISH HABITAT}

Generally, stream restoration design can proceed along one of the following two approaches: 1) a single-species restoration approach that focuses on habitat requirements of certain life stages of species, and 2) an ecosystem restoration approach that focuses on the chemical, hydrologic, and geomorphic functions of the stream channels and assumes that communities will recover to a sustainable level if the stream structure and functions are adequate (USDA, 2001).

For the single-species restoration approach, habitats for species at the higherend of the food chain (i.e. fishes) are usually the targeted species. Furthermore, fish swimming performance is a key factor since as it impacts food acquisition, habitat occupancy and susceptibility to predation (Reidy et al., 2000). Webb (1975) classified three categories of swimming performance based on swimming speed and endurance: sustained swimming, prolonged swimming, and burst speed. Sustained swimming is classified as swimming for more than 200 minutes without fatigue. Prolonged swimming can be maintained from 20 to 200 minutes and ends in fatigue. Burst speed is the highest swimming speed and can be maintained for less than 20 seconds. In contrast to sustained or prolong swimming, burst speed is anaerobic. The faster burst speed is characterized as fast-start swim speed which is a burst of less than 1 or 2 seconds and is usually related to prey capture or predator avoidance (Reidy et al., 2000; Webb, 1975; Smith, 2008). 
Fish swimming performance can be influenced by body shape (Vogel, 1994), fin type (Videlar, 1993), muscle function (Kieffer, 2000), swimming mode (Müller et al., 2000), surrounding temperatures (Brett and Glass, 1973), viscosity (Vogel, 1994; Müller et al., 2000), pH (Butler and Day, 1993), dissolved oxygen (Reidy et al., 2000), photoperiod (Kolok, 1991), salinity (Randall and Brauner, 1991), and various pollutants (Hammer, 1995). There are many cookbook-type fish habitat manuals and studies listed the swimming performance of different fish species (Smith, 2008; Katopodis, 1992; Alberta Transportation, 2009; MTO, 2006; DFO, 1995). McKenzie et al. (2003) conducted a research on the swimming performance between the growth hormone transgenic tilapia and wild-type tilapia and discovered that the maximum sustainable swimming speed for wild-type tilapia with an average size of $15.7 \pm 1.0 \mathrm{~cm}$ is around $4.94 \pm 0.45 \mathrm{BL} / \mathrm{s}$. This research provides some basic ideas on the swimming performance of the targeted species for the pilot site in Hong Kong (Section 3.4.3). 


\subsection{DEFLECTOR DESIGNS}

Deflectors have been used extensively in restoration projects to exaggerate pools creation for fish habitats (Garde et al., 1961; Copeland, 1983; Kuhnle et al, 1999; Kuhnle et al., 2002; Kothyari and Ranga Raju, 2001, Biron et al., 2004). Thompson (2002) carried out field studies to verify that high, narrow deflectors create backwater at higher flow with less overall protrusion into the channel and provide deeper pools with greater overall volume (Thompson, 2002, 2002a).

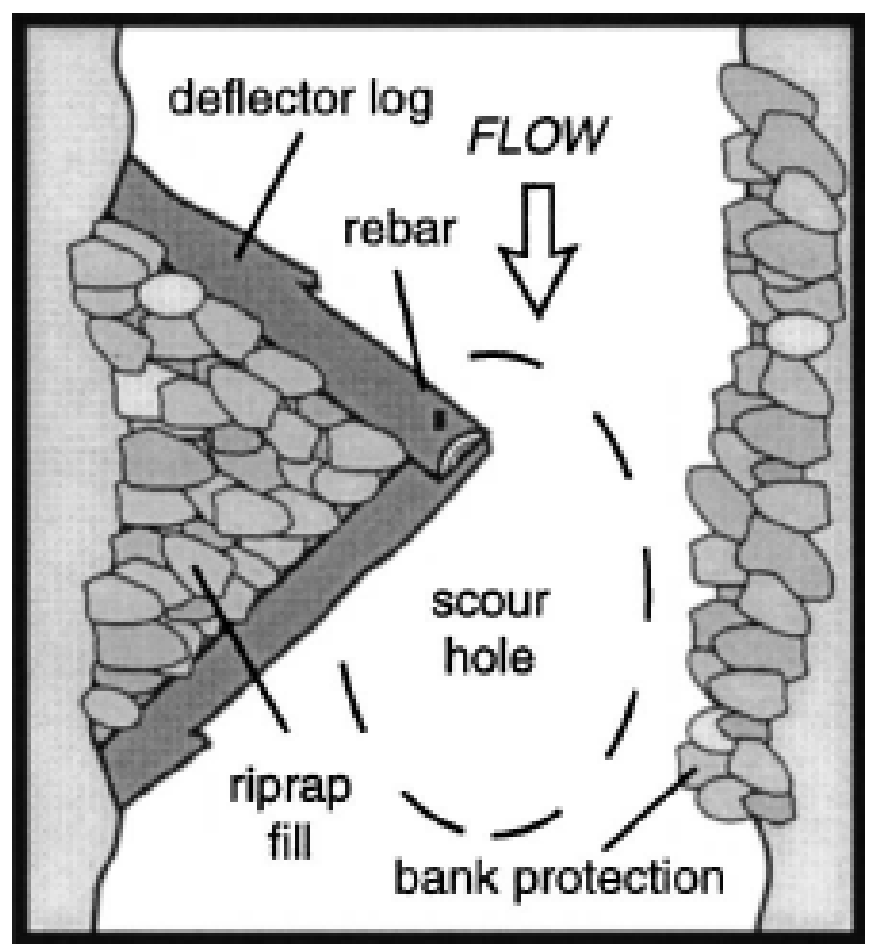

Figure 21: Deflector design in Thompson (2002) studies.

Rosgen (2001) introduced three river structures, the W-Weir, the Cross-Vane, and the J-Hook Vane, to meet the following design objectives: 1) Maintain the stable width/depth ratio of the channel; 2) Manage the shear stress to move the 
largest size particle to maintain stability (competence); 3) Decrease near-bank velocity, shear stress or stream power; 4) Maintain channel capacity; 5) Ensure stability of structure during major floods; 6) Maintain fish passage at all flows; 7) Provide safe passage or enhance recreational boating; 8) Improve fish habitat; 9) Be visually compatible with natural channels; 10) Be less costly than traditional structures; 11) Create maintenance-free diversion structures; and 12) Reduce bridge pier/footer scour, road fill erosion and prevent sediment deposition (Rosgen, 2001).
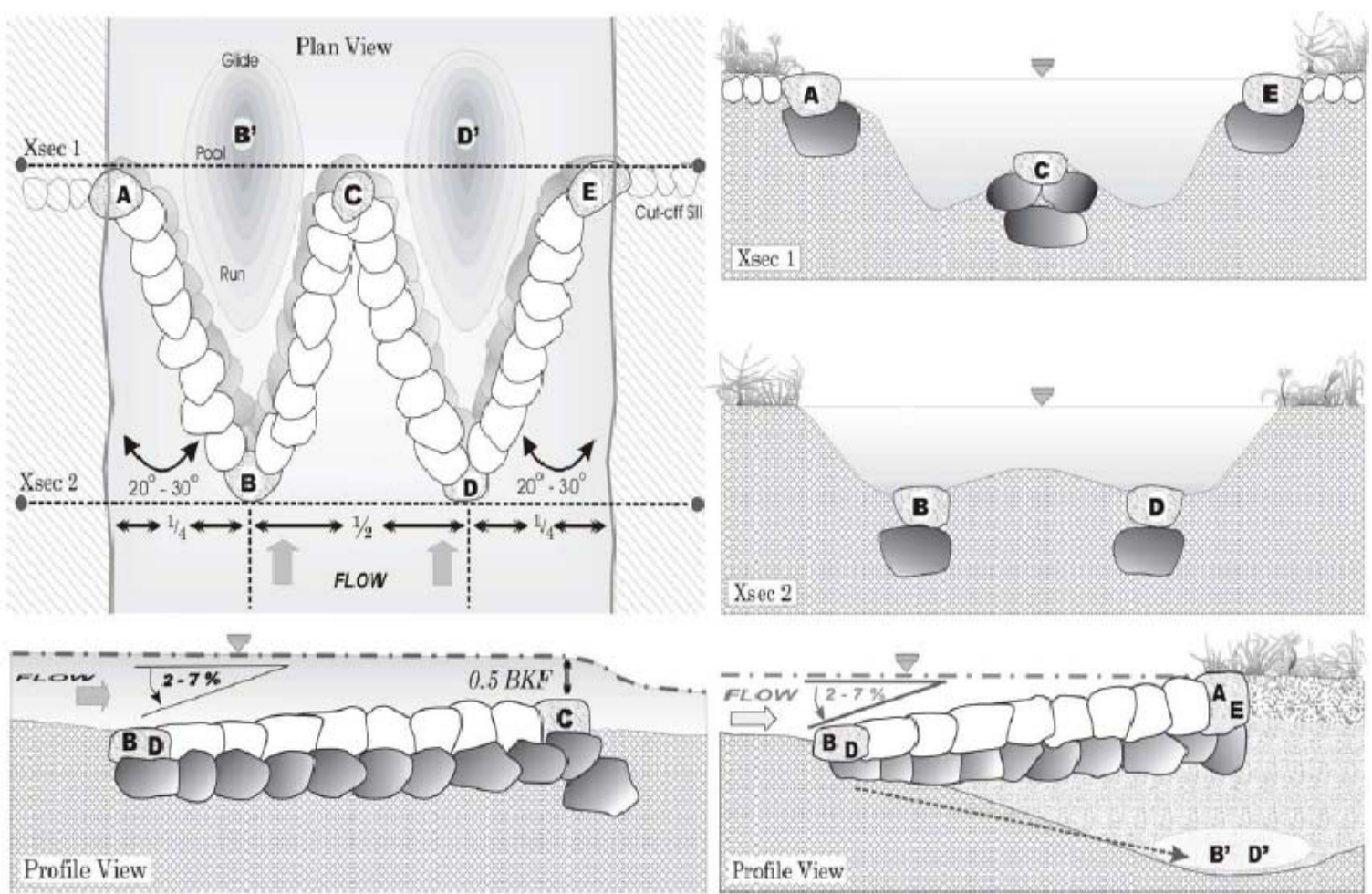

Figure 22: W-Weir design (Rosgen, 2001). 

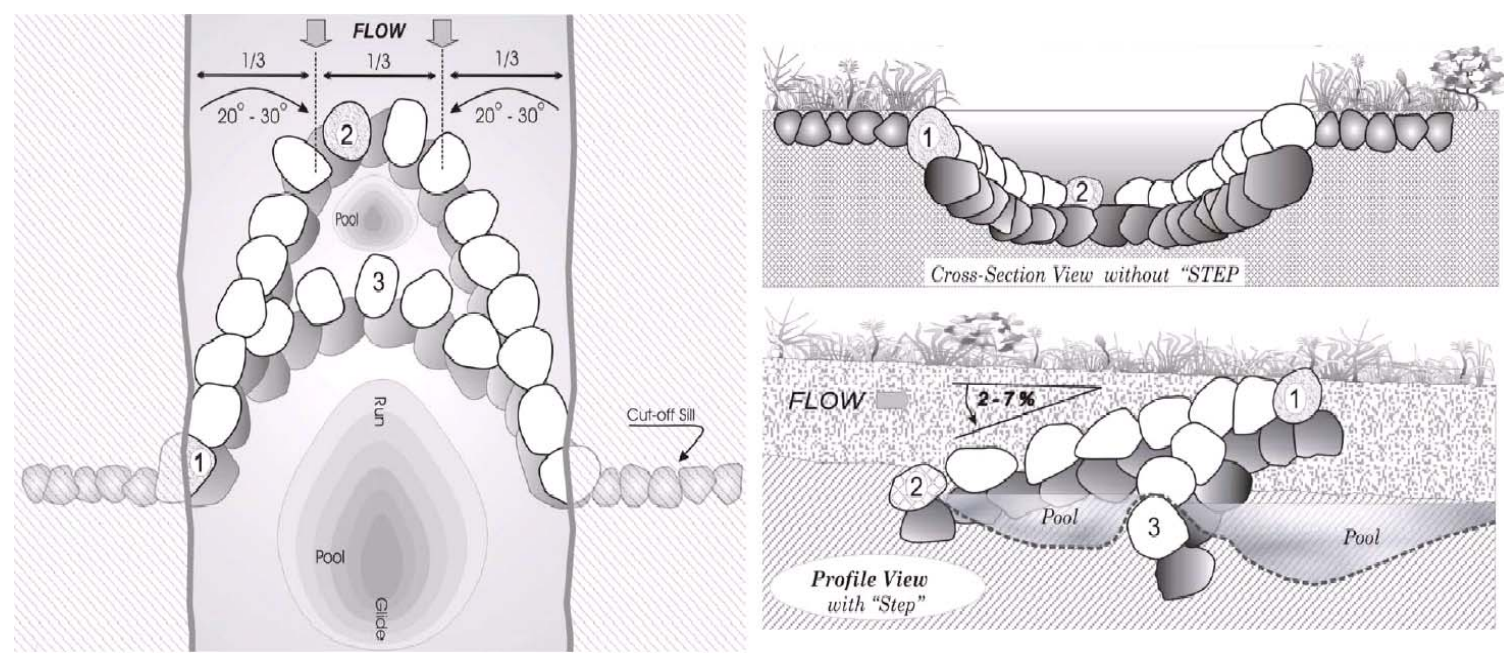

Figure 23: Cross-vane design (Rosgen, 2001).
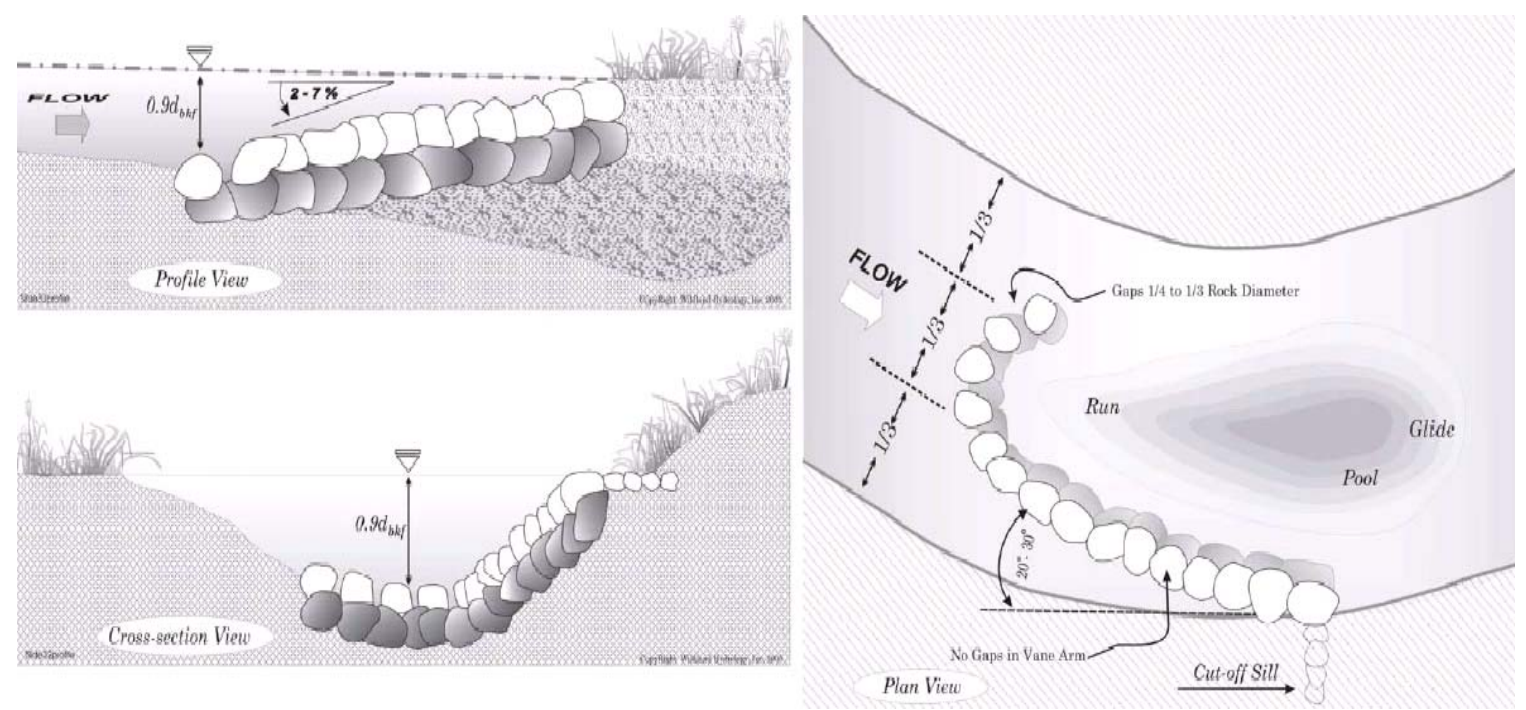

Figure 24: J-Hook vane design (Rosgen, 2001).

The function of deflectors in pools creation for natural channel restoration may be applicable for flood control channels restoration. However, the types of deflectors involved in natural channel restoration may not be necessary applicable for flood control channels restoration. 


\subsection{BED-LOAD TRANSPORT APPROACHES}

Bed-load transport is the motion of the sediment particles, such as rolling, sliding, or jumping along the bed, after the flow conditions satisfy or exceed the criteria of incipient motion. Generally, the bed-load transport rate of a meandering river is about $5 \%$ to $25 \%$ of that in suspension. However, for coarse bed material, which is similar to the pilot site of this research (Chapter 3), a higher percentage of sediment may be transported as bed-load (Yang, 1996).

Several bed-load transport approaches were reviewed in preparing the incoming sediment rate estimation in the physical experiments (Appendix N). The bed-load transport rate of each approach was also demonstrated in Appendix N. 


\subsection{LOCAL SCOUR EVALUATION USING ABUTMENT APPROACH}

This section reviews various approaches on local scour determination at abutments suggested by U.S. FHWA (Richardson and Davis, 2001). The differences between the subject of this research and abutments are the porosity involved in deflectors and the applicable locations. Deflectors in this research are applied along the meander section whereas abutments are usually located in straight channels. However, the methods used in determining the maximum scour depths for abutments may be able to use for the maximum scour depth estimation in deflectors.

\subsubsection{Basic Concepts of Scour Formation at Abutments}

Scour at abutments is the result of erosive action of flowing water, excavating and carrying away material from the bed and banks of streams. Total scour at abutments is comprised of three components: 1) long-term aggradation and degradation of the river bed, 2) general scour conditions such as contraction scour along the bridge, and 3) local scour at abutments. Each component is assumed to be independent from each other and adds some conservatism to scour depths prediction. Furthermore, lateral migration of the stream must be assessed when evaluating total scour at abutments (Richardson and Davis, 2001). 


\subsubsection{Aggradation and Degradation}

Aggradation and degradation are long-term and the net stream-bank sediment budget streambed elevation changes due to natural or man-induced causes which can affect the reach of the river on which a bridge is located. Aggradation involves deposition of material eroded from the channel or watershed upstream of the bridge. Degradation involves lowering or scouring of the streambed due to a deficit in sediment supply from upstream (Richardson and Davis, 2001).

\subsubsection{General Scour}

General scour is a lowering of the streambed across the stream or waterway bed at the bridge. It may result from contraction of the flow, or from other general scour conditions such as flow around a bend where scour may be concentrated near the outside of the bend. General scour is different from long-term degradation where general scour may be cyclic and/or related to the passing of a flood (Richardson and Davis, 2001).

\subsubsection{Local Scour}

Local scour involves removal of material around abutments. It is caused by an acceleration of flow and resulting vortices induced by obstructions to the flow. Local scour can be either clear-water scour or live-bed scour (Richardson and Davis, 2001). 


\section{Clear-Water Scour}

Clear-water scour occurs when there is no movement of the bed material in the flow upstream of the crossing or the bed material being transported in the upstream reach is transported in suspension through the scour hole at the abutment at less than the capacity of the flow. Typical clear-water scour situations include: 1) coarse-bed material streams; 2) flat gradient streams during low flow; 3) local deposits of larger bed materials that are larger than the coarsest fraction being transported by the flow (i.e. rock riprap); 4) armoured streambeds where the only locations that tractive forces are adequate to penetrate the armour layer are at abutments; and 5) vegetated channels or overbank areas (Richardson and Davis, 2001).

\section{Live-Bed Scour}

Live-bed scour occurs where there is transport of bed material from the upstream reach into the crossing. This type of local scour is cyclic in nature. The scour hole that develops during the rising stage of a flood likely refills during the falling stage (Richardson and Davis, 2001).

\subsubsection{Lateral Stream Migration}

Lateral migration occurs naturally in the main channel of a stream within a floodplain. It may affect the stability in a floodplain and bridge foundation, erode abutments or the approach roadway, or change the total scour by changing the 
flow angle of approach at abutments. Factors which affect lateral stream movement are: 1) morphology of the stream; 2) location of crossing on the stream; 3) flood characteristics; and 4) characteristics of the bed and bank materials (Richardson and Davis, 2001).

\subsubsection{Overview of Common Abutment Scour Equations}

Most of the existing equations for prediction of the scour depths around abutments, such as Liu et al. (1961), Laursen (1980), Froehlich (1989), and Melville (1992) are based on laboratory investigation. Liu et al.'s equations (1961) were developed by dimensional analysis of the abutment and channel variables with a best-fit curve drawn through the laboratory data. Laursen's equations (1980) were derived from inductive reasoning of the change in transport relations due to flow acceleration caused by the abutment. Froehlich's equations (1989) were based on dimensional and regression analysis of the available laboratory data. Melville's equations (1992) came from dimensional analysis and development of relations between dimensionless parameters using best-fit curves through laboratory data. The problem for these approaches is that there is limited field data to support the predictions. This may link to excessively conservative estimates on scour depth (Richardson and Davis, 2001).

Richardson and Richardson (1992) pointed out that abutment scour prediction would be more applicable to field conditions if discharge intercepted by the embankment is used. Strum (1999) identified a discharge distribution factor as an 
appropriate indicator of local scour depth. The U.S. FHWA had suggested certain methods, such as Froehlich's or HIRE Abutment Scour Equations, Maryland SHA Abutment Scour Evaluation Method, and Sturm Abutment Scour Equations guide scour depths prediction at abutments (Richardson and Davis, 2001). This research will use the first two methods to compare with the results of the physical experiments.

\subsubsection{Froehlich's or HIRE Abutment Scour Equations}

Froehlich's or the HIRE Abutment Scour Equations have been applied in scour depth prediction for both live-bed and clear-water scour conditions. Froehlich analyzed 170 live-bed scour measurements in laboratory flumes by regression analysis and its scour equation is suitable when the ratio of projected abutment length, $L$, to the flow depth, $y_{1}$, is small. The HIRE Abutment Scour Equation is based on field data of scour at the end of spurs in the Mississippi River. This field situation closely resembles the laboratory experiments for abutment scour with the discharge intercepted by the spurs a function of the spur length. The equation is applicable when the ratio of projected abutment length, $L$, to the flow depth, $y_{1}$, is greater than 25 (Richardson and Davis, 2001).

Froehlich's Abutment Scour Equation (Richardson and Davis, 2001):

$$
y_{s}=\left[2.27 K_{1} K_{2}\left(L^{\prime} / y_{a}\right)^{0.43} F^{0.61}+1\right] y_{a}
$$

where $K_{l}=$ coefficient for abutment shape, see Figure 25 and Table 1 , 
$K_{2}=$ coefficient for angle of abutment to flow, see Figure 26

$=(\theta / 90)^{0.13}$

$\theta=$ angle between the abutment and the downstream bank

$L=$ length of abutment projected normal to the flow, in metres

$L^{\prime}=$ length of active flow obstructed by the abutment, in metres

$V_{e}=$ velocity obstructed by the abutment and approach abutment, in $\mathrm{m} / \mathrm{s}$

$y_{a}=$ average depth of flow, in metres

$F r=$ Froude number of approach flow upstream of the abutment

$=V_{e} /\left(g y_{a}\right)^{0.5}$

$y_{s}=$ scour depth, in metres

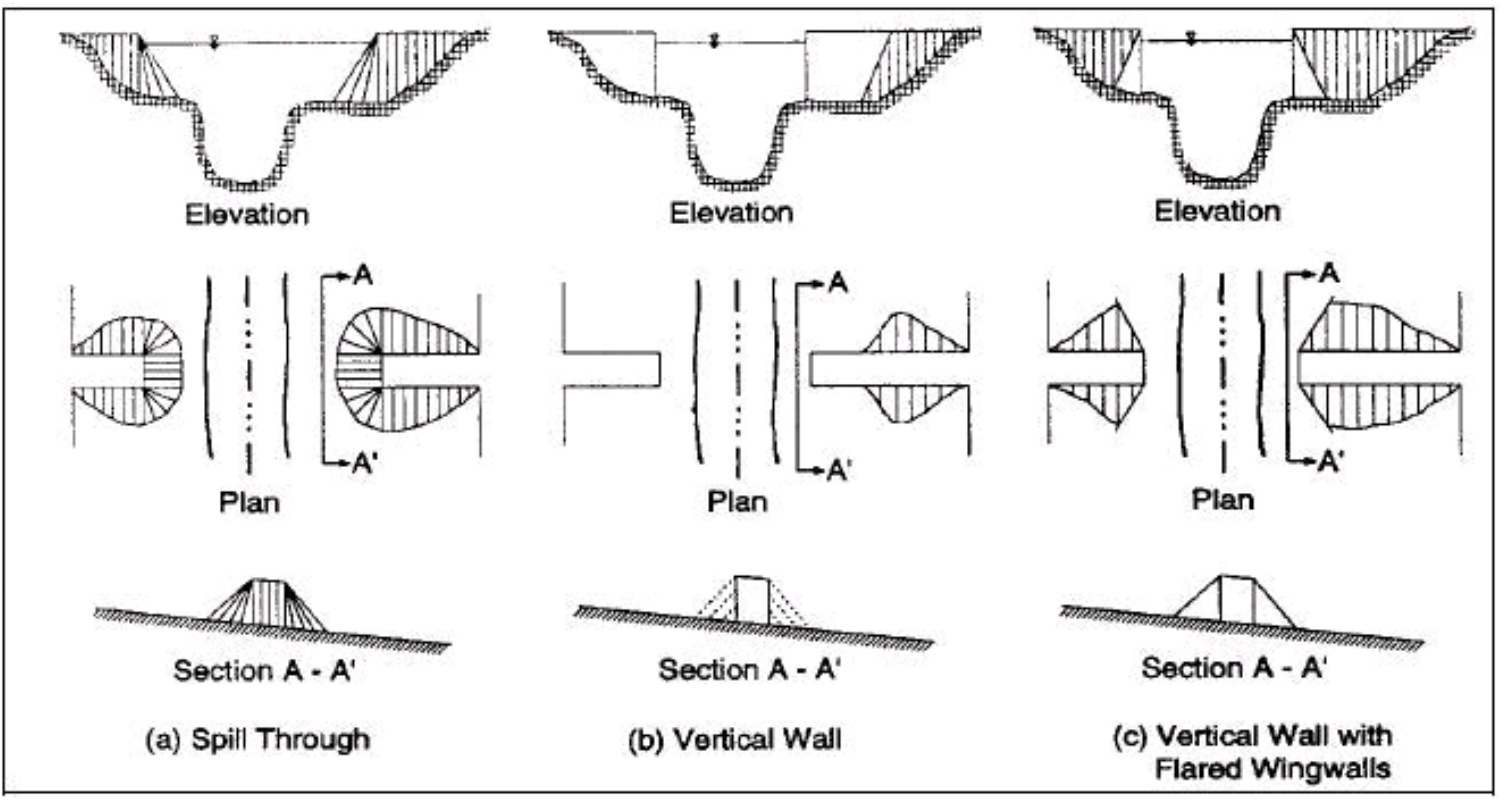

Figure 25: Abutment shapes (Richardson and Davis, 2001).

Table 1: Abutment shape coefficients (Richardson and Davis, 2001).

\begin{tabular}{|l|c|}
\hline \multicolumn{1}{|c|}{ Description } & $\boldsymbol{K}_{\boldsymbol{1}}$ \\
\hline Vertical-wall abutment & 1.00 \\
\hline Vertical-wall abutment with wing walls & 0.82 \\
\hline Spill-through abutment & 0.55 \\
\hline
\end{tabular}




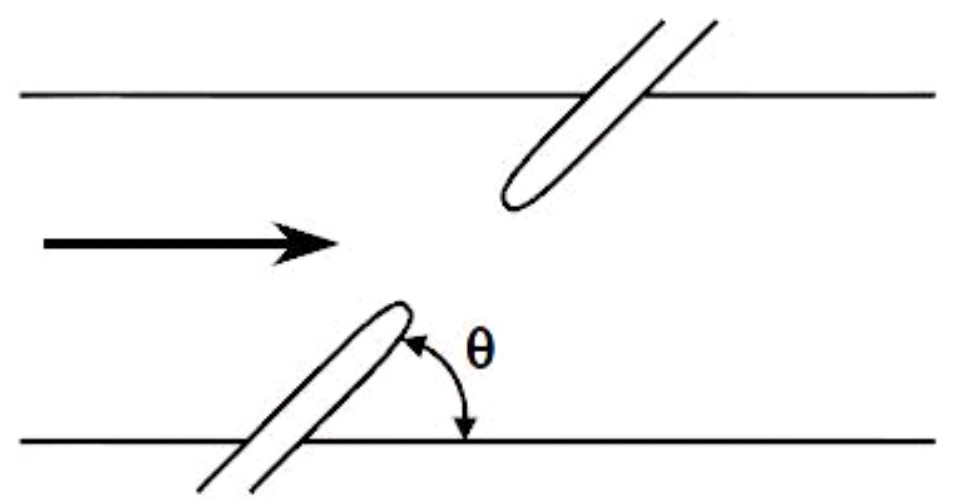

Figure 26: Orientation of embankment angles, $\theta$, to the Flow (Richardson and Davis, 2001).

For HIRE Abutment Scour Equation (Richardson and Davis, 2001):

$$
y_{s}=4 \mathrm{Fr}^{0.33}\left(K_{1} / 0.55\right) K_{2} y_{l}
$$

where $K_{l}=$ coefficient for abutment shape, see Figure 25 and Table 1

$K_{2}=$ coefficient for angle of abutment to flow, see Figure 26

$=(\theta / 90)^{0.13}$

$F r=$ Froude number of approach flow upstream of the abutment

$=V_{e} /\left(g y_{a}\right)^{0.5}$

$y_{1}=$ average depth of flow at the abutment on the overbank or in the main channel, in metres

$y_{s}=$ scour depth, in metres

Equations [2.1] and [2.2] are recommended for both live-bed and clear-water abutment scour conditions. If a method other than Froehlich's or HIRE equations is used. Scour for both the clear water and live bed condition should be computed. Engineering judgment should then be used to select the most appropriate scour depth. 


\subsubsection{Maryland SHA Abutment Scour Evaluation Method}

The Maryland SHA abutment scour equations are based on the research and development of Chang (1973). Chang applied Laursen's long contraction theory to both live-bed and clear-water scour. He developed a "velocity adjustment factor" $k_{v}$ to account for the non-uniform velocity distribution in the contracted section, and a "spiral-flow adjustment factor" $k_{f}$ at the abutment toe that depends on the approach Froude number. The value of $k_{v}$ was based on potential flow theory, and $k_{f}$ was determined by Chang from the analysis of a collection of abutment scour experiments in laboratory flumes (Chang, 1973; Brice \& Blodgett, 1978; Davis, 1984; Richardson and Davis, 2001).

For live-bed abutment scour (Richardson and Davis, 2001),

$$
y_{2 a}=k_{f} y_{1}\left[\left(k_{v} q_{2}\right) / q_{1}\right]^{K}
$$

where $y_{2 a}=$ total flow depth in the abutment scour hole after scour has occurred, measured from the water surface to the bottom of the scour hole, in metres

$y_{1}=$ average flow depth in the approach floodplain or channel section

$q_{1}=$ flow rate per unit width in the approach section, in $\left(\mathrm{m}^{3} / \mathrm{s}\right) / \mathrm{m}$

$q_{2}=$ flow rate per unit width in contracted section, in $\left(\mathrm{m}^{3} / \mathrm{s}\right) / \mathrm{m}$

$k_{v}=0.8\left(q_{1} / q_{2}\right)^{1.5}+1$

$V_{l}=$ average flow velocity in the approach floodplain or channel section, in $\mathrm{m} / \mathrm{s}$

$\mathrm{Fr}=$ Froude number in the approach section $=V_{l} /\left(g y_{1}\right)^{0.5}$

$k_{f}=0.35+3.2 F r$

$\tau_{c}=$ critical shear stress of the bed material, in $\mathrm{N} / \mathrm{m}^{2}$

$\tau_{1}=$ shear stress at approach section where $\tau_{1} \geq \tau_{c}$, in $\mathrm{N} / \mathrm{m}^{2}$

$K_{2}=$ Laursen's sediment transport function $=0.11\left(\tau_{c} / \tau_{1}+0.4\right)^{2.2}+0.623$ 
Values of $k_{v}$ should range from 1.0 to 1.8 and values of $k_{f}$ should range from 1.0 to 3.3. Limiting values should be used if the calculated value is smaller or larger than its range. Furthermore, value of $K_{2}$ varies from 0.637 to $0.857 . K_{2}$ should be equal to 0.857 if $\tau_{1} \leq \tau_{c}$. Even Equation 2.28 applies to live-bed scour, it can be used for clear-water scour if the shear stress in the approach section is at the critical value (Richardson and Davis, 2001).

Figure 27 illustrates the variables used in Equation 2.3. The same symbols are used for flow depth in the main channel and floodplain, but the subscript is changed to denote the approach section and the bridge section (Richardson and Davis, 2001).

Clear-water scour occurs if the shear stress in the approach section is less than critical, or if the approach section is armoured. The clear-water abutment scour equation is as follows (Richardson and Davis, 2001):

$$
y_{2 a}=K_{f}\left(k_{v}\right)^{0.857} y_{2 c}
$$

where $y_{2 a}=$ total flow depth in the abutment scour hole after scour has occurred, measured from the water surface to the bottom of the scour hole, in metres

$V_{c}=$ critical velocity above which bed material of size $D_{50}$ and smaller will be transported, in $\mathrm{m} / \mathrm{s}=K_{u} y^{1 / 6} D_{50}{ }^{1 / 3}$

$y=$ average depth of flow upstream of the abutment, in metres

$K_{u}=6.19$ for SI units

$y_{2 c}=$ clear water contraction scour depth in the channel at critical velocity, in metres $=q_{2} / V_{c}$

$q_{2}=$ flow rate per unit width in contracted section, in $\left(\mathrm{m}^{3} / \mathrm{s}\right) / \mathrm{m}$

$q_{1}=$ flow rate per unit width in the approach section, in $\left(\mathrm{m}^{3} / \mathrm{s}\right) / \mathrm{m}$ 
$k_{v}=0.8\left(q_{1} / q_{2}\right)^{1.5}+1$

$V_{l}=$ average flow velocity in the approach floodplain or channel section, in $\mathrm{m} / \mathrm{s}$

$y_{1}=$ average flow depth in the approach floodplain or channel section, in metres

$g$ = gravitational acceleration

$=9.806 \mathrm{~m} / \mathrm{s}^{2}$

$K_{f}=0.1+4.5 \mathrm{Fr}$

$\mathrm{Fr}=$ Froude number in the approach section

$=V_{l} /\left(g y_{1}\right)^{0.5}$

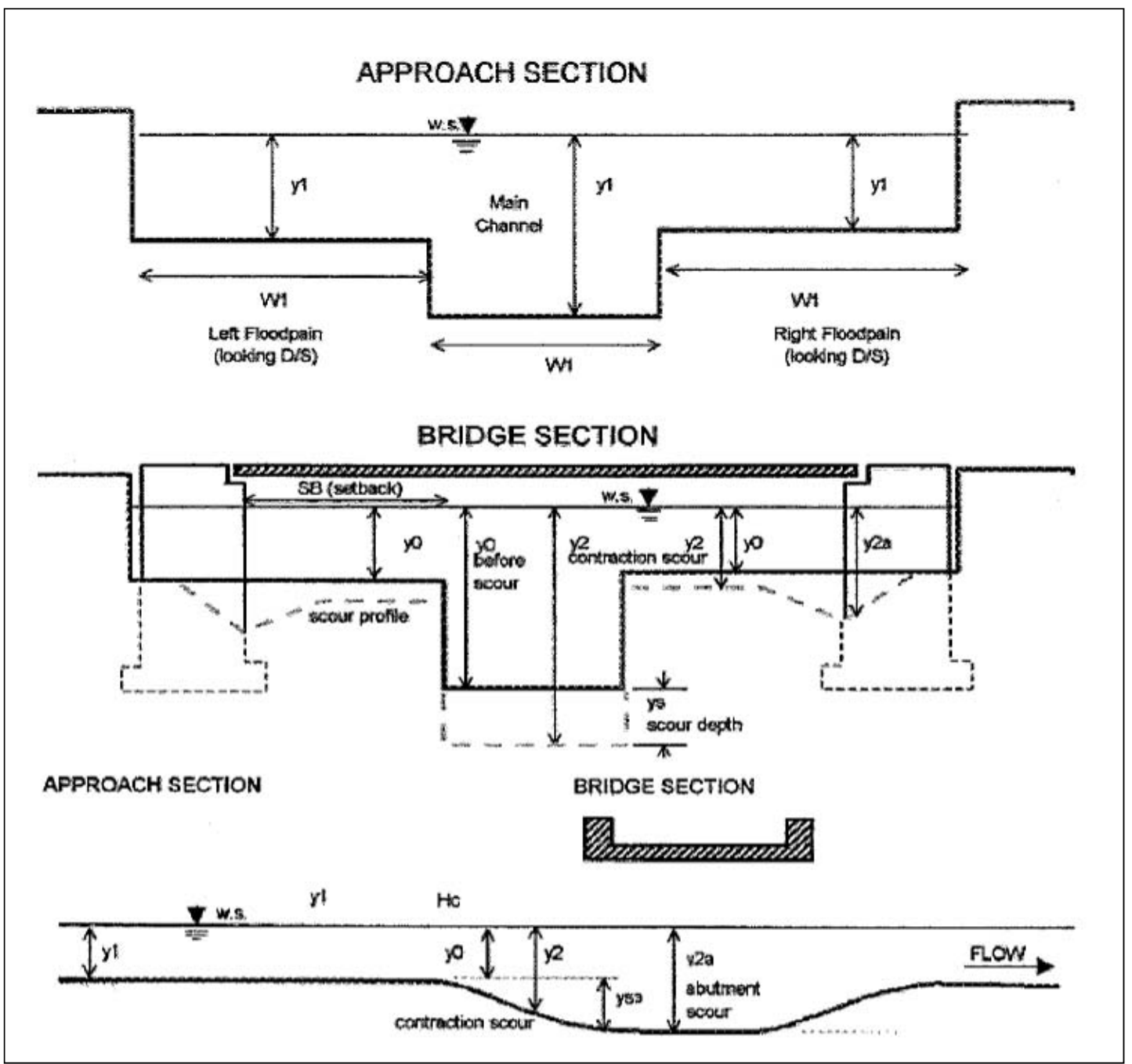

Figure 27: Definition sketches for scour predictions (Richardson and Davis, 2001). 


\subsection{NUMERICAL SOFTWARE INVESTIGATION}

Preliminary investigations of the sediment transport software that may be applicable for the stream restoration designs are listed in Table 2 and Appendix W. The reasons for selecting the software for preliminary review relate to the applications summarized in Table 3.

Further investigations were conducted on GSTARS 2.1, MIKE 21 and CCHE2D models due to their availability and variation of the base numerical methods among the software. The demo version of GSTARS 2.1 was provided by Professor Yang of Colorado State University, USA. The input file of the program was found to be very sensitive in space and significant digits and the manual did not explained clearly about the locations of the sensitive areas. Moreover, the manual also indicated that the model ignores secondary current phenomena. Thus, it was found not useful for the deflector designs in this research. For MIKE 21 , the version used for the investigation was not fully registered. During the preinvestigation of the program, uncertainties were also found between the original straight boundaries of the low-flow channel and flood channel. Thus, CCHE2D model was finally selected for the numerical modelling phase due to the following reasons:

- It is freeware;

- It has a finite element base;

- It has the capability to address secondary flow on the main flow and sediment transport in curved channels 
Table 2: Overview of 2D sediment transport models (Papanicolaou et. al. 2008; Garcia, 2008).

\begin{tabular}{|c|c|c|c|c|c|c|c|c|c|}
\hline Model and Reference & Flow & $\begin{array}{l}\text { Bed-Load } \\
\text { Transport }\end{array}$ & $\begin{array}{l}\text { Bed } \\
\text { Elevation } \\
\text { Changes }\end{array}$ & $\begin{array}{l}\text { Suspended } \\
\text { Sediment } \\
\text { Transport }\end{array}$ & $\begin{array}{l}\text { Sediment- } \\
\text { Exchange } \\
\text { Processes }\end{array}$ & $\begin{array}{l}\text { Sediment } \\
\text { Mixtures }\end{array}$ & $\begin{array}{l}\text { Cohesive } \\
\text { Sediment }\end{array}$ & $\begin{array}{c}\text { Base } \\
\text { Numerical } \\
\text { Method }\end{array}$ & Executable \\
\hline $\begin{array}{l}\text { SUTRENCH-2D: } \\
\text { SUspended sediment } \\
\text { transport in TRENCHes } \\
\text { (van Rijn \& Tan 1985,1987) }\end{array}$ & $\begin{array}{l}\text { Quasi } \\
\text { unsteady } \\
\text { 2D (width- } \\
\text { averaged) }\end{array}$ & Yes & $\begin{array}{l}\text { total-load } \\
\text { concept }\end{array}$ & Yes & $\begin{array}{l}\text { entrainment } \\
\text { and } \\
\text { deposition }\end{array}$ & No & No & $\begin{array}{l}\text { finite-volume } \\
\text { with } \\
\text { structured } \\
\text { grid }\end{array}$ & No \\
\hline $\begin{array}{l}\text { TABS-2 } \\
\text { (Thomas and McAnally, } \\
\text { 1985) }\end{array}$ & $\begin{array}{l}\text { unsteady } \\
\text { 2D (depth- } \\
\text { averaged) }\end{array}$ & Yes & $\begin{array}{l}\text { Exner } \\
\text { equation, } \\
\text { empirical } \\
\text { total-load } \\
\text { formula }\end{array}$ & Yes & $\begin{array}{l}\text { entrainment } \\
\text { and } \\
\text { deposition }\end{array}$ & No & Yes & $\begin{array}{l}\text { finite- } \\
\text { element }\end{array}$ & No \\
\hline $\begin{array}{l}\text { MOBED2: MObile BED } \\
\text { (Spasojevic and Holly, } \\
\text { 1990) }\end{array}$ & $\begin{array}{l}\text { unsteady } \\
\text { 2D (depth- } \\
\text { averaged) }\end{array}$ & Yes & $\begin{array}{l}\text { active- } \\
\text { layer and } \\
\text { active- } \\
\text { stratum } \\
\text { concept }\end{array}$ & Yes & $\begin{array}{l}\text { entrainment } \\
\text { and } \\
\text { deposition }\end{array}$ & Yes & No & $\begin{array}{l}\text { finite- } \\
\text { difference } \\
\text { with } \\
\text { Lagrangian } \\
\text { advection } \\
\end{array}$ & No \\
\hline $\begin{array}{l}\text { FAST2D: Flow Analysis } \\
\text { Simulation Tool } \\
\text { (Minh Duc et al., 1998) }\end{array}$ & $\begin{array}{l}\text { unsteady } \\
\text { 2D (depth- } \\
\text { averaged) }\end{array}$ & Yes & $\begin{array}{l}\text { total-load } \\
\text { concept }\end{array}$ & Yes & $\begin{array}{l}\text { entrainment } \\
\text { and } \\
\text { deposition }\end{array}$ & No & No & $\begin{array}{l}\text { finite-volume } \\
\text { with } \\
\text { structured } \\
\text { grid }\end{array}$ & No \\
\hline $\begin{array}{l}\text { MIKE 21: Danish acronym } \\
\text { of the word microcomputer } \\
\text { (DHI 2007, 2007a, 2004) }\end{array}$ & $\begin{array}{l}\text { unsteady } \\
2 D\end{array}$ & Yes & $\begin{array}{l}\text { total-load } \\
\text { concept }\end{array}$ & Yes & $\begin{array}{l}\text { entrainment } \\
\text { and } \\
\text { deposition }\end{array}$ & No & Yes & $\begin{array}{l}\text { finite- } \\
\text { difference }\end{array}$ & No \\
\hline $\begin{array}{l}\text { CCHE2D: The National } \\
\text { Center for Computational } \\
\text { Hydroscience and } \\
\text { Engineering (Zhang and } \\
\text { Jia 2005, 2009, 2009a) }\end{array}$ & $\begin{array}{l}\text { unsteady } \\
\text { 2D (depth- } \\
\text { averaged) }\end{array}$ & Yes & $\begin{array}{l}\text { Exner } \\
\text { equation }\end{array}$ & Yes & $\begin{array}{l}\text { convection- } \\
\text { diffusion }\end{array}$ & Yes & No & $\begin{array}{l}\text { finite- } \\
\text { element }\end{array}$ & Yes \\
\hline
\end{tabular}




\begin{tabular}{|c|c|c|c|c|c|c|c|c|c|}
\hline Model and Reference & Flow & $\begin{array}{l}\text { Bed-Load } \\
\text { Transport }\end{array}$ & $\begin{array}{c}\text { Bed } \\
\text { Elevation } \\
\text { Changes }\end{array}$ & $\begin{array}{c}\text { Suspended } \\
\text { Sediment } \\
\text { Transport }\end{array}$ & $\begin{array}{l}\text { Sediment- } \\
\text { Exchange } \\
\text { Processes }\end{array}$ & $\begin{array}{l}\text { Sediment } \\
\text { Mixtures }\end{array}$ & $\begin{array}{l}\text { Cohesive } \\
\text { Sediment }\end{array}$ & $\begin{array}{c}\text { Base } \\
\text { Numerical } \\
\text { Method }\end{array}$ & Executable \\
\hline $\begin{array}{l}\text { GSTARS 2.1: } \\
\text { Generalized Sediment } \\
\text { Transport models for } \\
\text { Alluvial River Simulation } \\
\text { (Yang and Simões, 2000) }\end{array}$ & $\begin{array}{l}\text { Quasi- } \\
\text { steady } \\
\text { semi-2D }\end{array}$ & Yes & $\begin{array}{l}\text { total-load } \\
\text { concept }\end{array}$ & Yes & $\begin{array}{l}\text { entrainment } \\
\text { and } \\
\text { deposition }\end{array}$ & Yes & No & stream tube & Yes \\
\hline $\begin{array}{l}\text { Delft 2D } \\
\text { (Walstra et al., 1998) }\end{array}$ & $\begin{array}{l}\text { unsteady } \\
\text { 2D }\end{array}$ & Yes & $\begin{array}{l}\text { total-load } \\
\text { concept }\end{array}$ & Yes & $\begin{array}{l}\text { convection- } \\
\text { diffusion }\end{array}$ & No & Yes & $\begin{array}{l}\text { finite- } \\
\text { difference }\end{array}$ & No \\
\hline
\end{tabular}

Table 3: Applications for selected models in Table 2 (Garcia, 2008).

\begin{tabular}{|l|l|}
\hline \multicolumn{1}{|c|}{ Model } & \multicolumn{1}{c|}{ Applications } \\
\hline \hline SUTRENCH-2D & $\begin{array}{l}\text { Simulation of sand transport processes and associated bed-level changes along dredged pits and trenches at the lower } \\
\text { Dutch coast, The Netherlands. (Walstra et al., 1998) }\end{array}$ \\
\hline TABS-2 & $\begin{array}{l}\text { Evaluation of the hydraulic performance of different structures found in the Missouri River for creating new shallow water } \\
\text { habitat. (Gee, 1995) }\end{array}$ \\
\hline MOBED2 & Simulation of mobile-bed dynamics in the Coralville Reservoir on the lowa River, lowa. (Spasojevic and Holly, 1990) \\
\hline FAST2D & $\begin{array}{l}\text { Simulation of sediment transport processes and associated bed level changes of a reach in the Bavarian Danube River, } \\
\text { Germany. (Minh Duc et al., 1998) }\end{array}$ \\
\hline MIKE 21 & Practical application in 1) Snake River, USA; 2) Skjern River, Denmark; 3) Loire River, France. (DHI, 2004) \\
\hline CCHE2D & $\begin{array}{l}\text { Investigation of the effects of large woody debris structures on the fluvial processes in the Little Topashaw Creek, } \\
\text { Mississippi. (Wu et al., 2005) }\end{array}$ \\
\hline GSTARS 2.1 & $\begin{array}{l}\text { Prediction of the scour depth and pattern at the Lock and Dam No. 26 replacement site on the Mississippi River, Illinois. } \\
\text { (Yang and Simões, 2000) }\end{array}$ \\
\hline Delft 2D & Morphodynamic modelling approach to Tenryuu River, Japan. (Sloff et al., 2001) \\
\hline
\end{tabular}




\subsection{CCHE2D PROGRAM}

The CCHE2D program is an analysis system composed of a structured mesh generator (CCHE2D-MESH program), a Graphical Users Interface (CCHE-GUI program), and a separate hydrodynamic numerical model (CCHE2D model). The following sections focus on the fundamental equations and concepts of the mesh generation method, hydrodynamic and sediment transport methods involved in preparing the numerical model (chapter 5).

\subsubsection{Mesh Generation}

Computational fluid dynamics (CFD) is based on solving a set of highly nonlinear partial differential equations (PDE) for a physical domain. This domain is usually discretized and represented by a computational mesh. Despite the numerical method used, the success of solving the PDE depends largely on the spatial resolution of the variability of fluid properties being modelled (Zhang and Jia, 2009). The following concerns are taken into consideration for mesh quality evaluation (Zhang, 2006):

- The interested zone(s) has sufficient resolution;

- Transition(s) between areas of different densities is smooth;

- Inlet(s) and outlet(s) are sufficiently far away from the interested zone(s);

- The mesh is smooth and orthogonal as much as possible. 
In CFD, there are two general types of meshes: structured and unstructured. The structured meshes consist of families of mesh lines with the property that members of a single family do not cross each other and cross each member of the other families only once, while the unstructured mesh does not have such a restriction. The advantage of the structured mesh is that any mesh node is uniquely identified by a set of two- (2D mesh) or three-indices (3D mesh) and it is easy to access. In the unstructured meshes, a connection table is required to identify the relationship of the mesh nodes (Zhang and Jia, 2009).

The CCHE-MESH program is developed to generate the structured meshes. The methods applied in the structured mesh generation are grouped into two categories: algebraic methods and numerical methods. The algebraic methods generate a mesh directly by interpolation while the numerical methods solve a set of PDE to determine the mesh distribution. Although the algebraic method can always resolve a mesh with the minimum computational effort, the quality of the mesh (i.e. smoothness and orthogonality) is often not globally satisfactory especially when the computational domain is complex. Thus, smoothing or optimizing methods may have to be used to further improve the quality of mesh (Zhang and Jia, 2009).

\subsubsection{Algebraic Mesh Generation}

In the CCHE-MESH program, a two-boundary method combined with a multiblock scheme is used to generate the algebraic meshes. A simple single-block 
domain is shown in Figure 28 for demonstration purposes. The domain consists of two kinds of boundaries: the outer boundaries and the inner boundaries. The shape of the domain is controlled by the outer boundaries, while the area surrounded by the inner boundaries (i.e. islands) is considered to be "outside" of the domain. That is, the mesh nodes in this area are inactive during the numerical simulation. Both the outer boundaries and the inner boundaries are composed of the top boundary (also called the "First" boundary in the "Block Editing" toolbar), bottom boundary (also called the "Second" boundary in the "Block Editing" toolbar), left boundary, and right boundary. In the two-boundary method, only the top boundary and the bottom boundary are independent and used to control the geometry. The left boundary and the right boundary are dependent on the top and bottom boundaries. The equal number of control points is distributed along the top and bottom boundaries to approximate the boundary curves. The control points divide the whole domain into sub-sections (Zhang and Jia, 2009).

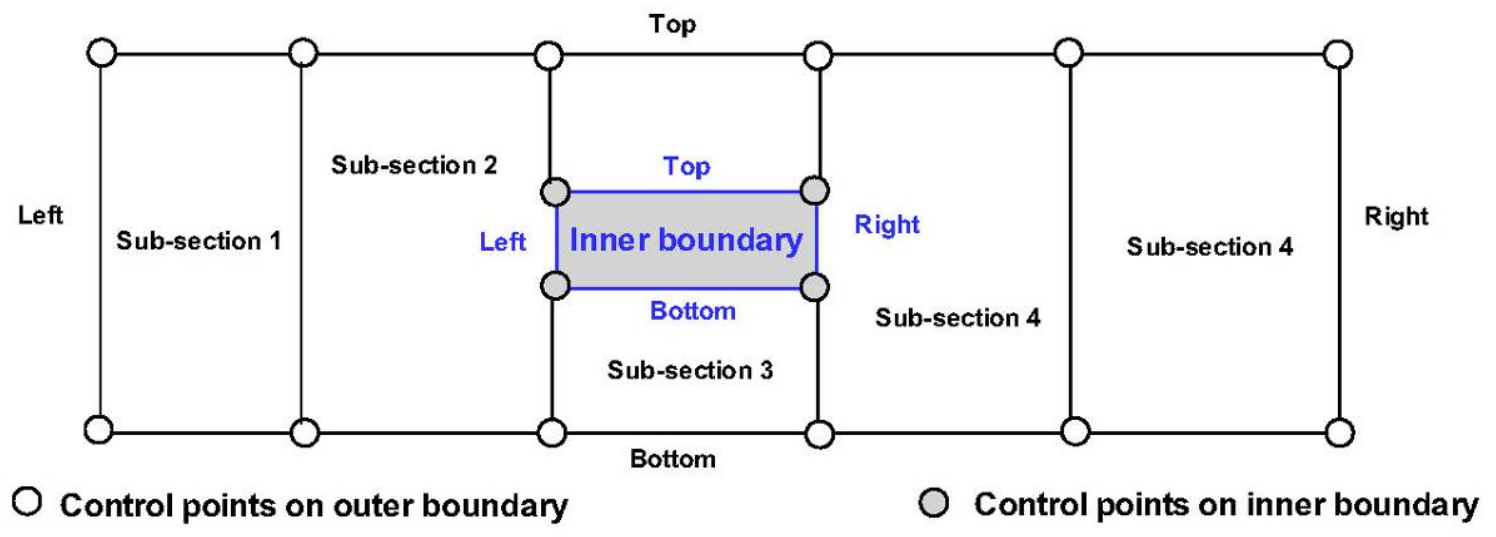

Figure 28: A single-block domain (Zhang and Jia, 2009). 


\subsubsection{Mesh Smoothness}

Generally, the effect of the computational mesh on the solutions of PDE may be influenced by: 1) errors from non-orthogonality, and 2) errors from nonsmoothness (Thompson et al., 1985). Thus, orthogonality and smoothness are considered as standard academic criteria to characterize the mesh quality. However, purely orthogonal and smooth meshes only exist in specific domains with simple geometries. For geometrically complex domains, compromises must be made between them (Zhang et al., 2006).

In this research, the "RL mesh with smoothness control" function in the CCHE2D program was applied after algebraic mesh generation. "RL" stands for Ryskin and Leal system (Ryskin and Leal, 1983). It is the most robust and widely used elliptic mesh generation systems and is derived according to the analogue of the Laplace equation for the stream function and velocity potential function. However, it is aimed at orthogonal mapping without considering smoothness. This means that when applying the RL system to geometrically complex domains using the "weak constraint' method (Ryskin and Leal, 1983), problems such as mesh distortion and overlapping may occur (Akcelik et al., 2001; Zhang et al., 2004). One way to resolve these problems is to introduce a source term without any construction of parameter into the RL system to control the mesh smoothness, which is the purpose of the "RL mesh with smoothness control" function in the CCHE2D program (Akcelik et al., 2001; Zhang et al., 2004, 2006). 


\subsubsection{Hydrodynamic Governing Equations}

The hydrodynamic depth-integrated two-dimensional governing equations in a CCHE2D model are obtained through formal Reynolds-averaged Navier-Stokes equations, which are derived from the incompressible-fluid Navier-Stokes equations through temporal averaging of instantaneous velocities over an appropriate time scale. This operation results in a shift of the stresses associated with momentum exchange of correlated fluctuating velocities from the momentum-advection terms to Reynolds stress terms (Zhang, 2006; Garcia, 2008). The depth-averaged mass conservation (continuity) equation then becomes

$$
\frac{\partial Z}{\partial t}+\frac{\partial(h u)}{\partial x}+\frac{\partial(h v)}{\partial y}=0
$$

The depth-averaged $u$ - and $v$-momentum conservation equations are (Zhang, 2006):

$$
\begin{aligned}
& \frac{\partial u}{\partial t}+u \frac{\partial u}{\partial x}+v \frac{\partial u}{\partial y}=-g \frac{\partial Z}{\partial x}+\frac{1}{h}\left[\frac{\partial\left(h \tau_{x x}\right)}{\partial x}+\frac{\partial\left(h \tau_{x y}\right)}{\partial y}\right]-\frac{\tau_{b x}}{\rho h}+f_{C o r} v \\
& \frac{\partial v}{\partial t}+u \frac{\partial v}{\partial x}+v \frac{\partial v}{\partial y}=-g \frac{\partial Z}{\partial y}+\frac{1}{h}\left[\frac{\partial\left(h \tau_{y x}\right)}{\partial x}+\frac{\partial\left(h \tau_{y y}\right)}{\partial y}\right]-\frac{\tau_{b y}}{\rho h}+f_{C o r} u
\end{aligned}
$$

where $u$ = depth-integrated velocity component in the $x$-direction

$v=$ depth-integrated velocity component in the $y$-direction

$g=$ gravitational acceleration

$Z=$ water surface elevation

$\rho=$ water density

$h=$ local water depth

$f_{\text {Cor }}=$ Coriolis parameter

$\tau_{x x}, \tau_{x y}, \tau_{y x}, \tau_{y y}=$ depth-integrated Reynolds stresses

$\tau_{b x}, \tau_{b y}=$ shear stresses on the bed surface 
The Reynolds stresses in equations [2.6] and [2.7] must be resolved using an appropriate turbulence model. One commonly used simplified approach to solve this "turbulence closure" problem is to express the Reynolds stresses through the Boussinesq eddy-viscosity model. It assumes that the Reynolds stress is related to the mean rate of strain, the eddy viscosity, and to the turbulent kinetic energy. The turbulent kinetic-energy term is usually absorbed into the pressure-gradient term, whereas the mean rate of strain is subject to further simplification. Thus, the Reynolds stresses become (Zhang, 2006; Garcia, 2008):

$$
\begin{aligned}
& \tau_{x x}=2 v_{t} \frac{\partial u}{\partial x} \\
& \tau_{x y}=\tau_{y x}=v_{t}\left(\frac{\partial u}{\partial y}+\frac{\partial v}{\partial x}\right) \\
& \tau_{y y}=2 v_{t} \frac{\partial v}{\partial y}
\end{aligned}
$$

where $v_{t}=$ eddy viscosity

\subsubsection{Two-Dimensional $k-\varepsilon$ Model}

The $k-\varepsilon$ model, one of the most common two-dimensional eddy-viscosity methods, in preparing the numerical model (chapter 5). The $k-\varepsilon$ model includes two extra transport equations, the turbulent kinetic energy $k$ and the turbulent dissipation $\varepsilon$, to represent the turbulent properties of flow where (Zhang, 2006; Wilcox, 1998), 


$$
\begin{aligned}
& k=\frac{1}{2} \overline{u_{i}{ }^{\prime} u_{i}{ }^{\prime}} \\
& \varepsilon=\mu_{t} \frac{\partial u_{i}{ }^{\prime}}{\partial x_{j}} \frac{\partial u_{i}{ }^{\prime}}{\partial x_{j}}
\end{aligned}
$$

Thus, the depth-integrated governing equations for $k$ and $\varepsilon$ become (Zhang, 2006; Garcia, 2008):

$$
\begin{gathered}
\frac{\partial k}{\partial t}+u \frac{\partial k}{\partial x}+v \frac{\partial k}{\partial y}-\frac{\partial}{\partial x}\left[\frac{v_{t}}{\sigma_{k}} \frac{\partial k}{\partial x}\right]-\frac{\partial}{\partial y}\left[\frac{v_{t}}{\sigma_{k}} \frac{\partial k}{\partial y}\right]=P-\varepsilon+P_{k V} \\
\frac{\partial \varepsilon}{\partial t}+u \frac{\partial \varepsilon}{\partial x}+v \frac{\partial \varepsilon}{\partial y}-\frac{\partial}{\partial x}\left[\frac{v_{t}}{\sigma_{\varepsilon}} \frac{\partial \varepsilon}{\partial x}\right]-\frac{\partial}{\partial y}\left[\frac{v_{t}}{\sigma_{\varepsilon}} \frac{\partial \varepsilon}{\partial y}\right]=c_{1 \varepsilon} \frac{\varepsilon}{k} P-c_{2 \varepsilon} \frac{\varepsilon^{2}}{k}+P_{\varepsilon V} \\
\text { where } P=-\overline{u_{i}{ }^{\prime} u_{j}{ }^{\prime} u_{i, j}}=v_{t}\left[2\left(\frac{\partial u}{\partial x}\right)^{2}+2\left(\frac{\partial v}{\partial y}\right)^{2}+\left(\frac{\partial u}{\partial x}+\frac{\partial v}{\partial y}\right)^{2}\right] \\
P_{k V}=C_{k} \frac{U_{*}{ }^{3}}{h} \\
P_{\varepsilon V}=C_{\varepsilon} \frac{U_{*}^{4}}{h^{2}} \\
U_{*}=\sqrt{c_{f}\left(u^{2}+v^{2}\right)} \\
C_{k}=\frac{1}{\sqrt{c_{f}}} \\
C_{\varepsilon}=3.6 \frac{c_{2 \varepsilon}}{c_{f}^{0.75}} \sqrt{c_{\mu}}
\end{gathered}
$$

and $\quad U_{*}=$ shear velocity

$c_{f}=$ friction coefficient

$\sigma_{\varepsilon}=$ turbulent Schmidt number for the diffusive transport of $\varepsilon$

$\sigma_{k}=$ turbulent Schmidt number for $k$

$c_{1 \varepsilon}=$ coefficient in the source term of the $\varepsilon$ equation 
$c_{2 \varepsilon}=$ coefficient in the sink term of the $\varepsilon$ equation

$c_{\mu}=$ coefficient in eddy viscosity specification

$P=$ rate of production of $k$ by the interaction of Reynolds stresses with the mean strain rate

$P_{k V}=$ effect on $k$ equation of other forces or strains

$P_{\varepsilon V}=$ effect on $\varepsilon$ equation of other forces or strains

The $k-\varepsilon$ model requires five model constants: $c_{1 \varepsilon}, c_{2 \varepsilon}, c_{\mu}, \sigma_{\varepsilon}$ and $\sigma_{k}$. The first three constants are determined from experimental observation where the last two were tuned to a variety of flows (Garcia, 2008). The constant values used in CCHE2D program are (Zhang, 2006): $c_{1 \varepsilon}=1.45, c_{2 \varepsilon}=1.90, c_{\mu}=0.09, \sigma_{\varepsilon}=1.3$, $\sigma_{k}=1.0$

\subsubsection{Sediment Transport Governing Equations}

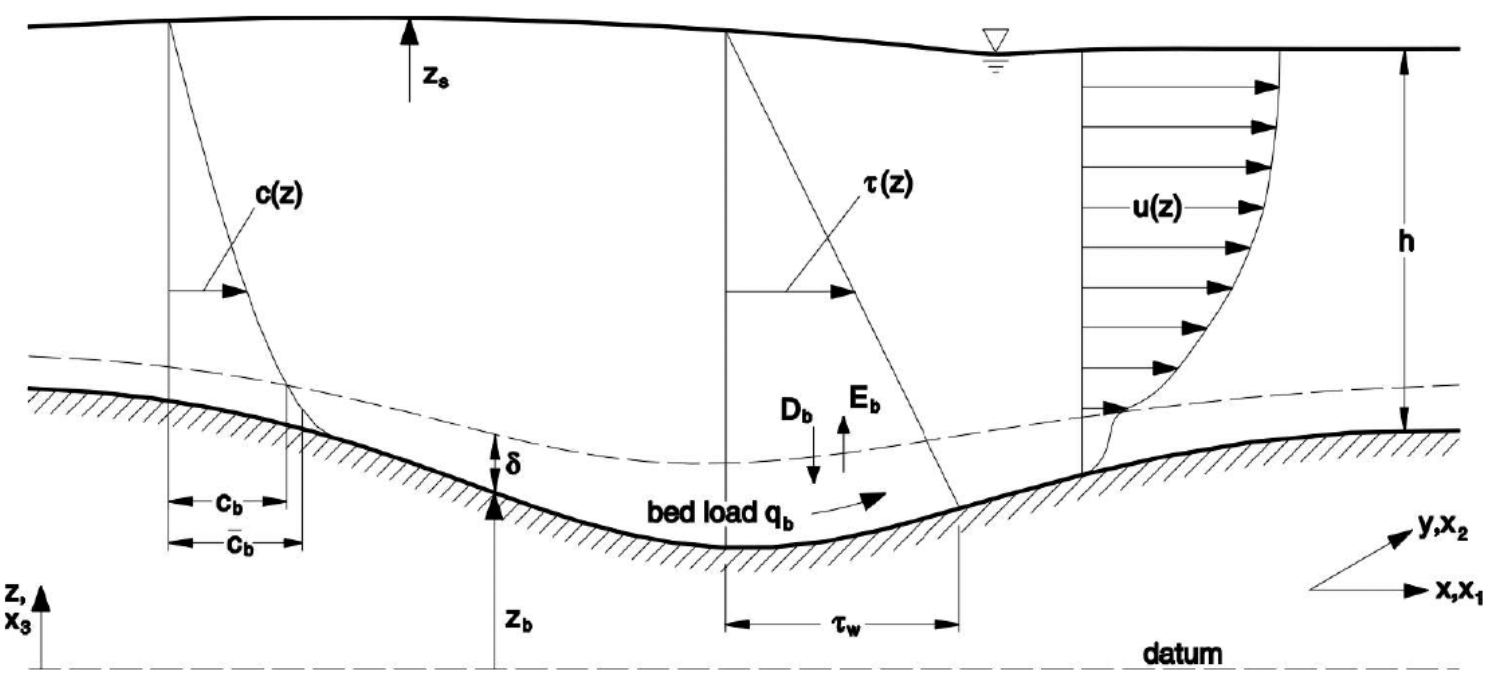

Figure 29: Vertical schematization of the sediment-processes domain (Zhang, 2006). 
Figure 28 depicts the vertical schematization of the sediment-processes domain. The full water depth is divided into two zones: suspended-load zone and bedload zone. The thickness of the bed-load zone, $\delta$, is a variable related to the saltation height of sediment particles. To simplify the problem, it is usually assumed to be twice the sediment diameter, $d$ (Einstein, 1950). Thus, the bedload zone can be defined as from $z_{b}$ to $\left(z_{b}+\delta\right)$ and the suspended-load zone is from $\left(z_{b}+\delta\right)$ to $z_{s}$.(Wu et al., 2000; Zhang, 2006).

For non-uniform sediment transport, the sediment mixture can be divided into several size classes. The three-dimensional convection-diffusion equation of sediment transport is (Zhang, 2006):

$$
\frac{\partial c_{k}}{\partial t}+\frac{\partial\left(u c_{k}\right)}{\partial x}+\frac{\partial\left(v c_{k}\right)}{\partial y}+\frac{\partial\left(w c_{k}\right)}{\partial z}-\frac{\partial\left(\omega_{s k} c_{k}\right)}{\partial z}=\frac{\partial}{\partial x}\left(\varepsilon_{s} \frac{\partial c_{k}}{\partial x}\right)+\frac{\partial}{\partial y}\left(\varepsilon_{s} \frac{\partial c_{k}}{\partial y}\right)+\frac{\partial}{\partial z}\left(\varepsilon_{s} \frac{\partial c_{k}}{\partial z}\right)
$$

where $c_{k}=$ concentration of $k$-th size class of sediment

$\omega_{s k}=$ settling velocity of the $k$-th size class of sediment

$\varepsilon_{s}=$ eddy diffusivity of sediment

$u, v, w=$ velocity components in $x$-, $y$ - and $z$-directions, respectively, with $z$-direction being assigned as the vertical direction along the gravity

The eddy diffusivity of sediment, $\varepsilon_{s}$, can be calculated as:

$$
\varepsilon_{s}=v_{t} / \sigma_{s}
$$

where $v_{t}=$ eddy viscosity of flow

$\sigma_{s}=$ turbulent Prandtl-Schmidt number ranging of 0.5 to 1.0 
The integration of the three-dimensional equation [2.21] over the suspended-load zone is:

$$
\begin{aligned}
& \int_{z_{b}+\delta}^{z_{s}} \frac{\partial c_{k}}{\partial t} d z+\int_{z_{b}+\delta}^{z_{\delta}} \frac{\partial\left(u c_{k}\right)}{\partial x} d z+\int_{z_{b}+\delta}^{z_{\delta}} \frac{\partial\left(v c_{k}\right)}{\partial y} d z+\int_{z_{b}+\delta}^{z_{\delta}} \frac{\partial\left(w c_{k}\right)}{\partial z} d z-\int_{z_{b}+\delta}^{z_{\delta}} \frac{\partial\left(\omega_{s k} c_{k}\right)}{\partial z} d z \\
& =\int_{z_{b}+\delta}^{z_{\delta}}\left[\frac{\partial}{\partial x}\left(\varepsilon_{s} \frac{\partial c_{k}}{\partial x}\right)\right] d z+\int_{z_{b}+\delta}^{z_{s}}\left[\frac{\partial}{\partial y}\left(\varepsilon_{s} \frac{\partial c_{k}}{\partial y}\right)\right] d z+\int_{z_{b}+\delta}^{z_{\delta}}\left[\frac{\partial}{\partial z}\left(\varepsilon_{s} \frac{\partial c_{k}}{\partial z}\right)\right] d z
\end{aligned}
$$

The boundary condition of suspended sediment at the water surface is:

$$
\frac{v_{t}}{\sigma_{c}} \frac{\partial c_{k}}{\partial z}+\omega_{s k} c_{k}=0
$$

The boundary condition of suspended sediment at the interface between suspended load and bed load is assumed to be:

$$
\frac{v_{t}}{\sigma_{c}} \frac{\partial c_{k}}{\partial z}+\omega_{s k} c_{b^{*} k}=0
$$

where $c_{b^{*} k}=$ equilibrium suspended-load concentration at the interface between the bed-load zone and the suspended-load zone.

Moreover, the depth-averaged suspended-load concentration, $C_{k}$, is defined as:

$$
C_{k}=\frac{1}{h-\delta} \int_{z_{b}+\delta}^{z_{s}} c_{k} d z
$$

By substituting equations [2.24], [2.25] and [2.26] into equation [2.23], the depthintegrated convection-diffusion equation of suspended load transport is: 


$$
\begin{aligned}
& \frac{\partial}{\partial t}\left[(h-\delta) C_{k}\right]+\frac{\partial}{\partial x}\left[U(h-\delta) C_{k}\right]+\frac{\partial}{\partial y}\left[V(h-\delta) C_{k}\right] \\
& =\frac{\partial}{\partial x}\left[\varepsilon_{s}(h-\delta) \frac{\partial C_{k}}{\partial x}\right]+\frac{\partial}{\partial y}\left[\varepsilon_{s}(h-\delta) \frac{\partial C_{k}}{\partial y}\right]+\frac{\partial S_{x x}}{\partial x}+\frac{\partial S_{x z}}{\partial z}+E_{b k}-D_{b k}
\end{aligned}
$$

where $U, V=$ depth-averaged flow velocities in $x$ - and $y$-directions

$$
\begin{aligned}
S_{x x}, S_{x z}= & \text { dispersion terms due to the non-uniform distributions of flow } \\
& \text { velocity and sediment concentration. } \\
E_{b k}, D_{b k}= & \text { entrainment and deposition fluxes of the } k \text {-th size class of } \\
& \text { sediment at the interface between suspended-load zone } \\
& \text { and bed-load zone }
\end{aligned}
$$

Since the bed-load zone is usually very thin (i.e. $\delta<<h$ ), equation [2.27] can be simplified to:

$$
\frac{\partial\left(h C_{k}\right)}{\partial t}+\frac{\partial\left(U h C_{k}\right)}{\partial x}+\frac{\partial\left(V h C_{k}\right)}{\partial y}=\frac{\partial}{\partial x}\left[\varepsilon_{s} h \frac{\partial C_{k}}{\partial x}\right]+\frac{\partial}{\partial y}\left[\varepsilon_{s} h \frac{\partial C_{k}}{\partial y}\right]+E_{b k}-D_{b k}
$$

The continuity equation of bed load is derived by integrating Equation [2.21] over the bed-load zone (Zhang, 2006; Garcia, 2008),

$$
\left(1-p^{\prime}\right) \frac{\partial z_{b k}}{\partial t}+\frac{\partial\left(\delta \bar{c}_{b k}\right)}{\partial t}+\frac{\partial q_{b k x}}{\partial x}+\frac{\partial q_{b k y}}{\partial y}=-E_{b k}+D_{b k}
$$

with $\quad q_{b k x}=\alpha_{b x} q_{b k}$

$$
q_{b k y}=\alpha_{b y} q_{b k}
$$

where $p^{\prime}=$ porosity of bed material

$\bar{c}_{b k}=$ average concentration of bed load at bed-load zone

$c_{b k}=$ actual concentration of suspended load at the interface

$q_{b k}=$ bed-load transport rate of $k$-th size class

$q_{b k x}, q_{b k y}=$ components of bed-load transport rate in $x$ - and $y$ directions

$\alpha_{b x}, \alpha_{b y}=$ direction cosines of bed-load movement, which is assumed to be along the direction of bed shear stress 
The first term on the left-hand side of Equation [2.29] stands for bed change, which results from sediment exchange between the moving sediment and the bed material (Zhang, 2006).

\subsubsection{Non-Equilibrium Bed Load Transport Model}

Most of the existing sediment transport models adopt the assumption of local equilibrium when simulating bed-load transport, which sets the actual bed-load transport rate to be the transport capacity under equilibrium conditions. This may lead to unrealistic predictions of bed deformation especially in strong erosion and deposition cases. Thus, non-equilibrium transport effects should be taken into account (Zhang, 2006; Garcia, 2008). In the case of bed-load transport, Wellington (1978), Phillips and Sutherland (1989), and Thuc (1991) developed an equation using the adaptation length of bed-load. Wu et al. (2000) extended this idea to formulate the bed change relation due to bed-material load (equation [2.32]), which is defined as particles that are generally found in the bed. The bedmaterial load is considered as the main role on the channel evolution.

$$
\left(1-p^{\prime}\right) \frac{\partial z_{b k}}{\partial t}=\alpha \omega_{s k}\left(C_{k}-C_{* k}\right)+\frac{\left(q_{b k}-q_{b^{*} k}\right)}{L_{t}}
$$

where $C_{k}=C_{t k}-q_{b k} /(\bar{U} h)$

$C_{*_{k}}=C_{t^{*} k}-q_{b^{*} k} /(\bar{U} h)$

$\bar{U}=\sqrt{U^{2}+V^{2}}$

and

$$
\begin{aligned}
& \bar{U}=\text { resultant flow velocity } \\
& L_{t}=\text { adaptation length of bed-material load }
\end{aligned}
$$




$$
\begin{aligned}
C_{t k}, C_{t^{*} k}= & \text { depth-averaged concentration and transport capacity of total } \\
& \text { load, which is suspended-load plus bed-load }
\end{aligned}
$$

A modified bed-load transport formula is then derived by substituting Equation [2.32] into Equation [2.29]:

$$
\frac{\partial\left(\delta \bar{c}_{b k}\right)}{\partial t}+\frac{\partial q_{b k x}}{\partial x}+\frac{\partial q_{b k y}}{\partial y}+\frac{1}{L_{t}}\left(q_{b k}-q_{b^{*} k}\right)=0
$$

The elimination of the net flux term $\left(E_{b k}-D_{b k}\right)$ in Wu et al. (2000) can improve the convergence of iteration solution, especially when suspended load is the main mode of sediment transport.

\section{Non-Equilibrium Adaptation Length $\underline{L}_{t}$}

The non-equilibrium adaptation length $L_{t}$ characterizes the distance for sediment to adjust from a non-equilibrium state to an equilibrium state. It is a length scale for the river bed to respond to disturbances in the environment. $L_{t}$ is a very important parameter in the CCHE2D program but significantly different values were derived by different researchers (Bell and Sutherland, 1983; Wang, 1999; Philips and Sutherland, 1989; Thuc, 1991; Wu et al., 2000; Rahuel et al., 1989; Fang, 2000). One reason is that $L_{t}$ is closely related to the dimensions of the studied sediment movements, bed forms and channel geometry, which are markedly different in laboratory and field situations. In laboratory experiments the sediment transport processes are mainly on small scale such as sand saltation, ripples and dunes, while natural sediment transport processes usually occur at 
larger scales with longer periods. Another reason is that $L_{t}$ is an important parameter for numerical stability. Wu and Vieira (2000) and Wu et al. (2000) concluded that a small $L_{t}$ value requires a small grid size and time step. In reality, large mesh size and long time steps are needed in natural situations in order to save computation time. Thus, it is understandable why different values of $L_{t}$ have been adopted in the literature (Zhang, 2006).

In the CCHE2D program, $L_{t}$ is given different values for bed load, suspended load, bed-material load and wash load. As mentioned earlier, $L_{t}$, especially the non-equilibrium adaptation length for bed-load $L_{b}$, is related to the dimensions of sediment movements, bed forms and channel geometry (Zhang, 2006). The three choices of $L_{b}$ in the CCHE2D program are: 1) set as average grid length, 2) set as 7.3 of average dune length, and 3) specify adaptation length. The first choice is based on the experimental results in Phillips and Sutherland (1989), Thuc (1991) and Wu et al. (2000) in which $L_{b}$ is close to the average saltation step length for sand or the length of sand ripples. If sand dunes are the dominant bed form, $L_{b}$ may take the sand dune length, which is about 7.3 times the flow depth (van Rijn, 1984, 1984a). The last choice is set as a user-defined parameter for more general applications (Zhang, 2006). 


\subsubsection{Channel Morphological Change}

When the equilibrium transport model is adopted for bed load, the bed change can be calculated from either the bed load continuity equation (Equation [2.54]) or the overall mass balance equation for sediment transport below (Zhang, 2006):

$$
\left(1-p^{\prime}\right) \frac{\partial z_{b k}}{\partial t}+\frac{\partial\left(h C_{t k}\right)}{\partial t}+\frac{\partial\left(q_{b k x}+q_{s k x}\right)}{\partial x}+\frac{\partial\left(q_{b k y}+q_{s k y}\right)}{\partial y}=0
$$

where $q_{s k x}=U h C_{k}+\varepsilon_{s} h \frac{\partial C_{k}}{\partial x}$

$$
q_{s k y}=V h C_{k}+\varepsilon_{s} h \frac{\partial C_{k}}{\partial y}
$$

and

$$
\begin{aligned}
q_{s k x}, q_{s k y}= & \text { suspended load transport rates in } x \text { - and } y \text {-directions, } \\
& \text { which the diffusion terms are usually neglected }
\end{aligned}
$$

When the non-equilibrium transport model is adopted for bed load, the calculation of bed change can be determined by the bed load continuity equation (Equation [2.29]), the overall mass balance equation for sediment transport (Equation [2.37]), or Equation [2.32] in the case of bed-material load transport. In the case of bed load only or suspended load only, the following equations can also be used to calculate bed change correspondingly (Zhang, 2006; Wellington, 1978; Phillips \& Sutherland, 1989; Wu et al., 2000; Thuc, 1991):

$$
\begin{aligned}
& \left(1-p^{\prime}\right) \frac{\partial z_{b k}}{\partial t}=\frac{1}{L_{b}}\left(q_{b k}-q_{b^{*} k}\right) \\
& \left(1-p^{\prime}\right) \frac{\partial z_{b k}}{\partial t}=\alpha \omega_{s k}\left(C_{k}-C_{* k}\right)
\end{aligned}
$$




\subsubsection{Total-Load Transport Modelling Approaches}

On the basis of the depth-averaged sediment transport model, three approaches are adopted in CCHE2D non-uniform sediment transport modelling: 1) bed-load type model, 2) suspended-load type model, and 3) separate simulation of bed load and suspended load. For the bed-load type model, it simulates bed load only or bed-material load without considering the diffusion of suspended load. The governing equation of bed-material load transport is (Zhang, 2006; Garcia, 2008):

$$
\frac{\partial\left(h C_{t k}\right)}{\partial t}+\frac{\partial\left(\alpha_{t x} q_{t k}\right)}{\partial x}+\frac{\partial\left(\alpha_{t y} q_{t k}\right)}{\partial y}+\frac{1}{L_{t}}\left(q_{t k}-q_{t^{*} k}\right)=0
$$

where $q_{t k}=$ actual transport rate of $k$-th size class of bed-material load $q_{t^{*} k}=$ actual transport capacity of $k$-th size class of bed-material load $\alpha_{t x}, \alpha_{t y}=$ direction cosines of total load transport

The bed deformation can be then determined by the following equation (Zhang, 2006),

$$
\left(1-p^{\prime}\right) \frac{\partial z_{b k}}{\partial t}=\frac{\left(q_{t k}-q_{t^{*} k}\right)}{L_{t}}
$$

Although Equations [2.42] and [2.43] are for bed-material load, they can be used for bed load if the first term on the left-hand side of Equation [2.42] is neglected and all the variables are replaced by the corresponding quantities of bed load. In CCHE2D program, the two equations are implemented in such a way that they can be used for bed-material load or bed load only depending on the choice of 
the empirical transport capacity formula for bed load or bed-material load (Zhang, 2006).

\subsubsection{Non-Cohesive Sediment Transport Capacity}

In the CCHE2D program, the four formulas or module, Modified Ackers and White Formula (Ackers and White, 1973; Proffit and Sutherland, 1983), SEDTRA Module (Garbrecht et al., 1995), Wu et al. Formula (2000b), and Modified Engelund and Hansen Formula (1967), are selected based on the following considerations: 1) available evaluation by investigators, 2) capability of accounting for the hiding and exposure effect, and 3) available test results with experimental and field data (Zhang, 2006). In this research, Wu et al. Formula was used in preparing the numerical model since its numerical results were the closest to the physical experiments.

\section{Wu et al. Formula (2000b)}

The formula for determining the fractional bed load transport capacity proposed by Wu et al. (2000b) is:

$$
\varphi_{b k}=0.0053\left[\left(\frac{n^{\prime}}{n}\right)^{1.5} \frac{\tau_{b}}{\tau_{c k}}-1\right]^{2.2}
$$

where $\varphi_{b k}=q_{b^{*} k}\left[p_{b k} \sqrt{\left(\gamma_{s} / \gamma-1\right) g d_{k}^{3}}\right]$

$$
n^{\prime}=d_{50}^{1 / 6} / 20
$$

$\tau_{c k}=0.03\left(\gamma_{s}-\gamma\right) d_{k}\left(p_{h k} / p_{e k}\right)^{0.6}$

$p_{h k}=\sum_{j=1}^{N} p_{b j} d_{j} /\left(d_{k}+d_{j}\right)$ 


$$
p_{e k}=\sum_{j=1}^{N} p_{b j} d_{k} /\left(d_{k}+d_{j}\right)
$$

and $\quad \phi_{b k}=$ non-dimensional bed load transport capacity

$q_{b^{*} k}=$ equilibrium transport rate of the $k$-th size class of bed load per unit width, in $\mathrm{m}^{2} / \mathrm{s}$

$p_{b k}=$ bed material gradation

$n$ = Manning's roughness coefficient for channel bed

$n^{\prime}=$ Manning's coefficient corresponding to the grain roughness

$\tau_{b}=$ bed shear stress

$\tau_{c k}=$ critical shear stress

$p_{h k}$ and $p_{e k}=$ hiding and exposure probabilities for the $k$-th size class of bed material

Wu et al. (2000b) formula for the fractional suspended load transport capacity is expressed as:

$$
\phi_{s k}=0.0000262\left[\left(\frac{\tau}{\tau_{c k}}-1\right) \frac{U}{\omega_{s k}}\right]^{1.74}
$$

where $\phi_{s k}=q_{s^{* k}}\left[p_{b k} \sqrt{\left(\gamma_{s} / \gamma-1\right) g d_{k}^{3}}\right]$

and $\quad q_{s^{*} k}=$ equilibrium transport rate of the $k$-th fraction of suspended load per unit width, in $\mathrm{m}^{2} / \mathrm{s}$

$\tau=$ shear stress of entire cross-section, which is the shear stress calculated by the flow model

$\omega_{s k}=$ settling velocity of sediment particles calculated with Zhang's formula (Zhang and Xie, 1993)

\subsubsection{Bed Material Sorting}

The bed material gradation usually varies on the vertical. Thus, bed material above the non-erodible layer can be divided into several layers (Figure 30). The top layer is the mixing layer, and the second layer is the subsurface layer. Wu 
(1991), and Wu and Li (1992) determined a variation of bed material gradation equation in the mixing layer, where the bed material gradations in the layers under the mixing layer are determined by using the mass conservation law (Zhang, 2006):

$$
\frac{\partial\left(\delta_{m} p_{b k}\right)}{\partial t}=\frac{\partial z_{b k}}{\partial t}+p_{b k}^{*}\left(\frac{\partial \delta_{m}}{\partial t}-\frac{\partial z_{b}}{\partial t}\right)
$$

where $\partial z_{b} / \partial t=\sum_{k=1}^{N} \partial z_{b k} / \partial t$

and $\quad p_{b k}=$ bed material gradation in the mixing layer

$\delta_{m}=$ thickness of the mixing layer, which is related to bed deformation, flow and sediment conditions

$N=$ total number of size classes

$p_{b k}^{*}=p_{b k}$ when $\partial \delta_{m} / \partial t-\partial z_{b} / \partial t \leq 0$

$=$ bed material gradation in the subsurface layer when $\partial \delta_{m} / \partial t-\partial z_{b} / \partial t>0$

$\partial z_{b} / \partial t=$ total bed deformation
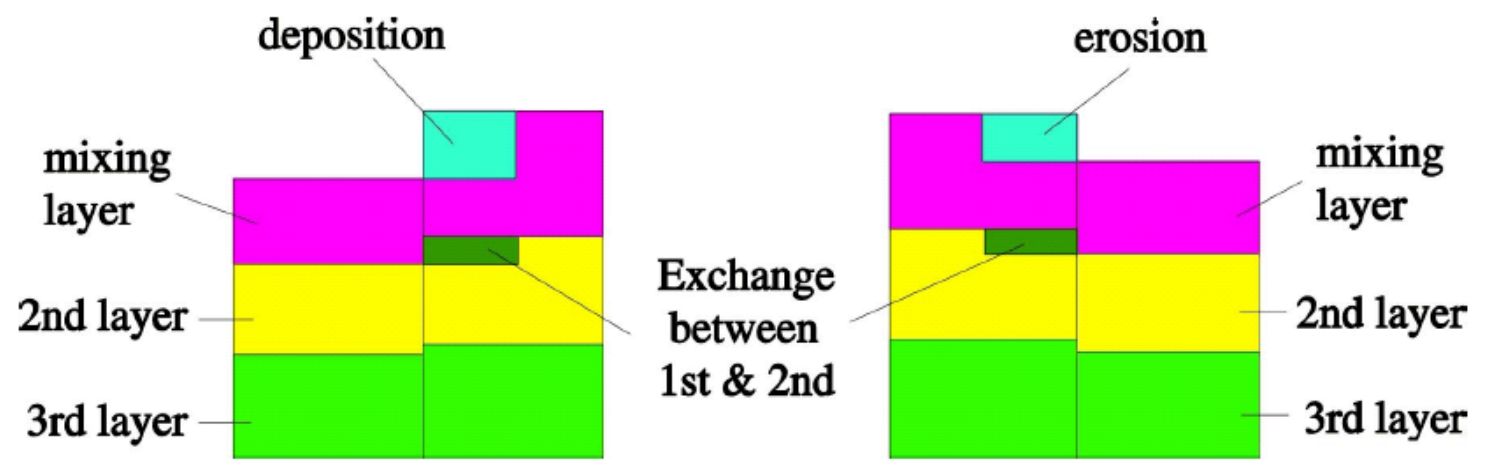

Figure 30: Multiple-Layer Sorting Model for Bed Material Gradation (Zhang, 2006). 


\subsubsection{Boundary Conditions and Initial Conditions}

In the depth-averaged 2-D simulation of sediment transport, inflow sediment discharge must be given at each inlet boundary. In case of non-uniform sediment transport, the size distribution of the inflow sediment is also needed. The user can provide the fractional sediment discharge for each size class directly. Once the fractional sediment discharge $Q_{b k}$ is given for the whole cross-section, CCHE2D program will distribute it along the inlet cross-section by the following equations (Zhang, 2006):

$$
\begin{gathered}
q_{b k}=\frac{Q_{b k} q^{m_{b}}}{\int_{0}^{B} q^{m_{b}} d y} \\
q_{s k}=\frac{Q_{s k} q^{m_{s}}}{\int_{0}^{B} q^{m_{s}} d y}
\end{gathered}
$$

where $q=\bar{U} h$

and $\quad q=$ specific flow discharge at each node $m_{b}$ and $m_{s}=$ empirical coefficients

On bank boundaries and other kind of fixed boundaries, such as islands, the bed load transport rate and the gradient of suspended load concentration on the normal direction of the boundary are set as zero (Zhang, 2006):

$$
\begin{aligned}
& q_{b k}=0 \\
& \partial C_{k} / \partial n=0
\end{aligned}
$$

where $n$ is along the normal direction of the boundary. 
The required initial conditions include the initial channel geometry and the initial bed material gradation. The initial bed material gradation must be given for the simulation of non-uniform sediment transport. It is particularly important for scouring and channel stability analysis but less important in cases of deposition. Information on the bed material gradation under the bed surface layer, if available, is also needed. 


\section{CHAPTER 3 RESTORATION APPROACH FOR CONCRETE FLOOD CONTROL CHANNELS}

This chapter discusses the framework of the environmental restoration approach for flood control channels and the first two phrases in detail using the concrete nullah in Yuen Long, Hong Kong as a showcase.

\subsection{FRAMEWORK OF THE ENVIRONMENTAL RESTORATION APPROACH}

The environmental restoration approach comprises four phases (Figure 12): 1) restoration goals identification; 2) stream assessment; 3) channel modification design and verification; and 4) flood control function validation. The development of restoration goals in phase 1 is essential for guiding the implementation of the restoration efforts as well as for establishing a means to measure progress and evaluate success. Generally, the procedures for identifying the restoration goals for stream restoration (FISRWG, 1998) can be also applied to flood control channels. Indeed, each stream or flood control channel has its unique characteristics and often requires unique restoration goals. For the pilot site, the restoration goals are assumed to be: 1) to design a natural and self-sustainable river system, 2) to establish appropriate pools and riffles and in-stream covers which support fish spawning and rearing; and 3) to maintain the original flood control function. 
After the restoration goals would be set up, detailed stream assessment should be conducted along the study area to collect the background information such as flow rates under different weather conditions, channel geometry, sediment size distribution, water quality, existing living habitats, etc. The procedures and level of detail of stream assessment are discussed in the following sections using the pilot site as a demonstration.

Phase 3 involves flood channel modifications and verification using a design model which is comprised of a physical model and a numerical model. Based on the stream assessment results, the low-flow channel was modified by manipulating the existing meander patterns in the reference reach (Rosgen, 1998) nearby the study area. The reason for only considering the low-flow channel is due to the flood control consideration in Phase 4. For the pilot site, the cross-section area of the low-flow channel was adjusted in order to meet the restoration goals. The adjusted cross-section area would be able to hold the proposed bed material and decrease the existing flow velocity until it is within the range of the swimming velocity for the targeted fish habitats. Deflectors, obstacles that exaggerate the pools' formation, will be applied to different locations in order to speed up the pools creation naturally and provide shaded areas for aquatic species. The design model will be used to verify the flood channel modification design under different flow conditions. The last phase will be the validation of the original flood control function using the design model. 


\subsection{PILOT SITE LOCATION}

A pilot site located at the upstream section of Yuen Long Nullah (Figure 32), was used to demonstrate the restoration approach discussed in the previous section. Yuen Long Nullah (Figure 31) is located in Yuen Long, a suburban area northeast of Hong Kong. It starts as a natural creek west of Tai Tong, flows north into the Town of Yuen Long, and drains into Mai Po Nature Reserve near Deep Bay. The reason for selecting the upstream section as the location of the pilot site is due to the natural area at the entrance of Yuen Long Nullah. 


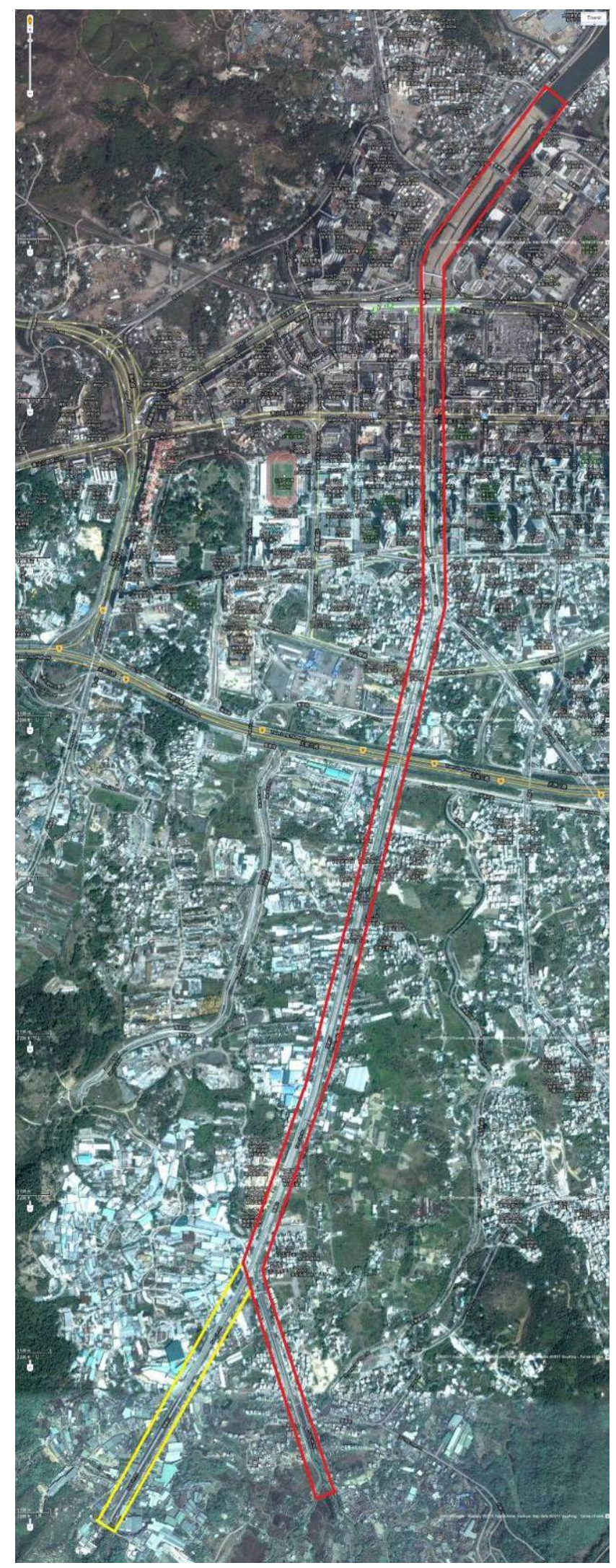

Figure 31: Yuen Long Nullah. 

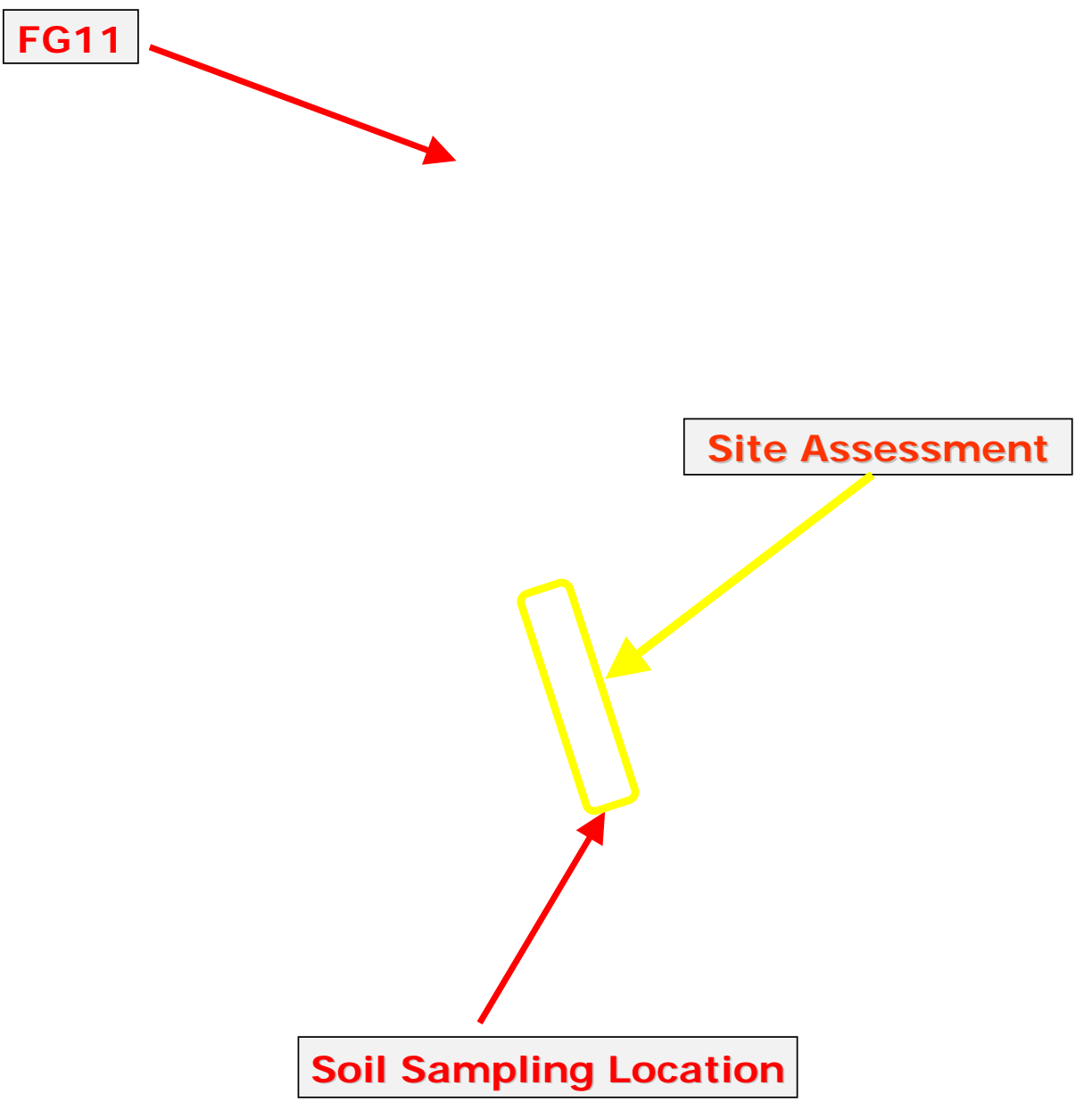

Figure 32: Close shot on the upstream of Yuen Long Nullah. 


\subsection{IDENTIFICATION OF RESTORATION GOALS}

The development of restoration goals began with a rough outline of identifying the problems and opportunities, and with the definition of the desired future condition of the flood channel corridor and potential surrounding landscape (Figure 49). The desired future condition represented the common vision of all participants. The vision statement should be consistent with the overall ecological goal of restoring the corridor structure and functions and bringing the system as close to a state of equilibrium or proper functioning condition as possible. Moreover, the development of the vision statement should be integrated ultimately with important social, political, economic and cultural values (FISRWG, 1998). By following the above general guidelines, the three restoration goals for the pilot site (Section 3.1) were met. 


\subsection{BACKGROUND INFORMATION COLLECTION}

This section discusses the stream assessment, the second phase of the restoration approach, and the collection of the background information in detail.

\subsubsection{Sediment Sampling}

A site visit was conducted at the upstream of Yuen Long Nullah (Figure 32) on November 20 of 2007 . The purpose of that was to collect soil samples of the bed material for particle size distributions studies. The weather condition of the site visit on that day was cloudy and windy. The locations of the soil samples collection, the particle size distribution curves of each soil sample, and the average particle size distribution are shown in Figure 33, Figure 34 and Table 4 respectively. The particle size distribution tests (Appendix A) were conducted at The Hong Kong Polytechnic University Soil Laboratory and the test procedures (Appendix B) were followed the British Standard Institution guidelines (BSI, 1990).

Table 4: Average particle size distribution of the soil samples data on Nov 20, 2007.

\begin{tabular}{|l|c|c|c|c|c|c|c|c|c|}
\hline \% Finer & $D_{90}$ & $D_{80}$ & $D_{70}$ & $D_{60}$ & $D_{50}$ & $D_{40}$ & $D_{30}$ & $D_{20}$ & $D_{10}$ \\
\hline $\begin{array}{l}\text { Particle Size, } \\
\text { in mm }\end{array}$ & 1.76 & 1.01 & 0.646 & 0.417 & 0.281 & 0.184 & 0.115 & 0.0634 & 0.0256 \\
\hline
\end{tabular}




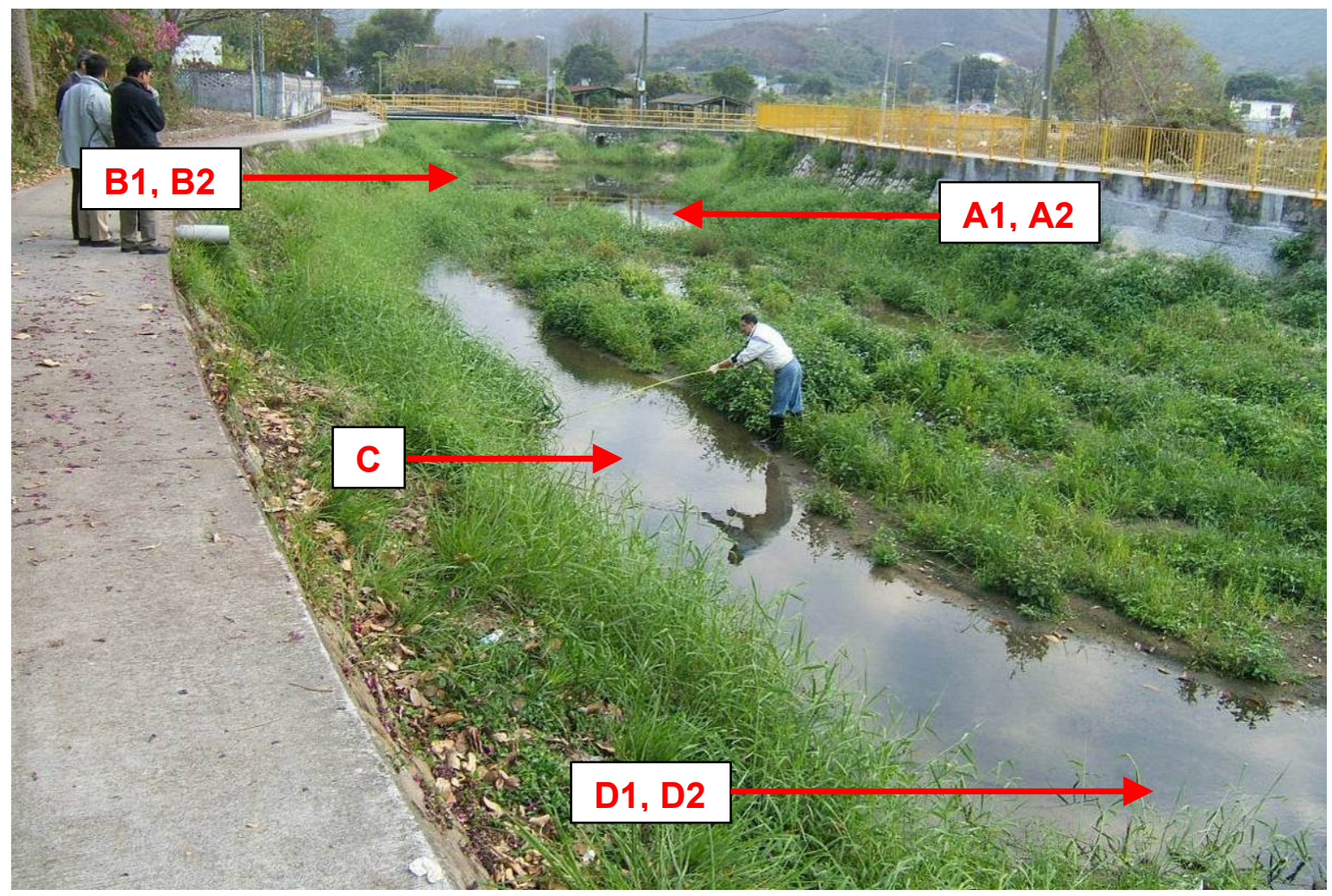

Figure 33: Locations of soil samples collection.

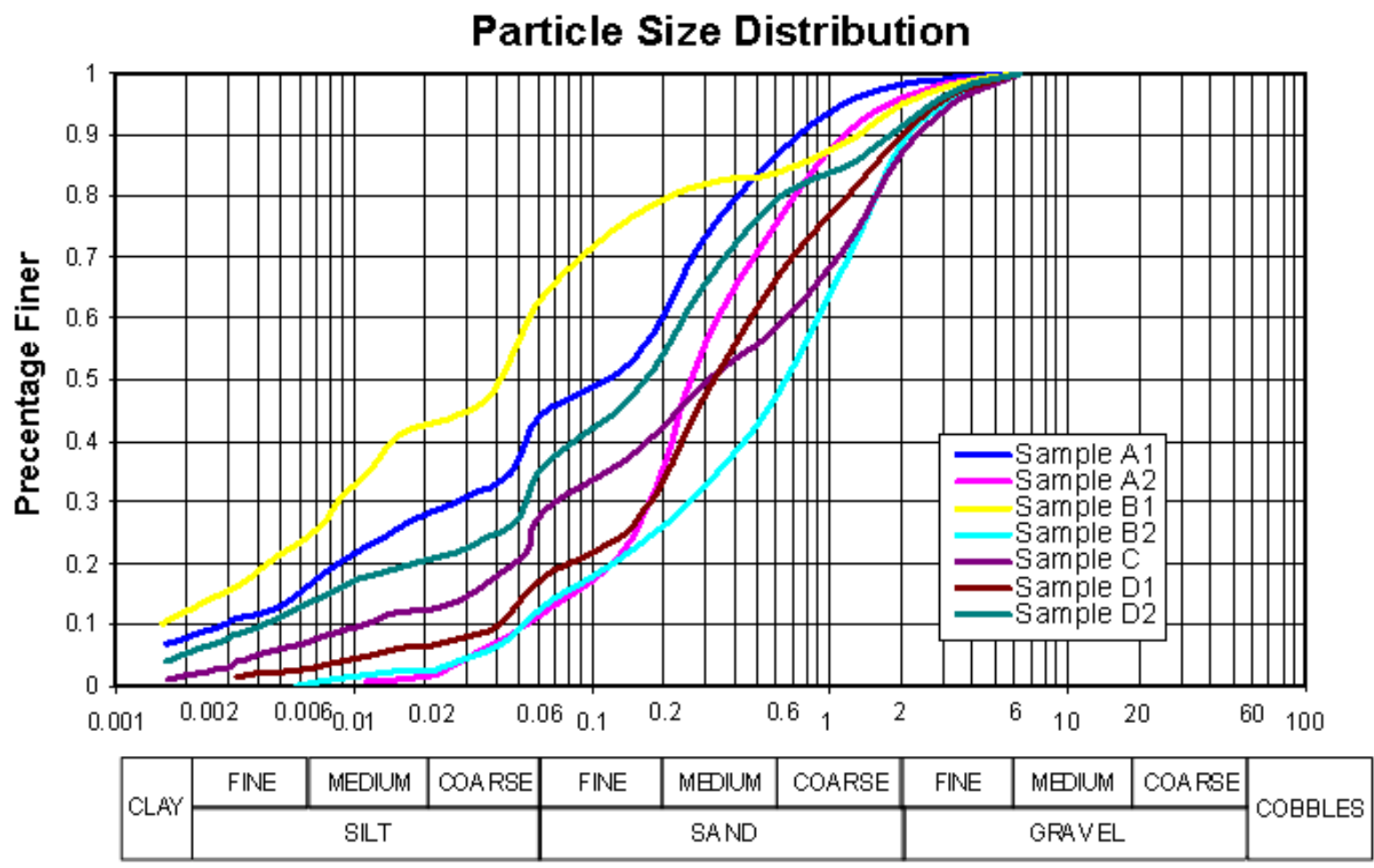

Particle Size (mm)

Figure 34: Particle size distribution of soil samples collected on Nov 20 of 2007. 


\subsubsection{Stream Assessment}

A detailed stream assessment was conducted along the upstream of Yuen Long Nullah (yellow rectangle in Figure 32) on January 16 of 2008. The weather condition was partly sunny, cool and dry. The purpose of the stream assessment was to collect baseflow and geomorphic information (Appendix C) along the upstream of Yuen Long Nullah and the natural area located at the entrance of Yuen Long Nullah. The baseflow measurements were conducted by a propeller velocity flow meter and Styrofoam spheres. Appendix D shows the calibration results between the propeller velocity flow meter and the Acoustic Doppler Velocimetry (ADV), device used to measure velocities in the physical experiments. The calibration test was conducted in a $0.3 \mathrm{~m} \times 15 \mathrm{~m}$ flume at The Hong Kong Polytechnic University Hydraulic Lab. All velocity measurements in the field using the propeller velocity flow meter were converted to the ADV standards using calibration curves to minimize the measuring errors between different devices. Styrofoam spheres were also used for the baseflow measurements as a verification of the propeller velocity flow meter results. The average flows along the upstream of Yuen Long Nullah using the propeller velocity flow meter and Styrofoam spheres were around $0.0318 \mathrm{~m}^{3} / \mathrm{s}$ and 0.0424 $\mathrm{m}^{3} / \mathrm{s}$ respectively. The performance of the propeller velocity flow meter was satisfied since its results were all slightly smaller than the velocities measured by the Styrofoam spheres. 
For the geomorphic investigation, the meander pattern (Figure 35), the channel widths, channel depths and flow velocities of various sections of the existing stream (Appendix C) in the natural area, and the dimensions of the rectangular low-flow channel (Figure 36) were collected during the site visit. The design of the meander section of the physical model was intended to follow the meander pattern of the existing stream (Chapter 4).

Besides the site assessment, a stream walk on Yuen Long Nullah was conducted on December 3 of 2008. The stream walk covered the entire Yuen Long Nullah (red bolded line in Figure 31) except for a small tributary (yellow bolded line in Figure 31) where access was impeded.

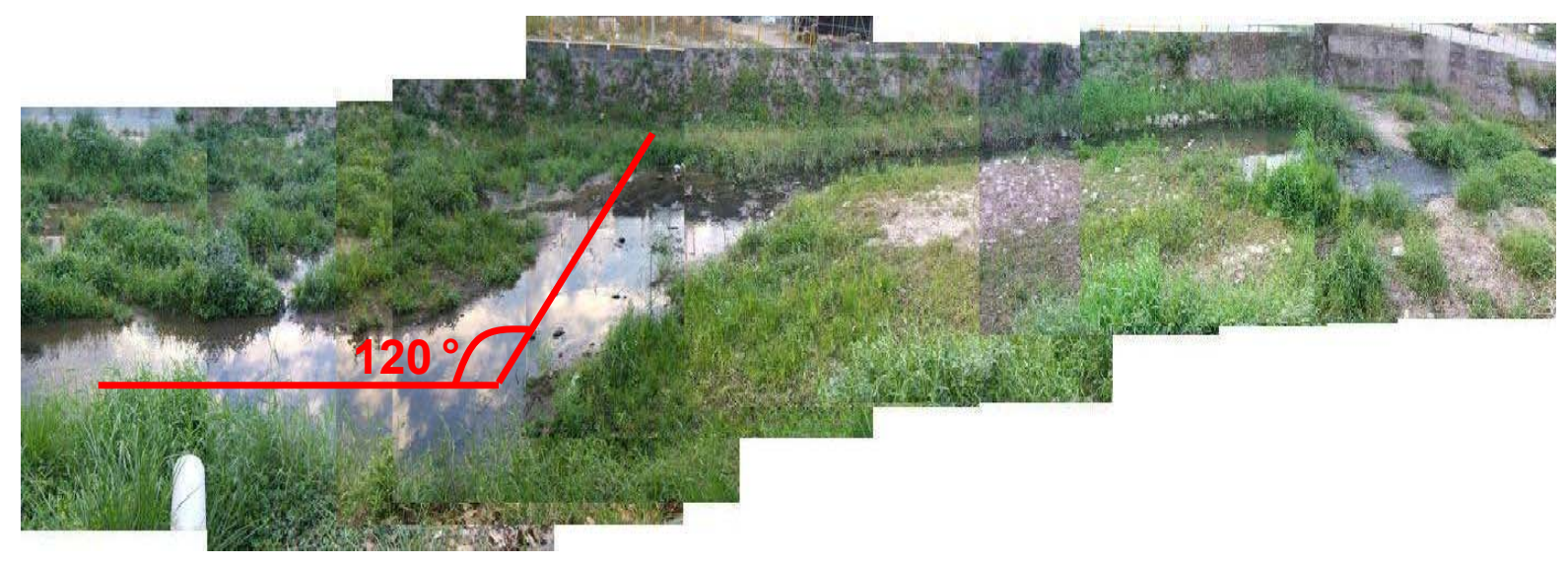

Figure 35: Radius of curvature of the stream in the natural area. 


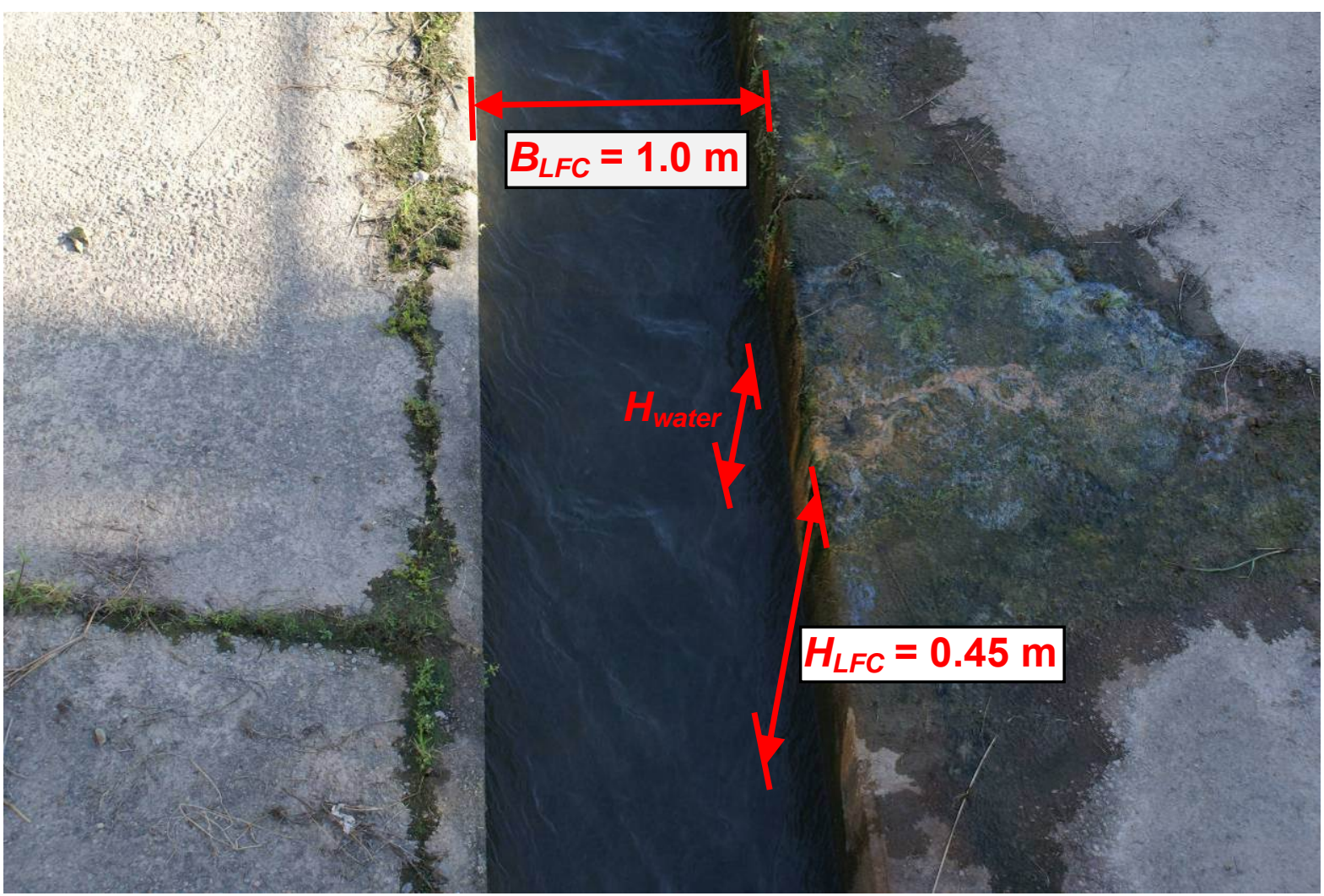

Figure 36: Closed view of the low-flow channel of Yuen Long Nullah.

The longitudinal slope along the upstream of Yuen Long Nullah is about 0.003. It was calculated from the topographic maps provided by The HK DSD (Appendix J).

\subsubsection{Aquatic Species Investigation}

Fishes were observed along the natural area at the entrance of Yuen Long Nullah during the preliminary site investigation conducted by Dr. Wai of The Hong Kong Polytechnic University and The Hong Kong Drainage Services Department (HK DSD) staffs (Figure 37) on August 24 of 2007. During the site assessment on January 16 of 2008, a substantial amount of shelled aquatic 
species (Figure 38) were found at Site \#3. Professor Dudgeon, the Head of the Department of Ecology and Biodiversity of The Hong Kong University, suggested that the fish habitat found during the preliminary site investigation was probably tilapia and the shell-typed aquatic species were Malaysian trumpet snails. Professor Dudgeon had also mentioned that there were no aquatic habitats assessments or studies conducted in the proposed pilot site in the past (Prof. Dudgeon, personal communication, January 27, 2008).

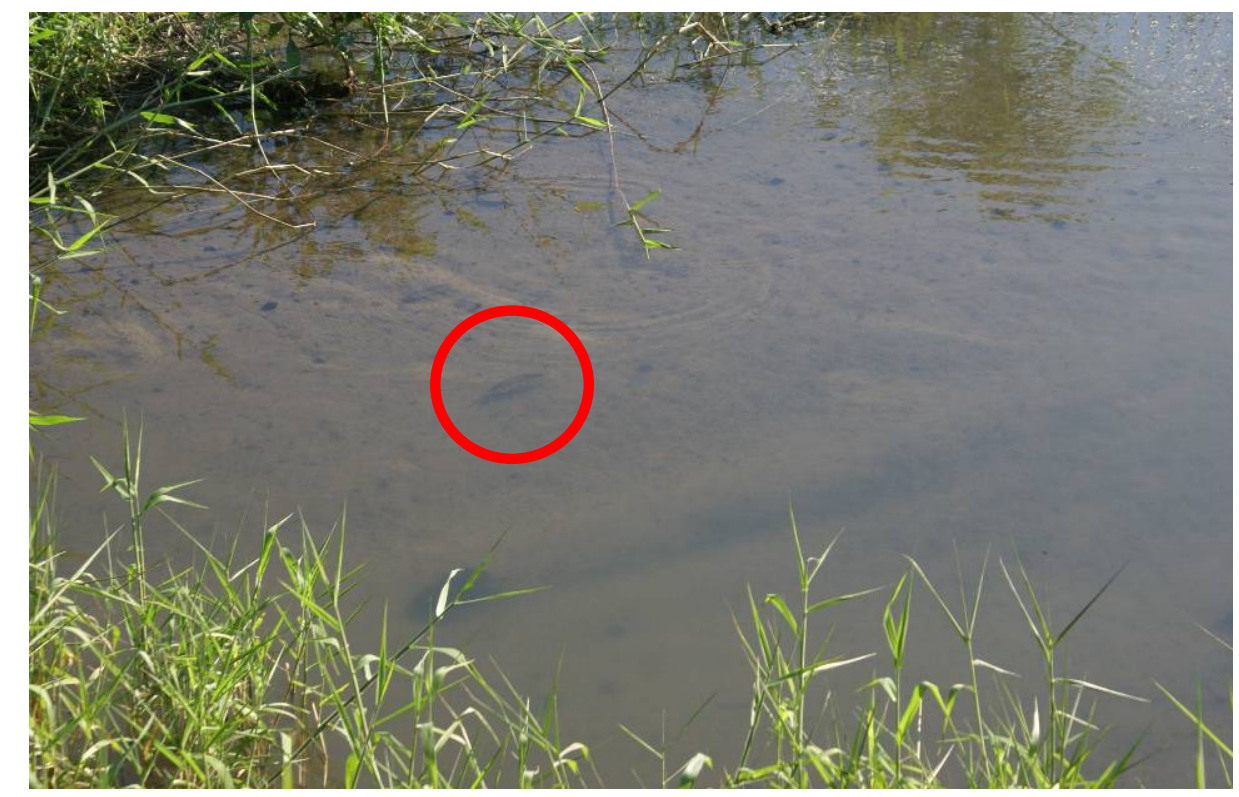

Figure 37: Fish habitat found (red circle) in the natural area near the upstream section of Yuen Long Nullah during preliminary site investigation. 


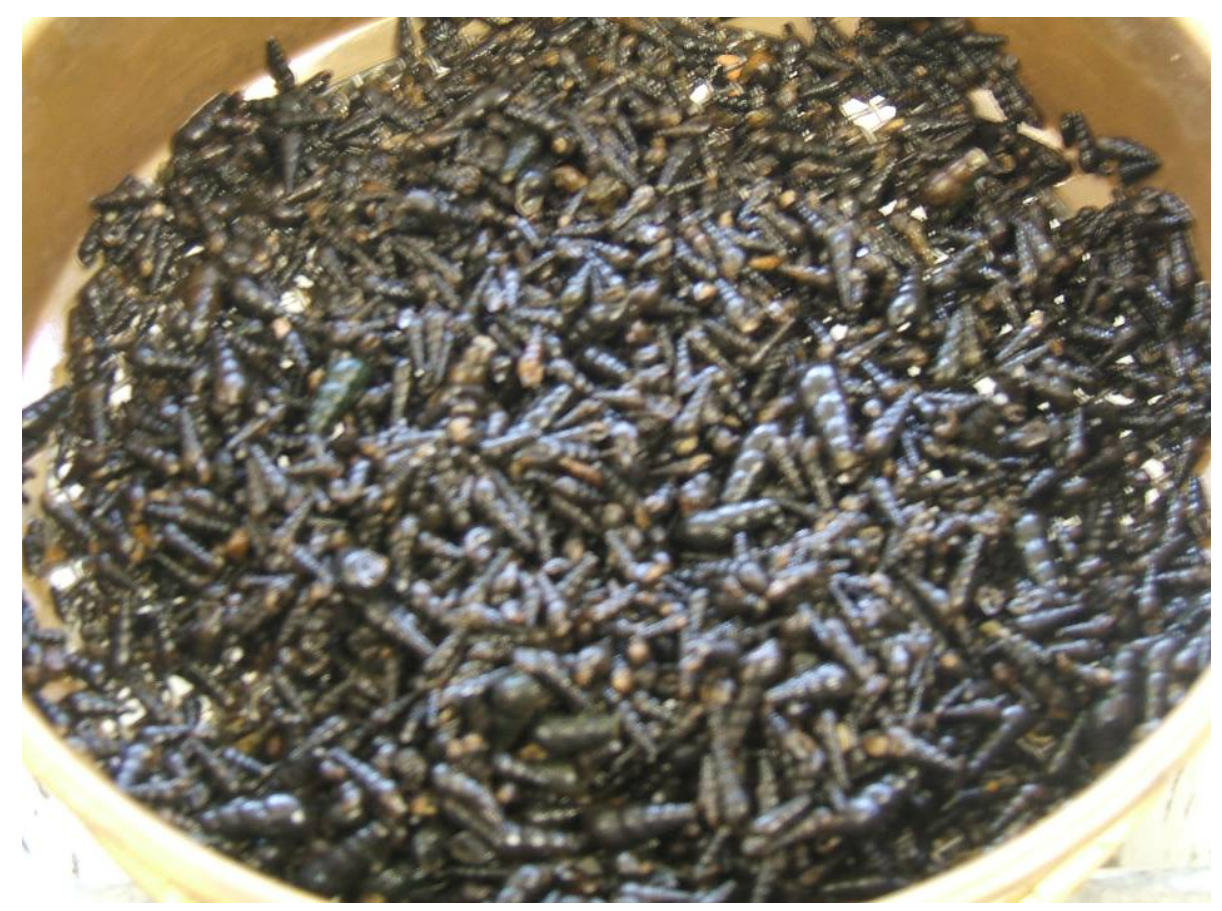

Figure 38: Malaysian trumpet snails found during the site assessment.

\subsubsection{Water Sampling}

Four water samples were collected during the site assessment on January 16 of 2008. Appendices $E$ and $F$ contain the concentration results of suspended particles and the metal analysis of the water samples. The average concentration of suspended particles is $2.625 \mathrm{mg} / \mathrm{L}$. For the metal analysis (Appendix $\mathrm{G}$ ), the results were compared with Hong Kong Water Pollution Control Ordinance Cap 358 Section 21 "Technical Memorandum Standards for Effluents Discharged into Drainage and Sewerage Systems, Inland and Coastal Waters" (HK DOJ, 1997). The concentrations of mercury and silver of all water samples (pink highlights in Appendix F) were exceeded the upper limits of effluents standards of inland waters significantly (Appendix G). This, especially the high concentration of 
mercury, has major impacts on the nervous and reproductive systems of fish habitats. Although the development of the restoration approach is more focused on quantitative components, further investigation of the private sectors or potential illegal discharges near the uppermost regions are needed prior to any implementation of any restoration works.

\subsubsection{Flow Monitoring}

The HK DSD had conducted detailed flow monitoring studies on various Nullahs in Yuen Long in 2008 (HK DSD, 2006). The closest monitoring site to the upstream of Yuen Long Nullah is FG11 (Figure 32). Appendix H contains the selective pages of the flow monitoring report with the flow measurements, dimensions of the low-flow and flood channel at FG11. The average flow rate of FG11 at dry weather condition is about $0.4 \mathrm{~m}^{3} / \mathrm{s}$. It is slightly higher than the average measured flow rate during the site assessment (Appendix C). 


\subsection{DISCUSSION OF STREAM ASSESSMENT}

Generally, the chemical and biological components play an important role in stream restoration. This research focused mainly on the physical components during the development of the design methodology on flood channels restoration. However, it suggested some generic chemical and biological approaches on the raw data collection, such as water sampling (Appendix F), aquatic and vegetation species investigation (Sections 2.3 and 3.4.3), in the site assessment. The water samples collected during the stream assessment indicated that the pilot site may have a serious problem with mercury loadings. This will affect the growing process of the fish. Further investigation of the source of the mercury loadings is needed if the Hong Kong government would like to conduct the stream restoration on the pilot site in the future.

From the oral communication with the HK DSD staff, streams in Hong Kong, especially the one in the pilot site, have excess sediment problems where too much sediment is trapped at the entrance of flood channels after thunderstorms. Thus, additional studies along the transition zone may also need on how to carry the incoming sediment to the flood channels restoration more effectively. 


\section{CHAPTER 4 PHYSICAL MODEL EXPERIMENTS}

This section discusses in detail the procedures for setting up the physical model, the physical experiments and results in detail. The objectives of the physical lab experiments are: 1) to investigate the hydraulic and sediment transport relationships around the meander area of the modified low-flow channel, and 2) to determine the dimensions and location of the deflector for maximizing the pool creation.

\subsection{DESIGN OPTIONS OF THE PHYSICAL MODEL}

The physical experiments were conducted at a $9 \mathrm{~m} \times 6 \mathrm{~m}$ interior deck (Figure 39) due to the configurations of the pumps and tanks set up at The Hong Kong Polytechnic University Hydraulic Lab. Thus, the design of the physical model was based on the available space. Three preliminary design options (Figure 40 to Figure 42) were developed for the physical model. Options \#1 and \#2 were actual scale models with channel widths of 2 metres and 1.5 metres respectively, which would mean $100 \%$ and $50 \%$ widening of the existing low-flow channel. It is proposed that the bed material for these options to be collected directly from the natural area at the upstream of Yuen Long Nullah. 


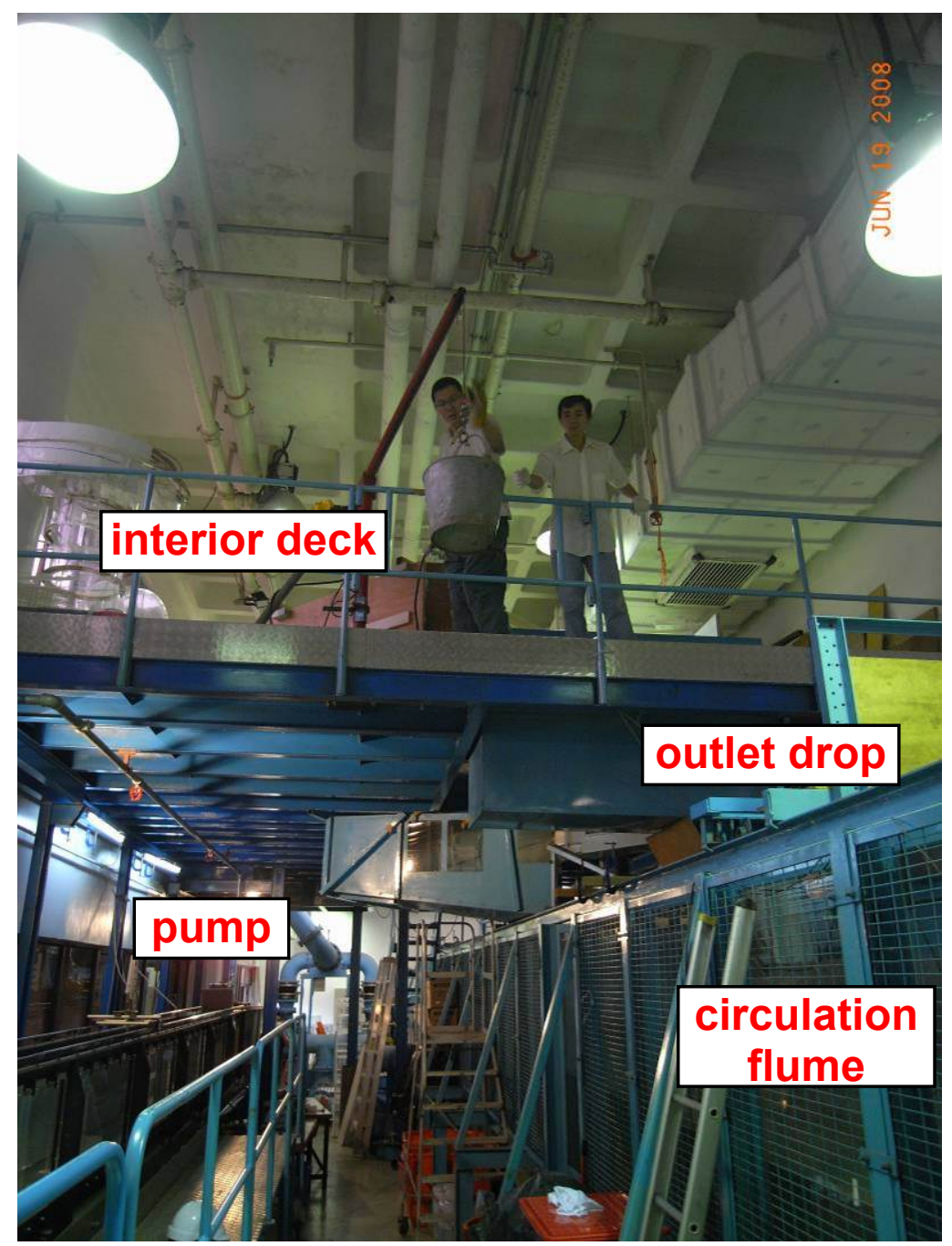

Figure 39: Location of the physical model. 


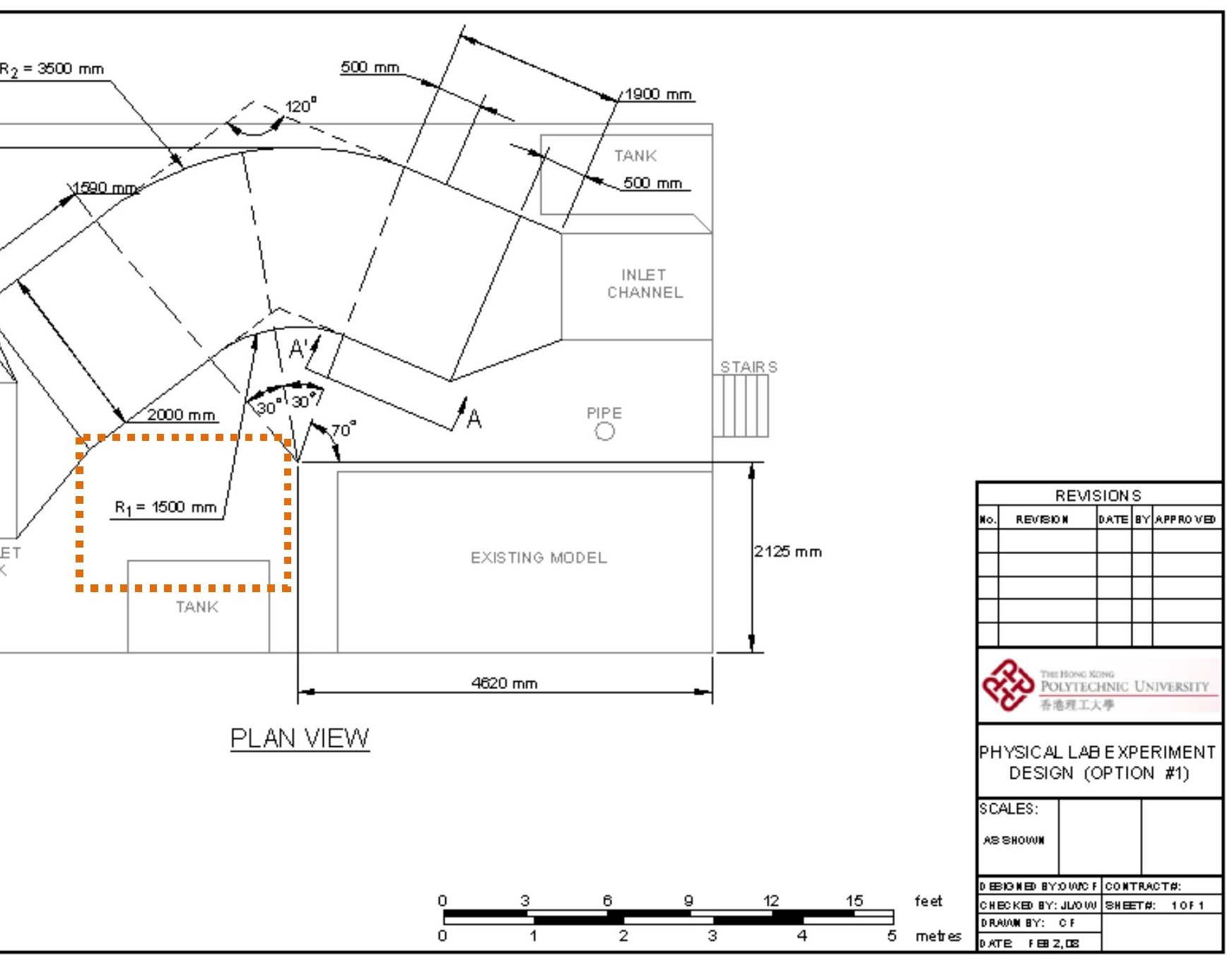




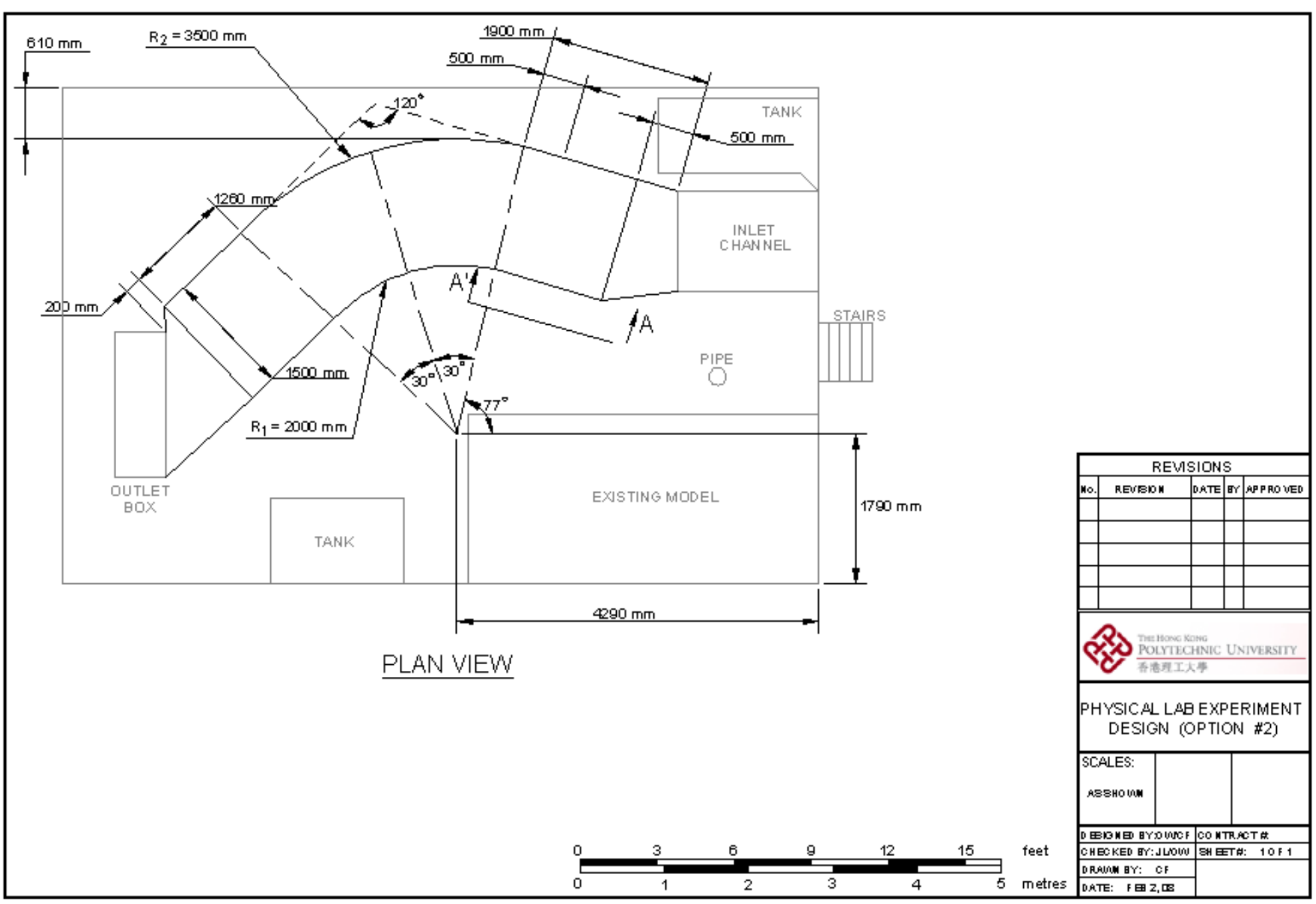

Figure 41: Physical Model Design Option \#2. 


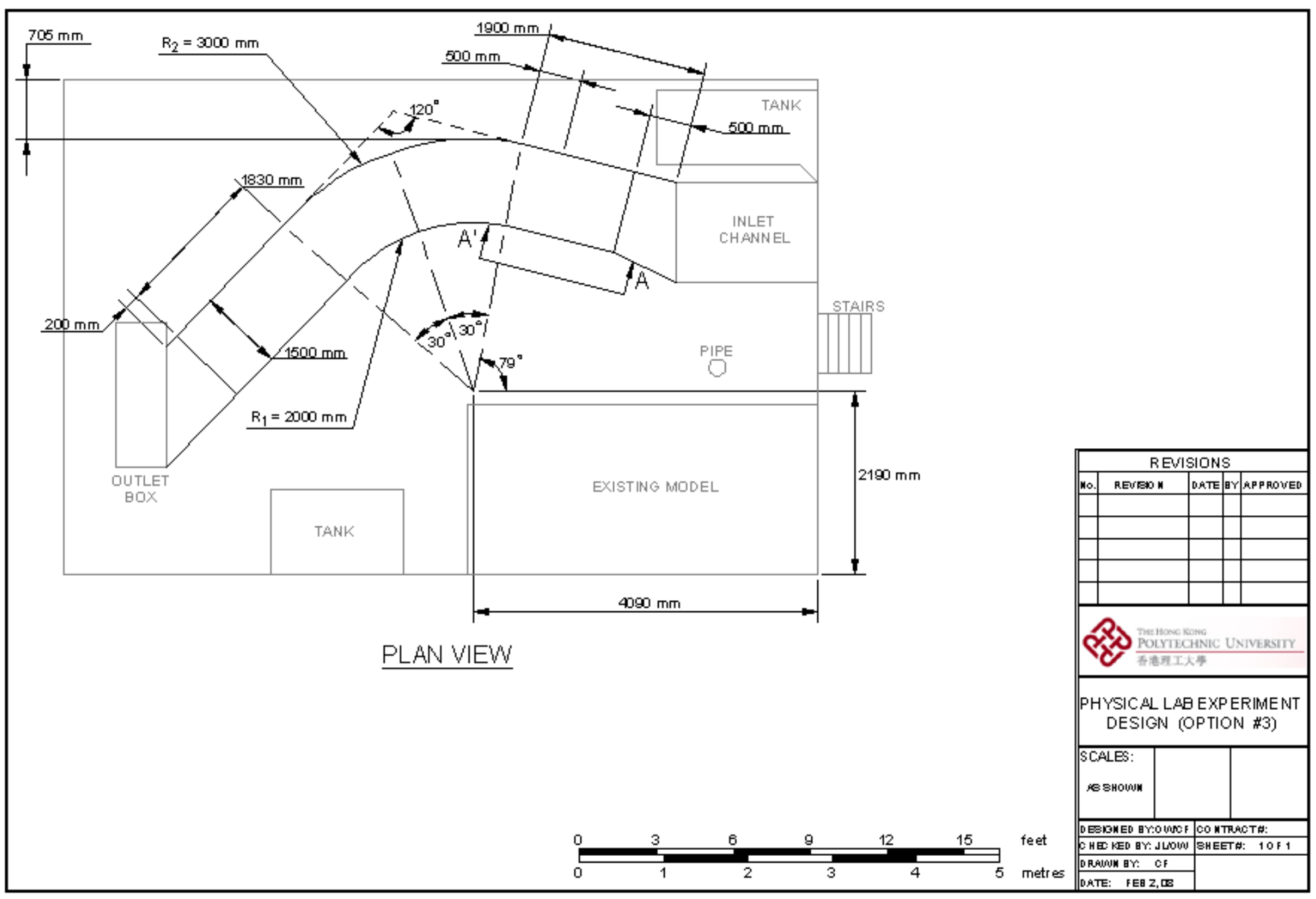

Figure 42: Physical Model Design Option \#3. 
Option \#3 is a 1 to 2 model with channel width of 1 metre. Small plastic balls, other than sand, were proposed to be used as the bed material of the physical experiments due to the down scaled design and the difficulties of getting uniform sand material in Hong Kong. The "explicit method" discussed by Henderson (1966) is shown below to determine the specific gravity of the proposed bed material:

From Shield's diagram (Appendix N),

$$
F_{s}=\frac{\tau_{o}}{\gamma\left(s_{s}-1\right) D}
$$

where $F_{s}=$ dimensionless entrainment function

$T_{o}=$ shear stress at the bed, in $\mathrm{Pa}$

$V=$ specific weight of the fluid, in $\mathrm{kN} / \mathrm{m}^{3}$

$s_{s}=$ specific gravity of the sediment, dimensionless

$D=$ diameter of the sediment, in $\mathrm{mm}$

Since, $\quad T_{o r}=\gamma_{r} R_{r} S_{r}$

where subscript $r=$ ratio of prototype to model quantity

Also, $\quad S=Y_{r} / X_{r}=1$

if no scale distortion involves in the physical model. $Y_{r}$ stands for the vertical scale and $X_{r}$ stands for the horizontal scale.

By substituting Equations [3.2] and [3.3] into Equation [3.1] :

$$
1=\frac{\gamma_{r} R_{r} S_{r}}{\gamma_{r} \alpha_{r} D_{r}}
$$




$$
1=\frac{R_{r}}{\alpha_{r} D_{r}}
$$

where setting $\alpha=s_{s}-1$ for convenience. Additionally, the purpose of the explicit design method is to make $F_{s}$ in Equation [3.1] and $R e^{*}$ in Equation [3.8] (see below) the same in the model as in the prototype. So, the left side of Equations [3.1] and [3.8] should be equal to 1 .

Since Option \#3 is a 1 to 2 model,

$$
R_{r}=L_{r}=\frac{L_{p}}{L_{m}}=\frac{2}{1}=2
$$

Also,

$$
\alpha_{r}=\frac{\alpha_{p}}{\alpha_{m}}=\frac{s_{p}-1}{s_{m}-1}
$$

By substituting Equation [3.6] into Equation [3.4] :

$$
\begin{aligned}
1 & =\frac{2}{\left(\frac{s_{p}-1}{s_{m}-1}\right)\left(\frac{D_{p}}{D_{m}}\right)} \\
\frac{D_{p}}{D_{m}} & =\frac{2\left(s_{m}-1\right)}{s_{p}-1}
\end{aligned}
$$

The particle Reynolds number in Shield's diagram is,

$$
R e^{*}=\frac{V_{\text {shear }} D}{v}=\frac{\sqrt{\tau_{o} / \rho_{f}} D}{v}
$$

where $\rho_{f}=$ fluid density, in $\mathrm{kg} / \mathrm{m}^{3}$ $v=$ kinematic fluid viscosity, in $\mathrm{m}^{2} / \mathrm{s}$ 
By substituting Equations [3.2] and [3.3] into Equation [3.8] :

$$
\begin{aligned}
& 1=\frac{\sqrt{\left(\gamma_{r} R_{r} S_{r}\right) / \rho_{f_{r}}} D_{r}}{v_{r}} \\
& 1=\frac{\sqrt{\left(\rho_{f_{r}} g_{r} R_{r} S_{r}\right) / \rho_{f_{r}}} D_{r}}{v_{r}} \\
& 1=\frac{\sqrt{g_{r} R_{r}} D_{r}}{v_{r}} \\
& 1=R_{r} D_{r}{ }^{2}
\end{aligned}
$$

where $g$ is the same in the model and prototype and the fluid involved in both the model and prototype is water. Thus, $g_{r}=1$ and $v_{r}=1$.

By substituting Equation [3.5] into Equation [3.9] :

$$
\begin{aligned}
1 & =2\left(\frac{D_{p}}{D_{m}}\right)^{2} \\
\frac{D_{p}}{D_{m}} & =\frac{1}{\sqrt{2}}
\end{aligned}
$$

Equating Equations [3.7] and [3.10],

$$
\begin{aligned}
\frac{1}{\sqrt{2}} & =\frac{2\left(s_{m}-1\right)}{s_{p}-1} \\
\frac{s_{p}-1}{2 \sqrt{2}} & =s_{m}-1 \\
s_{m} & =\frac{2.65-1}{2 \sqrt{2}}+1 \\
& =1.583
\end{aligned}
$$

Since the bed material of the prototype is soil, $s_{m}$ is determined by assuming $s_{p}=2.65$. 
If small plastic balls made of PVC flexible (yellow highlight in Appendix K) are chosen for the bed material, the particle size distribution (Table 5) can be calculated using Equation [3.10] and Table 4 by assuming the specific gravity of the PVC flexible plastic balls to be 1.58 .

Table 5: Average particle size distribution of the proposed PVC flexible balls.

\begin{tabular}{|l|c|c|c|c|c|c|c|c|c|}
\hline$\%$ Finer & $D_{90}$ & $D_{80}$ & $D_{70}$ & $D_{60}$ & $D_{50}$ & $D_{40}$ & $D_{30}$ & $D_{20}$ & $D_{10}$ \\
\hline $\begin{array}{l}\text { Particle Size, } \\
\text { in mm }\end{array}$ & 2.49 & 1.43 & 0.914 & 0.590 & 0.397 & 0.260 & 0.163 & 0.0897 & 0.0362 \\
\hline
\end{tabular}

Appendix $\mathrm{K}$ lists the specific gravities of common plastic materials. A detail search had been conducted on all the chemical and plastic manufacturing companies in Hong Kong and none of them have the material that is suitable for the physical experiments. Thus, an actual scale physical model must be considered for this study. Option \#1 was selected since it is wider and has more available space for the preparation works of the physical experiments.

\subsection{ESTIMATION OF WATER DEPTH IN DRY WEATHER CONDITION}

Since the restoration framework involves widening of the existing low-flow channel, it is essential to estimate the new water depth and determine whether it is sufficient for fish habitats during dry weather condition. Manning's equation was applied in the water depth estimation. 
The first step of estimating the design water depth is to determine Manning's roughness coefficient (or Manning's $n$ ) after channel restoration. Although many textbooks and technique manuals present discussions of Manning's $n$, it is very important to keep in mind that those values are just rough estimation. Manning's $n$ varies significantly, especially on natural channels and flood plains, due to the differences in bed form and vegetation involvement. Table 6 provides the values for Manning's $n$, ranging from 0.03 to 0.10 , in natural streams (Chow, 1959). Manning's $n$ after the restoration framework is similar to point \#7 (red bolded numbers in Table 6) and the pools may not be as deep as the situation described by Chow. Thus, a value of 0.060 was chosen to represent Manning's $n$.

Cowan's method suggested by the U.S. Federal Highway Administration (Arcement and Schneider, 1984) was also applied as another source for the determination of Manning's $n$ (Appendix L):

$$
\begin{aligned}
n & =\left(n_{b}+n_{1}+n_{2}+n_{3}+n_{4}\right) m \\
& =(0.016+0+0+0.025+0.05) * 1.5 \\
& =0.1365
\end{aligned}
$$

where $n_{b}=$ base value of $n$ for a straight, uniform, smooth channel in natural materials;

$n_{1}=$ correction factor for the effect of surface irregularities;

$n_{2}=$ value for variations in shape and size of the channel cross section;

$n_{3}=$ value for obstructions;

$n_{4}=$ value for vegetation and flow conditions; and

$m=$ correction factor for meandering of the channel. 
Based on the values of Manning's $n$ from the above two sources, a range of water level estimation was developed (Table 7). The smallest value of the water level estimation is $6.88 \mathrm{~cm}$. This would be enough for the small fish and Malaysian trumpet snails that based on the observations during the site visits.

Table 6: Values of Manning's roughness coefficients (Chow, 1959).

\begin{tabular}{|c|c|c|c|}
\hline Types of Natural Channels and Description & Minimum & Normal & Maximum \\
\hline \multicolumn{4}{|l|}{ Minor streams (top width at flood stage $<100 \mathrm{ft}$ ) } \\
\hline \multicolumn{4}{|l|}{ Streams on plain } \\
\hline $\begin{array}{l}\text { 1) Clean, straight, full stage, no rifts } \\
\text { or deep pools }\end{array}$ & 0.025 & 0.030 & 0.033 \\
\hline $\begin{array}{l}\text { 2) Same as 1), but more stones and } \\
\text { weeds }\end{array}$ & 0.030 & 0.035 & 0.040 \\
\hline $\begin{array}{l}\text { 3) Clean, winding, some pools and } \\
\text { shoals }\end{array}$ & 0.033 & 0.040 & 0.045 \\
\hline $\begin{array}{l}\text { 4) Same as 3), but some weeds and } \\
\text { stones }\end{array}$ & 0.035 & 0.045 & 0.050 \\
\hline $\begin{array}{l}\text { 5) Same as 4), lower stages, more } \\
\text { ineffective slopes and sections }\end{array}$ & 0.040 & 0.048 & 0.055 \\
\hline 6) Same as 4), but more stones & 0.045 & 0.050 & 0.060 \\
\hline $\begin{array}{l}\text { 7) Sluggish reaches, weedy, deep } \\
\text { pools }\end{array}$ & 0.050 & 0.070 & 0.080 \\
\hline $\begin{array}{l}\text { 8) Very weedy reaches, deep pools, } \\
\text { or floodways with heavy stand of } \\
\text { timber and underbrush }\end{array}$ & 0.075 & 0.100 & 0.150 \\
\hline \multicolumn{4}{|l|}{$\begin{array}{l}\text { Mountain streams, no vegetation in channel, } \\
\text { banks usually steep, trees and brush along } \\
\text { banks submerged at high stages }\end{array}$} \\
\hline $\begin{array}{l}\text { 1) Bottom: gravels, cobbles, and few } \\
\text { boulders }\end{array}$ & 0.030 & 0.040 & 0.050 \\
\hline 2) Bottom: cobbles with large boulders & 0.040 & 0.050 & 0.070 \\
\hline \multicolumn{4}{|l|}{ Major streams (top width at flood stage $>100 \mathrm{ft}$ ). } \\
\hline $\begin{array}{l}\text { 1) Regular section with no boulders for } \\
\text { brush }\end{array}$ & 0.025 & ---- & 0.060 \\
\hline 2) Irregular and rough section & 0.035 & ----- & 0.100 \\
\hline
\end{tabular}


Table 7: Estimation of water level at dry weather condition after low-flow channel restoration.

\begin{tabular}{|c|c|c|c|c|c|c|c|c|c|c|}
\hline $\begin{array}{l}\text { Width of the Low-Flow } \\
\text { Channel }\left(B_{L F C}\right) \text {, in metres }\end{array}$ & \multicolumn{10}{|c|}{2} \\
\hline $\begin{array}{l}\text { Flow Rate at Dry Weather } \\
\text { Condition }\left(Q_{d r y}\right) \text {, in } \mathrm{m}^{3} / \mathrm{s}\end{array}$ & \multicolumn{10}{|c|}{0.04} \\
\hline Roughness Coefficient ( $n$ ) & 0.03 & 0.04 & 0.05 & 0.06 & 0.07 & 0.08 & 0.10 & 0.12 & 0.14 & 0.16 \\
\hline Longitudinal Slope $(S)$ & \multicolumn{10}{|c|}{0.002943} \\
\hline Area $(A)$, in $\mathrm{m}^{2}$ & 0.1377 & 0.1644 & 0.1888 & 0.2116 & 0.2329 & 0.2533 & 0.2915 & 0.3272 & 0.3610 & 0.3933 \\
\hline $\begin{array}{l}\text { Wetted Perimeter }(P), \\
\text { in metres }\end{array}$ & 2.138 & 2.164 & 2.189 & 2.212 & 2.233 & 2.253 & 2.292 & 2.327 & 2.361 & 2.393 \\
\hline $\begin{array}{l}\text { Hydraulic Radius }(R) \text {, } \\
\text { in metres }\end{array}$ & 0.06441 & 0.07596 & 0.08627 & 0.09568 & 0.1043 & 0.1124 & 0.1272 & 0.1406 & 0.1529 & 0.1643 \\
\hline $\begin{array}{l}\text { Depth of Water }\left(H_{\text {water }}\right) \text {, } \\
\text { in metres }\end{array}$ & 0.06884 & 0.08221 & 0.09441 & 0.1058 & 0.1165 & 0.1266 & 0.1458 & 0.1636 & 0.1805 & 0.1966 \\
\hline Velocity $(V)$, in $\mathrm{m} / \mathrm{s}$ & 0.2905 & 0.2433 & 0.2118 & 0.1890 & 0.1717 & 0.1579 & 0.1372 & 0.1222 & 0.1108 & 0.1017 \\
\hline $\begin{array}{l}\text { Shear Velocity }\left(V_{\text {shear }}\right) \text {, } \\
\text { in } \mathrm{m} / \mathrm{s}\end{array}$ & 0.04311 & 0.04682 & 0.04990 & 0.05255 & 0.05487 & 0.05695 & 0.06059 & 0.06370 & 0.06643 & 0.06886 \\
\hline
\end{tabular}


Table 8: Estimation of flow rates at different water levels after low-flow channel restoration.

\begin{tabular}{|c|c|c|c|c|c|c|c|c|c|}
\hline $\begin{array}{l}\text { Width of the Low-Flow Channel }\left(B_{L F C}\right) \text {, } \\
\text { in metres }\end{array}$ & \multicolumn{9}{|c|}{2} \\
\hline Roughness Coefficient $(n)$ & \multicolumn{9}{|c|}{0.06} \\
\hline Longitudinal Slope $(S)$ & \multicolumn{9}{|c|}{0.002943} \\
\hline Height of Water $\left(H_{\text {water }}\right)$, in metres & 0.05 & 0.1 & 0.15 & 0.2 & 0.25 & 0.3 & 0.35 & 0.4 & 0.45 \\
\hline Area $(A)$, in $\mathrm{m}^{2}$ & 0.1000 & 0.2000 & 0.3000 & 0.4000 & 0.5000 & 0.6000 & 0.7000 & 0.8000 & 0.9000 \\
\hline Wetted Perimeter $(P)$, in metres & 2.100 & 2.200 & 2.300 & 2.400 & 2.500 & 2.600 & 2.700 & 2.800 & 2.900 \\
\hline Hydraulic Radius $(R)$, in metres & 0.04762 & 0.09091 & 0.1304 & 0.1667 & 0.2000 & 0.2308 & 0.2593 & 0.2857 & 0.3103 \\
\hline $\begin{array}{l}\text { Flow Rate at Dry Weather Condition } \\
\left(Q_{d r y}\right) \text {, in } \mathrm{m}^{3} / \mathrm{s}\end{array}$ & 0.01188 & 0.03656 & 0.06976 & 0.1095 & 0.1546 & 0.2041 & 0.2573 & 0.3138 & 0.3730 \\
\hline Velocity $(V)$, in $\mathrm{m} / \mathrm{s}$ & 0.1188 & 0.1828 & 0.2325 & 0.2738 & 0.3092 & 0.3402 & 0.3676 & 0.3922 & 0.4145 \\
\hline Shear Velocity $\left(V_{\text {shear }}\right)$, in $\mathrm{m} / \mathrm{s}$ & 0.03707 & 0.05122 & 0.06135 & 0.06935 & 0.07597 & 0.08161 & 0.0865 & 0.0908 & 0.09464 \\
\hline
\end{tabular}




\subsection{ESTIMATION OF FLOW RATES UNDER WET WEATHER CONDITIONS}

Flow rates with various water depths under wet weather conditions after the low-flow channel restoration were estimated using the Manning's equation (Table 8). When water depth is $25 \mathrm{~cm}$, the flow rate is about $0.155 \mathrm{~m}^{3} / \mathrm{s}$. This value was used as the flow rate for the physical experiments (Section 4.6).

\subsection{CONSTRUCTION OF THE PHYSICAL MODEL}

The physical model was made by wooden boards, Acrylic sheets and highdensity Styrofoam boards. Design Option \#1 (Figure 40) was first sketched on the floor as a construction guidance. Acrylic sheets of $9.53 \mathrm{~mm}$ thickness were then placed over the floor sketch for waterproofing purposes (Figure 43). Wooden boards of $15.9 \mathrm{~mm}$ thickness and wooden sticks were applied to the banks of the channel as supports and frames of the Acrylic sheets on the banks (Figure 44). All screwed connections between the Acrylic sheets and the wooden boards were sealed with silicone caulking for waterproofing before gluing the high density Styrofoam boards to the channel (Figure 45). The reason for applying high density Styrofoam boards was to create the required curvature of the physical model. Finally, a heavy layer of sediment from the pilot site was stuck on the banks to reproduce the bank roughness after channel restoration (Figure 46) as closely as possible. 


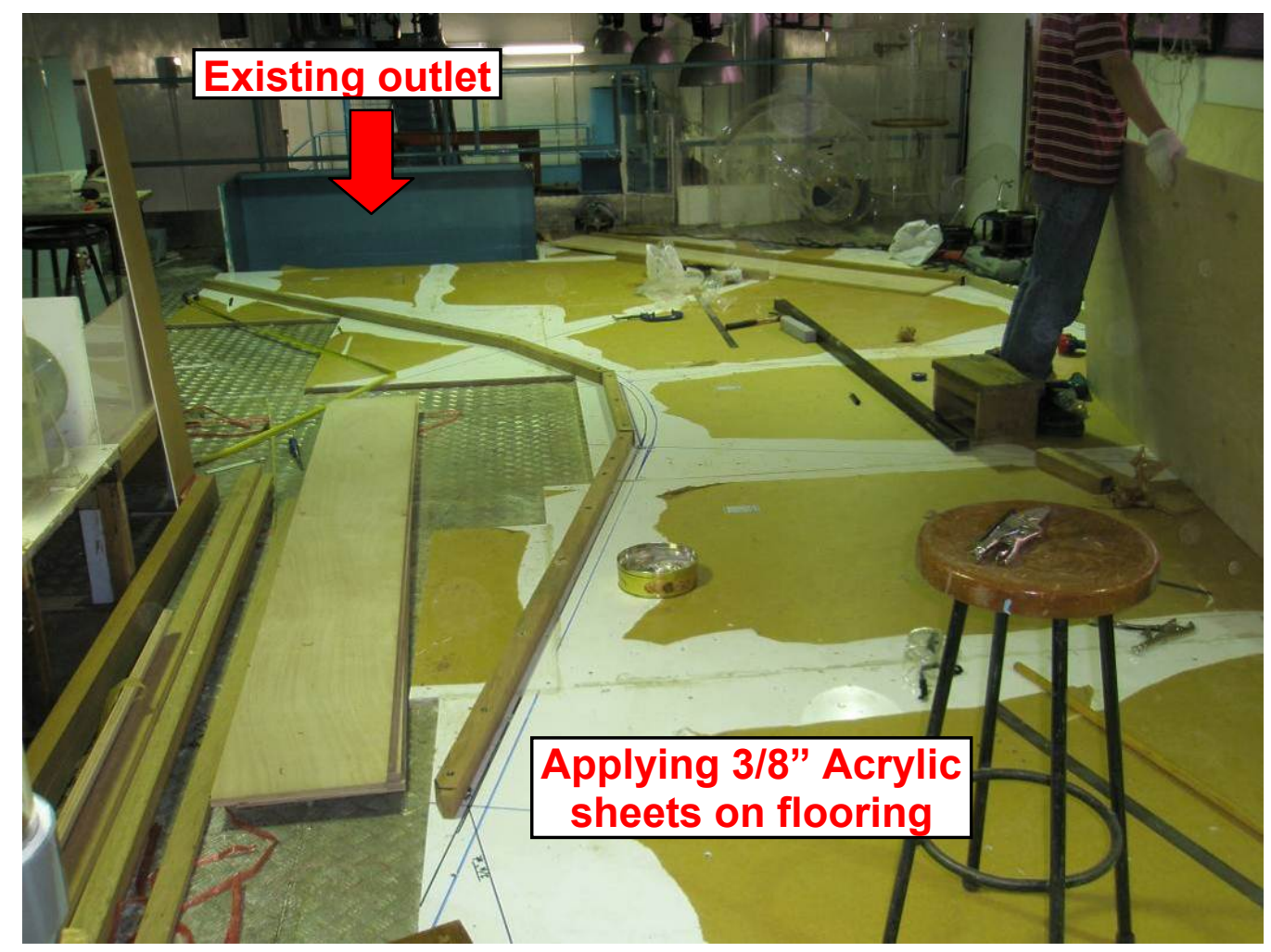

Figure 43: Flooring of the physical model.

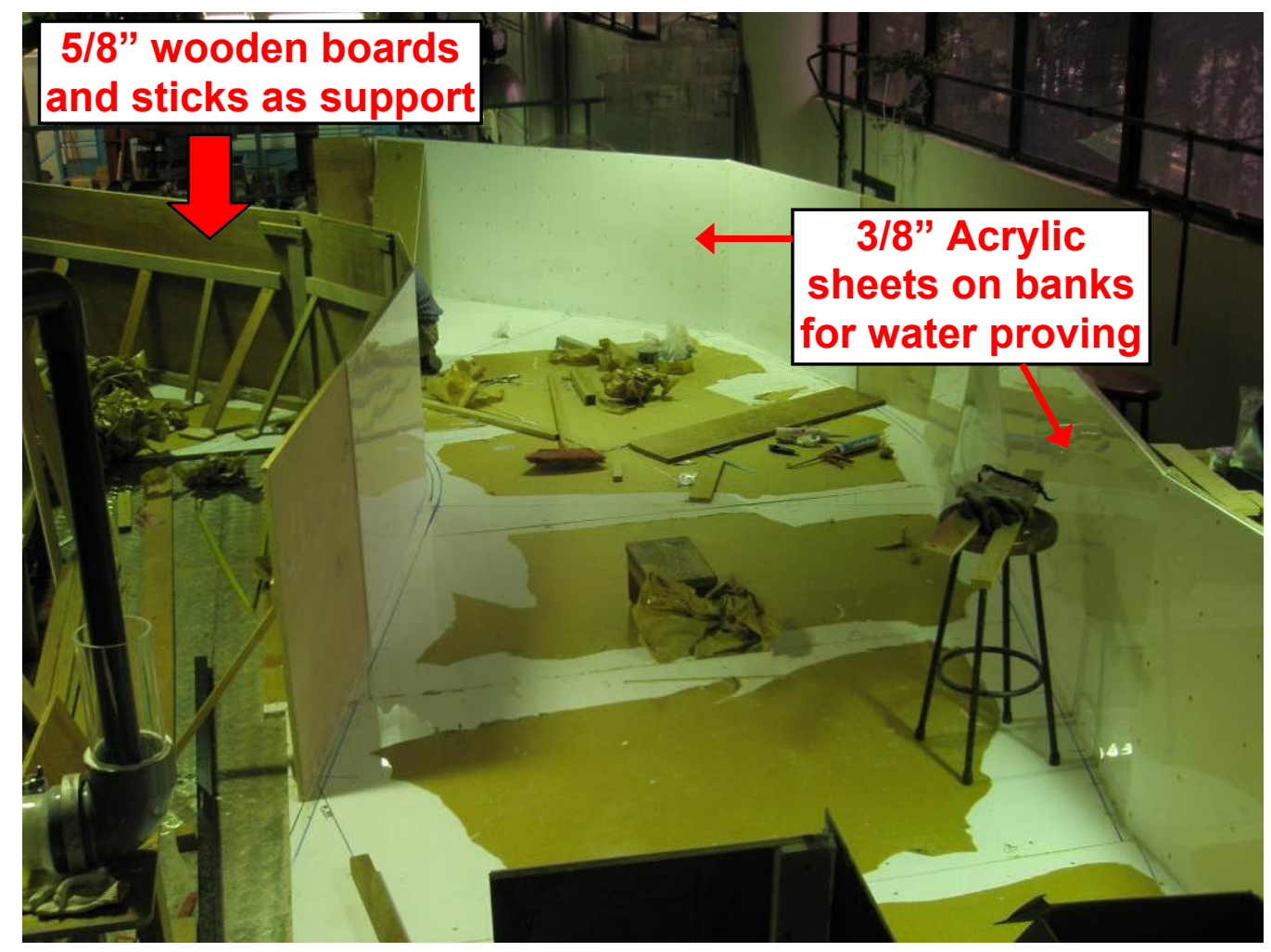

Figure 44: Construction process (1) of the physical model. 


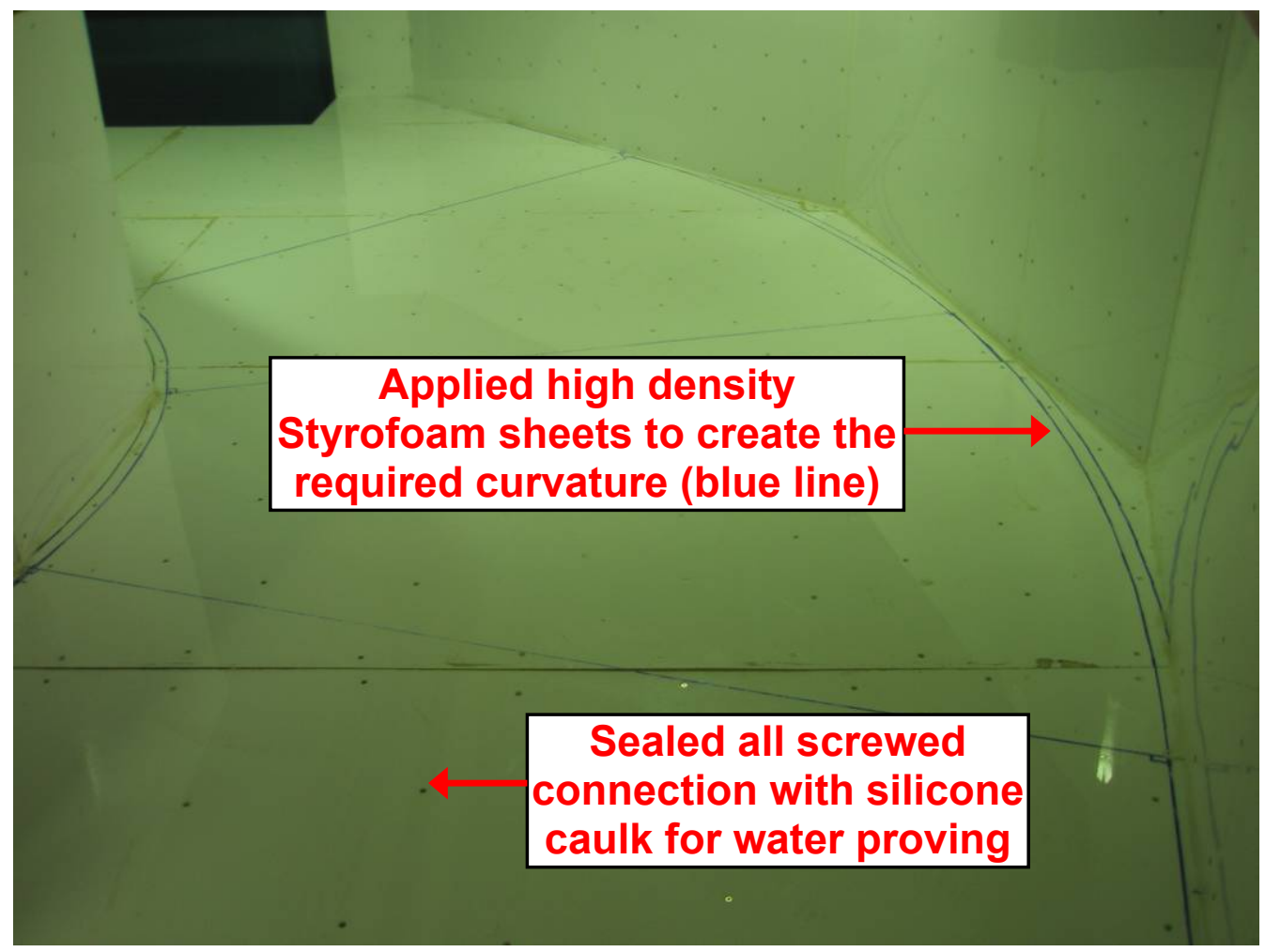

Figure 45: Construction process (2) of the physical model.

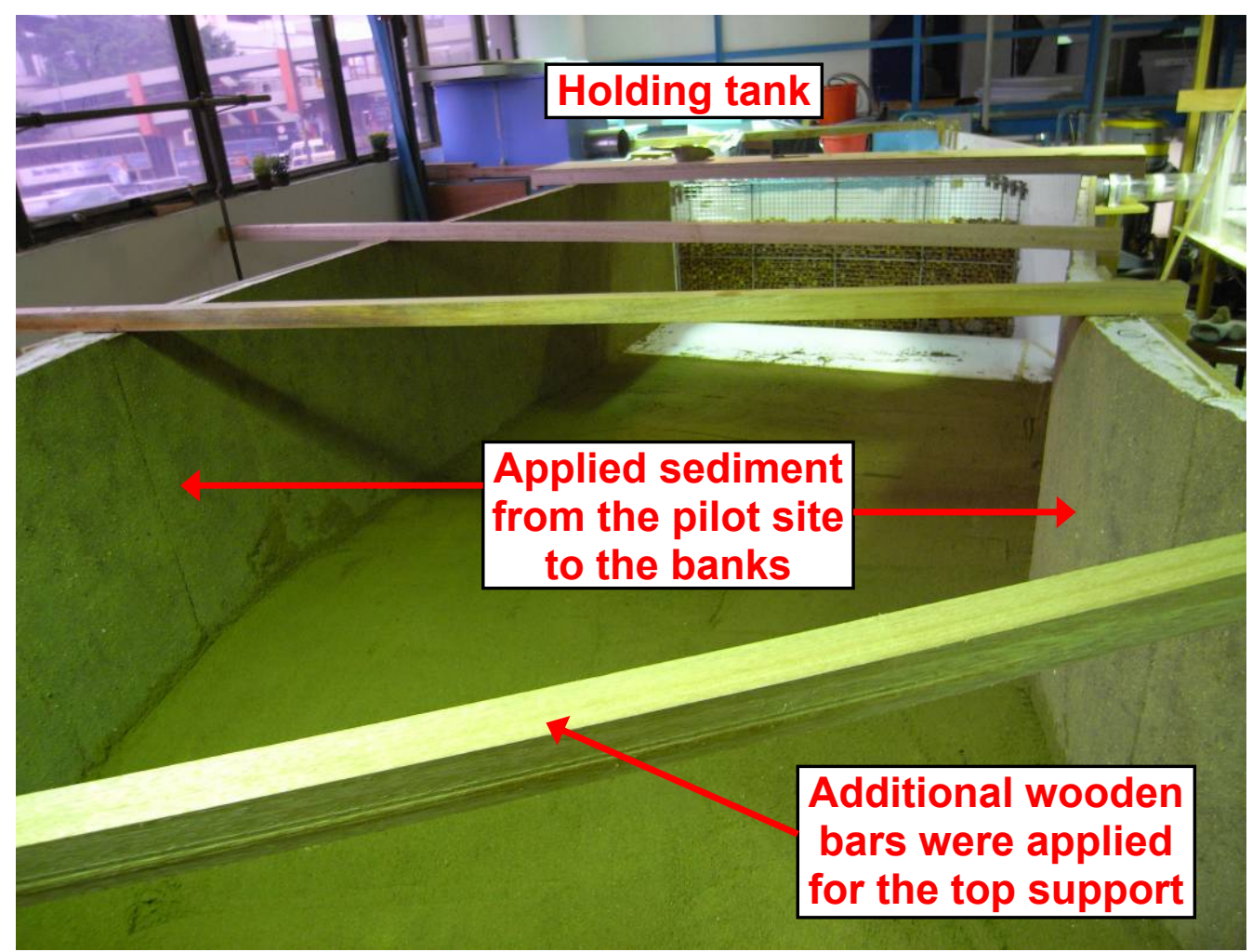

Figure 46: Construction process (3) of the physical model. 


\section{Outlet Control}

A rectangular adjustable weir made by aluminum plates (Figure 47) was applied to the outlet of the physical model. Five $25-\mathrm{mm}$ holes were drilled at the bottom of the weir for drainage purpose. Plastic plugs were applied to the holes during the physical experiments. A range of water depths between $5 \mathrm{~cm}$ and $45 \mathrm{~cm}$ can be created by the adjustable weir for the physical experiments.

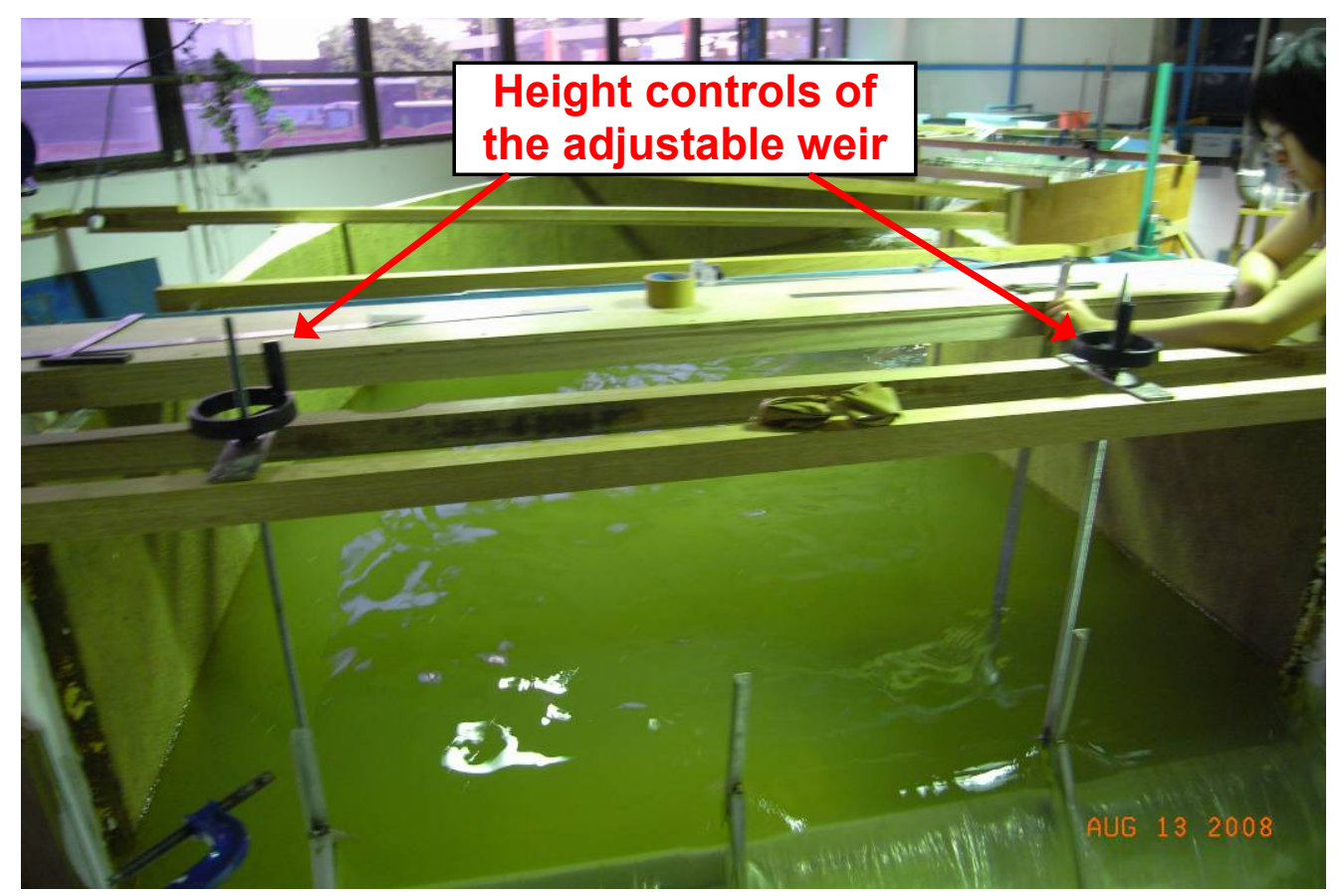

Figure 47: Rectangular adjustable weir at the outlet of the physical model.

\section{Sediment Bed Preparation Ramp}

A $30 \mathrm{~cm}$ sediment bed preparation ramp (Figure 48) with an inclined angle of $60^{\circ}$ at both sides was applied at the inlet of the channel. The function of the ramp 
was to minimize the impacts of the changes of bed material, from the Acrylic sheets to the actual sediment from the pilot site, at the inlet.

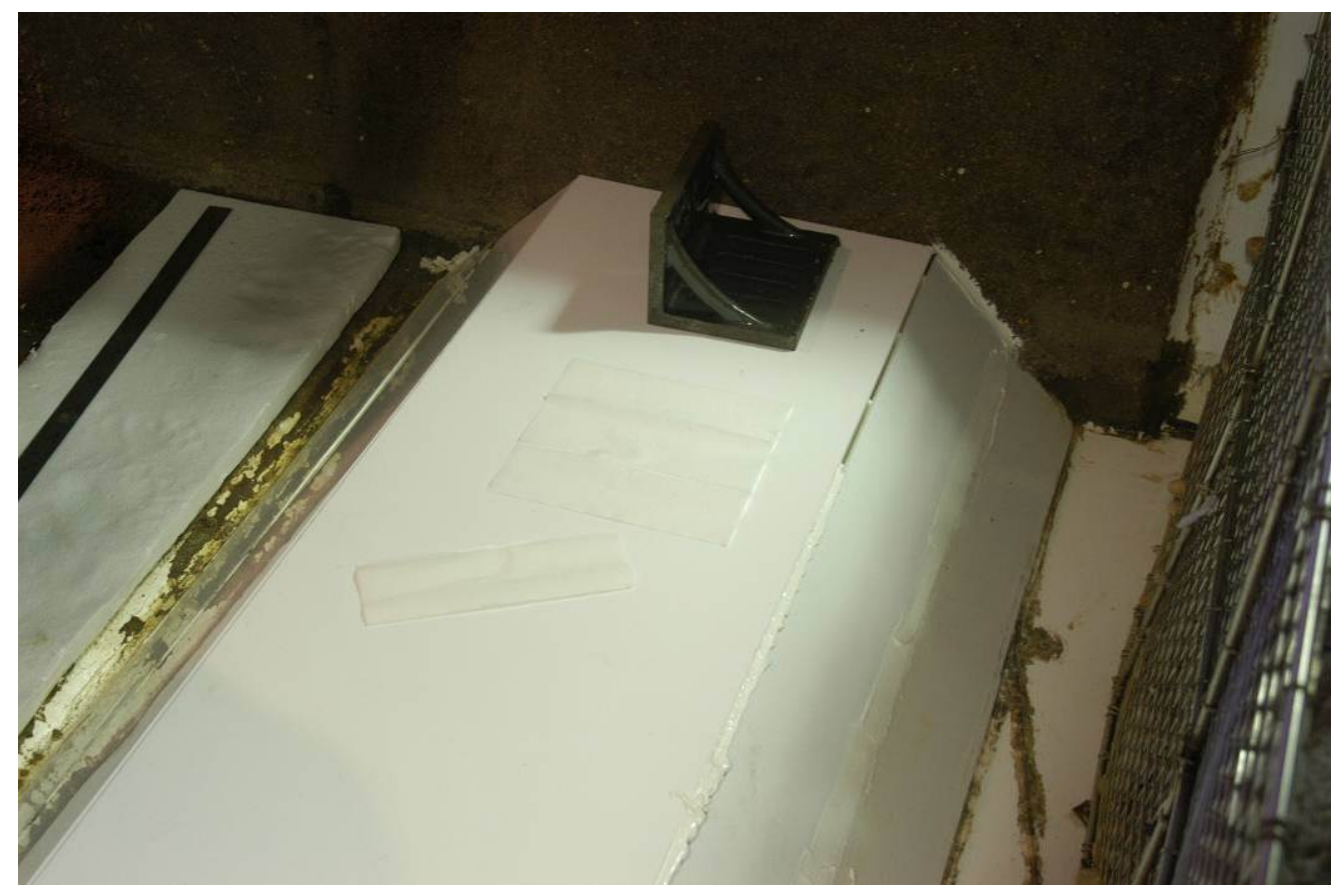

Figure 48: Sediment bed preparation ramp.

\section{Deflector Design}

Two Gabion baskets of $666.7 \mathrm{~mm}$ X $300 \mathrm{~mm}$ X $400 \mathrm{~mm}$ (Figure 50) were made for the physical experiments. The reasons for applying Gabion baskets for the deflector design are due to the stability they impose, particularly under wet weather conditions, and for vegetation establishment considerations. To increase the vegetation survival rate and potential vegetation extension to the deposition zone, the proposed vegetation needed to be well established in-house at the deflector prior to the obstacle being installed at the restoration site (Figure 49). Large crushed concrete blocks from The HK PolyU construction laboratory were 
used as the material in the Gabion baskets, instead of crushed stones, to minimize the construction cost. The size of the crushed concrete blocks was ranging from $7.5 \mathrm{~cm}$ to $20 \mathrm{~cm}$. The concrete blocks were considered to have similar surface roughness characteristics to the crushed stones that are normally applied to Gabion baskets. The contraction ratio, the length of the deflector measured perpendicular to the channel bank divided by the width of the channel, of each deflector is about 0.3 . This contraction ratio should provide sufficient space to investigate different deflector arrangement scenarios (Table 10). Only one set of contraction ratio was investigated in the physical experiments due to the long construction time required for the Gabion baskets.

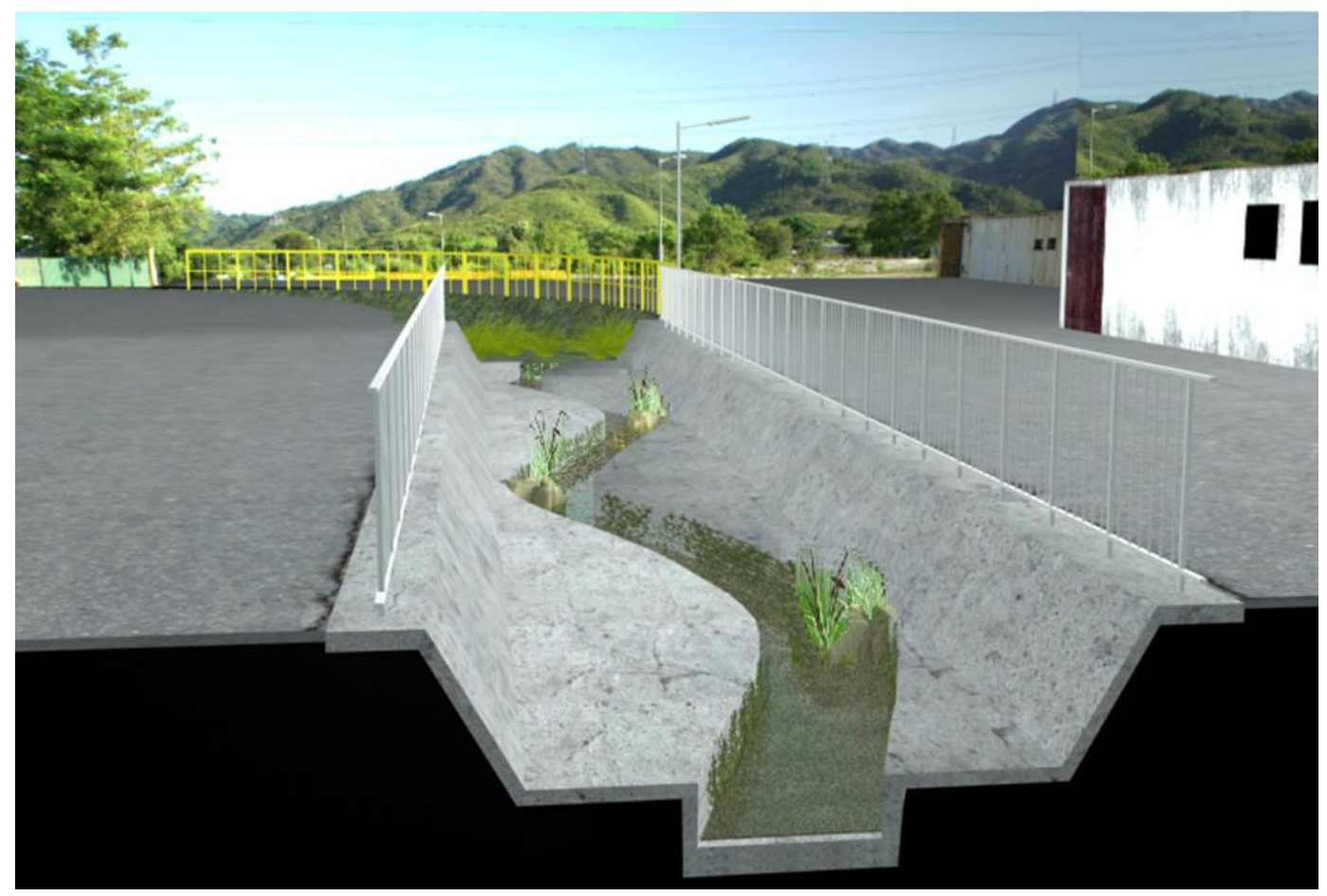

Figure 49: Deflector design with intended vegetation establishment. 


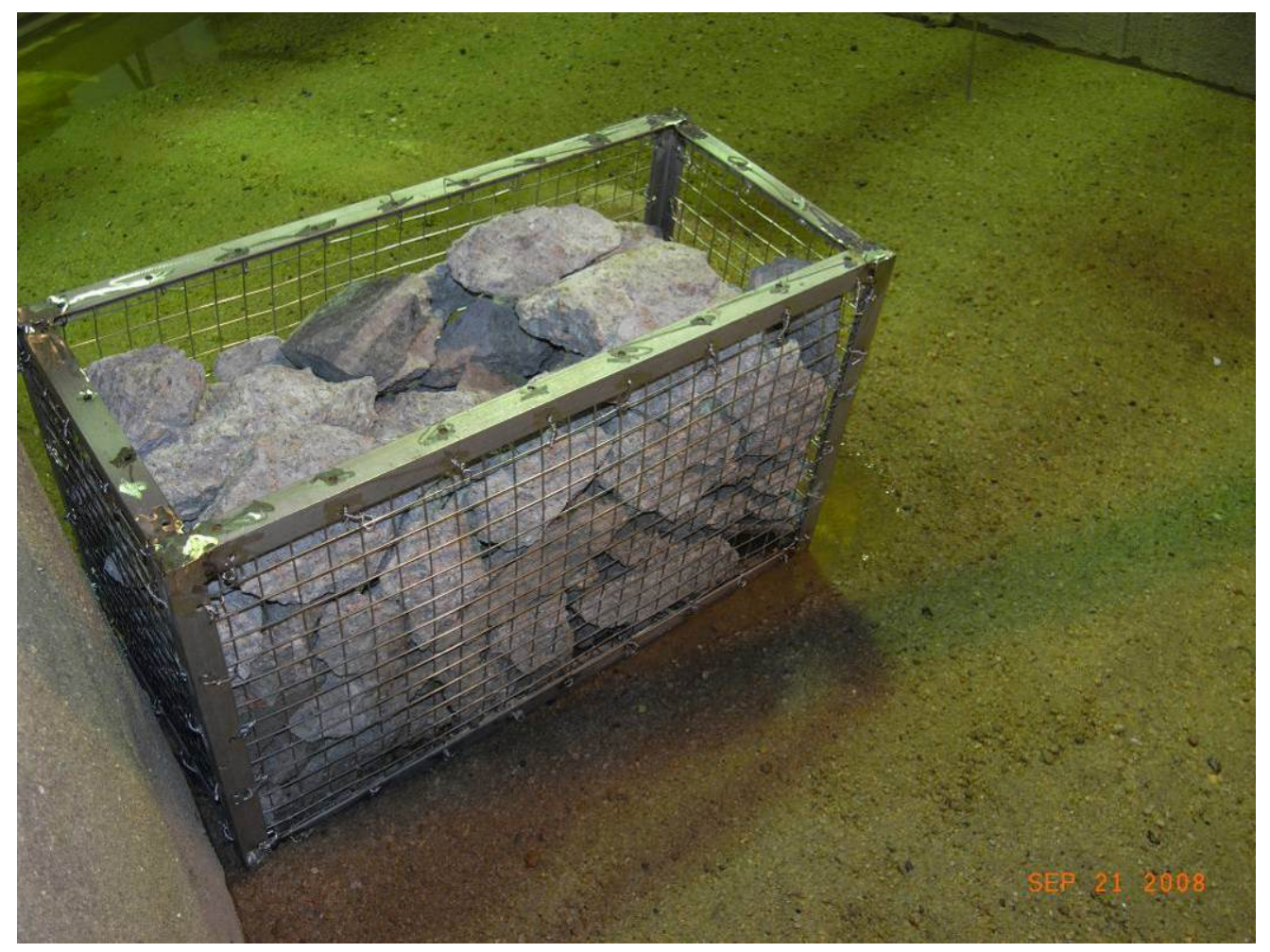

Figure 50: Deflector of the physical experiments.

\section{Incoming Sediment Feeder}

Two design options (Figure 51 and Figure 52) of the incoming sediment feeder had been developed for the physical experiments. The funnel option was selected (Figure 51) due to the longer construction time consideration for the PVC rolling pipe feeder (Figure 52). Sediment was manually evenly distributed into the feeder during the incoming sediment scenarios (Section 4.6.3). 
3" X 8" incoming sediment feeder with adjustable gap and plate at the lower corner of the triangular prism for unloading the sediment into the channel

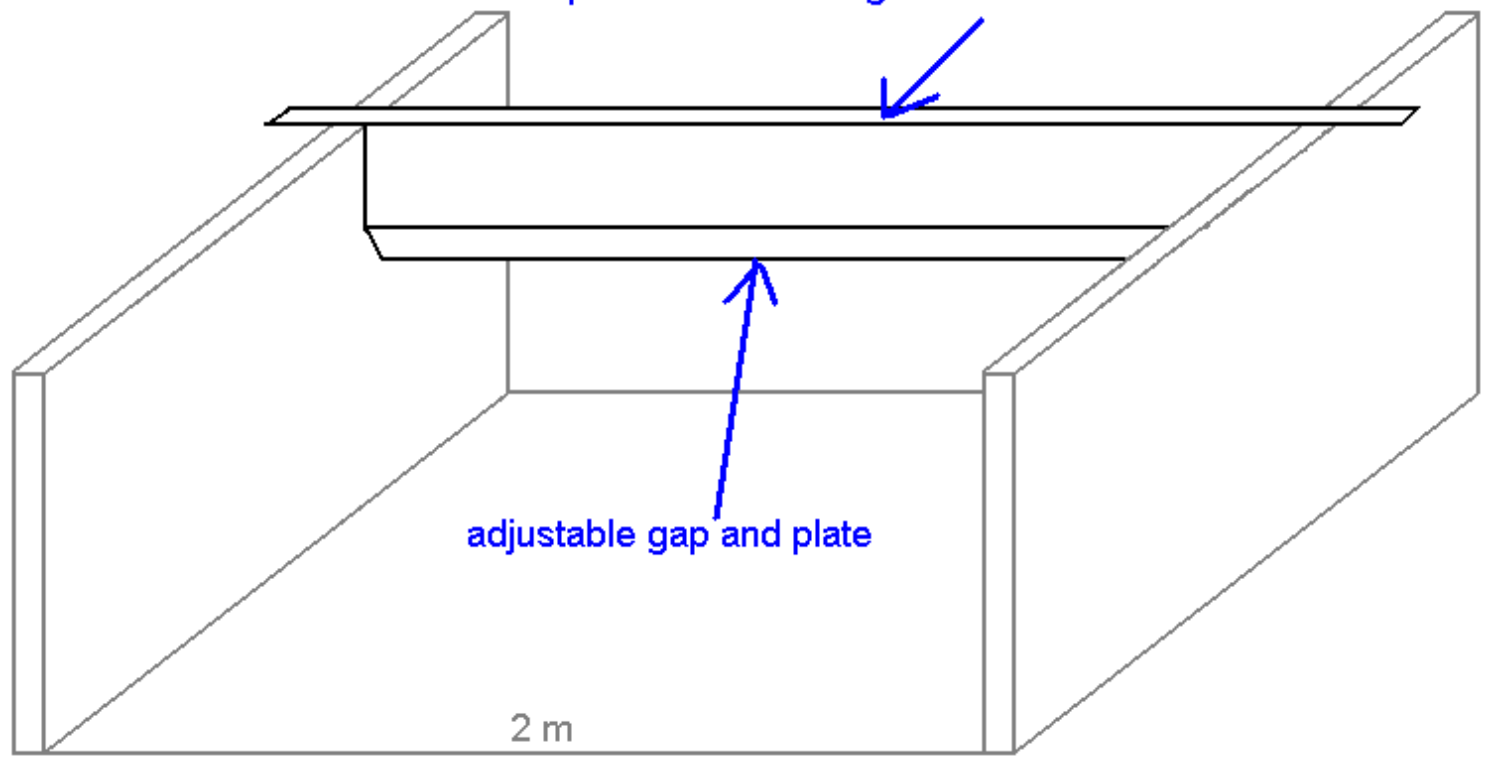

Figure 51: Incoming sediment feeder Design Option \#1.

2-inch PVC pipe with $5 \mathrm{~mm}$ wide of opening along the channel where sediment can be loaded to the channel by rolling the pipe

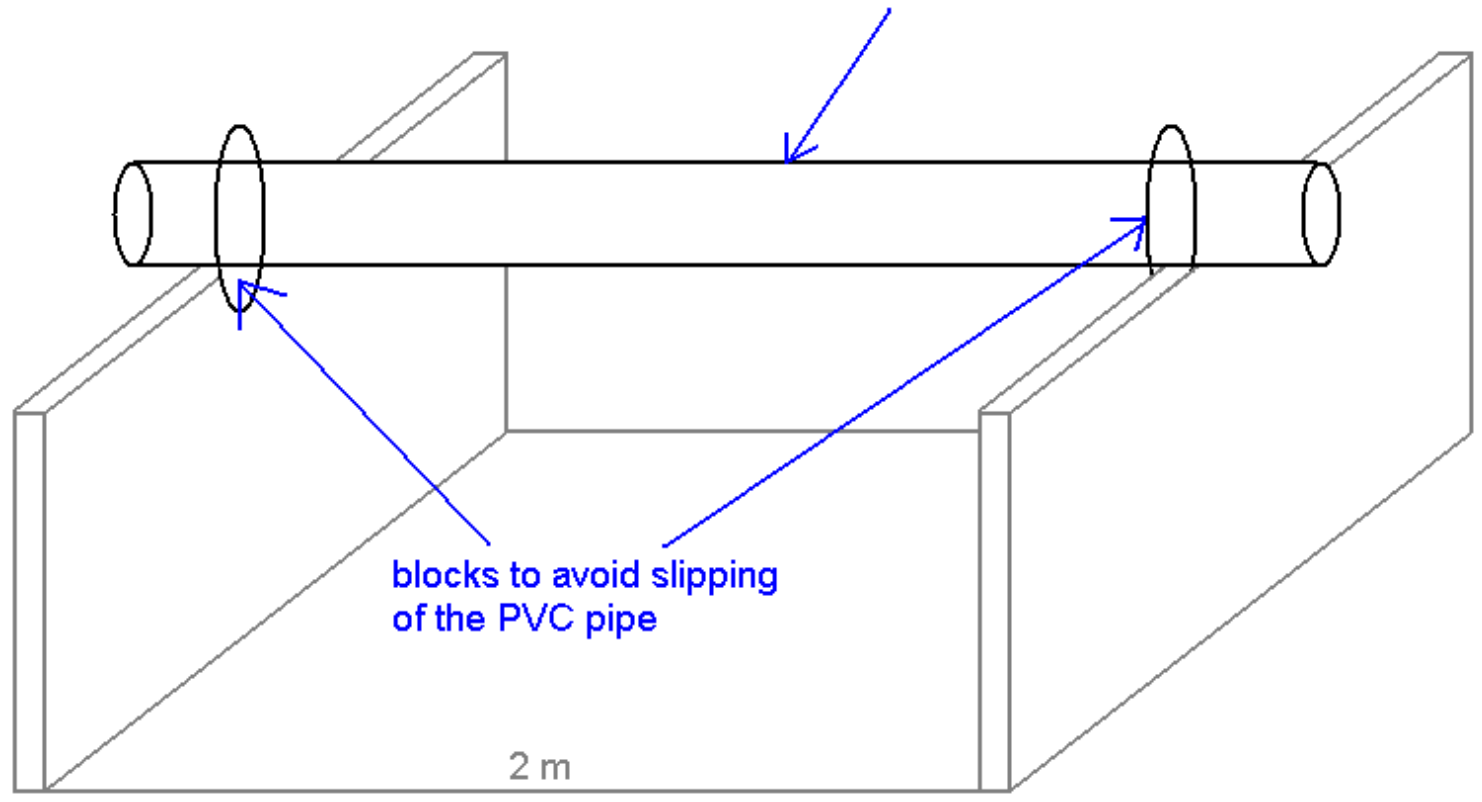

Figure 52: Incoming sediment feeder Design Option \#2. 


\subsection{MODIFICATION OF THE PHYSICAL MODEL}

Before the installation of the high density Styrofoam boards to the model (Figure 45), a trial experiment without applying any sediment bed was conducted. The purpose of the trial experiment was to determine whether the existing structure, the steel open channel (orange dotted line on Figure 40), had any significant influences on the inflow. As a result, the inflow cannot be uniformly distributed (Figure 53 and Figure 54) due to the changes of the alignments between the connection of the existing structure and the physical model. Modification includes: 1) shortening the steel open channel, 2) extending the walls of the physical model as much as possible (purple dotted rectangles on Figure 55), and 3) applying a baffle wall at the upstream of the sediment bed preparation ramp to minimize the impacts of the drop zone caused by the steel open channel, were applied to the inlet of the physical model to address the problems. Different material, crushed concrete blocks (Figure 56) and rounded pebble stones (Figure 57), were applied to the baffle wall to determine the best performance on forming a uniformly distributed inflow at the testing flow rate of $155 \mathrm{~L} / \mathrm{s}$ (Section 4.3). In conclusion, crushed concrete blocks were selected since rounded pebble stones backed up the inflow to the holding tank (Figure 46). 


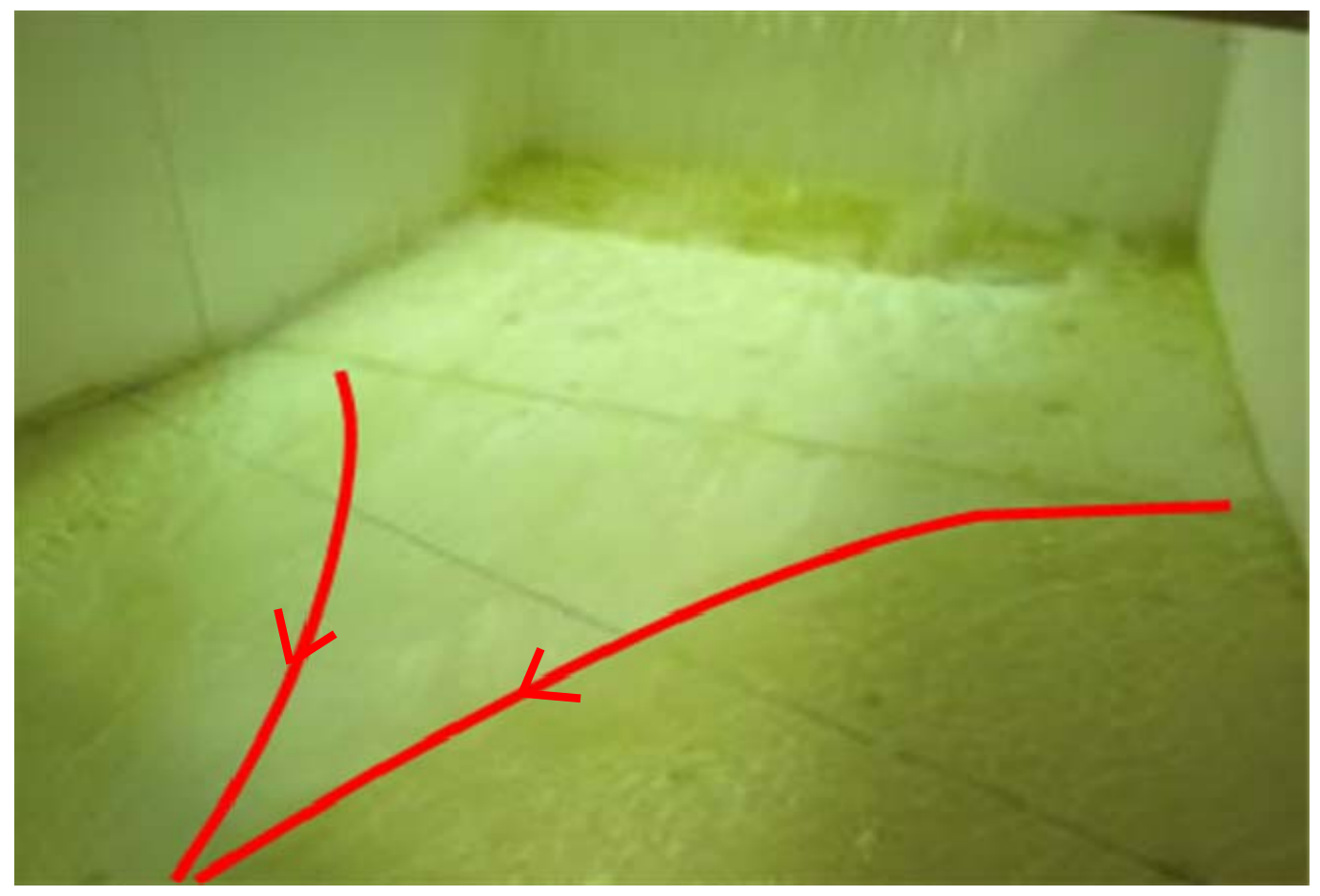

Figure 53: General flow pattern during the trial experiment.

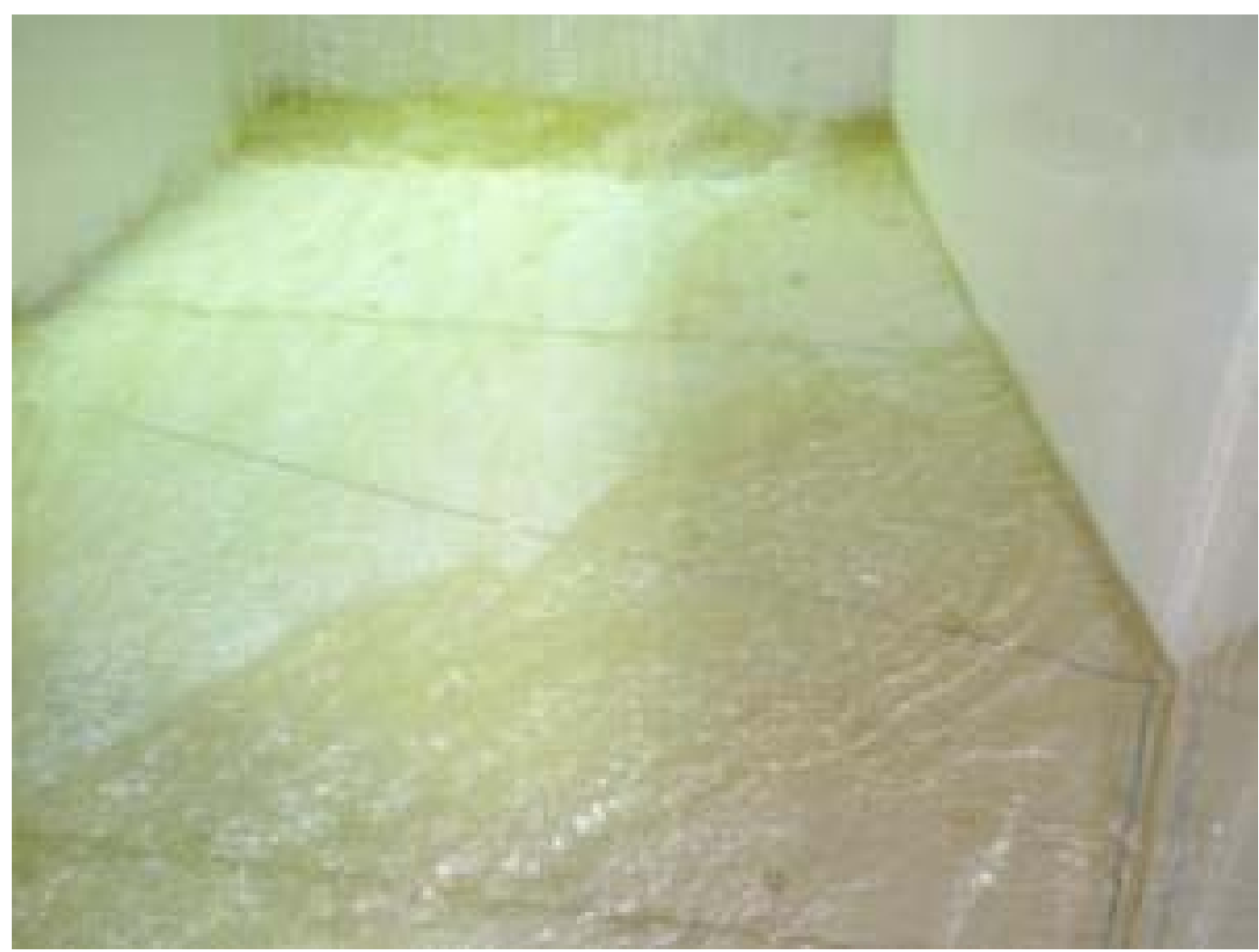

Figure 54: Flow pattern near the bank at the right-side (facing upstream) during the trial experiment. 


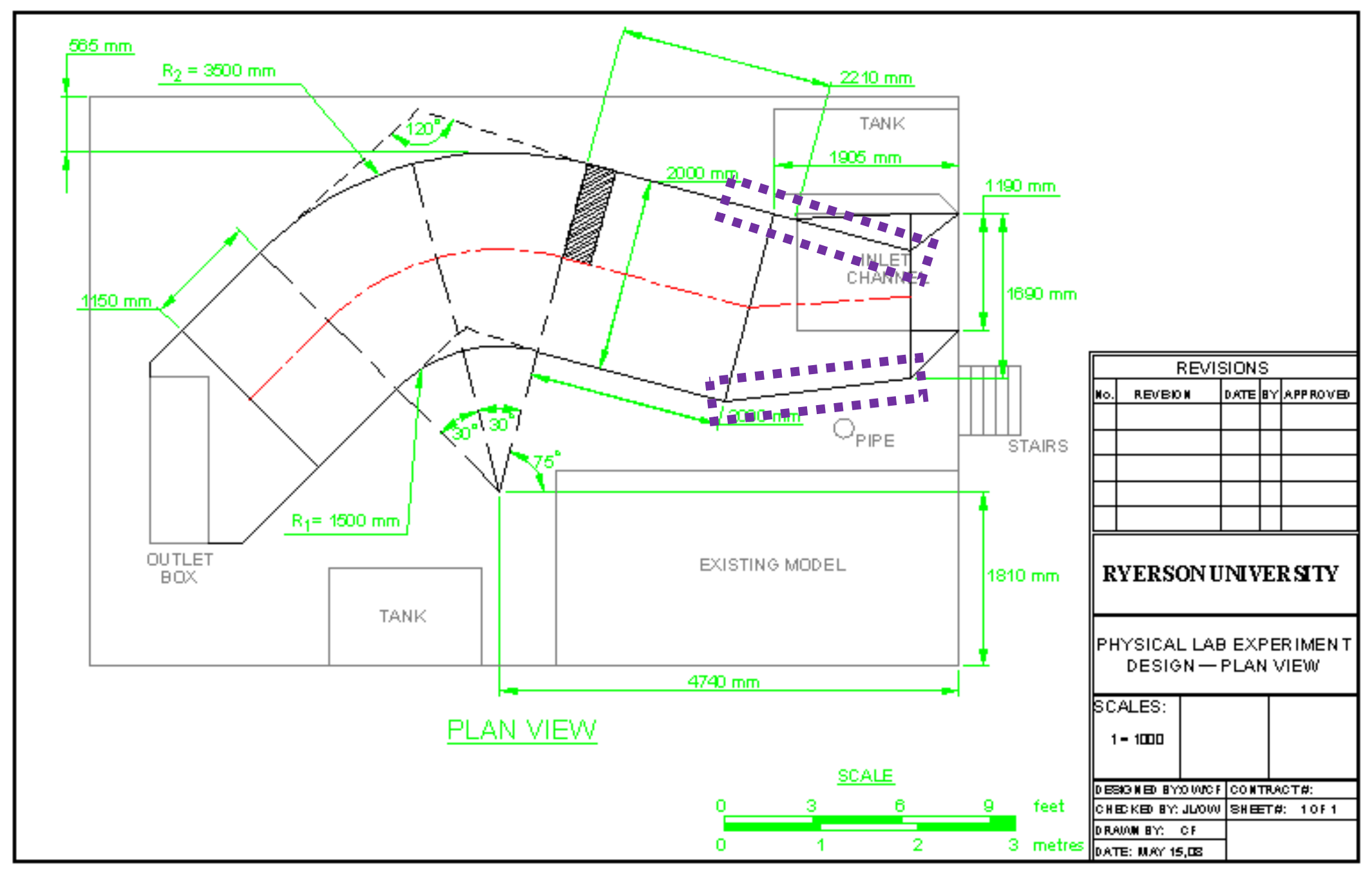

Figure 55: Modification of the physical model. 


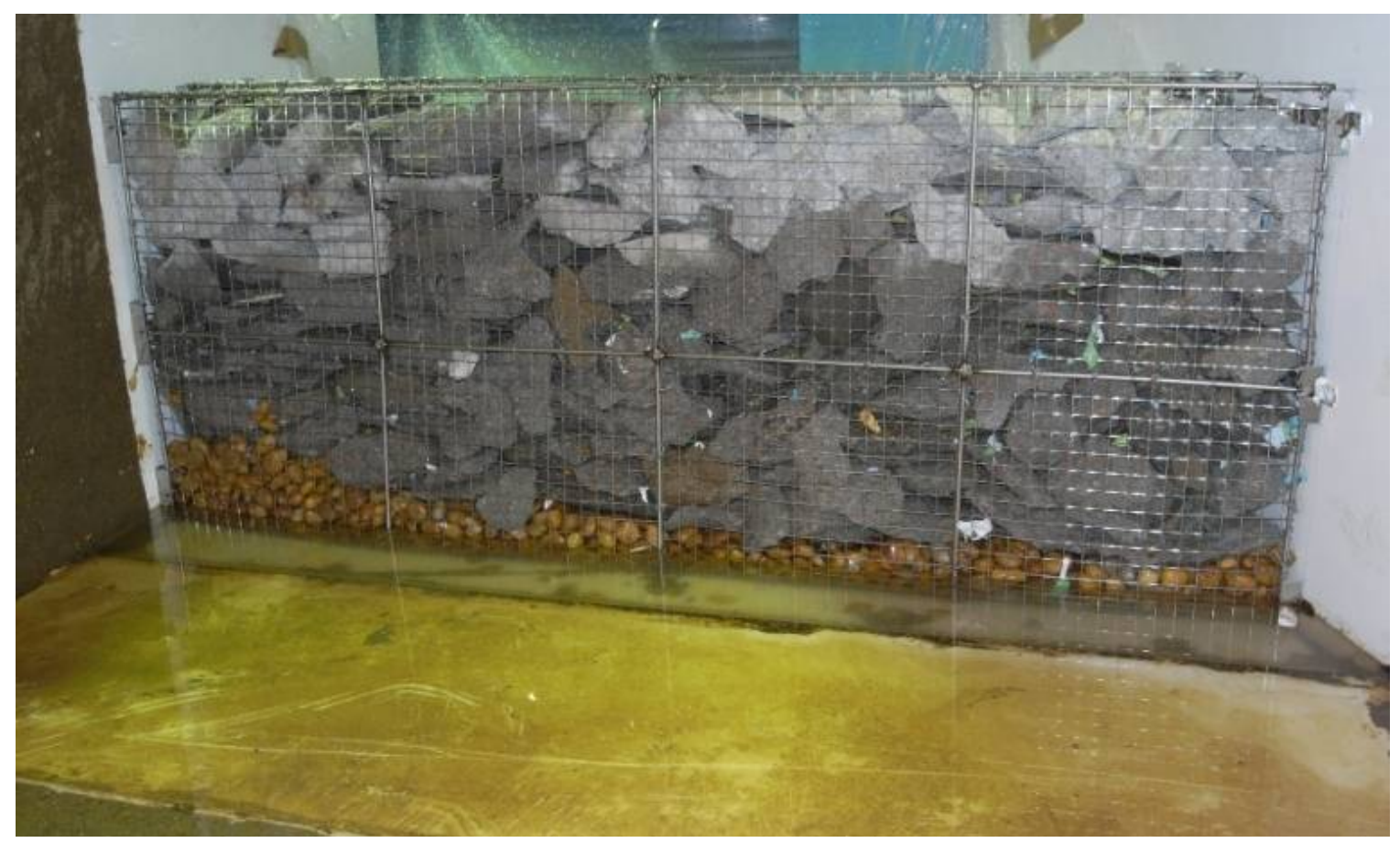

Figure 56: Baffle wall with crushed concrete.

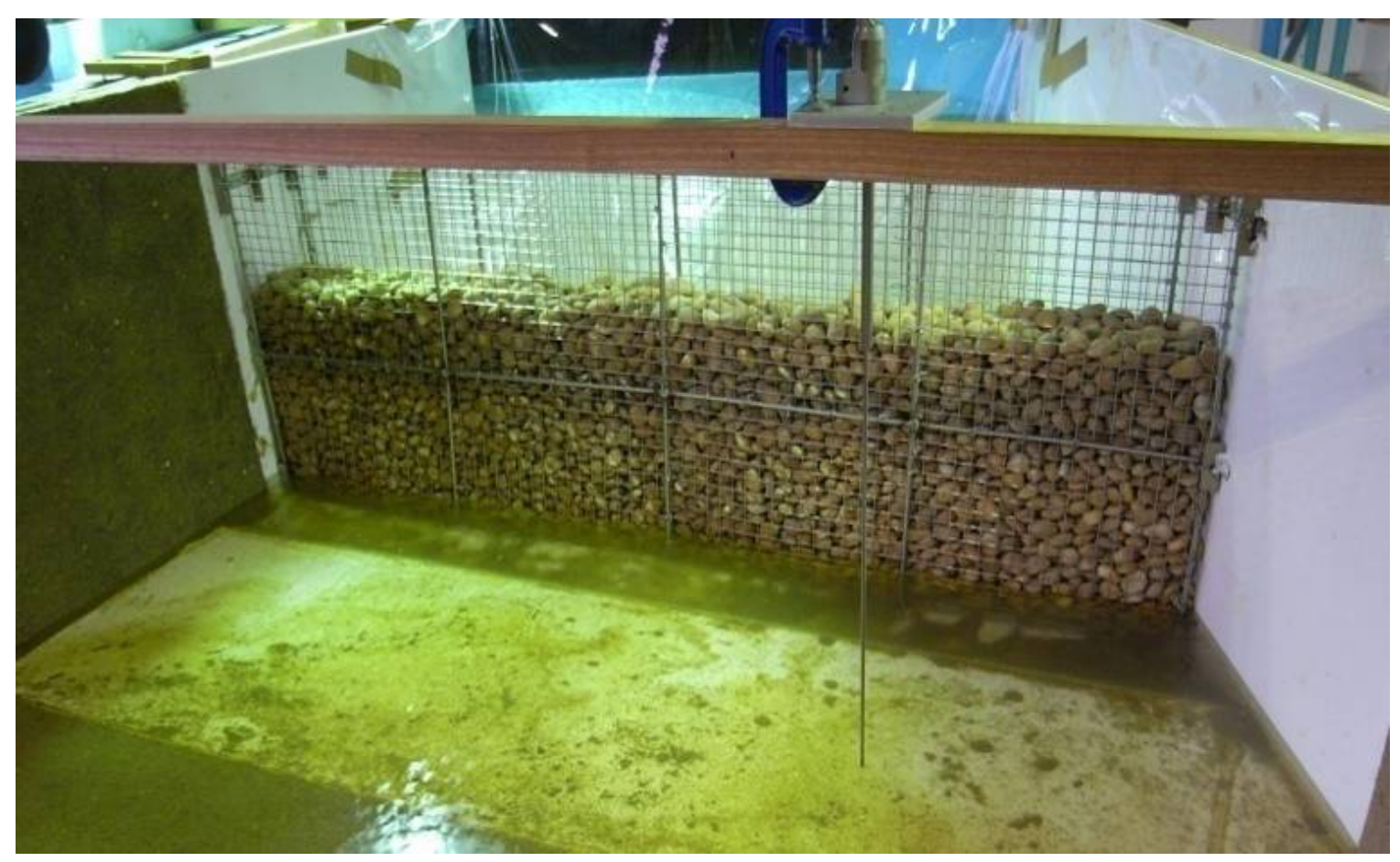

Figure 57: Baffle wall with rounded pebble stones. 


\subsection{DESIGN OF THE PHYSICAL EXPERIMENTS}

Three scenarios representing different weather conditions were investigated using the physical model: 1) dry weather condition without incoming sediment; 2) wet weather condition without incoming sediment; and 3) wet weather condition with incoming sediment. Single and double deflectors were applied to each scenario to facilitate the formation of pool and deposition zones. This section contains a detail discussion on all the physical experiments involved in each scenario.

\subsubsection{Dry Weather Condition}

Mr. Au Yeung, the inspector of the HK DSD, commented that the sediment transport rate of the pilot site is minimum during dry weather condition, with a maximum of $1 \mathrm{~L} /$ day. The source of the incoming sediment is mostly from erosion at the uppermost creek under wet weather conditions. Thus, the incoming sediment situation was not investigated for the dry weather condition.

Table 9 lists the experiments undertaken for the dry weather condition. The flow rate determined from a flow monitoring report by HK DSD (Appendix $\mathrm{H}$ ). The water depth was from the estimation developed in Table 7 (see orange bolded number). This was also close to the measured water depth where Malaysian trumpet snails had been observed during the site assessment (Section 3.4.3). 
Table 9: Physical Experiments for Dry Weather Condition.

\begin{tabular}{|c|c|c|c|c|}
\hline $\begin{array}{c}\text { Experiment } \\
\text { Number }\end{array}$ & $\begin{array}{c}\text { Flow Rate, } \\
\text { in } \mathbf{~ m}^{\mathbf{3}} \mathbf{s}\end{array}$ & $\begin{array}{c}\text { Water Depth, } \\
\text { in } \mathbf{~ m m}\end{array}$ & Deflector Types & $\begin{array}{c}\text { Incoming } \\
\text { Sediment? }\end{array}$ \\
\hline $\mathrm{A} 1$ & 0.040 & 100 & none & No \\
\hline $\mathrm{A} 2$ & 0.040 & 100 & single & No \\
\hline $\mathrm{A} 3$ & 0.040 & 100 & double (paired) & No \\
\hline $\mathrm{A} 4$ & 0.040 & 100 & double (staggered) & No \\
\hline
\end{tabular}

Reynolds number and Froude number were estimated using the following equations:

$$
\begin{aligned}
& \operatorname{Re}=\frac{U R}{v}=\frac{(Q / A)(A / P)}{v}=\frac{Q}{P v} \\
& F r=\frac{V}{\sqrt{g d}}
\end{aligned}
$$

where $\mathrm{Re}=$ Reynolds number

$F r=$ Froude number

$Q$ = flow discharge

$R=$ hydraulic radius

$V=$ velocity

$A=$ cross-sectional area

$P=$ wetted perimeter

$v=$ kinematic viscosity

$g$ = gravitational acceleration

$d=$ flow depth

Reynolds number at the upstream and downstream of the deflector is about $1.99 \times 10^{5}$ and at the contraction area of the deflector is about $2.99 \times 10^{5}$. Froude numbers at the upstream and downstream of the deflector and at the contraction area are about 0.2 and 0.3 respectively. 


\subsubsection{Wet Weather Condition Without Incoming Sediment}

Table 10 lists the physical experiments that were planned for the wet weather condition also without an incoming sediment scenario. The proposed flow rate was come from the estimation in Table 8 (see orange bolded number). This was also the maximum flow rate that could be created in The HK PolyU hydraulic laboratory. Two water depths, half and bankfull of the low-flow channel, were investigated in this scenario to determine whether there were any significant effects when water was passed under and over the deflector height. Figure 58 to Figure 62 depict the configuration of the deflectors that were mentioned in Table 10.

Reynolds numbers at the upstream and downstream of the deflector and at the contraction area of the deflector for the wet weather condition are about $3.09 \times 10^{5}$ and $4.63 \times 10^{5}$ respectively. Froude numbers at the upstream and downstream of the deflector and at the contraction area are about 0.2 and 0.3 respectively. 
Table 10: Physical experiments for wet weather condition without incoming sediment.

\begin{tabular}{|c|c|c|c|c|}
\hline $\begin{array}{l}\text { Experiment } \\
\text { Number }\end{array}$ & $\begin{array}{l}\text { Flow Rate, } \\
\text { in L/s }\end{array}$ & $\begin{array}{l}\text { Water Depth, } \\
\text { in } \mathrm{mm}\end{array}$ & $\begin{array}{c}\text { Deflector } \\
\text { Types }\end{array}$ & Location of Deflector \\
\hline $\mathrm{B} 1$ & 155 & 250 & single & $\begin{array}{c}\text { outer curvature; } \\
\text { center of meander } \\
\text { (Figure } 58 \text { ) }\end{array}$ \\
\hline B2 & 155 & 450 & single & $\begin{array}{l}\text { outer curvature; } \\
\text { center of meander } \\
\text { (Figure 58) }\end{array}$ \\
\hline B3 & 155 & 250 & single & $\begin{array}{l}\text { inner curvature; } \\
\text { center of meander } \\
\text { (Figure 58) }\end{array}$ \\
\hline B4 & 155 & 450 & single & $\begin{array}{c}\text { inner curvature; } \\
\text { center of meander } \\
\text { (Figure 58) }\end{array}$ \\
\hline B5 & 155 & 250 & single & $\begin{array}{c}\text { outer curvature; } \\
\text { upstream of meander } \\
\text { (Figure 58) }\end{array}$ \\
\hline B6 & 155 & 450 & single & $\begin{array}{l}\text { outer curvature; } \\
\text { upstream of meander } \\
\text { (Figure 58) }\end{array}$ \\
\hline B7 & 155 & 250 & single & $\begin{array}{c}\text { inner curvature; } \\
\text { upstream of meander } \\
\text { (Figure 58) }\end{array}$ \\
\hline B8 & 155 & 450 & single & $\begin{array}{c}\text { inner curvature; } \\
\text { upstream of meander } \\
\text { (Figure 58) }\end{array}$ \\
\hline B9 & 155 & 250 & double & $\begin{array}{l}\text { Staggered } \\
\text { (Figure 59) }\end{array}$ \\
\hline B10 & 155 & 450 & double & $\begin{array}{l}\text { Staggered } \\
\text { (Figure 59) }\end{array}$ \\
\hline B11 & 155 & 250 & double & $\begin{array}{l}\text { Staggered } \\
\text { (Figure 60) }\end{array}$ \\
\hline B12 & 155 & 450 & double & $\begin{array}{l}\text { Staggered } \\
\text { (Figure 60) }\end{array}$ \\
\hline B13 & 155 & 250 & double & $\begin{array}{c}\text { Paired; center of meander } \\
\text { (Figure 61) }\end{array}$ \\
\hline B14 & 155 & 450 & double & $\begin{array}{l}\text { Paired; center of meander } \\
\text { (Figure 61) }\end{array}$ \\
\hline B15 & 155 & 250 & double & $\begin{array}{l}\text { Paired; upstream of } \\
\text { meander (Figure 62) }\end{array}$ \\
\hline B16 & 155 & 450 & double & $\begin{array}{l}\text { Paired; upstream of } \\
\text { meander (Figure 62) }\end{array}$ \\
\hline B17 & 155 & 250 & none & ----- \\
\hline B18 & 155 & 450 & none & ----- \\
\hline
\end{tabular}




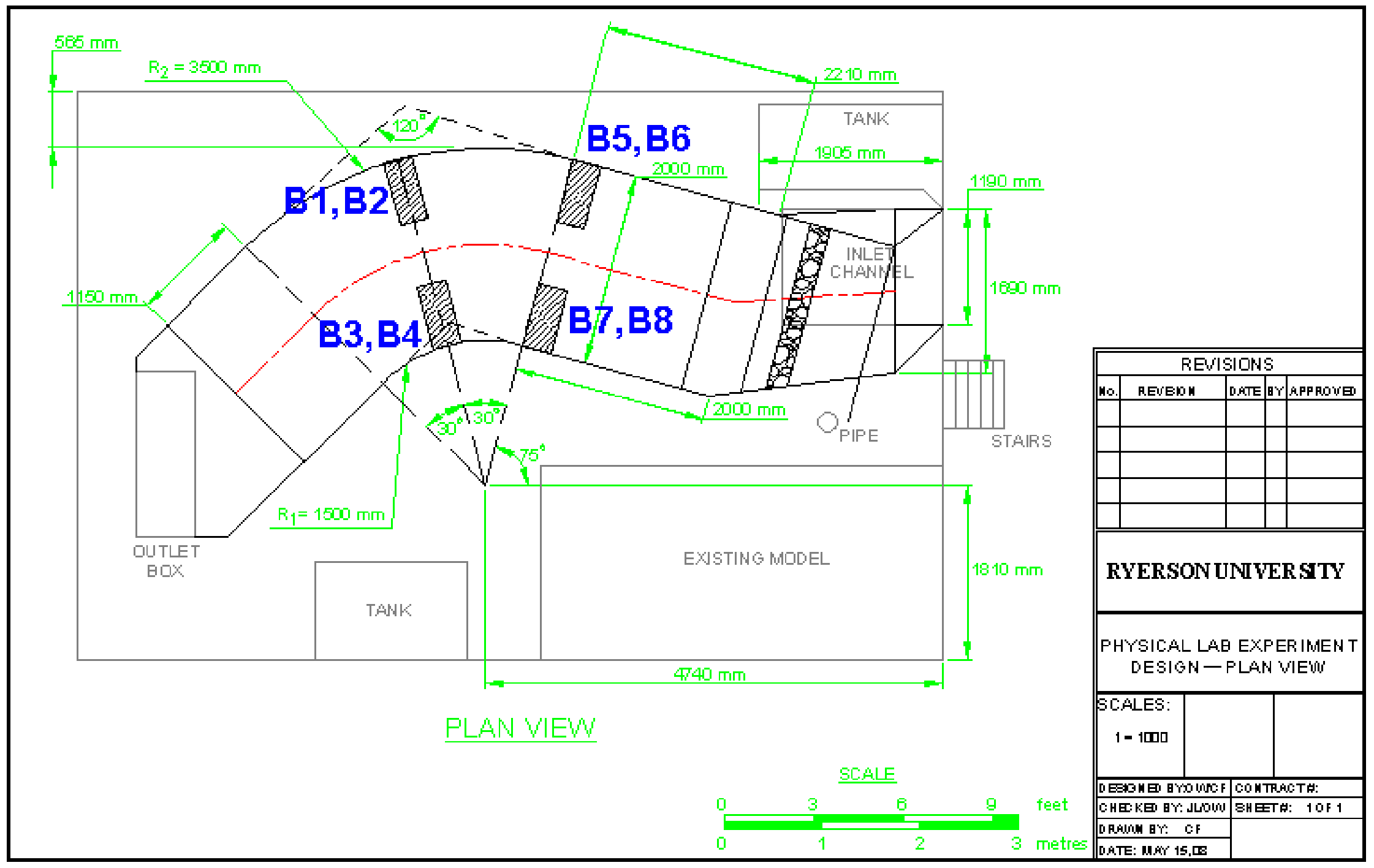

Figure 58: Deflector configurations for physical experiments \#B1 to \#B8. 


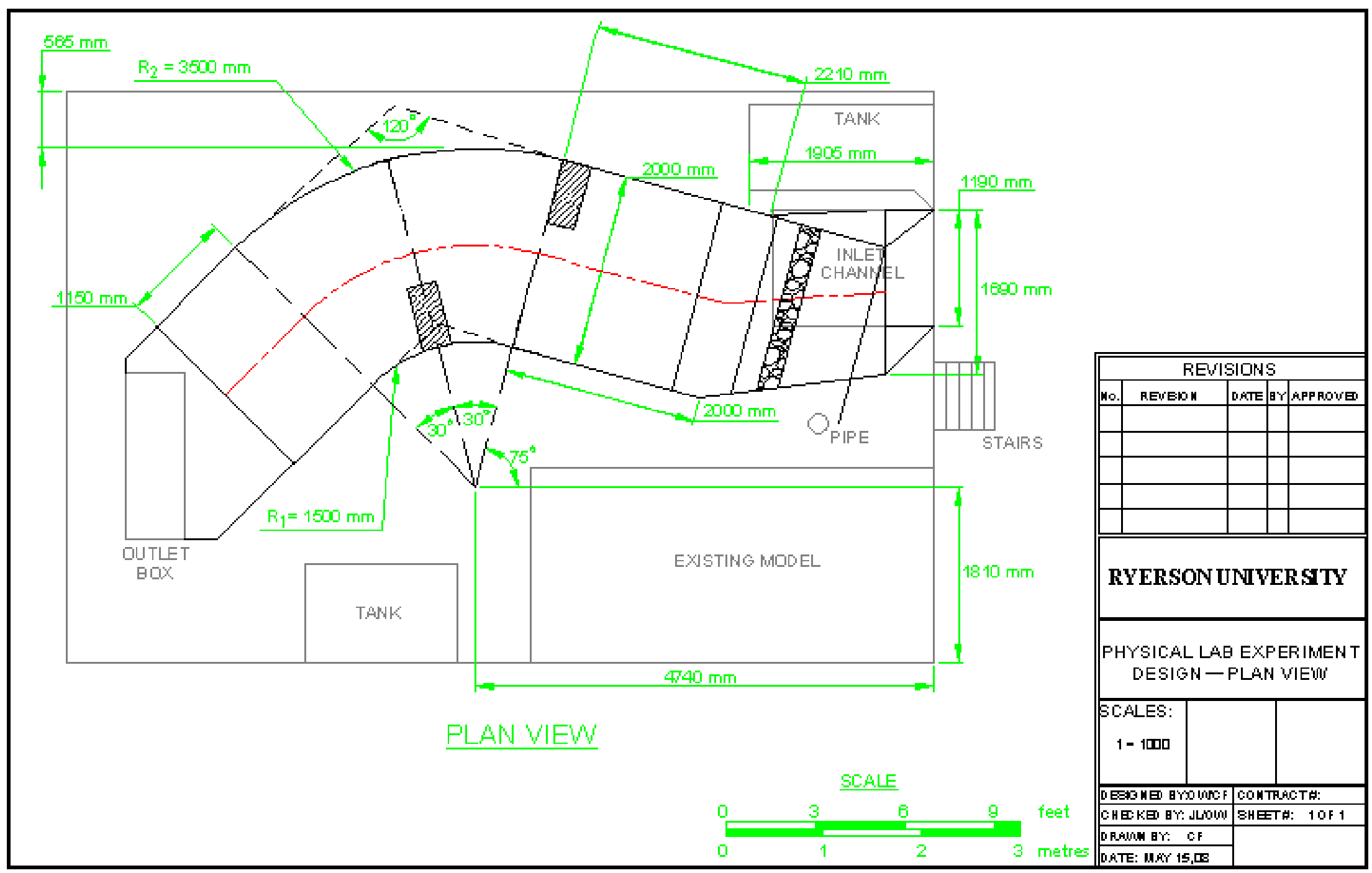

Figure 59: Deflector configurations for physical experiments \#B9 to \#B10. 


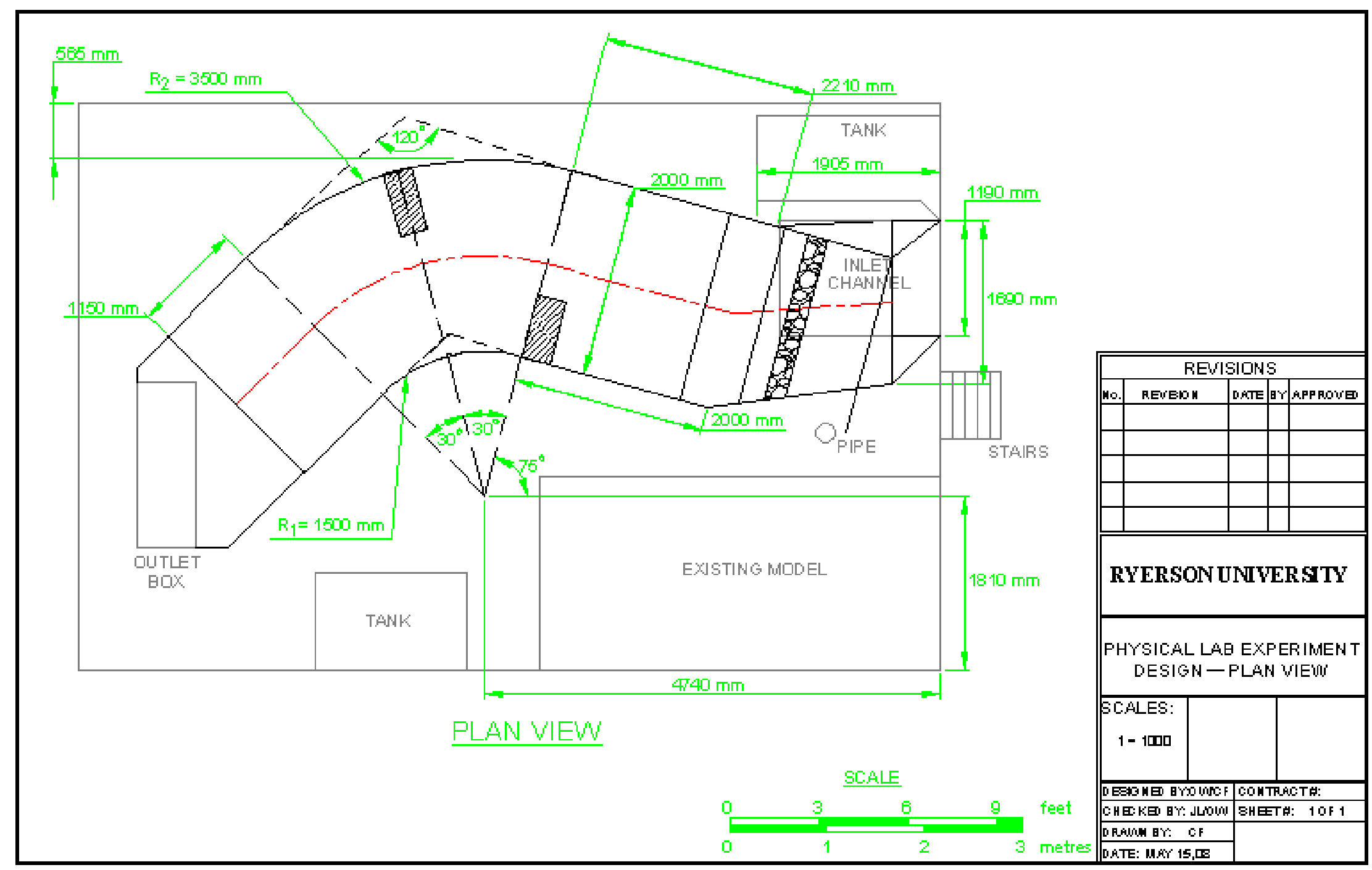

Figure 60: Deflector configurations for physical experiments \#B11 to \#B12. 


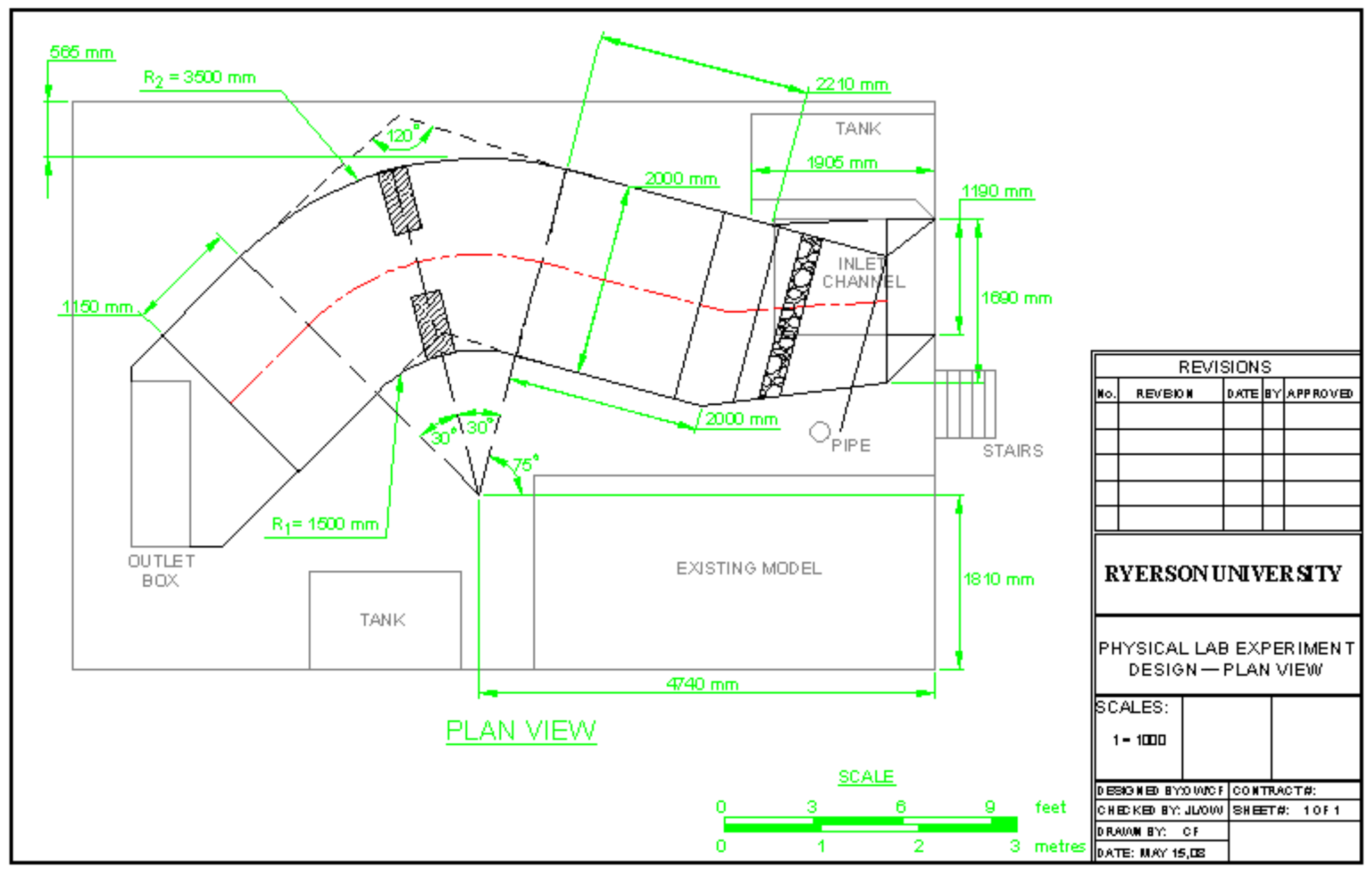

Figure 61: Deflector configurations for physical experiments \#B13 to \#B14. 


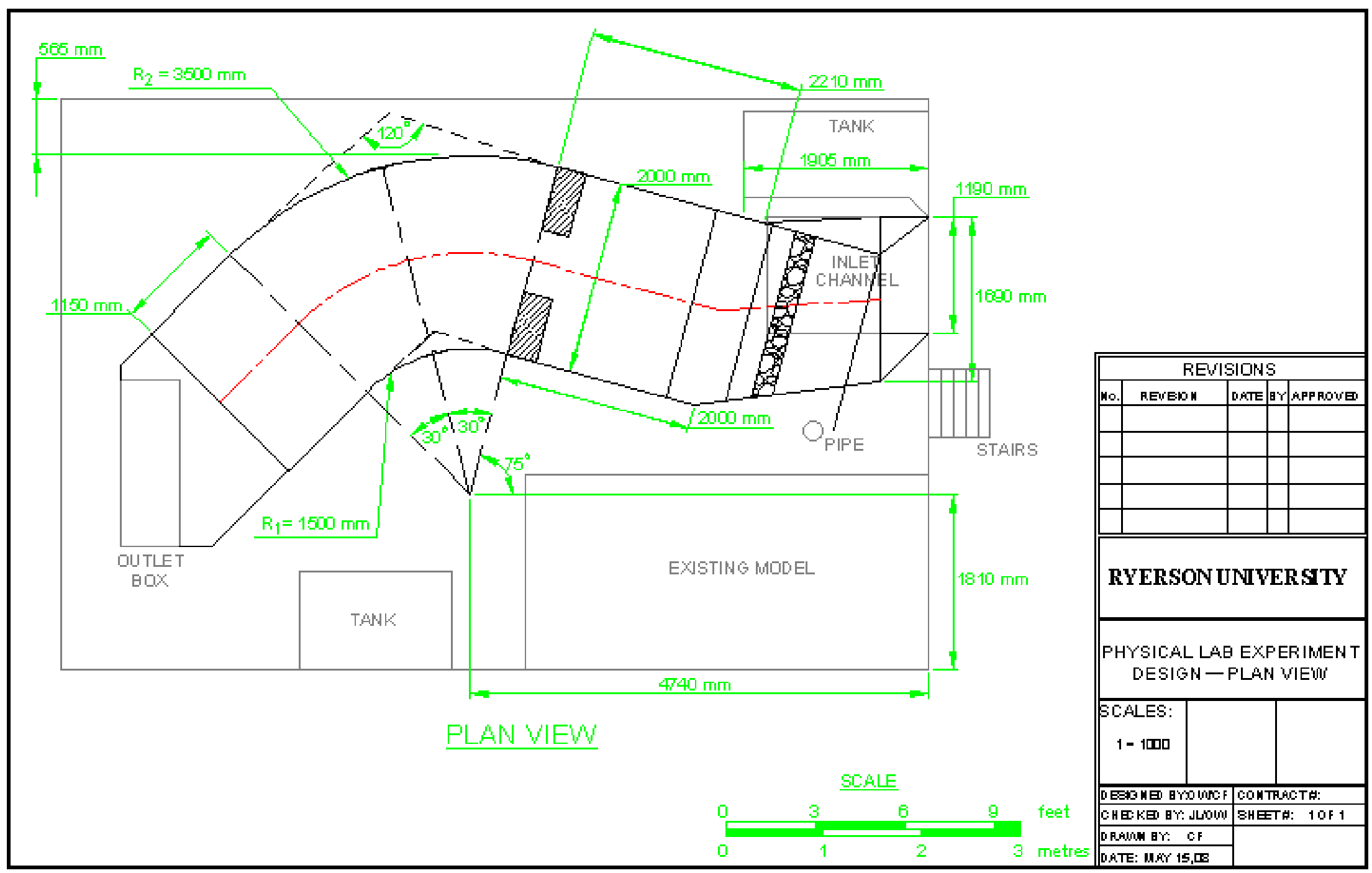

Figure 62: Deflector configurations for physical experiments \#B15 to \#B16. 


\subsubsection{Wet Weather Condition With Incoming Sediment}

There were four sets of physical experiments involved in the wet weather condition with incoming sediment scenario: the best single deflector at the centre and the beginning of the meander section, and the best double deflector for staggered and paired situations. Two incoming sediment rates, the low incoming sediment and large incoming sediment, were tested in each set of the experiments. The two incoming sediment rates were derived from Meyer-Peter and Müller's Approach and Schoklitch's Approach (Appendix N). The experiments discussed in the previous section were conducted prior this scenario in order to determine the best single and double deflector configurations. 


\subsection{PREPARATION OF THE PHYSICAL EXPERIMENTS}

This section discusses the sediment preparation, the estimation of the inception velocity, the porosity of deflector determination, and the measuring devices involved in the physical experiments in detail.

\subsubsection{Sediment Collection and Preparation}

The sediment involved in the physical experiments was collected at the natural area of the pilot site (Figure 63). Since debris were found in the collected sediment, a preliminary screening using a 1 -inch plastic mesh was conducted (Figure 64) to separate out the debris for the safety reasons prior the bed preparation.

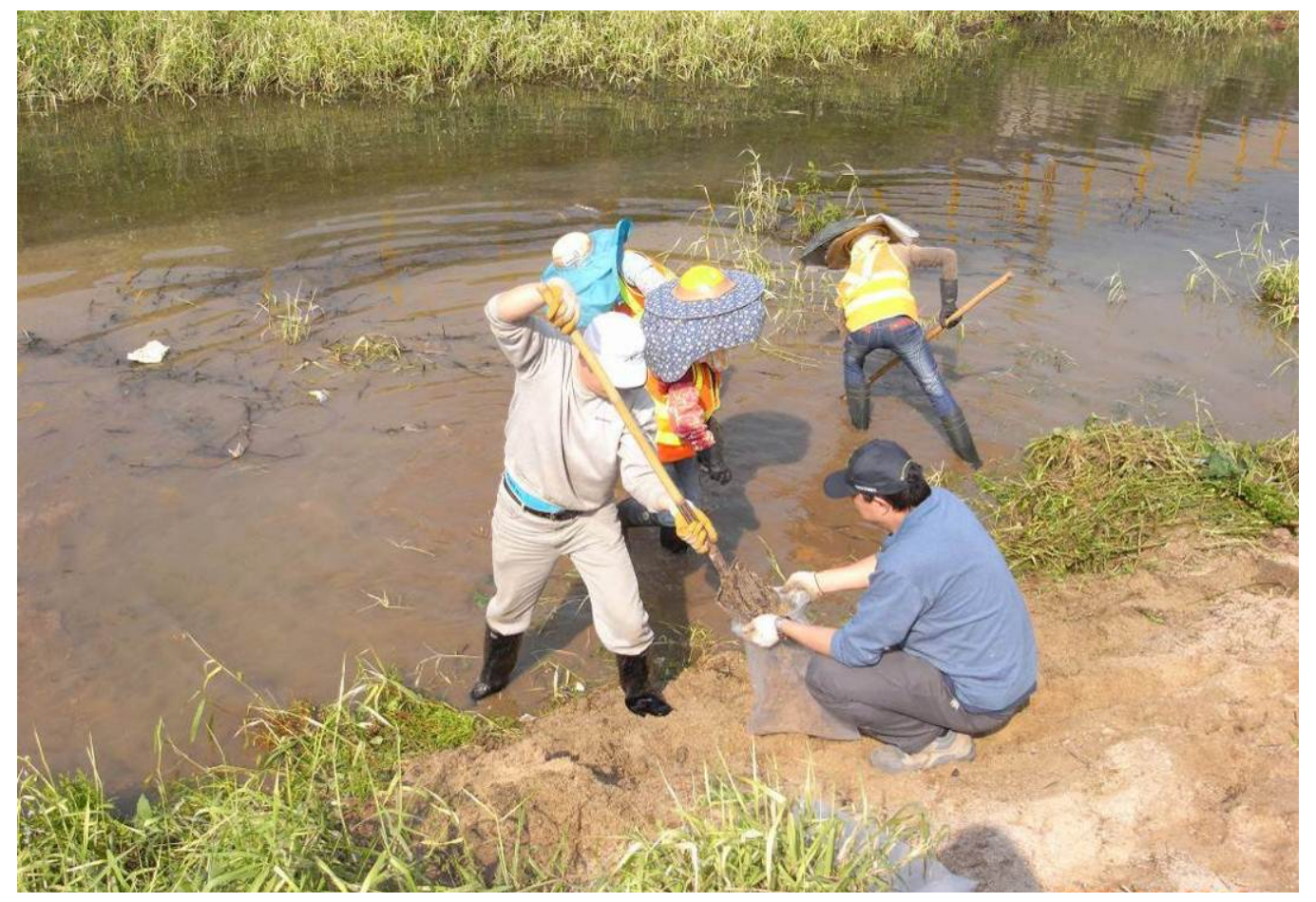

Figure 63: Sediment collection at the natural area of the pilot site. 


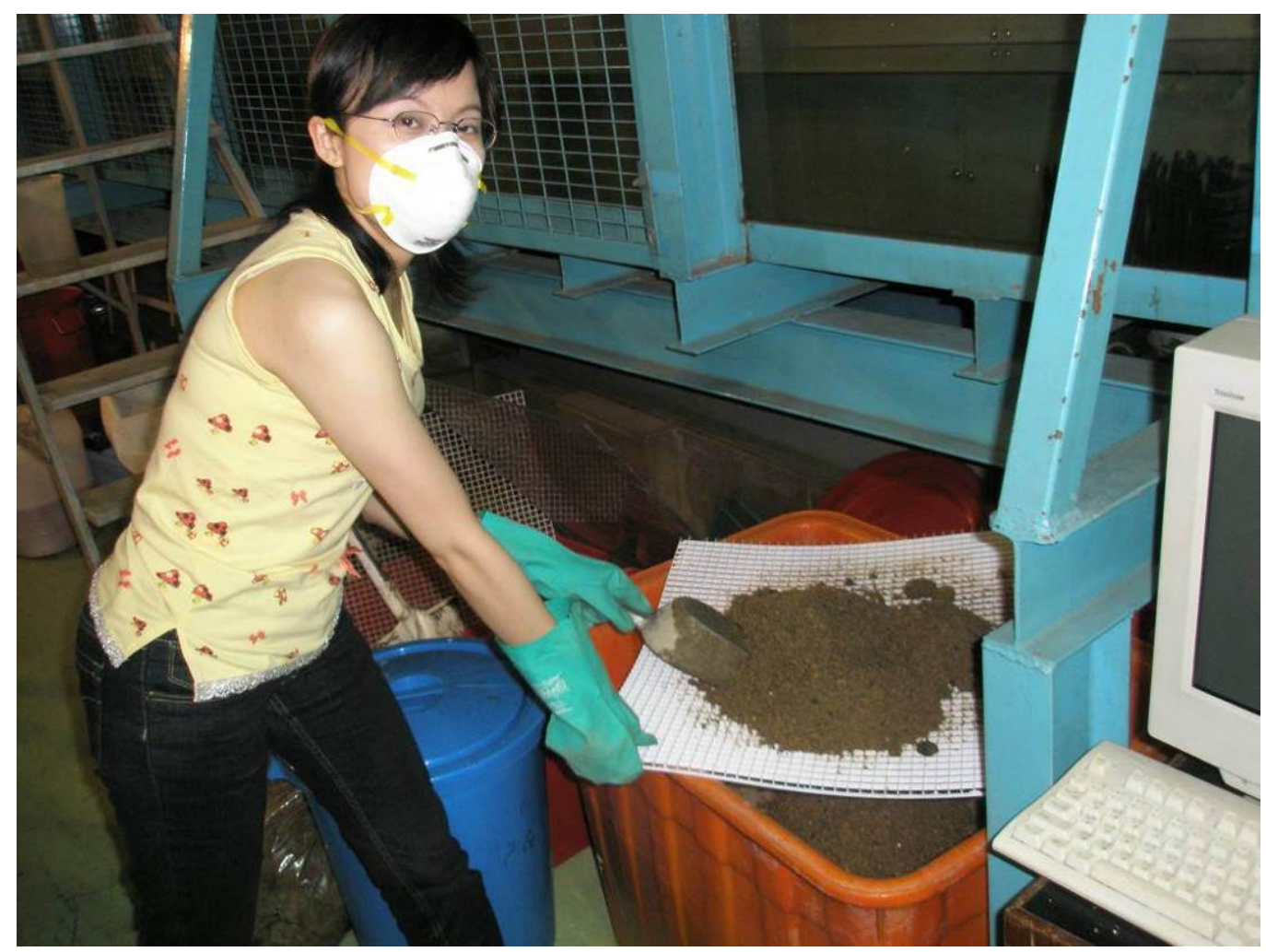

Figure 64: Preliminary screening of the sediment.

The depth of the sediment bed involved for the physical experiments was $15 \mathrm{~cm}$. It was prepared manually using a grout float and a height gauge (Figure 65) in order to create a longitudinal slope of 0.003 , which is close to the measured longitudinal slope at the pilot site (Appendix J). The height gauge involved in the sediment bed preparation was the same device used for the pool measurements in the physical experiments. 


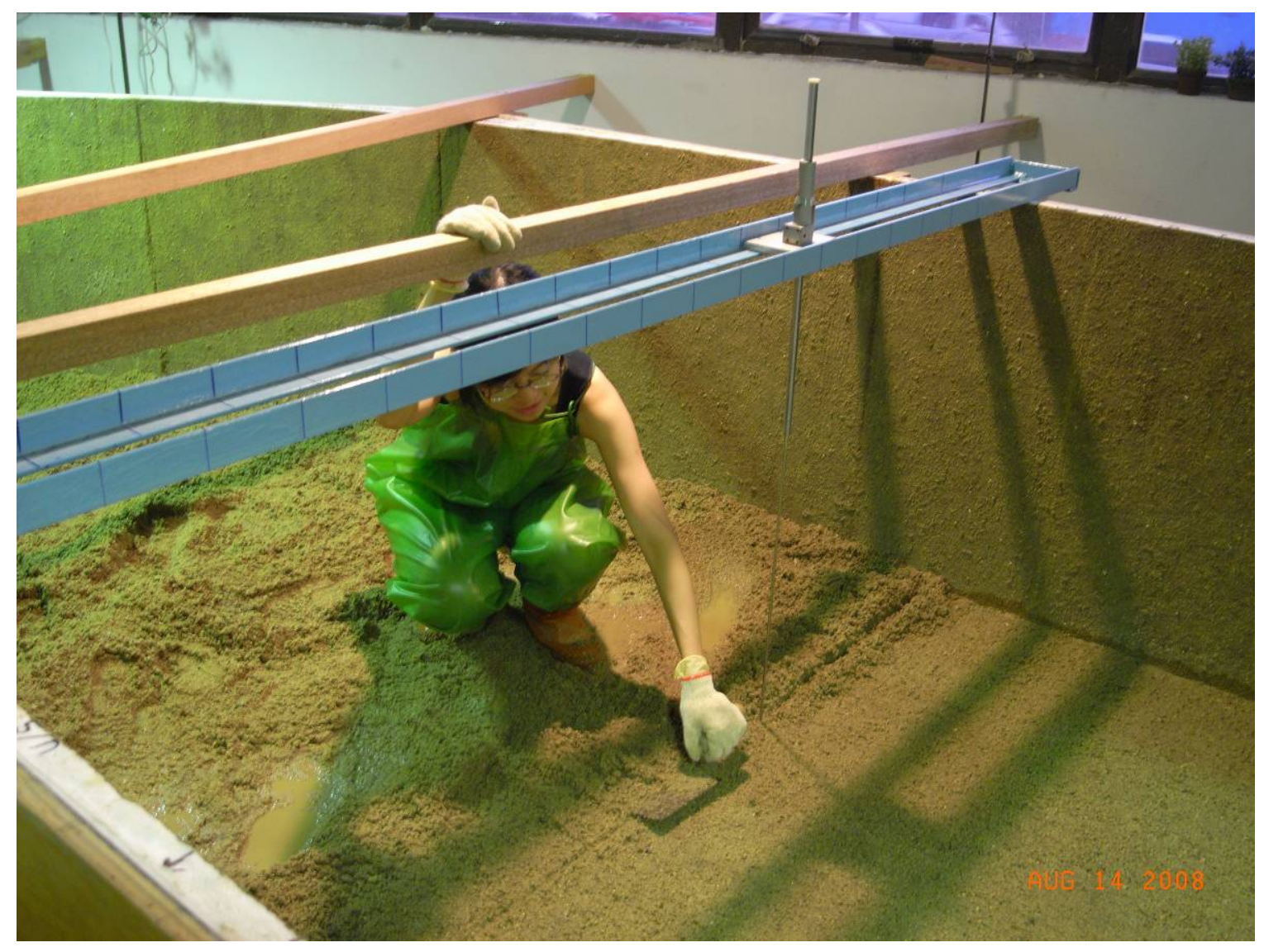

Figure 65: Sediment bed preparation.

\subsubsection{Estimation of Inception Velocity}

An investigation of the inception velocity was conducted in the $0.3 \mathrm{~m} \times 15 \mathrm{~m}$ flume (Figure 66) prior running any of the physical experiments discussed in Section 4.7.2. A small amount of the collected sediment from the pilot site was evenly distributed across a defined section in the flume. A constant circulated flow rate of $8.33 \times 10^{-3} \mathrm{~m}^{3} / \mathrm{s}$ with different downstream weir levels was then applied to the flume. Table 10 shows the percentage of sediment movement during the investigation. The inception velocity was around $0.185 \mathrm{~m} / \mathrm{s}$. 
Table 11: Estimation of inception velocity.

\begin{tabular}{|c|c|c|c|}
\hline $\begin{array}{c}\text { Water Depth, } \\
\text { in cm }\end{array}$ & $\begin{array}{c}\text { Percentage of } \\
\text { Movement }\end{array}$ & $\begin{array}{c}\text { Flow Cross-Sectional } \\
\text { Area, in } \mathbf{~ m}^{2}\end{array}$ & Velocity, $\mathbf{~ m / s}$ \\
\hline \hline 14.5 & $\begin{array}{c}10 \% \\
\text { (mostly fine material) }\end{array}$ & 0.04495 & 0.1854 \\
\hline 11 & $30 \%$ (sand) & 0.03410 & 0.2444 \\
\hline 9.5 & $50 \%$ & 0.02945 & 0.2830 \\
\hline 8 & $70 \%$ & 0.02480 & 0.3360 \\
\hline 7 & $90 \%$ & 0.02170 & 0.3840 \\
\hline
\end{tabular}

The purpose of estimating the inception velocity is to determine whether the maximum flow rate, $0.155 \mathrm{~m}^{3} / \mathrm{s}$, of the existing pump in The HK PolyU hydraulic laboratory will be able to create sediment movement during the bankfull situations (Table 10). From Table 8 , the cross-sectional area at bankfull situation is $0.09 \mathrm{~m}^{2}$. Thus, the average velocity from the continuity equation is:

$$
V=Q / A=0.155 \mathrm{~m}^{3} / \mathrm{s} \div 0.09 \mathrm{~m}^{2}=0.172 \mathrm{~m} / \mathrm{s}
$$

Although the calculated average velocity is slightly lower than the estimated inception velocity, the best configuration of the single deflector scenario was conducted for the bankfull situation due to the contraction of the channel created by the deflector. 


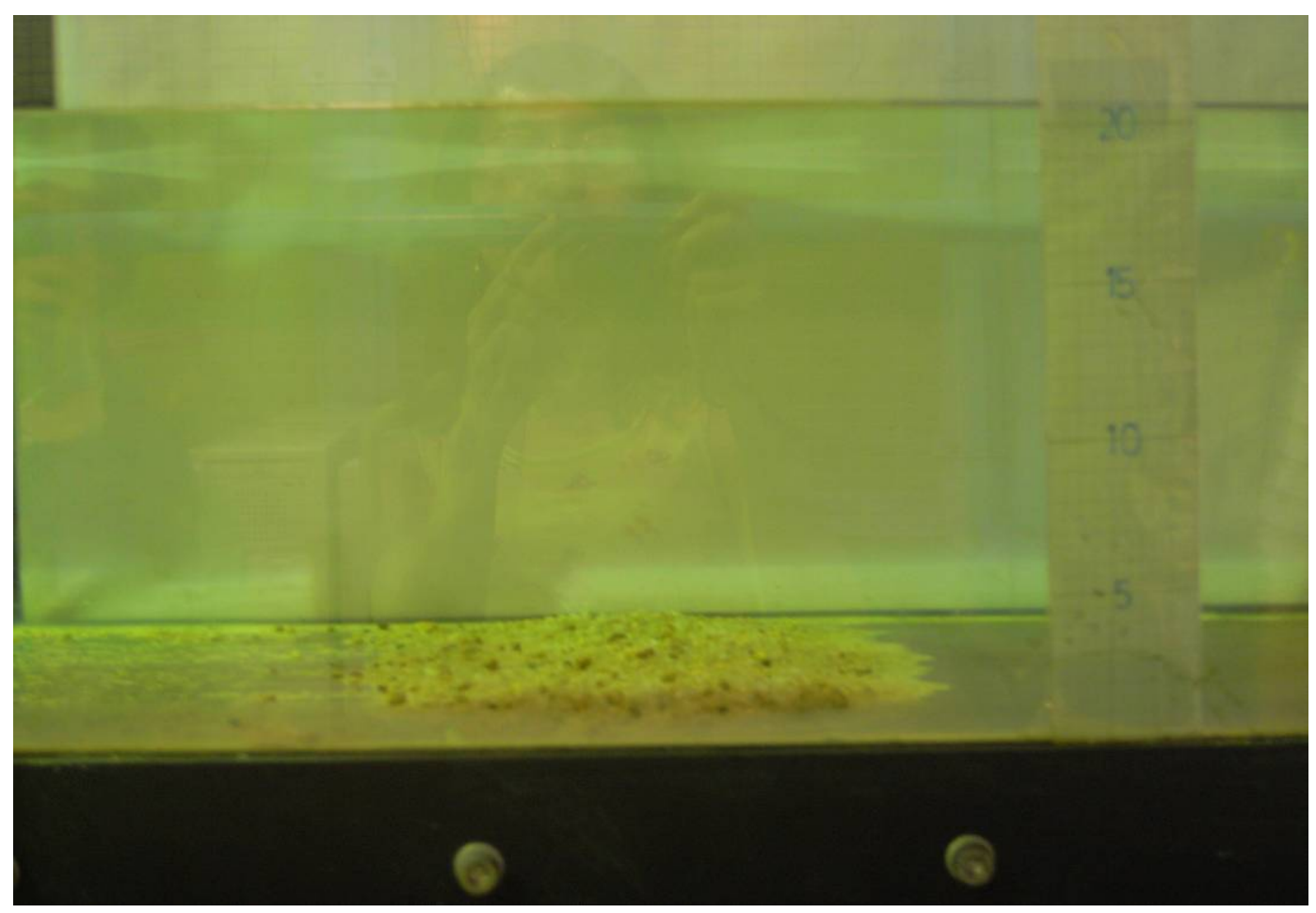

Figure 66: Inception velocity investigation.

\subsubsection{Porosity in the Deflector}

Appendix $M$ describes the porosity experiment on the deflectors used for the physical experiments in detail. The porosity experiment was conducted in The HK PolyU concrete laboratory. Four identical balances were involved due to the heavy weight of the crushed concrete stones and to provide a rigid support for the weighted material. The porosity was about $40 \%$. 


\subsubsection{Measuring Devices Involved in the Physical Experiments}

The major measuring devices involved in the physical experiments were the flow meters, the ADV and the height gauge for inflow, velocity and sediment profiles measurements.

\section{Flow Meters}

Two flow meters were involved in determining the inflow of the physical experiment. One was connected directly to the discharge side of the pump (Figure 68) and the other was fixed to the inlet pipe of the holding tank (Figure 67). The flow meter beside the pump (Figure 68) could not be calibrated since it was rigid to the pump. The smaller flow meter (Figure 67) was calibrated using a V-notch weir tank prior the physical experiments to make sure it functioned properly.

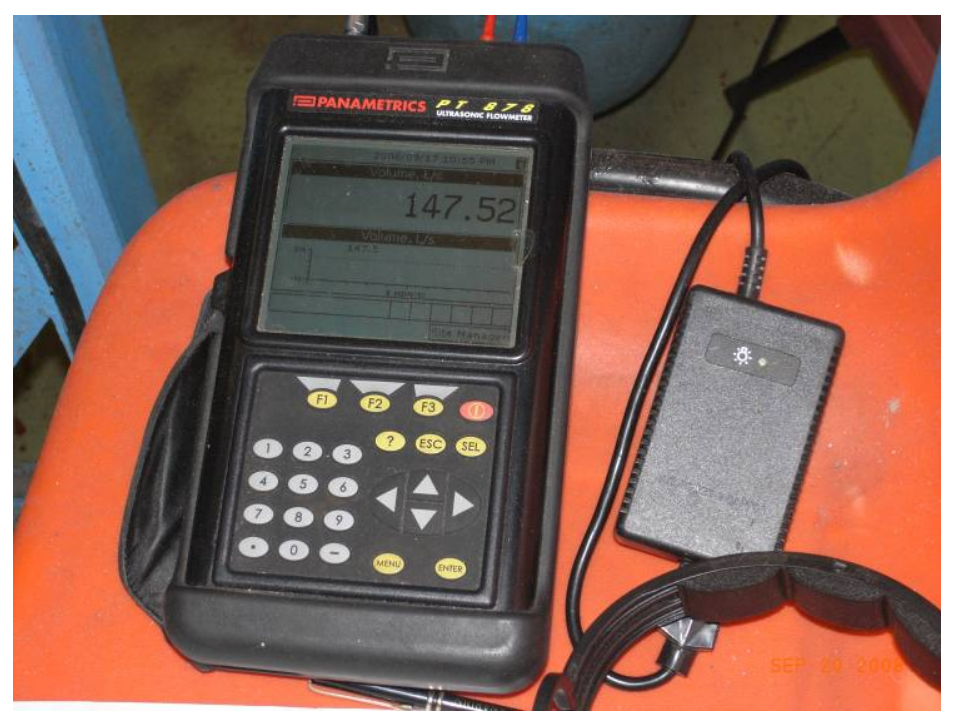

Figure 67: Flow meter with sensor connected to the inlet pipe of the holding tank. 


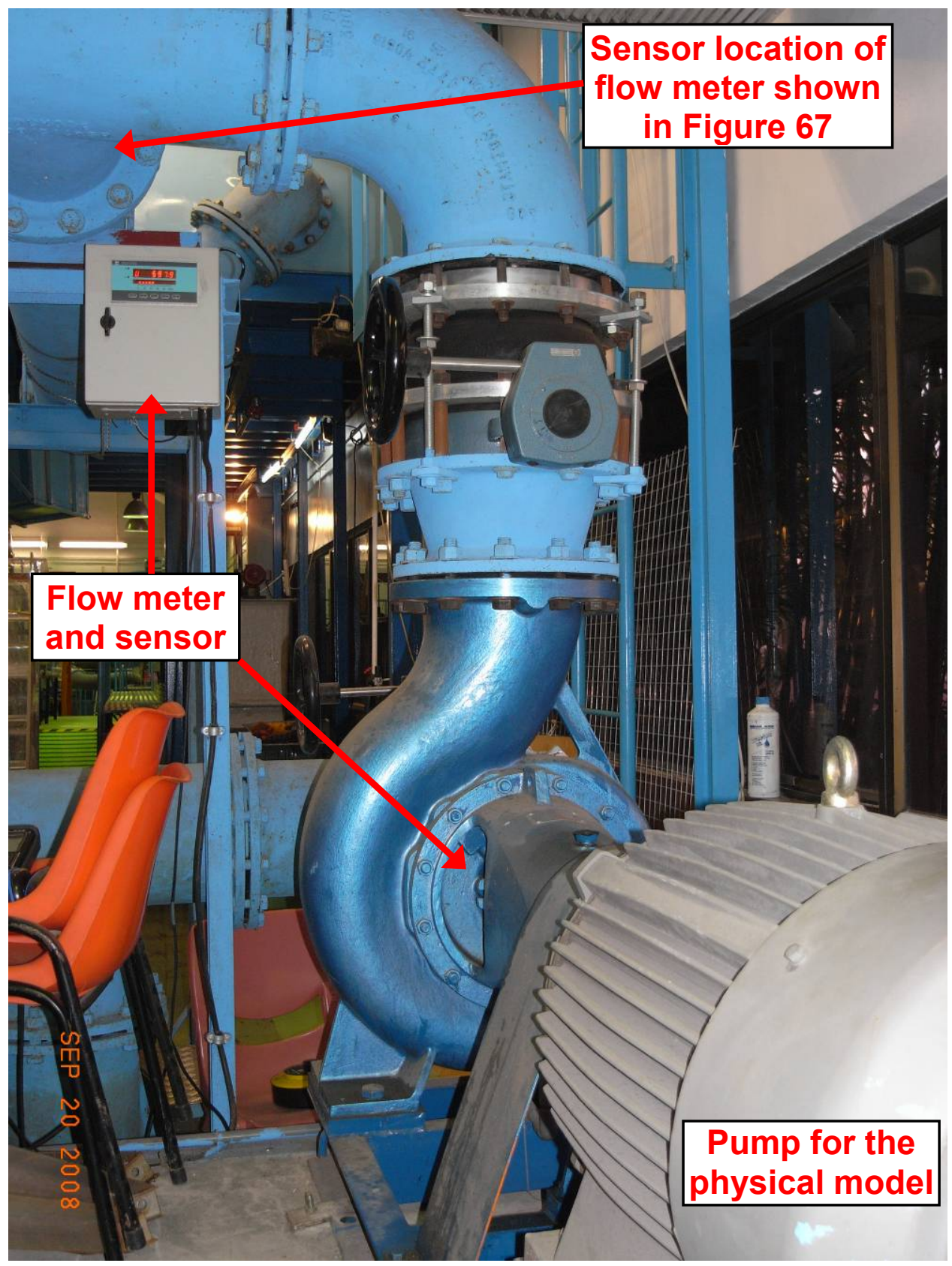

Figure 68: Flow meter connected to the discharge pipe of the pump. 


\section{$\underline{A D V}$}

A four-port ADV (Figure 69) was used to measure the velocity profiles of the physical experiments. The device was tested using the $0.3 \mathrm{~m} \times 15 \mathrm{~m}$ flume prior the physical experiments. Since ADV requires a minimum of $5 \mathrm{~cm}$ water depth to conduct the velocity measurements, no velocity profiles were prepared for the dry weather condition. Additionally, a minimum of $7.5 \mathrm{~cm}$ spacing is required due to the size of the ADV port (Figure 69). Thus, the closest velocity measurement along the banks was $10 \mathrm{~cm}$ (Appendix P).

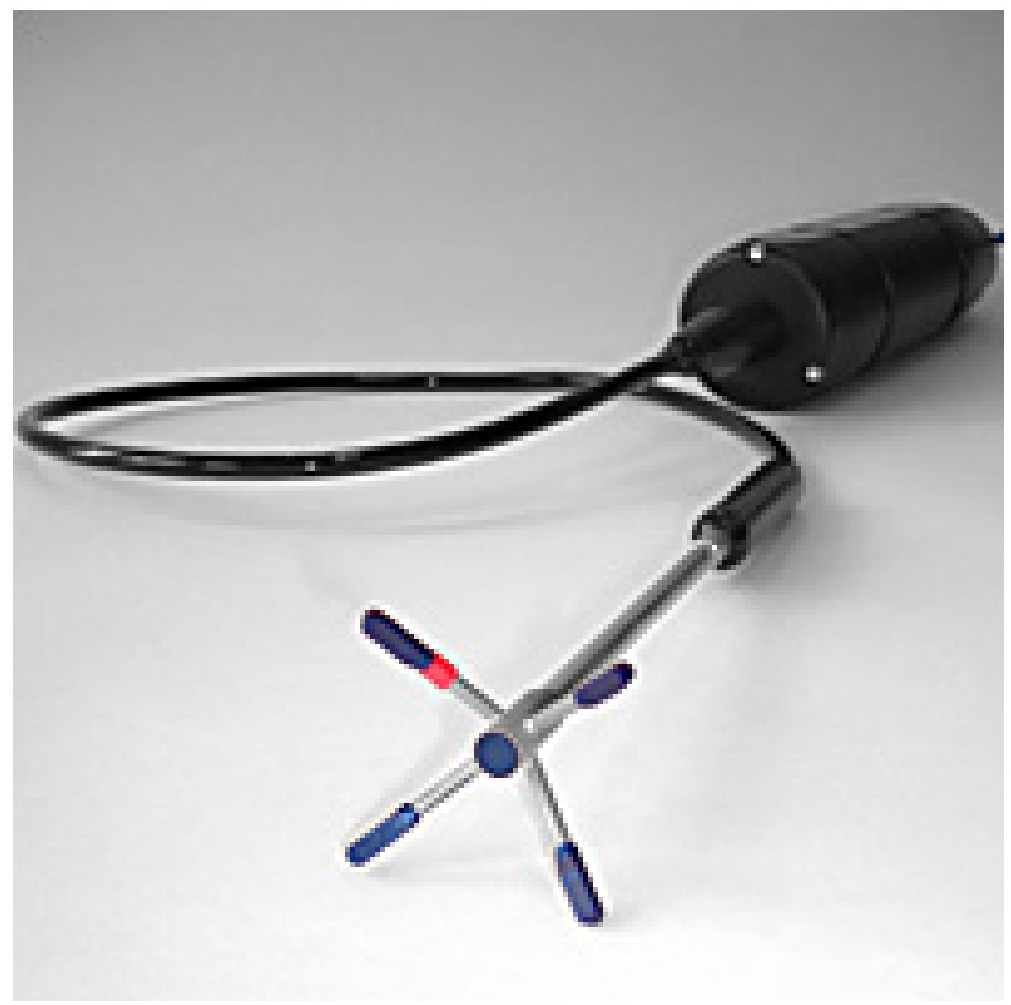

Figure 69: Four-port ADV used for the velocity profile measurement. 


\section{Height Gauge}

A height gauge with an accuracy of $\pm 0.5 \mathrm{~mm}$ (Figure 70) was used for the sediment profile measurement of the physical experiments. Although there are other alternatives in The HK PolyU hydraulic laboratory, the height gauge was still the only instrument that was easy to handle and could provide the fastest and accurate results especially in the pool zone with water ponds in it.

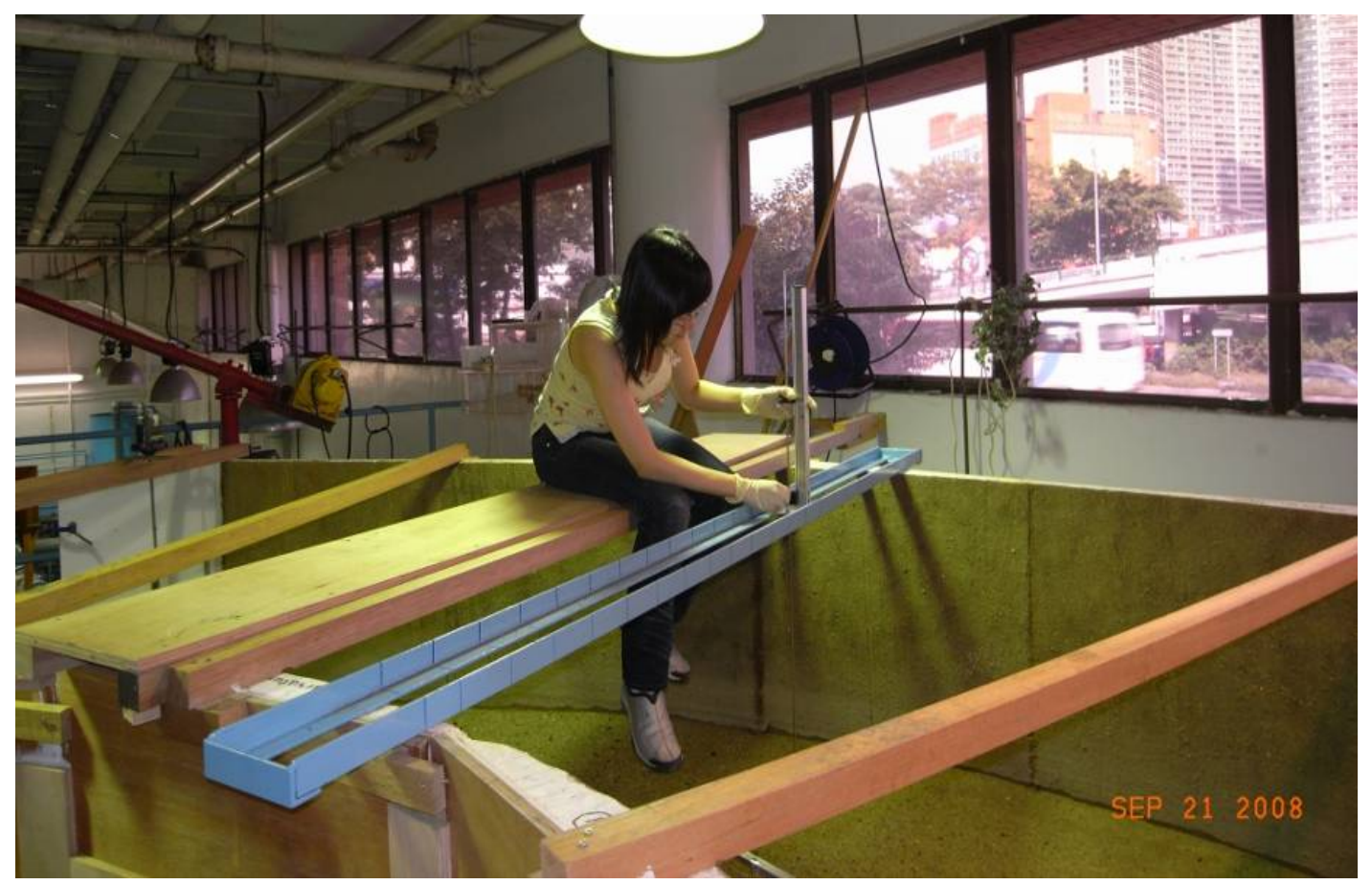

Figure 70: Sediment profile measurement using a height gauge. 


\subsection{PROCEDURES OF THE PHYSICAL EXPERIMENTS}

A thickness of $15-\mathrm{cm}$ sediment bed was prepared manually (Section 4.7.1) prior conducting any physical experiments. After the preparation of the sediment bed, two submerged pumps (Figure 71) were used to import water slowly from the circulation flume (Figure 39) located under the interior deck to the downstream of the physical model until the water level of the physical model reached the top of the adjustable weir at the downstream. The purpose of this was to minimize the sediment disturbance caused by the inflow and the downstream adjustable weir during the beginning of the physical experiment. Then, the pump used for the physical experiment was turned on and velocity profile starting from the $20 \%$ water depth (Appendix P) was measured. The sediment profile was measured every couple of hours to minimize the sediment disturbance during the water drainage process. Before conducting the sediment profile measurements, water had to drain out of the physical model through the holes at the adjustment downstream weir (Section 4.4). Once the sediment profile determinations were finished, water was returned to the physical model following the procedures mentioned previously. 


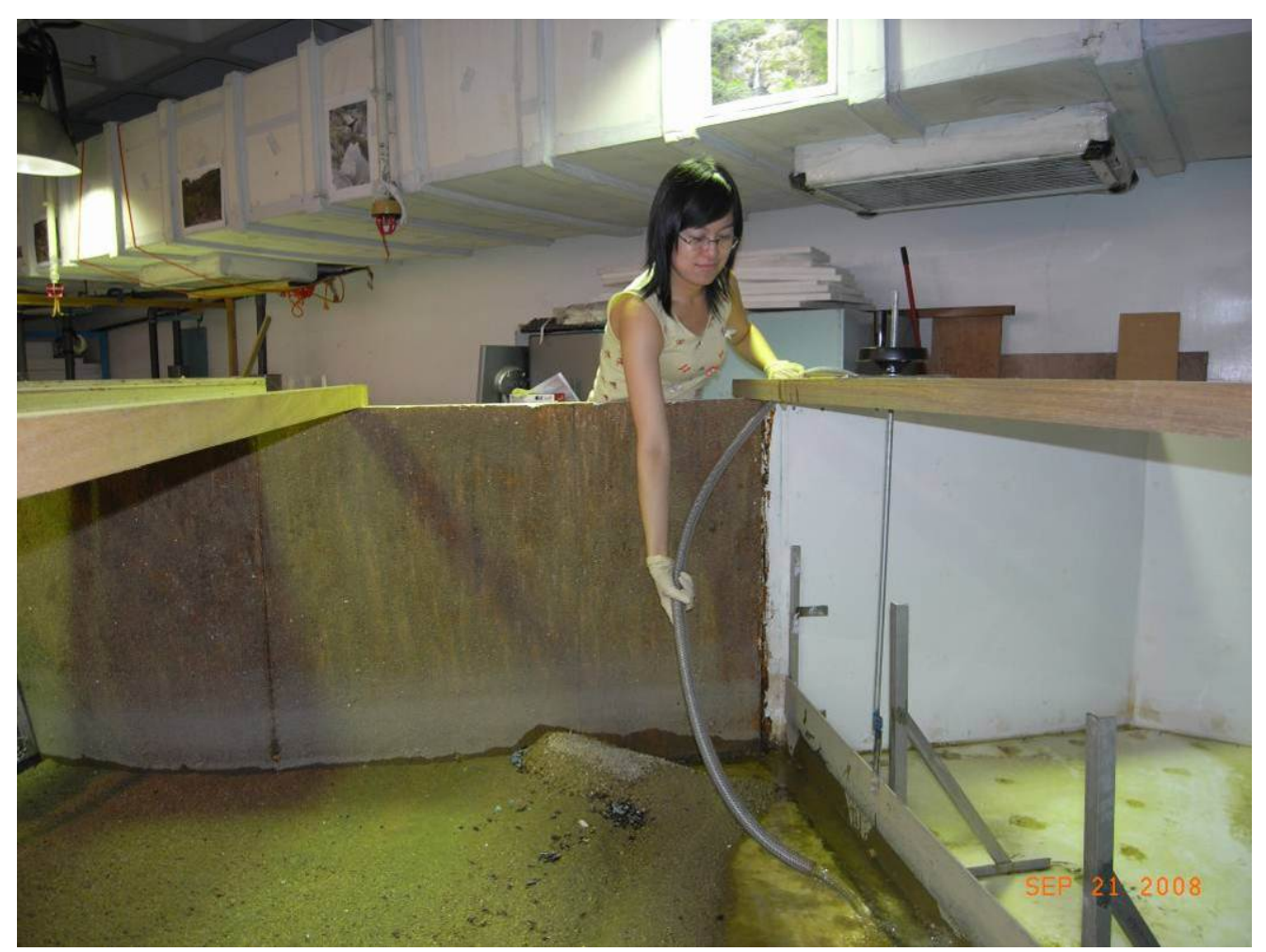

Figure 71: Filling water to the physical model from the outlet drop.

Both the ADV and the height gauge were held by a steel rails (Figure 70) with marks at every $5 \mathrm{~cm}$ during the profile measurements. The marks in the steel bar were to locate the measuring points at each cross-section. Solid marks were also drawn on the banks of the physical model for every 1 degree at the meander section and every $5 \mathrm{~cm}$ at the upstream and downstream straight channel sections to properly locate the steel rails during the profile measurements.

For the sediment profile, the separation between two measuring points was around $5 \mathrm{~cm}$ to $10 \mathrm{~cm}(2.5 \%$ to $5 \%$ of channel width) around the flat surface and $1 \mathrm{~cm}$ to $5 \mathrm{~cm}(0.5 \%$ to $2.5 \%$ of channel width) around pool and deposition zones depending on the steepness of the surface. The separation of two cross-sections 
was at 2 degrees in the meander region, except around the rigid top supporting bars, and 5 to $10 \mathrm{~cm}$ at the upstream and downstream straight channels. The average point density for each run was about 385 points $/ \mathrm{m}^{2}$. For the velocity profile, five to ten points were measured at each cross-section depending on the flow paths observed during the physical experiment. The separation between two cross-sections was 5 to 10 degrees at the meander region and $20 \mathrm{~cm}$ to $50 \mathrm{~cm}$ in the upstream and downstream straight channels.

\section{Incoming Sediment Scenario}

The actual loading rates could be measured directly at the pilot site due to the lack of measuring instruments and the governmental restrictions, a summary of bed load estimation using various approaches was prepared to determine the incoming sediment rate of the physical experiments (Appendix N). The reasons for considering bed load transport approaches were the low suspended particles concentration in the water samples that were collected during the site assessment (Appendix E), and the large particle size ranges (Table 4 and Figure 34) from the sediment particle distribution tests (Appendix A). In addition, the inspector of HK DSD who is responsible for the maintenance of the Yuen Long Nullah (Section 4.6.1) also concluded that bed-load transport dominates the incoming sediment source of Yuen Long Nullah. 
Based on the capability of the proposed incoming sediment feeder, the bed-load discharges derived from Meyer-Peter and Müller's approach and Schoklitsch's (1934) approach (yellow highlights in Appendix N) was used for the low and high incoming sediment-load tests. 


\subsection{DISCUSSION OF THE PHYSICAL EXPERIMENTS}

This section contains a detailed analysis of the velocities and sediment experimental results for all the scenarios discussed in Section 4.6. Since each physical experiment involved considerable preparation (i.e. bed preparation, prefilling the channel using submerged pumps) and was very time consuming, some of the physical experiments mentioned in the design stage (Section 4.6) were eventually omitted or verified using the numerical model (Chapter 5). The decision making was based on the observation and preliminary analysis of the sediment results after each physical experiment. Abutment analysis suggested by FHWA was also used to compare the experimental scour depths results.

\subsubsection{Experimental Results on Dry Weather Conditions}

For the dry weather conditions, a 24-hour continuous run was conducted for the no deflector scenario (Experiment \#A1 in Table 9). No change was observed for the bed profile. In Experiments \#A2, \#A3 and \#A4 (Table 9), minor elevation fluctuations of less than $5 \mathrm{~mm}$ were depicted at a few regions downstream of the best deflector locations. These minor changes did not cause any pool formation along the meander section.

The baseflow measured at the pilot site, $0.040 \mathrm{~m}^{3} / \mathrm{s}$, during the dry weather condition is not significant to cause any sediment movement after a 24-hour continuous run. Besides, the time involved to cause a small change in the 
sediment profile on the prototype may be huge. Since the water depth for the dry weather conditions was smaller than the minimum requirement of the ADV, there was no velocity profile evaluation in this scenario.

\subsubsection{Experimental Results on Wet Weather Condition without Incoming Sediment-Single Deflector}

\section{$\underline{\text { Scour/Deposition }}$}

Table 12, Figure 73 and Figure 74 show the general experimental results of scour/deposition for single deflector scenario at $25 \mathrm{~cm}$ water depth of the lowflow channel (i.e. \#B1, \#B3, \#B5, and \#B7). Preliminary investigation indicated that stable pools were developed after a 20 -hour run with $94 \%$ of maximum scour depth and $85 \%$ of maximum scour volume achieved in the first 10 hours. Detailed bed topography such as bed elevation contours, 3-D mesh bed profile and locations of scour area and maximum scour depth at different time are depicted in Appendix P. All pool-volume calculations were generated using AutoCAD Land Desktop Development (LDD) program. Prior to the pool-volume analysis, calibration of the volume parameters in AutoCAD LDD program was done using the experimental results of \#B5. A grid size of $0.002 \mathrm{~m}$ and an elevation tolerance difference of $0.001 \mathrm{~m}$ were concluded to provide the best volume calculation results.

Generally, the maximum scour depths were observed near the upstream deflector tips in all runs (Appendix P). Scour areas were formed around the 
deflector boundary and extended from the deflector tips along the centre line of the meander section (Appendix P). Deposition or elongated bars were consistently established downstream of the deflector. The best single deflector locations for both upstream (Experiment \#B7) and centre (Experiment \#B3) of the meander section were along the inner curvatures (Table 12).

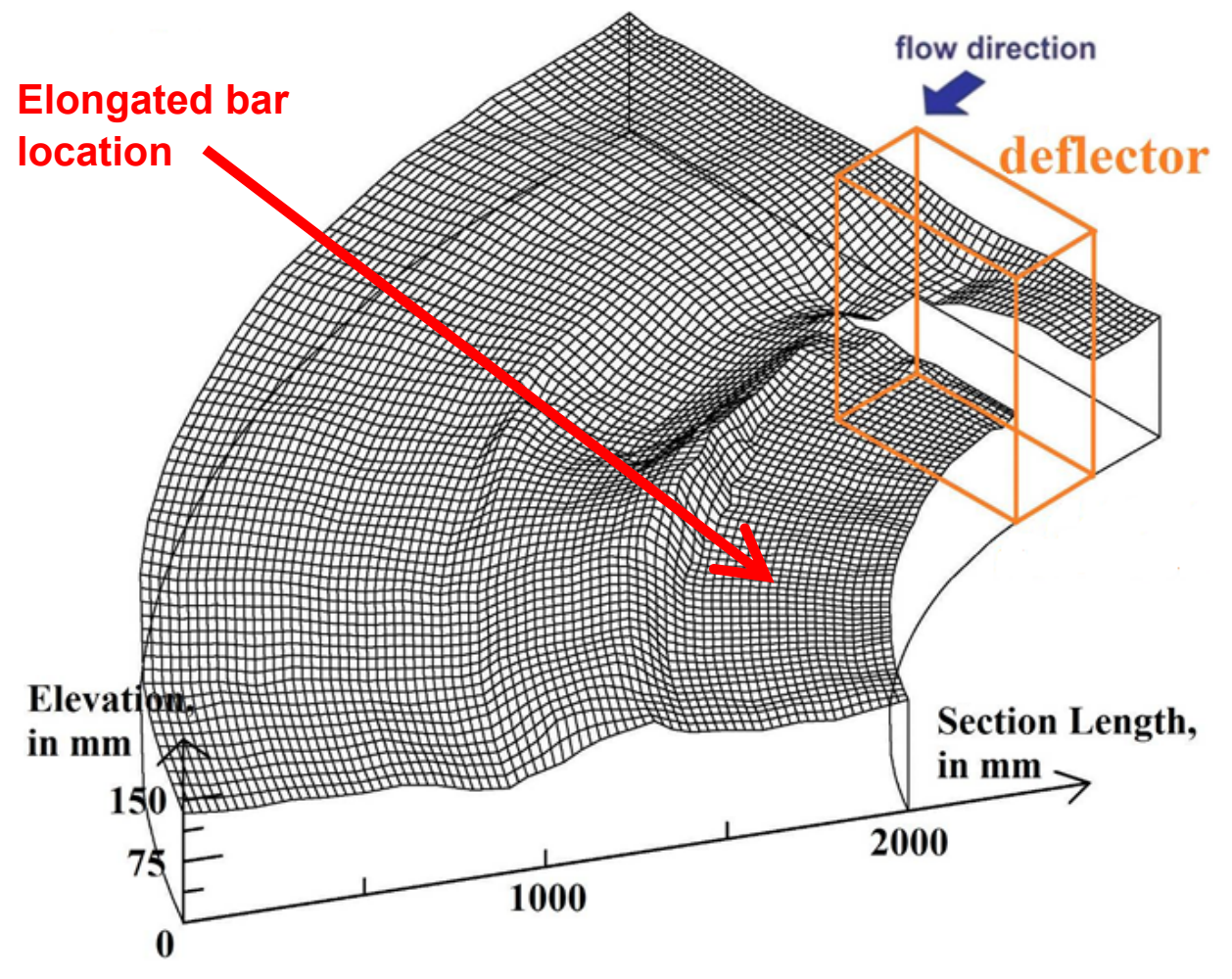

Figure 72: Bed profile for Experiment \#B7 after 21-hour run.

The experimental results were compared with two maximum scour depth predictions for abutments: Froehlich's or HIRE Abutment Scour Equation and Maryland SHA Abutment Scour Methodology suggested by US FWHA (Section 2.5), since the general shape of a deflector and the flow condition for this scenario are similar to bridge abutments. The only difference is this study's 
deflector has a porosity of $40 \%$ whereas abutments are usually solid concrete material. Furthermore, the location of the deflector in the physical model is at a meander section whereas abutments are generally located in straight channels.

Generally, the abutment scour depth prediction is much higher than the experimental results (Appendix S). The Maryland SHA Abutment Scour Methodology for Clear-Water had the closest results to the physical experiments. The maximum scour depth prediction for Experiment \#B7 was $0.227 \mathrm{~m}$, about 2.30 times higher than the experimental results (yellow highlight in Table 12), and for Experiment \#B3 was $0.183 \mathrm{~m}$, about 1.67 times higher than the experimental results (cyan highlight in Table 12). Besides the porosity and meander factors mentioned earlier, the safety factor involved in abutment scour depth prediction may be another reason to cause a huge difference between the prediction and the experimental results.

For the bankfull situation, Experiment \#B4 was first investigated since this location of the deflector provided one of the best performance records at the 25 $\mathrm{cm}$ water depth. The sediment profile remained stable after a 12-hour continuous run experiment. This result matches the prediction during the investigation of the incipient velocity (Section 4.7.2). Thus, the rest of the physical experiments for bankfull situation (Experiments \#B2, \#B6, and \#B8) were eliminated due to the experimental results of \#B4. The bankfull scenario is investigated using the numerical model instead (Chapter 5). 
Table 12: Experimental results of single deflector scenario (Experiment \#B1, \#B3, \#B5, and \#B7).

\begin{tabular}{|c|c|c|c|c|c|c|c|c|}
\hline $\begin{array}{c}\text { Experiment } \\
\quad \#\end{array}$ & $\begin{array}{c}\text { Time for } \\
\text { Conducting } \\
\text { Measurements, } \\
\text { in hr }\end{array}$ & $\begin{array}{c}\text { Section } \\
\text { where Pool } \\
\text { Formation } \\
\text { Begins }\end{array}$ & $\begin{array}{c}\text { Total } \\
\text { Scour } \\
\text { Volume, } \\
\text { in } \times 10^{-3} \mathrm{~m}^{3}\end{array}$ & $\begin{array}{c}\text { Total } \\
\text { Deposition } \\
\text { Volume, } \\
\text { in } \times 10^{-3} \mathrm{~m}^{3}\end{array}$ & $\begin{array}{c}\text { Total } \\
\text { Sediment } \\
\text { Loss, } \\
\text { in } \times 10^{-3} \mathrm{~m}^{3}\end{array}$ & $\begin{array}{l}\text { Maximum } \\
\text { Scour } \\
\text { Depth, } \\
\text { in cm }\end{array}$ & $\begin{array}{l}\text { Location of } \\
\text { Maximum } \\
\text { Scour Depth }\end{array}$ & $\begin{array}{l}\text { Surface } \\
\text { Area of } \\
\text { Pool, } \\
\text { in } \mathrm{m}^{2}\end{array}$ \\
\hline \multirow[t]{5}{*}{ B7 } & 3 & \multirow[t]{5}{*}{ u130i } & 2.256 & 0.2100 & 2.046 & 7.630 & u150,80 & 0.4795 \\
\hline & 9 & & 2.563 & 0.3940 & 2.169 & 9.470 & $\mathrm{m0}, 80$ & 0.7715 \\
\hline & 15 & & 2.875 & 0.4640 & 2.411 & 9.870 & $\mathrm{~m} 0,80$ & 0.8674 \\
\hline & 21 & & 3.151 & 0.6390 & 2.512 & 9.270 & $\mathrm{m0}, 80$ & 0.9520 \\
\hline & 27 & & 2.881 & 0.7400 & 2.141 & 9.570 & $\mathrm{~m} 0,80$ & 1.018 \\
\hline \multirow[t]{5}{*}{ B5 } & 3 & u140i & 2.224 & 0.5790 & 1.645 & 7.140 & $\mathrm{~m} 6,0$ & 0.3459 \\
\hline & 9 & \multirow[t]{4}{*}{ u130i } & 2.736 & 0.5600 & 2.176 & 7.570 & $\mathrm{~m} 8,10$ & 0.7008 \\
\hline & 15 & & 2.689 & 0.5900 & 2.099 & 7.570 & $\mathrm{~m} 8,10$ & 0.6825 \\
\hline & 21 & & 3.056 & 0.6300 & 2.426 & 7.540 & $\mathrm{~m} 10,10$ & 0.7861 \\
\hline & 27 & & 3.004 & 0.6640 & 2.340 & 7.370 & $\mathrm{~m} 8,10$ & 0.8918 \\
\hline \multirow[t]{5}{*}{ B3 } & 3 & \multirow[t]{5}{*}{$\mathrm{m} 18 \mathrm{i}$} & 1.704 & 0.4110 & 1.293 & 9.640 & $\mathrm{~m} 26,60$ & 0.5852 \\
\hline & 6 & & 1.836 & 0.4000 & 1.436 & 9.940 & $\mathrm{~m} 26,70$ & 0.7849 \\
\hline & 9 & & 1.994 & 0.3330 & 1.661 & 10.34 & $\mathrm{~m} 26,70$ & 0.9475 \\
\hline & 12 & & 2.094 & 0.3630 & 1.731 & 10.94 & $\mathrm{~m} 26,70$ & 1.072 \\
\hline & 18 & & 2.157 & 0.3790 & 1.778 & 9.990 & $\mathrm{~m} 26,70$ & 1.009 \\
\hline \multirow[t]{5}{*}{ B1 } & 3 & \multirow[t]{5}{*}{$m$ m18i } & 0.8130 & 0.2340 & 0.5790 & 4.940 & $\mathrm{~m} 26,140$ & 0.6838 \\
\hline & 9 & & 1.131 & 0.1990 & 0.9320 & 4.980 & $\mathrm{~m} 50,110$ & 0.7440 \\
\hline & 15 & & 1.300 & 0.1930 & 1.107 & 5.940 & $\mathrm{~m} 26,130$ & 0.8109 \\
\hline & 21 & & 1.472 & 0.1910 & 1.281 & 6.030 & $\mathrm{~m} 50,110$ & 0.8081 \\
\hline & 27 & & 1.491 & 0.2050 & 1.286 & 5.930 & $\mathrm{~m} 50,110$ & 0.8168 \\
\hline
\end{tabular}

Note: 1) Red bold numbers are the best case of each category (i.e. columns 4 to 9) for each Experiment (i.e. \#B1, \#B3, \#B5, \#B7).

2) Shaded cells are the best case for each single deflector scenarios.

3) The locations of the measurement sections are shown in Figure 75. 


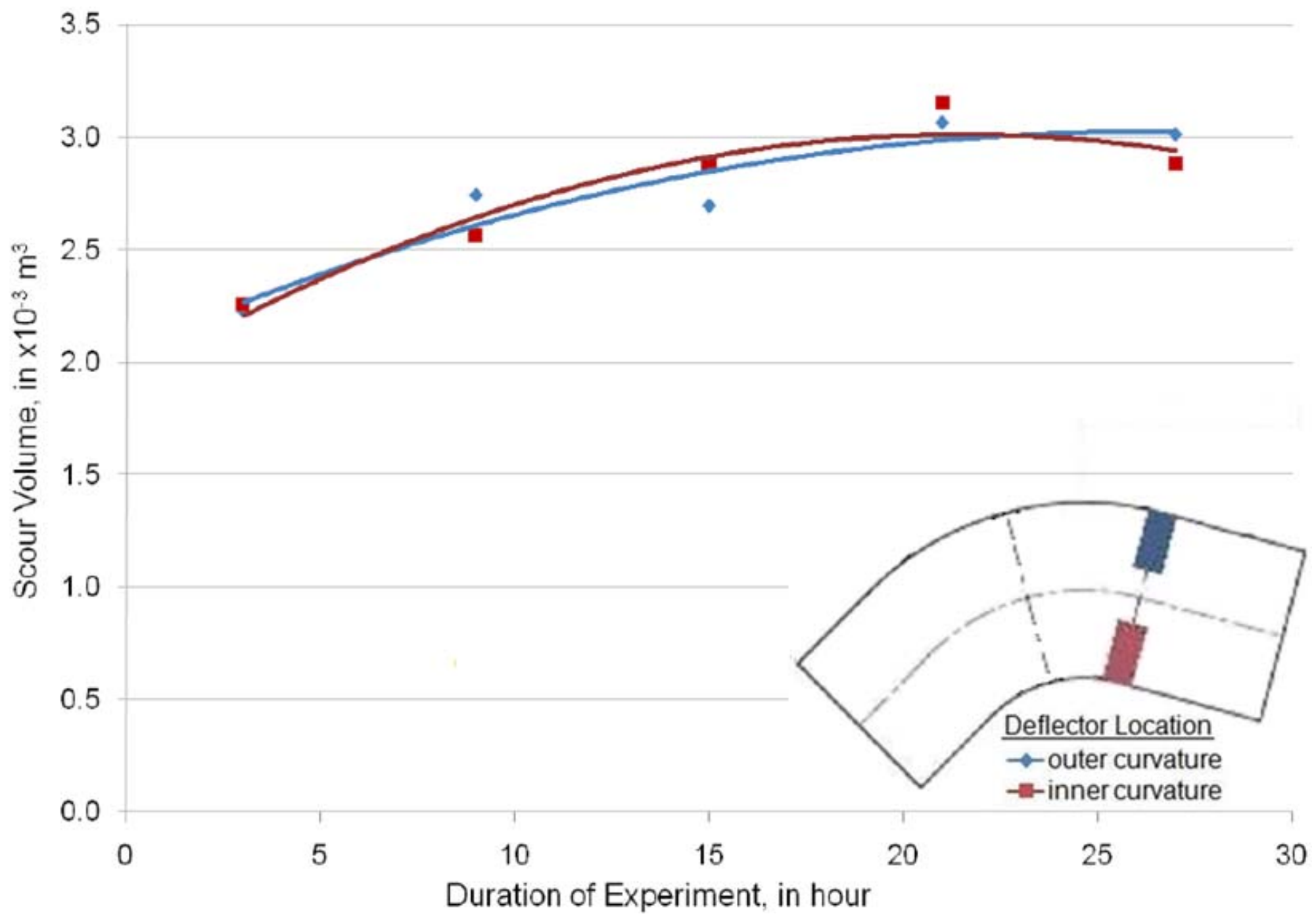

Figure 73: Scour formation at different time periods for Experiment \#B7 and \#B5. 


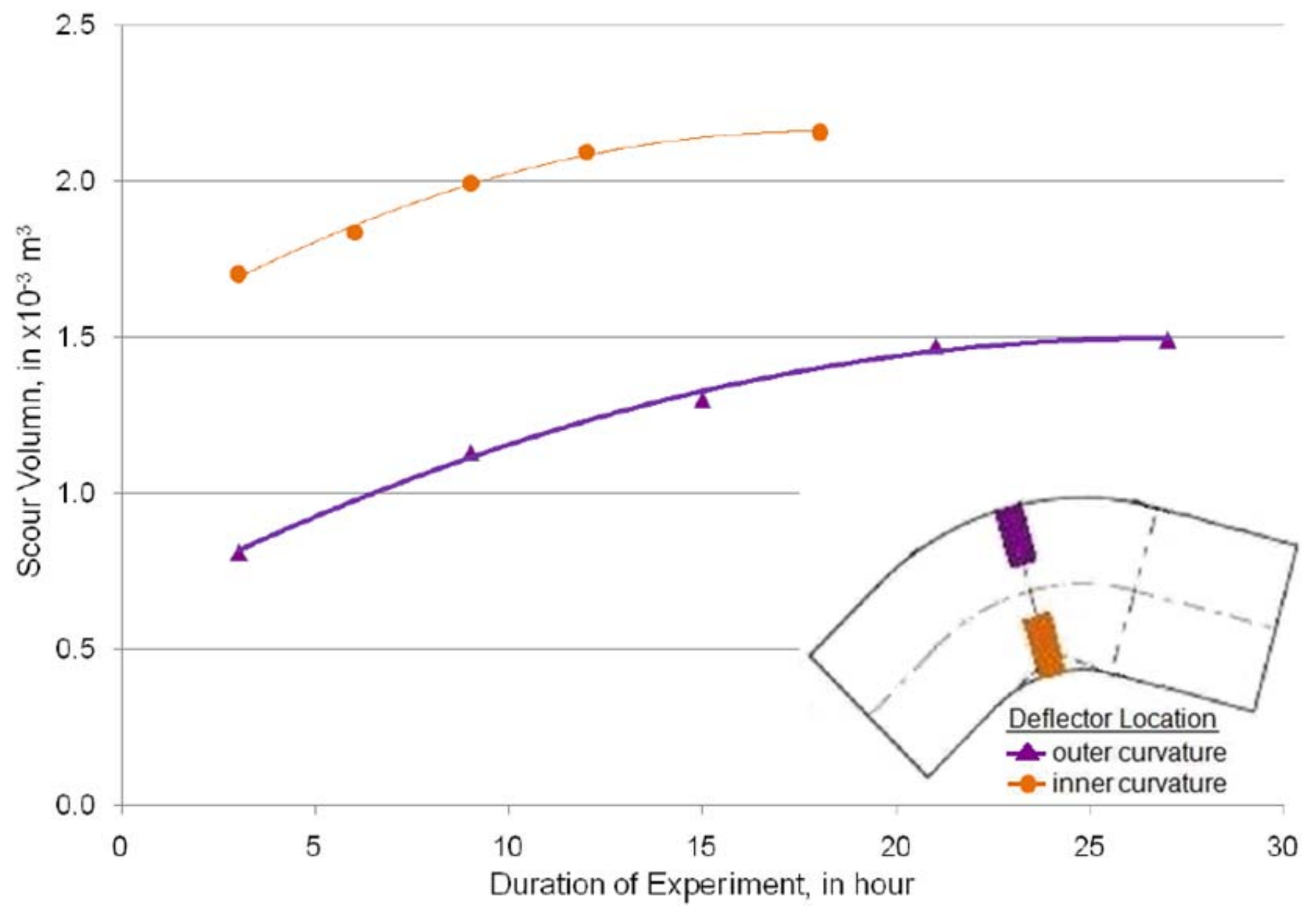

Figure 74: Scour formation at different time periods for Experiment \#B3 and \#B1. 


\section{$\underline{\text { Velocities }}$}

The velocity profiles at $x y-, x z-$, and $y z$-planes for Experiments \#B1, \#B3, \#B5, \#B7 were illustrated in Appendix P. The velocity profiles on a $x y$-plane were measured at $20 \%, 40 \%$, and $80 \%$ of water depths and the velocity profiles at $x Z-$, and $y z$-planes were measured at sections near the deflector. Generally and as expected, the flow velocities are reduced near the deflector while the velocities are accelerated in the centre of the channel downstream of the deflectors. The recirculation zone can be easily observed downstream of the deflector in all experiments. Flow velocities at the downstream of the recirculation zone are generally smaller than those in the upstream recirculation zone. For the best single deflector scenarios, a huge difference of flow velocities can be found around $70 \mathrm{~cm}$ to $80 \mathrm{~cm}$ from the inner curvature bank. The velocity difference is the invisible boundary between the recirculation zone and the flow accelerating zone. Furthermore, downward vertical velocities can be observed close to the tip of the deflector. Since pool formation was initiated at the tip of the deflector and extended longitudinally and laterally, this strong downward vertical velocity at the deflector tip may play an important role on sediment entrainment.

For the velocity profiles at the $x z$-plane (Appendix $\mathrm{P}$ ) of the best single deflector scenario (\#B7 and \#B3), the magnitudes of the velocities at the recirculation zone were reduced dramatically and remained in the downstream direction with upward and downward fluctuations. The downstream directions of the velocities 
contradicted with Duan's (2009) flow reverse observation in a straight flume with a 4-mm thick metal plate. This may be caused by the actual scale of physical model and the deflector with a porosity of $40 \%$ involved in the experiments. Furthermore, since the measurements were on a coarse grid, finer details of the flow recirculation were not captured in the velocity profiles.

\subsubsection{Experimental Results on Wet Weather Condition without Incoming Sediment-Double Deflectors}

Appendix $\mathrm{N}$ shows the general experimental results of the double deflector scenarios (i.e. \#B9, \#B11, \#B13, and \#B15). The objective of the staggered double deflector experiments (\#B9 and \#B11) was to investigate the effects of scour formation near the downstream deflector when there is an obstacle located at the upstream staggered direction. Additionally, paired deflector designs (Experiments \#B13 \& \#B15) were also studied to see whether it is a better solution in terms of scour performance than the single deflector design.

\section{Staggered Double Deflector Scenarios}

For the staggered double deflector scenarios, scour near the downstream deflector was reached its bottom limit after an hour run at $25 \mathrm{~cm}$ of water depth. Thus, water depths higher than $25 \mathrm{~cm}$ were investigated. The goal of the investigation was to determine the required water depths for the two staggered scenarios in order to create similar scour patterns to Experiments \#B3 and \#B1. 
For Experiment \#B9, the required water depth is $35 \mathrm{~cm}$ and for Experiment \#B11 is $30 \mathrm{~cm}$.

The detailed bed topography of the staggered double deflector scenarios was also illustrated in Appendix R. After a 10-hour run, the scour volume for Experiment \#B9 was $1.266 \times 10^{-3} \mathrm{~m}^{3}$ with a maximum scour depth of $8.14 \mathrm{~cm}$ located at the upstream tip of the deflector at the inner curvature of the meander section. For Experiment \#B11, the scour volume was $1.472 \times 10^{-3} \mathrm{~m}^{3}$ with a maximum scour depth of $10.0 \mathrm{~cm}$ located at the upstream tip of the deflector at the outer curvature.

The velocity profiles at the $x y$-plane can probably explain the increasing the water depths needed to create a comparative scour pattern for the single deflector scenarios. The recirculation zone and the flow accelerating zone can be easily observed along the staggered deflectors, where the magnitudes of the velocities in the flow accelerating zone are similar to the ones in the single deflector scenario. Experiment \#B9 has a longer recirculation zone near the upstream deflector than Experiment \#B11. The upstream recirculation zone of Experiment \#B9 ends around the midway of the meander section (section m30), where the upstream recirculation zone of Experiment \#B11 ends around onethird (section $m 20$ ) of the meander section. 
For the velocity profiles on the $y z$-plane, flow reverse and circulation at the transverse direction can be easily observed at the upstream and downstream sections of the deflectors. Strong downward vertical velocities can be found close to the tip of the deflector in Experiment \#B11. Moreover, the magnitudes of the velocities in the $X Z$-plane at the two recirculation zones decreased dramatically with upward and downward fluctuations. Weak flow reverse can be also observed near the tip of the deflectors.

\section{Paired Double Deflector Scenarios}

For the paired double deflector scenarios, severe scour formed at the centre of the channel between the paired deflectors. The maximum scour depth reached its bottom limit within an hour run at $25 \mathrm{~cm}$ of water depth. The experimental results of bed topography and flow patterns for the two paired double deflector scenarios (Experiments \#B13 and \#B15) can be found in Appendix Q. Since there is enormous amount of preparation works involved for each experiment, further investigation of the performance of the paired double deflectors should be conducted using the numerical model.

The bankfull situations for both the staggered and paired double deflector scenarios (Experiments \#B10 and \#B16) were also tested. Similar to the single deflector scenario, there is no change in the bed profiles after a continuous 10-hour run. 


\subsubsection{Experimental Results for Wet Weather Conditions with Incoming Sediment-Single Deflector}

Since the incoming sediment feeder (Figure 51) cannot maintain a uniform incoming sediment load for a long period of time, only a 1-hour run was performed in each incoming sediment experiment. Furthermore, it was impossible to prepare incoming sediment loads and conduct velocity measurements at the same time. The flow patterns in the incoming sediment scenarios were expected to be similar to the ones in Experiments \#B3 and \#B7. Thus, only bed-profile measurements were conducted after each experiment.

The bed topography of the experimental results were depicted in Appendix R. Generally, both the pool volume and scoured area had significant reductions compared with the no incoming sediment scenario. The scour starting near the downstream deflector tip and along the centre of the meander section was filled up by the incoming sediment. Only the scour near the upstream deflector tip and along the centreline of the upstream meander section still remained in the channel. The scour volume with deflector location as Experiment \#B7 for small and large incoming sediment scenarios were $0.602 \times 10^{-3} \mathrm{~m}^{3}$ and $1.000 \times 10^{-3}$ $\mathrm{m}^{3}$ respectively. With deflector location as Experiment \#B3, the scour volumes of small and large incoming sediment scenarios were $0.24 \times 10^{-3} \mathrm{~m}^{3}$ and $0.648 \times 10^{-3} \mathrm{~m}^{3}$ respectively. 
Although the first scour measurements of Experiments \#B7 and \#B3 start after a 3-hour continuous run, by interpolating the scour performance curves the scour volume of the large incoming sediment experiment is around $50 \%$ of the ones in the no incoming sediment scenario for Experiment \#B7. For Experiment \#B3, the scour volume of the large incoming sediment test is around $40 \%$ of the volume in the no incoming sediment scenario. 


\subsection{UNCERTAINTIES IN THE PHYSICAL EXPERIMENTS}

There are a couple of errors in the physical experiments which cannot be eliminated due to the limitations of the laboratory facilities. For instance, though the bed measurement was considered for the meander section of the physical model to minimize the upstream and downstream boundary effects, the bed profile, especially along the deposition zone, showed that the downstream boundary of the rectangular weir had backed up the bed form slightly. The numerical results indicated that the deposition zone happened further downstream from the meander section. This inconsistency was due to the scarce space, the holding tank and the pumps set-up of the laboratory. It cannot be further improved since the design of the physical model was already based on the maximum allowable space on the deck.

Secondly, the bed profile was disturbed slightly whenever a bed measurement was conducted due to the water removing and refilling processes prior to and after the measurement. The following solutions were already applied in order to minimize the disturbances:

- Water was refilled slowly using submerged pumps at the furthermost upstream and downstream ends of physical model to avoid any contacts with the bed material until the water level reached the top of the rectangular weir;

- The pump was turned on and off slowly until it reached the desire discharge rate; 
- Plastic plugs located at the rectangular weir were used to control the water removal process instead of the rectangular weir itself;

- When applying the vacuum machine to remove water from the scour hole, a thin layer of water was remained to minimize the sucking effects. The needle at the height gauge was used to sense the bed profile during scour hole measurements; and

- The number of times of bed measurements was minimized (i.e. every 3-hour instead of every hour).

The velocity measurements were conducted at the beginning of each experiment to minimize the bed form impacts. Since it takes about an hour to measure the velocity profiles of the entire channel, the bed form variation in the first hour will affect the velocity measurements.

The laboratory facilities take approximately a week to remove and refill the water in the circulation flume and the holding tank. Thus, it is impossible to use fresh water for each experiment. The water in all experiments was the same. Although the sediment in the pilot site is coarse, the suspended portion of the sediment would mix with the water once the first experiment started. Hence, there would be always a small amount of incoming sediment involved in all experiments.

For the incoming sediment scenarios, the rate of incoming sediment was not evenly distributed due to the manual operation of the incoming sediment feeder. 
Additionally, the incoming sediment in reality should enter the channel from the bed surface rather than the water surface. The buffer zone, the $2 \mathrm{~m}$ long straight channel upstream of the meander section, should minimize the impacts. Furthermore, the deflector wires in the physical experiments were in square shapes and the deflector material was crushed concrete. In reality, the deflector wires are usually in rhombus shapes and crushed stones are usually applied as deflector material. Although the deflector material has similar surface roughness, these slightly changes may affect the scour formation. 


\section{CHAPTER 5 NUMERICAL MODEL EXPERIMENTS}

This chapter discusses the set-up of the numerical model, the sensitivity analysis, the calibration, the numerical experiments and results in detail. The objective of the numerical experiments is to demonstrate how the numerical model can facilitate the design of the deflectors and channel modification in river restoration projects.

\subsection{NUMERICAL MODEL SET UP}

The physical model discussed in Chapter 4 (Figure 55) was used to set up the numerical model for the sensitivity analysis and calibration tests. The exact dimensions of the physical model (Figure 55) was first plotted using AutoCAD LDD program (white lines in Figure 75) in order to determine the $x$ - and $y$ coordinates of the first and second boundaries (Figure 75) of channel block and deflector block in the CCHE2D program. The points along the first and second boundaries, particularly the ones in the meander section, were set up following the measuring sections (i.e. $m 0$ to $m 60$ ) in the physical experiments. A "scatter points" input file (i.e. *.mesh_xyz) was then created using the sample file (i.e. warstwa.mesh_xyz) in the CCHE-MESH program and Microsoft Notepad program. The input file was opened by CCHE-MESH program where channel block and deflector block must be plotted point-by-point manually in the workspace view using the functions in the "Block Editing" toolbar (red rectangle 
in Figure 76). After the blocks were created, a block boundary file was created internally by the program. This file can be saved to simplify the modification in the future numerical experiments. A mesh was then generated using the "Mesh Generation" toolbar (red rectangle in Figure 77) and then fine-tuned using the "Mesh Editing" toolbar (green rectangle in Figure 77) especially around the deflector region (i.e. add more mesh lines, move points to smooth the mesh lines). The mesh was saved in a geometry file (i.e. * .geo) after its completion and re-opened again using CCHE-GUI program. Flow and sediment parameters were entered to the CCHE-GUI program based on the pilot site condition (red values in Table 13). A datum of 10 metres was chosen for the initial downstream bed elevation (row 4 in Table 13). Default values were used for the maximum deposition or erosion thickness (rows 11 and 12 in Table 13), and the parameters in the "Advanced" tab of "Flow Parameters" section (rows 48 to 52 in Table 13). The percentages of sediment size distribution for the bed sample (rows 99 to 103 in Table 13) and the incoming bed and suspended loading (rows 89 to 96 in Table 13) were assumed to be the same as the average particle size distribution of sediment samples collected from the pilot site.

For the boundary conditions, the inlet flow rates were determined using Manning's equation (Table 14 and Table 18). The longitudinal slope (Appendix J) and the height of the low-flow channel (Figure 36) were direct measurements from the pilot site. The width of the low-flow channel and the roughness coefficient followed the discussion in the previous chapter (Sections 4.1 and 4.2). 
The inlet flow rate and water depth for the dry weather condition (Table 9) was again come from the flow monitoring report by HK DSD (Appendix $\mathrm{H})$ and the site assessment (Appendix C). When flow reaches the flood channel, vertical cuts were applied to the boundaries between the low-flow channel and flood channel. The inlet flow rate is the sum of the flows in the three portions calculated again by Manning's equation (Table 18).

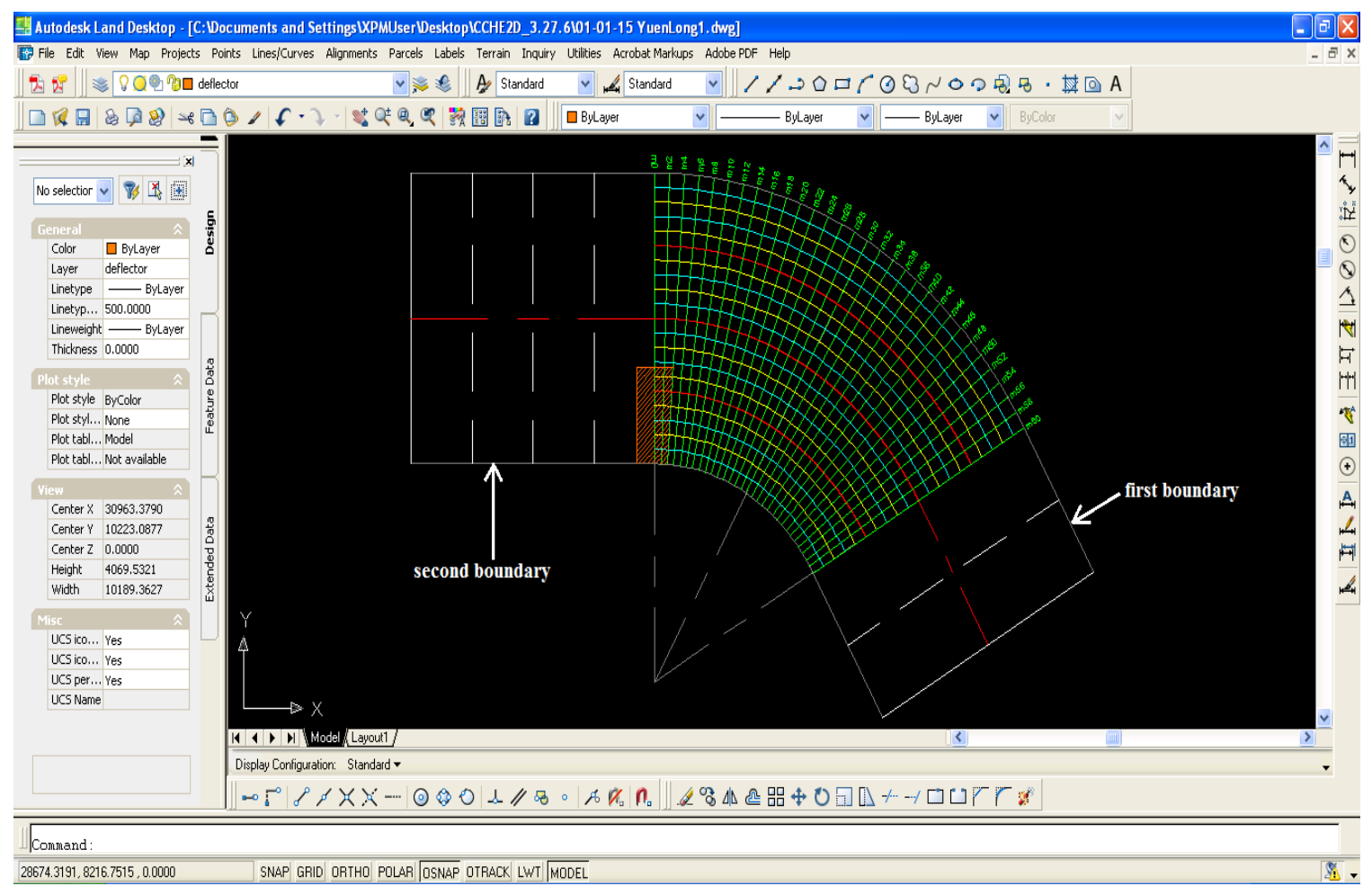

Figure 75: Sketch of the physical model in the AutoCAD LDD program. 


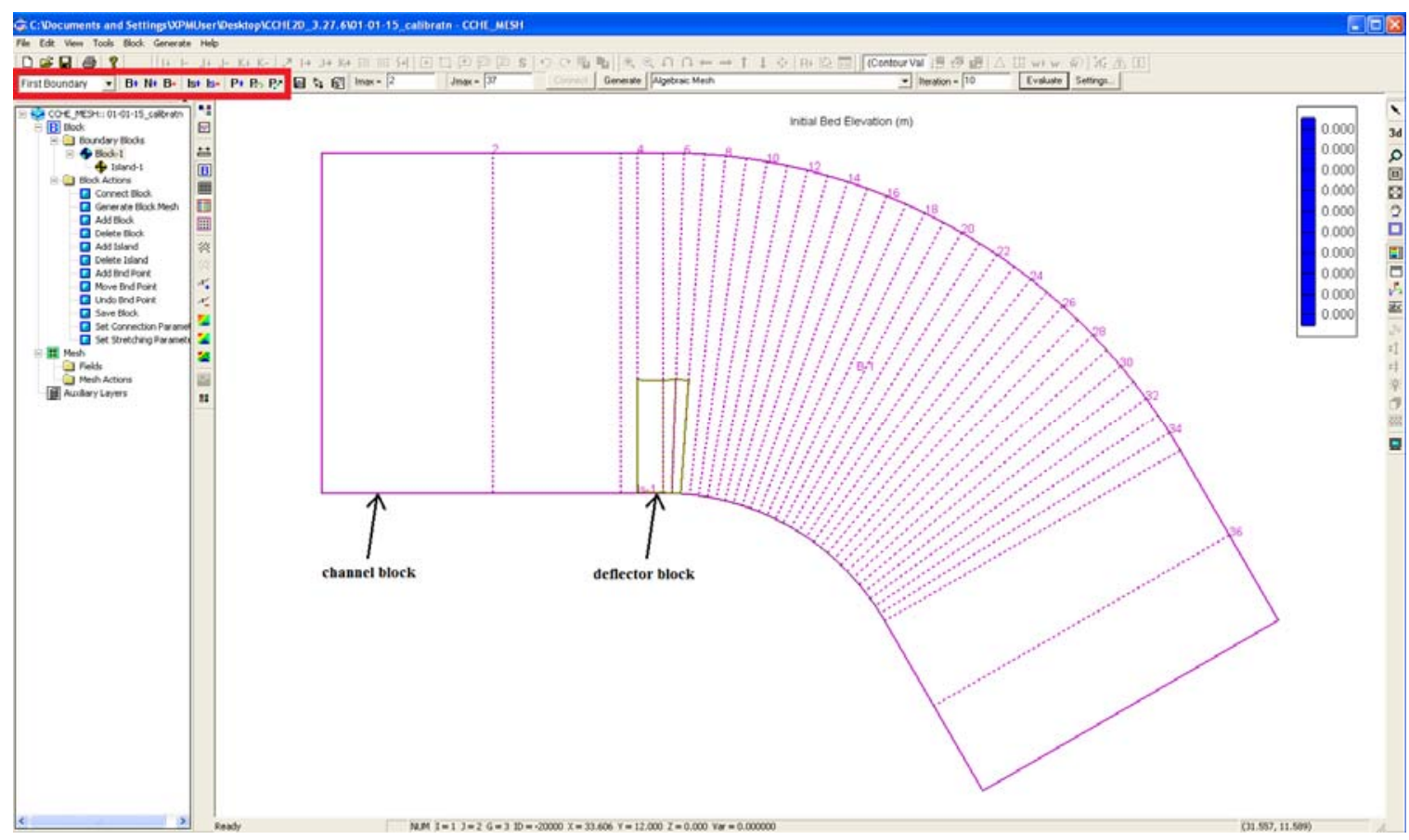

Figure 76: Preparation of channel block and deflector block in CCHE-MESH program.

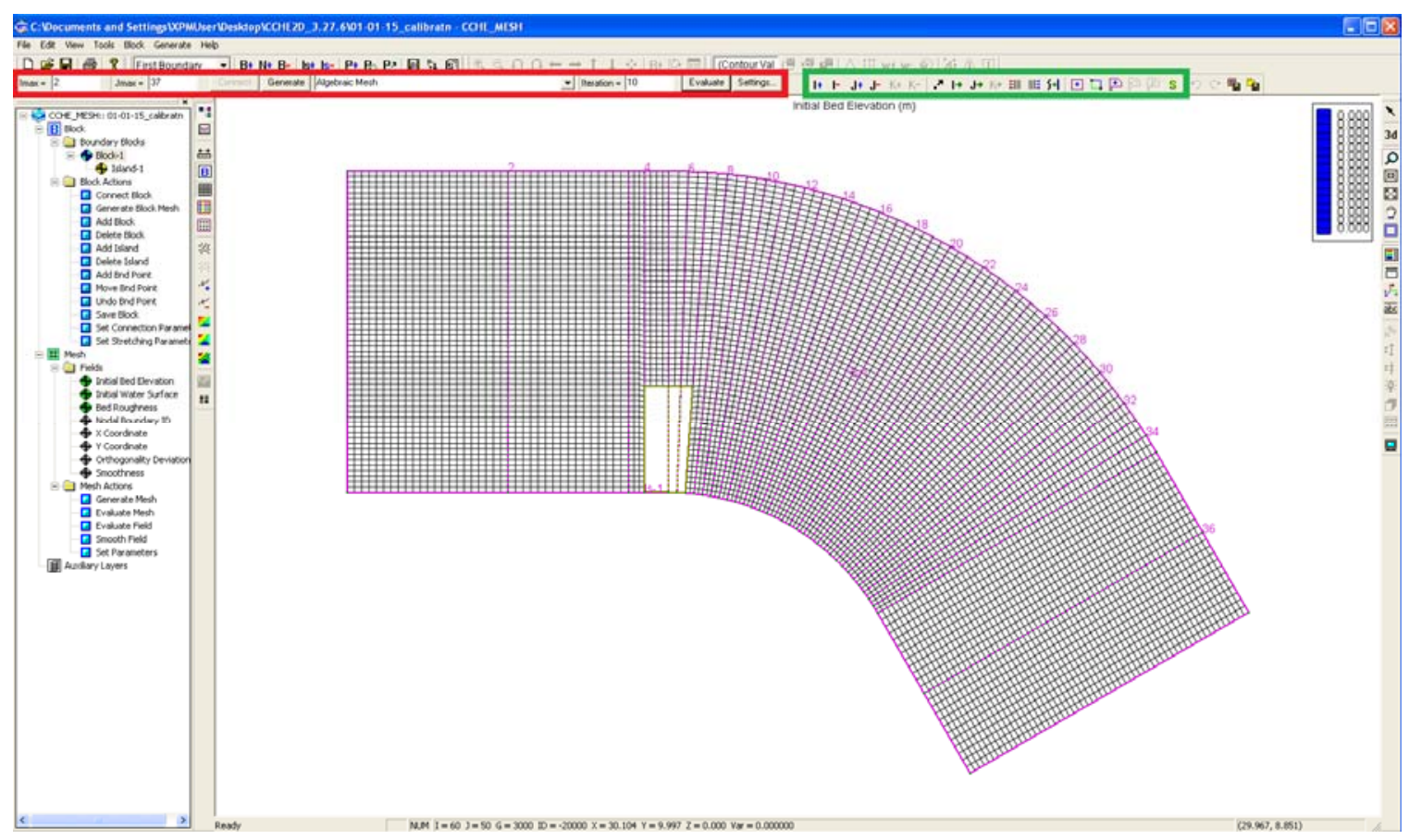

Figure 77: Mesh generation in CCHE-MESH program. 
Table 13: Parameters involved in the CCHE-GUI program.

\begin{tabular}{|c|c|}
\hline Parameters & Initial Values \\
\hline \multicolumn{2}{|l|}{ Initial Condition } \\
\hline Bed elevation (upstream), in metres & 10.015 \\
\hline Bed elevation (downstream), in metres & 10.00 \\
\hline Water surface (upstream), in metres & 10.265 \\
\hline Water surface (downstream), in metres & 10.25 \\
\hline Inlet boundary (Discharge), in $\mathrm{m} 3 / \mathrm{s}$ & 0.155 \\
\hline Outlet Boundary (water surface), in metres & 10.25 \\
\hline Bed roughness & 0.06 \\
\hline Bed erodibility & erodible \\
\hline Maximum deposition thickness, in metres & 90 \\
\hline Maximum erosion thickness, in metres & -90 \\
\hline \multicolumn{2}{|l|}{ Sediment size class, in metres } \\
\hline $\mathrm{D} 10$ & 0.0000256 \\
\hline D30 & 0.000115 \\
\hline D50 & 0.000281 \\
\hline D70 & 0.000646 \\
\hline D90 & 0.00176 \\
\hline \multicolumn{2}{|l|}{ Layer thickness, in metres } \\
\hline Layer 1 & 0.05 \\
\hline Layer 2 & 0.5 \\
\hline Layer 3 & 1 \\
\hline \multicolumn{2}{|l|}{ Layer sample } \\
\hline Layer 1 & 1 \\
\hline Layer 2 & 1 \\
\hline Layer 3 & 1 \\
\hline \multicolumn{2}{|l|}{ Set Flow Parameters } \\
\hline \multicolumn{2}{|l|}{ Simulation Parameters } \\
\hline Simulation time, in seconds & 172800 \\
\hline Time steps, in seconds & 1 \\
\hline \# Time Steps for Intermediate file & 90 \\
\hline \# Time Steps for History file & 90 \\
\hline Monitor points & 0 \\
\hline Convergence & 1 \\
\hline \multirow[t]{3}{*}{ Turbulence model option (3) } & Parabolic Eddy Viscosity Model \\
\hline & Mixing Length Model \\
\hline & K-Epsilon Model \\
\hline Turbulent viscosity coefficient & 1 \\
\hline Unsteady flow computation & unchecked \\
\hline
\end{tabular}




\begin{tabular}{|c|c|}
\hline Wall slipness coefficient & 0.5 \\
\hline Depth to consider dry, in metres & 0.04 \\
\hline \multirow{3}{*}{ Time iteration method ( 3 ) } & Method 1 \\
\hline & Method 2 \\
\hline & Method 3 \\
\hline \multicolumn{2}{|l|}{ Bed Roughness } \\
\hline Flow simulation method (4) & Manning's n \\
\hline Sediment transport simulation method (4) & Use the value in *.geo file \\
\hline \multicolumn{2}{|l|}{ Advanced } \\
\hline Coriolis force coefficient & 0 \\
\hline Gravity, in $\mathrm{m} / \mathrm{s}^{2}$ & 9.81672 \\
\hline von Karman constant & 0.41 \\
\hline Fluid kinematic viscosity, in $\mathrm{m}^{2} / \mathrm{s}$ & $1 \mathrm{E}-06$ \\
\hline \multicolumn{2}{|l|}{ Set Sediment Parameters } \\
\hline \multicolumn{2}{|l|}{ Sediment Size Classes } \\
\hline Number of bed layer & 3 \\
\hline Minimum mixing layer thickness & 0.05 \\
\hline Define Size Class & D10, D30, D50, D70, D90 \\
\hline \multicolumn{2}{|l|}{ Sediment Transport } \\
\hline \multirow[t]{3}{*}{ Transport mode (3) } & Total load as bed load model \\
\hline & $\begin{array}{c}\text { Total load as suspended load } \\
\text { model }\end{array}$ \\
\hline & $\begin{array}{l}\text { Total load as bed load plus } \\
\text { suspended load model }\end{array}$ \\
\hline \multirow[t]{4}{*}{ Transport capacity formula (4) } & Wu et al. formula \\
\hline & SENTRA module (Run-2) \\
\hline & $\begin{array}{l}\text { Modified Engelund \& Hansen } \\
\text { formula (Run-3) }\end{array}$ \\
\hline & Modified Ackers \& White formula \\
\hline \multirow[t]{2}{*}{ Sediment simulation mode (2) } & slow bed change with steady flow \\
\hline & $\begin{array}{l}\text { fast bed change with unsteady } \\
\text { flow }\end{array}$ \\
\hline \multirow[t]{3}{*}{ Adaptation length for bedload (3) } & set as average grid length \\
\hline & set as 7.3 of average dune length \\
\hline & specify adaptation length--52 \\
\hline \multirow[t]{2}{*}{ Adaption factor for suspended load (2) } & $\begin{array}{c}\text { based on Armanini and di Silvio } \\
\text { (1988) }\end{array}$ \\
\hline & specify adaptation factor \\
\hline Diffusivity - Schmidt Number & 0.5 \\
\hline \multicolumn{2}{|l|}{ Sediment } \\
\hline Sediment specific gravity & 2.65 \\
\hline Curvature effects & checked \\
\hline
\end{tabular}




\begin{tabular}{|c|c|}
\hline Average channel width, in metres & 2 \\
\hline Time steps to adjust flow & 100 \\
\hline Erosion/Deposition limit & 0.01 \\
\hline Bed rock simulation & unchecked \\
\hline Rock erosion coefficient & ----- \\
\hline Bed Roughness & same as flow simulation \\
\hline \multicolumn{2}{|l|}{ Bank Erosion } \\
\hline $\mathrm{i}=1$ & non-erodible \\
\hline$i=\operatorname{imax}$ & non-erodible \\
\hline $\mathrm{j}=1$ & non-erodible \\
\hline $\mathrm{j}=\mathrm{jmax}$ & non-erodible \\
\hline \multicolumn{2}{|l|}{ Boundary Condition File } \\
\hline Bed loading rate at each point, in $\mathrm{kg} / \mathrm{s}$ & 0 \\
\hline$\%$ of sediment class D10 & 0.125 \\
\hline$\%$ of sediment class D30 & 0.25 \\
\hline$\%$ of sediment class D50 & 0.25 \\
\hline$\%$ of sediment class D70 & 0.25 \\
\hline$\%$ of sediment class D90 & 0.125 \\
\hline Suspended loading rate at each point, in $\mathrm{kg} / \mathrm{m} 3$ & 0 \\
\hline$\%$ of sediment class D10 & 0.9500 \\
\hline$\%$ of sediment class D30 & 0.0500 \\
\hline \multicolumn{2}{|l|}{ Bed Samples } \\
\hline Porosity & 0.24 \\
\hline$\%$ of sediment class D10 & 0.125 \\
\hline$\%$ of sediment class D30 & 0.25 \\
\hline$\%$ of sediment class D50 & 0.25 \\
\hline$\%$ of sediment class D70 & 0.25 \\
\hline$\%$ of sediment class D90 & 0.125 \\
\hline
\end{tabular}


Table 14: Inlet flow rates input to the numerical model at various water depths within the low-flow channel (LFC).

\begin{tabular}{|l|c|c|c|c|}
\hline Width of the Low-Flow Channel $\left(B_{L F C}\right)$, in metres & \multicolumn{4}{|c|}{2} \\
\hline Conditions & $\begin{array}{c}1 / 2 \text { water depth } \\
\text { of LFC }\end{array}$ & $\begin{array}{c}3 / 4 \text { water depth } \\
\text { of LFC }\end{array}$ & $\begin{array}{c}5 \text { cm below } \\
\text { bankfull of LFC }\end{array}$ & $\begin{array}{c}\text { bankfull of } \\
\text { LFC }\end{array}$ \\
\hline Water Depth, in metres & 0.225 & 0.3375 & 0.4 & 0.45 \\
\hline Roughness Coefficient $(n)$ & \multicolumn{4}{|c|}{0.06} \\
\hline Longitudinal Slope $(S)$ & \multicolumn{4}{|c|}{0.002943} \\
\hline \hline Area $(A)$, in $\mathrm{m}^{2}$ & 0.4500 & 0.6750 & 0.8000 & 0.9000 \\
\hline Wetted Perimeter $(P)$, in metres & 2.450 & 2.675 & 2.800 & 2.900 \\
\hline Hydraulic Radius $(R)$, in metres & 0.1837 & 0.2523 & 0.2857 & 0.3103 \\
\hline Inlet Flow Rate, $\left(Q_{\text {in }}\right)$, in $\mathbf{m}^{\mathbf{3}} / \mathbf{s}$ & $\mathbf{0 . 1 3 1 5}$ & $\mathbf{0 . 2 4 3 7}$ & $\mathbf{0 . 3 1 3 8}$ & $\mathbf{0 . 3 7 3 0}$ \\
\hline
\end{tabular}




\subsection{NUMERICAL MODEL SIMULATION}

The yellow highlights in column 1 of Table 13 are the parameters involved in calibrating the numerical model. The flow, i.e. Turbulence Model Option (rows 35 to 37), and sediment transport methodologies, i.e. Transport Mode (rows 59 to 61) and Transport Capacity Formula (rows 62 to 65), were investigated before other parameters. For the flow simulation, only the Mixing Length Model and KEpilson Model had successful runs. The K-Epilson Model was finally selected due to the modification of the deflectors in the calibration process (Section 5.2). For the Transport Mode, only Total Load as Bed Load Model worked. A question about the failure of the other two approaches was raised to NCCHE technical support and their reply said that most of the cases are only workable in the bed load model. Since the size distribution of the bed samples in the pilot site were mainly sand (Figure 34) and the concentration of the suspended particles in the water samples were small (Appendix E), it should be applicable to consider the bed load model only in the numerical experiments. For the Transport Capacity Formula, only Wu et al. Formula and Modified Engelund and Hansen Formula worked. The Wu et al. Formula was finally selected due to its closer prediction of scour volume to the results of the physical experiments.

An upper and lower limits of $20 \%$ were then applied to the following parameters in Table 13 for the numerical model calibration: Bed Roughness (row 9), Layer Thickness (rows 19 to 22), Wall Slipness Coefficient (row 40), Diffusivity Schmidt Number (row 73), Time Steps to Adjust Flow (row 78), and Porosity (row 
99). There is a direct relationship between scour volume and parameters Bed Roughness, Wall Slipness Coefficient, and Porosity whereas scour volume increases as the parameters increase. Among the three parameters, the Wall Slipness Coefficient has the least significant impact on the scour volume. Additionally, there is no change in the scour volume for Diffusivity - Schmidt Number. This is reasonable since the Transport mode was set to the bed load model. For the three parameters (Layer 1, Layer 2, and Layer 3) in the Layer Thickness category, the model failed whenever there is an adjustment on any of the three parameters. Thus, the default values $(0.05,0.5$ and 1 for Layer 1 , Layer 2, and Layer 3 respectively) were maintained in the numerical experiments. The default values of other two parameters, Depth to Consider Dry (row 41) and Erosion/Deposition Limit (Row 79), were also selected for the numerical experiments due to the internal set up of the program.

The time parameters, such as Time Iteration Method (rows 42 to 44) and Time Steps to Adjust Flow (row 78), the parameters in the Sediment Size Classes category (row 54 to 57), the Adaptation Length for Bedload (row 68 to 70), and the Adaptation Factor for Suspended Load (row 71 and 72) were investigated at last. For the Time Iteration Method, only Method 1 and Method 2 produced successful runs. Since CCHE-GUI 3.0 User's Manual (Zhang, 2006), hereafter called the User's Manual, defines the three methods as "... small, medium, and large number of iterations per time step. The actual number is set by the computational model. The value should be based on the time step size, i.e. if the 
time step size is large the iteration control flag should be set to a higher value." and the time step in the numerical model calibration is 1 second (row 30). This explains why Method 3 fails during calibrating the numerical model. The Time Steps to Adjust Flow (row 78) parameter has some effects on delaying the time steps of failure run or even created a successful run as it increases (Section 5.4). Default values must also apply to the first two parameters in the Sediment Size Classes category, the Number of Bed Layer (row 55) and the Minimum Mixing Layer Thickness (row 56) or else the model would fail. The reason of the model failure may also due to the set up in the Layer Thickness category previously. There is an indirect relationship between the Adaptation Length for Bedload parameter and the scour volume. The scour volume decreased as the adaptation length increased. Last but not least, there is no change in the scour volume for the set-up of Adaption Factor for Suspended Load. This is reasonable since the Transport mode was set to the bed load model.

Table 13 also demonstrated the values (column 2) used for the numerical experiments after calibration, where the red fonts are the values adapted from the pilot site. The calibration was based on conditions of the best single deflector scenario (Experiment \#B7 in Table 10) without incoming sediment. Solid deflector (Figure 77) was used in the first-stage of the calibration and the scour volume at 21 -hour of the numerical simulation, after tuning the parameters in Table 13, was about $153 \%$ higher than the result in the physical experiments (Figure 73). Thus, the deflector in the numerical model was modified in two 
different options (Figure 78 and Figure 79), 3-blocks versus 7-blocks, to incorporate the porosity effects in the actual deflector design. The total area of space between the blocks in each option is equivalent to the percentage of porosity in the deflector measured in the physical experiments (Appendix M). The scour volumes in the 3-blocks deflector and 7-blocks deflector scenarios were about $63.8 \%$ and $51.6 \%$ higher than the physical experiment results respectively. Figure 78 to Figure 80 show the bed profiles for the solid deflector, 3-blocks deflector, and 7-blocks deflector calibration results at time $\approx 24$-hr. Since the time frames of the output results are controlled by the program rather than the user, 24-hr is the closest numerical output result to the equilibrium stage (Figure 73) determined by the physical experiments. The reason for the 7-blocks deflector scenario had the closest scour volume result to the physical experiments is probably due to its staggered arrangements among the two rows. The four-blocks in the second row can reduce the flow contraction effects created by the three-blocks in the first row. Moreover, the 7-blocks deflector scenario is the maximum number of blocks that the model can handle without causing any failure. Although the blocks and the spacing would not be truly represented the actual deflector design, it can at least address the porosity of the deflector to a certain degree. 


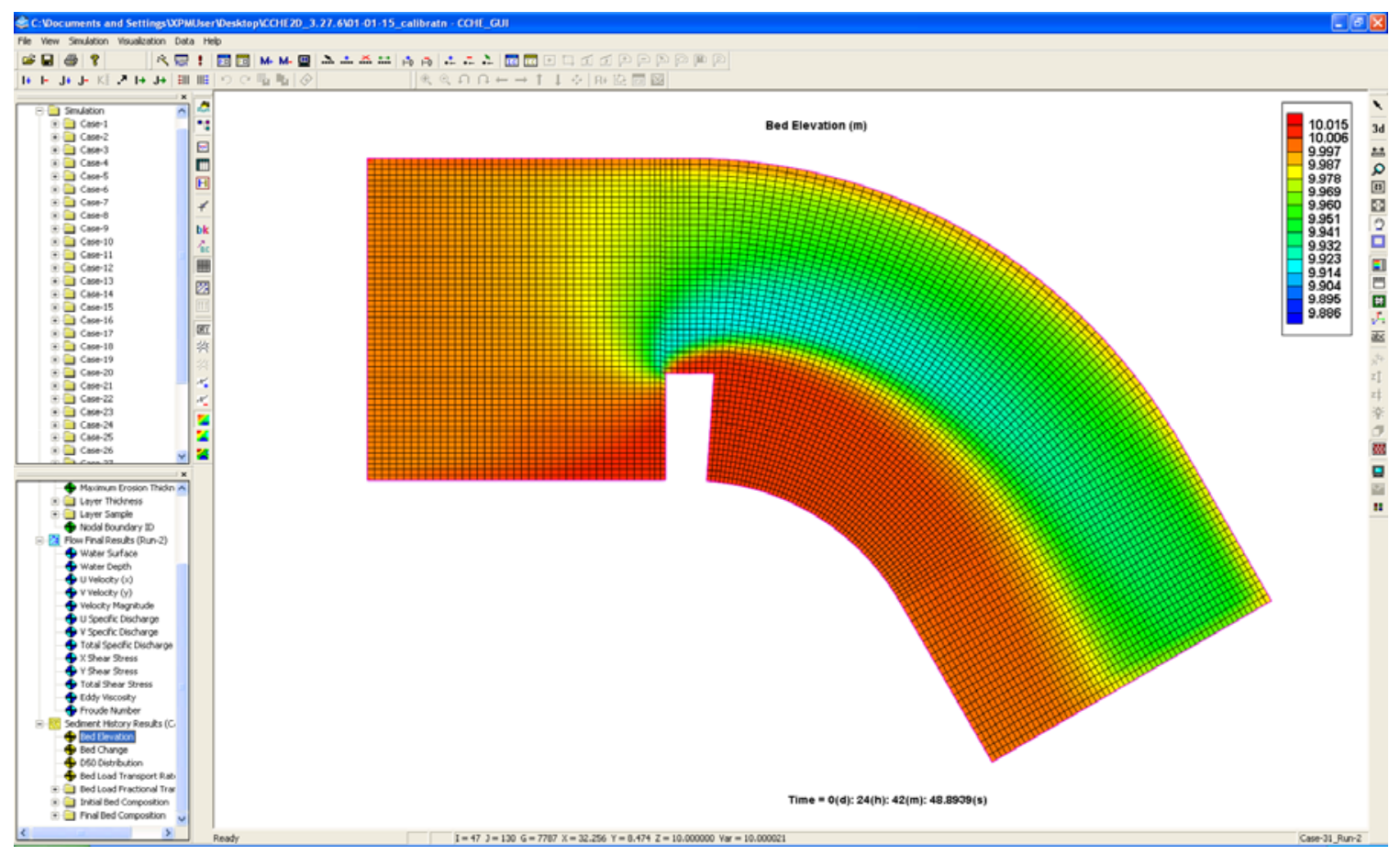

Figure 78: Bed profile for the solid deflector calibration scenario at time $\approx 24$-hr.

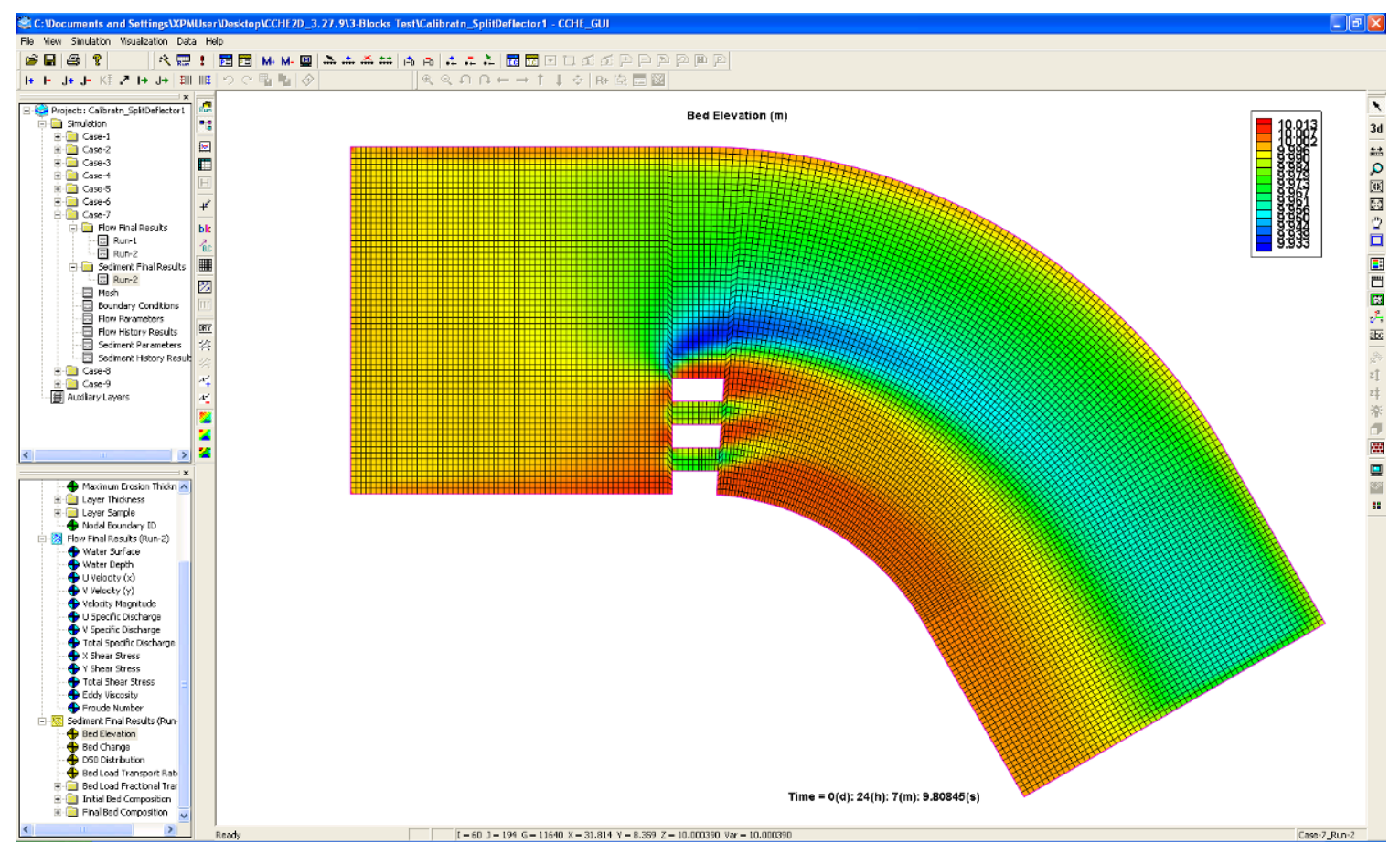

Figure 79: Bed profile for the 3-blocks deflector calibration scenario at time $\approx$ 24-hr. 


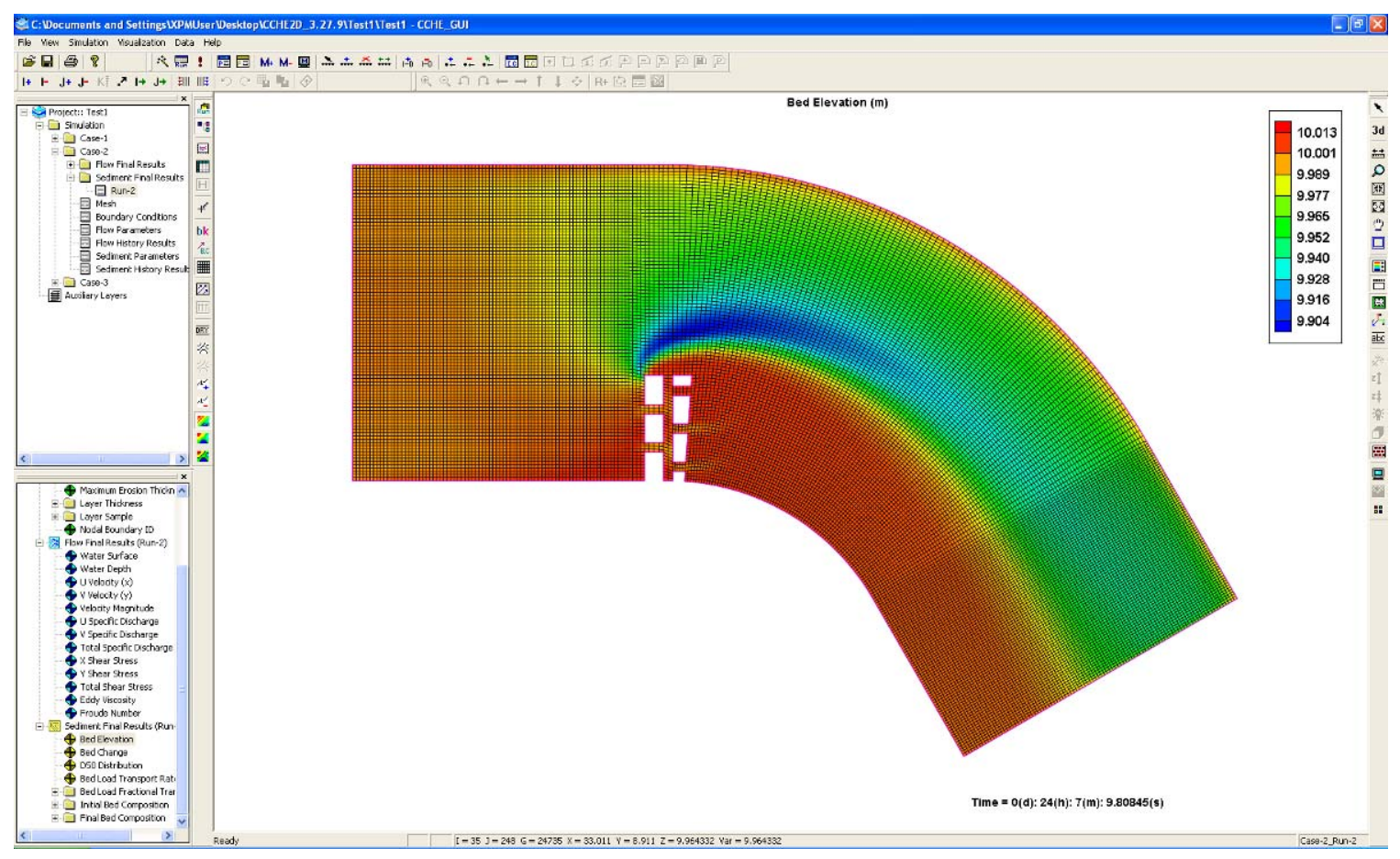

Figure 80: Bed profile for the 7-blocks deflector calibration scenario at time $\approx$ 24-hr.

Figure 81 to Figure 83 present the cumulative scour or deposition depths for the solid deflector, 3-blocks deflector, and 7-blocks deflector calibration results at time about 24-hr. From the bed profiles and scour/deposition depths figures, the numerical model produced similar results for the deposition zone downstream of the deflector along the inner curvature of the meander section to the physical experiment results. The discrepancies for the bed profile located just downstream of the deflector, which was caused by the spacing between the deflector blocks, the 7-block deflector scenario was much smaller than the 3-block deflector scenario. Moreover, the sour hole for all three scenarios started at the upstream corner of the deflector and extended along the centre of the meander section. The maximum scour depths were about $9.17 \mathrm{~cm}, 7.56 \mathrm{~cm}$, and $10.4 \mathrm{~cm}$ for solid 
deflector, 3-blocks deflector, and 7-blocks deflector calibration respectively. The 7-blocks deflector calibration again had the closet maximum scour depth prediction as to the physical experiment results. At last, the numerical model could not predict the deposition zone located downstream of the scour hole along the centre of the meander section as observed in the physical experiments. This contradiction may be a hint for further investigation whether the severe deposition zone in the physical experiment results represent the reality or was actually caused by downstream boundary effects (Section 4.10 ).

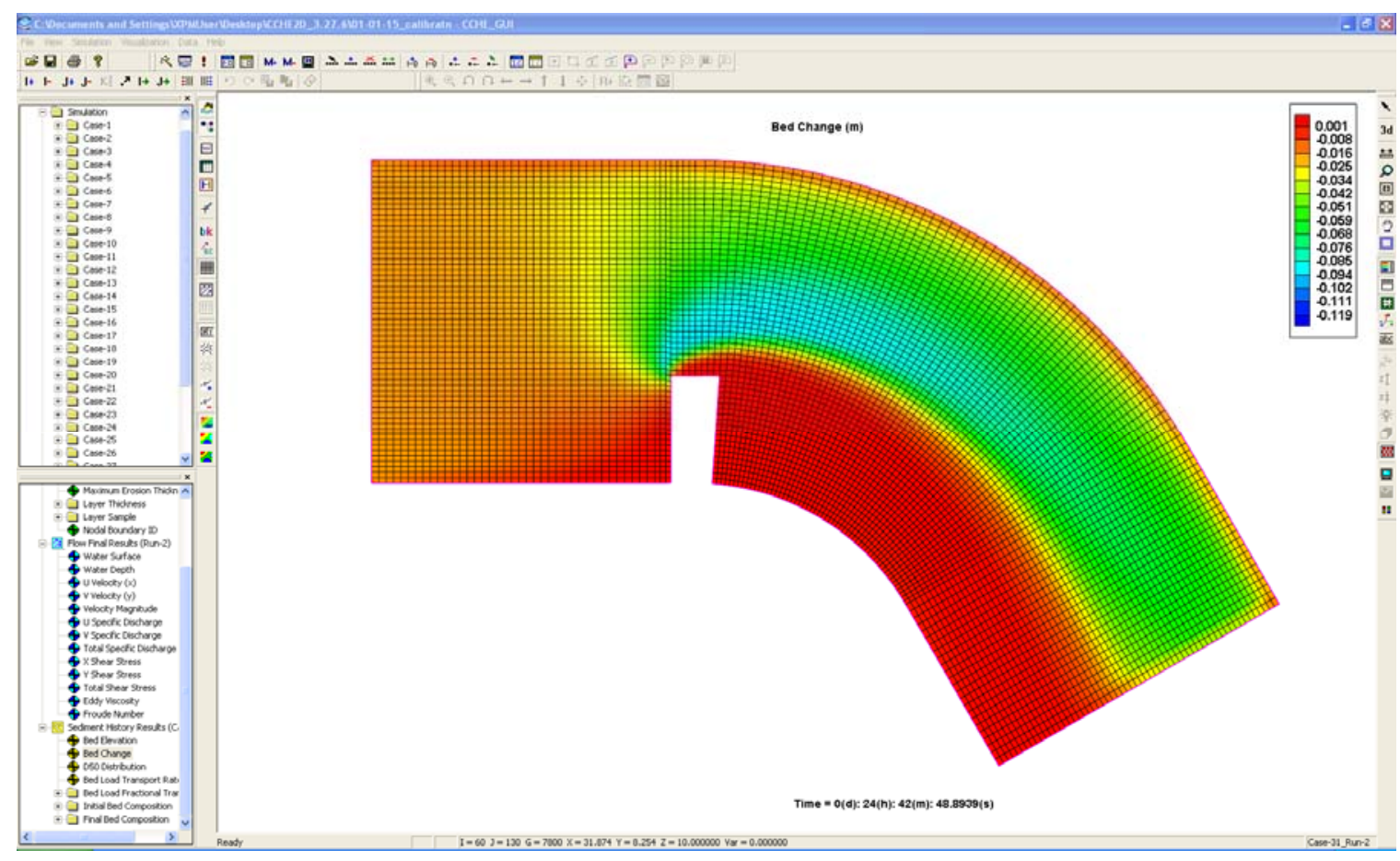

Figure 81: Bed change for the solid deflector calibration scenario at time $\approx 24-\mathrm{hr}$. 


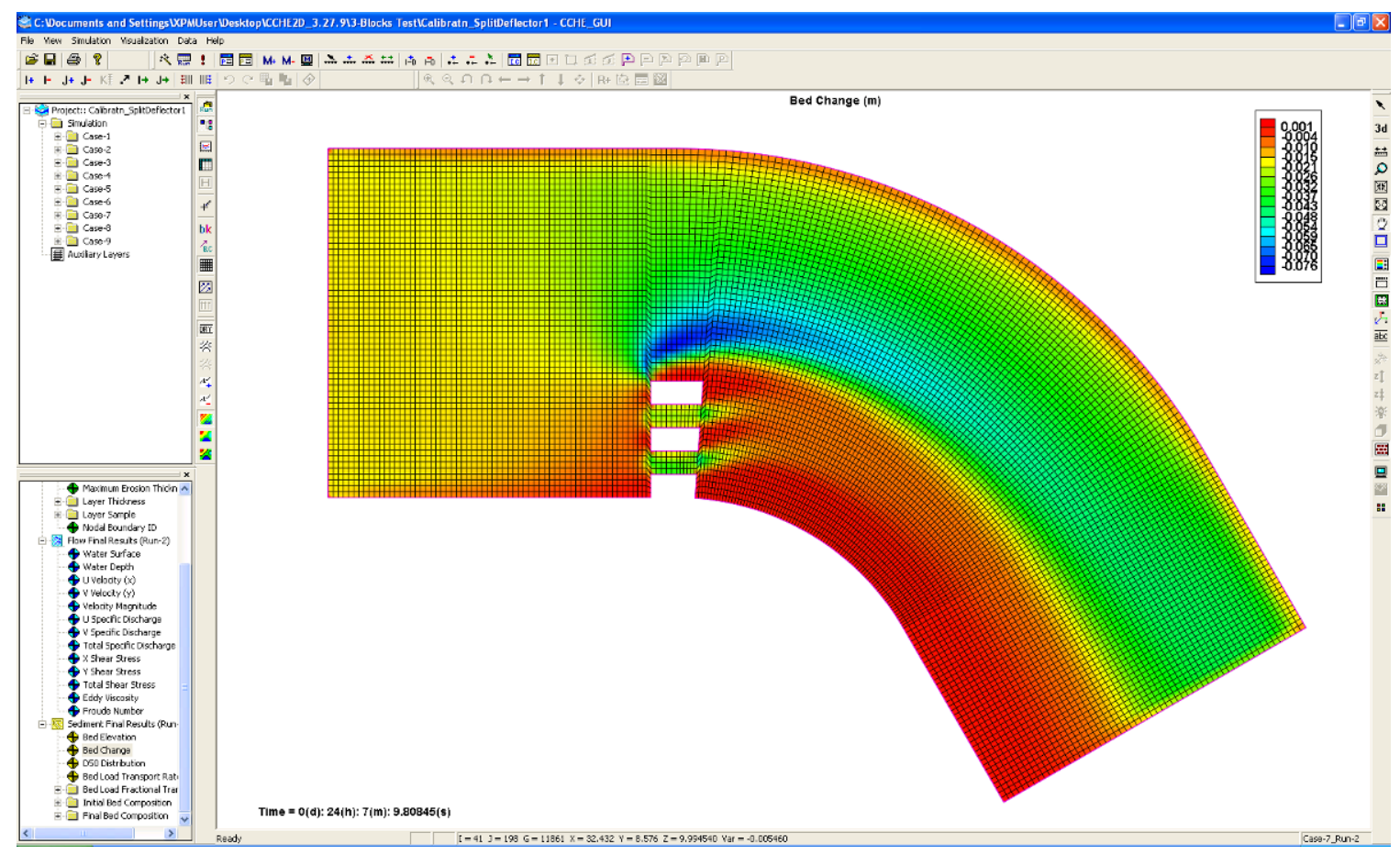

Figure 82: Bed change for the 3-blocks deflector calibration scenario at time $\approx$ 24-hr.

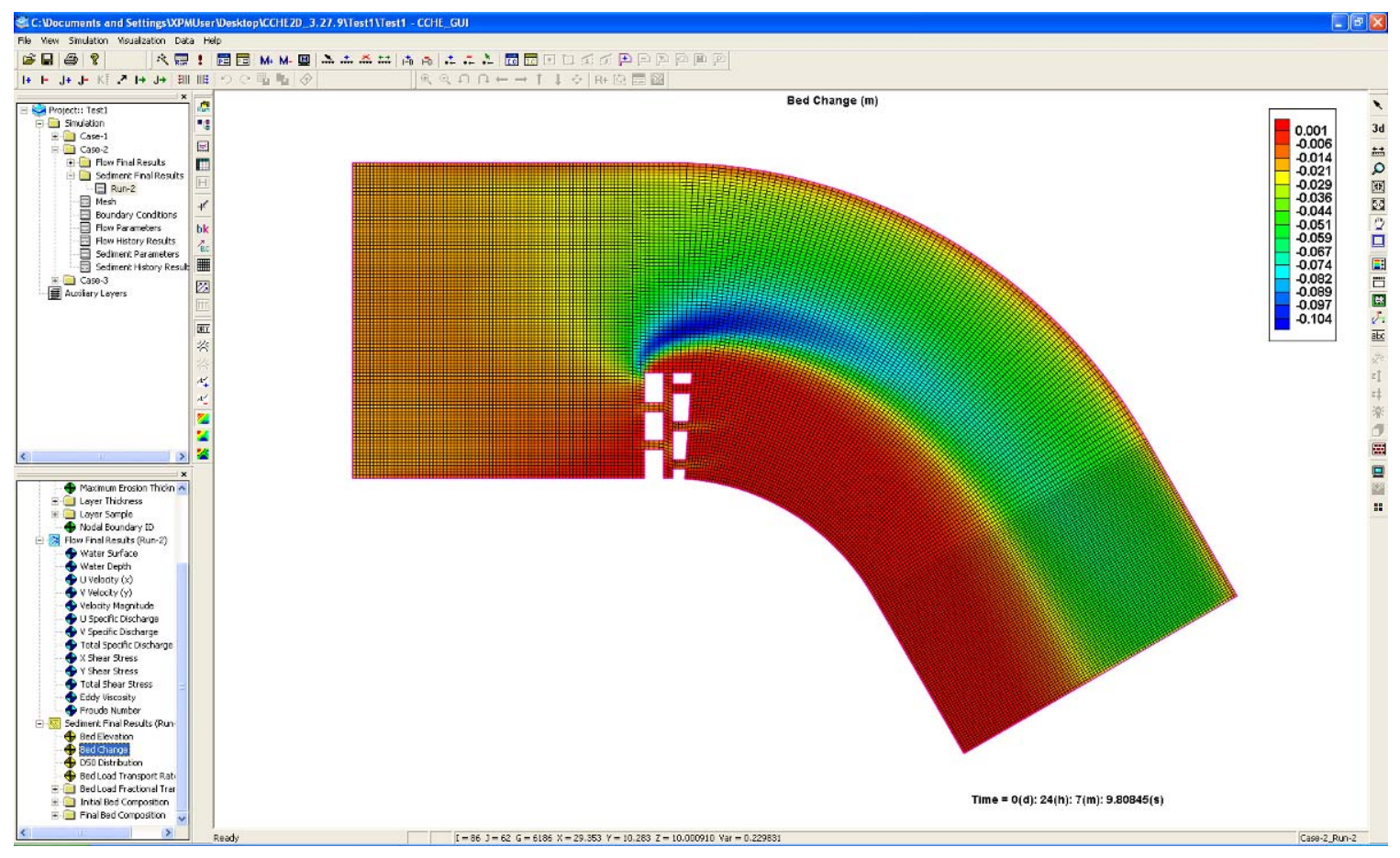

Figure 83: Bed change for the 7-blocks deflector calibration scenario at time $\approx$ 24-hr. 
Figure 84 to Figure 86 demonstrate the velocity magnitudes of solid deflector, 3blocks deflector, and 7-blocks deflector calibration results at time $\approx 24-\mathrm{hr}$. Generally, the numerical velocities at the circulation region, downstream of deflector along the inner curvature of the meander section, for all calibration scenarios were minimum. The 7-blocks deflector calibration had the best prediction at the circulation region disregard the impact caused by the spacing between the blocks in the second row. The highest velocities began at the upstream tip of the deflector and extended along the centre line of the meander section. Both the magnitudes and the locations of the highest velocity zone matched the physical experiment results. Moreover, the numerical model also depicted the transition zone (green areas at the meander section in Figure 84 to Figure 86) between the low velocities' and high velocities' regions.

From the calibration analysis, the 7-blocks deflector scenario generally had the best overall prediction for both bed and velocities. The scour volume predicted using the numerical model was about $44.3 \%$ greater than the measured scour volume in the physical experiments. Moreover, the scour depth prediction using the numerical model was about $9.90 \mathrm{~cm}$ which is close to the maximum scout depth of $9.87 \mathrm{~cm}$ measured in the physical experiments (Table 12). Thus, the 7blocks deflector set-up was applied to the numerical experiments discussed in the next section. 


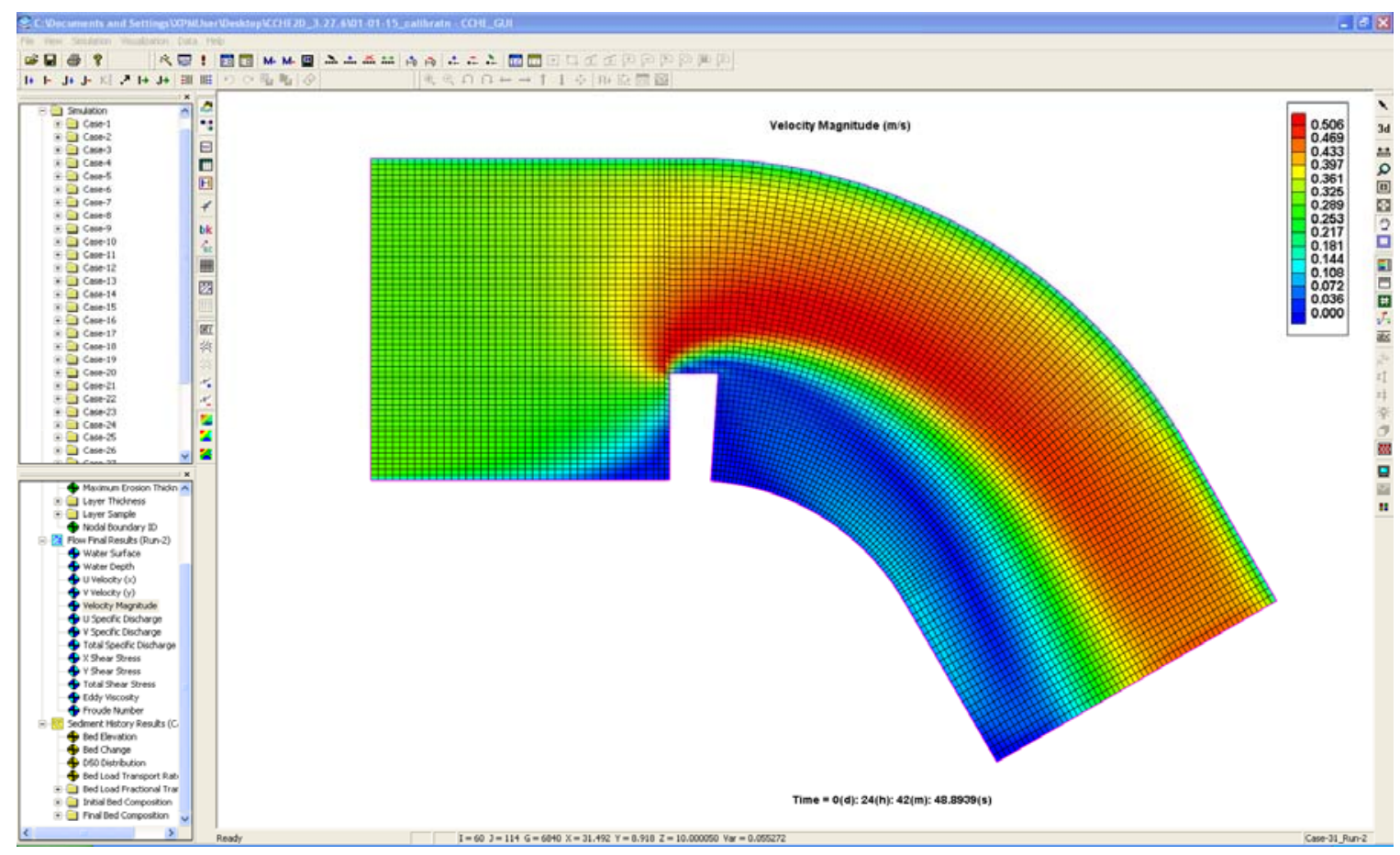

Figure 84: Velocity profile of the solid deflector calibration scenario at time $\approx$ 24-hr.

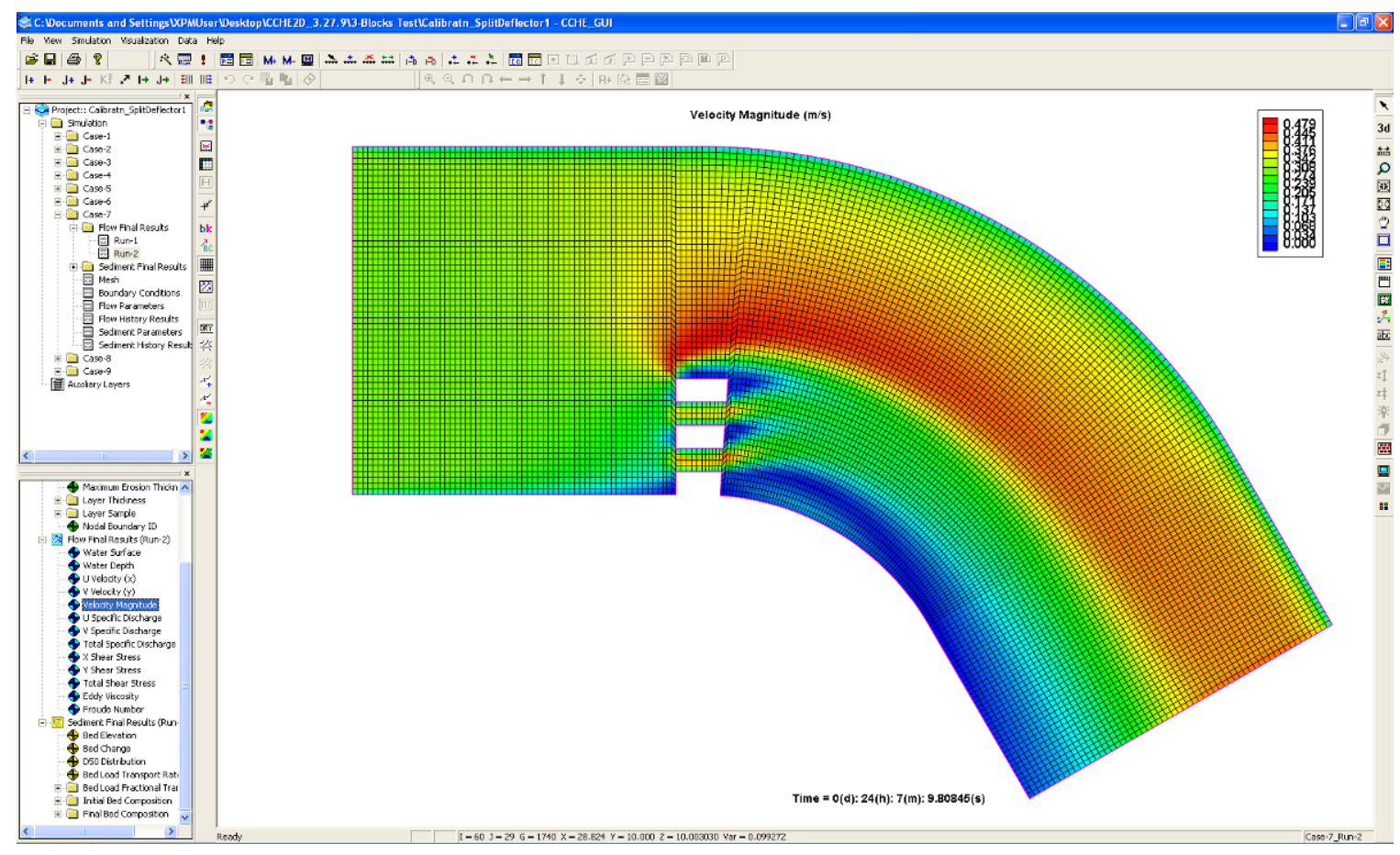

Figure 85: Velocity profile of the 3-blocks deflector calibration scenario at time $\approx$ 24-hr. 


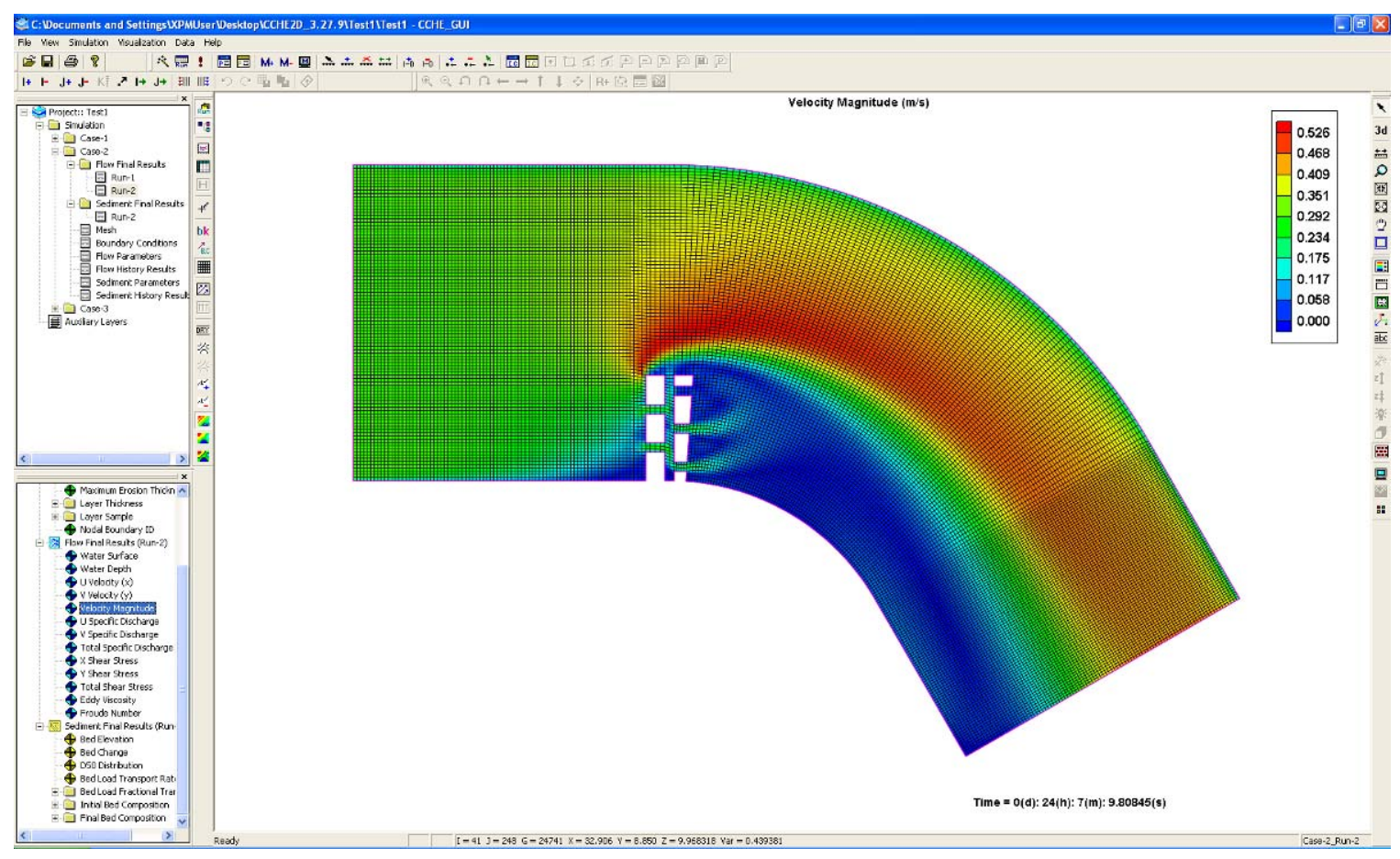

Figure 86: Velocity profile of the 7-blocks deflector calibration scenario at time $\approx$ 24-hr. 


\subsection{NUMERICAL EXPERIMENTS}

This section discusses the design of low-flow channel modification, the set-up and procedures of the numerical experiments, and the results of the numerical experiments in the pilot site.

\subsubsection{Low-Flow Channel Modification Design}

There were couple of preliminary plans (Figure 87 and Figure 88) developed for the low-flow channel modification using the AutoCAD program. The final design, option \#3 (Figure 89), involved six meander sections in which the dimensions of each meander section are the same as in the physical model, whereas option \#1 contains meanders other than the ones in the physical model and the distances between some of the meanders in option \#2 are close to each other. Indeed, the design difficulties in options \#1 and \#2 cannot be eliminated due to the boundary conditions of the flood channel in the pilot site.

In option \#3, the distances between the meander sections from upstream to downstream are $2.02 \mathrm{~m}, 5 \mathrm{~m}, 6.93 \mathrm{~m}, 5 \mathrm{~m}$ and $2.02 \mathrm{~m}$. Most of them, except the two horizontal distances of $5 \mathrm{~m}$, were driven by the boundary restriction of the bottom width of the flood channel. Additionally, a buffer zone of $5 \mathrm{~m}$ was applied to both the upstream and downstream of the channel restoration design to minimize the boundary effects of the numerical model. 


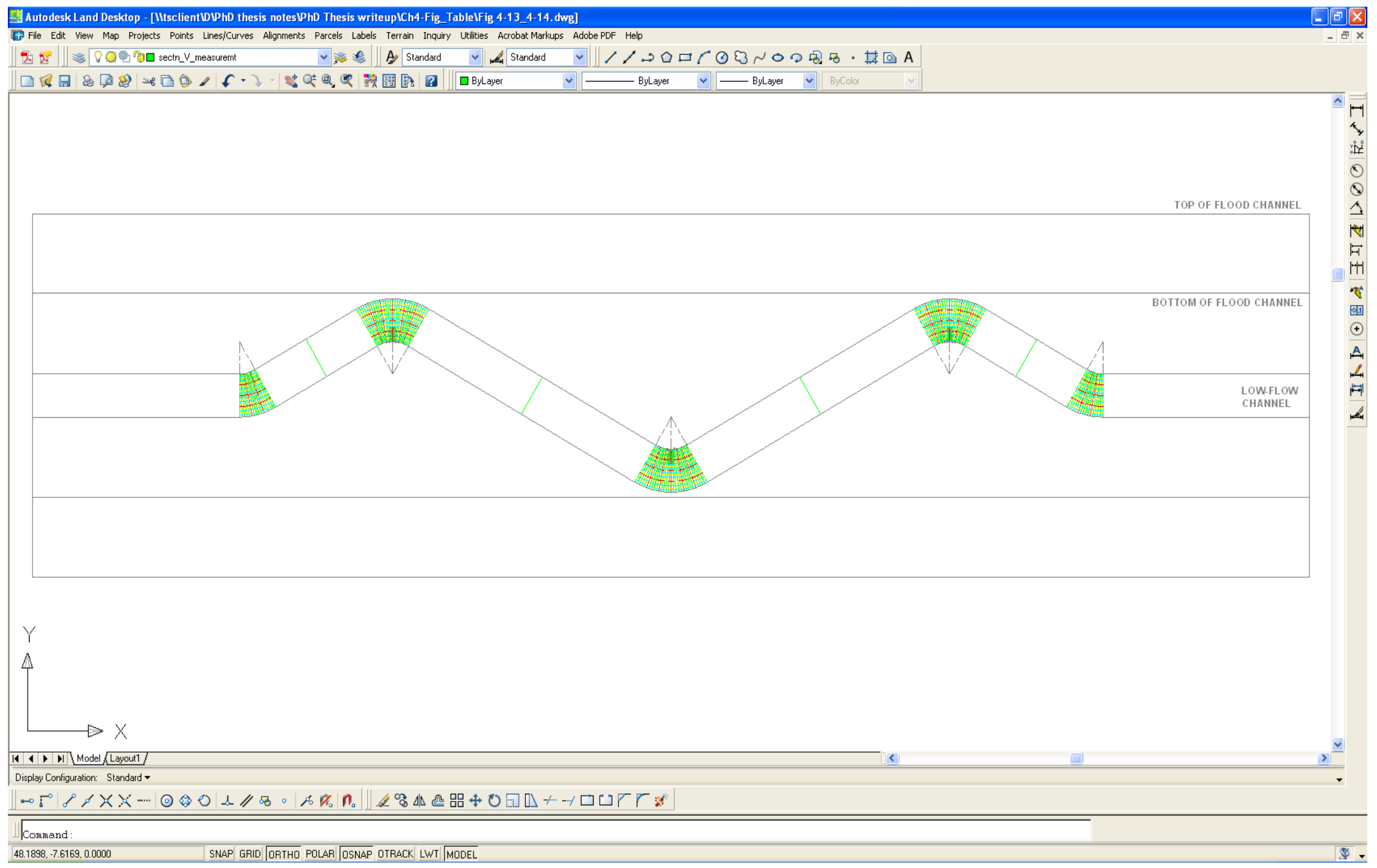

Figure 87: Preliminary design of the low-flow channel modification-option (1). 


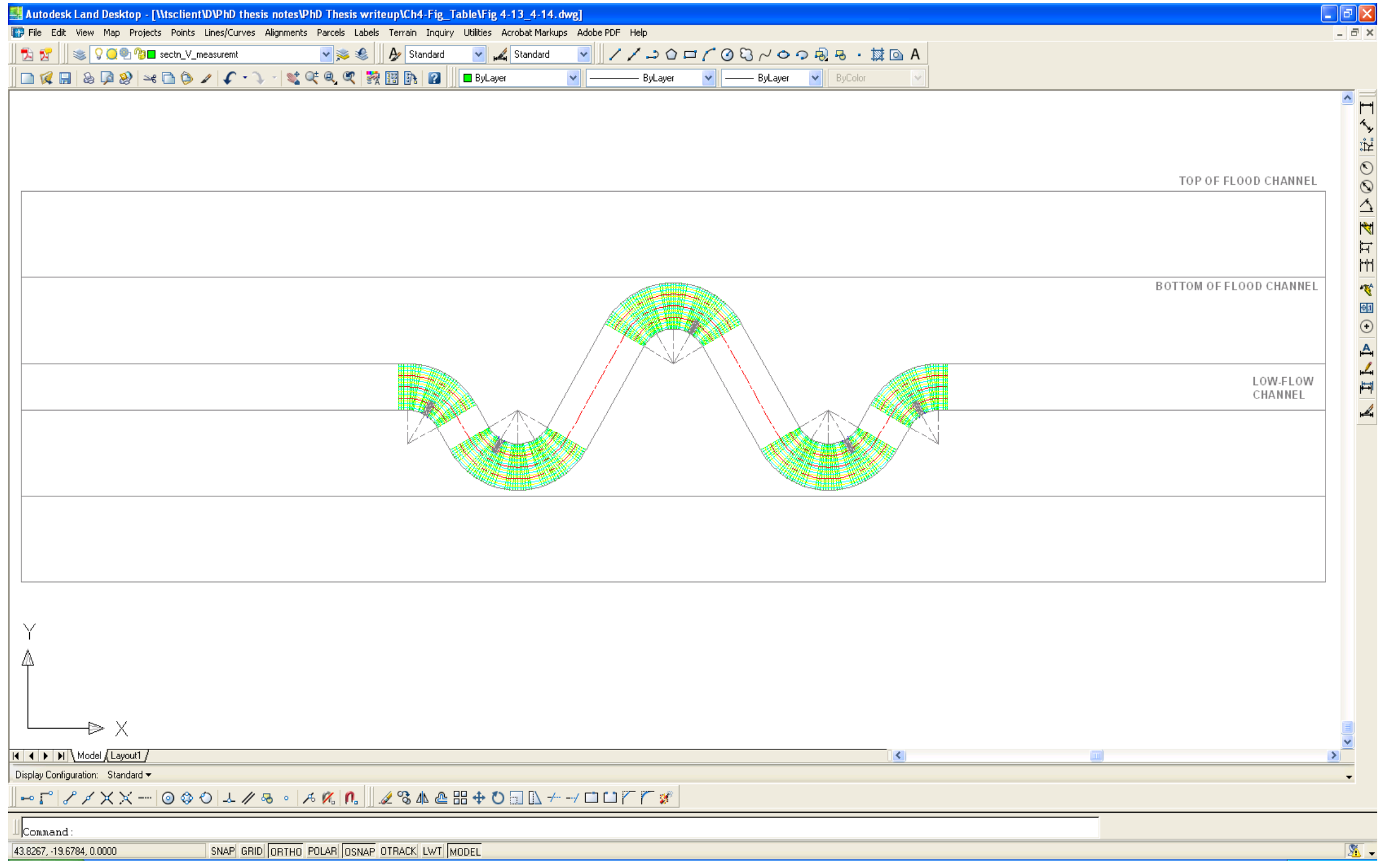

Figure 88: Preliminary design of the low-flow channel modification—option (2). 


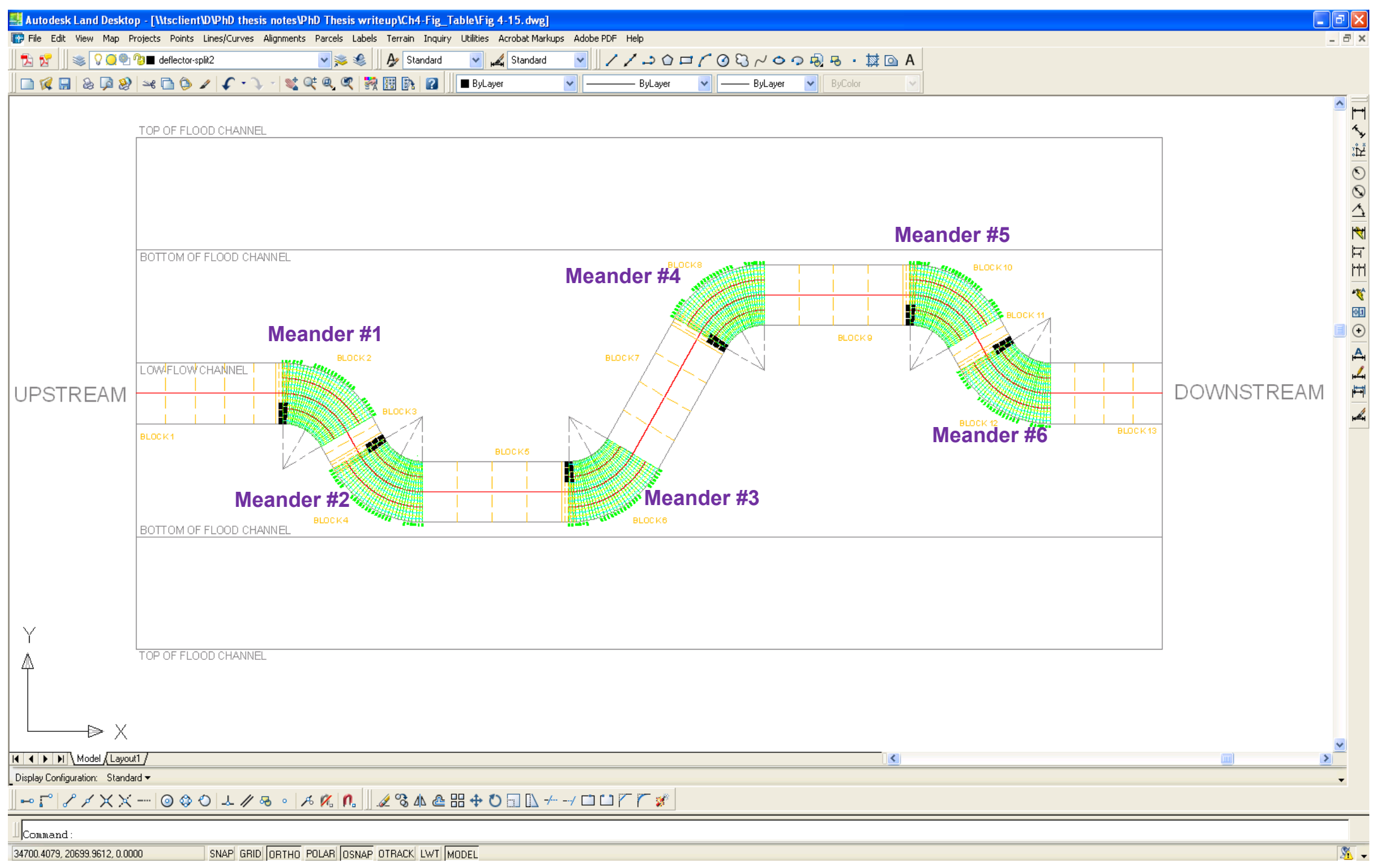

Figure 89: Final design of the low-flow channel modification. 


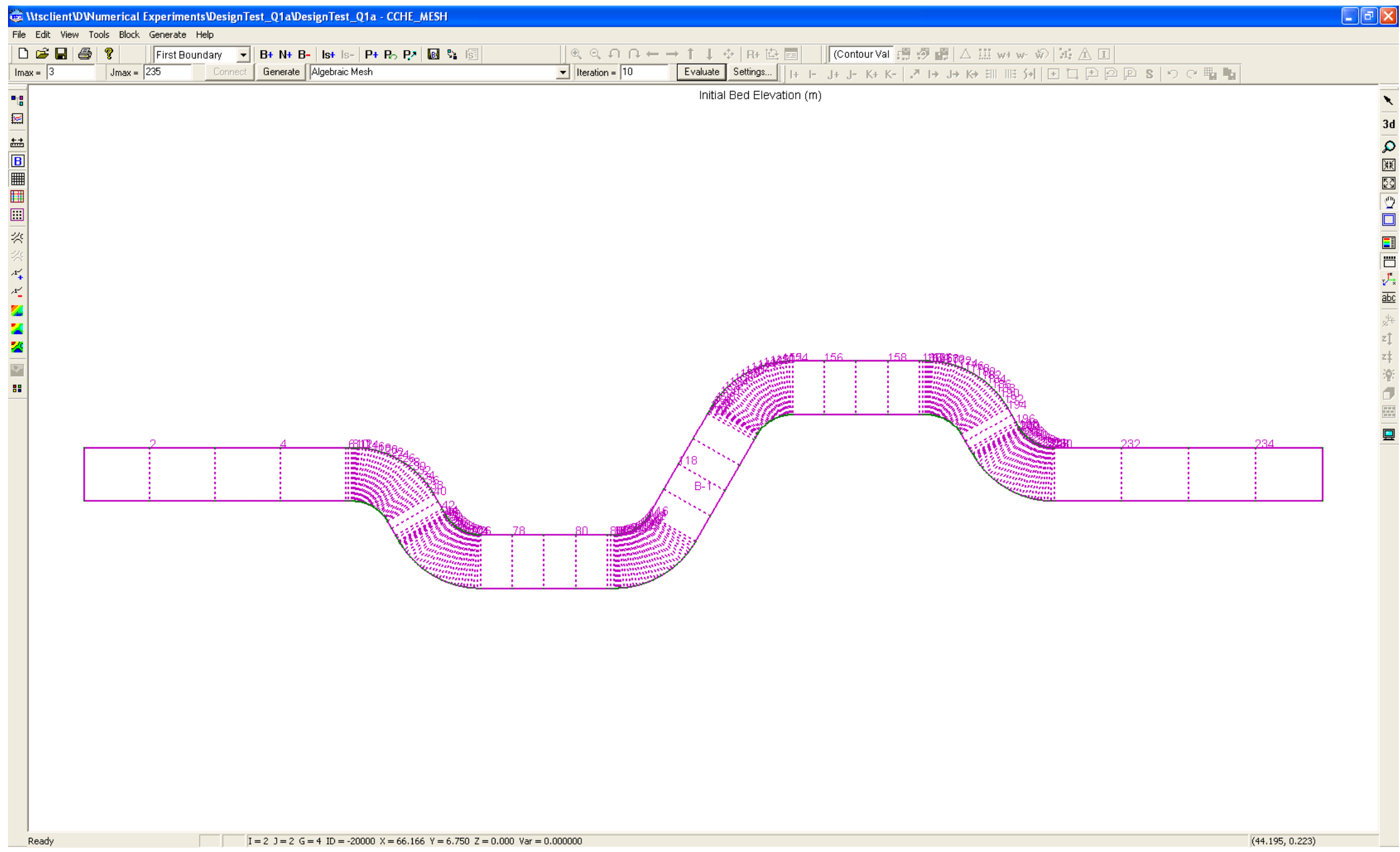

Figure 90: The setup of the elongated block in the CCHE2D program. 


\subsubsection{Numerical Experiments Set Up}

Multiple blocks (orange texts in Figure 89) were first applied to the modified lowflow channel but could not achieve a successful run. After consulting with the technical support of the CCHE2D program, an elongated block with 235 points in each of the "First Boundary" and "Second Boundary" was used to represent the modified low-flow channel (Figure 90). The coordinates of all the points were again determined using the AutoCAD program prior the preparation of the boundary input file. At each meander section, the coordinates were set at 2 degrees increments to match the measuring sections in the physical experiments. A 7-blocks deflector was applied to the upstream inner curvature of every meander section (black blocks in Figure 89). This preliminary idea of one deflector per one meander section could not achieve a successful flow simulation after numerous tuning of the parameters. Hence, two deflectors in meanders \#2 and \#6 were dropped due to shorter distance with the upstream deflectors in meanders \#1 and \#5 and a successful run can be achieved afterward.

There are two sets of experiments involved in the numerical model in order to address the following purposes: 1) to investigate the design of the meander section with multiple deflectors (Figure 89) at all flow conditions; and 2) to further investigate the effects on the bed material and deflector design of the meander section. For the first objective, the numerical experiments were set following the dry weather condition in the site assessments (Appendices $\mathrm{C}$ and $\mathrm{H}$ ) and the conditions listed in Table 13 and Table 14. Both without and with incoming 
sediment scenarios were tested in the numerical experiments following the bed loading rates applied to the physical experiments. For the dry weather condition, Meyer-Peter and Müller's approach was selected due to its low bed loading rates prediction. The rest of the experiments followed Schoklitch's approach. These two bed load rates prediction approaches again should be close to the sediment loading characteristics of the pilot site according to the information provided by HK DSD staffs.

For the second objective, five additional experiments listed below were conducted at bankfull stage of the low-flow channel, with deflectors located in meanders \#1, \#3, \#4, and \#5 (Figure 90). The first three experiments were to investigate the three parameters (porosity, length, width) for the deflector design and to provide some preliminary design range if a different bed material, other than the existing bed from the natural area, is selected.

- Solid deflector with same dimensions as before (i.e. $666.7 \mathrm{~mm} \times 300 \mathrm{~mm}$ )

- 7-block deflector blocks with contraction ratio $=0.50$ instead of 0.3 . Thus, the new dimension of the deflector is $1000 \mathrm{~mm} \times 300 \mathrm{~mm}$.

- 7-block deflector blocks with total width of the deflector $=600 \mathrm{~mm}$ instead of $300 \mathrm{~mm}$. Thus, the new dimension is $667 \mathrm{~mm} \times 600 \mathrm{~mm}$.

- Doubling the $D_{50}$ of bed material size. Thus, the new $D_{50}$ is $5.62 \times 10^{-4} \mathrm{~m}$.

- Decrease the bed material size by $50 \%$. Thus, the new $D_{50}$ is $1.41 \times 10^{-4} \mathrm{~m}$. 


\subsection{RESULTS AND ANALYSIS OF THE NUMERICAL EXPERIMENTS}

The final bed elevation, total bed change, and the final velocity magnitude and direction results of the numerical experiments are shown in Appendices $T$ and $U$. The dry weather and $1 / 2$ water depth of LFC conditions were the only experiments that had conducted a 5-hour flow simulation run due to their larger flow simulation time steps parameter (i.e. 0.1) and smaller sediment time steps to adjust flow parameter (i.e. 100 for dry weather condition and 200 for $1 / 2$ water depth of LFC condition) to cause successful runs. The rest of the experiments were all conducted for an hour because of its long requiring time to run a simulation (i.e. around 4 to 5 days for a flow simulation and around a week for a sediment simulation). Indeed, large flow rates required enormous simulation time. The long simulation running time was again due to the smaller flow simulation time steps parameter (i.e. 0.05), the larger sediment time steps to adjust flow parameter (i.e. 500 for dry weather condition), and the finer mesh required around the deflector region (i.e. $1 \mathrm{~cm} \times 1 \mathrm{~cm}$ ) in order to achieve a successful run. Moreover, trial-and-error method was applied to determine the required parameter values and mesh system for each successful run.

Table 15 to Table 17 demonstrate the final scour areas, scour volumes, and maximum scour depths at each meander of the modified low-flow channel for different scenarios. The red bolded fonts are the maximum value of each column and the cyan bolded fonts represent the minimum value of each column. There 
were no scour holes formation in meanders \#2 and \#6 due to the lack of the deflector. For the dry weather condition, the scour volumes for the no incoming sediment scenario ranged between 0.0446 and $0.0494 \mathrm{~m}^{3}$ and for the incoming sediment scenario ranged between 0.0431 and $0.0475 \mathrm{~m}^{3}$. The scour areas for the no incoming sediment scenario ranged between 1.67 and $1.82 \mathrm{~m}^{2}$ and for the incoming sediment scenario ranged between 1.31 and $1.41 \mathrm{~m}^{2}$. Generally, the ranges of scour volumes and scour areas in each scenario were small. The slightly decrease in the scour volumes and scour areas for the incoming sediment scenario indicate that some of the small incoming bed load actually filled up part of the scour hole. For the scour volumes, meander \#4 had the largest value for both without and with incoming sediment scenarios. The scour volumes in meanders \#1 and \#5 were similar to each other and the scour volumes in meander \#3 were the smallest for both scenarios. For the scour areas, meander \#3 again had the smallest value for both without and with incoming sediment scenarios. Both meanders \#4 and \#5 for the no incoming sediment scenario had the largest scour areas, whereas only meander \#5 for the incoming sediment scenario had the largest scour area. All maximum scour depths occurred near the upstream tip of the deflector, which was the same as the physical experiments' results. The ranges of maximum scour depths for both scenarios were also small. For the no incoming sediment scenario, the maximum scour depth occurred in meander \#3 where both the scour area and scour volume were minimum. The maximum scour depth for the incoming sediment scenario happened in meander \#1. Hence, the maximum scour depths were not 
occurred in the same meanders as the maximum scour areas and maximum scour volumes for both scenarios.

For the no incoming sediment scenario, the maximum scour areas and scour volumes for the rest of the experiments within the modified low-flow channel all occurred in meander \#1, whereas the minimum scour areas and scour volumes happened in either meanders \#4 or \#5. This concluded that the most upstream deflector in meander \#1 had the major impact in pool creation during wet weather conditions. Secondly, the ranges of the scour areas and scour volumes for the three experiments were huge. This contradicted the previous discussion for the dry weather condition. For $1 / 2$ water depth of the LFC condition, the difference between the maximum scour area and the second maximum scour area was almost 3.5 times and the difference between the largest scour volume and the second highest was over 2 times. Even the smallest scour area in meander \#4 was still $0.244 \mathrm{~m}^{2}$, its scour volume was very shallow. Moreover, the maximum scour depth occurred in meander \#3, which had the second highest scour area and scour volume, and it was as deep as $0.316 \mathrm{~m}$. This deep scour depth may be caused by the longer simulation time (i.e. 5-hour) compared to the other two wet weather experiments. For $3 / 4$ water depth of LFC condition, the gaps between the largest scour area and the second highest was almost 4 times and between the two largest scour volumes was over 5 times. This was severe than the ones in the 1/2 water depth of LFC condition. Additionally, the scour hole formation in meander \#4 was almost unobservable and the scour volumes other 
than the largest one were very small. The maximum scour depth was $15.5 \mathrm{~cm}$ and occurred in meander \#5. The second maximum scour depth was $13.2 \mathrm{~cm}$ and occurred in meander \#1, where the maximum scour volume and scour area were located.

For the $5 \mathrm{~cm}$ below bankfull of LFC condition in the no incoming sediment scenario, the maximum scour area happened in meander \#1 and was the largest $\left(3.781 \mathrm{~m}^{2}\right)$ among the three wet weather results. Although the simulation time for this condition was only an hour, its maximum scour volume was close to the $1 / 2$ water depth of LFC condition. Compare to the scour depths of the two conditions in meander \#1, the $5 \mathrm{~cm}$ below bankfull of the LFC condition is around three times smaller than the $1 / 2$ water depth of the LFC condition. The scour areas for the rest of the meanders in the $5 \mathrm{~cm}$ below bankfull of the LFC condition were also the largest among all three wet weather results. Thus, the flow discharge has the major impact on the scour area formation. The maximum scour depth was again not correlated to maximum scour area nor maximum scour volume. It occurred in meander \#5 where the scour area was the smallest and the scour volume was minimum even though the difference between the maximum scour depth and the second maximum scour depth, which happened in meander \#1, was small.

For the incoming sediment scenario in wet weather situation, only the $5 \mathrm{~cm}$ below bankfull of the LFC condition was conducted due to the long simulation time. 
Moreover, only $3 \mathrm{~kg}$ for every 5 minutes of incoming sediment can be added to the model. The rate was about six times smaller than Schoklitch's approach (Appendix $\mathrm{N}$ ) adopted in the physical experiment. The model failed once the incoming sediment exceeds this amount. The maximum scour area and scour volume both occurred in meander \#4. Compare to the without incoming sediment scenario, the maximum scour area in the incoming sediment scenario was slightly smaller than the no incoming sediment scenario. Additionally, the maximum scour volume was about three times smaller than the no incoming sediment scenario. This showed that some of the incoming sediment was actually filled in the scour holes. Although scour hole in meander \#4 had the largest scour area and scour volume, it was the shallowest and its scour depth was just $3.66 \mathrm{~cm}$. The maximum scour depth occurred in meander \#5 and its value was $11.1 \mathrm{~cm}$.

For bed material and deflector design investigation, the scour area, scour volume, and scour depth of the solid deflector scenario (Table 17) were generally much higher than the deflector blocks situation (Table 15). The maximum scour volume of the solid deflector scenario was about 2.5 times greater than the deflector blocks scenario. Additionally, both the maximum scour area and scour volume for the solid deflector scenario occurred in meander \#1 and the maximum scour depth occurred in meander \#4 (Table 17), where the locations were all the same as the deflector blocks scenario (Table 15). The minimum scour area, scour volume, and scour depth for the solid deflector scenario all happened in meander 
\#4 (Table 17). The locations of the minimum scour holes for the two cases were towards the end of the modified low-flow channel. Both minimum scour holes had large surface areas but small scour volumes.

When doubling the sediment size (i.e. $D_{50}$ ) for the $5 \mathrm{~cm}$ below bankfull of LFC condition (Table 17), the scour area, scour volume and scour depth were also greater than the original condition (Table 15). Thus, further investigation should be conducted (Appendix $\mathrm{V}$ ) using the abutment method discussed in Section 2.6.4 and the velocity results from the numerical model. From the Maryland SHA abutment scour method, the maximum scour depth of the doubled $D_{50}$ condition was smaller than the original condition. The contradiction between the numerical results and hand calculation may be due to the short simulation time. Thus, a longer simulation scenario (Section 7.2) should be conducted in a future study to further investigate this issue. Two other scenarios of bed material, $1 / 2$ of $D_{50}$ (i.e. $0.1405 \mathrm{~mm}$ ) and $3 / 4$ of $D_{50}$ (i.e. $0.2108 \mathrm{~mm}$ ), were also tested but could not achieve a successful run. Since the rest of the parameters were based on the pilot site conditions, this indicates that the pilot site is more capable for coarse material which matched to what had been observed during site assessment (Section 3.4.2). Furthermore, the rest of the deflector design investigation is postponed to tfuture study due to a recent update of the program. Since some edits must be done to the input file in order to fit the constraints in the new version, the other two deflector design scenarios also need to be investigated in a future study. 
The deposition zones of all the numerical experiments were the same as what had been observed in the physical experiment results. There was an elongated deposition zone located downstream of the deflector and a couple of deposition zones or islands was started forming at the downstream of the scour hole. The locations of the islands were much further apart to the scour hole than the physical experiment results. This was a good sense for channel restoration since the islands can create a variety of velocities which favourited fish. 
Table 15: Numerical results for no incoming sediment scenario.

\begin{tabular}{|c|c|c|c|c|c|c|c|c|c|c|c|c|}
\hline & \multicolumn{3}{|c|}{ Dry Weather Condition } & \multicolumn{3}{|c|}{$1 / 2$ water depth of LFC } & \multicolumn{3}{|c|}{$3 / 4$ water depth of LFC } & \multicolumn{3}{|c|}{$5 \mathrm{~cm}$ Below Bankfull of LFC } \\
\hline & $\begin{array}{l}\text { Scour } \\
\text { Area, } \\
\text { in } \mathrm{m}^{2}\end{array}$ & $\begin{array}{c}\text { Scour } \\
\text { Volume, } \\
\text { in } \mathrm{m}^{3}\end{array}$ & $\begin{array}{c}\text { Maximum } \\
\text { Scour } \\
\text { Depth, } \\
\text { in } \mathrm{m}\end{array}$ & $\begin{array}{l}\text { Scour } \\
\text { Area, } \\
\text { in } \mathrm{m}^{2}\end{array}$ & $\begin{array}{c}\text { Scour } \\
\text { Volume, } \\
\text { in } \mathrm{m}^{3}\end{array}$ & $\begin{array}{c}\text { Maximum } \\
\text { Scour } \\
\text { Depth, } \\
\text { in } m\end{array}$ & $\begin{array}{l}\text { Scour } \\
\text { Area, } \\
\text { in } \mathbf{m}^{2}\end{array}$ & $\begin{array}{l}\text { Scour } \\
\text { Volume, } \\
\text { in } \mathrm{m}^{3}\end{array}$ & $\begin{array}{l}\text { Maximum } \\
\text { Scour } \\
\text { Depth, } \\
\text { in } m\end{array}$ & $\begin{array}{l}\text { Scour } \\
\text { Area, } \\
\text { in } \mathrm{m}^{2}\end{array}$ & $\begin{array}{l}\text { Scour } \\
\text { Volume, } \\
\text { in } \mathrm{m}^{3}\end{array}$ & $\begin{array}{l}\text { Maximum } \\
\text { Scour } \\
\text { Depth, } \\
\text { in } m\end{array}$ \\
\hline Meander \#1 & 1.779 & 0.04643 & 0.1890 & 2.541 & 0.1095 & 0.2923 & 1.159 & 0.04578 & 0.1317 & 3.781 & 0.09344 & 0.1086 \\
\hline Meander \#3 & 1.674 & 0.04458 & 0.1929 & 0.6770 & 0.04659 & 0.3159 & 0.2660 & 0.008151 & 0.09158 & 1.387 & 0.03009 & 0.05905 \\
\hline Meander \#4 & 1.822 & 0.04937 & 0.1873 & 0.2442 & 0.003201 & 0.1374 & 0.04796 & 0.0008223 & 0.05192 & 3.197 & 0.04699 & 0.07229 \\
\hline Meander \#5 & 1.823 & 0.04678 & 0.1782 & 0.3171 & 0.01748 & 0.2573 & 0.2085 & 0.009403 & 0.1546 & 1.079 & 0.02789 & 0.1100 \\
\hline
\end{tabular}

Table 16: Numerical results for incoming sediment scenario.

\begin{tabular}{|c|c|c|c|c|c|c|}
\hline & \multicolumn{3}{|c|}{ Dry Weather Condition } & \multicolumn{3}{|c|}{$5 \mathrm{~cm}$ Below Bankfull of LFC } \\
\hline & $\begin{array}{l}\text { Scour } \\
\text { Area, } \\
\text { in } \mathrm{m}^{2}\end{array}$ & $\begin{array}{c}\text { Scour } \\
\text { Volume, } \\
\text { in } \mathrm{m}^{3}\end{array}$ & \begin{tabular}{|} 
Maximum \\
Scour Depth, \\
in $\mathrm{m}$
\end{tabular} & $\begin{array}{l}\text { Scour } \\
\text { Area, } \\
\text { in } \mathrm{m}^{2}\end{array}$ & $\begin{array}{l}\text { Scour } \\
\text { Volume, } \\
{\text { in } \mathrm{m}^{3}}^{3}\end{array}$ & \begin{tabular}{|} 
Maximum \\
Scour Depth, \\
in $\mathrm{m}$
\end{tabular} \\
\hline Meander \#1 & 1.313 & 0.04390 & 0.1999 & 1.280 & 0.02800 & 0.08093 \\
\hline Meander \#3 & 1.307 & 0.04309 & 0.1973 & 0.4719 & 0.007276 & 0.04440 \\
\hline Meander \#4 & 1.368 & 0.04750 & 0.1969 & 3.315 & 0.03344 & 0.03656 \\
\hline Meander \#5 & 1.414 & 0.04376 & 0.1792 & 0.6603 & 0.01785 & 0.1111 \\
\hline
\end{tabular}


Table 17: Numerical results for deflector and bed material design scenario at 5 $\mathrm{cm}$ below bankfull of LFC condition.

\begin{tabular}{|c|c|c|c|c|c|c|}
\hline & \multicolumn{3}{|c|}{ Solid Deflector } & \multicolumn{3}{|c|}{ Doubling $D_{50}$} \\
\hline & $\begin{array}{l}\text { Scour } \\
\text { Area, } \\
\text { in } \mathrm{m}^{2} \\
\end{array}$ & $\begin{array}{c}\text { Scour } \\
\text { Volume, } \\
\text { in } \mathrm{m}^{3}\end{array}$ & $\begin{array}{c}\text { Maximum } \\
\text { Scour Depth, } \\
\text { in } \mathbf{m}\end{array}$ & $\begin{array}{l}\text { Scour } \\
\text { Area, } \\
\text { in } \mathrm{m}^{2} \\
\end{array}$ & $\begin{array}{c}\text { Scour } \\
\text { Volume, } \\
\text { in } \mathrm{m}^{3}\end{array}$ & $\begin{array}{c}\text { Maximum } \\
\begin{array}{c}\text { Scour Depth, } \\
\text { in } \mathrm{m}\end{array} \\
\end{array}$ \\
\hline Meander \#1 & 4.602 & 0.2304 & 0.2576 & 2.595 & 0.1028 & 0.2949 \\
\hline Meander \#3 & 0.8952 & 0.03148 & 0.2408 & 2.139 & 0.08680 & 0.2826 \\
\hline Meander \#4 & 0.1878 & 0.006022 & 0.1939 & 1.299 & 0.08518 & 0.2897 \\
\hline Meander \#5 & 0.2968 & 0.01762 & 0.3139 & 1.007 & 0.07651 & 0.3319 \\
\hline
\end{tabular}

Regarding the velocity profiles, recirculation zones had been observed at the downstream of every deflector where velocities were minimum. These regions may be capable of acting as resting areas or shelters during rain storms for fish. In dry weather conditions, the velocities at the upstream of meander \#1 were about $0.2 \mathrm{~m} / \mathrm{s}$. Velocities were about 0.22 to $0.24 \mathrm{~m} / \mathrm{s}$ along the straight sections between meanders. At meanders \#2 and \#6 with no deflector, velocities near the inner curvatures reached $0.29 \mathrm{~m} / \mathrm{s}$. These velocity ranges are slightly smaller than the measured velocity where Malaysian snails were found during site assessment (Appendix C). They are suitable for wild tilapia of about 4.5 to $6 \mathrm{~cm}$ body length (McKenzie et al., 2003). In $5 \mathrm{~cm}$ below bankfull of the LFC condition, velocities along the straight sections between meanders were increased to about $0.45 \mathrm{~m} / \mathrm{s}$. Velocities were up to $0.72 \mathrm{~m} / \mathrm{s}$ near the inner curvatures of meanders \#2 and \#6. Moreover, the recirculation zones were extended further downstream when flow increased. 


\subsection{DISCUSSION ON THE NUMERICAL EXPERIMENTS}

There are some uncertainties or potential bugs in the numerical program that had been observed by the author during the numerical experiments. The objective of this section is to list out the uncertainties that had been observed by the author in order to facilitate other researchers and engineers if they would like to choose the CCHE2D program for their future studies or consulting projects.

The numerical model in this research involved 28 islands, or deflector blocks, and 235 points at each boundary of the low-flow channel block. The workspace in the CCHE-MESH program was not very stable during the creation of the massive boundary points, especially when the boundary points were closed to the deflector blocks. For instance, this research first applied the "scatter points" input file (i.e. *.mesh_xyz) where the coordinates of the boundary points were already determined using the AutoCAD program. The block boundary was never able to create perfectly following the methodology described in section 4.3 .6 of the CCHE-MESH User's Manual (Zhang and Jia, 2009). Although the boundary was shown perfectly in the workspace, the coordinates saved in the block boundary file was differ from what had been seen in the workspace. In order to solve this problem, the author opened the incorrect block boundary file using the Notepad program, studied the format of the file, and manually input the correct coordinates to the block boundary file. The modified block boundary file was loaded to the CCHE-MESH program for mesh creation. This method is not 
mentioned in CCHE-MESH User's Manual (Zhang and Jia, 2009) but is very useful to address the instability problem in the workspace.

The CCHE-MESH User's Manual or Quick Start Guide (Zhang and Jia, 2009) is also missing other important procedures related to island and mesh creation. For example, the nodes inside the islands cannot automatically switch to boundary nodes after island creation. The model cannot run if these nodes remain as "internal". Moreover, the model does not contain error message that especially indicate that the failure was due to the improper set up of the nodes. Thus, either section 3.5 of the Quick Start Guide or section 4.3.6 of the User's Manual should include extra steps after island creation about how to switch the nodes inside the islands manually to "boundary" type. Secondly, there are couple of locations for smoothness functions (i.e. the "smooth selected field" button, in the "mesh generation" toolbar, under the "Generate" menu) but the one that can only work in the numerical model was under the "Generate" menu. These confusions and potential instability of the program created many problems in the model set up and successful run simulation during the numerical experiments.

There are other potential bugs or uncertainties occurred particularly in the latest version (i.e. CCHE-MESH version 3.22.6 and CCHE-GUI version 3.28.4) of the CCHE-MESH or the CCHE-GUI programs. For instance, the program automatically assigned different values on certain nodes in the "layer sample" properties near the deflector region (Appendix $\mathrm{T}$ ), which links to failure run 
especially for the deflector blocks with large flow rate scenarios. This mysterious behaviour of the program was very difficult to observe unless with the assistance from the technical support. Additionally, the linkage of the geometry file between the parent folder and the case folder was destructed in the latest version. To run a successful simulation, the geometry file in the case folder must be re-opened and saved again using the CCHE-MESH program after inputting all the required parameters in the CCHE-GUI program. Then, the geometry file in the parent folder can be re-opened using the CCHE-GUI program and run the simulation. Furthermore, large deposition values (i.e. $38 \mathrm{~m}$ ) were observed around the corners of the deflector blocks at large flow rate scenarios after short simulation runs (i.e. 1-hr). Since the default maximum deposition value suggested by the manual is 90 metres, this may be an issue for long simulation runs in the future study (Section 7.2).

The ending time of the flow simulation (i.e. 1 hour) and sediment simulation (i.e. 15 minutes) for $5 \mathrm{~cm}$ below bankfull of LFC condition were also different. This may link to another instability or potential bug issues since the rest of the numerical experiments were having the same ending time for both flow and sediment simulations. This question had already discussed to the technical support of the program and he agreed with the author's opinion that the ending time of the sediment simulation should be the same as the flow simulation. Further investigation is currently conducted by the technical support to check 
whether the difference is caused by a simple bug in the clock system or other serious programming issue.

At last, this research did not address the boundary effect at the upstream-the transition between the natural channel and the flood channel during the development of the low-flow channel modification design. The current numerical results showed that the upstream boundary effect was minimum since the flow was evenly distributed to the wetted cross-sectional area of the modified low-flow channel while entering to the numerical system. In reality, the flow entered to the low-flow channel should be in a contraction mode since the width of the natural stream is usually greater than the width of the low-flow channel. Thus, turbulence and scouring will be created in the natural stream just before and after the lowflow channel. As mentioned in Section 1.2, flood channels in Ontario are applied in different sections along the streams. Based on the creek walks experience the author had on the urban creeks in southeastern Ontario, severe scour holes problems occur in the transition zone between the flood channels and natural streams. Moreover, the existing dissipation devices in the streams cannot address this problem. Hence, further studies on the transition zone problems are needed before applying the stream restoration approach to flood channels. 


\section{CHAPTER 6 VALIDATION OF FLOOD CONTROL FUNCTIONS}

This chapter discusses the modification of the numerical model and the numerical results for flood control validation.

\subsection{NUMERICAL MODEL SET UP}

Additional blocks were added (Figure 91) to the upper and lower sides of the existing numerical model (Figure 90) to address the flooding conditions (Table 18). Since CCHE2D is a two-dimensional program, the deflector blocks could not cut to its true heights once the flow depth reaches the bankfull of the low-flow channel. In another word, they were acted like columns in the program during flood situation. Thus, the original approach was to examine the difference in numerical results between with and without deflector blocks situations during flooding conditions in order to reflect the reality. Unfortunately, the model could not create a successful run once the flow reached the flood channel portion after numerous tests. The following tests were conducted for both with and without deflector blocks conditions to try to determine the reasons of failure:

- Instead of using vertical walls for the boundaries between blocks \#1 and \#2, and blocks \#1 and \#3, slide walls with rise to run ratio up to 1 to 2 were used;

- Manning's roughness (i.e. $0.03,0.06,0.013$ ) to all the blocks were applied. In reality, block \#1 should be 0.06 (Table 7 ) and all other blocks should be 0.013 to represent concrete bed; 
- For bed erodibility parameter, one selection (i.e. erodible, non-erodible) to all the blocks was applied. In reality, only block \#1 should be "erodible". The rest of the blocks should be "non-erodible";

- The flood channel was changed to rectangular shape by eliminating blocks \#4 and \#5;

- Same elevation was applied to the flood channel bed (i.e. elevation $=10.0$ for blocks \#1, \#2, \#3);

- The mesh dimension was reduced around the deflector zones to $0.5 \mathrm{~cm} \mathrm{X}$ $0.5 \mathrm{~cm}$, which is the limit of the number of cells that the program can be handled;

- The flow simulation time step parameter was decreased to 0.01 seconds; and

- The sediment simulation time steps to adjust flow parameter was increased to 500 seconds.

Table 18: Inlet flow rates input to the numerical model at various water depths in the flood channel $(\mathrm{FC})$.

\begin{tabular}{|l|c|c|c|c|c|c|}
\hline Conditions & $\begin{array}{c}5 \mathrm{~cm} \text { above } \\
\text { bottom of } \\
\text { FC }\end{array}$ & $\begin{array}{c}25 \mathrm{~cm} \text { above } \\
\text { bottom of } \\
\text { FC }\end{array}$ & $\begin{array}{c}0.5 \mathrm{~m} \text { above } \\
\text { bottom of } \\
\text { FC }\end{array}$ & $\begin{array}{c}1 \mathrm{~m} \text { above } \\
\text { bottom of } \\
\text { FC }\end{array}$ & $\begin{array}{c}2 \mathrm{~m} \text { above } \\
\text { bottom of } \\
\text { FC }\end{array}$ & $\begin{array}{c}3 \mathrm{~m} \text { above } \\
\text { bottom of } \\
\text { FC }\end{array}$ \\
\hline $\begin{array}{l}\text { Water Depth } \\
\begin{array}{l}\text { Measured } \\
\text { from Bottom } \\
\text { of LFC, } \\
\text { in metres }\end{array}\end{array}$ & 0.5000 & 0.7000 & 0.9500 & 1.450 & 2.450 & 3.450 \\
\hline Manning's $n$ & \multicolumn{7}{|c|}{0.06} \\
\hline $\begin{array}{l}\text { Longitudinal } \\
\text { Slope }(S)\end{array}$ & \multicolumn{7}{|c|}{0.002943} \\
\hline $\begin{array}{l}\text { Area }(A), \\
\text { in } \mathrm{m}^{2}\end{array}$ & 1.378 & 3.336 & 5.896 & 11.38 & 23.83 & 38.24 \\
\hline
\end{tabular}




\begin{tabular}{|l|l|l|l|l|l|l|}
\hline $\begin{array}{l}\text { Inlet Flow } \\
\text { Rate, }\left(Q_{\text {in }}\right),\end{array}$ & 0.6468 & 3.788 & 10.84 & 32.94 & 104.5 & 210.8 \\
in $\mathrm{m}^{3} \mathrm{~s}$
\end{tabular}




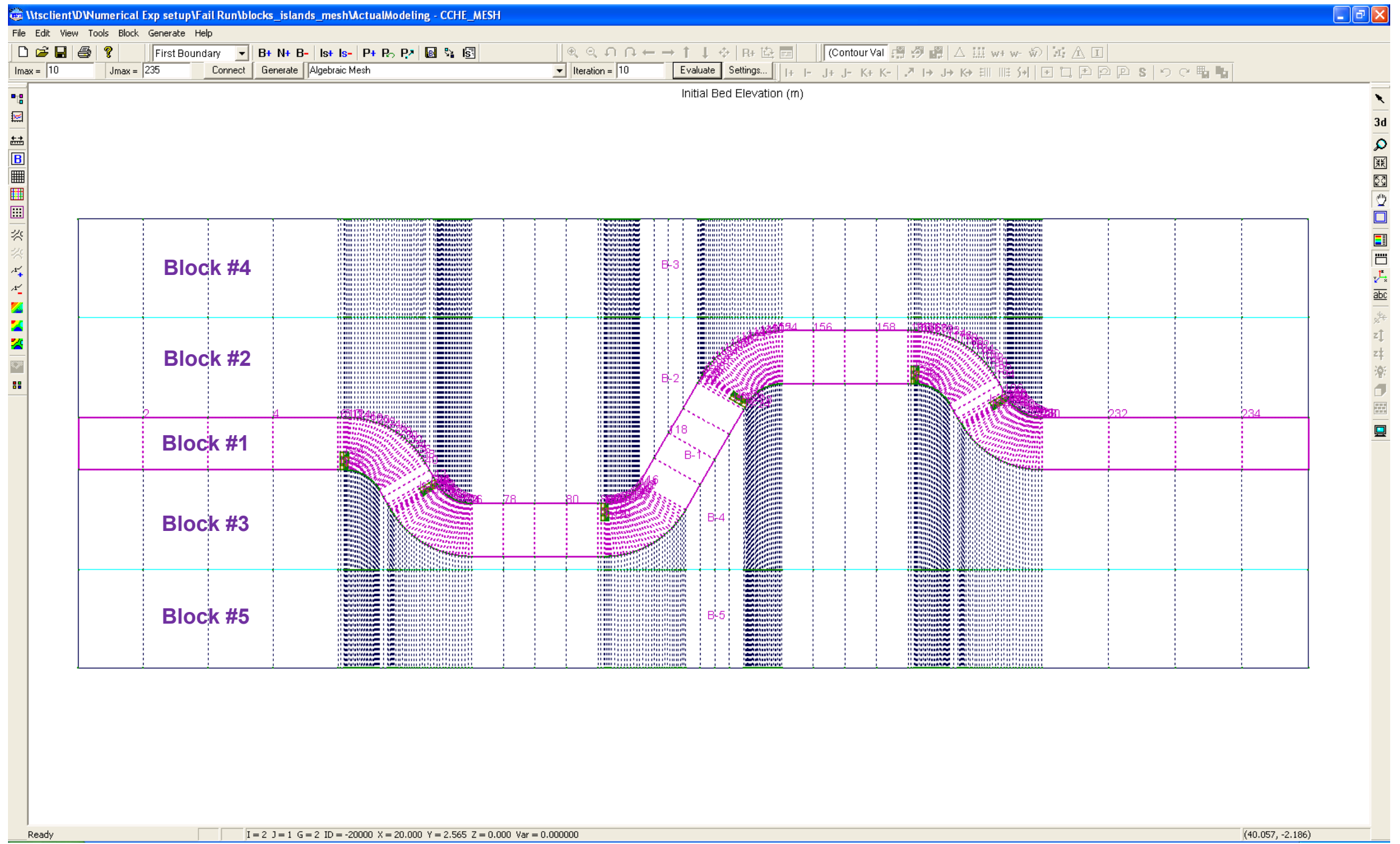

Figure 91: Boundary setup for the flood condition in CCHE2D program. 
Hence, it can be concluded that the cause of the failure runs was not the deflector blocks, the different zones (i.e. concrete bed versus sediment bed), nor other sensitive parameters. The stretch and shrinkage zones in blocks \#2 and \#3 caused by the meanders in block \#1 and the angles created between the vertical inclined mesh lines along the meander sections of block \#1 and the vertical mesh lines in blocks \#2 and \#3 are probably the reasons behind the failure. The technical support of the CCHE2D program was agreed with the above failure assumptions. He also mentioned that floodplains are usually not considered during sediment transport modelling and suggested that blocks \#2 to \#5 should be taken out or the boundaries of \#2 to \#5 should be aligned as the meander boundaries in block \#1. For this study, the flood channel should be a major factor of the restoration design since the scouring in the low-flow channel will be decreased once the flow reached the flood channel. Additionally, it may be difficult to align the flood channel as the meanders in block \#1 in reality due to the limited space along the corridors of the flood channel.

\subsubsection{Modification of the Numerical Model}

Solutions had developed to address the potential angle impacts between the vertical mesh lines:

1) The vertical mesh lines along the meander sections should be aligned in block \#1 to the flow direction of the flood channel instead of following the meander section measurements from the physical experiments. Thus, the 
vertical mesh lines for all the blocks involved in the flood channel scenarios would be parallel to each other.

2) The $x$-coordinates of all the points in the first boundary line of block \#2 should be adjusted so that the vertical mesh lines in block \#2 would be more aligned with the vertical mesh lines in block \#1 along the meander section. Currently, the $\mathrm{x}$-coordinates of all mesh points in the first boundary were the same as the $\mathrm{x}$-coordinates in the second boundary so that the vertical mesh lines were perpendicular to the incoming flow.

3) One rectangular block was used instead of using 5 blocks (Figure 91) to represent the entire flood channel. Then, small square mesh of about $1-\mathrm{cm}$ was inserted to the rectangular block using the algebraic mesh method and entered the input parameters manually (Figure 92) into its proper location according the coordinates developed in the AutoCAD program (Section 5.3.1). This solution was similar to the GIS raster analysis approach which would totally eliminate the inner boundary effects by the multiple blocks. 


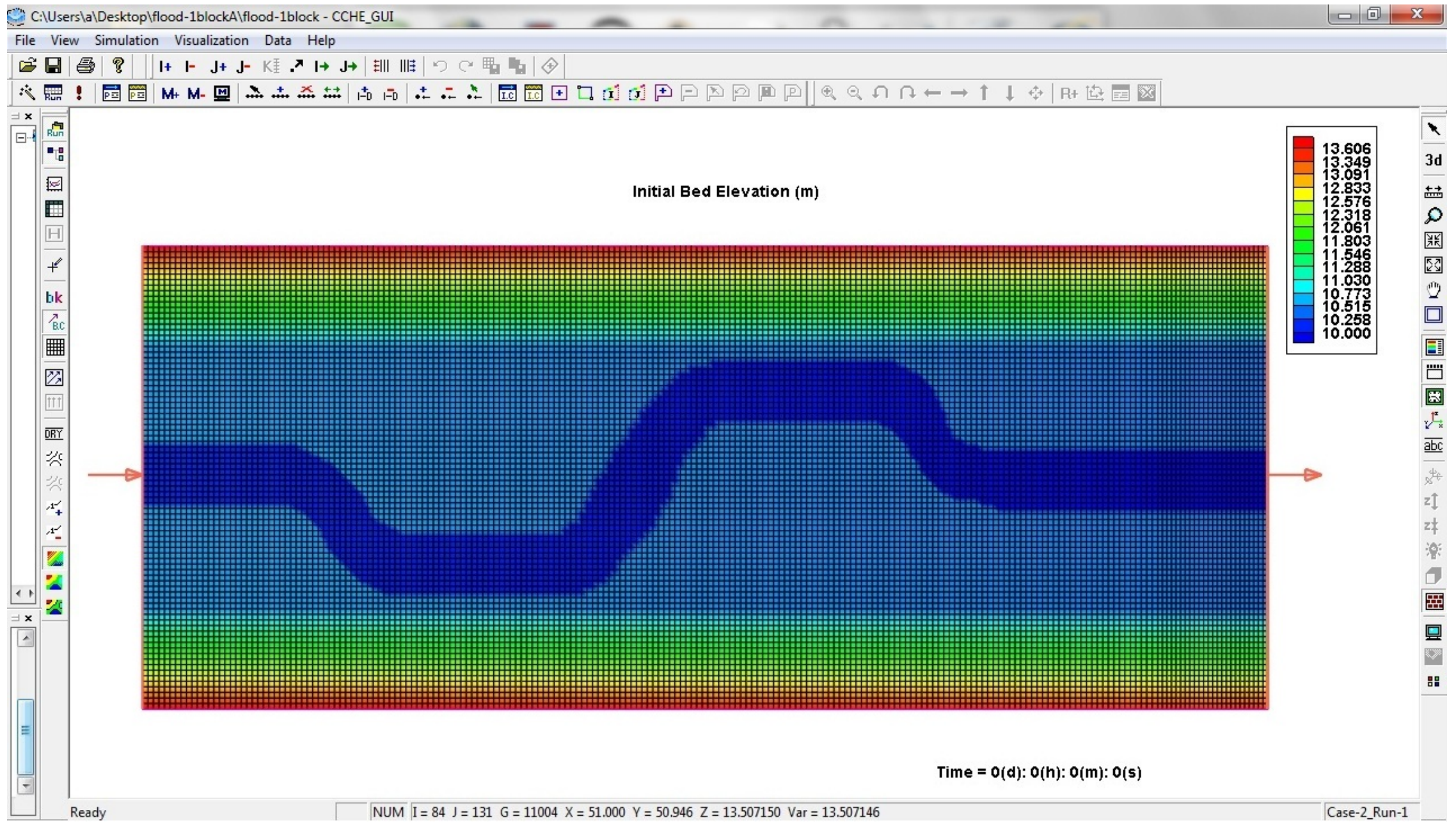

Figure 92: Bed elevation input parameter set up in Approach \#3. 
Since each solution requires long computation set up and running time, Approach \#3 was first settled as a tryout solution due to its elimination of inner boundaries between the five blocks (Figure 91). Additionally, only the worst scenario, $3 \mathrm{~m}$ above the bottom of flow channel (Table 18), had been tested due to the extensive time required for the input parameters entering in this approach. The deflector blocks were also eliminated because of the current computation difficulties that had been experienced. Shiono (2008) conducted a meander channel physical experiment study for overbank flows and observed a decrease in sediment transport rates as flow went just overbank up. Even Shiono's model set up was different than this research, the decrease in sediment transport rates might be an indication that the function of the deflector might be minimized once the flow reaches the flood channel. Thus, experiment without deflector blocks for flood control validation would be more reflected to real condition.

\subsection{RESULTS AND DISCUSSION}

A 10-hour run simulation for Approach \#3 was able to be achieved with additional fine-tuned on Manning's roughness parameter. The reason for selecting a 10hour run is the physical observation (Section 4.9.2) of the approximate time required for scouring to be close to equilibrium stage. There are two different beds involved in the flooding scenario: sediment bed in the low-flow channel, with Manning's roughness of 0.06 (Table 13), and concrete bed in the flood channel, with Manning's roughness of 0.013 to 0.015 . To achieve a successful run, it had 
been discovered through different trails that the gaps between the Manning's roughness of the two different beds could not be too far apart. Thus, the maximum range of Manning's roughness for a concrete bed was set to be 0.015 and for the sediment bed was 0.03 . For the sediment bed, Manning's roughness of 0.03 is still an acceptable value for natural channels even it was less than the original target value (Section 4.2). Secondly, a buffer zone of about $0.5 \mathrm{~m}$ wide must be created at the boundary of the low-flow channel and flood channel to gradually change the two Manning's values using the "interpolate in I direction" function in CCHE2D program. Without the creation of the buffer zone, the Manning's roughness range between the two beds must be even smaller (i.e. 0.02 for concrete bed and 0.03 for sediment bed).

The numerical results of bed and velocity profiles are depicted in Appendices T and $\mathrm{U}$. The first alternative, with a buffer zone of $0.5 \mathrm{~m}$, was selected to represent a flooding scenario since the two Manning's roughness values are closer to real situation. Generally, scour or bed undermining occurs in the entire low-flow channel. Meanders \#2 and \#3 had the largest and deepest scour hole. The scour hole started at about section $m 30$ of Meander \#2 and spread along the outer curvatures of the two meanders till about section $m 30$ of Meander \#3. The maximum scour depth was about $67 \mathrm{~cm}$ located $2 \mathrm{~m}$ downstream of Meander \#2 near the outer curvature region. Conversely, the scour depth along the inner curvature region of the straight section between Meanders \#2 and \#3 was about $14 \mathrm{~cm}$. The second largest scour hole occurred along the outer curvature of 
Meanders \#4 and \#5. Its shape is similar to the largest one with shallower depth. The maximum scour depth was about $54 \mathrm{~cm}$ located $1.6 \mathrm{~m}$ downstream of Meander \#4 near the outer curvature region. The scour depth along the inner curvature region was about the same depth of $14 \mathrm{~cm}$ as the largest one. The general bed undermined depth in Meander \#1 was about $10 \mathrm{~cm}$ and in Meander \#6 was about $6.0 \mathrm{~cm}$. There was no significant scour hole formed in the two meanders. Moreover, the general depth along the long straight section between Meanders \#3 and \#4 was about $5.0 \mathrm{~cm}$. The bed profiles proved that the sediment will not be totally rushed out during a severe flooding condition.

The velocity profile along the base section of the flood channel was quite evenly distributed. The only area that had observed velocity fluctuations was along the base and slide connections of the flood channel. These fluctuations may be relative to the formation of the two largest scour holes since the scour hole locations were the closest regions of the low-flow channel to the velocity fluctuation areas.

\subsection{SELF-SUSTAINABLE SYSTEM}

A 5-hour run simulation was conducted using the numerical model set up in Chapter 5 (Figure 90) to validate the self-sustainable function, which is one of the restoration goals that had been targeted before (Section 1.2). The purpose of this experiment was to test whether the current low-flow channel design can be able to trap some of the incoming sediment in dry weather condition and reform the 
pools and riffles characteristics assuming all the existing sediment had rushed out after a severe storm. Thus, the bed of the numerical experiment was concrete with Manning's roughness of 0.013 . The incoming sediment load was determined based on the verbal information from HK DSD (Section 4.6.1). The reason for conducting a 5-hr run was the available flow simulation results from the previous numerical experiment. Thus, this experiment is just a preliminary investigation the self-sustainable function.

Generally, only a small amount of sediment had been observed along the straight sections between Meanders \#1 and \#4. This may be an indication of a starting stage of the self-sustainable formation where the straight sections, or the riffle zones, usually have shallow depths. The reason for no sediment after the downstream of Meander \#4 might be the short simulation time. Thus, future studies should be conducted with a longer simulation time. 


\section{CHAPTER 7 CONCLUSION}

This chapter contains the conclusion and the future studies that should be carried on for this research.

\subsection{CONCLUSION}

This research developed a stream restoration design approach for flood control concrete channels in highly urbanized areas. The framework of the design methodology consisted of four phases: 1) restoration goals identification; 2) stream assessment; 3) channel modification design and verification; and 4) flood control function validation. The pilot site studies in Yuen Long, Hong Kong had demonstrated that the frameworks of the design methodology and the three restoration goals identified for the pilot site have been tentatively met. The following are the conclusions of this research:

- The physical experiments indicated that deflectors are a major factor of pool and deposition zone creation. Artificial meander section without a deflector can only form ripples after long runs (i.e. 24-hour), which are far beyond the equilibrium stage (i.e. 10 hours).

- The physical experimental results showed that double deflectors with $2 / 3$ of contraction ratio in total created excess scouring effects. Based on the limited scenarios conducted during the physical model investigation, a single deflector with $1 / 3$ contraction ratio is more appropriate for the pilot site. 
- From the physical experimental results, the best locations for single deflector would be located along the inner curvature of the meander section with the maximum scour depth of about $10 \mathrm{~cm}$ near the upstream tip of the deflector.

- The physical experiments also demonstrated that the velocity range created in the low-channel modification design can be suitable for the existing fish habitat in the pilot site. The recirculation zone just downstream of the deflector may also provide a suitable resting area for the existing fish. Furthermore, Malaysian snails, another aquatic species found in the pilot site, had been observed to congregate along the deposition zone located further downstream of the deflector.

- The numerical experiments covered the scenarios that were unable to be conducted in the physical model. These experiments introduced various numerical approaches, such as multiple blocks system was introduced to address deflector with porosity and the technique in preparing numerical model for flooding scenario with two different bed materials, and indicated the limitations in the CCHE2D program. The findings in numerical experiments are a valuable resource for future researches in this area.

- The numerical experiments using CCHE2D software also indicated that single deflector cannot apply to every meander section in the modified low-flow channel design. Whenever the meander sections were close to each other (i.e. Meanders \#1 and \#2, \#4 and \#5), deflector could not be applied to the downstream meander section in order to achieve a successful simulation. This may be a potential bug in the CCHE2D software. 
- The numerical results showed that the existing mobile bed sediment in the modified low-flow channel will not be totally rushed out after a severe thunder storm event. Instead, two elongated scour holes were created from the outer curvature of Meander \#2 to Meander \#3 and from the outer curvature of Meander \#4 and \#5. Bed undermining ranging from $5 \mathrm{~cm}$ to $10 \mathrm{~cm}$ was also found along the entire modified low-flow channel.

- Assuming the existing mobile bed sediment was totally rushed out after a severe thunder storm, small amount of incoming sediment in dry weather condition was observed to be deposited along the straight sections from Meander \#1 to \#4. This is a preliminary indication of self-sustainable establishment within the modified low-flow channel. Further investigation is needed in the future to confirm this observation.

\subsection{FUTURE WORKS}

The following lists out the future works that can be carried on after this research:

- Additional numerical scenarios mentioned in Sections 5.4 and 5.5 shall be further investigated;

- A longer simulation time (i.e. 24-hr) shall be conducted for the numerical experiments (Chapter 5) to verify the long-term scour/deposition formation.

- As mentioned in Section 5.4, the deflector blocks were acted as columns in CCHE2D programs. This is not true in reality since the height of the deflector should be only up to the top of the low-flow channel. Thus, a three- 
dimensional (3D) program should be used to verify the flood channel restoration approach that had been developed in this research.

- The upstream/downstream boundary effects on the transition zone as mentioned in Section 5.5 and the approaches to address this issue should be investigated in the future studies.

- This research only showed that the native vegetation (i.e. seeds mixing with the sediment collected through the pilot site) may be able to trap and grow along the pools region location downstream of the deflector due to the velocity preference. It did not address the vegetation component in the deflector design. Further studies on the vegetation selection process, the techniques of planting the selected vegetation type in the deflector in a controlled environment until the vegetation reaches its mutual stage, the difference of scour formation with and without vegetation components in the deflector, and the potential growing extension of the vegetation to the downstream deposition zone should be investigated.

- During the physical experiments, Malaysian snails' shells were deposited along the second half of the inner curvature in the meander section. Moreover, a few weeds were also grown along the inner curvature (Figure 93). Since the bed material was directly from the pilot site, Malaysian snails' shells and weed seeds in the native soil may have also been collected during the sediment collection process. This indicates that the recirculation zone created by the deflector may create a suitable environment for the growth of some existing biological species and 
vegetation in the pilot site. Further study on the biological habitats of the pilot site needs to be done to confirm this observation.

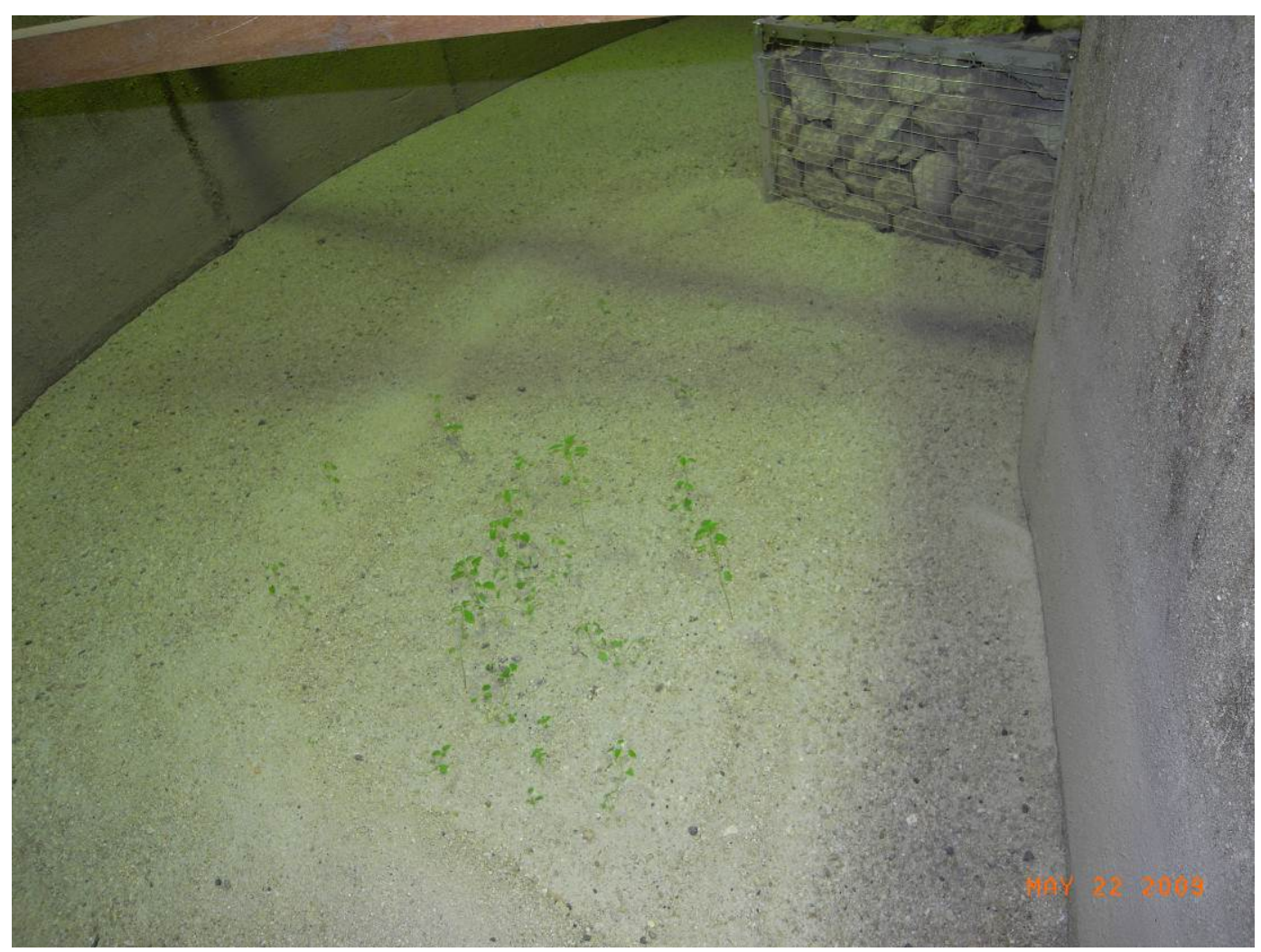

Figure 93: Plants grew along the inner curvature while conducting the physical experiments. 


\section{APPENDIX A}

\section{Particle Size Distribution Analysis of Soil Samples Collected at the Pilot Site}




\section{Sample A1}

Dry sieving:

\begin{tabular}{|l|cc|}
\hline Wt. of Total Soil & 100 & $\mathrm{~g}$ \\
\hline Wt. of Dry Soil $(>63)+$ Container & 229.67 & $\mathrm{~g}$ \\
\hline Wt. of Container & 174.375 & $\mathrm{~g}$ \\
\hline Wt. of Dry Soil $(>63)$ & 55.295 & $\mathrm{~g}$ \\
\hline Wt. of Dry Soil passing 63 micron sieve(Ws) & 44.705 & $\mathrm{~g}$ \\
\hline \% of total sample mass (Ws\%) & 44.705 & \\
\hline
\end{tabular}

\begin{tabular}{|c|c|c|c|c|c|c|c|}
\hline $\begin{array}{c}\text { Sieve } \\
\text { Number }\end{array}$ & Sieve size & $\begin{array}{c}\text { Mass Retained } \\
+ \text { Container } \\
(\mathrm{gm})\end{array}$ & $\begin{array}{c}\text { Mass } \\
\text { retained } \\
(\mathrm{gm} .)\end{array}$ & $\begin{array}{c}\text { Total mass } \\
\text { passing } \\
(\mathrm{gm} .)\end{array}$ & $\begin{array}{c}\% \\
\text { passing }\end{array}$ & $\begin{array}{c}\text { Mass Retained } \\
\text { by the Sieve } \\
(\mathrm{gm} .)\end{array}$ & $\begin{array}{c}\text { Mass } \\
\text { Retained by } \\
\text { the Sieve (\%) }\end{array}$ \\
\hline 1 & $6.30 \mathrm{~mm}$ & 174.959 & 0.584 & 99.416 & 99.416 & 0.584 & \\
2 & $3.35 \mathrm{~mm}$ & 176.185 & 1.81 & 98.19 & 98.19 & 1.226 & 1.226 \\
3 & $2 \mathrm{~mm}$ & 179.191 & 4.816 & 95.184 & 95.184 & 3.006 & 3.006 \\
4 & $1.18 \mathrm{~mm}$ & 187.626 & 13.251 & 86.749 & 86.749 & 8.435 & 8.435 \\
5 & $600 \mu \mathrm{m}$ & 201.18 & 26.805 & 73.195 & 73.195 & 13.554 & 13.554 \\
6 & $300 \mu \mathrm{m}$ & 221.214 & 46.839 & 53.161 & 53.161 & 20.034 & 20.034 \\
7 & $150 \mu \mathrm{m}$ & 229.671 & 55.296 & 44.704 & 44.704 & 8.457 & 8.457 \\
8 & $63 \mu \mathrm{m}$ & 230.358 & 55.983 & & & 44.705 & 44.705 \\
9 & Pan & & & & & \\
\hline
\end{tabular}




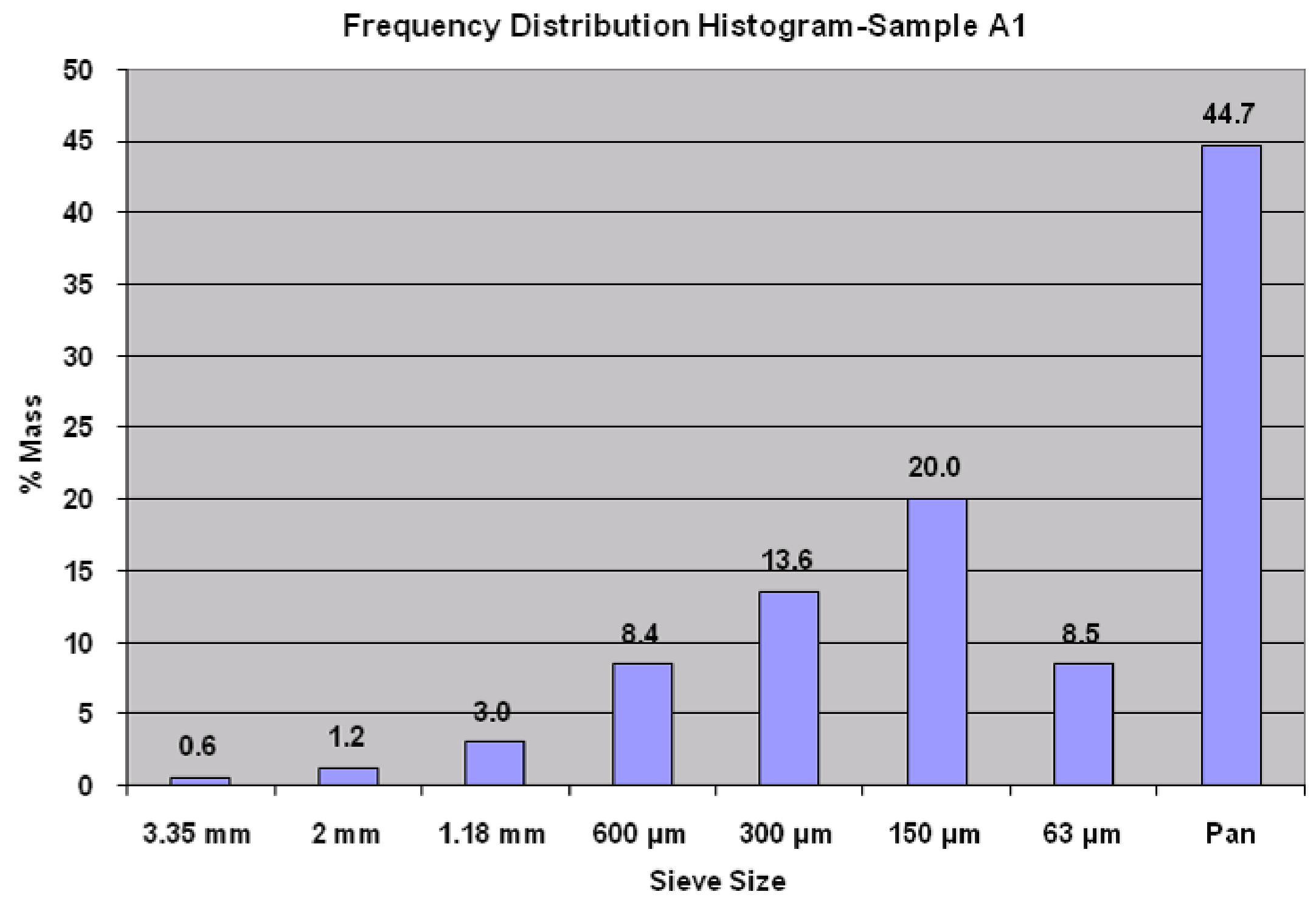

--- Page $A 2$ 
Hydrometer method:

\begin{tabular}{|l|cl|}
\hline Initial mass of dry soil: & 100 & $\mathrm{gm}$ \\
\hline Dispersion: & 100 & $\mathrm{ml}$ \\
\hline Specific Gravity assumed/measured: & 2.65 & $\mathrm{Mg} / \mathrm{m}^{\wedge} 3$ \\
\hline Cylinder No.: & 1 & \\
\hline Hydrometer No.: & $785404 / \mathrm{B}$ \\
\hline Meniscus correction(Cm): & 0.5 \\
\hline Dispersing agent correction(Cd): & 4.242 \\
\hline Viscosity of Water: & Viscosity $=0.0005 \mathrm{~T}^{\wedge} 2-0.0448 \mathrm{~T}+1.7016$ \\
\hline Hydrometer Calibration: & $\mathrm{Hr}=211.14-4.11^{*} \mathrm{Rh}$ \\
\hline
\end{tabular}

\begin{tabular}{|c|c|c|c|c|c|c|c|c|c|c|}
\hline Time & $\begin{array}{l}\text { Elapsed } \\
\text { Time } \\
\text { (min) }\end{array}$ & $\begin{array}{l}\text { Hydrometer } \\
\text { Reading (R'h) }\end{array}$ & $\begin{array}{c}\text { Temp } \\
\text { (degree) }\end{array}$ & $\begin{array}{l}\text { Corrected } \\
\text { Hydrometer } \\
\text { Reading } \\
\mathrm{Rh}=\mathrm{R} ' \mathrm{~h}+\mathrm{Cm}\end{array}$ & $\begin{array}{l}\text { Effective } \\
\text { Depth } \\
(\mathrm{Hr})\end{array}$ & $\begin{array}{l}\text { Equivalent } \\
\text { Particle } \\
\text { Diameter D } \\
(\mathrm{mm})\end{array}$ & $\begin{array}{c}\text { Temperature } \\
\text { Correction } \\
\text { Mt }\end{array}$ & $\mathrm{Rh}+\mathrm{Mt}-\mathrm{Cd}$ & $\begin{array}{l}\text { W } \\
\%\end{array}$ & $\begin{array}{c}\text { Summation } \\
\%\end{array}$ \\
\hline 0 & 0 & & & & & & & & & \\
\hline $15^{\prime \prime}$ & 0.25 & & & & & & & & & \\
\hline $30 "$ & 0.5 & 27.5 & 15.5 & 28 & 96.06 & 0.063368371 & -0.7 & 23.058 & 0.8284 & 37.032545 \\
\hline 1 & 1 & 26 & 15.5 & 26.5 & 102.23 & 0.046223712 & -0.7 & 21.558 & 0.7745 & 34.623455 \\
\hline $2^{\prime}$ & 2 & 24.2 & 15.5 & 24.7 & 109.62 & 0.033847149 & -0.7 & 19.758 & 0.7098 & 31.732545 \\
\hline $4^{\prime}$ & 4 & 22.8 & 15.5 & 23.3 & 115.38 & 0.02455364 & -0.7 & 18.358 & 0.6595 & 29.484061 \\
\hline $8^{\prime}$ & 8 & 21.5 & 14.3 & 22 & 120.72 & 0.018039913 & -0.84 & 16.918 & 0.6078 & 27.171333 \\
\hline $15^{\prime}$ & 15 & 19.8 & 14.2 & 20.3 & 127.71 & 0.013568164 & -0.85 & 15.208 & 0.5464 & 24.42497 \\
\hline $30^{\prime}$ & 30 & 18 & 14.2 & 18.5 & 135.11 & 0.009868121 & -0.85 & 13.408 & 0.4817 & 21.534061 \\
\hline 50 & 50 & 16.3 & 14.1 & 16.8 & 142.09 & 0.007849267 & -0.86 & 11.698 & 0.4203 & 18.787697 \\
\hline $2 \mathrm{~h}$ & 120 & 13.3 & 13.6 & 13.8 & 154.42 & 0.005316774 & -0.92 & 8.638 & 0.3103 & 13.873152 \\
\hline $4 \mathrm{~h}$ & 240 & 11.8 & 13.6 & 12.3 & 160.59 & 0.003833838 & -0.92 & 7.138 & 0.2564 & 11.464061 \\
\hline $6 \mathrm{~h}$ & 360 & 11.2 & 14.7 & 11.7 & 163.05 & 0.003109056 & -0.8 & 6.658 & 0.2392 & 10.693152 \\
\hline $7 \mathrm{~h}$ & 420 & 10.8 & 14.5 & 11.3 & 164.7 & 0.002900481 & -0.82 & 6.238 & 0.2241 & 10.018606 \\
\hline $24 \mathrm{~h}$ & 1440 & 9.1 & 13.1 & 9.6 & 171.68 & 0.001629037 & -0.98 & 4.378 & 0.1573 & 7.0313333 \\
\hline
\end{tabular}


Cumulative Frequency Curve:

\begin{tabular}{|c|c|c|}
\hline $\begin{array}{c}\text { Equivalent Particle } \\
\text { Diameter }(\mathrm{mm})\end{array}$ & $\begin{array}{c}\text { Cumulative } \% \\
\text { mass }\end{array}$ & $\begin{array}{c}\text { Cumulative } \\
\text { mass }\end{array}$ \\
\hline 6.3 & 100 & 1 \\
3.35 & 99.416 & 0.99416 \\
2 & 98.19 & 0.9819 \\
1.18 & 95.184 & 0.95184 \\
0.6 & 86.749 & 0.86749 \\
0.3 & 73.195 & 0.73195 \\
0.15 & 53.161 & 0.53161 \\
0.063 & 44.704 & 0.44704 \\
0.046223712 & 34.62345455 & 0.346234545 \\
0.033847149 & 31.73254545 & 0.317325455 \\
0.02455364 & 29.48406061 & 0.294840606 \\
0.018039913 & 27.17133333 & 0.271713333 \\
0.013568164 & 24.4249697 & 0.244249697 \\
0.009868121 & 21.53406061 & 0.215340606 \\
0.007849267 & 18.78769697 & 0.18787697 \\
0.005316774 & 13.87315152 & 0.138731515 \\
0.003833838 & 11.46406061 & 0.114640606 \\
0.003109056 & 10.69315152 & 0.106931515 \\
0.002900481 & 10.01860606 & 0.100186061 \\
0.001629037 & 7.031333333 & 0.070313333 \\
\hline
\end{tabular}

Analysis based on the cumulative curve:

\begin{tabular}{|c|c|}
\hline D50 = & 0.1175 \\
\hline $\mathrm{D} 60=$ & 0.2012 \\
\hline $\mathrm{D}_{10}=$ & 0.0029 \\
\hline D30 $=$ & 0.0267 \\
\hline
\end{tabular}

Coefficient of curvature: $\quad 1.2236$

Coefficient of uniformity: $\quad 69.5596$

\begin{tabular}{|c|c|c|c|}
\hline \multicolumn{4}{|c|}{ Particle Size Distribution } \\
\hline $\begin{array}{c}\text { Gravel } \\
(\%)\end{array}$ & $\begin{array}{c}\text { Sand } \\
(\%)\end{array}$ & $\begin{array}{c}\text { Silt } \\
(\%)\end{array}$ & $\begin{array}{c}\text { Clay } \\
(\%)\end{array}$ \\
\hline 1.8 & 55.3 & 35.0 & 7.9 \\
\hline
\end{tabular}




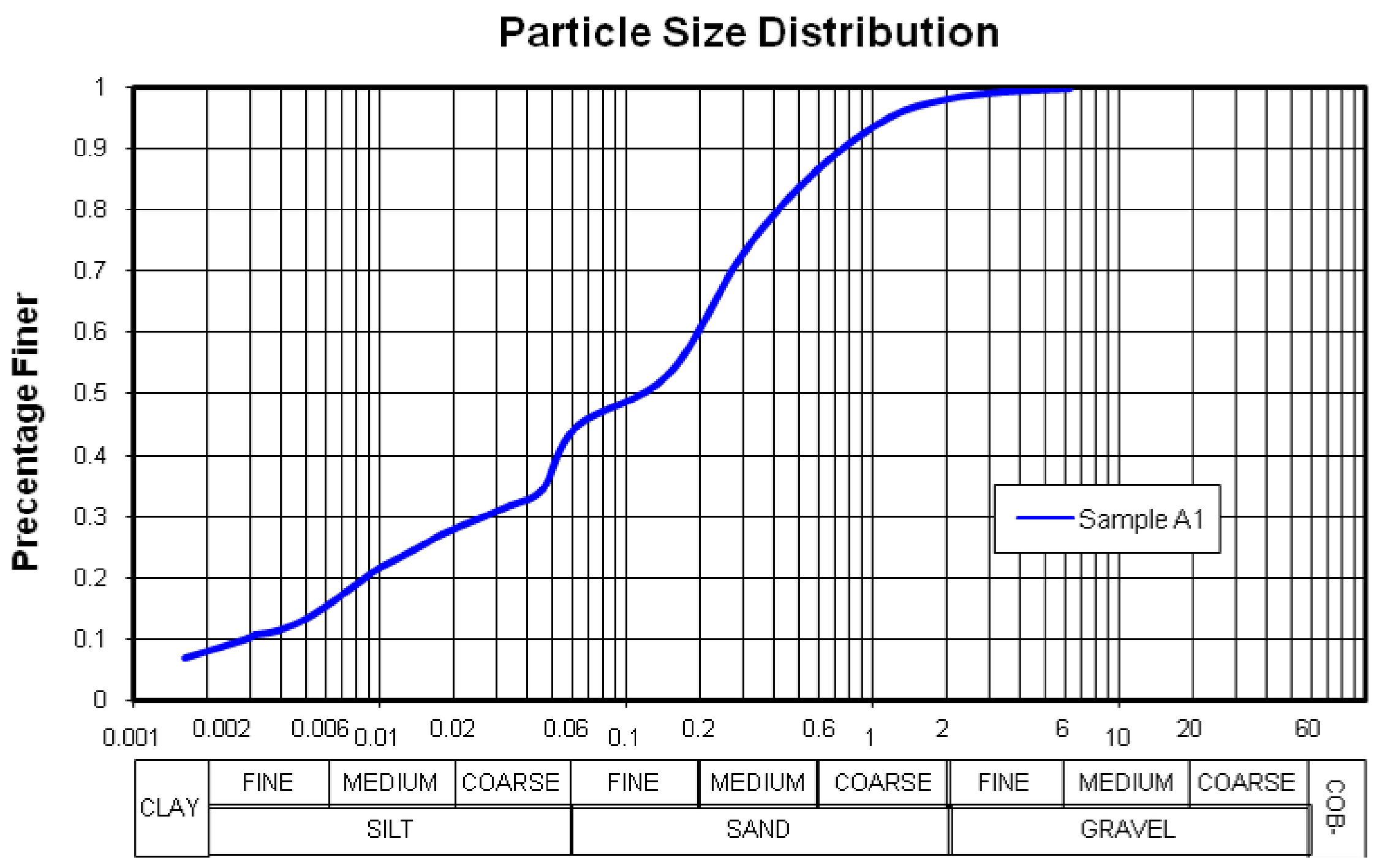




\section{Sample A2}

Dry sieving:

\begin{tabular}{|l|cc|}
\hline Wt. of Total Soil & 100 & $\mathrm{~g}$ \\
\hline Wt. of Dry Soil+Container: & 251.403 & $\mathrm{~g}$ \\
\hline Wt. of Dry Soil(>63)+Container & 250.909 & $\mathrm{~g}$ \\
\hline Wt. of Container & 162.987 & $\mathrm{~g}$ \\
\hline Wt. of Dry Soil(>63) & 87.922 & $\mathrm{~g}$ \\
\hline Wt. of Dry Soil passing 63 micron sieve(Ws) & 12.078 & $\mathrm{~g}$ \\
\hline \% of total sample mass (Ws\%) & 12.078 & \\
\hline
\end{tabular}

\begin{tabular}{|c|c|c|c|c|c|c|c|}
\hline $\begin{array}{c}\text { Sieve } \\
\text { Number }\end{array}$ & Sieve size & $\begin{array}{c}\text { Mass Retained } \\
\text { +Container (gm) }\end{array}$ & $\begin{array}{c}\text { Mass } \\
\text { retained } \\
(\mathrm{gm} .)\end{array}$ & $\begin{array}{c}\text { Total mass } \\
\text { passing } \\
(\mathrm{gm} .)\end{array}$ & $\begin{array}{c}\% \\
\text { passing }\end{array}$ & $\begin{array}{c}\text { Mass Retained } \\
\text { by the Sieve } \\
(\mathrm{gm} .)\end{array}$ & $\begin{array}{c}\text { Mass Retained } \\
\text { by the Sieve } \\
(\%)\end{array}$ \\
\hline 1 & $6.30 \mathrm{~mm}$ & 0 & & & & & \\
2 & $3.35 \mathrm{~mm}$ & 164.282 & 1.295 & 98.705 & 98.705 & 1.295 & 1.295 \\
3 & $2 \mathrm{~mm}$ & 167.128 & 4.141 & 95.859 & 95.859 & 2.846 & 2.846 \\
4 & $1.18 \mathrm{~mm}$ & 172.805 & 9.818 & 90.182 & 90.182 & 5.677 & 5.677 \\
5 & $600 \mu \mathrm{m}$ & 187.753 & 24.766 & 75.234 & 75.234 & 14.948 & 14.948 \\
6 & $300 \mu \mathrm{m}$ & 207.184 & 44.197 & 55.803 & 55.803 & 19.431 & 19.431 \\
7 & $150 \mu \mathrm{m}$ & 238.194 & 75.207 & 24.793 & 24.793 & 31.01 & 31.01 \\
8 & $63 \mu \mathrm{m}$ & 250.909 & 87.922 & 12.078 & 12.078 & 12.715 & 12.715 \\
9 & Pan & 251.364 & 88.377 & & & 12.078 & 12.078 \\
\hline
\end{tabular}


Frequency Distribution Histogram-Sample A2

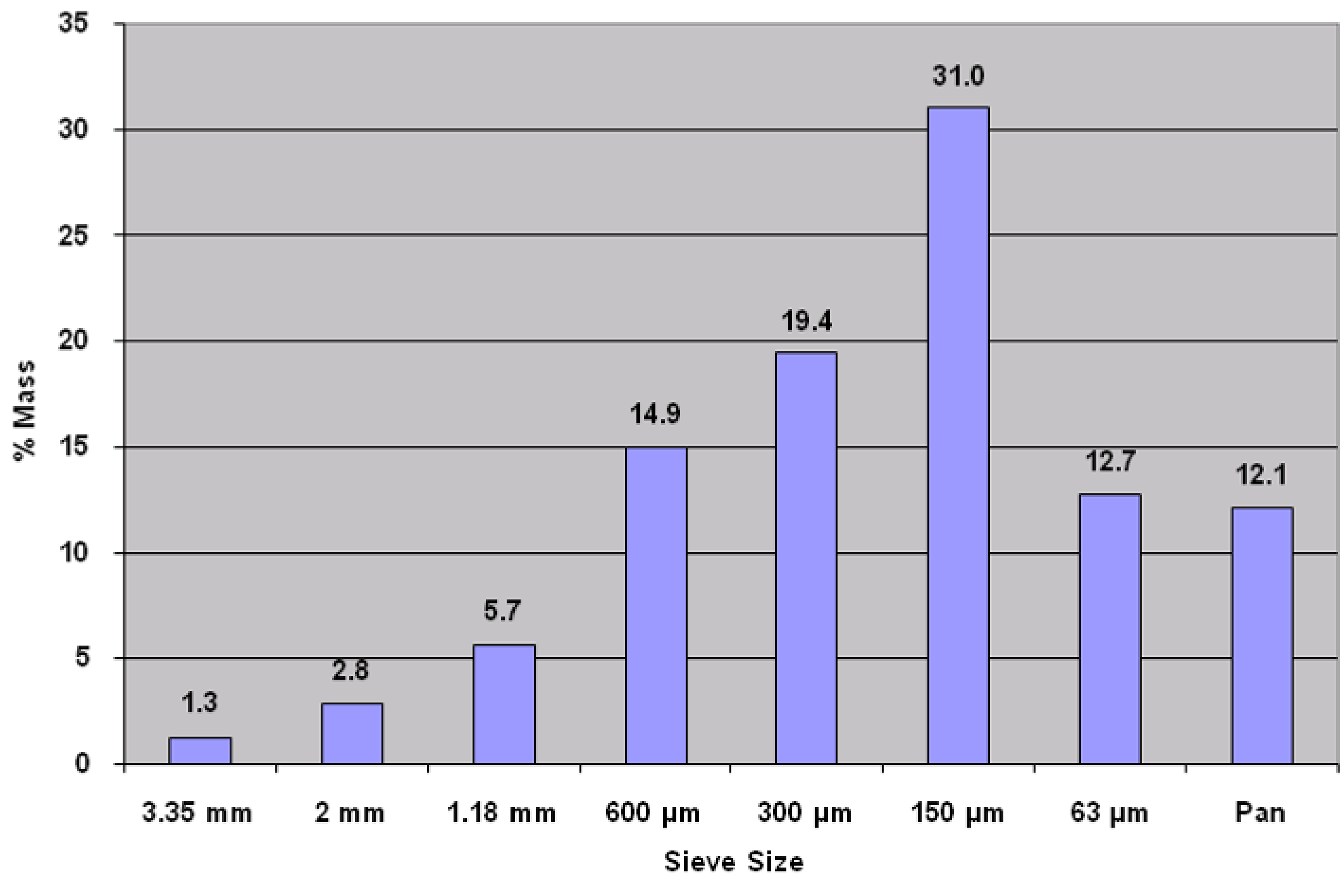

--- Page $A 7$--- 
Hydrometer method:

\begin{tabular}{|l|cl|}
\hline Initial mass of dry soil: & 100 & $\mathrm{gm}$ \\
\hline Dispersion: & 100 & $\mathrm{ml}$. \\
\hline Specific Gravity assumed/measured: & 2.65 & $\mathrm{Mg} / \mathrm{m}^{\wedge} 3$ \\
\hline Cylinder No.: & 1 & \\
\hline Hydrometer No.: & $785404 / \mathrm{B}$ \\
\hline Meniscus correction(Cm): & 0.5 \\
\hline Dispersing agent correction(Cd): & 4.397 \\
\hline Viscosity of Water: & Viscosity $=0.0005 \mathrm{~T}^{\wedge} 2-0.0448 \mathrm{~T}+1.7016$ \\
\hline Hydrometer Calibration: & $\mathrm{Hr}=211.14-4.11^{\star} \mathrm{Rh}$ \\
\hline
\end{tabular}

\begin{tabular}{|c|c|c|c|c|c|c|c|c|c|c|}
\hline Time & $\begin{array}{l}\text { Elapsed } \\
\text { Time } \\
\text { (min) }\end{array}$ & $\begin{array}{l}\text { Hydrometer } \\
\text { Reading } \\
\text { (R'h) }\end{array}$ & $\begin{array}{c}\text { Temp } \\
\text { (degree) }\end{array}$ & $\begin{array}{c}\text { Corrected } \\
\text { Hydrometer } \\
\text { Reading } \\
\text { Rh=R'h+Cm }\end{array}$ & $\begin{array}{l}\text { Effective } \\
\text { Depth } \\
\text { (Hr) }\end{array}$ & $\begin{array}{l}\text { Equivalent } \\
\text { Particle } \\
\text { Diameter D } \\
(\mathrm{mm})\end{array}$ & $\begin{array}{c}\text { Temperature } \\
\text { Correction } \\
\text { Mt }\end{array}$ & $\mathrm{Rh}+\mathrm{Mt}-\mathrm{Cd}$ & $\begin{array}{l}\text { W } \\
\%\end{array}$ & $\begin{array}{c}\text { Summation } \\
\%\end{array}$ \\
\hline 0 & 0 & & & & & & & & & \\
\hline $15^{\prime \prime}$ & 0.25 & & & & & & & & & \\
\hline $30 "$ & 0.5 & 11 & 15.5 & 11.5 & 163.88 & 0.082767075 & -0.7 & 6.403 & 0.8514 & 10.283606 \\
\hline 1 & 1 & 10 & 15.5 & 10.5 & 167.99 & 0.059254523 & -0.7 & 5.403 & 0.7185 & 8.6775455 \\
\hline $2^{\prime}$ & 2 & 9.4 & 15.5 & 9.9 & 170.45 & 0.042205693 & -0.7 & 4.803 & 0.6387 & 7.7139091 \\
\hline $4^{\prime}$ & 4 & 7.5 & 15.5 & 8 & 178.26 & 0.030519907 & -0.7 & 2.903 & 0.386 & 4.6623939 \\
\hline $8^{\prime}$ & 8 & 5.7 & 15.5 & 6.2 & 185.66 & 0.022024096 & -0.7 & 1.103 & 0.1467 & 1.7714848 \\
\hline $15^{\prime}$ & 15 & 5.3 & 15.5 & 5.8 & 187.3 & 0.016155181 & -0.7 & 0.703 & 0.0935 & 1.1290606 \\
\hline $30^{\prime}$ & 30 & 5 & 15.6 & 5.5 & 188.54 & 0.011446098 & -0.69 & 0.413 & 0.0549 & 0.663303 \\
\hline $1 \mathrm{~h}$ & 60 & 4.4 & 15.3 & 4.9 & 191 & 0.008178207 & -0.67 & -0.167 & -0.0222 & -0.268212 \\
\hline $2 \mathrm{~h}$ & 120 & 4.1 & 15.5 & 4.6 & 192.23 & 0.00578643 & -0.7 & -0.497 & -0.0661 & -0.798212 \\
\hline $4 \mathrm{~h}$ & 240 & 4 & 15.4 & 4.5 & 192.65 & 0.004101324 & -0.71 & -0.607 & -0.0807 & -0.974879 \\
\hline $6 \mathrm{~h}$ & 360 & 3.9 & 16 & 4.4 & 193.06 & 0.003326294 & -0.64 & -0.637 & -0.0847 & -1.023061 \\
\hline $7 \mathrm{~h}$ & 420 & 3.8 & 15 & 4.3 & 193.47 & 0.003123148 & -0.76 & -0.857 & -0.114 & -1.376394 \\
\hline $24 \mathrm{~h}$ & 1440 & 3.4 & 15.2 & 3.9 & 195.11 & 0.001689433 & -0.74 & -1.237 & -0.1645 & -1.986697 \\
\hline
\end{tabular}


Cumulative Frequency Curve:

\begin{tabular}{|c|c|c|}
\hline $\begin{array}{c}\text { Equivalent } \\
\text { Particle } \\
\text { Diameter }(\mathrm{mm})\end{array}$ & $\begin{array}{c}\text { Cumulative } \% \\
\text { mass }\end{array}$ & $\begin{array}{c}\text { Cumulative } \\
\text { mass }\end{array}$ \\
\hline 6.3 & 100 & 1 \\
3.35 & 98.705 & 0.98705 \\
2 & 95.859 & 0.95859 \\
1.18 & 90.182 & 0.90182 \\
0.6 & 75.234 & 0.75234 \\
0.3 & 55.803 & 0.55803 \\
0.15 & 24.793 & 0.24793 \\
0.063 & 12.078 & 0.12078 \\
0.042205693 & 7.713909091 & 0.077139091 \\
0.030519907 & 4.662393939 & 0.046623939 \\
0.022024096 & 1.771484848 & 0.017714848 \\
0.016155181 & 1.129060606 & 0.011290606 \\
0.011446098 & 0.66330303 & 0.00663303 \\
\hline
\end{tabular}

Analysis based on the cumulative curve:

$\begin{array}{lll}\text { D50 }= & 0.2719 & \mathrm{~mm} \\ \text { D60 }= & 0.3648 & \mathrm{~mm} \\ \text { D10 }= & 0.0531 & \mathrm{~mm} \\ \text { D30 }= & 0.1752 & \mathrm{~mm}\end{array}$

Coefficient of curvature: $\quad 1.5844$

Coefficient of uniformity: $\quad 6.8702$

\begin{tabular}{|c|c|c|c|}
\hline \multicolumn{4}{|c|}{ Particle Size Distribution } \\
\hline $\begin{array}{c}\text { Gravel } \\
(\%)\end{array}$ & $\begin{array}{c}\text { Sand } \\
(\%)\end{array}$ & $\begin{array}{c}\text { Silt } \\
(\%)\end{array}$ & $\begin{array}{c}\text { Clay } \\
(\%)\end{array}$ \\
\hline 4.1 & 84.4 & 11.4 & 0.0 \\
\hline
\end{tabular}




\section{Particle Size Distribution}

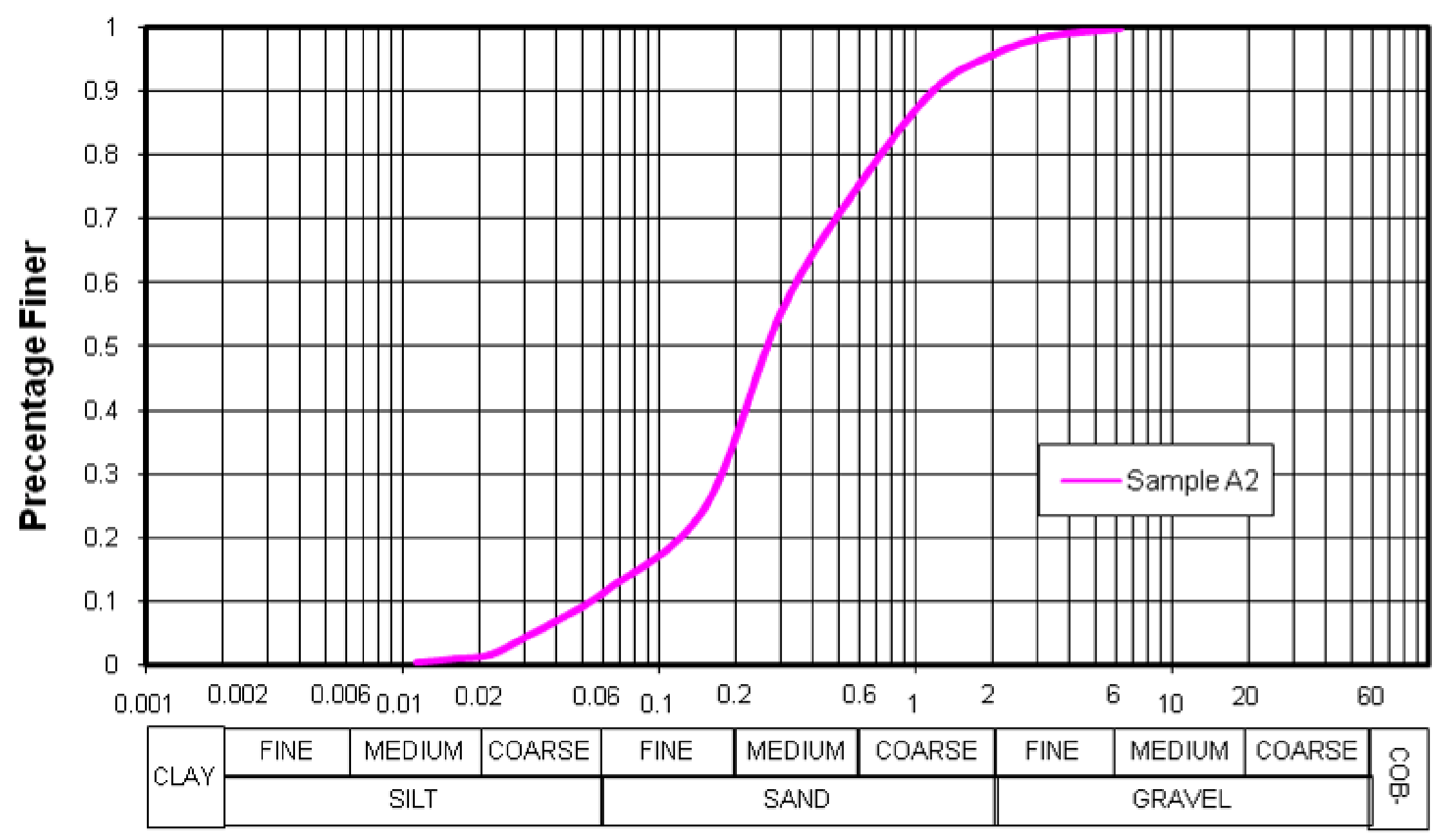




\section{Sample B1}

Dry sieving:

\begin{tabular}{|l|cc|}
\hline Wt. of Total Soil & 100 & $\mathrm{~g}$ \\
\hline Wt. of Dry Soil+Container: & 179.182 & $\mathrm{~g}$ \\
\hline Wt. of Dry Soil(>63)+Container & 177.348 & $\mathrm{~g}$ \\
\hline Wt. of Container & 141.182 & $\mathrm{~g}$ \\
\hline Wt. of Dry Soil(>63) & 36.166 & $\mathrm{~g}$ \\
\hline Wt. of Dry Soil passing 63 micron sieve(Ws) & 63.834 & $\mathrm{~g}$ \\
\hline \% of total sample mass (Ws\%) & 63.834 & \\
\hline
\end{tabular}

\begin{tabular}{|c|c|c|c|c|c|c|c|}
\hline $\begin{array}{c}\text { Sieve } \\
\text { Number }\end{array}$ & Sieve size & $\begin{array}{c}\text { Mass Retained } \\
+ \text { Container } \\
(\mathrm{gm})\end{array}$ & $\begin{array}{c}\text { Mass } \\
\text { retained } \\
(\mathrm{gm})\end{array}$ & $\begin{array}{c}\text { Total mass } \\
\text { passing } \\
(\mathrm{gm})\end{array}$ & $\begin{array}{c}\% \\
\text { passing }\end{array}$ & $\begin{array}{c}\text { Mass Retained } \\
\text { by the Sieve } \\
(\mathrm{gm} .)\end{array}$ & $\begin{array}{c}\text { Mass Retained } \\
\text { by the Sieve } \\
(\%)\end{array}$ \\
\hline 1 & $6.30 \mathrm{~mm}$ & 142.998 & 1.816 & 98.184 & 98.184 & 1.816 & 1.816 \\
2 & $3.35 \mathrm{~mm}$ & 146.306 & 5.124 & 94.876 & 94.876 & 3.308 & 3.308 \\
3 & $2 \mathrm{~mm}$ & 152.492 & 11.31 & 88.69 & 88.69 & 6.186 & 6.186 \\
4 & $1.18 \mathrm{~mm}$ & 157.361 & 16.179 & 83.821 & 83.821 & 4.869 & 4.869 \\
5 & $600 \mu \mathrm{m}$ & 159.398 & 18.216 & 81.784 & 81.784 & 2.037 & 2.037 \\
6 & $300 \mu \mathrm{m}$ & 164.298 & 23.116 & 76.884 & 76.884 & 4.9 & 4.9 \\
7 & $150 \mu \mathrm{m}$ & 177.348 & 36.166 & 63.834 & 63.834 & 13.05 & 13.05 \\
8 & $63 \mu \mathrm{m}$ & 179.322 & 38.14 & & & 63.834 & 63.834 \\
\hline
\end{tabular}




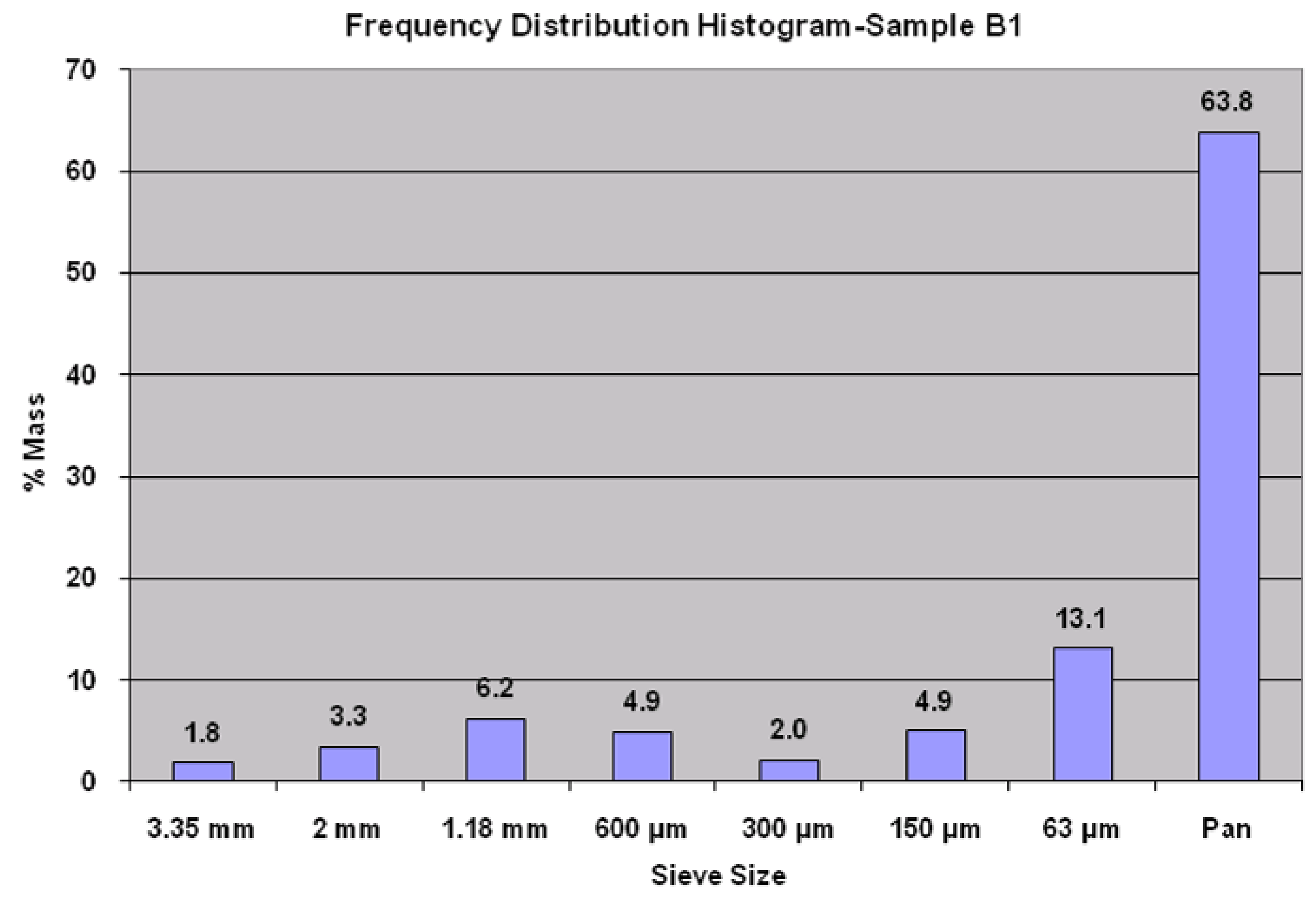

--- Page $A 12$--- 
Hydrometer method:

\begin{tabular}{|l|cl|}
\hline Initial mass of dry soil: & 100 & $\mathrm{gm}$ \\
\hline Dispersion: & 100 & $\mathrm{ml}$ \\
\hline Specific Gravity assumed/measured: & 2.65 & $\mathrm{Mg} / \mathrm{m}^{\wedge} 3$ \\
\hline Cylinder No.: & 1 & \\
\hline Hydrometer No.: & $785404 / \mathrm{B}$ \\
\hline Meniscus correction(Cm): & 0.5 \\
\hline Dispersing agent correction(Cd): & 4.073 \\
\hline Viscosity of Water: & Viscosity $=0.0005 \mathrm{~T}^{\wedge} 2-0.0448 \mathrm{~T}+1.7016$ \\
\hline Hydrometer Calibration: & $\mathrm{Hr}=211.14-4.11^{\star} \mathrm{Rh}$ \\
\hline
\end{tabular}

\begin{tabular}{|c|c|c|c|c|c|c|c|c|c|c|}
\hline Time & $\begin{array}{l}\text { Elapsed } \\
\text { Time } \\
\text { (min) }\end{array}$ & $\begin{array}{c}\text { Hydrometer } \\
\text { Reading } \\
\text { (R'h) }\end{array}$ & $\begin{array}{c}\text { Temp } \\
\text { (degree) }\end{array}$ & $\begin{array}{l}\text { Corrected } \\
\text { Hydrometer } \\
\text { Reading } \\
\text { Rh=R'h+Cm }\end{array}$ & $\begin{array}{l}\text { Effective } \\
\text { Depth } \\
\text { (Hr) }\end{array}$ & $\begin{array}{c}\text { Equivalent } \\
\text { Particle } \\
\text { Diameter D } \\
(\mathrm{mm})\end{array}$ & $\begin{array}{c}\text { Temperature } \\
\text { Correction } \\
\text { Mt }\end{array}$ & $\mathrm{Rh}+\mathrm{Mt}-\mathrm{Cd}$ & $\begin{array}{l}\text { W } \\
\%\end{array}$ & $\begin{array}{c}\text { Summation } \\
\%\end{array}$ \\
\hline 0 & 0 & & & & & & & & & \\
\hline $15^{\prime \prime}$ & 0.25 & & & & & & & & & \\
\hline $30 "$ & 0.5 & & & & & & & & & \\
\hline 1 & 1 & 34 & 15.1 & 34.5 & 69.345 & 0.038269691 & -0.75 & 29.677 & 0.7467 & 47.663061 \\
\hline $2^{\prime}$ & 2 & 32 & 15.1 & 32.5 & 77.565 & 0.028619713 & -0.75 & 27.677 & 0.6964 & 44.450939 \\
\hline $4^{\prime}$ & 4 & 31 & 15.1 & 31.5 & 81.675 & 0.020766435 & -0.75 & 26.677 & 0.6712 & 42.844879 \\
\hline $8^{\prime}$ & 8 & 29.5 & 15.1 & 30 & 87.84 & 0.015228199 & -0.75 & 25.177 & 0.6335 & 40.435788 \\
\hline $15^{\prime}$ & 15 & 26.4 & 15.2 & 26.9 & 100.58 & 0.011884852 & -0.74 & 22.087 & 0.5557 & 35.473061 \\
\hline $30^{\prime}$ & 30 & 23.6 & 15.2 & 24.1 & 112.09 & 0.008871607 & -0.74 & 19.287 & 0.4853 & 30.976091 \\
\hline 50 & 50 & 20.5 & 15.1 & 21 & 124.83 & 0.007261425 & -0.75 & 16.177 & 0.407 & 25.981242 \\
\hline $2 \mathrm{~h}$ & 120 & 17.6 & 15.2 & 18.1 & 136.75 & 0.004899513 & -0.74 & 13.287 & 0.3343 & 21.339727 \\
\hline $4 \mathrm{~h}$ & 240 & 15.1 & 15.6 & 15.6 & 147.02 & 0.003573638 & -0.69 & 10.837 & 0.2727 & 17.404879 \\
\hline $6 \mathrm{~h}$ & 360 & 13.9 & 15.7 & 14.4 & 151.96 & 0.002962553 & -0.68 & 9.647 & 0.2427 & 15.493667 \\
\hline $7 \mathrm{~h}$ & 420 & 13.5 & 15.8 & 14 & 153.6 & 0.002754014 & -0.67 & 9.257 & 0.2329 & 14.867303 \\
\hline $24 \mathrm{~h}$ & 1440 & 10.6 & 14.8 & 11.1 & 165.52 & 0.001564193 & -0.79 & 6.237 & 0.1569 & 10.017 \\
\hline
\end{tabular}


Cumulative Frequency Curve:

\begin{tabular}{|c|c|c|}
\hline $\begin{array}{c}\text { Equivalent } \\
\text { Particle } \\
\text { Diameter }(\mathrm{mm})\end{array}$ & $\begin{array}{c}\text { Cumulative } \% \\
\text { mass }\end{array}$ & $\begin{array}{c}\text { Cumulative } \\
\text { mass }\end{array}$ \\
\hline 6.3 & 100 & 1 \\
3.35 & 98.184 & 0.98184 \\
2 & 94.876 & 0.94876 \\
1.18 & 88.69 & 0.8869 \\
0.6 & 83.821 & 0.83821 \\
0.3 & 81.784 & 0.81784 \\
0.15 & 76.884 & 0.76884 \\
0.063 & 63.834 & 0.63834 \\
0.038269691 & 47.66306061 & 0.476630606 \\
0.028619713 & 44.45093939 & 0.444509394 \\
0.020766435 & 42.84487879 & 0.428448788 \\
0.015228199 & 40.43578788 & 0.404357879 \\
0.011884852 & 35.47306061 & 0.354730606 \\
0.008871607 & 30.97609091 & 0.309760909 \\
0.007261425 & 25.98124242 & 0.259812424 \\
0.004899513 & 21.33972727 & 0.213397273 \\
0.003573638 & 17.40487879 & 0.174048788 \\
0.002962553 & 15.49366667 & 0.154936667 \\
0.002754014 & 14.86730303 & 0.14867303 \\
0.001564193 & 10.017 & 0.10017 \\
\hline
\end{tabular}

Analysis based on the cumulative curve:

\begin{tabular}{|c|c|}
\hline D50 = & 0.0418 \\
\hline $\mathrm{D} 60=$ & 0.0571 \\
\hline $\mathrm{D} 10=$ & 0.001560 \\
\hline $\mathrm{D} 30=$ & 0.0086 \\
\hline
\end{tabular}

Coefficient of curvature: $\quad 0.8215$

Coefficient of uniformity: $\quad 36.6255$

\begin{tabular}{|c|c|c|c|}
\hline \multicolumn{4}{|c|}{ Particle Size Distribution } \\
\hline $\begin{array}{c}\text { Gravel } \\
(\%)\end{array}$ & $\begin{array}{c}\text { Sand } \\
(\%)\end{array}$ & $\begin{array}{c}\text { Silt } \\
(\%)\end{array}$ & $\begin{array}{c}\text { Clay } \\
(\%)\end{array}$ \\
\hline 5.1 & 33.0 & 50.1 & 11.8 \\
\hline
\end{tabular}




\section{Particle Size Distribution}

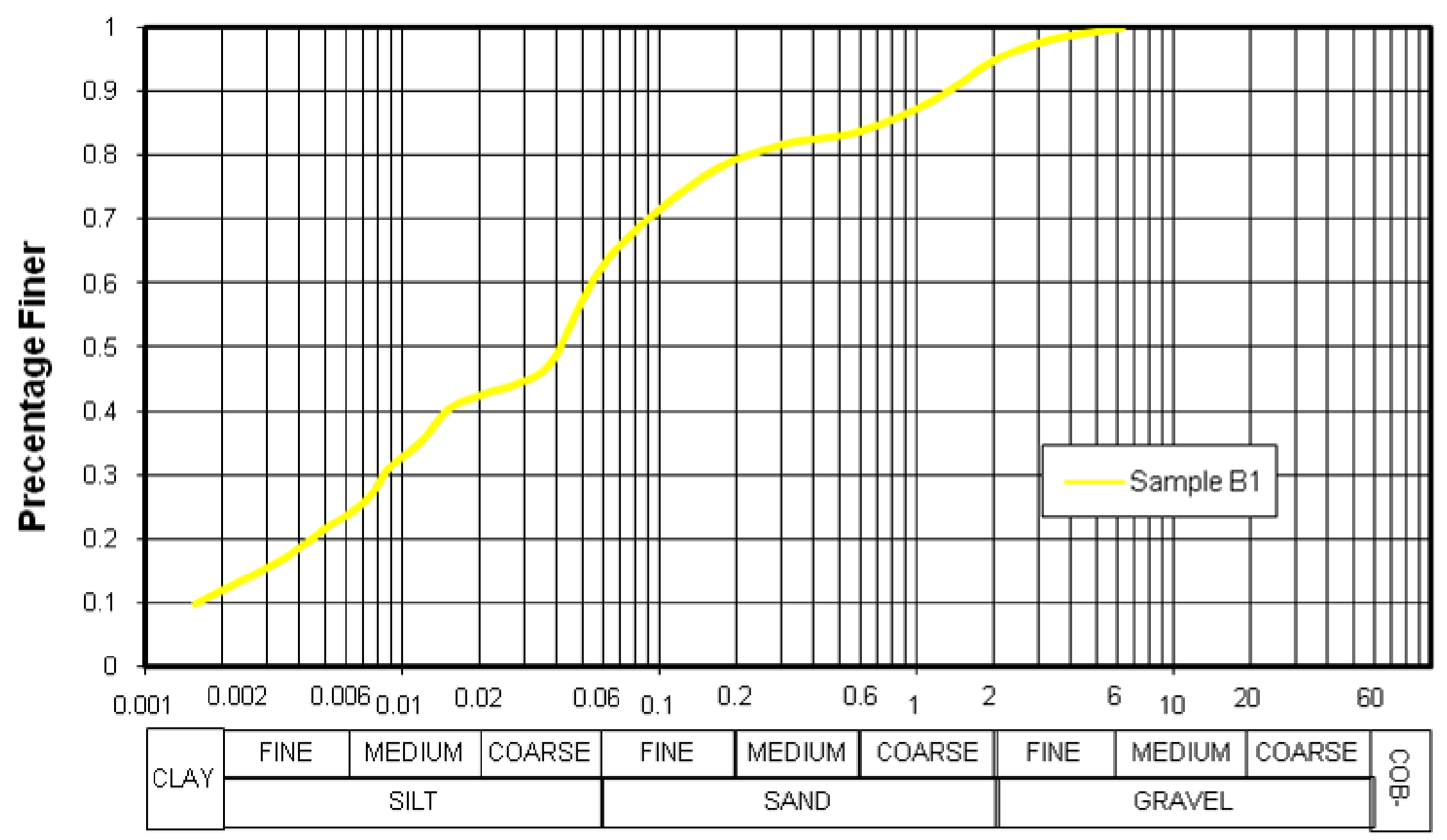




\section{Sample B2}

\section{Dry sieving:}

\begin{tabular}{|l|cc|}
\hline Wt. of Total Soil & 100 & $\mathrm{~g}$ \\
\hline Wt. of Dry Soil+Container: & 283.794 & $\mathrm{~g}$ \\
\hline Wt. of Dry Soil(>63)+Container & 283.575 & $\mathrm{~g}$ \\
\hline Wt. of Container & 196.538 & $\mathrm{~g}$ \\
\hline Wt. of Dry Soil(>63) & 87.037 & $\mathrm{~g}$ \\
\hline Wt. of Dry Soil passing 63 micron sieve(Ws) & 12.963 & $\mathrm{~g}$ \\
\hline \% of total sample mass (Ws\%) & 12.963 & \\
\hline
\end{tabular}

\begin{tabular}{|c|c|c|c|c|c|c|c|}
\hline $\begin{array}{c}\text { Sieve } \\
\text { Number }\end{array}$ & Sieve size & $\begin{array}{c}\text { Mass Retained } \\
+ \text { Container } \\
(\mathrm{gm})\end{array}$ & $\begin{array}{c}\text { Mass } \\
\text { retained } \\
(\mathrm{gm} .)\end{array}$ & $\begin{array}{c}\text { Total mass } \\
\text { passing } \\
(\mathrm{gm} .)\end{array}$ & $\begin{array}{c}\% \\
\text { passing }\end{array}$ & $\begin{array}{c}\text { Mass Retained } \\
\text { by the Sieve } \\
(\mathrm{gm} .)\end{array}$ & $\begin{array}{c}\text { Mass Retained } \\
\text { by the Sieve } \\
(\%)\end{array}$ \\
\hline 1 & $6.30 \mathrm{~mm}$ & 200.447 & 3.909 & 96.091 & 96.091 & 3.909 & 3.909 \\
2 & $3.35 \mathrm{~mm}$ & 208.047 & 11.509 & 88.491 & 88.491 & 7.6 & 7.6 \\
3 & $2 \mathrm{~mm}$ & 227.158 & 30.62 & 69.38 & 69.38 & 19.111 & 19.111 \\
4 & $1.18 \mathrm{~mm}$ & 249.469 & 52.931 & 47.069 & 47.069 & 22.311 & 22.311 \\
5 & $600 \mu \mathrm{m}$ & 263.963 & 67.425 & 32.575 & 32.575 & 14.494 & 14.494 \\
6 & $300 \mu \mathrm{m}$ & 274.056 & 77.518 & 22.482 & 22.482 & 10.093 & 10.093 \\
7 & $150 \mu \mathrm{m}$ & 283.575 & 87.037 & 12.963 & 12.963 & 9.519 & 9.519 \\
8 & $63 \mu \mathrm{m}$ & 283.762 & 87.224 & & & 12.963 & 12.963 \\
\hline
\end{tabular}




\section{Frequency Distribution Histogram-Sample B2}

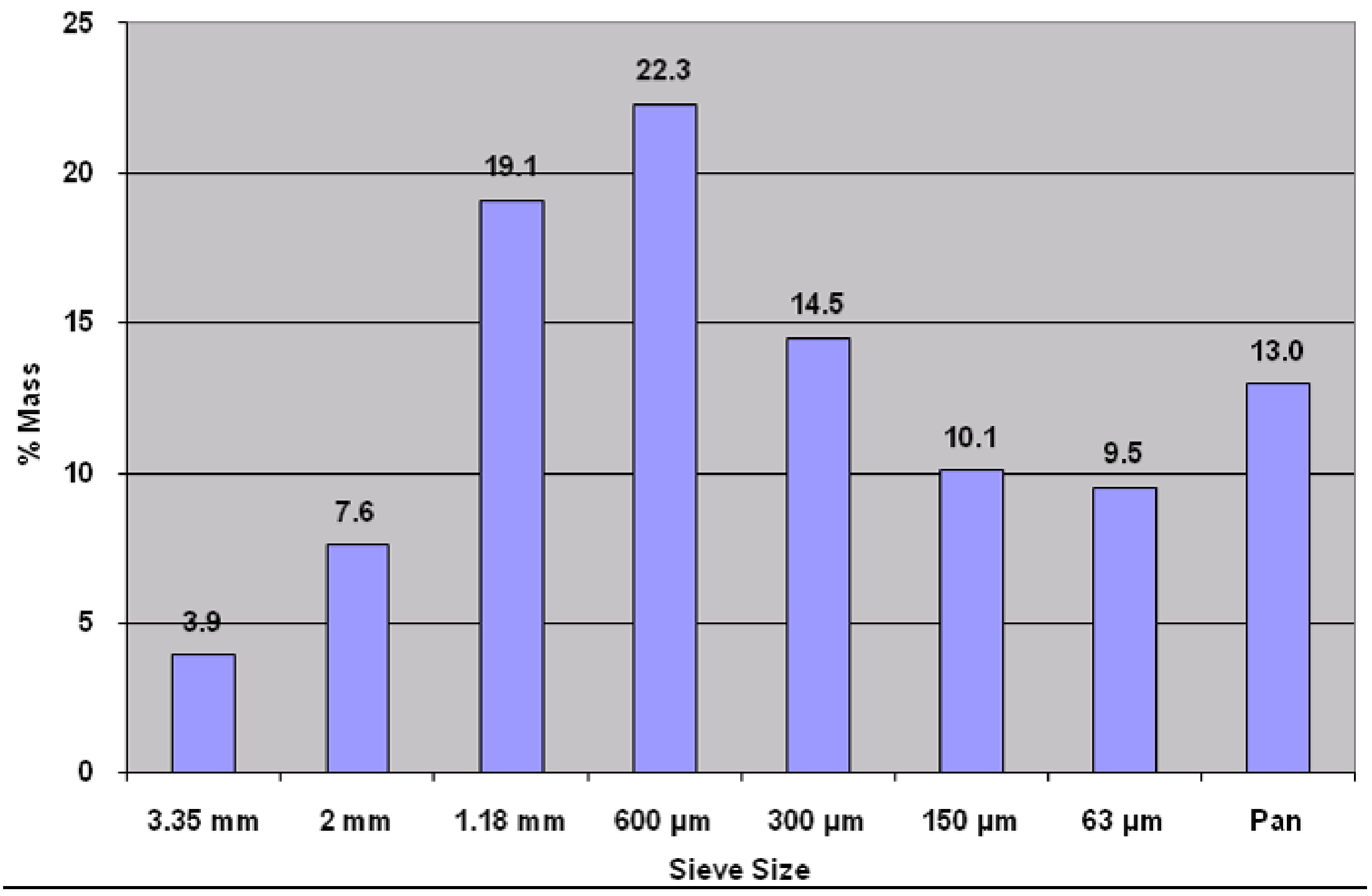


Hydrometer method:

\begin{tabular}{|l|cl|}
\hline Initial mass of dry soil: & 100 & $\mathrm{gm}$ \\
\hline Dispersion: & 100 & $\mathrm{ml}$ \\
\hline Specific Gravity assumed/measured: & 2.65 & $\mathrm{Mg} / \mathrm{m}^{\wedge} 3$ \\
\hline Cylinder No.: & 6 \\
\hline Hydrometer No.: & 41906 \\
\hline Meniscus correction(Cm): & 0.5 \\
\hline Dispersing agent correction(Cd): & 4.073 \\
\hline Viscosity of Water: & Viscosity $=0.0005 \mathrm{~T}^{\wedge} 2-0.0448 \mathrm{~T}+1.7016$ \\
\hline Hydrometer Calibration: & $\mathrm{Hr}=205.31-3.91^{\star} \mathrm{Rh}$ \\
\hline
\end{tabular}

\begin{tabular}{|c|c|c|c|c|c|c|c|c|c|c|}
\hline Time & $\begin{array}{l}\text { Elapsed } \\
\text { Time } \\
\text { (min) }\end{array}$ & $\begin{array}{l}\text { Hydrometer } \\
\text { Reading } \\
\left(\mathrm{R}^{\prime} \mathrm{h}\right)\end{array}$ & $\begin{array}{c}\text { Temp } \\
\text { (degree) }\end{array}$ & $\begin{array}{c}\text { Corrected } \\
\text { Hydrometer } \\
\text { Reading } \\
\text { Rh=R'h+Cm }\end{array}$ & $\begin{array}{l}\text { Effective } \\
\text { Depth } \\
\text { (Hr) }\end{array}$ & $\begin{array}{c}\text { Equivalent } \\
\text { Particle } \\
\text { Diameter D } \\
(\mathrm{mm})\end{array}$ & $\begin{array}{c}\text { Temperature } \\
\text { Correction } \\
\text { Mt }\end{array}$ & $\mathrm{Rh}+\mathrm{Mt}-\mathrm{Cd}$ & $\begin{array}{l}\text { W } \\
\%\end{array}$ & $\underset{\%}{\text { Summation }}$ \\
\hline 0 & 0 & & & & & & & & & \\
\hline $15^{\prime \prime}$ & 0.25 & & & & & & & & & \\
\hline $30 "$ & 0.5 & & & & & & & & & \\
\hline 1 & 1 & 9 & 15.1 & 9.5 & 168.17 & 0.059595735 & -0.75 & 4.677 & 0.5795 & 7.511545 \\
\hline $2^{\prime}$ & 2 & 8.5 & 15.1 & 9 & 170.12 & 0.042384793 & -0.75 & 4.177 & 0.5175 & 6.7085152 \\
\hline $4^{\prime}$ & 4 & 7.2 & 15.1 & 7.7 & 175.2 & 0.030415023 & -0.75 & 2.877 & 0.3564 & 4.6206364 \\
\hline $8^{\prime}$ & 8 & 6 & 15.2 & 6.5 & 179.9 & 0.021764364 & -0.74 & 1.687 & 0.209 & 2.7094242 \\
\hline $15^{\prime}$ & 15 & 5.8 & 15.2 & 6.3 & 180.68 & 0.015928953 & -0.74 & 1.487 & 0.1842 & 2.3882121 \\
\hline $30^{\prime}$ & 30 & 5.4 & 15.2 & 5.9 & 182.24 & 0.011312116 & -0.74 & 1.087 & 0.1347 & 1.7457879 \\
\hline $1 \mathrm{~h}$ & 60 & 4.9 & 15.1 & 5.4 & 184.2 & 0.00805215 & -0.75 & 0.577 & 0.0715 & 0.926697 \\
\hline $2 \mathrm{~h}$ & 120 & 4.4 & 15.2 & 4.9 & 186.15 & 0.005716412 & -0.74 & 0.087 & 0.0108 & 0.1397273 \\
\hline $4 \mathrm{~h}$ & 240 & 3.9 & 15.6 & 4.4 & 188.11 & 0.0040422 & -0.69 & -0.363 & -0.045 & -0.583 \\
\hline $6 \mathrm{~h}$ & 360 & 3.6 & 15.7 & 4.1 & 189.28 & 0.003306423 & -0.68 & -0.653 & -0.0809 & -1.048758 \\
\hline $7 \mathrm{~h}$ & 420 & 3.4 & 15.8 & 3.9 & 190.06 & 0.003063494 & -0.67 & -0.843 & -0.1044 & -1.353909 \\
\hline $24 \mathrm{~h}$ & 1440 & 3 & 14.8 & 3.5 & 191.63 & 0.001683033 & -0.79 & -1.363 & -0.1689 & -2.189061 \\
\hline
\end{tabular}


Cumulative Frequency Curve:

\begin{tabular}{|c|c|c|}
\hline $\begin{array}{c}\text { Equivalent Particle } \\
\text { Diameter }(\mathrm{mm})\end{array}$ & $\begin{array}{c}\text { Cumulative } \% \\
\text { mass }\end{array}$ & $\begin{array}{c}\text { Cumulative } \\
\text { mass }\end{array}$ \\
\hline 6.3 & 100 & 1 \\
3.35 & 96.091 & 0.96091 \\
2 & 88.491 & 0.88491 \\
1.18 & 69.38 & 0.6938 \\
0.6 & 47.069 & 0.47069 \\
0.3 & 32.575 & 0.32575 \\
0.15 & 22.482 & 0.22482 \\
0.063 & 12.963 & 0.12963 \\
0.042384793 & 6.708515152 & 0.06708515 \\
0.030415023 & 4.620636364 & 0.04620636 \\
0.021764364 & 2.709424242 & 0.02709424 \\
0.015928953 & 2.388212121 & 0.02388212 \\
0.011312116 & 1.745787879 & 0.01745788 \\
0.00805215 & 0.92669697 & 0.00926697 \\
0.005716412 & 0.139727273 & 0.00139727 \\
\hline
\end{tabular}

Analysis based on the cumulative curve:

$\begin{array}{lll}\text { D50 }= & 0.6762 & \mathrm{~mm} \\ \text { D60 }= & 0.9362 & \mathrm{~mm} \\ \text { D10 } & 0.0532 & \mathrm{~mm} \\ \text { D30 }= & 0.2617 & \mathrm{~mm}\end{array}$

Coefficient of curvature: $\quad 1.3746$

Coefficient of uniformity: $\quad 17.5858$

\begin{tabular}{|c|c|c|c|}
\hline \multicolumn{4}{|c|}{ Particle Size Distribution } \\
\hline $\begin{array}{c}\text { Gravel } \\
(\%)\end{array}$ & $\begin{array}{c}\text { Sand } \\
(\%)\end{array}$ & $\begin{array}{c}\text { Silt } \\
(\%)\end{array}$ & $\begin{array}{c}\text { Clay } \\
(\%)\end{array}$ \\
\hline 11.5 & 76.4 & 12.1 & 0.0 \\
\hline
\end{tabular}




\section{Particle Size Distribution}

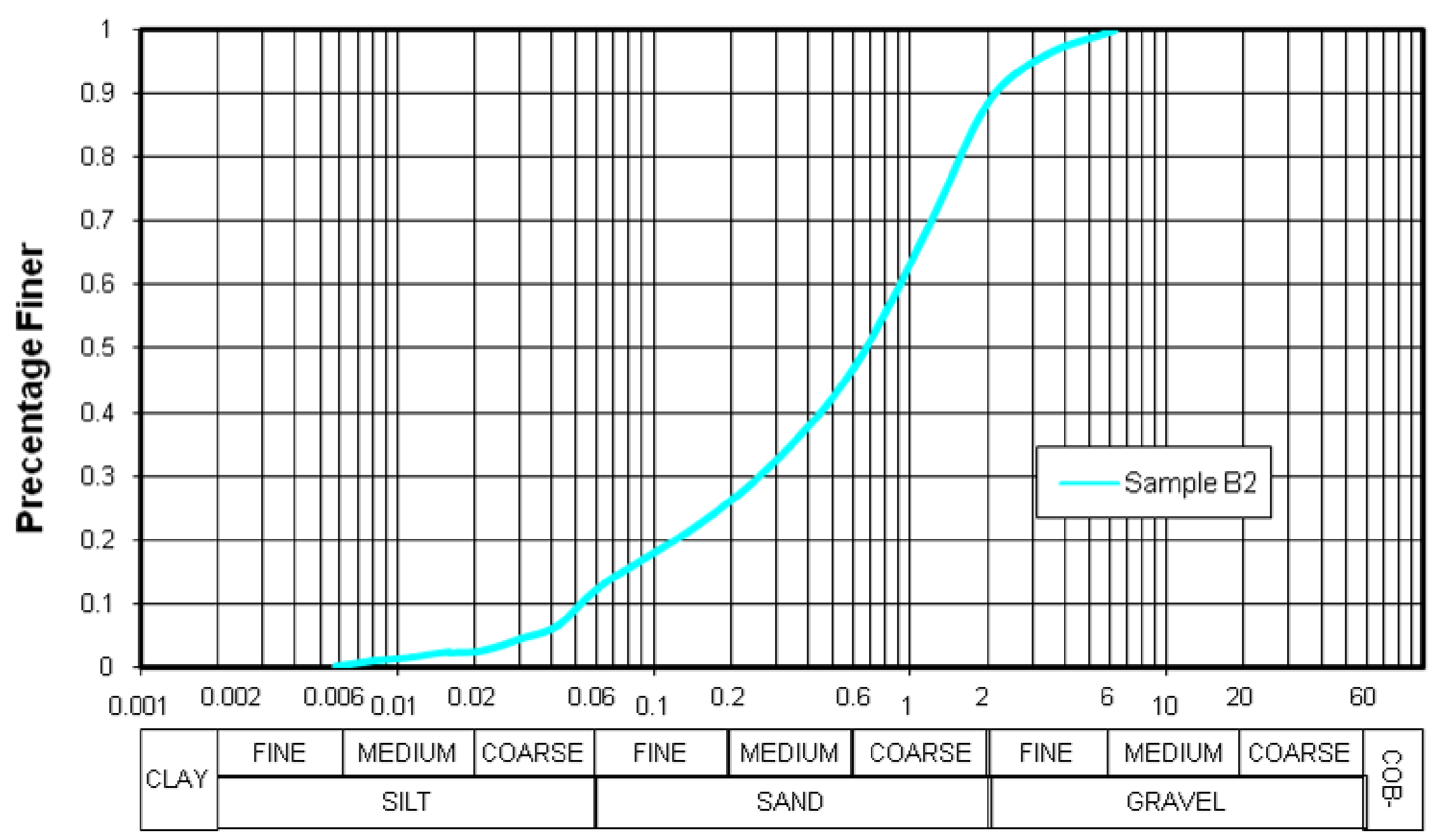




\section{Sample C}

Dry sieving:

\begin{tabular}{|l|cc|}
\hline Wt. of Total Soil & 100 & $\mathrm{~g}$ \\
\hline Wt. of Dry Soil+Container: & 213.64 & $\mathrm{~g}$ \\
\hline Wt. of Dry Soil(>63)+Container & 213.323 & $\mathrm{~g}$ \\
\hline Wt. of Container & 141.791 & $\mathrm{~g}$ \\
\hline Wt. of Dry Soil(>63) & 71.532 & $\mathrm{~g}$ \\
\hline Wt. of Dry Soil passing 63 micron sieve(Ws) & 28.468 & $\mathrm{~g}$ \\
\hline \% of total sample mass (Ws\%) & 28.468 & \\
\hline
\end{tabular}

\begin{tabular}{|c|c|c|c|c|c|c|c|}
\hline $\begin{array}{c}\text { Sieve } \\
\text { Number }\end{array}$ & Sieve size & $\begin{array}{c}\text { Mass Retained } \\
\text { + Container } \\
(\mathrm{gm})\end{array}$ & $\begin{array}{c}\text { Mass } \\
\text { retained } \\
(\mathrm{gm} .)\end{array}$ & $\begin{array}{c}\text { Total mass } \\
\text { passing } \\
(\mathrm{gm} .)\end{array}$ & $\begin{array}{c}\% \\
\text { passing }\end{array}$ & $\begin{array}{c}\text { Mass Retained } \\
\text { by the Sieve } \\
(\mathrm{gm} .)\end{array}$ & $\begin{array}{c}\text { Mass Retained } \\
\text { by the Sieve } \\
(\%)\end{array}$ \\
\hline 1 & $6.30 \mathrm{~mm}$ & & 0 & & & & \\
2 & $3.35 \mathrm{~mm}$ & 146.404 & 4.613 & 95.387 & 95.387 & 4.613 & 4.613 \\
3 & $2 \mathrm{~mm}$ & 154.663 & 12.872 & 87.128 & 87.128 & 8.259 & 8.259 \\
4 & $1.18 \mathrm{~mm}$ & 169.984 & 28.193 & 71.807 & 71.807 & 15.321 & 15.321 \\
5 & $600 \mu \mathrm{m}$ & 183.522 & 41.731 & 58.269 & 58.269 & 13.538 & 13.538 \\
6 & $300 \mu \mathrm{m}$ & 192.197 & 50.406 & 49.594 & 49.594 & 8.675 & 8.675 \\
7 & $150 \mu \mathrm{m}$ & 203.8 & 62.009 & 37.991 & 37.991 & 11.603 & 11.603 \\
8 & $63 \mu \mathrm{m}$ & 213.323 & 71.532 & 28.468 & 28.468 & 9.523 & 9.523 \\
9 & Pan & 213.71 & 71.919 & & & 28.468 & 28.468 \\
\hline
\end{tabular}




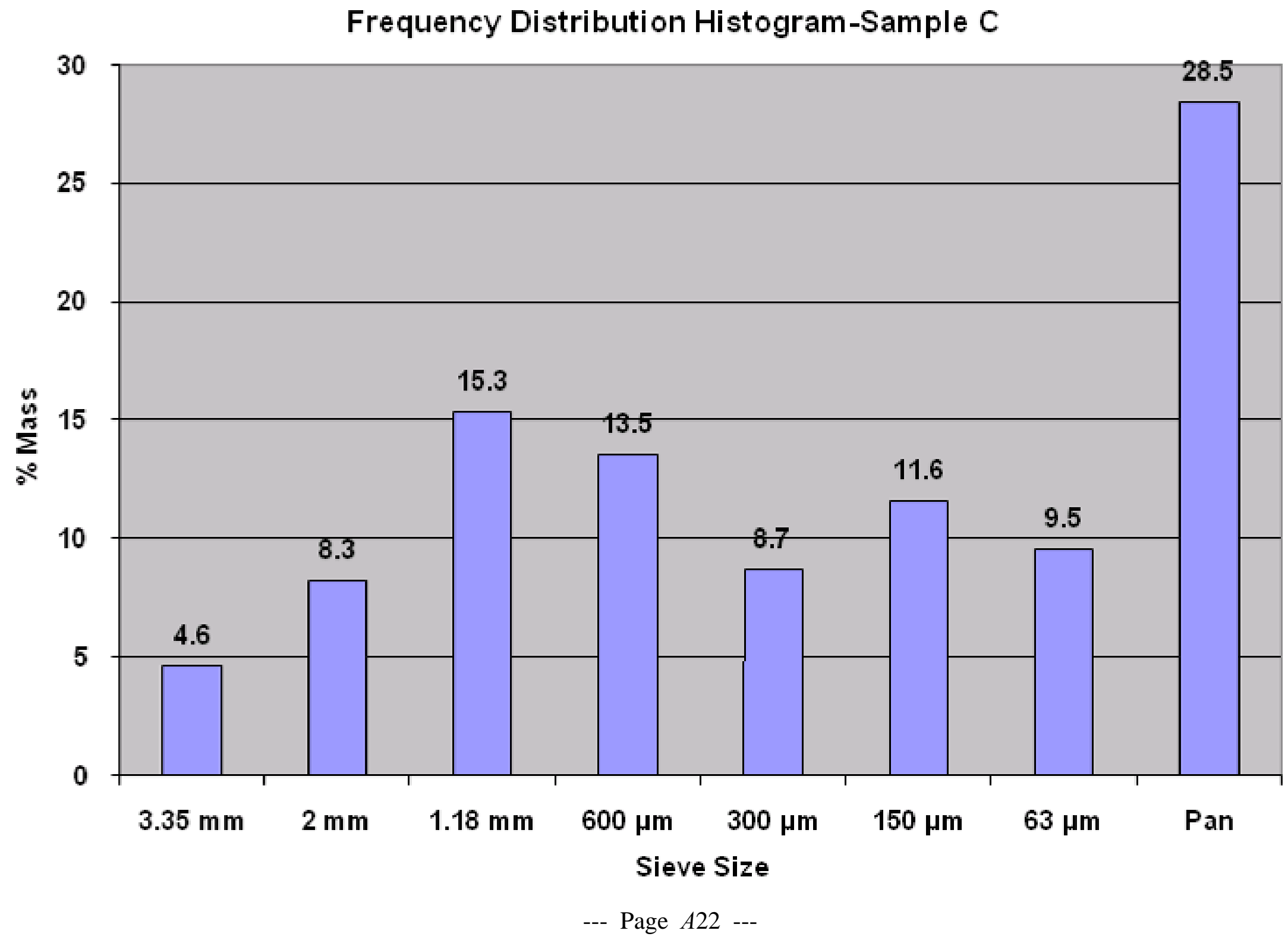


Hydrometer method:

\begin{tabular}{|l|cl|}
\hline Initial mass of dry soil: & 100 & $\mathrm{gm}$ \\
\hline Dispersion: & 100 & $\mathrm{ml}$ \\
\hline Specific Gravity assumed/measured: & 2.65 & $\mathrm{Mg} / \mathrm{m}^{\wedge} 3$ \\
\hline Cylinder No.: & 1 & \\
\hline Hydrometer No.: & $785404 / \mathrm{B}$ \\
\hline Meniscus correction(Cm): & 0.5 \\
\hline Dispersing agent correction(Cd): & 4.168 \\
\hline Viscosity of Water: & Viscosity $=0.0005 \mathrm{~T}^{\wedge} 2-0.0448 \mathrm{~T}+1.7016$ \\
\hline Hydrometer Calibration: & $\mathrm{Hr}=211.14-4.11^{\star} \mathrm{Rh}$ \\
\hline
\end{tabular}

\begin{tabular}{|c|c|c|c|c|c|c|c|c|c|c|}
\hline Time & $\begin{array}{l}\text { Elapsed } \\
\text { Time (min) }\end{array}$ & $\begin{array}{l}\text { Hydrometer } \\
\text { Reading } \\
\text { (R'h) }\end{array}$ & $\begin{array}{c}\text { Temp } \\
\text { (degree) }\end{array}$ & $\begin{array}{l}\text { Corrected } \\
\text { Hydrometer } \\
\text { Reading } \\
\text { Rh=R'h+Cm }\end{array}$ & $\begin{array}{l}\text { Effective } \\
\text { Depth } \\
(\mathrm{Hr})\end{array}$ & $\begin{array}{l}\text { Equivalent } \\
\text { Particle } \\
\text { Diameter D } \\
(\mathrm{mm})\end{array}$ & $\begin{array}{c}\text { Temperature } \\
\text { Correction } \\
\text { Mt }\end{array}$ & $\mathrm{Rh}+\mathrm{Mt}-\mathrm{Cd}$ & $\begin{array}{l}\text { W } \\
\%\end{array}$ & $\begin{array}{c}\text { Summation } \\
\%\end{array}$ \\
\hline 0 & 0 & & & & & & & & & \\
\hline $15^{\prime \prime}$ & 0.25 & & & & & & & & & \\
\hline $30 "$ & 0.5 & 19 & 15.2 & 19.5 & 131 & 0.074288877 & -0.74 & 14.592 & 0.8232 & 23.435636 \\
\hline 1 & 1 & 18 & 15.2 & 18.5 & 135.11 & 0.053347877 & -0.74 & 13.592 & 0.7668 & 21.829576 \\
\hline $2^{\prime}$ & 2 & 15.5 & 15.2 & 16 & 145.38 & 0.039130804 & -0.74 & 11.092 & 0.6258 & 17.814424 \\
\hline $4^{\prime}$ & 4 & 13.2 & 15.2 & 13.7 & 154.83 & 0.028555068 & -0.74 & 8.792 & 0.496 & 14.120485 \\
\hline $8^{\prime}$ & 8 & 12.1 & 15.2 & 12.6 & 159.35 & 0.020484149 & -0.74 & 7.692 & 0.434 & 12.353818 \\
\hline $15^{\prime}$ & 15 & 11.8 & 15.2 & 12.3 & 160.59 & 0.01501727 & -0.74 & 7.392 & 0.417 & 11.872 \\
\hline $30^{\prime}$ & 30 & 10.6 & 15 & 11.1 & 165.52 & 0.010808789 & -0.76 & 6.172 & 0.3482 & 9.9126061 \\
\hline $50^{\prime}$ & 50 & 9.7 & 15.4 & 10.2 & 169.22 & 0.008421494 & -0.71 & 5.322 & 0.3002 & 8.5474545 \\
\hline $2 \mathrm{~h}$ & 120 & 8.5 & 15.1 & 9 & 174.15 & 0.005536286 & -0.75 & 4.082 & 0.2303 & 6.5559394 \\
\hline $4 \mathrm{~h}$ & 240 & 7.4 & 15.9 & 7.9 & 178.67 & 0.003924225 & -0.65 & 3.082 & 0.1739 & 4.9498788 \\
\hline $6 \mathrm{~h}$ & 360 & 6.9 & 15.7 & 7.4 & 180.73 & 0.003230855 & -0.68 & 2.552 & 0.144 & 4.0986667 \\
\hline $7 \mathrm{~h}$ & 420 & 6.5 & 15.5 & 7 & 182.37 & 0.003012578 & -0.7 & 2.132 & 0.1203 & 3.4241212 \\
\hline $24 \mathrm{~h}$ & 1440 & 5 & 15.4 & 5.5 & 188.54 & 0.001656401 & -0.71 & 0.622 & 0.0351 & 0.9989697 \\
\hline
\end{tabular}


Cumulative Frequency Curve Plot:

\begin{tabular}{|c|c|c|}
\hline $\begin{array}{c}\text { Equivalent Particle } \\
\text { Diameter }(\mathrm{mm})\end{array}$ & $\begin{array}{c}\text { Cumulative } \% \\
\text { mass }\end{array}$ & $\begin{array}{c}\text { Cumulative } \\
\text { mass }\end{array}$ \\
\hline 6.3 & 100 & 1 \\
3.35 & 95.387 & 0.95387 \\
2 & 87.128 & 0.87128 \\
1.18 & 71.807 & 0.71807 \\
0.6 & 58.269 & 0.58269 \\
0.3 & 49.594 & 0.49594 \\
0.15 & 37.991 & 0.37991 \\
0.063 & 28.468 & 0.28468 \\
0.053347877 & 21.82957576 & 0.21829576 \\
0.039130804 & 17.81442424 & 0.17814424 \\
0.028555068 & 14.12048485 & 0.14120485 \\
0.020484149 & 12.35381818 & 0.12353818 \\
0.01501727 & 11.872 & 0.11872 \\
0.010808789 & 9.912606061 & 0.09912606 \\
0.008421494 & 8.547454545 & 0.08547455 \\
0.005536286 & 6.555939394 & 0.06555939 \\
0.003924225 & 4.949878788 & 0.04949879 \\
0.003230855 & 4.098666667 & 0.04098667 \\
0.003012578 & 3.424121212 & 0.03424121 \\
0.001656401 & 0.998969697 & 0.0099897 \\
\hline
\end{tabular}

Analysis based on the cumulative curve:

$\begin{array}{lll}\text { D50 }= & 0.3140 & \mathrm{~mm} \\ \text { D60 }= & 0.6742 & \mathrm{~mm} \\ \text { D10 } & 0.0110 & \mathrm{~mm} \\ \text { D30 }= & 0.0770 & \mathrm{~mm}\end{array}$

Coefficient of curvature: $\quad 0.7997$

Coefficient of uniformity: $\quad 61.3068$

\begin{tabular}{|c|c|c|c|}
\hline \multicolumn{4}{|c|}{ Particle Size Distribution } \\
\hline $\begin{array}{c}\text { Gravel } \\
(\%)\end{array}$ & $\begin{array}{c}\text { Sand } \\
(\%)\end{array}$ & $\begin{array}{c}\text { Silt } \\
(\%)\end{array}$ & $\begin{array}{c}\text { Clay } \\
(\%)\end{array}$ \\
\hline 12.9 & 60.7 & 24.8 & 1.6 \\
\hline
\end{tabular}




\section{Particle Size Distribution}

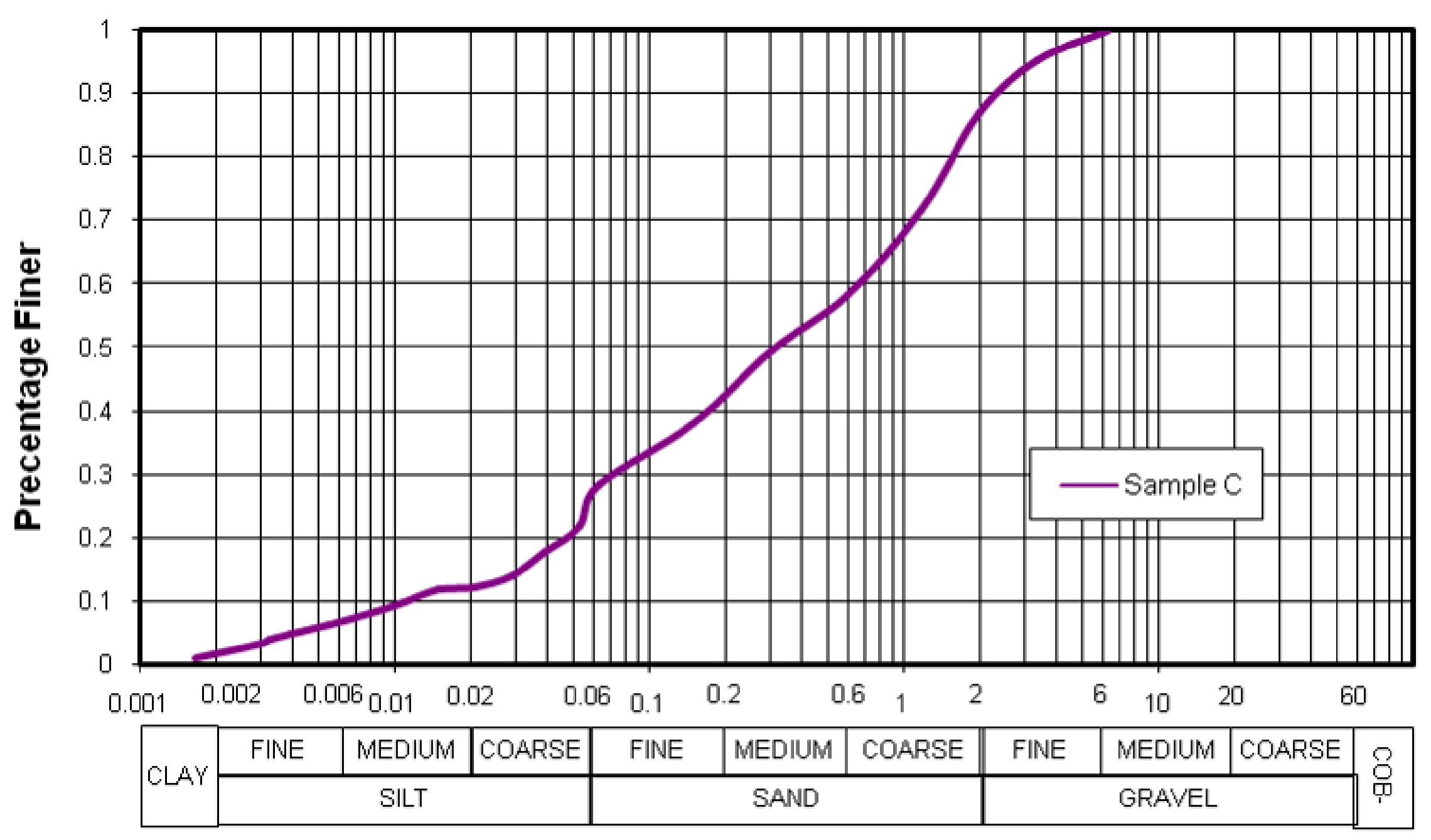




\section{Sample D1}

Dry sieving:

\begin{tabular}{|l|cc|}
\hline Wt. of Total Soil & 100 & $\mathrm{~g}$ \\
\hline Wt. of Dry Soil+Container: & 230.844 & $\mathrm{~g}$ \\
\hline Wt. of Dry Soil(>63)+Container & 230.863 & $\mathrm{~g}$ \\
\hline Wt. of Container & 148.596 & $\mathrm{~g}$ \\
\hline Wt. of Dry Soil(>63) & 82.267 & $\mathrm{~g}$ \\
\hline Wt. of Dry Soil passing 63 micron sieve(Ws) & 17.733 & $\mathrm{~g}$ \\
\hline \% of total sample mass (Ws\%) & 17.733 & \\
\hline
\end{tabular}

\begin{tabular}{|c|c|c|c|c|c|c|c|}
\hline $\begin{array}{c}\text { Sieve } \\
\text { Number }\end{array}$ & Sieve size & $\begin{array}{c}\text { Mass Retained } \\
\text { +Container } \\
(\mathrm{gm})\end{array}$ & $\begin{array}{c}\text { Mass } \\
\text { retained } \\
(\mathrm{gm} .)\end{array}$ & $\begin{array}{c}\text { Total mass } \\
\text { passing } \\
(\mathrm{gm} .)\end{array}$ & $\begin{array}{c}\% \\
\text { passing }\end{array}$ & $\begin{array}{c}\text { Mass Retained } \\
\text { by the Sieve } \\
(\mathrm{gm} .)\end{array}$ & $\begin{array}{c}\text { Mass Retained } \\
\text { by the Sieve } \\
(\%)\end{array}$ \\
\hline 1 & $6.30 \mathrm{~mm}$ & 0 & & & & & \\
2 & $3.35 \mathrm{~mm}$ & 151.852 & 3.256 & 96.744 & 96.744 & 3.256 & 3.256 \\
3 & $2 \mathrm{~mm}$ & 158.635 & 10.039 & 89.961 & 89.961 & 6.783 & 6.783 \\
4 & $1.18 \mathrm{~mm}$ & 168.967 & 20.371 & 79.629 & 79.629 & 10.332 & 10.332 \\
5 & $600 \mu \mathrm{m}$ & 182.177 & 33.581 & 66.419 & 66.419 & 13.21 & 13.21 \\
6 & $300 \mu \mathrm{m}$ & 201.024 & 52.428 & 47.572 & 47.572 & 18.847 & 18.847 \\
7 & $150 \mu \mathrm{m}$ & 222.032 & 73.436 & 26.564 & 26.564 & 21.008 & 21.008 \\
8 & $63 \mu \mathrm{m}$ & 230.863 & 82.267 & 17.733 & 17.733 & 8.831 & 8.831 \\
9 & Pan & 230.974 & 82.378 & & & 17.733 & 17.733 \\
\hline
\end{tabular}




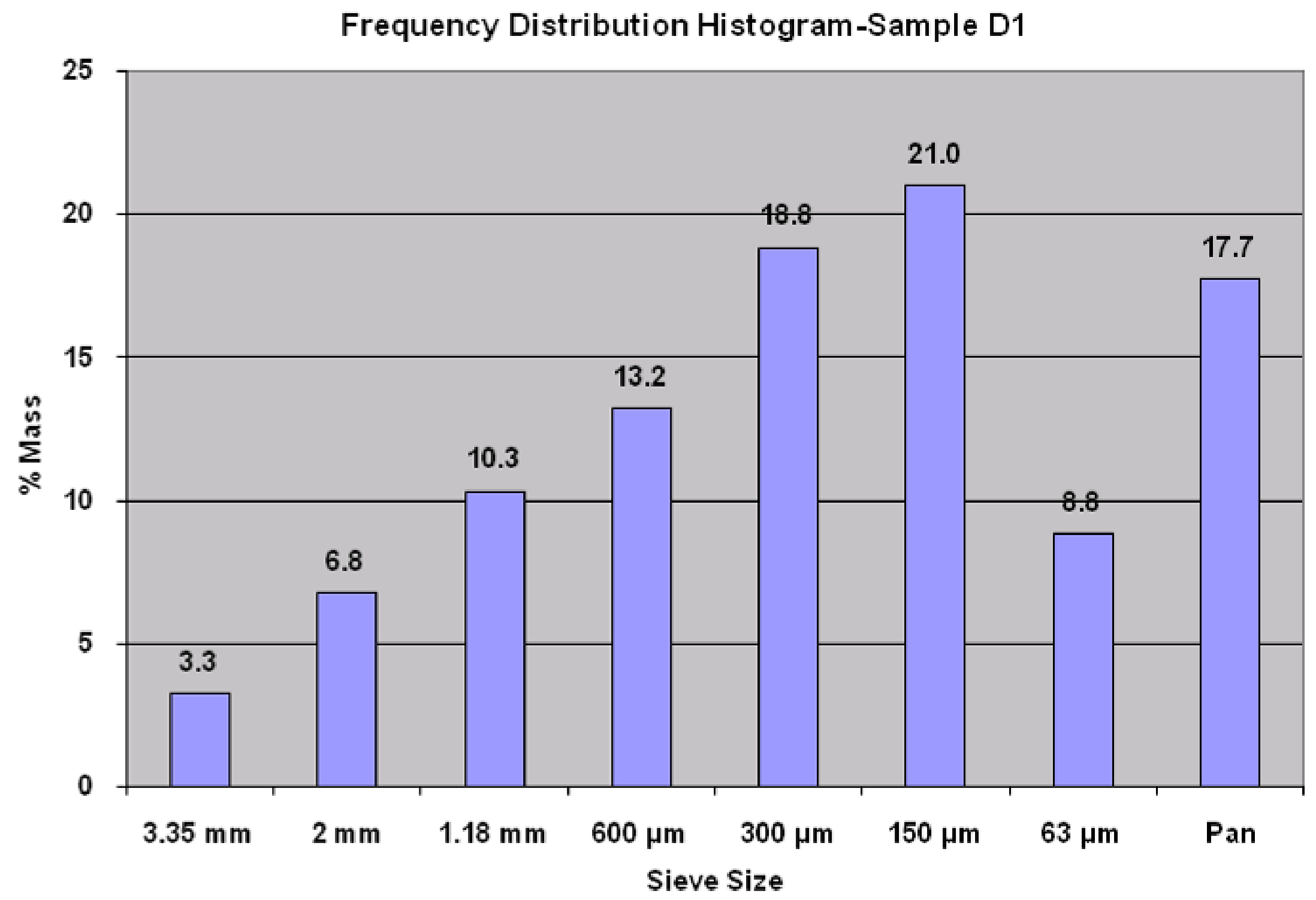

--- Page A27 --- 
Hydrometer method:

\begin{tabular}{|l|cl|}
\hline Initial mass of dry soil: & 100 & $\mathrm{gm}$ \\
\hline Dispersion: & 100 & $\mathrm{ml}$ \\
\hline Specific Gravity assumed/measured: & 2.65 & $\mathrm{Mg} / \mathrm{m}^{\wedge} 3$ \\
\hline Cylinder No.: & 6 \\
\hline Hydrometer No.: & 41906 \\
\hline Meniscus correction(Cm): & 0.5 \\
\hline Dispersing agent correction(Cd): & 4.397 \\
\hline Viscosity of Water: & Viscosity $=0.0005 \mathrm{~T}^{\wedge} 2-0.0448 \mathrm{~T}+1.7016$ \\
\hline Hydrometer Calibration: & $\mathrm{Hr}=205.31-3.91^{\star} \mathrm{Rh}$ \\
\hline
\end{tabular}

\begin{tabular}{|c|c|c|c|c|c|c|c|c|c|c|}
\hline Time & $\begin{array}{c}\text { Elapsed } \\
\text { Time } \\
\text { (min) }\end{array}$ & $\begin{array}{c}\text { Hydrometer } \\
\text { Reading } \\
\text { (R'h) }\end{array}$ & $\begin{array}{c}\text { Temp } \\
\text { (degree) }\end{array}$ & $\begin{array}{l}\text { Corrected } \\
\text { Hydrometer } \\
\text { Reading } \\
\text { Rh=R'h+Cm }\end{array}$ & $\begin{array}{l}\text { Effective } \\
\text { Depth } \\
(\mathrm{Hr})\end{array}$ & $\begin{array}{l}\text { Equivalent } \\
\text { Particle } \\
\text { Diameter D } \\
(\mathrm{mm})\end{array}$ & $\begin{array}{c}\text { Temperature } \\
\text { Correction } \\
\text { Mt }\end{array}$ & $\mathrm{Rh}+\mathrm{Mt}-\mathrm{Cd}$ & $\begin{array}{l}W \\
\%\end{array}$ & $\begin{array}{c}\text { Summation } \\
\%\end{array}$ \\
\hline 0 & 0 & & & & & & & & & \\
\hline $15^{\prime \prime}$ & 0.25 & & & & & & & & & \\
\hline 30" & 0.5 & & & & & & & & & \\
\hline 1 & 1 & 12.4 & 15.5 & 12.9 & 154.87 & 0.056894634 & -0.7 & 7.803 & 0.7067 & 12.532091 \\
\hline $2^{\prime}$ & 2 & 11 & 15.5 & 11.5 & 160.35 & 0.040935393 & -0.7 & 6.403 & 0.5799 & 10.283606 \\
\hline $4^{\prime}$ & 4 & 9.5 & 15.5 & 10 & 166.21 & 0.029470319 & -0.7 & 4.903 & 0.4441 & 7.8745152 \\
\hline $8^{\prime}$ & 8 & 8.7 & 15.5 & 9.2 & 169.34 & 0.021033836 & -0.7 & 4.103 & 0.3716 & 6.5896667 \\
\hline $15^{\prime}$ & 15 & 8.4 & 15.5 & 8.9 & 170.51 & 0.015414052 & -0.7 & 3.803 & 0.3444 & 6.1078485 \\
\hline $30^{\prime}$ & 30 & 7.6 & 15.6 & 8.1 & 173.64 & 0.010984622 & -0.69 & 3.013 & 0.2729 & 4.8390606 \\
\hline $1 \mathrm{~h}$ & 60 & 6.8 & 15.3 & 7.3 & 176.77 & 0.007867575 & -0.67 & 2.233 & 0.2022 & 3.5863333 \\
\hline $2 \mathrm{~h}$ & 120 & 6.2 & 15.5 & 6.7 & 179.11 & 0.005585463 & -0.7 & 1.603 & 0.1452 & 2.5745152 \\
\hline $4 \mathrm{~h}$ & 240 & 5.9 & 15.4 & 6.4 & 180.29 & 0.003967585 & -0.71 & 1.293 & 0.1171 & 2.0766364 \\
\hline $6 h$ & 360 & 5.4 & 16 & 5.9 & 182.24 & 0.003231782 & -0.64 & 0.863 & 0.0782 & 1.3860303 \\
\hline $7 \mathrm{~h}$ & 420 & 5.3 & 15 & 5.8 & 182.63 & 0.003034433 & -0.76 & 0.643 & 0.0582 & 1.032697 \\
\hline $24 \mathrm{~h}$ & 1440 & 4.5 & 15.2 & 5 & 185.76 & 0.001648452 & -0.74 & -0.137 & -0.0124 & -0.22003 \\
\hline
\end{tabular}


Cumulative Frequency Curve:

\begin{tabular}{|c|c|c|}
\hline $\begin{array}{c}\text { Equivalent Particle } \\
\text { Diameter }(\mathrm{mm})\end{array}$ & $\begin{array}{c}\text { Cumulative } \% \\
\text { mass }\end{array}$ & $\begin{array}{c}\text { Cumulative } \\
\text { mass }\end{array}$ \\
\hline 6.3 & 100 & 1 \\
3.35 & 96.744 & 0.96744 \\
2 & 89.961 & 0.89961 \\
1.18 & 79.629 & 0.79629 \\
0.6 & 66.419 & 0.66419 \\
0.3 & 47.572 & 0.47572 \\
0.15 & 26.564 & 0.26564 \\
0.063 & 17.733 & 0.17733 \\
0.040935393 & 10.28360606 & 0.10283606 \\
0.029470319 & 7.874515152 & 0.07874515 \\
0.021033836 & 6.589666667 & 0.06589667 \\
0.015414052 & 6.107848485 & 0.06107848 \\
0.010984622 & 4.839060606 & 0.04839061 \\
0.007867575 & 3.586333333 & 0.03586333 \\
0.005585463 & 2.574515152 & 0.02574515 \\
0.003967585 & 2.076636364 & 0.02076636 \\
0.003231782 & 1.386030303 & 0.0138603 \\
\hline
\end{tabular}

Analysis based on the cumulative curve:

$\begin{array}{lll}\text { D50 }= & 0.3386 & \mathrm{~mm} \\ \text { D60 }= & 0.4978 & \mathrm{~mm} \\ \text { D10 }= & 0.0396 & \mathrm{~mm} \\ \text { D30 }= & 0.1745 & \mathrm{~mm}\end{array}$

Coefficient of curvature: $\quad 1.5458$

Coefficient of uniformity: $\quad 12.5759$

\begin{tabular}{|c|c|c|c|}
\hline \multicolumn{4}{|c|}{ Particle Size Distribution } \\
\hline $\begin{array}{c}\text { Gravel } \\
(\%)\end{array}$ & $\begin{array}{c}\text { Sand } \\
(\%)\end{array}$ & $\begin{array}{c}\text { Silt } \\
(\%)\end{array}$ & $\begin{array}{c}\text { Clay } \\
(\%)\end{array}$ \\
\hline 10.0 & 73.2 & 16.7 & 0.0 \\
\hline
\end{tabular}




\section{Particle Size Distribution}

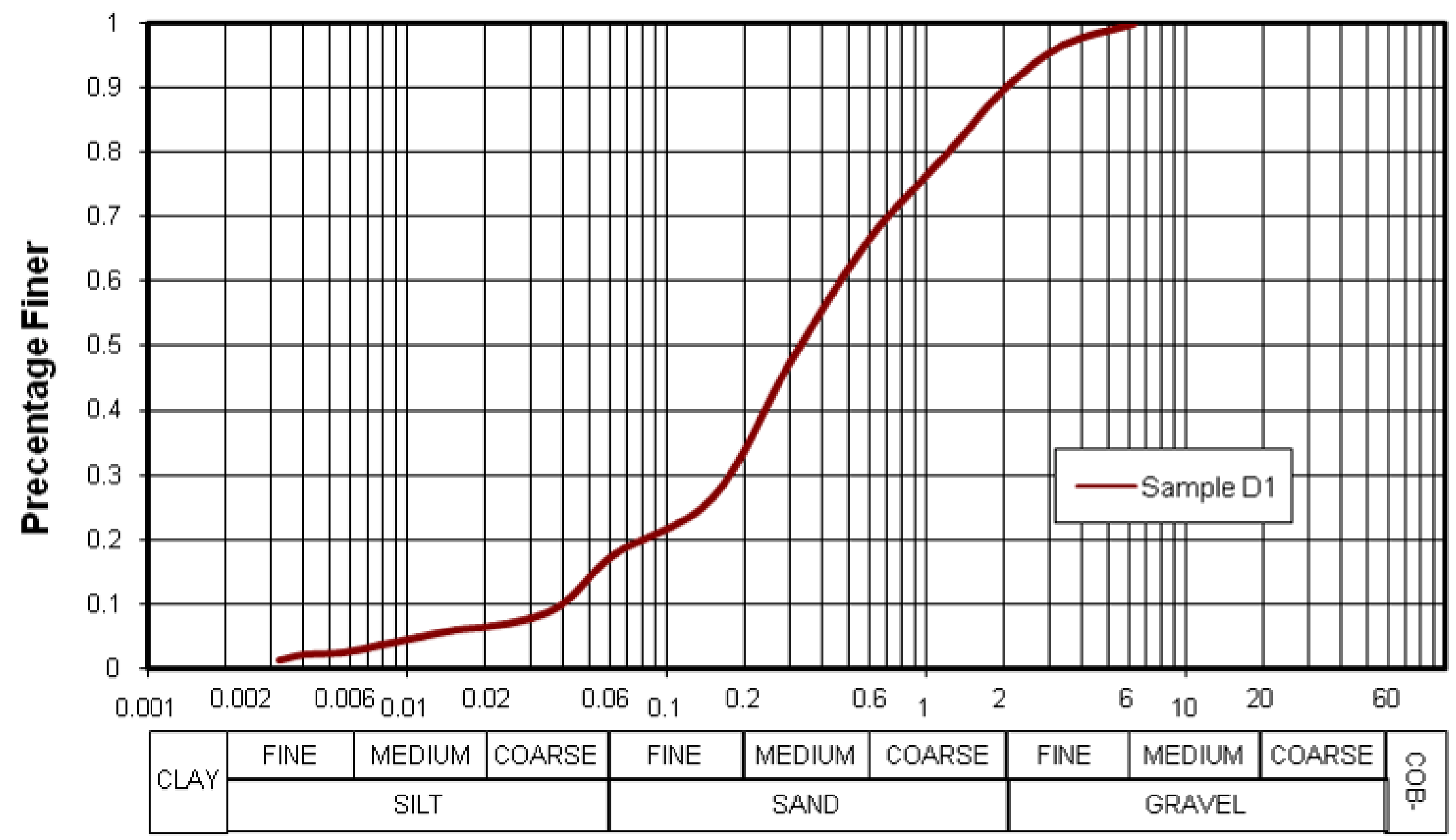




\section{Sample D2}

Dry sieving:

\begin{tabular}{|l|cc|}
\hline Wt. of Total Soil & 100 & $\mathrm{~g}$ \\
\hline Wt. of Dry Soil+Container: & 261.381 & $\mathrm{~g}$ \\
\hline Wt. of Dry Soil(>63)+Container & 260.846 & $\mathrm{~g}$ \\
\hline Wt. of Container & 196.535 & $\mathrm{~g}$ \\
\hline Wt. of Dry Soil(>63) & 64.311 & $\mathrm{~g}$ \\
\hline Wt. of Dry Soil passing 63 micron sieve(Ws) & 35.689 & $\mathrm{~g}$ \\
\hline \% of total sample mass (Ws\%) & 35.689 & \\
\hline
\end{tabular}

\begin{tabular}{|c|c|c|c|c|c|c|c|}
\hline $\begin{array}{c}\text { Sieve } \\
\text { Number }\end{array}$ & Sieve size & $\begin{array}{c}\text { Mass Retained } \\
\text { +Container } \\
(\mathrm{gm})\end{array}$ & $\begin{array}{c}\text { Mass } \\
\text { retained } \\
(\mathrm{gm} .)\end{array}$ & $\begin{array}{c}\text { Total mass } \\
\text { passing } \\
(\mathrm{gm} .)\end{array}$ & $\begin{array}{c}\% \\
\text { passing }\end{array}$ & $\begin{array}{c}\text { Mass Retained } \\
\text { by the Sieve } \\
(\mathrm{gm} .)\end{array}$ & $\begin{array}{c}\text { Mass Retained } \\
\text { by the Sieve } \\
(\%)\end{array}$ \\
\hline 1 & $6.30 \mathrm{~mm}$ & & 0 & & & & \\
2 & $3.35 \mathrm{~mm}$ & 199.508 & 2.973 & 97.027 & 97.027 & 2.973 & 2.973 \\
3 & $2 \mathrm{~mm}$ & 205.232 & 8.697 & 91.303 & 91.303 & 5.724 & 5.724 \\
4 & $1.18 \mathrm{~mm}$ & 211.58 & 15.045 & 84.955 & 84.955 & 6.348 & 6.348 \\
5 & $600 \mu \mathrm{m}$ & 217.299 & 20.764 & 79.236 & 79.236 & 5.719 & 5.719 \\
6 & $300 \mu \mathrm{m}$ & 230.921 & 34.386 & 65.614 & 65.614 & 13.622 & 13.622 \\
7 & $150 \mu \mathrm{m}$ & 248.792 & 52.257 & 47.743 & 47.743 & 17.871 & 17.871 \\
8 & $63 \mu \mathrm{m}$ & 260.846 & 64.311 & 35.689 & 35.689 & 12.054 & 12.054 \\
9 & Pan & 261.285 & 64.75 & & & 35.689 & 35.689 \\
\hline
\end{tabular}




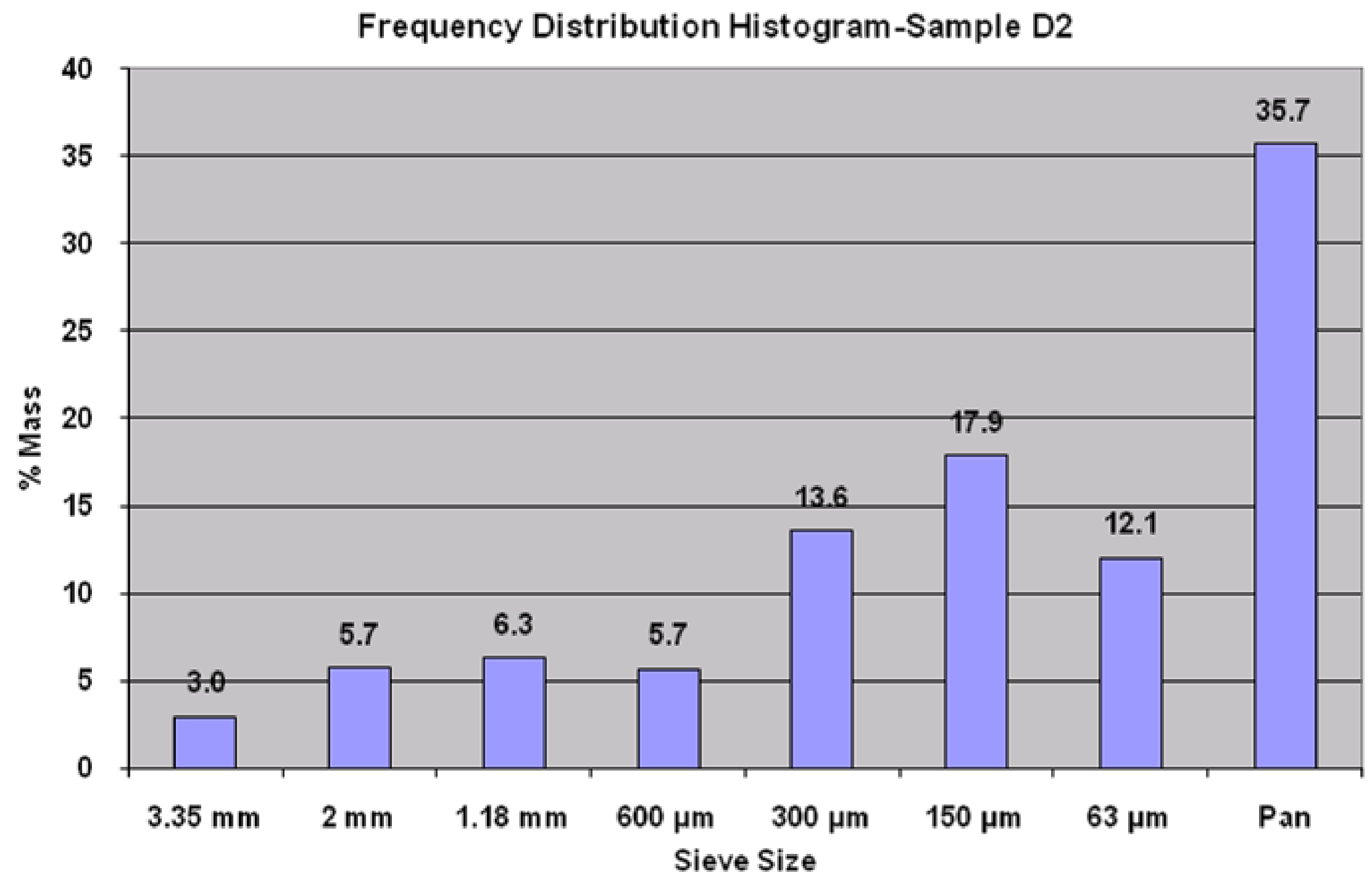

--- Page A32 --- 
Hydrometer method:

\begin{tabular}{|c|c|}
\hline Initial mass of dry soil: & 100 \\
\hline Dispersion: & 100 \\
\hline Specific Gravity assumed/measured: & $\mathrm{Mg} / \mathrm{m}^{\wedge} 3$ \\
\hline Cylinder No.: & 6 \\
\hline Hydrometer No: & 41906 \\
\hline Meniscus correction $(\mathrm{Cm})$ & 0.5 \\
\hline Dispersing agent correction(Cd): & 4.242 \\
\hline Viscosity of Water: & Viscosity $=0.0005 T^{\wedge} 2-0.0448 T+1.7016$ \\
\hline Hydrometer Calibration: & $\mathrm{Hr}=205.31-3.91^{*} \mathrm{Rh}$ \\
\hline
\end{tabular}

\begin{tabular}{|c|c|c|c|c|c|c|c|c|c|c|}
\hline Time & $\begin{array}{l}\text { Elapsed } \\
\text { Time } \\
\text { (min) }\end{array}$ & $\begin{array}{l}\text { Hydrometer } \\
\text { Reading } \\
\text { (R'h) }\end{array}$ & $\begin{array}{c}\text { Temp } \\
\text { (degree) }\end{array}$ & $\begin{array}{l}\text { Corrected } \\
\text { Hydrometer } \\
\text { Reading } \\
\text { Rh= }=\mathrm{R}^{\prime} \mathrm{h}+\mathrm{Cm}\end{array}$ & $\begin{array}{l}\text { Effective } \\
\text { Depth } \\
\text { (Hr) }\end{array}$ & $\begin{array}{c}\text { Equivalent } \\
\text { Particle } \\
\text { Diameter D } \\
(\mathrm{mm})\end{array}$ & $\begin{array}{c}\text { Temperature } \\
\text { Correction } \\
\text { Mt }\end{array}$ & $\mathrm{Rh}+\mathrm{Mt}-\mathrm{Cd}$ & $\begin{array}{l}\text { W } \\
\%\end{array}$ & $\begin{array}{c}\text { Summation } \\
\%\end{array}$ \\
\hline 0 & 0 & & & & & & & & & \\
\hline $15^{\prime \prime}$ & 0.25 & & & & & & & & & \\
\hline $30 "$ & 0.5 & & & & & & & & & \\
\hline 1 & 1 & 21.5 & 15.5 & 22 & 119.29 & 0.049933071 & -0.7 & 17.058 & 0.7676 & 27.396182 \\
\hline $2^{\prime}$ & 2 & 19.5 & 15.5 & 20 & 127.11 & 0.036446944 & -0.7 & 15.058 & 0.6776 & 24.184061 \\
\hline $4^{\prime}$ & 4 & 18.2 & 14.3 & 18.7 & 132.19 & 0.026697098 & -0.84 & 13.618 & 0.6128 & 21.871333 \\
\hline $8^{\prime}$ & 8 & 17.3 & 14.2 & 17.8 & 135.71 & 0.019152413 & -0.85 & 12.708 & 0.5719 & 20.409818 \\
\hline $15^{\prime}$ & 15 & 16.4 & 14.2 & 16.9 & 139.23 & 0.014167125 & -0.85 & 11.808 & 0.5314 & 18.964364 \\
\hline $30^{\prime}$ & 30 & 15.4 & 14.2 & 15.9 & 143.14 & 0.010157358 & -0.85 & 10.808 & 0.4864 & 17.358303 \\
\hline $1 \mathrm{~h}$ & 60 & 13.7 & 14.1 & 14.2 & 149.79 & 0.007356855 & -0.86 & 9.098 & 0.4094 & 14.611939 \\
\hline $2 \mathrm{~h}$ & 120 & 12.1 & 13.6 & 12.6 & 156.04 & 0.005344624 & -0.92 & 7.438 & 0.3347 & 11.945879 \\
\hline $4 \mathrm{~h}$ & 240 & 10.6 & 13.6 & 11.1 & 161.91 & 0.003849587 & -0.92 & 5.938 & 0.2672 & 9.5367879 \\
\hline $6 \mathrm{~h}$ & 360 & 9.7 & 14.8 & 10.2 & 165.43 & 0.003127527 & -0.79 & 5.168 & 0.2326 & 8.3001212 \\
\hline $7 \mathrm{~h}$ & 420 & 9.3 & 14.5 & 9.8 & 166.99 & 0.00292062 & -0.82 & 4.738 & 0.2132 & 7.6095152 \\
\hline $24 \mathrm{~h}$ & 1440 & 7.3 & 13.1 & 7.8 & 174.81 & 0.00164381 & -0.98 & 2.578 & 0.116 & 4.1404242 \\
\hline
\end{tabular}


Cumulative Frequency Curve:

\begin{tabular}{|c|c|c|}
\hline $\begin{array}{c}\text { Equivalent Particle } \\
\text { Diameter }(\mathrm{mm})\end{array}$ & $\begin{array}{c}\text { Cumulative } \% \\
\text { mass }\end{array}$ & $\begin{array}{c}\text { Cumulative } \\
\text { mass }\end{array}$ \\
\hline 6.3 & 100 & 1 \\
3.35 & 97.027 & 0.97027 \\
2 & 91.303 & 0.91303 \\
1.18 & 84.955 & 0.84955 \\
0.6 & 79.236 & 0.79236 \\
0.3 & 65.614 & 0.65614 \\
0.15 & 47.743 & 0.47743 \\
0.063 & 35.689 & 0.35689 \\
0.049933071 & 27.396182 & 0.273962 \\
0.036446944 & 24.18406061 & 0.241840606 \\
0.026697098 & 21.87133333 & 0.218713333 \\
0.019152413 & 20.40981818 & 0.204098182 \\
0.014167125 & 18.96436364 & 0.189643636 \\
0.010157358 & 17.35830303 & 0.17358303 \\
0.007356855 & 14.61193939 & 0.146119394 \\
0.005344624 & 11.94587879 & 0.119458788 \\
0.003849587 & 9.536787879 & 0.095367879 \\
0.003127527 & 8.300121212 & 0.083001212 \\
0.00292062 & 7.609515152 & 0.076095152 \\
0.00164381 & 4.140424242 & 0.041404242 \\
\hline
\end{tabular}

Analysis based on the cumulative curve:

$\begin{array}{lll}\text { D50 }= & 0.1689 & \mathrm{~mm} \\ \text { D60 }= & 0.2529 & \mathrm{~mm} \\ \text { D10 }= & 0.0041 & \mathrm{~mm} \\ \text { D30 }= & 0.0540 & \mathrm{~mm}\end{array}$

Coefficient of curvature: $\quad 2.7910$

Coefficient of uniformity: $\quad 61.1255$

\begin{tabular}{|c|c|c|c|}
\hline \multicolumn{4}{|c|}{ Particle Size Distribution } \\
\hline $\begin{array}{c}\text { Gravel } \\
(\%)\end{array}$ & $\begin{array}{c}\text { Sand } \\
(\%)\end{array}$ & $\begin{array}{c}\text { Silt } \\
(\%)\end{array}$ & $\begin{array}{c}\text { Clay } \\
(\%)\end{array}$ \\
\hline 8.7 & 57.5 & 28.7 & 5.1 \\
\hline
\end{tabular}




\section{Particle Size Distribution}

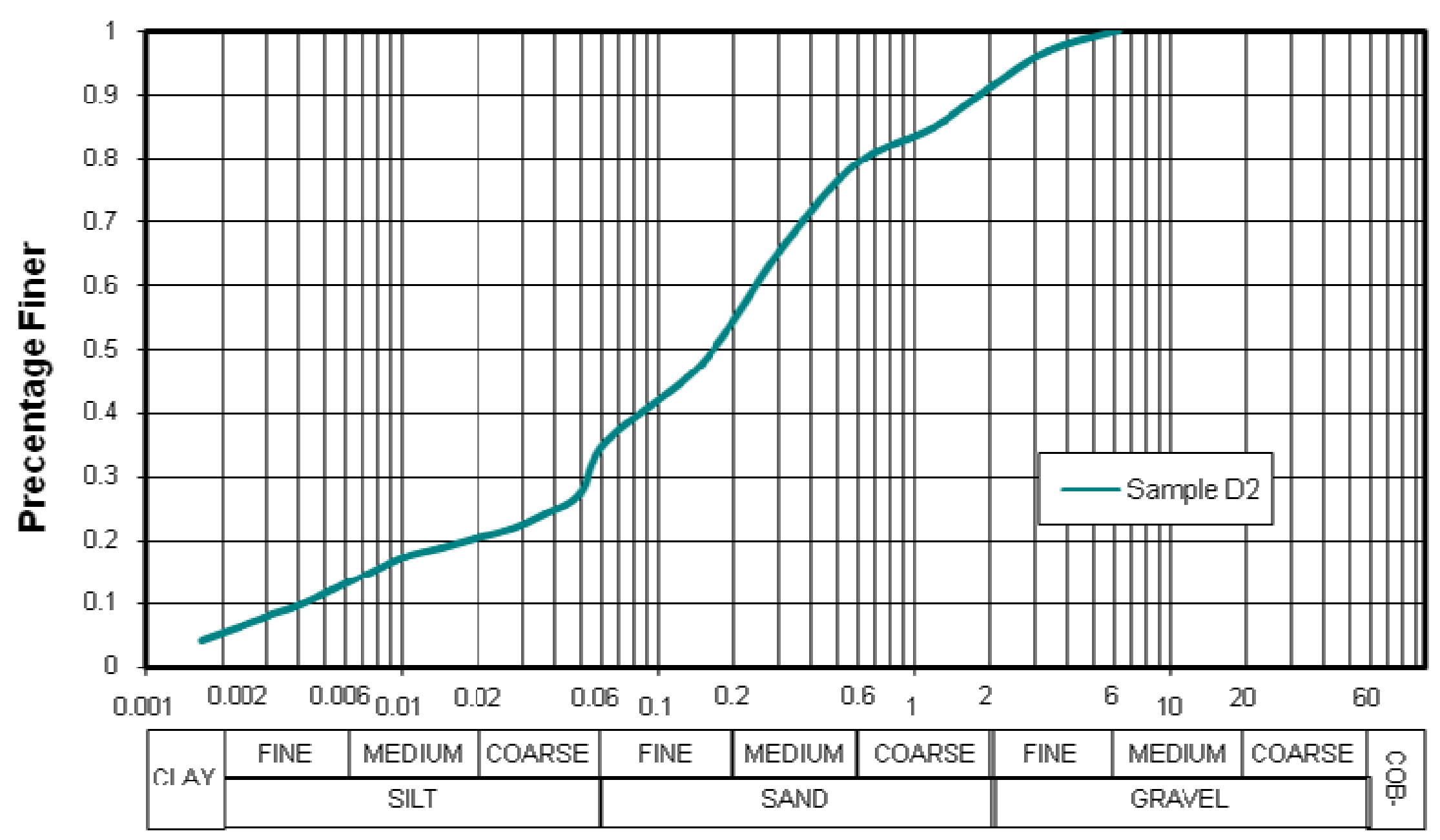


Organic Matter

\begin{tabular}{|c|c|c|c|c|c|c|c|}
\hline $\begin{array}{c}\text { Container } \\
\text { No. }\end{array}$ & $\begin{array}{c}\text { Field } \\
\text { Position }\end{array}$ & $\begin{array}{l}\text { Wt. of } \\
\text { Container } \\
\text { (grams) }\end{array}$ & $\begin{array}{l}\text { Wt. of Dry Soil } \\
+ \text { Container } \\
\text { (grams) }\end{array}$ & $\begin{array}{l}\text { Wt. of } \\
\text { Dry Soil } \\
\text { (grams) }\end{array}$ & $\begin{array}{c}\text { Wt. of Soil }\left(@ 500^{\circ} \mathrm{C}\right) \\
+ \text { Container } \\
\text { (grams) }\end{array}$ & $\begin{array}{c}\text { Wt. of organic } \\
\text { matter }\left(@ 500^{\circ} \mathrm{C}\right) \\
\text { (grams) }\end{array}$ & $\begin{array}{c}\text { Percentage of } \\
\text { organic matter } \\
(\%)\end{array}$ \\
\hline 1 & A1 & 53.6783 & 95.1952 & 41.5169 & 94.4082 & 0.787 & 1.90 \\
\hline 2 & $\mathrm{~A} 2$ & 53.1846 & 126.0035 & 72.8189 & 125.4875 & 0.516 & 0.71 \\
\hline 3 & B1 & 48.4621 & 97.0018 & 48.5397 & 93.3284 & 3.6734 & 7.57 \\
\hline 4 & B2 & 53.3158 & 112.4068 & 59.091 & 110.8292 & 1.5776 & 2.67 \\
\hline 5 & $\mathrm{C}$ & 52.7182 & 123.276 & 70.5578 & 121.318 & 1.958 & 2.78 \\
\hline 6 & D1 & 50.1161 & 117.2182 & 67.1021 & 116.003 & 1.2152 & 1.81 \\
\hline 7 & $\mathrm{D} 2$ & 50.4598 & 97.8712 & 47.4114 & 95.1788 & 2.6924 & 5.68 \\
\hline
\end{tabular}

Organic Matter

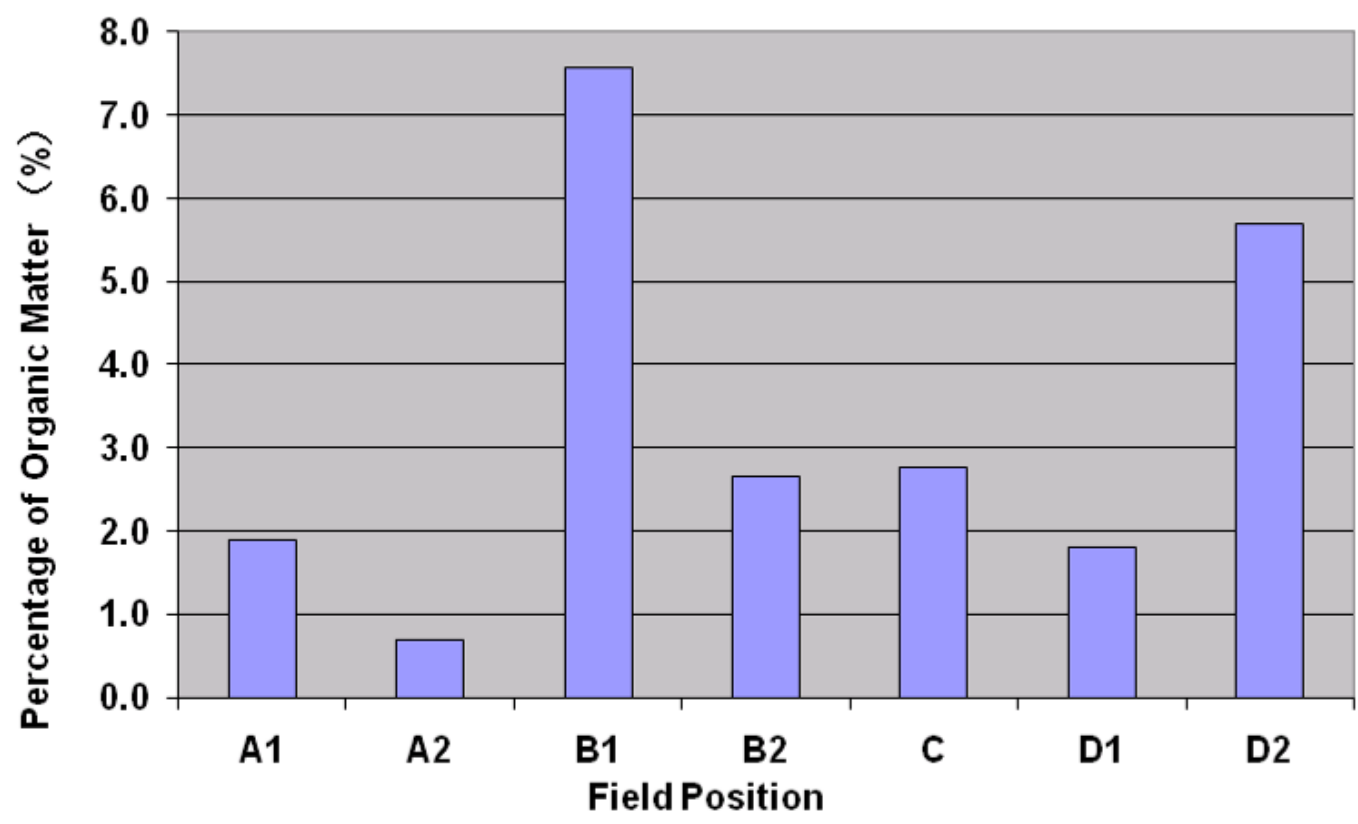




\title{
APPENDIX B
}

\author{
British Standards
}

BS 1377-2: 1990 (clause $9.2 \&$ 9.3) 
8.4.4.5 Agitate by shaking the pyknometer, or by rolling it on the bench, while holding one finger over the hole in the conical top. Allow air to escape and froth to disperse. Leave the pyknometer standing for at least $24 \mathrm{~h}$ at room temperature constant to within $\pm 2{ }^{\circ} \mathrm{C}$.

NOTE Air may also be removed by applying suction to the hole in the cap from an efficient filter pump.

8.4.4.6 Top up the pyknometer with water so that the water surface is flush with the hole in the conical cap. Take care that air bubbles or froth are not trapped under the cap.

8.4.4.7 Dry the pyknometer on the outside and weigh the whole to the nearest $0.5 \mathrm{~g}\left(m_{3}\right)$.

8.4.4.8 Empty the pyknometer, wash it thoroughly and fill it completely with water at room temperature. Ensure that the reference marks on the screw cap coincide, that no air bubbles are entrapped (see note to 8.4.4.5), and that the water surface is flush with the hole in the conical cap.

8.4.4.9 Dry the pyknometer on the outside and weigh to the nearest $0.5 \mathrm{~g}\left(m_{4}\right)$.

8.4.4.10 Repeat 8.4.4.1 to 8.4.4.7 using the second specimen of the same soil so that two values of particle density can be obtained. If the results differ by more than $0.05 \mathrm{Mg} / \mathrm{m}^{3}$ repeat the tests.

8.4.5 Calculations and expression of results (See Form 2.L of appendix A.)

Calculate the particle density, $\rho_{\mathrm{S}}$ (in $\mathrm{Mg} / \mathrm{m}^{3}$ ), from the equation:

$$
\rho_{\mathrm{s}}=\frac{m_{2}-m_{1}}{\left(m_{4}-m_{1}\right)-\left(m_{3}-m_{2}\right)}
$$

where

$m_{1}$ is the mass of pyknometer and cap assembly (in g);

$m_{2}$ is the mass of pyknometer, cap and soil (in g);

$m_{3}$ is the mass of pyknometer, cap, soil and water (in g);

$m_{4}$ is the mass of pyknometer, cap and water (in g).

Calculate the average of the two results if they differ by no more than $0.05 \mathrm{Mg} / \mathrm{m}^{3}$.

Express the average value of the particle size density to the nearest $0.05 \mathrm{Mg} / \mathrm{m}^{3}$.

8.4.6 Test report. The test report shall affirm that the test was carried out in accordance with BS 1377-2:1990 and shall include the following information:

a) the method of test used;

b) the average value of the particle density of the soil specimen; c) the information required by clause 9 of BS 1377-1:1990.

\section{Determination of particle size distribution}

\subsection{General}

Two methods of sieving are specified. Wet sieving is the definitive method applicable to essentially cohesionless soils. Dry sieving is suitable only for soils containing insignificant quantities of silt and clay.

Two methods of determining the size distribution of fine particles down to the clay size by sedimentation are specified, namely the pipette method and the hydrometer method, in both of which the density of the soil suspension at various intervals is measured. Combined sieving and sedimentation procedures enable a continuous particle size distribution curve of a soil to be plotted from the size of the coarsest particles down to the clay size.

\subsection{Wet sieving method}

9.2.1 General. This method covers the quantitative determination of the particle size distribution in an essentially cohesionless soil, down to the fine sand size. The combined silt and clay fraction can be obtained by difference.

The procedure given involves preparation of the sample by wet sieving to remove silt and clay-sized particles, which are rejected, followed by dry sieving of the remaining coarser material.

If the soil does not contain particles retained on a $2 \mathrm{~mm}$ test sieve in significant quantity, the method specified in $\mathbf{9 . 4}$ or $\mathbf{9 . 5}$ can be used.

The requirements of Part 1 of this standard, where appropriate, shall apply to this test method.

\subsubsection{Apparatus}

9.2.2.1 Test sieves having the following aperture sizes:

$75 \mathrm{~mm}, 63 \mathrm{~mm}, 50 \mathrm{~mm}, 37.5 \mathrm{~mm}, 28 \mathrm{~mm}, 20 \mathrm{~mm}$, $14 \mathrm{~mm}, 10 \mathrm{~mm}, 6.3 \mathrm{~mm}, 5 \mathrm{~mm}, 3.35 \mathrm{~mm}, 2 \mathrm{~mm}$, $1.18 \mathrm{~mm}, 600 \mu \mathrm{m}, 425 \mu \mathrm{m}, 300 \mu \mathrm{m}, 212 \mu \mathrm{m}$,

$150 \mu \mathrm{m}, 63 \mu \mathrm{m}$ and appropriate receivers.

NOTE 1 Alternatively, test sieves complying with BS 410 having the ISO series of aperture sizes may be used.

NOTE 2 The aperture sizes of the test sieves used for the test should adequately cover the range for the particular soil used, but it will not generally be necessary to use every size for every test.

NOTE 3 Where large numbers of tests are to be carried out it may be advantageous to have two sets of sieves, one for the wet sieving and one for the dry sieving processes.

9.2.2.2 A balance readable to $1.0 \mathrm{~g}$.

9.2.2.3 A balance readable to $0.1 \mathrm{~g}$. 
9.2.2.4 Sample dividers, e.g. the multiple slot type (riffle boxes).

9.2.2.5 A drying oven capable of maintaining a temperature of $105^{\circ} \mathrm{C}$ to $110^{\circ} \mathrm{C}$.

9.2.2.6 An evaporating dish about $150 \mathrm{~mm}$ diameter.

9.2.2.7 A corrosion-resistant tray, a convenient size being about $300 \mathrm{~mm}$ square and $40 \mathrm{~mm}$ deep.

9.2.2.8 Two or more large corrosion-resistant metal or plastics watertight trays with sides about $80 \mathrm{~mm}$ deep, or a bucket of about $12 \mathrm{~L}$ capacity.

9.2.2.9 A scoop.

9.2.2.10 Sieve brushes, and a wire brush or similar stiff brush.

\subsubsection{Sodium hexametaphosphate.}

9.2.2.12 A quantity of rubber tubing about $6 \mathrm{~mm}$ bore.

9.2.2.13 A sprayer such as a small watering-can rose.

9.2.2.14 A mechanical sieve shaker (optional).

9.2.3 Sample preparation. The soil shall be prepared as specified in 7.3 and 7.4.5 of BS 1377-1:1990. The test sample shall be obtained by riffling or quartering and shall then be oven dried at $105^{\circ} \mathrm{C}$ to $110{ }^{\circ} \mathrm{C}$ to give a minimum mass complying with Table 3. (See also Figure 10.)

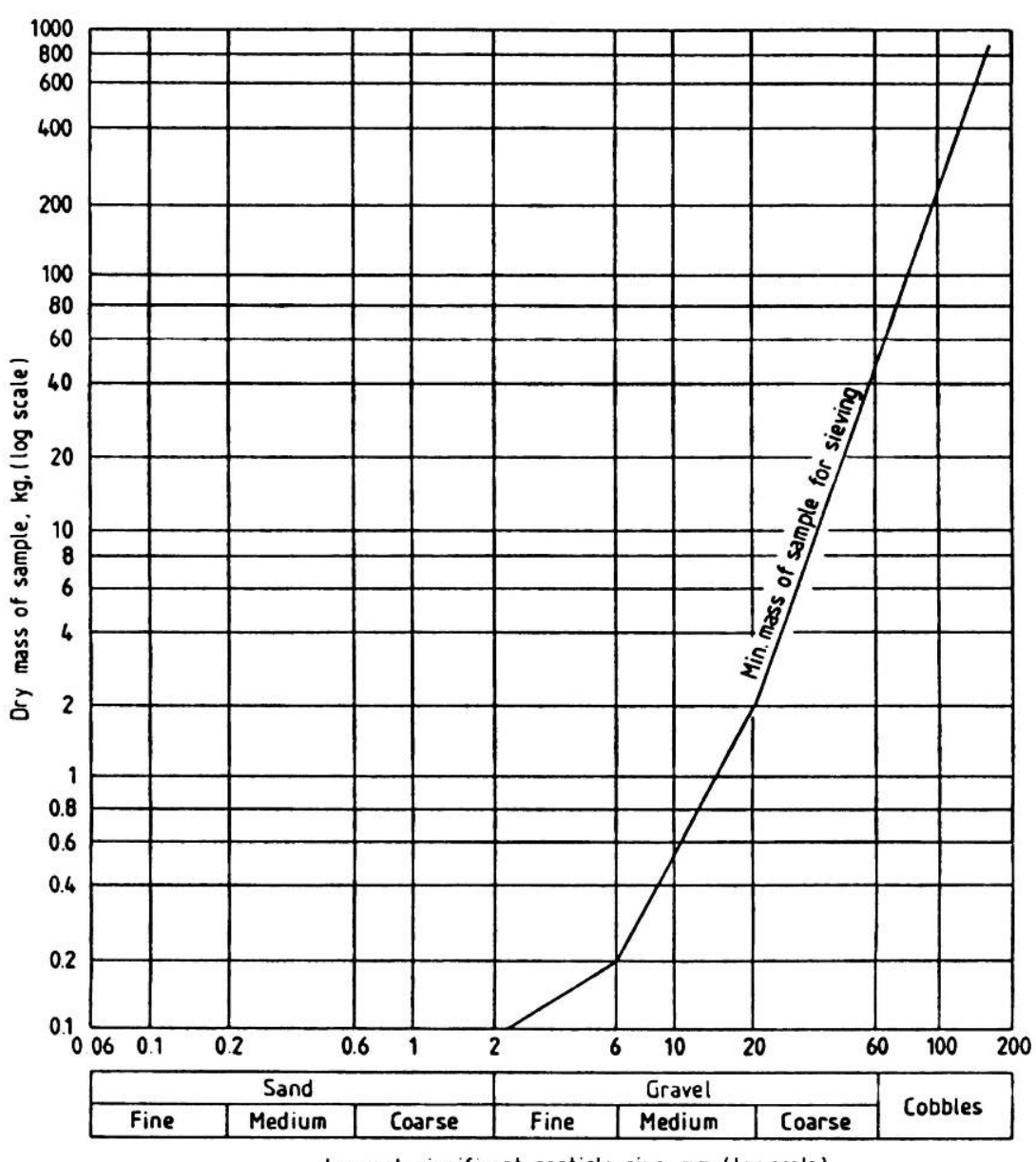

Largest significant particle size. $\mathrm{mm},(\log$ scale $)$

Figure 10 - Minimum mass of sample required for particle size test 
If separation of the silt and clay fractions is to be carried out, or if the particle size distribution is to be extended below $63 \mu \mathrm{m}$, a second riffled sample shall be obtained for a fine analysis as specified in $\mathbf{9 . 4}$ or 9.5 .

\subsubsection{Procedure}

9.2.4.1 Weigh the oven-dried test sample to $0.1 \%$ of its total mass $\left(m_{1}\right)$.

9.2.4.2. Place the sample on the $20 \mathrm{~mm}$ test sieve and brush any particles too coarse to pass through the test sieve with a wire brush or similar stiff brush until the individual particles are clean of any finer material.

NOTE 1 If adhering fine material cannot be removed easily by brushing, the following procedure may be followed.

a) Remove the fine material from the coarse particles by washing

b) Dry and weigh the coarse particles to $0.1 \%$ of their mass.

c) Dry the washings, add them to the material passing

the $20 \mathrm{~mm}$ test sieve, and mix thoroughly.

Take care when dealing with soft materials to ensure that the brushing does not remove parts of the large particles.

NOTE 2 Certain soils, e.g. tropical residual soils, have sionificant amounts of the clay fraction in the interstices of the larger particles. Treat these soils as specified in this method but then wash the large particles retained on the $20 \mathrm{~mm}$ test sieve in sodium hexametaphosphate solution; estimate the amount of clay removed and allow for it in the final calculations.

Sieve the fraction retained on the $20 \mathrm{~mm}$ test sieve on the appropriate larger test sieves and weigh the amount retained on each test sieve. If any test sieve becomes overloaded sieve the material on the test sieve in parts, the parts not to exceed the masses given in Table 4.

Table 3 - Mass of soil sample for sieving

\begin{tabular}{|l|l|}
\hline $\begin{array}{c}\text { Maximum size of material } \\
\text { present in substantial } \\
\text { proportion (more than 10 \%) }\end{array}$ & $\begin{array}{c}\text { Minimum mass of } \\
\text { sampling to be taken } \\
\text { for sieving }\end{array}$ \\
\hline Test sieve aperture & \\
\hline \multicolumn{1}{|c|}{$\mathrm{mm}$} & 50 \\
63 & $\mathrm{~kg}$ \\
50 & 35 \\
37.5 & 15 \\
28 & 6 \\
20 & 2 \\
14 & 1 \\
10 & 0.5 \\
6.3 & 0.2 \\
5 & 0.2 \\
3.35 & 0.15 \\
2 or smaller & 0.1 \\
\hline
\end{tabular}

Table 4-Maximum mass of material to be retained on each test sieve at the completion of sieving

\begin{tabular}{|c|c|c|c|}
\hline \multirow{2}{*}{$\begin{array}{c}\text { Test sieve } \\
\text { aperture size }\end{array}$} & \multicolumn{3}{|c|}{ Maximum mass on sieve of diameter } \\
\hline & $450 \mathrm{~mm}$ & $300 \mathrm{~mm}$ & $200 \mathrm{~mm}$ \\
\hline $\mathrm{mm}$ & $\mathrm{kg}$ & $\mathrm{kg}$ & $\mathrm{g}$ \\
\hline 50 & 10 & 4.5 & - \\
\hline 37.5 & 8 & 3.5 & - \\
\hline 28 & 6 & 2.5 & - \\
\hline 20 & 4 & 2.0 & - \\
\hline 14 & 3 & 1.5 & - \\
\hline 10 & 2 & 1.0 & - \\
\hline 6.3 & 1.5 & 0.75 & - \\
\hline 5 & 1.0 & 0.5 & - \\
\hline 3.35 & - & - & 300 \\
\hline 2 & - & - & 200 \\
\hline 1.18 & - & - & 100 \\
\hline$\mu \mathrm{m}$ & & & \\
\hline 600 & - & - & 75 \\
\hline 425 & - & - & 75 \\
\hline 300 & - & - & 50 \\
\hline 212 & - & - & 50 \\
\hline 150 & - & - & 40 \\
\hline 63 & - & - & 25 \\
\hline
\end{tabular}

9.2.4.3 Weigh the portion of the oven-dried material passing the $20 \mathrm{~mm}$ test sieve to $0.1 \%$ of its total mass, $m_{2}$.

Riffle that portion so that a fraction of convenient mass (about $2 \mathrm{~kg}$ ) is obtained. Weigh the fraction to $0.1 \%$ of its total mass, $m_{3}$.

9.2.4.4 Spread the riffled fraction in the large tray, or place it in the bucket, and cover with water. If the soil is cohesive add sodium hexametaphosphate to the water first at a concentration of $2 \mathrm{~g} / \mathrm{L}$.

9.2.4.5 Stir the mixture well to wet the soil. Allow the soil to stand for at least $1 \mathrm{~h}$ in this solution, stirring frequently.

9.2.4.6 Wash the material, a little at a time, through a $2 \mathrm{~mm}$ test sieve nested in a $63 \mu \mathrm{m}$ test sieve, allowing the material passing the $63 \mu \mathrm{m}$ test sieve is virtually clear. Ensure that neither test sieve is overloaded in the process, either with solids or with water (see Table 4). The maximum amount of material initially on the $63 \mu \mathrm{m}$ test sieve shall not exceed $150 \mathrm{~g}$ for a $200 \mathrm{~mm}$ diameter test sieve, $350 \mathrm{~g}$ for a $300 \mathrm{~mm}$ diameter test sieve or $750 \mathrm{~g}$ for a $450 \mathrm{~mm}$ diameter test sieve. 
9.2.4.7 Transfer all the material retained on the sieves into a tray or evaporating dish and dry in an oven at $105^{\circ} \mathrm{C}$ to $110^{\circ} \mathrm{C}$.

NOTE The retained material should not be dried on the sieve as it is detrimental to sieves to heat them.

9.2.4.8 Weigh the dried fraction when cool to $0.1 \%$ of its total mass, $m_{4}$.

9.2.4.9 Sieve the dried fractions through the appropriate sieves down to the $6.3 \mathrm{~mm}$ test sieve, using the dry sieving procedure specified in 9.3.4. Weigh the amount retained on each sieve to $0.1 \%$ of the total dry fraction.

NOTE The $6.3 \mathrm{~mm}$ sieve is stated as the size at which riffling is carried out, but the sieve aperture size chosen for this operation should be appropriate to the grading of the soil. The principle remains the same, but Form $2 \mathrm{M}$ should be modified accordingly.

9.2.4.10 If the fraction passing the $6.3 \mathrm{~mm}$ test sieve is small, i.e. not more than $150 \mathrm{~g}$, the sample may be sieved by dry sieving on the appropriate sieves down to and including the $63 \mu \mathrm{m}$ test sieve. Weigh the amount retained on each seive and any fines passing the $63 \mu \mathrm{m}$ test seive, $m_{\mathrm{F}}$, to $0.1 \%$ of the total fraction passing the $6.3 \mathrm{~mm}$ sieve.

NOTE 1 If a mechanical shaker is available 9.2.4.9 and 9.2.4.10 can be performed in one operation provided the test sieves are all of the same diameter. Take care to ensure that sieving is complete. The minimum period of shaking should be $10 \mathrm{~min}$. NOTE 2 The $6.3 \mathrm{~mm}$ sieve is stated as the size at which riffling is carried out, but the sieve aperture size chosen for this operation should be appropriate to the grading of the soil. The principle remains the same but Form $\mathrm{M}$ should be modified accordingly.

9.2.4.11 If the fraction passing the $6.3 \mathrm{~mm}$ test sieve is large, i.e. substantially greater than $150 \mathrm{~g}$, weigh it $\left(m_{5}\right)$, and then riffle it so that a fraction of $100 \mathrm{~g}$ to $150 \mathrm{~g}$ is obtained. Weigh this fraction, $m_{6}$, and then sieve on the appropriate sieves down to and including the $63 \mu \mathrm{m}$ test sieve. Weigh the amounts retained on each sieve, and any fines passing the $63 \mu \mathrm{m}$ test sieve, $m_{\mathrm{E}}$. If riffling is not necessary, $m_{6}$ is the same as $m_{5}$. Weigh to $0.1 \%$ of the total fraction passing the $6.3 \mathrm{~mm}$ sieve.

NOTE The $6.3 \mathrm{~mm}$ sieve is stated as the size at which riffling is carried out, but the sieve aperture size chosen for this operation should be appropriate to the grading of the soil. The principle remains the same, but Form $2 \mathrm{M}$ should be modified accordingly. 9.2.5 Calculations and expression of results (See form 2.M appendix A.)

9.2.5.1 For samples containing particles larger than $20 \mathrm{~mm}$ in size, calculate the sum of the masses retained on each sieve together with the mass $m_{2}$ passing the $20 \mathrm{~mm}$ sieve.

If this total differs from the initial dry mass $m_{1}$ by more than $1 \%$ this stage of the test shall be repeated.

Calculate the proportion by mass of material retained on each of the coarse series of sieves as a percentage of $m_{1}$.
For example:

Percentage retained on $28 \mathrm{~mm}$ sieve $=$

$$
\left\{\frac{m(28 m m)}{m_{1}}\right\} 100
$$

9.2.5.2 Calculate the sum of the masses retained on each sieve together with the mass $m_{5}$ passing the $6.3 \mathrm{~mm}$ sieve. If this total differs from the dried riffled mass $m_{4}$ by more than $1 \%$ this stage of the test shall be repeated.

Calculate the corrected mass of material retained on each of the sieves between $20 \mathrm{~mm}$ and $6.3 \mathrm{~mm}$ by multiplying by $m_{2} / m_{3}$, then calculate this mass as a percentage of $m_{1}$.

For example:

Percentage retained on $10 \mathrm{~mm}$ sieve

$$
=m(10 \mathrm{~mm})\left(\frac{m_{2}}{m_{3}}\right)\left(\frac{100}{m_{1}}\right)
$$

9.2.5.3 Calculate the sum of the masses retained on each sieve together with the mass $m_{\mathrm{F}}$ or $m_{\mathrm{E}}$ passing the $63 \mu \mathrm{m}$ sieve. If this total differs from the tried riffled mass $m_{6}$ by more than $1 \%$ this stage of the test shall be repeated.

Calculate the corrected mass of material retained on each of the sieves finer than the $6.3 \mathrm{~mm}$ sieve by multiplying by $\left(\frac{m_{5}}{m_{6}}\right)\left(\frac{m_{2}}{m_{3}}\right)$ and then calculate this mass as a percentage of $m_{1}$.

For example:

Percentage retained on

$300 \mu \mathrm{m}$ sieve $=m(300 \mu \mathrm{m})\left(\frac{m_{5}}{m_{6}}\right)\left(\frac{m_{2}}{m_{3}}\right)\left(\frac{100}{m_{1}}\right)$

9.2.5.4 Calculate the cumulative percentages by mass of the sample passing each of the sieves from the general relationship:

$(\%$ passing this sieve $)=(\%$ passing previous sieve) - (\% retained on this sieve)

9.2.5.5 Calculate the fraction passing the $63 \mu \mathrm{m}$ test sieve by difference. The mass of fines lost by washing in 9.2.4.6 is equal to $\left(m_{3}-m_{4}\right)$. To this is added the mass of any fine material $\left(m_{\mathrm{F}}\right)$ passing the $63 \mu \mathrm{m}$ sieve when dry sieved (see 9.2.4.10), and the percentage finer than $63 \mu \mathrm{m}$ is equal to:

$$
\left\{\frac{\left(m_{3}-m_{4}\right)+m_{F}}{m_{3}}\right\}\left(\frac{m_{2}}{m_{1}}\right) 100
$$


If the sample was subdivided (see 9.2.4.11) the mass of fines, $m_{\mathrm{E}}$, is increased in the ratio $m_{5} / m_{6}$, and the percentage finer than $63 \mu \mathrm{m}$ is equal to:

$$
\left\{\frac{\left(m_{3}-m_{4}\right)+\left(\frac{m_{\mathrm{E}} \times m_{5}}{m_{6}}\right)}{m_{3}}\right\}\left(\frac{m_{2}}{m_{1}}\right) 100
$$

for $m_{1}$ see 9.2.4.1;

for $m_{2}$ see 9.2.4.3;

for $m_{3}$ see $\mathbf{9 . 2 . 4 . 3}$;

for $m_{4}$ see 9.2.4.8;

for $m_{5}$ see 9.2.4.11;

for $m_{6}$ see 9.2.4.11;

for $m_{\mathrm{E}}$ see 9.2.4.11;

for $m_{\mathrm{F}}$ see 9.2.4.10.

Express the results on a semi-logarithmic chart of the type shown as Form 2.N in appendix A. Alternatively, the results may be reported in the form of a table showing, to the nearest $1 \%$, the percentage by mass passing each of the sieves used. 9.2.6 Test report. The test report shall affirm that the test was carried out in accordance with BS 1377-2:1990 and shall include the following information:

a) the method of test used;

b) the particle size distribution curve or the tabulated percentages, as specified in 9.2.5.5;

c) the information required by clause 9 of BS 1377-1:1990.

\subsection{Dry sieving method}

9.3.1 General. This method covers the quantitative determination of the particle size distribution in a cohesionless soil down to the fine-sand size. This method shall not be used unless it has been shown that for the type of material under test it gives the same results as the method of analysis by wet sieving. In cases of doubt the method shall not be used.

The requirements of Part 1 of this standard, where appropriate, shall apply to this test method.

\subsubsection{Apparatus}

9.3.2.1 Test sieves having the following aperture sizes may be used:

$75 \mathrm{~mm}, 63 \mathrm{~mm}, 50 \mathrm{~mm}, 37.5 \mathrm{~mm}, 28 \mathrm{~mm}, 20 \mathrm{~mm}$,

$14 \mathrm{~mm}, 10 \mathrm{~mm}, 6.3 \mathrm{~mm}, 5 \mathrm{~mm}, 3.35 \mathrm{~mm}, 2 \mathrm{~mm}$,

$1.18 \mathrm{~mm}, 600 \mu \mathrm{m}, 425 \mu \mathrm{m}, 300 \mu \mathrm{m}, 212 \mu \mathrm{m}$,

$150 \mu \mathrm{m}, 63 \mu \mathrm{m}$ and appropriate receivers.

NOTE 1 Alternatively, test sieves complying with BS 410 having the ISO series of aperture sizes may be used.
NOTE 2 The sizes of test sieves used for the test should cover adequately the range for the particular soil used, but it will not generally be necessary to use every size for every test.

9.3.2.2 A balance readable to $1.0 \mathrm{~g}$.

9.3.2.3 A balance readable to $0.1 \mathrm{~g}$.

9.3.2.4 Sample dividers, e.g. the multiple slot type (riffle box).

9.3.2.5 A drying oven capable of maintaining a temperature of $105^{\circ} \mathrm{C}$ to $110^{\circ} \mathrm{C}$.

9.3.2.6 A tray.

9.3.2.7 A scoop.

9.3.2.8 Sieve brushes.

9.3.2.9 A mechanical sieve shaker (optional).

9.3.3 Sample preparation. The soil shall be prepared as specified in $\mathbf{7 . 3}$ and $\mathbf{7 . 4 . 5}$ of BS 1377-1:1990. The test sample shall be obtained by riffling or quartering and shall then be oven dried at $105^{\circ} \mathrm{C}$ to $110^{\circ} \mathrm{C}$ to give a minimum mass complying with Table 3. (See also Figure 10.)

\subsubsection{Procedure}

9.3.4.1 Weigh the oven-dried sample to $0.1 \%$ of its total mass $\left(m_{1}\right)$.

9.3.4.2 Fit the largest size test sieve appropriate to the maximum size of material present to the receiver and place the sample on the sieve (see BS 1796).

NOTE If the assembly is not too heavy to handle, several sieves, in order of size, may be fitted together and used at the same time 9.3.4.3 Agitate the test sieve so that the sample rolls in an irregular motion over the test sieve. Particles may be hand placed to see if they will fall through but they shall not be pushed through. Make sure that only individual particles are retained. Weigh the amount retained on the test sieve to $0.1 \%$ of its total mass.

9.3.4.4 Transfer the material retained in the receiver to a tray and fit the receiver to the next largest sized test sieve. Place the contents of the tray on the sieve and repeat $\mathbf{9 . 3 . 4 . 3}$

NOTE If the mass of the sample passing the $20 \mathrm{~mm}$ test sieve is substantially greater than $2 \mathrm{~kg}$ the sample should be riffled to obtain a sample of about $2 \mathrm{~kg}$ and care taken to make due allowance in the calculation for the subdivision of the original sample.

9.3.4.5 Repeat 9.3.4.3 and 9.3.4.4 through all the test sieve sizes used.

NOTE If a mechanical shaker is available 9.3.4.3 and 9.3.4.4 can be performed in one operation provided the test sieves are all of the same diameter. Take care to ensure that sieving is complete. The minimum period of shaking should be $10 \mathrm{~min}$

9.3.4.6 If any test sieve becomes overloaded sieve the material on the test sieve in parts, the parts not to exceed the masses given in Table 4.

9.3.5 Calculations (See form 2.M of appendix A.) 
Calculate the percentage by mass of material retained on each test sieve.

Obtain the percentage passing the $63 \mu \mathrm{m}$ test sieve by difference, and check by weighing the amount in the receiver.

Calculate the cumulative percentage (by mass of the total sample) passing each of the sieves.

Express the results obtained on a semi-logarithmic chart of the type shown as Form 2.N in appendix A. Alternatively, the results may be reported as a table showing, to the nearest $1 \%$, the percentage by mass passing each of the sieves used.

9.3.6 Test report. The test report shall affirm that the test was carried out in accordance with BS 1377-2:1990 and shall include the following information.

a) the method of test used;

b) the particle size distribution curve, or the tabulated percentages, as specified in 9.3.5;

c) the information required by clause $\mathbf{9}$ of BS 1377-1:1990.

\subsection{Sedimentation by the pipette method}

9.4.1 General. This method covers the quantitative determination of the particle size distribution in a soil from the coarse sand size to the clay size (about $2 \mu \mathrm{m}$ ). (See note.) The procedure enables the percentages of coarse, medium and fine silt, and clay, to be determined. These percentages can be linked to the curve obtained by sieving to provide a single curve for the whole material.

The analysis of data requires that the particle density of the soil specimen is known or can be assumed.

The test as specified is not usually necessary if less than $10 \%$ of the material passes the $63 \mu \mathrm{m}$ test sieve as specified in $\mathbf{9 . 2}$.

NOTE If the sample has been wet sieved down to the $63 \mu \mathrm{m}$ test sieve size then only the material passing the $63 \mu \mathrm{m}$ test sieve need be used to carry out this test, thus eliminating the necessity of repeating the determinations of the same fractions.

The requirements of Part 1 of this standard, where appropriate, shall apply to this test method.

\subsubsection{Apparatus}

9.4.2.1 A sampling pipette of the type illustrated in Figure 11, fitted with a pressure and suction inlet, and having a capacity of approximately $10 \mathrm{~mL}$. The pipette shall be so arranged that it can be inserted to a fixed depth into a cylinder (see 9.4.2.2), when the latter is immersed in a constant-temperature bath (see Figure 12).

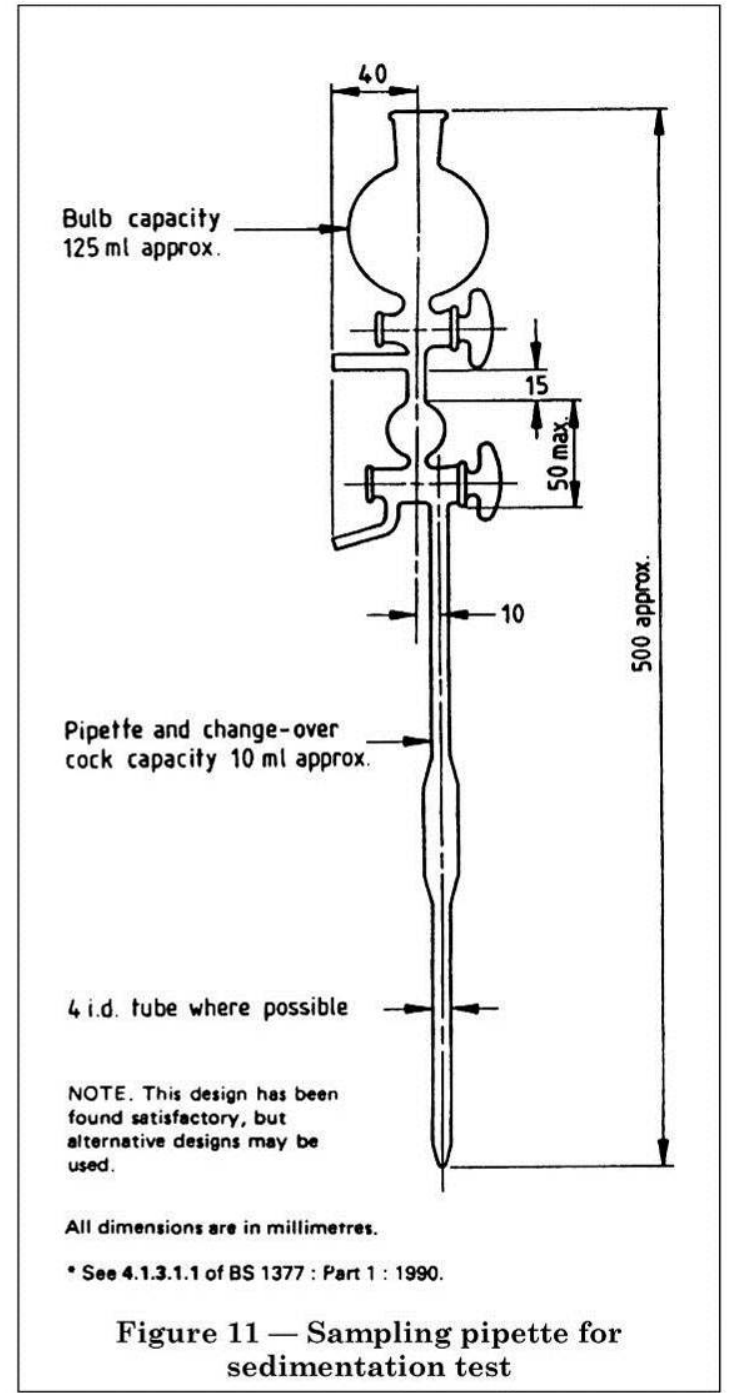

9.4.2.2 Two glass cylinders, each approximately $50 \mathrm{~mm}$ diameter and approximately $350 \mathrm{~mm}$ long graduated at $500 \pm 10 \mathrm{~mL}$ volume, with rubber bungs to fit.

9.4.2.3 Nine glass weighing bottles, approximately $25 \mathrm{~mm}$ in diameter and $50 \mathrm{~mm}$ high fitted with ground glass stoppers. The masses of the bottles shall be known to the nearest $0.001 \mathrm{~g}$.

9.4.2.4 A constant-temperature bath capable of being maintained at $25^{\circ} \mathrm{C}$, to an accuracy of $\pm 0.5^{\circ} \mathrm{C}$ into which the cylinder can be immersed up to the $500 \mathrm{~mL}$ mark. The bath shall not vibrate the sample. 


\section{APPENDIX C}

Site Assessment on January 16 of 2008 
Date of Site Visit: February 18, 2008 (Monday) between $3 \mathrm{pm}$ and 5:30 pm

Weather Condition: partly sunny, cool and dry

Scope of Site Visit: baseflow measurement at low-flow channel

Propeller Diameter: $30 \mathrm{~mm}$

Propeller Elevation: $40 \%$ of water depth from channel bed

\section{Site \#1}

Site Location:

Water Depth, $\boldsymbol{H}_{\text {water: }}$

Channel Width, $B_{L F C}$ :

Water Sampling?

Soil Sampling? $\approx 5 \mathrm{~m}$ downstream of the entrance of the Yuen Long Nullah

$\approx 6 \mathrm{~cm}$

$1 \mathrm{~m}$

No Water Sample \#: n/a

No Soil Sample \#: n/a

Table C.1: Velocities Details in Site \#1.

\begin{tabular}{|c|c|c|c|c|}
\hline $\begin{array}{c}\text { Location of Rotary Propeller } \\
\text { (left, centre, right facing upstream) }\end{array}$ & $\begin{array}{c}\text { \# Rotation } \\
\text { in } \mathbf{6 0} \mathbf{~ s e c}\end{array}$ & $\begin{array}{c}\text { \# Rotation } \\
\text { per second }\end{array}$ & $\begin{array}{c}\text { Velocities Measured by Rotary } \\
\text { Propeller Flow Meter, in m/sec }\end{array}$ & $\begin{array}{c}\text { Velocities Converted } \\
\text { to ADV, in m/sec }\end{array}$ \\
\hline \hline centre & 789 & 13.15 & 0.7637 & 0.7422 \\
\hline centre & 817 & 13.62 & 0.7891 & 0.7656 \\
\hline centre & 678 & 11.30 & 0.6629 & 0.6494 \\
\hline \multicolumn{7}{|c|}{ Average Velocity: } & $\mathbf{0 . 7 3 8 5}$ & $\mathbf{0 . 7 1 9 1}$
\end{tabular}

Flow Rate, $Q=V A: \quad 0.04315 \mathrm{~m}^{3} / \mathrm{sec} \quad(\underline{\text { Note: }} V=0.7191 \mathrm{~m} / \mathrm{sec})$

Manning's $\boldsymbol{n}: \quad 0.01072 \quad$ (Note: $V=0.7191 \mathrm{~m} / \mathrm{sec}, S=0.002943$, see APPENDIX ) 


\section{$\underline{\text { Site \#2 }}$}

Site Location:

Water Depth:

Water Sampling?

Soil Sampling? $\approx 10 \mathrm{~m}$ downstream of the entrance of the Yuen Long Nullah

$\approx 6 \mathrm{~cm}$

Yes Water Sample \#: A

No Soil Sample \#: n/a

Table C.2a: Velocities Details in Site \#2.

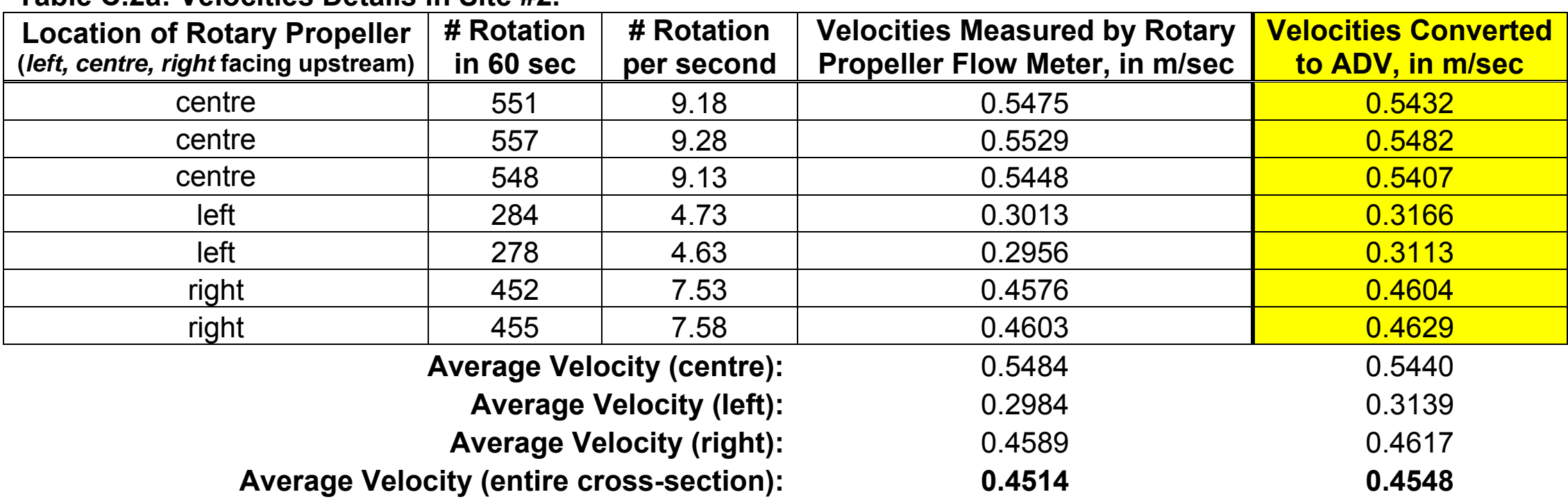

Flow Rate, $Q=V A: \quad 0.02729 \mathrm{~m}^{3} / \mathrm{sec} \quad(\underline{\text { Note }}: V=0.4548 \mathrm{~m} / \mathrm{sec})$

Manning's $\boldsymbol{n}: \quad 0.01695 \quad$ (Note: $V=0.4548 \mathrm{~m} / \mathrm{sec}, S=0.002943$, see APPENDIX ) 
Table C.2b: Velocities Measured by Styrofoam Sphere in Site \#2.

Distance, in metres $\quad$ Time, in sec $\quad$ Velocity, in $\mathrm{m} / \mathrm{sec}$

\begin{tabular}{|c|c|c|}
\hline Distance, in metres & Time, in sec & Velocity, in m/sec \\
\hline 5 & 6.4 & 0.7813 \\
\hline 5 & 6.1 & 0.8197 \\
\hline 5 & 8.7 & 0.5747 \\
\hline 5 & 6.3 & 0.7937 \\
\hline 5 & 6.5 & 0.7692 \\
\hline 5 & 6.6 & 0.7576 \\
\hline \multicolumn{2}{|c|}{ Average Velocity: } & 0.7493
\end{tabular}

Average Velocity: $\quad 0.7493$

Flow Rate, $Q=V A: \quad 0.04496 \mathrm{~m}^{3} / \mathrm{sec} \quad(\underline{\text { Note }}: V=0.7493 \mathrm{~m} / \mathrm{sec})$

Manning's $\boldsymbol{n}: \quad 0.01029 \quad(\underline{\text { Note }}: V=0.7493 \mathrm{~m} / \mathrm{sec}, S=0.002943$, see APPENDIX ) 


\section{Site \#3}

Site Location:

Water Depth:

Water Sampling?

Soil Sampling? $\approx 22 \mathrm{~m}$ downstream of Site \#2

$\approx 10 \mathrm{~cm}$

Yes

Yes
Water Sample \#: B

Soil Sample \#: $\quad$ A

Table C.3a: Velocities Details in Site \#3.

\begin{tabular}{|c|c|c|c|c|}
\hline $\begin{array}{l}\text { Location of Rotary Propeller } \\
\text { (left, centre, right facing upstream) }\end{array}$ & $\begin{array}{c}\text { \# Rotation } \\
\text { in } 60 \mathrm{sec}\end{array}$ & $\begin{array}{l}\text { \# Rotation } \\
\text { per second }\end{array}$ & $\begin{array}{l}\text { Velocities Measured by Rotary } \\
\text { Propeller Flow Meter, in } \mathrm{m} / \mathrm{sec}\end{array}$ & $\begin{array}{l}\text { Velocities Converted } \\
\text { to ADV, in } \mathrm{m} / \mathrm{sec}\end{array}$ \\
\hline centre & 318 & 5.30 & 0.3336 & 0.3463 \\
\hline centre & 306 & 5.10 & 0.3222 & 0.3358 \\
\hline centre & 309 & 5.15 & 0.3251 & 0.3385 \\
\hline left & 272 & 4.53 & 0.2899 & 0.3060 \\
\hline left & 255 & 4.25 & 0.2737 & 0.2911 \\
\hline left & 273 & 4.55 & 0.2908 & 0.3069 \\
\hline right & 135 & 2.25 & 0.1595 & 0.1860 \\
\hline right & 125 & 2.08 & 0.1500 & 0.1773 \\
\hline right & 159 & 2.65 & 0.1823 & 0.2070 \\
\hline \multicolumn{3}{|c|}{ Average Velocity (centre): } & 0.3270 & 0.3402 \\
\hline \multicolumn{3}{|c|}{ Average Velocity (left): } & 0.2848 & 0.3014 \\
\hline \multicolumn{3}{|c|}{ Average Velocity (right): } & 0.1639 & 0.1901 \\
\hline \multicolumn{3}{|c|}{ Average Velocity (entire cross-section): } & 0.2586 & 0.2772 \\
\hline
\end{tabular}

Flow Rate, $Q=V A: \quad 0.02772 \mathrm{~m}^{3} / \mathrm{sec} \quad$ (Note: $V=0.2772 \mathrm{~m} / \mathrm{sec}$ )

Manning's $\boldsymbol{n}: \quad 0.03734 \quad$ (Note: $V=0.2772 \mathrm{~m} / \mathrm{sec}, S=0.002943$, see APPENDIX ) 
Table C.3b: Velocities Measured by Styrofoam Sphere in Site \#3.

\begin{tabular}{|c|c|c|}
\hline Distance, in metres & $\begin{array}{c}\text { Time, in } \\
\text { seconds }\end{array}$ & $\begin{array}{c}\text { Velocity, in } \\
\text { m/sec }\end{array}$ \\
\hline 5 & 11.5 & 0.4348 \\
\hline 5 & 12.8 & 0.3906 \\
\hline 5 & 12.2 & 0.4098 \\
\hline
\end{tabular}
Average Velocity:
0.4117

Flow Rate, $Q=V A: \quad 0.04117 \mathrm{~m}^{3} / \mathrm{sec} \quad(\underline{\text { Note }}: V=0.4117 \mathrm{~m} / \mathrm{sec})$

Manning's $\boldsymbol{n}: \quad 0.02514 \quad$ (Note: $V=0.4117 \mathrm{~m} / \mathrm{sec}, S=0.002943$, see APPENDIX ) 


\section{Site \#4}

Site Location:

Water Depth:

Water Sampling?

Soil Sampling? $\approx 45 \mathrm{~m}$ downstream of Site \#3 $(\approx 11 \mathrm{~m}$ downstream of the first outlet at the left side of Yuen Long Nullah, facing upstream)

$\approx 6 \mathrm{~cm}$

Yes Water Sample \#: C

No Soil Sample \#: n/a

Table C.4a: Velocities Details in Site \#4.

\begin{tabular}{|c|c|c|c|c|}
\hline $\begin{array}{c}\text { Location of Rotary Propeller } \\
\text { (left, centre, right facing upstream) }\end{array}$ & $\begin{array}{c}\text { \# Rotation } \\
\text { in 60 sec }\end{array}$ & $\begin{array}{c}\text { \# Rotation } \\
\text { per second }\end{array}$ & $\begin{array}{c}\text { Velocities Measured by Rotary } \\
\text { Propeller Flow Meter, in m/sec }\end{array}$ & $\begin{array}{c}\text { Velocities Converted } \\
\text { to ADV, in m/sec }\end{array}$ \\
\hline centre & 515 & 8.58 & 0.5148 & 0.5131 \\
\hline centre & 531 & 8.85 & 0.5293 & 0.5265 \\
\hline centre & 513 & 8.55 & 0.5130 & 0.5114 \\
\hline left & 605 & 10.08 & 0.5965 & 0.5884 \\
\hline left & 580 & 9.67 & 0.5738 & 0.5675 \\
\hline right & 563 & 9.38 & 0.5584 & 0.5532 \\
\hline right & 575 & 9.58 & 0.5693 & 0.5633 \\
\hline \multicolumn{4}{r}{ Average Velocity (centre): } \\
Average Velocity (left): & 0.5190 & 0.5170 \\
\hline \multicolumn{4}{r|}{ Average Velocity (right): } \\
Average Velocity (entire cross-section): & 0.5852 & 0.5779 \\
&
\end{tabular}

Flow Rate, $Q=V A: \quad 0.03277 \mathrm{~m}^{3} / \mathrm{sec} \quad$ (Note: $V=0.5462 \mathrm{~m} / \mathrm{sec}$ )

Manning's $\boldsymbol{n}: \quad 0.01411 \quad$ (Note: $V=0.5462 \mathrm{~m} / \mathrm{sec}, S=0.002943$, see APPENDIX ) 
--- Page C7 --- 
Table C.4b: Velocities Measured by Styrofoam Sphere in Site \#4.

\begin{tabular}{|c|c|c|}
\hline Distance, in metres & $\begin{array}{c}\text { Time, in } \\
\text { seconds }\end{array}$ & $\begin{array}{c}\text { Velocity, in } \\
\text { m/sec }\end{array}$ \\
\hline 5 & 6.7 & 0.7463 \\
\hline 5 & 7.7 & 0.6494 \\
\hline 5 & 7.3 & 0.6849 \\
\hline 5 & 7.9 & 0.6329 \\
\hline 5 & 7.2 & 0.6944 \\
\hline 5 & 7.1 & 0.7042 \\
\hline \multicolumn{2}{|c|}{ Average Velocity: } & $\mathbf{0 . 6 8 5 4}$ \\
\hline
\end{tabular}

Flow Rate, $Q=V A: \quad 0.04112 \mathrm{~m}^{3} / \mathrm{sec} \quad(\underline{\text { Note}}: V=0.6854 \mathrm{~m} / \mathrm{sec})$

Manning's $\boldsymbol{n}: \quad 0.01125 \quad$ (Note: $V=0.6854 \mathrm{~m} / \mathrm{sec}, S=0.002943$, see APPENDIX )

Average Flow Rate Using Rotary Propeller Flow Meter: $\quad(0.03277+0.02772+0.02729) / 3=0.02926 \mathrm{~m}^{3} / \mathrm{sec}$

(Note: Site \#1 results are not included in the calculation since it is too close to the entrance of Yuen Long Nullah.)

Average Flow Rate Using Styrofoam Sphere: $\quad(0.04112+0.04117+0.04496) / 3=0.04242 \mathrm{~m}^{3} / \mathrm{sec}$ 


\section{Site \#5}

Site Location: midway of the two bends just upstream of the entrance of the Yuen Long Nullah Water Sampling? Soil Sampling?

Yes

No
Water Sample \#: D

Soil Sample \#: n/a

Table C.5a: Velocities Measured by Styrofoam Sphere in Site \#5.

\begin{tabular}{|c|c|c|}
\hline Distance, in metres & Time, in seconds & Velocity, in $\mathbf{~} / \mathbf{s e c}$ \\
\hline 5 & 41.5 & 0.1205 \\
\hline 5 & 42.3 & 0.1182 \\
\hline 5 & 38 & 0.1316 \\
\hline \multicolumn{2}{|c|}{ Average Velocity: } & $\mathbf{0 . 1 2 3 4}$ \\
\hline
\end{tabular}

Table C.5b: Water Depth Measurement (Channel Width $=2.2 \mathrm{~m}$ ).

\begin{tabular}{|c|c|}
\hline Cross-Section Details & Depth, in $\mathbf{~ m}$ \\
\hline middle & 29 \\
\hline left (facing upstream) & 19 \\
\hline right (facing upstream) & 38.5 \\
\hline Average Depth: & $\mathbf{2 8 . 8 3}$ \\
\hline
\end{tabular}

Note: Water depths were measured at the midway of the two bends. 
Table C.5c: Water Depth Measurement (Channel Width $=2.5 \mathrm{~m}$ ).

\begin{tabular}{|c|c|}
\hline Cross-Section Details & Depth, in cm \\
\hline middle & 29 \\
\hline left (facing upstream) & 17 \\
\hline right (facing upstream) & 30 \\
\hline
\end{tabular}

Average Depth: 25.33

Note: Water depth measured at around 2 metres upstream of the midway of the two bends.

Table C.5d: Water Depth Measurement (Channel Width $=2.5 \mathrm{~m})^{2}$.

\begin{tabular}{|c|c|}
\hline Cross-Section Details & Depth, in cm \\
\hline middle & 28 \\
\hline left (facing upstream) & 13 \\
\hline right (facing upstream) & 22 \\
\hline
\end{tabular}
Average Depth:
21.00

Note: Water depth measured at around 3.5 metres upstream of the midway of the two bends. 


\title{
APPENDIX D
}

Calibration Between Propeller Velocity

Flow Meter and Acoustic Doppler

\author{
Velocimetry (ADV)
}


Table D.1: Calibration Between the Two Velocity Measurement Devices.

\begin{tabular}{|c||c|c|c|}
\hline \multicolumn{1}{|c||}{ ADV } & \multicolumn{3}{c|}{ Propeller Velocity Flowmeter } \\
\hline $\begin{array}{c}\text { Velocity, in } \\
\text { m/sec }\end{array}$ & \# Rotation per minute & \# Rotation per second & $\begin{array}{c}\text { Velocity, in } \\
\text { m/sec }\end{array}$ \\
\hline 0.204 & 162 & 2.70 & 0.1852 \\
0.201 & 161 & 2.68 & 0.1842 \\
0.205 & 160 & 2.67 & 0.1833 \\
\hline 0.143 & 81 & 1.35 & 0.1081 \\
0.144 & 83 & 1.38 & 0.1100 \\
0.144 & 81 & 1.35 & 0.1081 \\
\hline 0.365 & 339 & 5.65 & 0.3536 \\
0.367 & 341 & 5.68 & 0.3555 \\
0.366 & 340 & 5.67 & 0.3546 \\
\hline 0.498 & 488 & 8.13 & 0.4954 \\
0.499 & 492 & 8.20 & 0.4992 \\
0.501 & 496 & 8.27 & 0.5030 \\
\hline 0.641 & 657 & 11.0 & 0.6562 \\
0.640 & 652 & 10.9 & 0.6515 \\
0.649 & 662 & 11.0 & 0.6610 \\
\hline
\end{tabular}




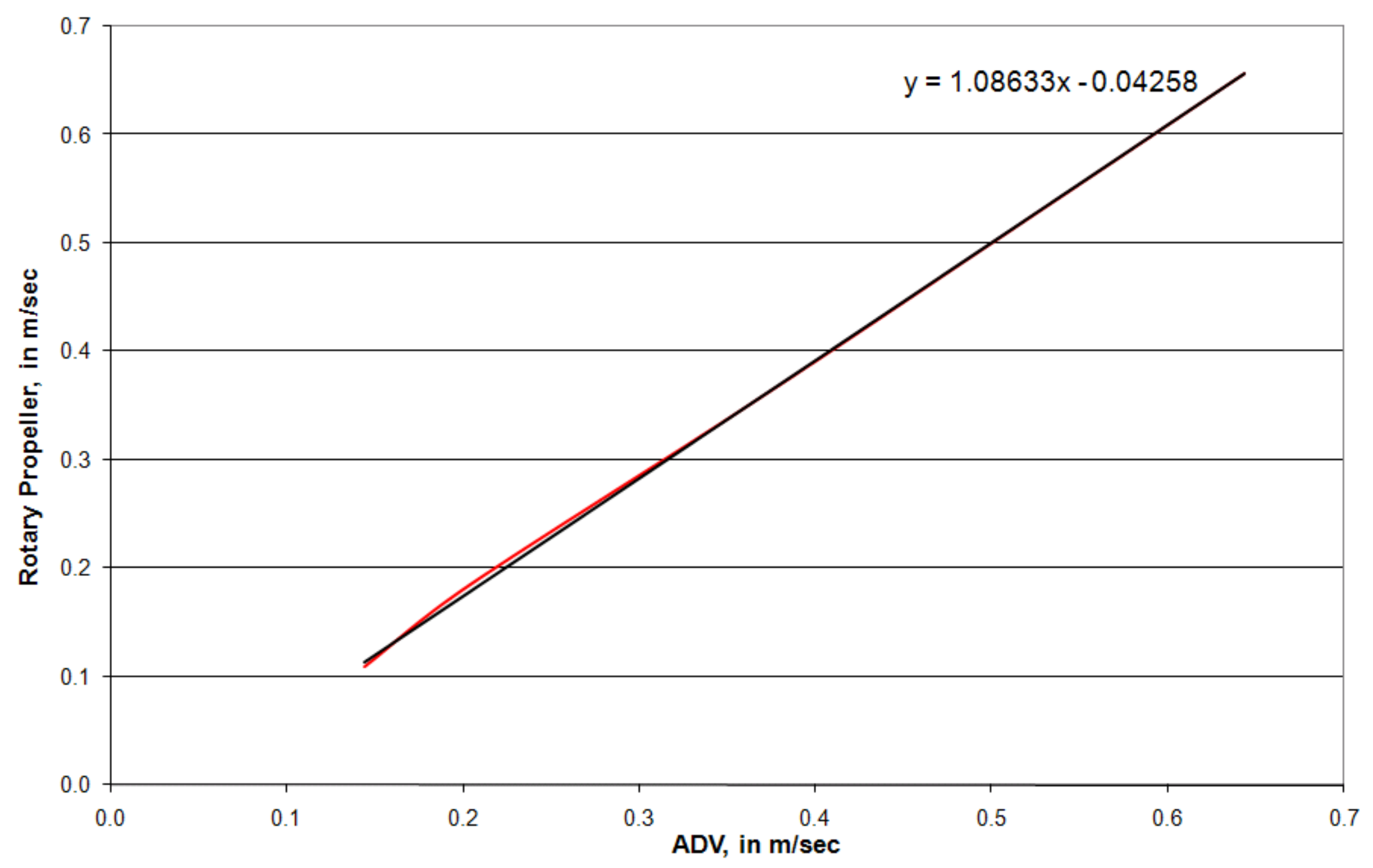

Figure D-1: Calibration curve fitting between the two velocity measurement devices. 


\title{
APPENDIX E
}

\section{Determination of Suspended Particles}

\author{
Concentration
}


Sampling Date: February 18, 2008 (Monday) between $3 \mathrm{pm}$ and 5:30 pm Weather Condition on the Sampling Date: partly sunny, windy and dry

Date of Conducting Suspended Particles Concentration Experiments: February 20, 2008 (Wednesday morning) Volume of Water Bottle of Each Sample: 1 liter

\begin{tabular}{|c|c|c|c|c|c|}
\hline $\begin{array}{c}\text { Water } \\
\text { Sample } \\
\#\end{array}$ & $\begin{array}{c}\text { Filter } \\
\text { Paper } \\
\#\end{array}$ & $\begin{array}{c}\text { Weight of } \\
\text { Filter Paper, } \\
\text { in grams }\end{array}$ & $\begin{array}{c}\text { Weight of Filter Paper and } \\
\text { Suspended Particles, } \\
\text { in grams }\end{array}$ & $\begin{array}{c}\text { Weight of } \\
\text { Suspended Particles, } \\
\text { in grams }\end{array}$ & $\begin{array}{c}\text { Suspended Particles } \\
\text { Concentration, } \\
\text { in mg/L }\end{array}$ \\
\hline A & 07397 & 0.1921 & 0.1944 & 0.0023 & 2.3 \\
\hline B & 07352 & 0.1896 & 0.1920 & 0.0024 & 2.4 \\
\hline C & 07353 & 0.1902 & 0.1940 & 0.0038 & 3.8 \\
\hline$D$ & 07400 & 0.1861 & 0.1881 & 0.0020 & 2.0 \\
\hline \multicolumn{7}{|r}{} \\
\hline
\end{tabular}


APPENDIX $F$

Metal Analysis on Water Samples 
Table F.1: Metal analysis of Water Sample \#A (APPENDIX C) using ICP method.

\begin{tabular}{|c|c|c|c|c|c|c|c|c|c|c|}
\hline $\begin{array}{c}\text { Sample } \\
\text { ID }\end{array}$ & Date & Time & $\begin{array}{c}\text { Analyte } \\
\text { Name }\end{array}$ & $\begin{array}{l}\text { Conc } \\
\text { (Calib) } \\
\end{array}$ & $\begin{array}{c}\text { RSD } \\
\text { (Conc) }\end{array}$ & $\begin{array}{c}\text { SD } \\
\text { (Calib) }\end{array}$ & $\begin{array}{l}\text { Calib } \\
\text { Units }\end{array}$ & $\begin{array}{c}\text { Conc } \\
\text { (Calib) } 1\end{array}$ & $\begin{array}{c}\text { Conc } \\
\text { (Calib)2 } \\
\end{array}$ & $\begin{array}{c}\text { Conc } \\
\text { (Calib) } 3 \\
\end{array}$ \\
\hline $\mathrm{A}$ & $3 / 5 / 2008$ & $16: 03: 00$ & Fe 238.204 & 0.1222 & 8.413 & 0.01028 & $\mathrm{mg} / \mathrm{L}$ & 0.1263 & 0.1299 & 0.1105 \\
\hline A & $3 / 5 / 2008$ & 16:03:00 & B 249.677 & 0.1186 & 10.54 & 0.01250 & $\mathrm{mg} / \mathrm{L}$ & 0.1275 & 0.1240 & 0.1044 \\
\hline$A$ & $3 / 5 / 2008$ & $16: 03: 00$ & Ba 233.527 & 0.06334 & 20.82 & 0.01319 & $\mathrm{mg} / \mathrm{L}$ & 0.05230 & 0.07794 & 0.05978 \\
\hline A & $3 / 5 / 2008$ & $16: 03: 00$ & Hg 253.652 & 0.2366 & 4.166 & 0.009859 & $\mathrm{mg} / \mathrm{L}$ & 0.2458 & 0.2378 & 0.2262 \\
\hline A & $3 / 5 / 2008$ & 16:03:00 & Cd 228.802 & -0.04076 & 22.26 & 0.009072 & $\mathrm{mg} / \mathrm{L}$ & -0.03695 & -0.03420 & -0.05111 \\
\hline$A$ & $3 / 5 / 2008$ & $16: 03: 00$ & Se 196.026 & -0.05994 & 25.37 & 0.01521 & $\mathrm{mg} / \mathrm{L}$ & -0.04350 & -0.06281 & -0.07351 \\
\hline$A$ & $3 / 5 / 2008$ & 16:03:00 & $\mathrm{Ag} 328.068$ & 0.3290 & 2.583 & 0.008497 & $\mathrm{mg} / \mathrm{L}$ & 0.3326 & 0.3351 & 0.3193 \\
\hline A & $3 / 5 / 2008$ & $16: 03: 00$ & Cu 327.393 & 0.06782 & 4.906 & 0.003327 & $\mathrm{mg} / \mathrm{L}$ & 0.06834 & 0.07085 & 0.06426 \\
\hline$A$ & $3 / 5 / 2008$ & $16: 03: 00$ & $\mathrm{~Pb} 220.353$ & -0.02422 & 55.94 & 0.01355 & $\mathrm{mg} / \mathrm{L}$ & -0.01600 & -0.01680 & -0.03985 \\
\hline A & $3 / 5 / 2008$ & $16: 03: 00$ & Ni 231.604 & 0.02829 & 38.05 & 0.01077 & $\mathrm{mg} / \mathrm{L}$ & 0.03202 & 0.03669 & 0.01616 \\
\hline A & $3 / 5 / 2008$ & 16:03:00 & Sb 206.836 & 0.02894 & 46.45 & 0.01344 & $\mathrm{mg} / \mathrm{L}$ & 0.03164 & 0.04083 & 0.01435 \\
\hline A & $3 / 5 / 2008$ & $16: 03: 00$ & Be 313.107 & -0.01454 & 15.57 & 0.002263 & $\mathrm{mg} / \mathrm{L}$ & -0.01552 & -0.01195 & -0.01615 \\
\hline$A$ & $3 / 5 / 2008$ & $16: 03: 00$ & Cr 267.716 & 0.008371 & 98.56 & 0.008250 & $\mathrm{mg} / \mathrm{L}$ & 0.01164 & 0.01449 & -0.001012 \\
\hline$A$ & $3 / 5 / 2008$ & $16: 03: 00$ & Mn 257.610 & -0.002910 & 306.4 & 0.008916 & $\mathrm{mg} / \mathrm{L}$ & 0.001039 & 0.003350 & -0.01312 \\
\hline A & $3 / 5 / 2008$ & $16: 03: 00$ & TI 190.801 & 0.05531 & 49.79 & 0.02753 & $\mathrm{mg} / \mathrm{L}$ & 0.02436 & 0.06447 & 0.07709 \\
\hline A & $3 / 5 / 2008$ & $16: 03: 00$ & V 290.880 & 0.01192 & 31.58 & 0.003765 & $\mathrm{mg} / \mathrm{L}$ & 0.01049 & 0.01619 & 0.009087 \\
\hline A & $3 / 5 / 2008$ & 16:03:00 & Zn 206.200 & -0.002891 & 304.5 & 0.008804 & $\mathrm{mg} / \mathrm{L}$ & -0.0001407 & 0.004209 & -0.01274 \\
\hline A & $3 / 5 / 2008$ & 16:03:00 & As 188.979 & -0.03295 & 59.36 & 0.01956 & $\mathrm{mg} / \mathrm{L}$ & -0.01037 & -0.04464 & -0.04383 \\
\hline A & $3 / 5 / 2008$ & $16: 03: 00$ & $\mathrm{Hg} 194.168$ & 0.1775 & 5.624 & 0.009980 & $\mathrm{mg} / \mathrm{L}$ & 0.1888 & 0.1733 & 0.1702 \\
\hline
\end{tabular}


Table F.2: Metal analysis of Water Sample \#B (APPENDIX C) using ICP method.

\begin{tabular}{|c|c|c|c|c|c|c|c|c|c|c|}
\hline $\begin{array}{c}\text { Sample } \\
\text { ID }\end{array}$ & Date & Time & $\begin{array}{c}\text { Analyte } \\
\text { Name } \\
\end{array}$ & $\begin{array}{l}\text { Conc } \\
\text { (Calib) } \\
\end{array}$ & $\begin{array}{l}\text { RSD } \\
\text { (Conc) } \\
\end{array}$ & SD (Calib) & $\begin{array}{l}\text { Calib } \\
\text { Units } \\
\end{array}$ & $\begin{array}{c}\text { Conc } \\
\text { (Calib)1 } \\
\end{array}$ & $\begin{array}{c}\text { Conc } \\
\text { (Calib)2 } \\
\end{array}$ & $\begin{array}{c}\text { Conc } \\
\text { (Calib)3 } \\
\end{array}$ \\
\hline B & $3 / 5 / 2008$ & $16: 05: 37$ & Fe 238.204 & 0.08316 & 0.1903 & 0.0001582 & $\mathrm{mg} / \mathrm{L}$ & 0.08324 & 0.08298 & 0.08326 \\
\hline B & $3 / 5 / 2008$ & $16: 05: 37$ & В 249.677 & 0.07009 & 2.788 & 0.001954 & $\mathrm{mg} / \mathrm{L}$ & 0.07234 & 0.06910 & 0.06882 \\
\hline B & $3 / 5 / 2008$ & 16:05:37 & Ba 233.527 & 0.04730 & 1.932 & 0.0009139 & $\mathrm{mg} / \mathrm{L}$ & 0.04806 & 0.04755 & 0.04629 \\
\hline B & $3 / 5 / 2008$ & $16: 05: 37$ & Hg 253.652 & 0.1549 & 0.4094 & 0.0006340 & $\mathrm{mg} / \mathrm{L}$ & 0.1555 & 0.1548 & 0.1543 \\
\hline B & $3 / 5 / 2008$ & $16: 05: 37$ & Cd 228.802 & -0.05154 & 0.5977 & 0.0003081 & $\mathrm{mg} / \mathrm{L}$ & -0.05124 & -0.05186 & -0.05154 \\
\hline$B$ & $3 / 5 / 2008$ & 16:05:37 & Se 196.026 & -0.05611 & 22.68 & 0.01273 & $\mathrm{mg} / \mathrm{L}$ & -0.07046 & -0.05169 & -0.04619 \\
\hline B & $3 / 5 / 2008$ & $16: 05: 37$ & Ag 328.068 & 0.3177 & 0.1420 & 0.0004510 & $\mathrm{mg} / \mathrm{L}$ & 0.3179 & 0.3172 & 0.3180 \\
\hline B & $3 / 5 / 2008$ & $16: 05: 37$ & Cu 327.393 & 0.04531 & 4.460 & 0.002021 & $\mathrm{mg} / \mathrm{L}$ & 0.04731 & 0.04534 & 0.04327 \\
\hline B & $3 / 5 / 2008$ & $16: 05: 37$ & $\mathrm{~Pb} 220.353$ & -0.04587 & 23.17 & 0.01063 & $\mathrm{mg} / \mathrm{L}$ & -0.05547 & -0.04769 & -0.03445 \\
\hline B & $3 / 5 / 2008$ & $16: 05: 37$ & Ni 231.604 & 0.01978 & 1.917 & 0.0003791 & $\mathrm{mg} / \mathrm{L}$ & 0.02017 & 0.01941 & 0.01974 \\
\hline B & $3 / 5 / 2008$ & $16: 05: 37$ & Sb 206.836 & 0.01205 & 28.28 & 0.003408 & $\mathrm{mg} / \mathrm{L}$ & 0.01370 & 0.01432 & 0.008133 \\
\hline B & $3 / 5 / 2008$ & $16: 05: 37$ & Be 313.107 & -0.01726 & 4.131 & 0.0007131 & $\mathrm{mg} / \mathrm{L}$ & -0.01644 & -0.01771 & -0.01763 \\
\hline B & $3 / 5 / 2008$ & $16: 05: 37$ & Cr 267.716 & -0.004095 & 34.72 & 0.001422 & $\mathrm{mg} / \mathrm{L}$ & -0.003802 & -0.005641 & -0.002843 \\
\hline$B$ & $3 / 5 / 2008$ & $16: 05: 37$ & Mn 257.610 & -0.01611 & 3.270 & 0.0005268 & $\mathrm{mg} / \mathrm{L}$ & -0.01592 & -0.01670 & -0.01570 \\
\hline B & $3 / 5 / 2008$ & $16: 05: 37$ & TI 190.801 & 0.03941 & 74.76 & 0.02947 & $\mathrm{mg} / \mathrm{L}$ & 0.05683 & 0.05602 & 0.005391 \\
\hline B & $3 / 5 / 2008$ & $16: 05: 37$ & V 290.880 & 0.006514 & 6.904 & 0.0004498 & $\mathrm{mg} / \mathrm{L}$ & 0.006947 & 0.006049 & 0.006547 \\
\hline$B$ & $3 / 5 / 2008$ & $16: 05: 37$ & Zn 206.200 & -0.02091 & 4.208 & 0.0008797 & $\mathrm{mg} / \mathrm{L}$ & -0.02153 & -0.02129 & -0.01990 \\
\hline B & $3 / 5 / 2008$ & $16: 05: 37$ & As 188.979 & -0.03595 & 27.76 & 0.009979 & $\mathrm{mg} / \mathrm{L}$ & -0.03893 & -0.04410 & -0.02482 \\
\hline B & $3 / 5 / 2008$ & $16: 05: 37$ & Hg 194.168 & 0.08948 & 7.716 & 0.006904 & $\mathrm{mg} / \mathrm{L}$ & 0.09505 & 0.09164 & 0.08176 \\
\hline
\end{tabular}


Table F.3: Metal analysis of Water Sample \#C (APPENDIX C) using ICP method.

\begin{tabular}{|c|c|c|c|c|c|c|c|c|c|c|}
\hline $\begin{array}{c}\text { Sample } \\
\text { ID }\end{array}$ & Date & Time & $\begin{array}{l}\text { Analyte } \\
\text { Name } \\
\end{array}$ & $\begin{array}{l}\text { Conc } \\
\text { (Calib) } \\
\end{array}$ & $\begin{array}{l}\text { RSD } \\
\text { (Conc) } \\
\end{array}$ & SD (Calib) & $\begin{array}{l}\text { Calib } \\
\text { Units } \\
\end{array}$ & $\begin{array}{c}\text { Conc } \\
\text { (Calib)1 } \\
\end{array}$ & $\begin{array}{c}\text { Conc } \\
\text { (Calib)2 } \\
\end{array}$ & $\begin{array}{c}\text { Conc } \\
\text { (Calib) } 3 \\
\end{array}$ \\
\hline C & $3 / 5 / 2008$ & 16:08:14 & Fe 238.204 & 0.08106 & 1.290 & 0.001046 & $\mathrm{mg} / \mathrm{L}$ & 0.08224 & 0.08025 & 0.08069 \\
\hline C & $3 / 5 / 2008$ & 16:08:14 & В 249.677 & 0.06279 & 3.620 & 0.002273 & $\mathrm{mg} / \mathrm{L}$ & 0.06261 & 0.06062 & 0.06515 \\
\hline C & $3 / 5 / 2008$ & 16:08:14 & Ba 233.527 & 0.04573 & 2.360 & 0.001079 & $\mathrm{mg} / \mathrm{L}$ & 0.04651 & 0.04618 & 0.04449 \\
\hline C & $3 / 5 / 2008$ & 16:08:14 & Hg 253.652 & 0.1410 & 0.4796 & 0.0006761 & $\mathrm{mg} / \mathrm{L}$ & 0.1403 & 0.1416 & 0.1410 \\
\hline C & $3 / 5 / 2008$ & 16:08:14 & $\mathrm{Cd} 228.802$ & -0.05256 & 0.7792 & 0.0004096 & $\mathrm{mg} / \mathrm{L}$ & -0.05221 & -0.05301 & -0.05246 \\
\hline$C$ & $3 / 5 / 2008$ & 16:08:14 & Se 196.026 & -0.06792 & 10.79 & 0.007330 & $\mathrm{mg} / \mathrm{L}$ & -0.07638 & -0.06371 & -0.06366 \\
\hline C & $3 / 5 / 2008$ & 16:08:14 & Ag 328.068 & 0.3168 & 0.05594 & 0.0001772 & $\mathrm{mg} / \mathrm{L}$ & 0.3170 & 0.3167 & 0.3166 \\
\hline C & $3 / 5 / 2008$ & $16: 08: 14$ & Cu 327.393 & 0.02557 & 5.178 & 0.001324 & $\mathrm{mg} / \mathrm{L}$ & 0.02702 & 0.02524 & 0.02444 \\
\hline C & $3 / 5 / 2008$ & 16:08:14 & $\mathrm{Pb} 220.353$ & -0.03784 & 40.82 & 0.01545 & $\mathrm{mg} / \mathrm{L}$ & -0.05293 & -0.03852 & -0.02206 \\
\hline C & $3 / 5 / 2008$ & 16:08:14 & Ni 231.604 & 0.01825 & 8.355 & 0.001525 & $\mathrm{mg} / \mathrm{L}$ & 0.01977 & 0.01672 & 0.01828 \\
\hline C & $3 / 5 / 2008$ & 16:08:14 & Sb 206.836 & 0.01442 & 26.68 & 0.003847 & $\mathrm{mg} / \mathrm{L}$ & 0.01147 & 0.01302 & 0.01877 \\
\hline C & $3 / 5 / 2008$ & 16:08:14 & Be 313.107 & -0.01743 & 0.8366 & 0.0001458 & $\mathrm{mg} / \mathrm{L}$ & -0.01757 & -0.01743 & -0.01728 \\
\hline C & $3 / 5 / 2008$ & $16: 08: 14$ & Cr 267.716 & -0.003312 & 7.614 & 0.0002522 & $\mathrm{mg} / \mathrm{L}$ & -0.003104 & -0.003593 & -0.003239 \\
\hline C & $3 / 5 / 2008$ & $16: 08: 14$ & Mn 257.610 & -0.01918 & 0.6712 & 0.0001288 & $\mathrm{mg} / \mathrm{L}$ & -0.01931 & -0.01919 & -0.01905 \\
\hline$C$ & $3 / 5 / 2008$ & $16: 08: 14$ & TI 190.801 & 0.02784 & 165.6 & 0.04612 & $\mathrm{mg} / \mathrm{L}$ & 0.007082 & 0.08069 & -0.004245 \\
\hline C & $3 / 5 / 2008$ & 16:08:14 & V 290.880 & 0.007944 & 15.84 & 0.001258 & $\mathrm{mg} / \mathrm{L}$ & 0.006504 & 0.008831 & 0.008497 \\
\hline$C$ & $3 / 5 / 2008$ & 16:08:14 & Zn 206.200 & -0.02141 & 4.519 & 0.0009673 & $\mathrm{mg} / \mathrm{L}$ & -0.02031 & -0.02177 & -0.02214 \\
\hline C & $3 / 5 / 2008$ & 16:08:14 & As 188.979 & -0.03188 & 51.61 & 0.01645 & $\mathrm{mg} / \mathrm{L}$ & -0.04583 & -0.03606 & -0.01374 \\
\hline C & $3 / 5 / 2008$ & 16:08:14 & Hg 194.168 & 0.07193 & 6.617 & 0.004759 & $\mathrm{mg} / \mathrm{L}$ & 0.06656 & 0.07360 & 0.07563 \\
\hline
\end{tabular}


Table F.4: Metal analysis of Water Sample \#D (APPENDIX C) using ICP method.

\begin{tabular}{|c|c|c|c|c|c|c|c|c|c|c|}
\hline $\begin{array}{c}\text { Sample } \\
\text { ID }\end{array}$ & Date & Time & $\begin{array}{c}\text { Analyte } \\
\text { Name } \\
\end{array}$ & $\begin{array}{l}\text { Conc } \\
\text { (Calib) } \\
\end{array}$ & $\begin{array}{c}\text { RSD } \\
\text { (Conc) } \\
\end{array}$ & SD (Calib) & $\begin{array}{l}\text { Calib } \\
\text { Units } \\
\end{array}$ & $\begin{array}{c}\text { Conc } \\
\text { (Calib) } 1 \\
\end{array}$ & $\begin{array}{c}\text { Conc } \\
\text { (Calib)2 } \\
\end{array}$ & $\begin{array}{c}\text { Conc } \\
\text { (Calib) } 3 \\
\end{array}$ \\
\hline D & $3 / 5 / 2008$ & $16: 10: 51$ & Fe 238.204 & 0.04936 & 1.267 & 0.0006252 & $\mathrm{mg} / \mathrm{L}$ & 0.04864 & 0.04977 & 0.04968 \\
\hline D & $3 / 5 / 2008$ & $16: 10: 51$ & В 249.677 & 0.05522 & 2.534 & 0.001399 & $\mathrm{mg} / \mathrm{L}$ & 0.05542 & 0.05373 & 0.05651 \\
\hline D & $3 / 5 / 2008$ & 16:10:51 & Ba 233.527 & 0.04297 & 0.5026 & 0.0002160 & $\mathrm{mg} / \mathrm{L}$ & 0.04317 & 0.04300 & 0.04274 \\
\hline D & $3 / 5 / 2008$ & $16: 10: 51$ & Hg 253.652 & 0.1356 & 0.3457 & 0.0004686 & $\mathrm{mg} / \mathrm{L}$ & 0.1353 & 0.1361 & 0.1353 \\
\hline D & $3 / 5 / 2008$ & $16: 10: 51$ & Cd 228.802 & -0.05337 & 0.7729 & 0.0004125 & $\mathrm{mg} / \mathrm{L}$ & -0.05296 & -0.05337 & -0.05379 \\
\hline$D$ & $3 / 5 / 2008$ & 16:10:51 & Se 196.026 & -0.05772 & 35.34 & 0.02040 & $\mathrm{mg} / \mathrm{L}$ & -0.07079 & -0.03422 & -0.06816 \\
\hline D & $3 / 5 / 2008$ & $16: 10: 51$ & Ag 328.068 & 0.3171 & 0.1464 & 0.0004641 & $\mathrm{mg} / \mathrm{L}$ & 0.3165 & 0.3173 & 0.3174 \\
\hline D & $3 / 5 / 2008$ & $16: 10: 51$ & Cu 327.393 & 0.008450 & 4.416 & 0.0003731 & $\mathrm{mg} / \mathrm{L}$ & 0.008419 & 0.008838 & 0.008093 \\
\hline D & $3 / 5 / 2008$ & $16: 10: 51$ & $\mathrm{~Pb} 220.353$ & -0.04839 & 8.746 & 0.004232 & $\mathrm{mg} / \mathrm{L}$ & -0.05069 & -0.04351 & -0.05098 \\
\hline D & $3 / 5 / 2008$ & $16: 10: 51$ & Ni 231.604 & 0.01448 & 13.57 & 0.001966 & $\mathrm{mg} / \mathrm{L}$ & 0.01608 & 0.01508 & 0.01229 \\
\hline D & $3 / 5 / 2008$ & $16: 10: 51$ & Sb 206.836 & 0.005280 & 145.0 & 0.007657 & $\mathrm{mg} / \mathrm{L}$ & -0.002014 & 0.004599 & 0.01325 \\
\hline$D$ & $3 / 5 / 2008$ & $16: 10: 51$ & Be 313.107 & -0.01790 & 0.6800 & 0.0001217 & $\mathrm{mg} / \mathrm{L}$ & -0.01803 & -0.01788 & -0.01779 \\
\hline D & $3 / 5 / 2008$ & $16: 10: 51$ & Cr 267.716 & -0.004743 & 21.47 & 0.001018 & $\mathrm{mg} / \mathrm{L}$ & -0.004966 & -0.003631 & -0.005631 \\
\hline$D$ & $3 / 5 / 2008$ & $16: 10: 51$ & Mn 257.610 & -0.01767 & 0.4405 & 0.00007785 & $\mathrm{mg} / \mathrm{L}$ & -0.01769 & -0.01759 & -0.01774 \\
\hline $\mathrm{D}$ & $3 / 5 / 2008$ & $16: 10: 51$ & TI 190.801 & 0.02960 & 58.01 & 0.01717 & $\mathrm{mg} / \mathrm{L}$ & 0.03370 & 0.04435 & 0.01075 \\
\hline D & $3 / 5 / 2008$ & $16: 10: 51$ & V 290.880 & 0.006239 & 21.53 & 0.001344 & $\mathrm{mg} / \mathrm{L}$ & 0.007473 & 0.004808 & 0.006437 \\
\hline$D$ & $3 / 5 / 2008$ & $16: 10: 51$ & Zn 206.200 & -0.02393 & 0.9474 & 0.0002267 & $\mathrm{mg} / \mathrm{L}$ & -0.02369 & -0.02414 & -0.02396 \\
\hline D & $3 / 5 / 2008$ & $16: 10: 51$ & As 188.979 & -0.03893 & 33.82 & 0.01316 & $\mathrm{mg} / \mathrm{L}$ & -0.05190 & -0.03930 & -0.02558 \\
\hline D & $3 / 5 / 2008$ & $16: 10: 51$ & Hg 194.168 & 0.06981 & 3.764 & 0.002628 & $\mathrm{mg} / \mathrm{L}$ & 0.06682 & 0.07082 & 0.07177 \\
\hline
\end{tabular}




\section{APPENDIX G}

Hong Kong Water Pollution Control

Ordinance Cap 358 Section 21

"Technical Memorandum Standards for

Effluents Discharged into Drainage and

Sewerage Systems, Inland and

Coastal Waters" 


\begin{tabular}{|l|l|l|l|l|}
\hline Chapter: & 358AK & $\begin{array}{l}\text { TECHNICAL MEMORANDUM STANDARDS FOR } \\
\text { EFFLUENTS DISCHARGED INTO DRAINAGE AND } \\
\text { SEWERAGE SYSTEMS, INLAND AND COASTAL } \\
\text { WATERS }\end{array}$ & Gazette Number & Version Date \\
\hline
\end{tabular}

Empowering section

$30 / 06 / 1997$

(Water Pollution Control Ordinance, Cap 358 section 21)

[30 November 1990]

(Special Gazette Supplement No. 5 dated 30.11.1990)

\begin{tabular}{|l|l|l|l|l|}
\hline Part: & 1 & PRELIMINARY & $30 / 06 / 1997$ \\
\hline
\end{tabular}

PART I PRELIMINARY

1. Citation and commencement

1.1 This technical memorandum is issued under section 21 of the Water Pollution Control Ordinance. It may be cited as the Technical Memorandum on Effluent Standards.

2. Application and scope

2.1 The Technical Memorandum on Effluent Standards is a guide to the Authority under the Ordinance. It sets the limits that make effluents acceptable into foul sewers, storm water drains, inland and coastal waters. The limits control the physical, chemical and microbial quality of effluents.

2.2 The standards apply to effluents through licences, which the Authority issues under sections 15,16 and 20 of the Ordinance. The Authority is the Director of Environmental Protection. He will consult this memorandum when fixing the conditions that he will include in a licence. He will not normally impose conditions that are more stringent than those in the memorandum. To do so, he must have good reason.

W.3 Where a user takes water from a nature water course or water body, and then returns it after use, different standards may apply. The Authority will not impose standards requiring the effluent to be cleaner than the water that the user takes.

2.4 This memorandum does not apply to discharges or deposits of wastes that are controlled by the Waste Disposal (Livestock Waste) Regulations (Cap $354 \mathrm{sub}$. leg. A). Nor does it apply to dredging, dumping for land formation or solid waste disposal. Other laws and standards control them. The memorandum does apply to all other discharges and deposits.

2.5 This memorandum sets standards for effluents that differ in different areas and between surface waters and sewers. The standards also vary with the rate of effluent flow, which the Authority may also limit.

2.6 The flow rates the memorandum covers appear in Tables 1 to $10 \mathrm{~b}$. The Authority will set standards for effluents outside the listed flow ranges case by case. Standards for effluents above the highest flow band will be more stringent than those in the tables.

2.7 Some effluents may have characteristics or components that are not listed and could be harmful. In these cases, the Authority may set limits case by case. There are certain general prohibitions that apply besides the tables, which are listed in paragraphs $6.2,8.4$ and 9.2.

2.8 At present, the Government Chemist is the only analyst designated by the Ordinance. He alone certifies the quality of an effluent sample in a prosecution. The effluent standards refer to his analytical methods, which appear for reference only in Annex I.

3. Interpretation

3.1 This memorandum uses standard scientific terms. Where the Ordinance defines a term, that definition applies.

3.2 In this memorandum the following definitions also apply.

"Effluent" (流出物) means any discharge or deposit subject to control under the Ordinance.

"Coastal waters" (海岸水域) means the waters of Hong Kong except inland waters and storm water drains.

"Inshore waters" (沿岸水域) means all coastal waters where the water depth is less than $6 \mathrm{~m}$ at mean 
low tide, or that are within $200 \mathrm{~m}$ of the mean low water mark, whichever position is further from the shore.

"Marine waters" (海洋水域) means all coastal waters except inshore waters.

"Flow rate" (流量率) means the measured volume per unit time of effluent from a premises, averaged over the period of operation in any day accepted by the Authority. Where the flow cannot by measured, it is determined by a method the Authority approves.

"Foul sewer" (骿水渠) means a sewer built for the carriage of foul or waste water or so designated by the Authority.

"Storm water drain" (雨水渠) means a man made conduit built for natural surface drainage or so designated by the Authority.

"Toxic metals" (有毒金屬) includes antimony, arsenic, beryllium, cadmium, chromium, copper, lead, mercury, nickel, selenium, silver, thallium, vanadium and any other metals that the Authority specifies.

4.

4.1

4.2

4.4.4

4.4.4.2 Determining the acceptable characteristics of effluents

The Ordinance allows the Government to declare water control zones and to set water quality objectives. The objectives describe the water quality that will promote the conservation and best use of the waters in the public interest.

In deciding whether to grant a licence for an effluent, the Authority's purpose is to meet the relevant objectives. The same purpose governs the conditions that the Authority attaches to the licence. He also must consider the need to protect the drainage or sewerage system, including disposal works, treatment processes, and the health and safety of workers in them.

Each control zone contains four systems into which wastes may be discharged. They are foul sewers, storm water drains, inland waters (which include water in the ground) and coastal waters.

The effluent standards take account of the beneficial uses of the different systems, but the systems and control zones fall into convenient groups. In general terms the standards for each group are as follows.

Foul sewers

Effluent standards for foul sewers leading to similar Government sewage treatment plants do not differ from zone to zone. Effluents into foul sewers leading to a treatment plant with microbial processes must meet more stringent standards for some toxic metals. This is to protect the processes and ensure that they can continue to treat domestic sewage effectively.

Storm water drains

Most storm water drains discharge directly into inland or coastal waters. The Authority will not normally allow effluents to them. If, exceptionally, he does so, effluents to them must meet the standards for the next receiving waters downstream.

Inland waters

The beneficial use of inland waters is the only factor governing the effluent quality and quantity that the Authority will license. There is no distinction between zones. There are four groups of inland waters.

Inland water grouping Beneficial use

Group A abstraction for potable water supply

Group B irrigation

Group C pond fish culture

Group D general amenity and secondary

contact recreation

There are four sets of effluent standards corresponding to these groups. Streams which enter the sea at gazetted beaches need special attention; they belong to Group D.

\section{Coastal waters}

The water quality and beneficial uses of coastal waters vary in different water control zones. They need separate effluent standards. In practice this memorandum groups together zones with similar objectives.

The memorandum makes a distinction between inshore and marine waters, except in Tolo Harbour, Port Shelter and Deep Bay where tidal flow is restricted. This results in six sets of standards. Coastal water group Control Zones 


\begin{tabular}{|ll|}
\hline Group ITolo Harbour, Port Shelter \\
Group II & Deep Bay \\
Group IIIa & Victoria Harbour inshore \\
Group IIIb & Victoria Harbour marine \\
Group IVa & Southern, Mirs Bay, Western Buffer, \\
Eastern Buffer, Junk Bay, North Western inshore \\
$\begin{array}{ll}\text { Group IVb } & \text { Southern, Mirs Bay, Western Buffer, } \\
\text { Eastern Buffer, Junk Bay, North Western marine }\end{array}$ \\
\hline
\end{tabular}

4.4.4.3 Within the coastal waters are special areas that need specific restrictions. These areas include bathing beaches, sites of special scientific interest, marinas and mariculture sites. Paragraph 9.1 lists the restrictions.

5. Charges for effluent disposal

5.1 Some effluent components can be treated much more efficiently in big communal treatment plants than in individual premises. In some cases, factories do not have the space to treat their own effluents properly.

5.2 The components that can be treated in this way are measured as biochemical oxygen demand, chemical oxygen demand, and suspended solids. The allowable levels of these determinands in effluents to foul sewers are high; this reflects their treatability in the public sewage disposal system.

5.3 All other effluent components have stricter standards. Those who produce effluents must control these other components in their own premises.

5.4 A charge will be levied to pay for the safe disposal of the treatable effluent components. It will be the actual extra cost of treating strong industrial and commercial effluents to the same level as domestic sewage. This charge will be independent of any other fees and charges that may be introduced under the Ordinance.

(Enacted 1990)

\begin{tabular}{|l|l|l|l|}
\hline Part: & 2 & EFFLUENT STANDARDS & $30 / 06 / 1997$ \\
\hline
\end{tabular}

PART II EFFLUENT STANDARDS

6. Discharges to foul sewers

6.1 Table 1 lists the standards for effluents to foul sewers leading to Government sewage disposal works. If the works include microbial treatment, there are extra requirements. Table 2 lists them. Information on the catchments of sewage disposal works is available for inspection in the Drainage Services Department.

6.2 In addition to the effluent standards, there are some substances that are harmful to the sewers, or resistant to removal by treatment processes. The Authority will not permit them to be discharged into foul sewers. They are listed below.

\section{Prohibited substances-FOUL SEWERS}

polychlorinated biphenyls (PCB)

polyaromatic hydrocarbon $(\mathrm{PAH})$

fumigant or pesticide

radioactive substances

chlorinated hydrocarbons

flammable or toxic solvents

petroleum oil or tar

calcium carbide

wastes liable to form scum or deposits in any part of the public sewer

any substance of a nature and quantity likely to damage the sewer or to interfere with any of the treatment processes 
6.3 The Authority will not normally allow sludge discharges to sewers. To avoid overloading the foul sewers, the Authority will not allow unpolluted water to be discharged into them.

6.4 The Authority will not allow dilution as a means of meeting effluent standards. This would cause excessive hydraulic loading on the disposal system. For this purpose the licence may specify an instantaneous peak flow. This does not necessarily prohibit mixing different effluent streams within the premises.

7. Discharges to storm water drains

7.1 The Authority will not normally allow effluent to storm water drains. In exceptional circumstances, he may do so, in which case the effluent standards will be as for the downstream environmental waters. This may be inland waters or inshore waters. The Authority will also take the advice of the Director of Drainage Services on the available capacity of the storm water drain.

7.2 In a few areas, the foul sewerage is not adequate for existing sewage flows, and storm water drains may serve as combined sewers. The Authority will, after consulting the Director of Drainage Services, declare these combined sewers to be foul sewers for the purpose of fixing effluent standards. This will continue until the effluents can be diverted to separate foul sewers. The Government is working on a territory wide sewerage improvement programme to make this possible.

8. Discharges to inland waters

8.1 Tables 3, 4, 5 and 6 list the standards for effluents to Group A, B, Group C and Group D inland waters respectively. The standards apply to groundwater as to other inland waters.

8.2 For general guidance, Group A inland waters include all waters in water gathering grounds and within the boundaries of country parks. Group B waters are mainly those draining agricultural areas in the New Territories. Group $\mathrm{C}$ waters are those running through areas where there are large numbers of fish ponds, mostly in the Yuen Long area. Group D waters are those large enough to permit secondary contact recreation and those draining urban and semi-urban areas.

8.3 The Authority will not allow new effluents to rivers, streams or storm water drains that are within $100 \mathrm{~m}$ of a gazetted bathing beach and flow through the beach area. This is to protect the health and comfort of bathers.

8.4 They are some substances that the Authority will not allow in effluents to inland waters. They are listed below.

Prohibited substances-INLAND WATERS

polychlorinated biphenyls (PCB)

polyaromatic hydrocarbon $(\mathrm{PAH})$

fumigant, pesticide or toxicant

radioactive substances

chlorinated hydrocarbons

flammable or toxic solvents

petroleum oil or tar

calcium carbide

wastes liable to form scum, deposits or discoloration

sludge or solid refuse of any kind

detergents in Group A inland waters only

8.5 The Authority will not allow dilution as a means of meeting effluent standards. This would cause excessive loading on the receiving waters and their biota. For this purpose the licence may specify an instantaneous peak flow. This does not necessarily prohibit mixing different effluent streams within the premises.

8.6 The effluent standards in the tables do not apply to household septic tanks that discharge to the ground. The Authority will control them by design and maintenance standards. The general prohibitions still apply.

9. Discharges to coastal waters

9.1 Tables 7, 8,9a and $9 \mathrm{~b}$, and $10 \mathrm{a}$ and $10 \mathrm{~b}$ list the standards for effluents in the various groups of coastal waters. Regardless of these standards, the Authority will not allow new effluents in certain areas. They are listed below. 


\section{Prohibited Effluents-COASTAL WATERS}

No new effluent will be allowed:

- within $100 \mathrm{~m}$ of the boundaries of a gazetted beach in any direction, including rivers, streams and storm water drains;

- within $200 \mathrm{~m}$ of the seaward boundaries of a marine fish culture zone or a site of special scientific interest, and within $100 \mathrm{~m}$ of the landward boundaries;

- in any typhoon shelter;

- in any marina;

- within $100 \mathrm{~m}$ of a seawater intake point.

There are some substances that the Authority will not allow in effluents to coastal waters. They are listed below.

\section{Prohibited substances-COASTAL WATERS}

polychlorinated biphenyls (PCB)

polyaromatic hydrocarbon (PAH)

fumigant, pesticide or toxicant

radioactive substances

chlorinated hydrocarbons

flammable or toxic solvents

petroleum oil or tar

calcium carbide

wastes liable to form scum, deposits or discoloration

sludge, floatable substances or solids larger than $10 \mathrm{~mm}$

9.3 The Authority will not allow dilution as a means of meeting effluent standards. This would cause excessive loading on the receiving waters and their biological systems. For this purpose the licence may specify and instantaneous peak flow. This does not necessarily prohibit mixing different effluent streams within the premises.

(Enacted 1990)

\begin{tabular}{|l|l|l|l|l|}
\hline Annex: & 1 & REFERENCE TO ANALYTICAL METHODS & 32 of 2000 & $09 / 06 / 2000$ \\
\hline
\end{tabular}

Annex 1

This table lists the methods used by the Government Chemist.

Parameter

$\mathrm{pH}$

Temperature

Colour

Conductivity

Total Suspended Solids

Settleable Solid

Dissolved Oxygen

Biochemical Oxygen Demand (BOD)

Chemical Oxygen Demand (COD)

Oil \& Grease

Metals

Pretreatment for total metals
Reference

APHA 17ed 4500- $\mathrm{H}+\mathrm{B}$

Note (a)

Lovibond Tintometer, $25 \mathrm{~mm}$ cell

BS 2690: Part 9: 1970: Method 6

APHA 17 ed $2540 \mathrm{D}$

APHA 17ed 2540 F

APHA 17ed 4500-O G

BS 6068: Section 2.14: 1984

ASTM D 1252-88 Test Method B or

APHA 17 ed $5220 \mathrm{C} \& \mathrm{D}$

APHA 17ed 5520 C

Sample Digestion 


\section{Antimony \\ Beryllium \\ Barium \\ Cadmium \\ Chromium \\ Copper \\ Iron \\ Lead \\ Manganese \\ Nickel \\ Silver \\ Thallium \\ Vanadium \\ Zine}

Arsenic

Selenium

Mercury

Boron

Cyanide

Sulphide

total

free

$\mathrm{H}_{2} \mathrm{~S}$

Phenols

Surfactants (total)

(total means anionic and non-ionic)

Anionic

Non-ionic

Total residual chlorine

Total Phosphorus (TP)

Total Reactive Phosphorus

Sulphate

Chloride

Fluoride

Nitrogen-Ammonia

Nitrogen-Nitrate

Nitrogen-Nitrite

Total Kjeldahl Nitrogen (TKN)

E. coli

APHA 17ed $3030 \mathrm{~A}$ and $3030 \mathrm{~F} .3 \mathrm{~b}$

\}

\}

\}$\quad$ APHA 17ed 3111,3113 and 3120 as

$\int$ appropriate

\}

\}

\}

APHA 17ed 3113 and 3114

as appropriate

APHA 17ed 3112

APHA 17ed 3120

ASTM D 2036-89 or

APHA 17ed 4500-CN

\}

APHA 17ed 4500-S ${ }^{2-}$

APHA 17ed 5530

BS 6068: Section 2.23: 1986 or

APHA 17ed $5540 \mathrm{C}$

BS 6068: Section 2.24: 1986

APHA 17ed 4500-Cl G

ASTM D 515-88

APHA 17ed 4500-P

APHA 17ed 4500- $\mathrm{SO}_{4}{ }^{2-}$

APHA 17ed 4500-Cl

APHA 17ed 4500-(F) -C

APHA 17ed 4500- $\mathrm{NH}_{3}$

APHA 17ed 4500- $\mathrm{NO}_{3}{ }^{-}$

APHA 17ed 4500- $\mathrm{NO}_{2}^{-}$

ASTMD 3590-89

Notes (b), (c)

Reference Notes:

ASTM -Annual Book of American Society for Testing and Materials Standards, Vol 11.01 \& 11.02. 
BS -British Standards Institution.

APHA 17ed -American Public Health Association. Standard Methods 17th Edition (1989).

(a) Temperature sensor should be calibrated against a mercury thermometer of $0.1^{\circ} \mathrm{C}$ scale.

(b) DoE(1983): The Bacteriological Examination of Drinking Water Supplies 1982, Sec. 7.8 \& 7.9.

(c) Membrane lauryl sulphate method with in situ urease test for E. coli:

Reports on Public Health and Medical Subjects No. 71. Methods for the Examination of Waters and Associated Materials. London: Her Majesty's Stationery Office 1983.

(Enacted 1990)

Table 1 Standards for effluents discharged into foul sewers leading into Government sewage treatment plants

(All units in $\mathrm{mg} / \mathrm{L}$ unless otherwise stated; all figures are upper limits unless otherwise indicated)

\begin{tabular}{|c|c|c|c|c|c|c|c|c|c|c|c|c|c|}
\hline $\begin{array}{l}\text { Flow rate } \\
\left(\mathrm{m}^{3} / \mathrm{day}\right)\end{array}$ & $\leq 10$ & $\begin{array}{l}>10 \text { and } \\
\leqq 100\end{array}$ & $\begin{array}{c}>100 \text { and } \\
\leqq 200\end{array}$ & $\begin{array}{c}>200 \text { and } \\
\$ 400\end{array}$ & $\begin{array}{c}>400 \text { and } \\
\leq 600\end{array}$ & $\begin{array}{c}>600 \text { and } \\
\leqq 800\end{array}$ & $\begin{array}{c}>800 \text { and } \\
\leq 1000\end{array}$ & $\begin{array}{c}>1000 \\
\text { and } \\
\leqq 1500\end{array}$ & $\begin{array}{c}>1500 \\
\text { and } \\
\leqq 2000\end{array}$ & $\begin{array}{c}>2000 \\
\text { and } \\
\leqq 3000\end{array}$ & $\begin{array}{c}>3000 \\
\text { and } \\
\leqq 4000\end{array}$ & $\begin{array}{l}>4000 \\
\text { and } \\
\leqq 5000\end{array}$ & $\begin{array}{c}>5000 \text { and } \\
\leqq 6000\end{array}$ \\
\hline$\overline{\mathrm{pH} \text { (pH units) }}$ & $6-10$ & $6-10$ & $6-10$ & $6-10$ & $6-10$ & $6-10$ & $6-10$ & $6-10$ & $6-10$ & $6-10$ & $6-10$ & $6-10$ & $6-10$ \\
\hline Temperature $\left({ }^{\circ} \mathrm{C}\right)$ & 43 & 43 & 43 & 43 & 43 & 43 & 43 & 43 & 43 & 43 & 43 & 43 & 43 \\
\hline Suspended solids & 1200 & 1000 & 900 & 800 & 800 & 800 & 800 & 800 & 800 & 800 & 800 & 800 & 800 \\
\hline Settleable solids & 100 & 100 & 100 & 100 & 100 & 100 & 100 & 100 & 100 & 100 & 100 & 100 & 100 \\
\hline BOD & 1200 & 1000 & 900 & 800 & 800 & 800 & 800 & 800 & 800 & 800 & 800 & 800 & 800 \\
\hline COD & 3000 & 2500 & 2200 & 2000 & 2000 & 2000 & 2000 & 2000 & 2000 & 2000 & 2000 & 2000 & 2000 \\
\hline Oil \& Grease & 100 & 100 & 50 & 50 & 50 & 40 & 30 & 20 & 20 & 20 & 20 & 20 & 20 \\
\hline Iron & 30 & 25 & 25 & 25 & 15 & 12.5 & 10 & 7.5 & 5 & 3.5 & 2.5 & 2 & 1.5 \\
\hline Boron & 8 & 7 & 6 & 5 & 4 & 3 & 2.4 & 1.6 & 1.2 & 0.8 & 0.6 & 0.5 & 0.4 \\
\hline Barium & 8 & 7 & 6 & 5 & 4 & 3 & 2.4 & 1.6 & 1.2 & 0.8 & 0.6 & 0.5 & 0.4 \\
\hline Mercury & 0.2 & 0.15 & 0.1 & 0.1 & 0.001 & 0.001 & 0.001 & 0.001 & 0.001 & 0.001 & 0.001 & 0.001 & 0.001 \\
\hline Cadmium & 0.2 & 0.15 & 0.1 & 0.1 & 0.001 & 0.001 & 0.001 & 0.001 & 0.001 & 0.001 & 0.001 & 0.001 & 0.001 \\
\hline Copper & 4 & 4 & 4 & 3 & 1.5 & 1.5 & 1 & 1 & 1 & 1 & 1 & 1 & 1 \\
\hline Nickel & 4 & 3 & 3 & 2 & 1.5 & 1.5 & 1 & 0.8 & 0.7 & 0.7 & 0.6 & 0.6 & 0.6 \\
\hline Chromium & 2 & 2 & 2 & 2 & 1 & 0.7 & 0.6 & 0.4 & 0.3 & 0.2 & 0.1 & 0.1 & 0.1 \\
\hline Zinc & 5 & 5 & 4 & 3 & 1.5 & 1.5 & 1 & 0.8 & 0.7 & 0.7 & 0.6 & 0.6 & 0.6 \\
\hline Silver & 4 & 3 & 3 & 2 & 1.5 & 1.5 & 1 & 0.8 & 0.7 & 0.7 & 0.6 & 0.6 & 0.6 \\
\hline Other toxic metals individually & 2.5 & 2.2 & 2 & 1.5 & 1 & 0.7 & 0.6 & 0.4 & 0.3 & 0.2 & 0.15 & 0.12 & 0.1 \\
\hline Total toxic metals & 10 & 10 & 8 & 7 & 3 & 2 & 2 & 1.6 & 1.4 & 1.2 & 1.2 & 1.2 & 1 \\
\hline Cyanide & 2 & 2 & 2 & 1 & 0.7 & 0.5 & 0.4 & 0.27 & 0.2 & 0.13 & 0.1 & 0.08 & 0.06 \\
\hline Phenols & 1 & 1 & 1 & 1 & 0.7 & 0.5 & 0.4 & 0.27 & 0.2 & 0.13 & 0.1 & 0.1 & 0.1 \\
\hline Sulphide & 10 & 10 & 10 & 10 & 5 & 5 & 4 & 2 & 2 & 2 & 1 & 1 & 1 \\
\hline Sulphate & 1000 & 1000 & 1000 & 1000 & 1000 & 1000 & 1000 & 900 & 800 & 600 & 600 & 600 & 600 \\
\hline Total nitrogen & 200 & 200 & 200 & 200 & 200 & 200 & 200 & 100 & 100 & 100 & 100 & 100 & 100 \\
\hline Total phosphorus & 50 & 50 & 50 & 50 & 50 & 50 & 50 & 25 & 25 & 25 & 25 & 25 & 25 \\
\hline Surfactants (total) & 200 & 150 & 50 & 40 & 30 & 25 & 25 & 25 & 25 & 25 & 25 & 25 & 25 \\
\hline
\end{tabular}

(Enacted 1990)

Table 2 Standards for effluents discharged into foul sewers leading into Government sewage treatment plants with microbial treatment

(All units in $\mathrm{mg} / \mathrm{L}$ unless otherwise stated; all figures are upper limits unless otherwise indicated)

\begin{tabular}{|c|c|c|c|c|c|c|c|c|c|c|c|c|c|c|}
\hline Determinand & $\begin{array}{l}\text { Flow rate } \\
(\mathrm{m} 3 / \text { day })\end{array}$ & $\leq 10$ & $\begin{array}{l}>10 \text { and } \\
\leq 100\end{array}$ & $\begin{array}{l}>100 \text { and } \\
\leq 200\end{array}$ & $\begin{array}{c}>200 \text { and } \\
\leq 400\end{array}$ & $\begin{array}{c}>400 \text { and } \\
\leq 600\end{array}$ & $\begin{array}{c}>600 \text { and } \\
\leq 800\end{array}$ & $\begin{array}{c}>800 \text { and } \\
\leq 1000\end{array}$ & $\begin{array}{c}>1000 \\
\text { and } \\
\leq 1500\end{array}$ & $\begin{array}{c}>1500 \\
\text { and } \\
\leq 2000\end{array}$ & $\begin{array}{c}>2000 \\
\text { and } \\
\leq 3000\end{array}$ & $\begin{array}{c}>3000 \\
\text { and } \\
\leq 4000\end{array}$ & $\begin{array}{c}>4000 \\
\text { and } \\
\leq 5000\end{array}$ & $\begin{array}{c}>5000 \text { and } \\
\leq 6000\end{array}$ \\
\hline Copper & & 1.5 & 1 & 1 & 1 & 0.8 & 0.6 & 0.5 & 0.4 & 0.3 & 0.2 & 0.15 & 0.1 & 0.05 \\
\hline
\end{tabular}

NOTE : Standards in this table apply in place of those in Table 1 for the corresponding determinand.

(Enacted 1990)

Table 3 Standards for effluents discharged into Group A inland waters

(All units in $\mathrm{mg} / \mathrm{L}$ unless otherwise stated; all figures are upper limits unless otherwise indicated)

\begin{tabular}{|c|c|c|c|c|c|}
\hline $\begin{array}{l}\text { Flow rate } \\
\left(\mathrm{m}^{3} / \text { day) }\right. \\
\text { Determinand }\end{array}$ & $\leqq 10$ & $\begin{array}{l}>10 \\
\text { and } \\
\leqq 100\end{array}$ & $\begin{array}{l}>100 \\
\text { and } \\
\leqq 500\end{array}$ & $\begin{array}{l}>500 \\
\text { and } \\
\leqq 1000\end{array}$ & $\begin{array}{l}>1000 \\
\text { and } \\
\leqq 2000\end{array}$ \\
\hline pH (pH units) & $35 \quad 6.5-8.5$ & $\begin{array}{c}6.5-8.5 \\
35\end{array}$ & $\begin{array}{c}6.5-8.5 \\
30\end{array}$ & $\begin{array}{c}6.5-8.5 \\
30\end{array}$ & $\begin{array}{c}6.5-8.5 \\
30\end{array}$ \\
\hline
\end{tabular}

Cap 358AK-TECHNICAL MEMORANDUM STANDARDS FOR EFFLUENTS DISCHARGED INTO DRAINAGE AND SEWERAGE SYSTEMS, INLAND 7 AND COASTAL WATERS 


\begin{tabular}{|l|c|c|c|c|c|} 
cell length) & & & & \\
Conductivity $\left(\mu \mathrm{s} / \mathrm{cm}\right.$ at $\left.20^{\circ} \mathrm{C}\right)$ & 1000 & 1000 & 1000 & 1000 & 1000 \\
Suspended solids & 10 & 10 & 5 & 5 & 5 \\
Dissolved oxygen & $\geqq 4$ & $\geq 4$ & $\geqq 4$ & $\geqq 4$ & $\geqq 4$ \\
$\mathrm{BOD}$ & 10 & 10 & 5 & 5 & 5 \\
$\mathrm{COD}$ & 50 & 50 & 20 & 20 & 10 \\
Oil \& Grease & 1 & 1 & 1 & 1 & 1 \\
Boron & 2 & 2 & 1 & 0.5 & 0.5 \\
Barium & 2 & 2 & 1 & 0.5 & 0.5 \\
Iron & 2 & 2 & 1 & 0.5 & 0.5 \\
Arsenic & 0.05 & 0.05 & 0.05 & 0.05 & 0.05 \\
Total chromium & 0.05 & 0.05 & 0.05 & 0.05 & 0.05 \\
Mercury & 0.001 & 0.001 & 0.001 & 0.001 & 0.001 \\
Cadmium & 0.001 & 0.001 & 0.001 & 0.001 & 0.001 \\
Selenium & 0.01 & 0.01 & 0.01 & 0.01 & 0.01 \\
Copper & 0.2 & 0.2 & 0.2 & 0.2 & 0.1 \\
Lead & 0.1 & 0.1 & 0.1 & 0.1 & 0.1 \\
Manganese & 0.5 & 0.5 & 0.5 & 0.5 & 0.5 \\
Zinc & 1 & 1 & 1 & 1 & 1 \\
Other toxic metals individually & 0.1 & 0.1 & 0.1 & 0.1 & 0.1 \\
Total toxic metals & 0.3 & 0.3 & 0.2 & 0.2 & 0.15 \\
Cyanide & 0.05 & 0.05 & 0.05 & 0.05 & 0.02 \\
Phenols & 0.1 & 0.1 & 0.1 & 0.1 & 0.1 \\
Hydrogen sulphide & 0.05 & 0.05 & 0.05 & 0.05 & 0.05 \\
Sulphide & 0.2 & 0.2 & 0.1 & 0.1 & 0.1 \\
Fluoride & 1 & 1 & 1 & 1 & 0.5 \\
Sulphate & 800 & 600 & 500 & 400 & 200 \\
Chloride & 800 & 500 & 500 & 200 & 200 \\
Total reactive phosphorus & 1 & 0.7 & 0.7 & 0.5 & 0.5 \\
Ammonia nitrogen & 1 & 1 & 1 & 1 & 0.5 \\
Nitrate + nitrite nitrogen & 15 & 15 & 15 & 10 & 10 \\
E. coli (count/100 ml) & $<1$ & $<1$ & $<1$ & $<1$ & $<1$ \\
\hline
\end{tabular}

(Enacted 1990. 32 of 2000 s. 48)

Table 4 Standards for effluents discharged into Group B inland waters (All units in $\mathrm{mg} / \mathrm{L}$ unless otherwise stated; all figures are upper limits unless otherwise indicated)

\begin{tabular}{|c|c|c|c|c|c|c|c|c|}
\hline Determinand & $\begin{array}{r}\text { Flow rate } \\
\left(\mathrm{m}^{3} / \text { day }\right)\end{array}$ & $\begin{array}{l}>200 \\
\text { and } \\
\leqq 400\end{array}$ & $\begin{array}{l}>400 \\
\text { and } \\
\leqq 600\end{array}$ & $\begin{array}{l}>600 \\
\text { and } \\
\leqq 800\end{array}$ & $\begin{array}{c}>800 \\
\text { and } \\
\leqq 1000\end{array}$ & $\begin{array}{c}>1000 \\
\text { and } \\
\leqq 1500\end{array}$ & $\begin{array}{c}>1500 \\
\text { and } \\
\leqq 2000\end{array}$ & $\begin{array}{c}>2000 \\
\text { and } \\
\leqq 3000\end{array}$ \\
\hline $\mathrm{pH}$ (pH units) & $6.5-8.5$ & $6.5-8.5$ & $6.5-8.5$ & $6.5-8.5$ & $6.5-8.5$ & $6.5-8.5$ & $6.5-8.5$ & $6.5-8.5$ \\
\hline Temperature $\left({ }^{\circ} \mathrm{C}\right)$ & 35 & 30 & 30 & 30 & 30 & 30 & 30 & 30 \\
\hline $\begin{array}{l}\text { Colour (lovibond units) } \\
\text { (25mm cell length) }\end{array}$ & 1 & 1 & 1 & 1 & 1 & 1 & 1 & 1 \\
\hline Suspended solids & 30 & 30 & 30 & 30 & 30 & 30 & 30 & 30 \\
\hline BOD & 20 & 20 & 20 & 20 & 20 & 20 & 20 & 20 \\
\hline $\mathrm{COD}$ & 80 & 80 & 80 & 80 & 80 & 80 & 80 & 80 \\
\hline Oil \& Grease & 10 & 10 & 10 & 10 & 10 & 10 & 10 & 10 \\
\hline Iron & 10 & 8 & 7 & 5 & 4 & 3 & 2 & 1 \\
\hline Boron & 5 & 4 & 3 & 2.5 & 2 & 1.5 & 1 & 0.5 \\
\hline Barium & 5 & 4 & 3 & 2.5 & 2 & 1.5 & 1 & 0.5 \\
\hline Mercury & 0.001 & 0.001 & 0.001 & 0.001 & 0.001 & 0.001 & 0.001 & 0.001 \\
\hline Cadmium & 0.001 & 0.001 & 0.001 & 0.001 & 0.001 & 0.001 & 0.001 & 0.001 \\
\hline Selenium & 0.2 & 0.2 & 0.2 & 0.2 & 0.2 & 0.1 & 0.1 & 0.1 \\
\hline Other toxic metals individually & 0.5 & 0.5 & 0.2 & 0.2 & 0.2 & 0.1 & 0.1 & 0.1 \\
\hline Total Toxic metals & 2 & 1.5 & 1 & 0.5 & 0.5 & 0.2 & 0.2 & 0.2 \\
\hline Cyanide & 0.1 & 0.1 & 0.1 & 0.08 & 0.08 & 0.05 & 0.05 & 0.03 \\
\hline Phenols & 0.1 & 0.1 & 0.1 & 0.1 & 0.1 & 0.1 & 0.1 & 0.1 \\
\hline Sulphide & 0.2 & 0.2 & 0.2 & 0.2 & 0.2 & 0.2 & 0.2 & 0.2 \\
\hline Fluoride & 10 & 10 & 8 & 8 & 8 & 5 & 5 & 3 \\
\hline Sulphate & 800 & 800 & 600 & 600 & 600 & 400 & 400 & 400 \\
\hline Chloride & 1000 & 1000 & 800 & 800 & 800 & 600 & 600 & 400 \\
\hline Total phosphorus & 10 & 10 & 10 & 8 & 8 & 8 & 5 & 5 \\
\hline Ammonia nitrogen & 5 & 5 & 5 & 5 & 5 & 5 & 5 & 5 \\
\hline Nitrate + nitrite nitrogen & 30 & 30 & 30 & 20 & 20 & 20 & 10 & 10 \\
\hline Surfactants (total) & 5 & 5 & 5 & 5 & 5 & 5 & 5 & 5 \\
\hline E. coli (count $/ 100 \mathrm{ml})$ & 100 & 100 & 100 & 100 & 100 & 100 & 100 & 100 \\
\hline
\end{tabular}

Table 5 Standards for effluents discharged into Group C inland waters 
(All units in $\mathrm{mg} / \mathrm{L}$ unless otherwise stated; all figures are upper limits unless otherwise indicated)

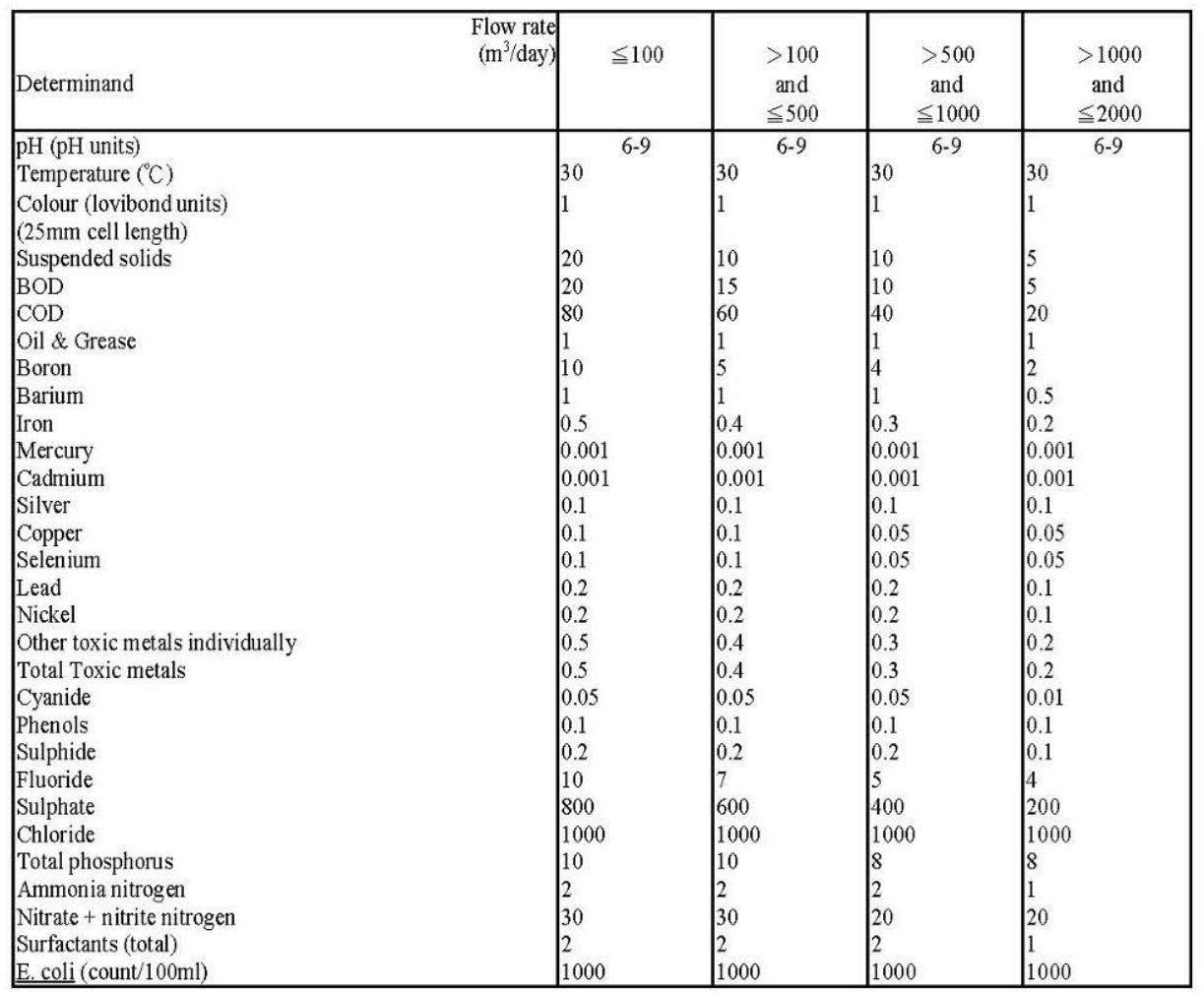

(Enacted 1990)

Table 6 Standards for effluents discharged into Group D inland waters (All units in $\mathrm{mg} / \mathrm{L}$ unless otherwise stated; all figures are upper limits unless otherwise indicated)

\begin{tabular}{|c|c|c|c|c|c|c|c|c|}
\hline $\begin{array}{r}\text { Flow rate } \\
\left(\mathrm{m}^{3} / \text { day }\right)\end{array}$ & $\leqq 200$ & $\begin{array}{l}>200 \\
\text { and } \\
\leqq 400\end{array}$ & $\begin{array}{c}>400 \\
\text { and } \\
\leqq 600\end{array}$ & $\begin{array}{l}>600 \\
\text { and } \\
\leqq 800\end{array}$ & $\begin{array}{c}>800 \\
\text { and } \\
\leqq 1000\end{array}$ & $\begin{array}{c}>1000 \\
\text { and } \\
\leqq 1500\end{array}$ & $\begin{array}{c}>1500 \\
\text { and } \\
\leqq 2000\end{array}$ & $\begin{array}{l}>2000 \\
\text { and } \\
\leqq 3000\end{array}$ \\
\hline $\mathrm{pH}$ (pH units) & $6-10$ & $6-10$ & $6-10$ & $6-10$ & $6-10$ & $6-10$ & $6-10$ & $6-10$ \\
\hline Temperature $\left({ }^{\circ} \mathrm{C}\right)$ & 30 & 30 & 30 & 30 & 30 & 30 & 30 & 30 \\
\hline $\begin{array}{l}\text { Colour (lovibond units) } \\
\text { (25mm cell length) }\end{array}$ & 1 & 1 & 1 & 1 & 1 & 1 & 1 & 1 \\
\hline Suspended solids & 30 & 30 & 30 & 30 & 30 & 30 & 30 & 30 \\
\hline BOD & 20 & 20 & 20 & 20 & 20 & 20 & 20 & 20 \\
\hline COD & 80 & 80 & 80 & 80 & 80 & 80 & 80 & 80 \\
\hline Oil \& Grease & 10 & 10 & 10 & 10 & 10 & 10 & 10 & 10 \\
\hline Iron & 10 & 8 & 7 & 5 & 4 & 2.7 & 2 & 1.3 \\
\hline Boron & 5 & 4 & 3.5 & 2.5 & 2 & 1.5 & 1 & 0.7 \\
\hline Barium & 5 & 4 & 3.5 & 2.5 & 2 & 1.5 & 1 & 0.7 \\
\hline Mercury & 0.1 & 0.05 & 0.001 & 0.001 & 0.001 & 0.001 & 0.001 & 0.001 \\
\hline Cadmium & 0.1 & 0.05 & 0.001 & 0.001 & 0.001 & 0.001 & 0.001 & 0.001 \\
\hline Other toxic metals individually & 1 & 1 & 0.8 & 0.8 & 0.5 & 0.5 & 0.2 & 0.2 \\
\hline Total Toxic metals & 2 & 2 & 1.6 & 1.6 & 1 & 1 & 0.5 & 0.4 \\
\hline Cyanide & 0.4 & 0.4 & 0.3 & 0.3 & 0.2 & 0.1 & 0.1 & 0.05 \\
\hline Phenols & 0.4 & 0.3 & 0.2 & 0.1 & 0.1 & 0.1 & 0.1 & 0.1 \\
\hline Sulphide & 1 & 1 & 1 & 1 & 1 & 1 & 1 & 1 \\
\hline Sulphate & 800 & 600 & 600 & 600 & 600 & 400 & 400 & 400 \\
\hline Chloride & 1000 & 800 & 800 & 800 & 600 & 600 & 400 & 400 \\
\hline Fluoride & 10 & 8 & 8 & 8 & 5 & 5 & 3 & 3 \\
\hline Total phosphorus & 10 & 10 & 10 & 8 & 8 & 8 & 5 & 5 \\
\hline Ammonia nitrogen & 20 & 20 & 20 & 20 & 20 & 20 & 20 & 10 \\
\hline Nitrate + nitrite nitrogen & 50 & 50 & 50 & 30 & 30 & 30 & 30 & 20 \\
\hline
\end{tabular}




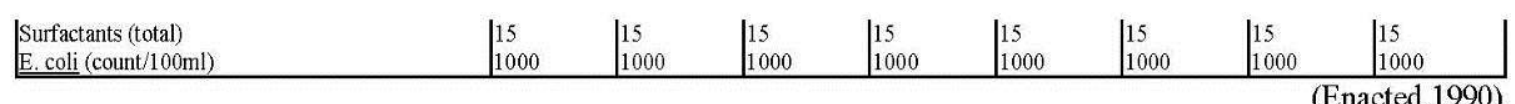

Table 7 Standards for effluents discharged into the coastal waters of Tolo and Port Shelter Water Control Zones

(ALl units in $\mathrm{mg} / \mathrm{L}$ unless otherwise stated; all figures are upper limits unless otherwise indicated)

\begin{tabular}{|c|c|c|c|c|c|c|c|c|c|c|c|c|}
\hline $\begin{array}{l}\text { Flow rate } \\
\left(\mathrm{m}^{3} / \text { day }\right)\end{array}$ & $\leq 10$ & $\begin{array}{l}>10 \text { and } \\
\leqq 200\end{array}$ & $\begin{array}{c}>200 \text { and } \\
\leqq 400\end{array}$ & $\begin{array}{c}>400 \text { and } \\
\leqq 600\end{array}$ & $\begin{array}{c}>600 \text { and } \\
\leqq 800\end{array}$ & $\begin{array}{c}>800 \text { and } \\
\leqq 1000\end{array}$ & $\begin{array}{l}>1000 \\
\text { and } \\
\leqq 1500\end{array}$ & $\begin{array}{c}>1500 \\
\text { and } \\
\leqq 2000\end{array}$ & $\begin{array}{c}>2000 \\
\text { and } \\
\leqq 3000\end{array}$ & $\begin{array}{c}>3000 \\
\text { and } \\
\leqq 4000\end{array}$ & $\begin{array}{l}>4000 \\
\text { and } \\
\leqq 5000\end{array}$ & $\begin{array}{c}>5000 \text { and } \\
\leqq 6000\end{array}$ \\
\hline$\overline{\mathrm{pH}}$ (pH units) & $6-9$ & $6-9$ & $6-9$ & $6-9$ & $6-9$ & $6-9$ & $6-9$ & $6-9$ & $6-9$ & $6-9$ & $6-9$ & $6-9$ \\
\hline Temperature $\left({ }^{\circ} \mathrm{C}\right)$ & 45 & 45 & 45 & 45 & 45 & 45 & 45 & 45 & 45 & 45 & 45 & 45 \\
\hline $\begin{array}{l}\text { Colour (lovibond units) }(25 \mathrm{~mm} \text { cell } \\
\text { length) }\end{array}$ & 1 & 1 & 1 & 1 & 1 & 1 & 1 & 1 & 1 & 1 & 1 & 1 \\
\hline Suspended solids & 30 & 30 & 30 & 30 & 30 & 30 & 15 & 15 & 15 & 15 & 15 & 15 \\
\hline BOD & 20 & 20 & 20 & 20 & 20 & 20 & 10 & 10 & 10 & 10 & 10 & 10 \\
\hline COD & 80 & 80 & 80 & 80 & 80 & 80 & 50 & 50 & 50 & 50 & 50 & 50 \\
\hline Oil \& Grease & 20 & 20 & 20 & 20 & 20 & 20 & 10 & 10 & 10 & 10 & 10 & 10 \\
\hline Iron & 10 & 10 & 10 & 7 & 5 & 4 & 2.7 & 2 & 1.3 & 1 & 0.8 & 0.6 \\
\hline Boron & 5 & 4 & 3 & 2.5 & 2 & 1.6 & 1.1 & 0.8 & 0.5 & 0.4 & 0.3 & 0.2 \\
\hline Barium & 5 & 4 & 3 & 2.5 & 2 & 1.6 & 1.1 & 0.8 & 0.5 & 0.4 & 0.3 & 0.2 \\
\hline Mercury & 0.1 & 0.001 & 0.001 & 0.001 & 0.001 & 0.001 & 0.001 & 0.001 & 0.001 & 0.001 & 0.001 & 0.001 \\
\hline Cadmium & 0.1 & 0.001 & 0.001 & 0.001 & 0.001 & 0.001 & 0.001 & 0.001 & 0.001 & 0.001 & 0.001 & 0.001 \\
\hline Other toxic metals individually & 1 & 1 & 0.8 & 0.5 & 0.5 & 0.4 & 0.1 & 0.1 & 0.1 & 0.1 & 0.1 & 0.1 \\
\hline Total toxic metals & 2 & 2 & 1.6 & 1 & 1 & 0.8 & 0.2 & 0.2 & 0.2 & 0.2 & 0.14 & 0.1 \\
\hline Cyanide & 0.1 & 0.1 & 0.1 & 0.1 & 0.1 & 0.1 & 0.05 & 0.05 & 0.03 & 0.02 & 0.02 & 0.01 \\
\hline Phenols & 0.5 & 0.5 & 0.5 & 0.25 & 0.25 & 0.25 & 0.1 & 0.1 & 0.1 & 0.1 & 0.1 & 0.1 \\
\hline Sulphide & 5 & 5 & 5 & 5 & 5 & 5 & 2.5 & 2.5 & 1.5 & 1 & 1 & 0.5 \\
\hline Total residual chlorine & 1 & 1 & 1 & 1 & 1 & 1 & 1 & 1 & 1 & 1 & 1 & 1 \\
\hline Total nitrogen & 20 & 20 & 20 & 15 & 15 & 15 & 15 & 15 & 10 & 10 & 10 & 10 \\
\hline Total phosphorus & 8 & 8 & 5 & 5 & 5 & 5 & 5 & 5 & 5 & 5 & 5 & 5 \\
\hline Surfactants (total) & 15 & 15 & 15 & 15 & 15 & 15 & 10 & 10 & 10 & 10 & 10 & 10 \\
\hline E. coli (count $/ 100 \mathrm{ml}$ ) & 1000 & 1000 & 1000 & 1000 & 1000 & 1000 & 1000 & 1000 & 1000 & 1000 & 1000 & 1000 \\
\hline
\end{tabular}

(Enacted 1990)

Table 8 Standards for effluents discharged into the coastal waters of Deep Bay Water Control Zone

(All units in $\mathrm{mg} / \mathrm{L}$ unless otherwise stated; all figures are upper limits unless otherwise indicated)

\begin{tabular}{|c|c|c|c|c|c|c|c|c|c|c|c|c|}
\hline $\begin{array}{r}\text { Flow rate } \\
\left(\mathrm{m}^{3} / \text { day }\right)\end{array}$ & $\leqq 10$ & $\begin{array}{c}>10 \text { and } \\
\leq 200\end{array}$ & $\begin{array}{c}>200 \text { and } \\
\leqq 400\end{array}$ & $\begin{array}{c}>400 \text { and } \\
\leqq 600\end{array}$ & $\begin{array}{c}>600 \text { and } \\
\leqq 800\end{array}$ & $\begin{array}{c}>800 \text { and } \\
\leqq 1000\end{array}$ & $\begin{array}{l}>1000 \\
\text { and } \\
\leq 1500\end{array}$ & $\begin{array}{c}>1500 \\
\text { and } \\
\leq 2000\end{array}$ & $\begin{array}{c}>2000 \\
\text { and } \\
\leq 3000\end{array}$ & $\begin{array}{c}>3000 \\
\text { and } \\
\leq 4000\end{array}$ & $\begin{array}{c}>4000 \\
\text { and } \\
\leq 5000\end{array}$ & $\begin{array}{c}>5000 \text { and } \\
\leqq 6000\end{array}$ \\
\hline $\mathrm{pH}$ (pH units) & $6-9$ & $6-9$ & $6-9$ & $6-9$ & $6-9$ & $6-9$ & $6-9$ & $6-9$ & $6-9$ & $6-9$ & $6-9$ & $6-9$ \\
\hline Temperature $\left({ }^{\circ} \mathrm{C}\right)$ & 45 & 45 & 45 & 45 & 45 & 45 & 45 & 45 & 45 & 45 & 45 & 45 \\
\hline $\begin{array}{l}\text { Colour (lovibond units) }(25 \mathrm{~mm} \text { cell } \\
\text { length) }\end{array}$ & 1 & 1 & 1 & 1 & 1 & 1 & 1 & 1 & 1 & 1 & 1 & 1 \\
\hline Suspended solids & 50 & 50 & 50 & 50 & 50 & 50 & 25 & 25 & 25 & 25 & 25 & 25 \\
\hline BOD & 20 & 20 & 20 & 20 & 20 & 20 & 10 & 10 & 10 & 10 & 10 & 10 \\
\hline COD & 80 & 80 & 80 & 80 & 80 & 80 & 50 & 50 & 50 & 50 & 50 & 50 \\
\hline Oil \& Grease & 20 & 20 & 20 & 20 & 20 & 20 & 10 & 10 & 10 & 10 & 10 & 10 \\
\hline Iron & 10 & 10 & 10 & 7 & 5 & 4 & 3 & 2 & 1 & 1 & 1 & 1 \\
\hline Boron & 5 & 4 & 3 & 2.5 & 2 & 1.6 & 1.1 & 0.8 & 0.5 & 0.4 & 0.3 & 0.2 \\
\hline Barium & 5 & 4 & 3 & 2.5 & 2 & 1.6 & 1.1 & 0.8 & 0.5 & 0.4 & 0.3 & 0.2 \\
\hline Mercury & 0.1 & 0.001 & 0.001 & 0.001 & 0.001 & 0.001 & 0.001 & 0.001 & 0.001 & 0.001 & 0.001 & 0.001 \\
\hline Cadmium & 0.1 & 0.001 & 0.001 & 0.001 & 0.001 & 0.001 & 0.001 & 0.001 & 0.001 & 0.001 & 0.001 & 0.001 \\
\hline Other toxic metals individually & 1 & 0.5 & 0.5 & 0.5 & 0.4 & 0.4 & 0.25 & 0.2 & 0.15 & 0.1 & 0.1 & 0.1 \\
\hline Total toxic metals & 2 & 1 & 1 & 1 & 0.8 & 0.8 & 0.5 & 0.4 & 0.3 & 0.2 & 0.14 & 0.1 \\
\hline Cyanide & 0.1 & 0.1 & 0.1 & 0.1 & 0.1 & 0.08 & 0.06 & 0.04 & 0.03 & 0.02 & 0.01 & 0.01 \\
\hline Phenols & 0.5 & 0.5 & 0.4 & 0.3 & 0.25 & 0.2 & 0.1 & 0.1 & 0.1 & 0.1 & 0.1 & 0.1 \\
\hline Sulphide & 5 & 5 & 5 & 5 & 5 & 5 & 2.5 & 2.5 & 1.5 & 1 & 1 & 0.5 \\
\hline Total residual chlorine & 1 & 1 & 1 & 1 & 1 & 1 & 1 & 1 & 1 & 1 & 1 & 1 \\
\hline Total nitrogen & 100 & 100 & 100 & 100 & 100 & 100 & 80 & 80 & 50 & 50 & 50 & 50 \\
\hline Total phosphorus & 10 & 10 & 10 & 10 & 10 & 10 & 8 & 8 & 5 & 5 & 5 & 5 \\
\hline Surfactants (total) & 15 & 15 & 15 & 15 & 15 & 15 & 10 & 10 & 10 & 10 & 10 & 7 \\
\hline E. coli (count $/ 100 \mathrm{ml})$ & 1000 & 1000 & 1000 & 1000 & 1000 & 1000 & 1000 & 1000 & 1000 & 1000 & 1000 & 1000 \\
\hline
\end{tabular}

(Enacted 1990)

Table 9a Standards for effluents discharged into the inshore waters of Victoria Harbour

Water Control Zone

(All units in $\mathrm{mg} / \mathrm{L}$ unless otherwise stated; all figures are upper limits unless otherwise indicated) 


\begin{tabular}{|c|c|c|c|c|c|c|c|c|c|c|c|c|}
\hline $\begin{array}{l}\text { Flow rate } \\
\left(\mathrm{m}^{3} / \text { day }\right)\end{array}$ & $\leqq 10$ & $\begin{array}{c}>10 \text { and } \\
\leq 200\end{array}$ & $\begin{array}{c}>200 \text { and } \\
\leq 400\end{array}$ & $\begin{aligned} &> 400 \text { and } \\
& \leq 600\end{aligned}$ & $\begin{array}{c}>600 \text { and } \\
\leq 800\end{array}$ & $\begin{array}{c}>800 \text { and } \\
\leq 1000\end{array}$ & $\begin{array}{c}>1000 \\
\text { and } \\
\leqq 1500\end{array}$ & $\begin{array}{c}>1500 \\
\text { and } \\
\leqq 2000 \\
\end{array}$ & $\begin{array}{c}>2000 \\
\text { and } \\
\leqq 3000\end{array}$ & $\begin{array}{c}>3000 \\
\text { and } \\
\leqq 4000\end{array}$ & $\begin{array}{c}>4000 \\
\text { and } \\
\leqq 5000\end{array}$ & $\begin{array}{c}>5000 \text { and } \\
\leq 6000\end{array}$ \\
\hline $\mathrm{pH}$ (pH units) & $6-9$ & $6-9$ & $6-9$ & $6-9$ & $6-9$ & $6-9$ & $6-9$ & 6-9 & $6-9$ & $6-9$ & $6-9$ & $6-9$ \\
\hline Temperature $\left({ }^{\circ} \mathrm{C}\right)$ & 40 & 40 & 40 & 40 & 40 & 40 & 40 & 40 & 40 & 40 & 40 & 40 \\
\hline $\begin{array}{l}\text { Colour (lovibond units) }(25 \mathrm{~mm} \text { cel } \\
\text { length) }\end{array}$ & 1 & 1 & 1 & 1 & 1 & 1 & 1 & 1 & 1 & 1 & 1 & 1 \\
\hline Suspended solids & 50 & 30 & 30 & 30 & 30 & 30 & 30 & 30 & 30 & 30 & 30 & 30 \\
\hline BOD & 50 & 20 & 20 & 20 & 20 & 20 & 20 & 20 & 20 & 20 & 20 & 20 \\
\hline COD & 100 & 80 & 80 & 80 & 80 & 80 & 80 & 80 & 80 & 80 & 80 & 80 \\
\hline Oil \& Grease & 30 & 20 & 20 & 20 & 20 & 20 & 20 & 20 & 20 & 20 & 20 & 20 \\
\hline Iron & 15 & 10 & 10 & 7 & 5 & 4 & 2.7 & 2 & 1.3 & 1 & 08 & 0.6 \\
\hline Boron & 5 & 4 & 3 & 2.7 & 2 & 1.6 & 1.1 & 0.8 & 0.5 & 0.4 & 0.3 & 0.2 \\
\hline Barium & 5 & 4 & 3 & 2.7 & 2 & 1.6 & 1.1 & 0.8 & 0.5 & 0.4 & 0.3 & 0.2 \\
\hline Mercury & 0.1 & 0.001 & 0.001 & 0.001 & 0.001 & 0.001 & 0.001 & 0.001 & 0.001 & 0.001 & 0.001 & 0.001 \\
\hline Cadmium & 0.1 & 0.001 & 0.001 & 0.001 & 0.001 & 0.001 & 0.00 & 0.001 & 0.001 & 0.001 & 0.001 & 0.001 \\
\hline Other toxic metals individually & 1 & 1 & 0.8 & 0.7 & 0.5 & 0.4 & 0.25 & 0.2 & 0.15 & 0.1 & 0.1 & 0.1 \\
\hline Total toxic metals & 2 & 2 & 1.6 & 1.4 & 1 & 0.8 & 0.5 & 0.4 & 0.3 & 0.2 & 0.14 & 0.1 \\
\hline Cyanide & 0.2 & 0.1 & 0.1 & 0.1 & 0.1 & 0.1 & 0.05 & 0.05 & 0.03 & 0.02 & 0.02 & 0.01 \\
\hline Phenols & 0.5 & 0.5 & 0.5 & 0.3 & 0.25 & 0.2 & 0.13 & 0.1 & 0.1 & 0.1 & 0.1 & 0.1 \\
\hline Sulphide & 5 & 5 & 5 & 5 & 5 & 5 & 2.5 & 2.5 & 1.5 & 1 & 1 & 0.5 \\
\hline Total residual chlorine & 1 & 1 & 1 & 1 & 1 & 1 & 1 & 1 & 1 & 1 & 1 & 1 \\
\hline Total nitrogen & 100 & 100 & 100 & 100 & 100 & 100 & 80 & 80 & 50 & 50 & 50 & 50 \\
\hline Total phosphorus & 10 & 10 & 10 & 10 & 10 & 10 & 8 & 8 & 5 & 5 & 5 & 5 \\
\hline Surfactants (total) & 20 & 15 & 15 & 15 & 15 & 15 & 10 & 10 & 10 & 10 & 10 & 10 \\
\hline E. coli (count $/ 100 \mathrm{ml})$ & 5000 & 5000 & 5000 & 5000 & 5000 & 5000 & 5000 & 5000 & 5000 & 5000 & 5000 & 5000 \\
\hline
\end{tabular}

(Enacted 1990)

Table 9b Standards for effluents discharged into the marine waters of Victoria Harbour

Water Control Zone

(All units in $\mathrm{mg} / \mathrm{L}$ unless otherwise stated; all figures are upper limits unless otherwise indicated)

\begin{tabular}{|c|c|c|c|c|c|c|c|c|c|c|c|c|}
\hline $\begin{array}{l}\text { Flow rate } \\
\left(\mathrm{m}^{3} / \text { day }\right)\end{array}$ & $\leqq 10$ & $\begin{array}{l}>10 \text { and } \\
\leqq 200\end{array}$ & $\begin{array}{c}>200 \text { and } \\
\leqq 400\end{array}$ & $\begin{array}{c}>400 \text { and } \\
\leqq 600\end{array}$ & $\begin{array}{l}>600 \text { and } \\
\leqq 800\end{array}$ & $\begin{array}{c}>800 \text { and } \\
\leqq 1000\end{array}$ & $\begin{array}{l}>1000 \\
\text { and } \\
\leqq 1500\end{array}$ & $\begin{array}{c}>1500 \\
\text { and } \\
\leqq 2000 \\
\end{array}$ & $\begin{array}{c}>2000 \\
\text { and } \\
\leqq 3000\end{array}$ & $\begin{array}{c}>3000 \\
\text { and } \\
\leqq 4000\end{array}$ & $\begin{array}{c}>4000 \\
\text { and } \\
\leqq 5000\end{array}$ & $\begin{array}{c}>5000 \text { and } \\
\leqq 6000\end{array}$ \\
\hline $\mathrm{pH}(\mathrm{pH}$ units) & $6-10$ & $6-10$ & $6-10$ & $6-10$ & $6-10$ & 6-10 & $6-10$ & $6-10$ & $6-10$ & $6-10$ & $6-10$ & 6-10 \\
\hline Temperature $\left({ }^{\circ} \mathrm{C}\right)$ & 45 & 45 & 45 & 45 & 45 & 45 & 45 & 45 & 45 & 45 & 45 & 45 \\
\hline $\begin{array}{l}\text { Colour (lovibond units) }(25 \mathrm{~mm} \text { cel } \\
\text { length) }\end{array}$ & 4 & 1 & 1 & 1 & 1 & 1 & 1 & 1 & 1 & 1 & 1 & 1 \\
\hline Suspended solids & 700 & 600 & 600 & 500 & 375 & 300 & 200 & 150 & 100 & 75 & 60 & 40 \\
\hline BOD & 700 & 600 & 600 & 500 & 375 & 300 & 200 & 150 & 100 & 75 & 60 & 40 \\
\hline COD & 1500 & 1200 & 1200 & 1000 & 700 & 600 & 400 & 300 & 200 & 100 & 100 & 85 \\
\hline Oil \& Grease & 50 & 50 & 50 & 30 & 25 & 20 & 20 & 20 & 20 & 20 & 20 & 20 \\
\hline Iron & 20 & 15 & 13 & 10 & 7.5 & 6 & 4 & 3 & 2 & 1.5 & 1.2 & 1 \\
\hline Boron & 6 & 5 & 4 & 3.5 & 2.5 & 2 & 1.5 & 1 & 0.7 & 0.5 & 0.4 & 0.3 \\
\hline Barium & 6 & 5 & 4 & 3.5 & 2.5 & 2 & 1.5 & 1 & 0.7 & 0.5 & 0.4 & 0.3 \\
\hline Mercury & 0.1 & 0.1 & 0.05 & 0.001 & 0.001 & 0.001 & 0.001 & 0.001 & 0.001 & 0.001 & 0.001 & 0.001 \\
\hline Cadmium & 0.1 & 0.1 & 0.05 & 0.001 & 0.001 & 0.001 & 0.001 & $1 \quad 0.001$ & 10.001 & $1 \quad 0.001$ & 0.001 & 0.001 \\
\hline Other toxic metals individually & 2 & 1.5 & 1 & 0.8 & 0.6 & 0.5 & 0.32 & 0.24 & 0.16 & 0.12 & 0.1 & 0.1 \\
\hline Total toxic metals & 4 & 3 & 2 & 1.6 & 1.2 & 1 & 0.64 & 0.48 & 0.32 & 0.24 & 0.2 & 0.14 \\
\hline Cyanide & 1 & 0.5 & 0.5 & 0.5 & 0.4 & 0.3 & 0.2 & 0.1 & 0.1 & 0.08 & 0.06 & 0.04 \\
\hline Phenols & 0.5 & 0.5 & 0.5 & 0.3 & 0.3 & 0.2 & 0.1 & 0.1 & 0.1 & 0.1 & 0.1 & 0.1 \\
\hline Sulphide & 5 & 5 & 5 & 5 & 5 & 5 & 2.5 & 2.5 & 1.5 & 1 & 1 & 0.5 \\
\hline Total residual chlorine & 1 & 1 & 1 & 1 & 1 & 1 & 1 & 1 & 1 & 1 & 1 & 1 \\
\hline Total nitrogen & 100 & 100 & 100 & 100 & 100 & 100 & 100 & 100 & 100 & 100 & 100 & 50 \\
\hline Total phosphorus & 10 & 10 & 10 & 10 & 10 & 10 & 10 & 10 & 10 & 10 & 10 & 5 \\
\hline Surfactants (total) & 30 & 20 & 20 & 20 & 15 & 15 & 15 & 15 & 15 & 15 & 15 & 15 \\
\hline E. coli (count $/ 100 \mathrm{ml})$ & 5000 & 5000 & 5000 & 5000 & 5000 & 5000 & 5000 & 5000 & 5000 & 5000 & 5000 & 5000 \\
\hline
\end{tabular}

(Enacted 1990)

Table 10a Standards for effluents discharged into the inshore waters of Southern, Mirs Bay, Junk Bay, North Western, Eastern Buffer and Western Buffer Water Control Zones

(All units in $\mathrm{m} g / \mathrm{L}$ unless otherwise stated; all figures are upper limits unless otherwise indicated)

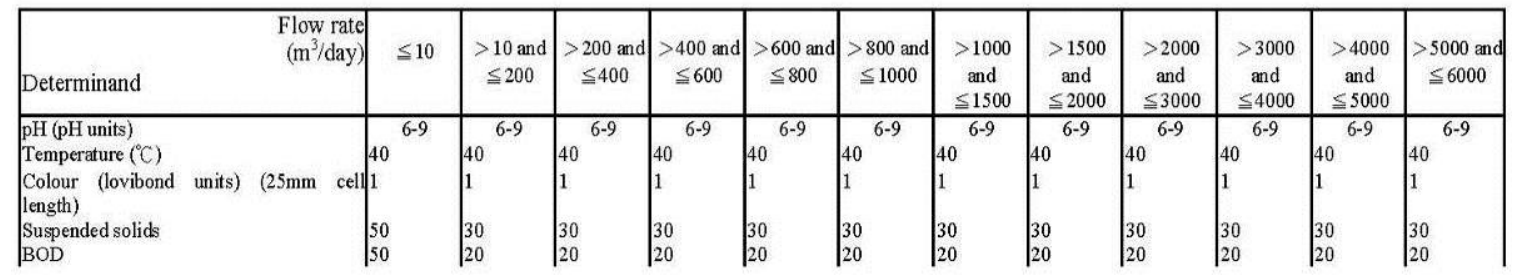

Cap 358AK - TECHNICAL MEMORANDUM STANDARDS FOR EFFLUENTS DISCHARGED INTO DRAINAGE AND SEWERAGE SYSTEMS, INLAND 


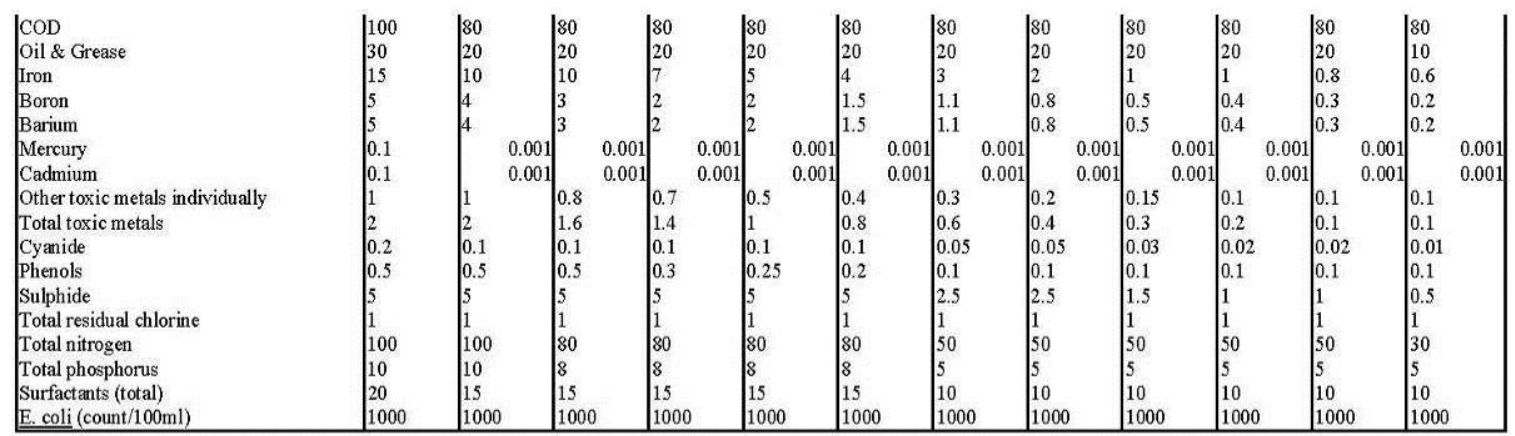

(Enacted 1990)

Table 10b Standards for effluents discharged into the marine waters of Southern, Mirs

Bay, Junk Bay, North Western, Eastern Buffer and Western Buffer Water

Control Zones

(All units in $\mathrm{mg} / \mathrm{L}$ unless otherwise stated; all figures are upper limits unless otherwise indicated)

\begin{tabular}{|c|c|c|c|c|c|c|c|c|c|c|c|c|}
\hline $\begin{array}{l}\text { Flow rate } \\
\left(\mathrm{m}^{3} / \text { day }\right)\end{array}$ & $\leq 10$ & $\begin{array}{c}>10 \text { and } \\
\leq 200\end{array}$ & $\begin{array}{c}>200 \text { and } \\
\leq 400\end{array}$ & $\begin{array}{c}>400 \text { and } \\
\leq 600\end{array}$ & $\begin{array}{c}>600 \text { and } \\
\leq 800\end{array}$ & $\begin{array}{c}>800 \text { and } \\
\leq 1000\end{array}$ & $\begin{array}{c}>1000 \\
\text { and } \\
\leq 1500\end{array}$ & $\begin{array}{c}>1500 \\
\text { and } \\
\leq 2000\end{array}$ & $\begin{array}{c}>2000 \\
\text { and } \\
\leqq 3000\end{array}$ & $\begin{array}{c}>3000 \\
\text { and } \\
\leqq 4000\end{array}$ & $\begin{array}{c}>4000 \\
\text { and } \\
\leq 5000\end{array}$ & $\begin{array}{c}>5000 \text { and } \\
\leq 6000\end{array}$ \\
\hline $\mathrm{pH}$ (pH units) & $6-10$ & 6-10 & $6-10$ & $6-10$ & 6-10 & $6-10$ & $6-10$ & $6-10$ & $6-10$ & $6-10$ & $6-10$ & $6-10$ \\
\hline Temperature $\left({ }^{\circ} \mathrm{C}\right)$ & 45 & 45 & 45 & 45 & 45 & 45 & 45 & 45 & 45 & 45 & 45 & 45 \\
\hline $\begin{array}{l}\text { Colour (lovibond units) }(25 \mathrm{~mm} \text { cell } \\
\text { length) }\end{array}$ & 4 & 1 & 1 & 1 & 1 & 1 & 1 & 1 & 1 & 1 & 1 & 1 \\
\hline Suspended solids & 500 & 500 & 500 & 300 & 200 & 200 & 100 & 100 & 50 & 50 & 40 & 30 \\
\hline BOD & 500 & 500 & 500 & 300 & 200 & 200 & 100 & 100 & 50 & 50 & 40 & 30 \\
\hline COD & 1000 & 1000 & 1000 & 700 & 500 & 400 & 300 & 200 & 150 & 100 & 80 & 80 \\
\hline Oil \& Grease & 50 & 50 & 50 & 30 & 25 & 20 & 20 & 20 & 20 & 20 & 20 & 20 \\
\hline Iron & 20 & 15 & 13 & 10 & 7 & 6 & 4 & 3 & 2 & 1.5 & 1.2 & 1 \\
\hline Boron & 6 & 5 & 4 & 3.5 & 2.5 & 2 & 1.5 & 1 & 0.7 & 0.5 & 0.4 & 0.3 \\
\hline Barium & 6 & 5 & 4 & 3.5 & 2.5 & 2 & 1.5 & 1 & 0.7 & 0.5 & 0.4 & 0.3 \\
\hline Mercury & 0.1 & 0.1 & 0.1 & 0.001 & 0.001 & 0.001 & 0.001 & 0.001 & 0.001 & 0.001 & 0.001 & 0.001 \\
\hline Cadmium & 0.1 & 0.1 & 0.1 & 0.001 & 0.001 & 0.001 & 0.001 & 0.001 & 0.001 & 0.001 & 0.001 & 0.001 \\
\hline Other toxic metals individually & 2 & 1.5 & 1.2 & 0.8 & 0.6 & 0.5 & 0.32 & 0.24 & 0.16 & 0.12 & 0.1 & 0.1 \\
\hline Total toxic metals & 4 & 3 & 2.4 & 1.6 & 1.2 & 1 & 0.64 & 0.48 & 0.32 & 0.24 & 0.2 & 0.14 \\
\hline Cyanide & 1 & 0.5 & 0.5 & 0.5 & 0.4 & 0.3 & 0.2 & 0.15 & 0.1 & 0.08 & 0.06 & 0.04 \\
\hline Phenols & 0.5 & 0.5 & 0.5 & 0.3 & 0.25 & 0.2 & 0.13 & 0.1 & 0.1 & 0.1 & 0.1 & 0.1 \\
\hline Sulphide & 5 & 5 & 5 & 5 & 5 & 5 & 2.5 & 2.5 & 1.5 & 1 & 1 & 0.5 \\
\hline Total residual chlorine & 1 & 1 & 1 & 1 & 1 & 1 & 1 & 1 & 1 & 1 & 1 & 1 \\
\hline Total nitrogen & 100 & 100 & 80 & 80 & 80 & 80 & 50 & 50 & 50 & 50 & 50 & 50 \\
\hline Total phosphorus & 10 & 10 & 8 & 8 & 8 & 8 & 5 & 5 & 5 & 5 & 5 & 5 \\
\hline Surfactants (total) & 30 & 20 & 20 & 20 & 15 & 15 & 15 & 15 & 15 & 15 & 15 & 15 \\
\hline E. coli (count/100ml) & 4000 & 4000 & 4000 & 4000 & 4000 & 4000 & 4000 & 4000 & 4000 & 4000 & 4000 & 4000 \\
\hline
\end{tabular}

(Enacted 1990) 


\section{APPENDIX H}

Selective Sections of Black \& Veatch's

Flow Monitoring Report 


\section{Survey Field Works}

The flow monitors were installed in 32 different locations. The exact location refer to the Appendix A and the brief description of the methodology for these surveys is included in Appendix $\mathrm{C}$ for reference. During the flow monitoring works carried on dry season, the flow monitors were re-located to the low flow channel at nullahs.

\subsection{Flow Monitor Survey}

The summary table of dimension of nullah, pipe or box culvert for the installation of flow monitors are listed as follows:

Table 5.1 - Dimension of Nullah/ Pipe/Box Culvert

\begin{tabular}{|c|c|c|c|c|c|c|c|c|}
\hline $\begin{array}{c}\text { Flow Gauge } \\
\text { No. }\end{array}$ & Type & $\begin{array}{l}\text { Shape of } \\
\text { Drainage }\end{array}$ & $\begin{array}{c}\text { Lower } \\
\text { Width (m) }\end{array}$ & $\begin{array}{c}\text { Upper } \\
\text { Width (m) }\end{array}$ & $\begin{array}{l}\text { Height } \\
\text { (m) }\end{array}$ & $\begin{array}{c}\text { Diameter } \\
\text { of pipe } \\
\text { (m) }\end{array}$ & $\begin{array}{l}\text { Depth of } \\
\text { pipe (m) }\end{array}$ & Remark \\
\hline FG1 & Nullah & Trapezoid & 58.80 & 68.80 & 3.70 & & & \\
\hline FG2 & Nullah & Trapezoid & 7.20 & 14.07 & 3.40 & & & \\
\hline FG3 & Nullah & Rectangular & 30.50 & & 3.80 & & & \\
\hline FG4 & Nullah & Trapezoid & 4.48 & 10.22 & 2.86 & & & \\
\hline FG5 & Nullah & Trapezoid & 10.11 & 15.48 & 3.55 & & & \\
\hline FG6 & Nullah & Trapezoid & 7.10 & 14.40 & 3.43 & & & \\
\hline FG7 & Nullah & Rectangular & 13.30 & & 4.70 & & & \\
\hline FG8 & Nullah & Trapezoid & 9.60 & 16.30 & 3.70 & & & \\
\hline FG9 & Nullah & Rectangular & 9.00 & & 4.10 & 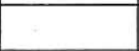 & & \\
\hline FG10 & Nullah & Rectangular & 7.22 & & 3.11 & & & \\
\hline FG11 & Nullah & Trapezoid & 9.50 & 16.87 & 3.75 & & & \\
\hline FG12 & Nullah & Trapezoid & 7.13 & 13.78 & 4.00 & & & \\
\hline FG13 & Nullah & Rectangular & 15.03 & & 4.58 & & & $\begin{array}{l}\text { No low } \\
\text { flow } \\
\text { channel }\end{array}$ \\
\hline FG14 & Nullah & Trapezoid & 4.97 & 18.55 & 3.49 & & & \\
\hline FG15 & Nullah & Trapezoid & 6.49 & 15.01 & 2.88 & & & \\
\hline FG16 & Nullah & Trapezoid & 26.73 & 44.75 & 4.67 & & & \\
\hline FG17 & Pipe & Circular & & & & 1.50 & 2.99 & \\
\hline FG18 & Pipe & Circular & & & & 1.50 & 3.12 & \\
\hline FG19 & Pipe & Circular & & & & 1.50 & 3.18 & \\
\hline FG20 & Pipe & Circular & & & & 1.20 & 1.76 & \\
\hline FG21 & Pipe & Circular & & & & 1.35 & 3.83 & \\
\hline FG22 & Pipe & Circular & & & & 0.45 & 3.0 & \\
\hline FG23 & Box Culvert & Rectangular & 2.50 & & 1.80 & & 3.3 & \\
\hline FG24 & Pipe & Circular & & & & 0.90 & 3.3 & \\
\hline FG25 & Pipe & Circular & & & & 1.35 & 3.45 & \\
\hline FG26 & Box Culvert & Rectangular & 2.50 & & 1.80 & & 4.9 & \\
\hline FG27 & Pipe & Circular & & & & 1.20 & 3.28 & \\
\hline FG28 & Pipe & Circular & & & & 2.10 & 4.55 & \\
\hline FG29 & Box Culvert & Rectangular & 2.34 & & 1.68 & & 2.65 & \\
\hline FG30 & Pipe & Circular & & & & 1.80 & 4 & \\
\hline
\end{tabular}




\begin{tabular}{|c|c|c|c|c|c|c|c|c|}
\hline $\begin{array}{c}\text { Flow Gauge } \\
\text { No. }\end{array}$ & Type & $\begin{array}{c}\text { Shape of } \\
\text { Drainage }\end{array}$ & $\begin{array}{c}\text { Lower } \\
\text { Width (m) }\end{array}$ & $\begin{array}{c}\text { Upper } \\
\text { Width (m) }\end{array}$ & $\begin{array}{c}\text { Height } \\
(\mathrm{m})\end{array}$ & $\begin{array}{c}\text { Diameter } \\
\text { of pipe } \\
(\mathrm{m})\end{array}$ & $\begin{array}{c}\text { Depth of } \\
\text { pipe (m) }\end{array}$ & Remark \\
\hline FG31 & Box Culvert & Rectangular & 2.50 & & 1.80 & & 5.72 & \\
\hline FG32 & Pipe & Circular & & & & 0.80 & & \\
\hline
\end{tabular}

Table 5.2 - Dimension of Low Flow Channel

\begin{tabular}{|c|c|c|}
\hline Flow Monitor No. & Depth (mm) & Width (mm) \\
\hline FG1 & 1375 & 4999 \\
\hline FG2 & 414 & 1464 \\
\hline FG3 & 589 & 3284 \\
\hline FG4 & 360 & 681 \\
\hline FG5 & 580 & 1014 \\
\hline FG6 & 490 & 1071 \\
\hline FG7 & 939 & 1573 \\
\hline FG8 & 520 & 1049 \\
\hline FG9 & 150 & 1322 \\
\hline FG10 & 400 & 1003 \\
\hline FG11 & 480 & 1049 \\
\hline FG12 & 510 & 862 \\
\hline FG13 & - & - \\
\hline FG14 & 300 & 1345 \\
\hline FG15 & 500 & 664 \\
\hline FG16 & 1510 & 2529 \\
\hline
\end{tabular}

\section{Results of Survey}

\subsection{Flow Monitoring Survey}

Total 32 nos. of flow monitoring result and 5 raingauge data on 5 critical rainfall are shown below: 


\begin{tabular}{|c|c|c|c|c|c|c|c|c|c|c|}
\hline \multirow[b]{2}{*}{$\begin{array}{c}\text { Flow } \\
\text { Gauge } \\
\text { No. }\end{array}$} & \multirow[b]{2}{*}{ Type } & \multicolumn{3}{|c|}{ Date of Survey $15 / 12 / 2007$} & \multicolumn{3}{|c|}{ Date of Survey: $31 / 12 / 2007$} & \multicolumn{3}{|c|}{ Date of Survey: $15 / 1 / 2008$} \\
\hline & & $\begin{array}{l}\text { Average } \\
\text { Depth } \\
(\mathrm{cm})\end{array}$ & $\begin{array}{l}\text { Average } \\
\text { Velocity } \\
(\mathrm{m} / \mathrm{s})\end{array}$ & $\begin{array}{l}\text { Average Flow } \\
\left(\mathrm{m}^{3} / \mathrm{s}\right)\end{array}$ & $\begin{array}{l}\text { Average } \\
\text { Depth } \\
(\mathrm{cm})\end{array}$ & $\begin{array}{c}\text { Average } \\
\text { Velocity } \\
(\mathrm{m} / \mathrm{s})\end{array}$ & $\begin{array}{l}\text { Average Flow } \\
\left(\mathrm{m}^{3} / \mathrm{s}\right)\end{array}$ & $\begin{array}{l}\text { Average } \\
\text { Depth } \\
(\mathrm{cm})\end{array}$ & $\begin{array}{c}\text { Average } \\
\text { Velocity } \\
(\mathrm{m} / \mathrm{s})\end{array}$ & $\begin{array}{c}\text { Average } \\
\text { Flow }\left(\mathrm{m}^{3} / \mathrm{s}\right)\end{array}$ \\
\hline FG30 & Pipe & 27.23 & 0.03 & $7.27 \mathrm{E}-03$ & 27.82 & 0.03 & $7.50 \mathrm{E}-03$ & 28.55 & 0.01 & $2.60 \mathrm{E}-03$ \\
\hline FG31 & $\begin{array}{c}\text { Box } \\
\text { Culvert }\end{array}$ & 2.553 & 0 & 0 & 3.938 & 0 & 0 & 2.129 & 0 & 0 \\
\hline FG32 & Pipe & 0.016 & 0.04 & $3.05 \mathrm{E}-07$ & 1.296 & 0.05 & $2.78 \mathrm{E}-04$ & 1.691 & 0.04 & $3.32 \mathrm{E}-04$ \\
\hline
\end{tabular}

\section{Conclusion}

\subsection{Flow Monitoring Survey}

Flow monitoring survey was undertaken for a total of 32 locations on 5 different survey dates.

The average flow monitoring result for each survey points are shown below:

\begin{tabular}{|c|c|c|c|}
\hline $\begin{array}{c}\text { Flow Gauge } \\
\text { No. } \\
\end{array}$ & Type & $\begin{array}{c}\text { Average } \\
\text { Flow }\left(\mathrm{m}^{3} / \mathrm{s}\right)\end{array}$ & Remark \\
\hline FG1 & Nullah & 0.63 & \\
\hline FG2 & Nullah & 0.12 & \\
\hline FG3 & Nullah & 0.23 & \\
\hline FG4 & Nullah & 0.01 & \\
\hline FG5 & Nullah & 0.06 & \\
\hline FG6 & Nullah & 0.02 & \\
\hline FG7 & Nullah & 0.00 & \\
\hline FG8 & Nullah & 0.01 & $\begin{array}{l}\text { Flow monitoring data did not } \\
\text { reflect the actual flow } \\
\text { condition. Therefore the } \\
\text { result should be deleted. }\end{array}$ \\
\hline FG9 & Nullah & 0.01 & \\
\hline FG10 & Nullah & 0.01 & \\
\hline FG11 & Nullah & 0.04 & dry weather cond \\
\hline FG12 & Nullah & 0.05 & \\
\hline FG13 & Nullah & 0.01 & \\
\hline $\begin{array}{l}\text { FG14 } \\
\text { FG15 }\end{array}$ & Nullah & 0.02 & \\
\hline FG18 & $\begin{array}{l}\text { Pipe } \\
\text { Pipe }\end{array}$ & $\begin{array}{l}3.56 \mathrm{E}-05 \\
6.82 \mathrm{E}-06 \\
\end{array}$ & \\
\hline FG19 & Pipe & $\begin{array}{l}6.82 \mathrm{E}-06 \\
8.52 \mathrm{E}-05 \\
\end{array}$ & \\
\hline FG20 & Pipe & $\begin{array}{l}8.52 \mathrm{E}-05 \\
1.89 \mathrm{E}-04 \\
\end{array}$ & \\
\hline FG21 & Pipe & $0.00 \mathrm{E}+00$ & \\
\hline FG22 & Pipe & $0.00 \mathrm{E}+00$ & \\
\hline FG23 & Box Culvert & - & Flow monitor damaged \\
\hline FG24 & Pipe & $2.69 \mathrm{E}-05$ & \\
\hline FG25 & Pipe & 3.53E-08 & \\
\hline FG26 & Box Culvert & $9.88 \mathrm{E}-05$ & \\
\hline FG27 & Pipe & $1.05 \mathrm{E}-03$ & \\
\hline
\end{tabular}




\title{
APPENDIX $\mathbf{J}$
}

\author{
Determination of Longitudinal Slope on \\ the Upstream Section of Yuen Long Nullah
}



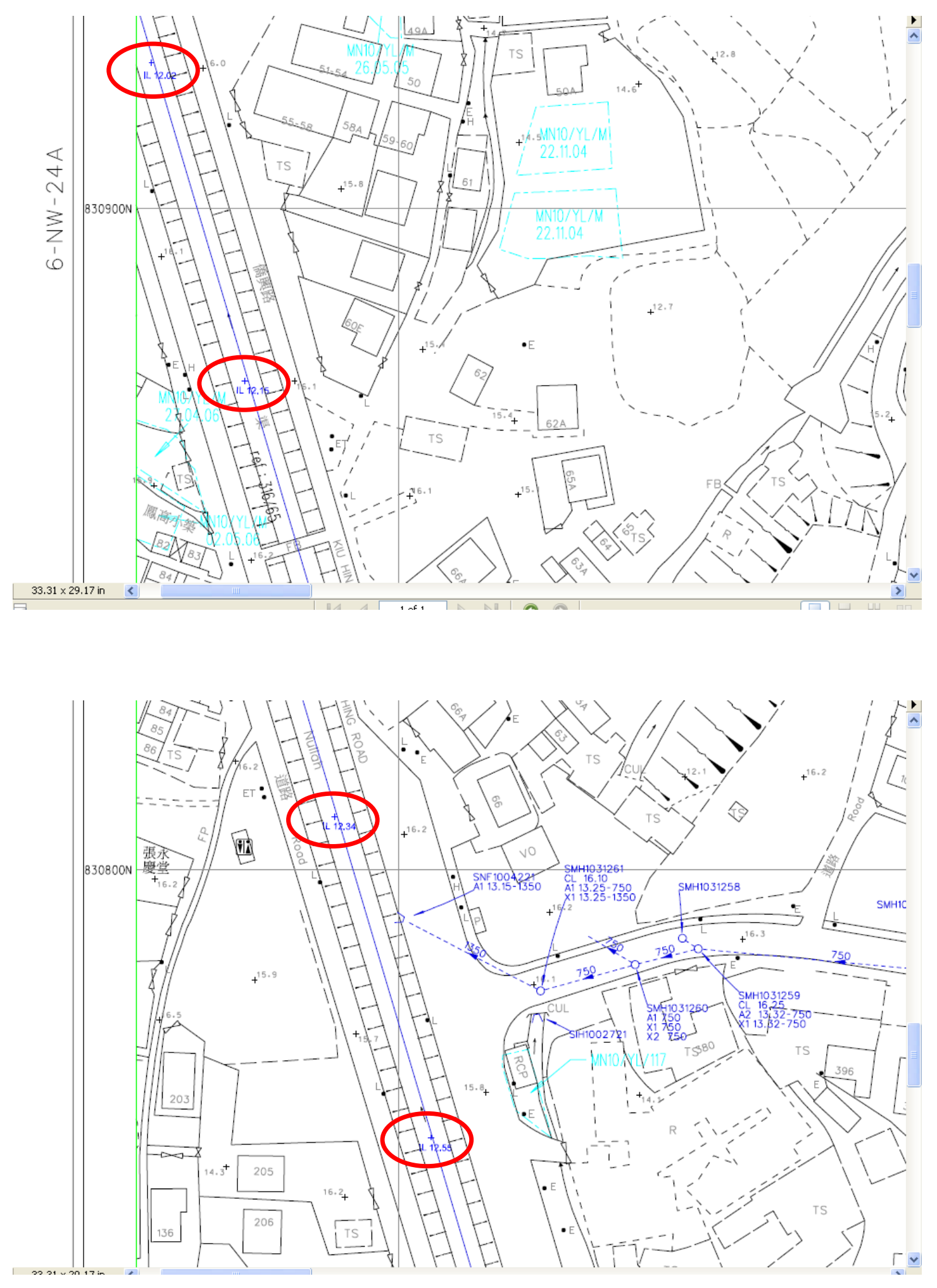

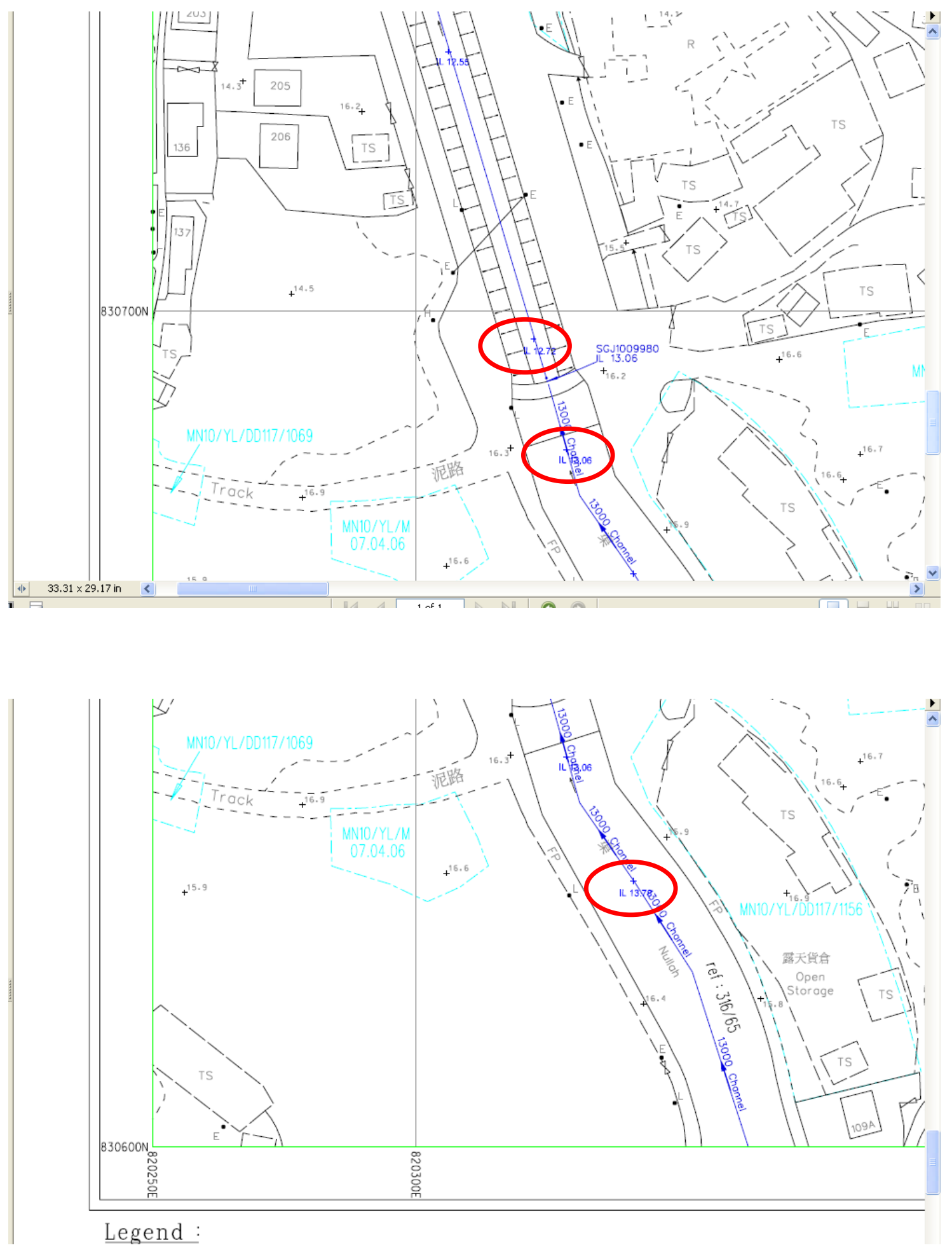
Table J.1: Determination of Average Longitudinal Slope.

\begin{tabular}{|c|c|c|c|}
\hline $\begin{array}{c}\text { Elevation Provided } \\
\text { by Winnie of BV }\end{array}$ & $\begin{array}{c}\text { Length Between Elevation } \\
\text { Points, in metres }\end{array}$ & $\begin{array}{c}\text { Individual } \\
\text { Slopes }\end{array}$ & Average Slope \\
\hline 12.02 & 62.87 & 0.002227 & $\mathbf{0 . 0 0 2 9 4 3}$ \\
12.16 & 58.24 & 0.003091 & \\
12.34 & 61.59 & 0.003410 & \\
12.55 & 55.83 & 0.003045 & \\
12.72 & 21.71 & 0.015663 & \\
\hline 13.06 & 25.96 & 0.027739 & \\
13.78 & & & \\
\hline
\end{tabular}

Note: Data in cyan color is located on the concrete channel.

Data is yellow color is located on the upstream of the concrete channel.

Average slope is calculated using the data in cyan color only and excluding the red highlight. 


\section{APPENDIX $K$}

\section{Specific Gravities of Common \\ Plastic Materials}




\begin{tabular}{|l|c|}
\hline Common Plastic Materials & Specific Gravity \\
\hline Polybutylene & 0.6 \\
\hline Polymethylpentene & 0.83 \\
\hline Ethylene-propylene & 0.86 \\
\hline Polypropylene & $0.90-0.92$ \\
\hline Polyethylene & \\
\hline LDPE & $0.91-0.93$ \\
\hline LLDPE & $0.91-0.94$ \\
\hline HDPE & $0.96-0.97$ \\
\hline Polybutene & $0.91-0.92$ \\
\hline Natural rubber & 0.91 \\
\hline Butyl rubber & 0.92 \\
\hline Styrene-butadiene & 0.93 \\
\hline Polyamide & \\
\hline PA-12 & 1.02 \\
\hline PA-11 & 1.04 \\
\hline PA-6 & $1.12-1.13$ \\
\hline PA-66 & $1.13-1.15$ \\
\hline ABS & $1.04-1.07$ \\
\hline Polystyrene & 1.05 \\
\hline Polyacronitrile & 1.17 \\
\hline Polyvinyl acetate & 1.19 \\
\hline Polycarbonate & 1.2 \\
\hline Polychloroprene rubber & 1.23 \\
\hline Polysulphone & 1.24 \\
\hline Polyethylene terephtalate & $1.34-1.39$ \\
\hline PVC & $1.37-1.39$ \\
\hline POM & $1.41-1.43$ \\
\hline Polytetrafluorethylene & 2.27 \\
\hline Epoxy (Low Density) & $0.75-1.00$ \\
\hline Methylpentene Polymer (TPX) & $0.83-$ \\
\hline Polypropylene Copolymer & $0.89-0.905$ \\
\hline Polypropylene Impact & $0.90-0.91$ \\
\hline Polypropylene Unmodified & $0.902-0.906$ \\
\hline Polyethylene (Low Density) & $0.91-0.925$ \\
\hline Ethylene Vinyl Acetate Copolymer & $0.925-0.95$ \\
\hline Potyethytene (Medium Density) & $0.925-0.940$ \\
\hline Ethylene Ethyl Acrylate Copolymer & $0.93-$ \\
\hline lonomers & $0.93-0.96$ \\
\hline Styrene Butadiene Thermoplastic & $0.93-1.10$ \\
\hline Polyethylene High Molecular Weight & $0.94-$ \\
\hline & \\
\hline
\end{tabular}




\begin{tabular}{|l|c|}
\hline Common Plastic Materials & Specific Gravity \\
\hline Potyethylene (High Density) & $0.941-0.965$ \\
\hline Polyethylene Cross Linkable & $0.95-1.4,5$ \\
\hline Polypropylene (inert Filler) & $1.00-1.30$ \\
\hline Nylon 12 (Unfilled) & $1.01-1.02$ \\
\hline ABS (High Impact) & $1.01-1.04$ \\
\hline Nylon 11 (Untilled) & $1.04-1.05$ \\
\hline ABS (Medium Impact) & $1.04-1.07$ \\
\hline Polystyrene (General Purpose) & $1.04-1.09$ \\
\hline Polystyrene (Medium \& High Impact) & $1.04-1.10$ \\
\hline Polystyrene Heat \& Chemical & $1.04-1.10$ \\
\hline PVC Flexib (Untilled) & $1.05-$ \\
\hline ABS High (Heat Resistant) & $1.05-1.08$ \\
\hline Polypropylene (Glass filler) & $1.05-1.24$ \\
\hline Nyion 6/12 & $1.06-1.08$ \\
\hline Potyphenylene Oxides Modified (Noryl) & $1.06-1.10$ \\
\hline Polyphenylene Oxide (PPO) & $1.06-$ \\
\hline Styrene Acrylonitrile Copolymer (Unfilled) (SAN) & $1.075-1.10$ \\
\hline Nyion 6/10 (Unfilled) & $1.09-$ \\
\hline Acrylics Multipolymer & $1.09-1.14$ \\
\hline Ethyl Cellulose & $1.09-1.17$ \\
\hline Polycarbonate (ABS Polycabonate Alloy) & $1.10-120$ \\
\hline Acrylic Impact & $1.11-1.18$ \\
\hline Urethane Elastomers & $1.11-1.25$ \\
\hline Nyton 6 (Unfilled) & $1.12-1.14$ \\
\hline Nylon 6/6 (Unfilled) & $1.13-1.15$ \\
\hline ABS Self Extinguishing & $1.15-1.21$ \\
\hline Cellulose Acetate Butyrate & $1.15-1.22$ \\
\hline PVC Flexible (Unfilled) & $1.16-1.30$ \\
\hline Acrylics & $1.17-1.20$ \\
\hline Cellulose Propionate & $1.17-1.24$ \\
\hline Phenoxy & $1.18-$ \\
\hline Rubber (Hard) & $1.2-$ \\
\hline Polycarbonate (Unfilled) & $1.2-$ \\
\hline Polystyrene (20-30\% Glass filler) & $1.25-1.33$ \\
\hline Styrene Acrylonitrile Copolymer (20-33\% Glass filler) & $1.20-1.46$ \\
\hline Polyphenylene Oxides Modifed (Noryl) (20-30\% Glass & $1.21-1.36$ \\
\hline filler) & $1.22-1.34$ \\
\hline Cellulose Acetate & \\
\hline Nylon 12 (Glass filler) & 1.23 \\
\hline ABS (2040\% Glass filler) & 1.23 \\
\hline
\end{tabular}




\begin{tabular}{|l|c|}
\hline Common Plastic Materials & Specific Gravity \\
\hline Polysulfone & $1.24-$ \\
\hline Polycarbonate (10-40\% Glass filler) & $1.24-1.52$ \\
\hline Alkyd Polyester Synthetic Fiber & $1.24-2.10$ \\
\hline Polycarbonate (Less than 10\% Glass filler) & 1.25 \\
\hline Nylon 11 (Glass filler) & 1.26 \\
\hline Polypropylene Modified Vinyl Chloride & $1.28-1.58$ \\
\hline PVC Flexible (Filled) & $1.30-1.70$ \\
\hline Polyterephtalete 6PRO & 1.31 \\
\hline Celanese CDY-246 & $1.32-$ \\
\hline Nylon 6/12 (Glass filler) & $1.32-1.46$ \\
\hline Phenolic Woodflour \& Cotton & $1.34-1.45$ \\
\hline PVC (Rigid) & $1.35-1.45$ \\
\hline Polyester Preformed Chopped Roving & $1.35-2.30$ \\
\hline Casein & 1.35 \\
\hline Phenolic Macerated Fabric \& Cord. & $1.36-1.43$ \\
\hline Nylon 6 (20-40\% Glass filler) & $1.37-1.46$ \\
\hline Polyesters (Thermoplastic) & $1.37-1.38$ \\
\hline Chlorinated Polyether & $1.4-$ \\
\hline Acetal Copolymer & 1.41 \\
\hline Acetal Homopolymer & $1.42-$ \\
\hline Polyimides Aromatic & $1.43-$ \\
\hline Melamine Cellulose & $1.45-1.52$ \\
\hline Phenolic (Asbestos Filler) & $1.45-2.00$ \\
\hline Melamine Alphacellulose & $1.47-1.52$ \\
\hline Urea Formaldehyde Alpha Cellulose & $1.47-1.52$ \\
\hline Melamine---Formaldehyde (No filler) & $1,48-$ \\
\hline Polyester (Thermoplastic 18\% Glass filler) & $1.48-1.50$ \\
\hline Melamine (Fabric filler) & $1.5-$ \\
\hline Melamine Fabric (Phenolic Modified) & $1.50-$ \\
\hline Melamine Phenol & $1.50-1.70$ \\
\hline Polyester Woven Cloth & $1.50-2.10$ \\
\hline Celanex 917 & $1.52-$ \\
\hline Acetal (20\% Glass filler) & $1.56-$ \\
\hline Acrylonitrile Copolymer Asbestos & $1.57-1.65$ \\
\hline Sillicones (Asbestos filler) & $1.60-1.90$ \\
\hline Epoxy (Glass fiber filler) & $1.60-2.00$ \\
\hline Epoxy (Mineral filler) & $1.60-2.00$ \\
\hline Alkyd Granular end Putty (Mineral filler) & $1.60-2.30$ \\
\hline & \\
\hline
\end{tabular}




\section{APPENDIX L}

Guides from FHWA of Selecting Manning's $\boldsymbol{n}$

for Natural Channels and Floodplains 
Table L.1: Base Values of Manning's $n$.

\begin{tabular}{|c|c|c|c|}
\hline \multirow{2}{*}{ Bed Material } & \multirow{2}{*}{$\begin{array}{l}\text { Median Size of Bed Material, } \\
\text { in } \mathbf{~ m m}\end{array}$} & \multicolumn{2}{|c|}{ Base $n$ Value } \\
\hline & & Straight Uniform Channel & Smooth Channel \\
\hline \multicolumn{4}{|l|}{ Sand Channels } \\
\hline \multirow[t]{7}{*}{ sand } & 0.2 & 0.012 & ----- \\
\hline & 0.3 & 0.017 & ---- \\
\hline & 0.4 & 0.020 & ----- \\
\hline & 0.5 & 0.022 & ----- \\
\hline & 0.6 & 0.023 & ----- \\
\hline & 0.8 & 0.025 & ----- \\
\hline & 1.0 & 0.026 & ----- \\
\hline \multicolumn{4}{|c|}{ Stable Channels and Flood Plains } \\
\hline concrete & ----- & 0.012 to 0.018 & 0.011 \\
\hline rock cut & $\begin{array}{ll}---- \\
\end{array}$ & ----- & 0.025 \\
\hline firm soil & ----- & 0.025 to 0.032 & 0.020 \\
\hline coarse sand & 1 to 2 & 0.026 to 0.035 & ----- \\
\hline fine gravel & ----- & ----- & 0.024 \\
\hline gravel & 2 to 64 & 0.028 to 0.035 & ----- \\
\hline coarse gravel & ---- & ---- & 0.026 \\
\hline cobble & 64 to 256 & 0.030 to 0.050 & ----- \\
\hline boulder & $>256$ & 0.040 to 0.070 & $\begin{array}{ll}---- \\
\end{array}$ \\
\hline
\end{tabular}


Table L.2: Adjustment Values for Factors that Affect the Roughness of a Channel.

\begin{tabular}{|c|c|l|}
\hline Channel Conditions & $\boldsymbol{n}$ Value Adjustment & Example \\
\hline Degree of Meandering $(m)$ & 1.00 & Ratio of the channel length to valley length is 1.0 to 1.2. \\
\hline Minor & 1.15 & Ratio of the channel length to valley length is 1.2 to 1.5. \\
\hline Appreciable & 1.3 & Ratio of the channel length to valley length is greater than 1.5. \\
\hline Severe & 0.000 & Compares to the smoothest channel attainable in a given bed material. \\
\hline \hline Degree of Irregularity $\left(n_{1}\right)$ & 0.001 to 0.005 & $\begin{array}{l}\text { Compares to carefully degraded channels in good condition but having } \\
\text { slightly eroded or scoured side slopes. }\end{array}$ \\
\hline Smooth & 0.006 to 0.010 & $\begin{array}{l}\text { Compares to dredged channels having moderate to considerable bed } \\
\text { roughness and moderately sloughed or eroded side slopes. }\end{array}$ \\
\hline Minor & 0.011 to 0.020 & $\begin{array}{l}\text { Badly sloughed or scalloped banks of natural streams; badly eroded or } \\
\text { sloughed sides of canals or drainage channels; unshaped, jagged, or } \\
\text { irregular surfaces of channel. }\end{array}$ \\
\hline Moderate & \multicolumn{2}{|l}{} \\
\hline Severe & \begin{tabular}{l} 
Size and shape of channel cross-sections change gradually. \\
\hline Variation in Channel Cross-Section $\left(n_{2}\right)$
\end{tabular} & $\begin{array}{l}\text { Large and small cross-sections alternate occasionally, or the main flow } \\
\text { occasionally shifts from side to side owing to changes in cross-sectional } \\
\text { shape. }\end{array}$ \\
\hline Gradual & 0.000 & $\begin{array}{l}\text { Large and small cross-sections alternate frequently, or the main flow } \\
\text { occasionally shifts from side to side owing to changes in cross-sectional } \\
\text { shape. }\end{array}$ \\
\hline $\begin{array}{l}\text { Alternating } \\
\text { occasionally }\end{array}$ & 0.001 to 0.005 \\
\hline $\begin{array}{l}\text { Alternating } \\
\text { frequently }\end{array}$ & 0.010 to 0.015
\end{tabular}


Table L.2: Adjustment Values for Factors that Affect the Roughness of a Channel (cont.).

\begin{tabular}{|c|l|l|}
\hline Channel Conditions & $\boldsymbol{n}$ Value Adjustment & Example \\
\hline Effect of Obstruction $\left(n_{3}\right)$ & 0.000 to 0.004 & $\begin{array}{l}\text { A few scattered obstructions, which include debris deposits, stumps, } \\
\text { exposed roots, logs, piers, or isolated boulders, that occupy less than } \\
5 \% \text { of the cross-sectional area. }\end{array}$ \\
\hline Negligible & 0.005 to 0.015 & $\begin{array}{l}\text { Obstructions occupy less than 15\% of the cross-sectional area, and the } \\
\text { spacing between obstructions is such that the sphere of influence } \\
\text { around one obstruction does not extend to the sphere of influence } \\
\text { around another obstruction. Smaller adjustments are used for curved } \\
\text { smooth-surfaced objects than are used for sharp-edged angular objects. }\end{array}$ \\
\hline Appreciable & 0.020 to 0.030 & $\begin{array}{l}\text { Obstructions occupy from 15\% to 50\% of the cross-sectional area, or the } \\
\text { space between obstructions is small enough to cause the effects of } \\
\text { several obstructions to be additive, thereby blocking an equivalent part } \\
\text { of a cross section. }\end{array}$ \\
\hline Severe & 0.040 to 0.050 & $\begin{array}{l}\text { Obstructions occupy more than 50\% of the cross-sectional area, or the } \\
\text { space between obstructions is small enough to cause turbulence across } \\
\text { most of the cross-section. }\end{array}$ \\
\hline
\end{tabular}


Table L.2: Adjustment Values for Factors that Affect the Roughness of a Channel (cont.).

\begin{tabular}{|c|l|l|}
\hline Channel Conditions & $\boldsymbol{n}$ Value Adjustment & Example \\
\hline Amount of Vegetation $\left(n_{4}\right)$ & 0.002 to 0.010 & $\begin{array}{l}\text { Dense growths of flexible turf grass, such as Bermuda, or weeds } \\
\text { growing where the average depth of flow is at least two times the height } \\
\text { of the vegetation; supple tree seedlings such as willow, cottonwood, } \\
\text { arrowhead, or saltcedar growing where the average depth of flow is at } \\
\text { least three times the height of the vegetation. }\end{array}$ \\
\hline Medium & 0.010 to 0.025 & $\begin{array}{l}\text { Turf grass growing where the average depth of flow is from one to two } \\
\text { times the height of the vegetation; moderately dense stemy grass, } \\
\text { weeds, or tree seedlings growing whe the average depth of flow is } \\
\text { from two to three times the height of the vegetation; brushy, moderately } \\
\text { dense vegetation, similar to 1-to-2 year old willow trees in the dormant } \\
\text { season, growing along the banks, and no significant vegetation is } \\
\text { evident along the channel bottoms where the hydraulic radius exceeds } \\
\text { o.61 meters. }\end{array}$ \\
\hline Large & 0.025 to 0.050 & $\begin{array}{l}\text { Turf grass growing where the average depth of flow is about equal to the } \\
\text { height of the vegetation; 8-to-10 years old willow or cottonwood trees } \\
\text { intergrown with some weeds and brush (none of the vegetation in } \\
\text { foliage) where the hydraulic radius exceeds 0.60 m; bushy willows about } \\
1 \text { year old intergrown with some weeds along side slopes (all vegetation } \\
\text { in full foliage), and no significant vegetation exists along channel } \\
\text { bottoms where the hydraulic radius is greater than 0.61 meters. }\end{array}$ \\
\hline Very Large & $\begin{array}{l}\text { Turf grass growing where the average depth of flow is less than half the } \\
\text { height of the vegetation; bushy willow trees about 1 year old intergrown } \\
\text { with weeds along side slopes C all vegetation in full foliage), or dense } \\
\text { cattails growing along channel bottom; trees intergrown with weeds and } \\
\text { brush (all vegetation in full foliage). }\end{array}$ \\
\hline
\end{tabular}




\section{APPENDIX M}

\section{Determination of the Porosity of the Deflectors}


Table M.1: Determination of the Porosity of the Deflector.

\begin{tabular}{|l|c|c|c|c|}
\hline 1) Mass of Red Cylinder Container, in kilograms & \multicolumn{3}{|c|}{2.15} \\
\hline 2) Mass of Concrete Stones, in kilograms & 36.95 & 28.65 & 37.00 & 26.80 \\
\hline $\begin{array}{l}\text { 3) Mass of Concrete Stones + Amount of Water Used to Cover the } \\
\text { Concrete Stones, in kilograms }\end{array}$ & 68.10 & 63.90 & 70.10 & 62.50 \\
\hline 4) Amount of Water Used to Cover the Concrete Stones, in kilograms & 31.15 & 35.25 & 33.10 & 35.70 \\
\hline $\begin{array}{l}\text { 5) Amount of Water Added to the Red Cylinder Container until the Water } \\
\text { Reaches to the Original Mark, in kilograms }\end{array}$ & 18.85 & 14.75 & 16.90 & 14.30 \\
\hline 6) step 5 $\div$ 998.2 kg/m ${ }^{3}$, in cubic metres & 0.01888 & 0.01478 & 0.01693 & 0.01433 \\
\hline 7) Total Volume of Concrete Stones in the Deflector, in cubic metres & \multicolumn{4}{|c|}{0.06492} \\
\hline 8) Volume of Deflector $(55 \mathrm{~cm} X 30 \mathrm{~cm} \times 66.7 \mathrm{~cm})$, in cubic metres & \multicolumn{4}{|c|}{$\mathbf{4 1 . 0 1}$} \\
\hline 9) \% of Voids within the Deflector, in \% & \multicolumn{4}{|c|}{} \\
\hline
\end{tabular}


Table M.2: Properties of Water at Various Temperatures.

\begin{tabular}{|c|c|c|c|c|}
\hline $\begin{array}{c}\text { Temperature, } t \\
\text { in }{ }^{\circ} \mathrm{C}\end{array}$ & $\begin{array}{c}\text { Density, } \rho \\
\text { in } \mathrm{kg} / \mathrm{m}^{3}\end{array}$ & $\begin{array}{c}\text { Specific Weight, } \gamma \\
\text { in } \mathrm{kN} / \mathrm{m}^{3}\end{array}$ & $\begin{array}{c}\text { Dynamic Viscosity, } \mu \\
\text { in } \times 10^{-3} \mathrm{~N} \mathrm{~s} / \mathrm{m}^{2}\end{array}$ & $\begin{array}{c}\text { Kinematic Viscosity, } v \\
\text { in } \times 10^{-6} \mathrm{~m}^{2} / \mathrm{s}\end{array}$ \\
\hline 0 & 999.9 & 9.806 & 1.787 & 1.787 \\
\hline 5 & 1000 & 9.807 & 1.519 & 1.519 \\
\hline 10 & 999.7 & 9.804 & 1.307 & 1.307 \\
\hline 20 & 998.2 & 9.789 & 1.002 & 0.004 \\
\hline 30 & 995.7 & 9.765 & 0.798 & 0.658 \\
\hline 40 & 992.2 & 9.731 & 0.653 & 0.553 \\
\hline 50 & 988.1 & 9.690 & 0.547 & 0.475 \\
\hline 60 & 983.2 & 9.642 & 0.467 & 0.413 \\
\hline 70 & 977.8 & 9.589 & 0.404 & 0.365 \\
\hline 80 & 971.8 & 9.530 & 0.355 & 0.326 \\
\hline 90 & 965.3 & 9.467 & 0.315 & 0.294 \\
\hline 100 & 958.4 & 9.399 & 0.282 & \\
\hline
\end{tabular}




\section{APPENDIX $\mathbf{N}$}

\section{Bed Load Estimation}




\section{Existing Conditions of the Physical Experiments}

\begin{tabular}{|c|c|c|c|c|}
\hline & \multicolumn{2}{|c|}{ Metric } & \multicolumn{2}{|c|}{ Imperial } \\
\hline Water Discharge, $Q$ & 0.155 & $\mathrm{~m}^{3} / \mathrm{sec}$ & 5.474 & $\mathrm{ft}^{3} / \mathrm{sec}$ \\
\hline Channel Width, $W$ & 2 & metres & 6.562 & $\mathrm{ft}$ \\
\hline Longitundinal Slope, S & 0.002943 & & 0.002943 & \\
\hline Water Depth, $D$ & 0.25 & metres & 0.8202 & $\mathrm{ft}$ \\
\hline Average Velocity, $V$ & 0.31 & $\mathrm{~m} / \mathrm{sec}$ & 1.017 & $\mathrm{ft} / \mathrm{sec}$ \\
\hline Hydraulic Radius, $R=A / P$ & 0.2 & metres & 0.6562 & \\
\hline Sediment Particle Diameter & & & & \\
\hline$d_{25}$ & 0.00008920 & metres & 0.0002927 & $\mathrm{ft}$ \\
\hline$d_{50}$ & 0.000281 & metres & 0.0009219 & $\mathrm{ft}$ \\
\hline$d_{80}$ & 0.00101 & metres & 0.003314 & $\mathrm{ft}$ \\
\hline$d_{90}$ & 0.00176 & metres & 0.005774 & $\mathrm{ft}$ \\
\hline Gravitational Acceleration, $g$ & 9.806 & $\mathrm{~m} / \mathrm{s}^{2}$ & 32.174 & $\mathrm{ft} / \mathrm{s}^{2}$ \\
\hline Specific Weight of Water, Y & 9.806 & $\mathrm{kN} / \mathrm{m}^{3}$ & 62.43 & $\mathrm{lb} / \mathrm{ft}^{3}$ \\
\hline Specific Weight of Sediment, $\gamma_{s}$ & 25.99 & $\mathrm{kN} / \mathrm{m}^{3}$ & 165.4 & $\mathrm{lb} / \mathrm{ft}^{3}$ \\
\hline Density of Soil & 2650 & $\mathrm{~kg} / \mathrm{m}^{3}$ & 165.4 & $\mathrm{lb} / \mathrm{ft}^{3}$ \\
\hline Kinematic Viscosity, $v$ & 0.000001004 & $\mathrm{~m}^{2} / \mathrm{sec}$ & 0.00001081 & $\mathrm{ft}^{2} / \mathrm{sec}$ \\
\hline Shear Stress, $T=\gamma R S$ & 0.005772 & $\mathrm{kN} / \mathrm{m}^{2}$ & 0.1206 & $\mathrm{Ib} / \mathrm{ft}^{2}$ \\
\hline Shear Velocity, $V_{s}=(g R S)^{0.5}$ & 0.07597 & $\mathrm{~m} / \mathrm{sec}$ & 0.2493 & $\mathrm{ft} / \mathrm{sec}$ \\
\hline
\end{tabular}




\section{Duboys' Approach (1879)}

DuBoys (1879) assumed that sediment particles move in layers along the bed (Figure N.1). These layers move because of tractive force acting along the bed. Under equilibrium conditions, the tractive force should be balanced by the total resistance force between the sediment layers (Yang, 1996; Simons and Sentürk, 1976):

$$
\begin{aligned}
\tau & =\gamma D S \\
& =C_{f} m \varepsilon\left(\gamma_{s}-\gamma\right)
\end{aligned}
$$

where $\quad C_{f}=$ friction coefficient,

$m=$ total number of sediment layers,

$\varepsilon$ = layer thickness,

$D$ = water depth,

$S$ = channel slope,

$\gamma_{s}=$ specific weight of sediment, and

$\gamma=$ specific weight of water.

For incipient motion (i.e. $m=1$ ), Equation [N.1] becomes,

$$
\tau_{c}=C_{f} \varepsilon\left(\gamma_{s}-\gamma\right)
$$

where $\tau_{c}=$ critical tractive force along the bed (Yang, 1996; Simons and Sentürk, 1976). Thus,

$$
m=\tau / \tau_{c}
$$

If the velocity varies linearly between the first and $m$ th layers (Figure N.1), the total bed-load discharges by volume per unit channel width is,

$$
q_{b}=\varepsilon V_{s} \frac{m(m-1)}{2}
$$

where $V_{s}=$ velocity of the second layer in Figure N.1 (Yang, 1996). 


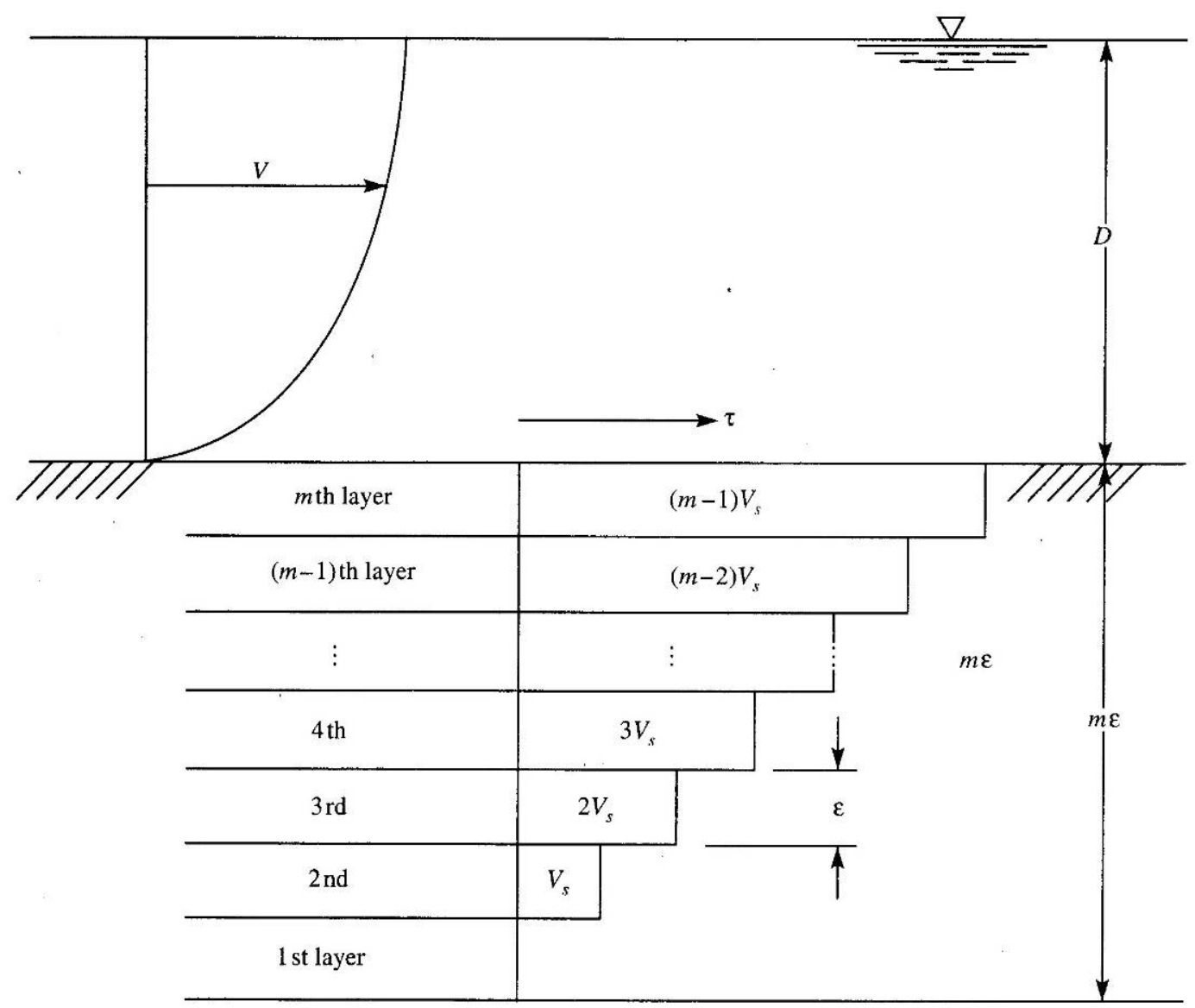

Figure N.1: Sketch of DuBoys' (1879) approach (Yang, 1996).

By combining Equations [N.3] and [N.4],

$$
\begin{aligned}
q_{b} & =\frac{\varepsilon V_{s}}{2 \tau_{c}^{2}} \tau\left(\tau-\tau_{c}\right) \\
& =K \tau\left(\tau-\tau_{c}\right)
\end{aligned}
$$

where $K=$ coefficient related to the characteristics of sediment particles (Yang, 1996; Simons and Sentürk, 1976).

Straub (1935) found that

$$
K=0.173 d^{-0.75}
$$


where the unit of $K=\mathrm{ft}^{6} /\left(\mathrm{lb}^{2}-\mathrm{sec}\right)$ and the unit of $d=\mathrm{mm}$ (Yang, 1996). Figure N.2 demonstrates the relationship among $\tau_{c}, K$ and $d$. The value of $\tau_{c}$ can be determined from the Shield's diagram (Figure N.3).

By substituting Equation [N.6] into Equation [N.5], DuBoys' equation becomes (Yang, 1996),

$$
q_{b}=\frac{0.173}{d^{0.75}} \tau\left(\tau-\tau_{c}\right)=\left(\mathrm{ft}^{3} / \mathrm{sec}\right) / \mathrm{ft}
$$

DuBoys' equation was later modified and improved by different investigators. The equation was criticized for the following reasons (Yang, 1996; Simons and Sentürk, 1976):

1) The data used to derive the equation was obtained from small laboratory flumes with a small range of particle size variation.

2) It is not clear whether the equation is applicable to field conditions.

Table N.1: Bed-Load Estimation of the Physical Experiments using Duboys' Approach.

\begin{tabular}{|l|c|c|c|}
\cline { 2 - 4 } \multicolumn{1}{c|}{} & $d_{50}$ & $d_{80}$ & $d_{25}$ \\
\hline Critical Shear Stress, $\tau_{c}$, in $\mathrm{Ib}^{6} / \mathrm{It}^{2}$ & 0.4482 & 0.1717 & 1.060 \\
Bed-Load Discharge, $Q_{b}$, in $\mathrm{ft}^{3} / \mathrm{sec}$ & 0.04 & & \\
\hline Bed-Load Discharge per every 5 minutes, in $\mathrm{ft}^{3}$ & 0.028566 & & \\
Bed-Load Weight per every 5 minutes, in $\mathbf{~ k g}$ & $\mathbf{6 4 3 . 1}$ & & \\
\hline
\end{tabular}




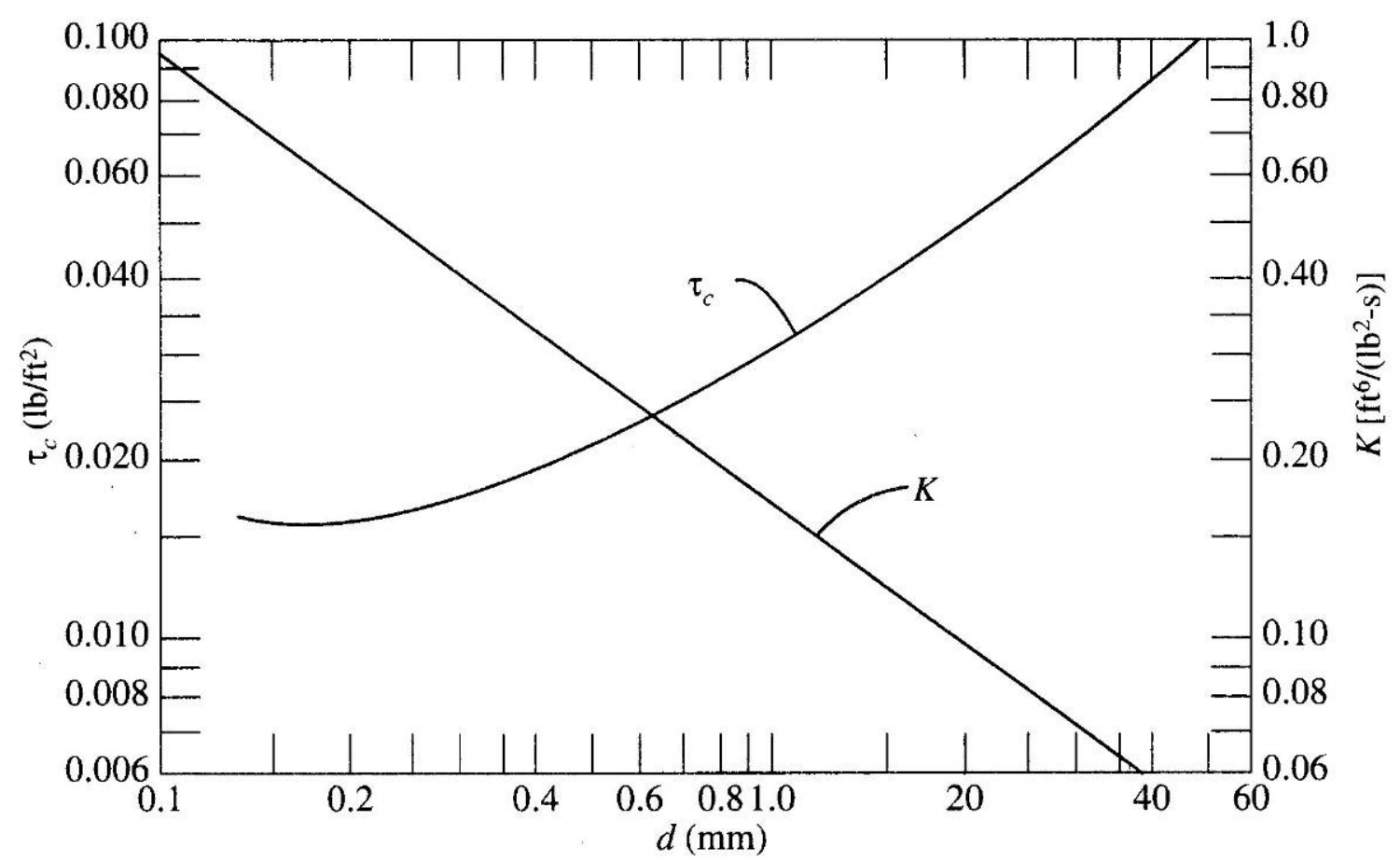

(a)

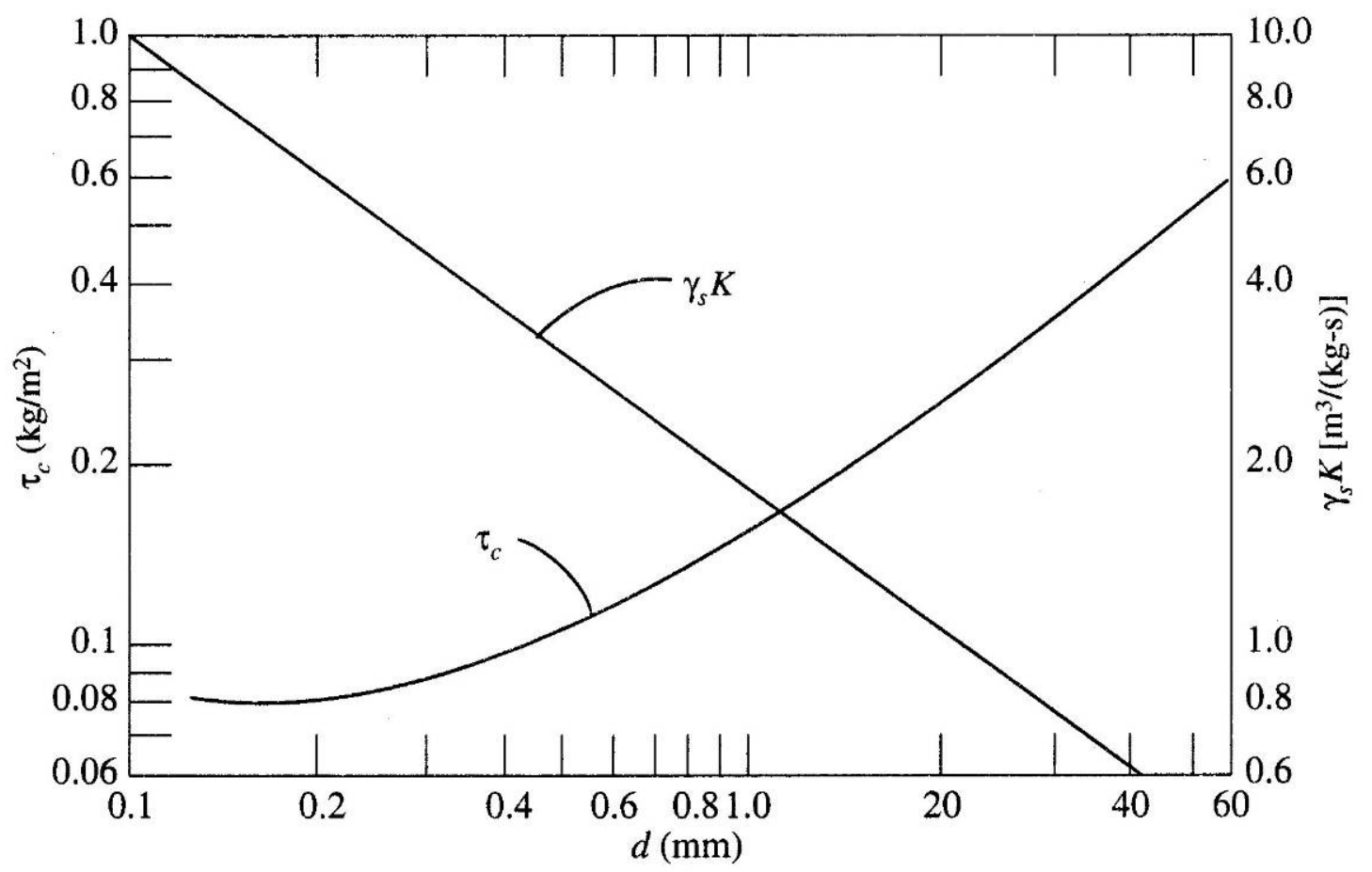

(b)

Figure N.2: Sediment parameters for DuBoys' approach in Imperial units (a) and metric units (b) (Yang, 1996). 


\section{Shield's Approach (1936)}

Shields (1936) measured flow conditions for sediment transport greater than zero.

The relationship was then extended to obtain the flow condition corresponding to incipient motion. Thus, a dimensionless semi-empirical equation for bed-load was developed (Yang, 1996; Simons and Sentürk, 1976):

$$
\frac{q_{b} \gamma_{s}}{q \gamma S}=10 \frac{\tau-\tau_{c}}{\left(\gamma_{s}-\gamma\right) d}
$$

where $q_{b}=$ bed-load discharge per unit width of the channel,

$q$ = water discharge per unit width of the channel,

$\tau=\gamma R S$,

$\tau_{c}=$ critical shear stress which can be obtained from the Shields diagram (Figure N.3),

$d$ = sediment particle diameter,

$V=$ specific weight of water, and

$v_{s}=$ specific weight of sediment.

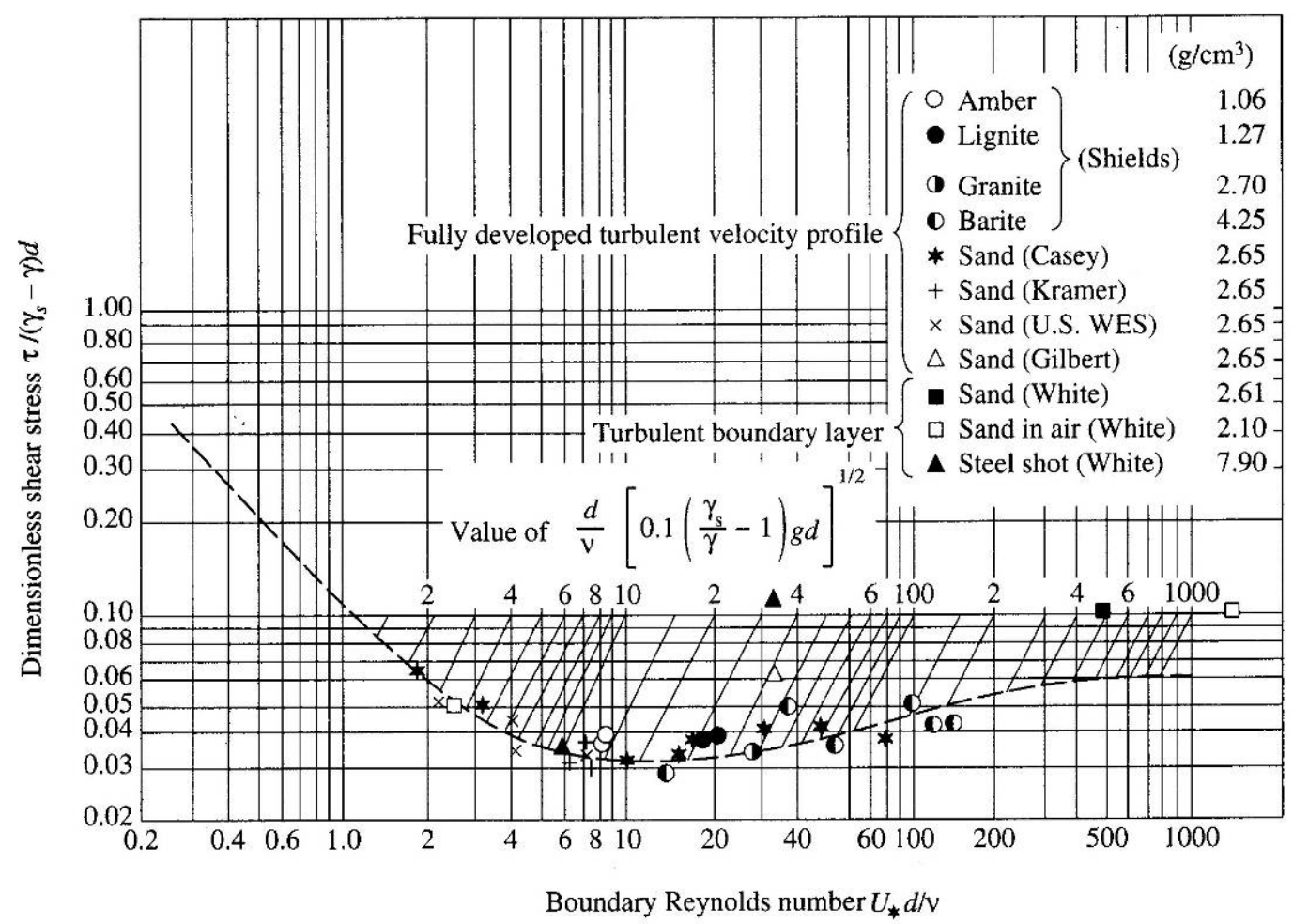

Figure N.3: Shields diagram (Yang, 1996). 
Table N.2: Bed-Load Estimation of the Physical Experiments using Shields' Approach.

\begin{tabular}{|c|c|c|c|}
\hline & & & \\
\hline & $d_{50}$ & $d_{80}$ & $d_{25}$ \\
\hline \multirow{4}{*}{$\begin{array}{l}\text { Shear Velocity, } U_{*}=(g R S)^{0.5} \text {, in } \mathrm{m} / \mathrm{sec} \\
\text { Boundary Reynolds Number, }(U * d) / v \\
\text { Dimensionless Shear Stress, } T_{c} /\left(\gamma_{s}-\gamma\right) d \text {, } \\
\text { in } \mathrm{kN} / \mathrm{m}^{2} \\
\text { Critical Shear Stress, } T_{c} \text {, in } \mathrm{kN} / \mathrm{m}^{2}\end{array}$} & \multicolumn{3}{|c|}{0.07597} \\
\hline & 21.3 & 76.4 & 6.7 \\
\hline & 0.034 & 0.043 & 0.032 \\
\hline & 0.0001546 & 0.0007027 & 0.00004618 \\
\hline \multirow{2}{*}{$\begin{array}{l}\text { Bed-Load Discharge, } Q_{b}, \text { in } \mathrm{m}^{3} / \mathrm{sec} \\
\text { Bed-Load Weight per every } 5 \text { minutes, } \\
\text { in } \mathbf{~ g ~}\end{array}$} & 0.002127 & 0.0005340 & 0.006829 \\
\hline & 1691 & 424.5 & 5429 \\
\hline \multirow{4}{*}{$\begin{array}{l}\text { Inception Velocity, } V_{\text {incep }} \text {, in } \mathrm{m} / \mathrm{sec} \\
\text { Boundary Reynolds Number, }(U * d) / v \\
\text { Dimensionless Shear Stress, } T_{c} /\left(V_{s}-\gamma\right) d \text {, } \\
\text { in } \mathrm{kN} / \mathrm{m}^{2} \\
\text { Critical Shear Stress, } T_{c} \text {, in } \mathrm{kN} / \mathrm{m}^{2}\end{array}$} & \multicolumn{3}{|c|}{0.18540} \\
\hline & \multicolumn{3}{|c|}{186.5} \\
\hline & 0.040 & 0.053 & 0.033 \\
\hline & 0.0001819 & 0.0008661 & 0.00004763 \\
\hline Bed-Load Discharge, $Q_{b}$, in $\mathrm{m}^{3} / \mathrm{sec}$ & 0.002116 & 0.0005167 & 0.006827 \\
\hline $\begin{array}{l}\text { Bed-Load Weight per every } 5 \text { minutes, } \\
\text { in kg }\end{array}$ & 1683 & 410.8 & 5428 \\
\hline
\end{tabular}

\section{Kalinske's Approach (1947)}

Kalinske (1947) assumed that

$$
u_{s}=b\left(u-V_{c}\right)
$$

where $u_{s}=$ instantaneous velocities of sediment at the particle level,

$u=$ instantaneous velocities of fluid at the particle level,

$V_{c}=$ critical flow velocity at incipient motion, and

$b=$ constant close to unity.

For turbulent flows (Yang, 1996),

$$
\frac{\bar{u}_{s}}{U_{*}}=f\left(\frac{\tau_{c}}{\tau}\right)
$$

where $\bar{u}_{s}=$ time-averaged value of $u_{s}$, and

$U_{*}=$ shear velocity. 
By the definition of bed-load movement (Yang, 1996; Simons and Sentürk, 1976),

$$
q_{b}=\alpha P d \bar{u}
$$

where $q_{b}=$ bed-load per unit channel width,

$P=$ fraction of bed covered by sediment particles,

$d$ = median sediment particle size , and

$\alpha=$ shape factor for packing ( $=2 / 3$ for uniform spheres).

Thus,

$$
\frac{q_{b}}{U_{*} d}=f^{\prime}\left(\frac{\tau_{c}}{\tau}\right)
$$

and the relationship is shown in Figure N.4 below (Yang, 1996).

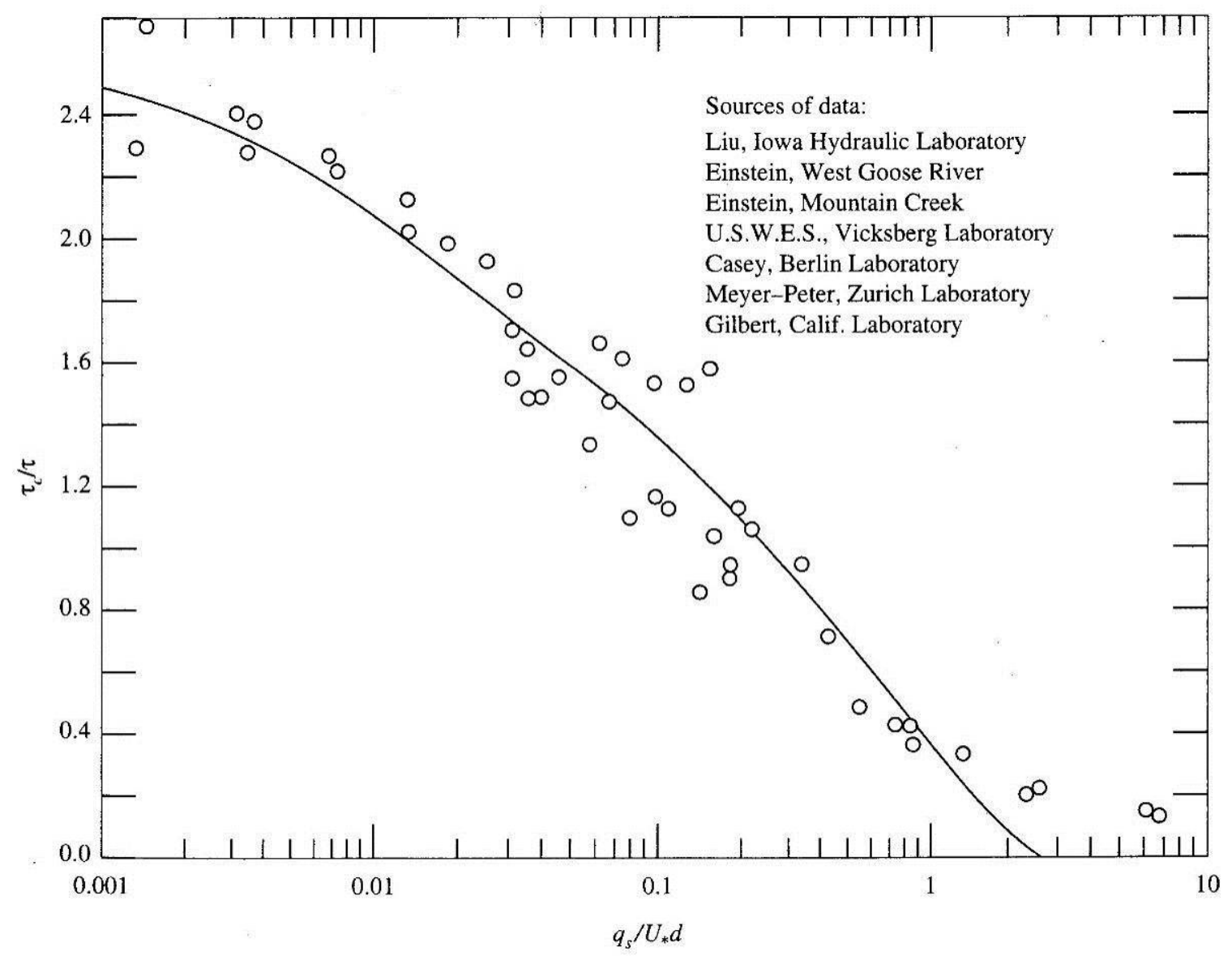

Figure N.4: Kalinske's (1947) approach (Yang, 1996). 
Table N.3: Bed-Load Estimation of the Physical Experiments using Kalinske's Approach.

\begin{tabular}{|l|c|c|c|}
\cline { 2 - 4 } \multicolumn{1}{c|}{} & $d_{50}$ & $d_{80}$ & $d_{25}$ \\
\hline$\tau_{d} / T \rightarrow$ y-axis of Kalinske's graph & 0.02678 & 0.1217 & 0.008002 \\
$q_{b} /(U \times d) \rightarrow$ x-axis of Kalinske's graph & 2.5 & 2 & 2.5 \\
\hline $\begin{array}{l}\text { Bed-Load Discharge, } Q_{b}, \text { in } \mathrm{m}^{3} / \mathrm{sec} \\
\begin{array}{l}\text { Bed-Load Weight per every } \mathbf{5} \\
\text { minutes, in kg }\end{array}\end{array}$ & 0.0001067 & 0.0003069 & 0.00003388 \\
\hline
\end{tabular}

\section{Chang, Simons, and Richardson's Approach (1967)}

Chang et al. (1967) suggested that the bed-load discharge by weight can be determined by:

$$
\begin{aligned}
q_{b} & =\frac{K_{b} \gamma_{s} V\left(\tau-\tau_{c}\right)}{\left(\gamma_{s}-\gamma\right) \tan \phi} \\
& =K_{t} V\left(\tau-\tau_{c}\right)
\end{aligned}
$$

where $K_{b}=$ constant, and

$\phi=$ angle of repose of submerged bed material.

Equation [N.13] is expressed in Imperial units, where $q_{b}$ is expressed in terms of pounds per second per foot of channel width on a dry weight basis. $K_{t}$ can be determined from Figure N.5. The equivalent particle diameter, $d_{e}$, in Figure N.5 is based on the fall velocity of a particle that is equal to or slightly larger than the $d_{50}$ based on standard fall diameters (Yang, 1996; Simons and Sentürk, 1976). 


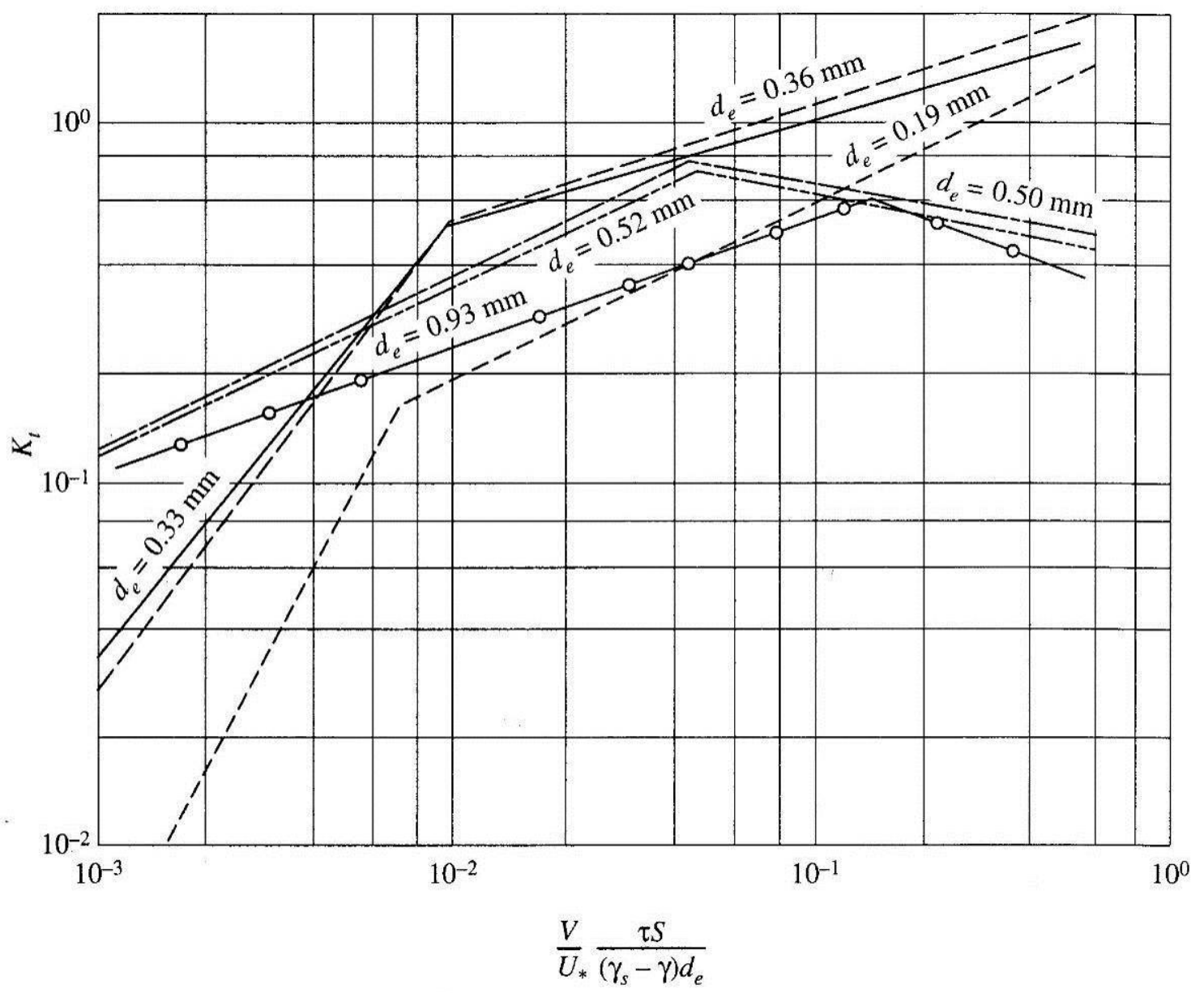

Figure N.5: Total bed-material discharge coefficient $K_{t}$ for various sands derived from flume experiments (Chang et al., 1967).

Table N.4: Bed-Load Estimation of the Physical Experiments using Chang et al.'s Approach.

\begin{tabular}{|l|c|}
\cline { 2 - 2 } \multicolumn{1}{c|}{} & $d_{e}=d_{50}$ \\
\hline$\left(V / U_{*}\right)\left(T S /\left(Y_{s}-\gamma\right) d_{50}\right) \rightarrow$ x-axis of Chang's graph & 0.9517 \\
Parameter $K_{t} \rightarrow$ y-axis of Chang's graph & 1.2 \\
\hline Bed-Load Discharge, $Q_{b}$, in Ib/sec & 0.9654 \\
Bed-Load Weight per every 5 minutes, in kg & $\mathbf{1 3 1 . 4}$ \\
\hline
\end{tabular}

Note: 1) Assume $d_{e}=0.33 \mathrm{~mm}$ (slightly larger than $d_{50}$ )

2) $T_{c}$ is derived from Figure N.3 


\section{Meyer-Peter and Müller's Approach (1948)}

Meyer-Peter and Müller (1948) transformed Meyer-Peter et al. formula (1934) to the following equation after 14 years of research and analysis (Yang, 1996; Simons and Sentürk, 1976):

$$
\gamma\left(\frac{K_{s}}{K_{r}}\right)^{3 / 2} R S=0.047\left(\gamma_{s}-\gamma\right) d+0.25 \rho^{1 / 3} q_{b}{ }^{2 / 3}
$$

where $\quad y=$ specific weight of water in metric tons $/ \mathrm{m}^{3}$,

$V_{s}=$ specific weight of sediment in metric tons $/ \mathrm{m}^{3}$,

$R=$ hydraulic radius in metre,

$S=$ energy slope,

$d=$ mean particle diameter in metre,

$\rho=$ specific mass of water in metric ton-s $/ \mathrm{m}^{4}$, and

$q_{b}=$ bed-load rate in underwater weight per unit time and width in (metric ton/s)/m.

Part of the expression in the left-side of Equation [N.14], $\left(K_{S} / K_{r}\right) S$, is the kind of slope which is adjusted in a such way that only a portion of the total energy loss that due to the grain resistance, $S_{r}$, is responsible for the bed-load motion. Equation [N.15] can be expressed in dimensionless form as (Yang, 1996; Simons and Sentürk, 1976):

$$
\left[\frac{q_{s}\left(\gamma_{s}-\gamma\right)}{\gamma_{s}}\right]^{2 / 3}\left(\frac{\gamma}{g}\right) \frac{0.25}{\left(\gamma_{s}-\gamma\right) d}=\frac{\left(K_{s} / K_{r}\right)^{3 / 2} \gamma R S}{\left(\gamma_{s}-\gamma\right) d}-0.047
$$

Test results by Meyer-Peter and Müller (1948) showed that the relationship between energy loss due to grain resistance and energy loss is (Yang, 1996; Simons and Sentürk, 1976): 


$$
\left(\frac{K_{s}}{K_{r}}\right)^{3 / 2}=\frac{S_{r}}{S}
$$

where the energy loss due to grain resistance, $S_{r}$, can be obtained from Strickler's formula (Yang, 1996; Simons and Sentürk, 1976):

$$
S_{r}=\frac{V^{2}}{K_{r}^{2} R^{4 / 3}}
$$

Furthermore, the coefficient, $K_{r}$, was determined by Müller as:

$$
K_{r}=\frac{26}{d_{90}^{1 / 6}}
$$

where $\quad d_{90}=$ size of sediment for which $90 \%$ of the material is finer (Yang, 1996; Simons and Sentürk, 1976).

Table N.5: Bed-Load Estimation of the Physical Experiments using Meyer-Peter and Müller's Approach.

\begin{tabular}{|l|c|}
\cline { 2 - 2 } \multicolumn{1}{c|}{} & $d_{50}$ \\
\hline$K_{r}$ & 74.83 \\
Average Velocity, $V$, in $\mathrm{m} / \mathrm{sec}$ & 0.3100 \\
$S_{r}$ & 0.0001467 \\
$K_{s}$ & 10.14 \\
Specific Weight of Water, $V$, in metric ton $/ \mathrm{m}^{3}$ & 1 \\
Specific Gravity of Sediment, $\gamma_{s}$, in metric ton $/ \mathrm{m}^{3}$ & 2.65 \\
Specific Mass of Water, $\rho$, in metric ton-s ${ }^{2} / \mathrm{m}^{4}$ & 0.1020 \\
Bed-Load Discharge in Submerged Weight, $Q_{b}$, & 0.000001041 \\
in metric-tons/sec & $\mathbf{0 . 5 0 1 6}$ \\
\hline Bed-Load Weight per every $\mathbf{5}$ minutes, in $\mathbf{~} \mathbf{g}$ & \\
\hline
\end{tabular}




\section{Schoklitch's Approach}

Schoklitsch pioneered the use of water discharge and published two formulae in 1934 and 1943 for the determination of bed-load. Schoklitsch (1934) is expressed in metric system as (Yang, 1996):

$$
q_{b}=7000\left(q-q_{c}\right)\left(S^{3 / 2} / d^{1 / 2}\right)
$$

where

$$
\begin{aligned}
q_{b} & =\text { bed-load in }(\mathrm{kg} / \mathrm{s}) / \mathrm{m}, \\
d & =\text { particle size in } \mathrm{mm}, \\
S & =\text { longitudinal slope } \\
q & =\text { water discharge at incipient motion in }\left(\mathrm{m}^{3} / \mathrm{sec}\right) / \mathrm{m}, \text { and } \\
q_{c} & =\text { critical discharge at incipient motion in }\left(\mathrm{m}^{3} / \mathrm{sec}\right) / \mathrm{m} .
\end{aligned}
$$

The critical water discharge in Equation [N.19] for sediments with specific gravity 2.65 is given by (Yang, 1996):

$$
q_{c}=0.00001944 d / S^{4 / 3}
$$

The Schoklitsch (1943) formula in metric system is (Yang, 1996):

$$
q_{b}=2500 S^{3 / 2}\left(q-q_{c}\right)
$$

For sediments with specific gravity of 2.65 , the critical discharge in Equation [N.21] is (Yang, 1996):

$$
q_{c}=0.6 d^{3 / 2} / S^{7 / 6}
$$

where $d=$ particle size in metres. 
Table N.6: Bed-Load Estimation of the Physical Experiments using Schoklitsch's Approach (1934).

\begin{tabular}{|l|c|c|c|}
\cline { 2 - 4 } \multicolumn{1}{c|}{} & $d_{50}$ & $d_{80}$ & $d_{25}$ \\
\hline Critical Water Discharge, $q_{c}$, in $\left(\mathrm{m}^{3} / \mathrm{sec}\right) / \mathrm{m}$ & 0.01295 & 0.04655 & 0.004112 \\
\hline Bed-Load Discharge, $Q_{b}$, in $\mathrm{kg} / \mathrm{sec}$ & 0.2722 & 0.06883 & 0.5492 \\
Bed-Load Weight per every 5 minutes, in kg & $\mathbf{8 1 . 6 5}$ & $\mathbf{2 0 . 6 5}$ & $\mathbf{1 6 4 . 8}$ \\
\hline
\end{tabular}

Table N.7: Bed-Load Estimation of the Physical Experiments using Schoklitsch's Approach (1943).

\begin{tabular}{|l|c|c|c|}
\cline { 2 - 4 } \multicolumn{1}{c|}{} & $d_{50}$ & $d_{80}$ & $d_{25}$ \\
\hline Critical Water Discharge, $q_{c}$, in $\left(\mathrm{m}^{3} / \mathrm{sec}\right) / \mathrm{m}$ & 0.002537 & 0.01729 & 0.0004537 \\
\hline Bed-Load Discharge, $Q_{b}$, in $\mathrm{kg} / \mathrm{sec}$ & 0.05984 & 0.04807 & 0.06150 \\
Bed-Load Weight per every $\mathbf{5}$ minutes, in $\mathbf{~ k g}$ & $\mathbf{1 7 . 9 5}$ & $\mathbf{1 4 . 4 2}$ & $\mathbf{1 8 . 4 5}$ \\
\hline
\end{tabular}

\section{Donate's Approach (1929)}

Donate (1929) revised DuBoys formula into the following expression (Yang, 1996):

$$
q_{b}=K(\gamma S D)\left(\gamma S D-\gamma S D_{c}\right)
$$

where $\quad D_{c}=$ critical water depth at incipient motion, and

$$
D=\text { normal water depth at incipient motion. }
$$

He assumed that Chezy's equation can be used in Equation [N.23] and Chezy's roughness coefficient, $C$, remains the same for $D$ and $D_{c}$. Equation [N.23] can then be modified to (Yang, 1996):

$$
q_{b}=\frac{K}{C^{4}} V^{2} V^{2}\left(V^{2}-V_{c}^{2}\right)
$$

where $\quad V=$ average velocity at incipient motion, $V_{c}=$ critical velocity at incipient motion, 
$C=$ Chezy's roughness coefficient, and

$V=$ specific weight of water.

Table N.8: Bed-Load Estimation of the Physical Experiments using Donate's Approach.

\begin{tabular}{|l|c|c|c|}
\cline { 2 - 4 } \multicolumn{1}{c|}{} & $d_{50}$ & $d_{80}$ & $d_{25}$ \\
\hline Manning's $n$ & \multicolumn{3}{|c|}{0.06} \\
Chezy's Roughness Coefficient, $C$, in $\mathrm{ft}^{1 / 2} / \mathrm{sec}$ & \multicolumn{3}{c|}{15.54} \\
\hline$K$, in $\mathrm{ft}^{6} /\left(\mathrm{lb}^{2}\right.$-sec) & 0.4482 & 0.1717 & 1.060 \\
\hline Bed-Load Discharge, $Q_{b}$, in $\mathrm{ft}^{3} / \mathrm{sec}$ & 0.02061 & 0.007894 & 0.04873 \\
Bed-Load Weight per every 5 minutes, in kg & $\mathbf{4 6 3 . 9}$ & $\mathbf{1 7 7 . 7}$ & 1097 \\
\hline
\end{tabular}

where $C=(1 / n)\left(R^{1 / 6}\right)$

\section{Rottner's Approach (1959)}

Rottner (1959) derived an equation based on dimensional considerations and regression analysis to express bed-load discharge in terms of flow parameters and relative roughness parameter $d_{50} / D$ (Yang, 1996):

$q_{b}=\gamma_{s}\left[\left(\zeta_{s}-1\right) g D^{3}\right]^{1 / 2}\left\{\frac{V}{\left[\left(\zeta_{s}-1\right) g D\right]^{1 / 2}}\left[0.667\left(\frac{d_{50}}{D}\right)^{2 / 3}+0.14\right]-0.778\left(\frac{d_{50}}{D}\right)^{2 / 3}\right\}^{3}$

where $q_{b}=$ bed-load discharge in $(\mathrm{lb} / \mathrm{sec}) / \mathrm{ft}$,

$V_{s}=$ specific weight of sediment in $\mathrm{lb} / \mathrm{ft}^{3}$,

$\zeta_{s}=$ specific gravity of the sediment $(=2.65)$,

$g=$ gravitational acceleration in $\mathrm{ft} / \mathrm{s}^{2}$,

$D=$ mean depth in $\mathrm{ft}$,

$V=$ mean velocity in $\mathrm{ft} / \mathrm{sec}$, and

$d_{50}=$ particle size at which $50 \%$ of the bed material by weight is finer, in $\mathrm{ft}$. 
Table N.9: Bed-Load Estimation of the Physical Experiments using Rottner's Approach.

\begin{tabular}{|l|c|c|c|}
\cline { 2 - 4 } \multicolumn{1}{c|}{} & $d_{50}$ & $d_{80}$ & $d_{25}$ \\
\hline$d_{50} / D$ & 0.001124 & 0.004040 & 0.0003568 \\
\hline $\begin{array}{l}\text { Bed-Load Discharge, } Q_{b}, \text { in Ib/sec } \\
\text { Bed-Load Weight per every 5 minutes, } \\
\text { in kg }\end{array}$ & 0.01711 & 0.0005182 & 0.03531 \\
\hline
\end{tabular}




\section{APPENDIX $\mathbf{P}$}

\section{Experimental Results of Single Deflector Scenarios for Wet Weather Conditions \\ Without Incoming Sediment}




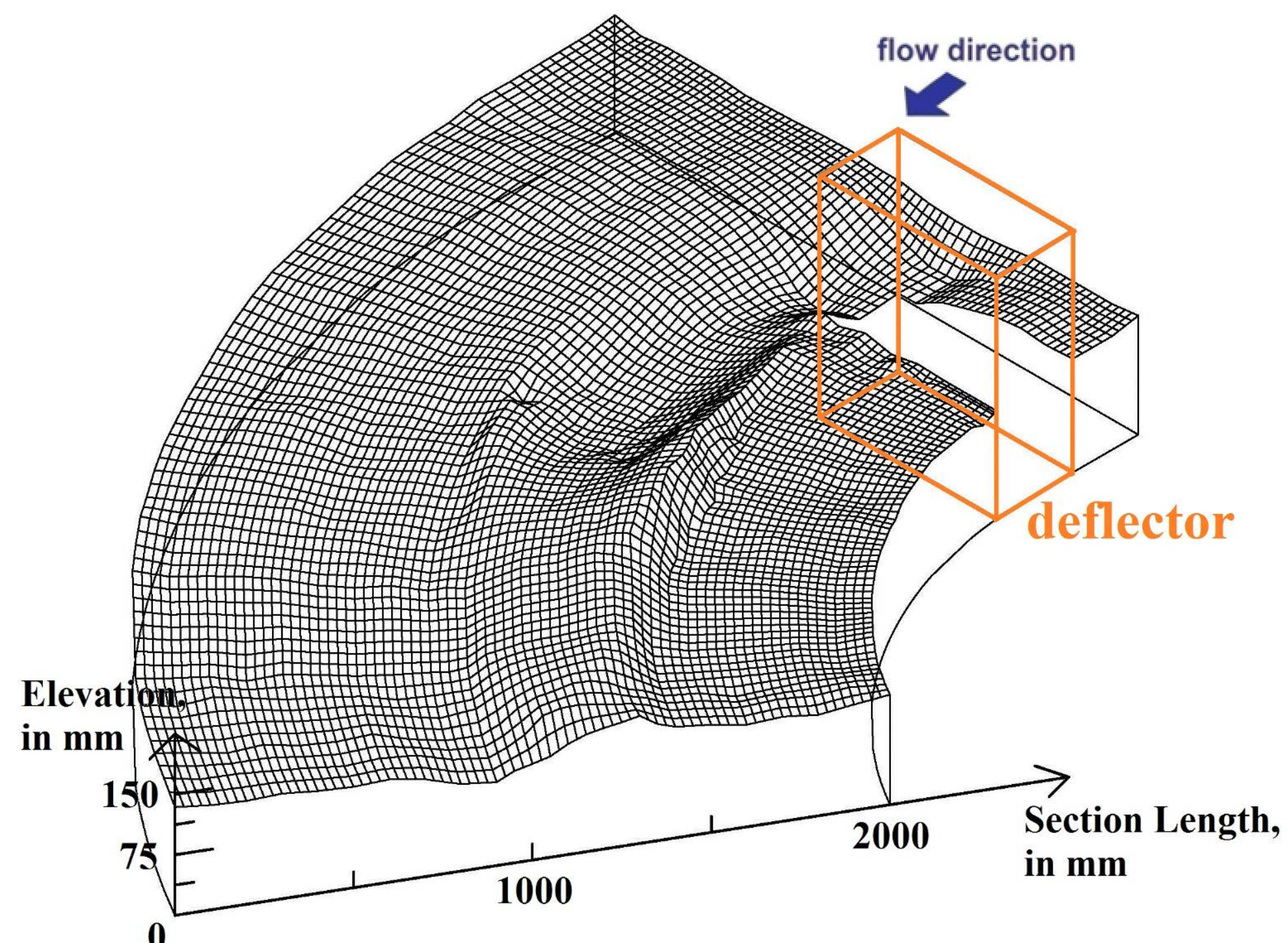

Figure P-1: Sediment Profile (3-D mesh) of Experiment \#B7 at time $=21$ hours. 


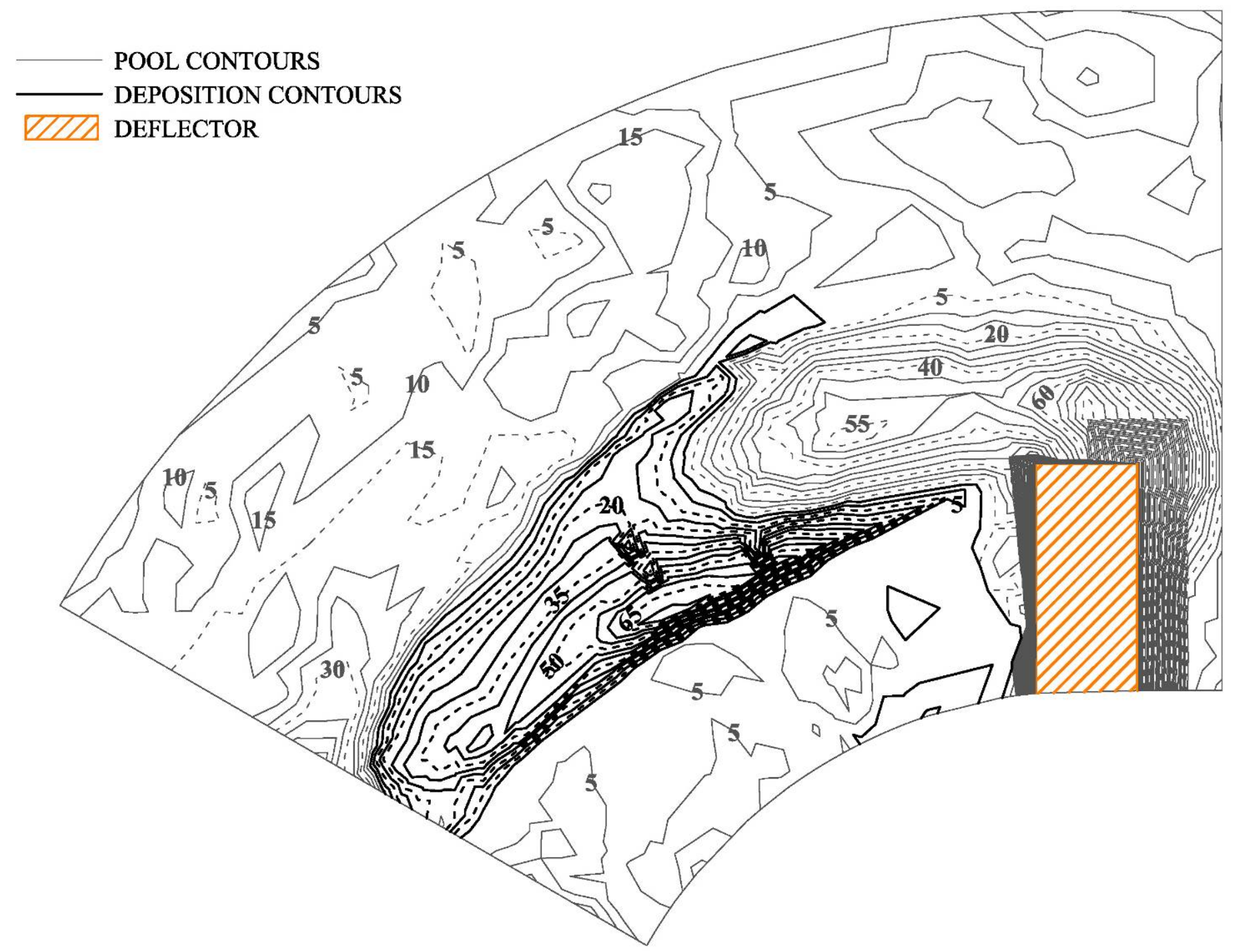

Figure P-2: Sediment Contours of Experiment \#B7 at time $=21$ hours. 


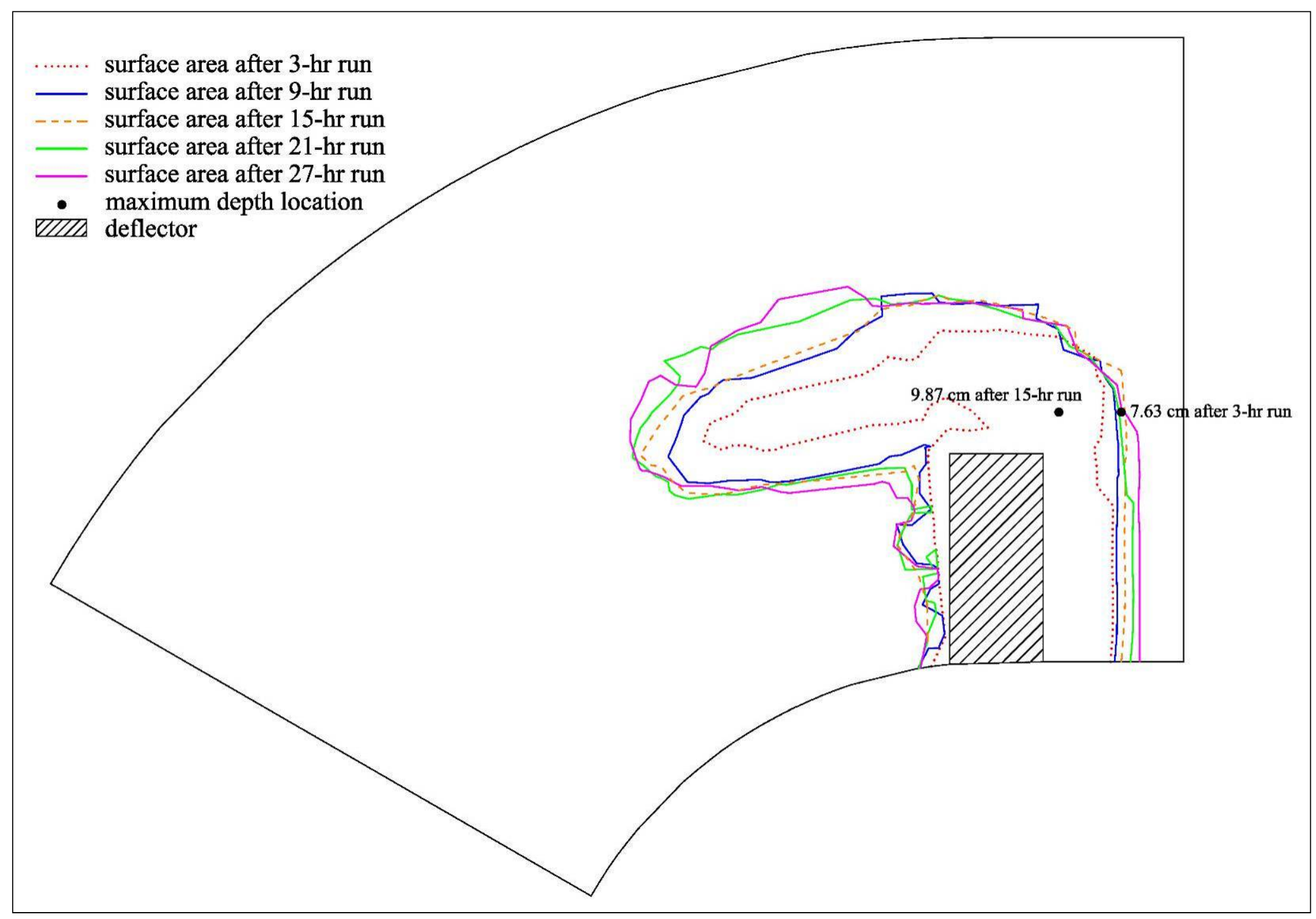

Figure R-3: Changes of Surface Area of Pool for Experiment \#B7 at Different Time Intervals. 


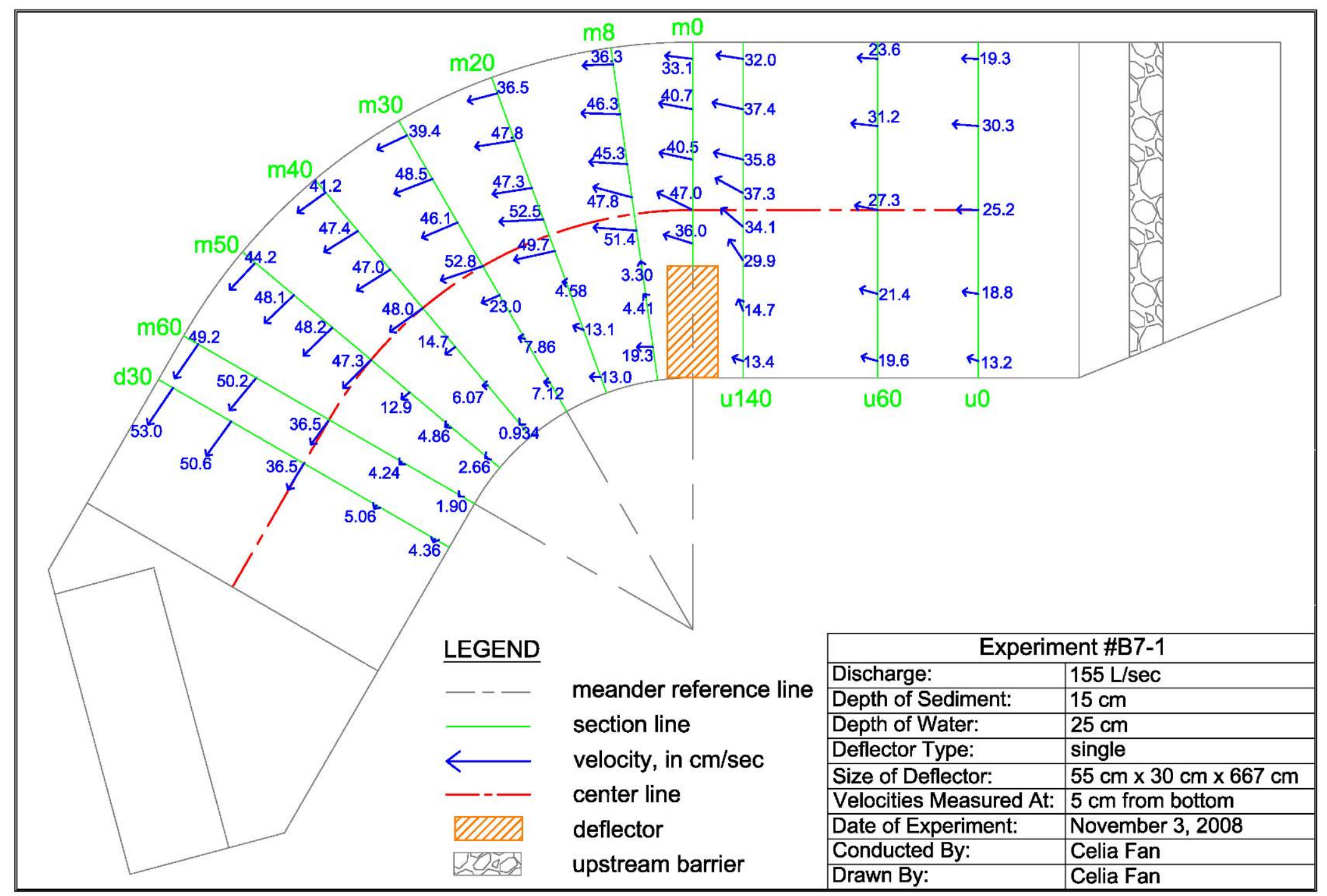

Figure P-4: Velocity Profile in $x y$-plane of Experiment \#B7 at 20\% Water Depth. 


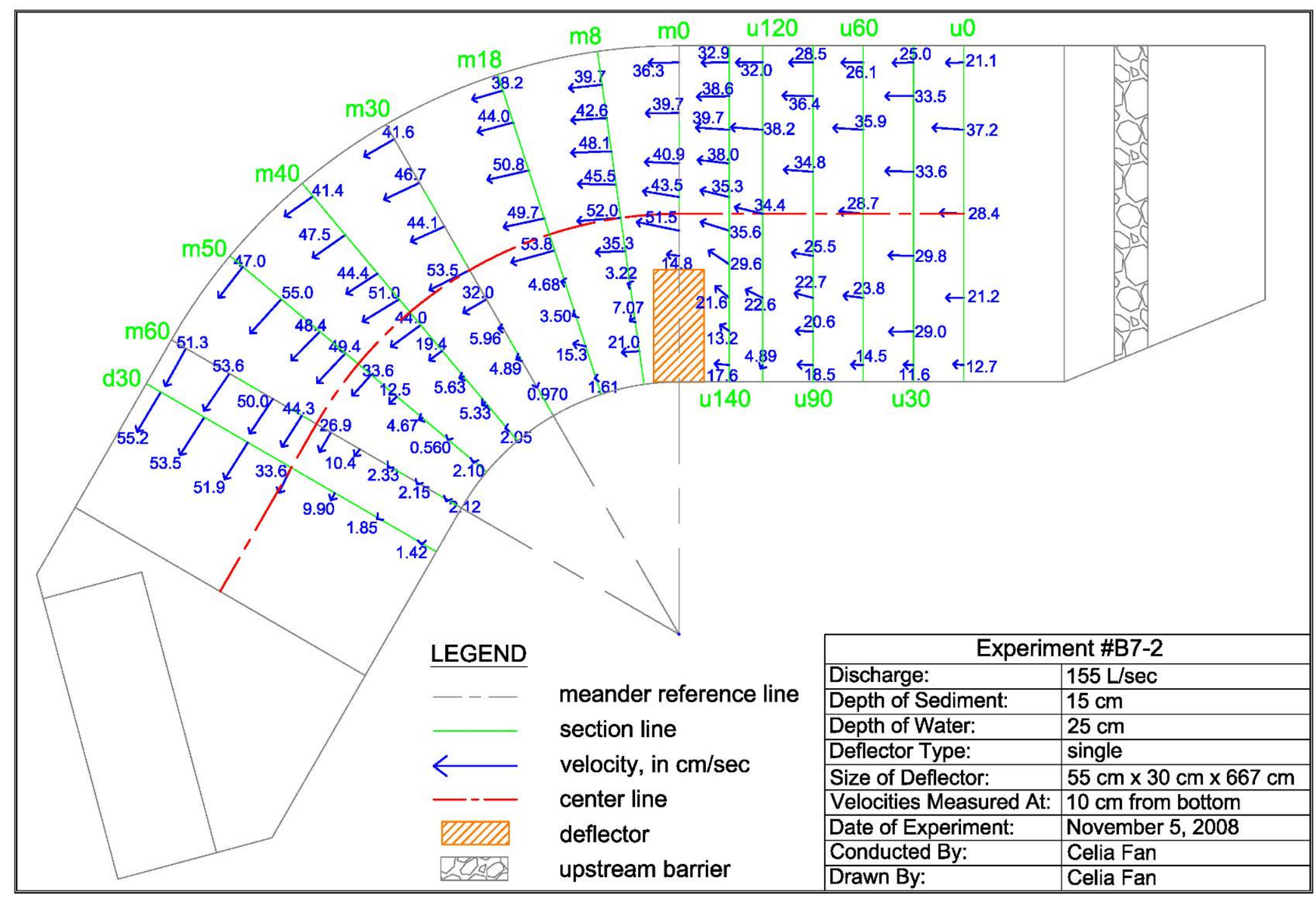

Figure P-5: Velocity Profile in $x y$-plane of Experiment \#B7 at 40\% Water Depth. 


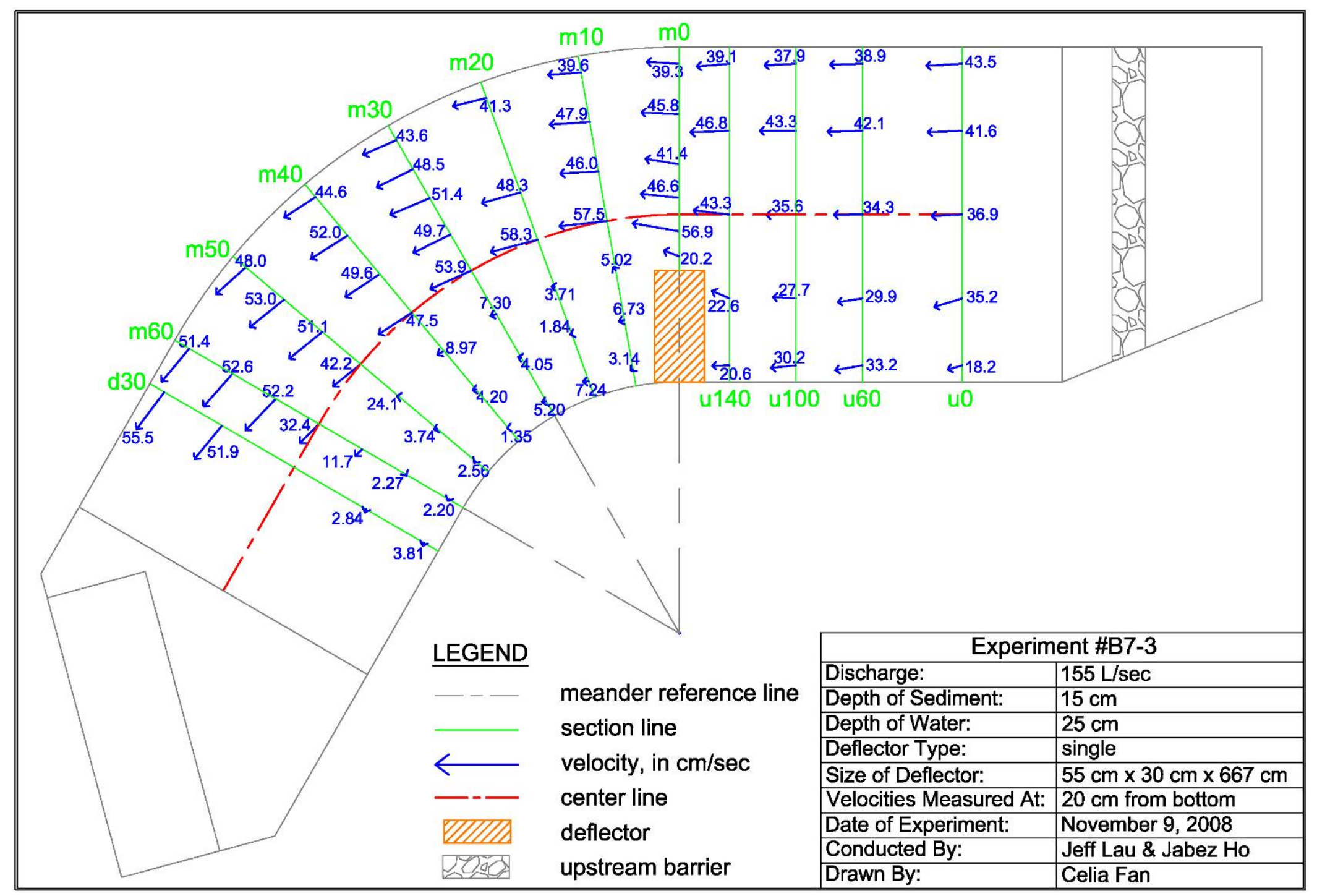

Figure P-6: Velocity Profile in xy-plane of Experiment \#B7 at 80\% Water Depth. 

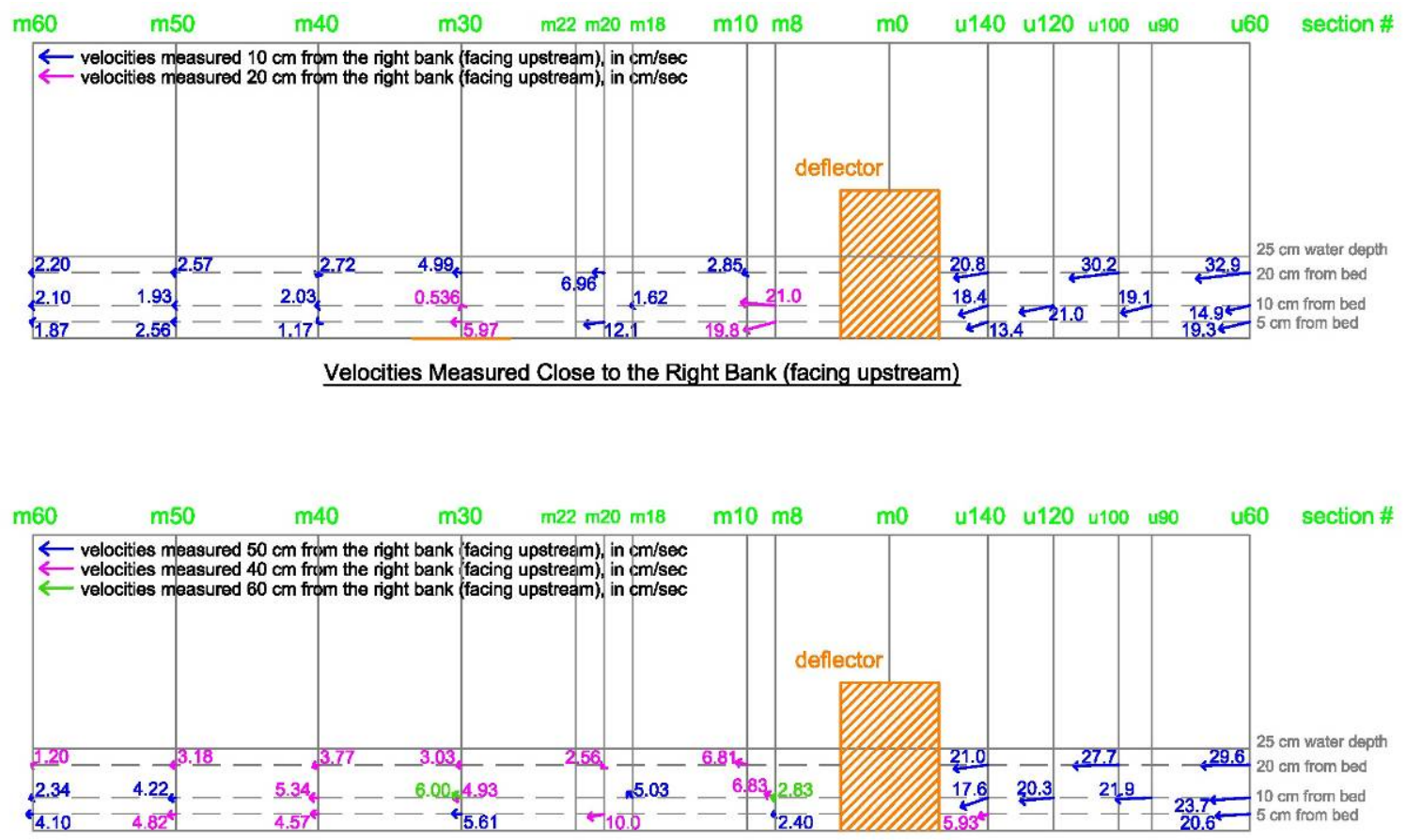

Velocities Measured around the Middle of the Deflector

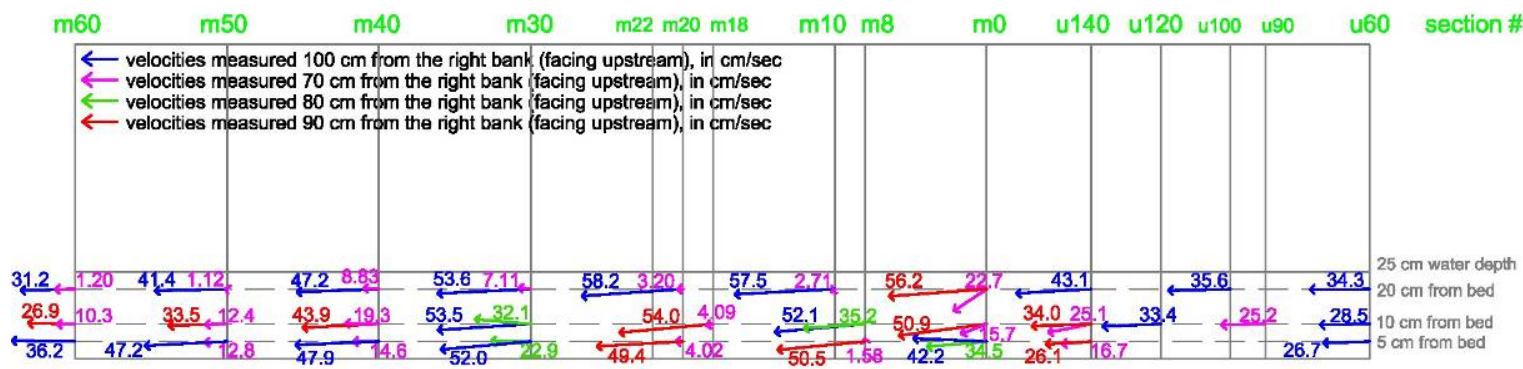

Velocities Measured Around the Tip of the Deflector

Figure P-7: Velocity Profile in xz-planes of Experiment \#B7 at the Meander Section. 


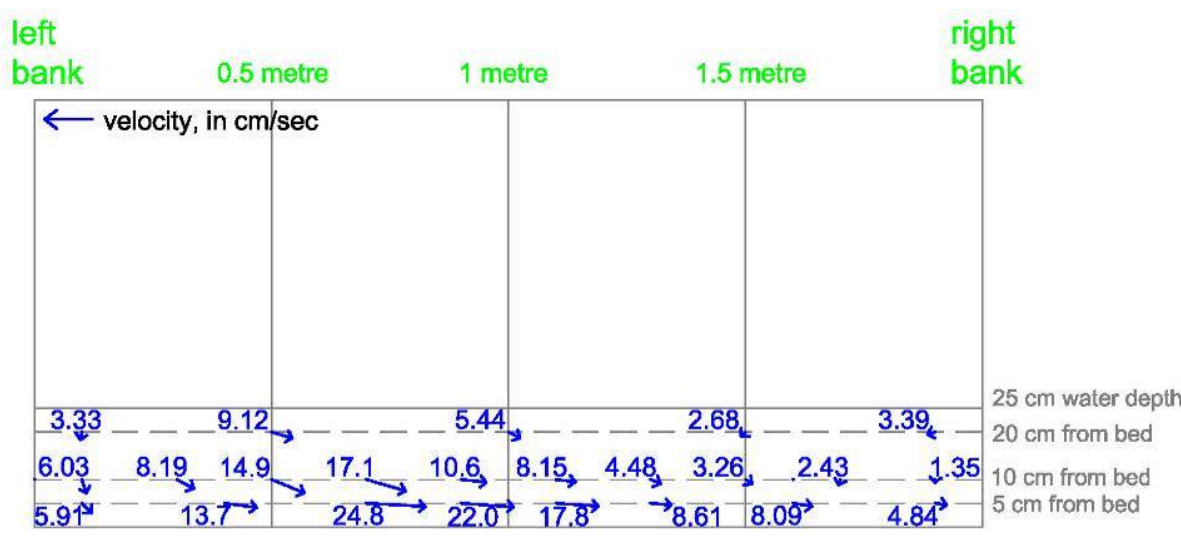

Velocities Mesured at Section u140 (Just Before the Deflector)

\section{Facing Downstream}

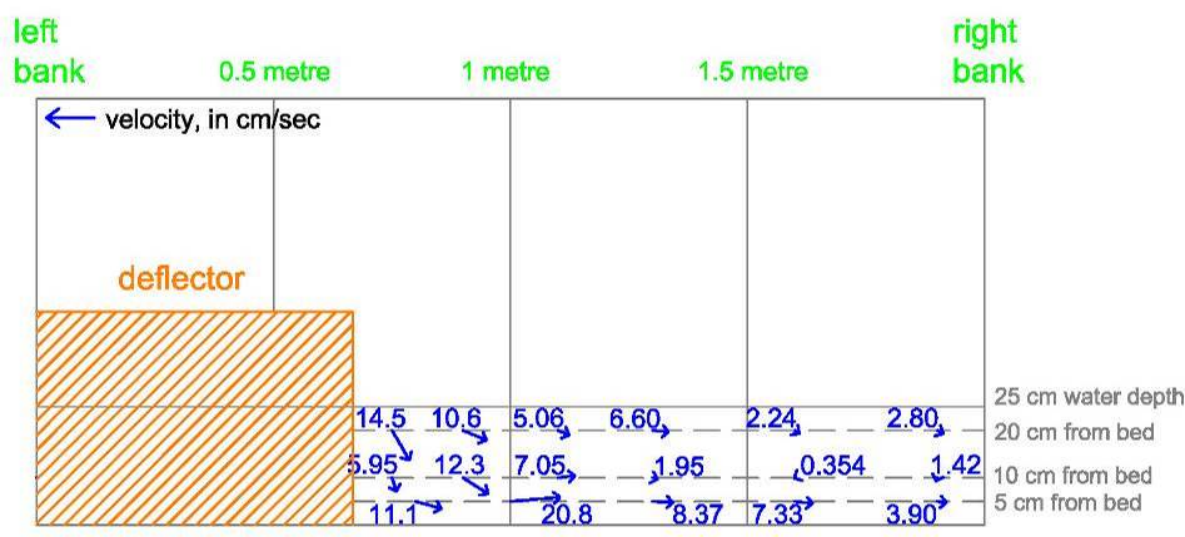

Velocities Mesured at Section mo (Middle of the Deflector)

Facing Downstream

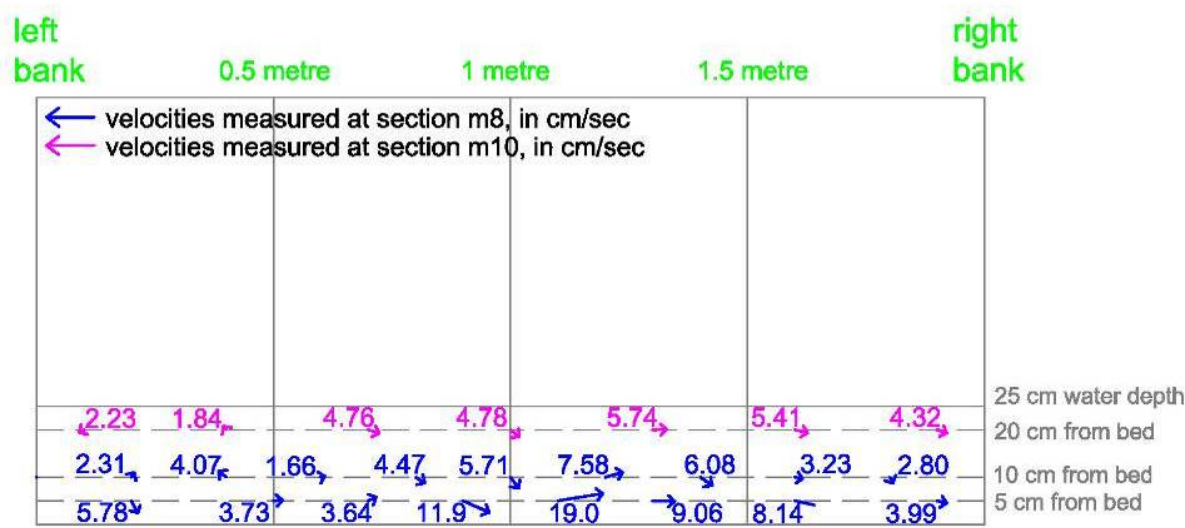

\section{Velocities Mesured at Sections Downstream of Deflector}

(Facing Downstream)

Figure P-8: Velocity Profile in yz-planes of Experiment \#B7 at the Meander Section. 


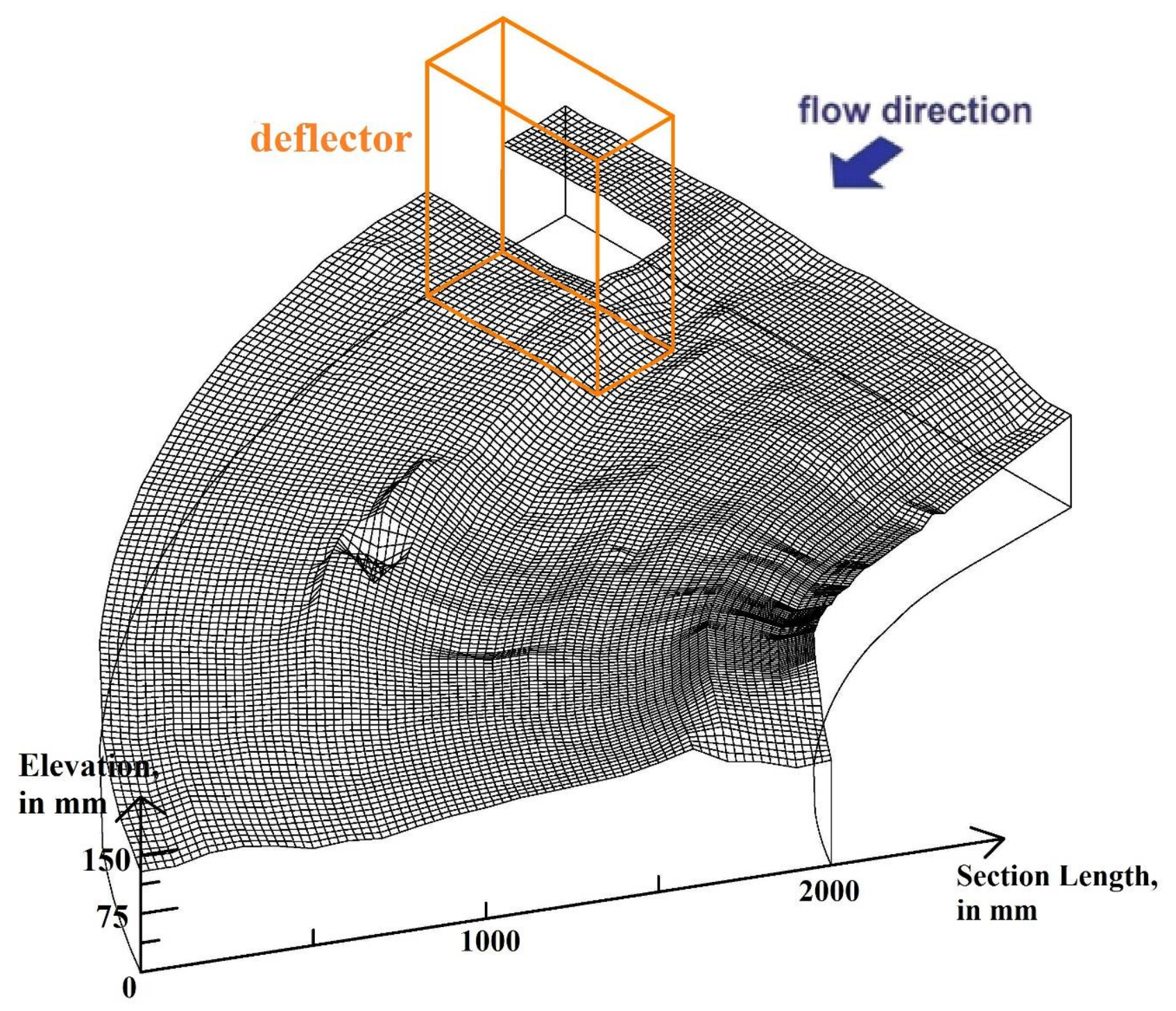

Figure P-9: Sediment Profile (3-D mesh) of Experiment \#B5 at time $=21$ hours. 


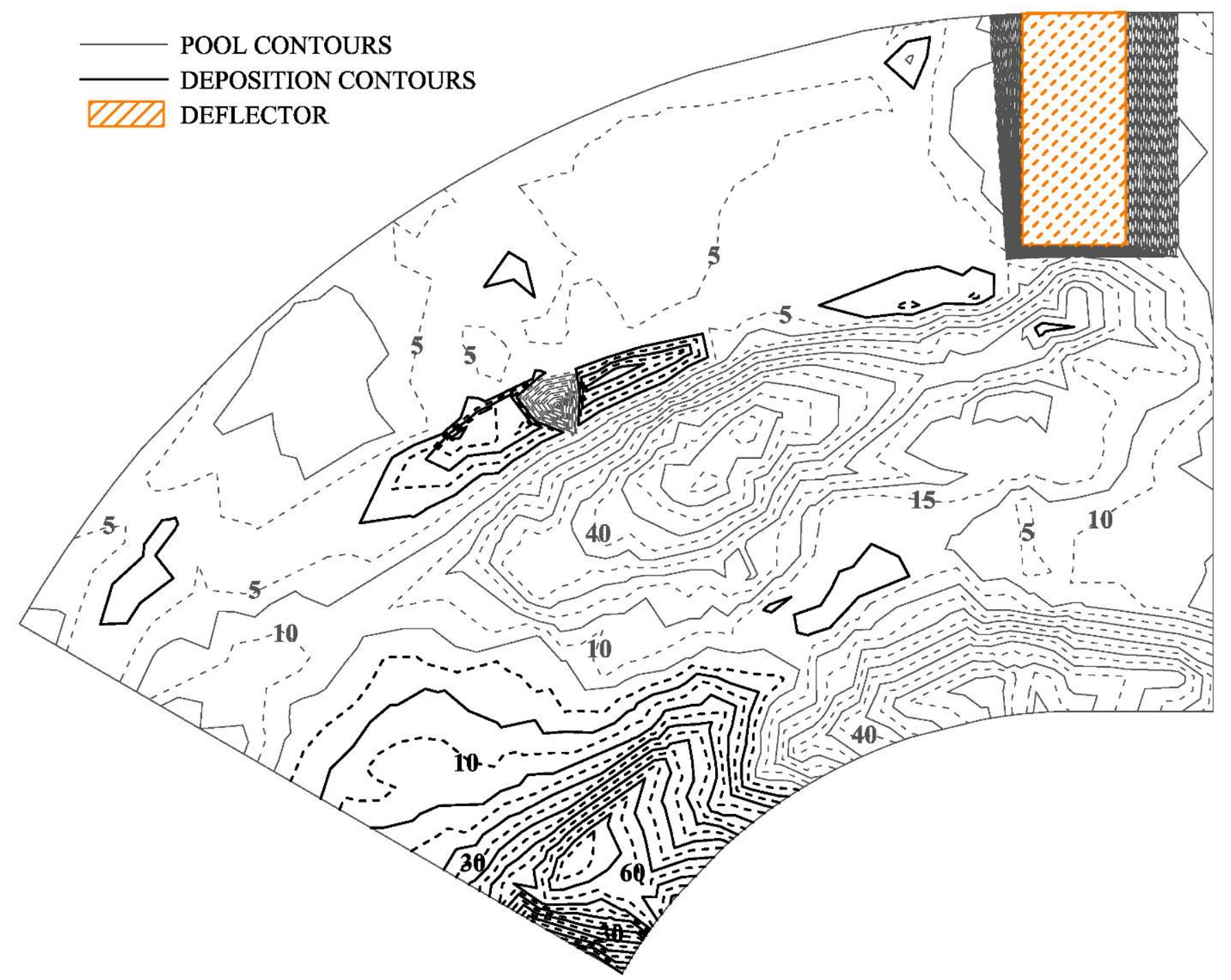

Figure P-10: Sediment Contours of Experiment \#B5 at time $=21$ hours. 


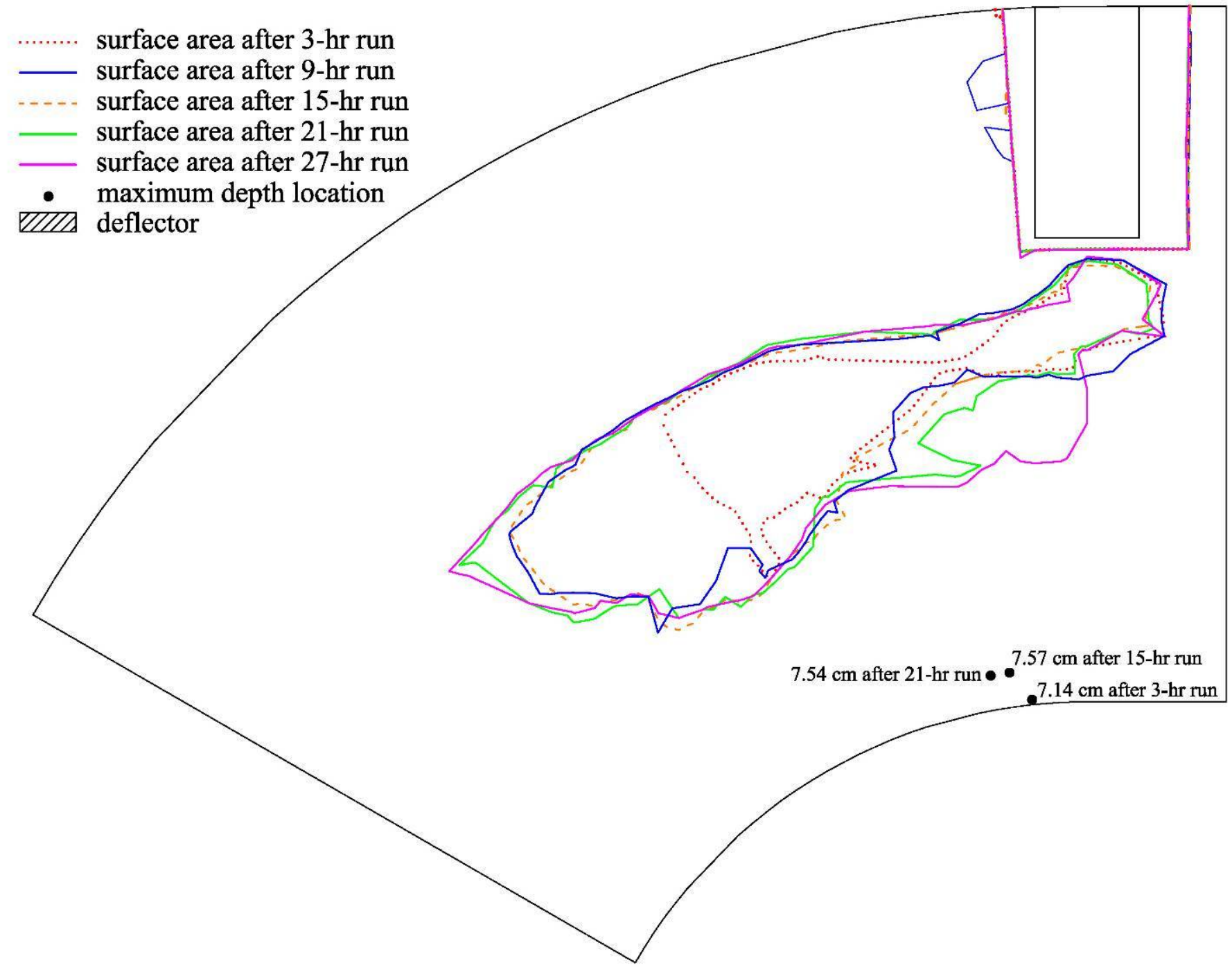

Figure P-11: Changes of Surface Areas of Pool Formation for Experiment \#B5 at Different Time. 


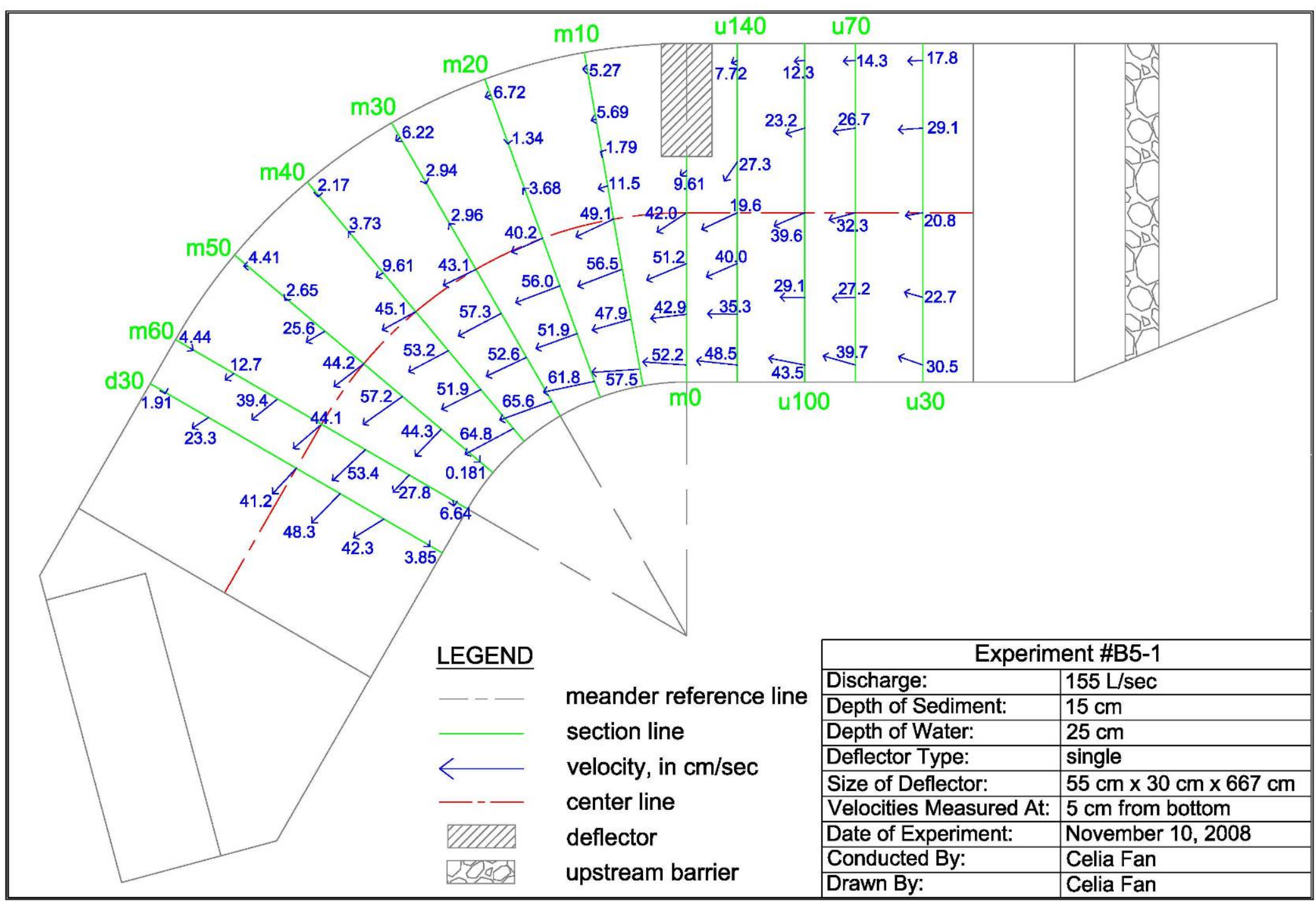

Figure P-12: Velocity Profile in $x y$-plane of Experiment \#B5 at 20\% Water Depth. 


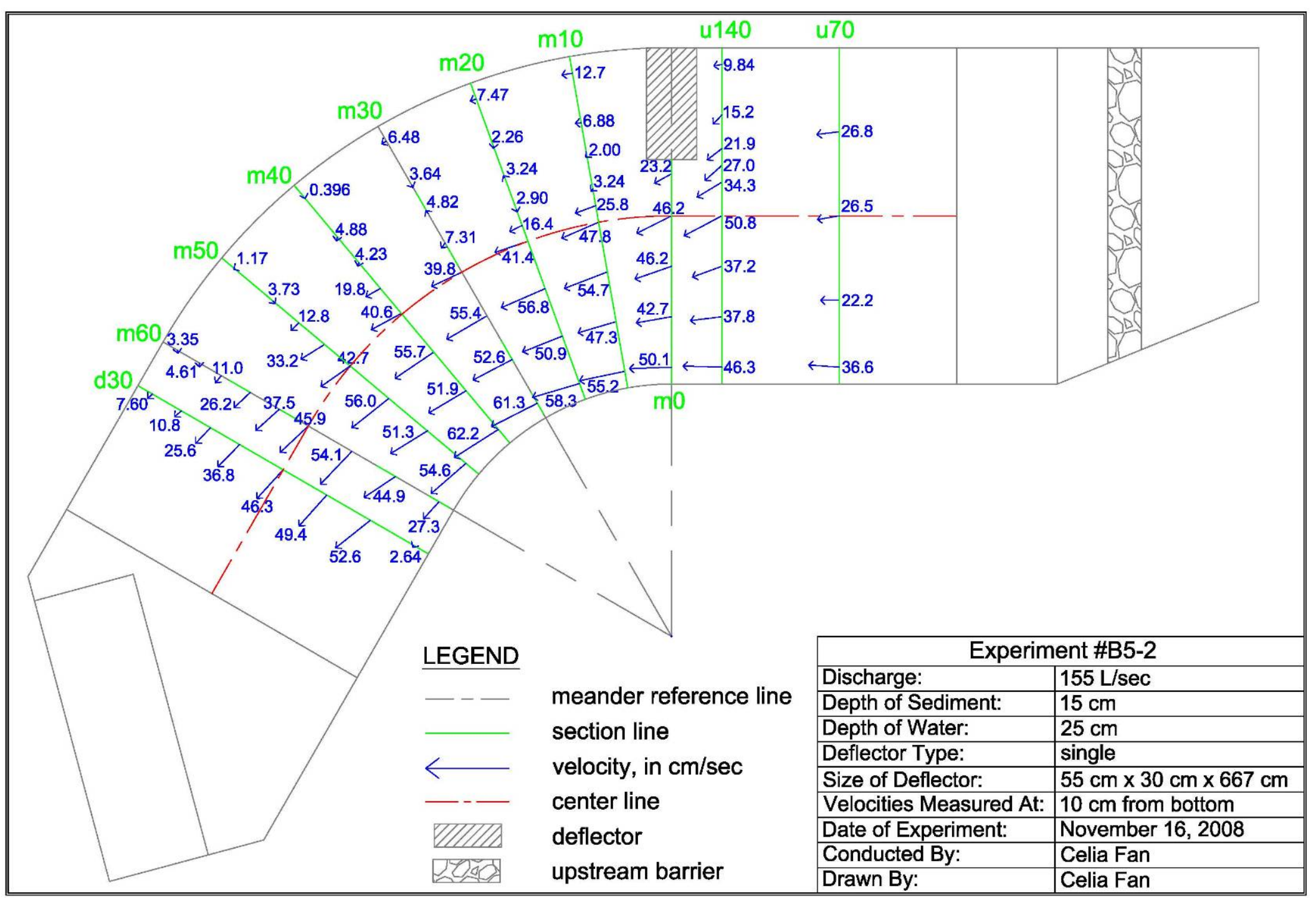

Figure P-13: Velocity Profile in $x y$-plane of Experiment \#B5 at 40\% Water Depth. 


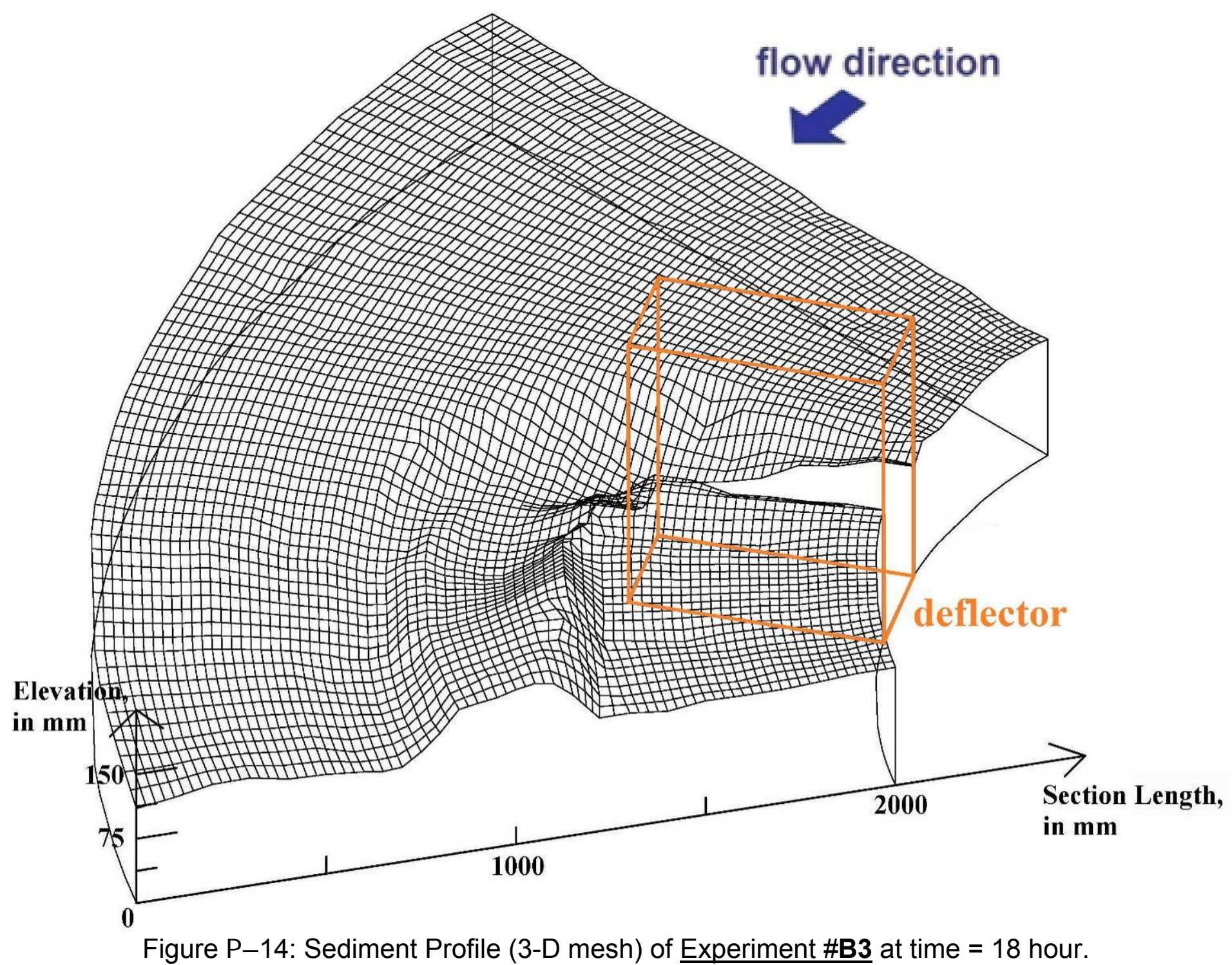

Figure P-14: Sediment Profile (3-D mesh) of Experiment \#B3 at time $=18$ hour. 


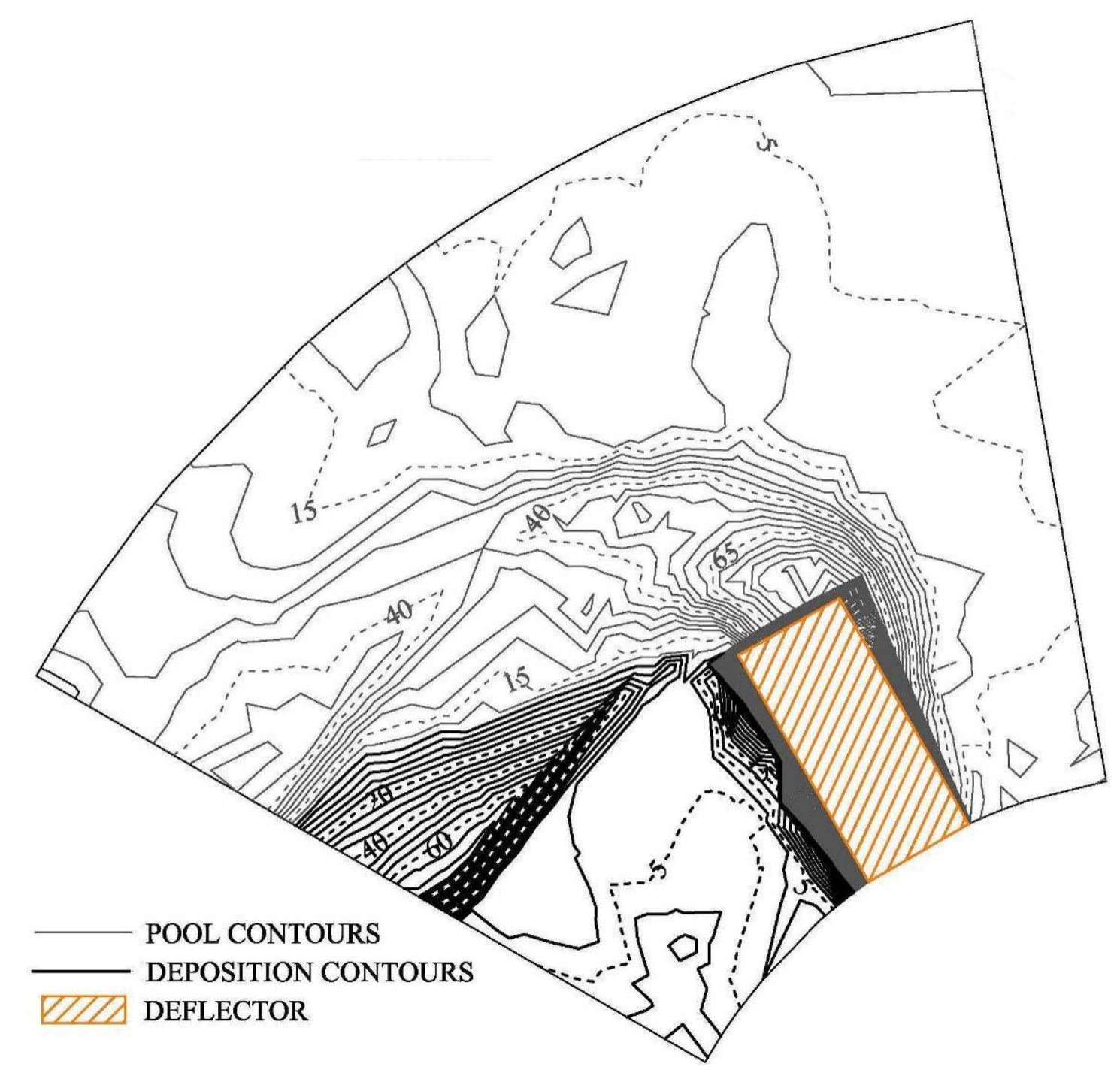

Figure P-15: Sediment Contours of Experiment \#B3 at time $=18$ hours. 
surface area after $3-\mathrm{hr}$ run surface area after $6-\mathrm{hr}$ run surface area after 9-hr run surface area after 12-hr run surface area after 18-hr run

- maximum depth location

WIIA deflector

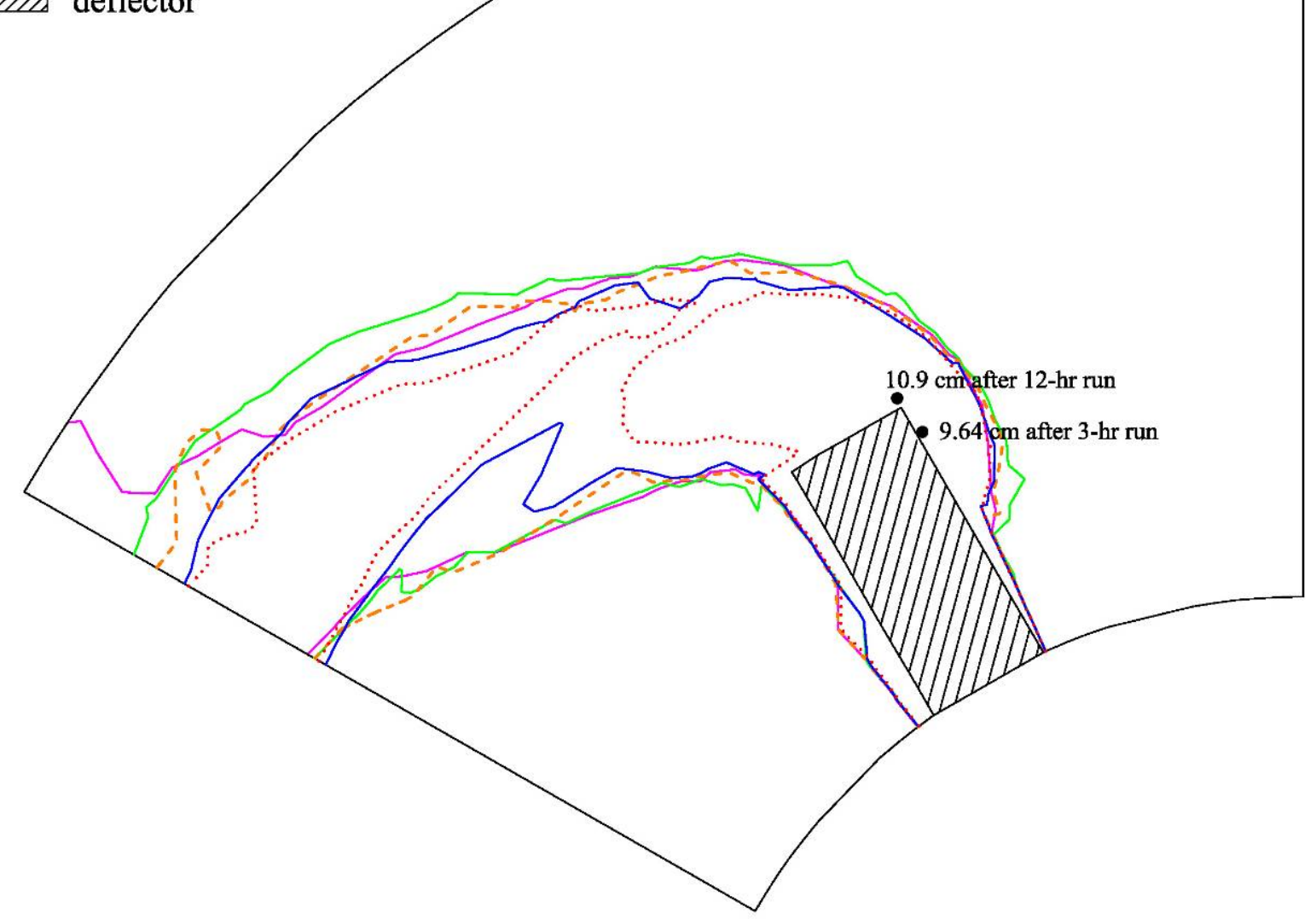

Figure P-16: Changes of Surface Areas of Pool Formation for Experiment \#B3 at Different Time. 


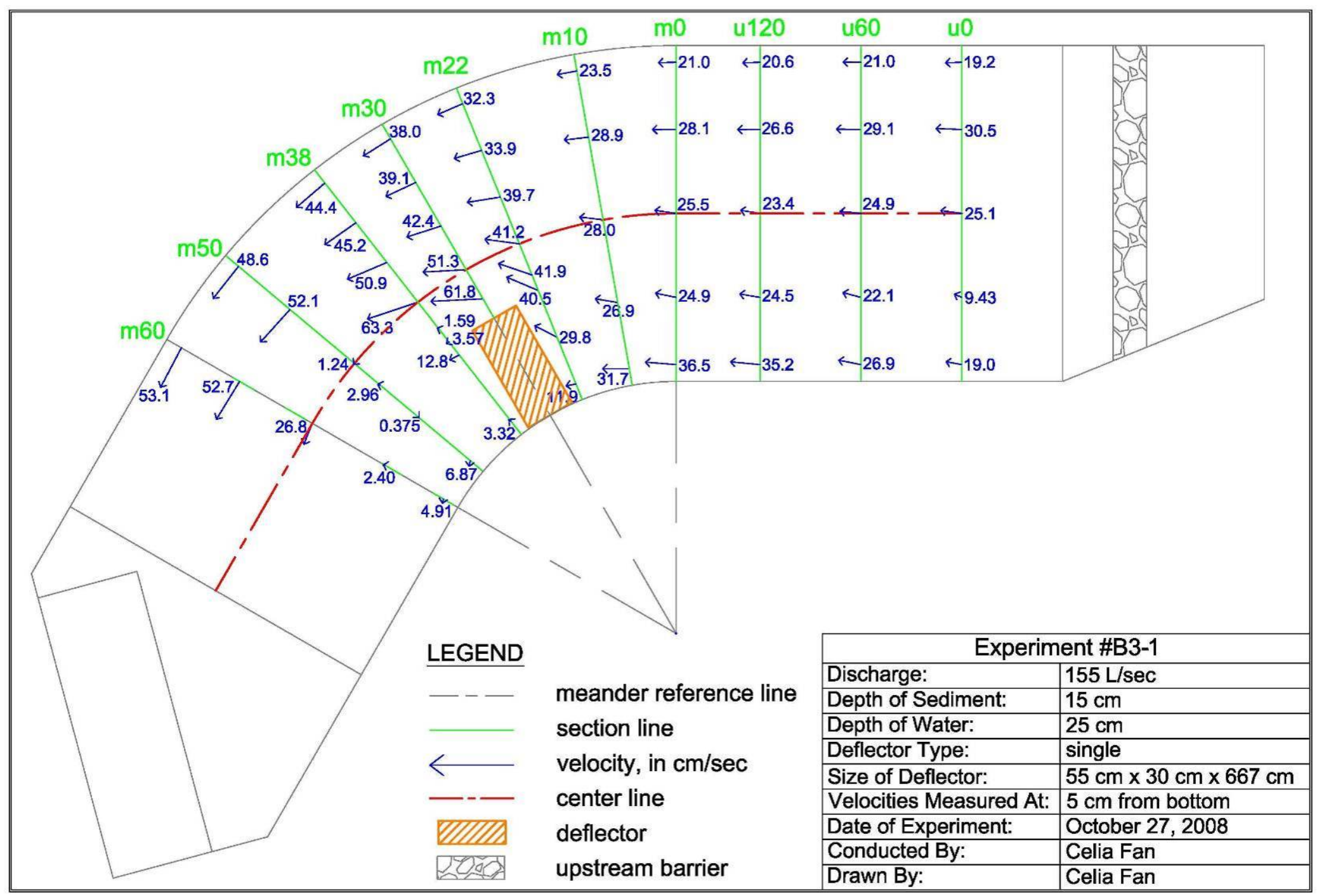

Figure P-17: Velocity Profile in $x y$-plane of Experiment \#B3 at 20\% Water Depth. 


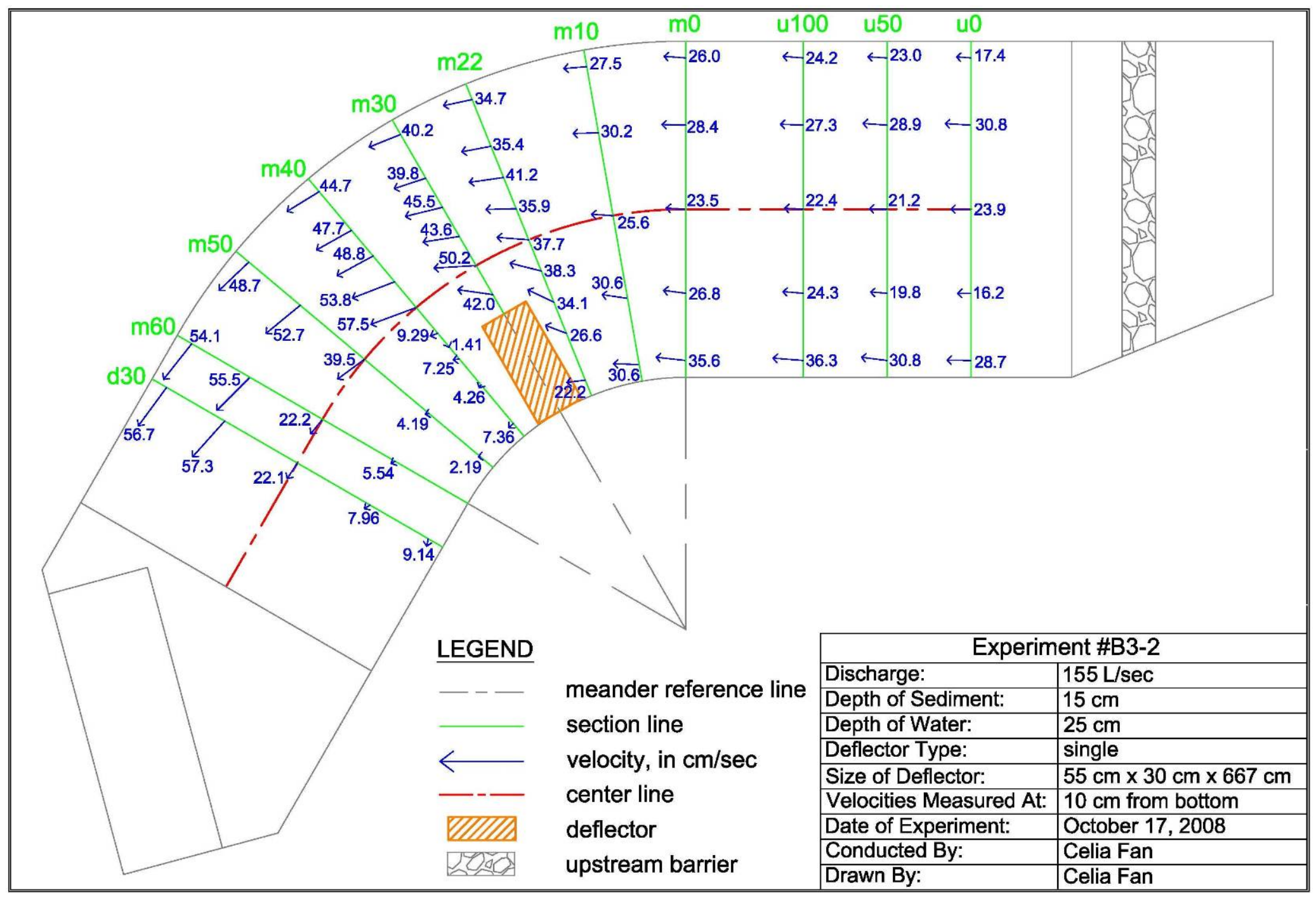

Figure P-18: Velocity Profile in $x y$-plane of Experiment \#B3 at 40\% Water Depth. 


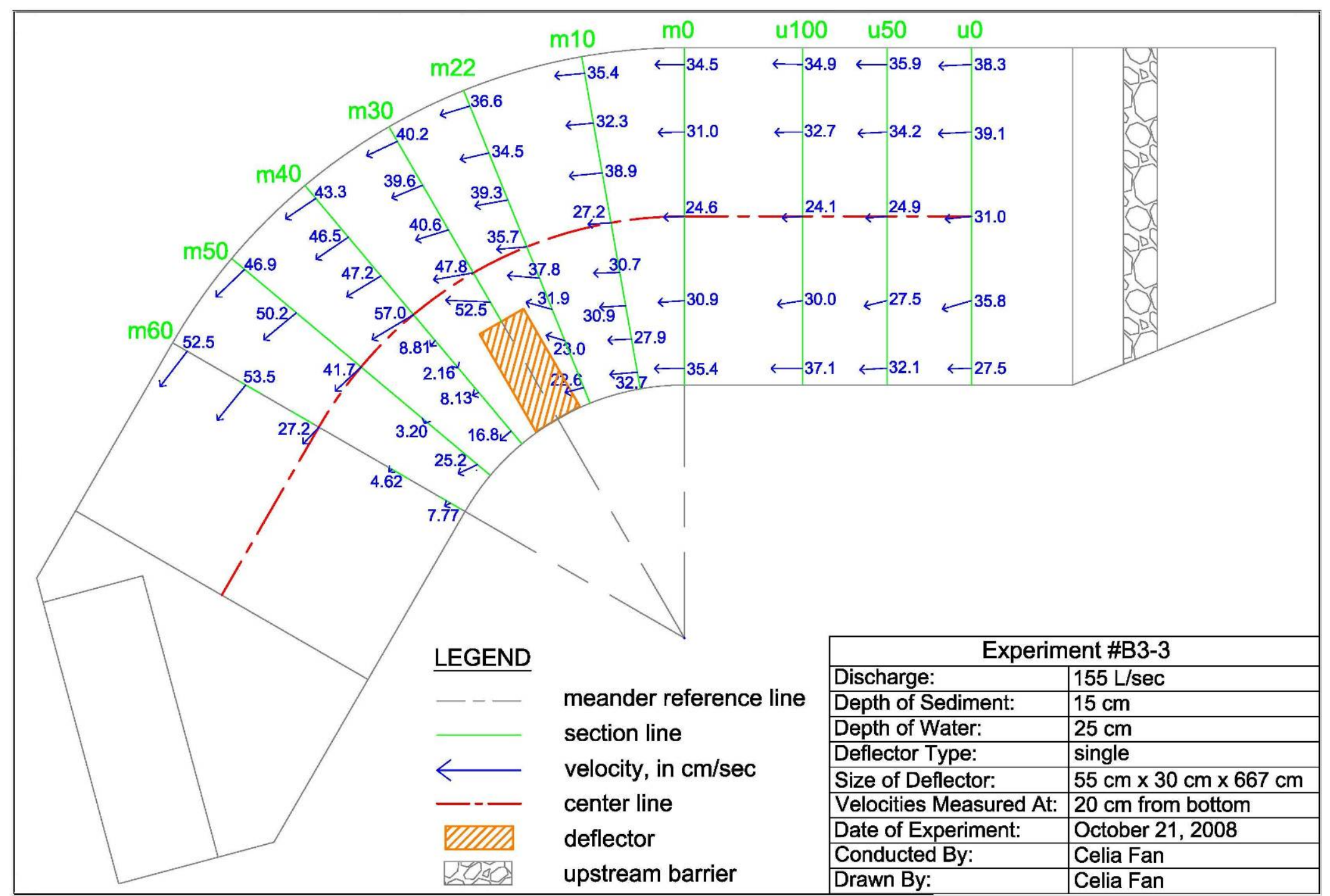

Figure P-19: Velocity Profile in $x y$-plane of Experiment \#B3 at 80\% Water Depth. 

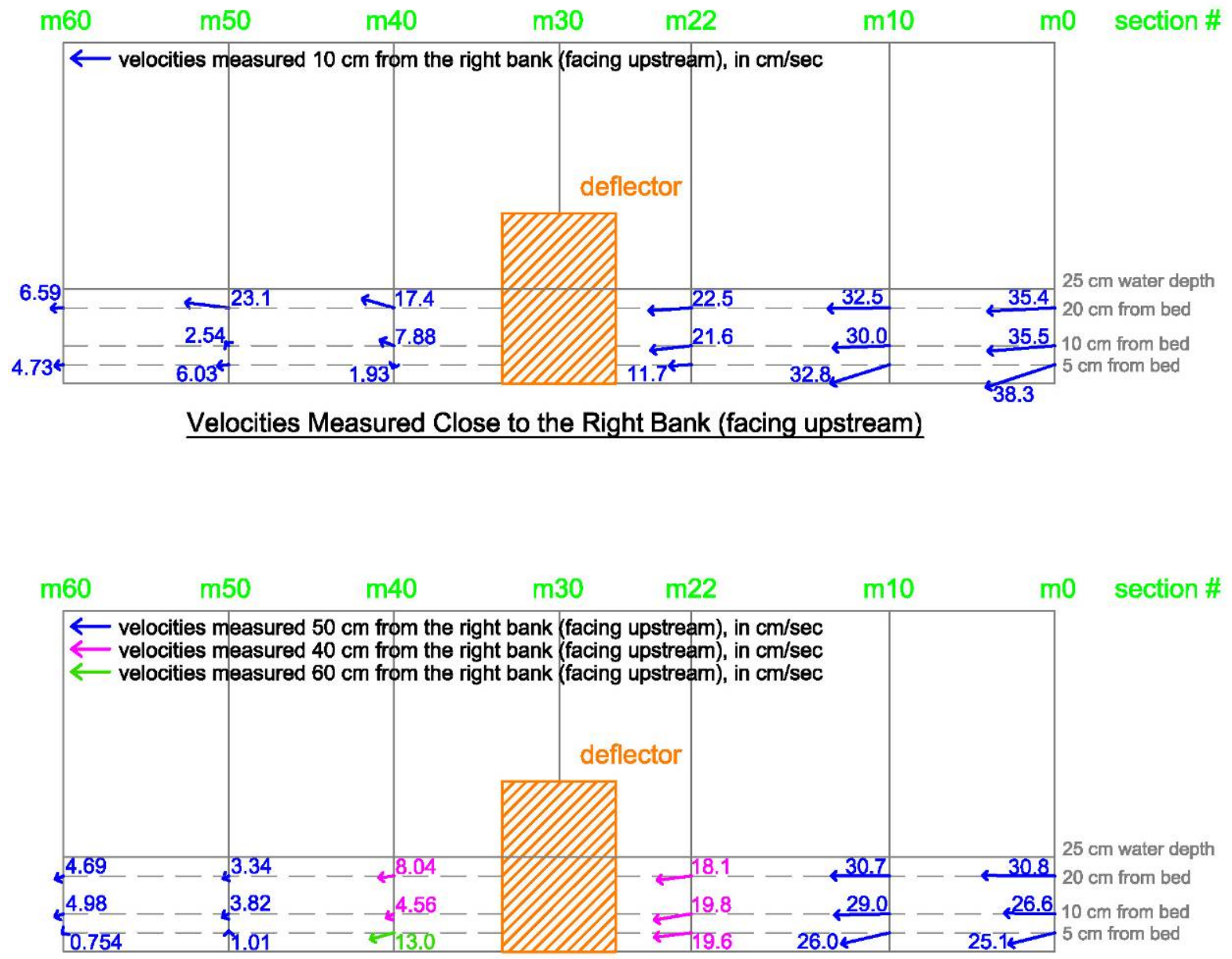

Velocities Measured around the Middle of the Deflector

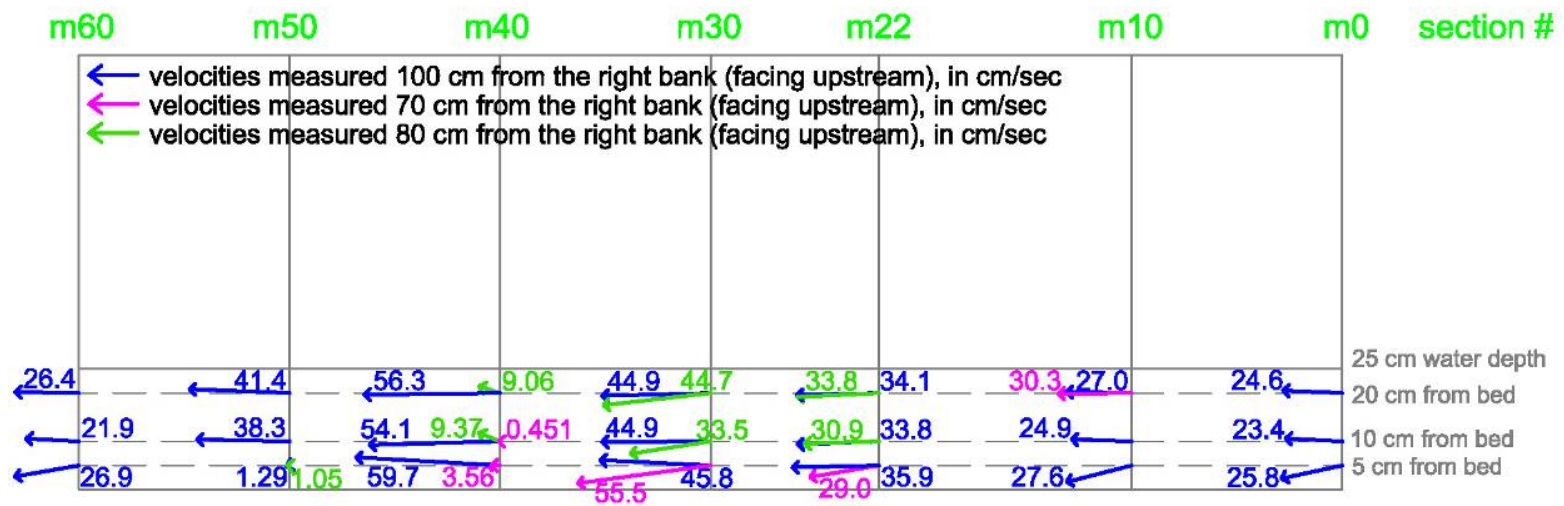

\section{Velocities Measured Around the Tip of the Deflector}

Figure P-20: Velocity Profile in xz-plane of Experiment \#B3 at the Meander Section. 


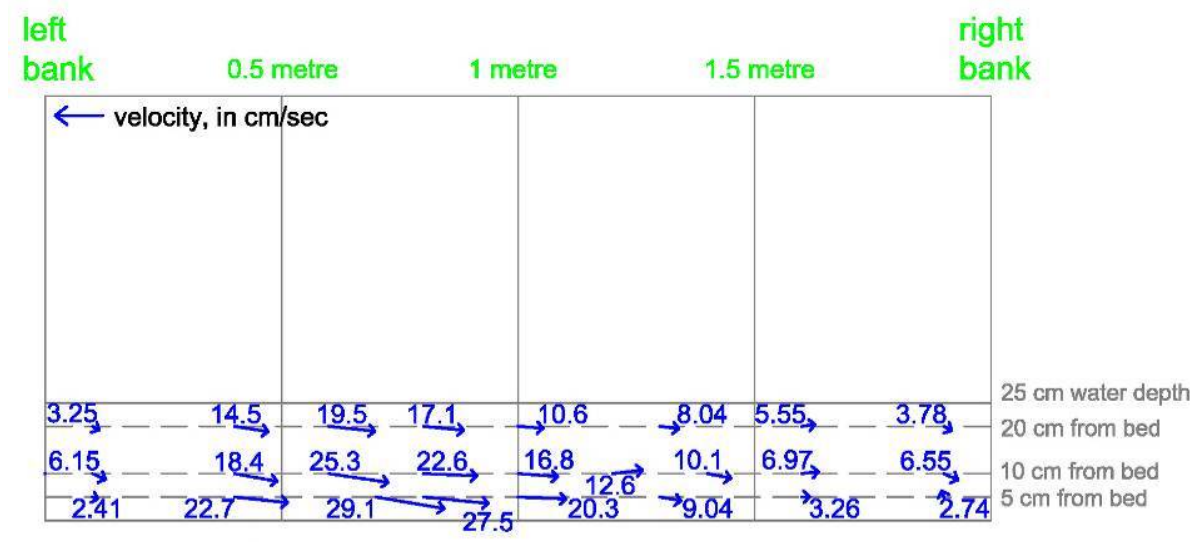

Velocities Mesured at Section m22 (Just Before the Deflector) Facing Downstream

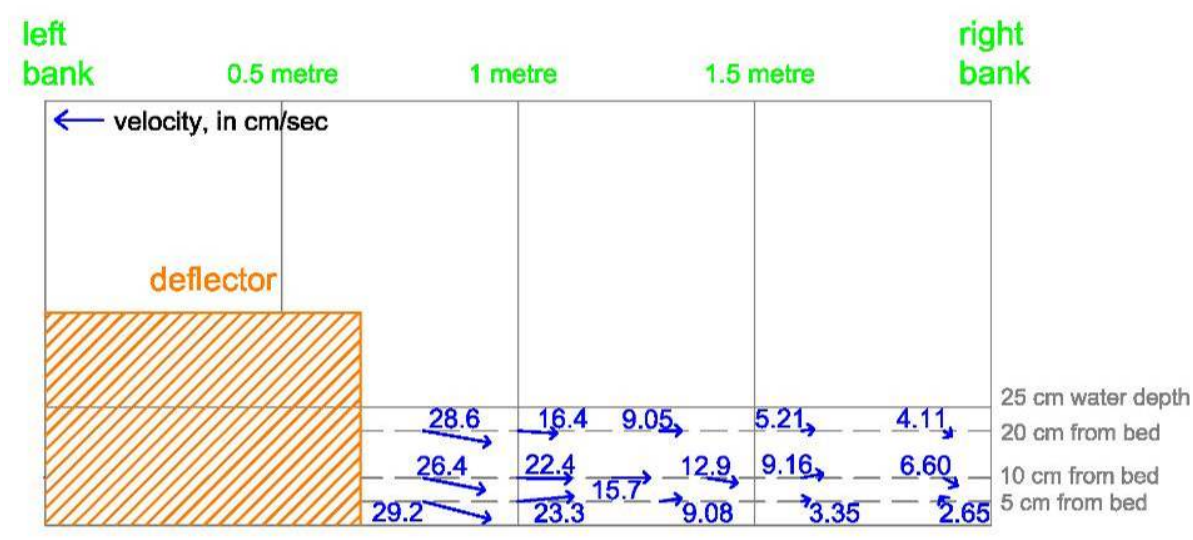

\section{Velocities Mesured at Section m30 (Middle of the Deflector)}

\section{Facing Downstream}

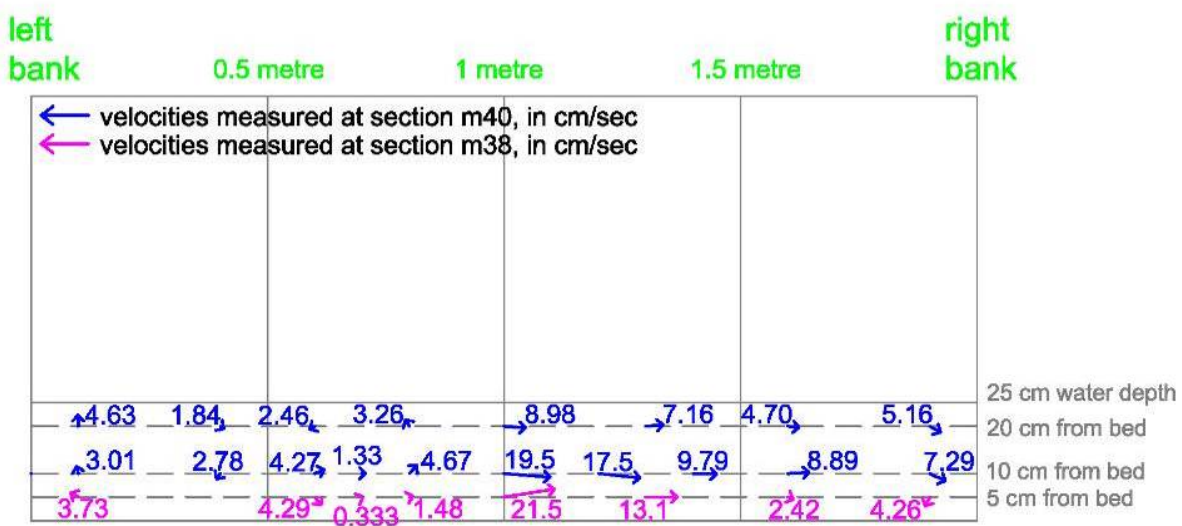

Velocities Mesured at Sections Downstream of Deflector (Facing Downstream)

Figure P-21: Velocity Profile in yz-plane of Experiment \#B3 at the Meander Section. 


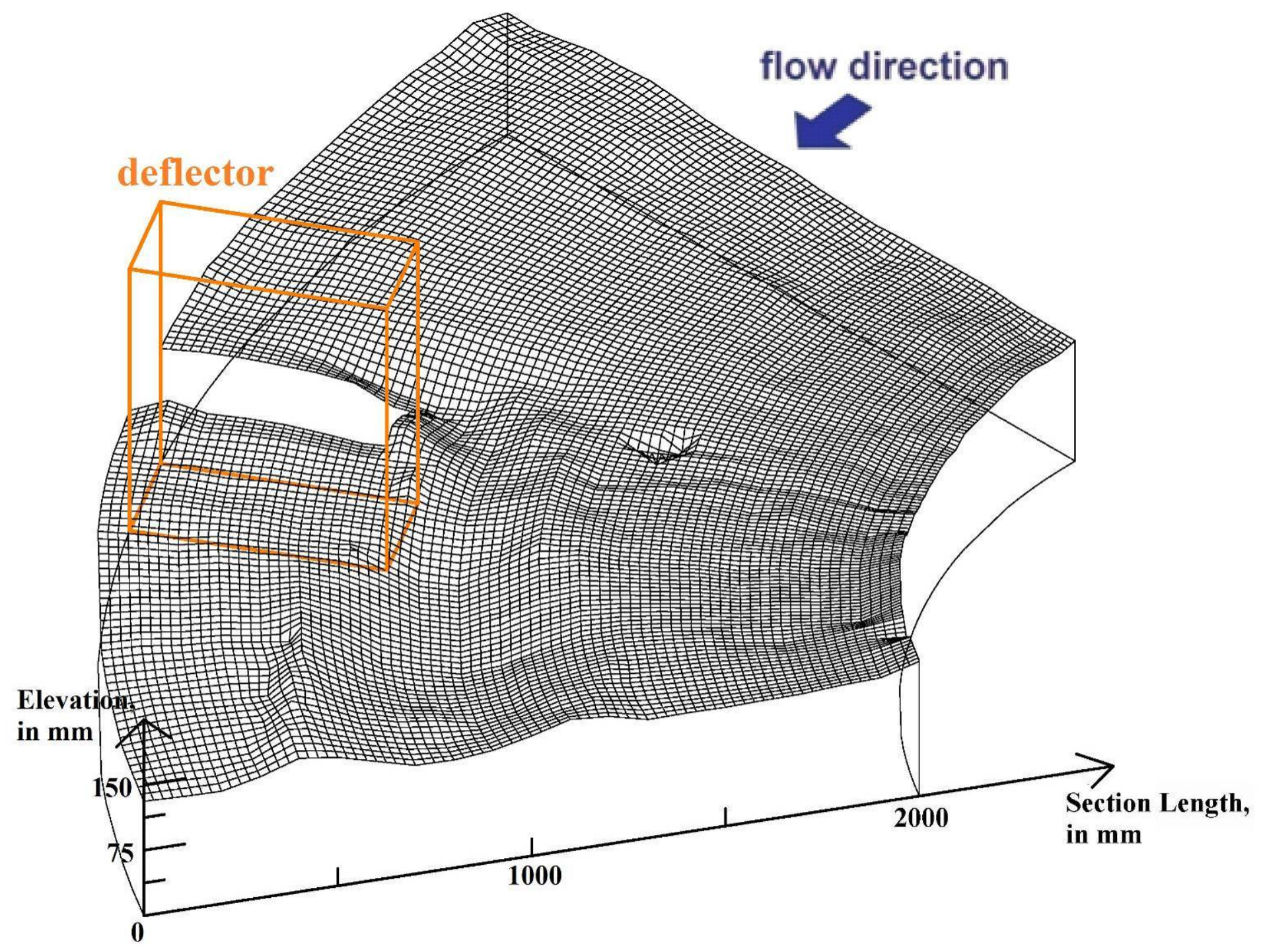

Figure P-22: Sediment Profile (3-D mesh) of Experiment \#B1 at time $=21$ hours. 


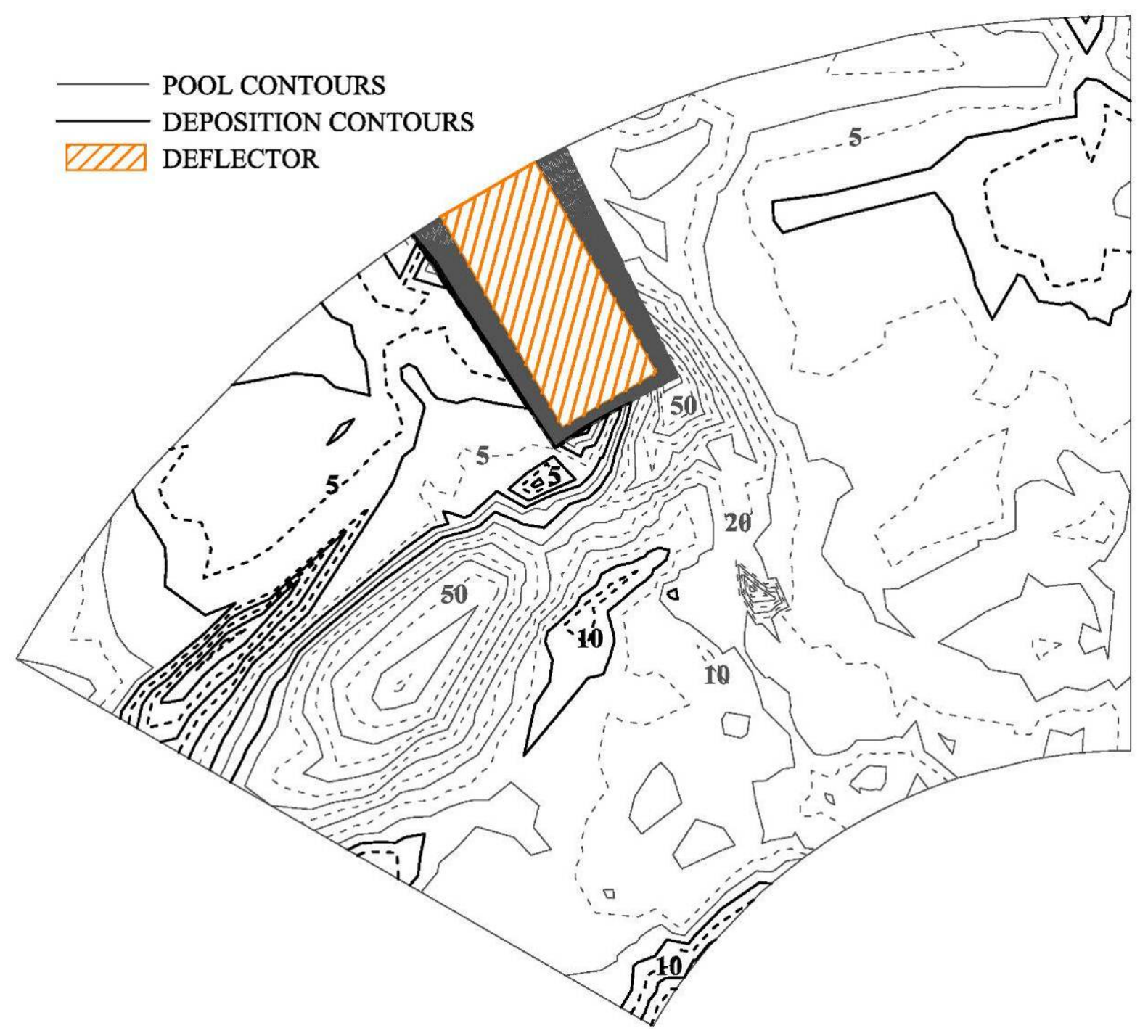

Figure P-23: Sediment Contours of Experiment \#B1 at time $=21$ hours. 


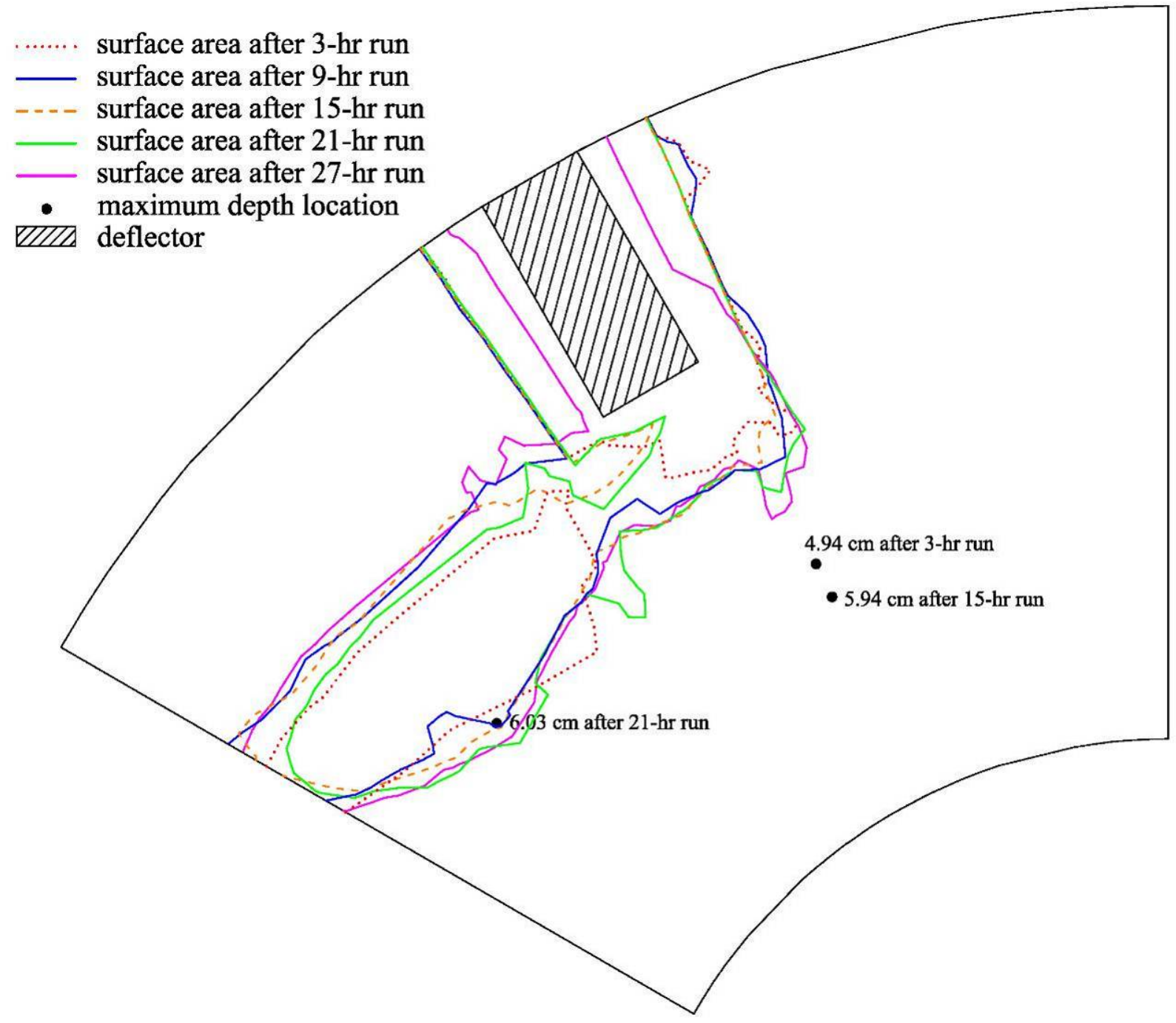

Figure P-24: Changes of Surface Areas of Pool Formation for Experiment \#B1 at Different Time. 


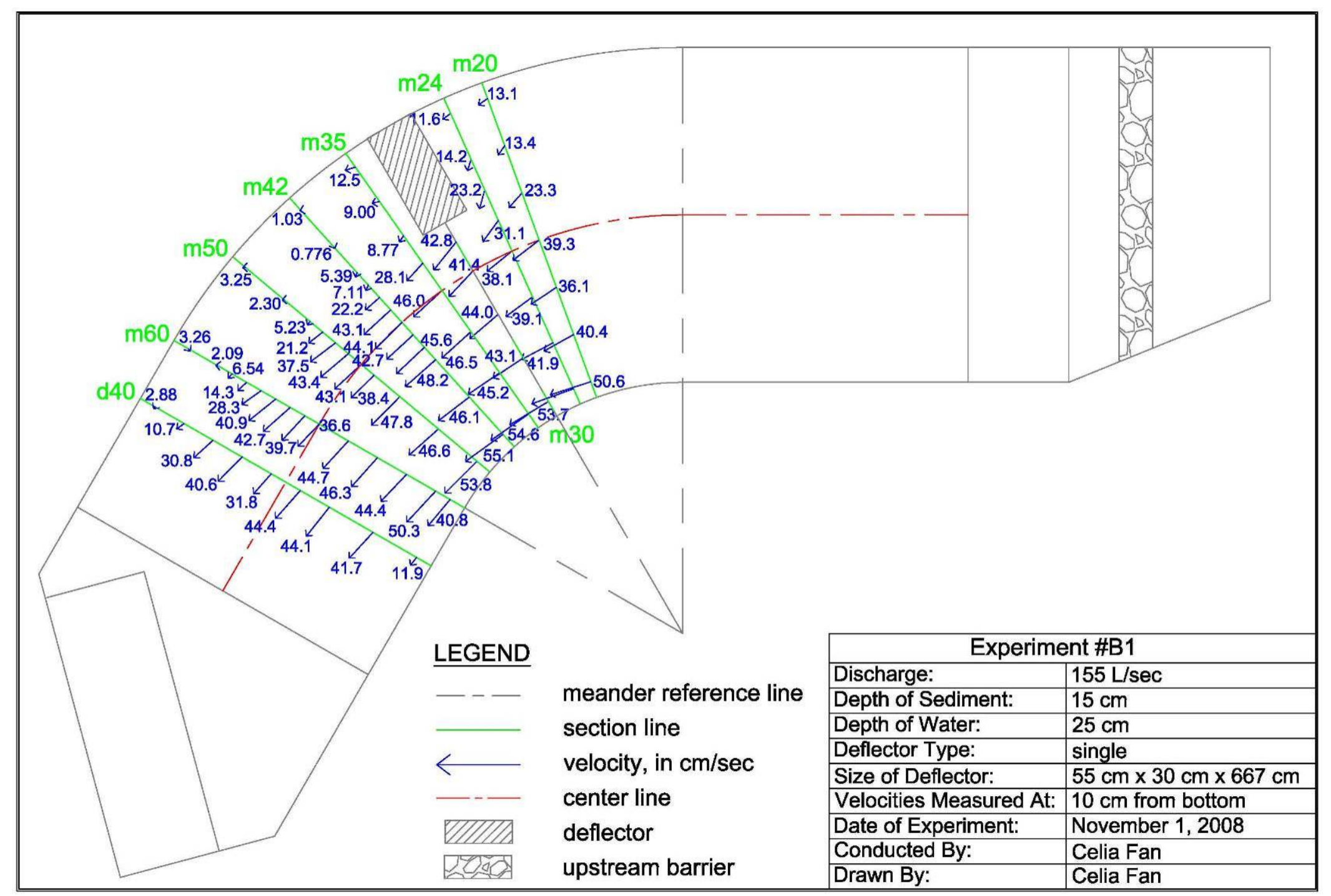

Figure P-25: Velocity Profile of Experiment \#B1 at 40\% Water Depth. 


\section{APPENDIX Q}

\section{Experimental Results of Double Deflector Scenarios for Wet Weather Conditions \\ Without Incoming Sediment}




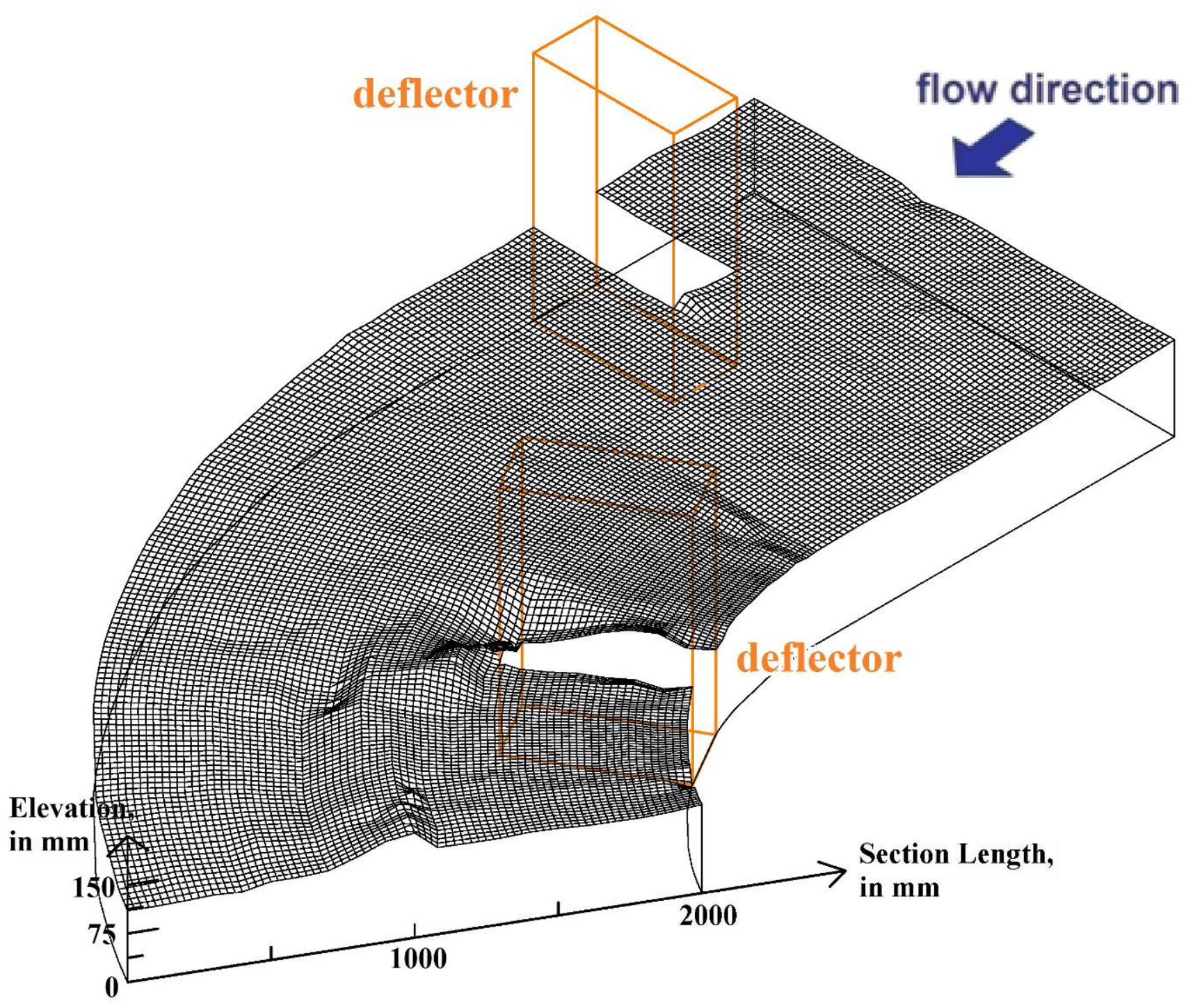

Figure Q- 1: Sediment Profile (3-D mesh) of Experiment \#B9a at time $=10$ hours. 


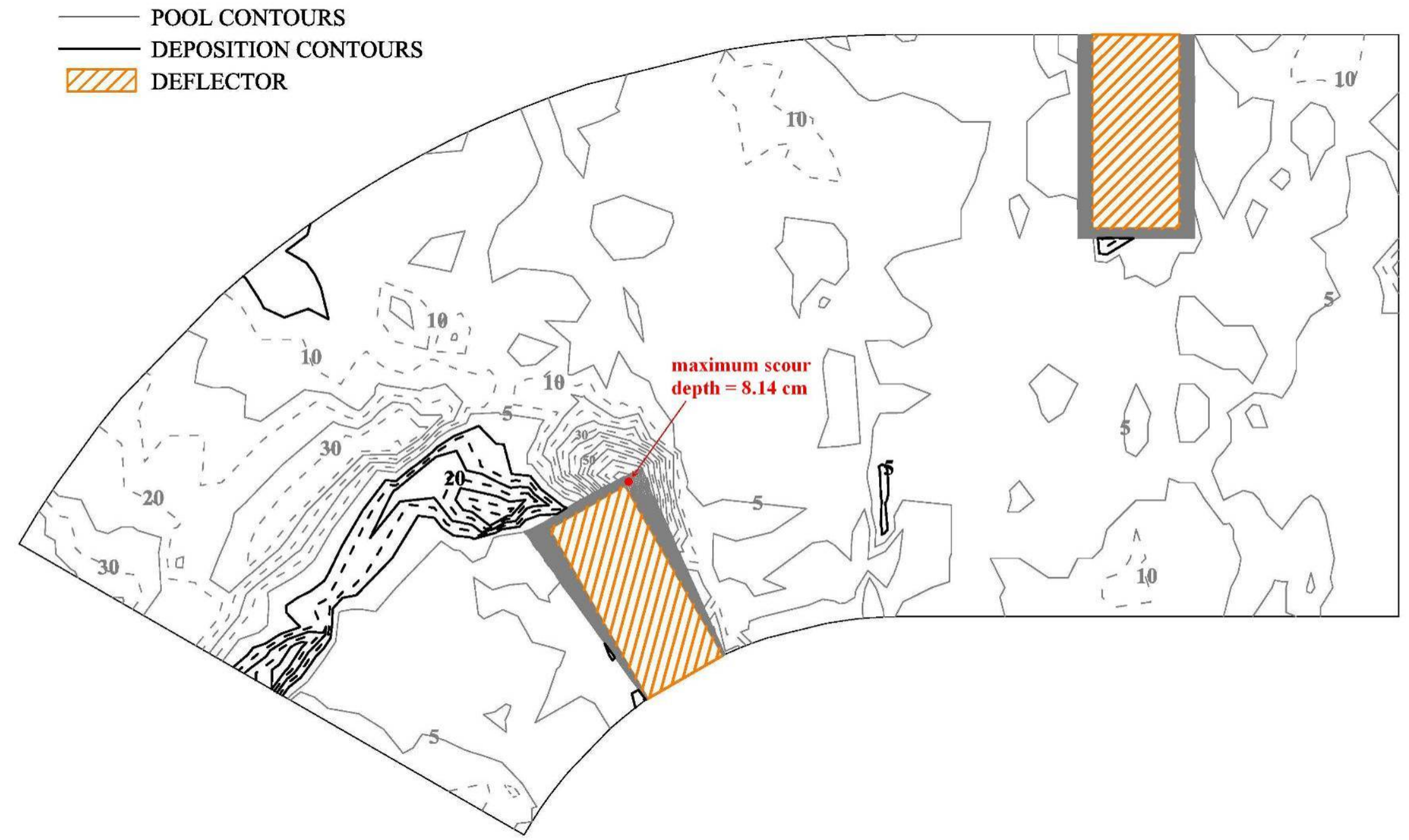

Figure Q-2: Sediment Contours of Experiment \#B9a at time $=10$ hours. 


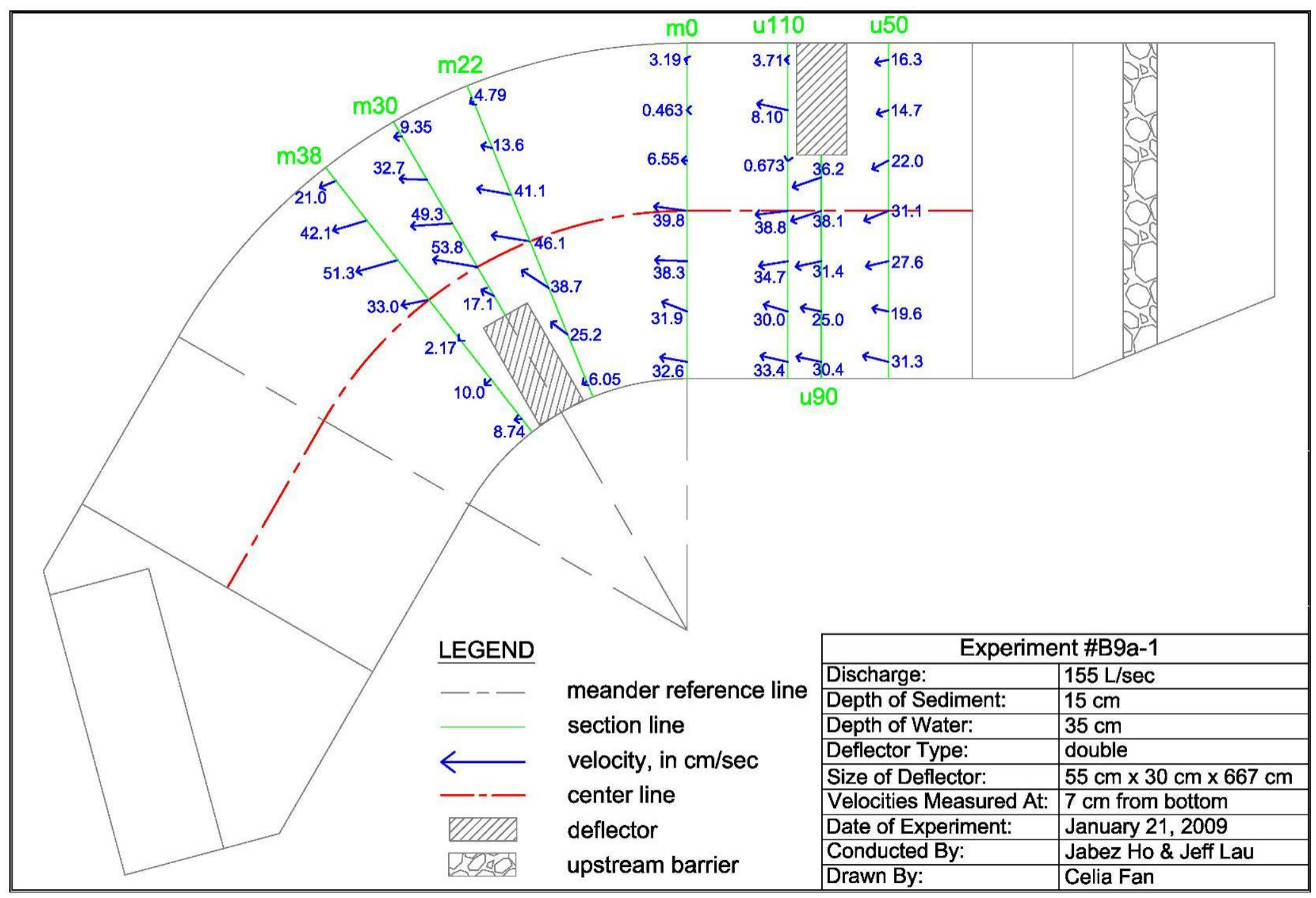

Figure Q-3: Velocity Profile in xy-plane of Experiment \#B9a at 20\% Water Depth. 


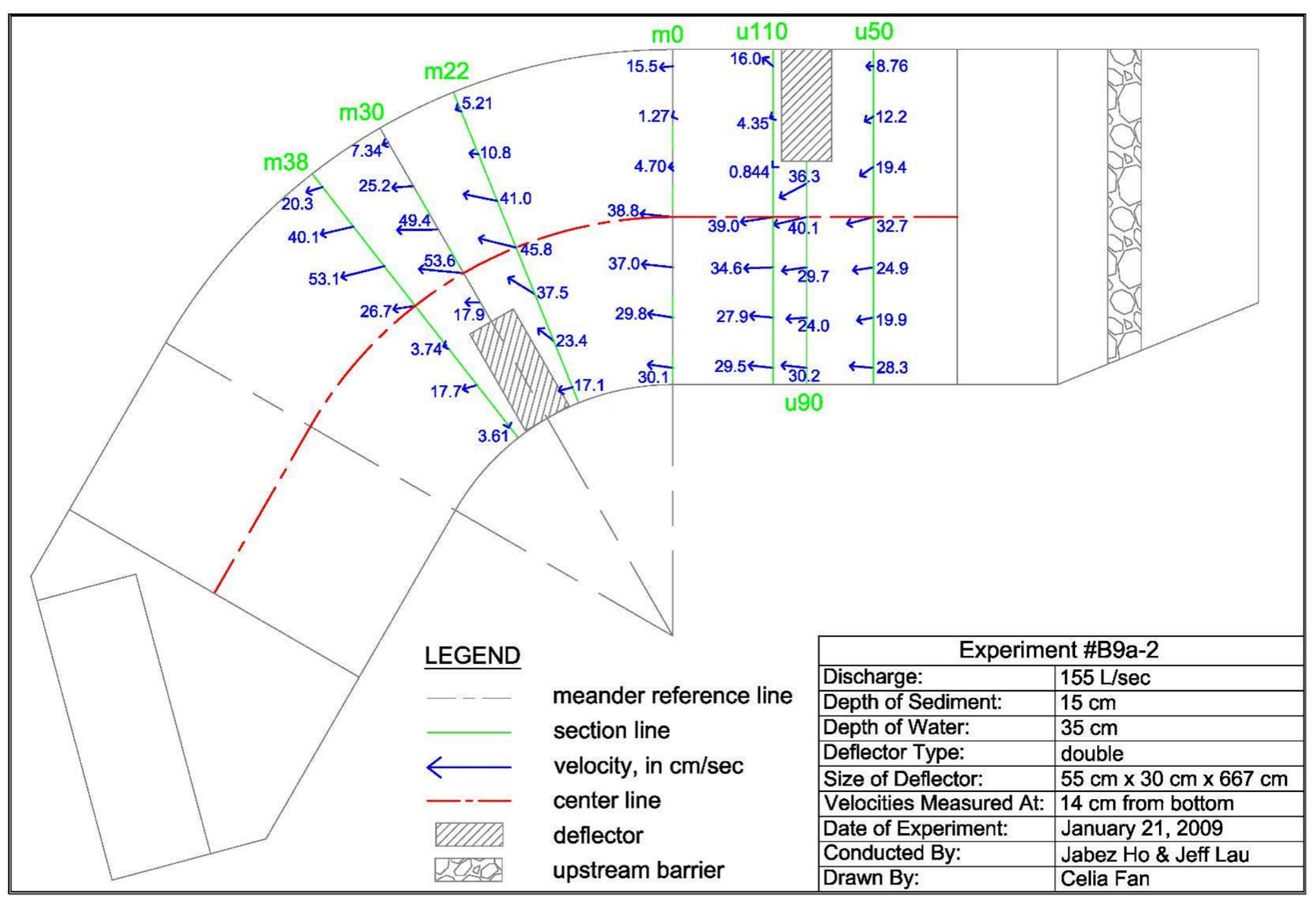

Figure Q- 4: Velocity Profile in xy-plane of Experiment \#B9a at 40\% Water Depth. 


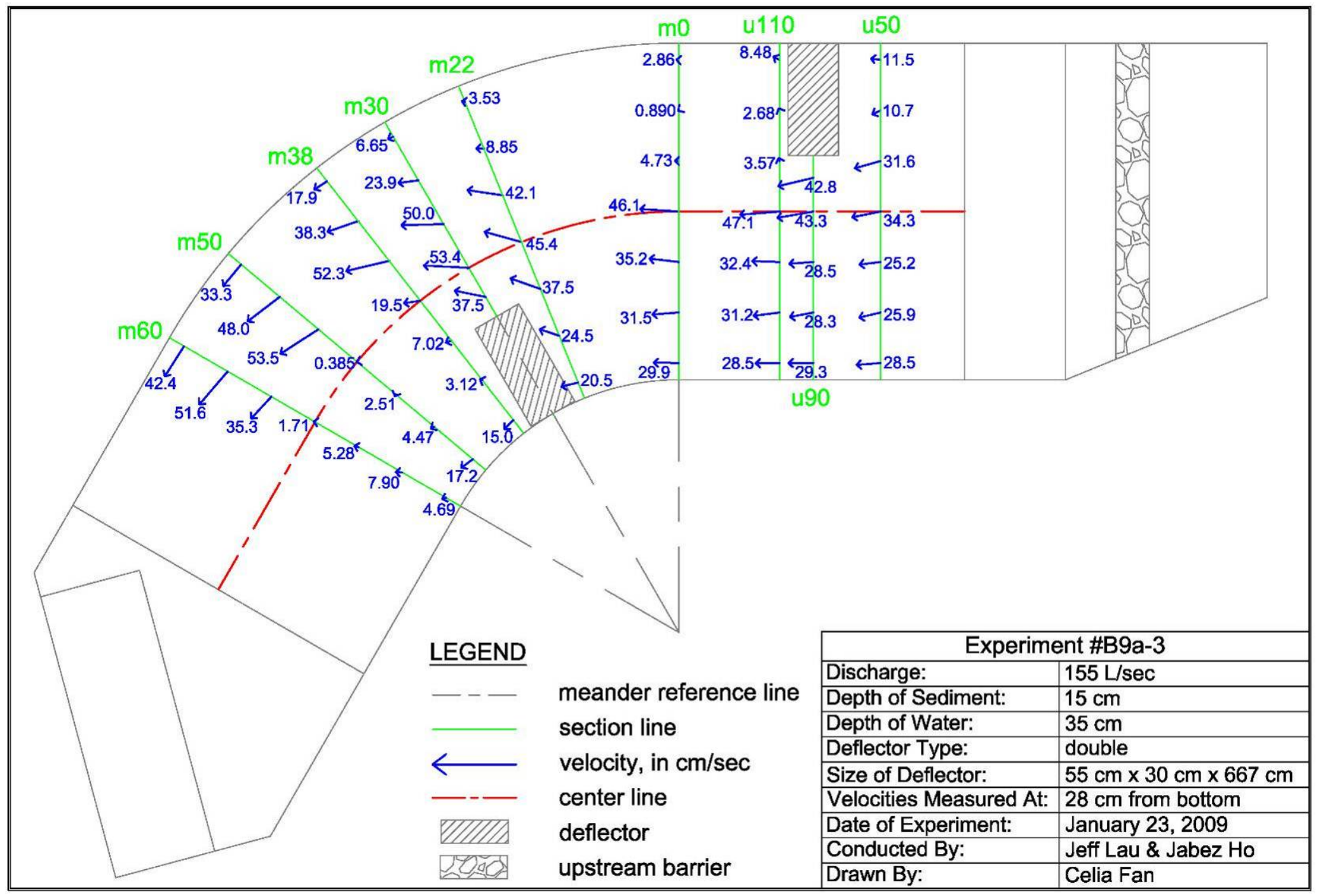

Figure Q-5: Velocity Profile in xy-plane of Experiment \#B9a at 80\% Water Depth. 


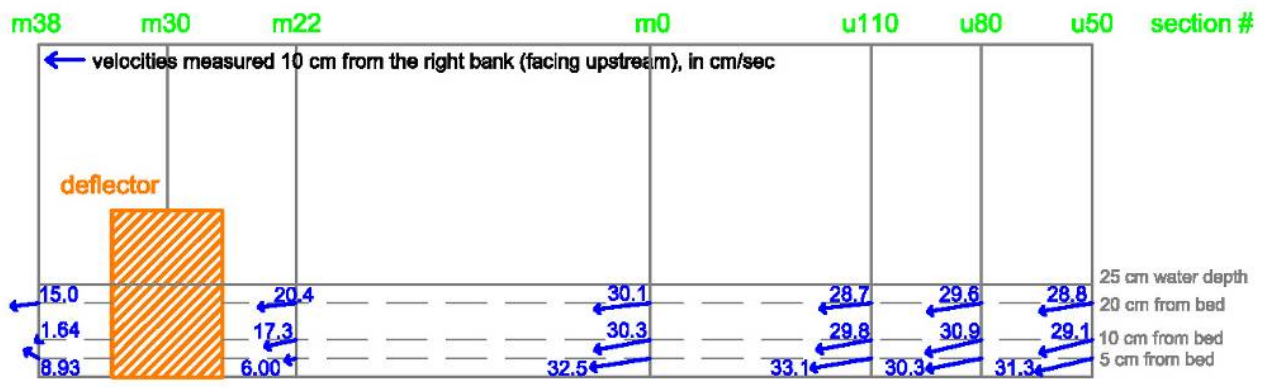

Flow Path Measured Close to the Right Bank (facing upstream)

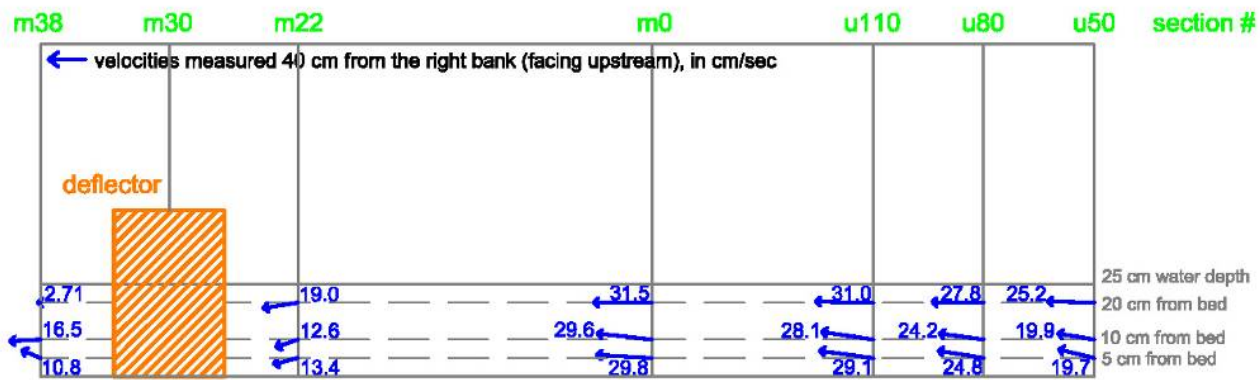

Flow Path Measured Along Midway of the Downstream Deflector (facing upstream)

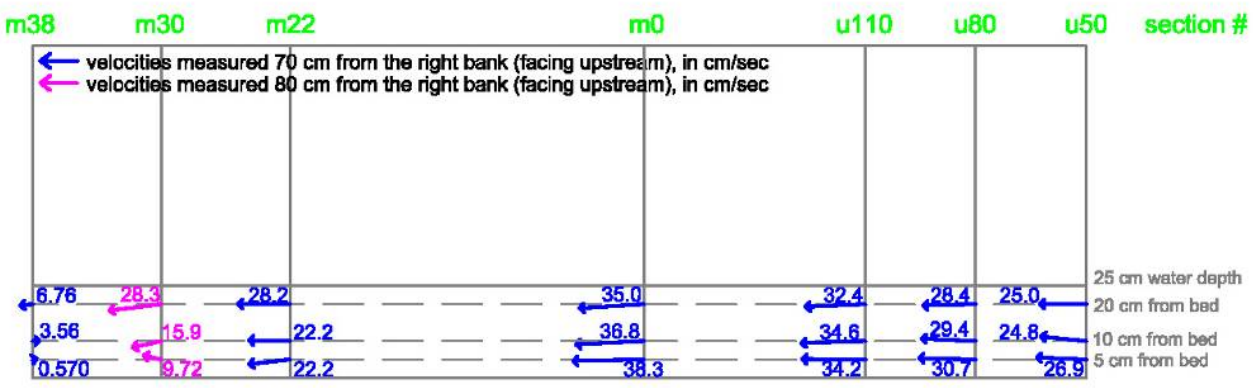

Flow Path Measured Along the Tip of the Downstream Deflector (facing upstream)

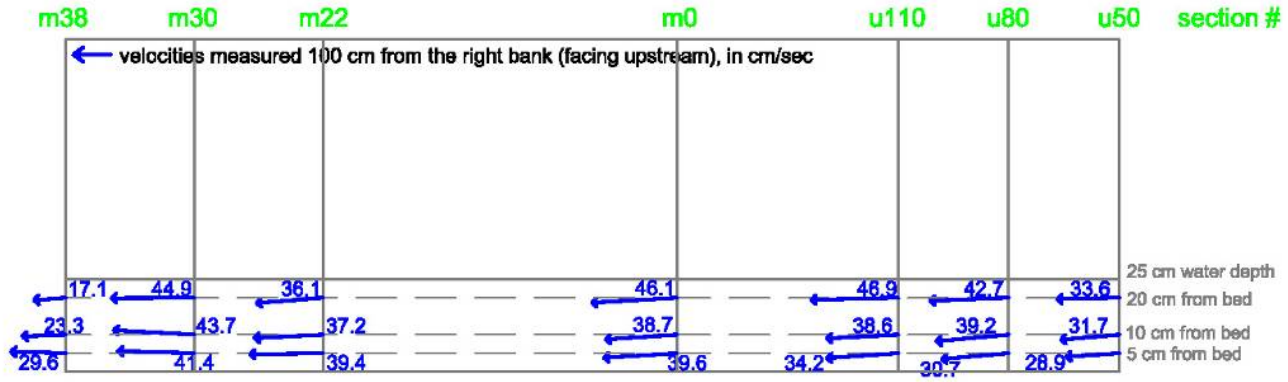

Flow Path Measured at the Centre of the Channel

Figure Q-6: Velocity Profile in xz-plane of Experiment \#B9a at the Meander Section. 


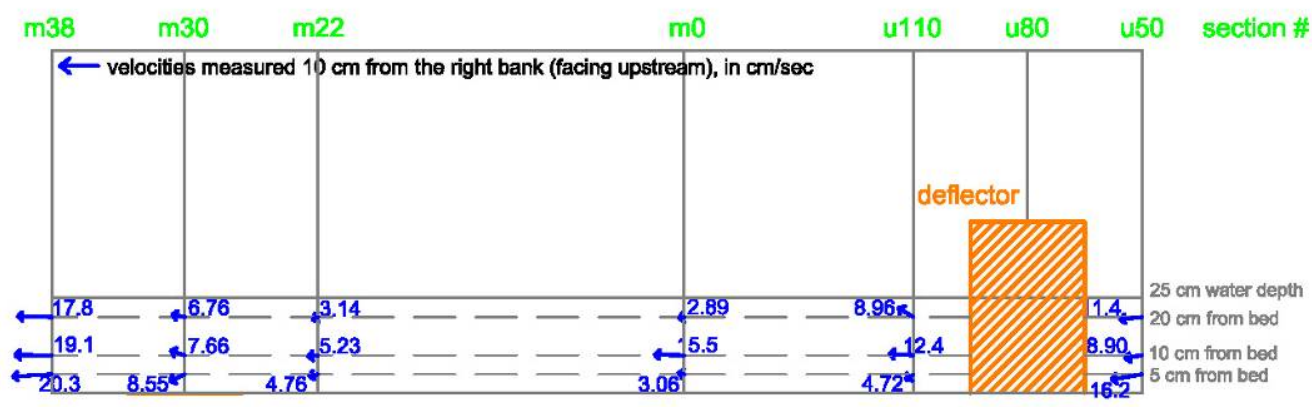

Flow Path Measured Close to the Left Bank (facing upstream)

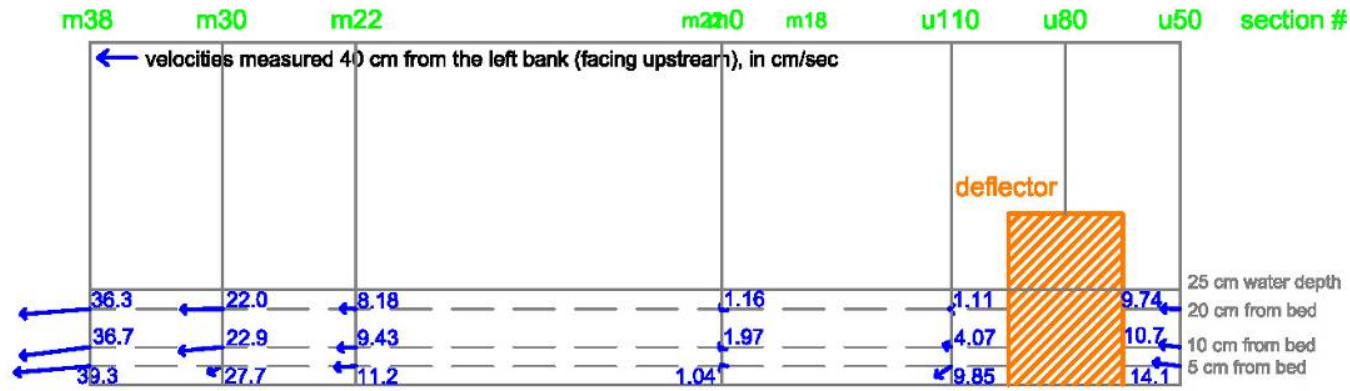

Flow Path Measured around the Middle of the Deflector

Locating at the Left Bank (facing upstream)

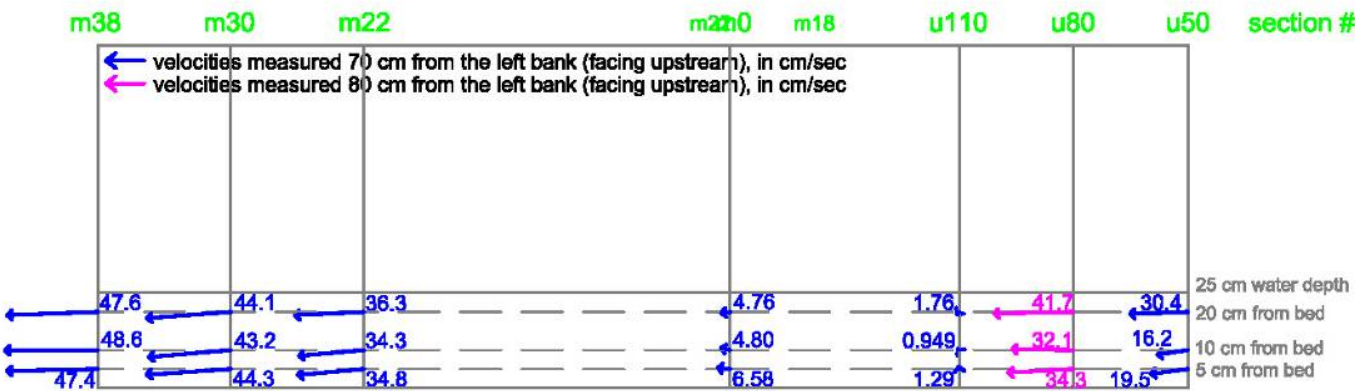

Flow Path Measured Around the Tip of the Deflector Locating at the Left Bank (Facing Upstream)

Figure Q-7: Velocity Profile in xz-plane (cont.) of Experiment \#B9a at the Meander Section. 


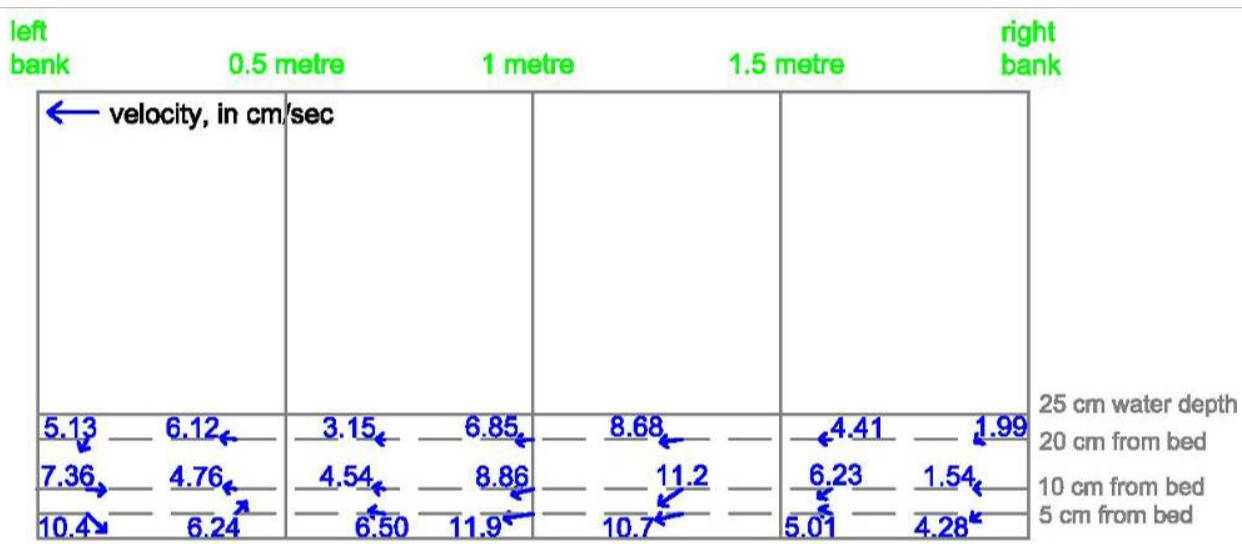

Velocities Mesured at Section u50

(Just Before the Upstream Deflector) Facing Downstream

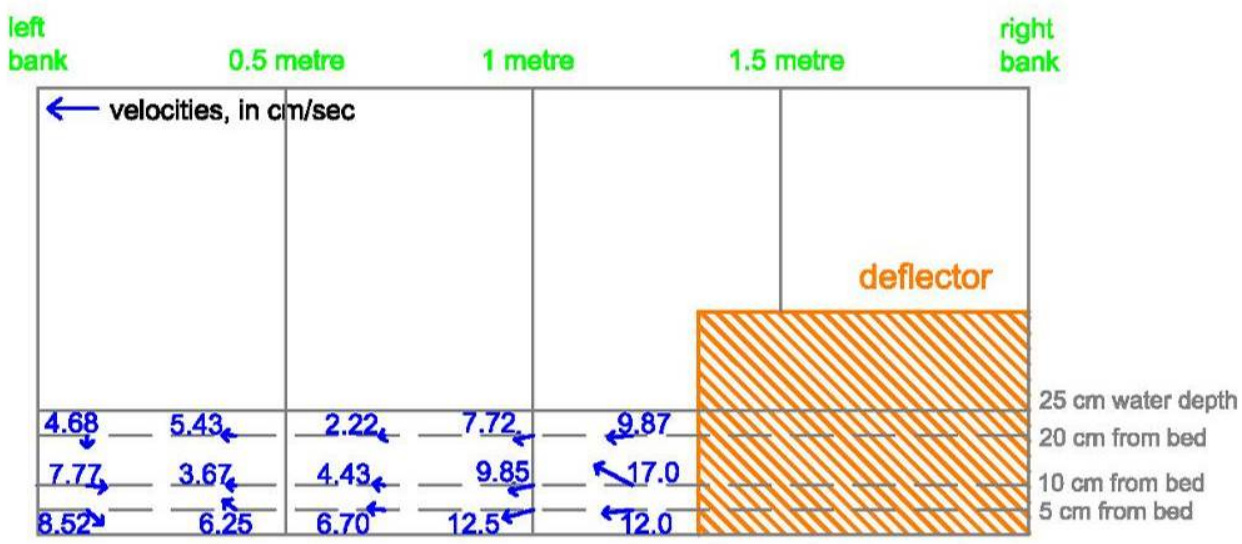

Velocities Mesured at Section 480

(Middle of Upstream Deflector) Facing Downstream

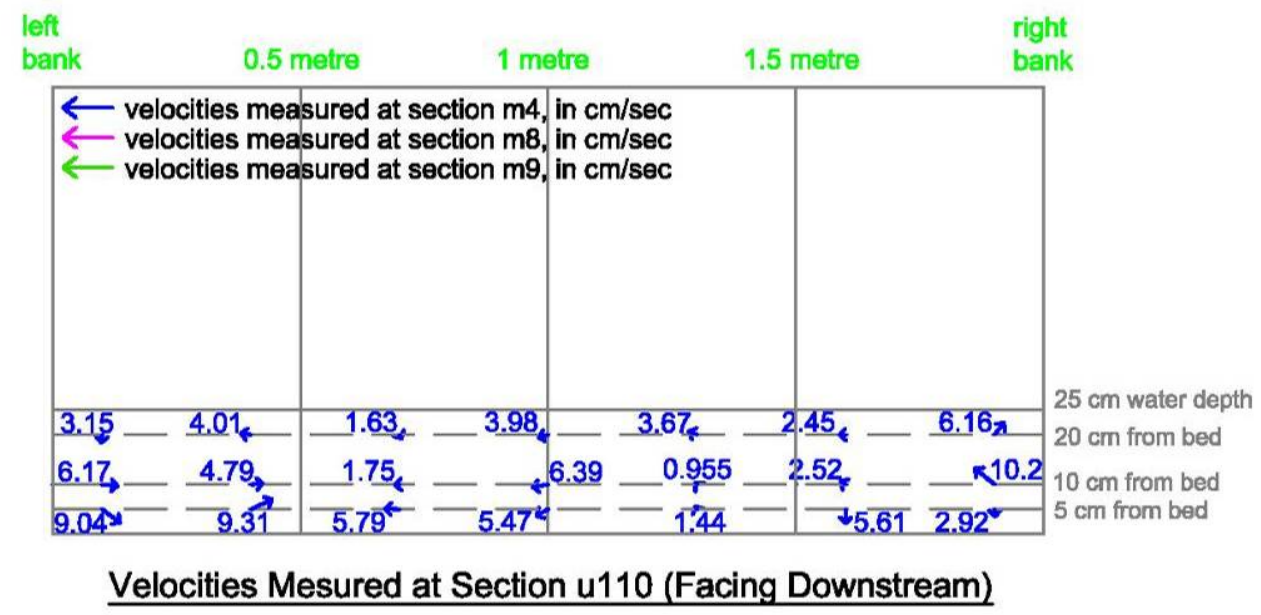

Figure Q-8: Velocity Profile in yz-plane of Experiment \#B9a at the Meander Section. 


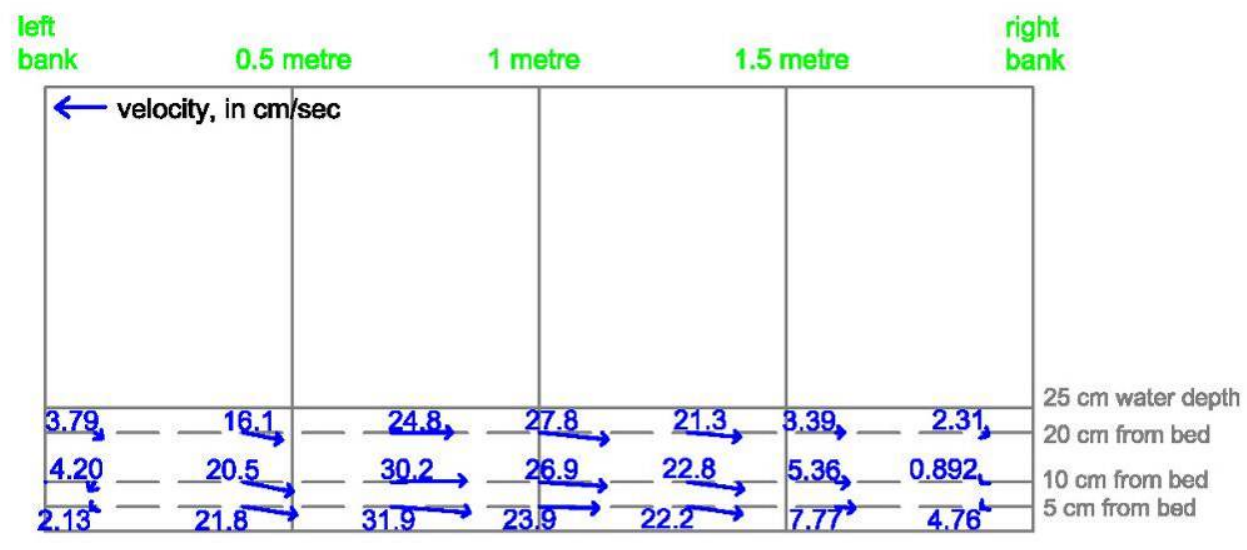

Velocities Mesured at Section m22

(Just Before the Upstream Deflector) Facing Downstream

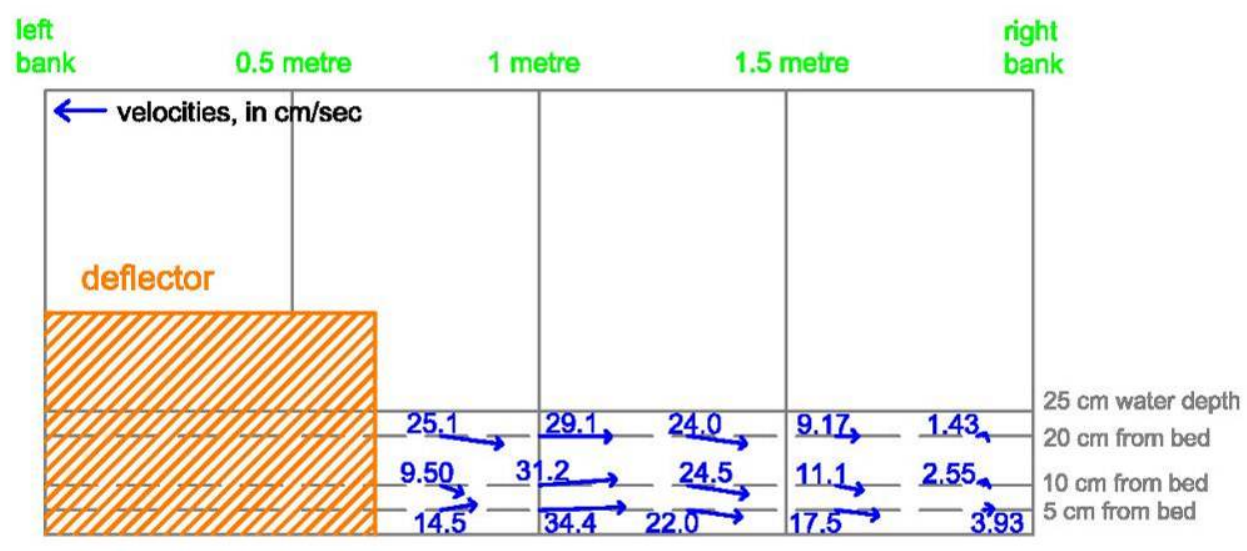

Velocities Mesured at Section m30

(Middle of Deflector) Facing Downstream

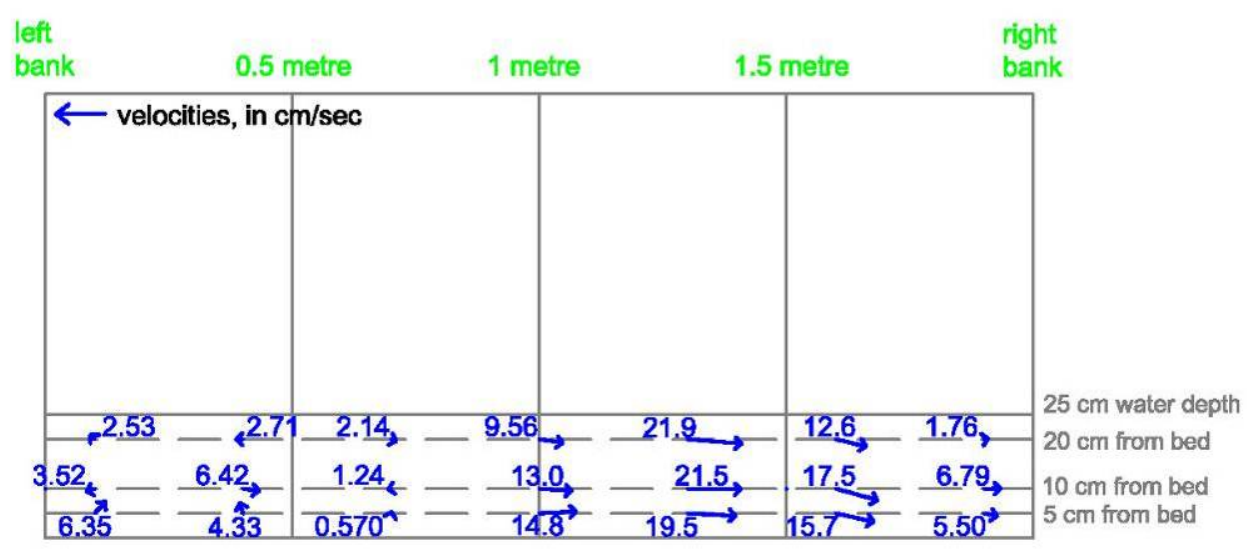

Velocities Mesured at Section m38 (Facing Downstream)

Figure Q-9: Velocity Profile in yz-plane (cont.) of Experiment \#B9a at the Meander Section. 


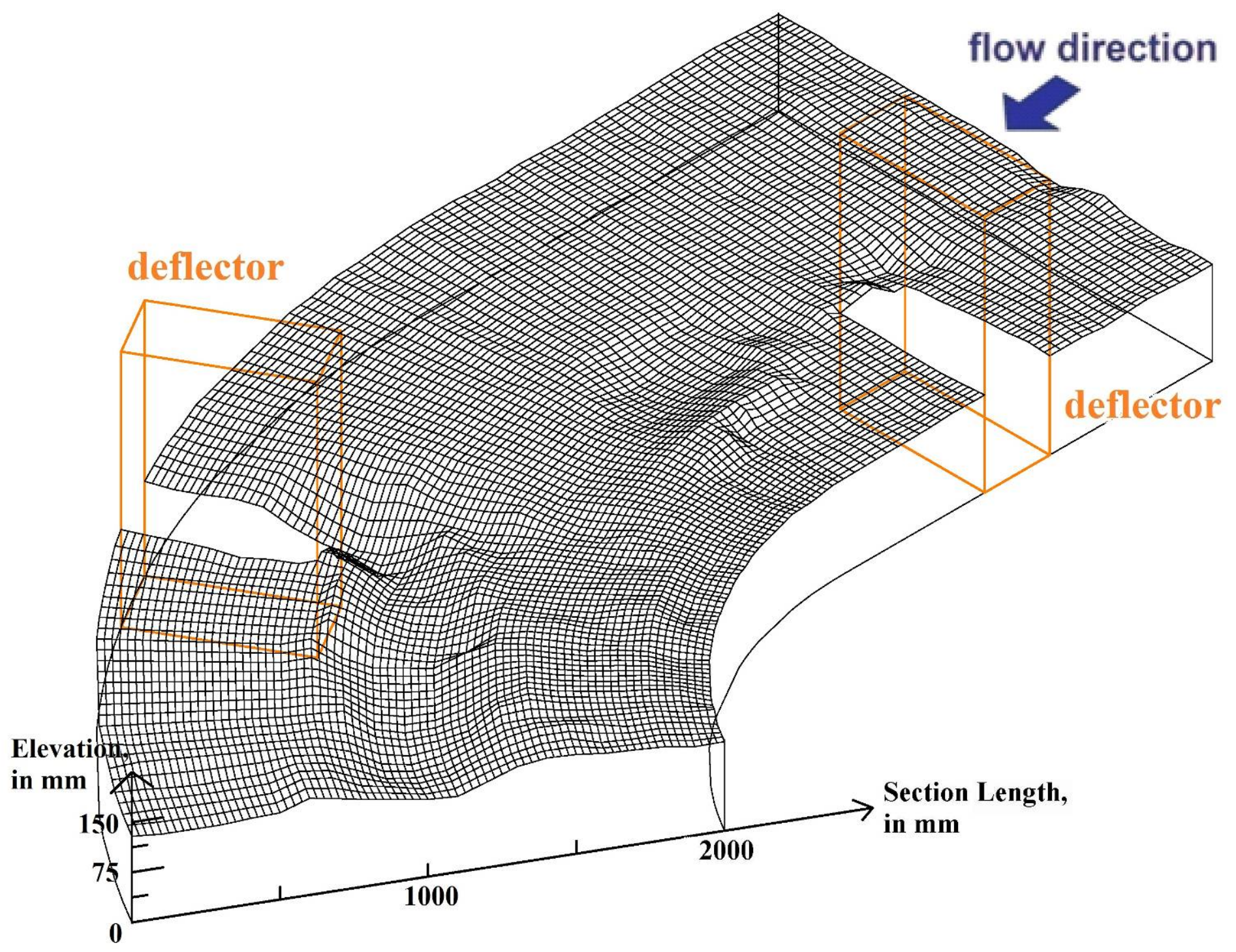

Figure Q-10: Sediment Profile (3-D mesh) of Experiment \#B11a at time $=10$ hours. 


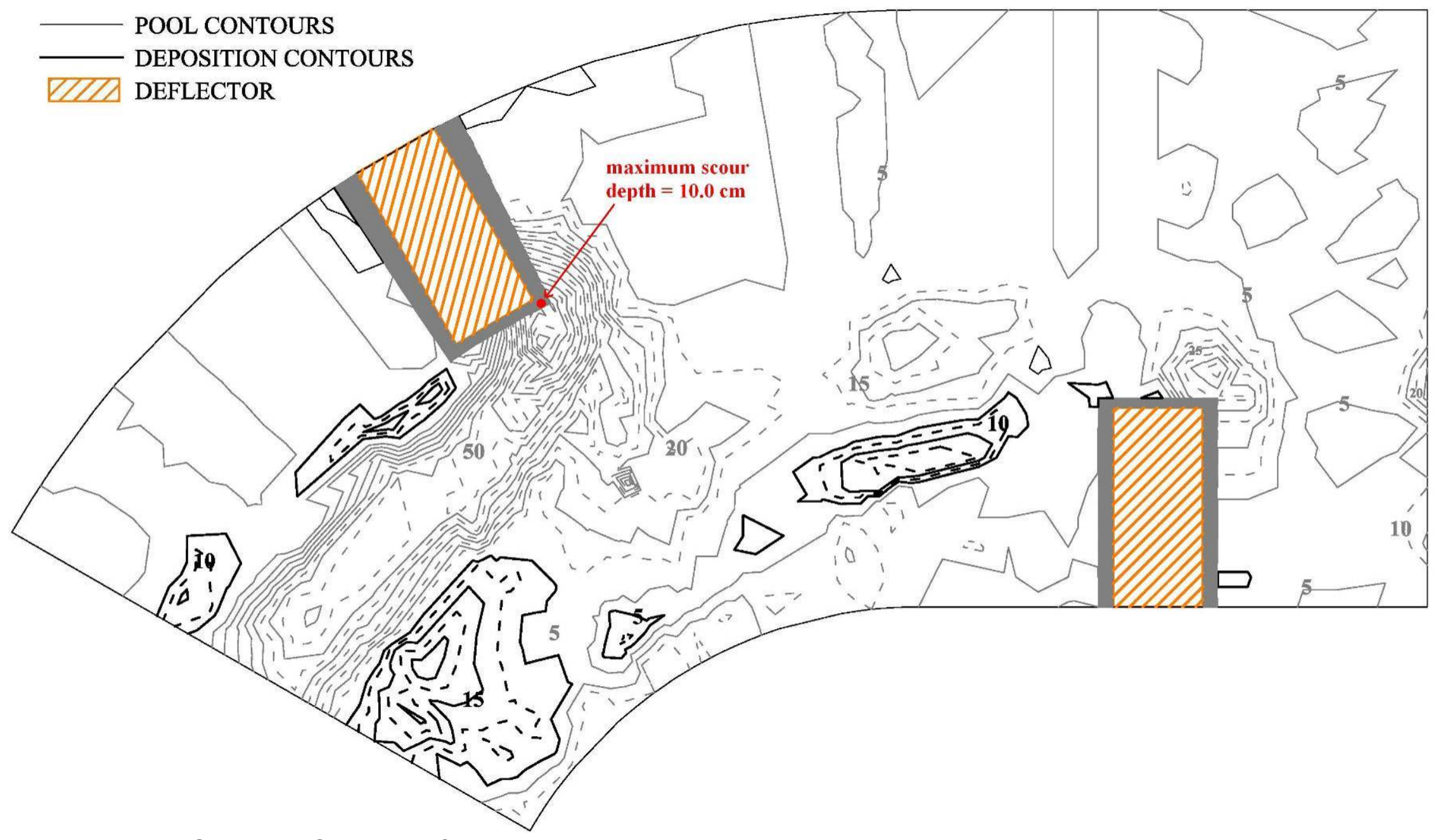

Figure Q-11: Sediment Contours of Experiment \#B11a at time $=10$ hours. 


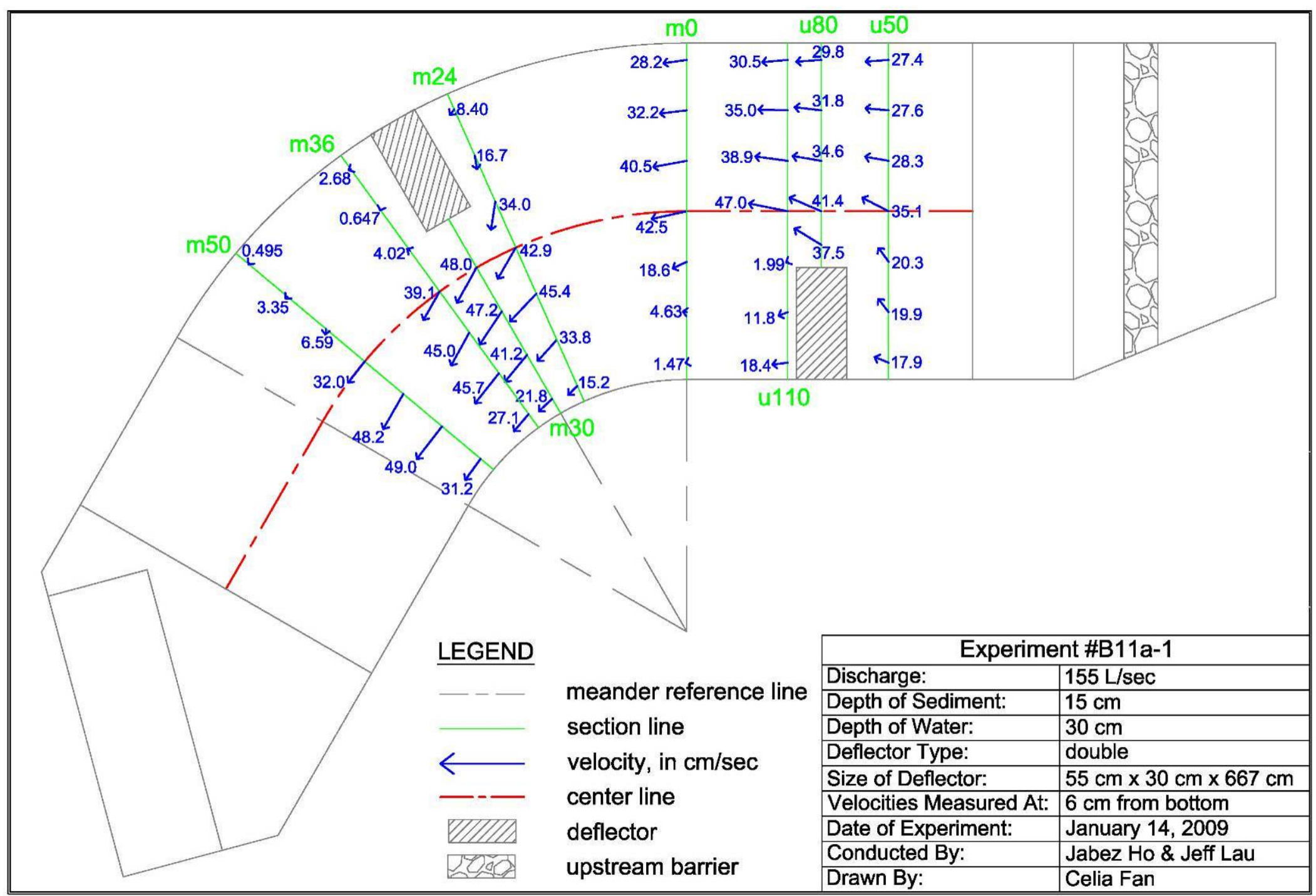

Figure Q-12: Velocity Profile in xy-plane of Experiment \#B11a at 20\% Water Depth. 


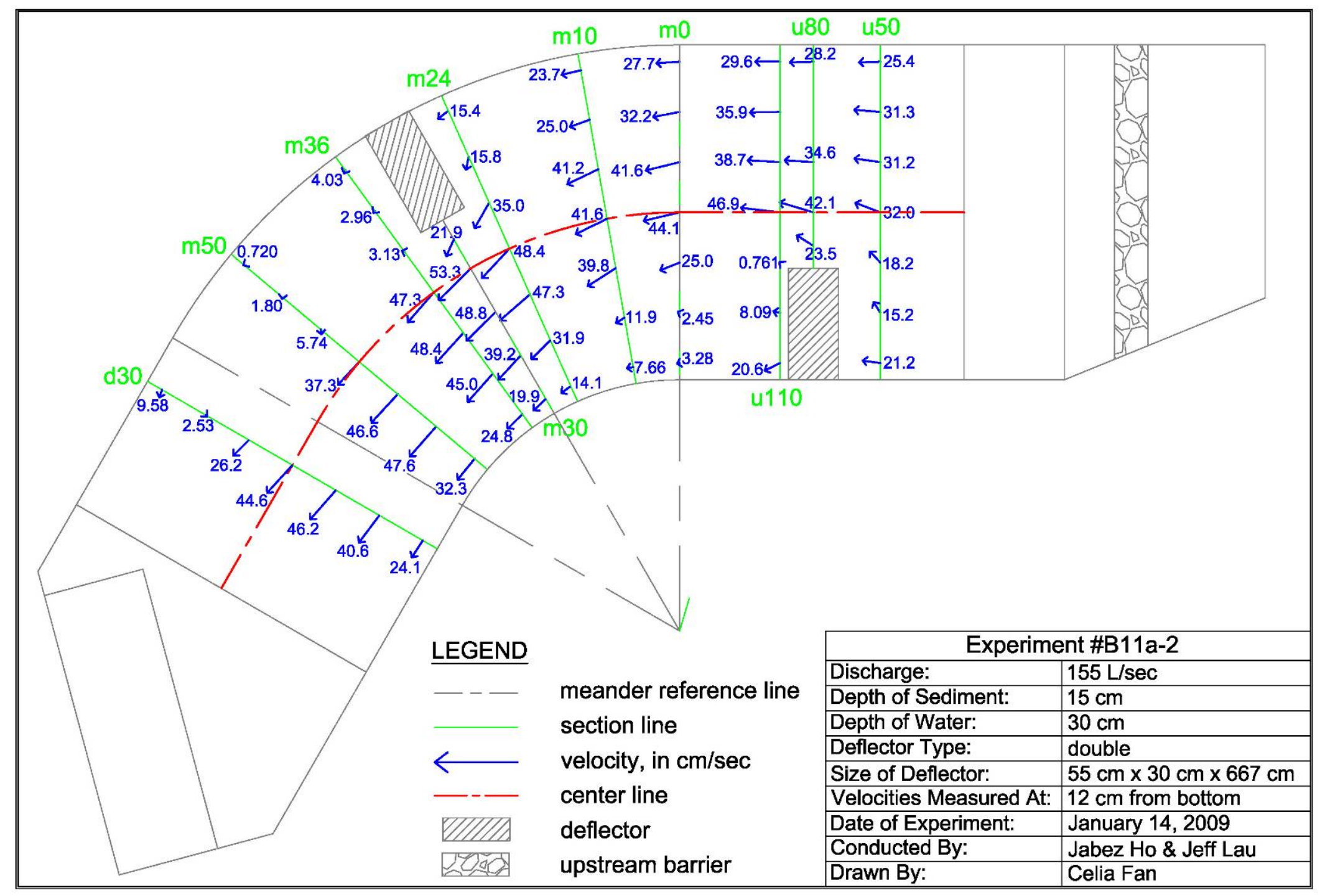

Figure Q-13: Velocity Profile in $x y$-plane of Experiment \#B11a at 40\% Water Depth. 


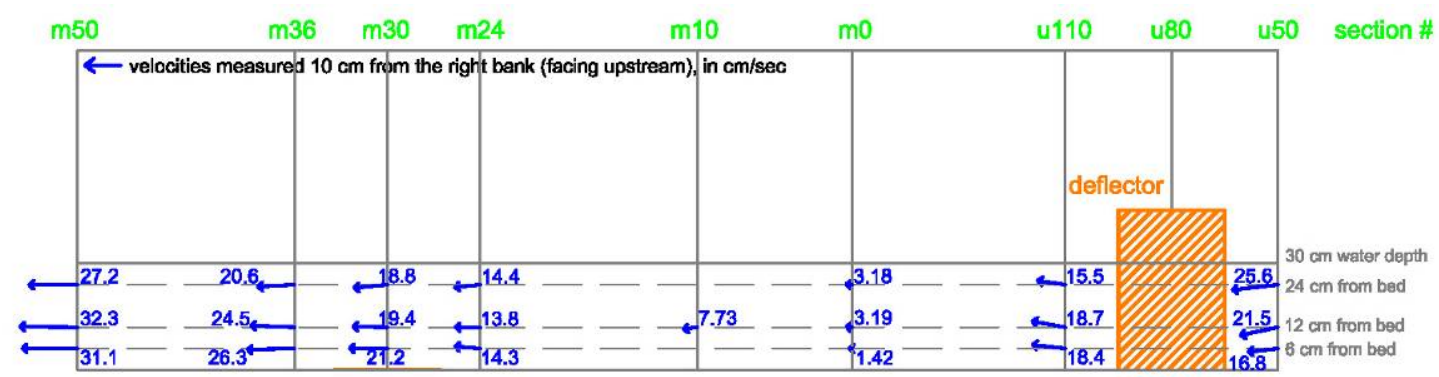

Flow Path Measured Close to the Right Bank (facing upstream)

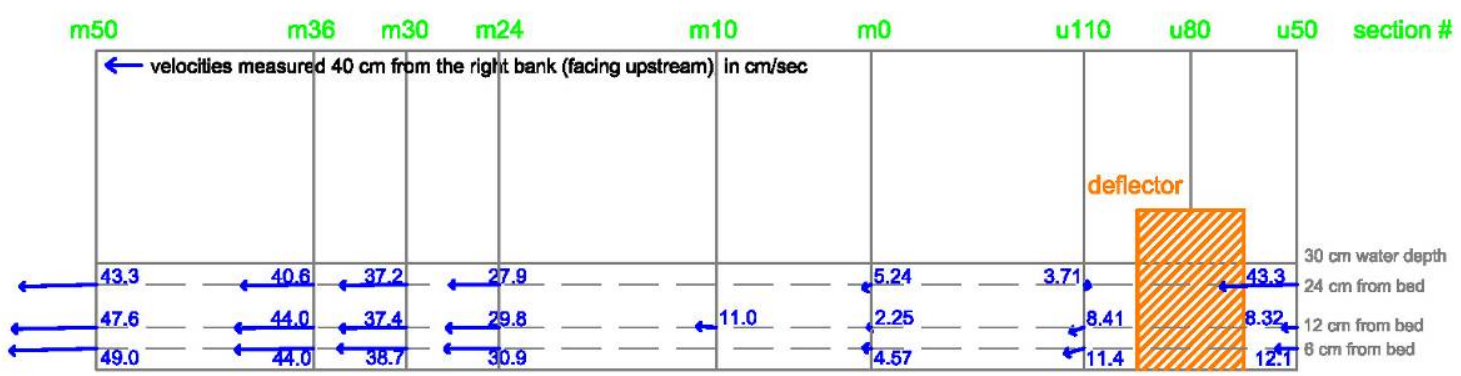

Flow Path Measured Along Midway of the Upstream Deflector (facing upstream)

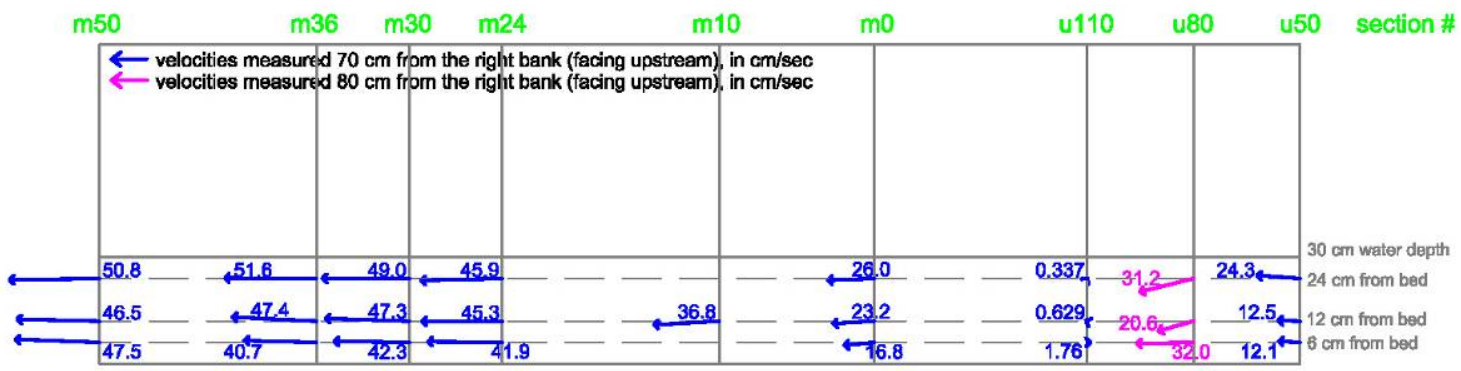

Flow Path Measured Along the Tip of the Upstream Deflector (facing upstream)

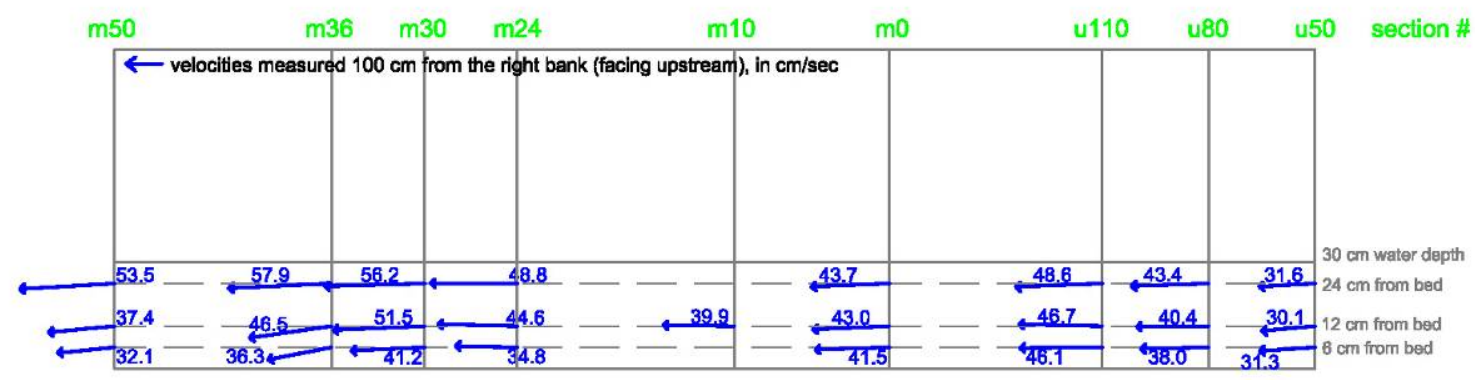

Flow Path Measured at the Centre of the Channel

Figure Q-14: Velocity Profile in xz-plane of Experiment \#B11a at the Meander Section. 


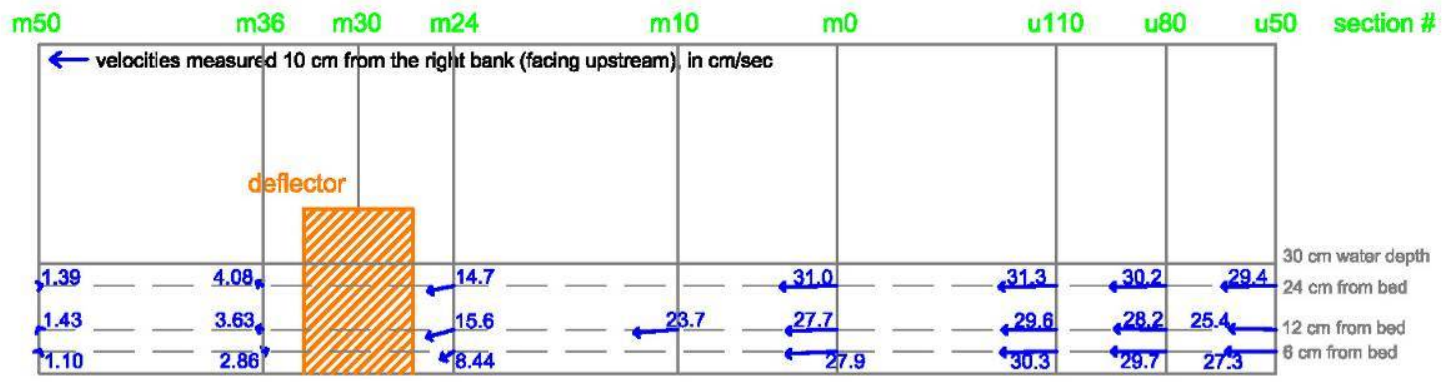

Flow Path Measured Close to the Left Bank (facing upstream)

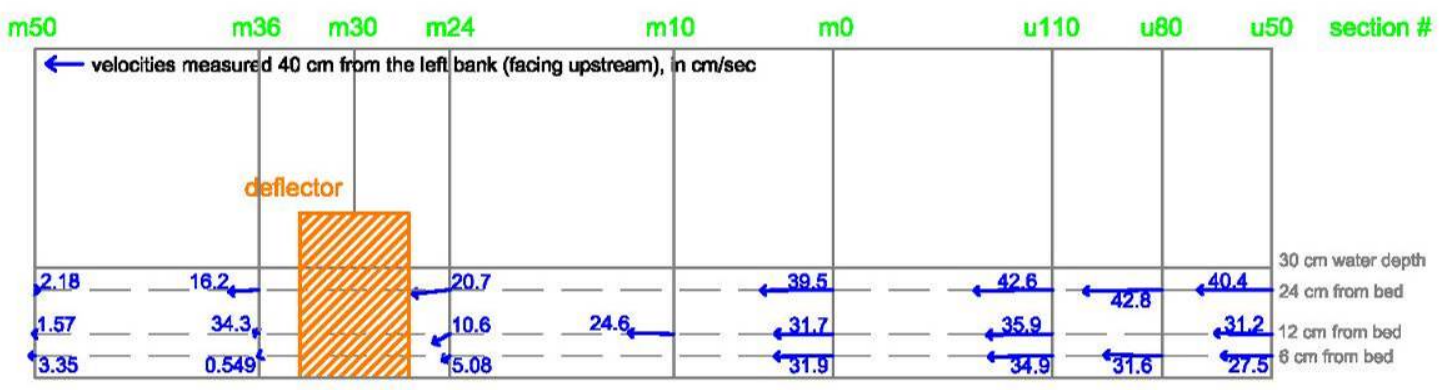

Flow Path Measured around the Middle of the Deflector Locating at the Left Bank (facing upstream)

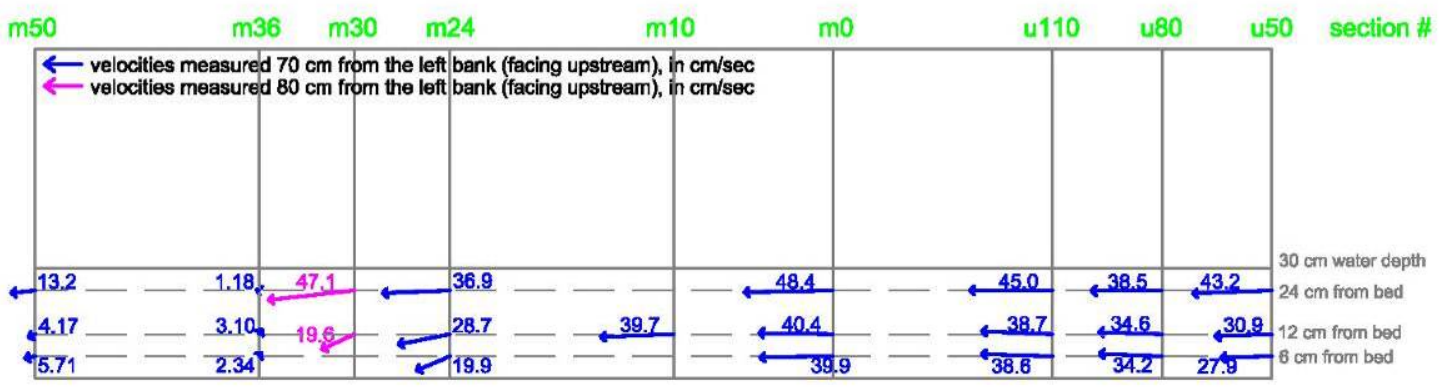

Flow Path Measured Around the Tip of the Deflector Locating at the Left Bank (Facing Upstream)

Figure Q-15: Velocity Profile in xz-plane (cont.) of Experiment \#B11a at the Meander Section. 


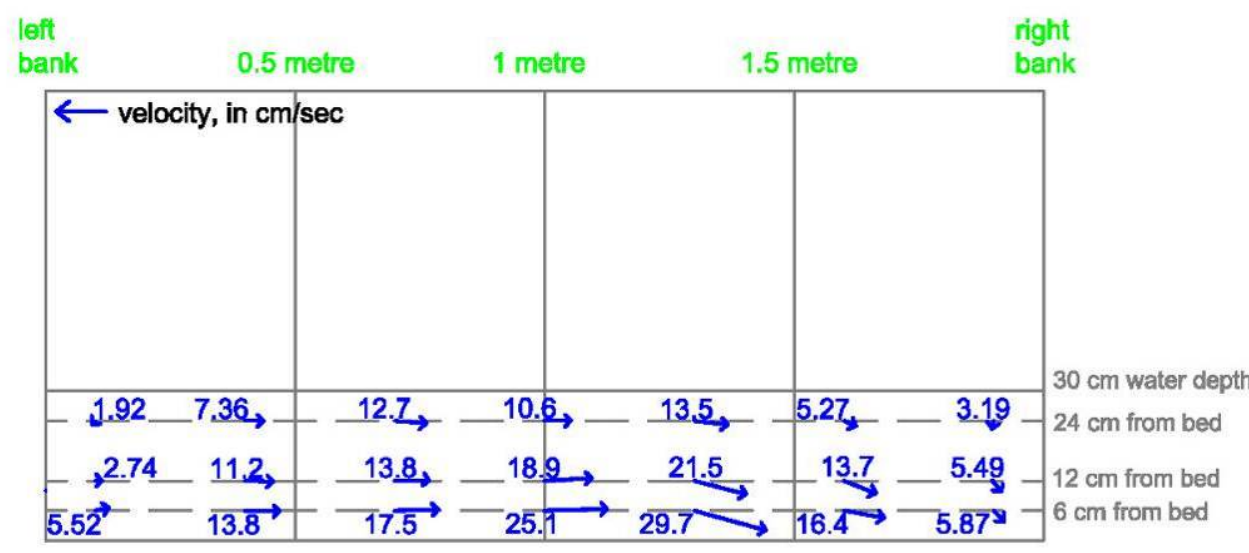

Velocities Mesured at Section m24

(Just Before the Downstream Deflector) Facing Downstream

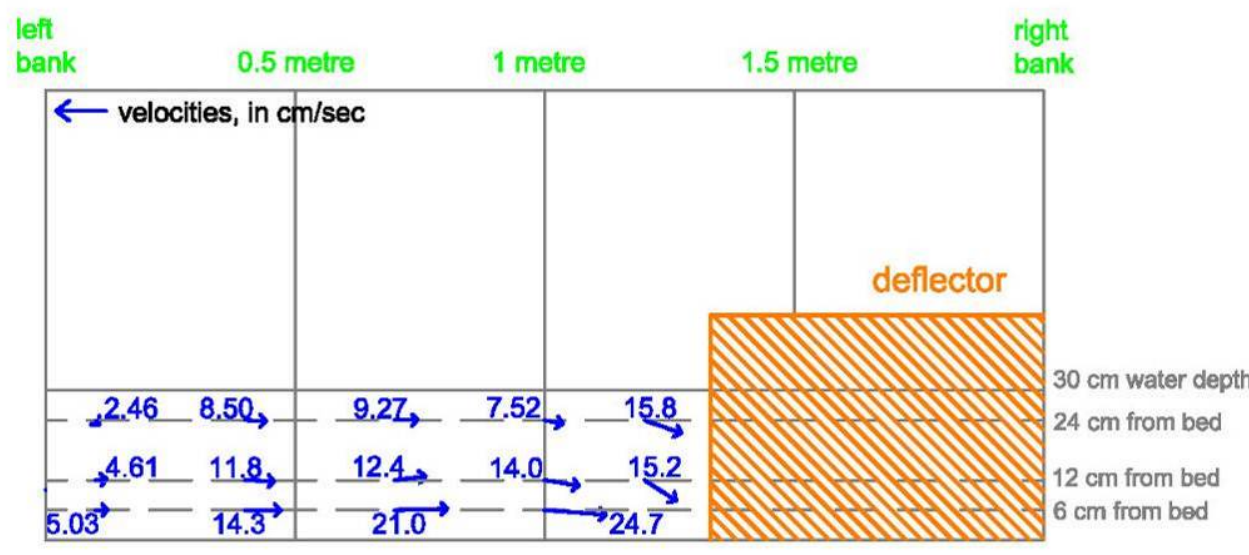

Velocities Mesured at Section m30

(Middle of Downstream Deflector) Facing Downstream

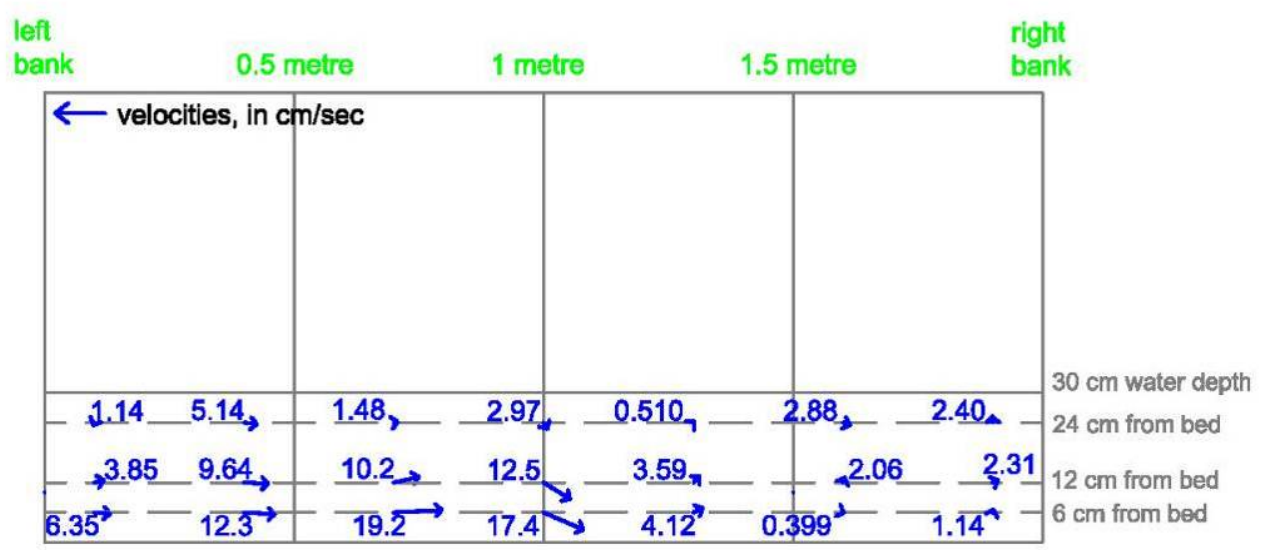

Velocities Mesured at Section m36 (Facing Downstream)

Figure Q-16: Velocity Profile in yz-plane of Experiment \#B11a at the Meander Section. 


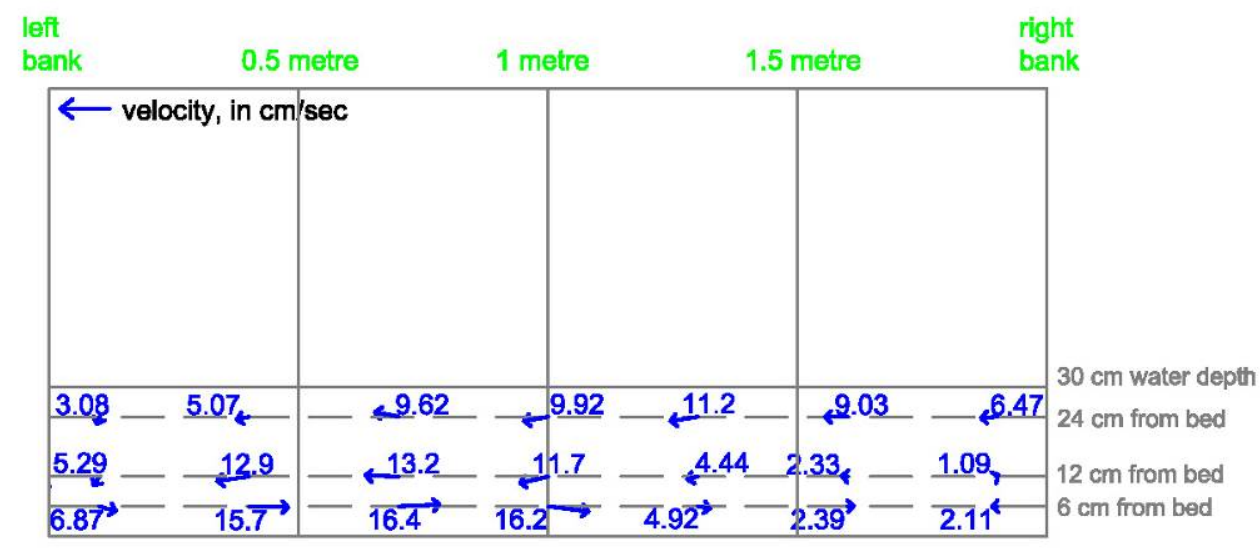

Velocities Mesured at Section u50

(Just Before the Upstream Deflector) Facing Downstream

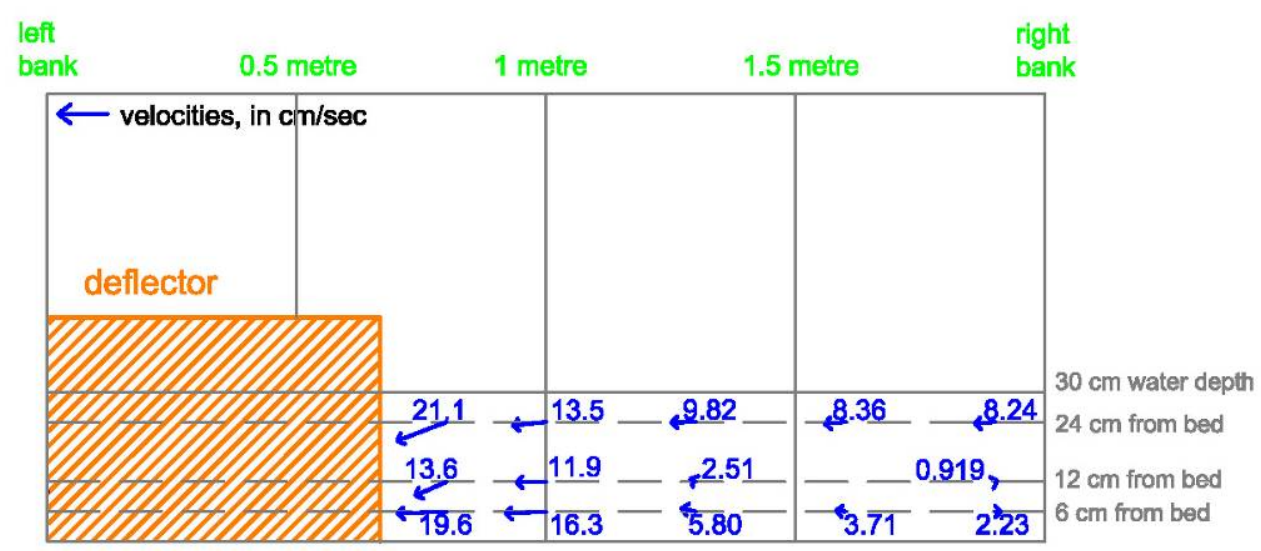

Velocities Mesured at Section u80 (Middle of Deflector) Facing Downstream

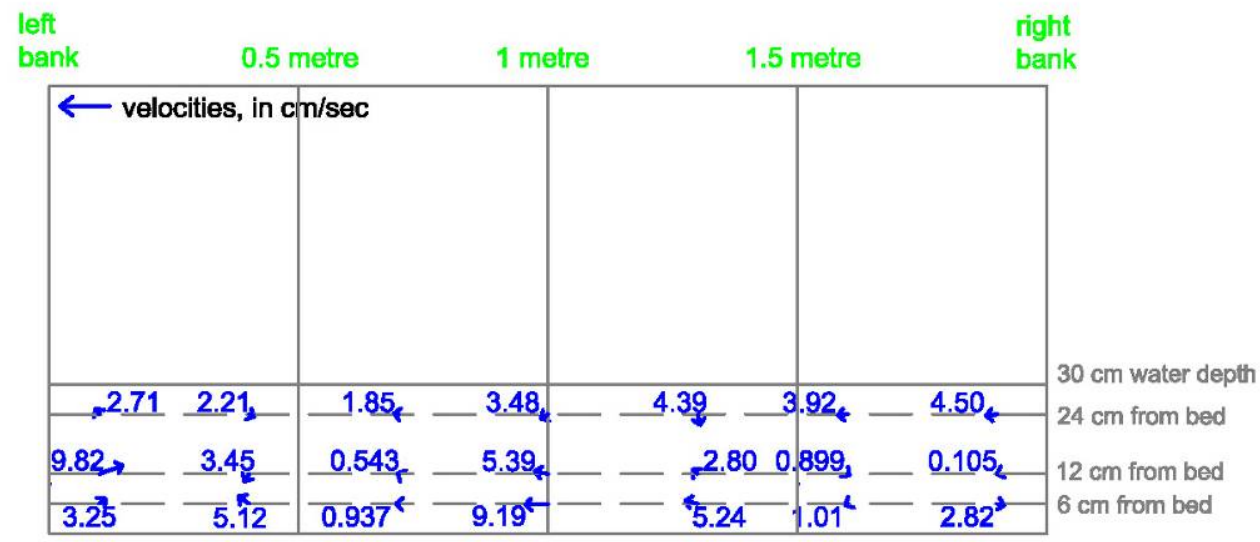

Velocities Mesured at Section u110 (Facing Downstream)

Figure Q-17: Velocity Profile in yz-plane (cont.) of Experiment \#B11a at the Meander Section. 


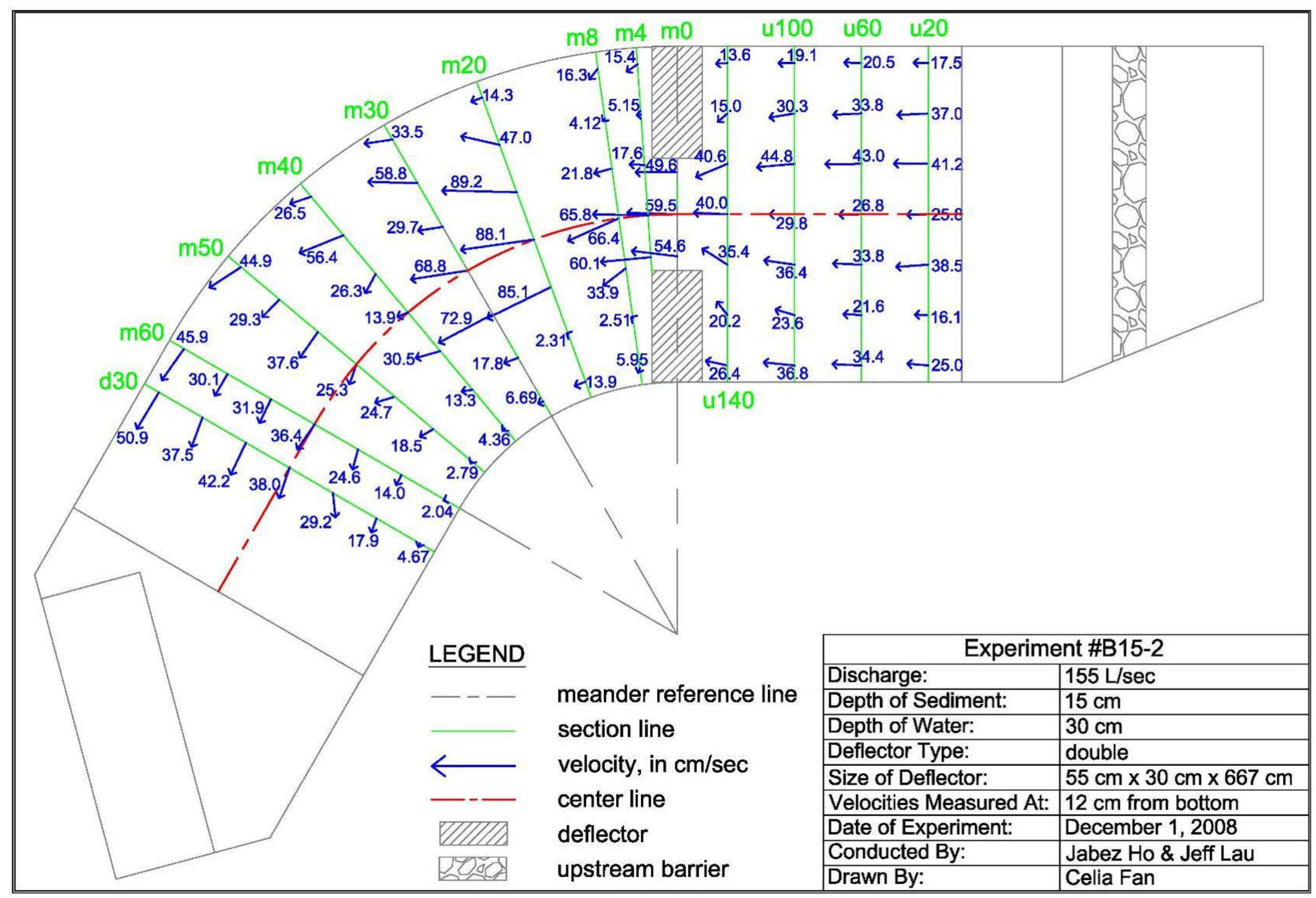

Figure Q-18: Velocity Profile in xy-plane of Experiment \#B15 at 40\% Water Depth. 


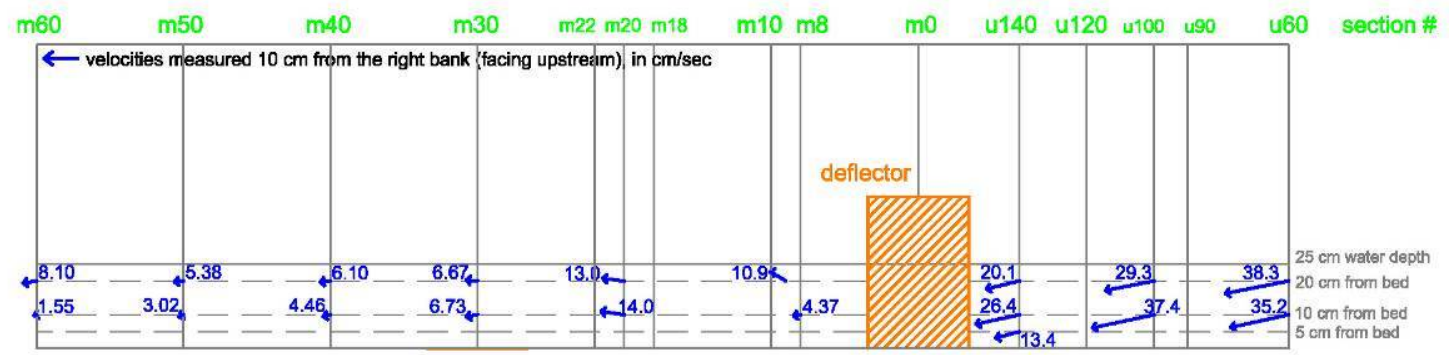

Velocities Measured Close to the Right Bank (facing upstream)

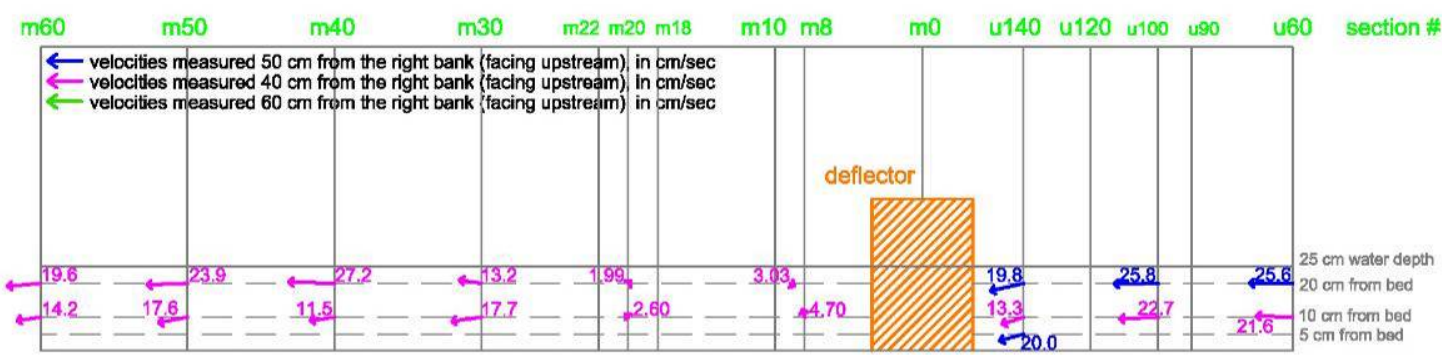

Velocities Measured around the Middle of the Deflector Locating at the Right Bank (facing upstream)

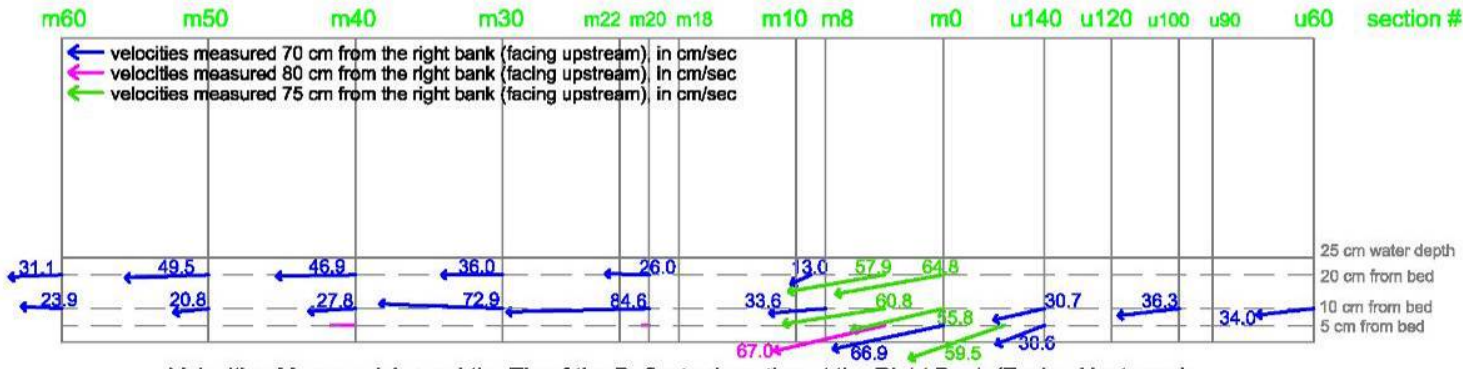

Velocities Measured Around the Tip of the Deflector Locating at the Right Bank (Facing Upstream)

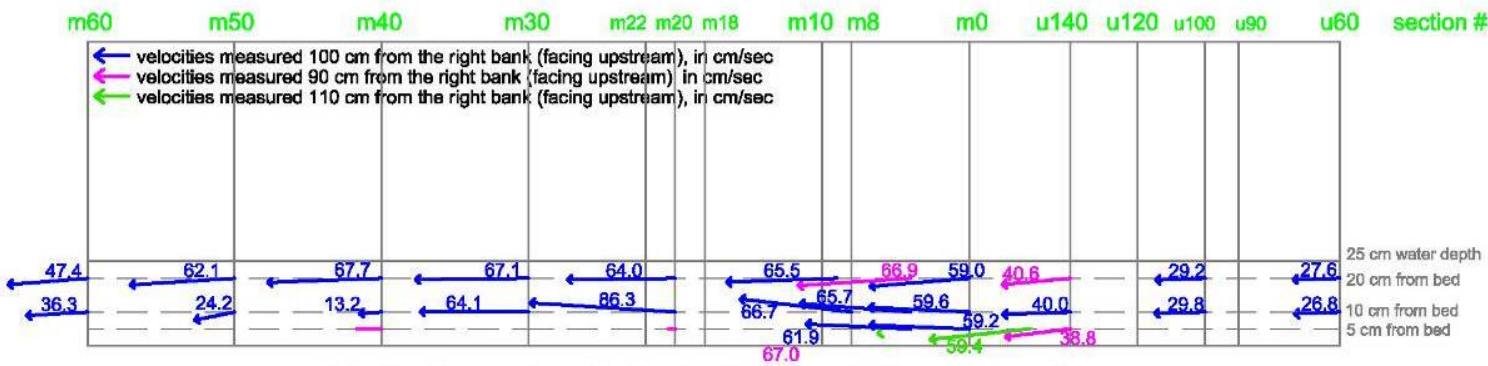

Velocities Measured near the Centre of the Channel (Facing Upstream)

Figure Q-19: Velocity Profile in xz-plane of Experiment \#B15 at the Meander Section. 
--- Page $S 20$--- 


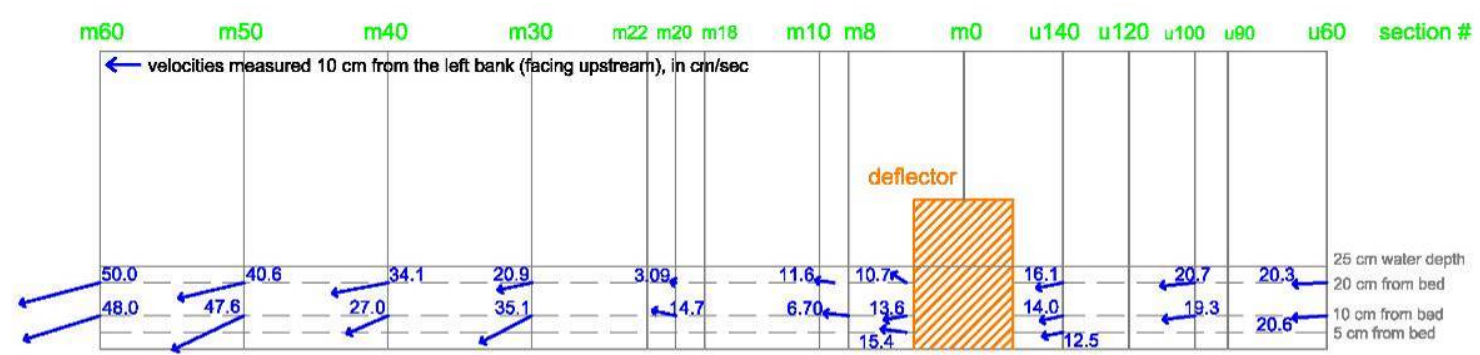

Velocities Measured Close to the Left Bank (facing upstream)

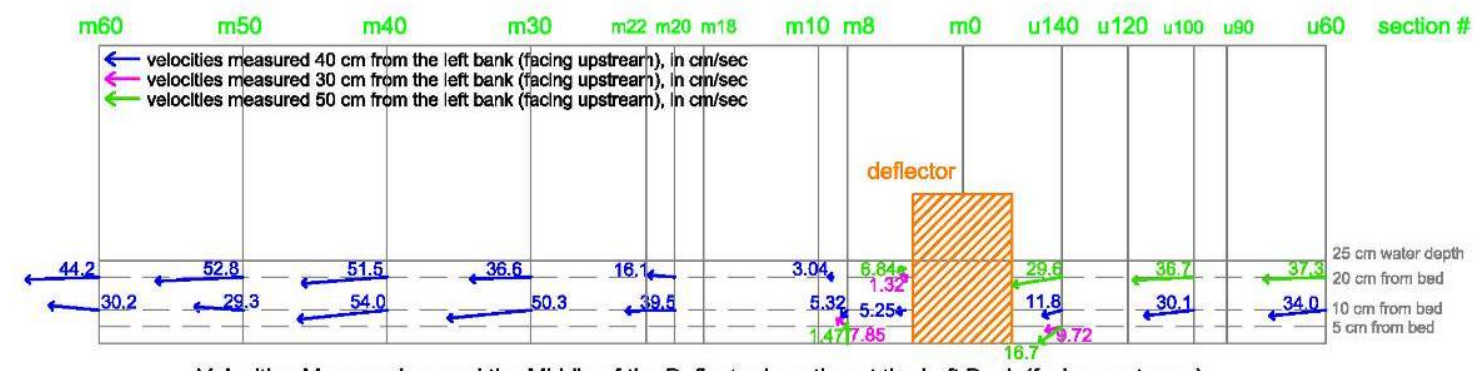

Velocities Measured around the Middle of the Deflector Locating at the Left Bank (facing upstream)

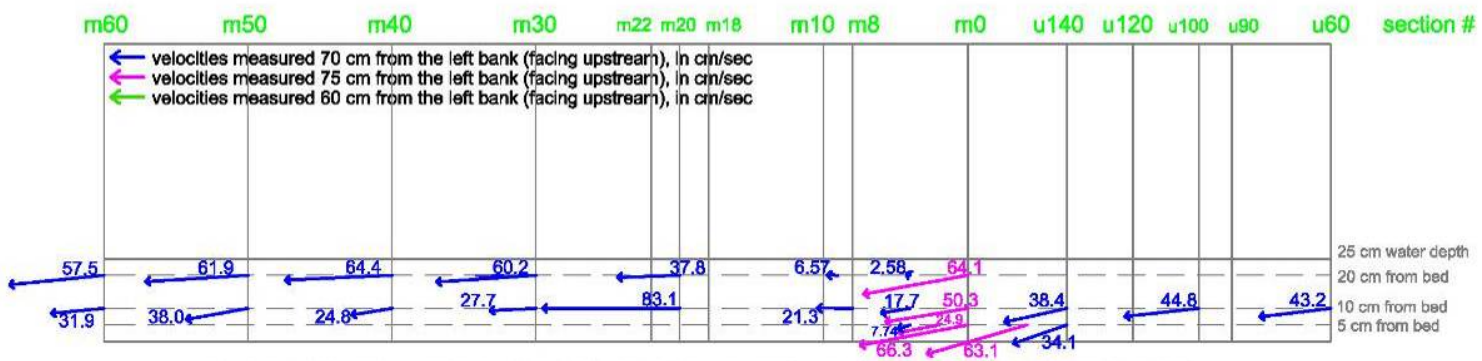

Velocities Measured Around the Tip of the Deflector Locating at the Left Bank (Facing Upstream)

Figure Q-20: Velocity Profile in xz-plane (cont.) of Experiment \#B15 at the Meander Section. 

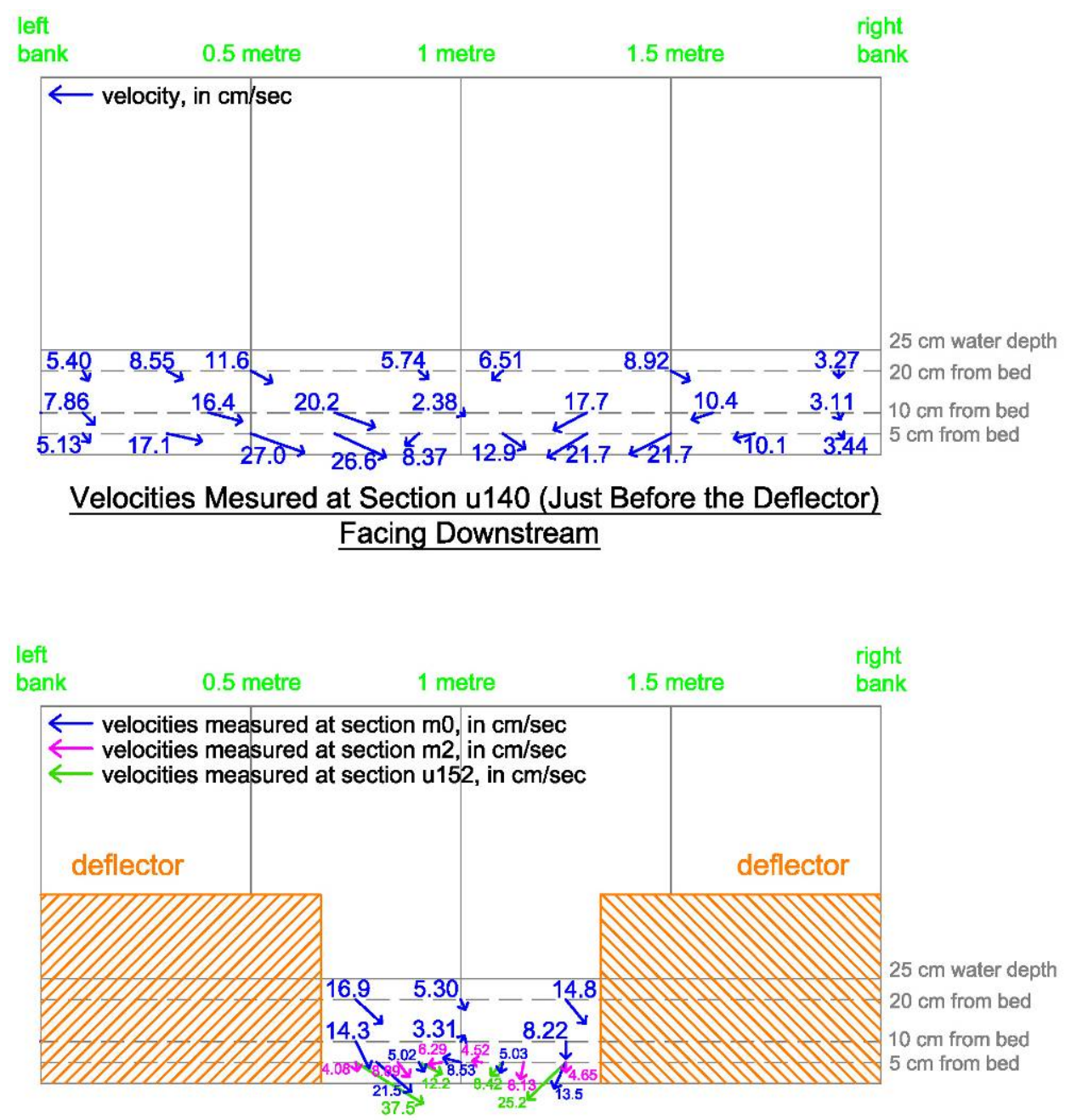

Velocities Mesured at the Middle of the Deflector

(Facing Downstream)

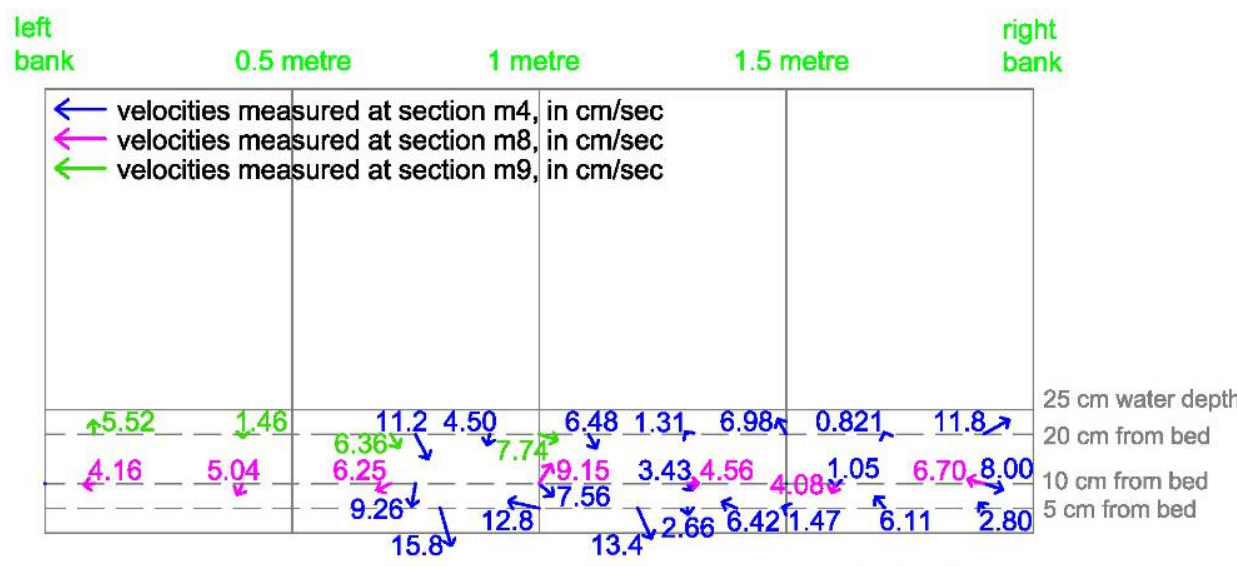

Velocities Mesured at Sections Downstream of Deflector

(Facing Downstream)

Figure Q-21: Velocity Profile in yz-plane of Experiment \#B15 at the Meander Section. 


\section{APPENDIX $\mathbf{R}$}

Experimental Results for Wet Weather

Conditions With Incoming Sediment 


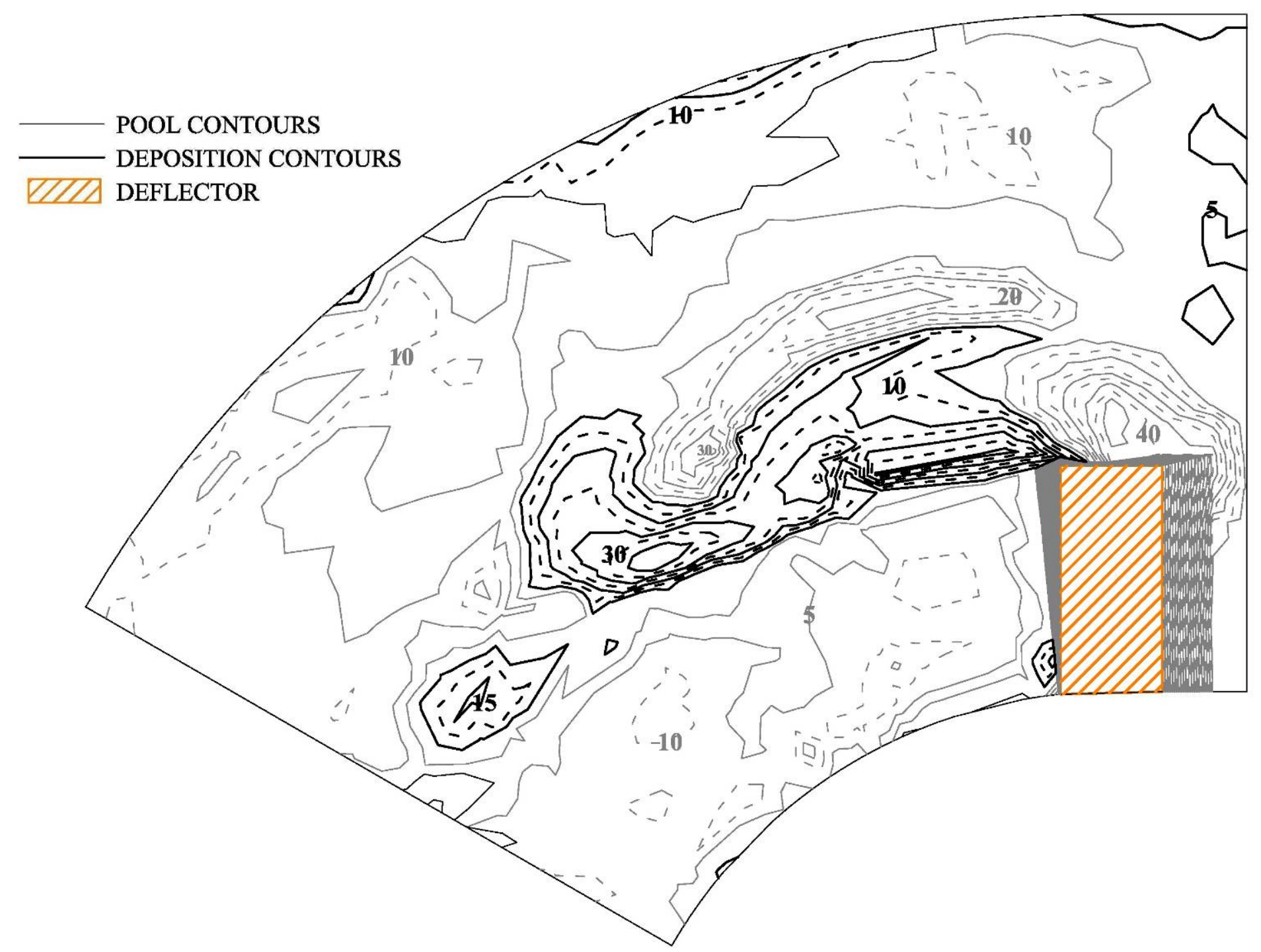

Figure R-1: Large Incoming Sediment Contours for Experiment \#B7 at time = 1 hour. 


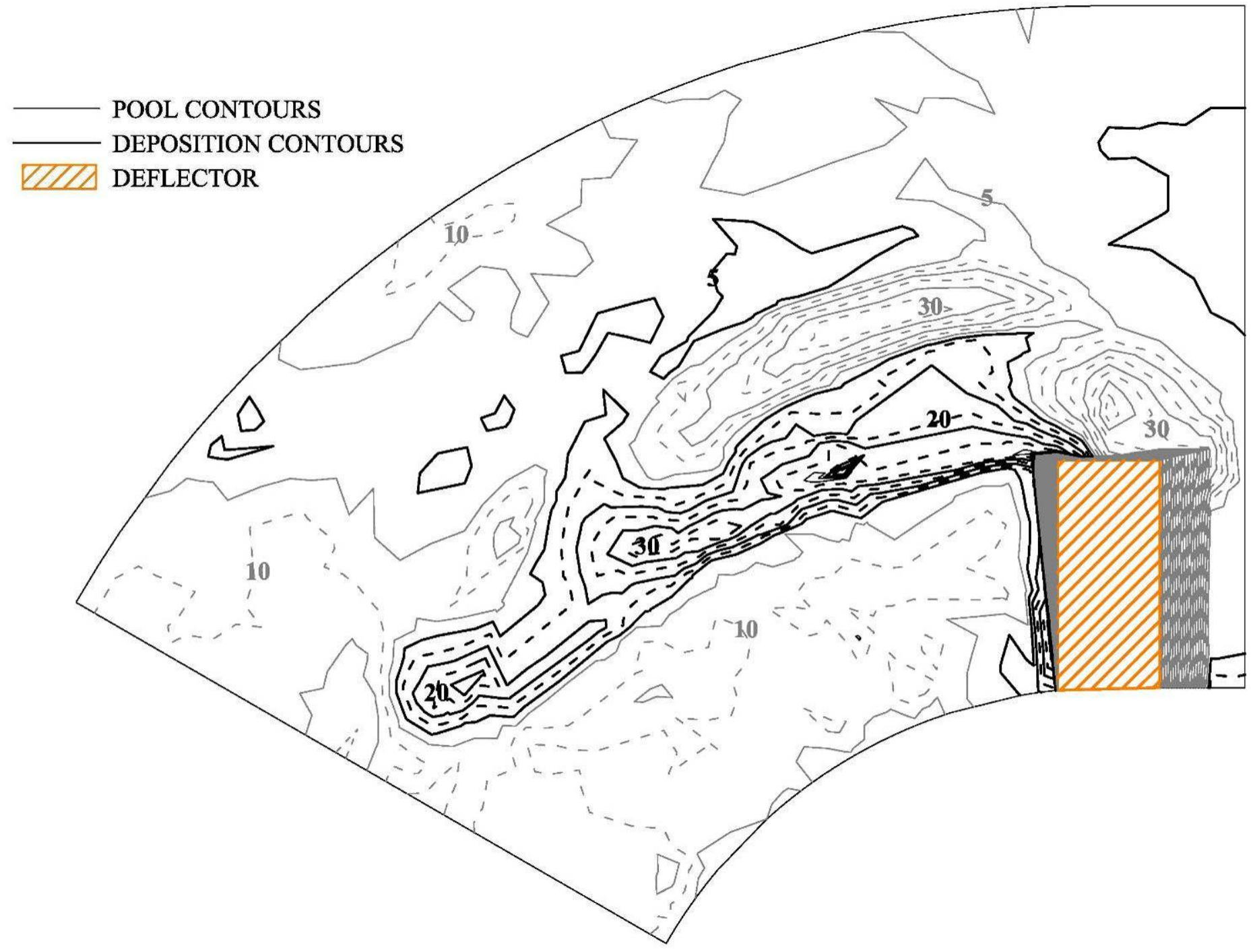

Figure R-2: Small Incoming Sediment Contours for Experiment \#B7 at time $=1$ hour. 


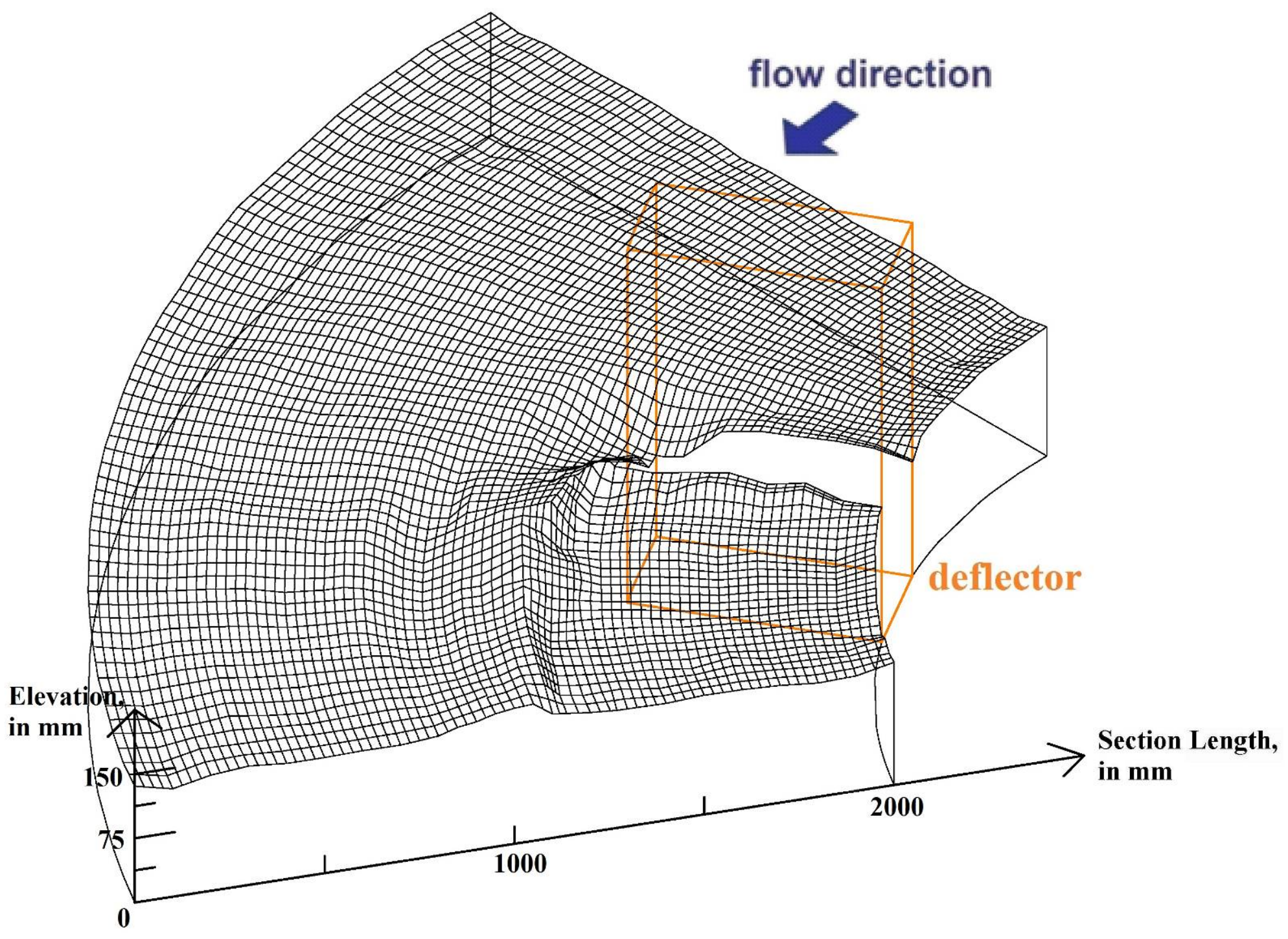

Figure R-3: Large Incoming Sediment Profile (3-D mesh) for Experiment \#B3 at time $=1$ hour.

--- Page $R 3$--- 


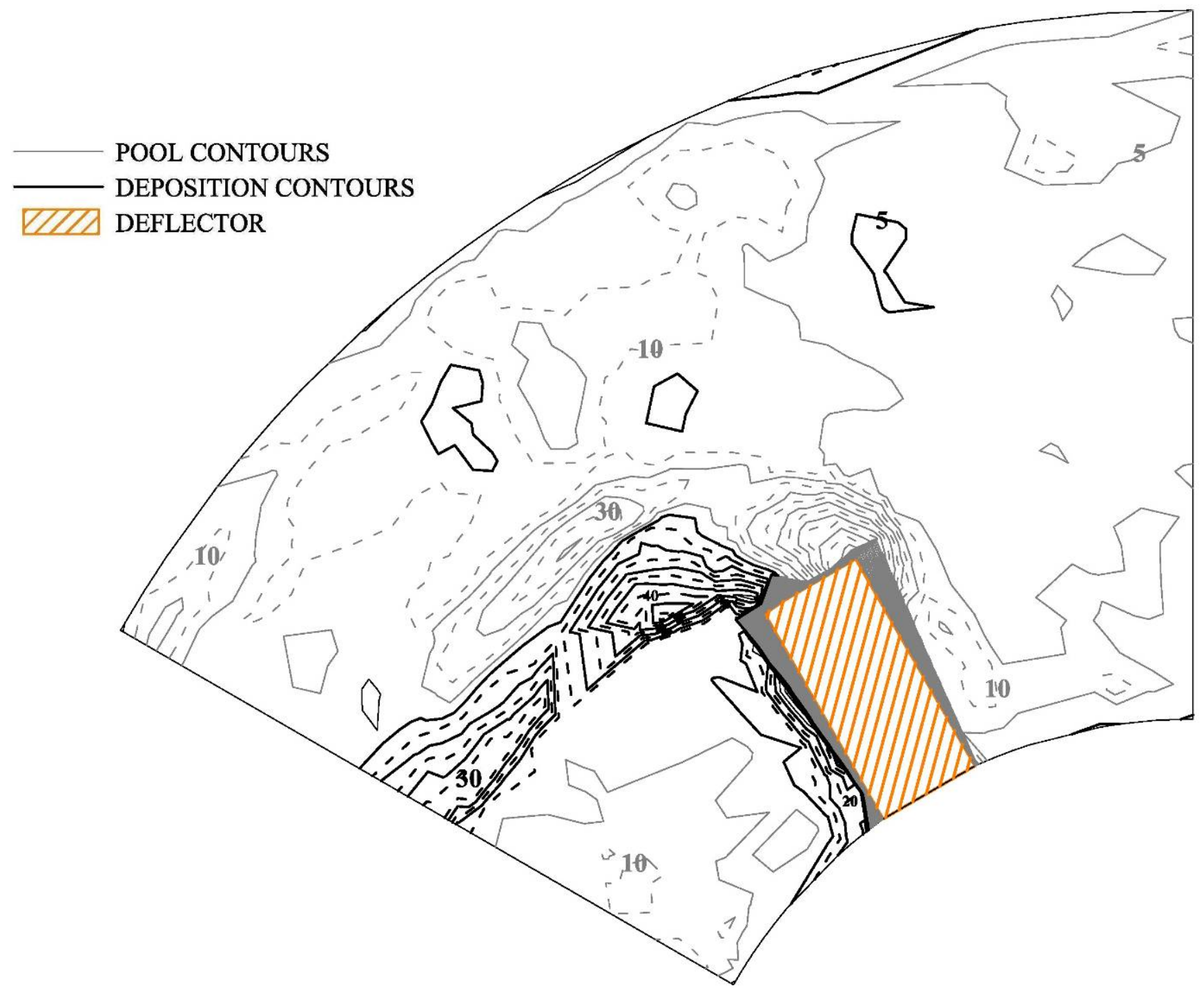

Figure R-4: Large Incoming Sediment Contours for Experiment \#B3 at time = 1 hour. 


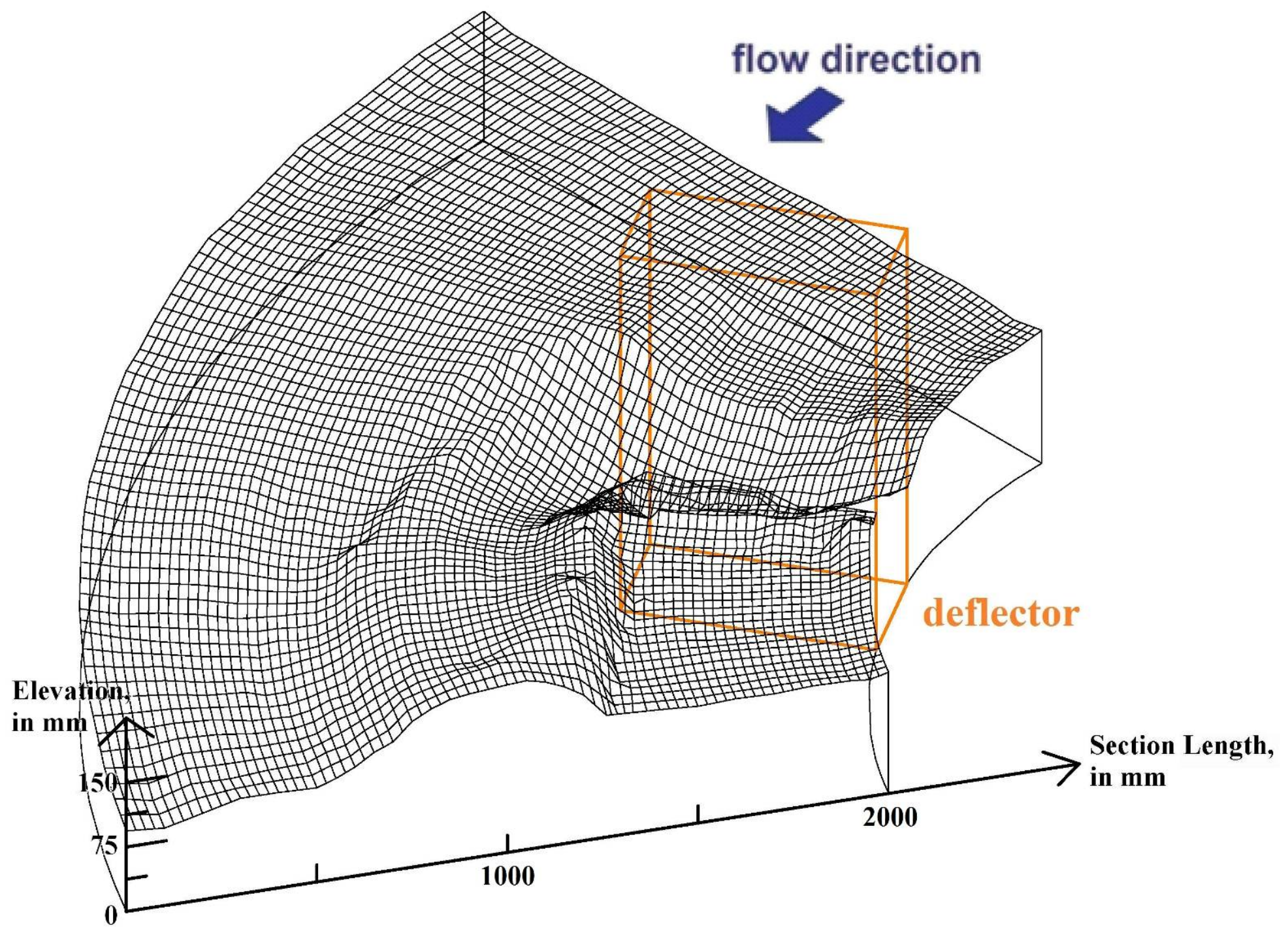

Figure R-5: Small Incoming Sediment Profile (3-D mesh) for Experiment \#B3 at time $=1$ hour. 


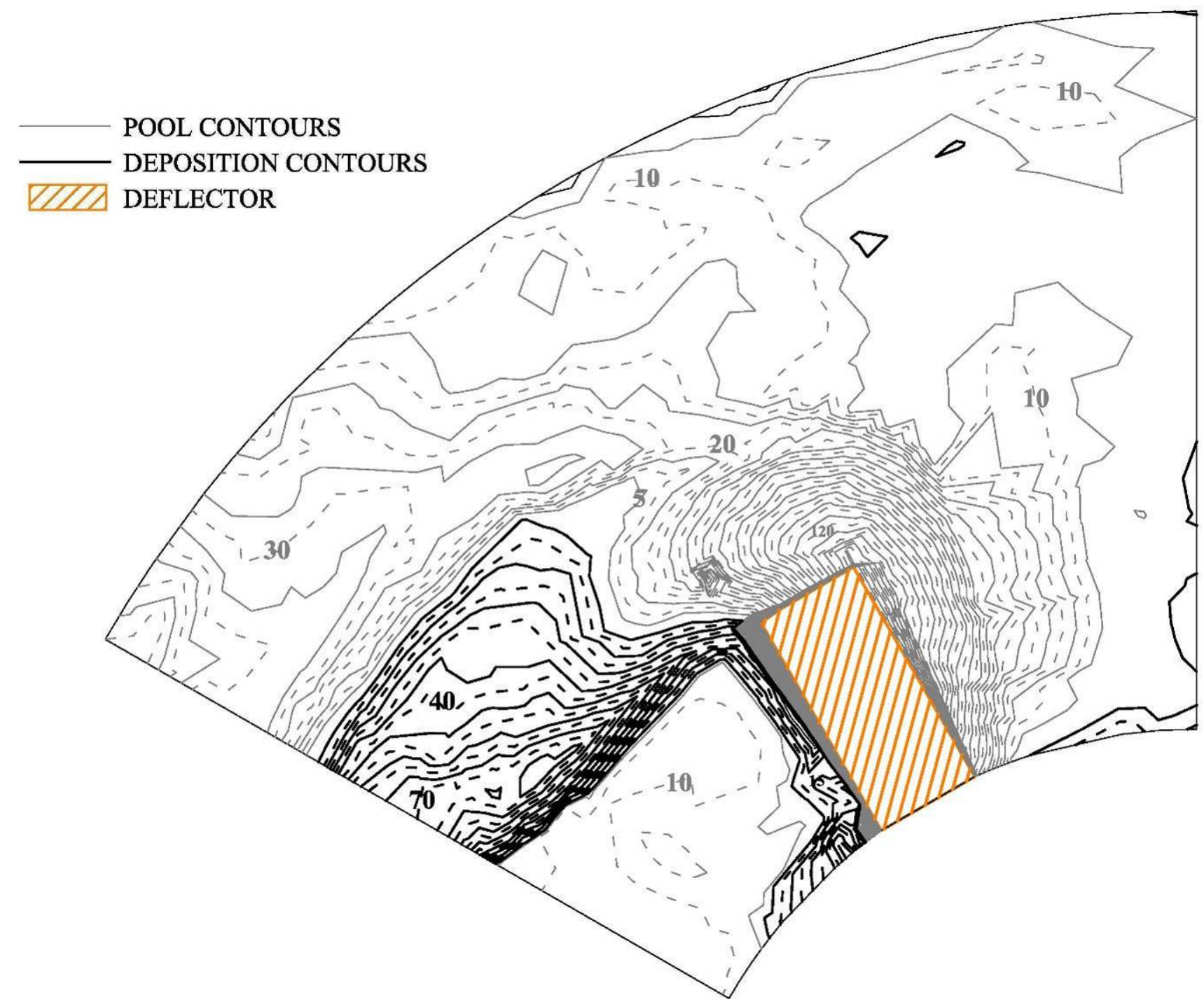

Figure R-6: Small Incoming Sediment Contours for Experiment \#B3 at time $=1$ hour. 
APPENDIX $\mathbf{S}$

\section{Abutment Calculation}




\section{Froehlich's or HIRE Abutment Scour Equation}

$$
\begin{aligned}
& L^{\prime}=0.8 \mathrm{~m} \quad \text { (Note: } \text { This value was estimated during the physical experiments.) } \\
& L=0.667 \mathrm{~m} \\
& y_{a}=0.25 \mathrm{~m} \\
& K_{1}=1 \text { for vertical-wall abutment } \quad \text { (see Figure } 25 \& \text { Table } 1 \text { ) } \\
& K_{2}=(\theta / 90)^{0.13} \\
& =(90 / 90)^{0.13} \\
& =1 \\
& \text { (see Figure 26) }
\end{aligned}
$$

Check Which Method, Froehlich or HIRE Equations, Should Be Used:

$$
\begin{aligned}
L / y_{a} & =0.667 / 0.25 \\
& =2.668<25
\end{aligned}
$$

\section{(use Froehlich equation)}

Determine Variables Involved with Froehlich Equation for Exp \#B7:

$$
\begin{aligned}
V_{e} & =(0.2058+0.2061+0.2024) / 3 \\
& =0.2048 \mathrm{~m} / \mathrm{sec} \\
F r & =0.2048 /\left(9.806^{*} 0.25\right)^{0.5} \\
& =0.1308
\end{aligned}
$$

Determine Variables Involved with Froehlich Equation for Exp \#B3:

$$
\begin{aligned}
V_{e} & =(0.2142+0.1951+0.2309) / 3 \\
& =0.2134 \mathrm{~m} / \mathrm{sec} \\
F r & =0.2134 /\left(9.806^{*} 0.25\right)^{0.5} \\
& =0.1363
\end{aligned}
$$

\section{Maximum Scour Depth Prediction for Exp \#B7:}

$$
\begin{aligned}
y_{s} & =\left[2.27 K_{1} K_{2}\left(L^{\prime} / y_{a}\right)^{0.43} \mathrm{Fr}^{0.61}+1\right] \mathrm{y}_{a} \\
& =\left[(2.27)(1)(1)(0.8 / 0.25)^{0.43}\left(0.1308^{0.61}\right)+1\right](0.25) \\
& =\underline{\underline{0.3321 \mathrm{~m}}}
\end{aligned}
$$

\section{Maximum Scour Depth Prediction for Exp \#B3:}

$$
\begin{aligned}
y_{s} & =\left[2.27 K_{1} K_{2}\left(L^{\prime} / y_{a}\right)^{0.43} \mathrm{Fr}^{0.61}+1\right] y_{a} \\
& =\left[(2.27)(1)(1)(0.8 / 0.25)^{0.43}\left(0.1363^{0.61}\right)+1\right](0.25) \\
& =\underline{\underline{0.5275 \mathrm{~m}}}
\end{aligned}
$$




\section{Maryland SHA Abutment Scour Methodology}

\section{1) Live-Bed Abutment Scour:}

$$
\begin{aligned}
y_{1} & =0.25 \mathrm{~m} \\
q_{1} & =0.155 \mathrm{~m}^{3} / \mathrm{sec} \div 2 \mathrm{~m} \\
& =0.0775 \mathrm{~m}^{3} / \mathrm{sec} / \mathrm{m} \\
q_{2} & =0.155 \mathrm{~m}^{3} / \mathrm{sec} \div(2 \mathrm{~m}-0.667 \mathrm{~m}) \\
& =0.1163 \mathrm{~m}^{3} / \mathrm{sec} / \mathrm{m} \\
k_{v} & =0.8\left(q_{1} / q_{2}\right)^{1.5}+1 \\
& =0.8(0.0775 / 0.1163)^{1.5}+1 \\
& =1.435 \\
\tau_{c} & =\text { critical shear stress of soil using Shields diagram (APPENDIX ) } \\
& =0.1546 \mathrm{~N} / \mathrm{m}^{2} \\
\tau_{1} & =\text { shear stress at approach section (APPENDIX ) } \\
& =\gamma R S \\
& =\left(9806 \mathrm{~N} / \mathrm{m}^{3}\right)(0.2 \mathrm{~m})(0.002943) \\
& =5.772 \mathrm{~N} / \mathrm{m}^{2} \\
K_{2} & =0.11\left(\tau_{c} / \tau_{1}+0.4\right)^{2.2}+0.623 \\
& =(0.11)(0.1546 / 5.772+0.4)^{2.2}+0.623 \\
& =0.6399
\end{aligned}
$$

Determine Variables Involved for Exp \#B7:

$$
\begin{aligned}
V_{1}= & (0.2058+0.2061+0.2024+0.2467+0.3399+0.3338+0.3432+0.3779+0.3806 \\
& +0.3857) / 10 \\
= & 0.3022 \mathrm{~m} / \mathrm{sec} \\
F r= & V_{1} /\left(g y_{1}\right)^{0.5} \\
= & 0.3022 /\left(9.806^{*} 0.25\right)^{0.5} \\
= & 0.1930 \\
k_{f}= & 0.35+3.2 F r \\
= & 0.35+(3.2)(0.1930) \\
= & 0.9677
\end{aligned}
$$

Determine Variables Involved for Exp \#B3:

$$
\begin{aligned}
V_{1} & =(0.2142+0.1951+0.2309+0.3089+0.3375+0.3363+0.4+0.3475+0.3422) / 10 \\
& =0.2713 \mathrm{~m} / \mathrm{sec} \\
F r & =V_{1} /\left(g y_{1}\right)^{0.5} \\
& =0.2713 /\left(9.806^{*} 0.25\right)^{0.5} \\
& =0.1733 \\
k_{f} & =0.35+3.2 F r \\
& =0.35+(3.2)(0.1930) \\
& =0.9044
\end{aligned}
$$


Maximum Scour Depth Prediction for Exp \#B7:

$$
\begin{aligned}
y_{2 a} & =k_{f} y_{1}\left[\left(k_{v} q_{2}\right) / q_{1}\right]^{K_{2}} \\
& =(0.9677)(0.25)\left[\left(1.435^{\star} 0.1163\right) / 0.0775\right]^{0.6399} \\
& =0.3952 \mathrm{~m}
\end{aligned}
$$

Depth of scour hole $=y_{2 a}-y=0.3952-0.25=\underline{\underline{0.1452 \mathrm{~m}}}$

Maximum Scour Depth Prediction for Exp \#B3:

$$
\begin{aligned}
y_{2 a} & =k_{f} y_{1}\left[\left(k_{v} q_{2}\right) / q_{1}\right]^{K_{2}} \\
& =(0.9044)(0.25)\left[\left(1.435^{\star} 0.1163\right) / 0.0775\right]^{0.6399} \\
& =0.3694 \mathrm{~m}
\end{aligned}
$$

Depth of scour hole $=y_{2 a}-y=0.3694-0.25=\underline{\underline{0.1194 m}}$

\section{2) Clear-Water Abutment Scour:}

$$
\begin{aligned}
y= & 0.25 \mathrm{~m} \\
D_{50} & =2.81 \times 10^{-4} \mathrm{~m} \\
K_{u} & =6.19 \text { for SI units } \\
V_{c} & =K_{u} y^{1 / 6} D_{50} 0^{1 / 3} \\
& =(6.19)\left(0.25^{1 / 6}\right)\left(0.000281^{1 / 3}\right) \\
& =0.3218 \mathrm{~m} / \mathrm{sec} \\
y_{2 c} & =q_{2} / V_{c} \\
& =0.1163 \div 0.3218 \\
& =0.3613 \mathrm{~m}
\end{aligned}
$$

For Exp \#B7, $K_{f}=0.1+4.5 \mathrm{Fr}$

$$
\begin{aligned}
& =0.1+(4.5)(0.1930) \\
& =0.9686
\end{aligned}
$$

For $\operatorname{Exp}$ \#B3, $K_{f}=0.1+4.5 \mathrm{Fr}$

$$
\begin{aligned}
& =0.1+(4.5)(0.1733) \\
& =0.8796
\end{aligned}
$$

\section{Maximum Scour Depth Prediction for Exp \#B7:}

$$
\begin{aligned}
y_{2 a} & =K_{f}\left(k_{v}\right)^{0.857} y_{2 c} \\
& =(0.9686)(1.435)^{0.857}(0.3613) \\
& =0.4770 \mathrm{~m}
\end{aligned}
$$

Depth of scour hole $=y_{2 a}-y=0.4770-0.25=\underline{\underline{0.2270 m}}$

\section{Maximum Scour Depth Prediction for Exp \#B3:}




$$
\begin{aligned}
y_{2 a} & =(0.8796)(1.435)^{0.857}(0.3613) \\
& =0.4332 \mathrm{~m}
\end{aligned}
$$

Depth of scour hole $=y_{2 a}-y=0.4332-0.25=\underline{\underline{0.1832 m}}$ 
APPENDIX T

\author{
Numerical Results
}

\title{
(without Incoming Sediment)
}




\section{Dry Weather Condition}

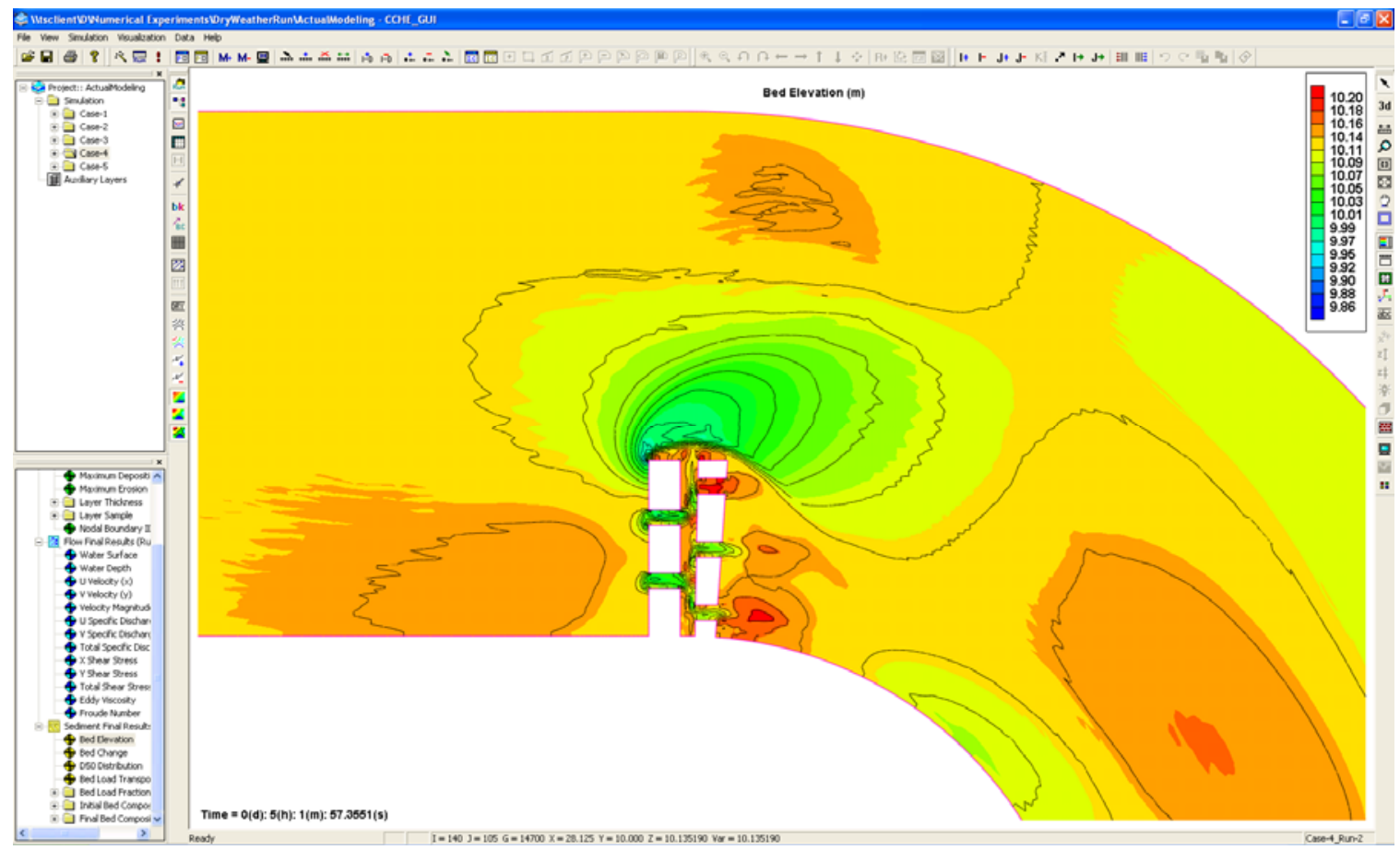

Figure T-1: Bed elevation for dry weather condition at meander \#1 after 5-hr simulation.

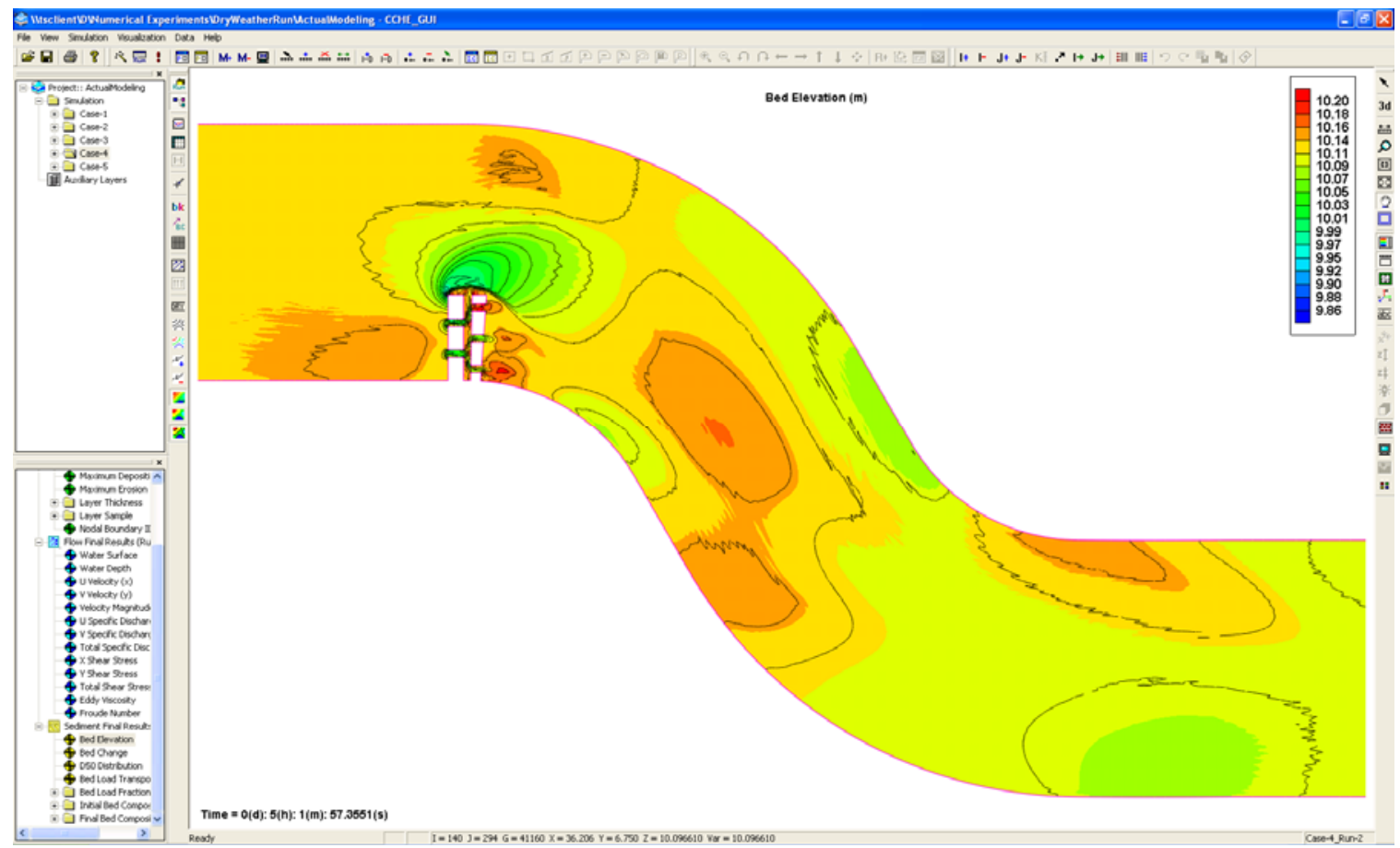

Figure T-2: Bed elevation for dry weather condition between meanders \#1 and \#2 after 5-hr simulation. 


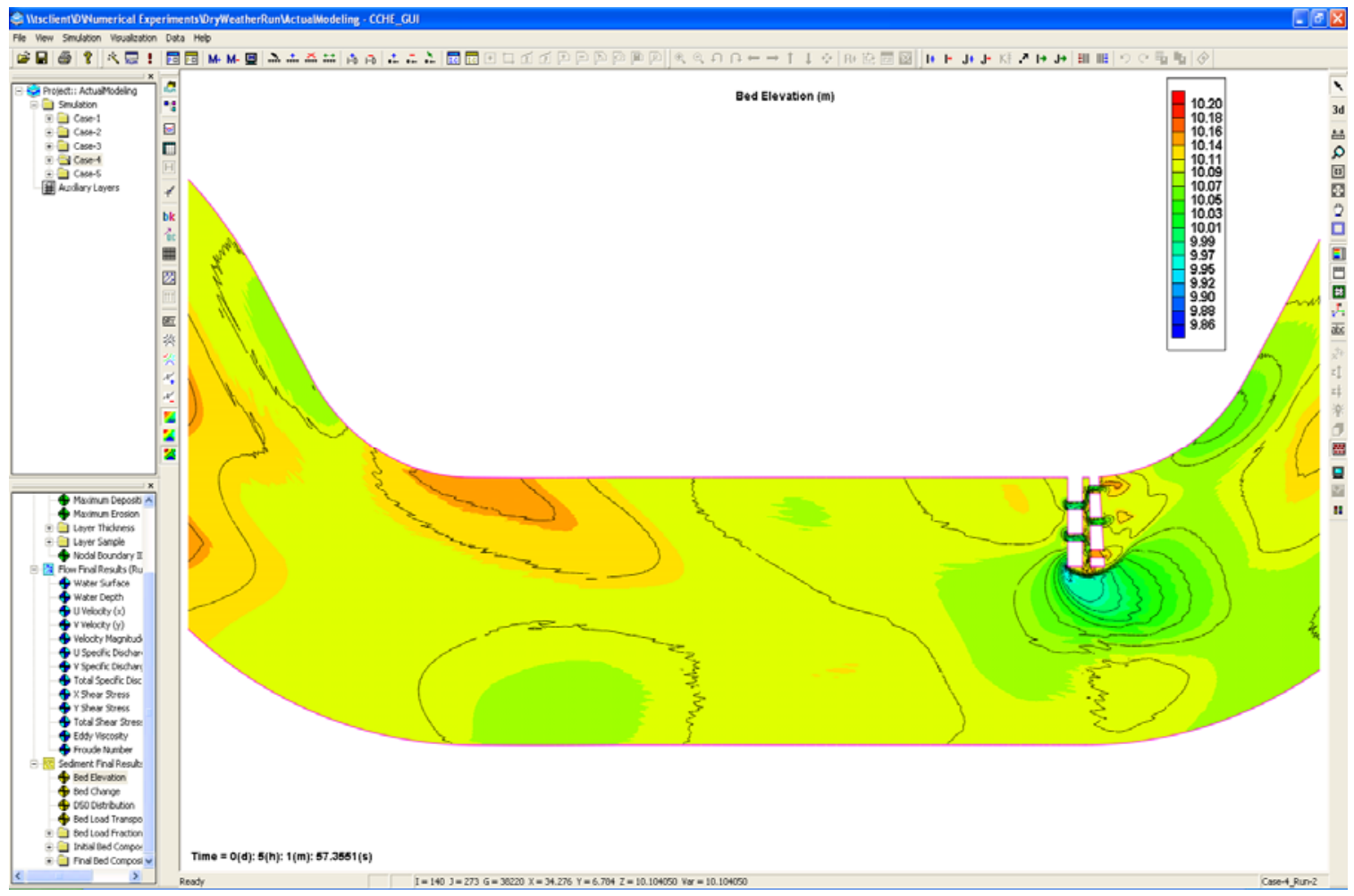

Figure T-3: Bed elevation for dry weather condition between meanders \#2 and \#3 after 5-hr simulation.

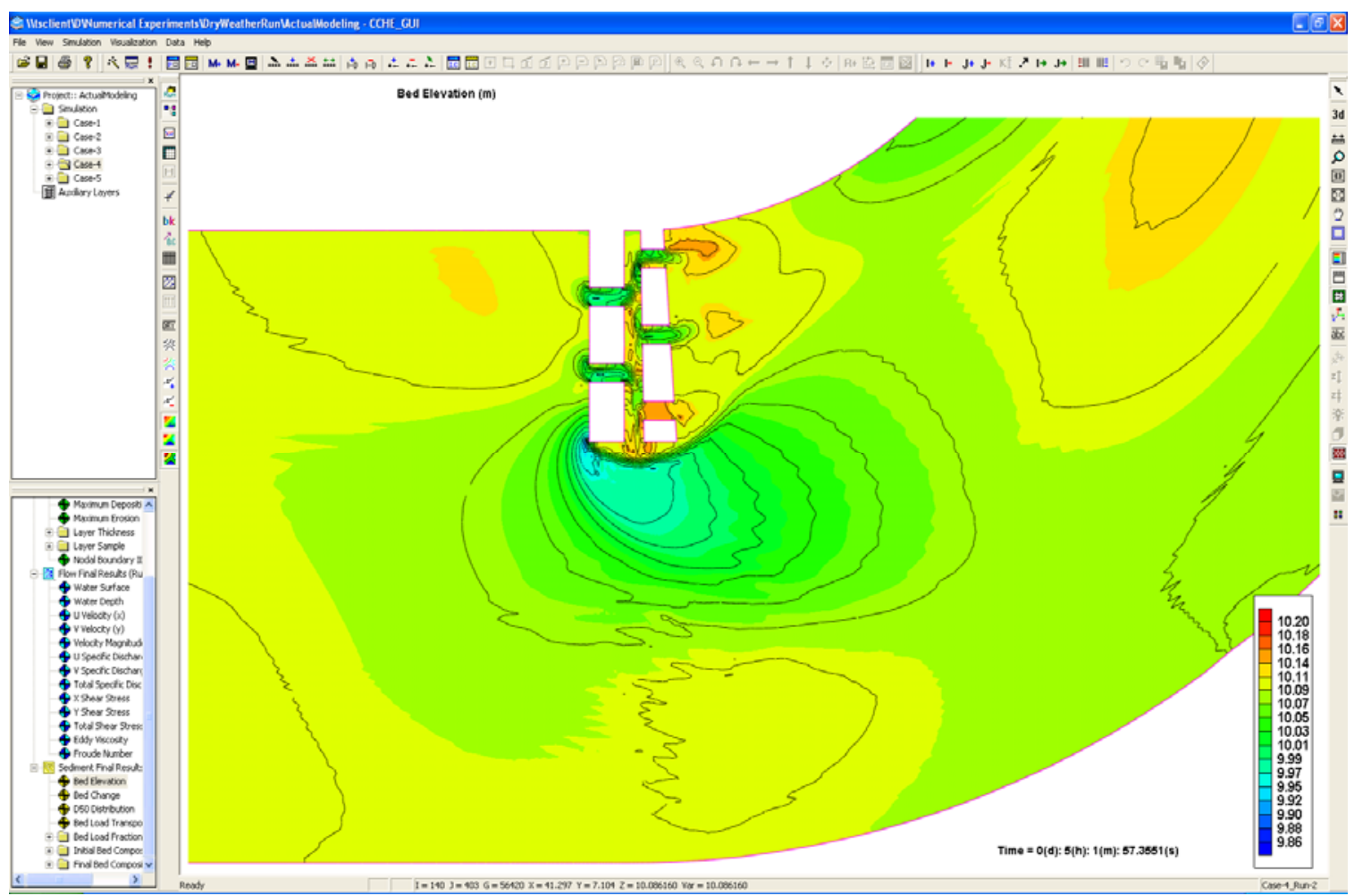

Figure T-4: Bed elevation for dry weather condition at meander \#3 after 5-hr simulation. 


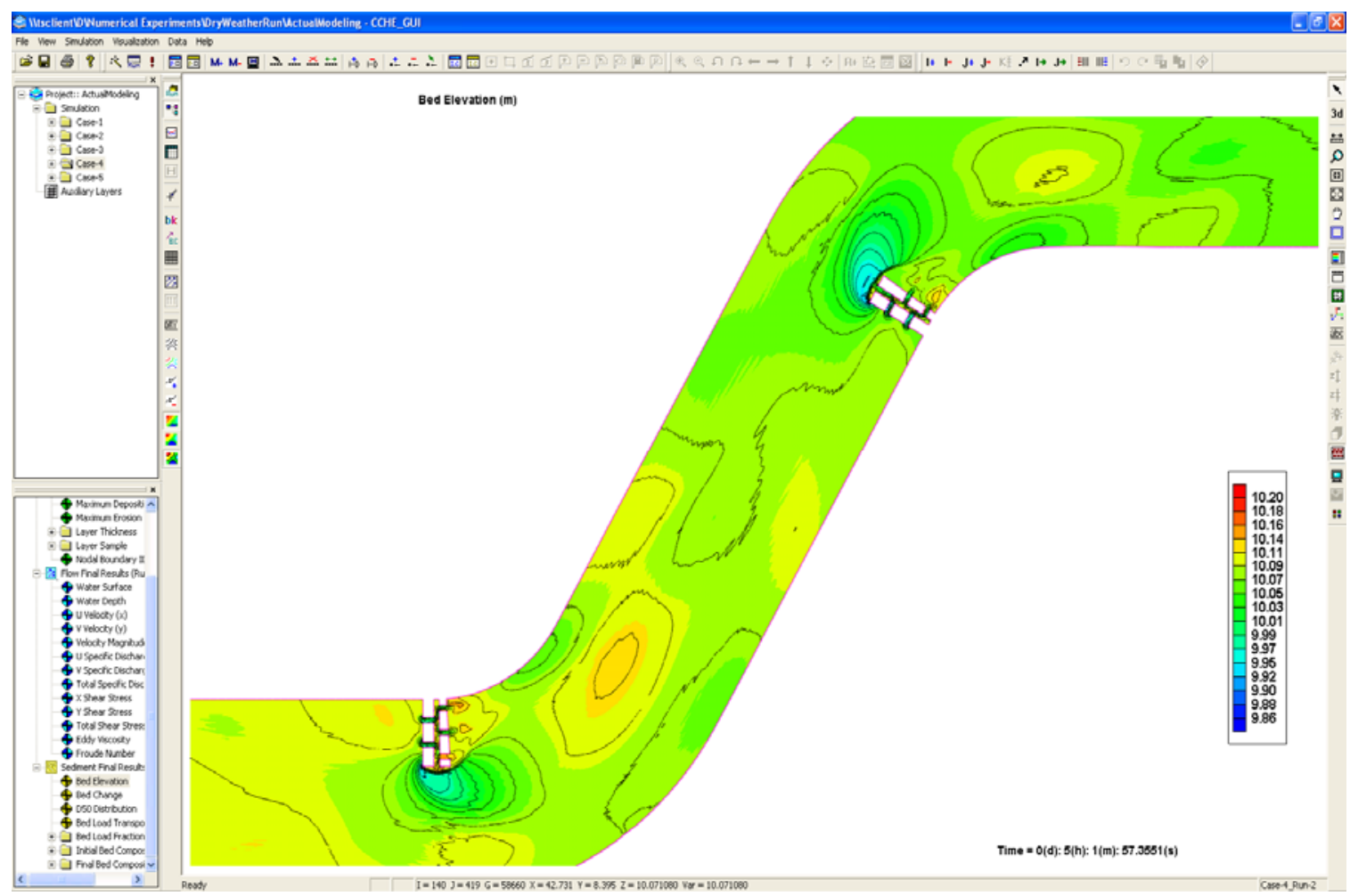

Figure T-5: Bed elevation for dry weather condition between meanders \#3 and \#4 after 5-hr simulation.

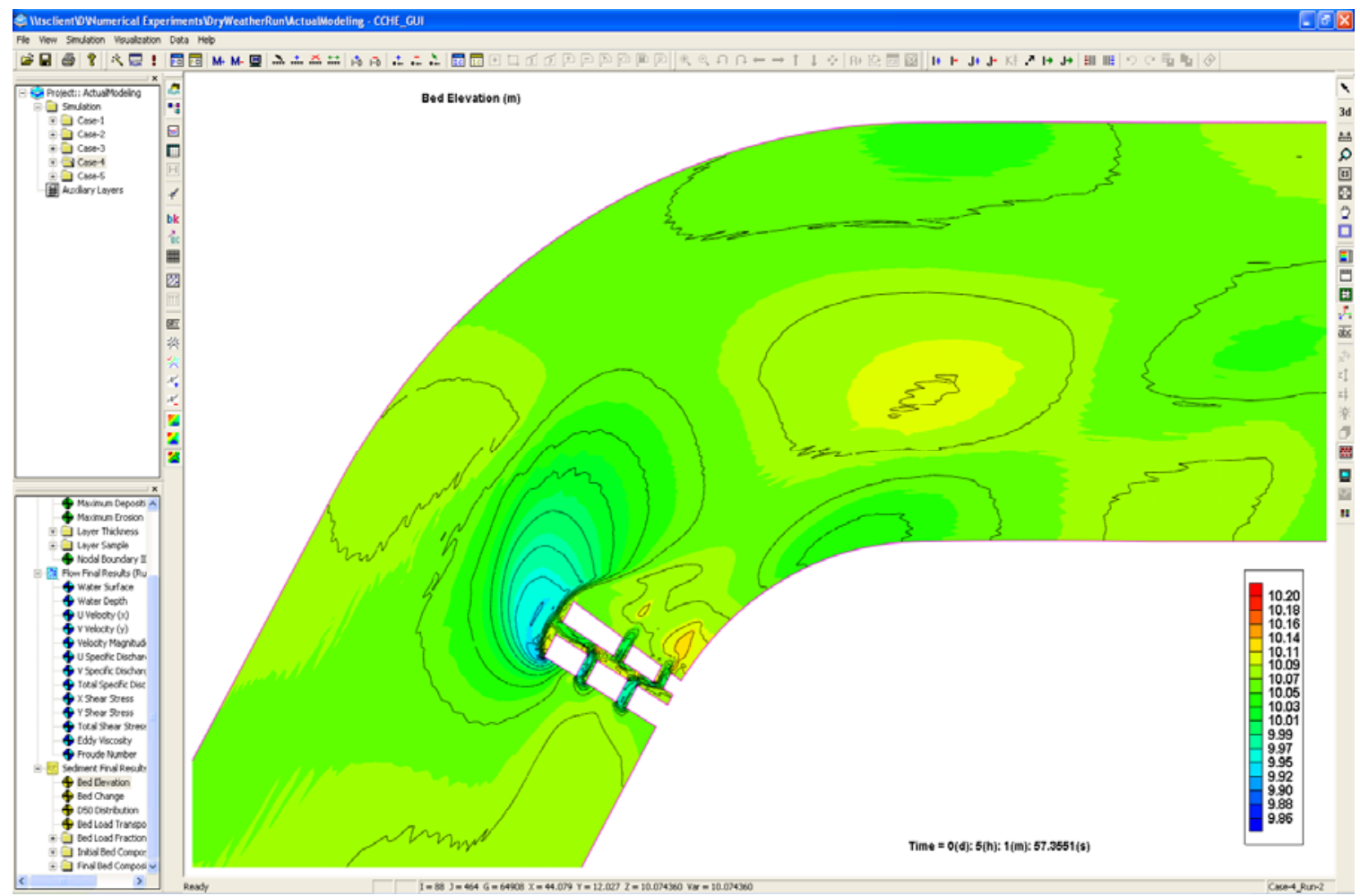

Figure T-6: Bed elevation for dry weather condition at meander \#4 after 5-hr simulation. 


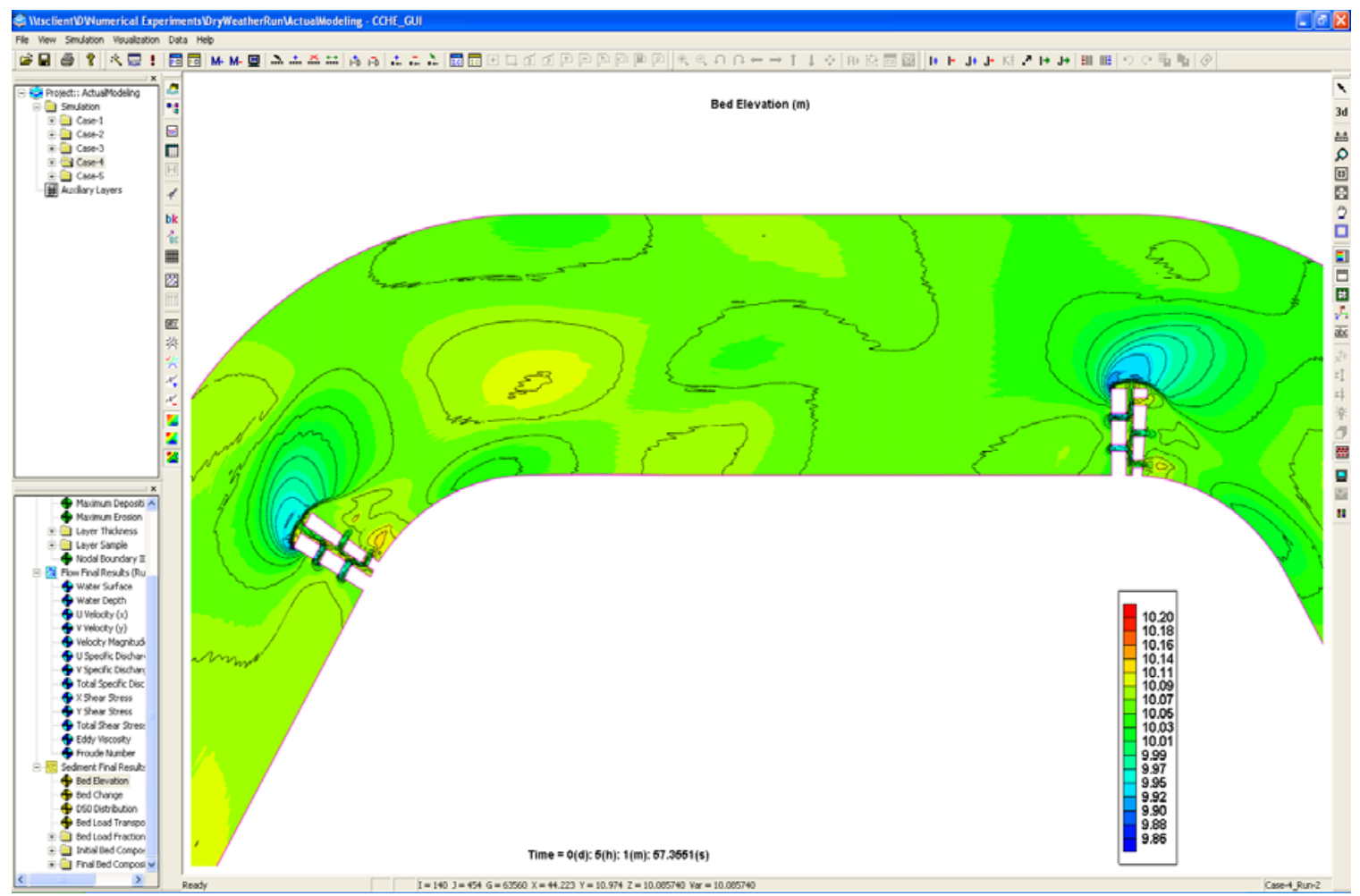

Figure T-7: Bed elevation for dry weather condition between meanders \#4 and \#5 after 5-hr simulation.

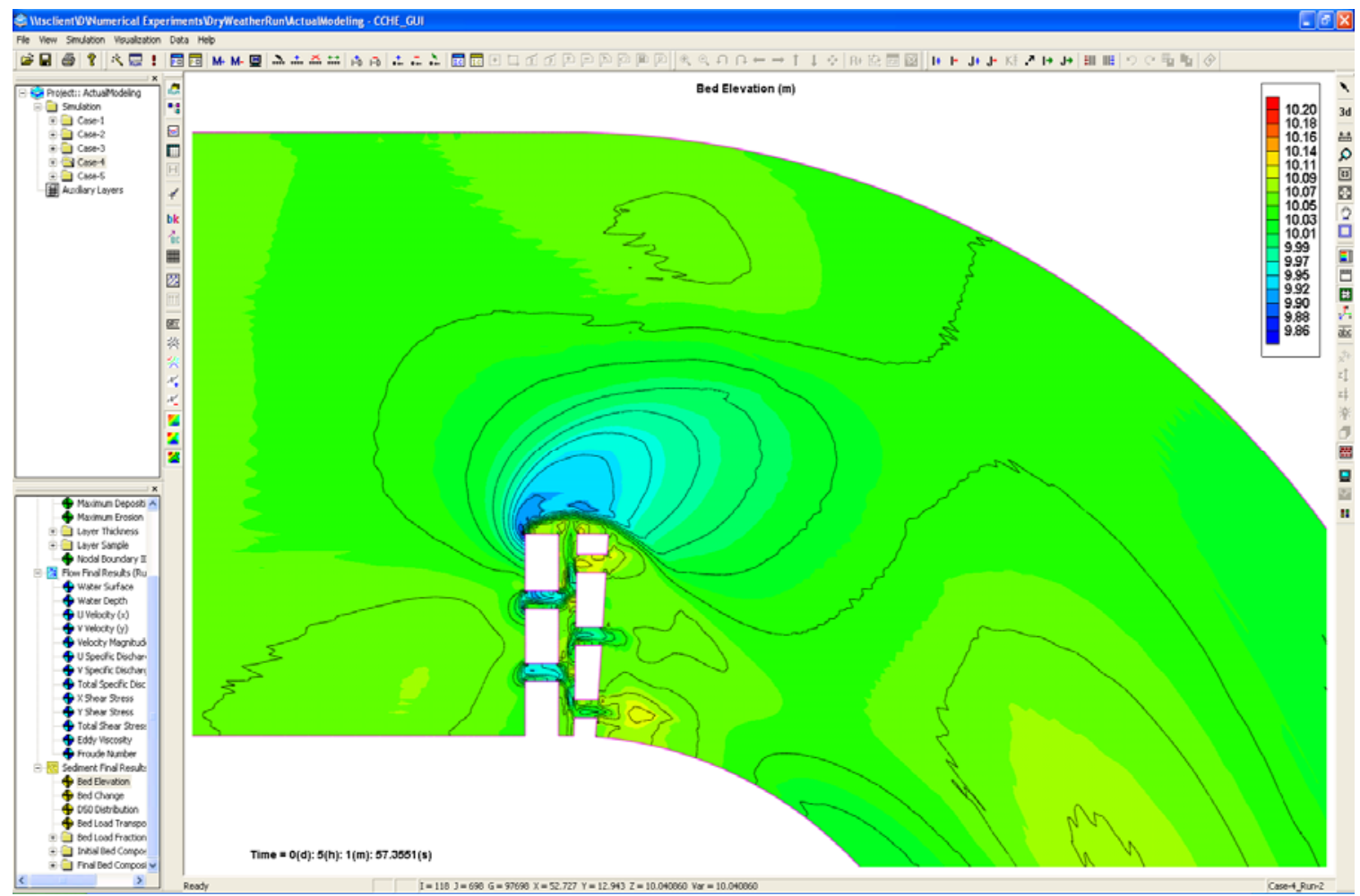

Figure T-8: Bed elevation for dry weather condition at meander \#5 after 5-hr simulation. 


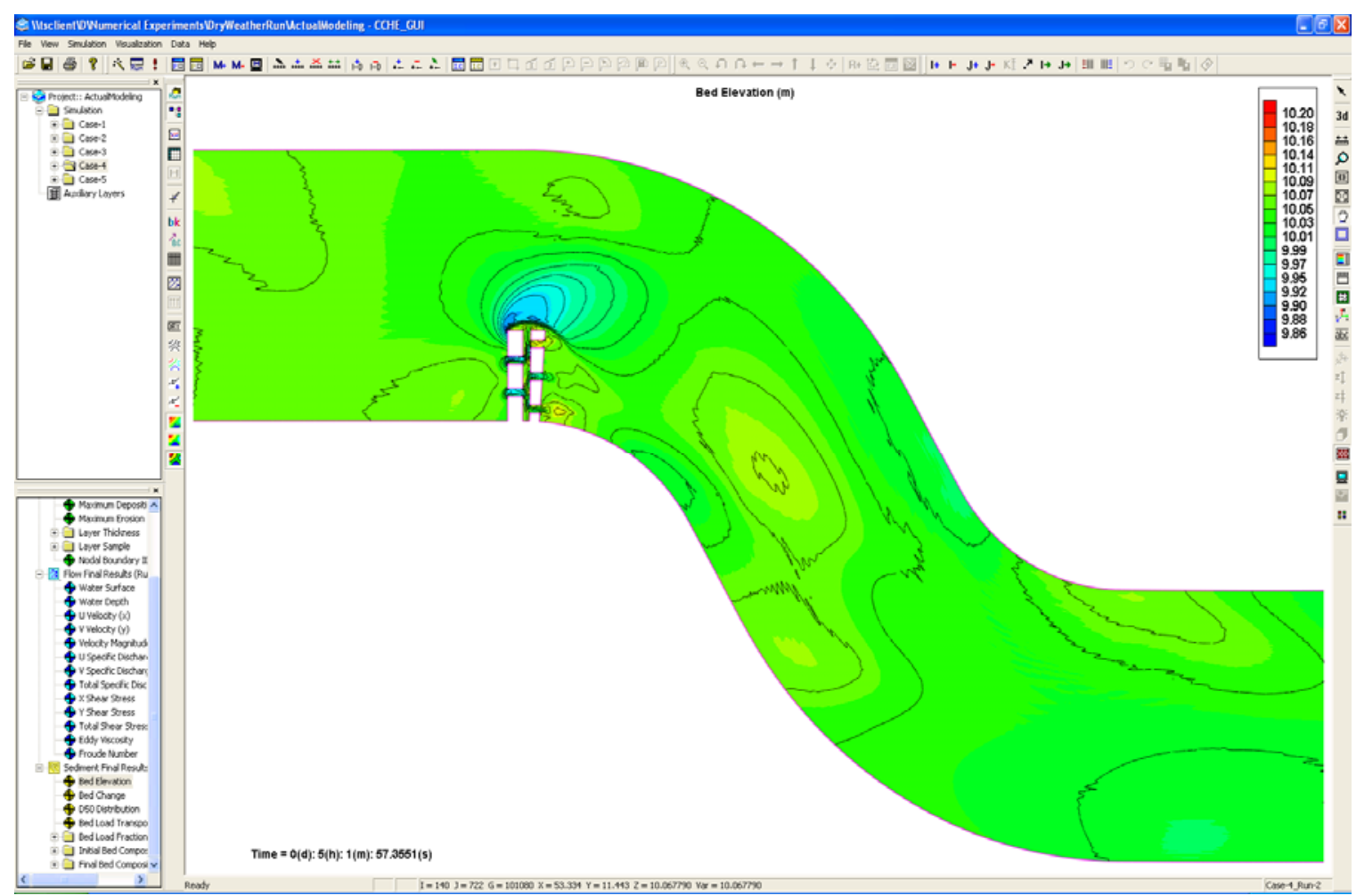

Figure T-9: Bed elevation for dry weather condition between meanders \#5 and \#6 after 5-hr simulation.

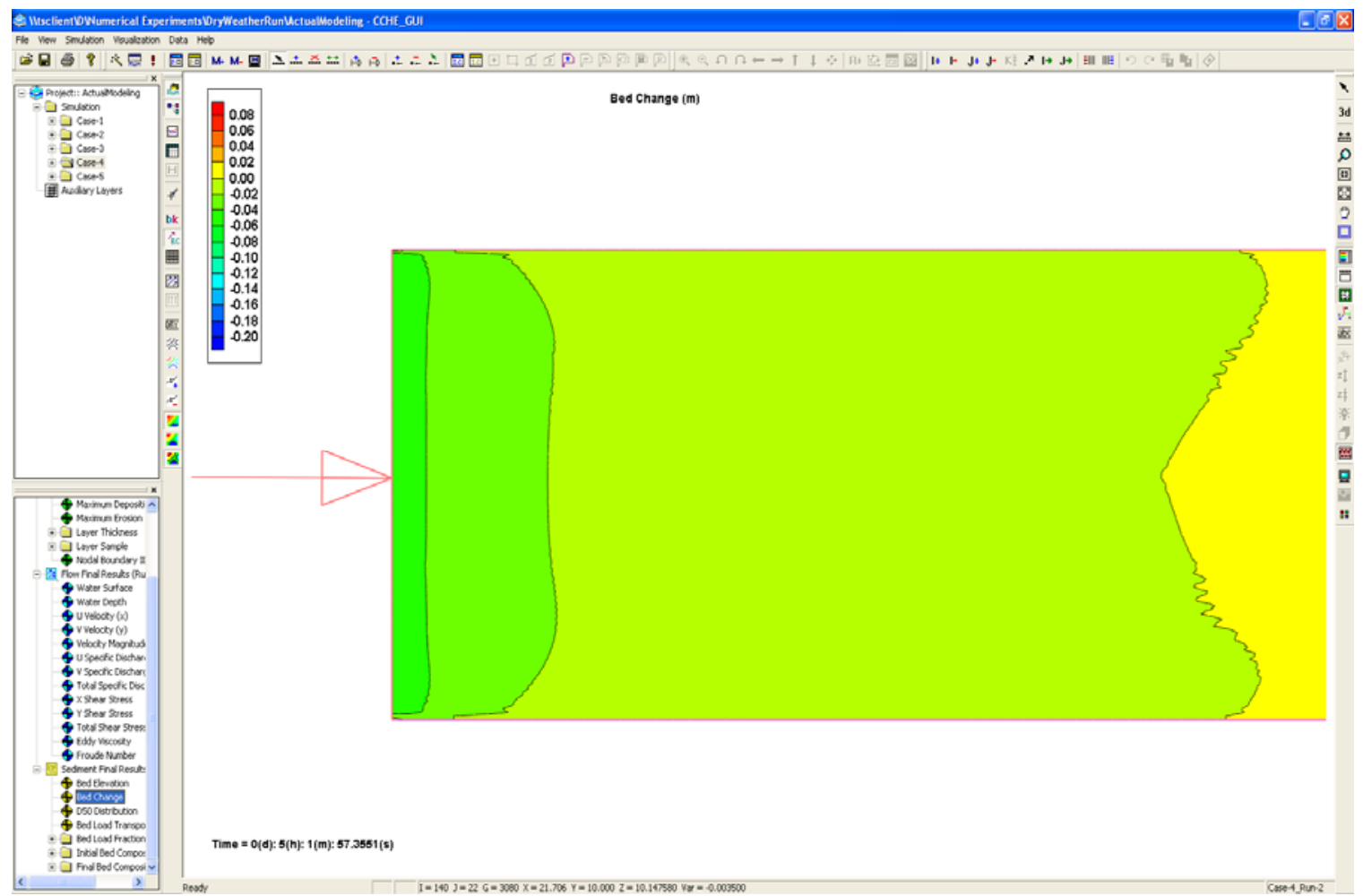

Figure T-10: Bed change for dry weather condition at upstream boundary after 5-hr simulation. 


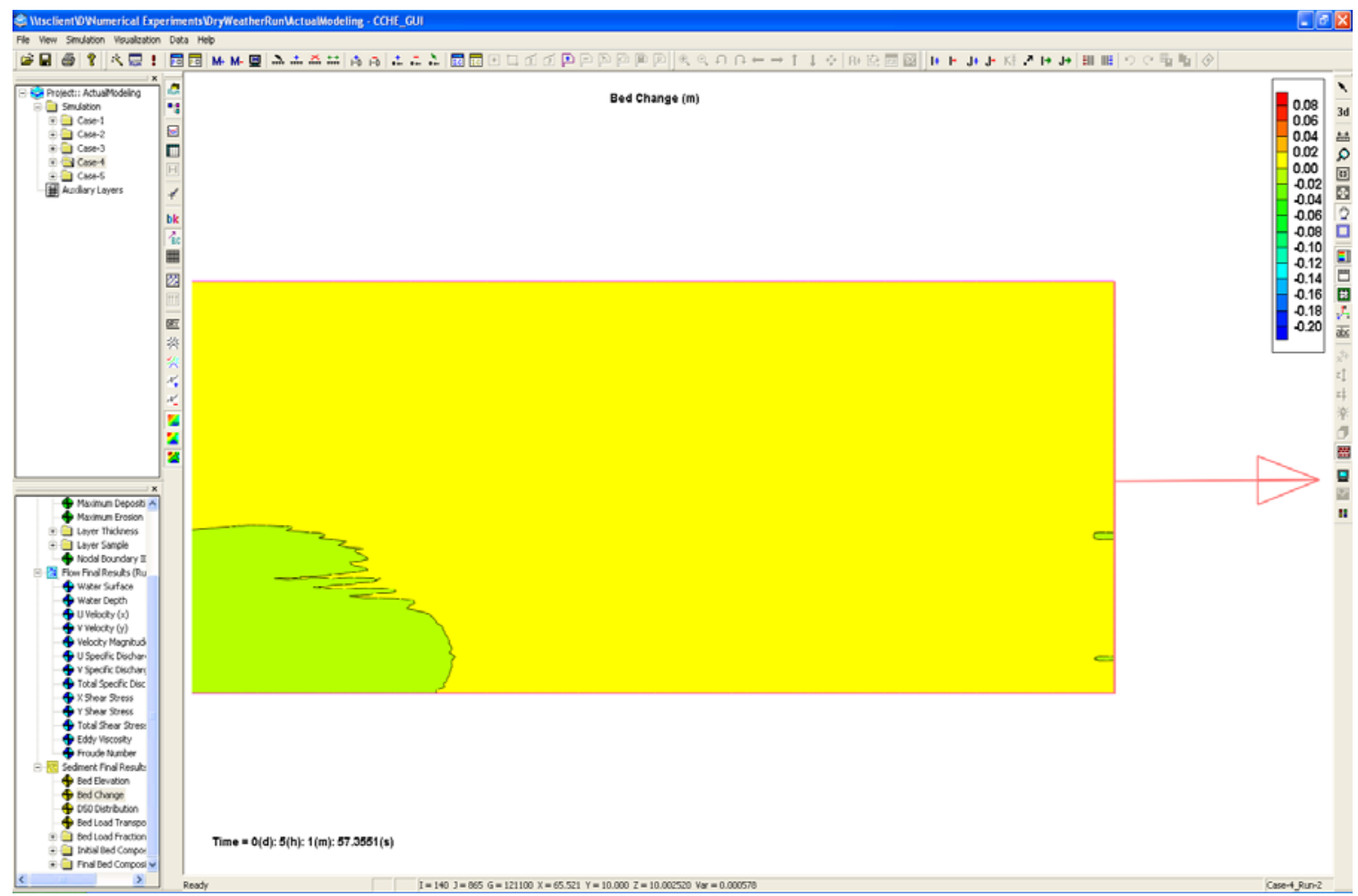

Figure T-11: Bed change for dry weather condition at downstream boundary after 5 -hr simulation.

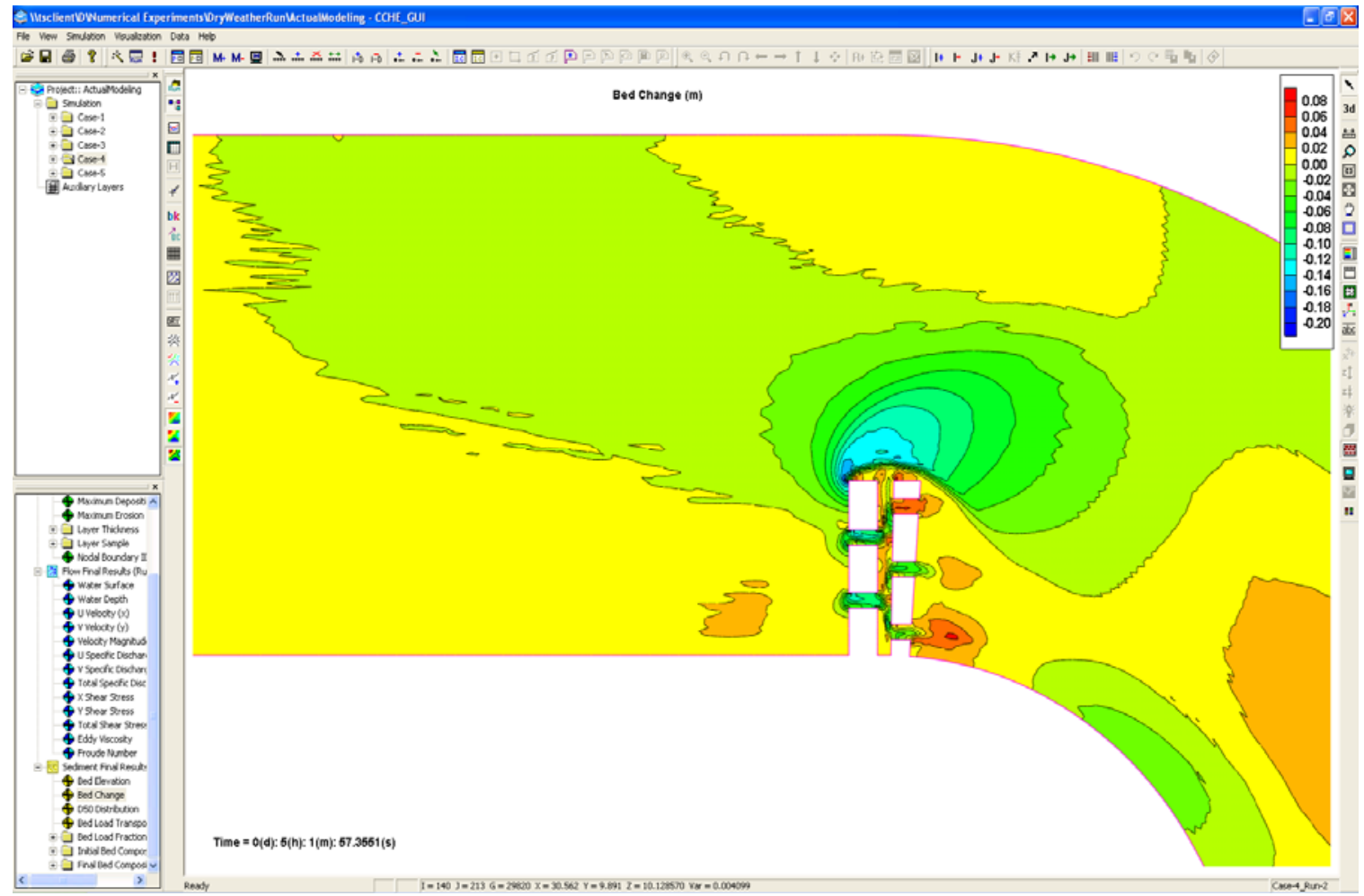

Figure T-12: Bed change for dry weather condition at meander \#1 after 5-hr simulation. 


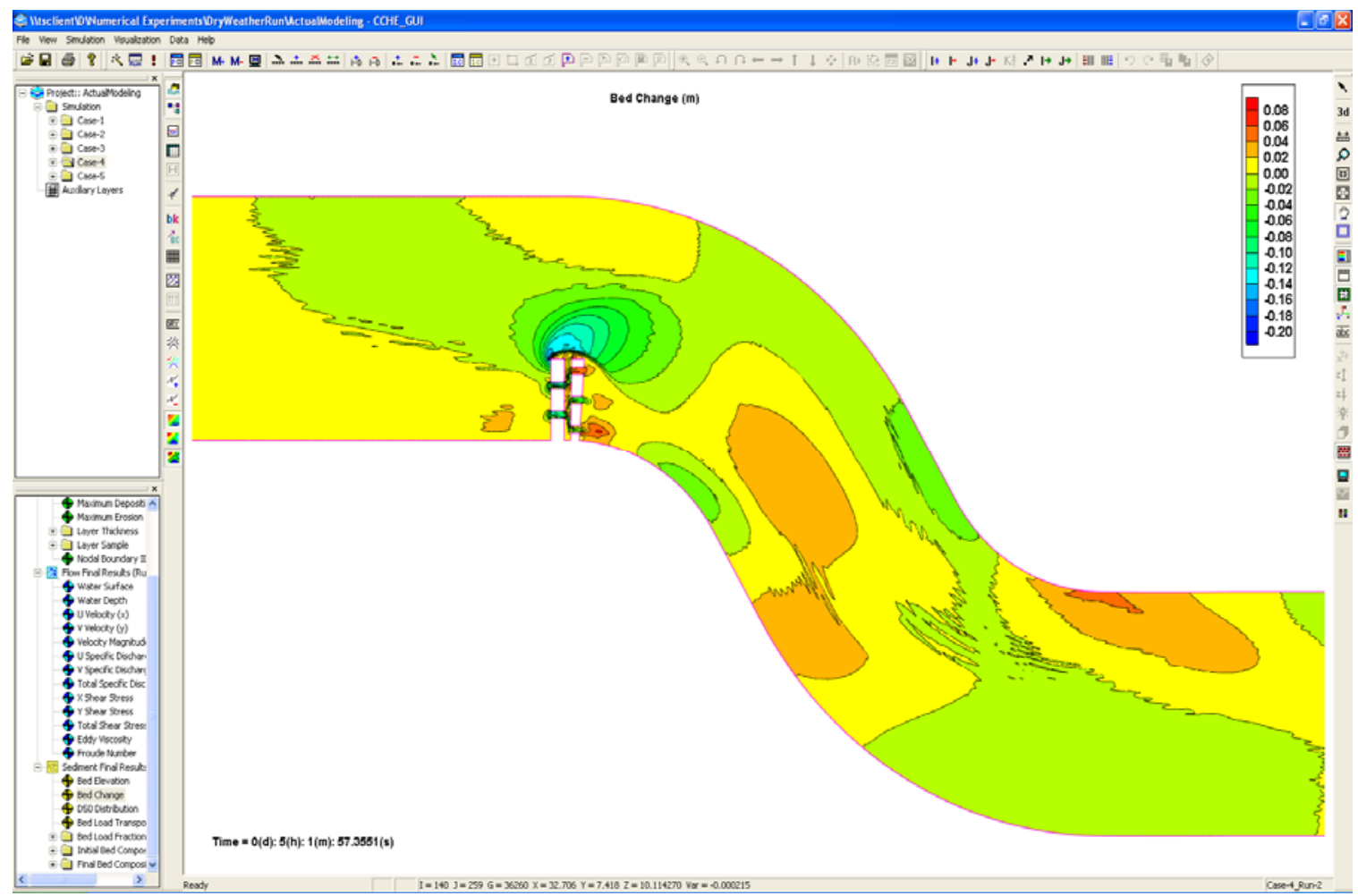

Figure T-13: Bed change for dry weather condition between meanders \#1 and \#2 after 5-hr simulation.

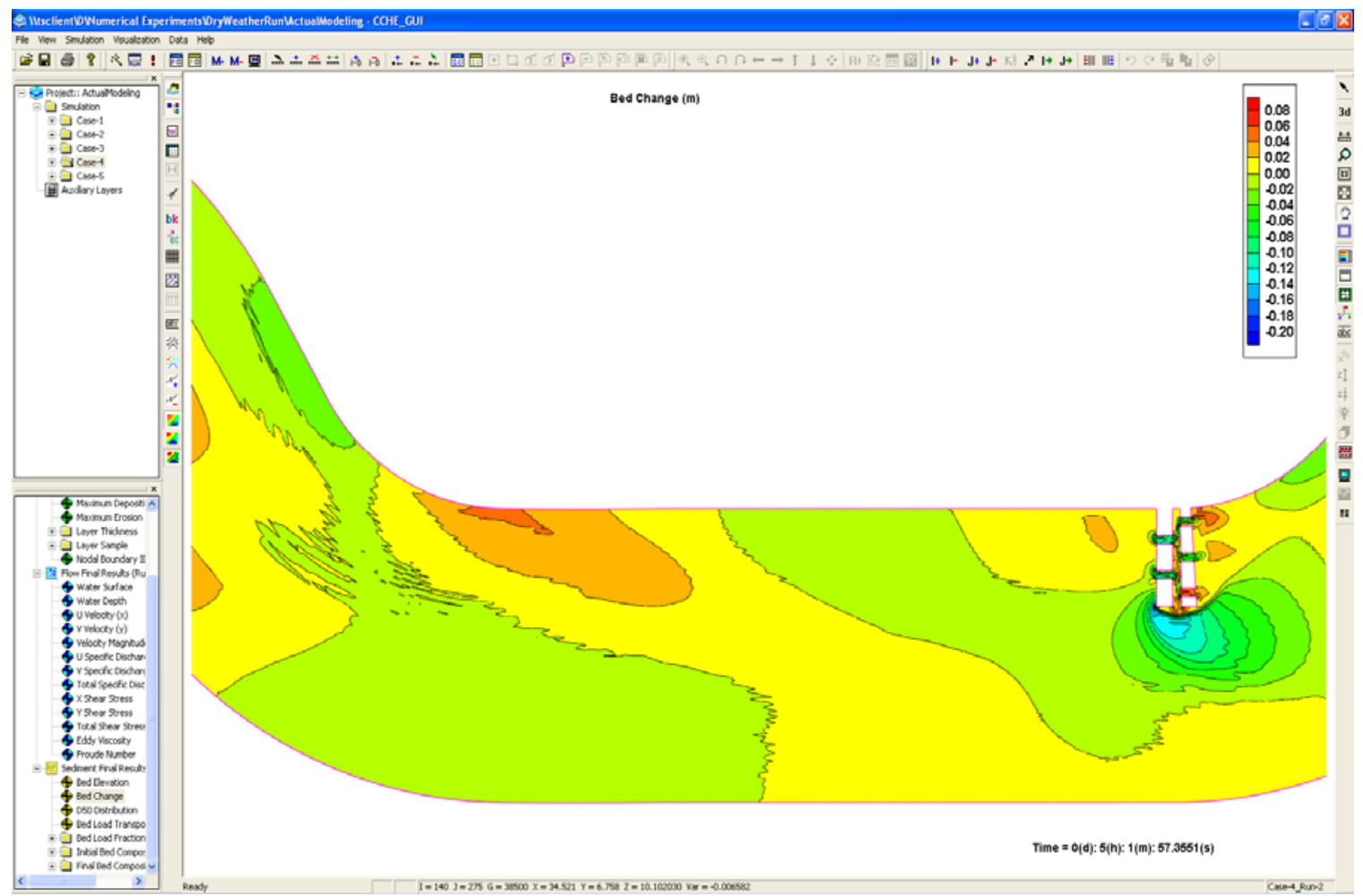

Figure T-14: Bed change for dry weather condition between meanders \#2 and \#3 after 5-hr simulation. 


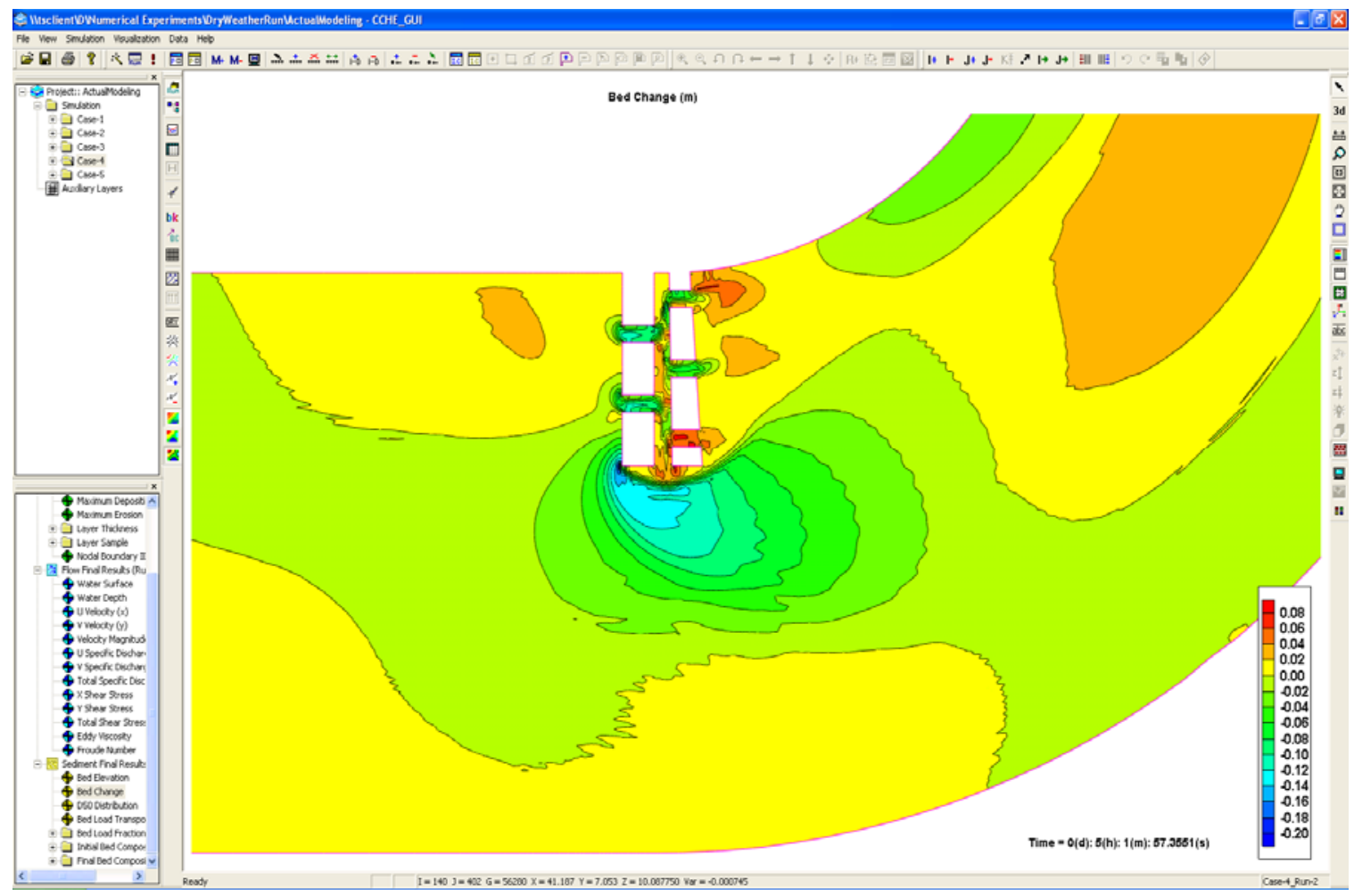

Figure T-15: Bed change for dry weather condition at meander \#3 after 5-hr simulation.

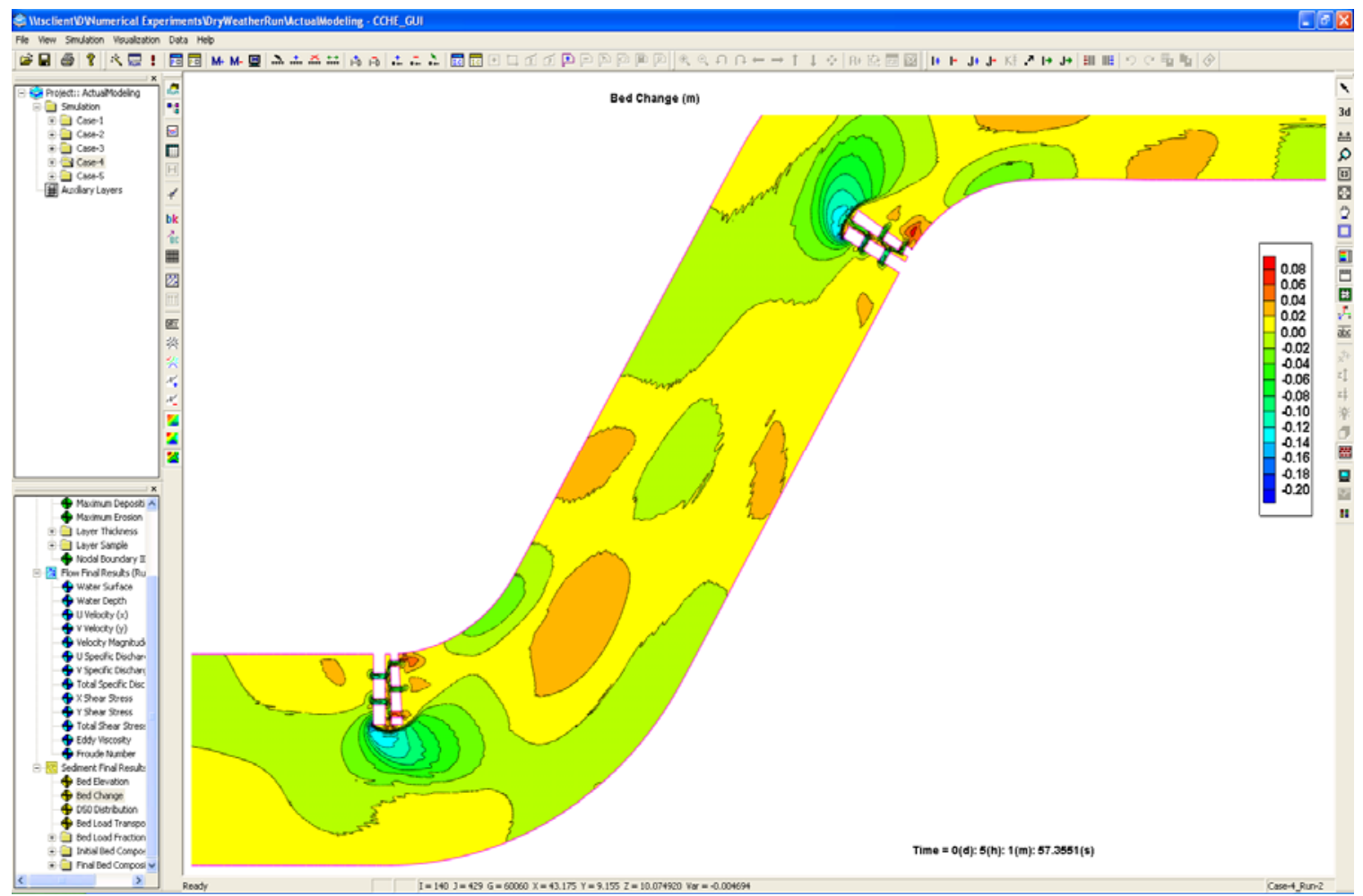

Figure T-16: Bed change for dry weather condition between meanders \#3 and \#4 after 5-hr simulation. 


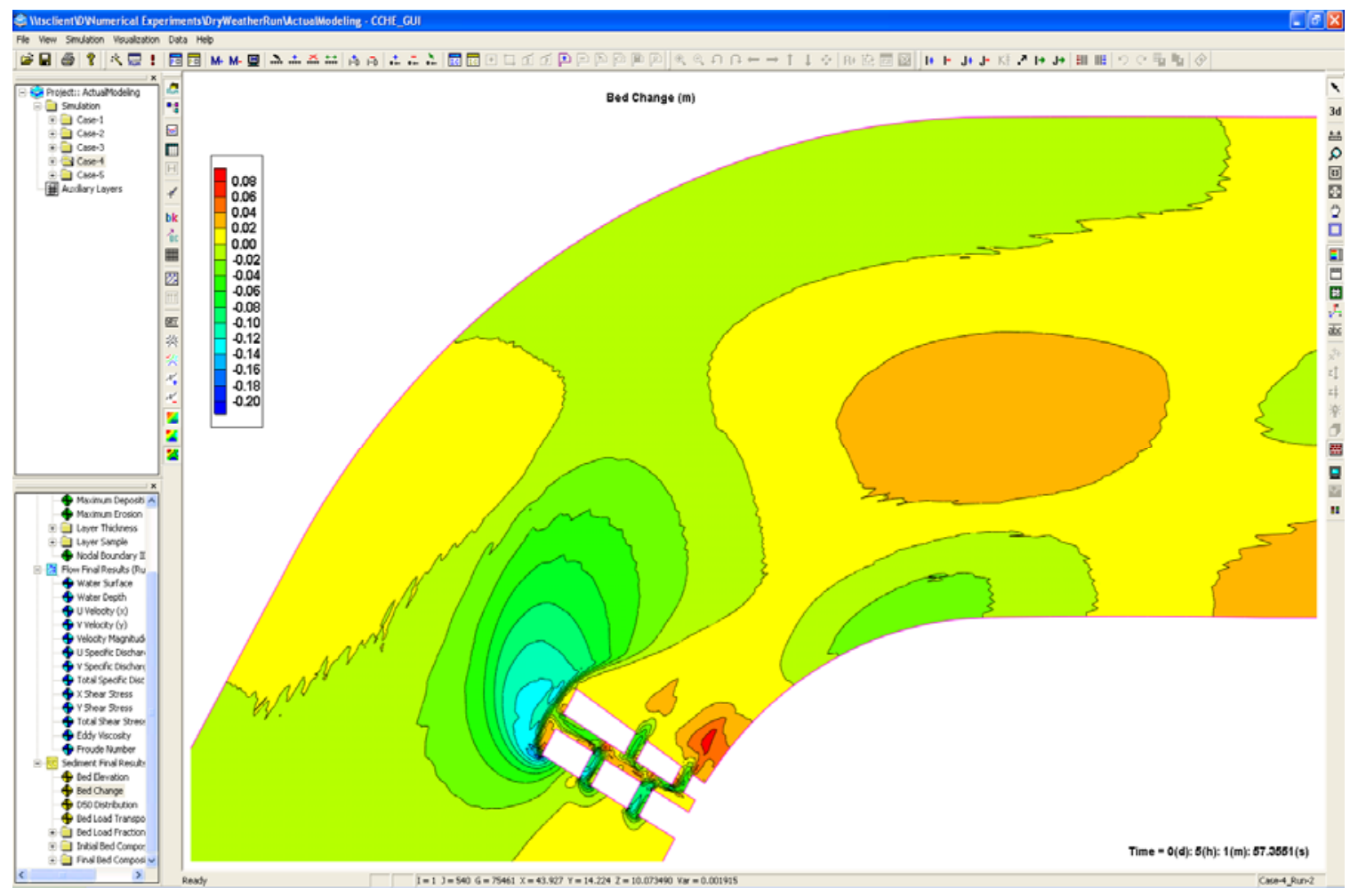

Figure T-17: Bed change for dry weather condition at meander \#4 after 5-hr simulation.

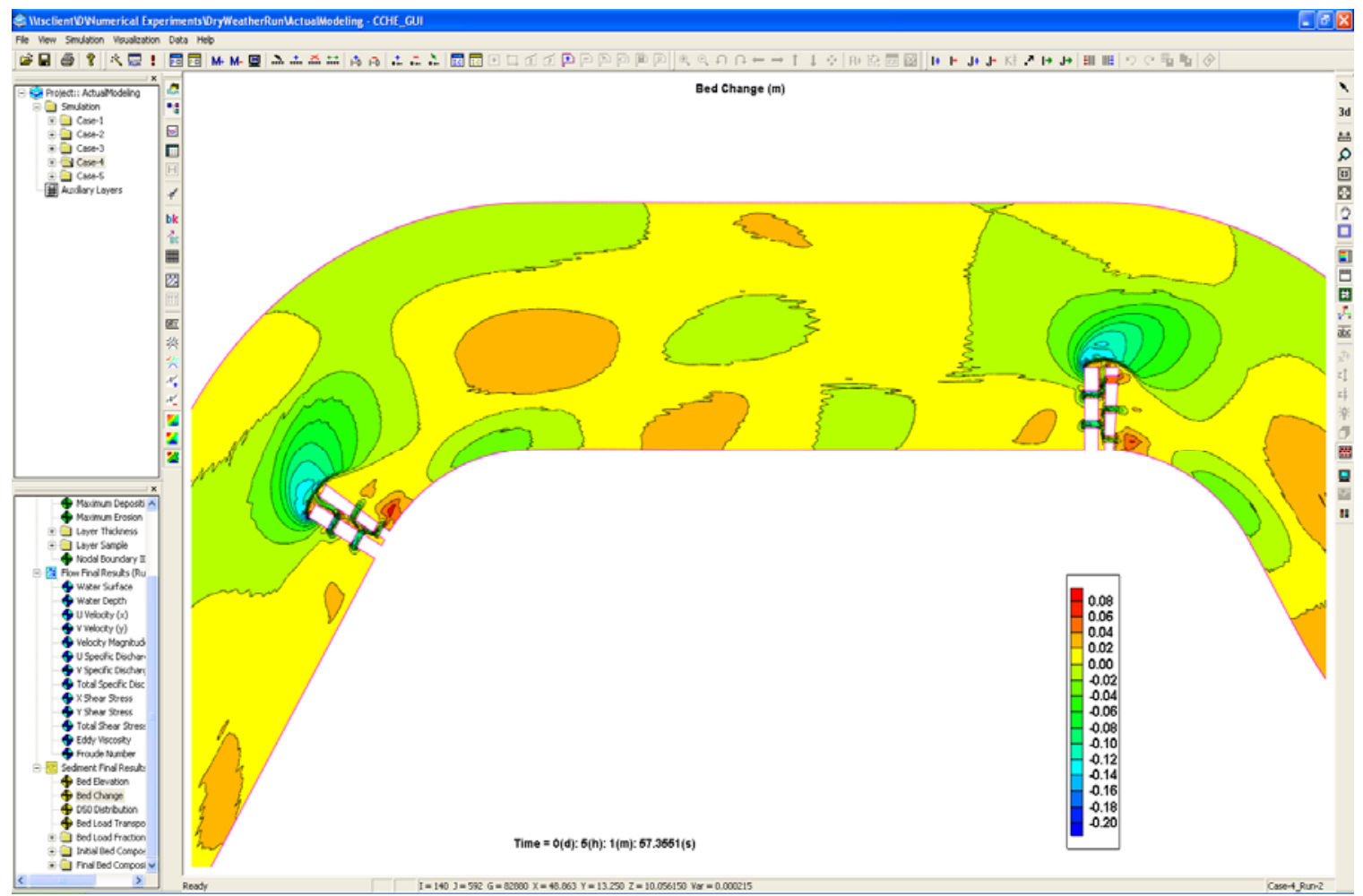

Figure T-18: Bed change for dry weather condition between meanders \#4 and \#5 after 5-hr simulation. 


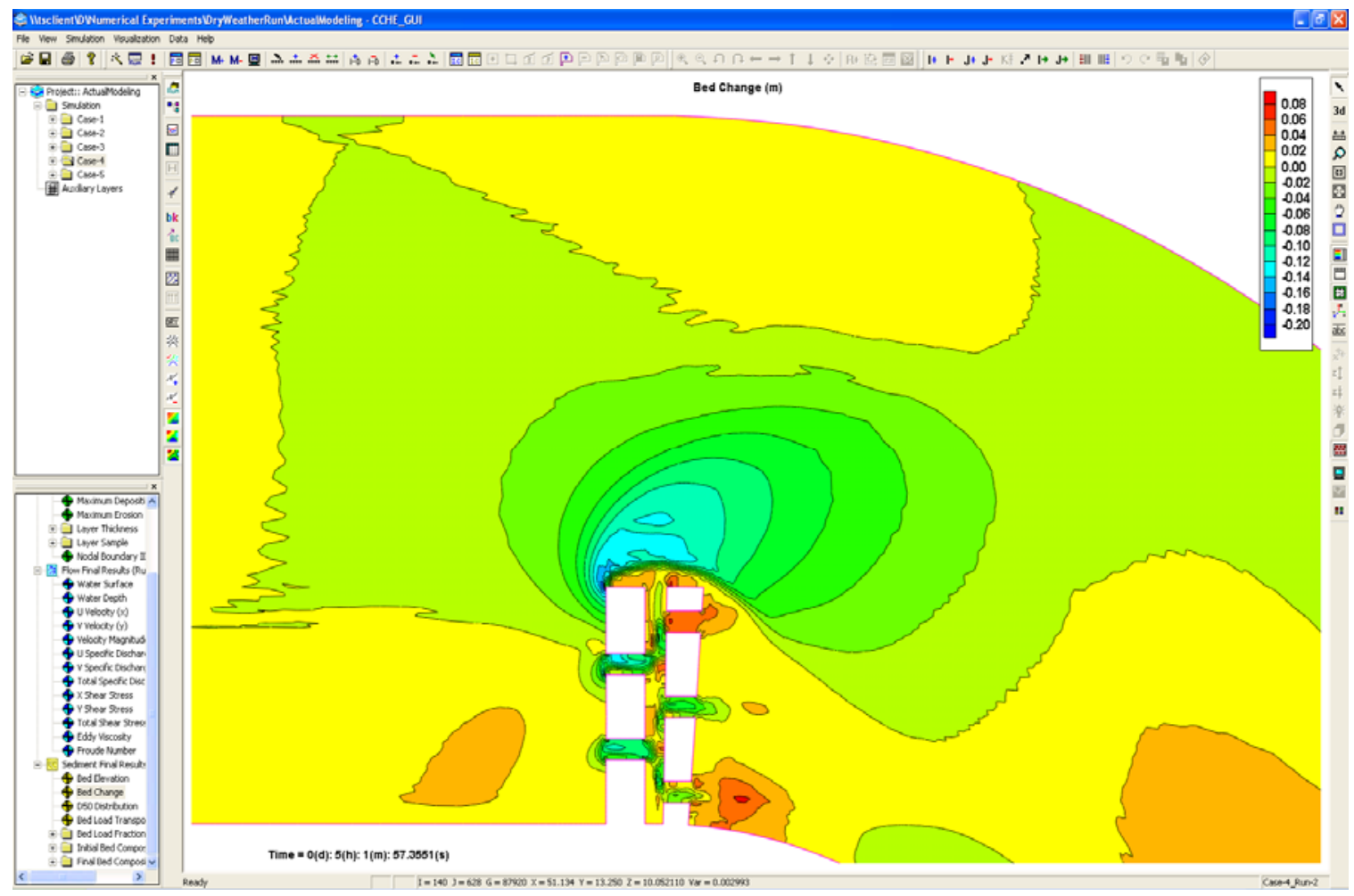

Figure T-19: Bed change for dry weather condition at meander \#5 after 5-hr simulation.

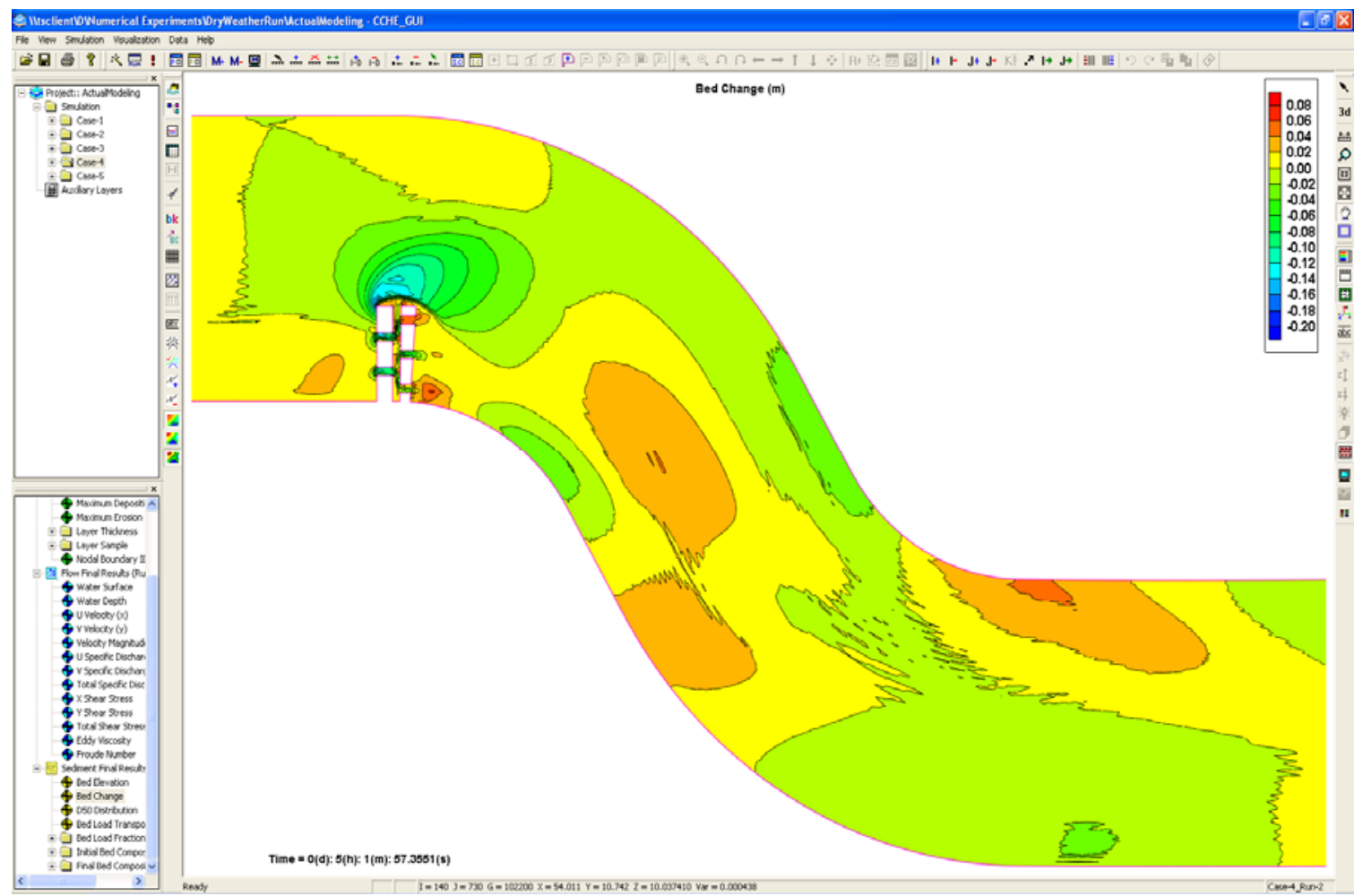

Figure T-20: Bed change for dry weather condition between meanders \#5 and \#6 after 5-hr simulation. 


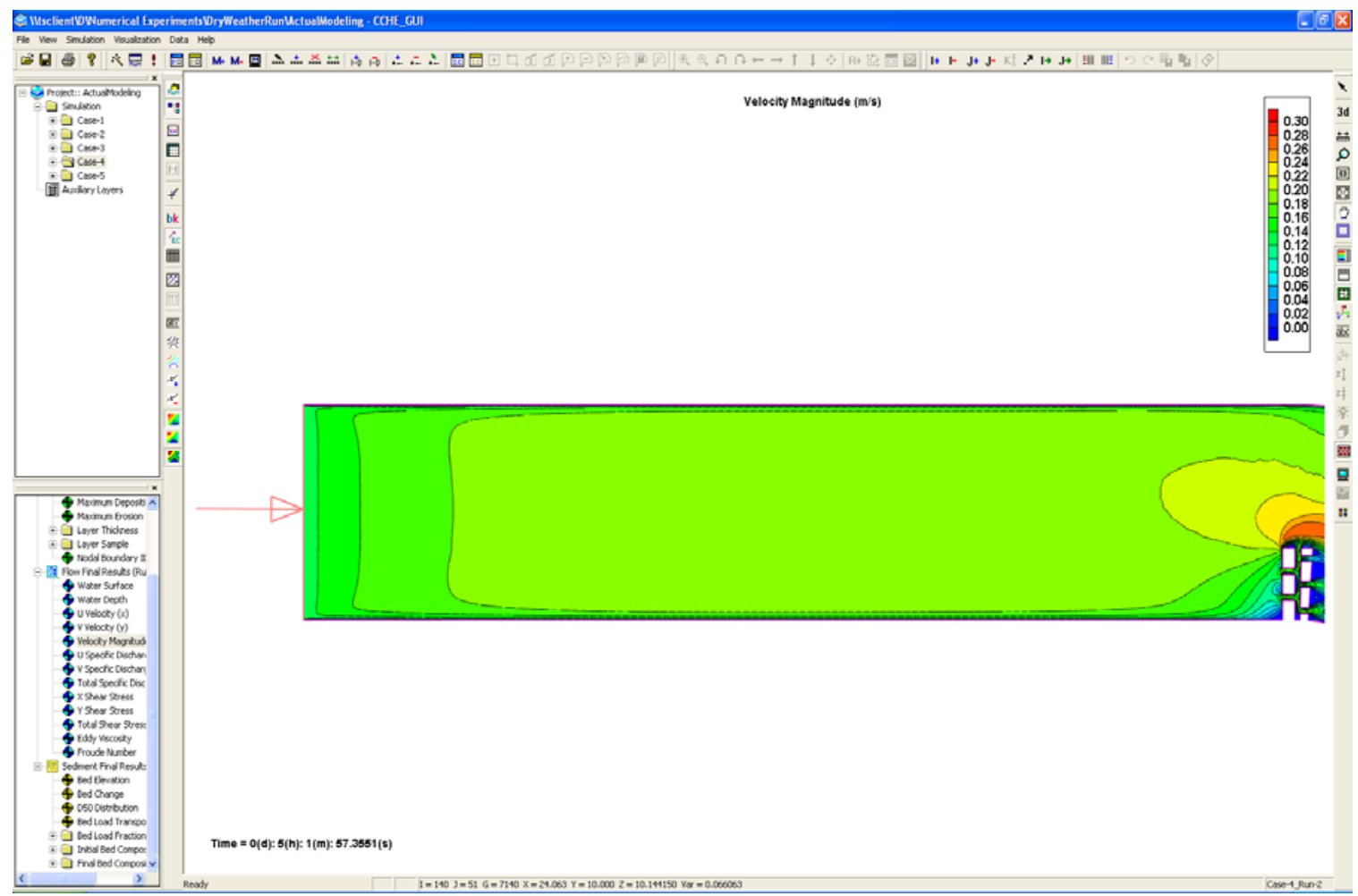

Figure T-21: Velocity magnitude for dry weather condition at upstream boundary after 5-hr simulation.

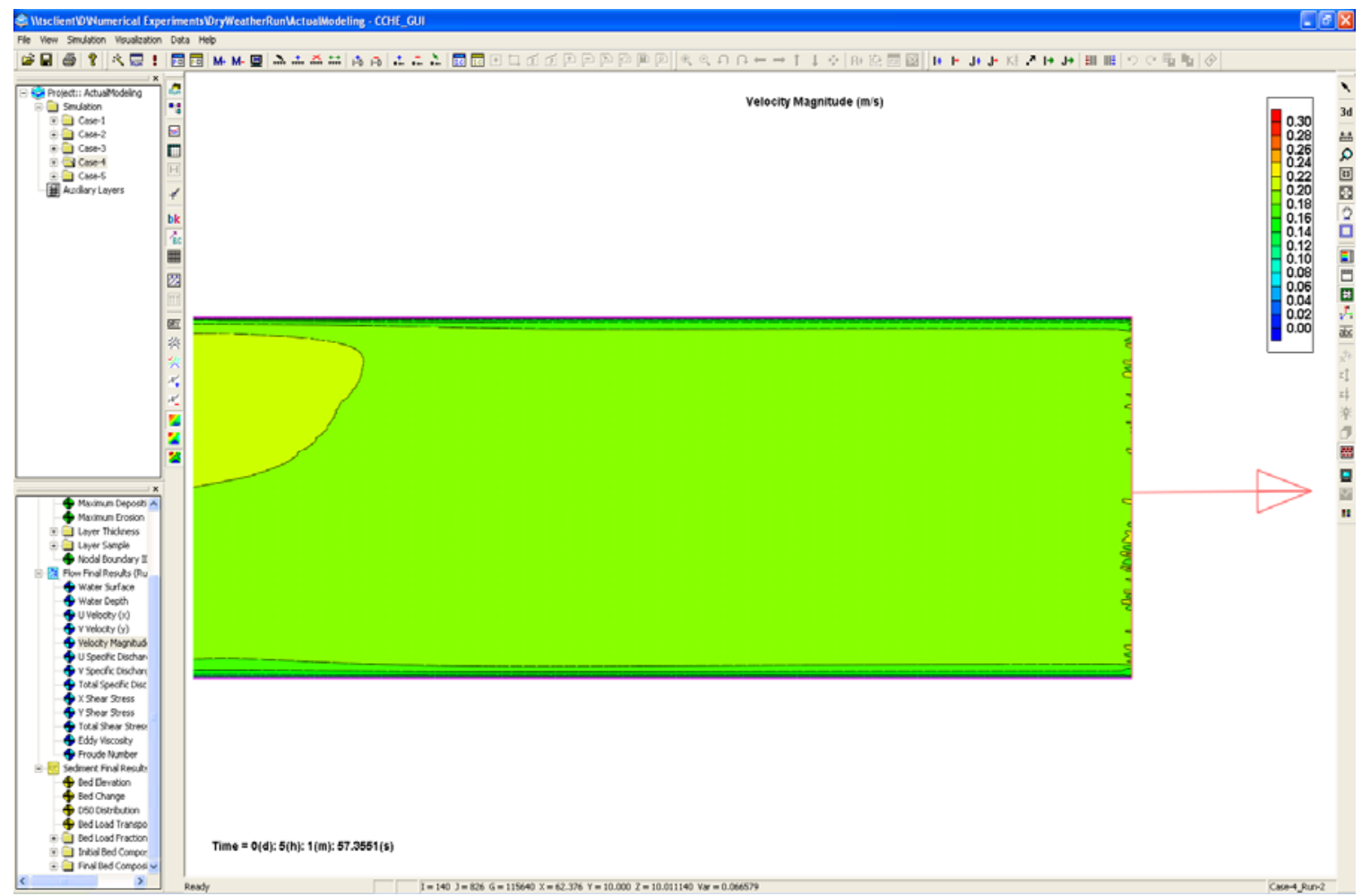

Figure T-22: Velocity magnitude for dry weather condition at downstream boundary after $5-\mathrm{hr}$ simulation. 


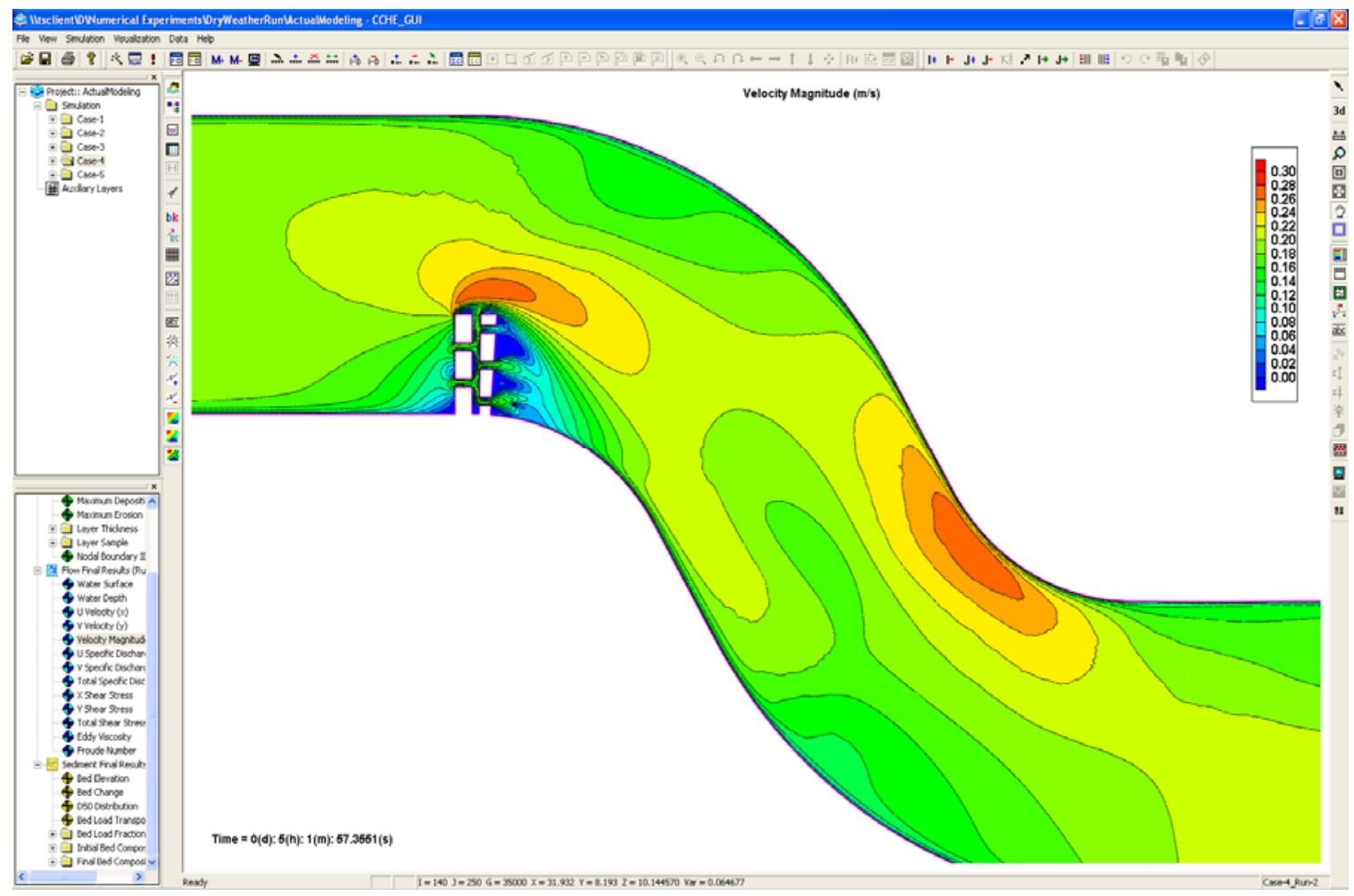

Figure T-23: Velocity magnitude for dry weather condition between meanders \#1 and \#2 after 5-hr simulation.

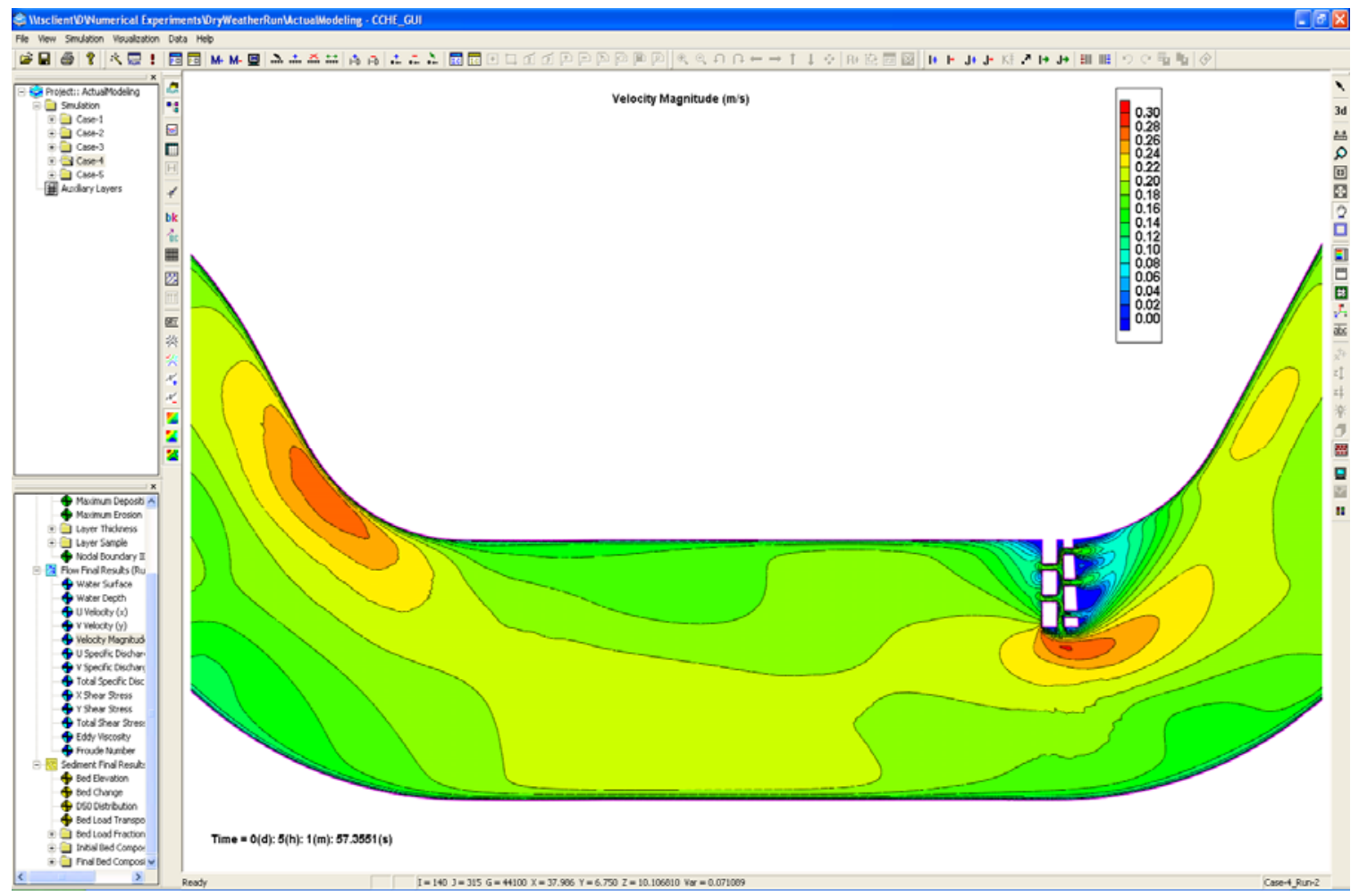

Figure T-24: Velocity magnitude for dry weather condition between meanders \#2 and \#3 after 5-hr simulation. 


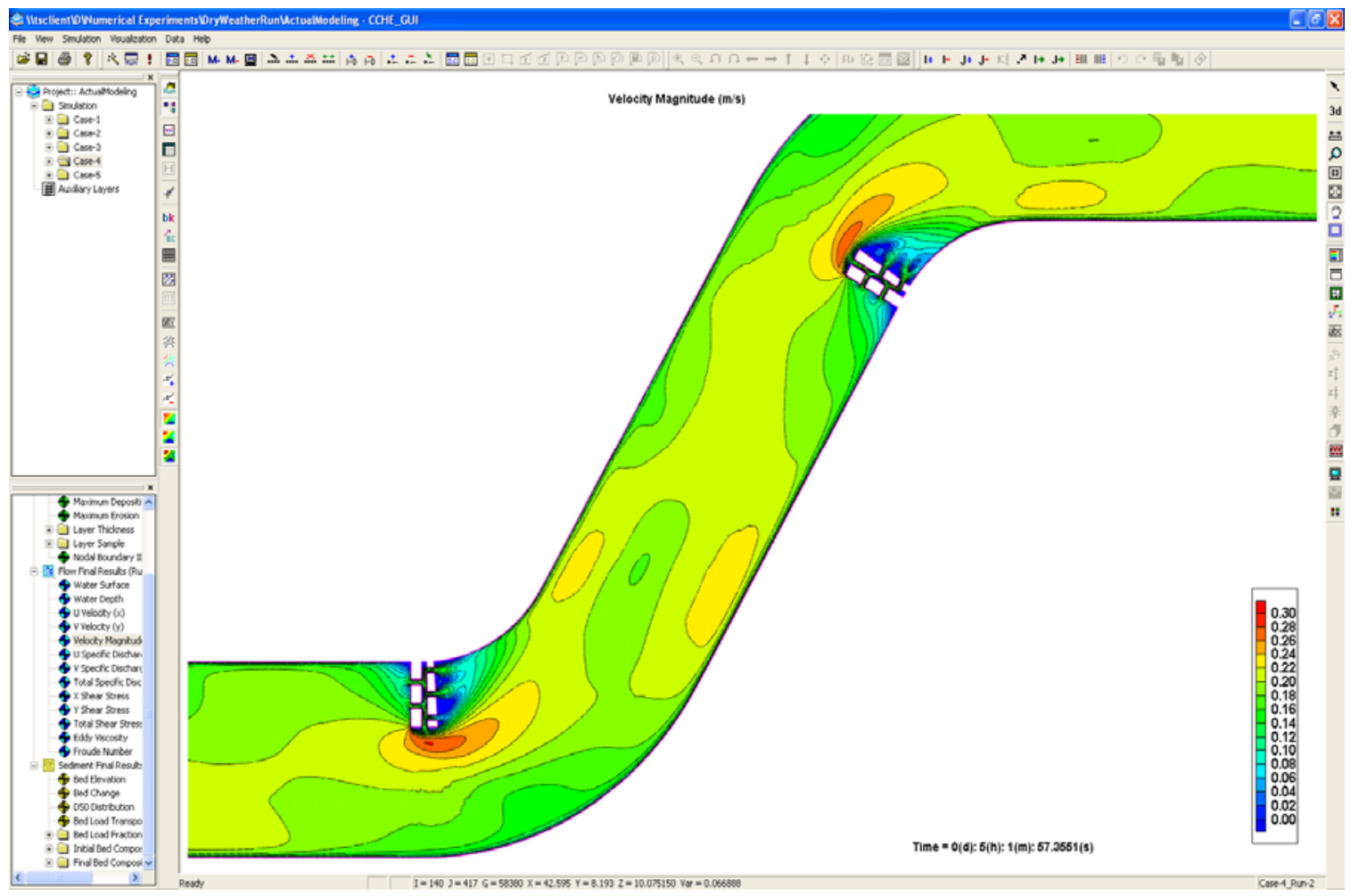

Figure T-25: Velocity magnitude for dry weather condition between meanders \#3 and \#4 after 5-hr simulation.

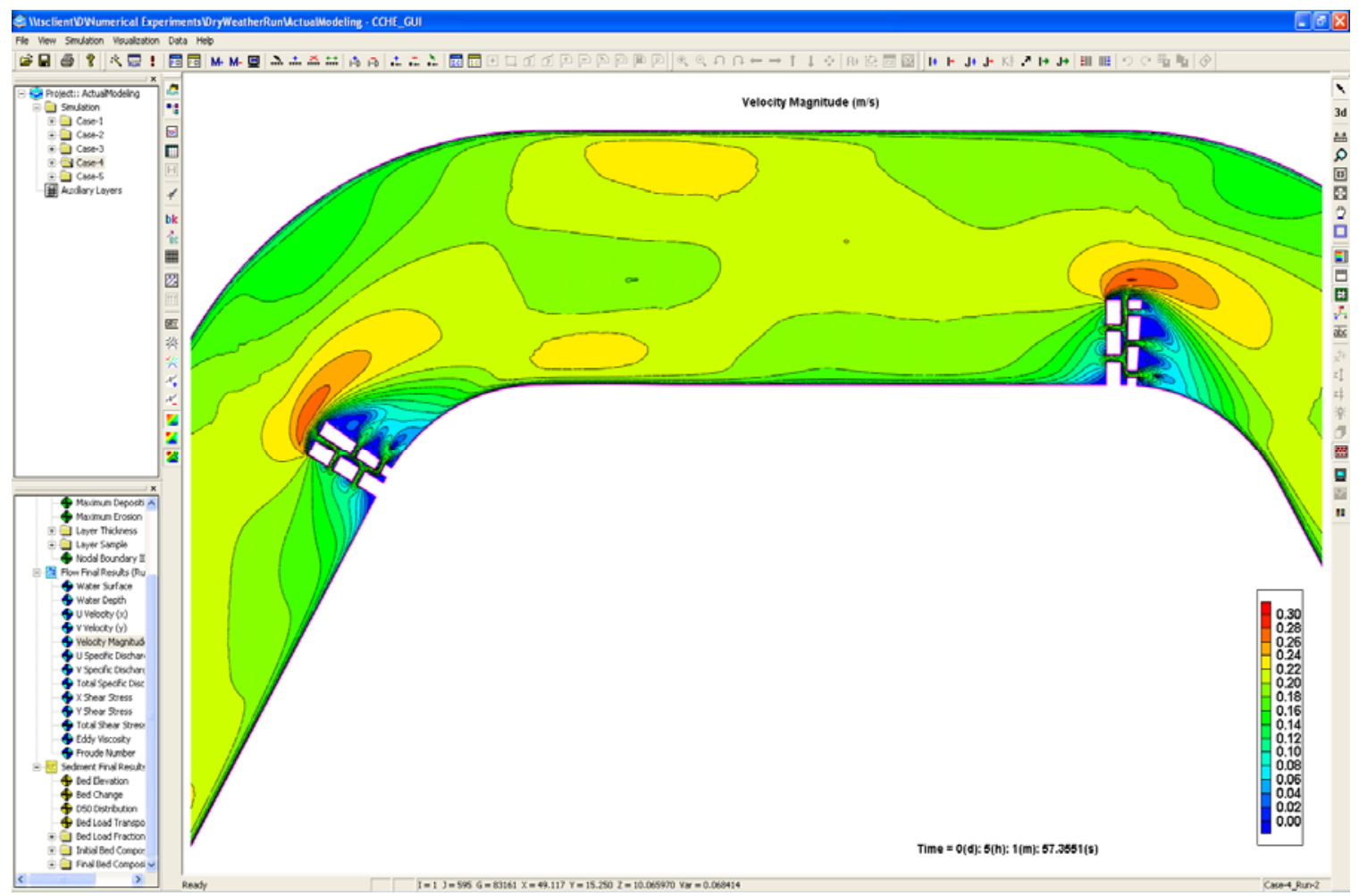


Figure T-26: Velocity magnitude for dry weather condition between meanders \#4 and \#5 after 5-hr simulation. 


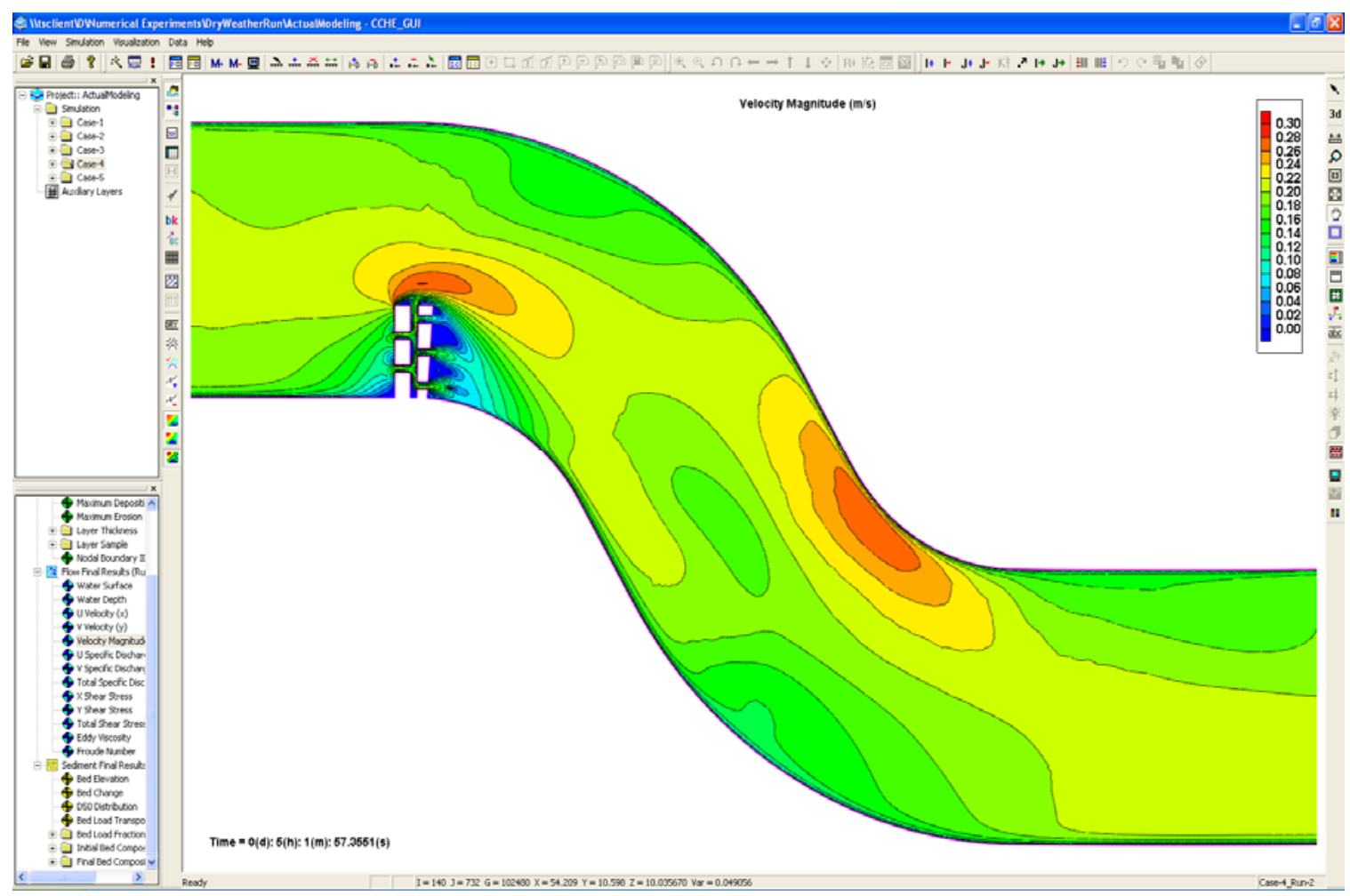

Figure T-27: Velocity magnitude for dry weather condition between meanders \#5 and \#6 after 5-hr simulation.

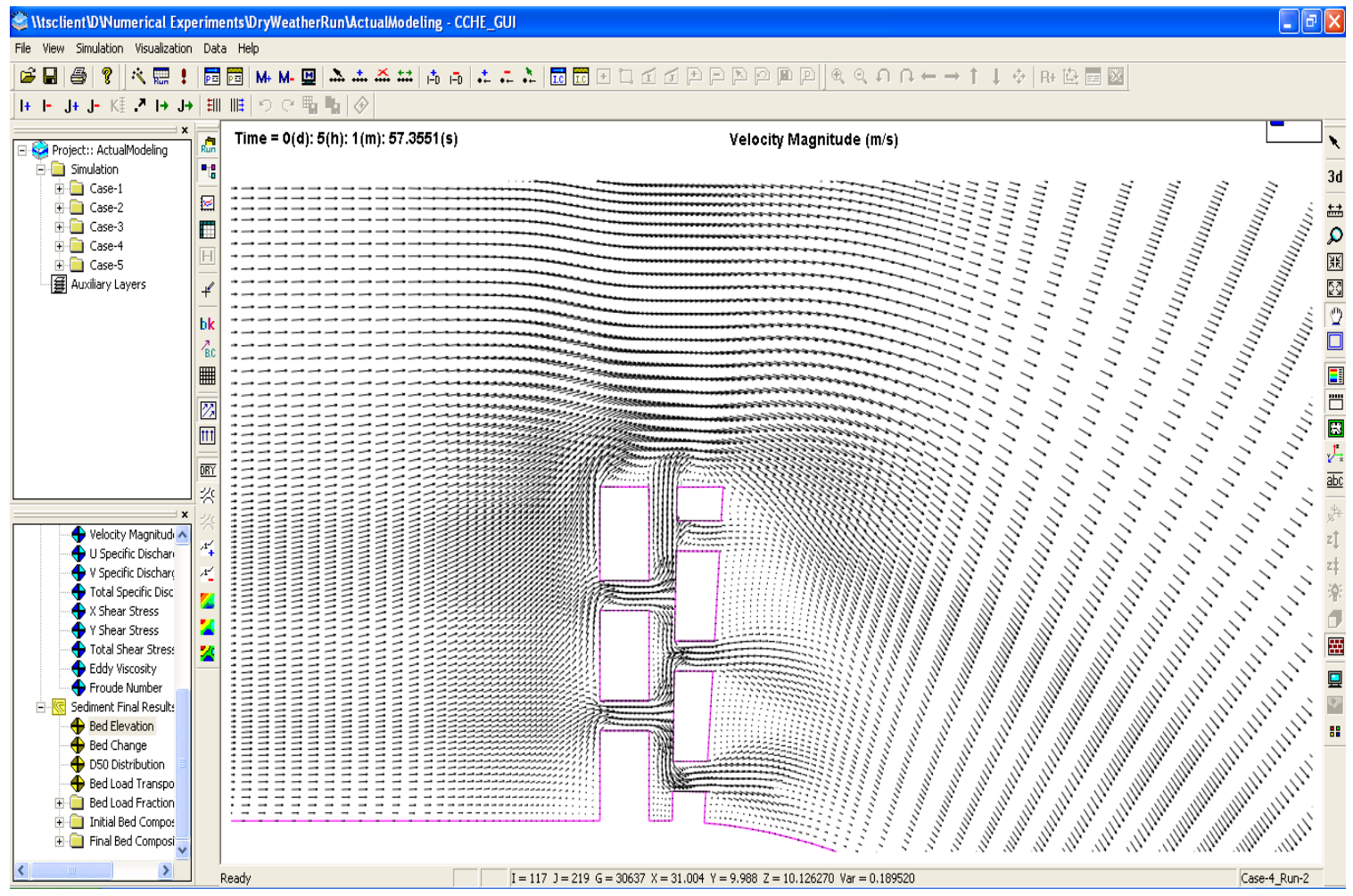

Figure T-28: Velocity direction for dry weather condition around meander \#1 after 5 -hr simulation. 


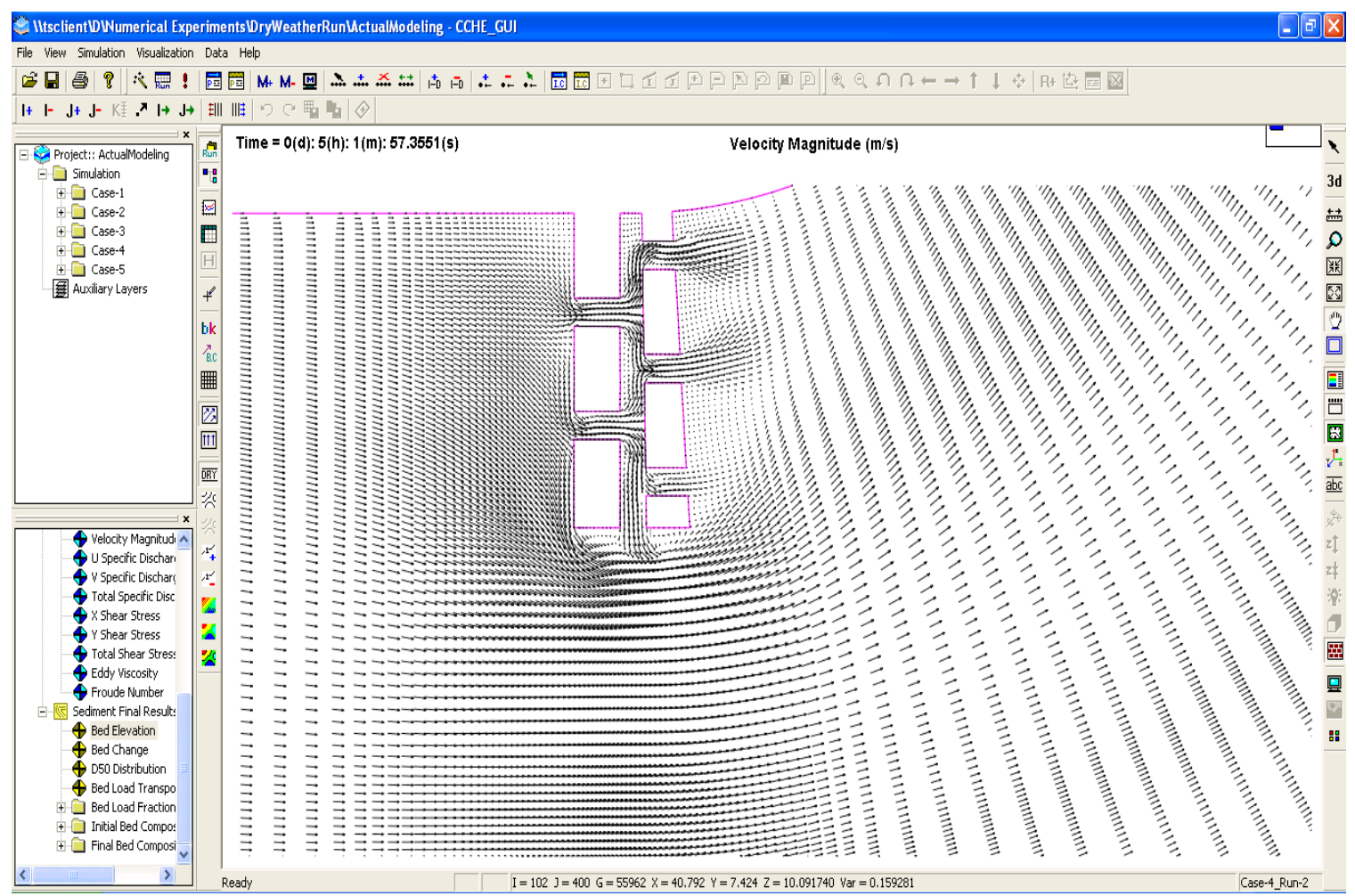

Figure T-29: Velocity direction for dry weather condition around meander \#3 after 5-hr simulation.

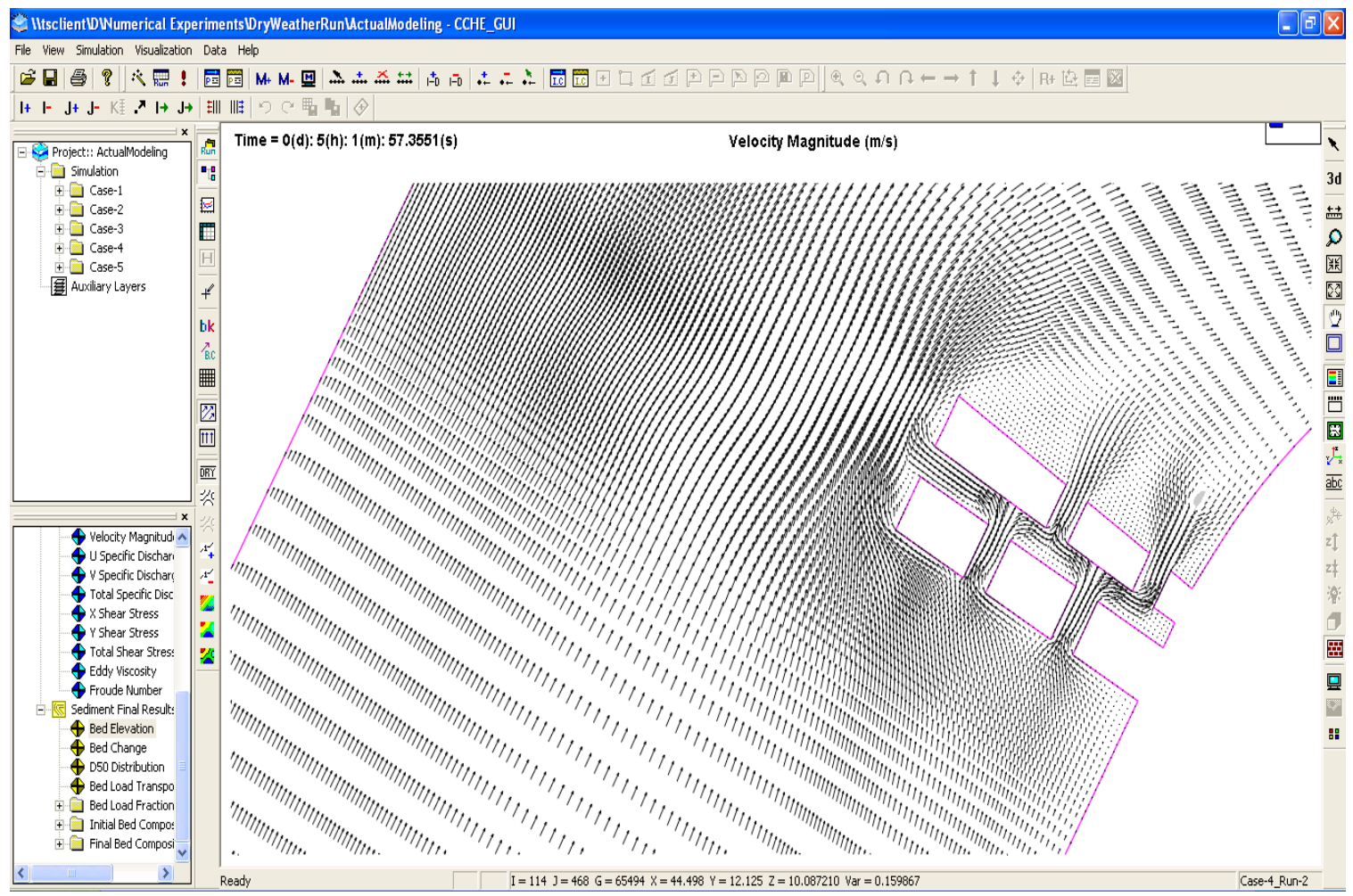

Figure T-30: Velocity direction for dry weather condition around meander \#4 after 5 -hr simulation. 


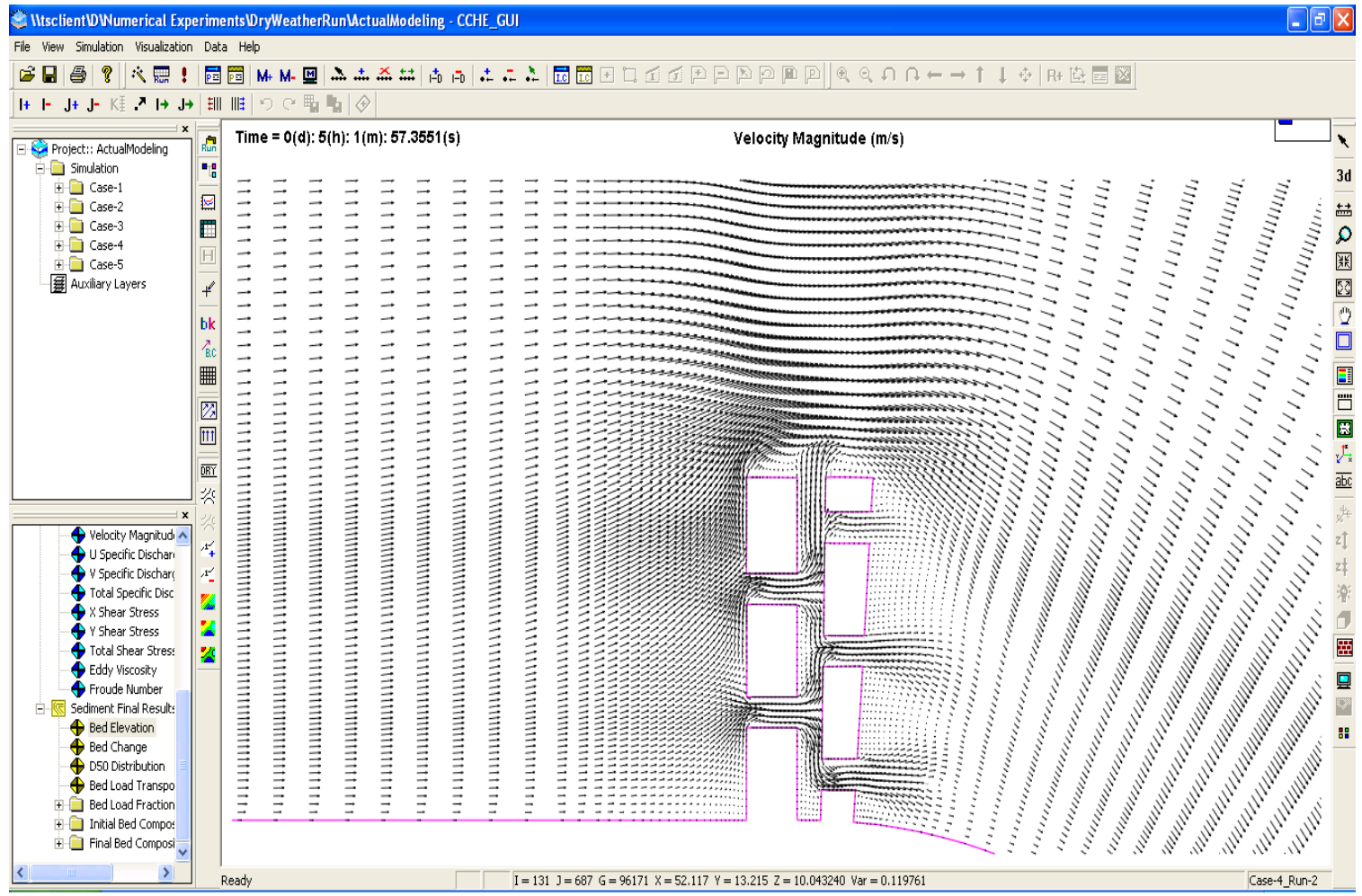

Figure T-31: Velocity direction for dry weather condition around meander \#5 after 5 -hr simulation. 


\section{$1 / 2$ water depth of LFC}

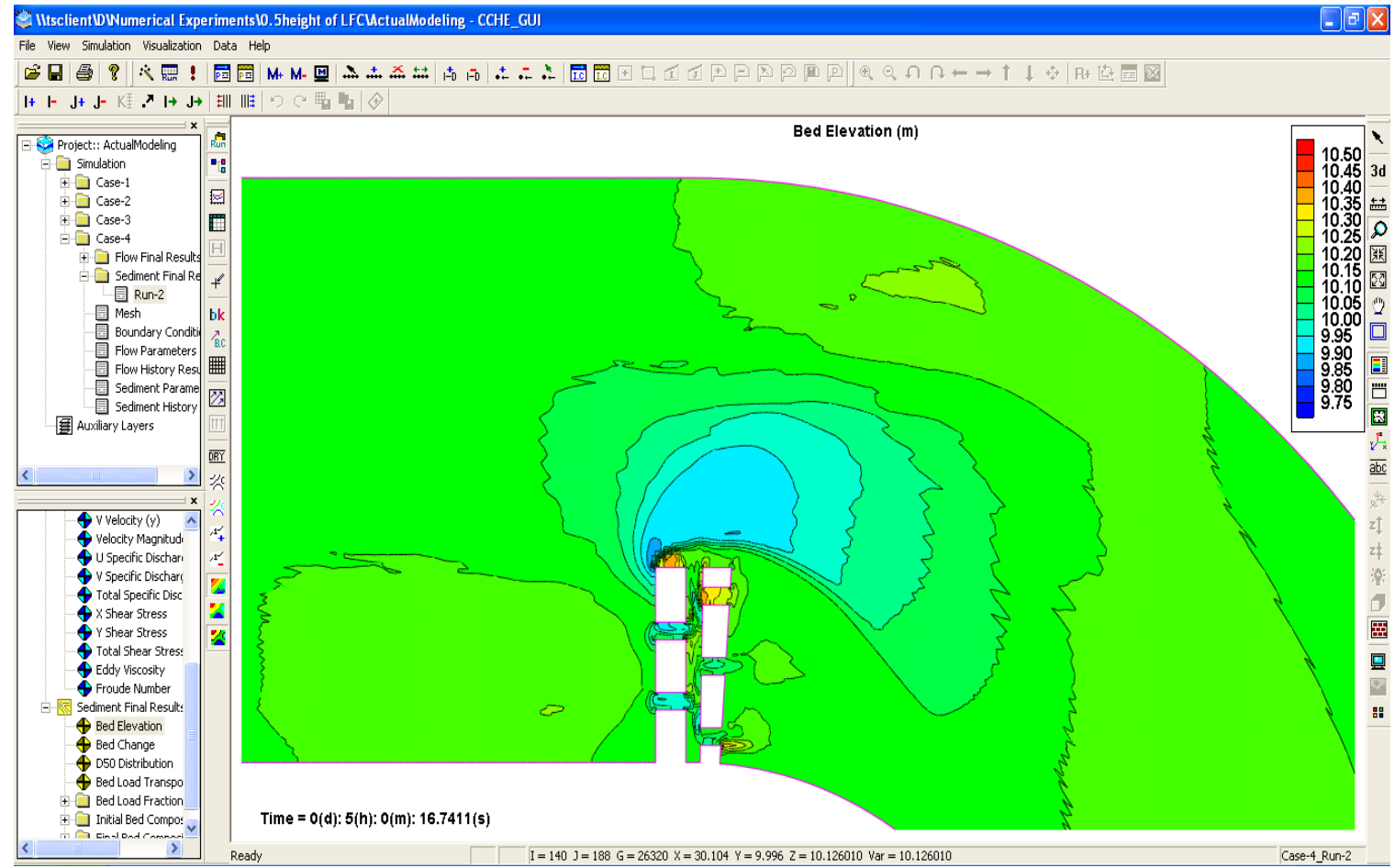

Figure T-32: Bed elevation when water depth of LFC $=22.5 \mathrm{~cm}$ at meander \#1 after 5-hr simulation.

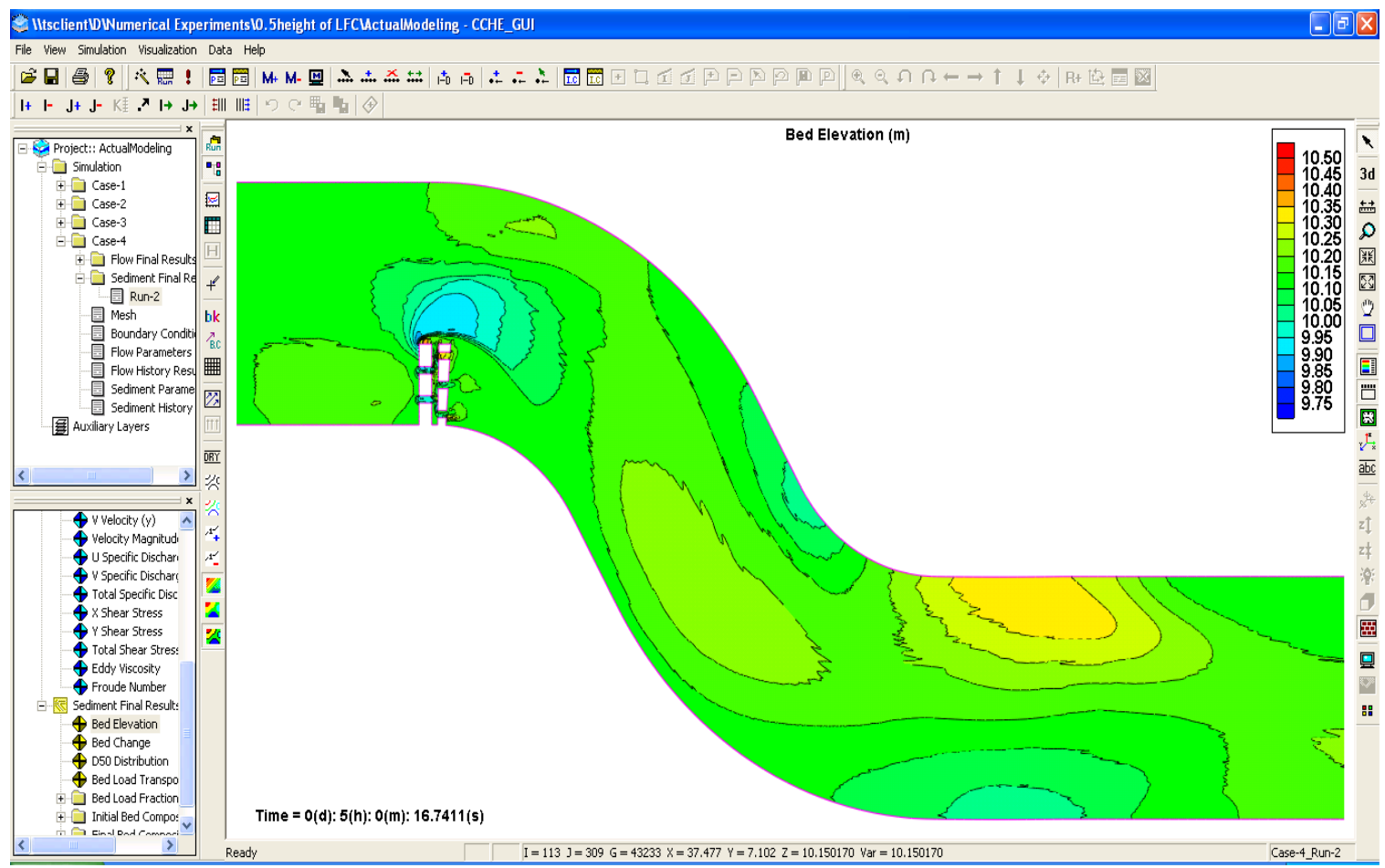

Figure T-33: Bed elevation when water depth of LFC $=22.5 \mathrm{~cm}$ between meanders \#1 and \#2 after 5-hr simulation. 


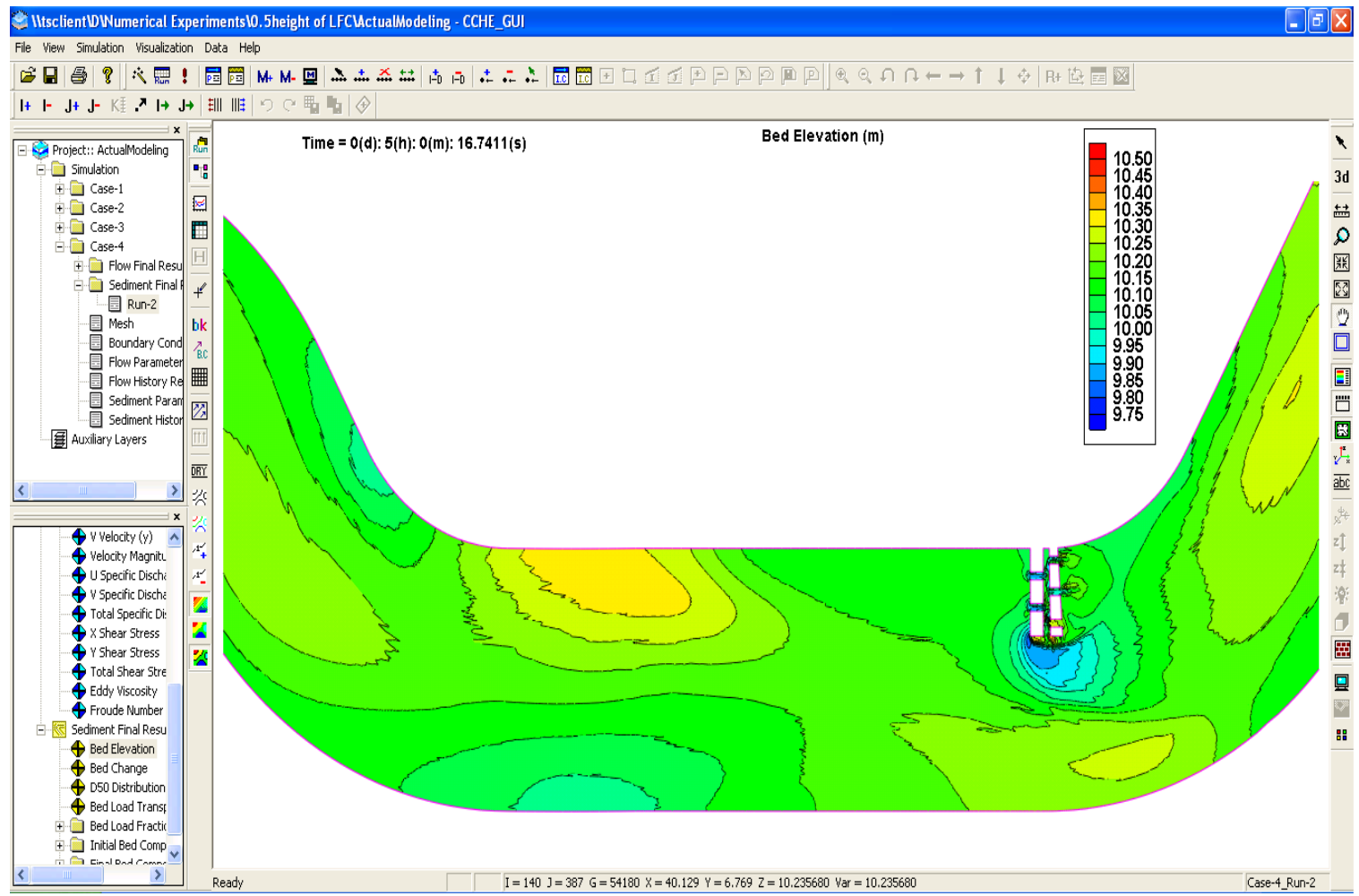

Figure T-34: Bed elevation when water depth of LFC $=22.5 \mathrm{~cm}$ between meanders \#2 and \#3 after 5-hr simulation.

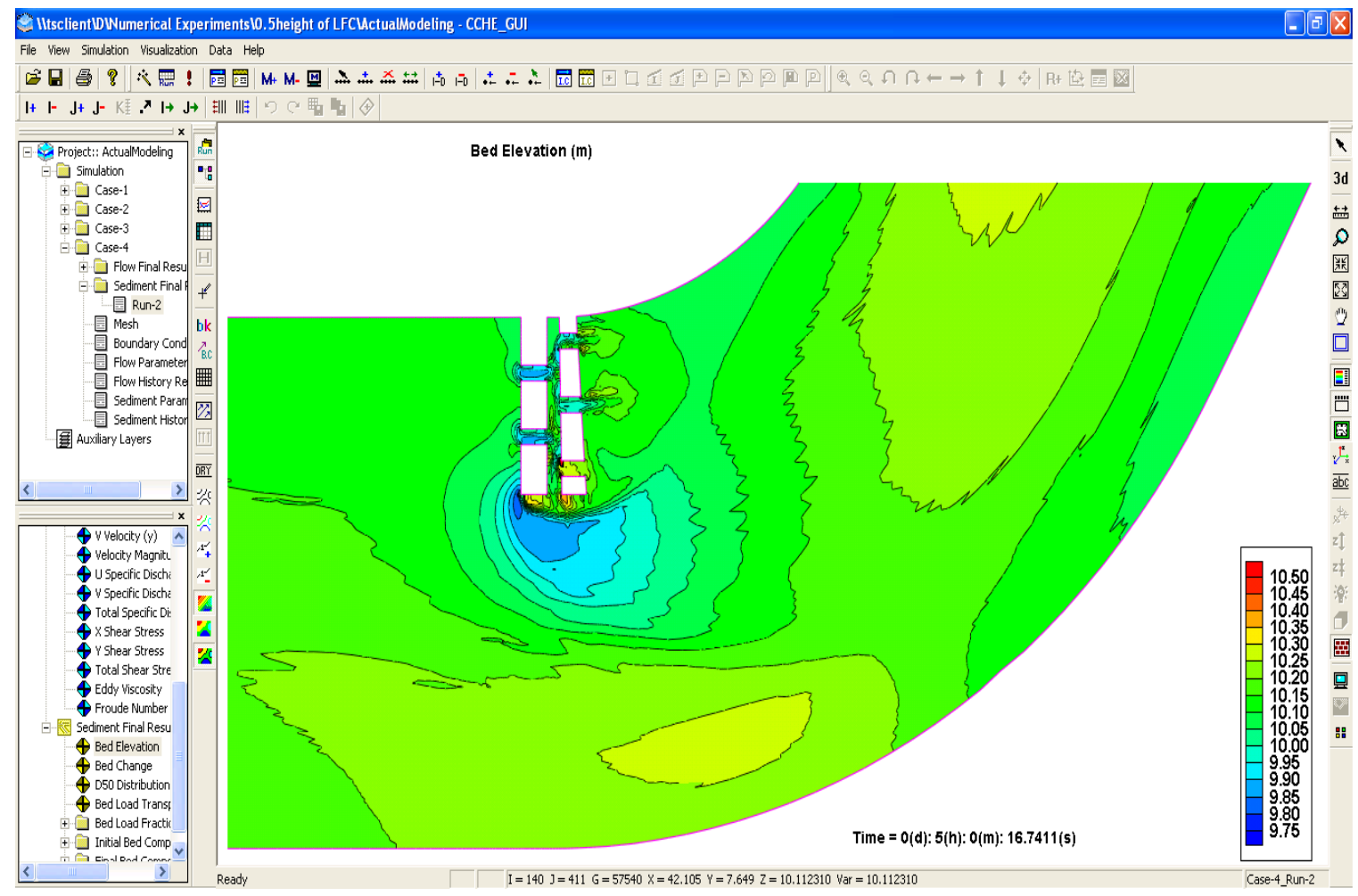

Figure T-35: Bed elevation when water depth of LFC $=22.5 \mathrm{~cm}$ at meander \#3 after 5 -hr simulation. 


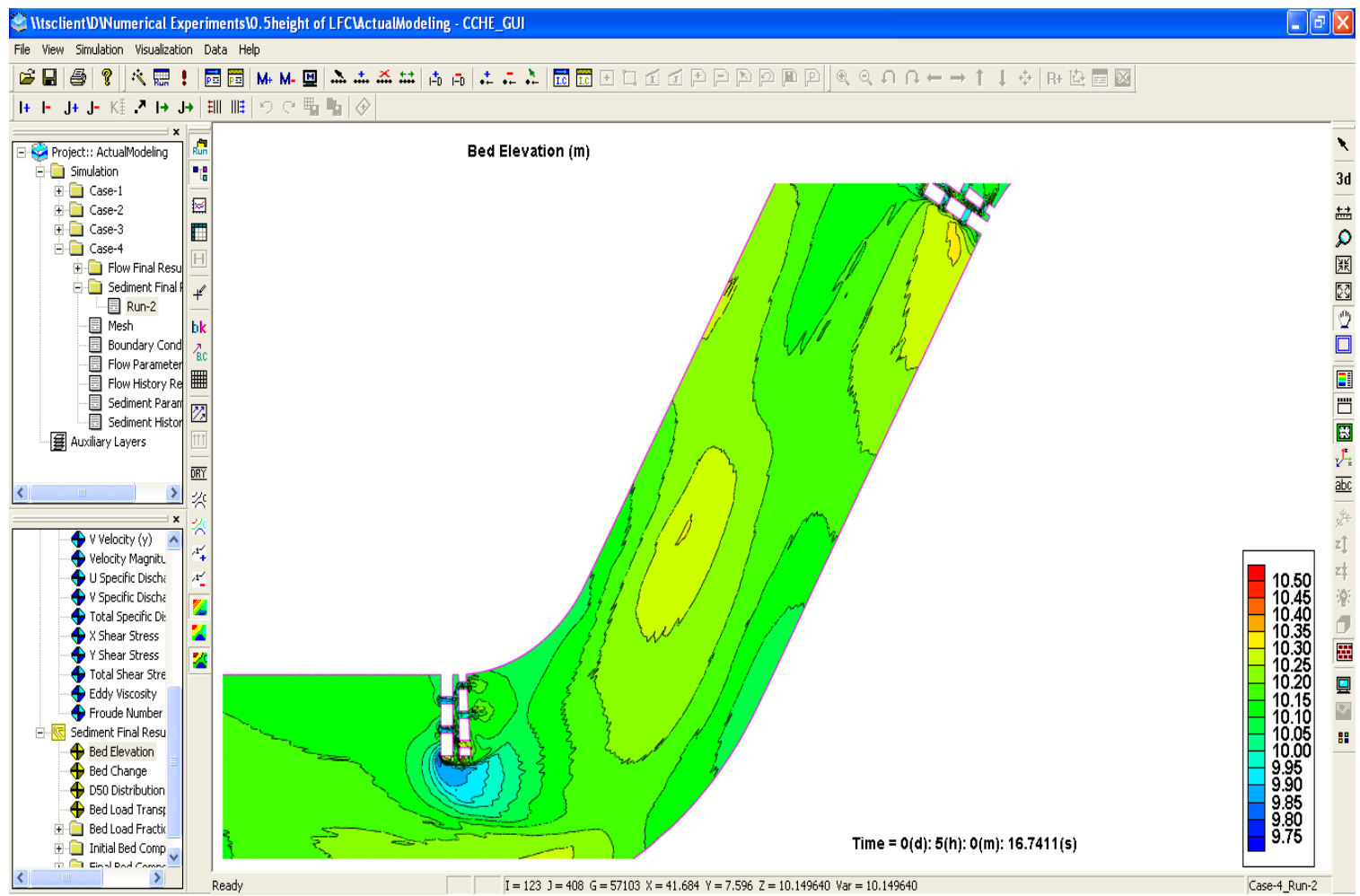

Figure T-36: Bed elevation when water depth of LFC $=22.5 \mathrm{~cm}$ between meanders \#3 and \#4 after 5-hr simulation.

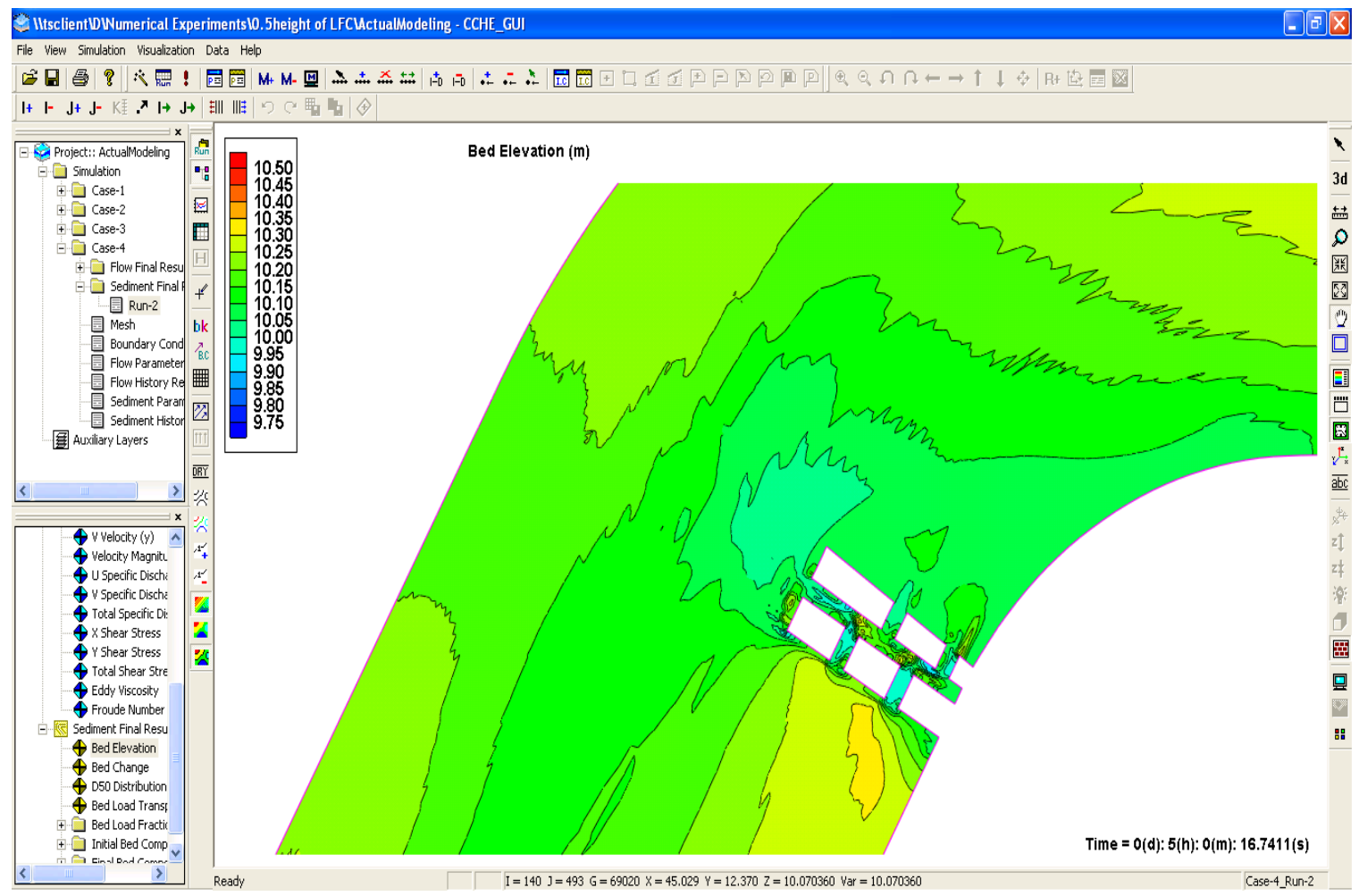

Figure T-37: Bed elevation when water depth of LFC $=22.5 \mathrm{~cm}$ at meander \#4 after 5-hr simulation. 


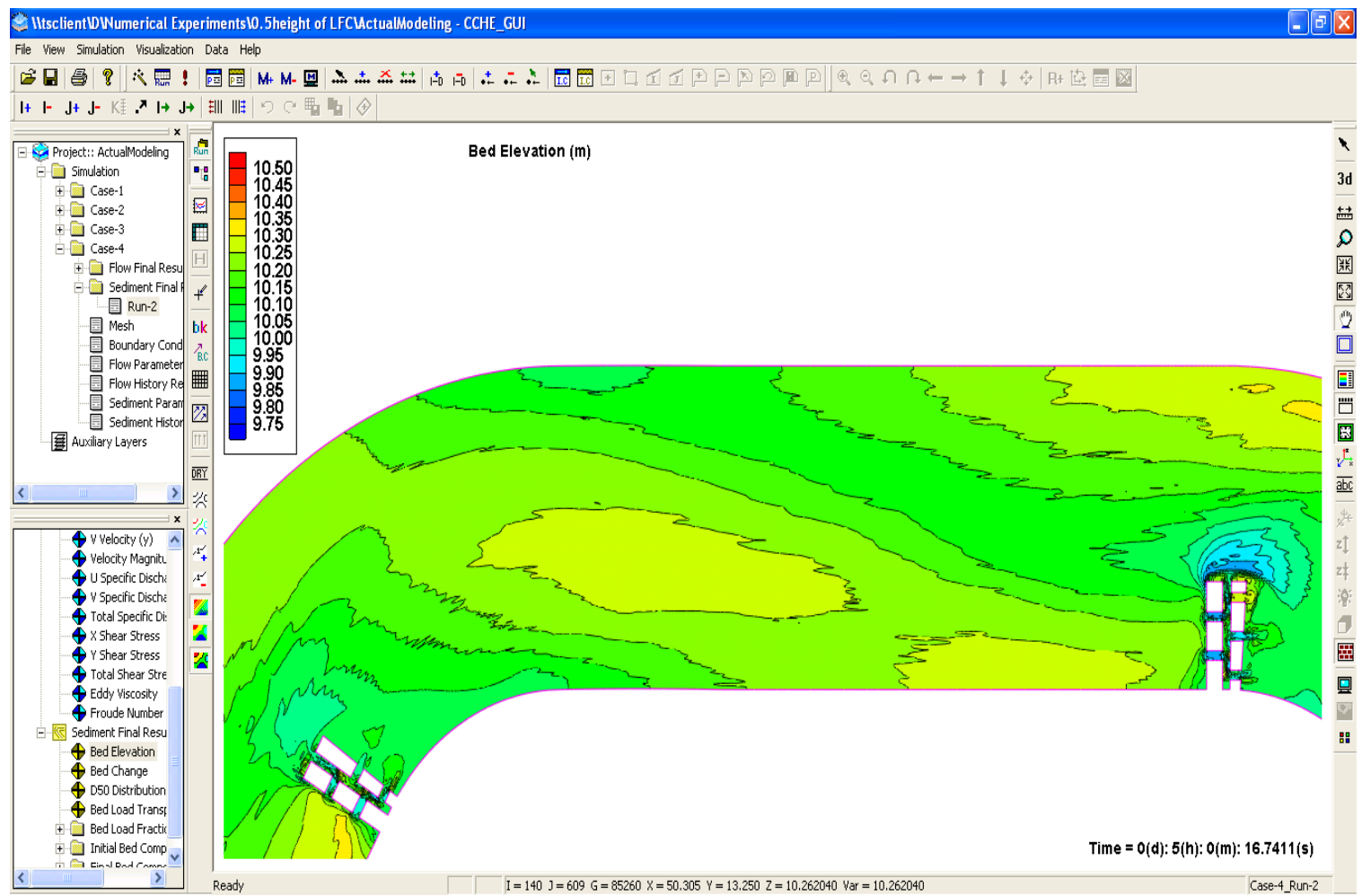

Figure T-38: Bed elevation when water depth of LFC $=22.5 \mathrm{~cm}$ between meanders \#4 and \#5 after 5-hr simulation.

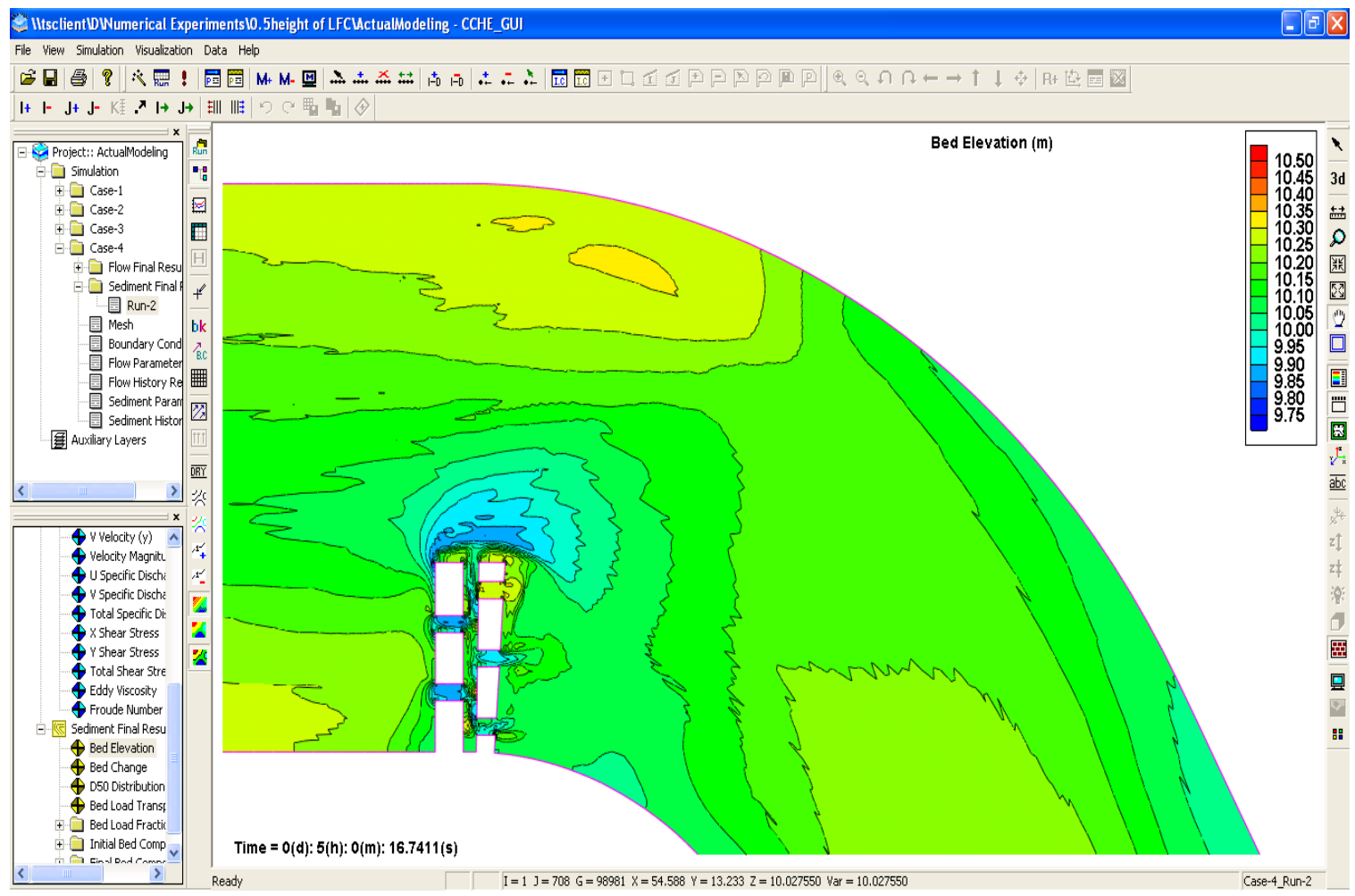

Figure T-39: Bed elevation when water depth of LFC $=22.5 \mathrm{~cm}$ at meander \#5 after 5 -hr simulation. 


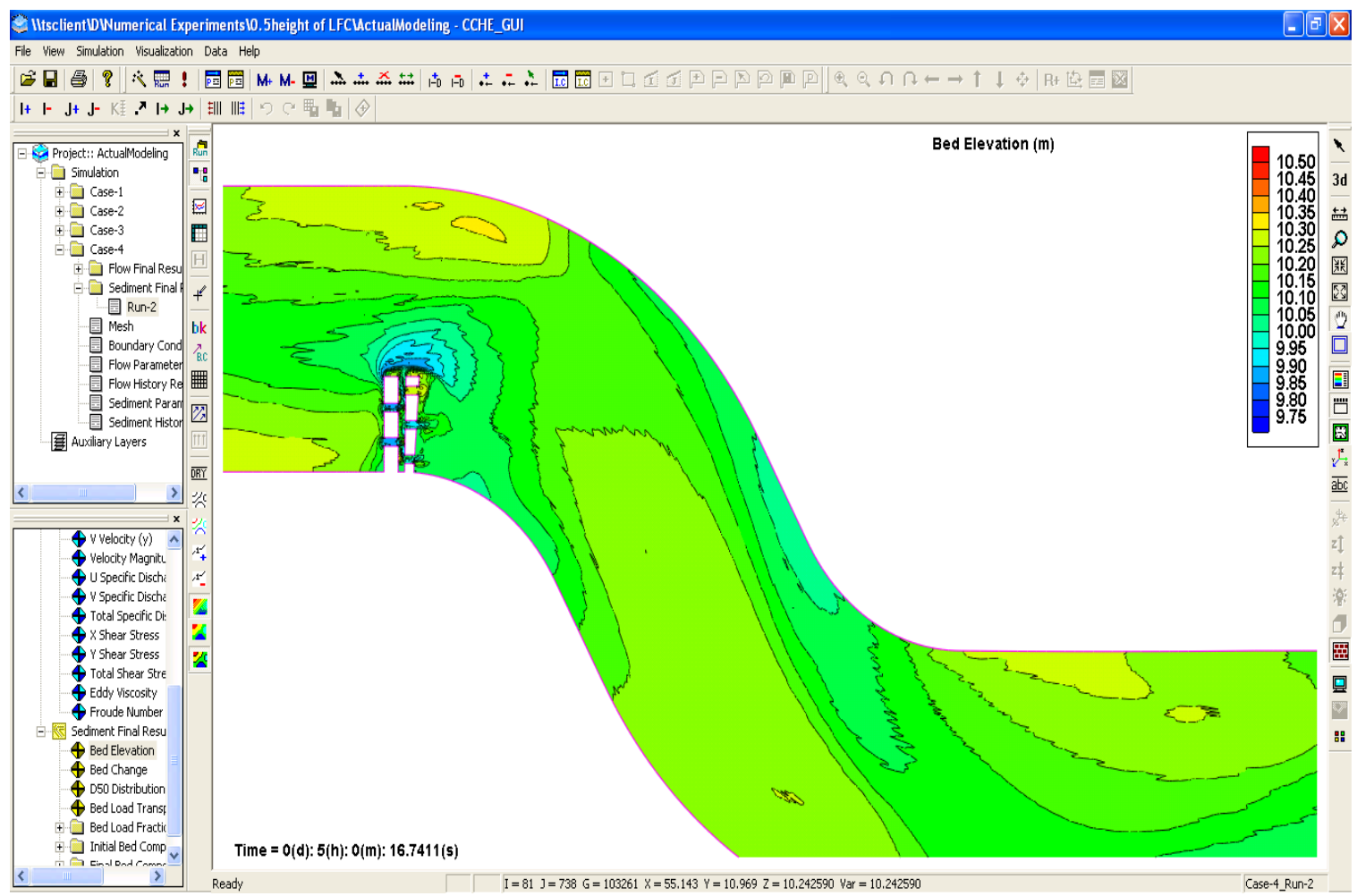

Figure T-40: Bed elevation when water depth of LFC $=22.5 \mathrm{~cm}$ between meanders \#5 and \#6 after 5-hr simulation.

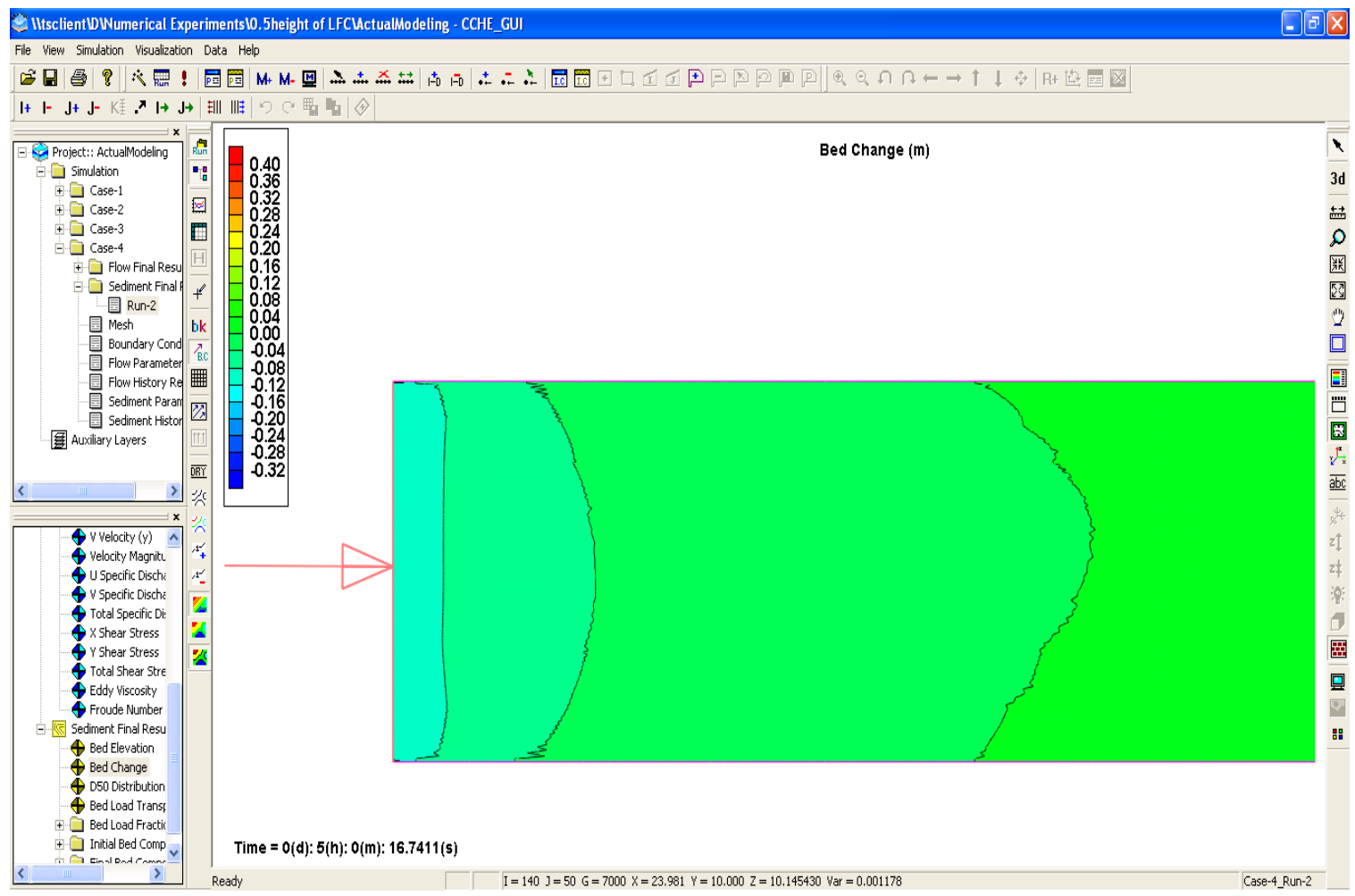

Figure T-41: Bed change when water depth of LFC $=22.5 \mathrm{~cm}$ at upstream boundary after $5-\mathrm{hr}$ simulation. 


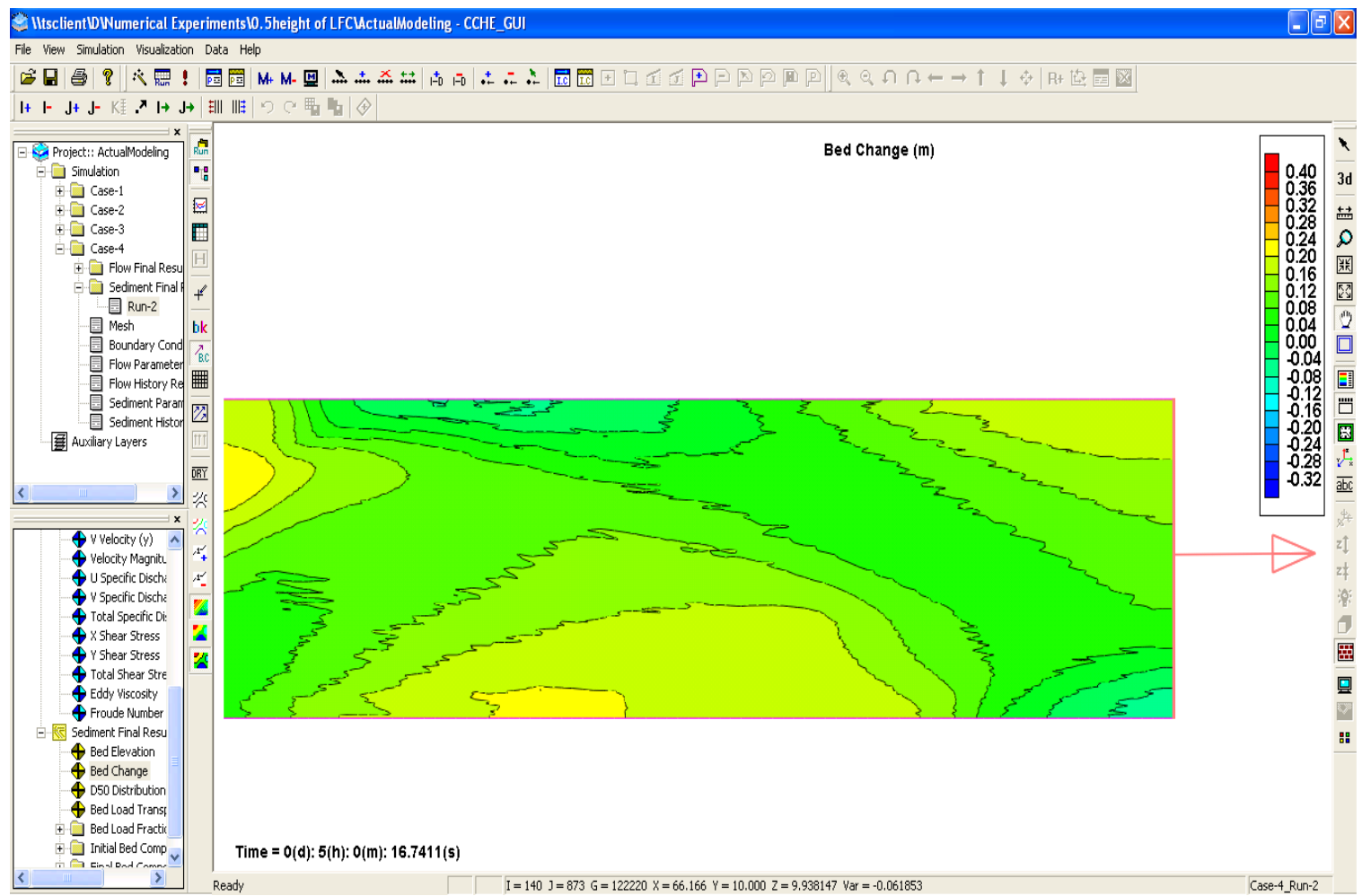

Figure T-42: Bed change when water depth of LFC $=22.5 \mathrm{~cm}$ at downstream boundary after $5-\mathrm{hr}$ simulation.

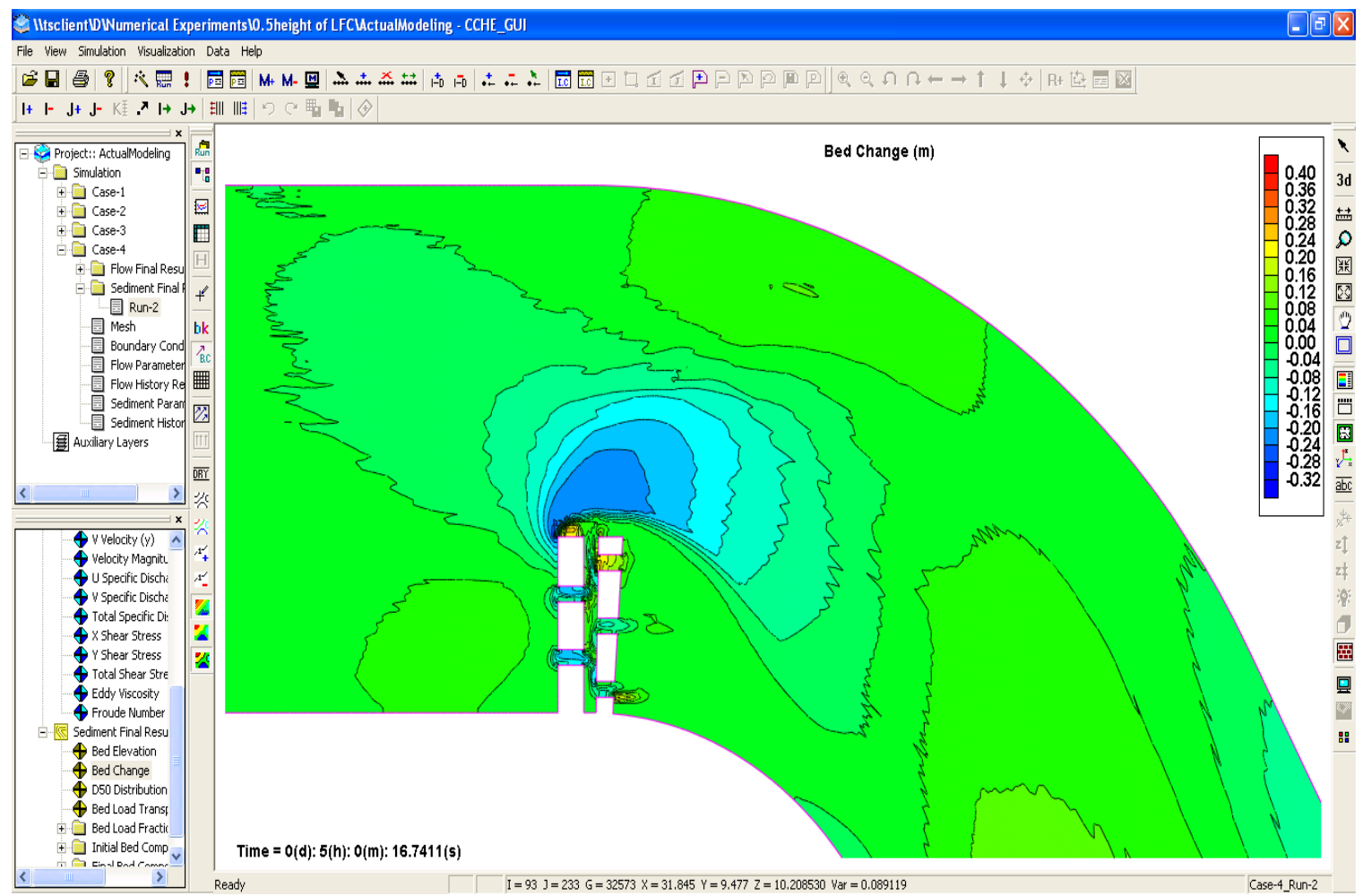

Figure T-43: Bed change when water depth of LFC $=22.5 \mathrm{~cm}$ at meander \#1 after 5-hr simulation. 


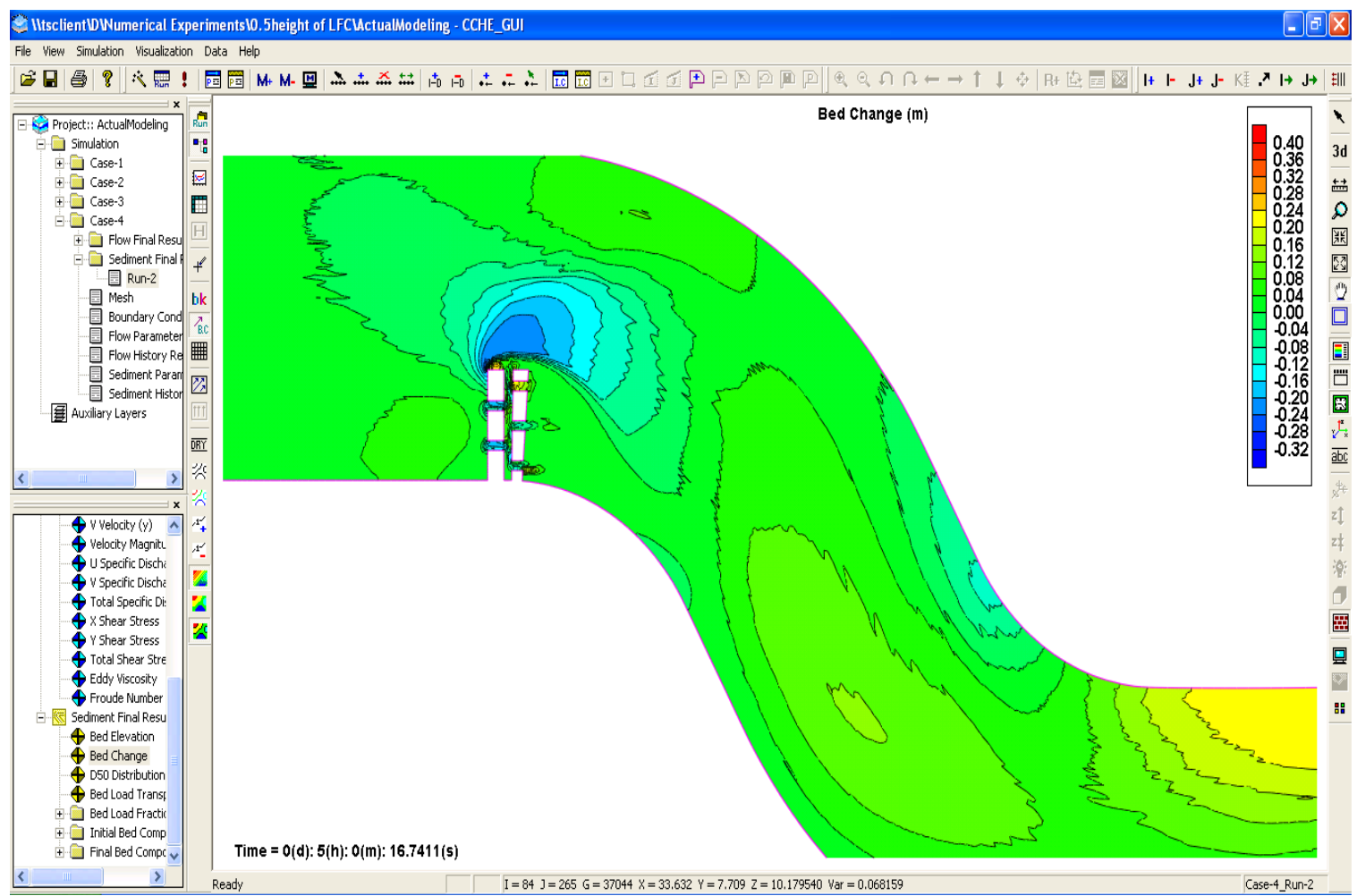

Figure T-44: Bed change when water depth of LFC $=22.5 \mathrm{~cm}$ between meanders \#1 and \#2 after 5-hr simulation.

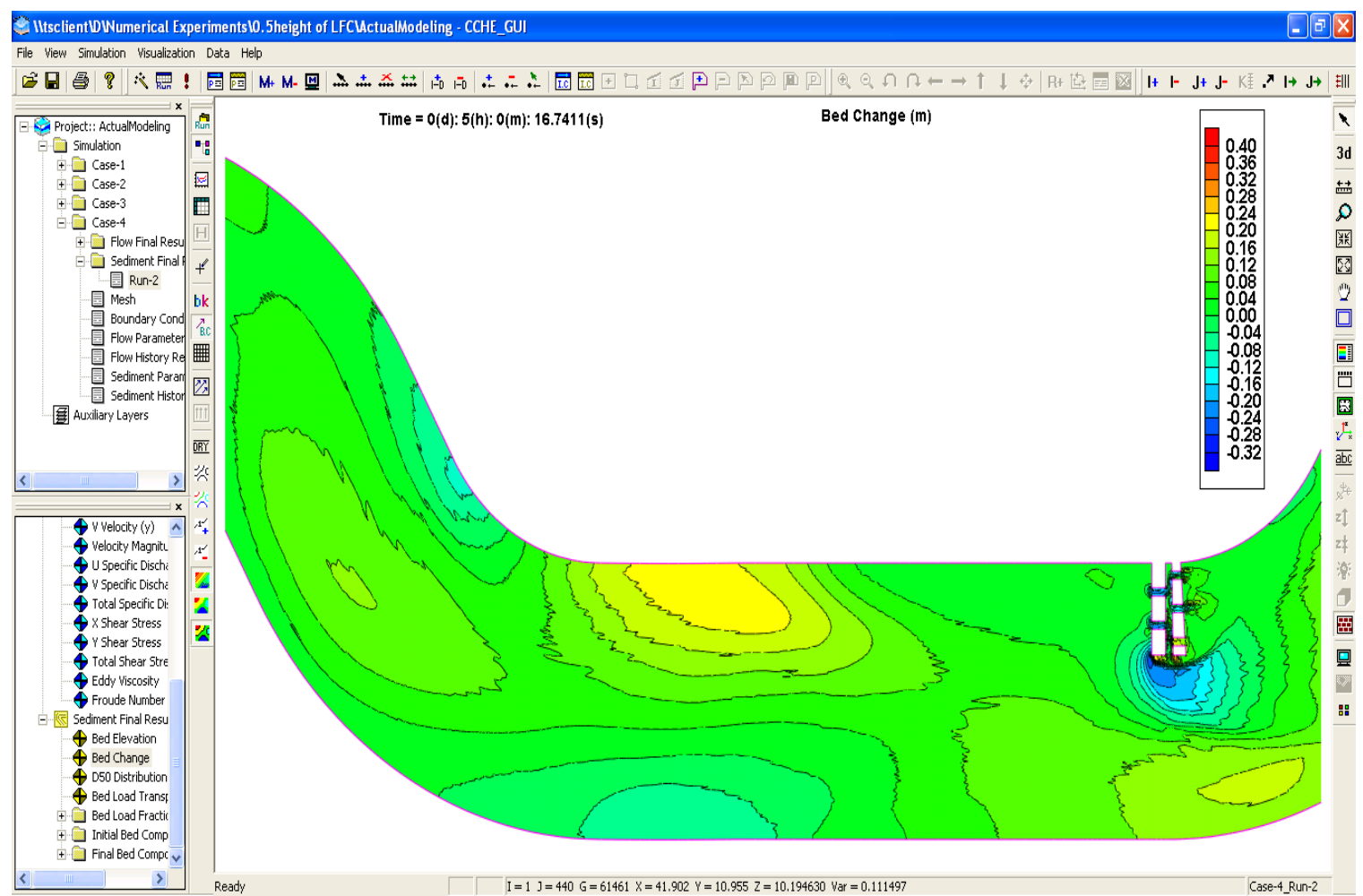

Figure T-45: Bed change when water depth of LFC $=22.5 \mathrm{~cm}$ between meanders \#2 and \#3 after 5-hr simulation. 


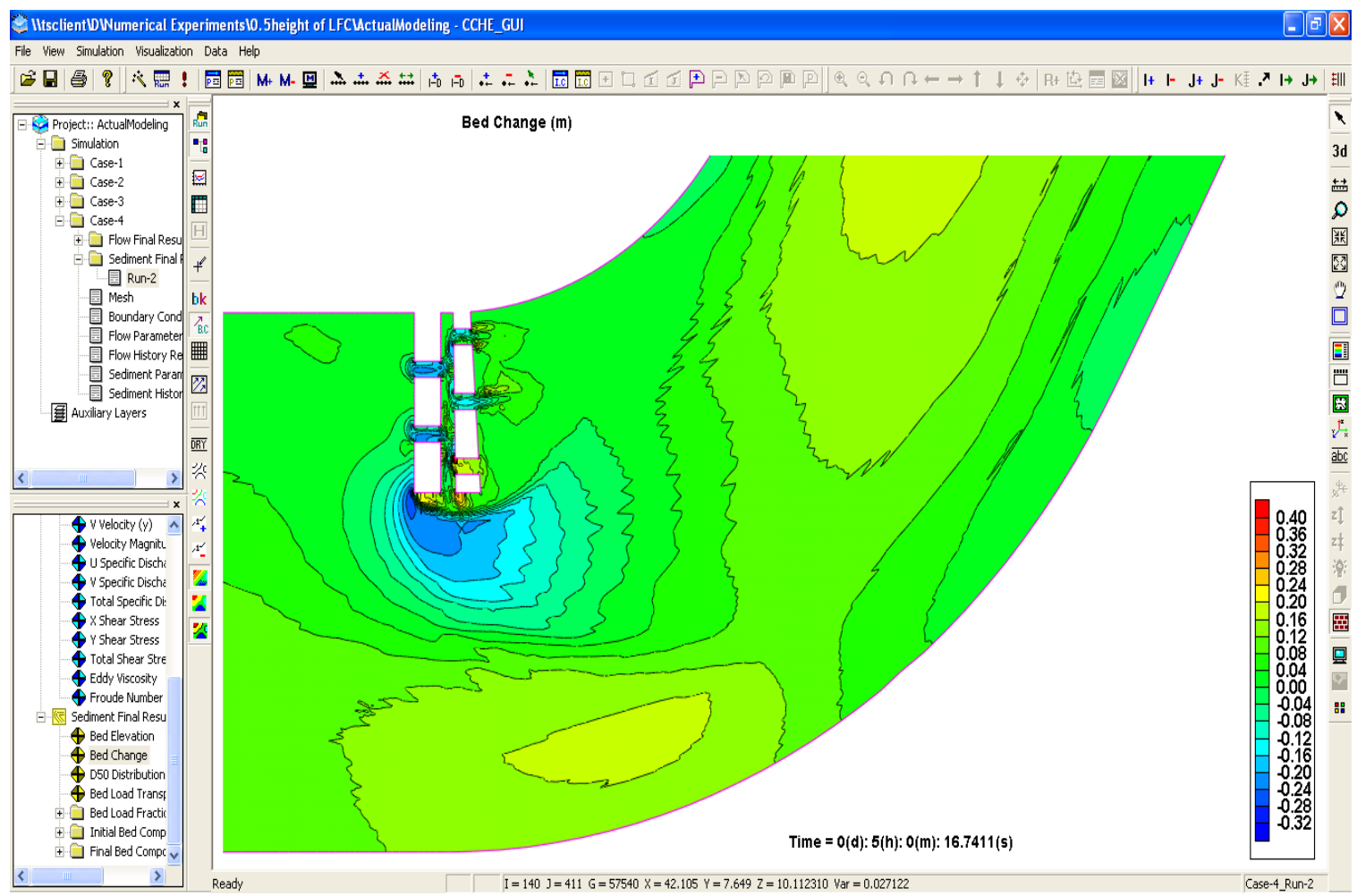

Figure T-46: Bed change when water depth of LFC $=22.5 \mathrm{~cm}$ at meander \#3 after 5 -hr simulation.

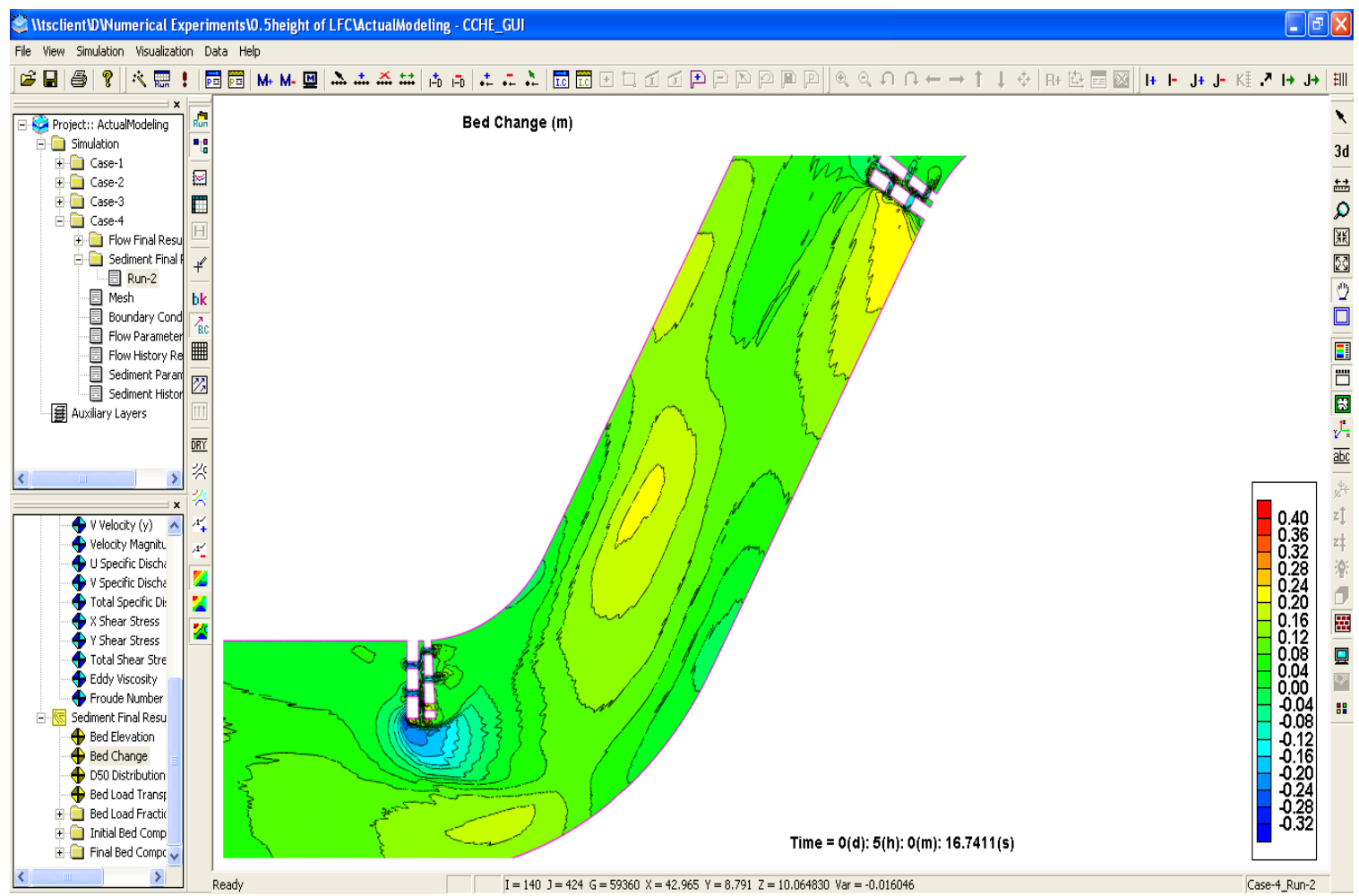

Figure T-47: Bed change when water depth of LFC $=22.5 \mathrm{~cm}$ between meanders \#3 and \#4 after 5-hr simulation. 


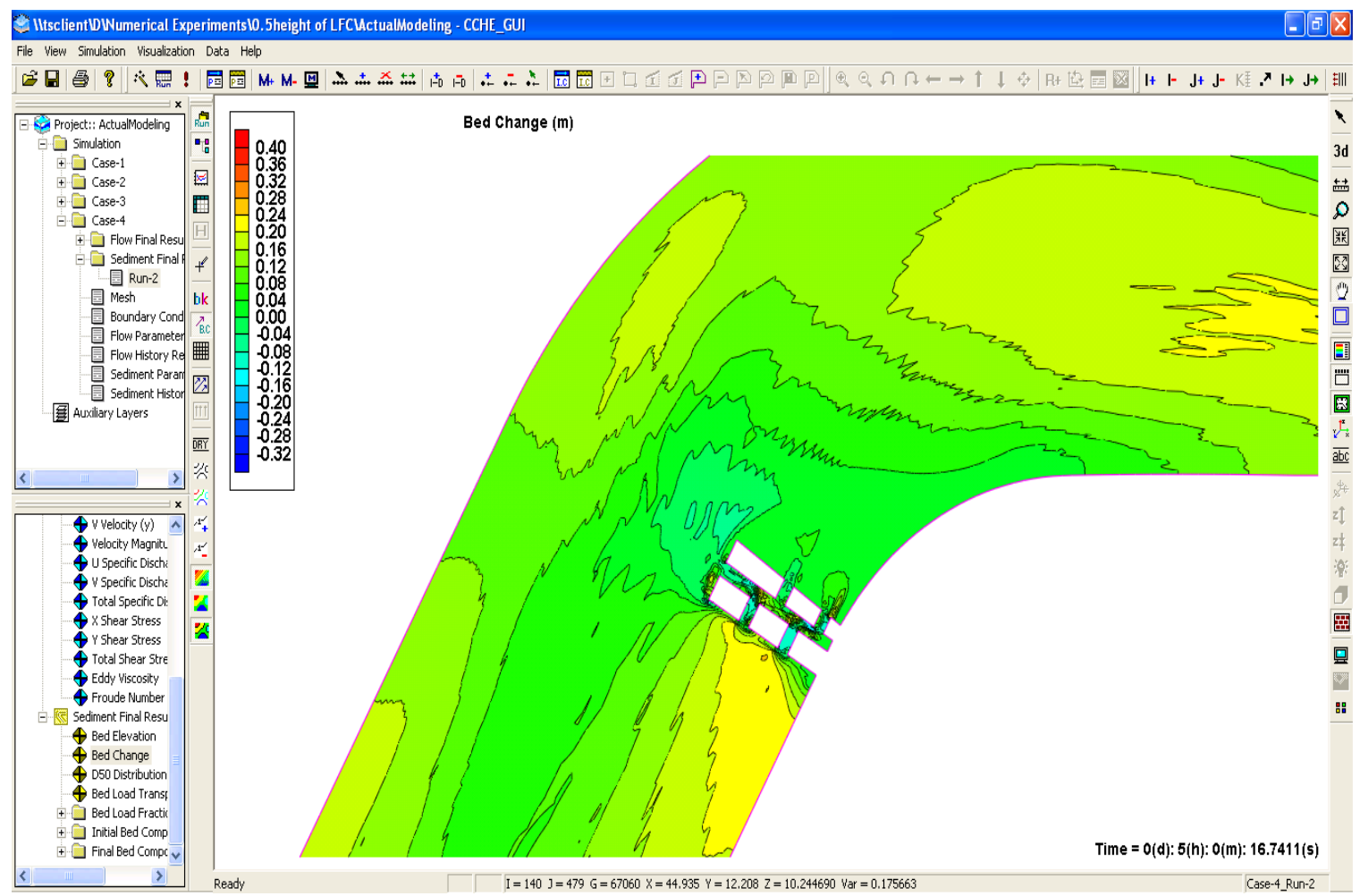

Figure T-48: Bed change when water depth of LFC $=22.5 \mathrm{~cm}$ at meander \#4 after 5 -hr simulation.

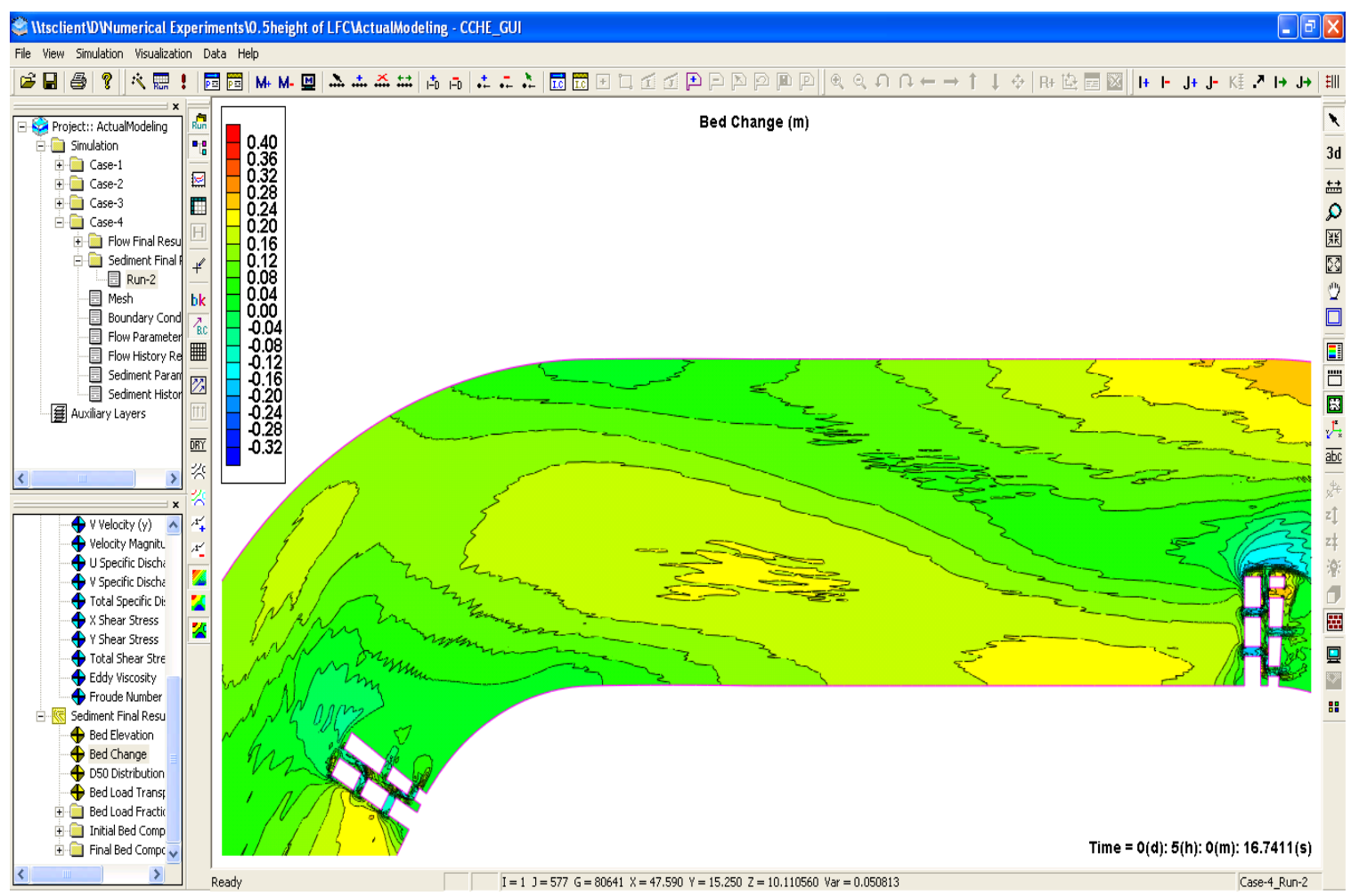

Figure T-49: Bed change when water depth of LFC $=22.5 \mathrm{~cm}$ between meanders \#4 and \#5 after 5-hr simulation. 


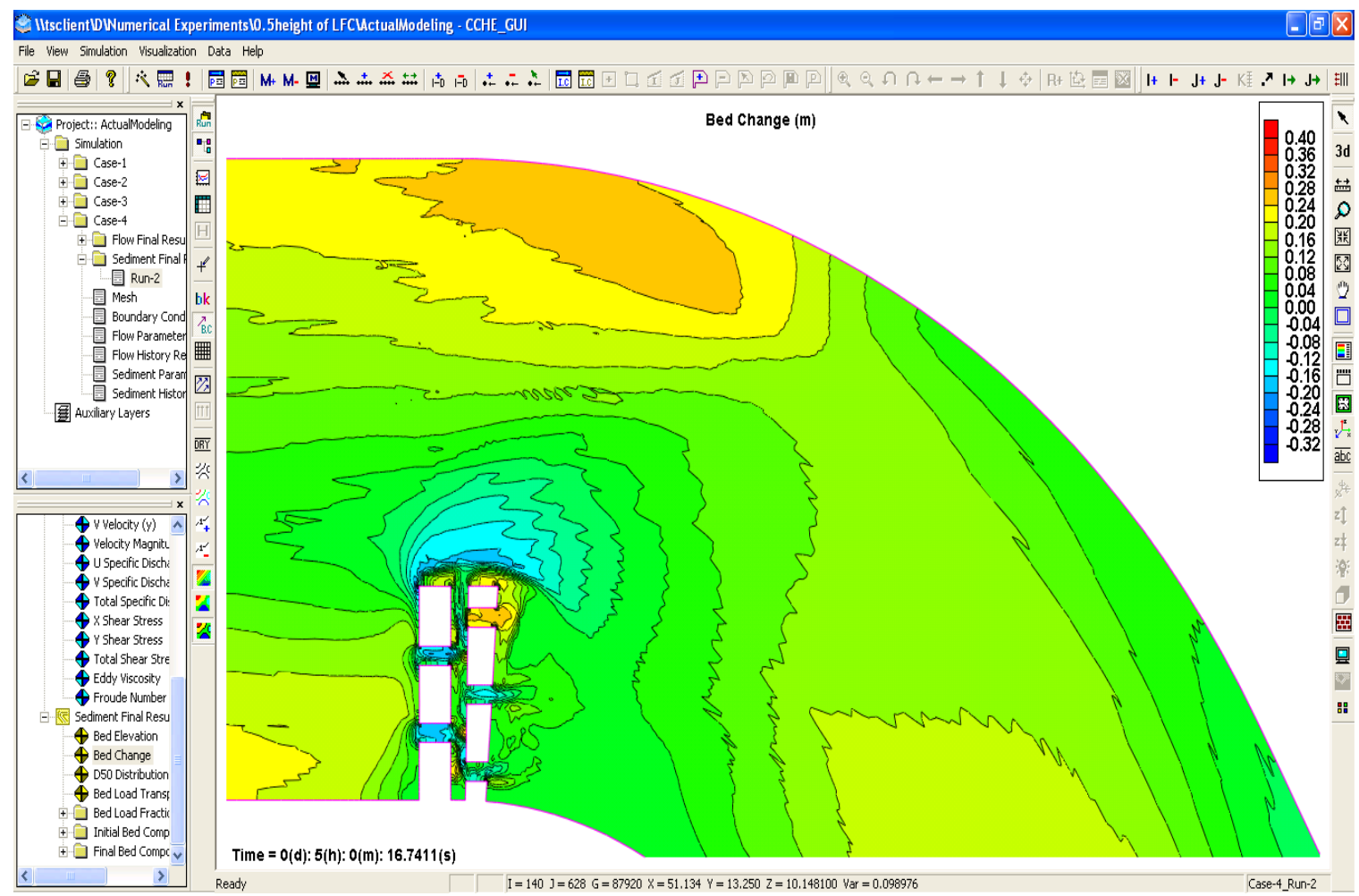

Figure T-50: Bed change when water depth of LFC $=22.5 \mathrm{~cm}$ at meander \#5 after 5-hr simulation.

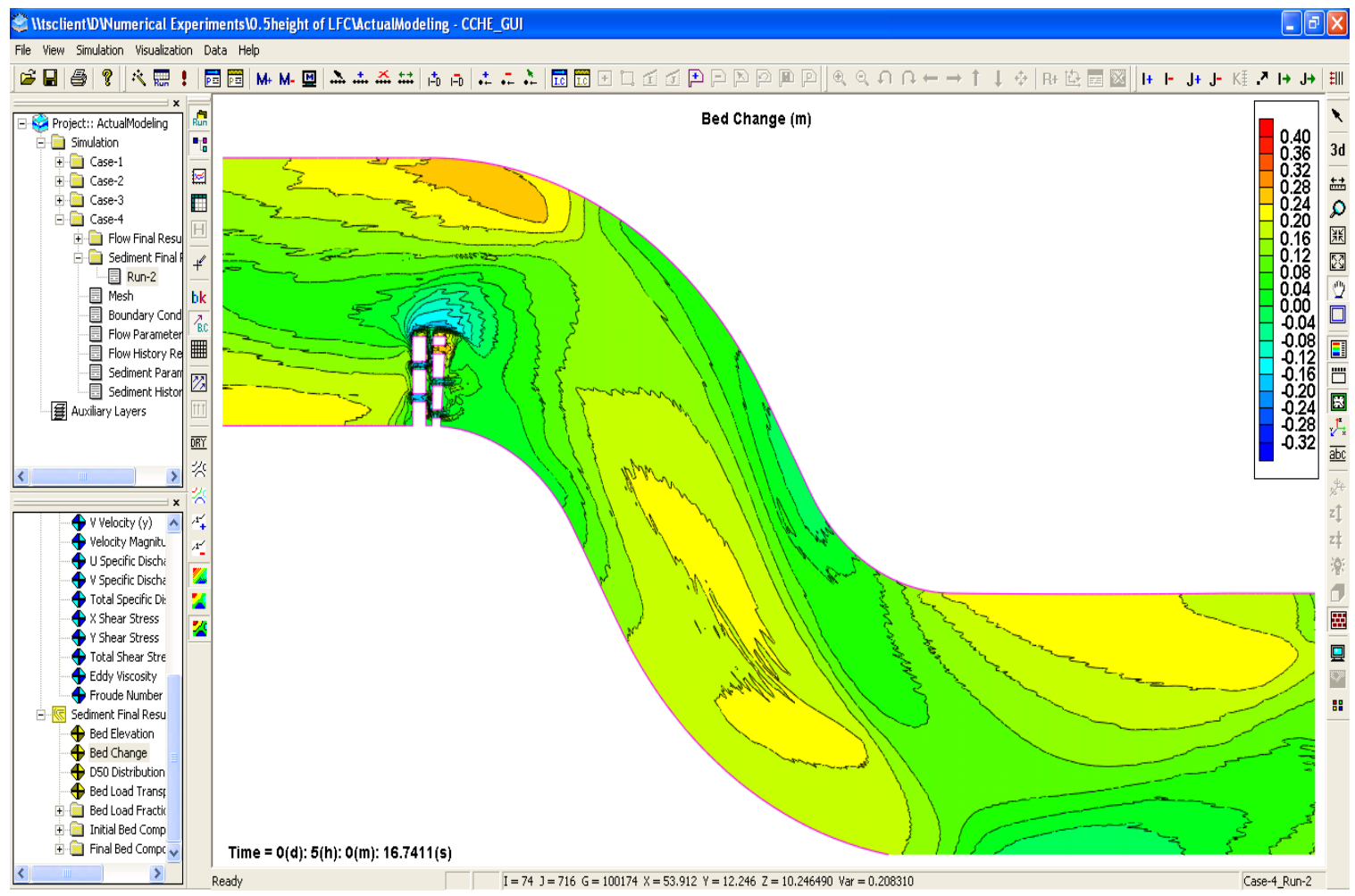

Figure T-51: Bed change when water depth of LFC $=22.5 \mathrm{~cm}$ between meanders \#5 and \#6 after 5-hr simulation. 


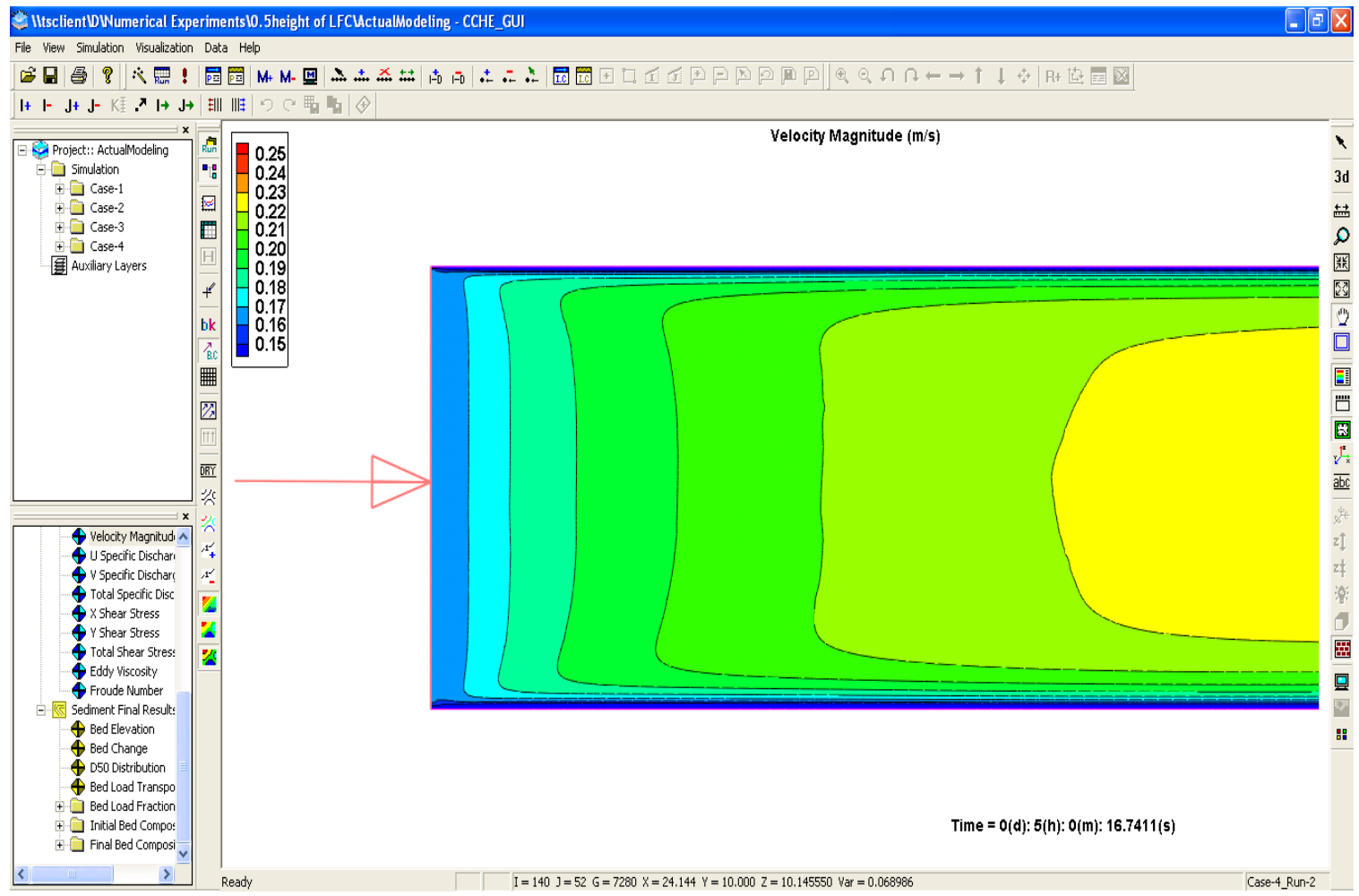

Figure T-52: Velocity magnitude when water depth of LFC $=22.5 \mathrm{~cm}$ at upstream boundary after 5 -hr simulation.

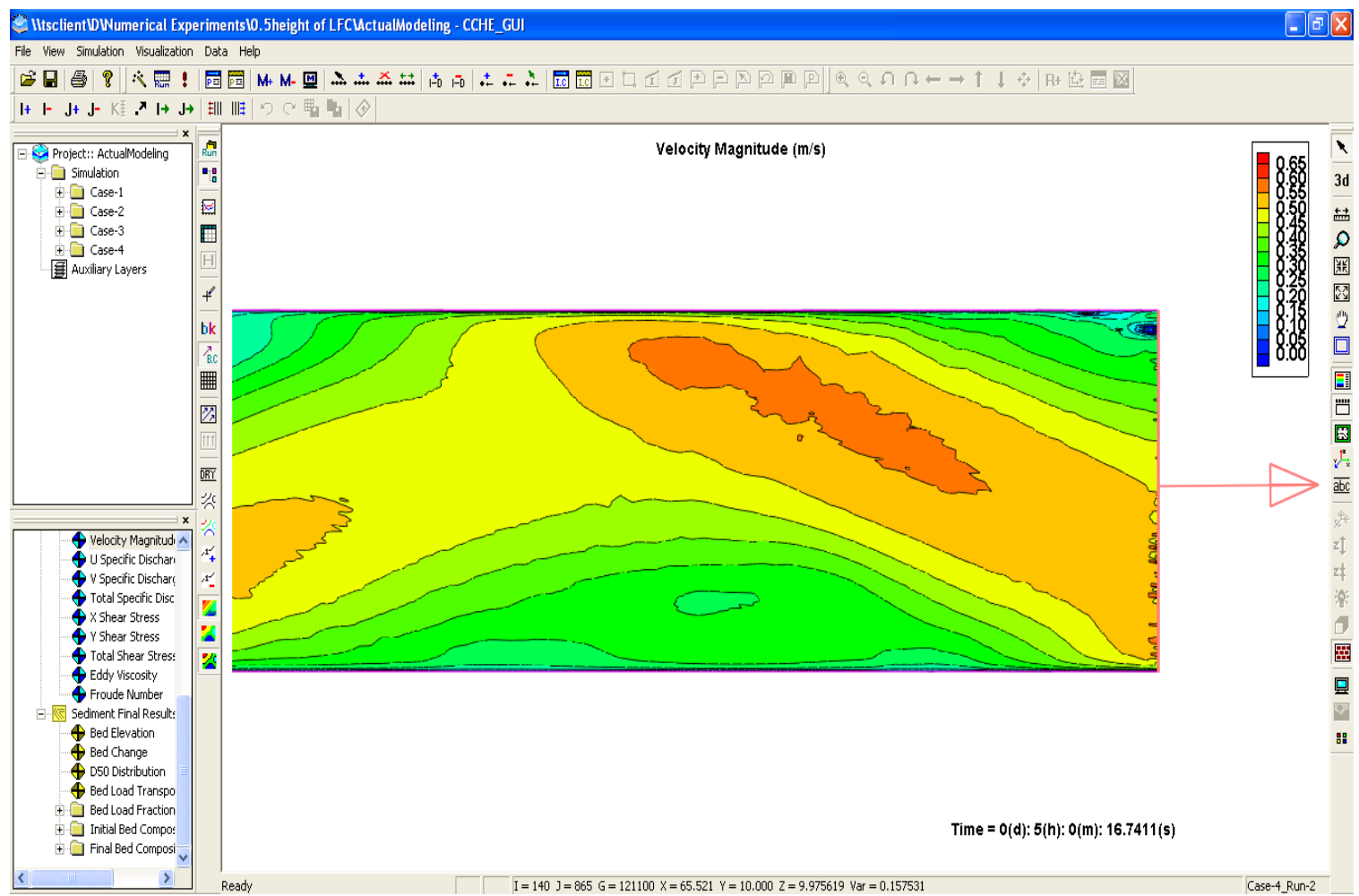

Figure T-53: Velocity magnitude when water depth of LFC $=22.5 \mathrm{~cm}$ at downstream boundary after 5 -hr simulation. 


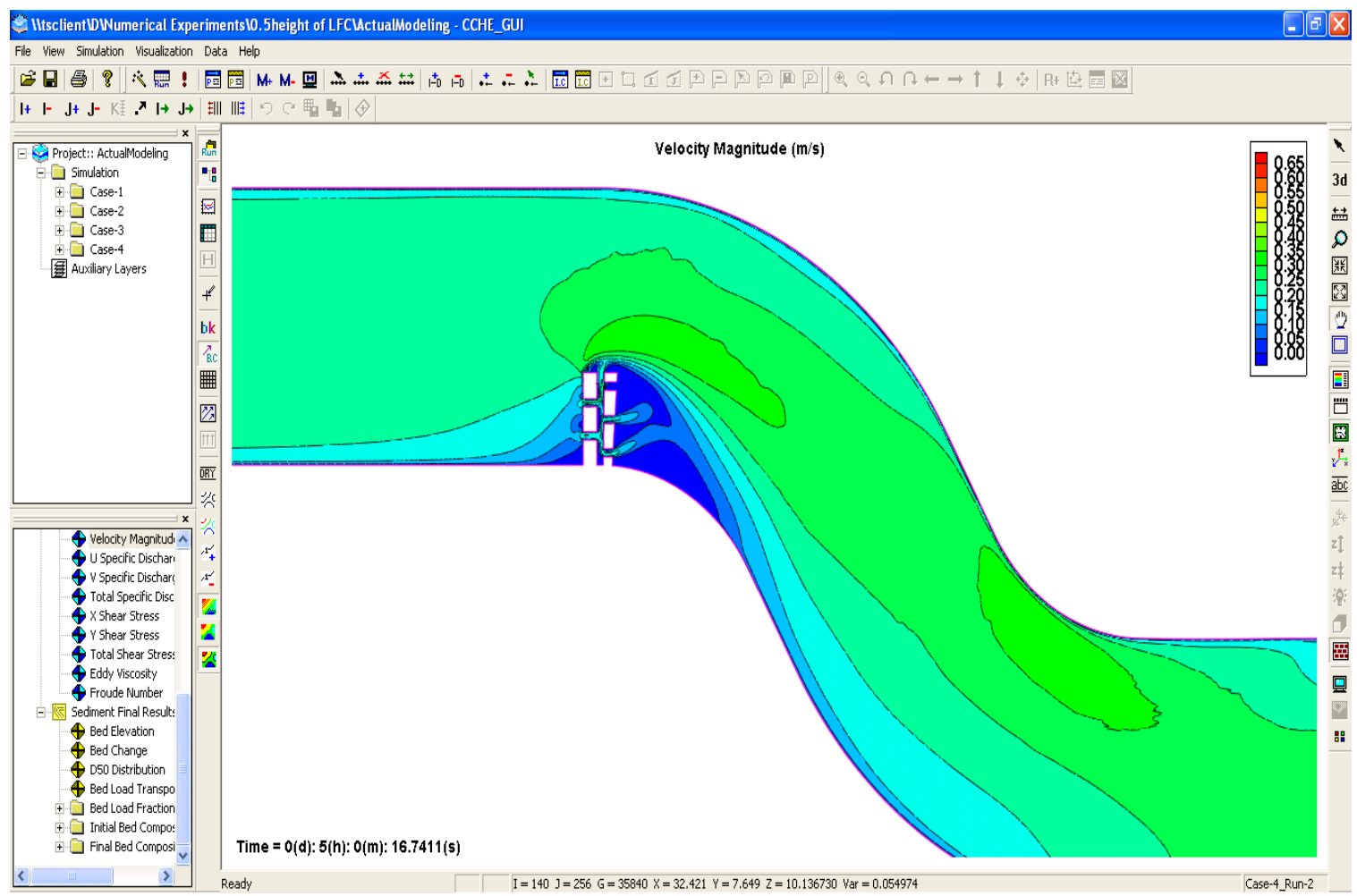

Figure T-54: Velocity magnitude when water depth of LFC $=22.5 \mathrm{~cm}$ between meanders \#1 and \#2 after 5-hr simulation.

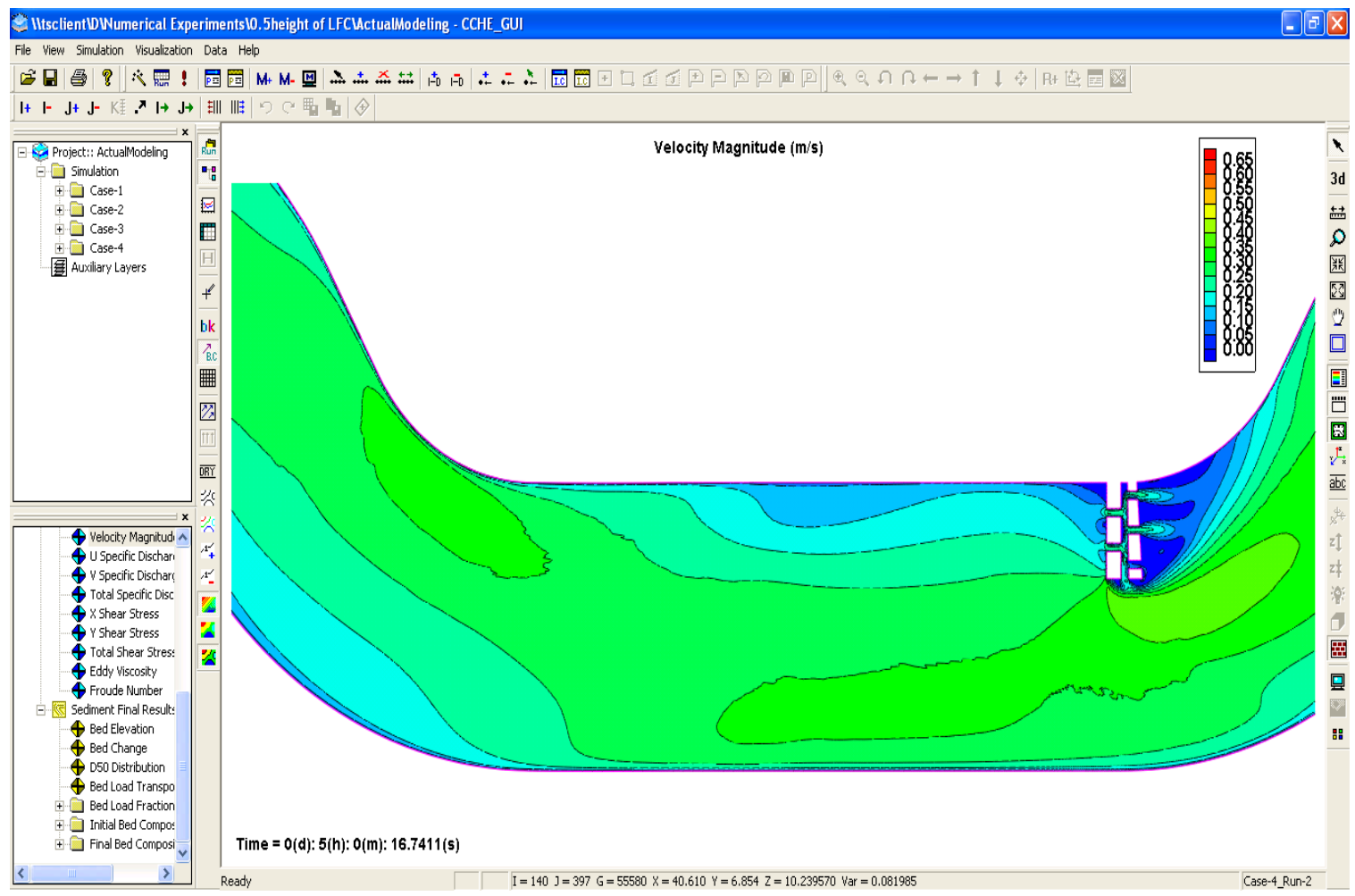

Figure T-55: Velocity magnitude when water depth of LFC $=22.5 \mathrm{~cm}$ between meanders \#2 and \#3 after 5-hr simulation. 


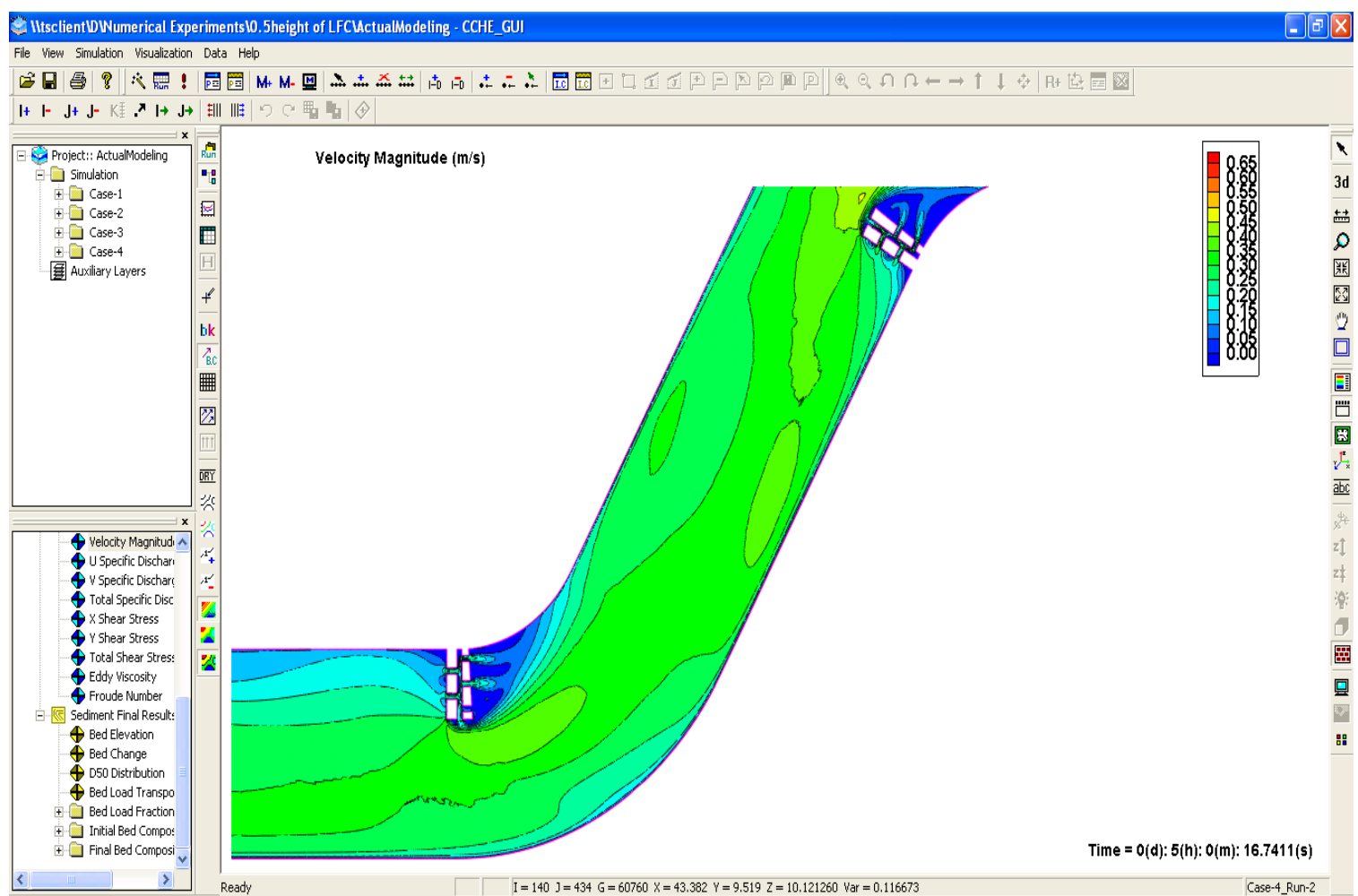

Figure T-56: Velocity magnitude when water depth of LFC $=22.5 \mathrm{~cm}$ between meanders \#3 and \#4 after 5-hr simulation.

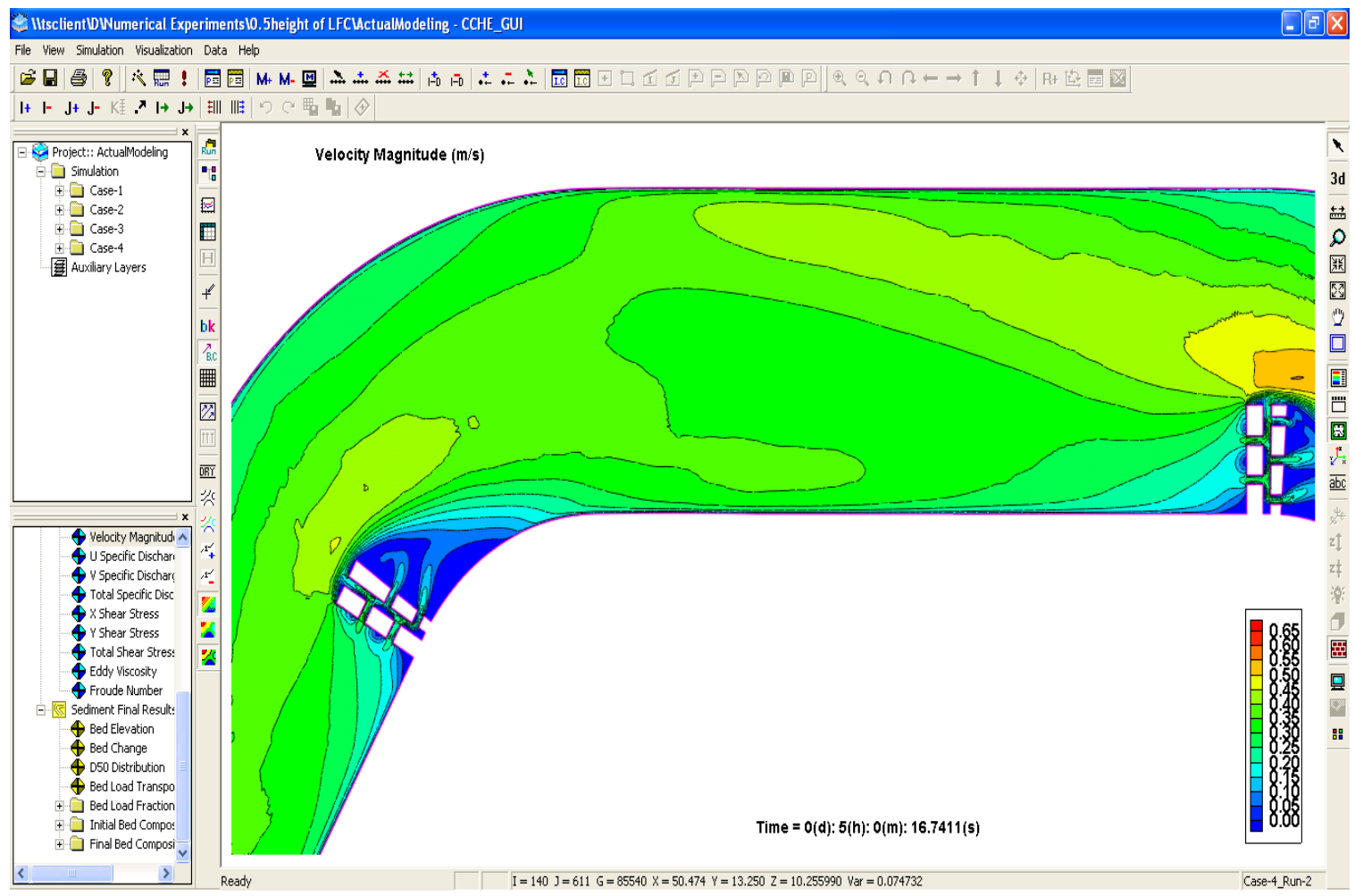

Figure T-57: Velocity magnitude when water depth of LFC $=22.5 \mathrm{~cm}$ between meanders \#4 and \#5 after 5-hr simulation. 


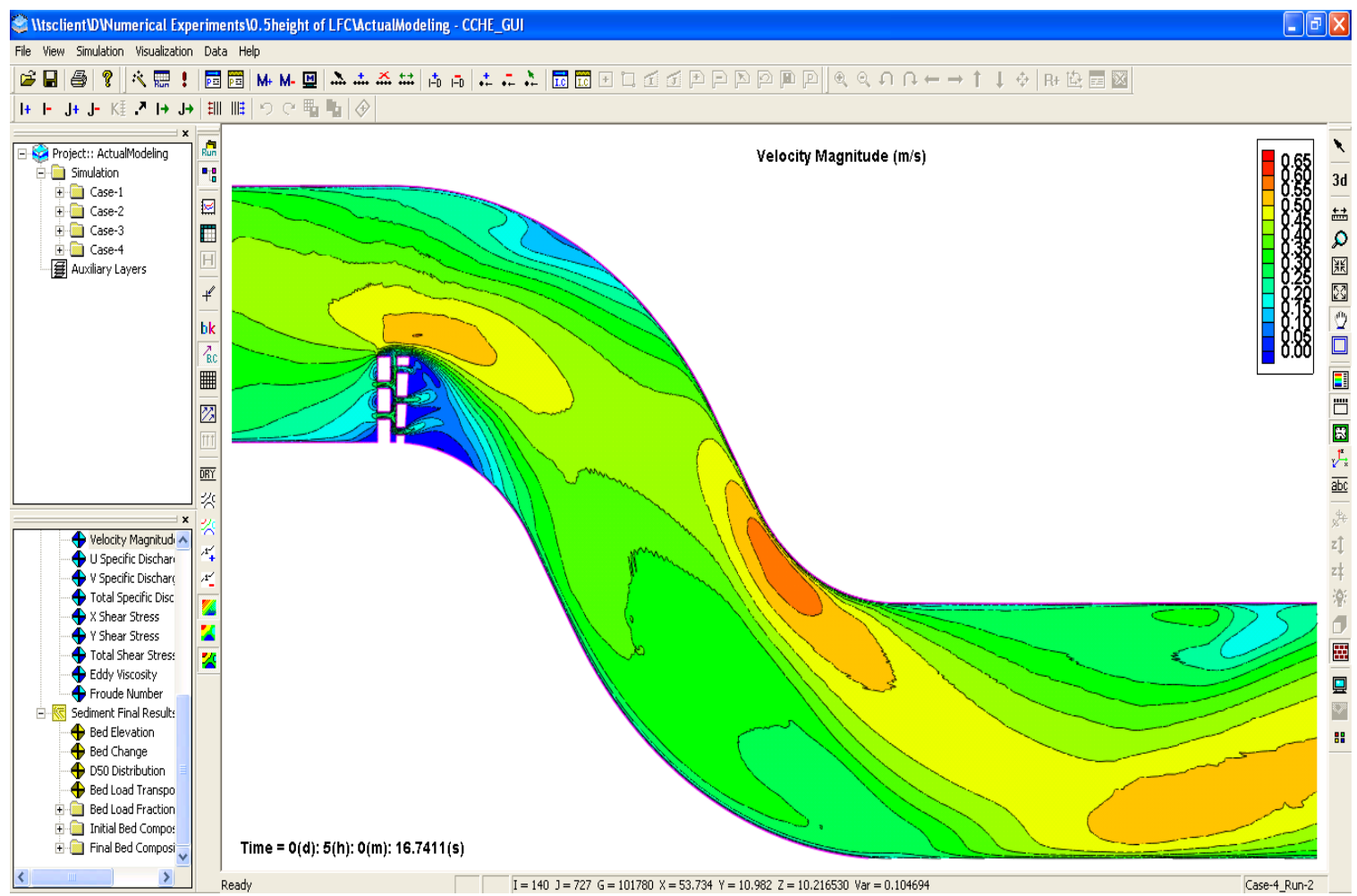

Figure T-58: Velocity magnitude when water depth of LFC $=22.5 \mathrm{~cm}$ between meanders \#5 and \#6 after 5-hr simulation.

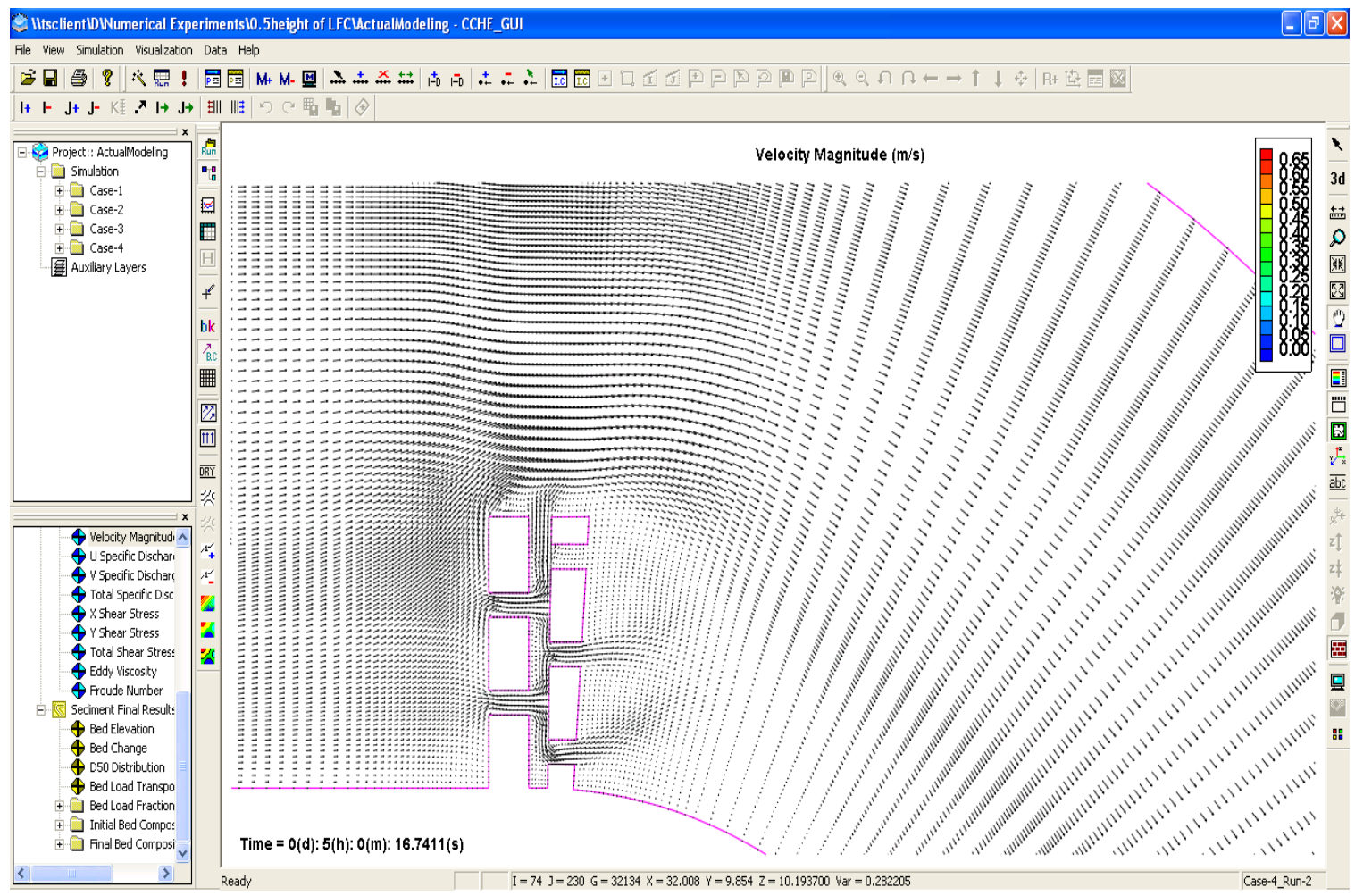

Figure T-59: Velocity direction when water depth of LFC $=22.5 \mathrm{~cm}$ at meander \#1after 5-hr simulation. 


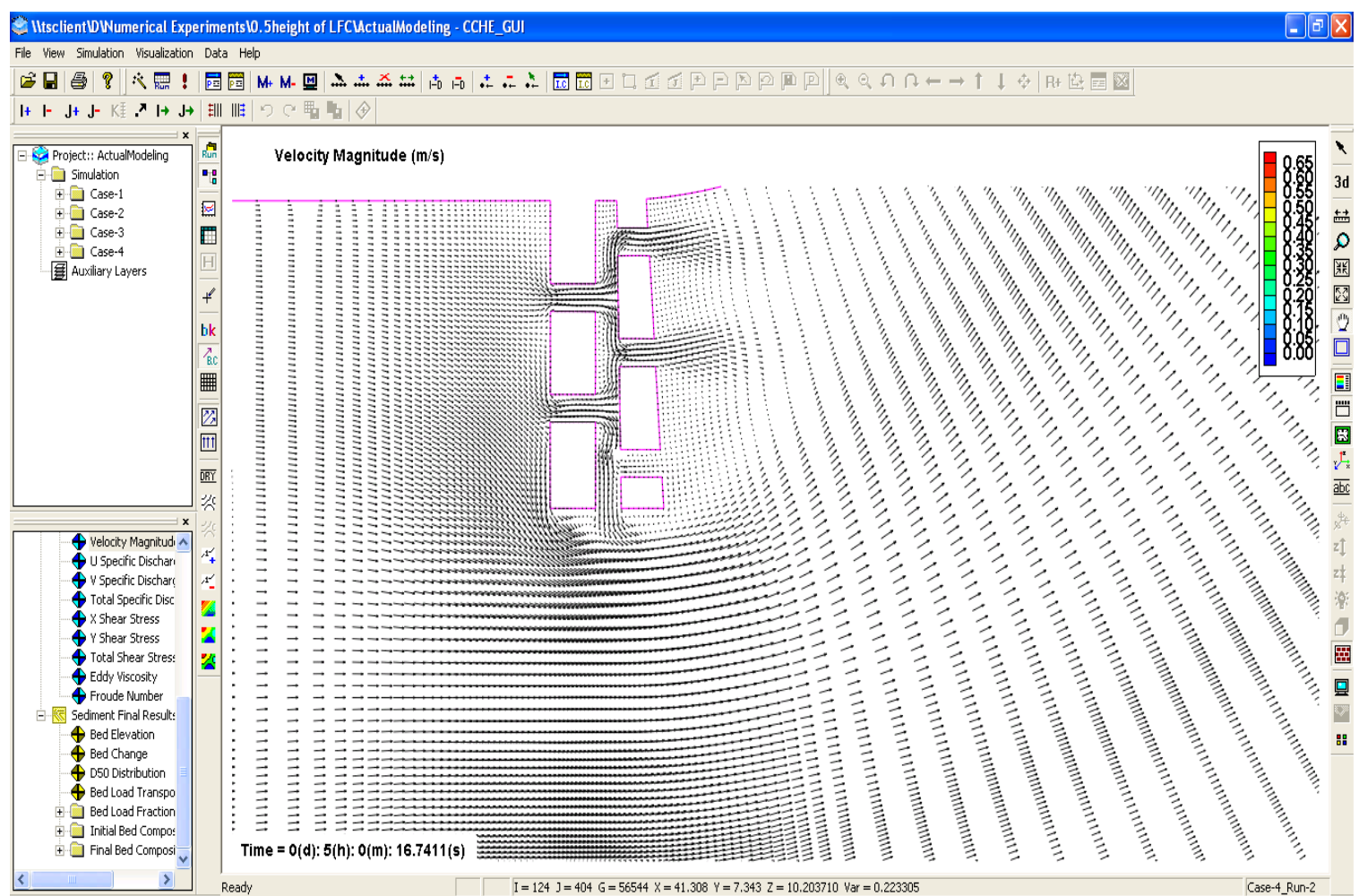

Figure T-60: Velocity direction when water depth of LFC $=22.5 \mathrm{~cm}$ at meander \#3 after 5-hr simulation.

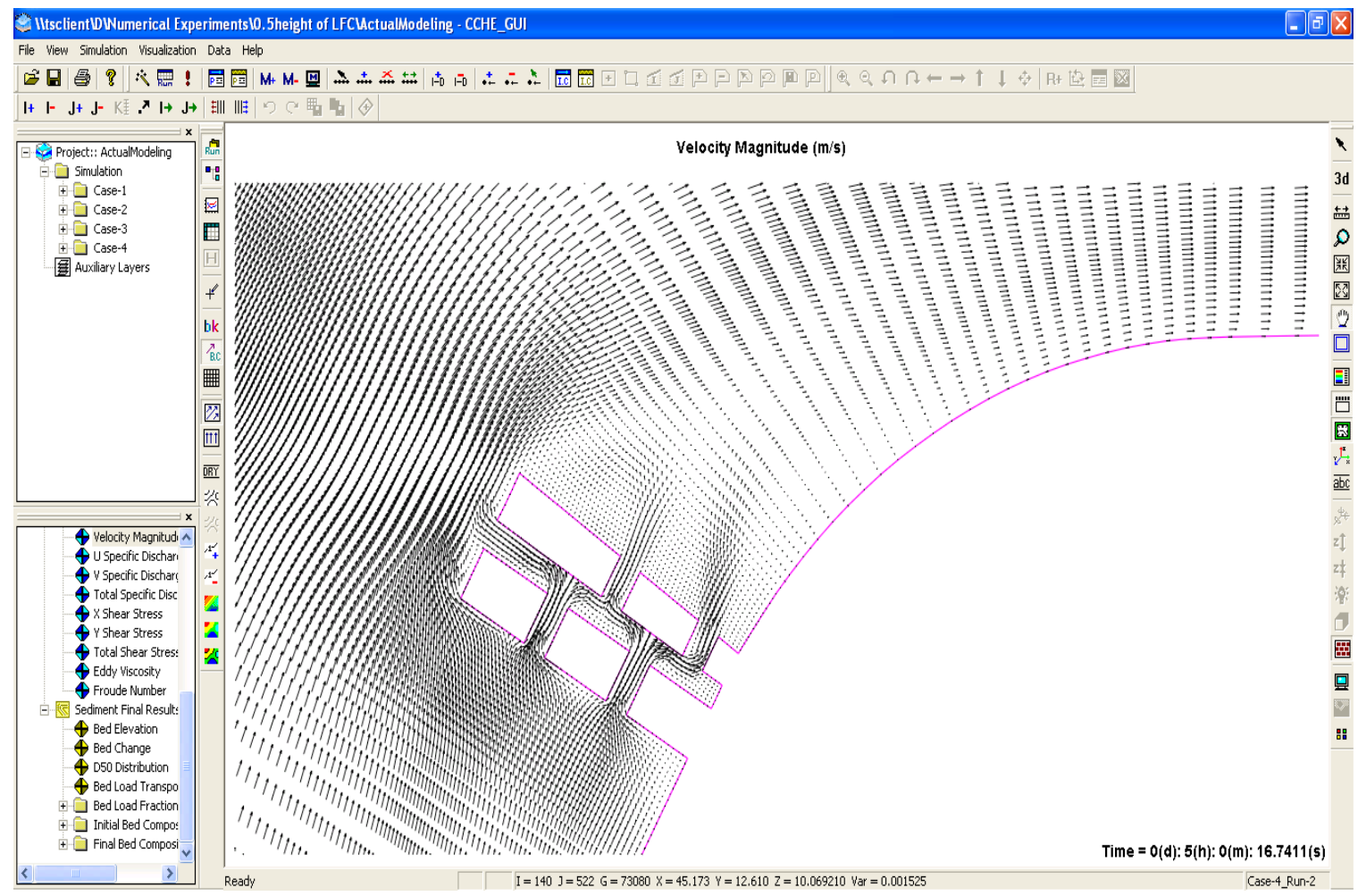

Figure T-61: Velocity direction when water depth of LFC $=22.5 \mathrm{~cm}$ at meander \#4 after 5-hr simulation. 


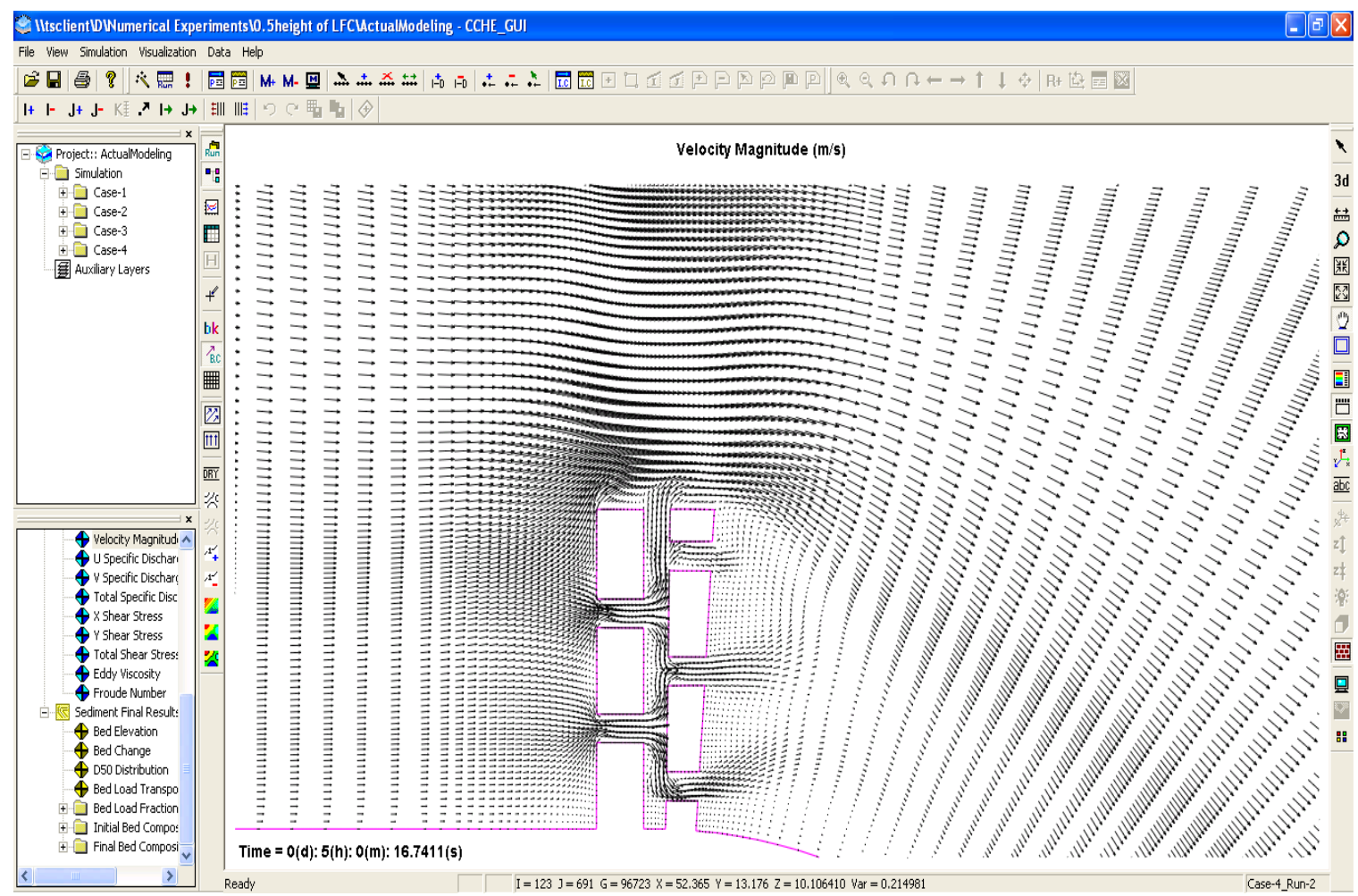

Figure T-62: Velocity direction when water depth of LFC $=22.5 \mathrm{~cm}$ at meander \#5 after 5-hr simulation. 


\section{3/4 water depth of LFC}

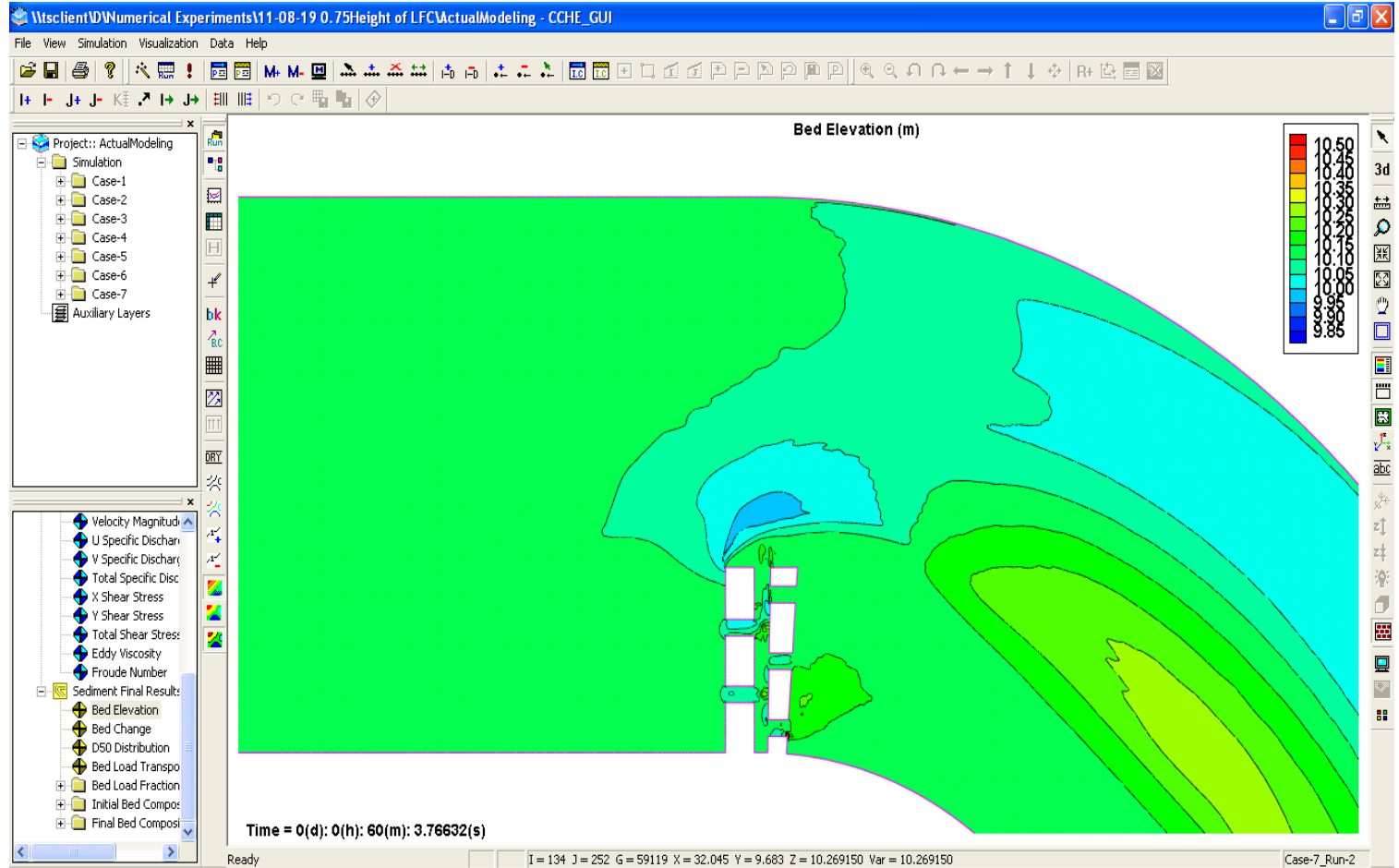

Figure T-63: Bed elevation when water depth of LFC $=33.75 \mathrm{~cm}$ at meander \#1 after 1-hr simulation.

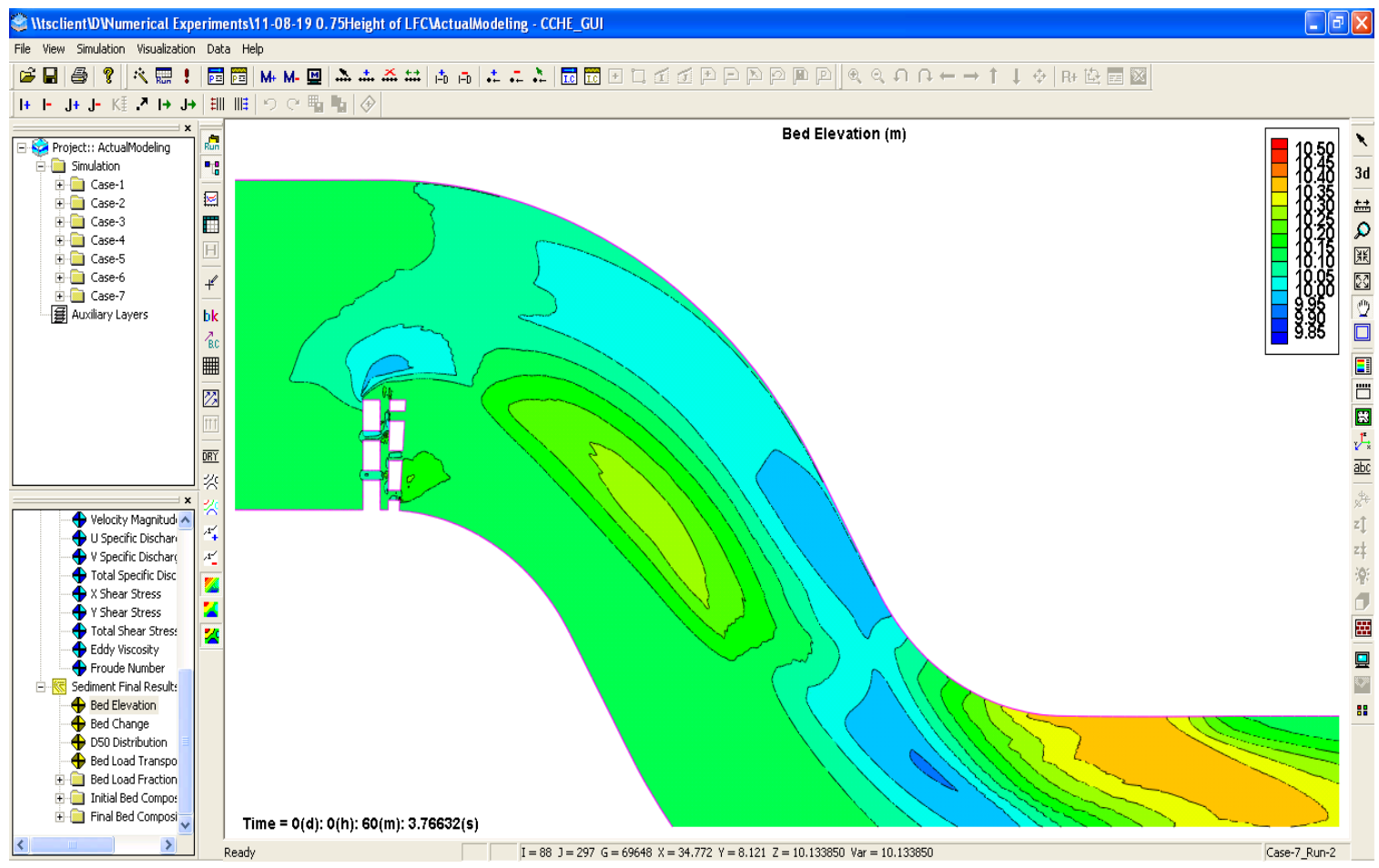

Figure T-64: Bed elevation when water depth of LFC $=33.75 \mathrm{~cm}$ between meanders \#1 and \#2 after 1-hr simulation. 


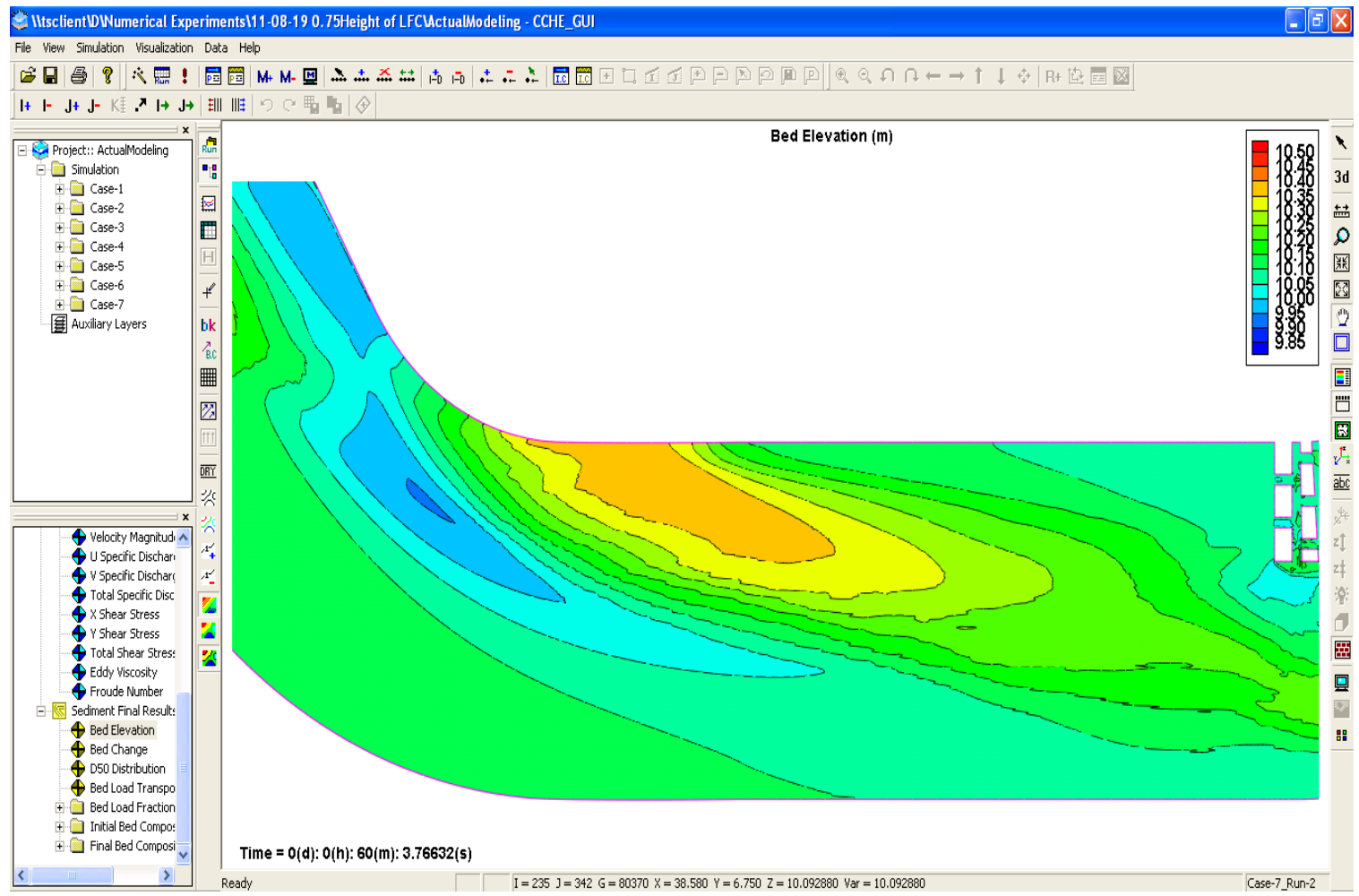

Figure T-65: Bed elevation when water depth of LFC $=33.75 \mathrm{~cm}$ between meanders \#2 and \#3 after 1-hr simulation.

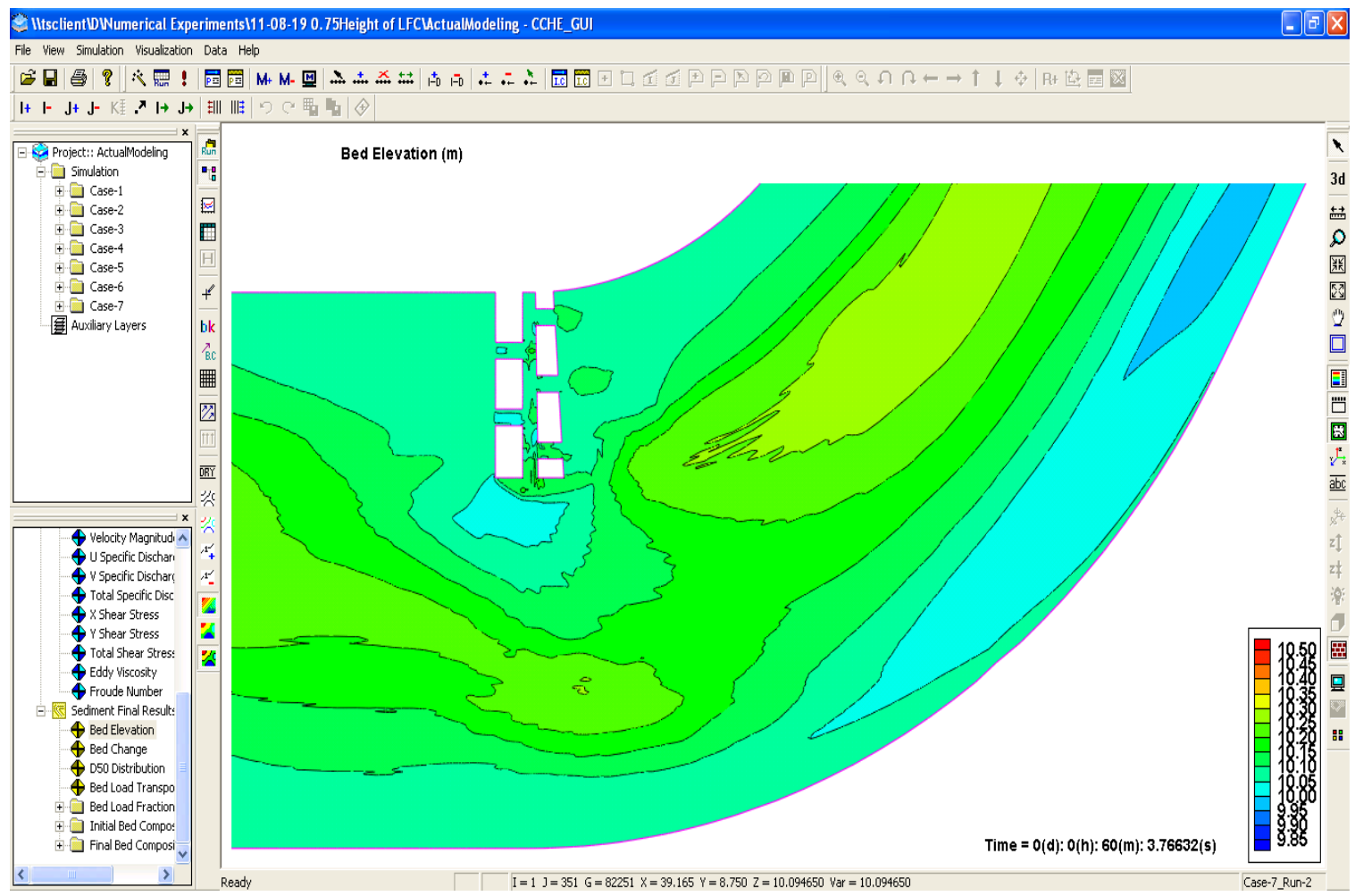

Figure T-66: Bed elevation when water depth of LFC $=33.75 \mathrm{~cm}$ at meander \#3 after 1 -hr simulation. 


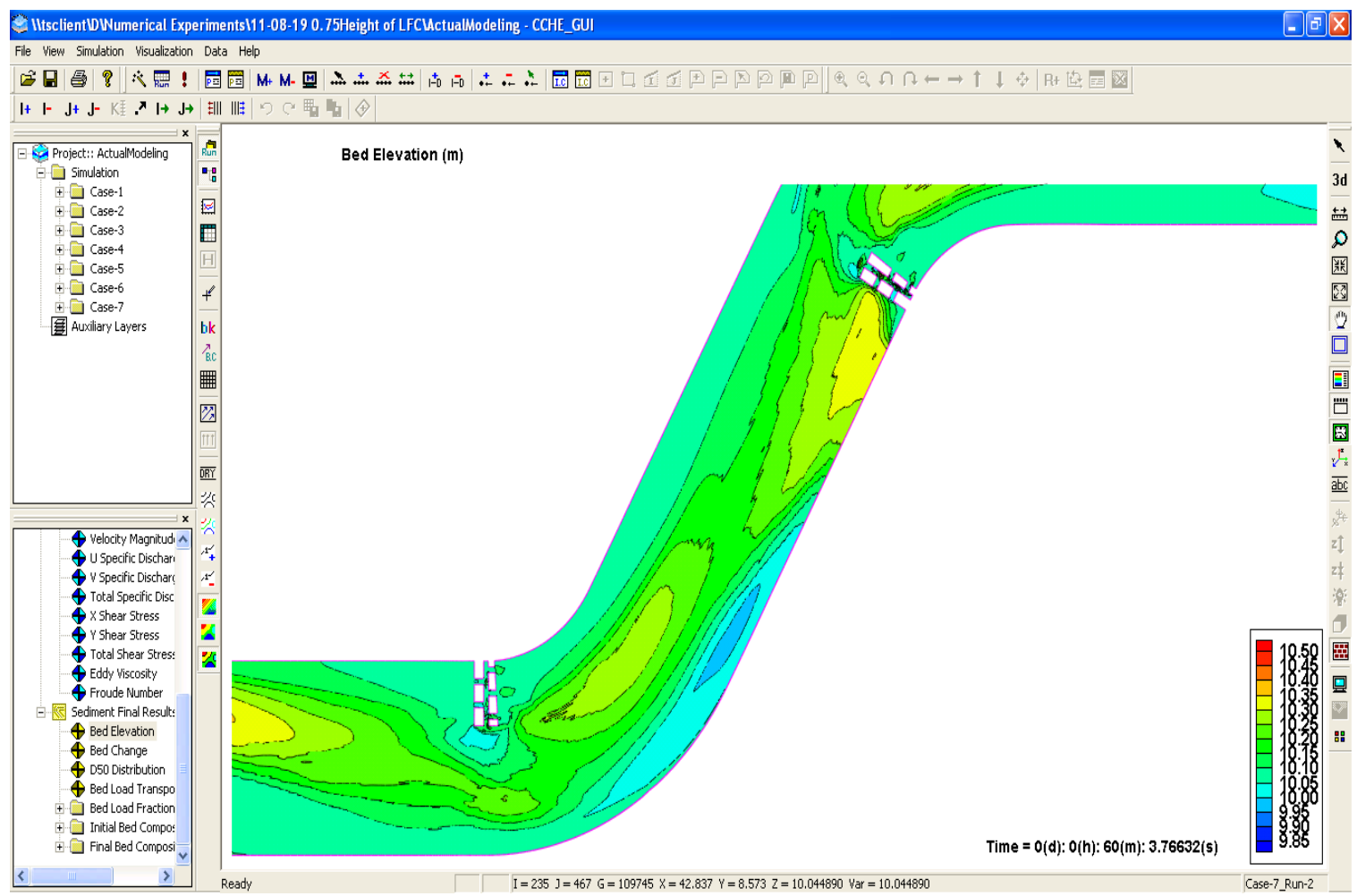

Figure T-67: Bed elevation when water depth of LFC $=33.75 \mathrm{~cm}$ between meanders \#3 and \#4 after 1-hr simulation.

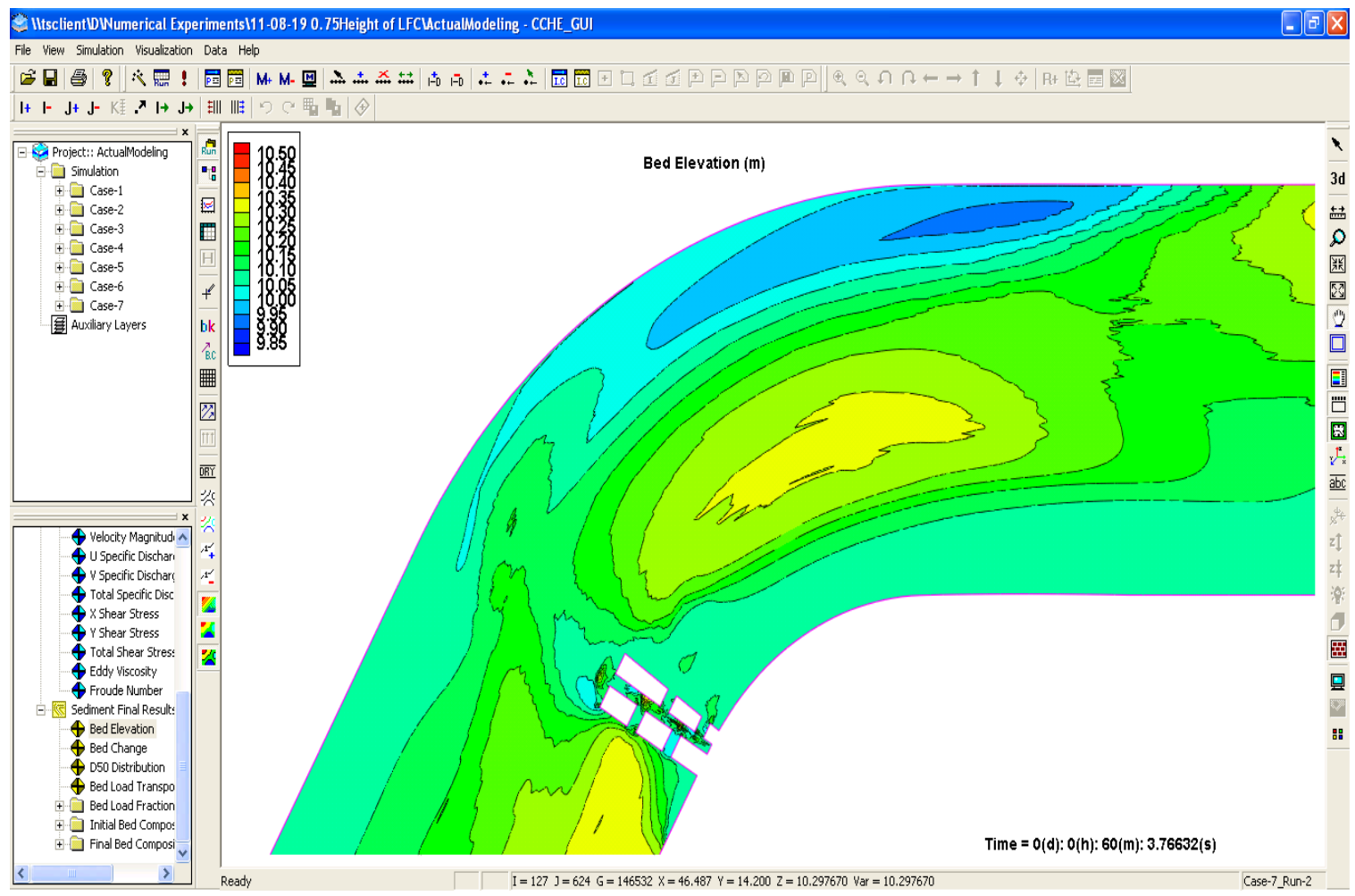

Figure T-68: Bed elevation when water depth of LFC $=33.75 \mathrm{~cm}$ at meander \#4 after 1 -hr simulation. 


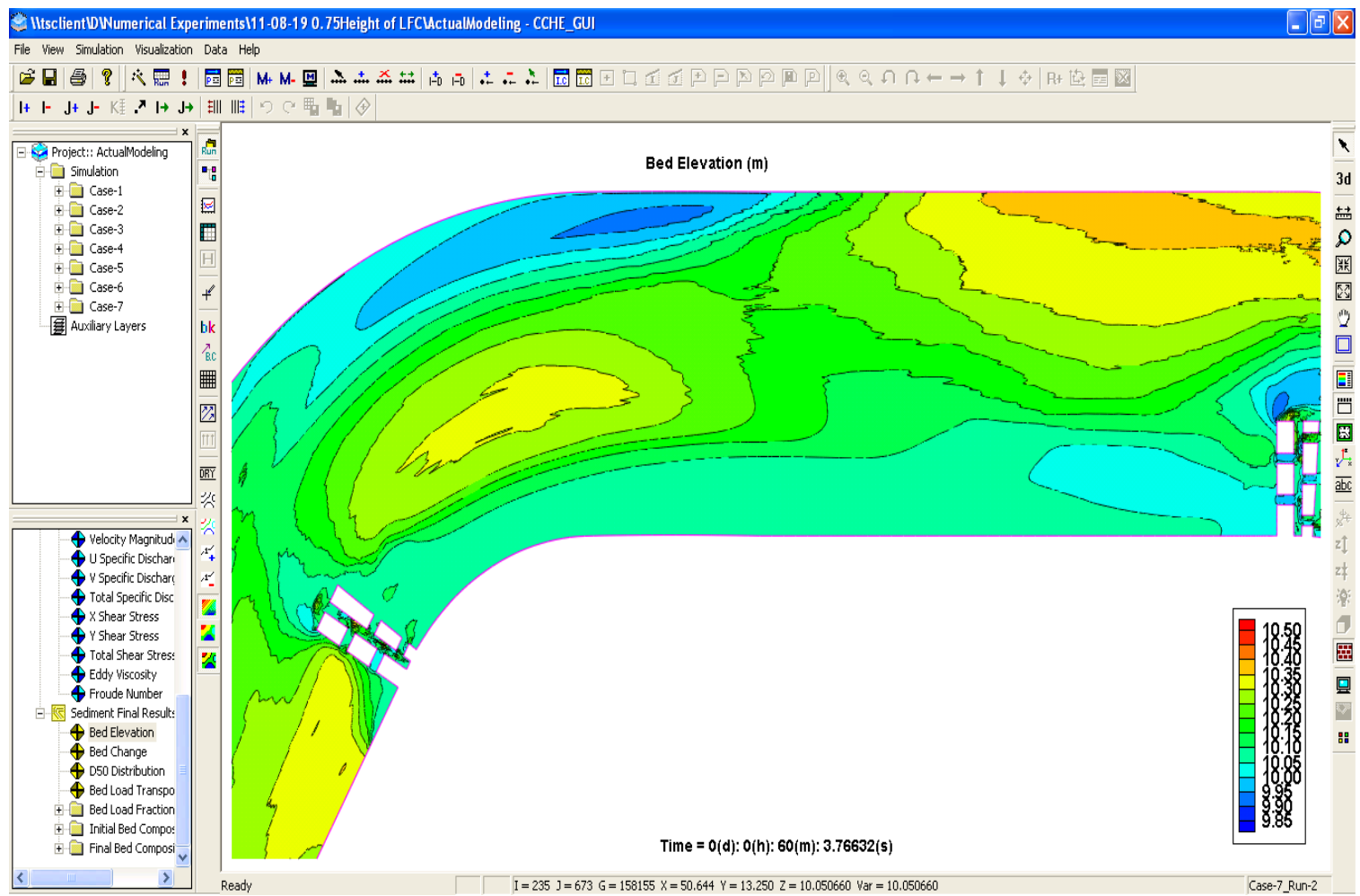

Figure T-69: Bed elevation when water depth of LFC $=33.75 \mathrm{~cm}$ between meanders \#4 and \#5 after 1-hr simulation.

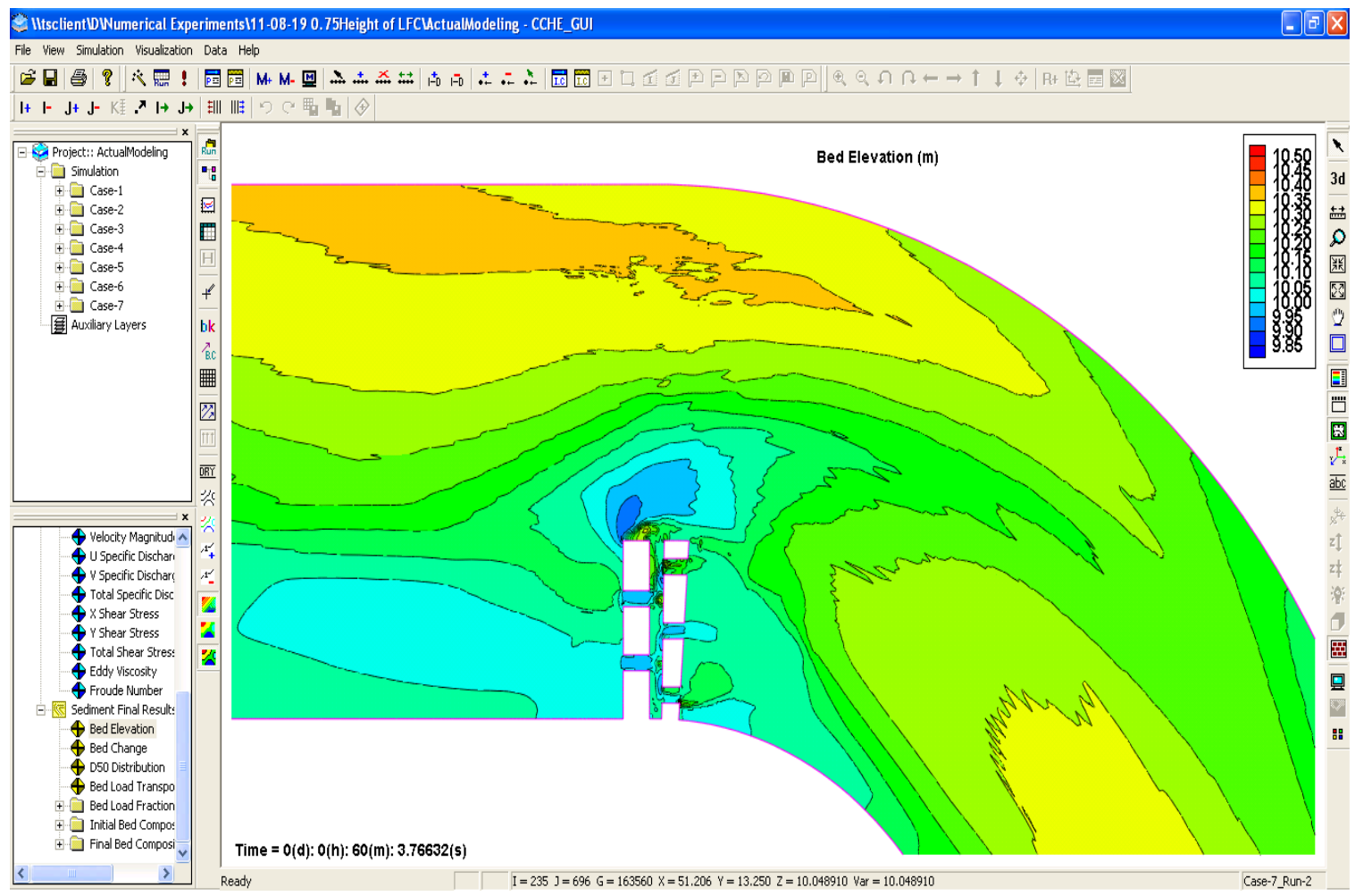

Figure T-70: Bed elevation when water depth of LFC $=33.75 \mathrm{~cm}$ at meander \#5 after 1-hr simulation. 


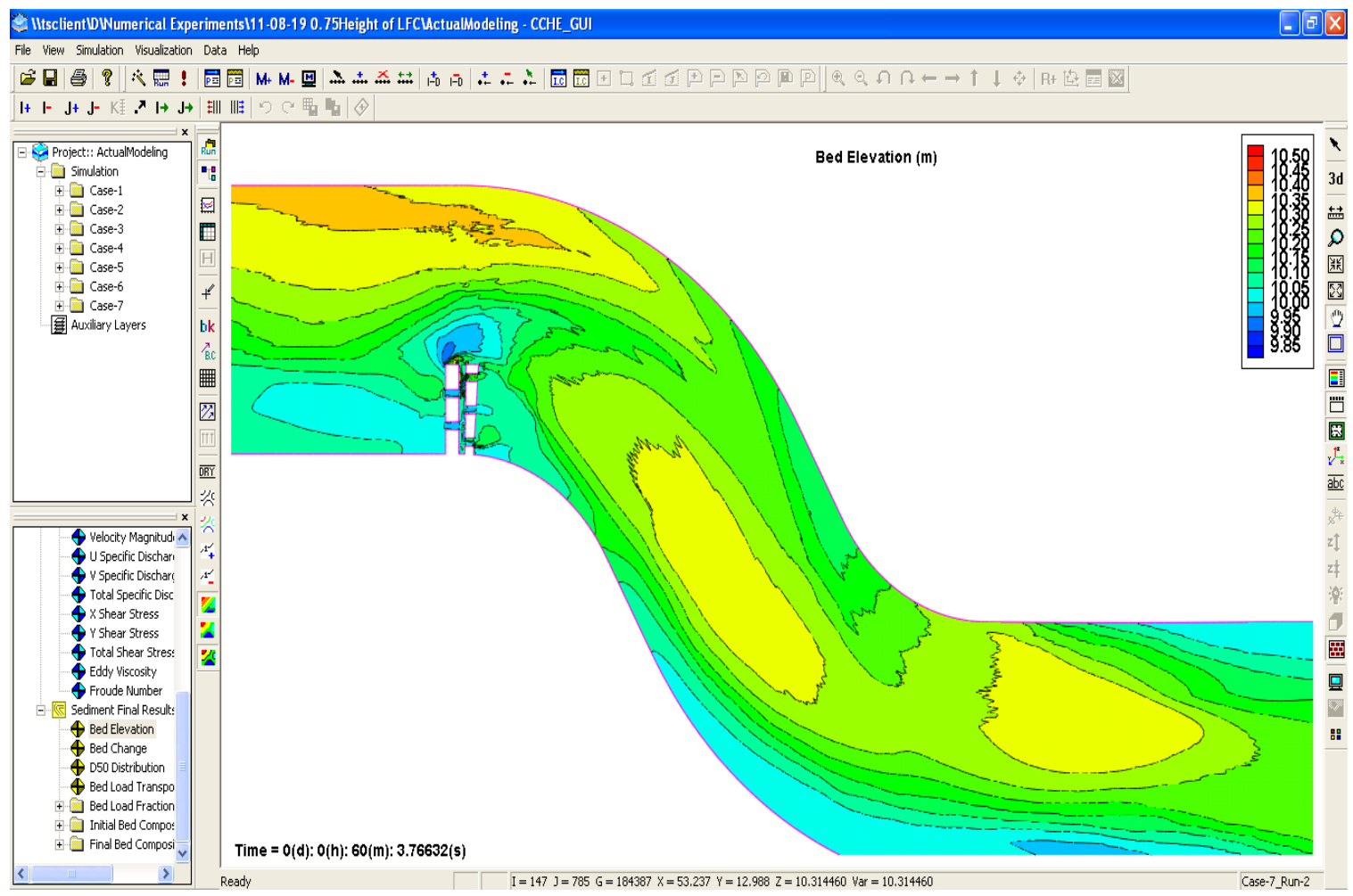

Figure T-71: Bed elevation when water depth of LFC $=33.75 \mathrm{~cm}$ between meanders \#5 and \#6 after 1-hr simulation.

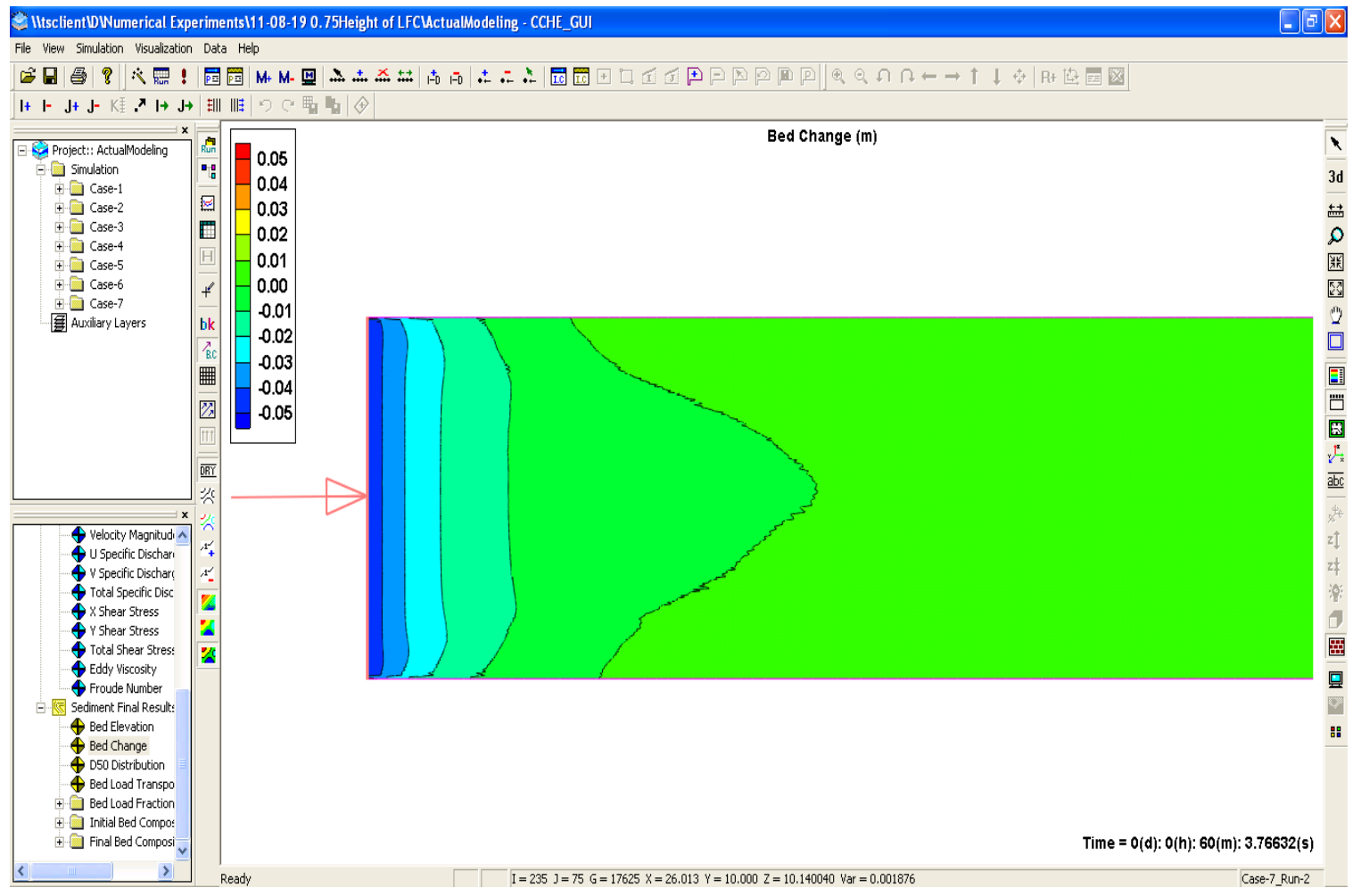

Figure T-72: Bed change when water depth of LFC $=33.75 \mathrm{~cm}$ at upstream boundary after 1-hr simulation. 


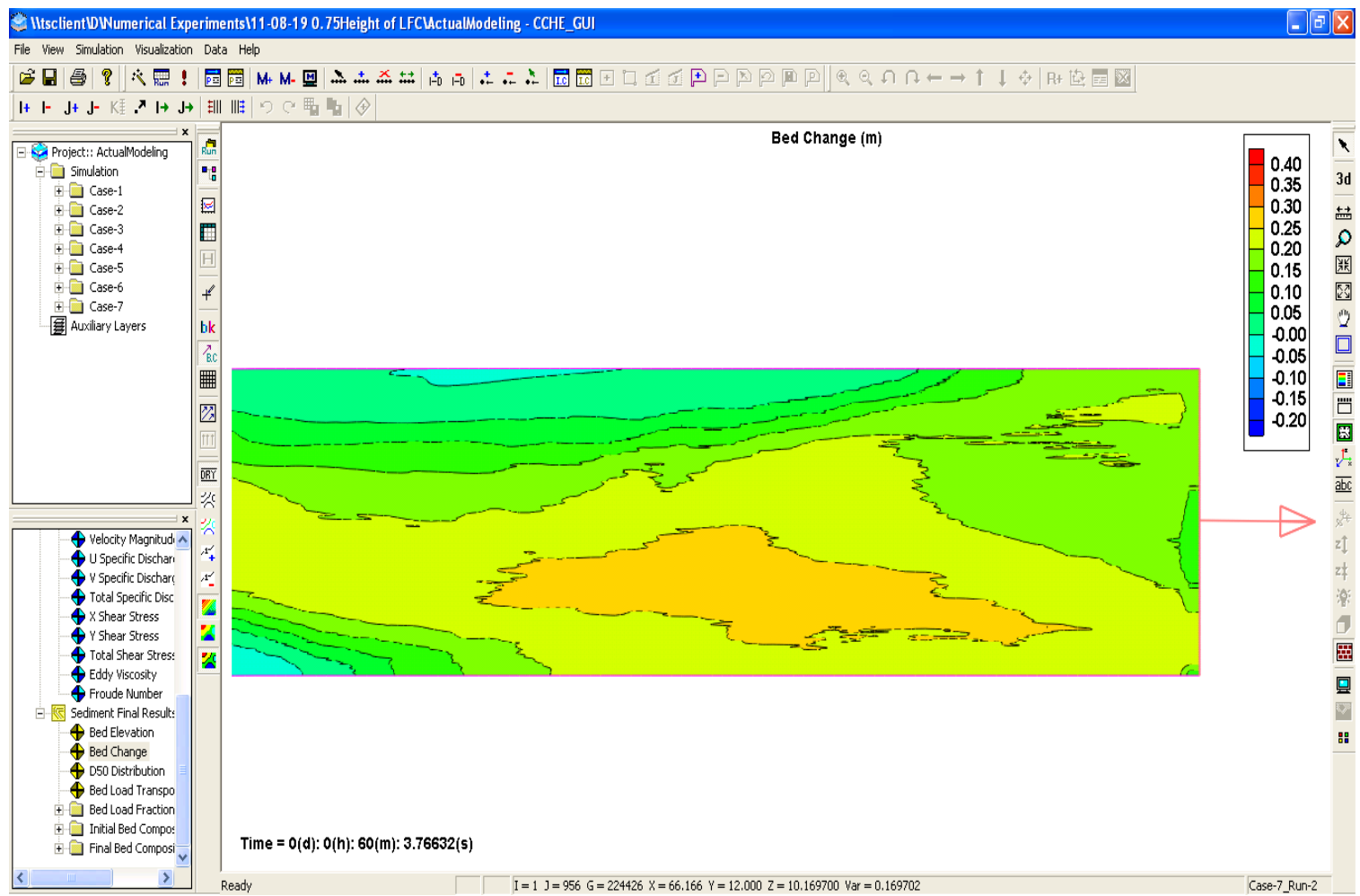

Figure T-73: Bed change when water depth of LFC $=33.75 \mathrm{~cm}$ at downstream boundary after 1 -hr simulation.

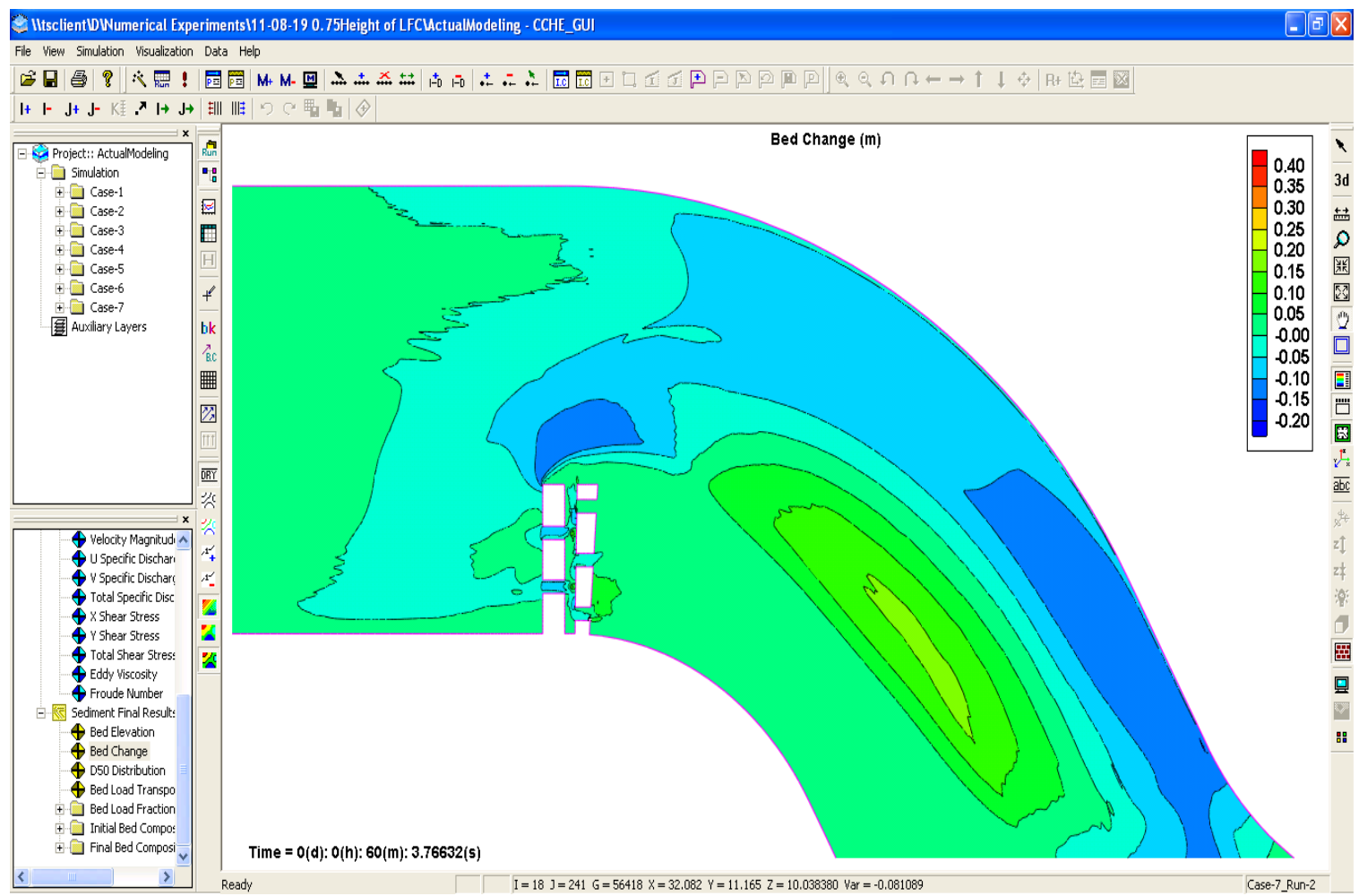

Figure T-74: Bed change when water depth of LFC $=33.75 \mathrm{~cm}$ at meander \#1 after 1 -hr simulation. 


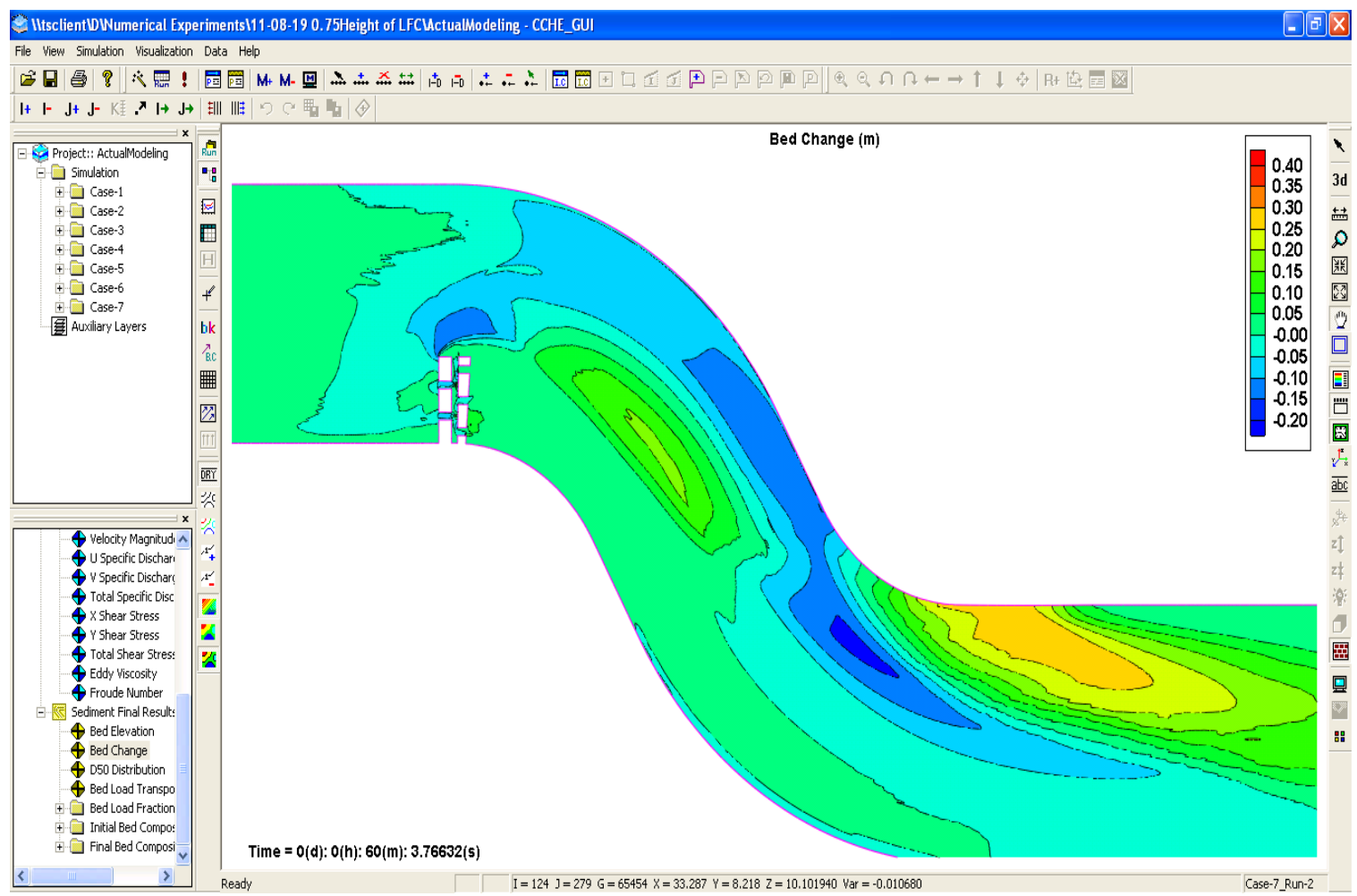

Figure T-75: Bed change when water depth of LFC $=33.75 \mathrm{~cm}$ between meanders \#1 and \#2 after 1-hr simulation.

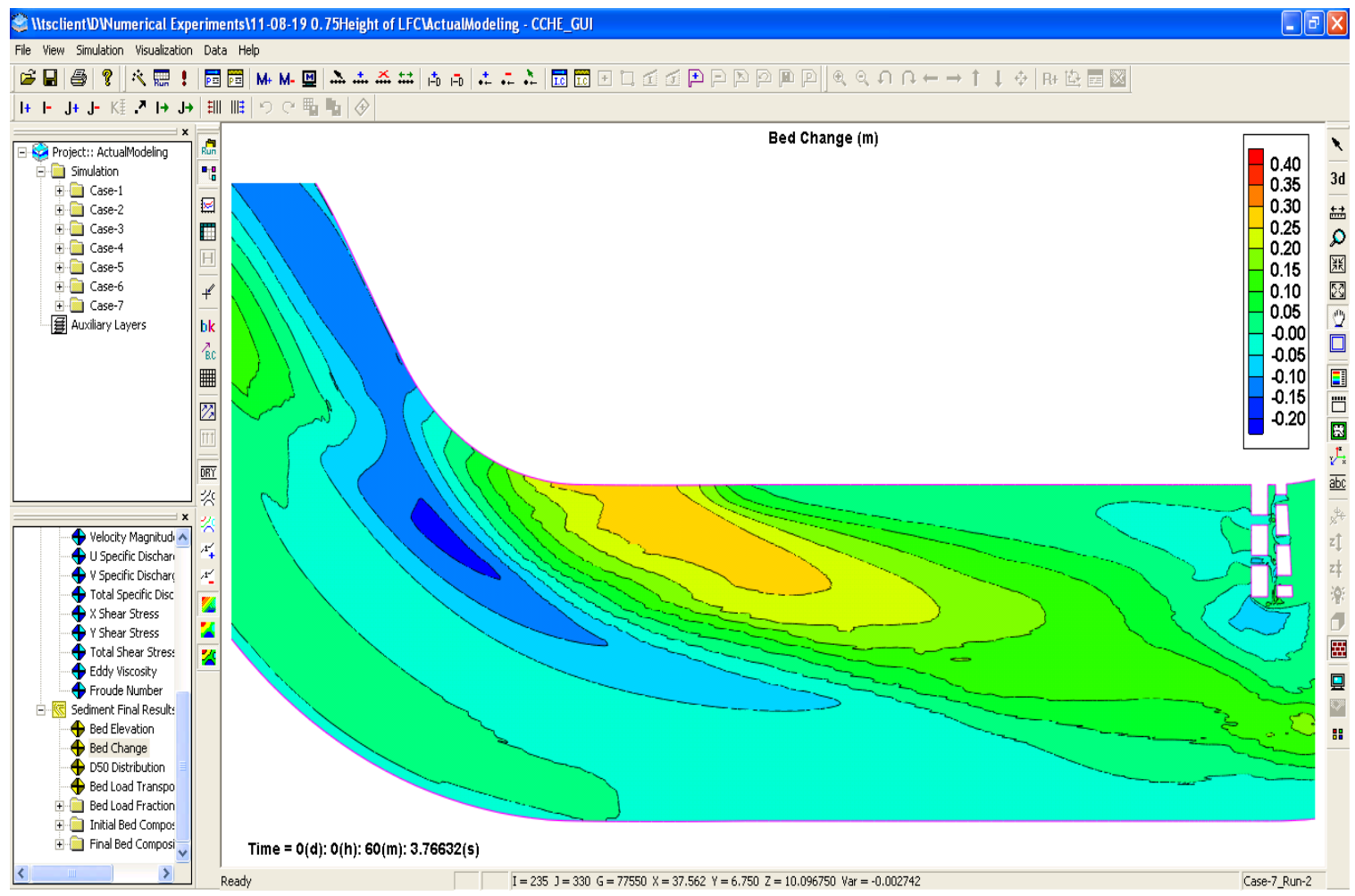

Figure T-76: Bed change when water depth of LFC $=33.75 \mathrm{~cm}$ between meanders \#2 and \#3 after 1-hr simulation. 


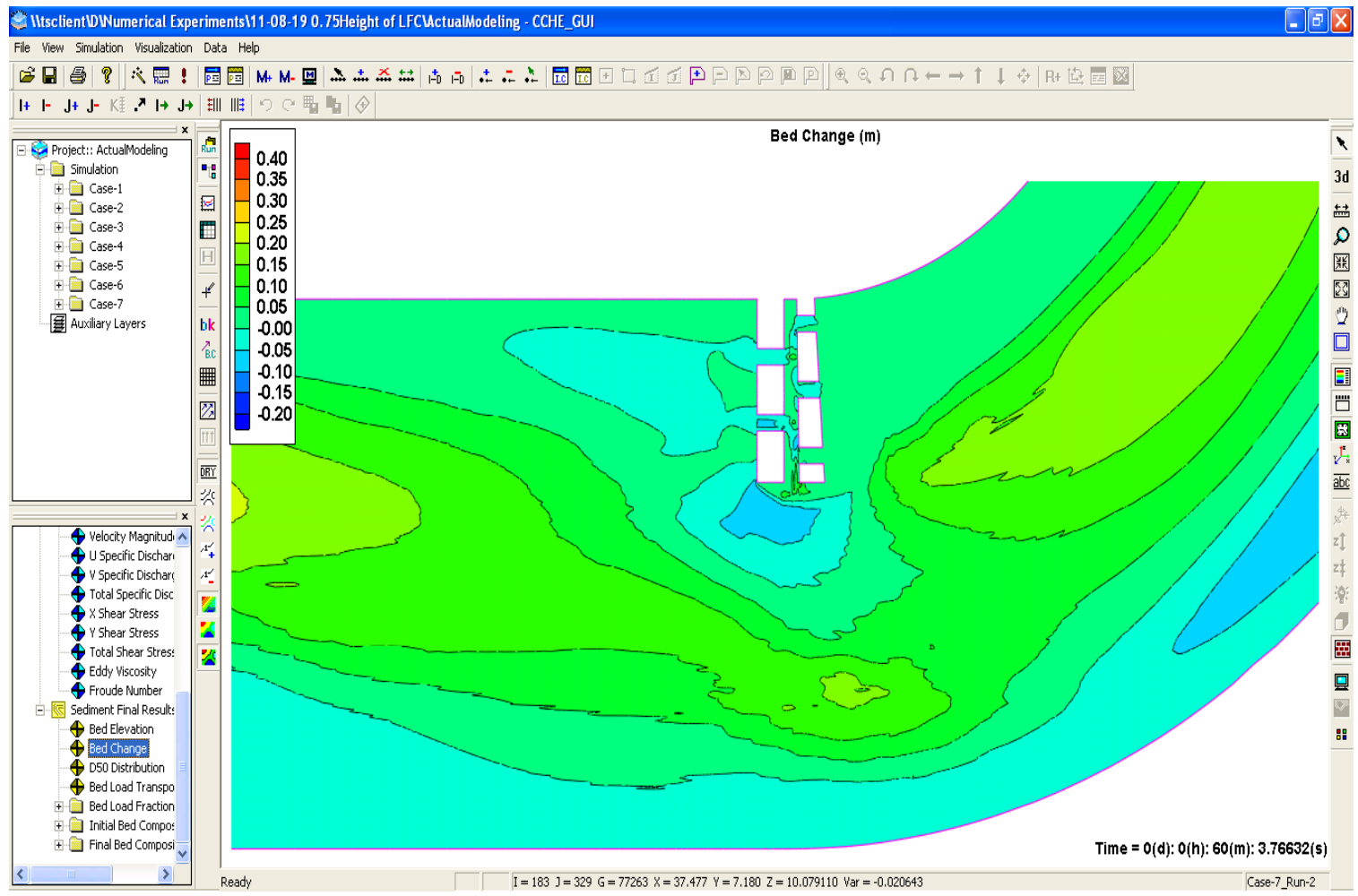

Figure T-77: Bed change when water depth of LFC $=33.75 \mathrm{~cm}$ at meander \#3 after 1 -hr simulation.

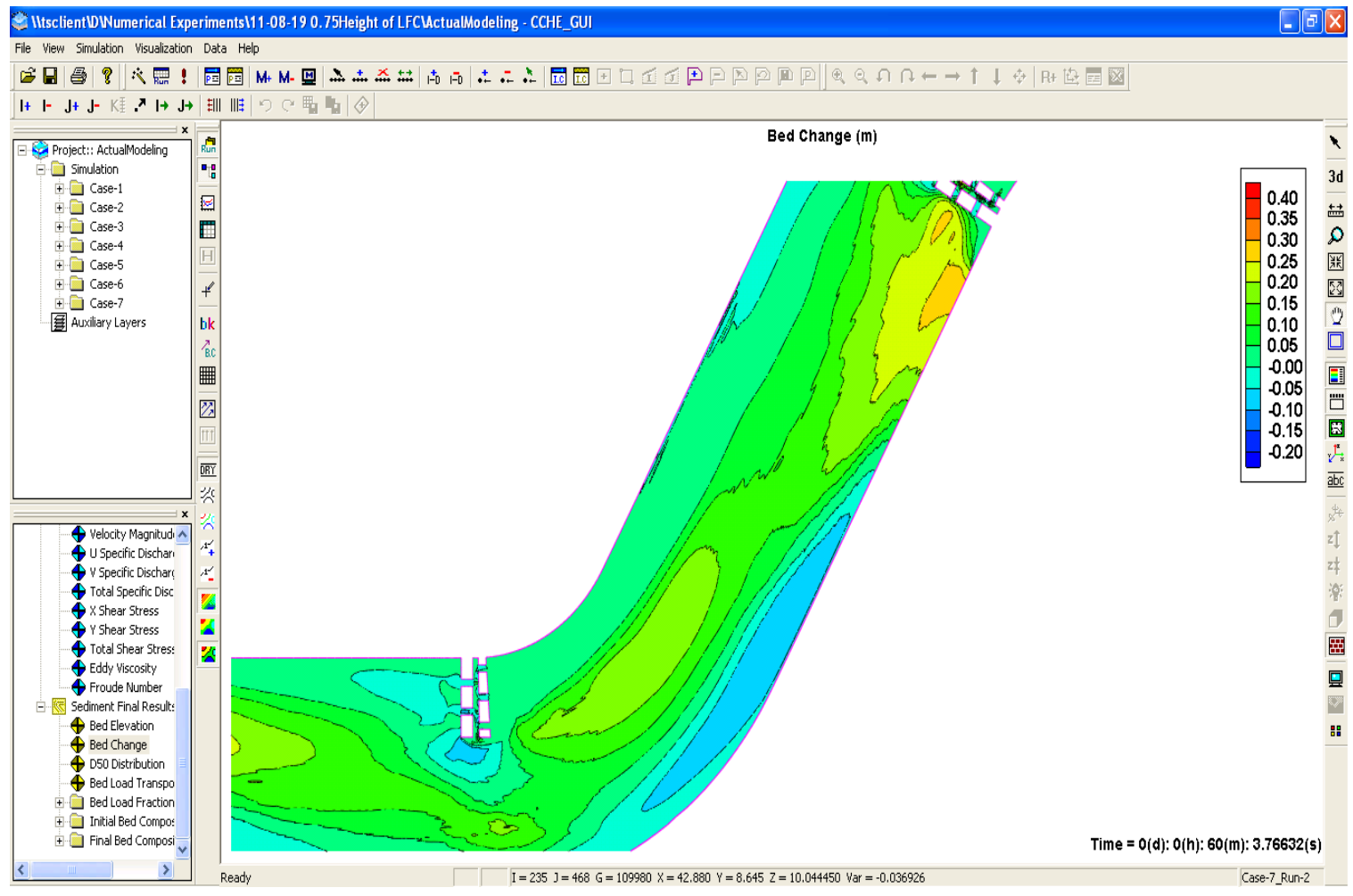

Figure T-78: Bed change when water depth of LFC $=33.75 \mathrm{~cm}$ between meanders \#3 and \#4 after 1-hr simulation. 


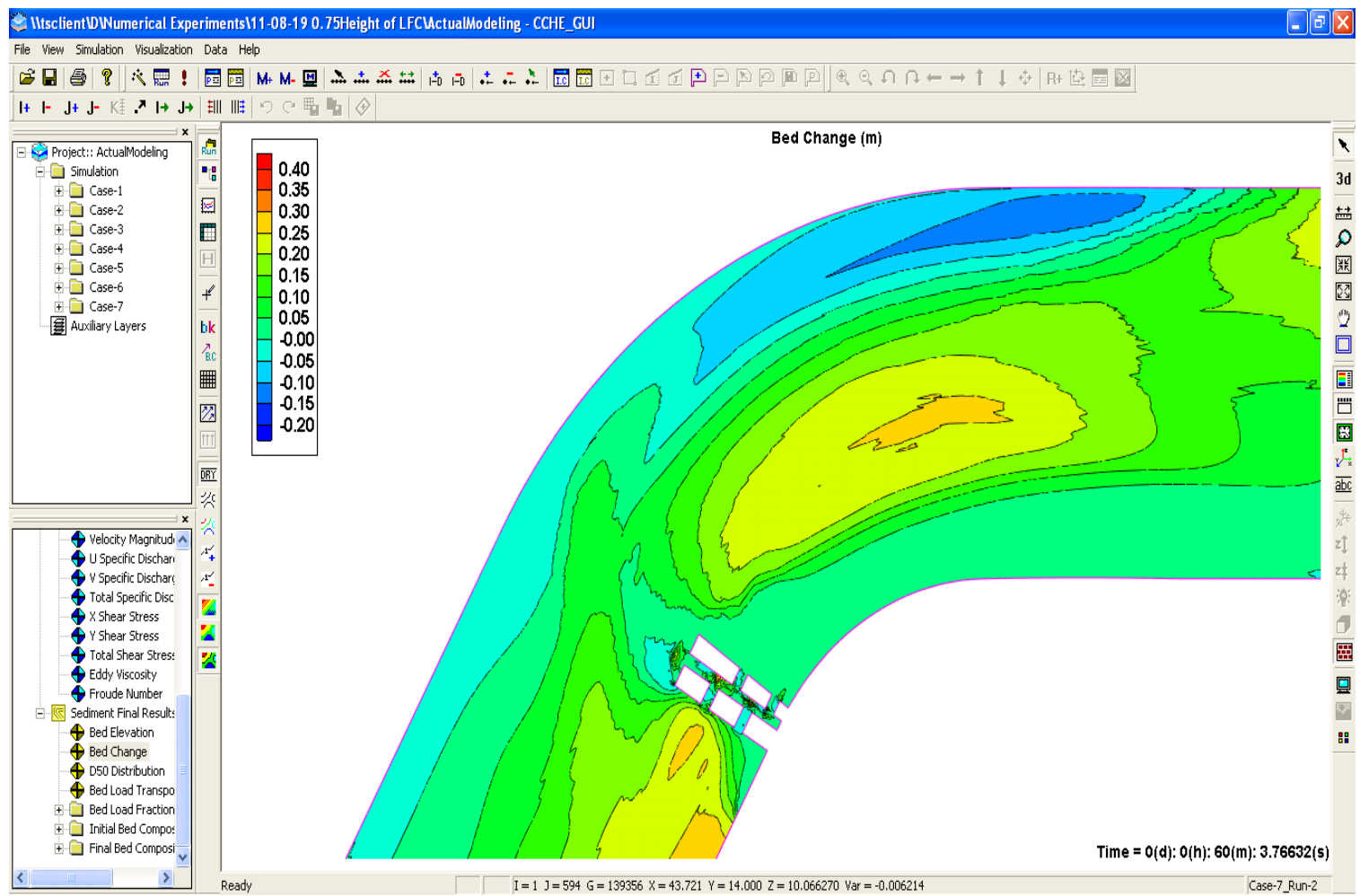

Figure T-79: Bed change when water depth of LFC $=33.75 \mathrm{~cm}$ at meander \#4 after 1 -hr simulation.

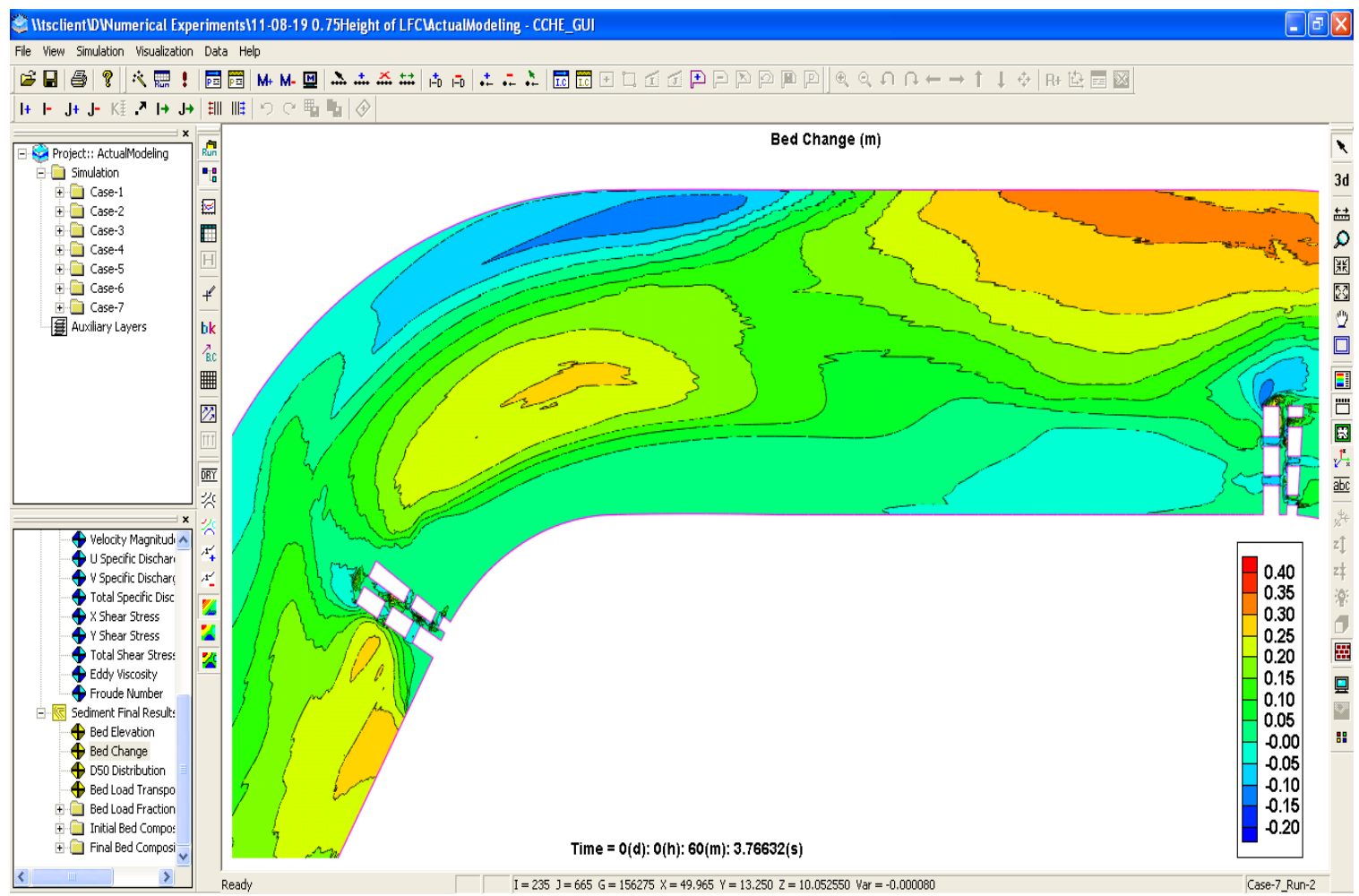

Figure T-80: Bed change when water depth of LFC $=33.75 \mathrm{~cm}$ between meanders \#4 and \#5 after 1-hr simulation. 


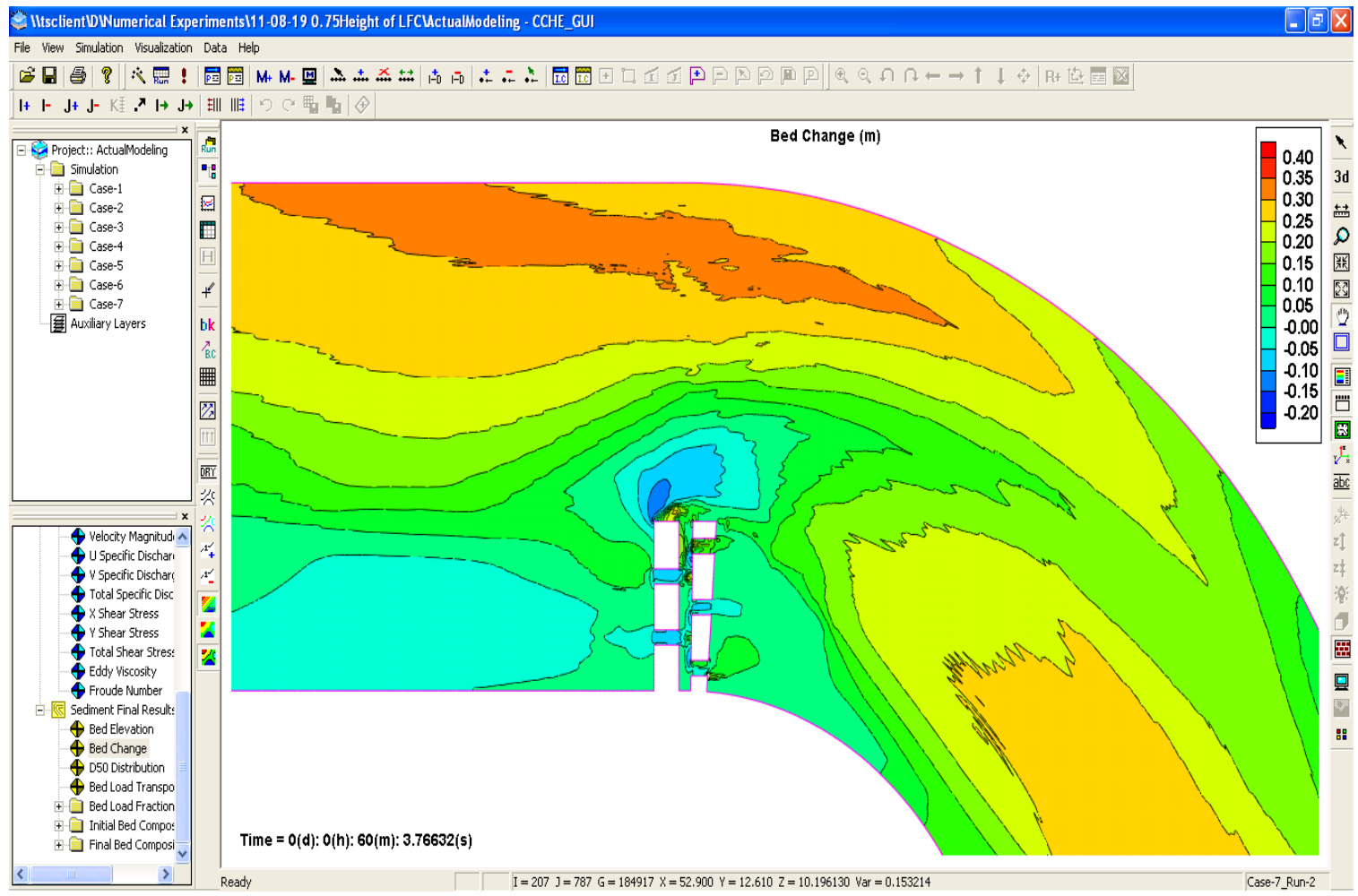

Figure T-81: Bed change when water depth of LFC $=33.75 \mathrm{~cm}$ at meander \#5 after 1 -hr simulation.

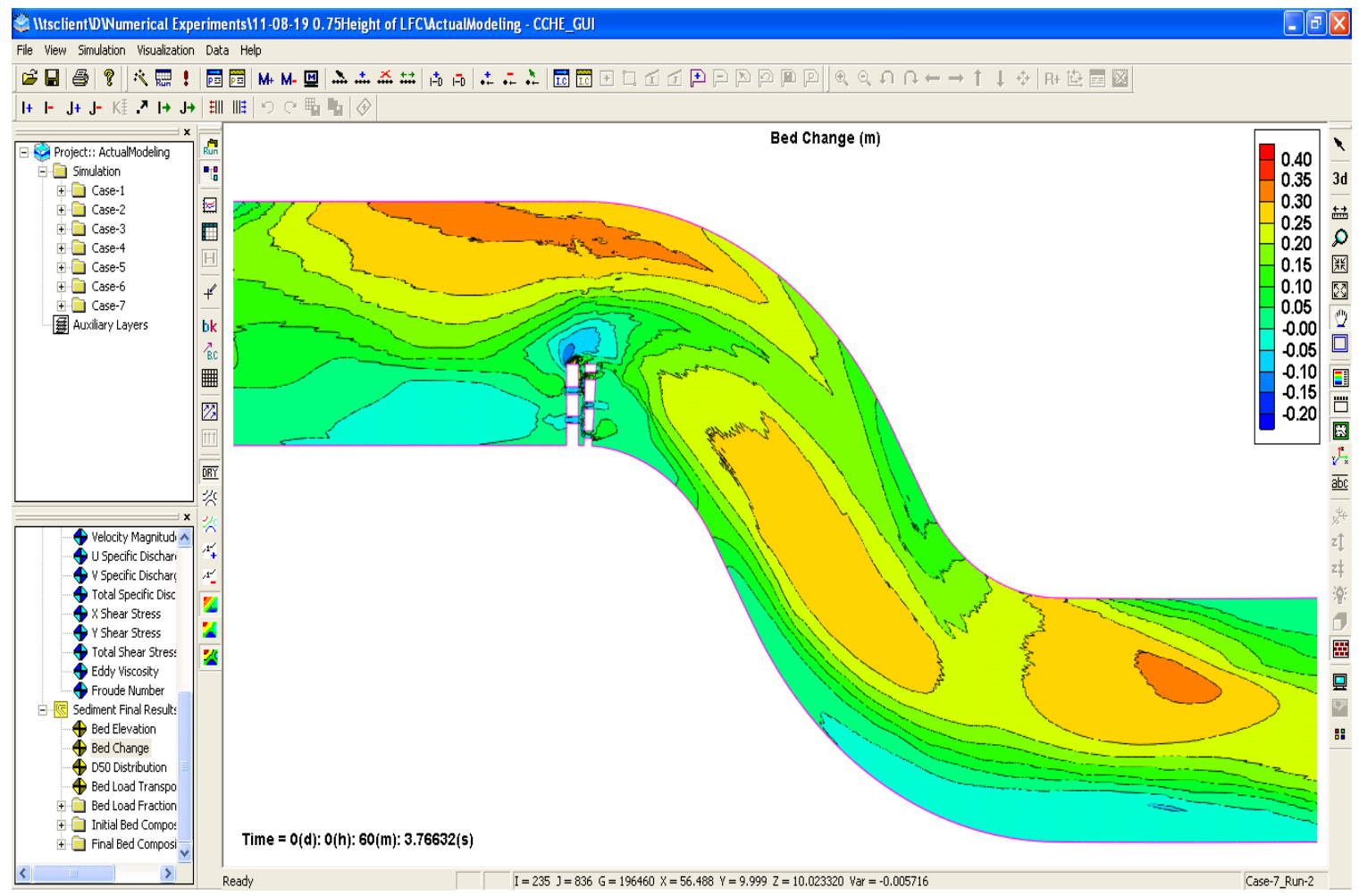

Figure T-82: Bed change when water depth of LFC $=33.75 \mathrm{~cm}$ between meanders \#5 and \#6 after 1-hr simulation. 


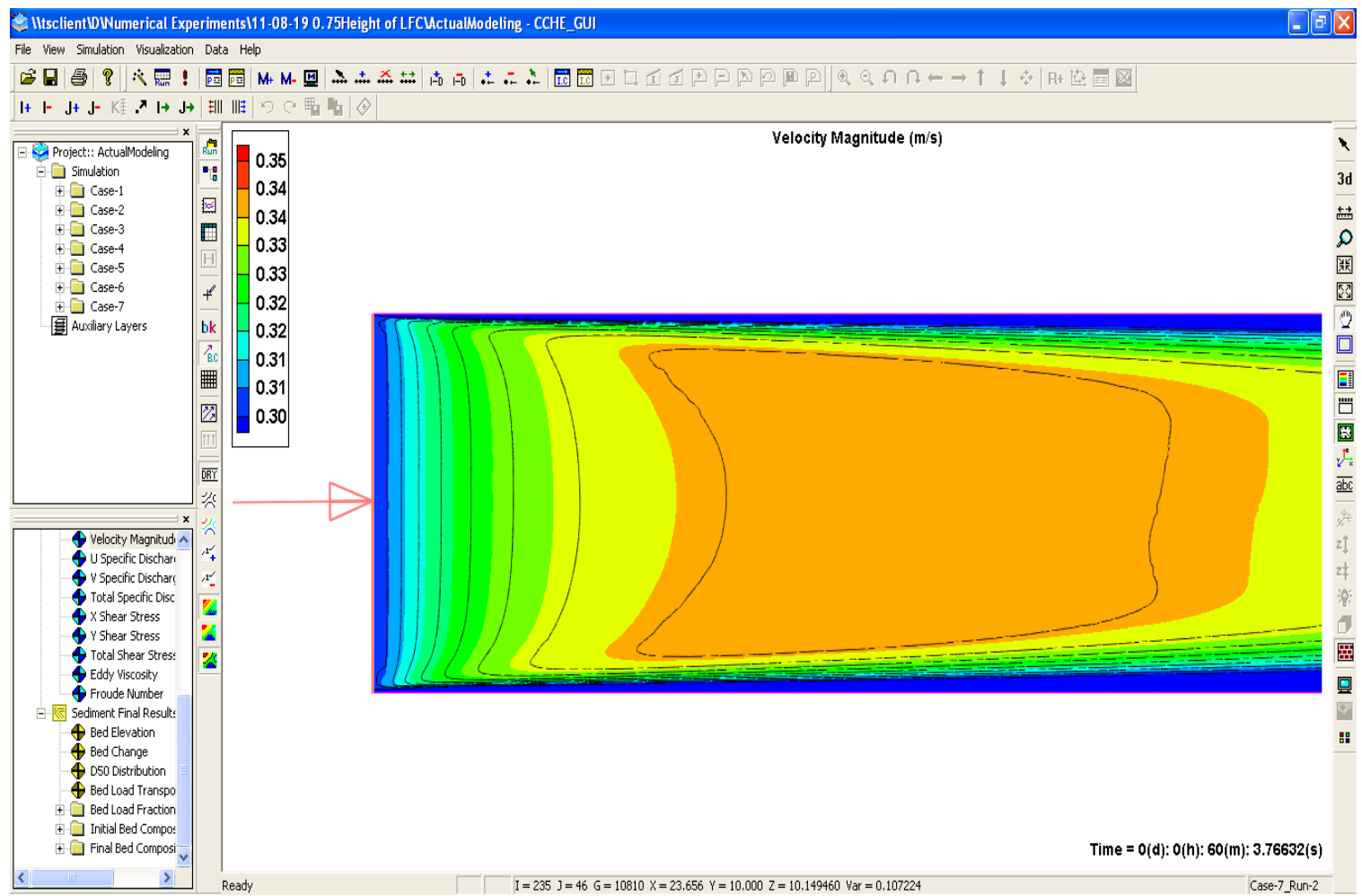

Figure T-83: Velocity magnitude when water depth of LFC $=33.75 \mathrm{~cm}$ at upstream boundary after 1-hr simulation.

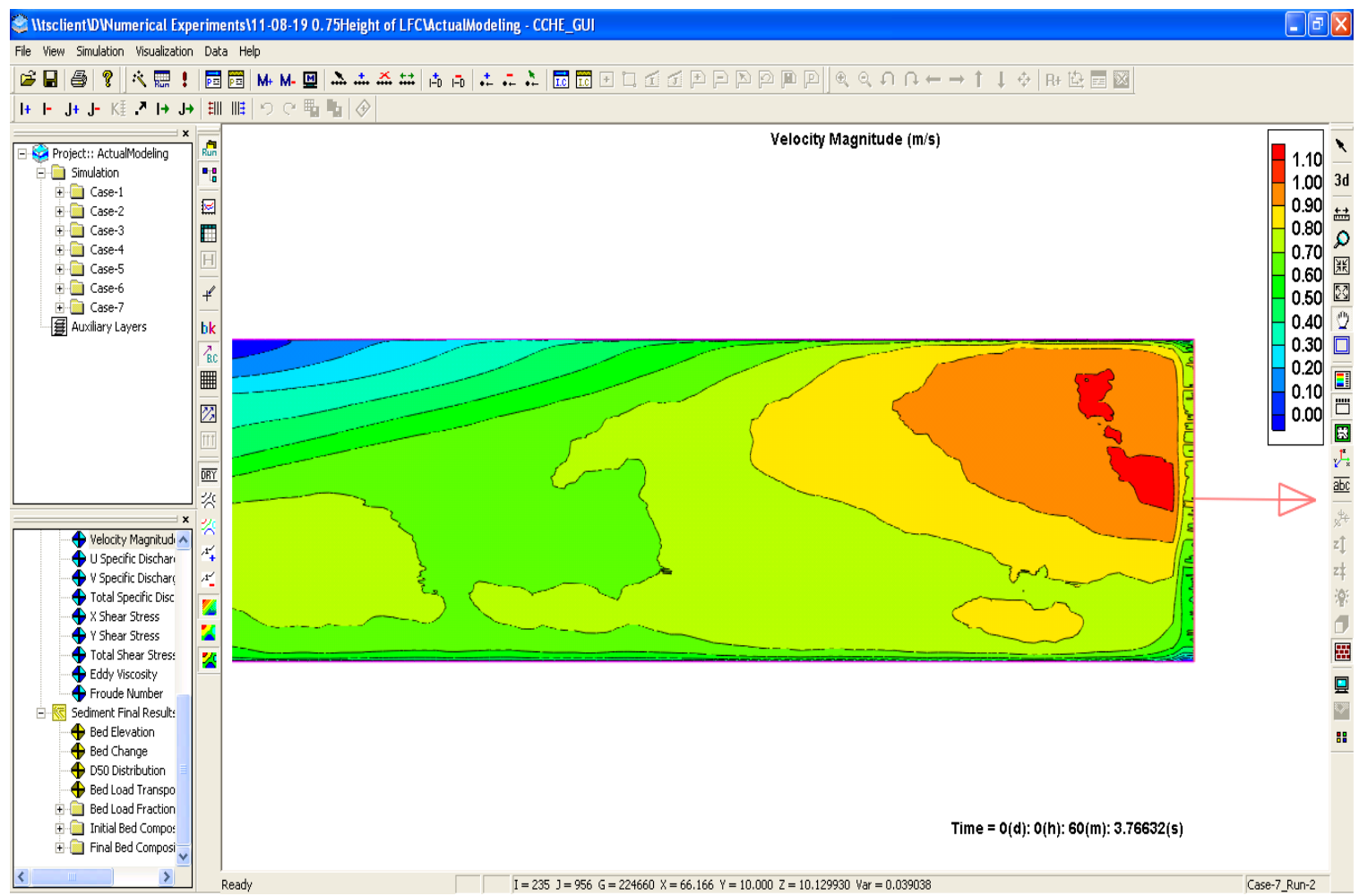

Figure T-84: Velocity magnitude when water depth of LFC $=33.75 \mathrm{~cm}$ at downstream boundary after 1-hr simulation. 


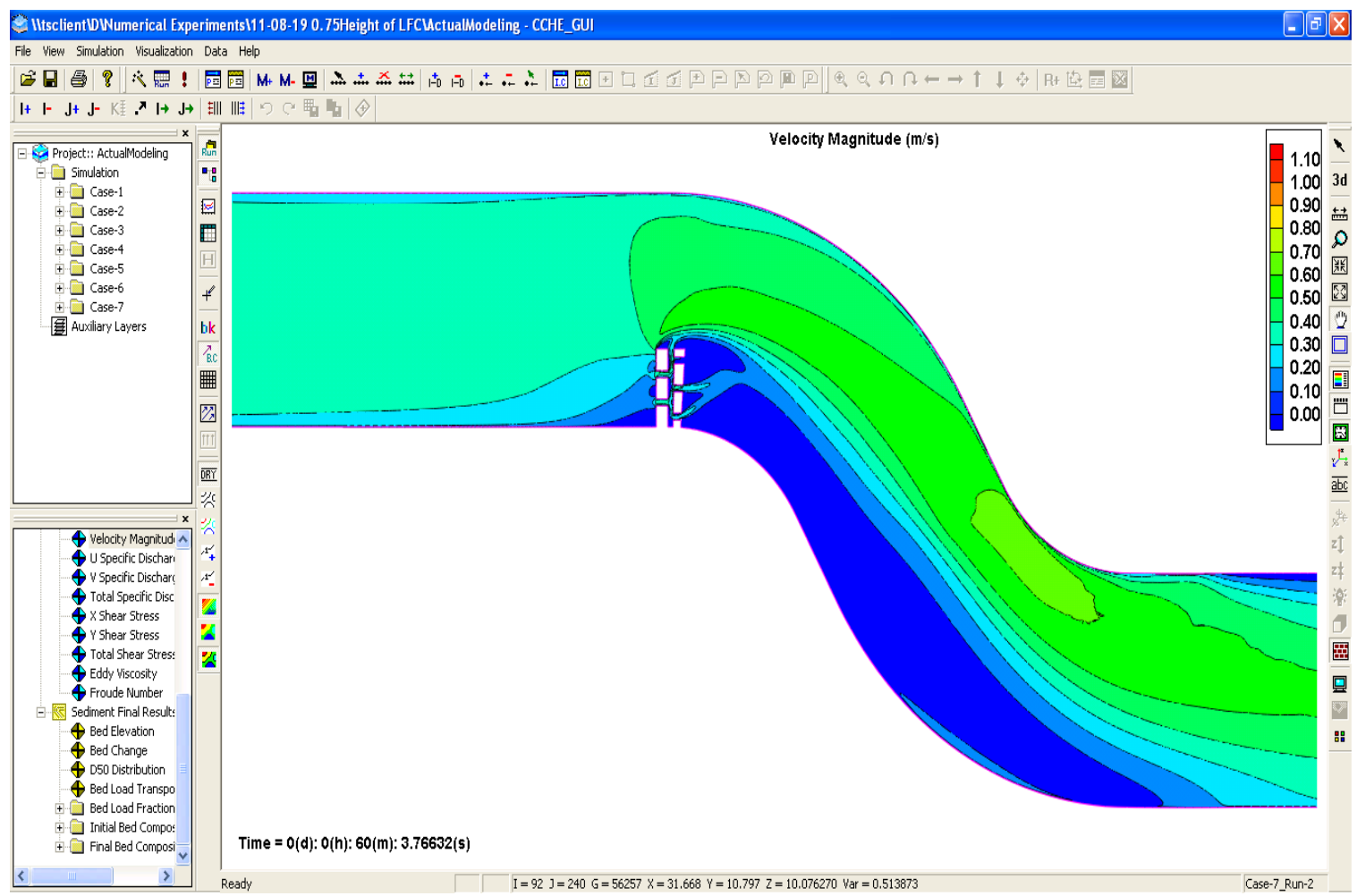

Figure T-85: Velocity magnitude when water depth of LFC $=33.75 \mathrm{~cm}$ between meanders \#1 and \#2 after 1-hr simulation.

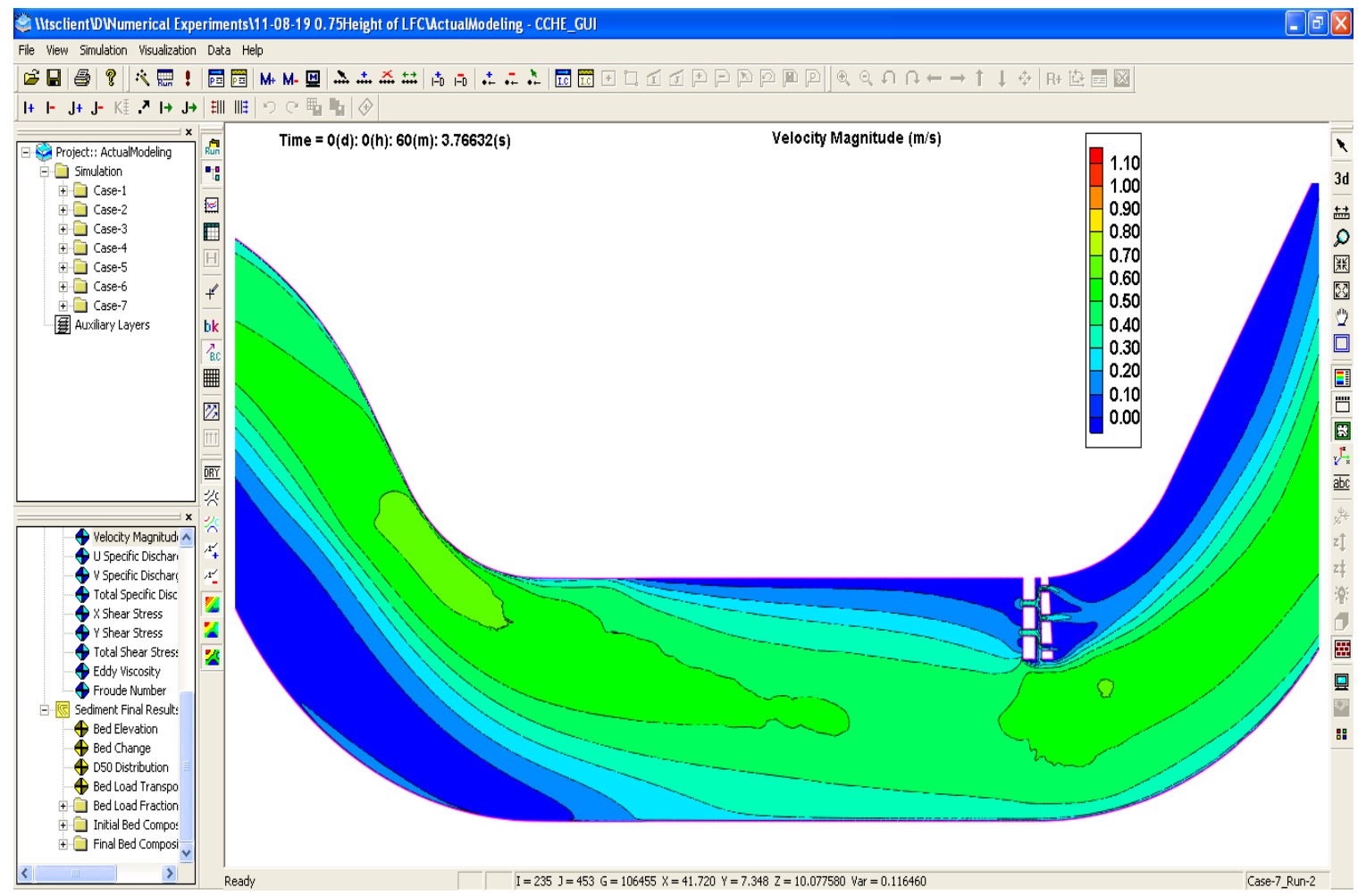

Figure T-86: Velocity magnitude when water depth of LFC $=33.75 \mathrm{~cm}$ between meanders \#2 and \#3 after 1-hr simulation. 


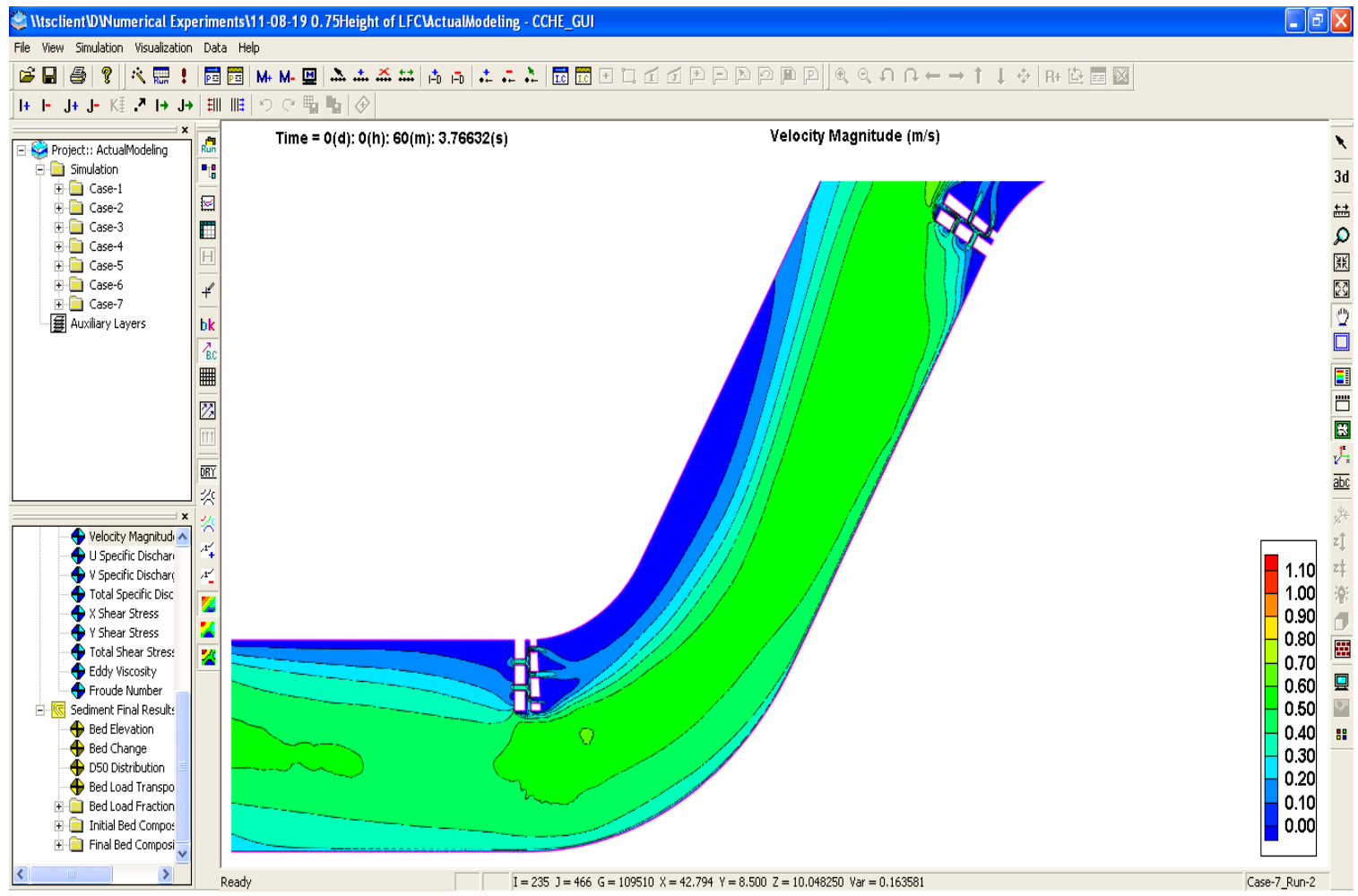

Figure T-87: Velocity magnitude when water depth of LFC $=33.75 \mathrm{~cm}$ between meanders \#3 and \#4 after 1-hr simulation.

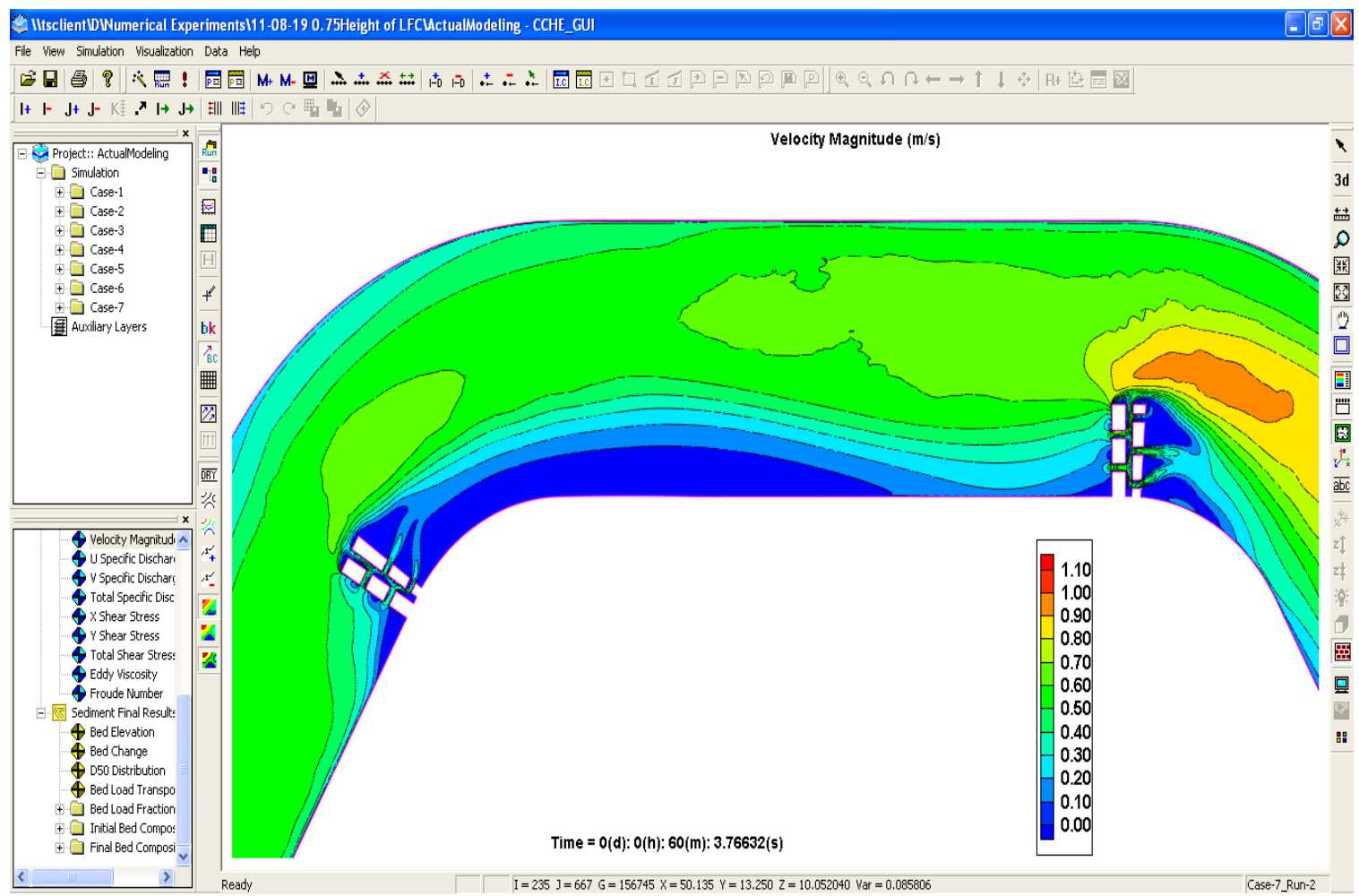

Figure T-88: Velocity magnitude when water depth of LFC $=33.75 \mathrm{~cm}$ between meanders \#4 and \#5 after 1-hr simulation. 


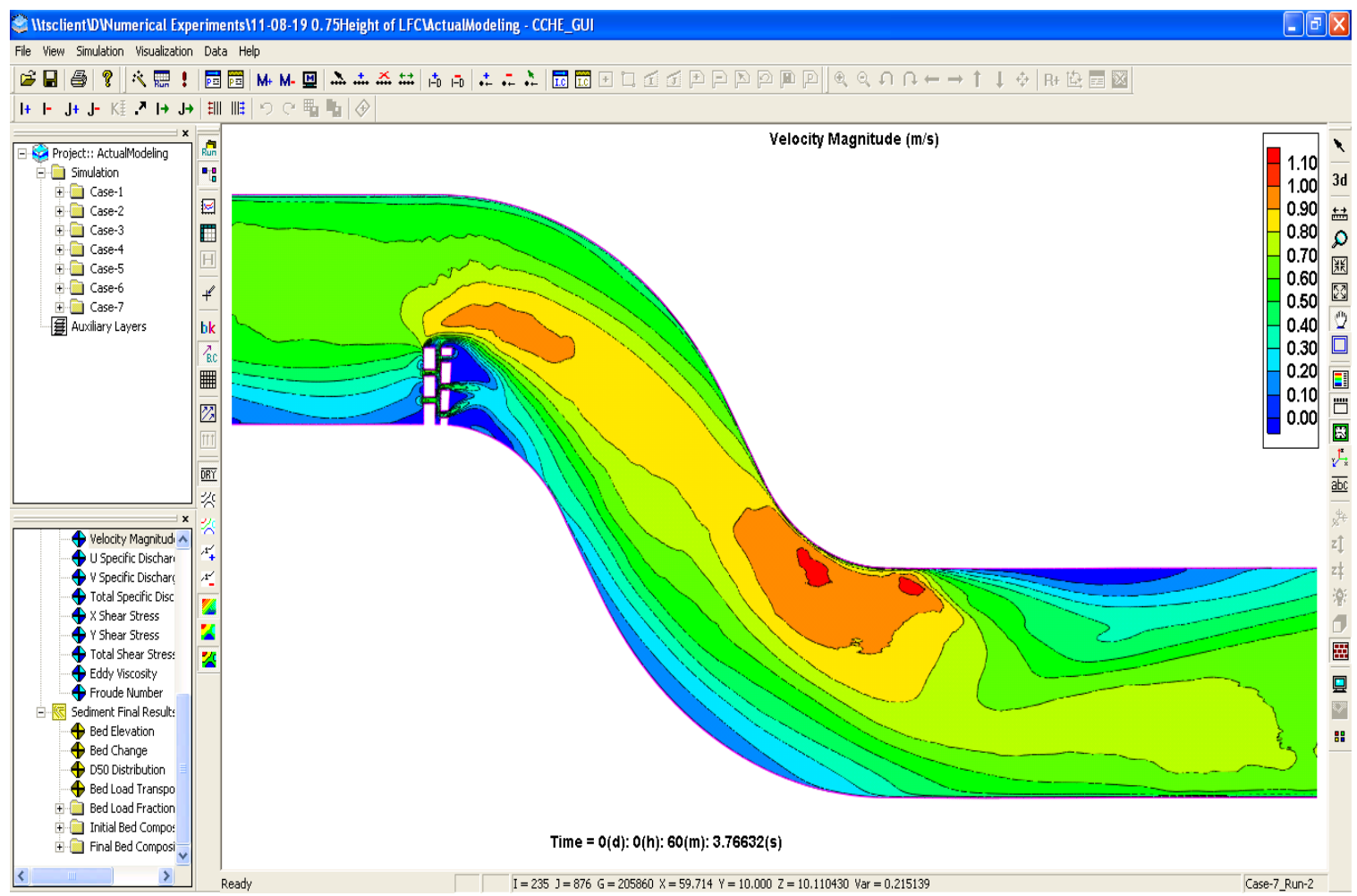

Figure T-89: Velocity magnitude when water depth of LFC $=33.75 \mathrm{~cm}$ between meanders \#5 and \#6 after 1 -hr simulation.

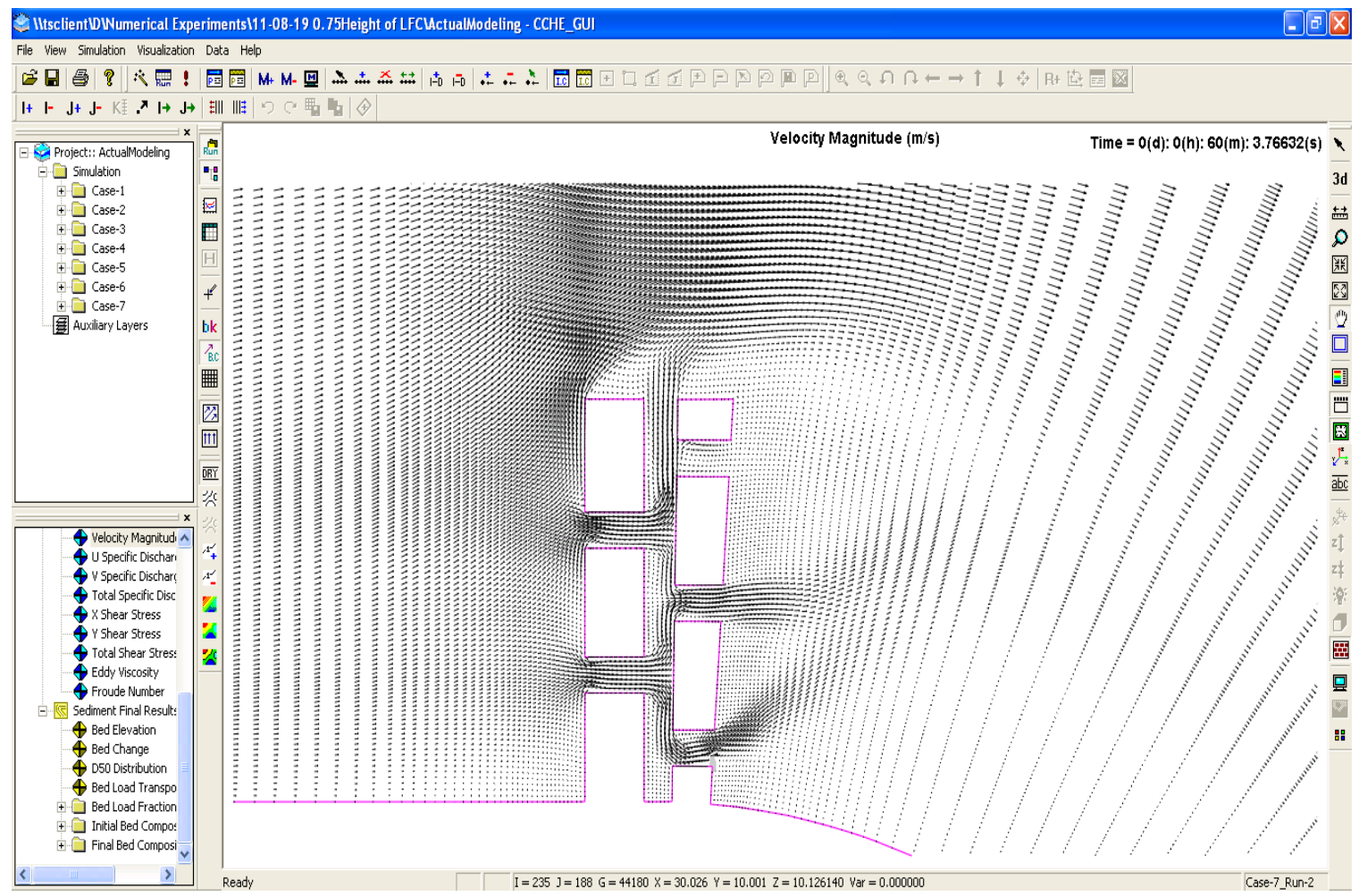

Figure T-90: Velocity direction when water depth of LFC $=33.75 \mathrm{~cm}$ at meander \#1 after 1-hr simulation. 


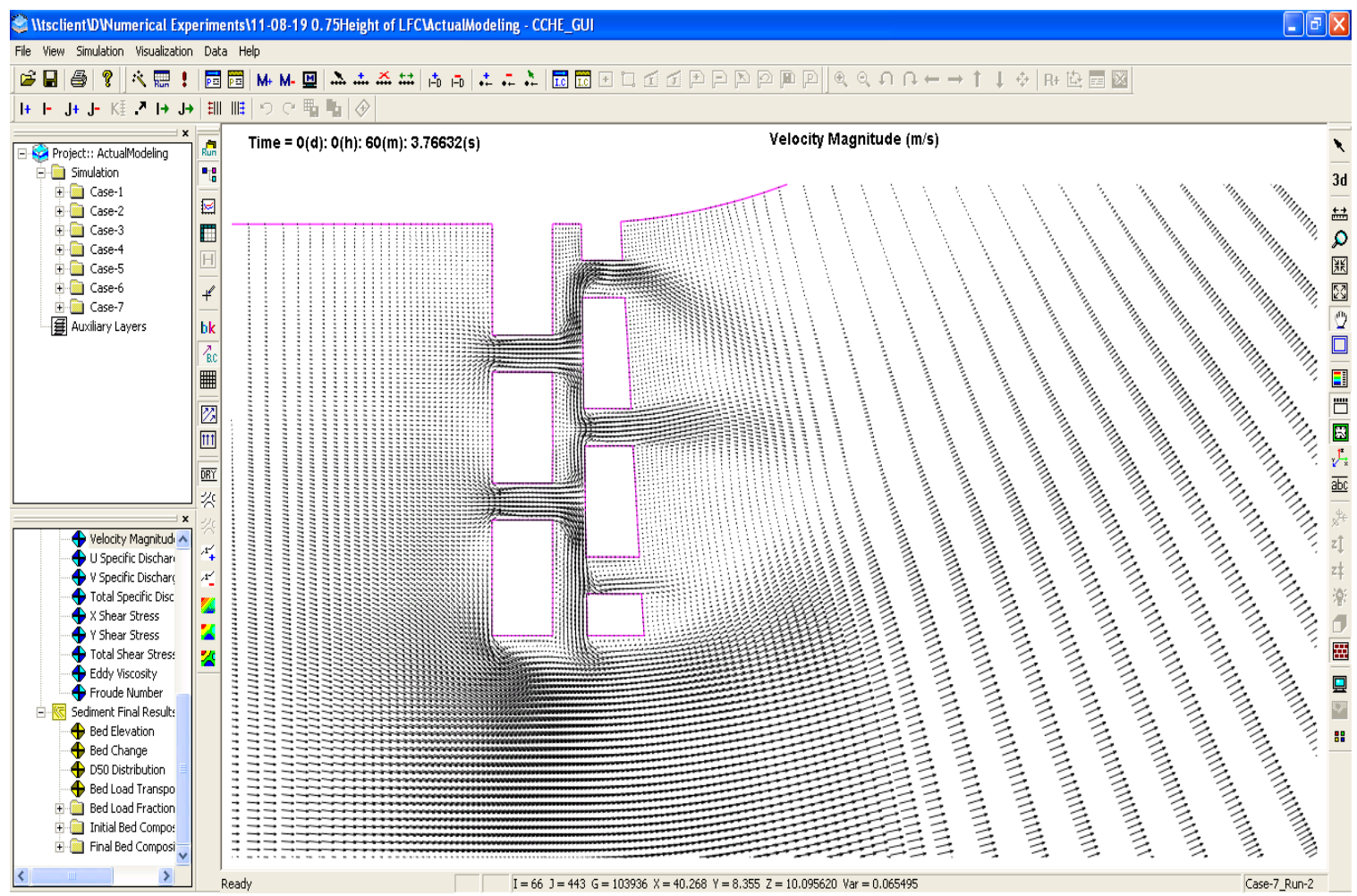

Figure T-91: Velocity direction when water depth of LFC $=33.75 \mathrm{~cm}$ at meander \#3 after 1-hr simulation.

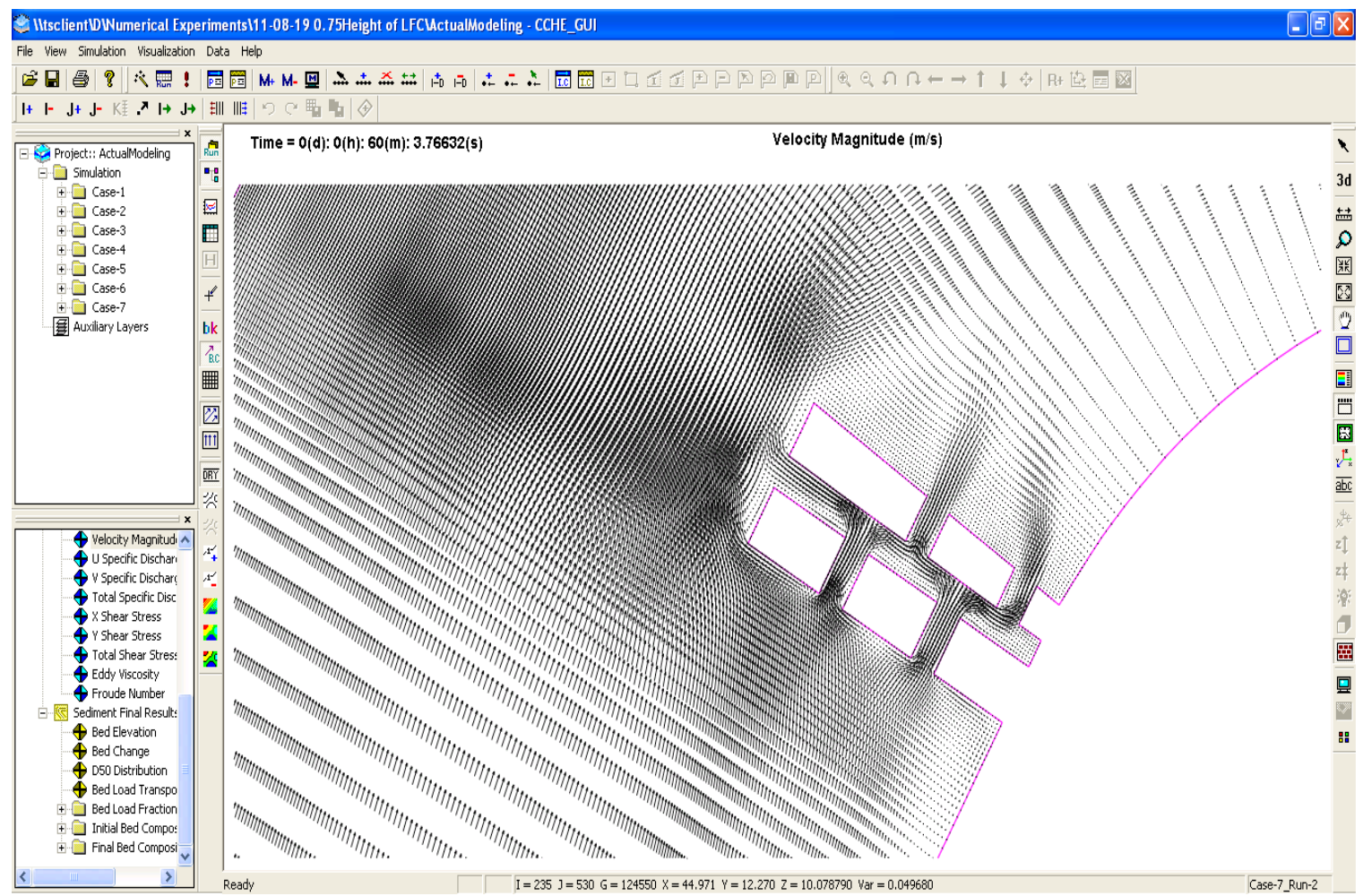

Figure T-92: Velocity direction when water depth of LFC $=33.75 \mathrm{~cm}$ at meander \#4 after 1-hr simulation. 


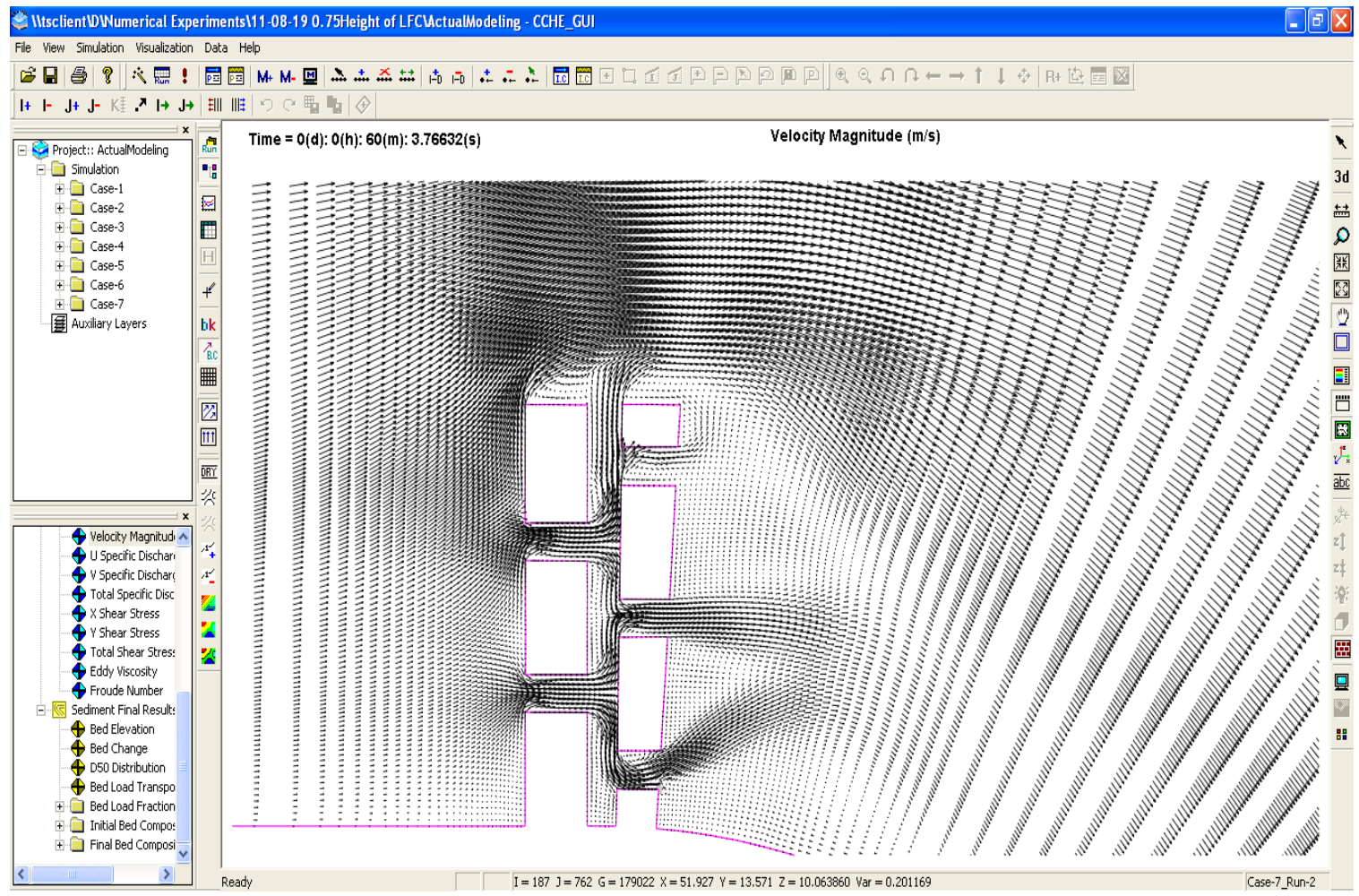

Figure T-93: Velocity direction when water depth of LFC $=33.75 \mathrm{~cm}$ at meander \#5 after 1-hr simulation.

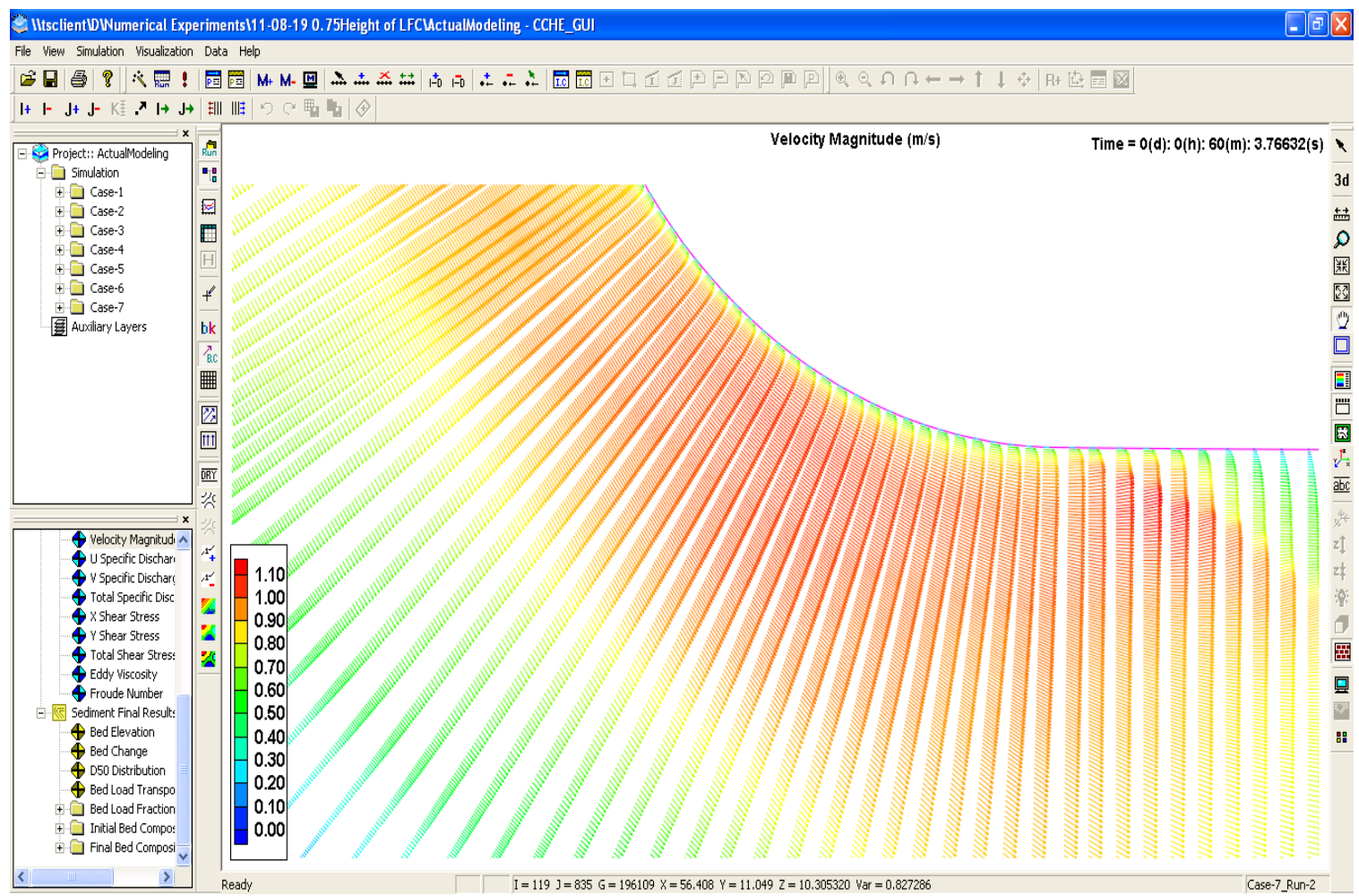

Figure T-94: Velocity direction when water depth of LFC $=33.75 \mathrm{~cm}$ at meander \#6 after 1-hr simulation. 


\section{$5 \mathrm{~cm}$ Below Bankfull of LFC}

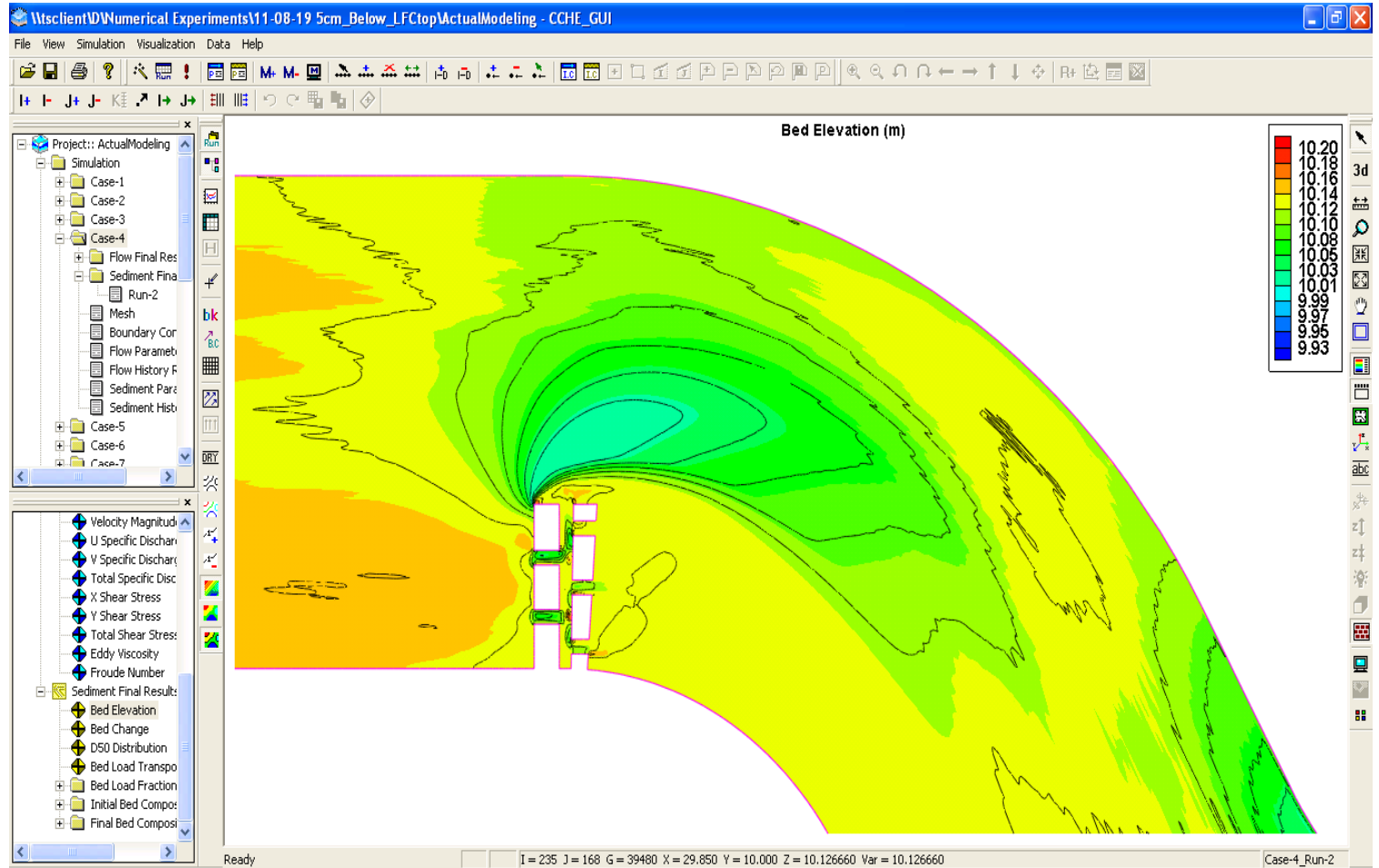

Figure T-95: Bed elevation when water depth of LFC $=40 \mathrm{~cm}$ at meander \#1 after 1 -hr simulation.

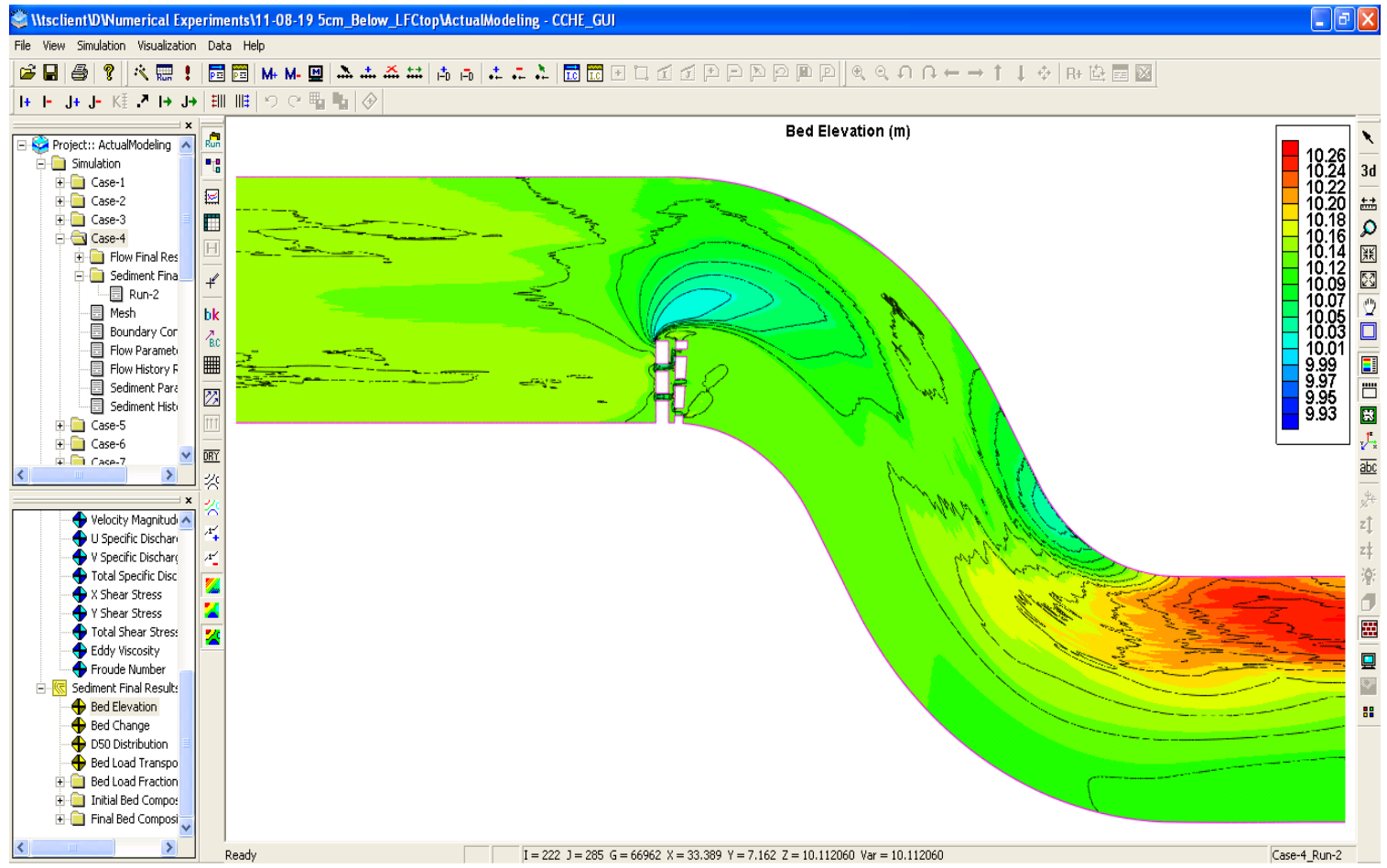

Figure T-96: Bed elevation when water depth of LFC $=40 \mathrm{~cm}$ between meanders \#1 and \#2 after 1-hr simulation. 


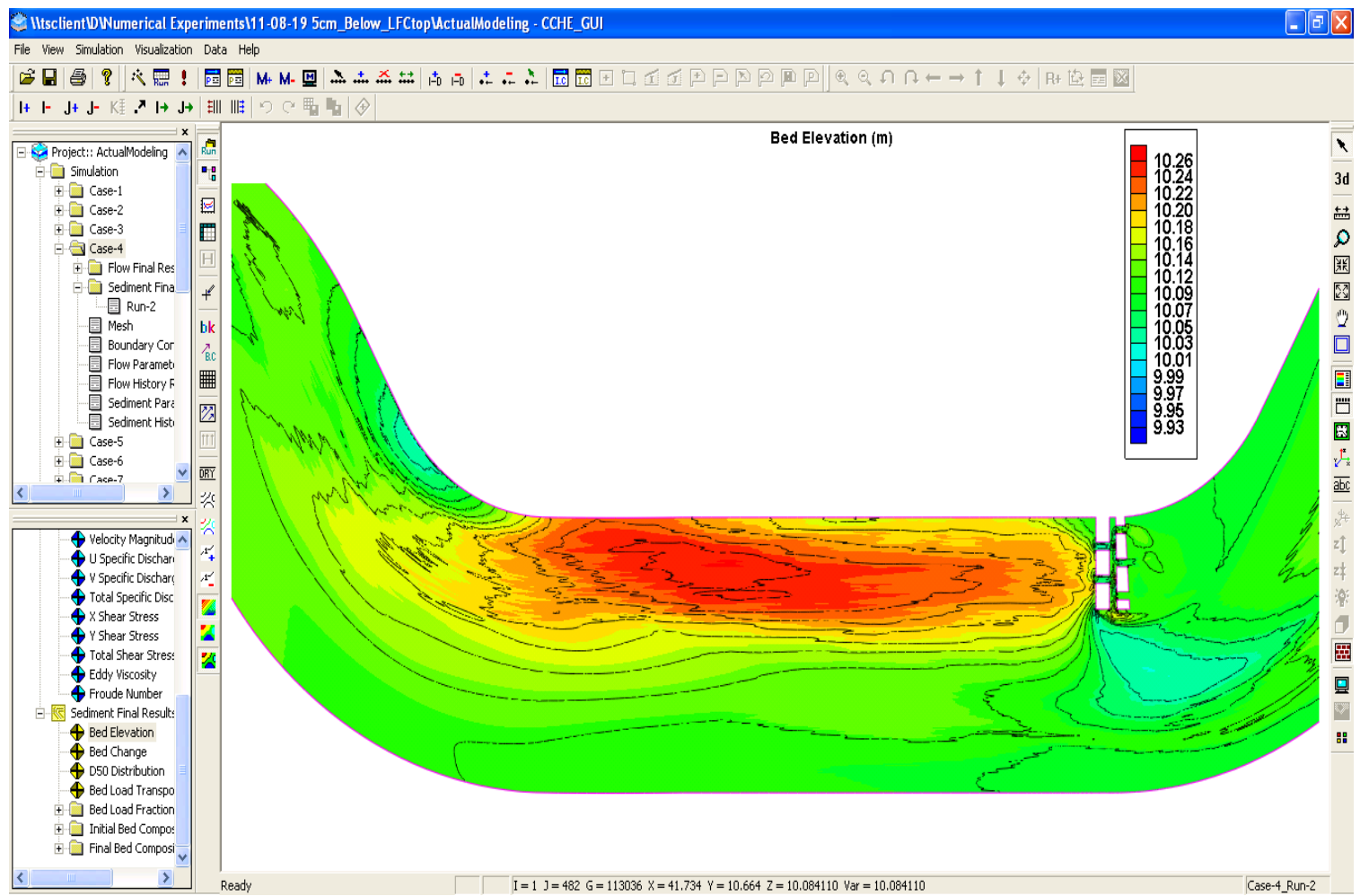

Figure T-97: Bed elevation when water depth of LFC $=40 \mathrm{~cm}$ between meanders \#2 and \#3 after 1-hr simulation.

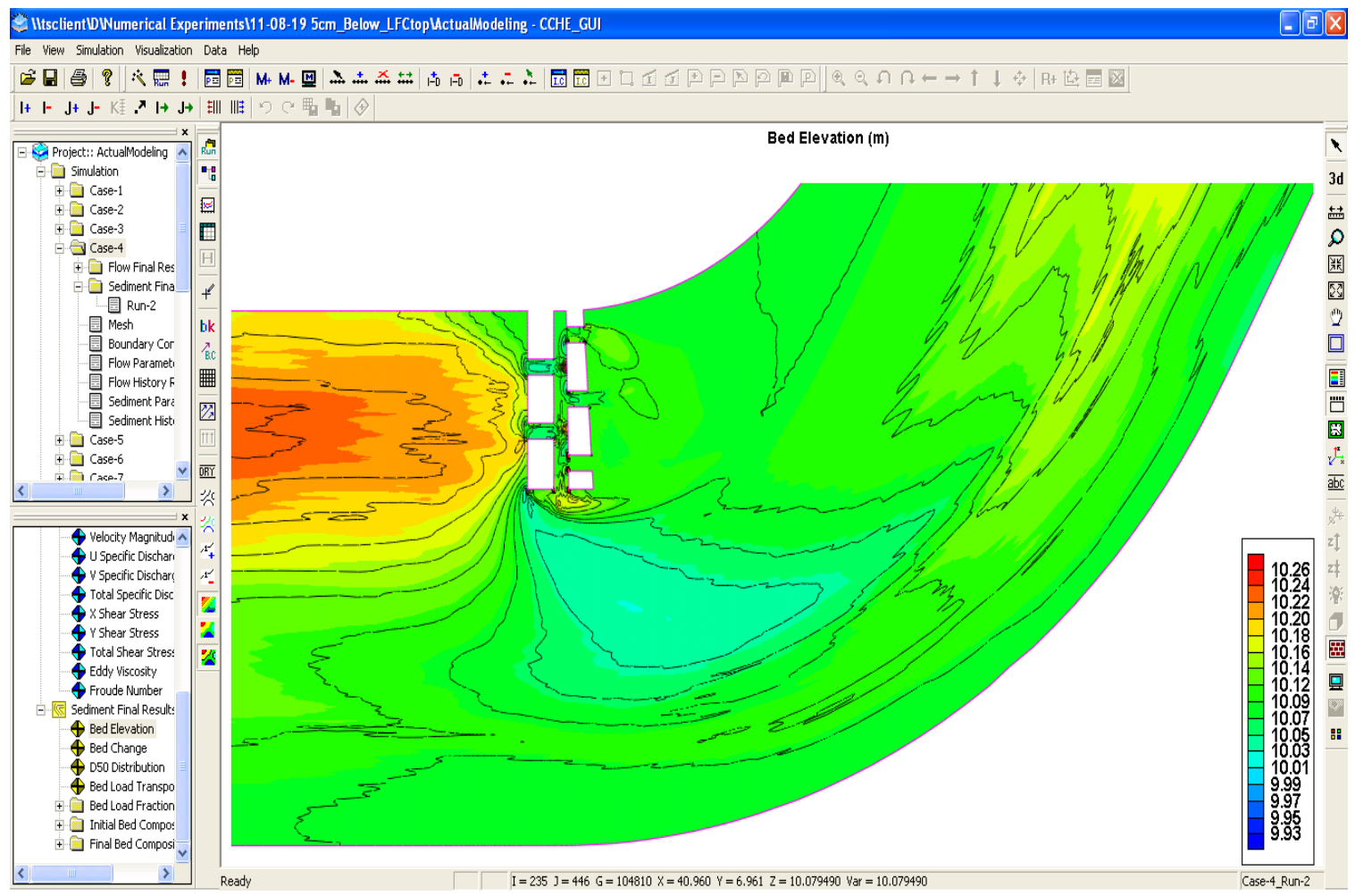

Figure T-98: Bed elevation when water depth of LFC $=40 \mathrm{~cm}$ at meander \#3 after 1-hr simulation. 


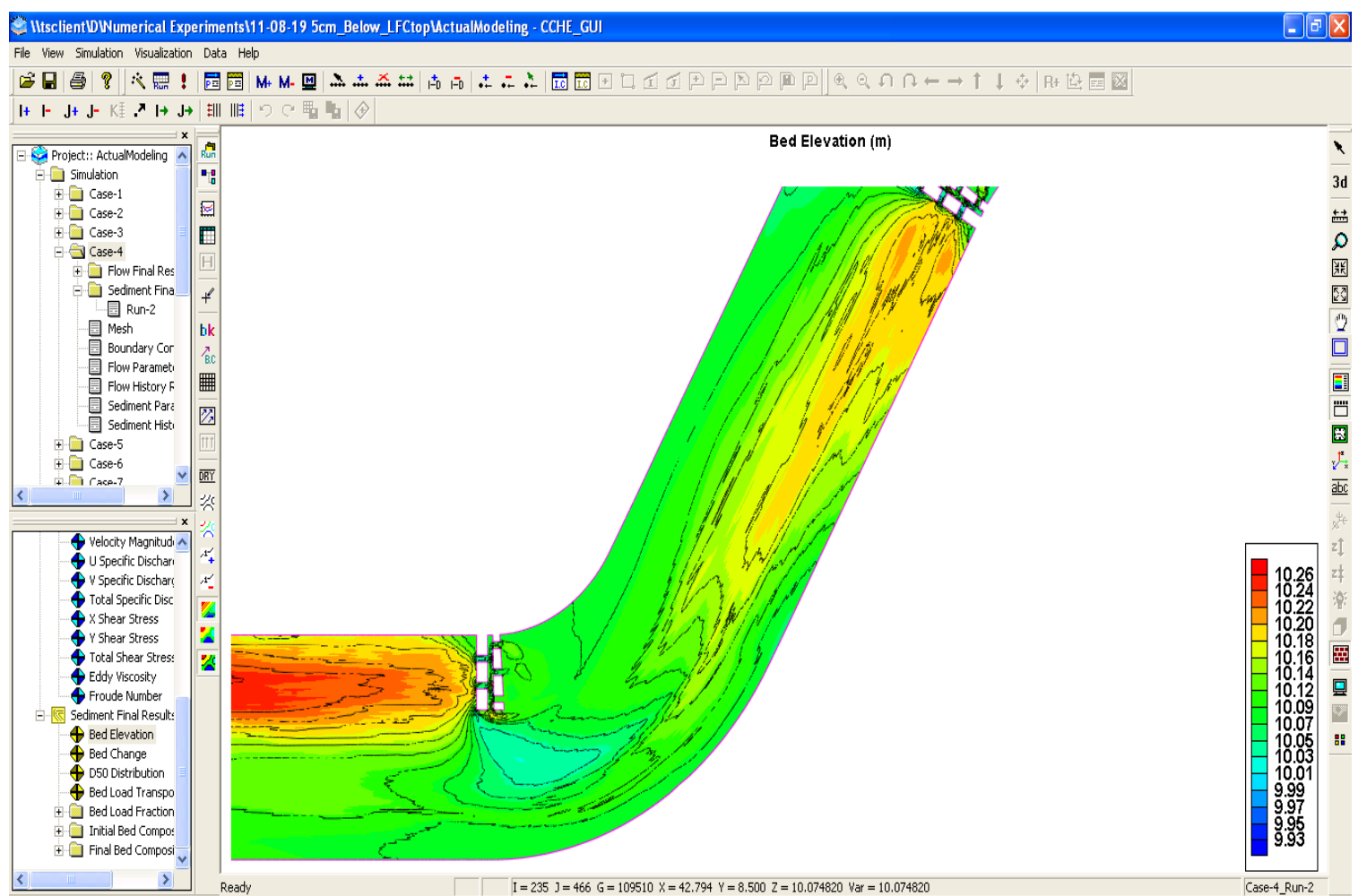

Figure T-99: Bed elevation when water depth of LFC $=40 \mathrm{~cm}$ between meanders \#3 and \#4 after 1-hr simulation.

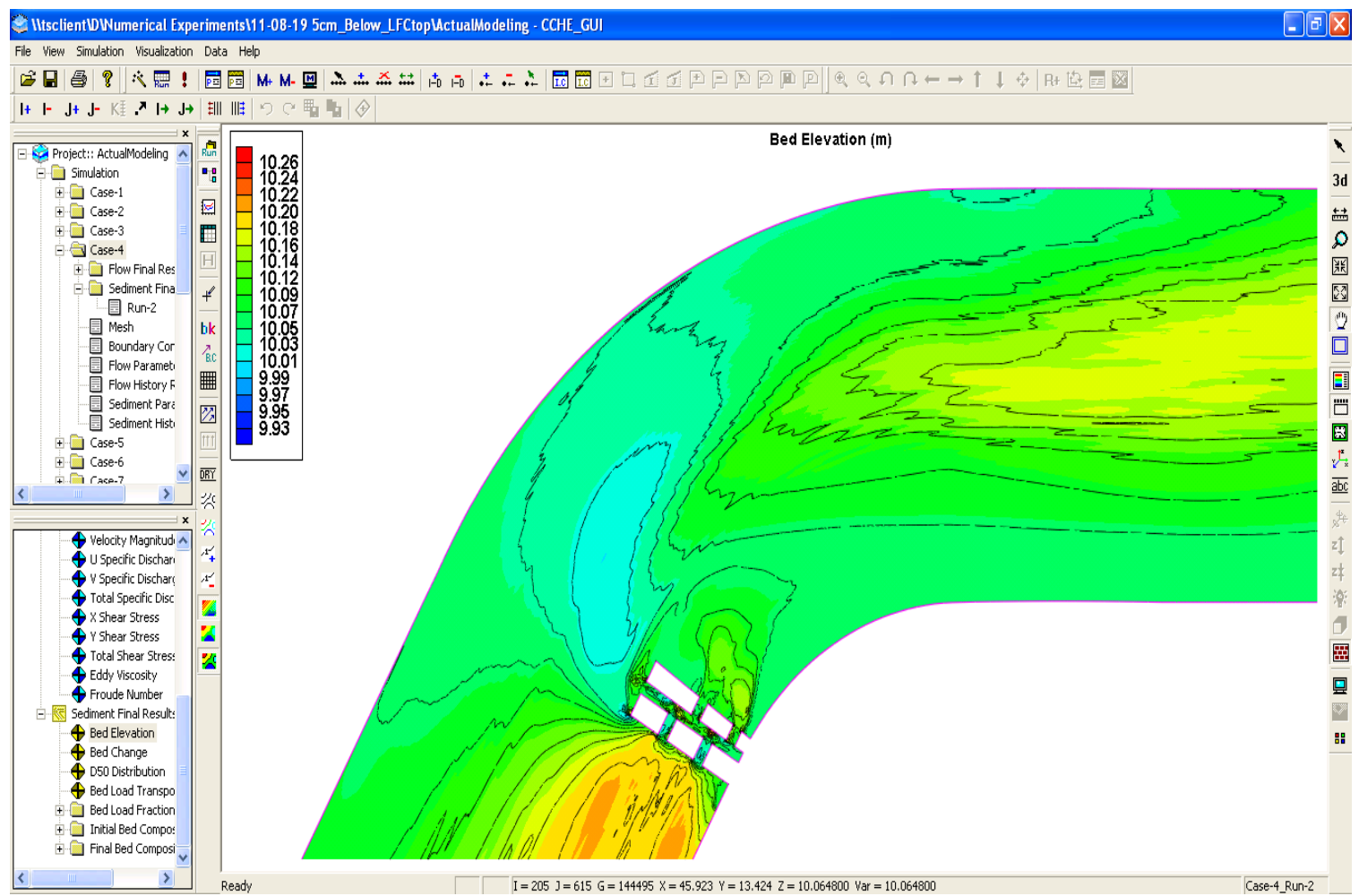

Figure T-100: Bed elevation when water depth of LFC $=40 \mathrm{~cm}$ at meander \#4 after 1-hr simulation. 


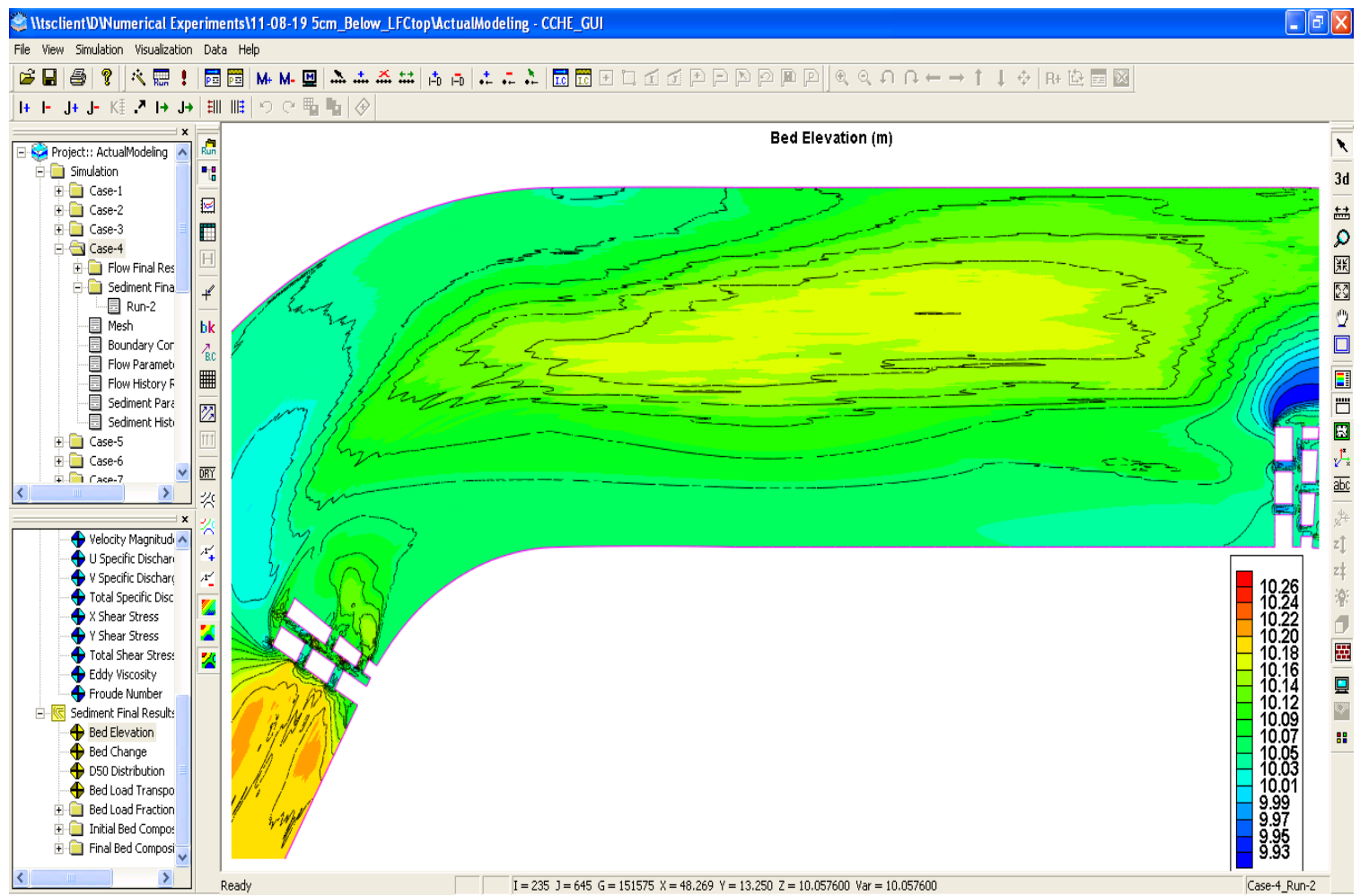

Figure T-101: Bed elevation when water depth of LFC $=40 \mathrm{~cm}$ between meanders \#4 and \#5 after 1-hr simulation.

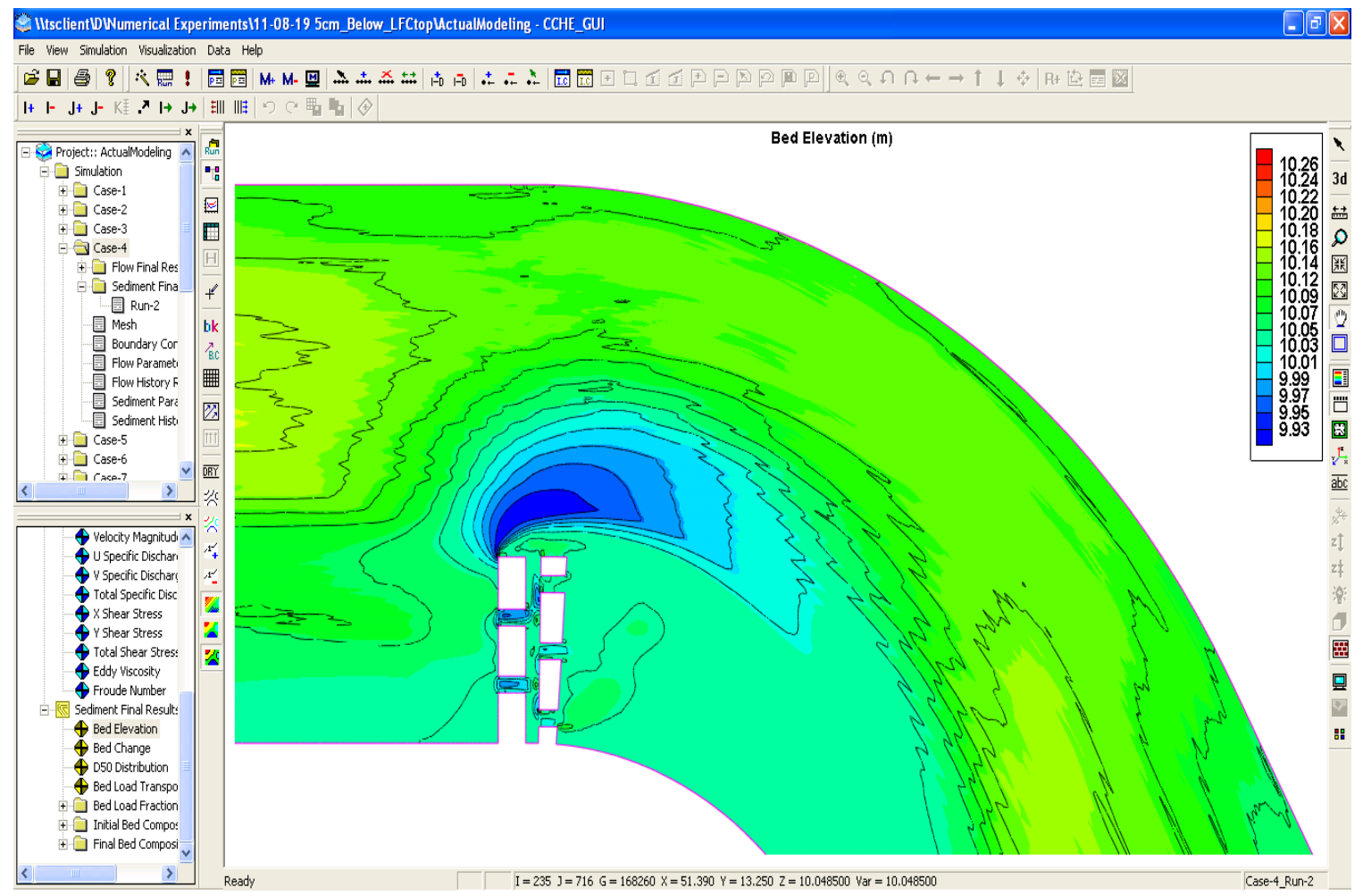

Figure T-102: Bed elevation when water depth of $L F C=40 \mathrm{~cm}$ at meander \#5 after 1 -hr simulation. 


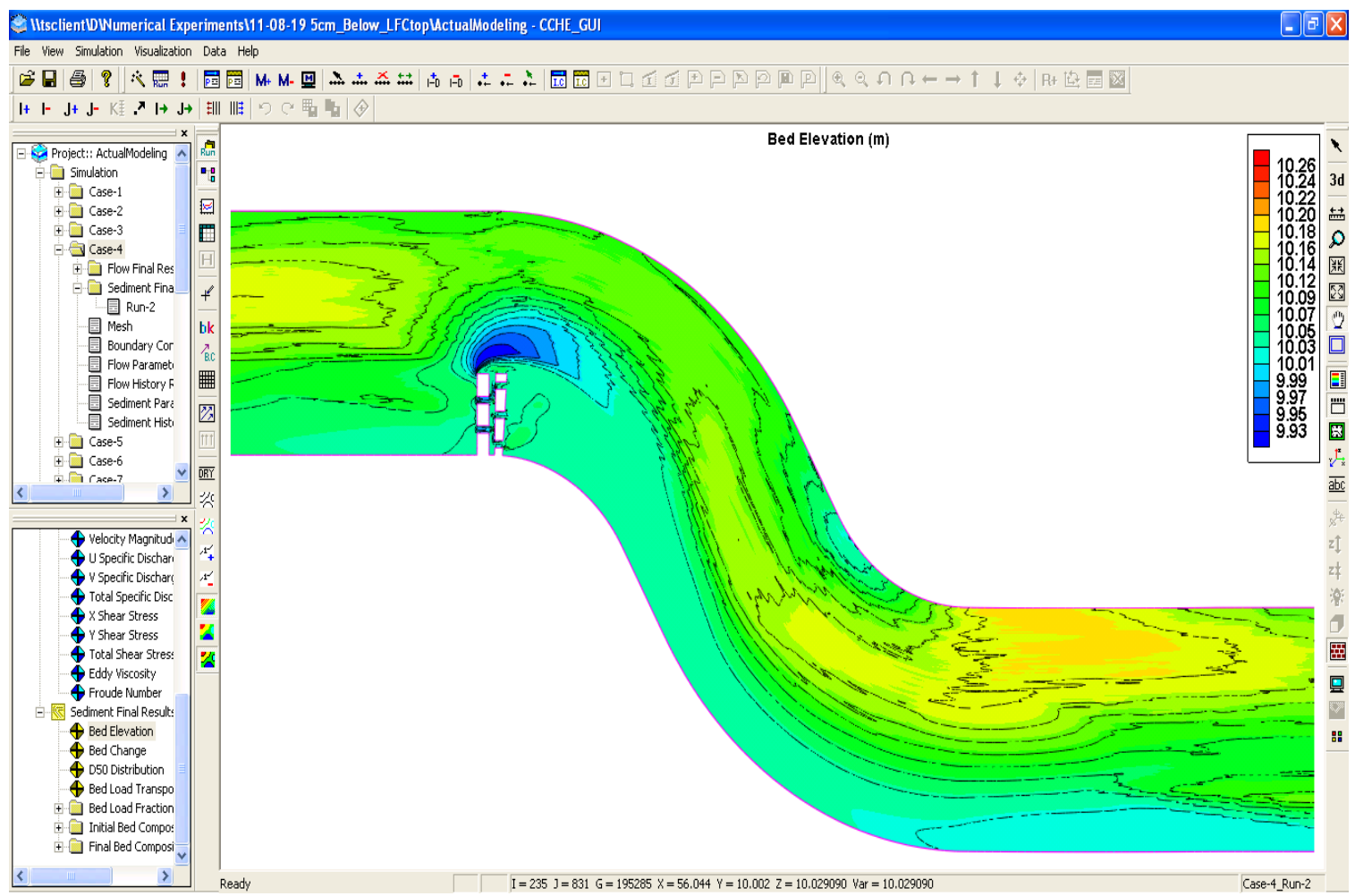

Figure T-103: Bed elevation when water depth of LFC $=40 \mathrm{~cm}$ between meanders \#5 and \#6 after 1-hr simulation.

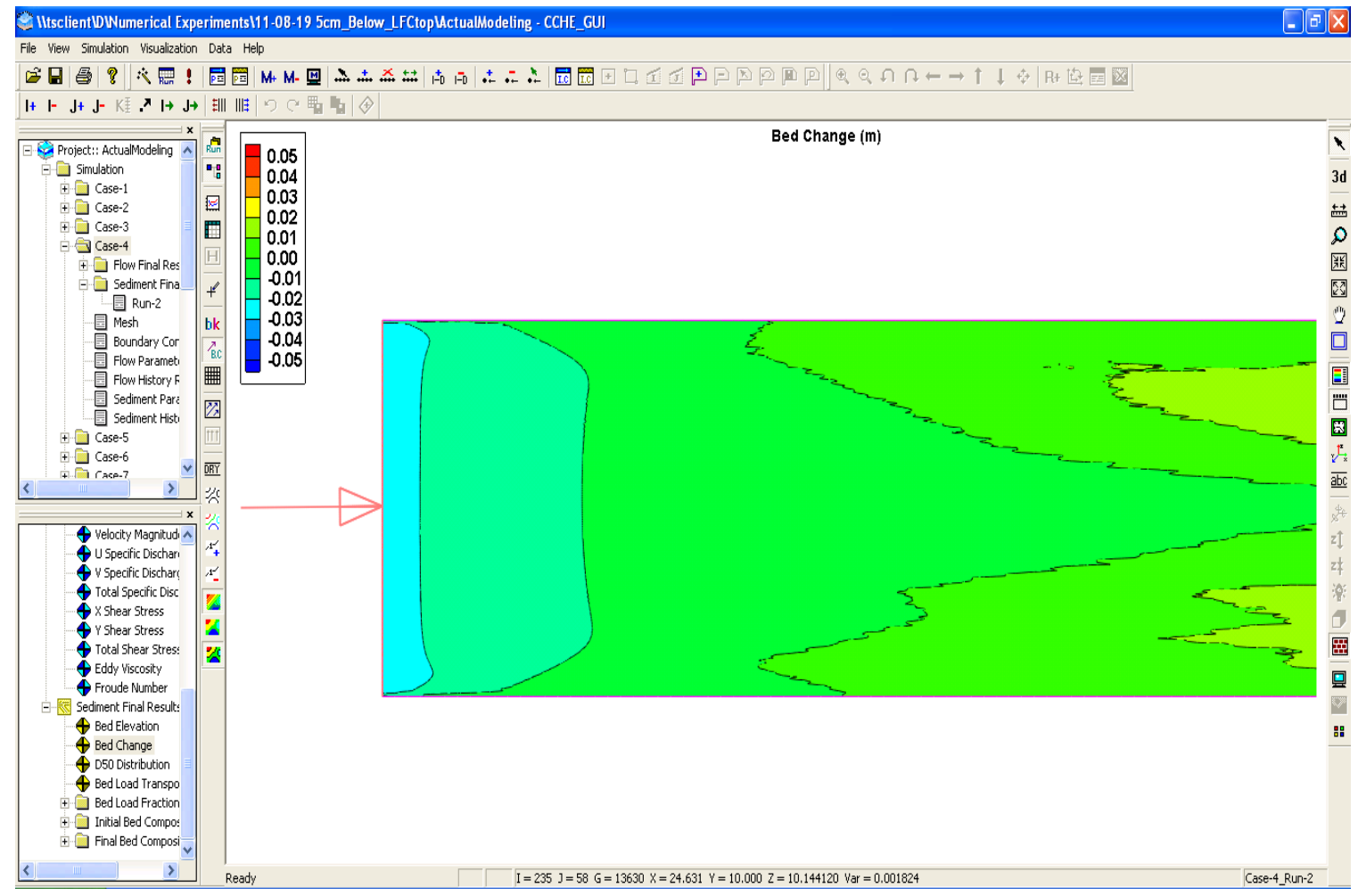

Figure T-104: Bed change when water depth of LFC $=40 \mathrm{~cm}$ at upstream boundary after 1-hr simulation. 


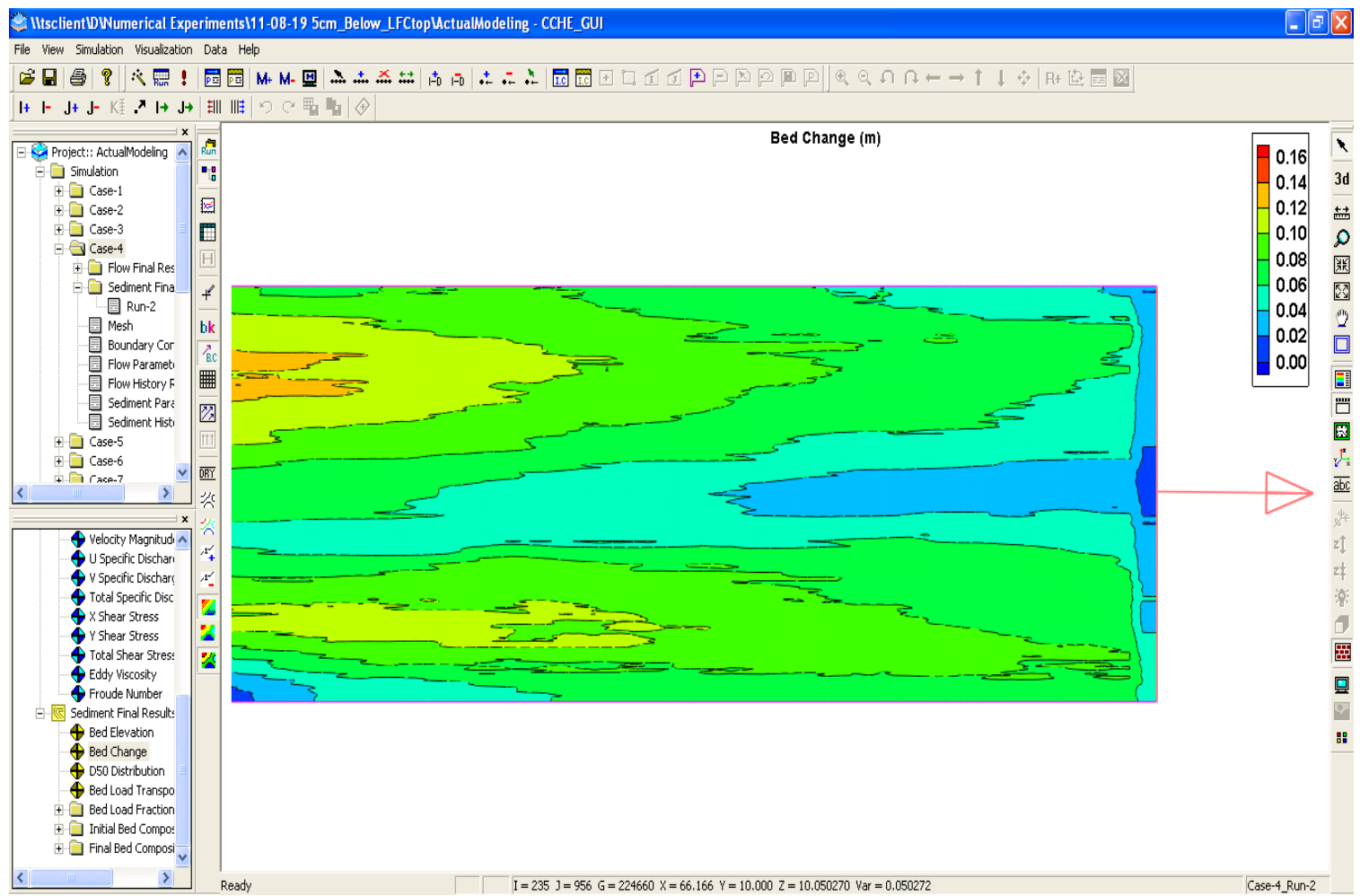

Figure T-105: Bed change when water depth of LFC $=40 \mathrm{~cm}$ at downstream boundary after 1-hr simulation.

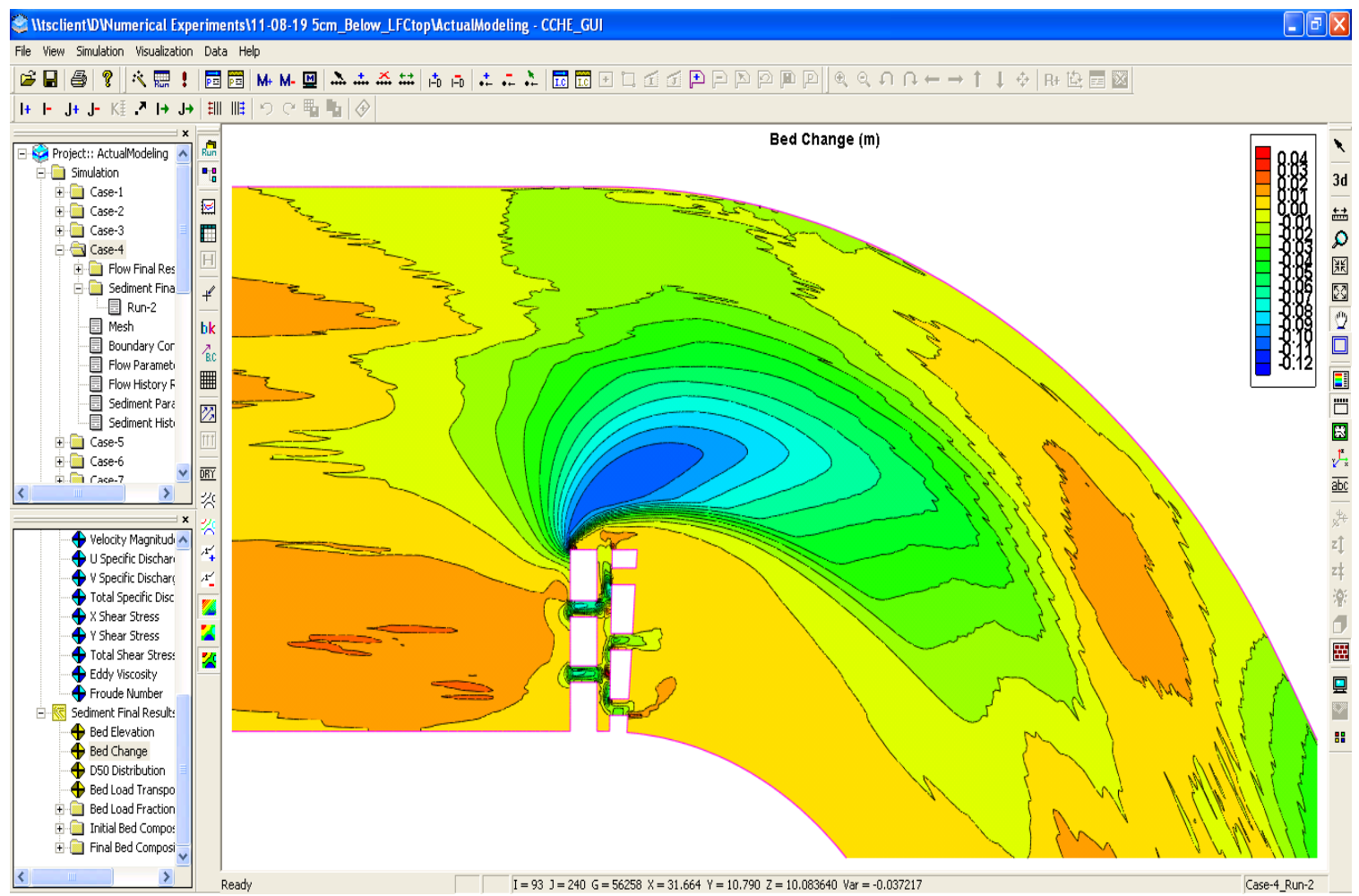

Figure T-106: Bed change when water depth of LFC $=40 \mathrm{~cm}$ at meander $\# 1$ after 1 -hr simulation. 


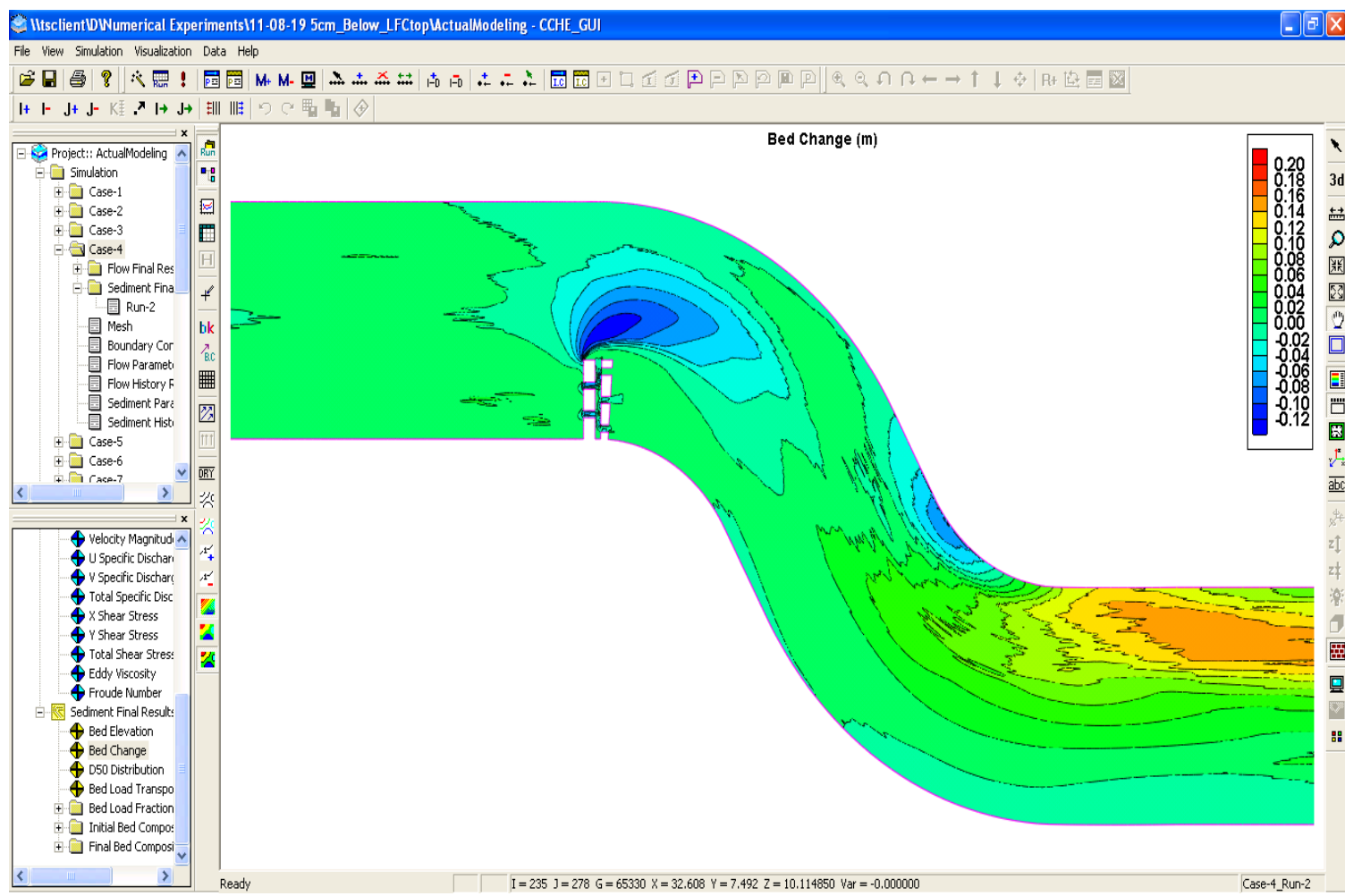

Figure T-107: Bed change when water depth of LFC $=40 \mathrm{~cm}$ between meanders \#1 and \#2 after 1-hr simulation.

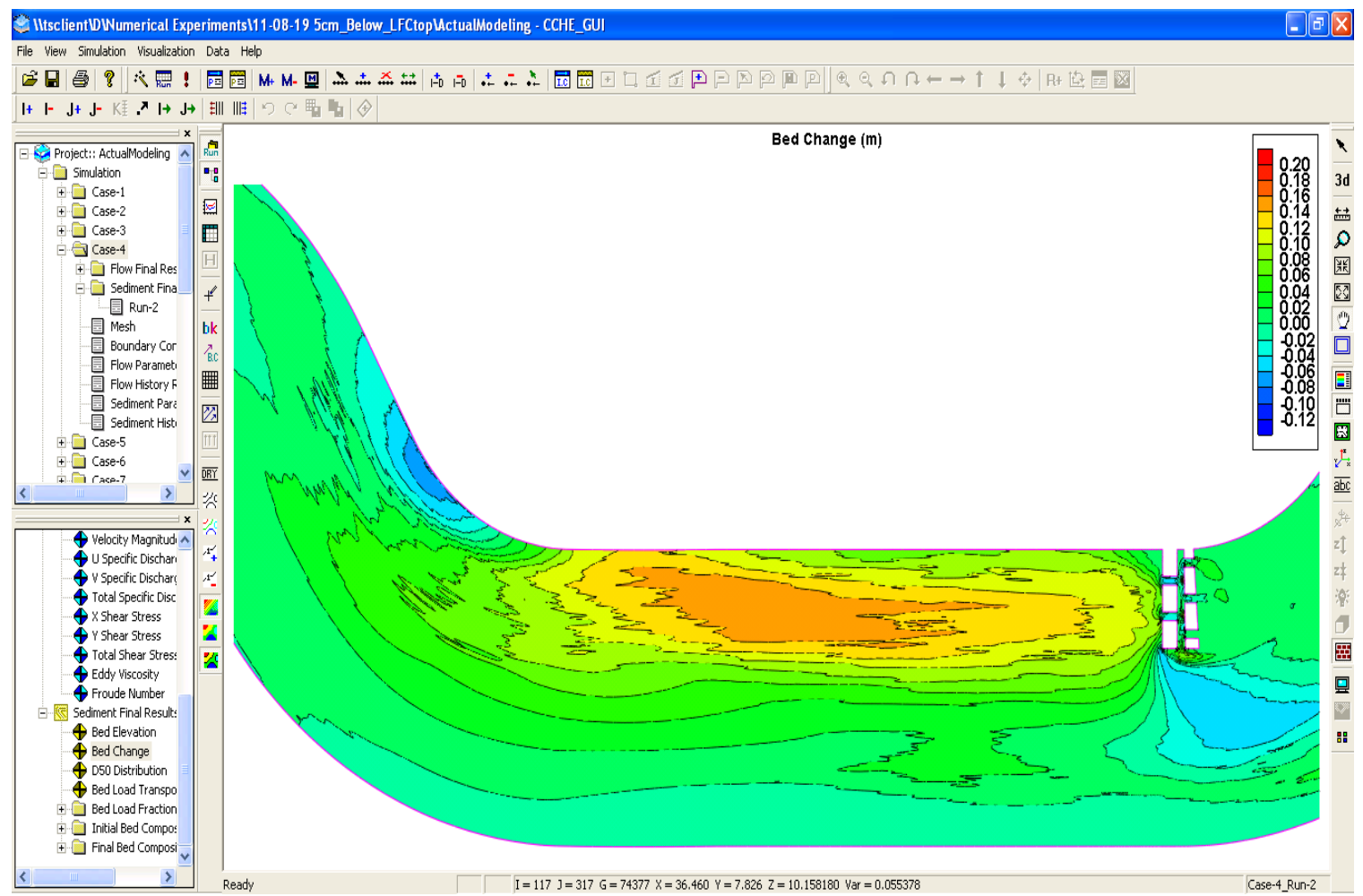

Figure T-108: Bed change when water depth of LFC $=40 \mathrm{~cm}$ between meanders \#2 and \#3 after 1-hr simulation. 


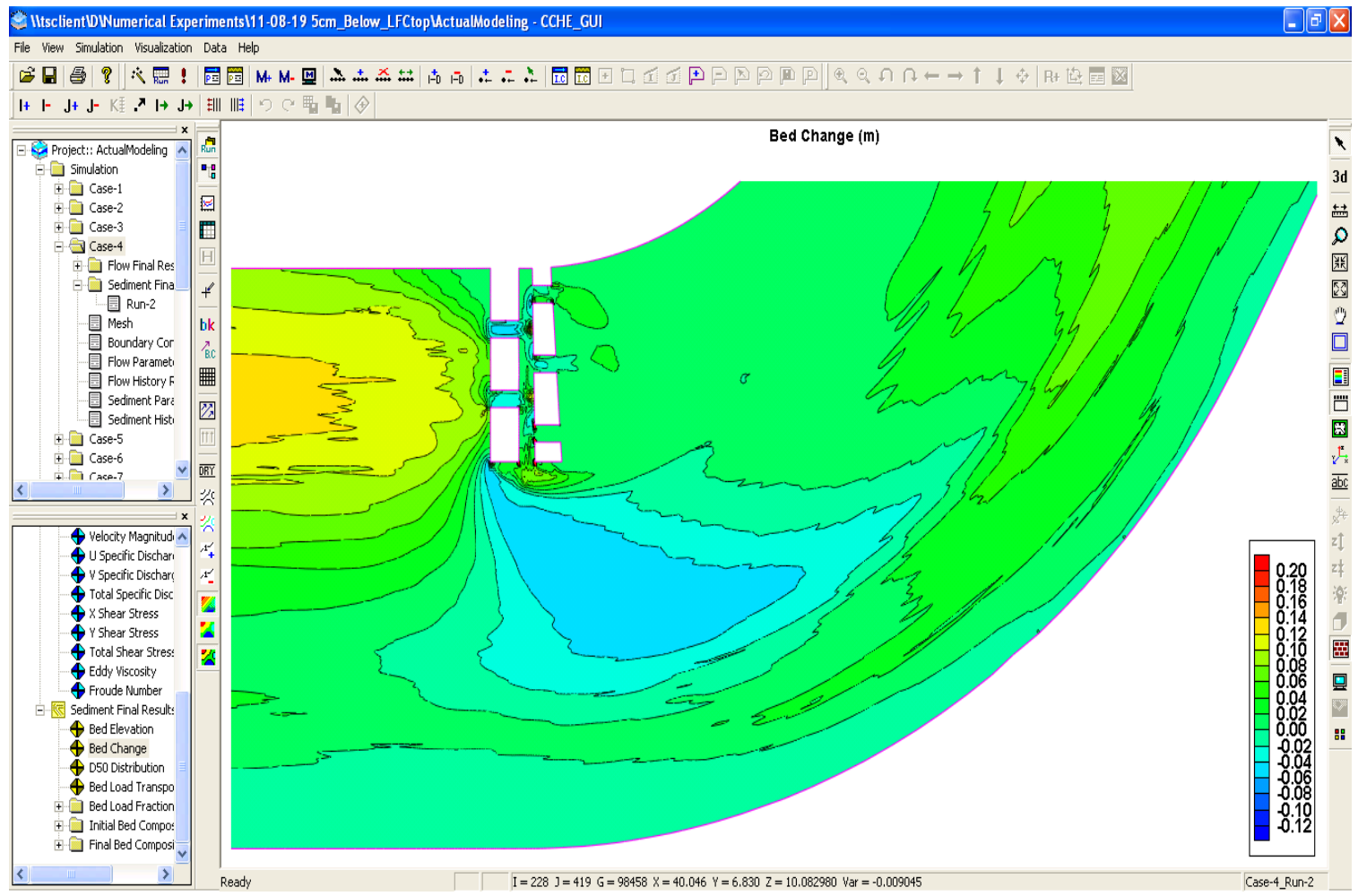

Figure T-109: Bed change when water depth of $L F C=40 \mathrm{~cm}$ at meander $\# 3$ after 1-hr simulation.

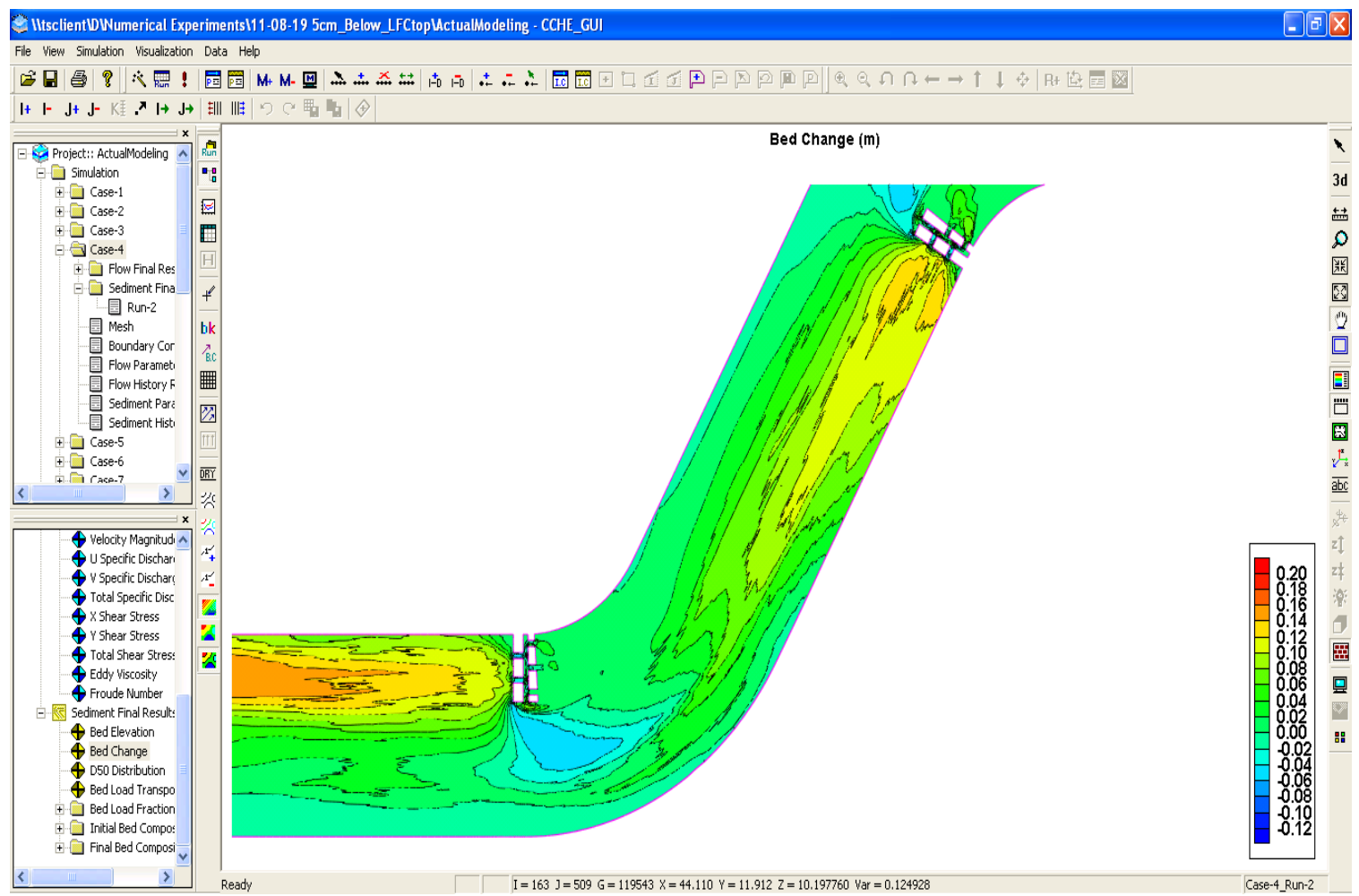

Figure T-110: Bed change when water depth of LFC $=40 \mathrm{~cm}$ between meanders \#3 and \#4 after 1-hr simulation. 


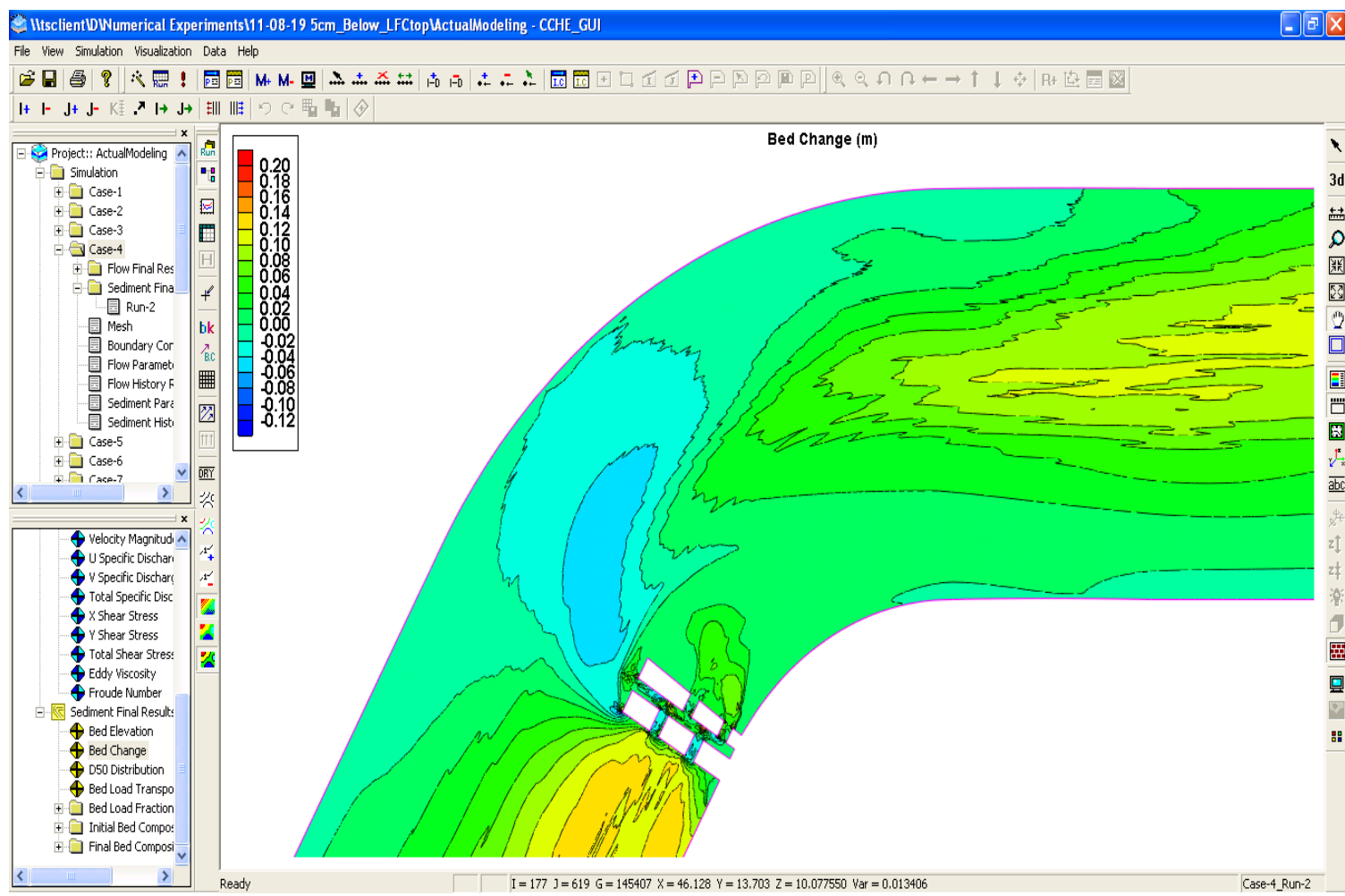

Figure T-111: Bed change when water depth of LFC $=40 \mathrm{~cm}$ at meander \#4 after 1-hr simulation.

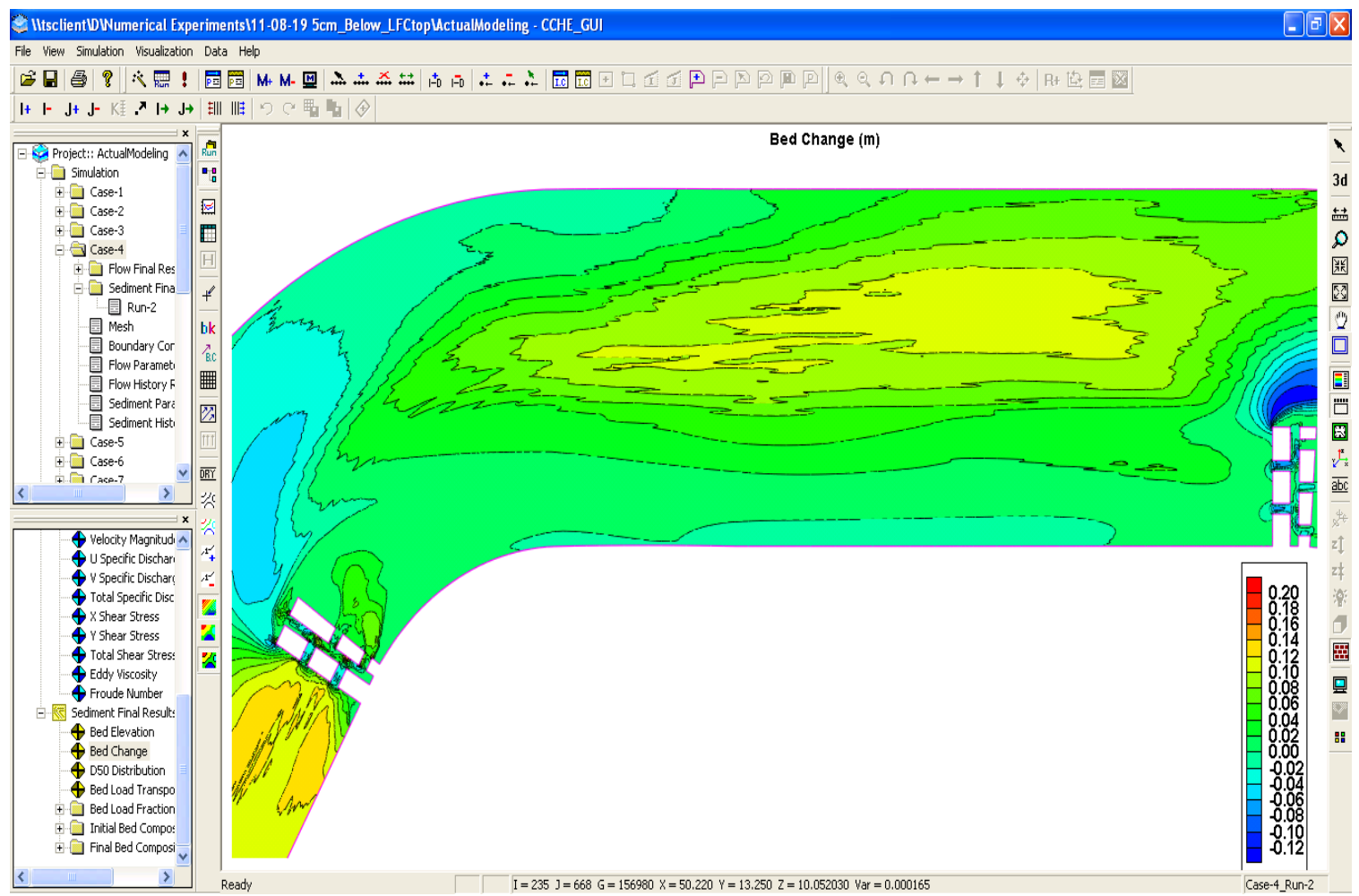

Figure T-112: Bed change when water depth of LFC $=40 \mathrm{~cm}$ between meanders \#4 and \#5 after 1-hr simulation. 


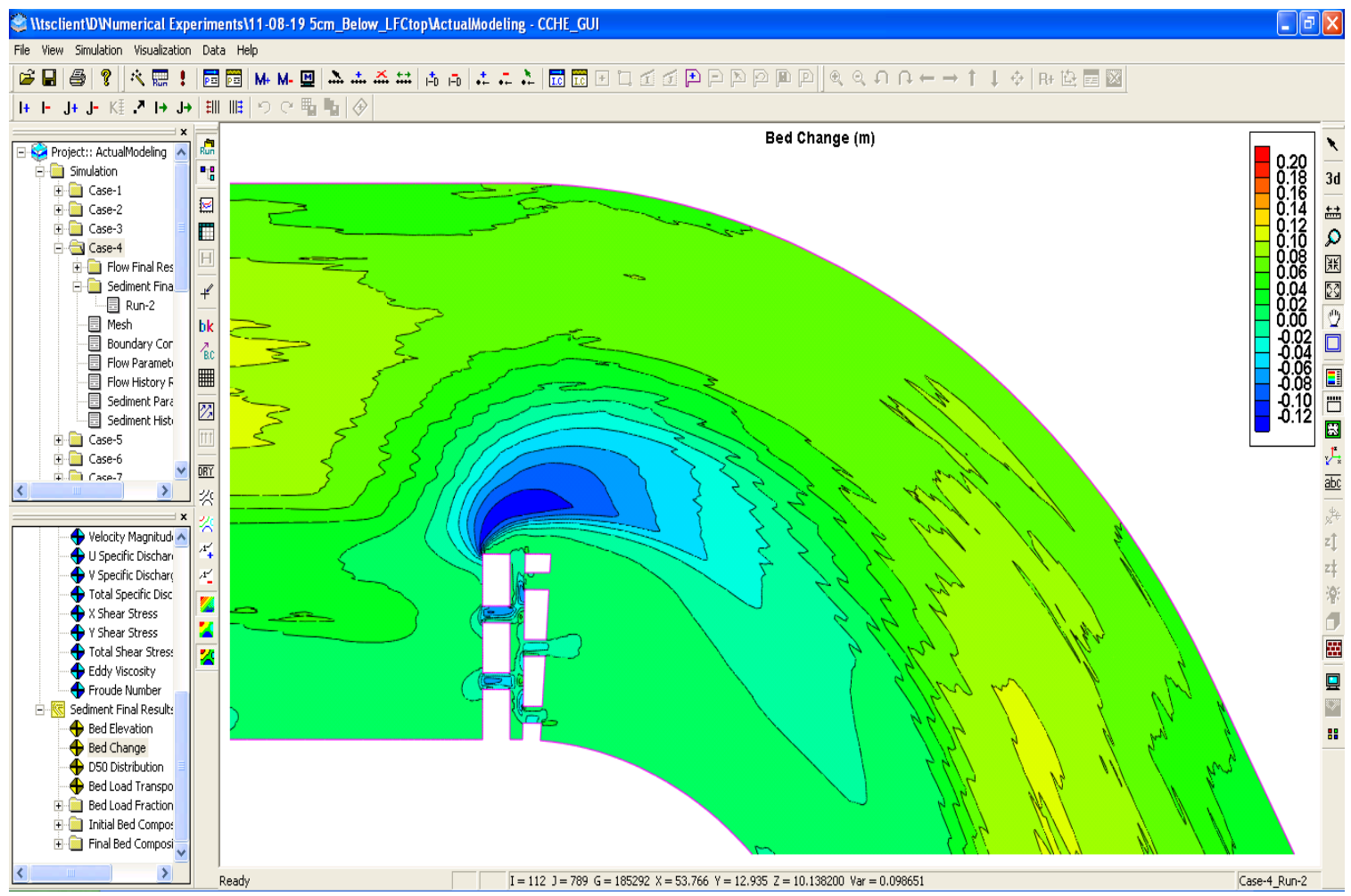

Figure T-113: Bed change when water depth of LFC $=40 \mathrm{~cm}$ at meander $\# 5$ after 1-hr simulation.

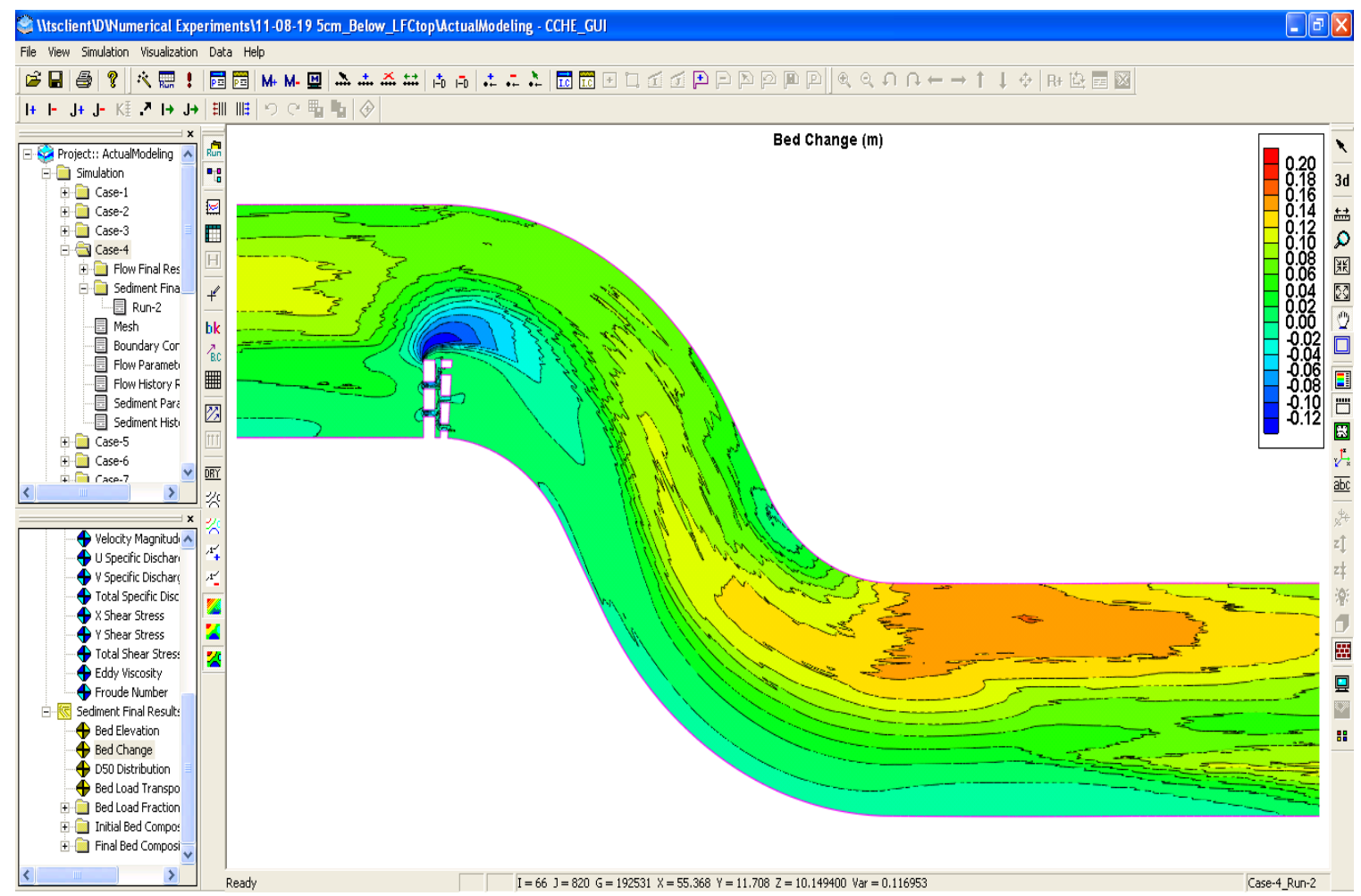

Figure T-114: Bed change when water depth of LFC $=40 \mathrm{~cm}$ between meanders \#5 and \#6 after 1-hr simulation. 


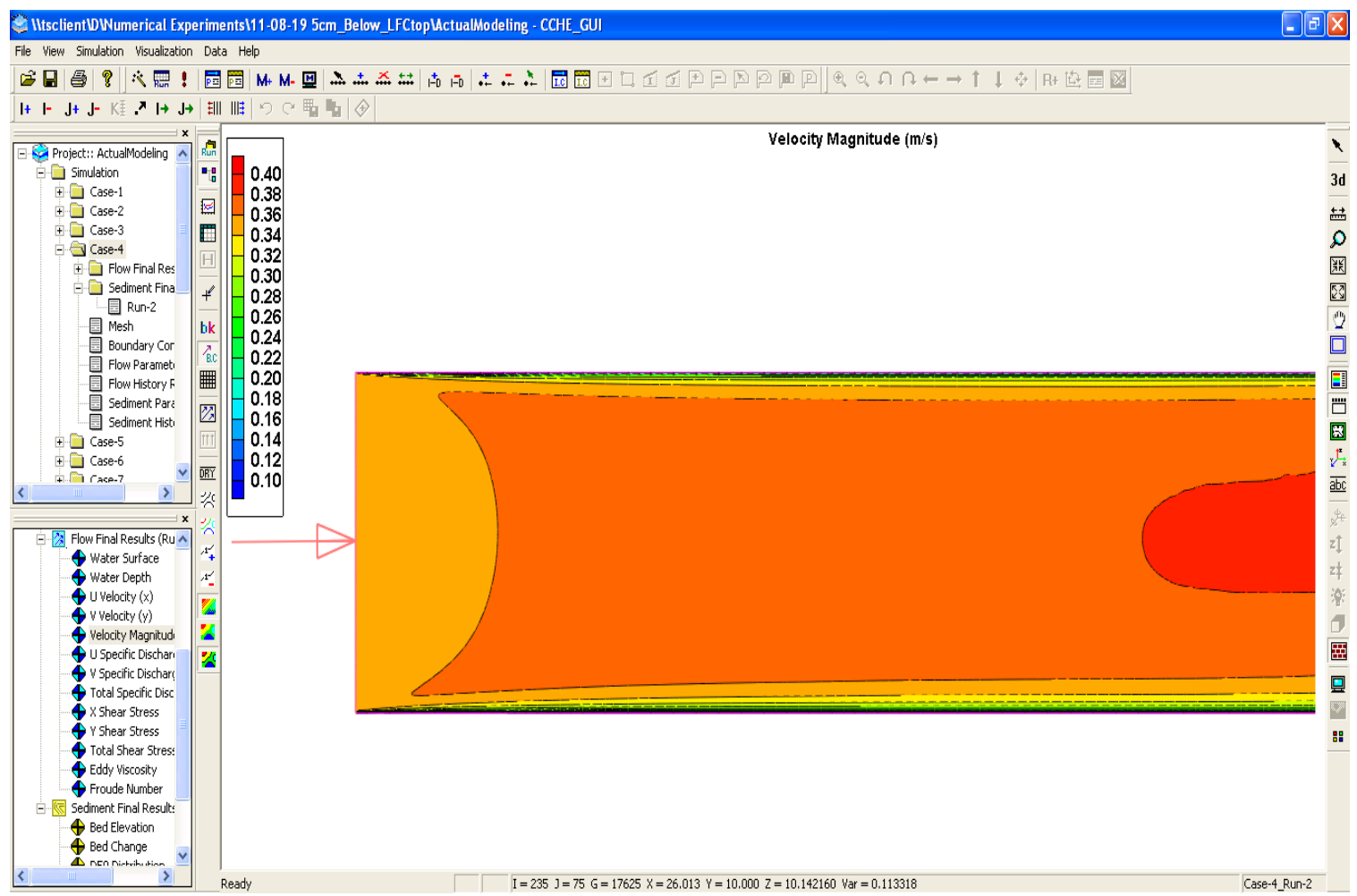

Figure T-115: Velocity magnitude when water depth of LFC $=40 \mathrm{~cm}$ at upstream boundary after 1-hr simulation.

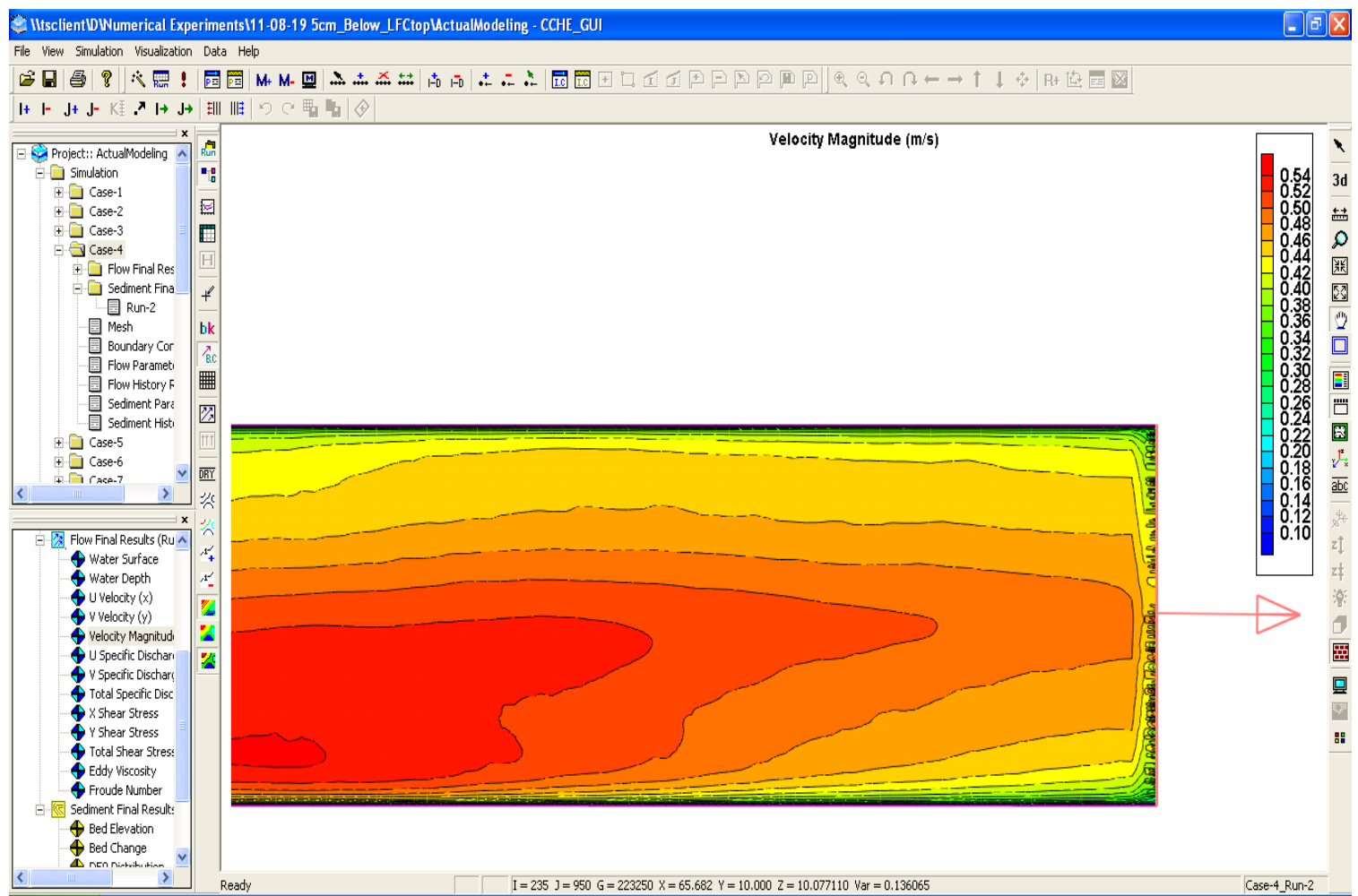

Figure T-116: Velocity magnitude when water depth of LFC $=40 \mathrm{~cm}$ at downstream boundary after 1-hr simulation. 


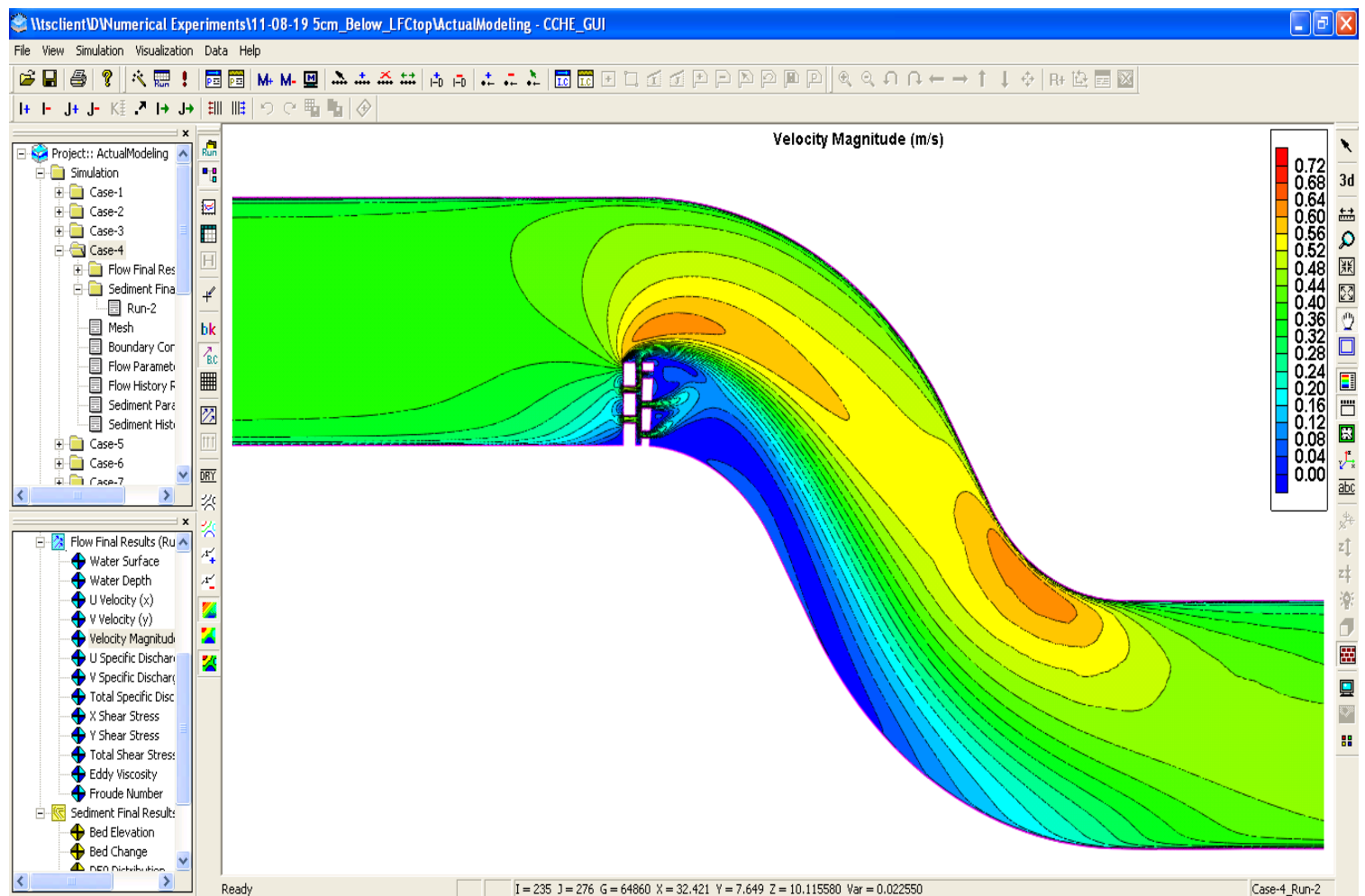

Figure T-117: Velocity magnitude when water depth of LFC $=40 \mathrm{~cm}$ between meanders \#1 and \#2 after 1-hr simulation.

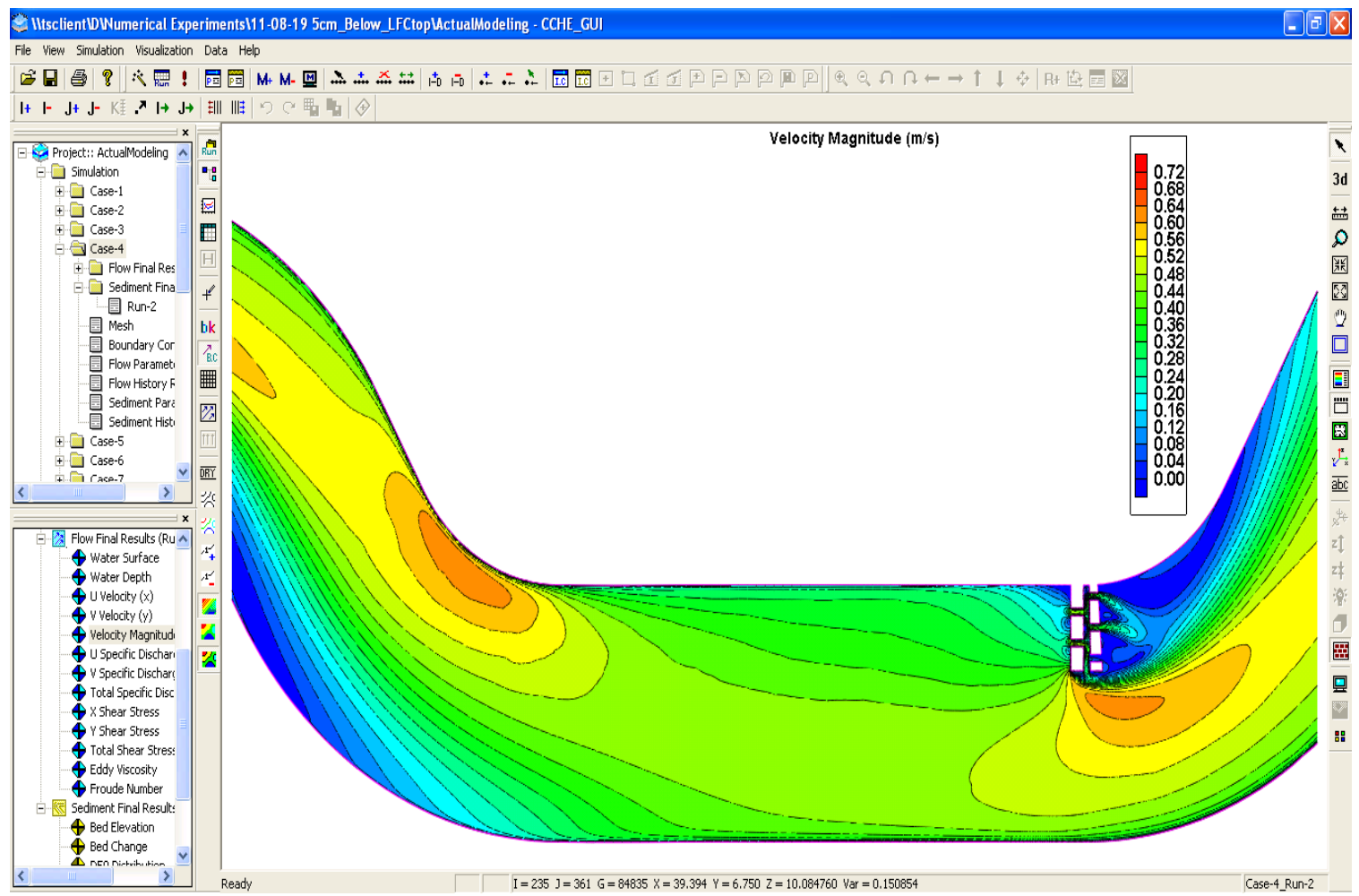


Figure T-118: Velocity magnitude when water depth of LFC $=40 \mathrm{~cm}$ between meanders \#2 and \#3 after 1-hr simulation. 


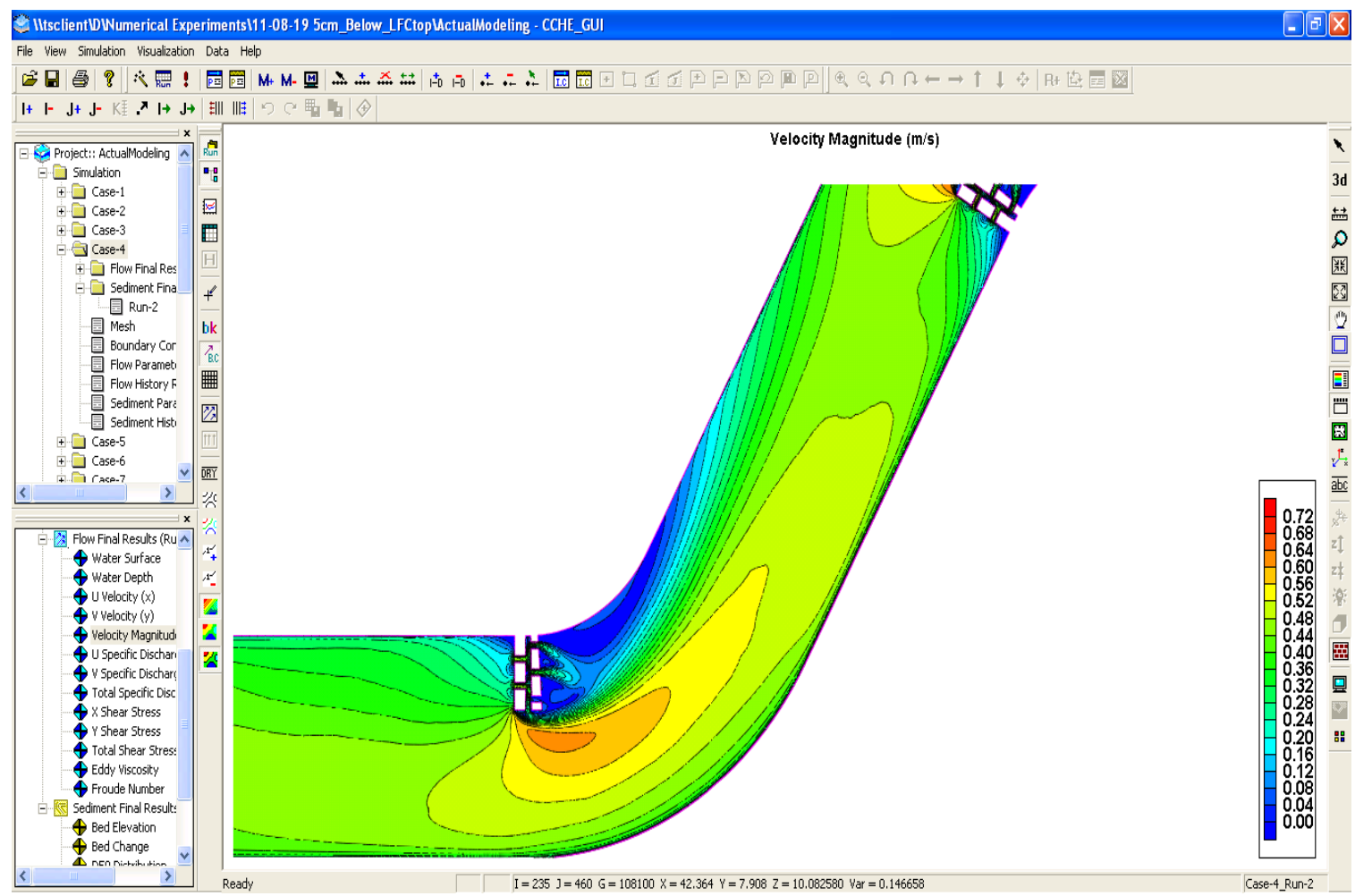

Figure T-119: Velocity magnitude when water depth of LFC $=40 \mathrm{~cm}$ between meanders \#3 and \#4 after 1-hr simulation.

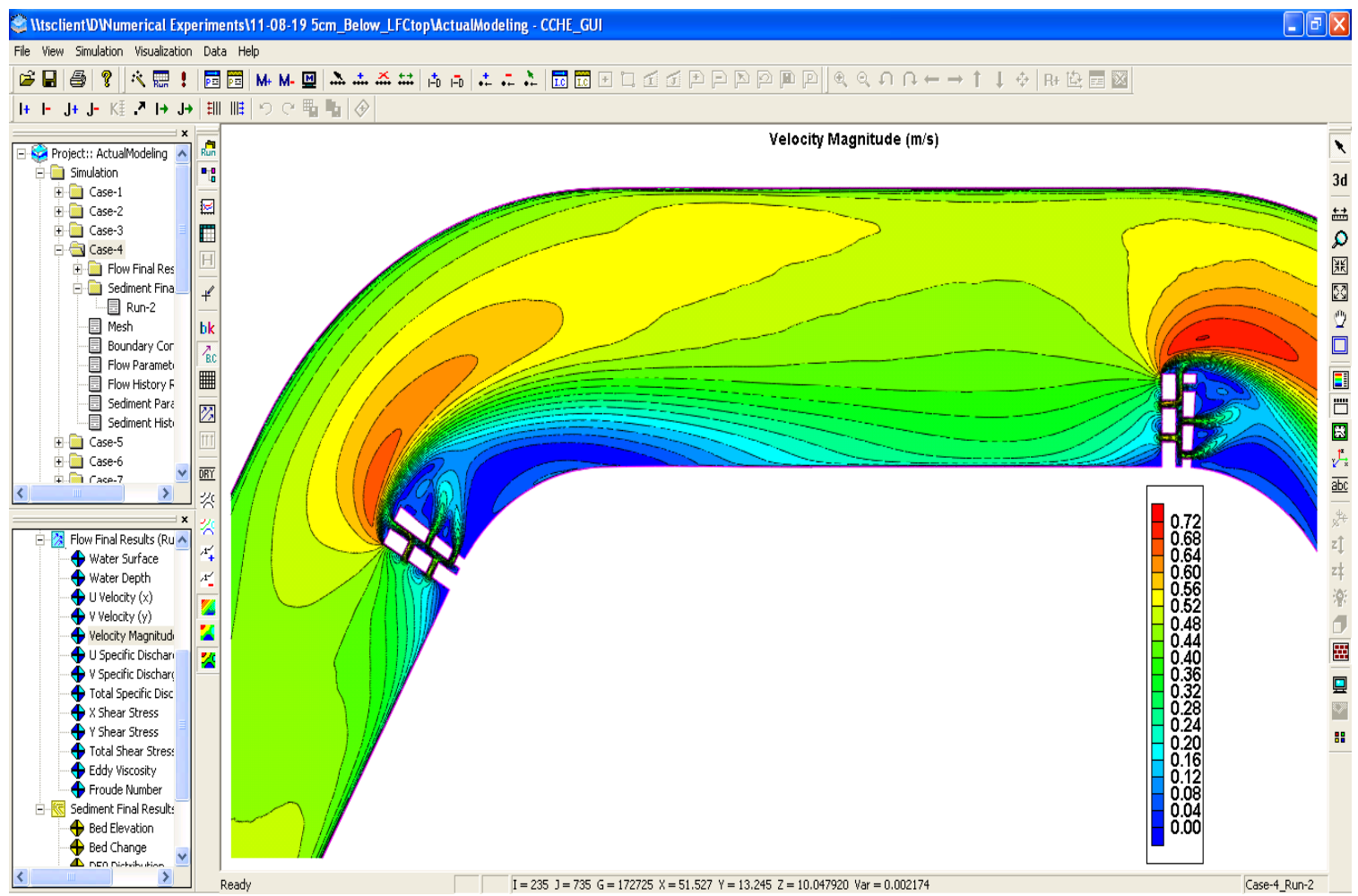

Figure T-120: Velocity magnitude when water depth of LFC $=40 \mathrm{~cm}$ between meanders \#4 and \#5 after 1-hr simulation. 


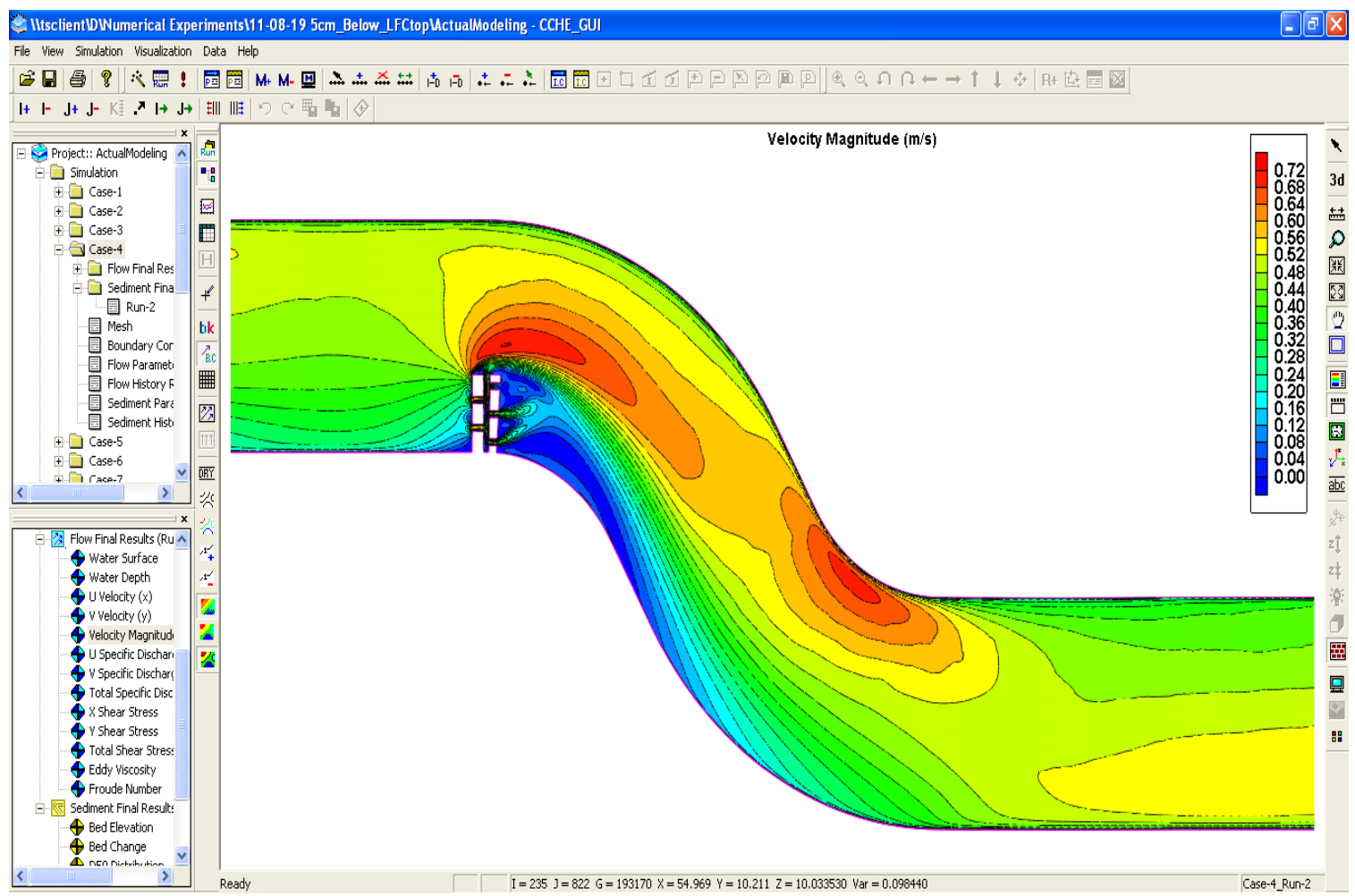

Figure T-121: Velocity magnitude when water depth of LFC $=40 \mathrm{~cm}$ between meanders \#5 and \#6 after 1-hr simulation.

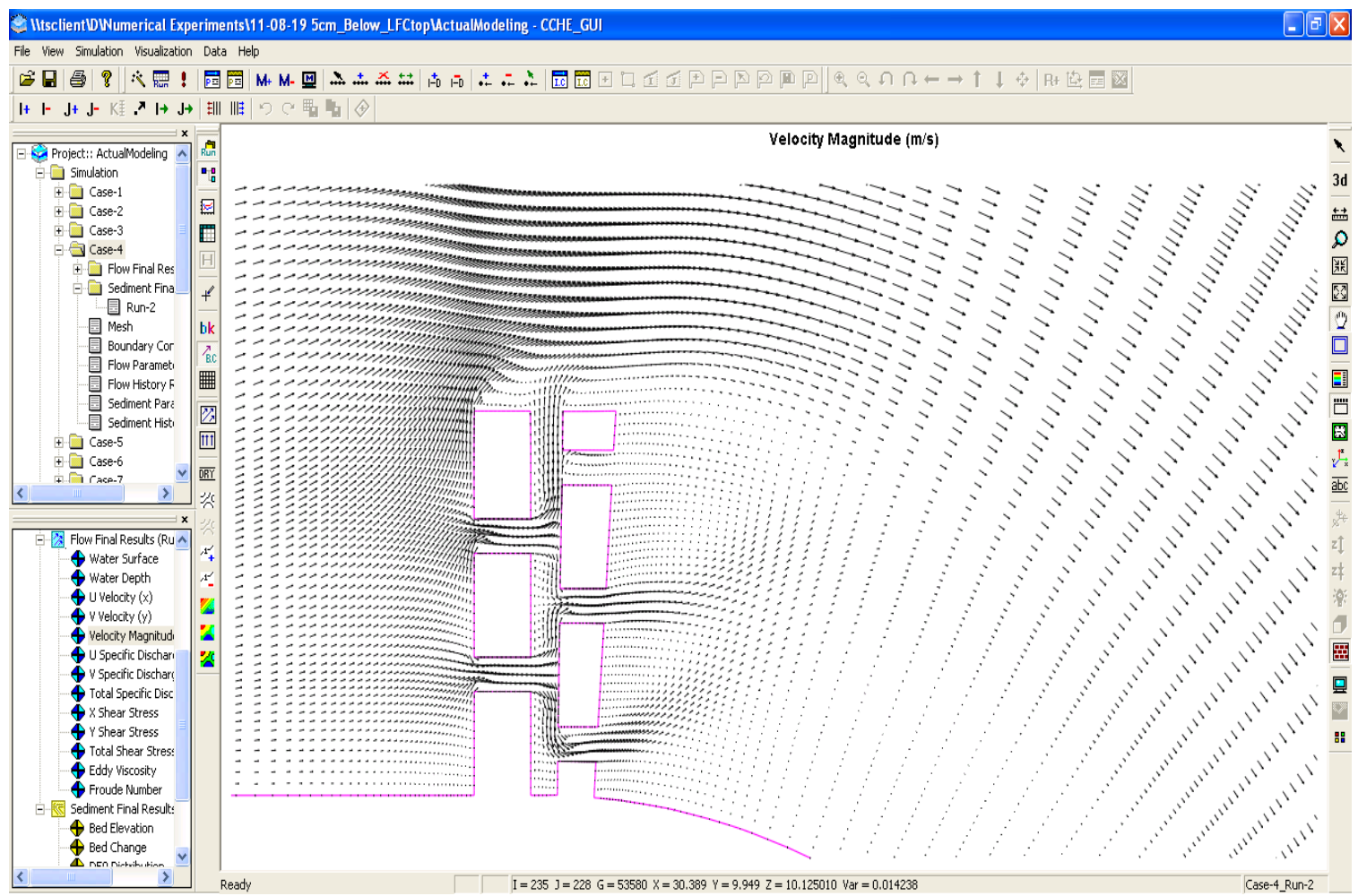

Figure T-122: Velocity direction when water depth of LFC $=40 \mathrm{~cm}$ at meander \#1 after 1-hr simulation. 


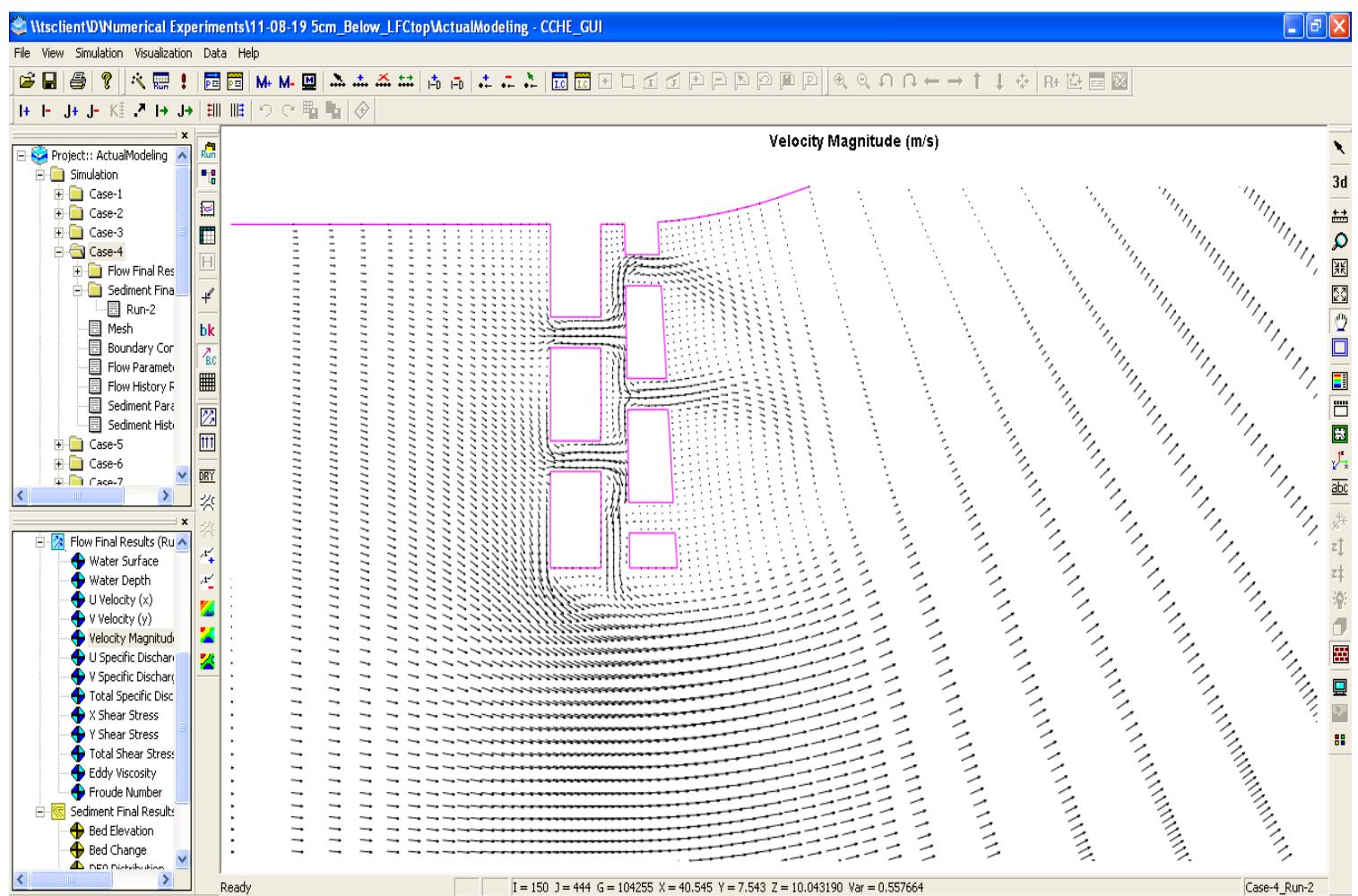

Figure T-123: Velocity direction when water depth of LFC $=40 \mathrm{~cm}$ at meander \#3 after 1-hr simulation.

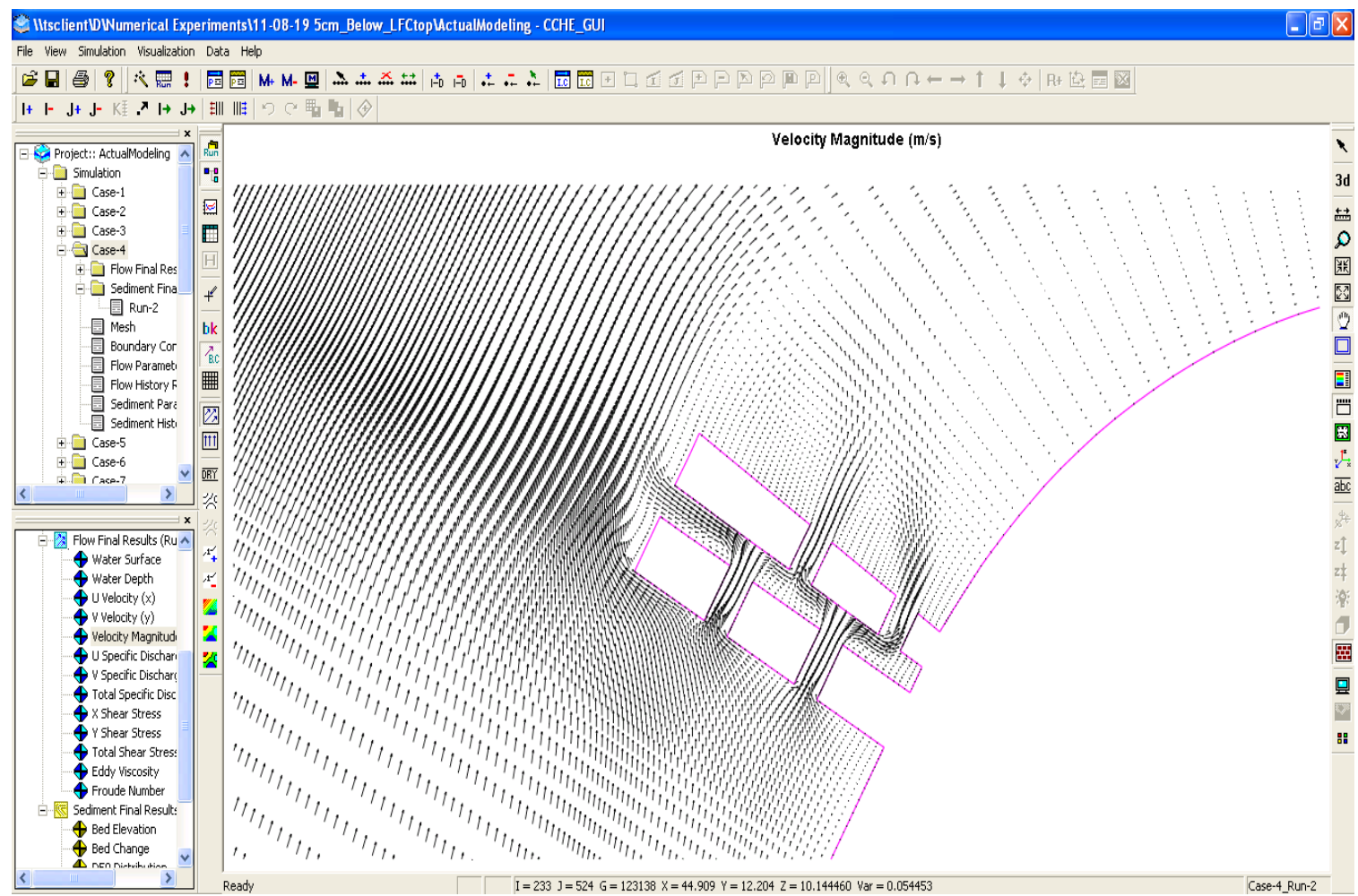

Figure T-124: Velocity direction when water depth of LFC $=40 \mathrm{~cm}$ at meander \#4 after 1-hr simulation. 


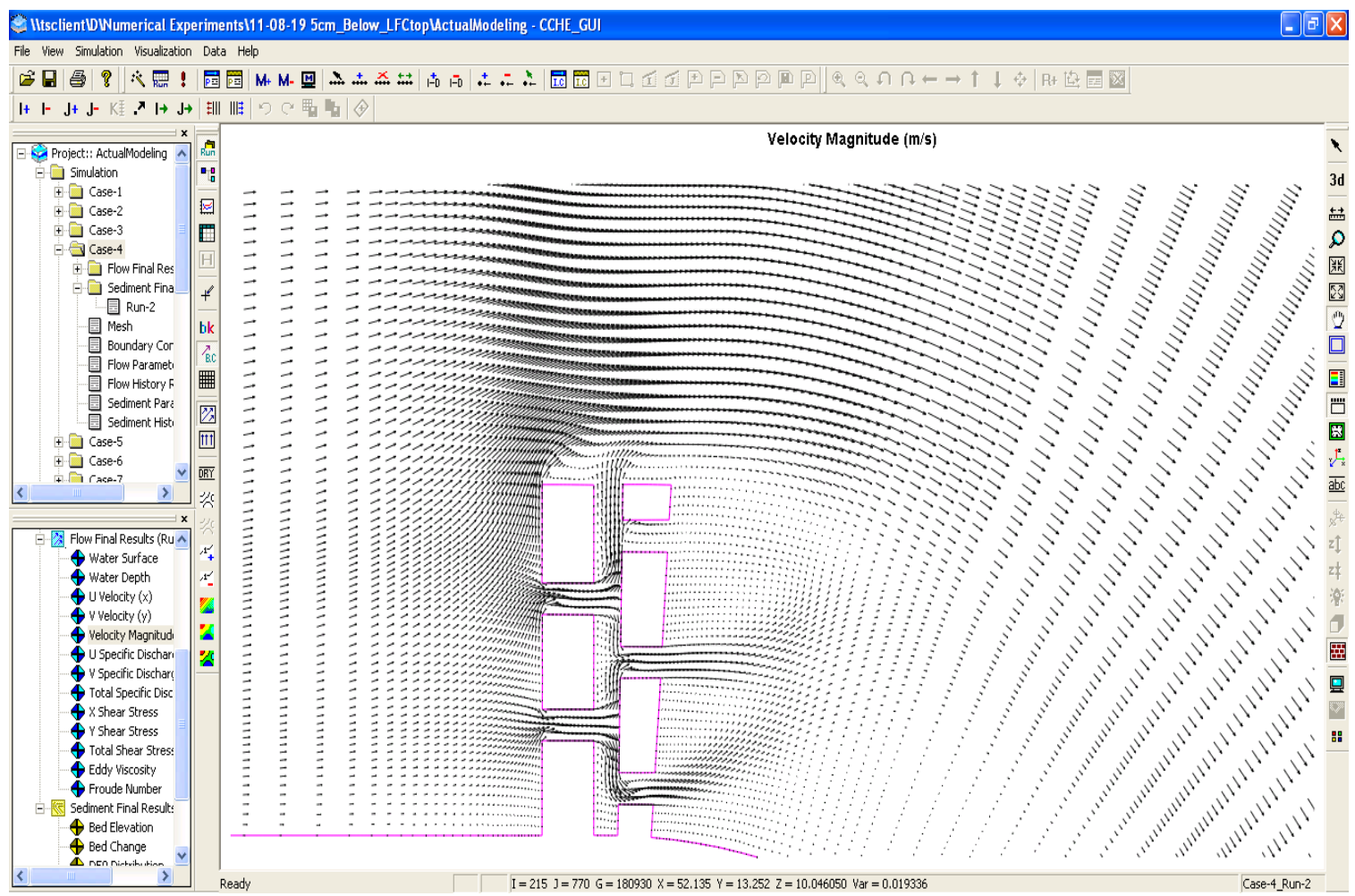

Figure T-125: Velocity direction when water depth of LFC $=40 \mathrm{~cm}$ at meander \#5 after 1-hr simulation. 


\section{Solid Deflectors}

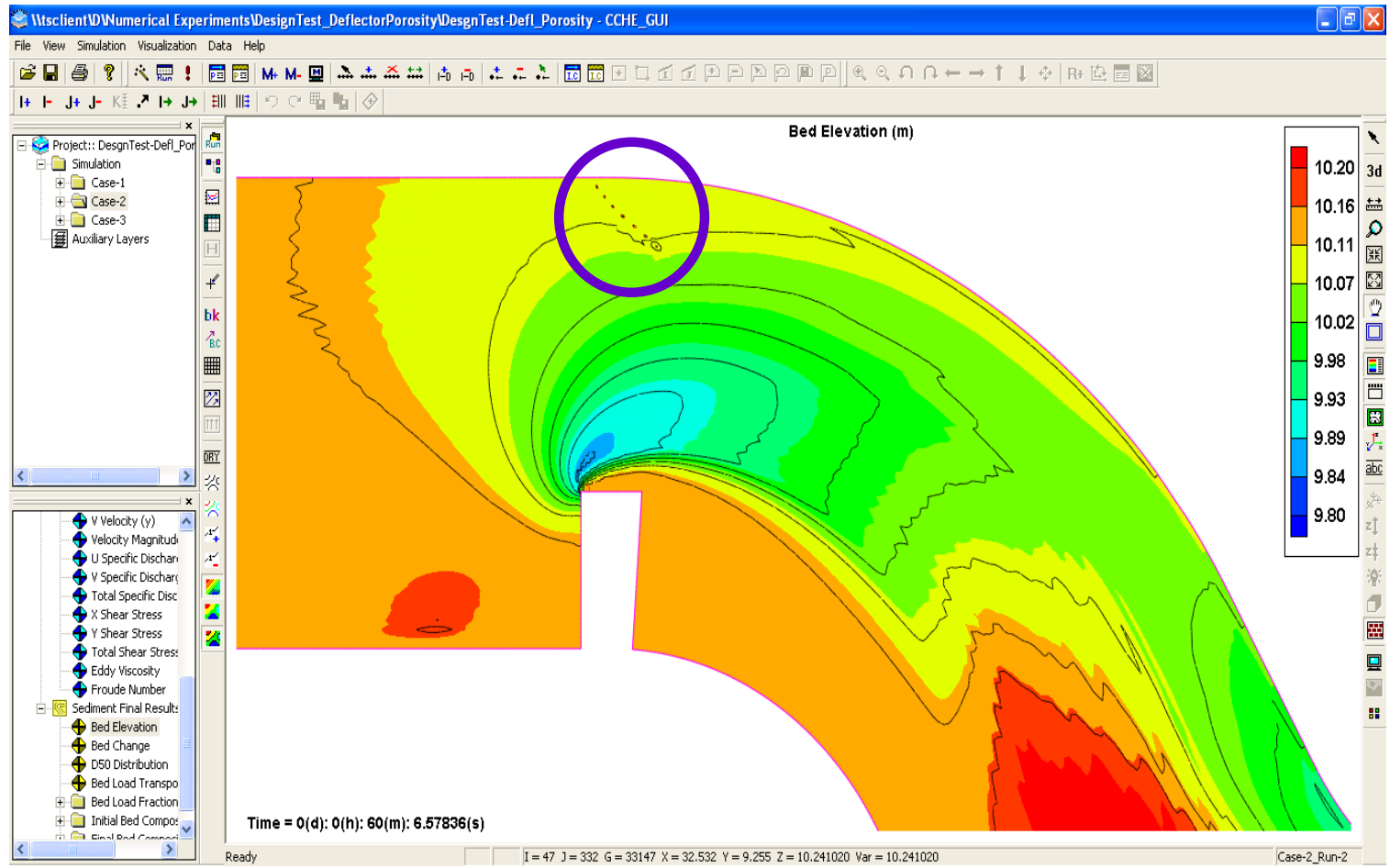

Figure T-126: Bed elevation for solid deflector scenario at meander \#1 after 1-hr simulation.

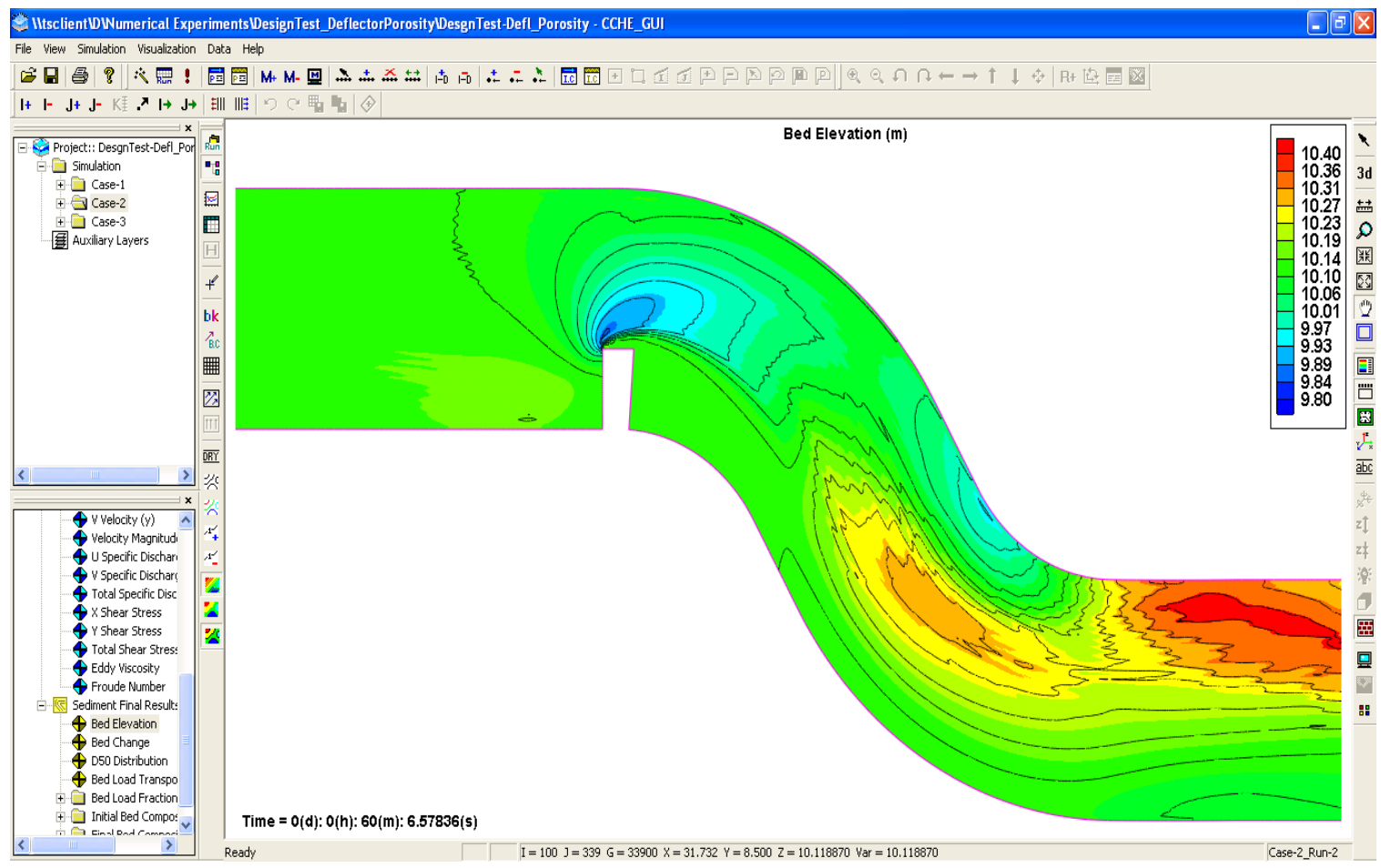

Figure T-127: Bed elevation for solid deflector scenario between meanders \#1 and \#2 after 1-hr simulation. 


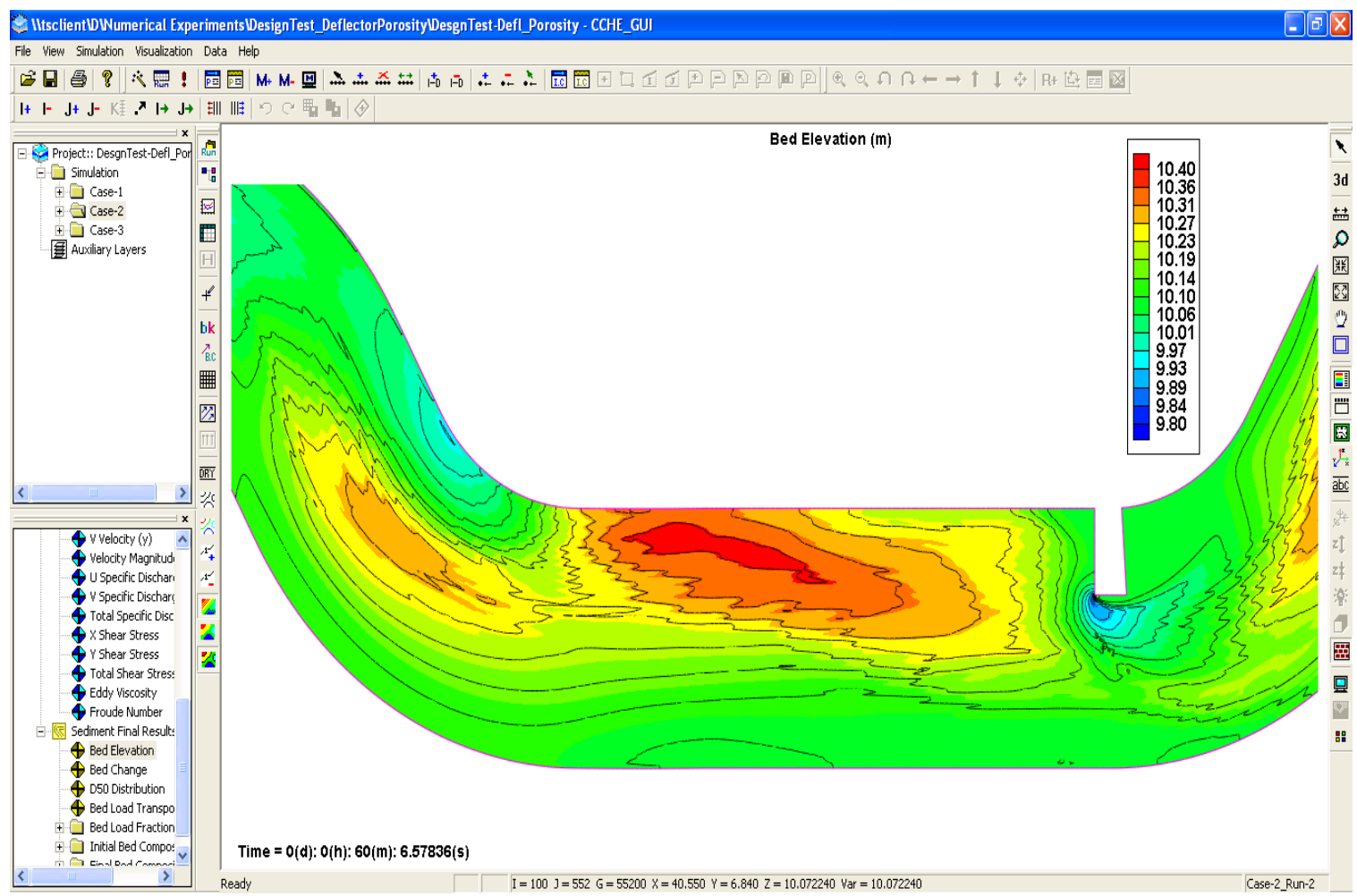

Figure T-128: Bed elevation for solid deflector scenario between meanders \#2 and \#3 after 1-hr simulation.

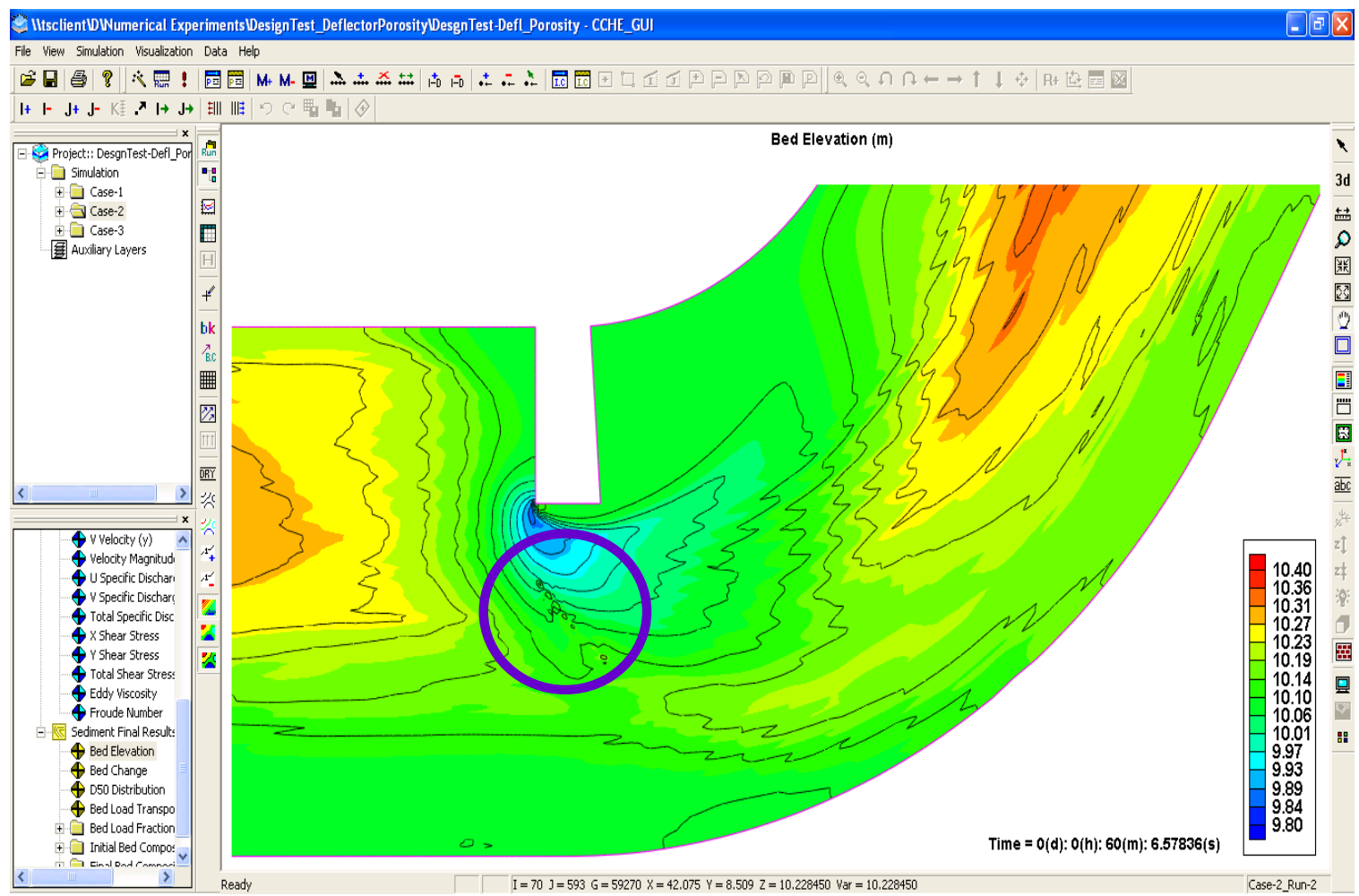

Figure T-129: Bed elevation for solid deflector scenario at meander \#3 after 1-hr simulation. 


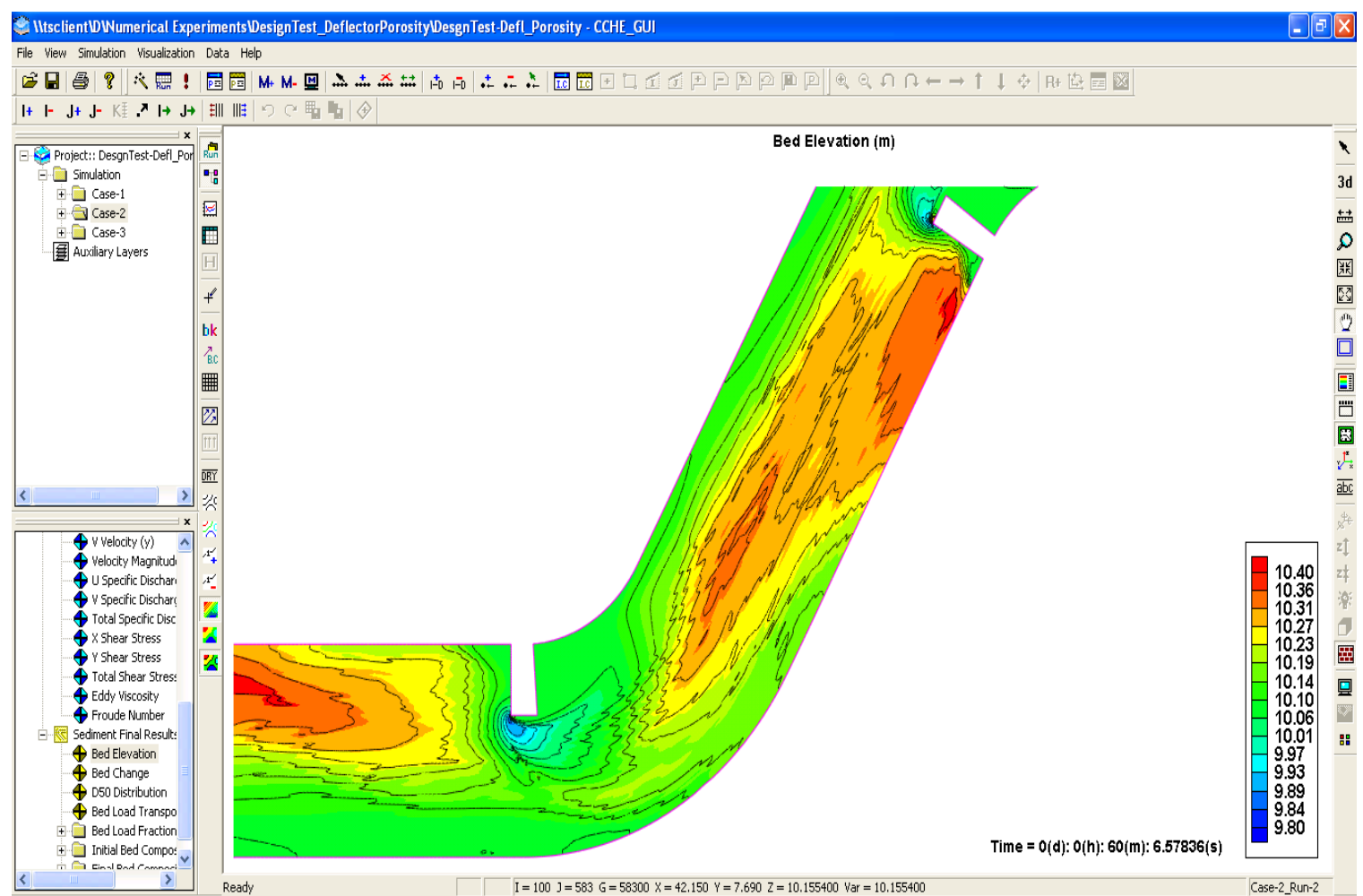

Figure T-130: Bed elevation for solid deflector scenario between meanders \#3 and \#4 after 1-hr simulation.

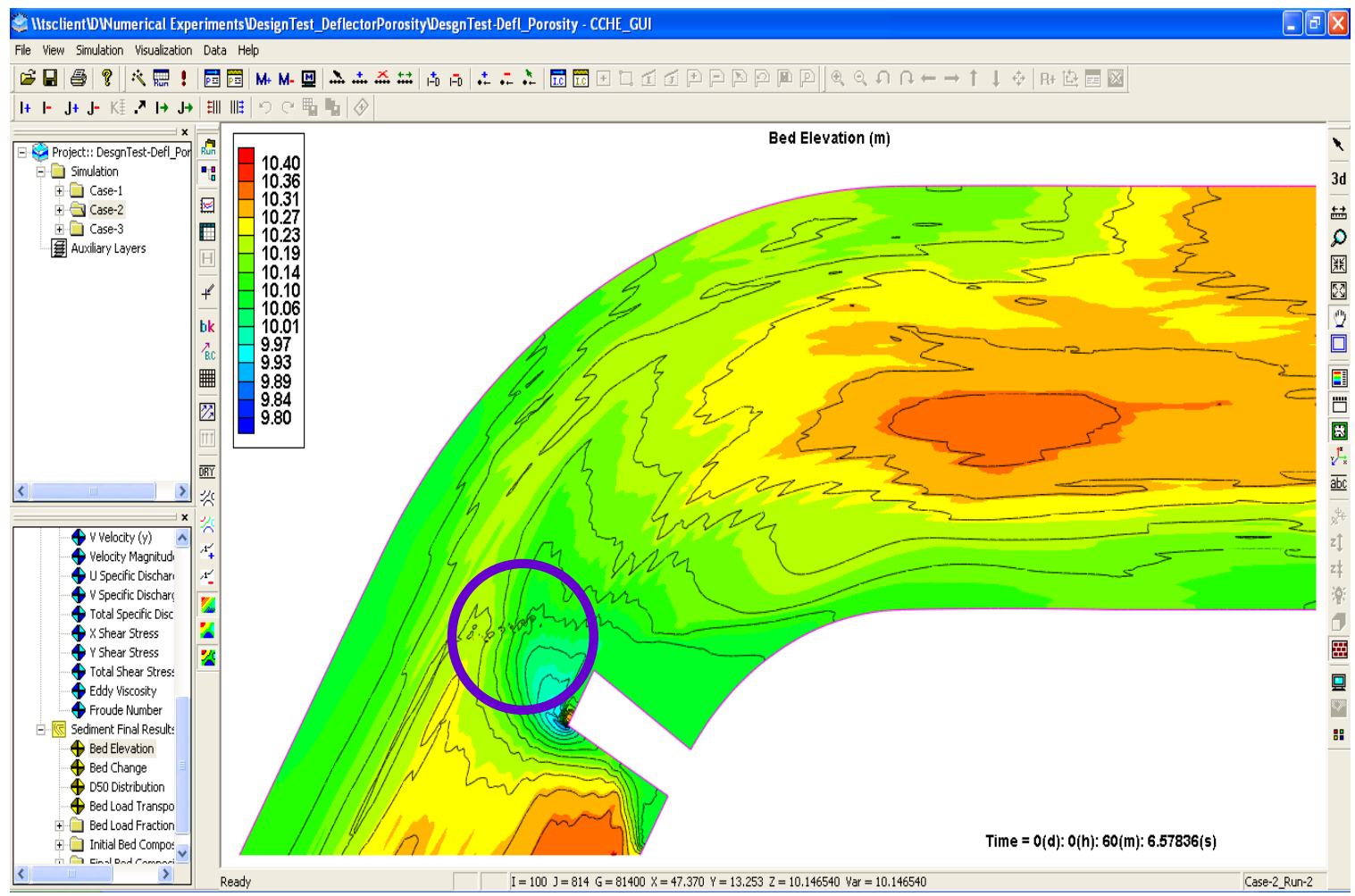

Figure T-131: Bed elevation for solid deflector scenario at meander \#4 after 1-hr simulation. 


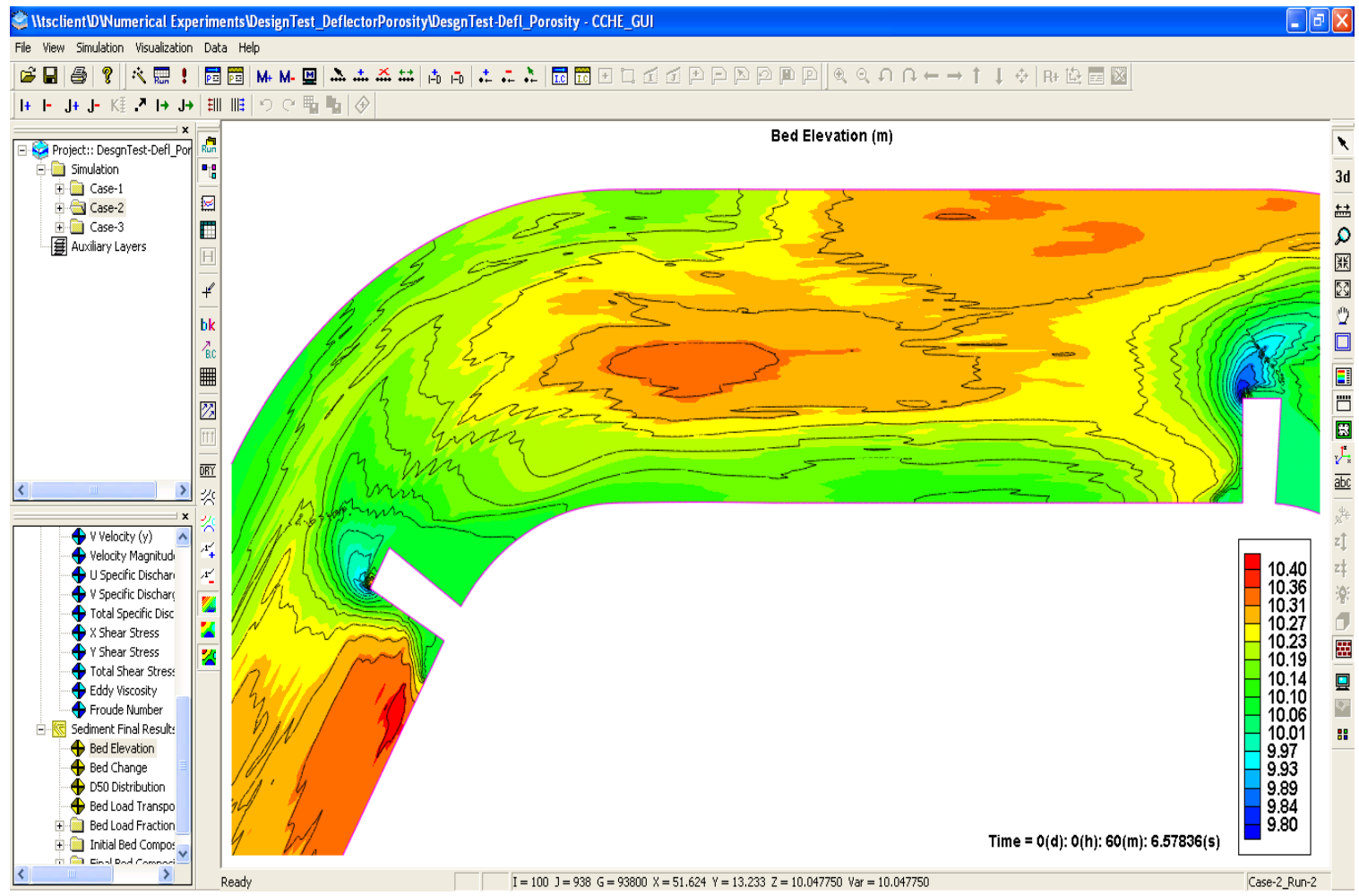

Figure T-132: Bed elevation for solid deflector scenario between meanders \#4 and \#5 after 1-hr simulation.

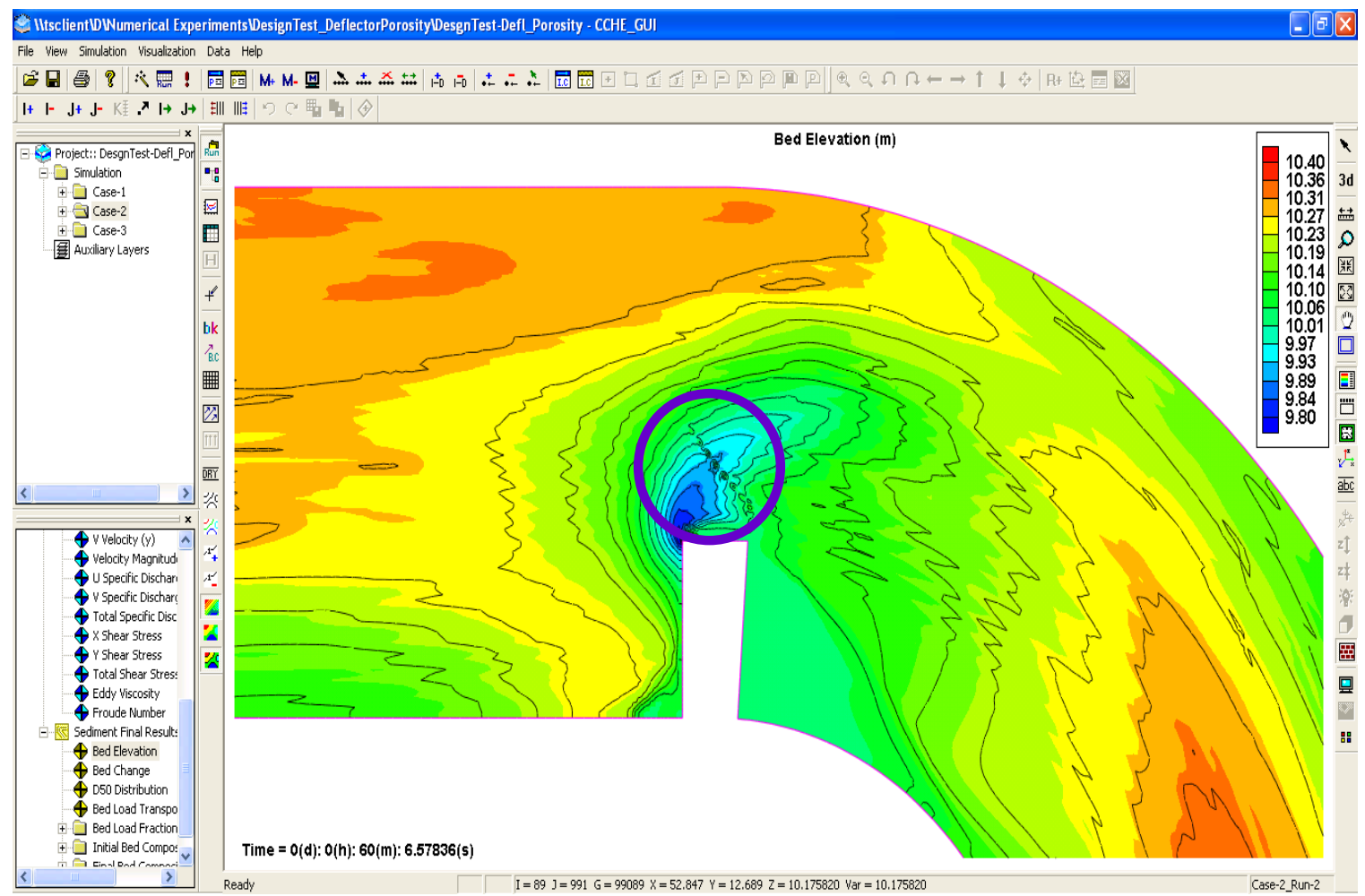

Figure T-133: Bed elevation for solid deflector scenario at meander \#5 after 1-hr simulation. 


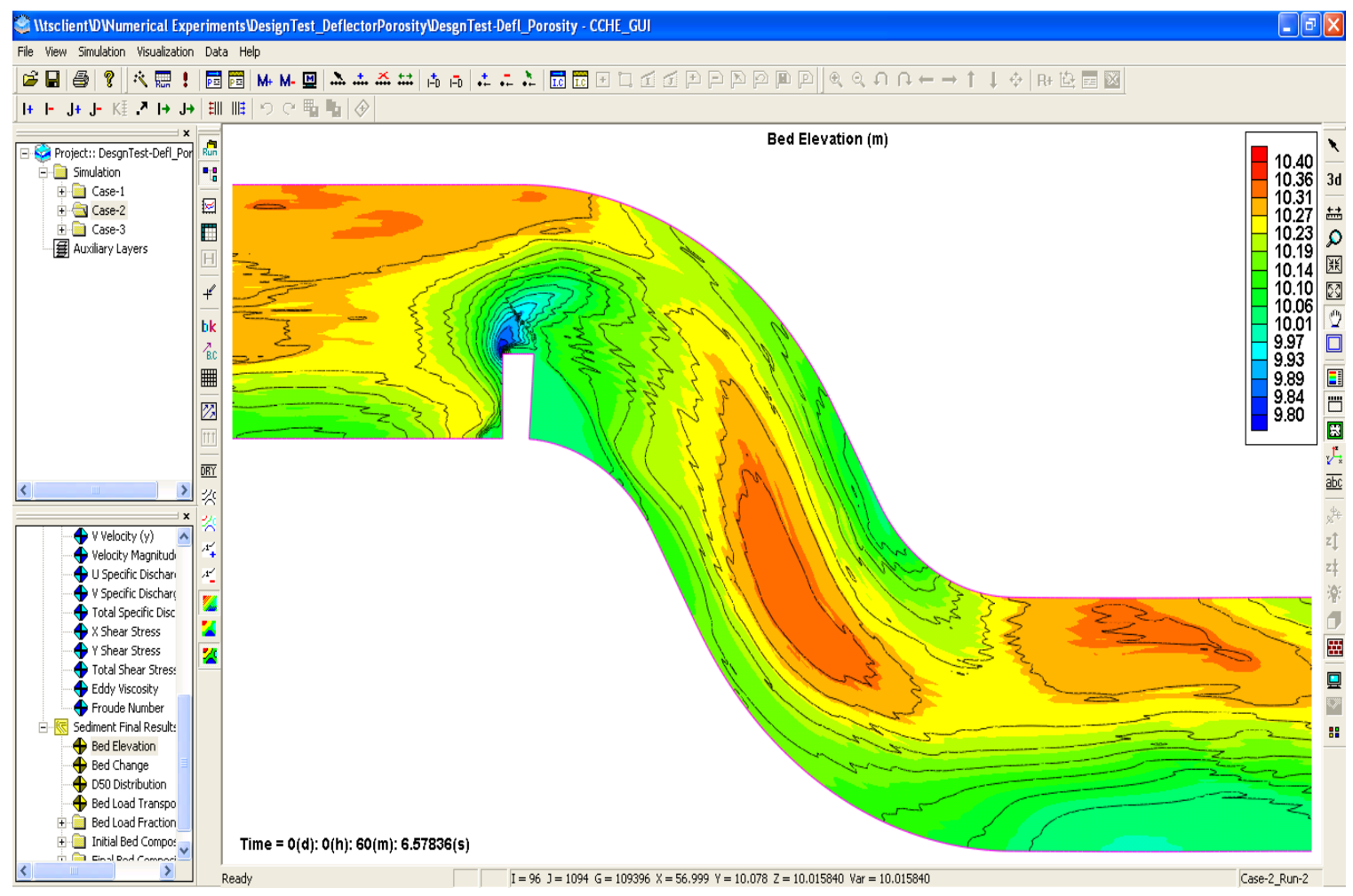

Figure T-134: Bed elevation for solid deflector scenario between meanders \#5 and \#6 after 1-hr simulation.

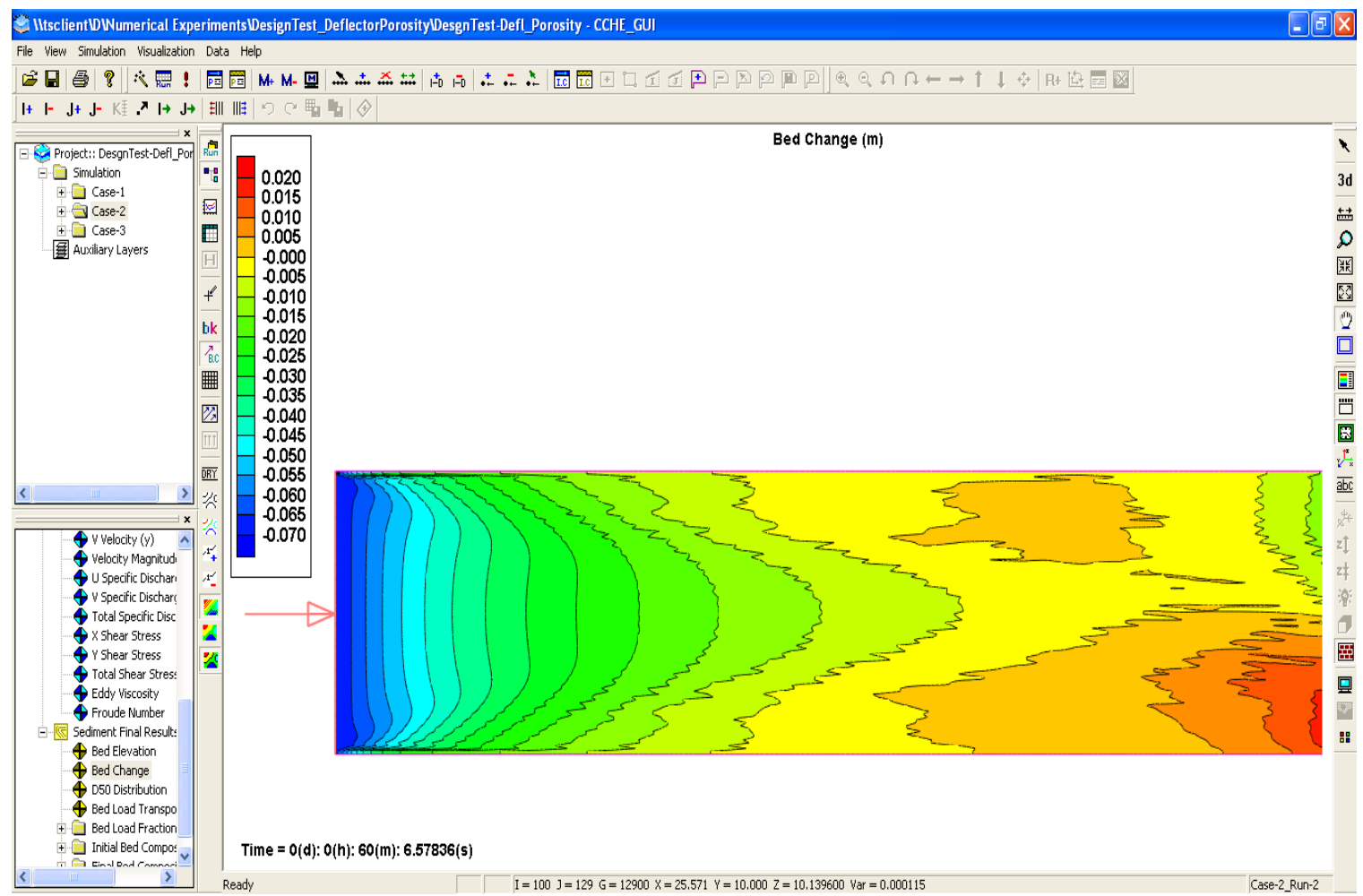

Figure T-135: Bed change for solid deflector scenario at upstream boundary after 1 -hr simulation. 


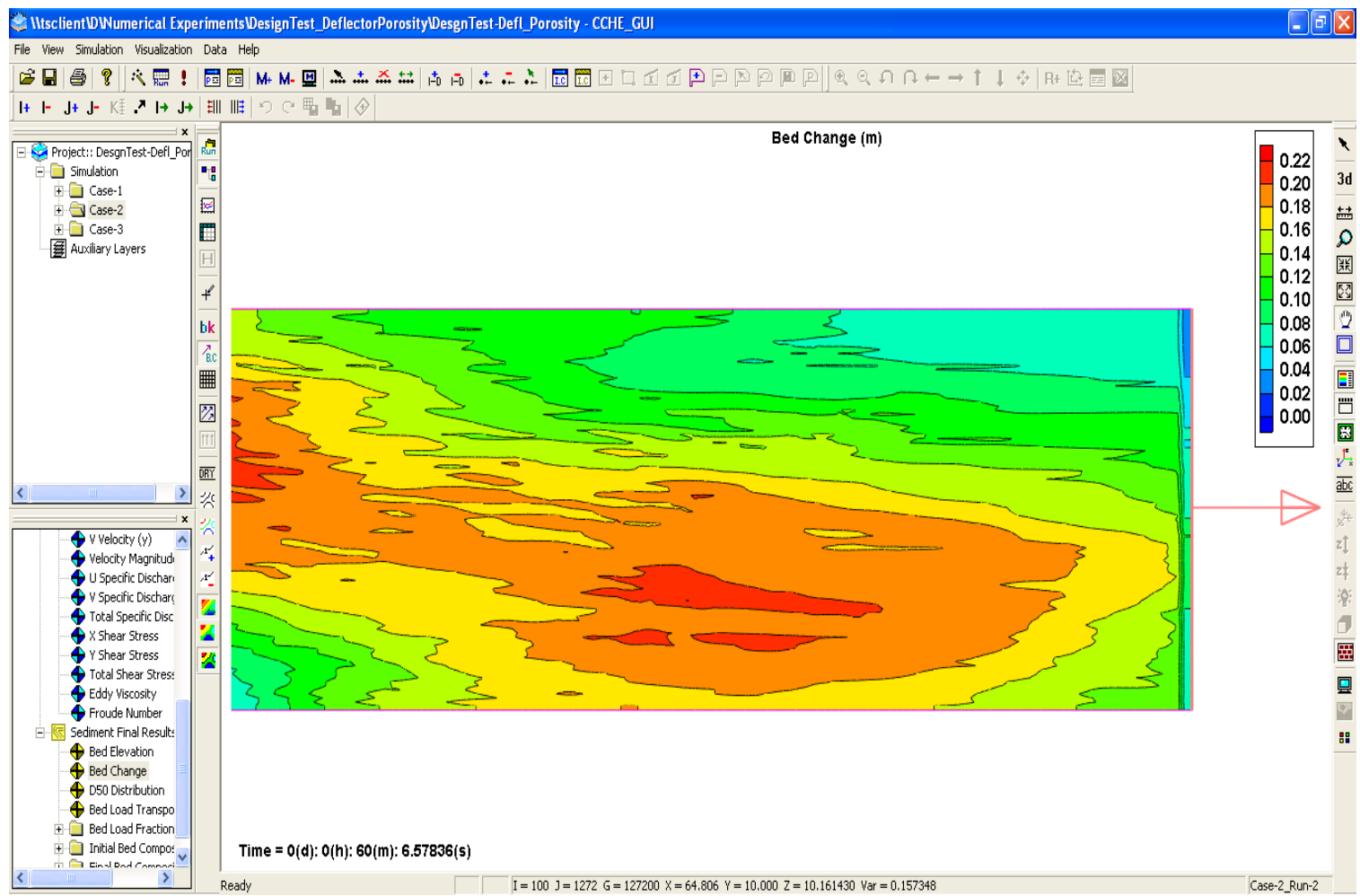

Figure T-136: Bed change for solid deflector scenario at downstream boundary after 1-hr simulation.

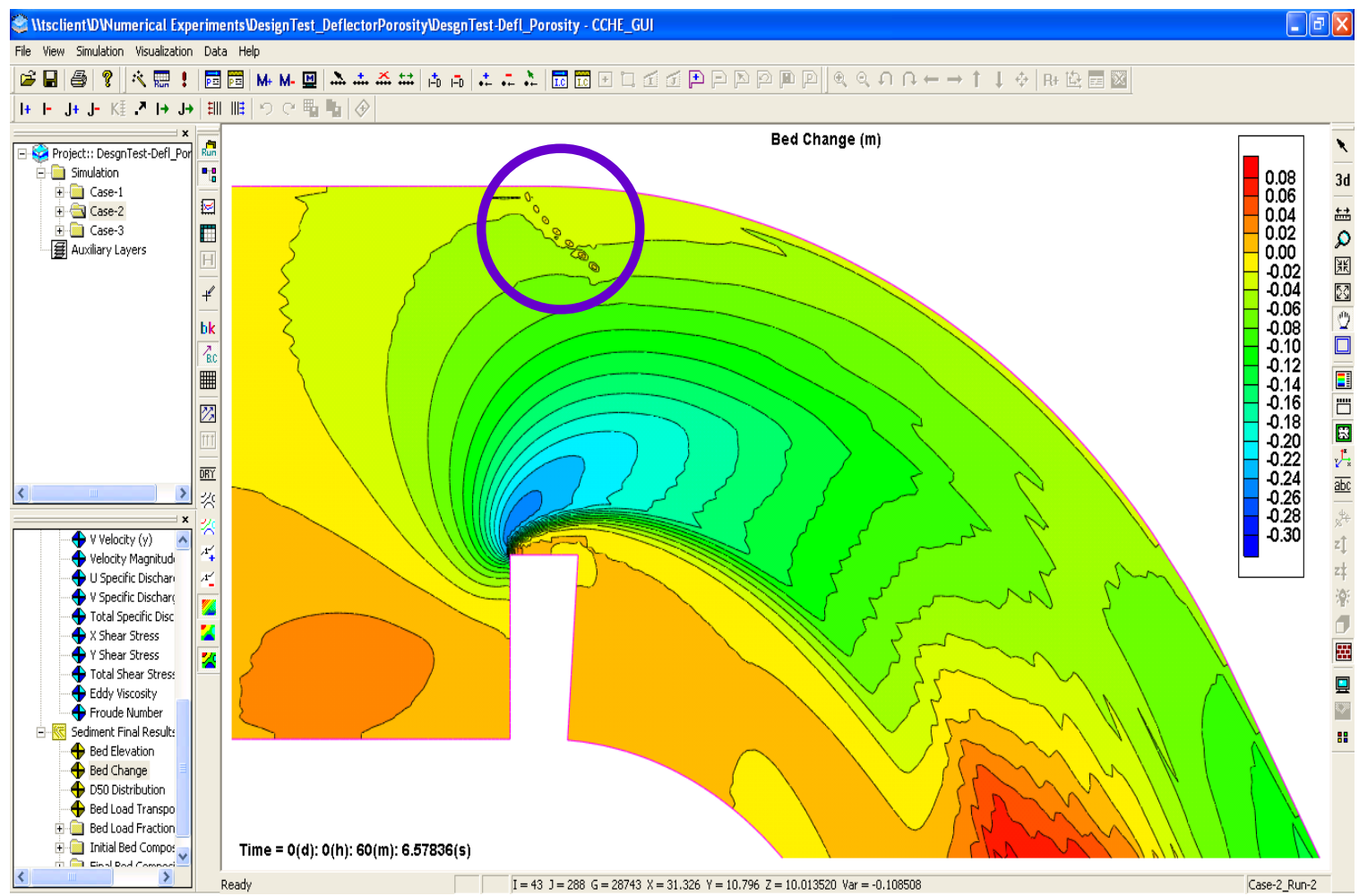

Figure T-137: Bed change for solid deflector scenario at meander \#1 after 1-hr simulation. 


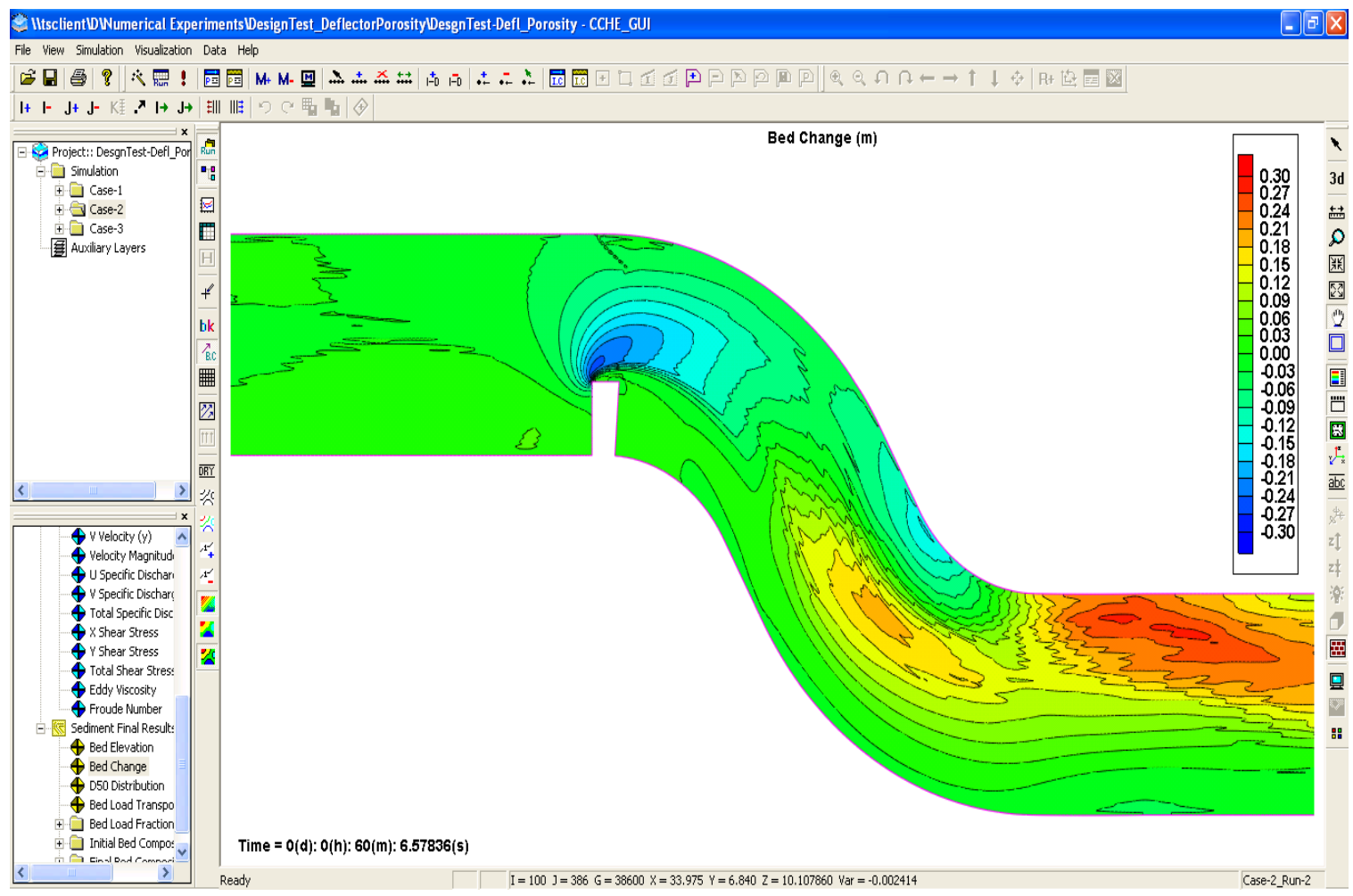

Figure T-138: Bed change for solid deflector scenario between meanders \#1 and \#2 after 1-hr simulation.

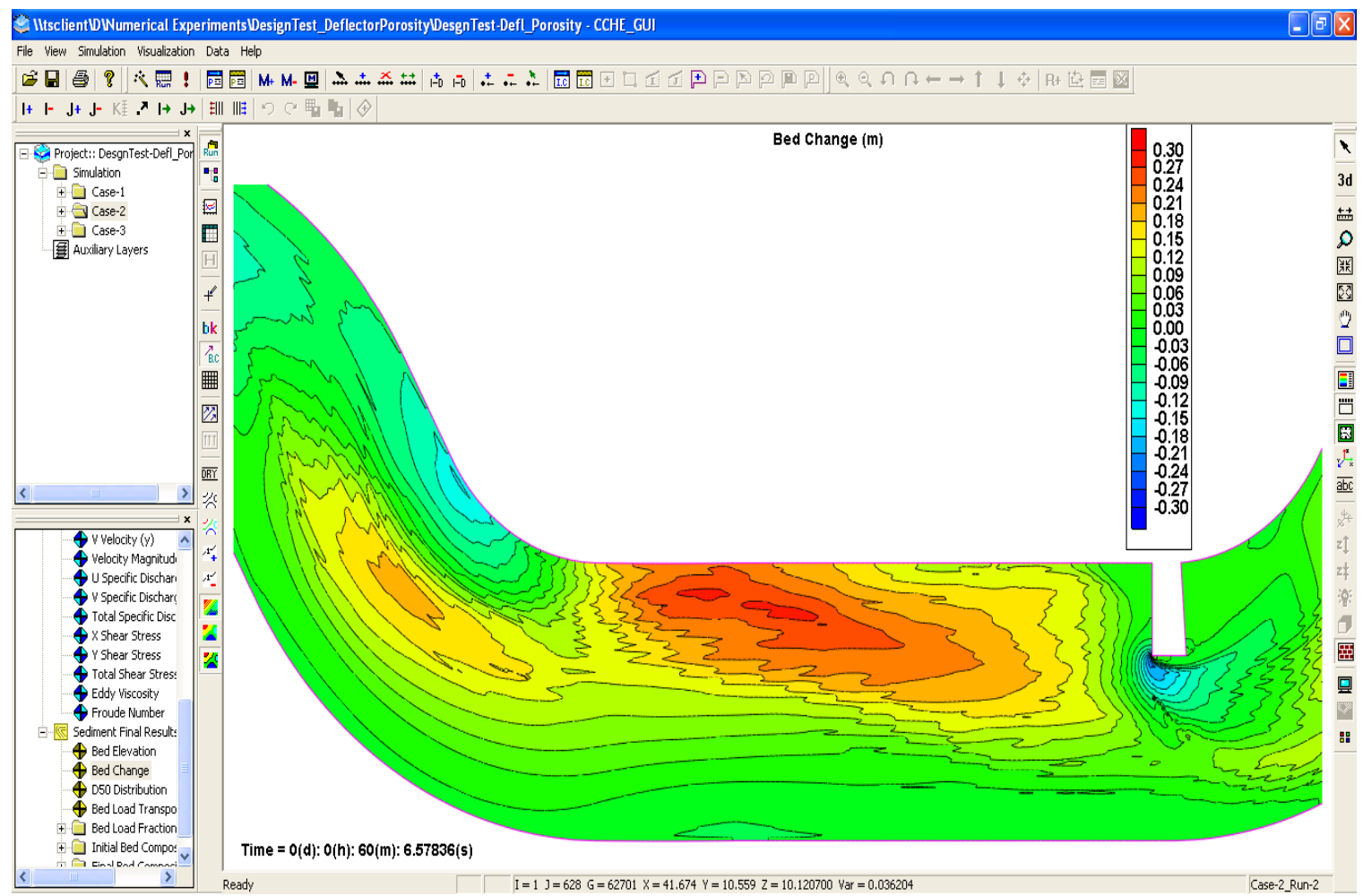

Figure T-139: Bed change for solid deflector scenario between meanders \#2 and \#3 after 1-hr simulation. 


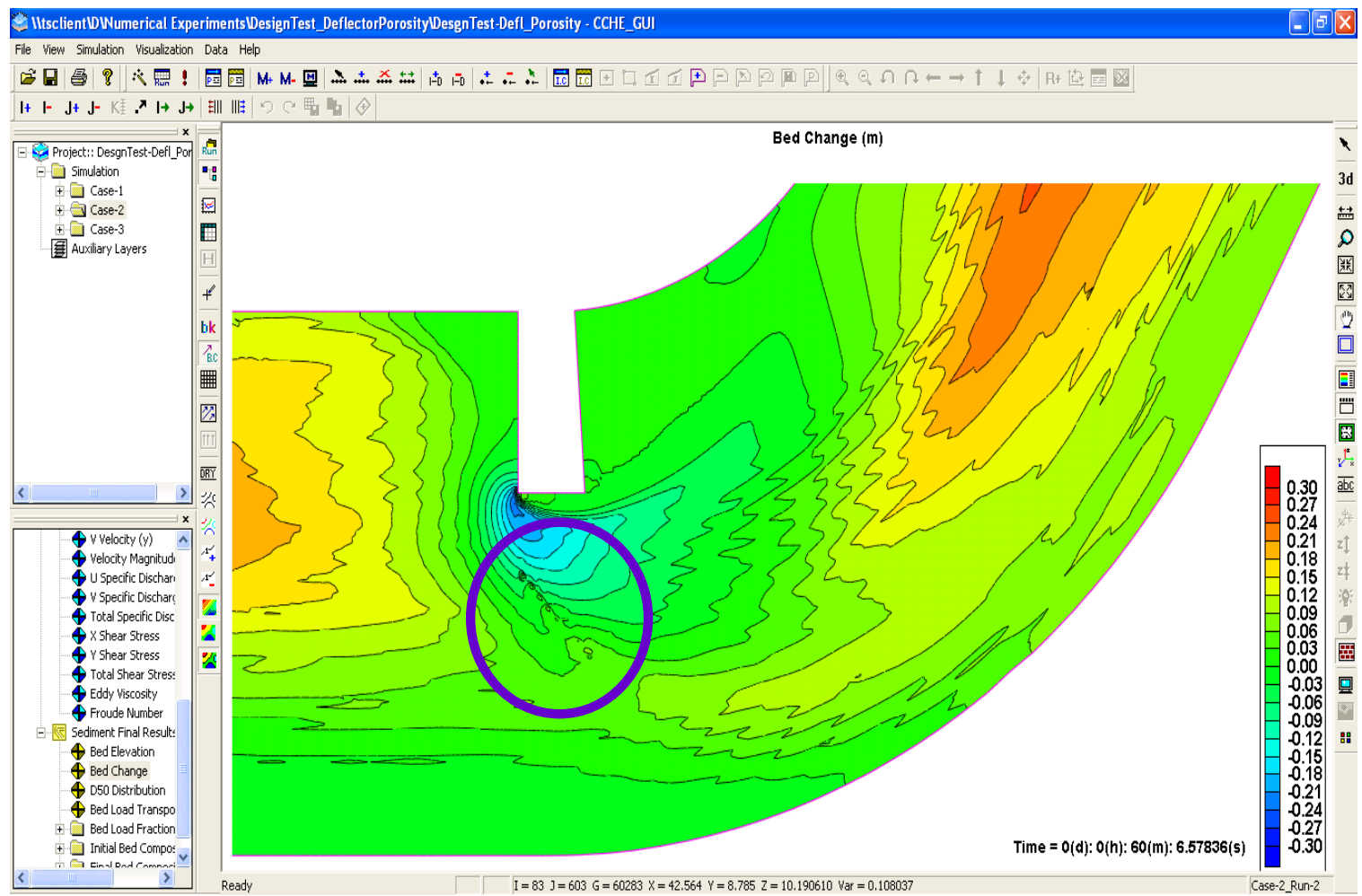

Figure T-140: Bed change for solid deflector scenario at meander \#3 after 1-hr simulation.

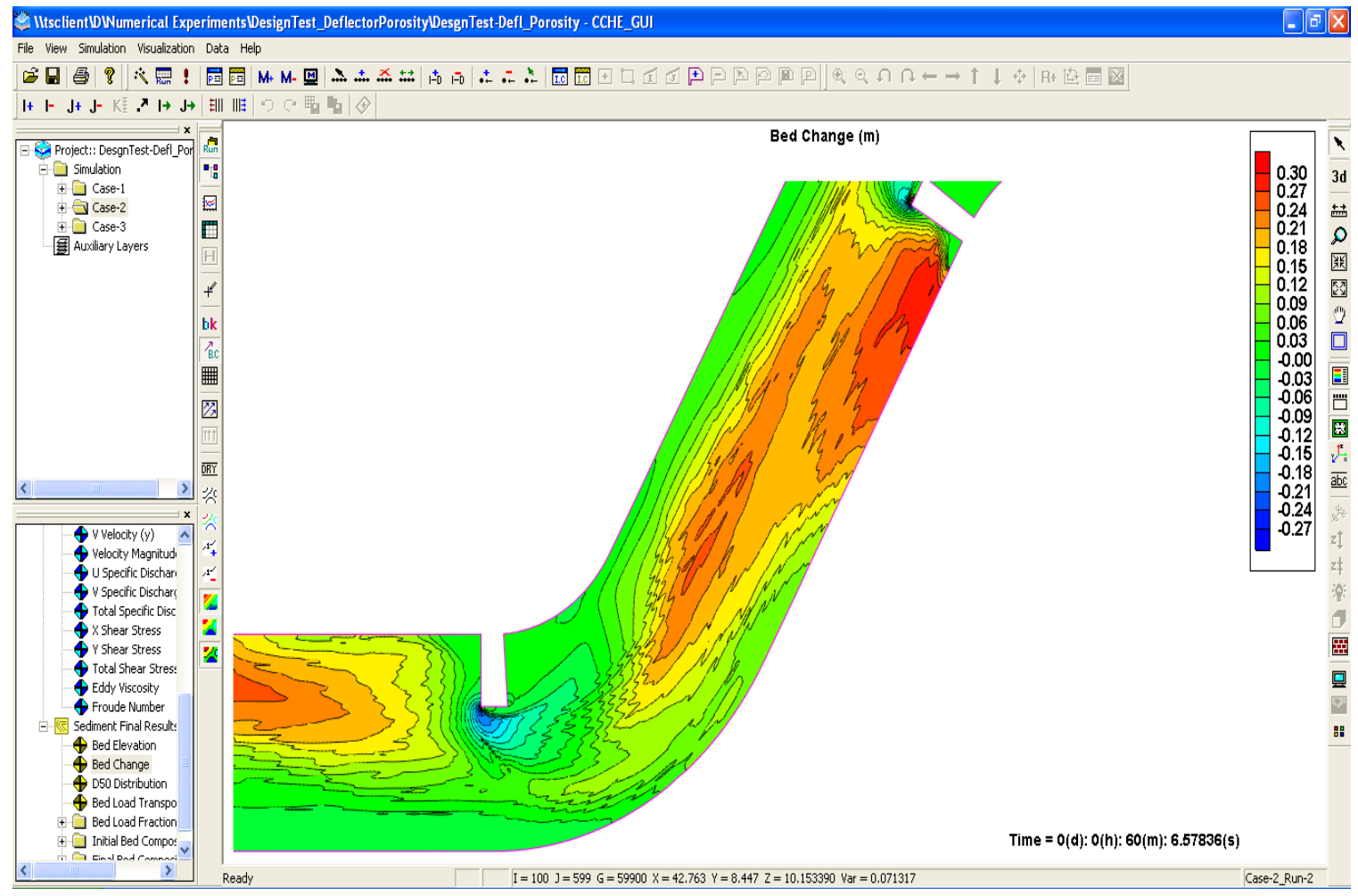

Figure T-141: Bed change for solid deflector scenario between meanders \#3 and \#4 after 1-hr simulation. 


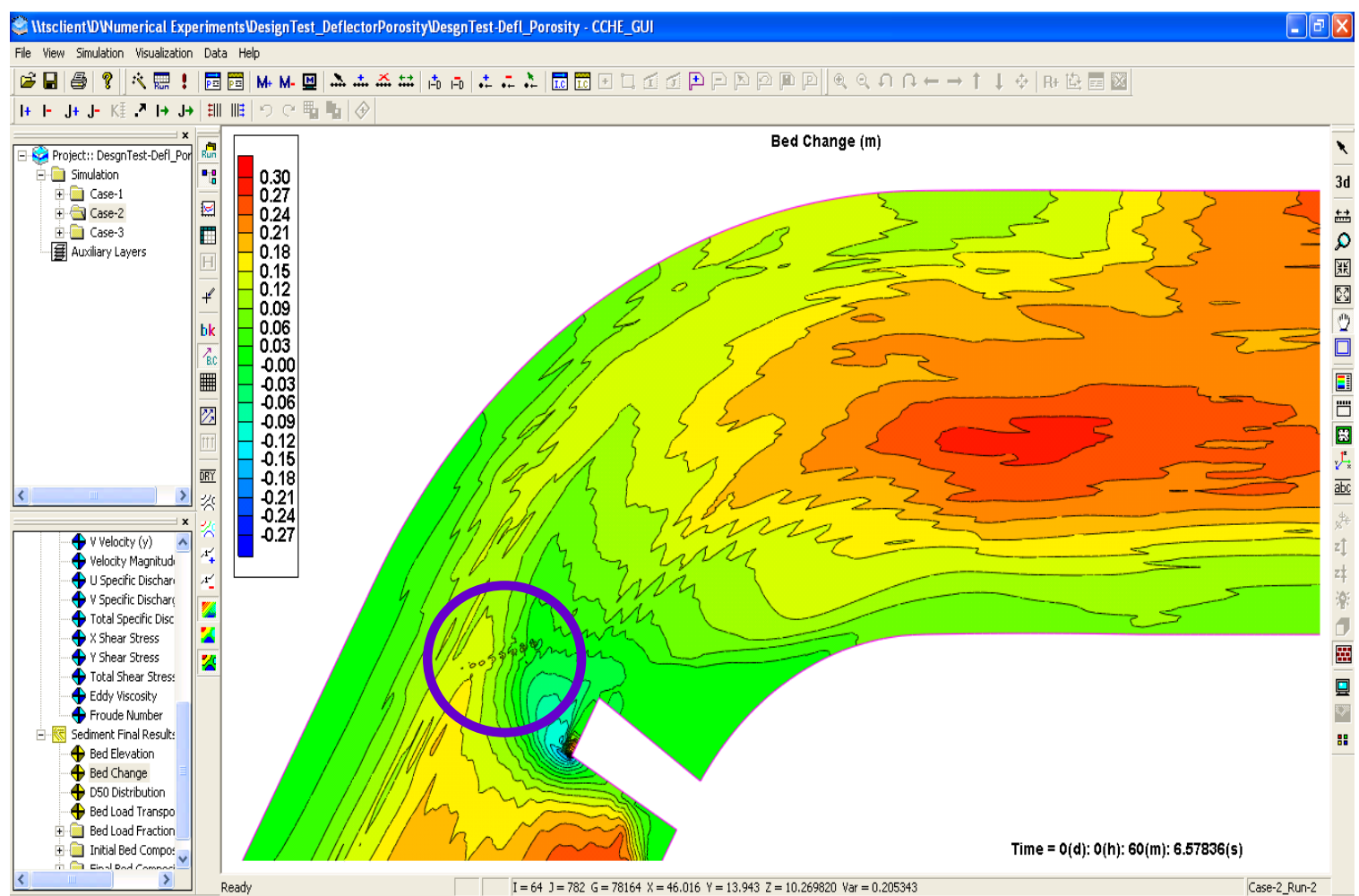

Figure T-142: Bed change for solid deflector scenario at meander \#4 after 1-hr simulation.

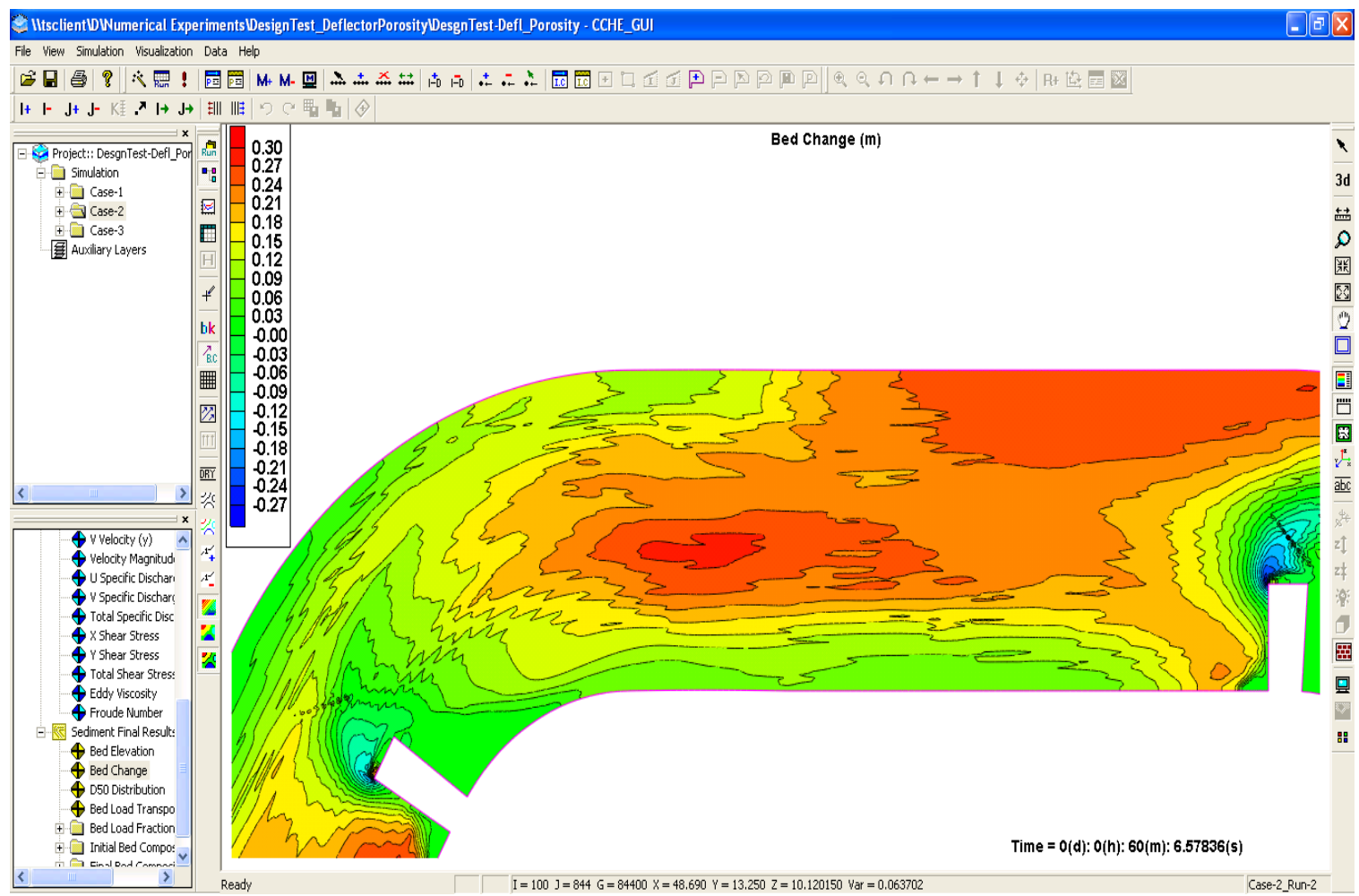

Figure T-143: Bed change for solid deflector scenario between meanders \#4 and \#5 after 1-hr simulation. 


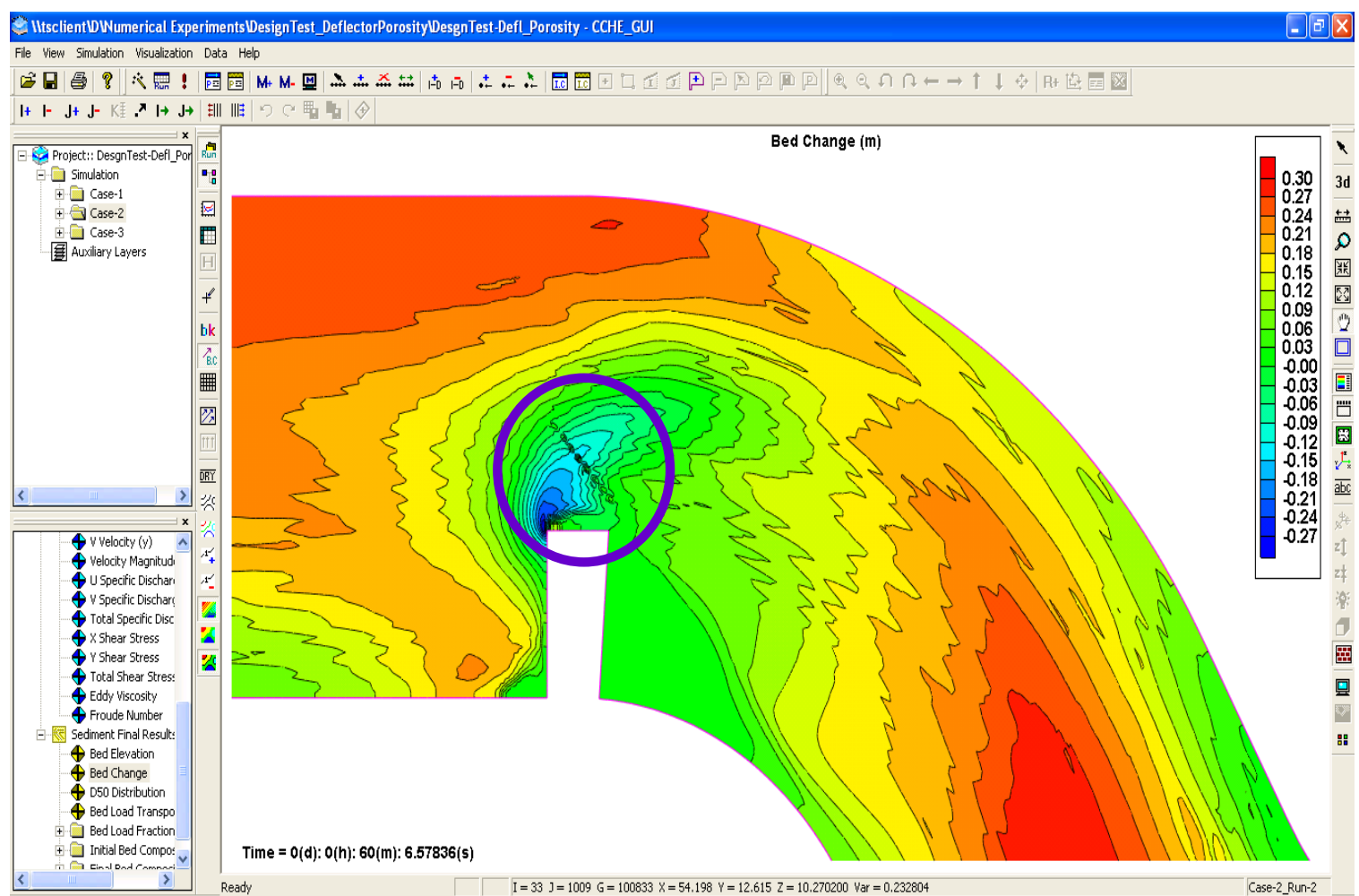

Figure T-144: Bed change for solid deflector scenario at meander \#5 after 1-hr simulation.

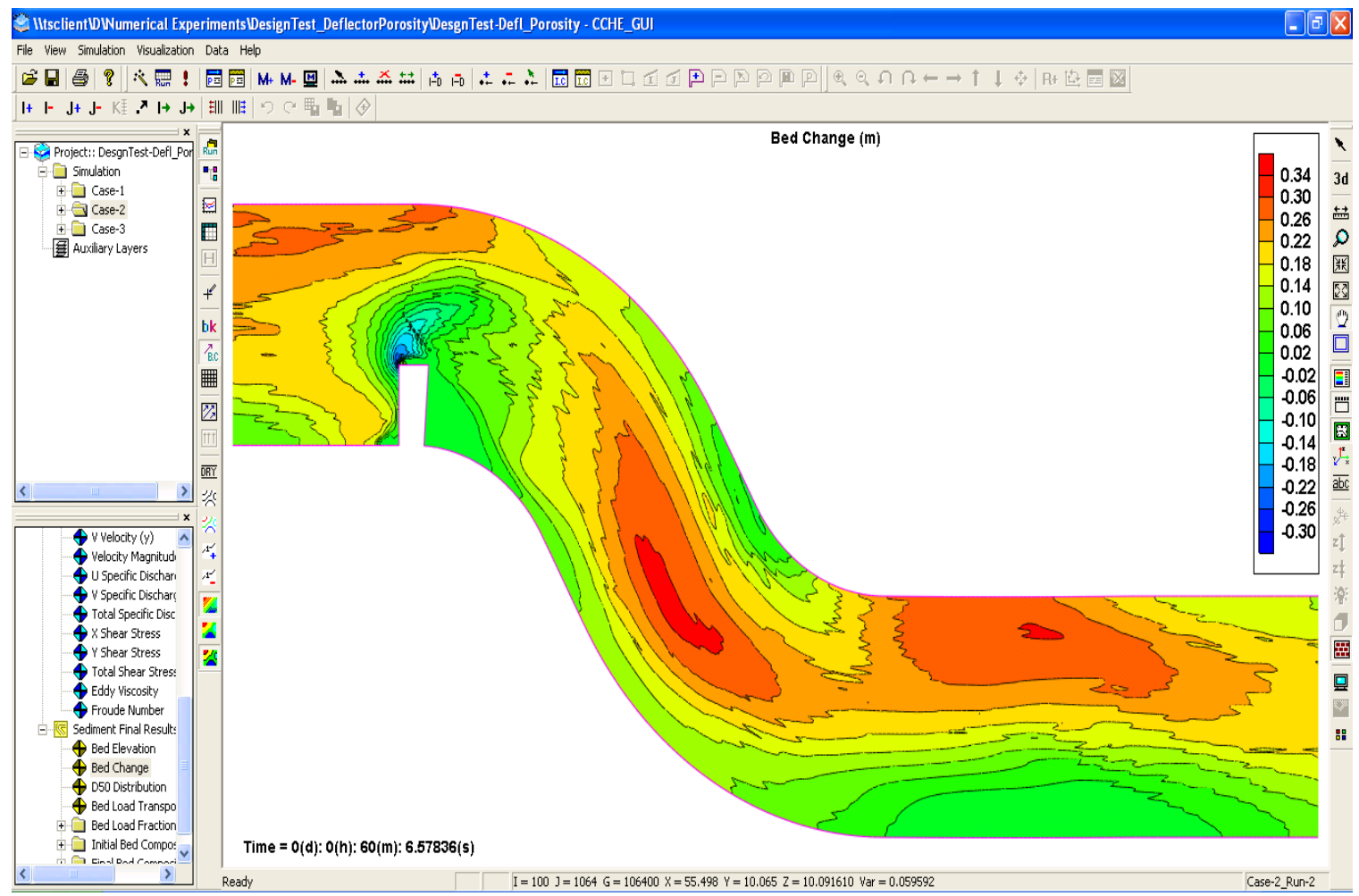

Figure T-145: Bed change for solid deflector scenario between meanders \#5 and \#6 after 1-hr simulation. 


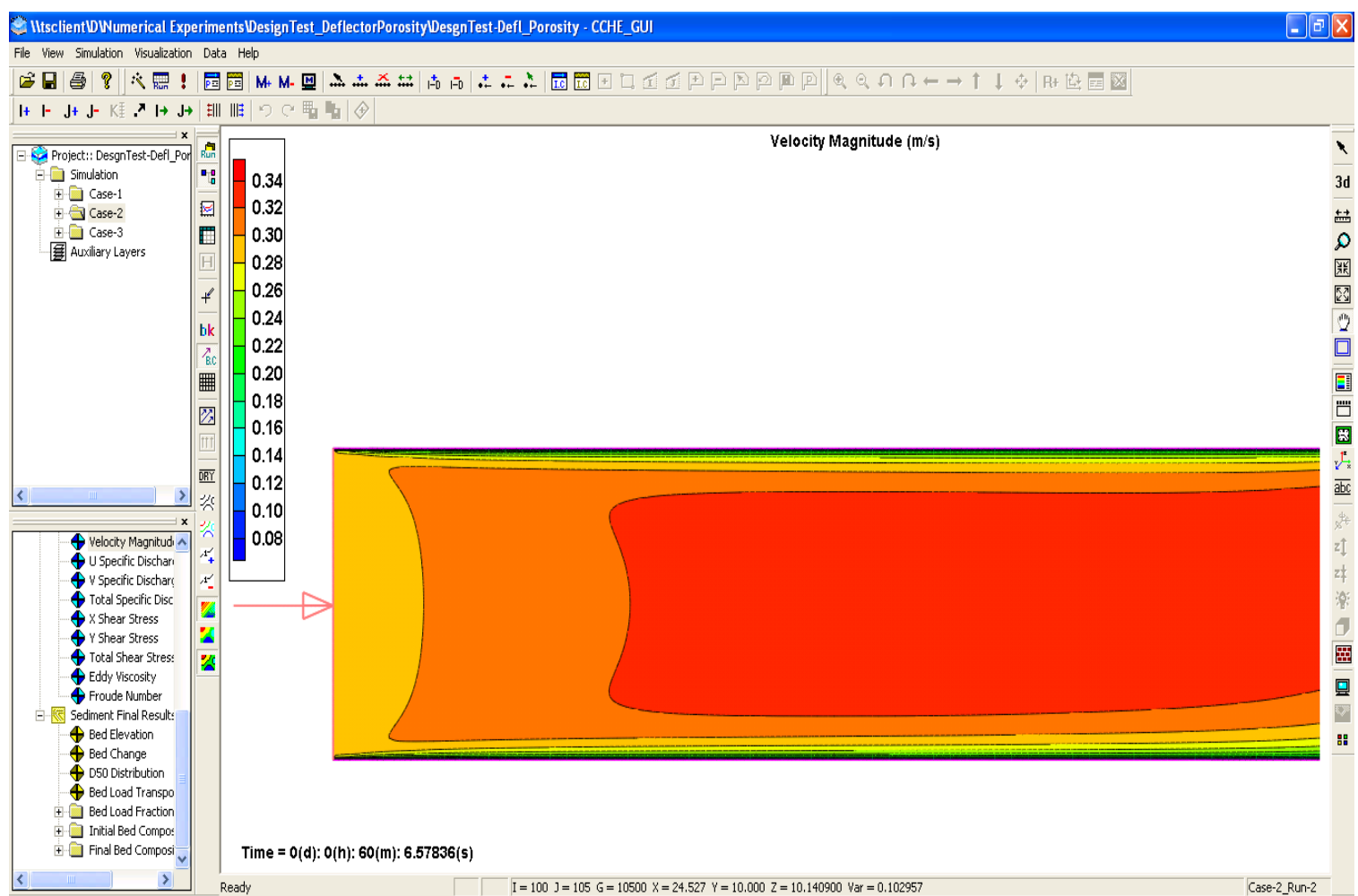

Figure T-146: Velocity magnitude for solid deflector scenario at upstream boundary after 1-hr simulation.

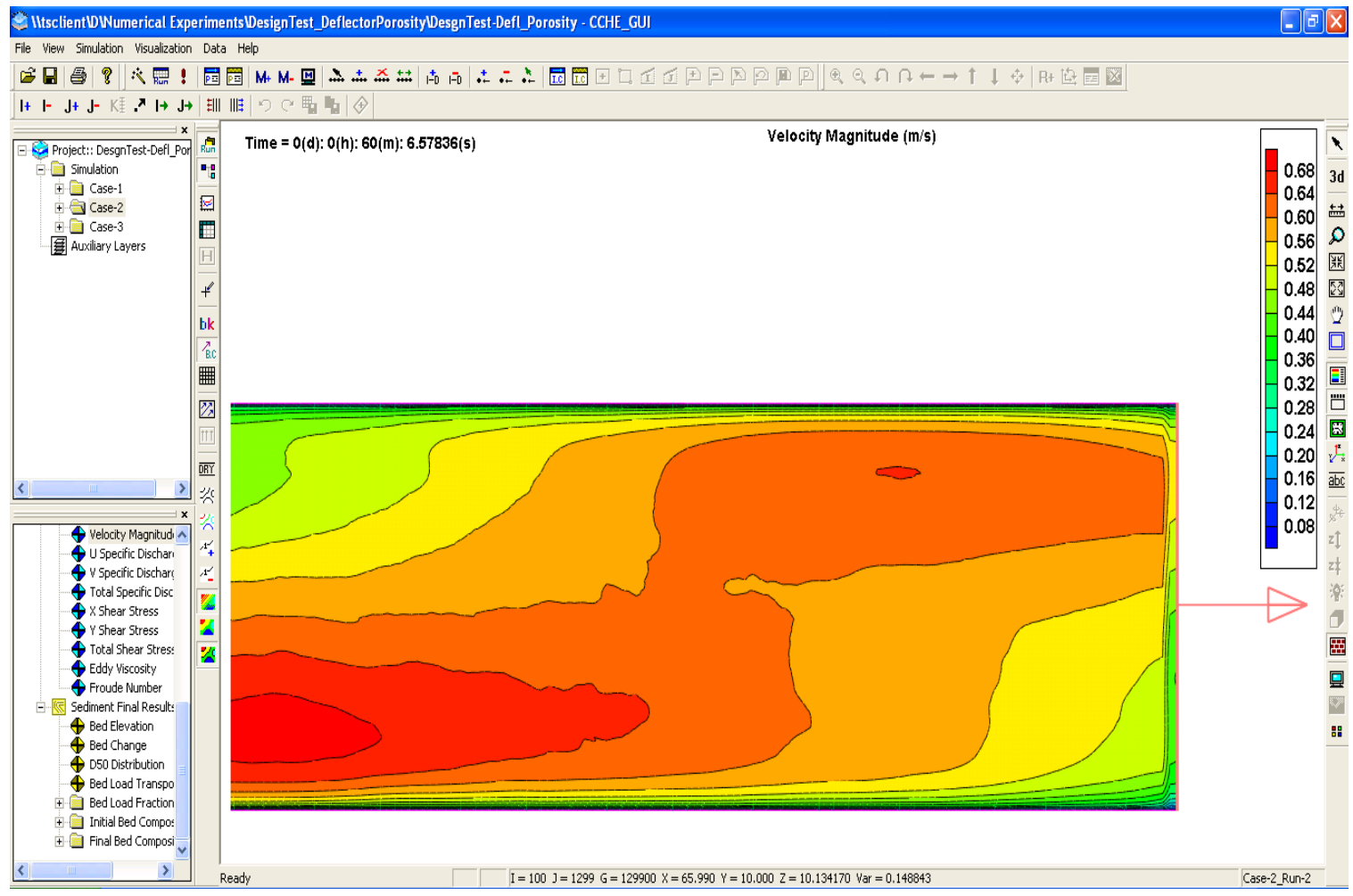

Figure T-147: Velocity magnitude for solid deflector scenario at downstream boundary after 1 -hr simulation. 


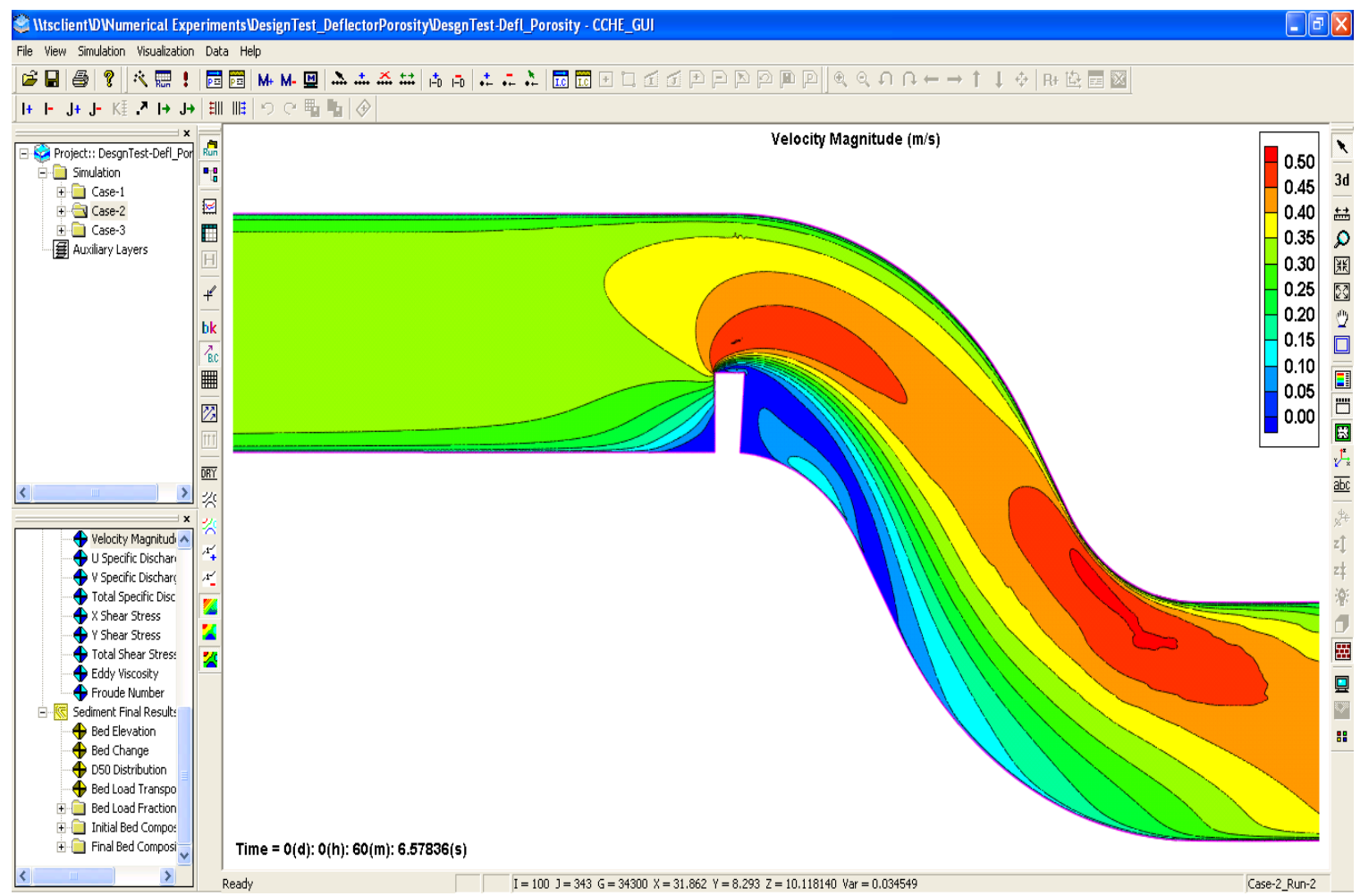

Figure T-148: Velocity magnitude for solid deflector scenario between meanders \#1 and \#2 after 1-hr simulation.

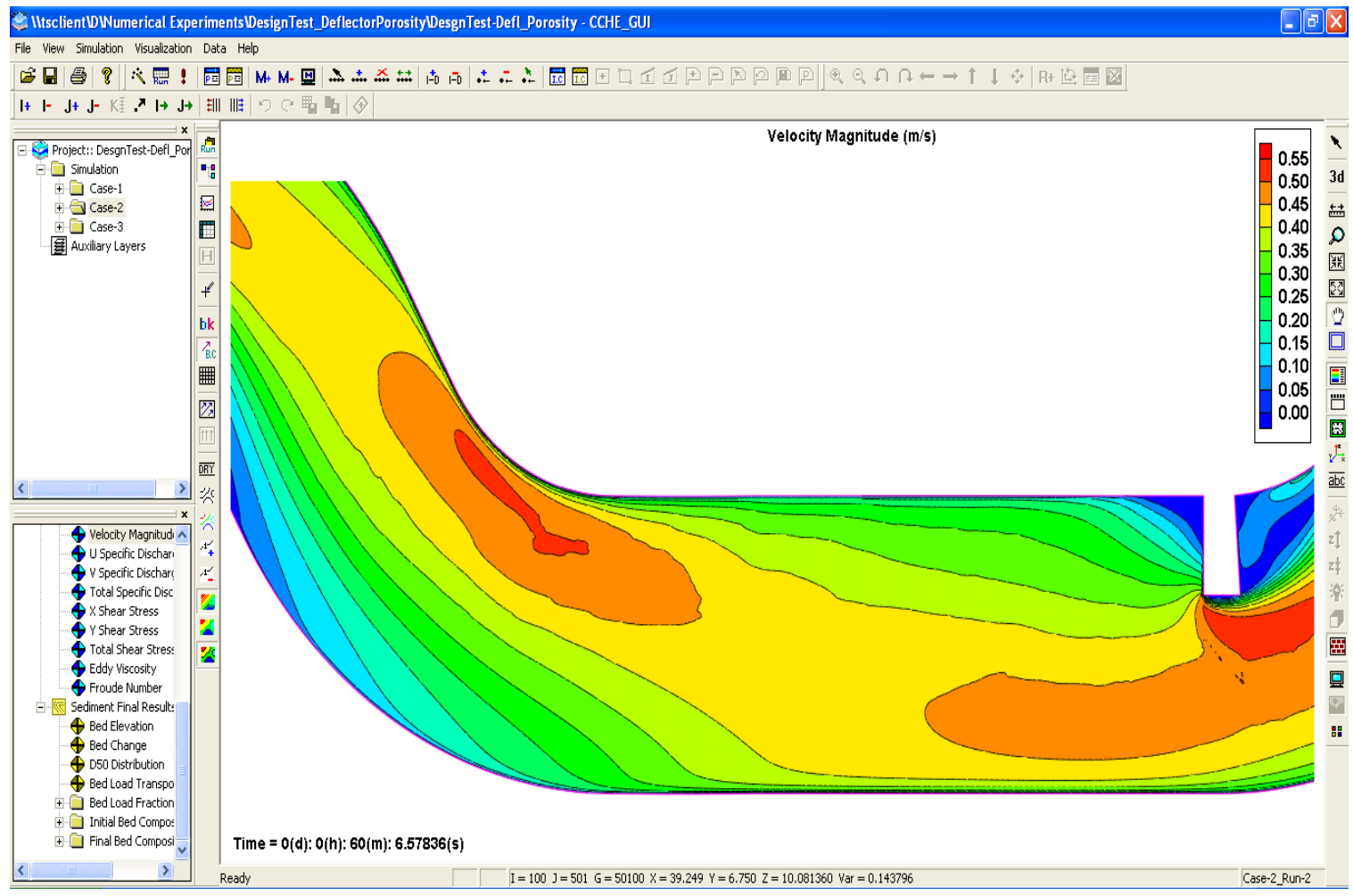

Figure T-149: Velocity magnitude for solid deflector scenario between meanders \#2 and \#3 after 1-hr simulation. 


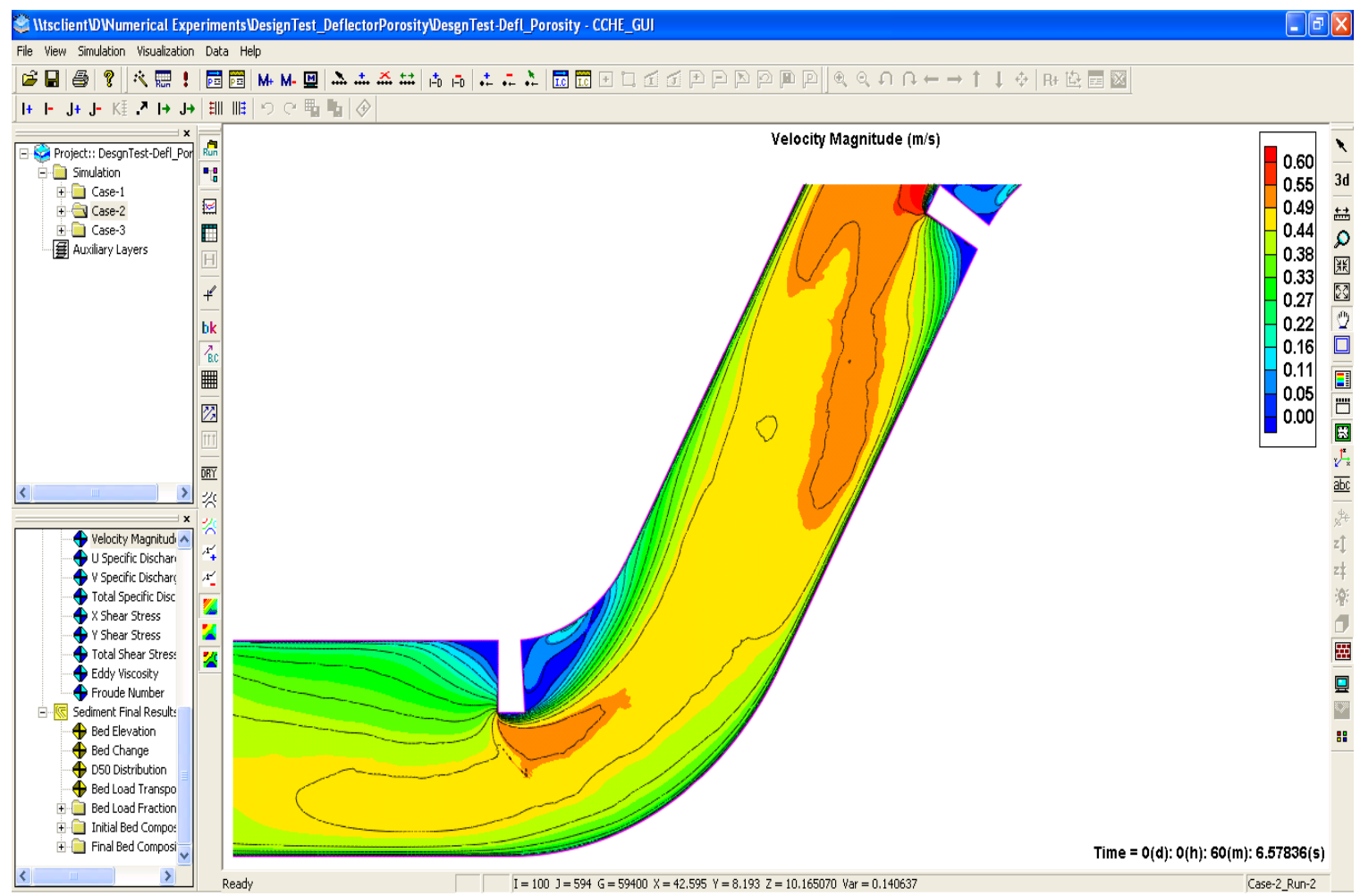

Figure T-150: Velocity magnitude for solid deflector scenario between meanders \#3 and \#4 after 1-hr simulation.

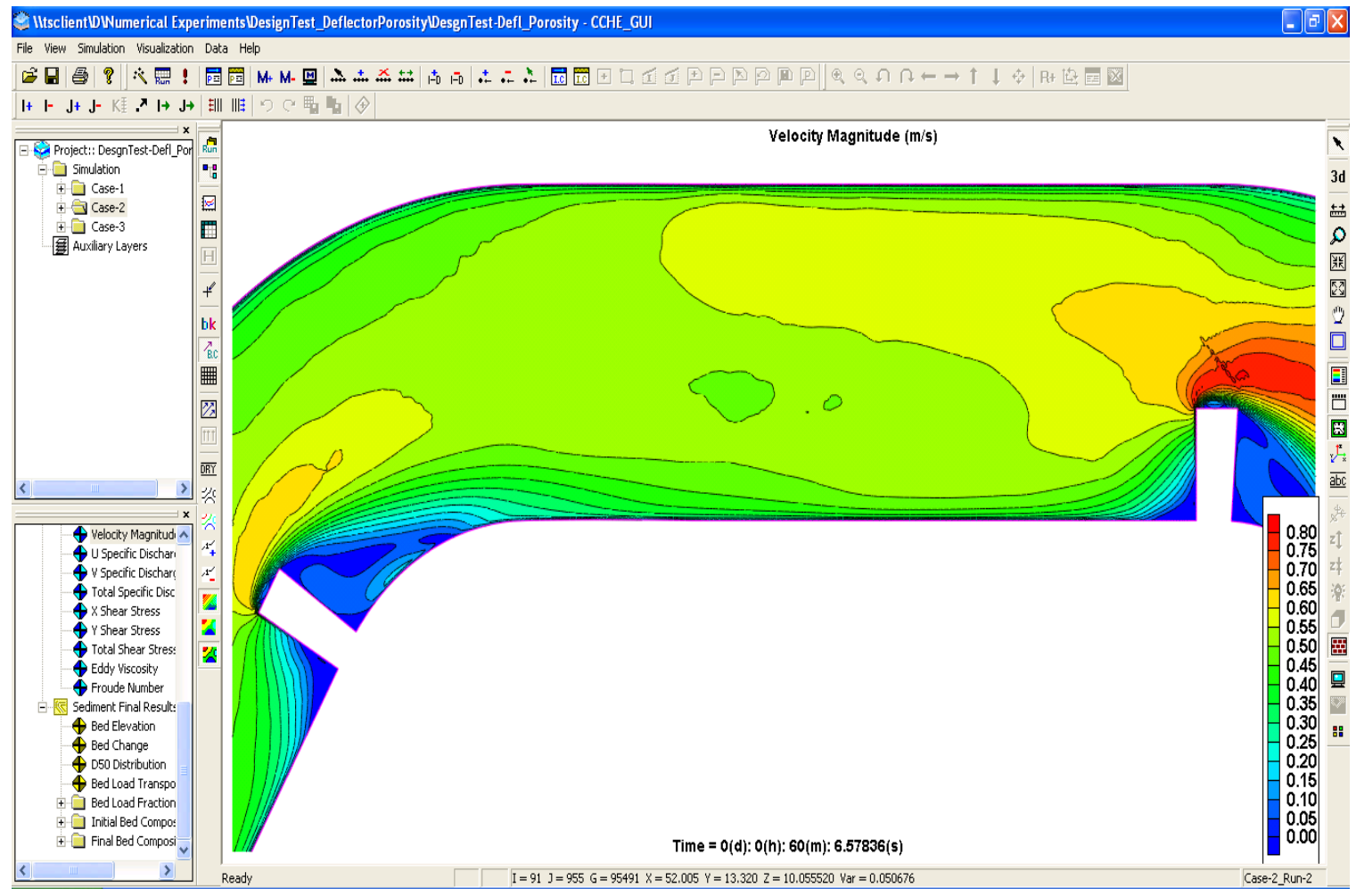

Figure T-151: Velocity magnitude for solid deflector scenario between meanders \#4 and \#5 after 1-hr simulation. 


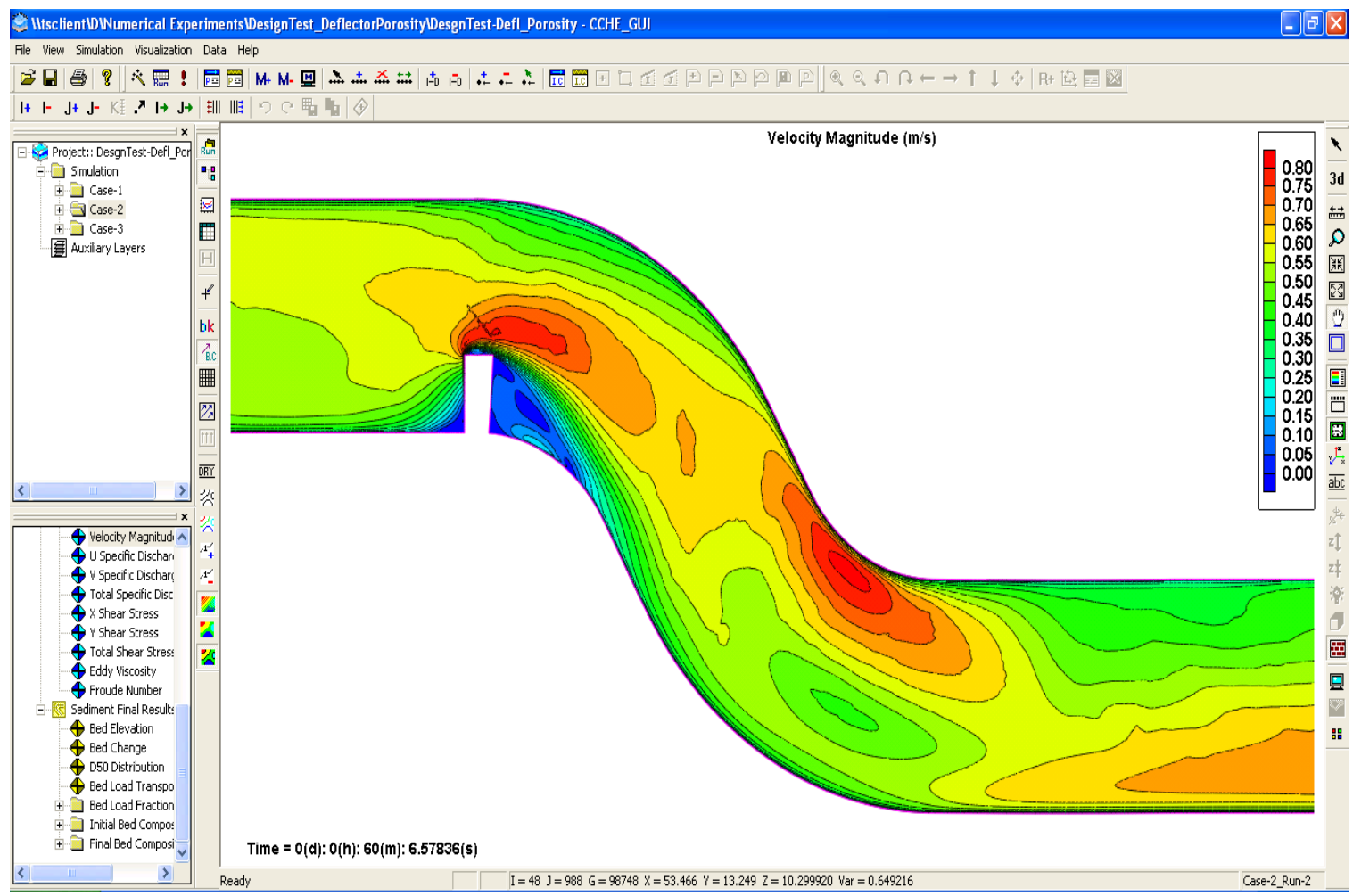

Figure T-152: Velocity magnitude for solid deflector scenario between meanders \#5 and \#6 after 1-hr simulation.

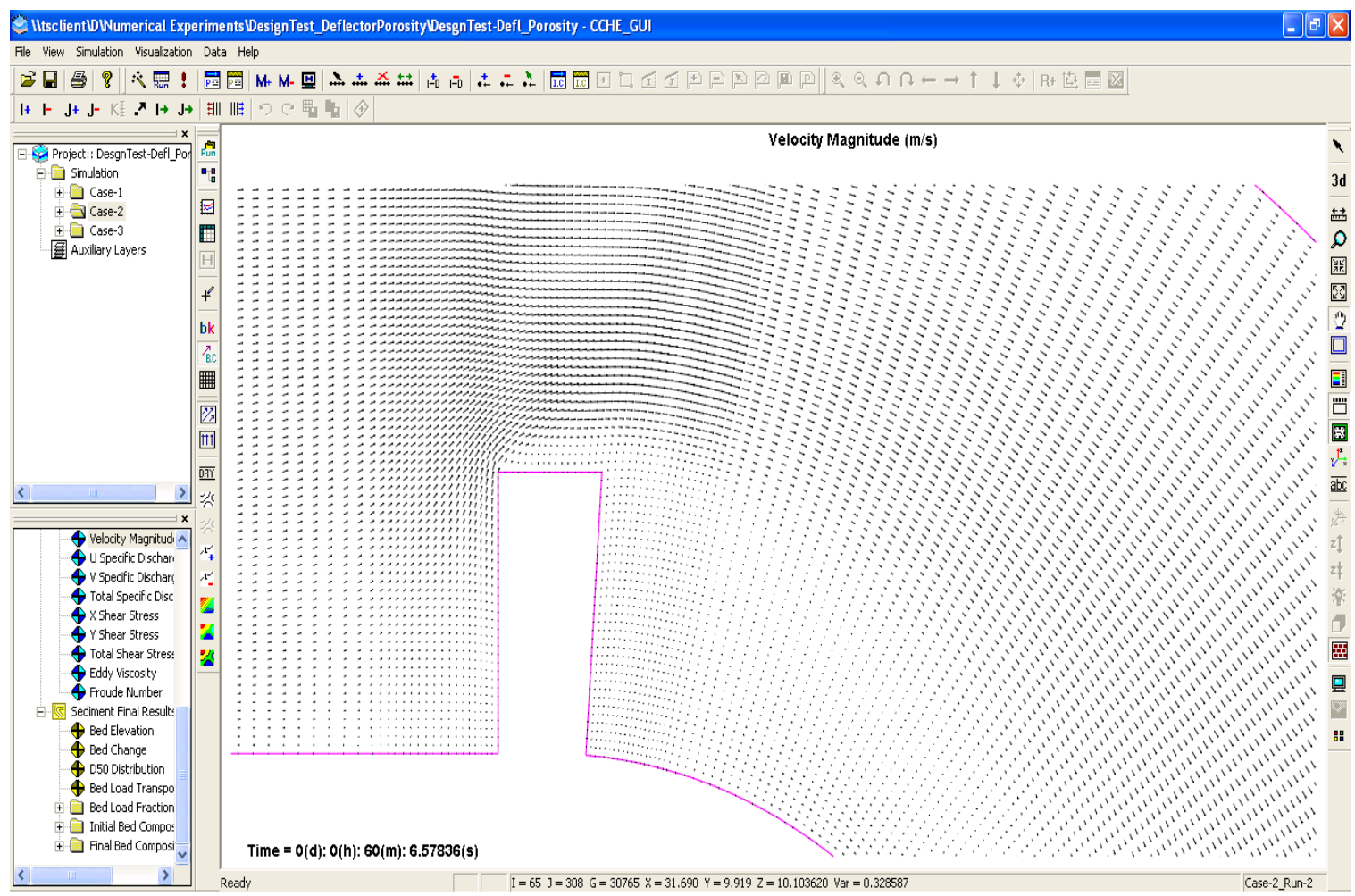

Figure T-153: Velocity direction for solid deflector scenario at meander \#1 after 1-hr simulation. 


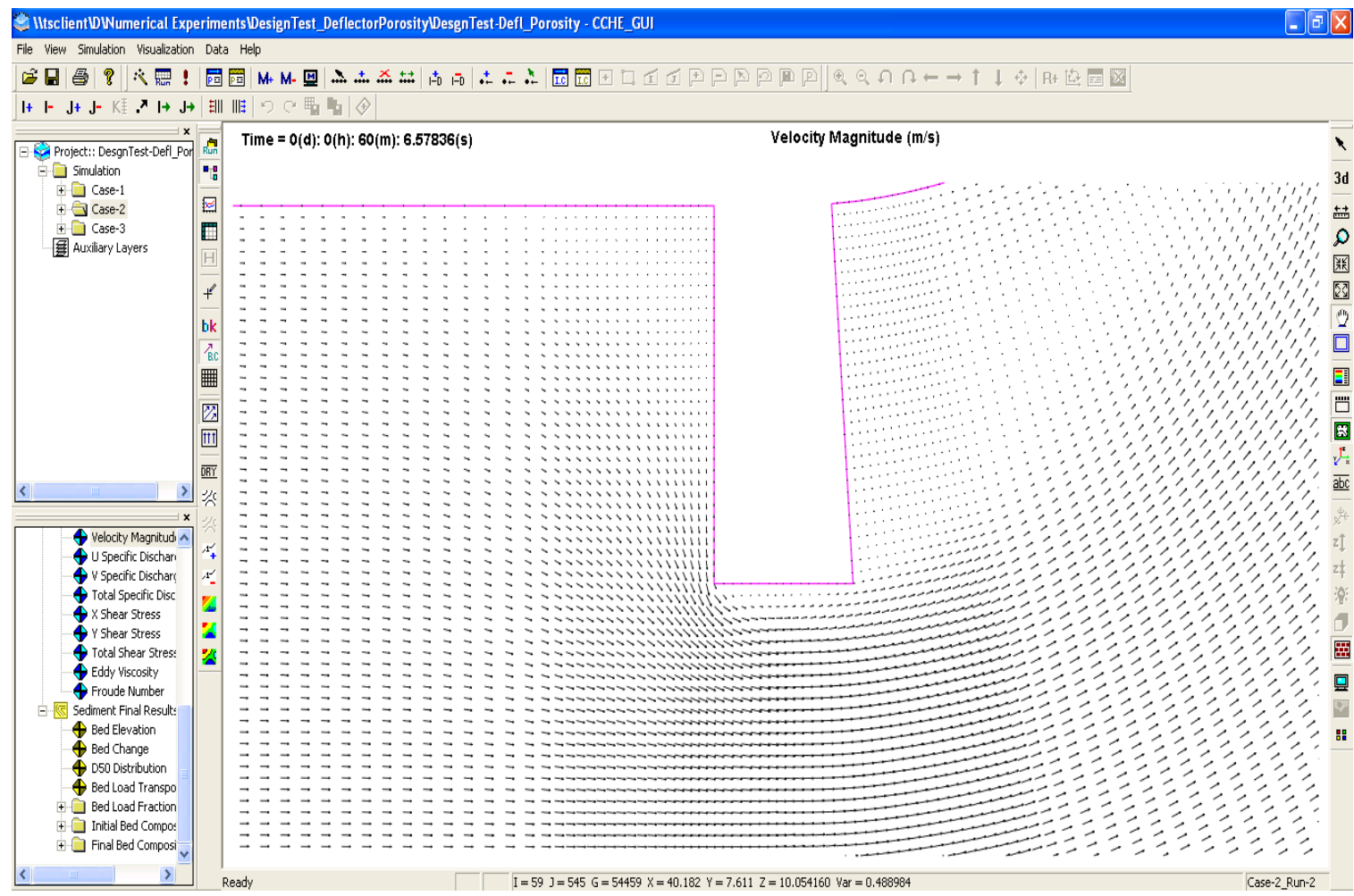

Figure T-154: Velocity direction for solid deflector scenario at meander \#3 after 1-hr simulation.

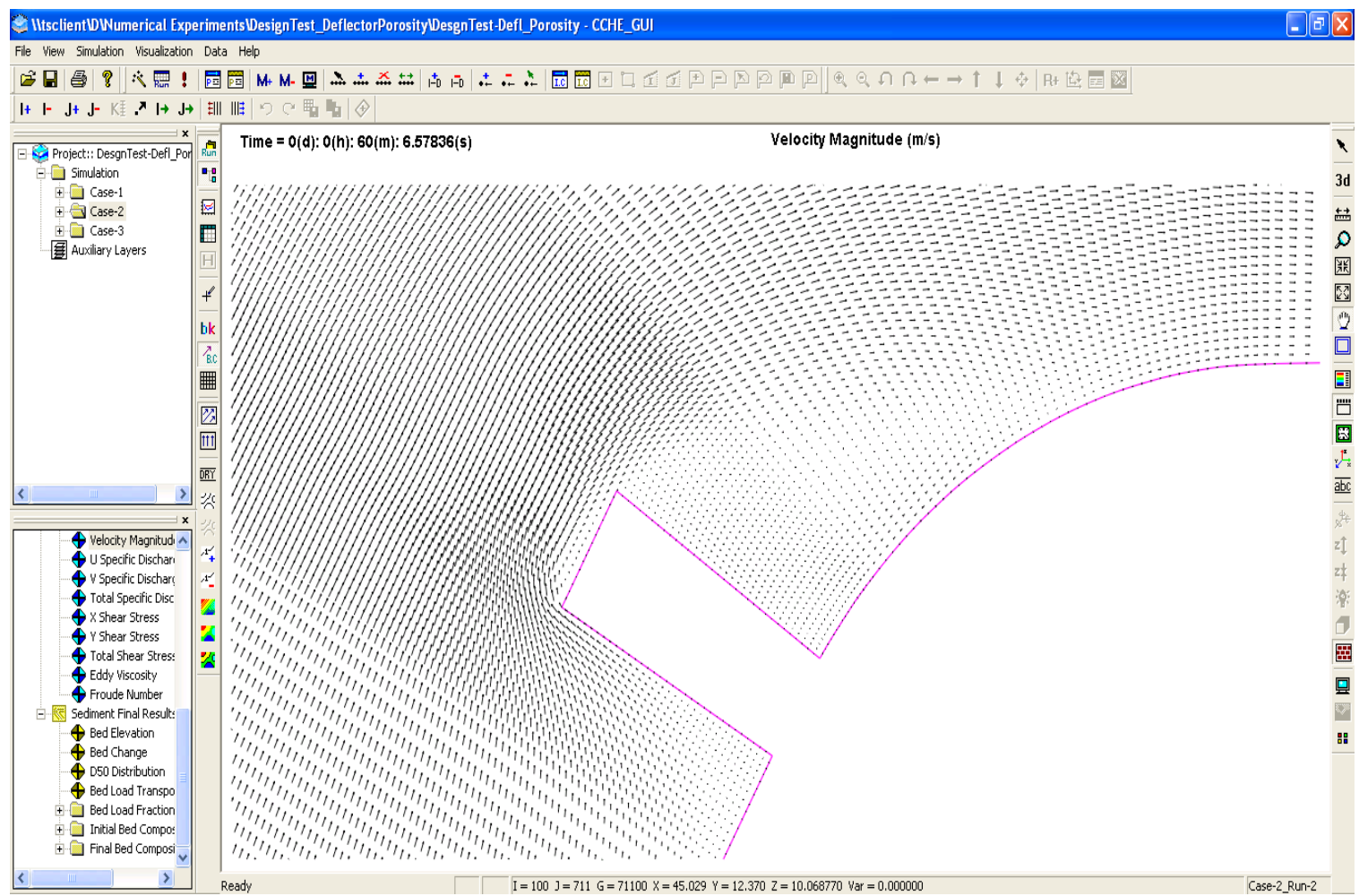

Figure T-155: Velocity direction for solid deflector scenario at meander \#4 after 1-hr simulation. 


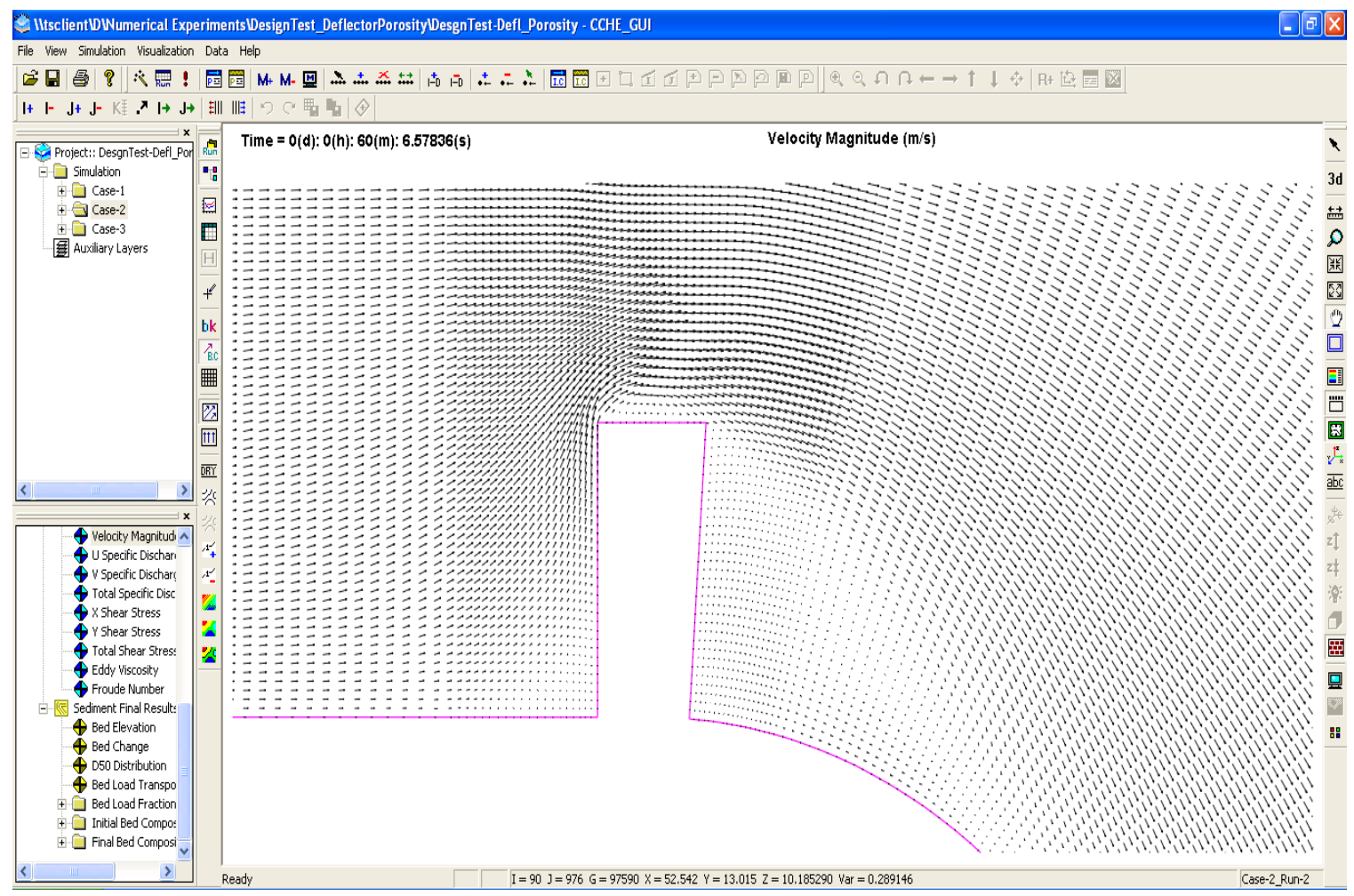

Figure T-156: Velocity direction for solid deflector scenario at meander \#5 after 1-hr simulation. 


\section{Doubling the Size (i.e. $D_{50}$ ) of the Bed Material}

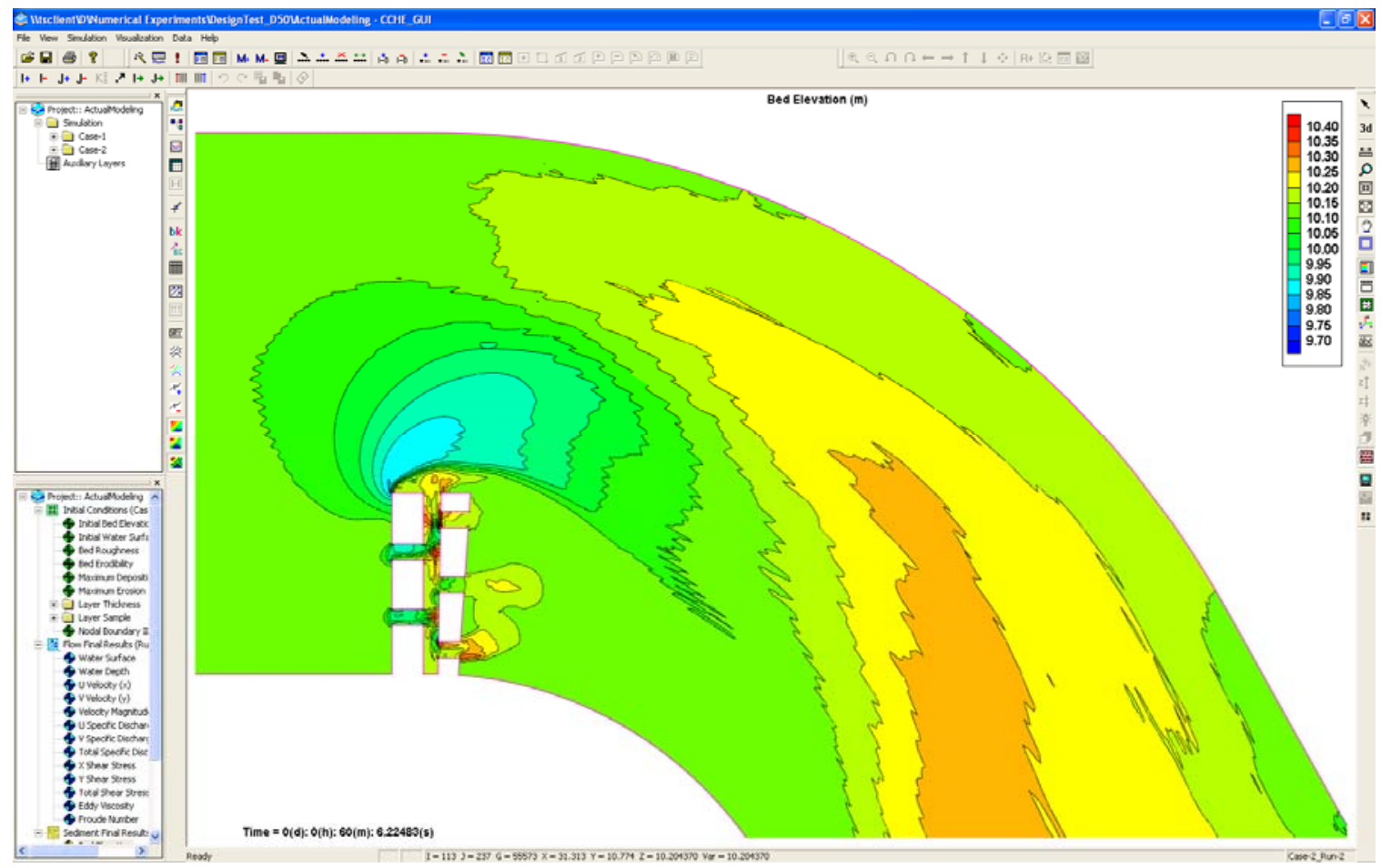

Figure T-157: Bed elevation for doubling the size of bed material scenario at meander \#1 after 1-hr simulation.

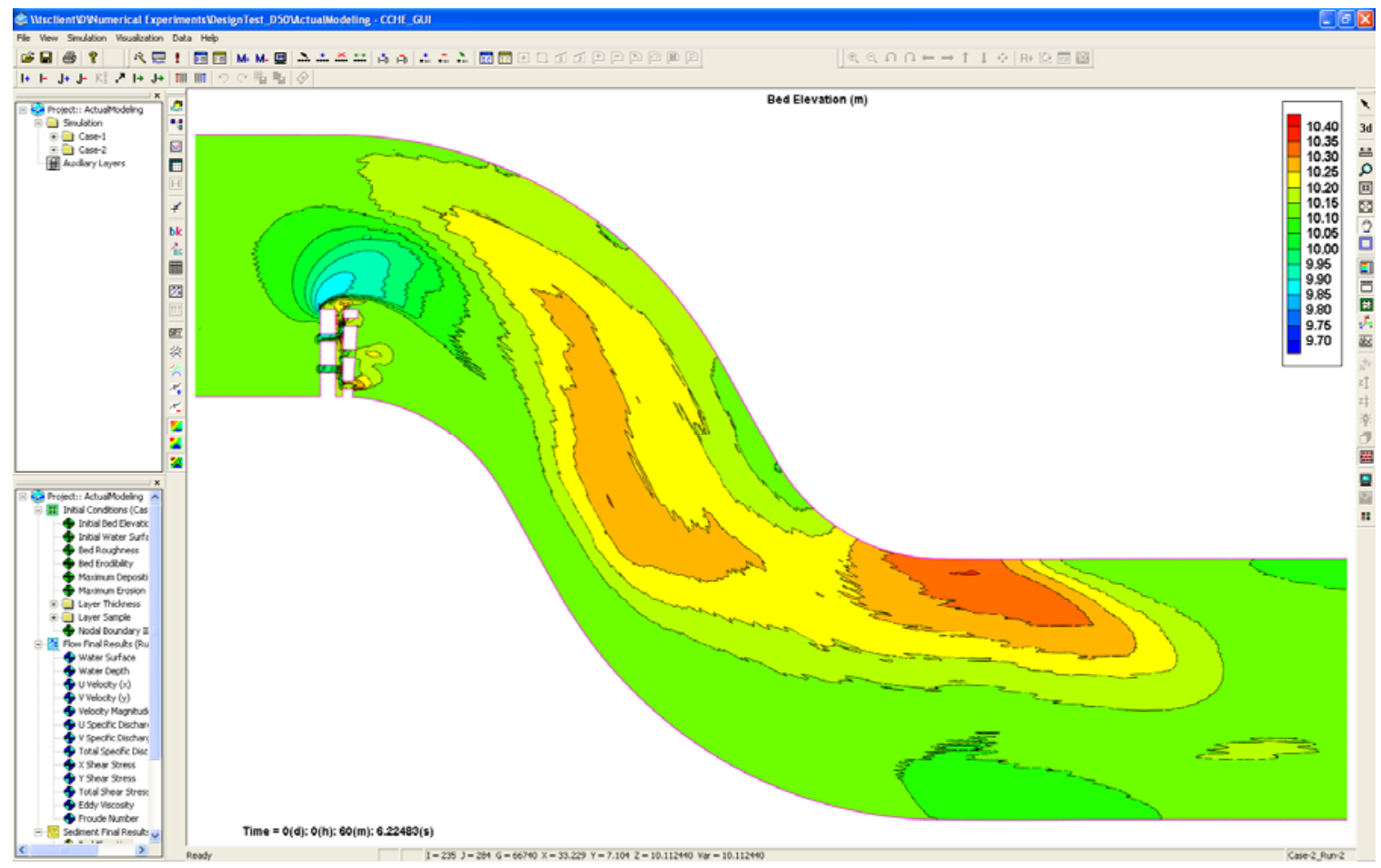

Figure T-158: Bed elevation for doubling the size of bed material scenario between meanders \#1 and \#2 after 1-hr simulation. 


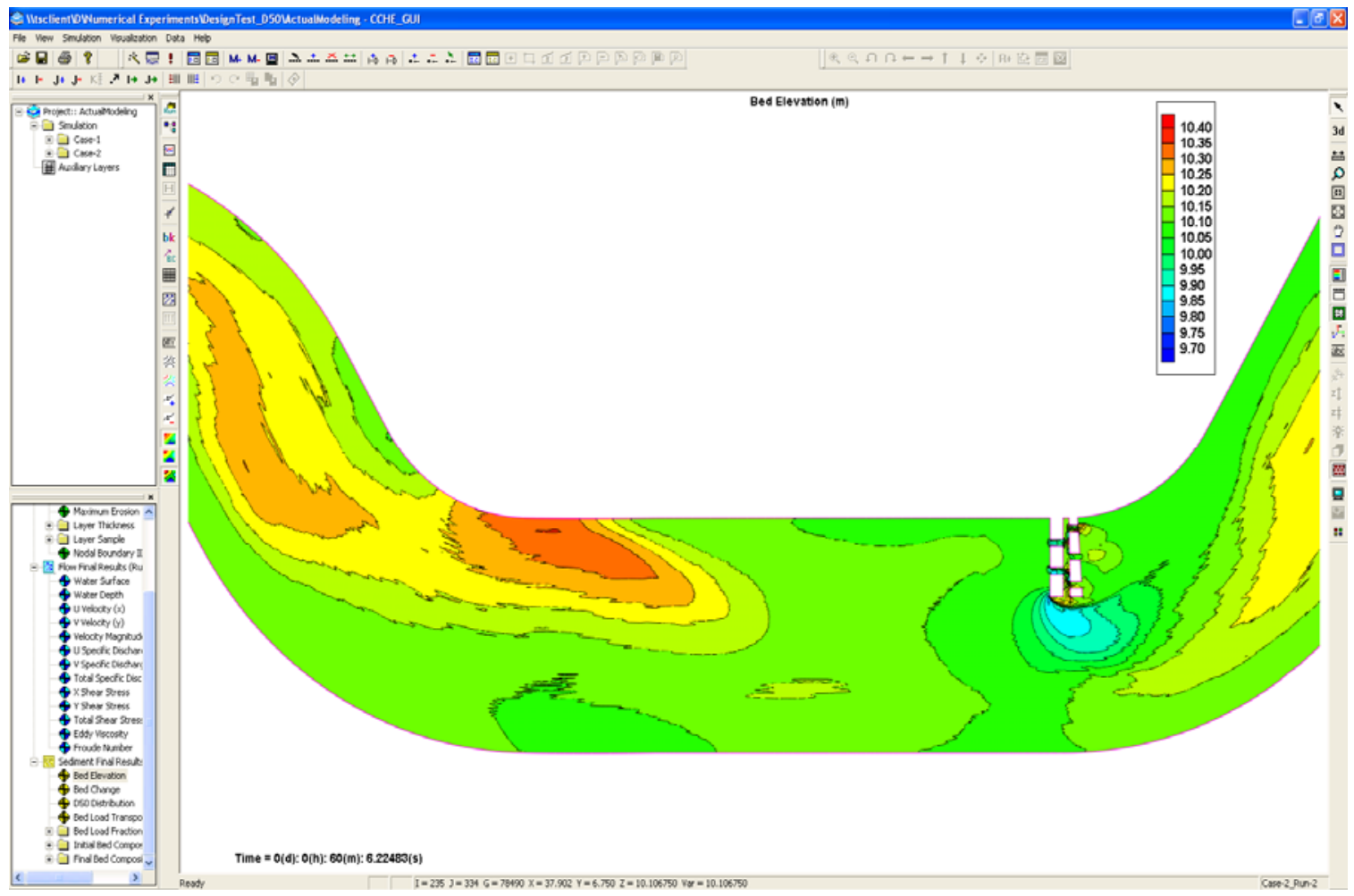

Figure T-159: Bed elevation for doubling the size of bed material scenario between meanders \#2 and \#3 after 1-hr simulation.

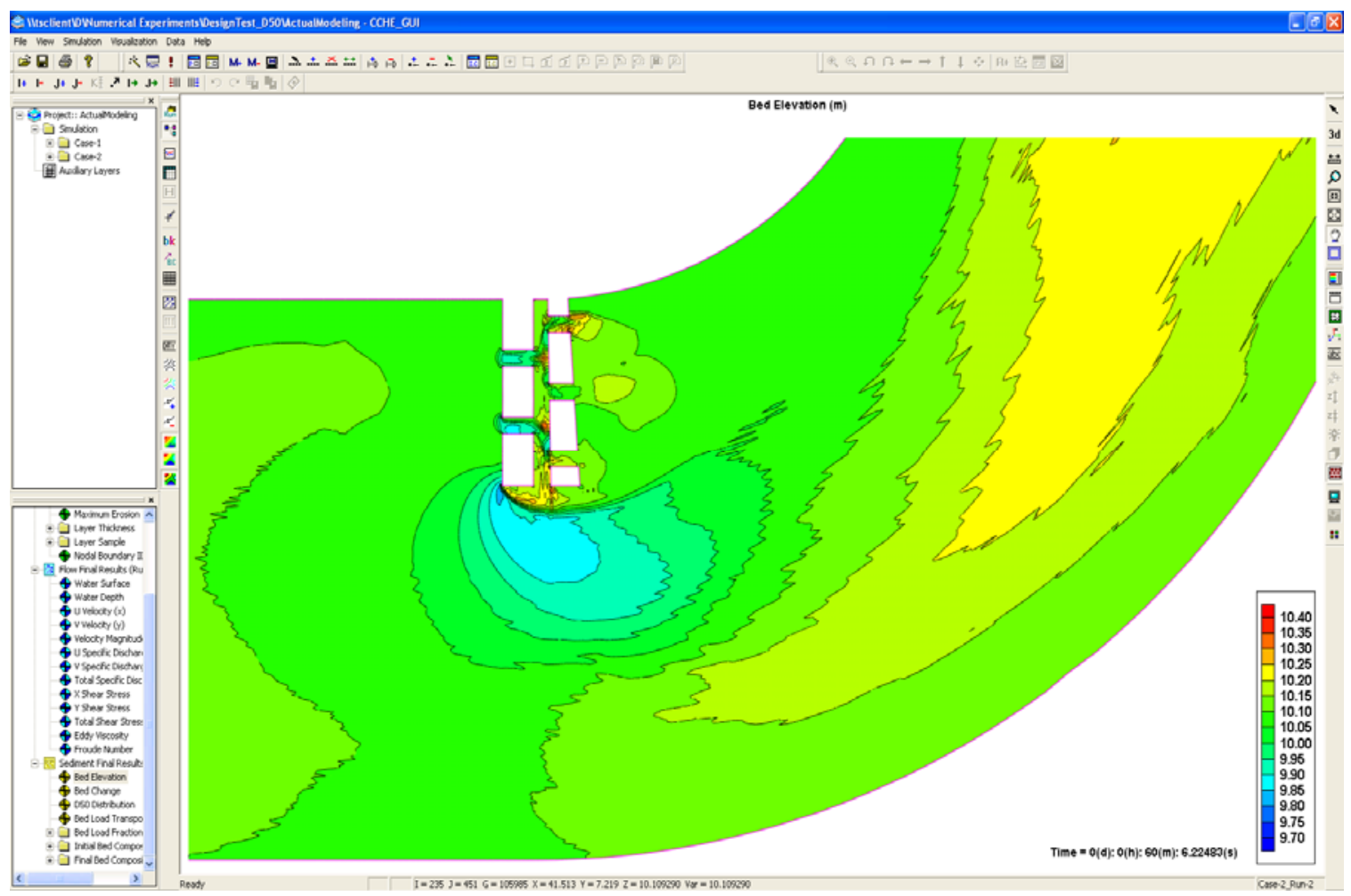

Figure T-160: Bed elevation for doubling the size of bed material scenario at meander \#3 after 1-hr simulation. 


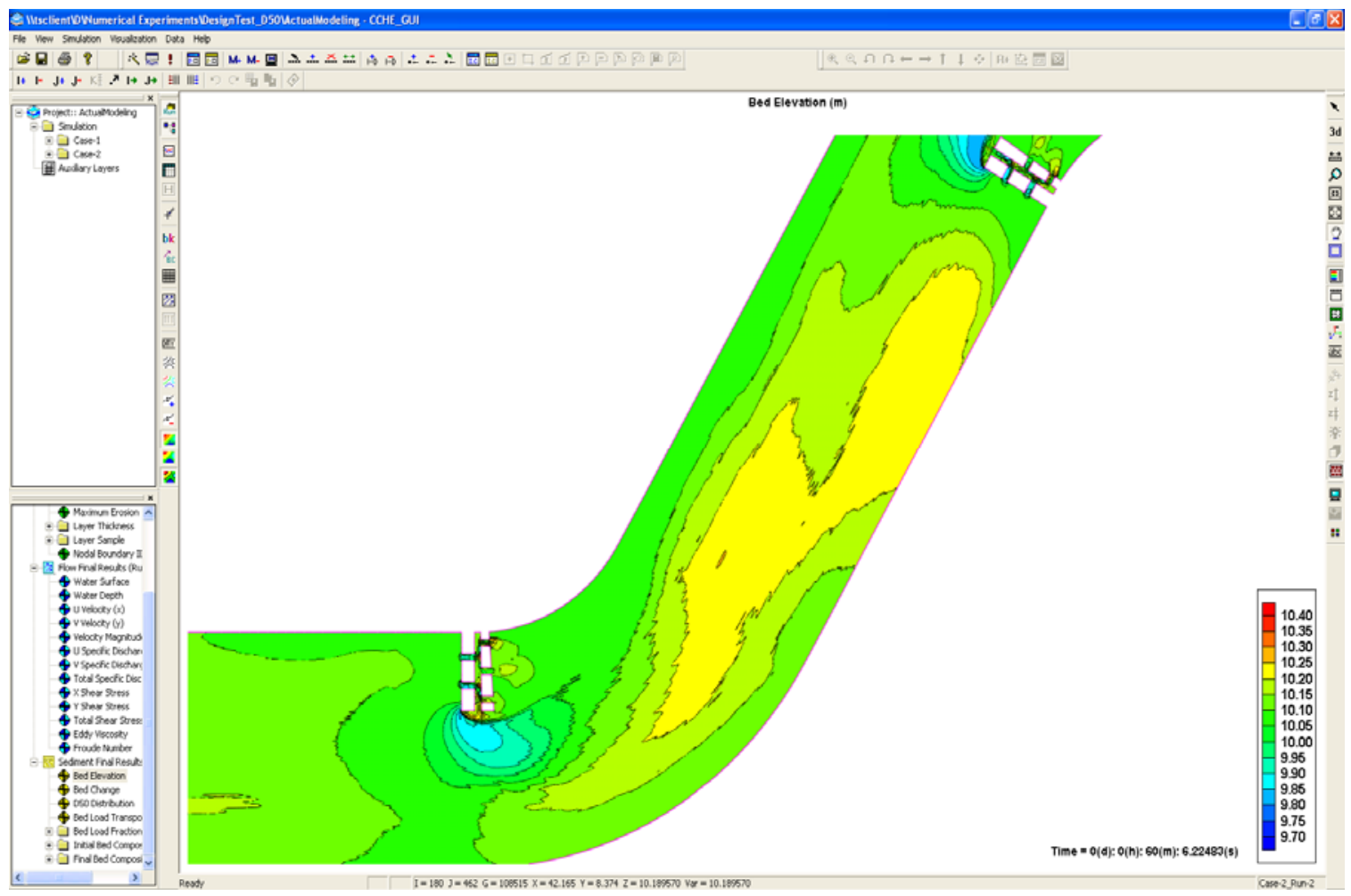

Figure T-161: Bed elevation for doubling the size of bed material scenario between meanders \#3 and \#4 after 1-hr simulation.

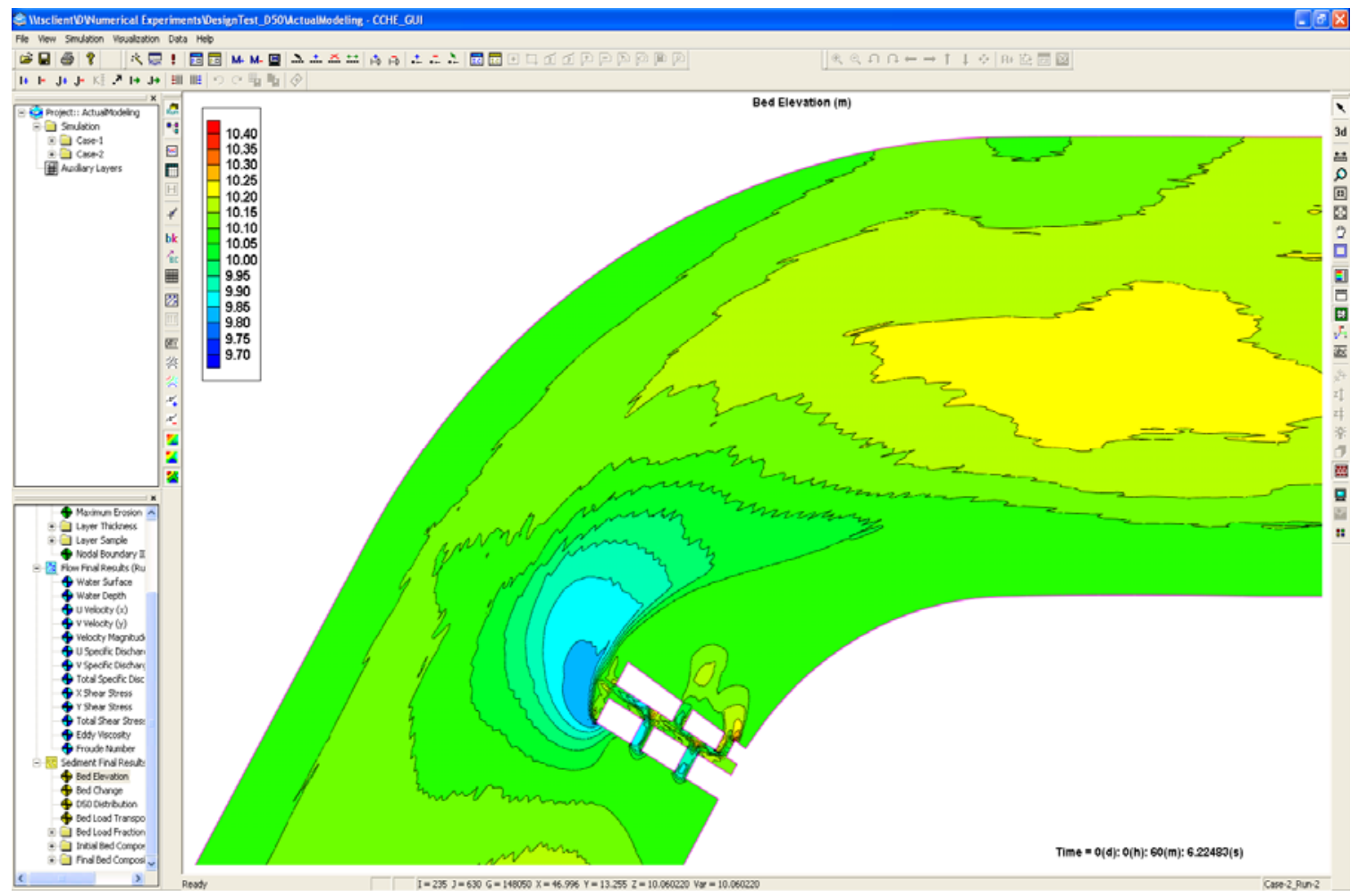

Figure T-162: Bed elevation for doubling the size of bed material scenario at meander \#4 after 1-hr simulation. 


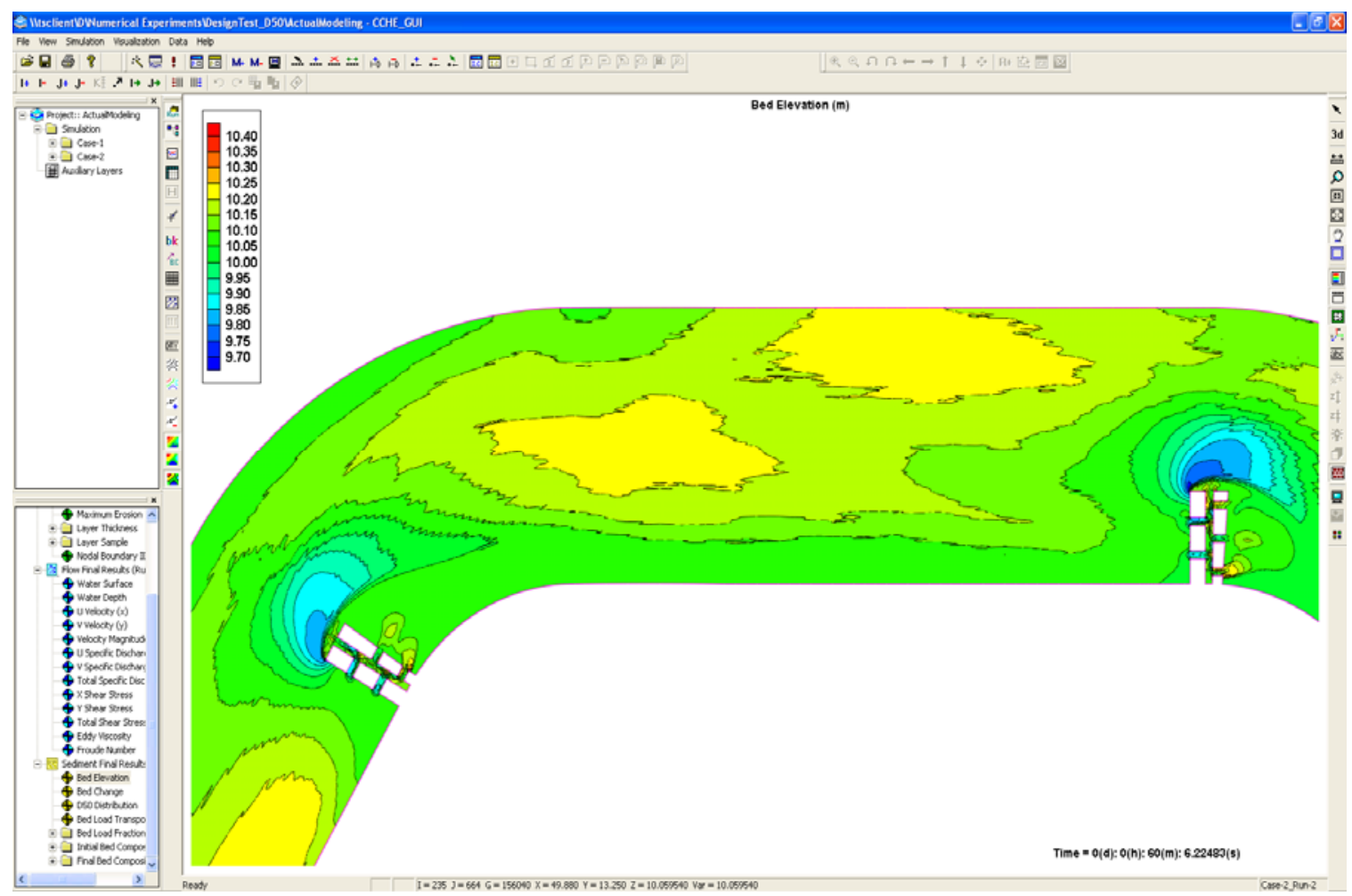

Figure T-163: Bed elevation for doubling the size of bed material scenario between meanders \#4 and \#5 after 1-hr simulation.

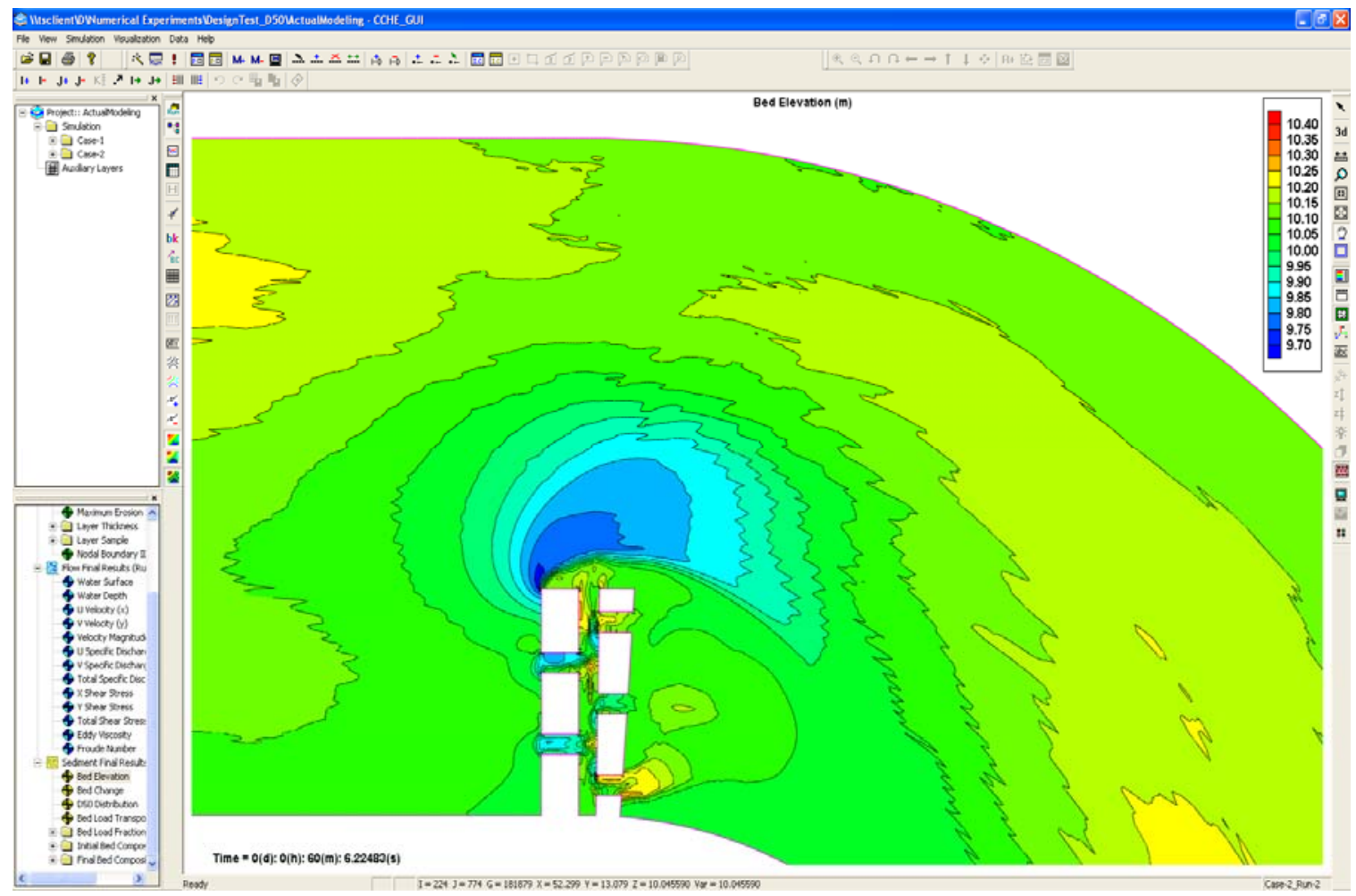

Figure T-164: Bed elevation for doubling the size of bed material scenario at meander \#5 after 1-hr simulation. 


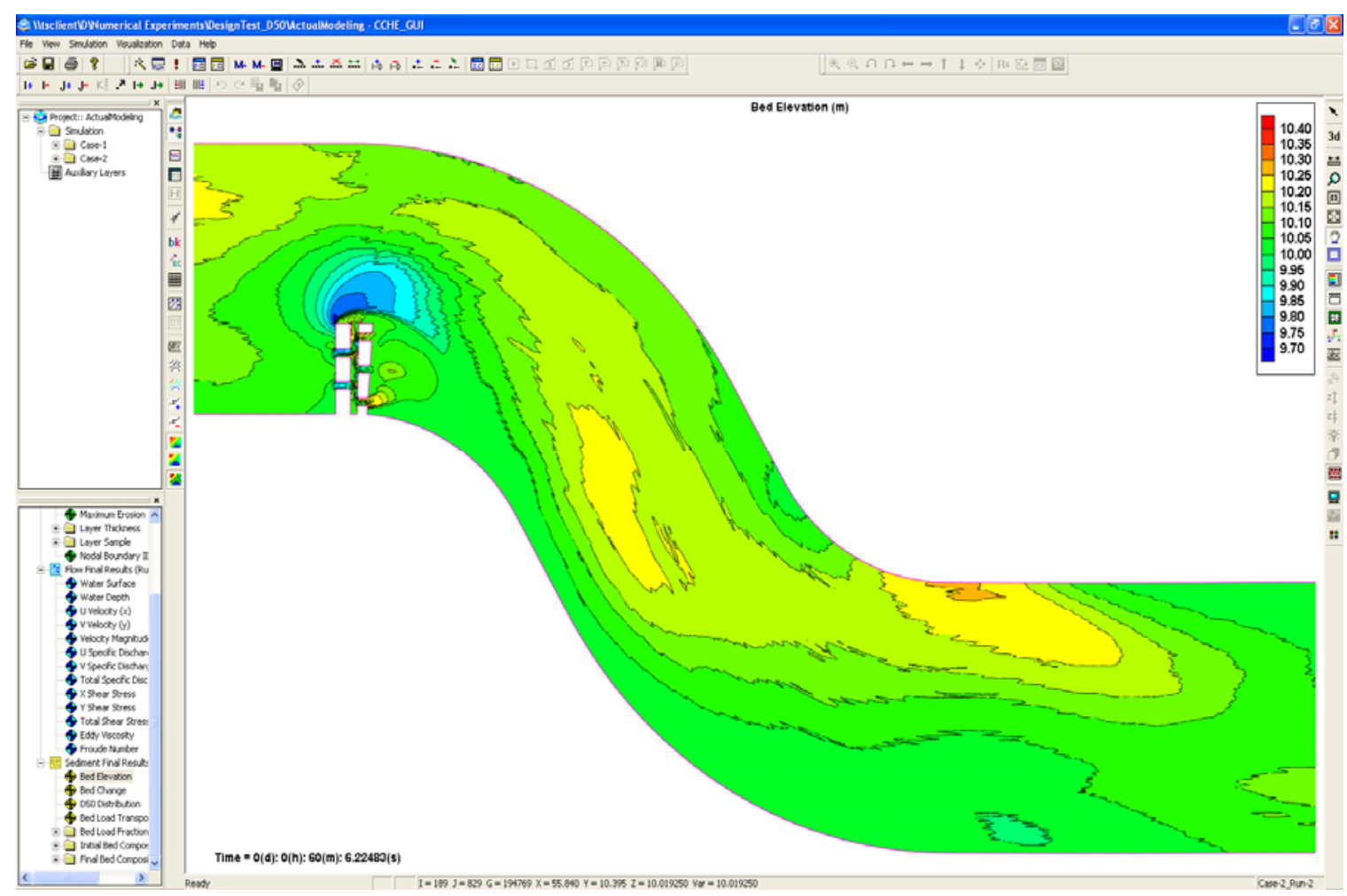

Figure T-165: Bed elevation for doubling the size of bed material scenario between meanders \#5 and \#6 after 1-hr simulation.

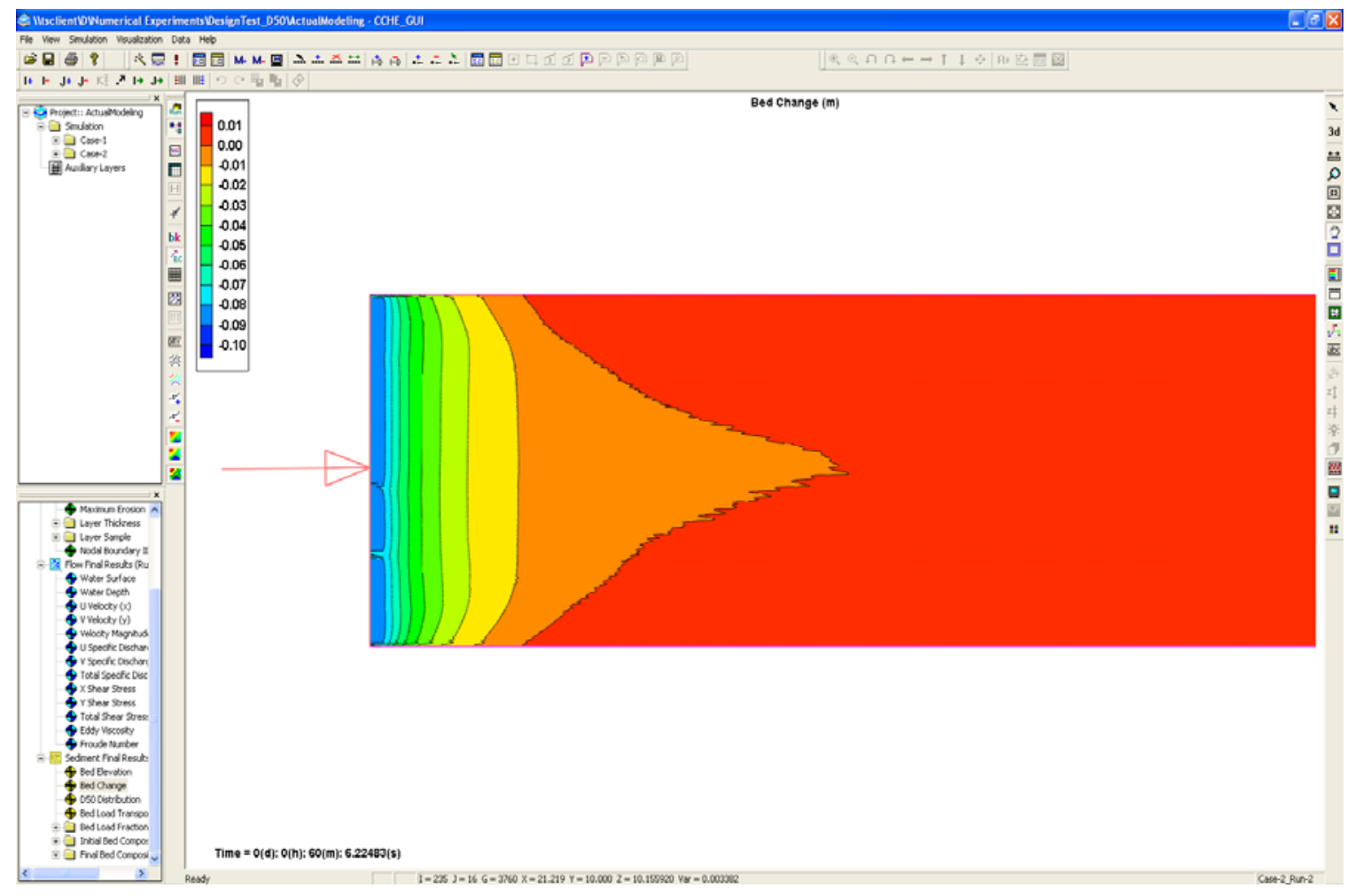

Figure T-166: Bed change for doubling the size of bed material scenario at upstream boundary after 1 -hr simulation. 


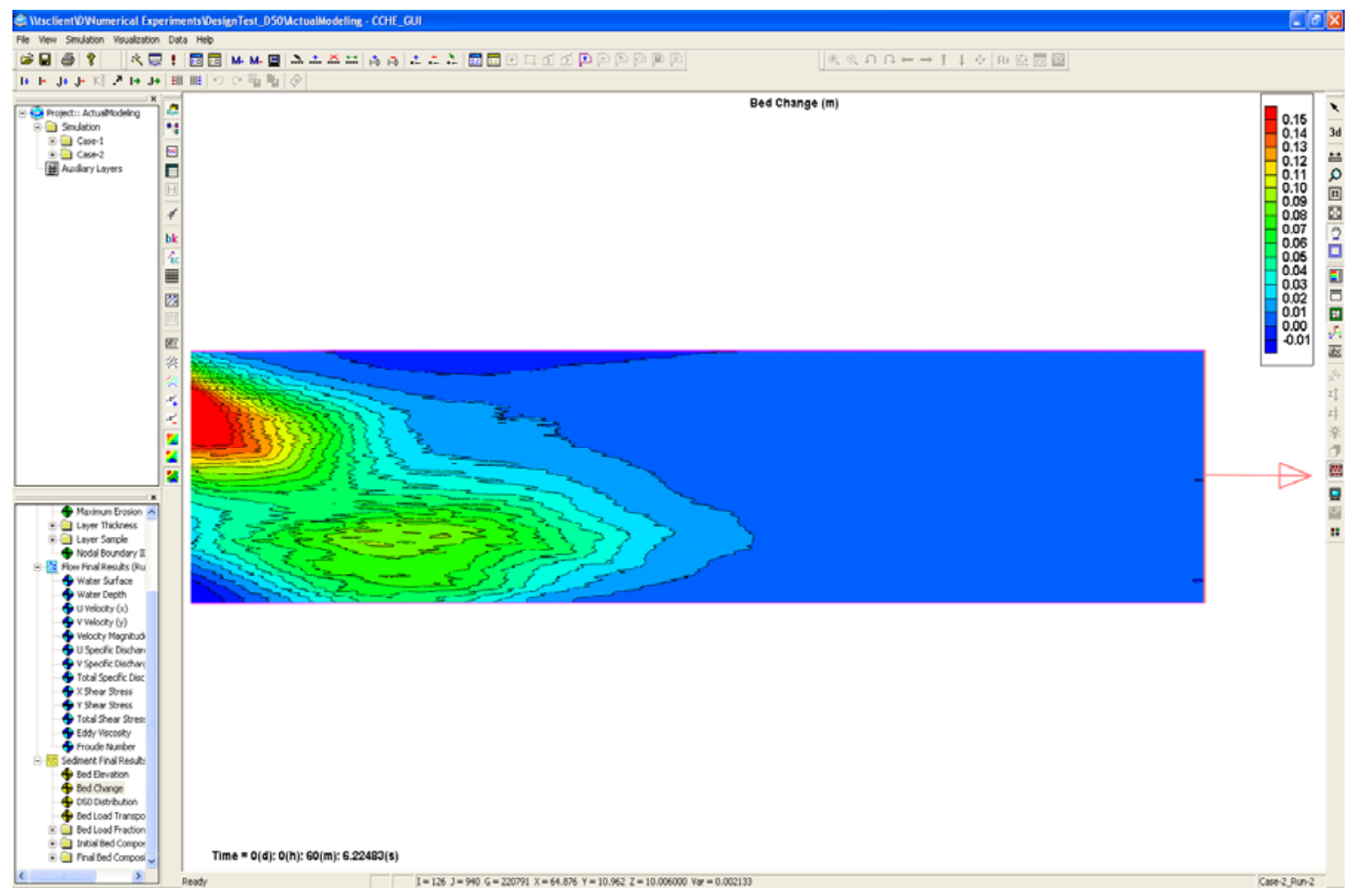

Figure T-167: Bed change for doubling the size of bed material scenario at downstream boundary after 1-hr simulation.

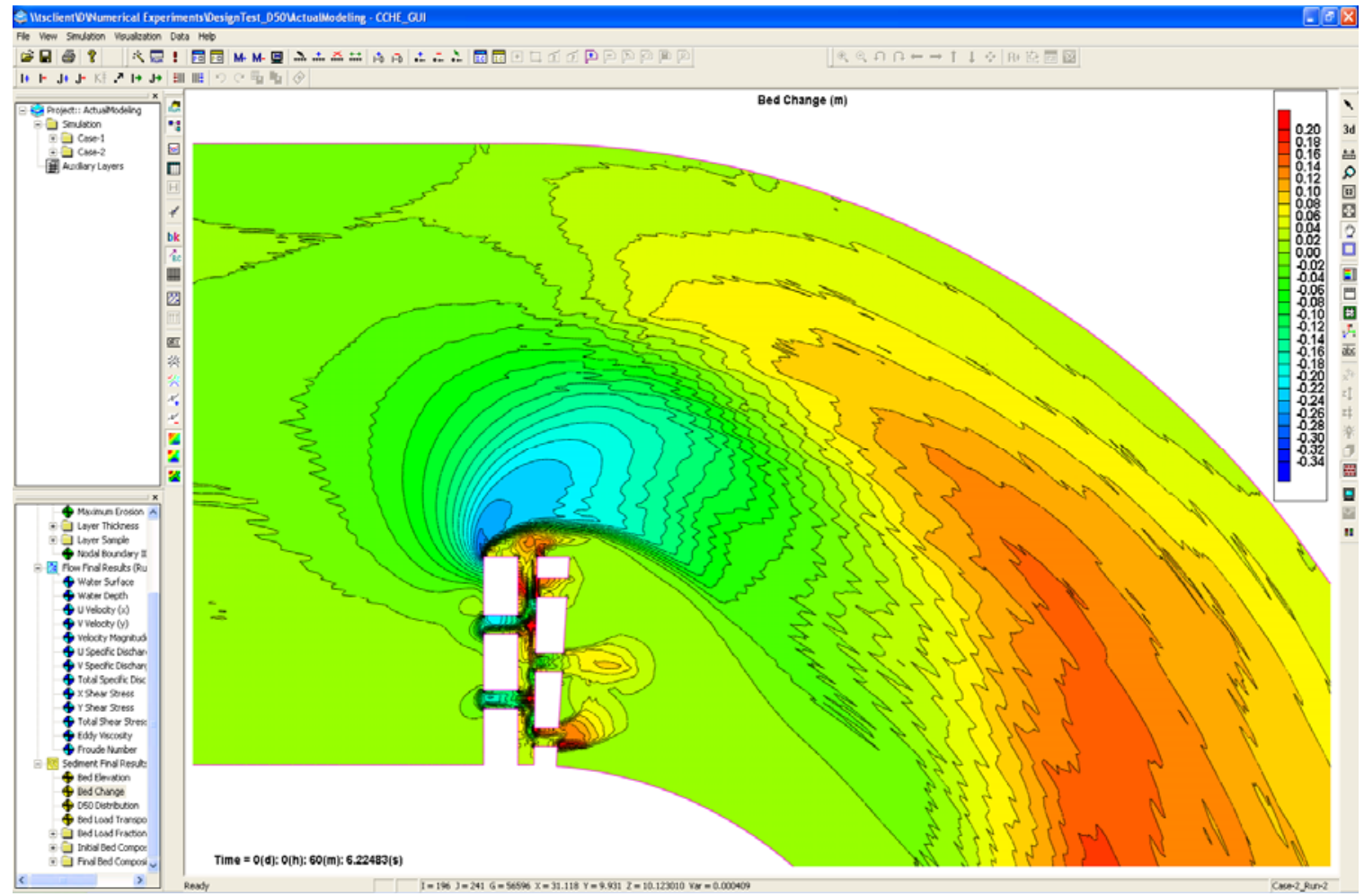

Figure T-168: Bed change for doubling the size of bed material scenario at meander \#1 after 1-hr simulation. 


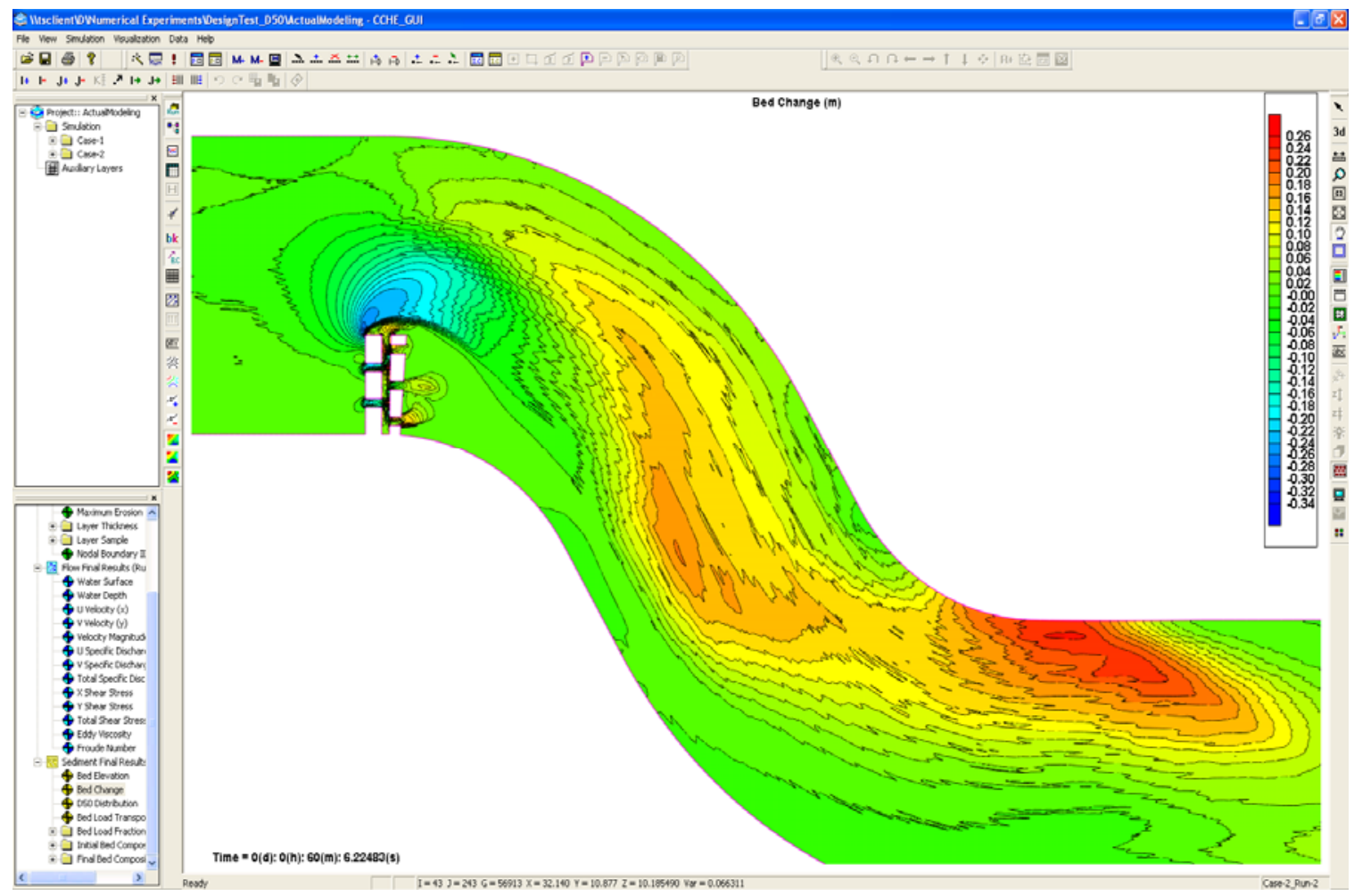

FigureT-169: Bed change for doubling the size of bed material scenario between meanders \#1 and \#2 after 1-hr simulation.

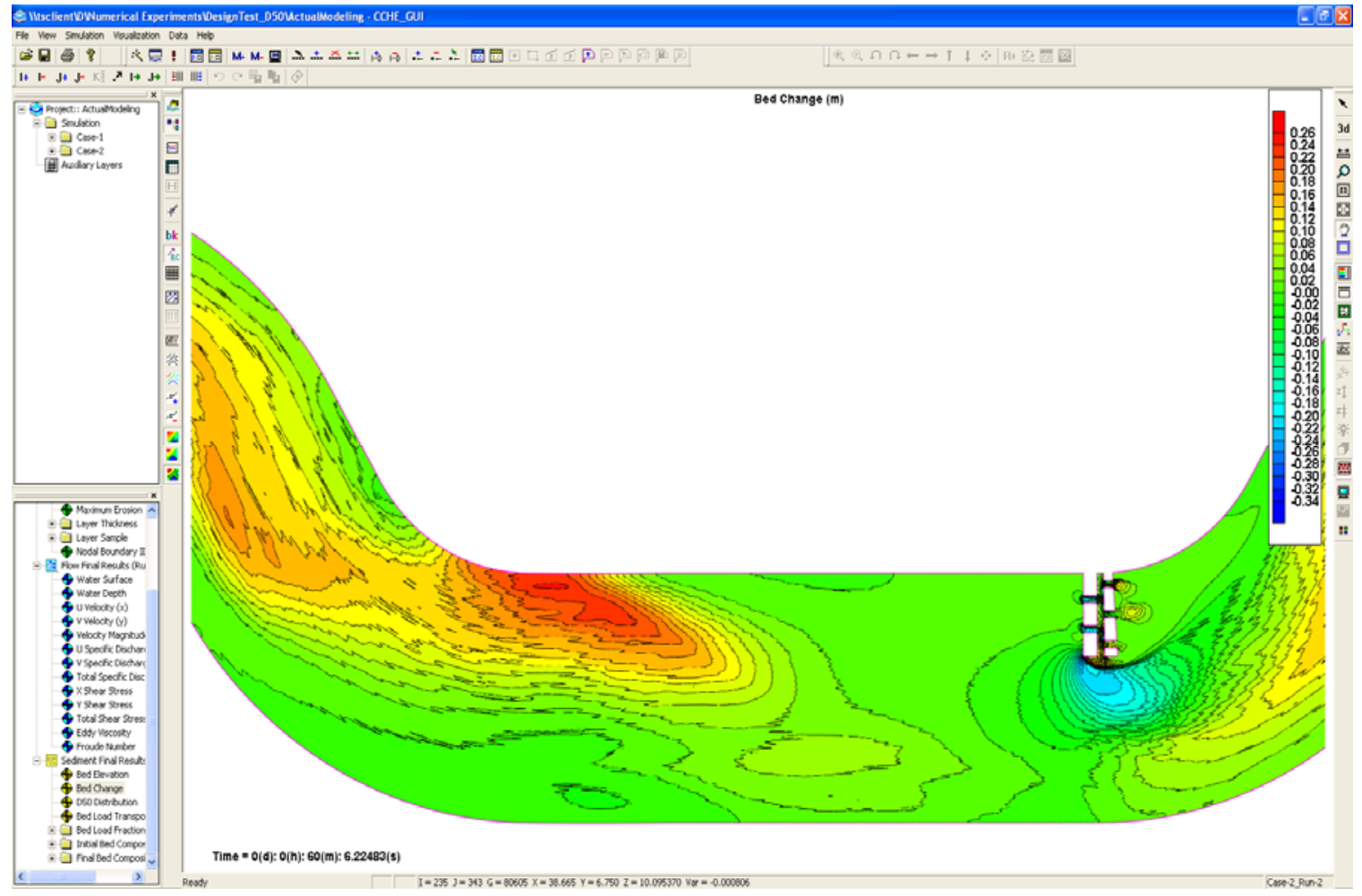

Figure T-170: Bed change for doubling the size of bed material scenario between meanders \#2 and \#3 after 1-hr simulation. 


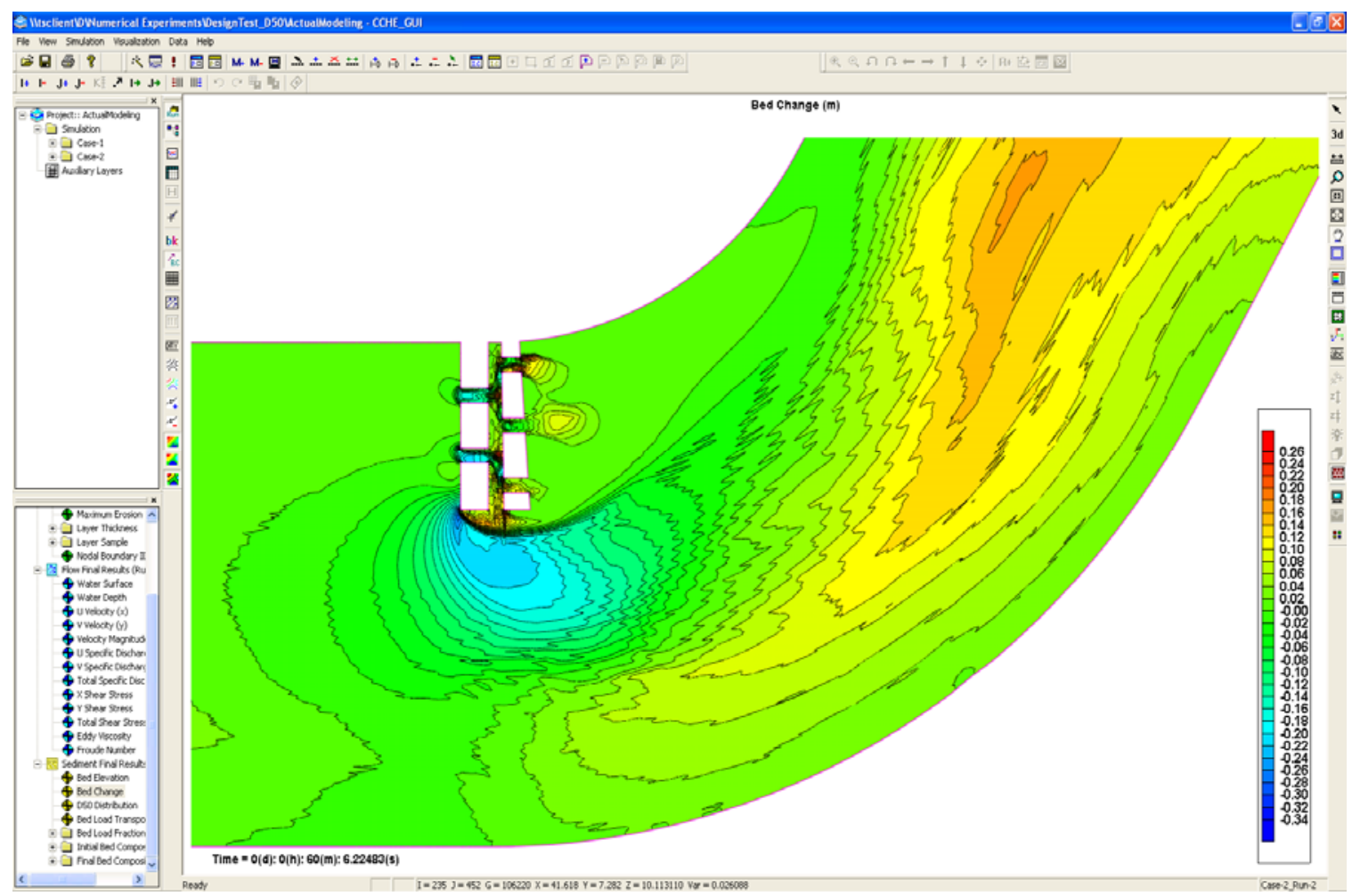

Figure T-171: Bed change for doubling the size of bed material scenario at meander \#3 after 1-hr simulation.

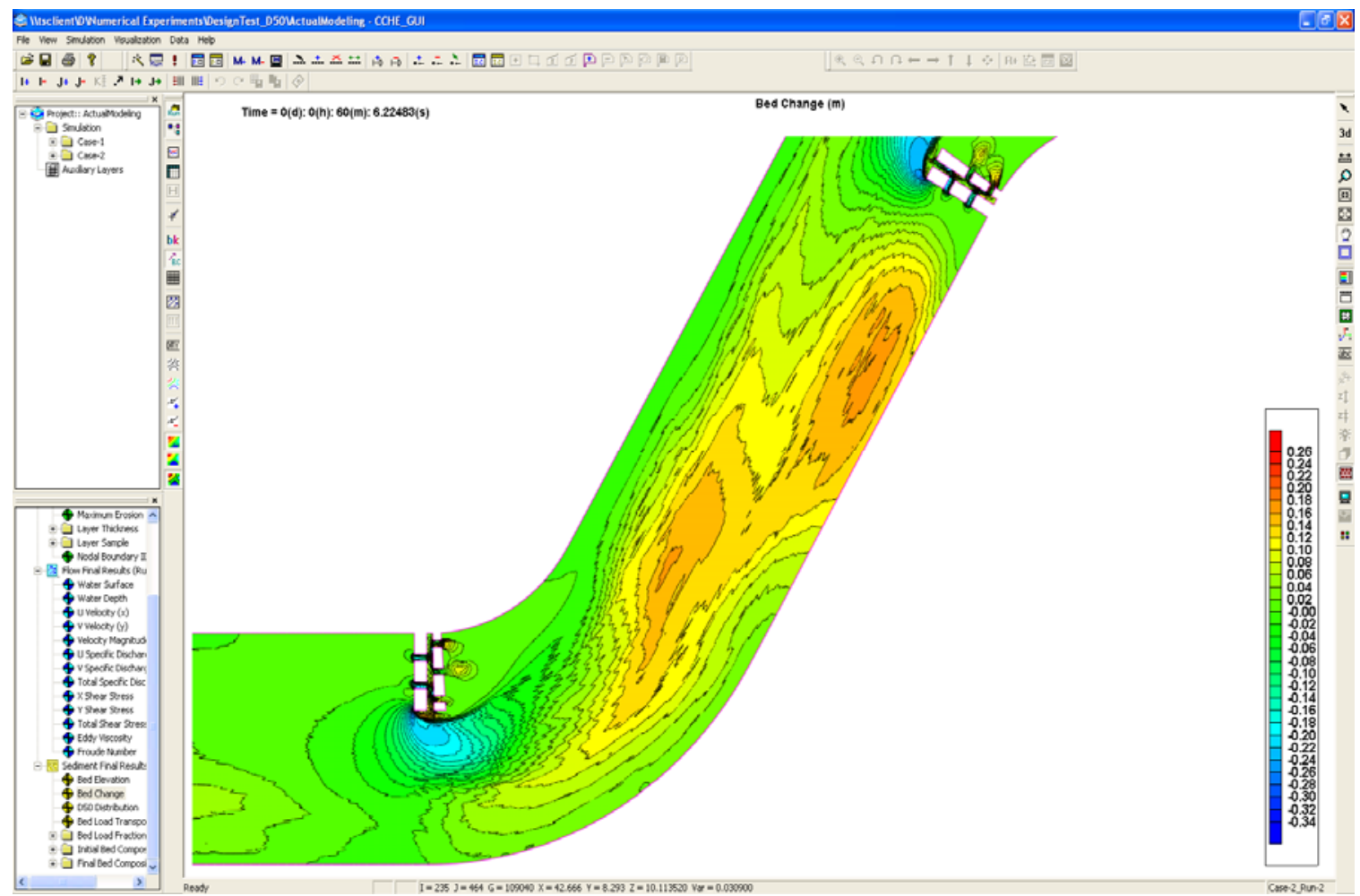

Figure T-172: Bed change for doubling the size of bed material scenario at meanders \#3 and \#4 after 1-hr simulation. 


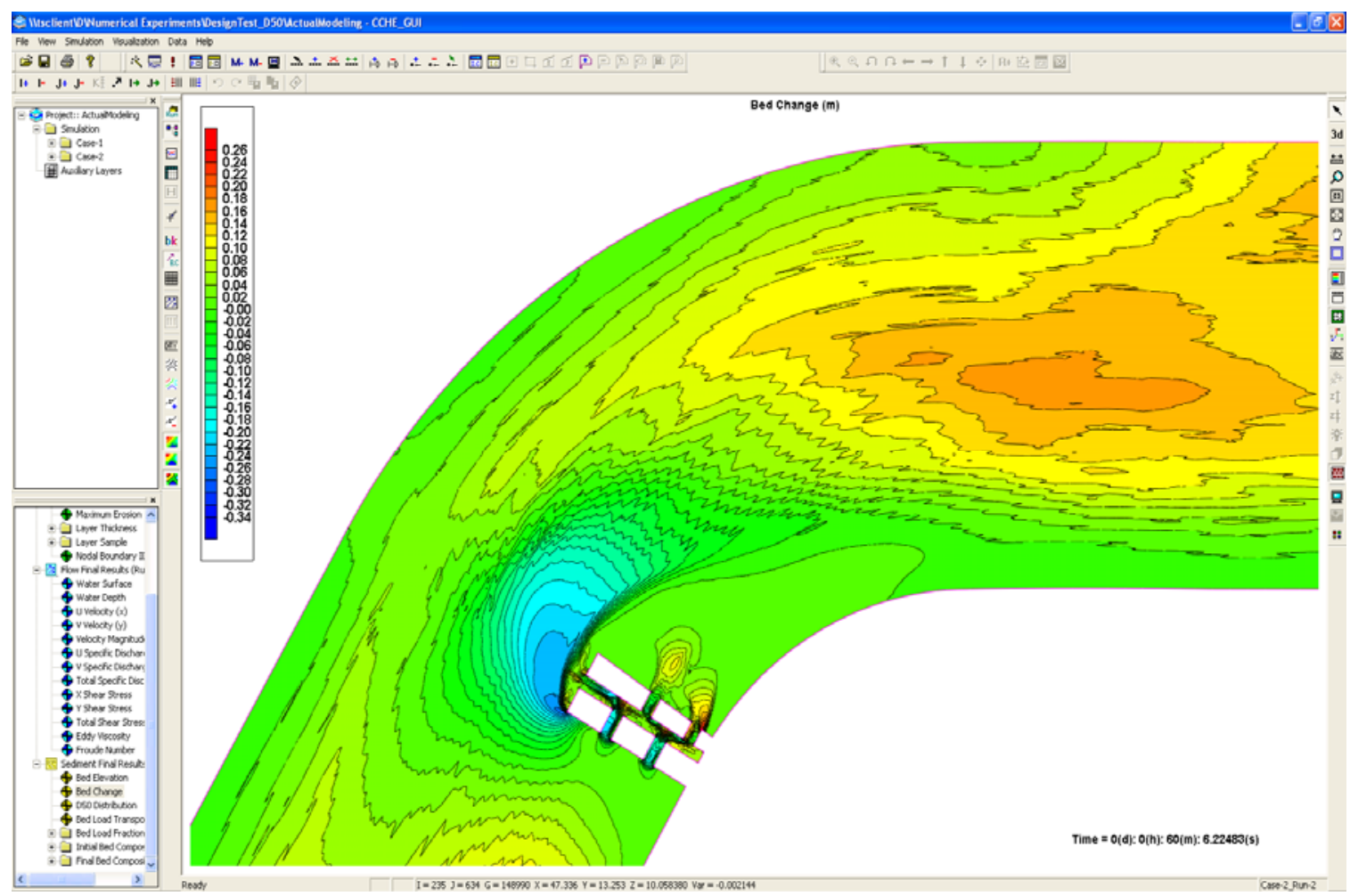

Figure T-173: Bed change for doubling the size of bed material scenario at meander \#4 after 1-hr simulation.

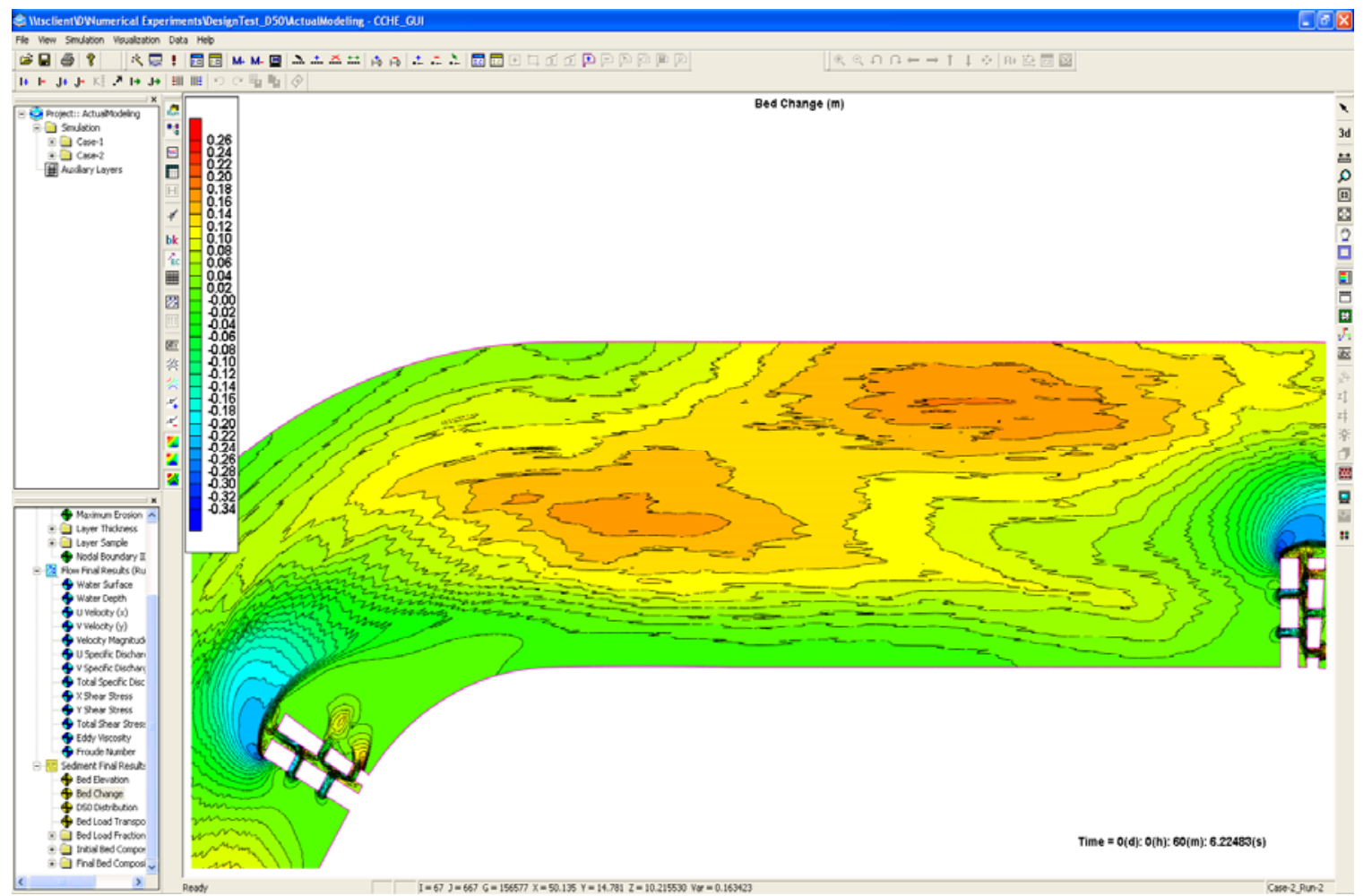

Figure T-174: Bed change for doubling the size of bed material scenario between meanders \#4 and \#5 after 1-hr simulation. 


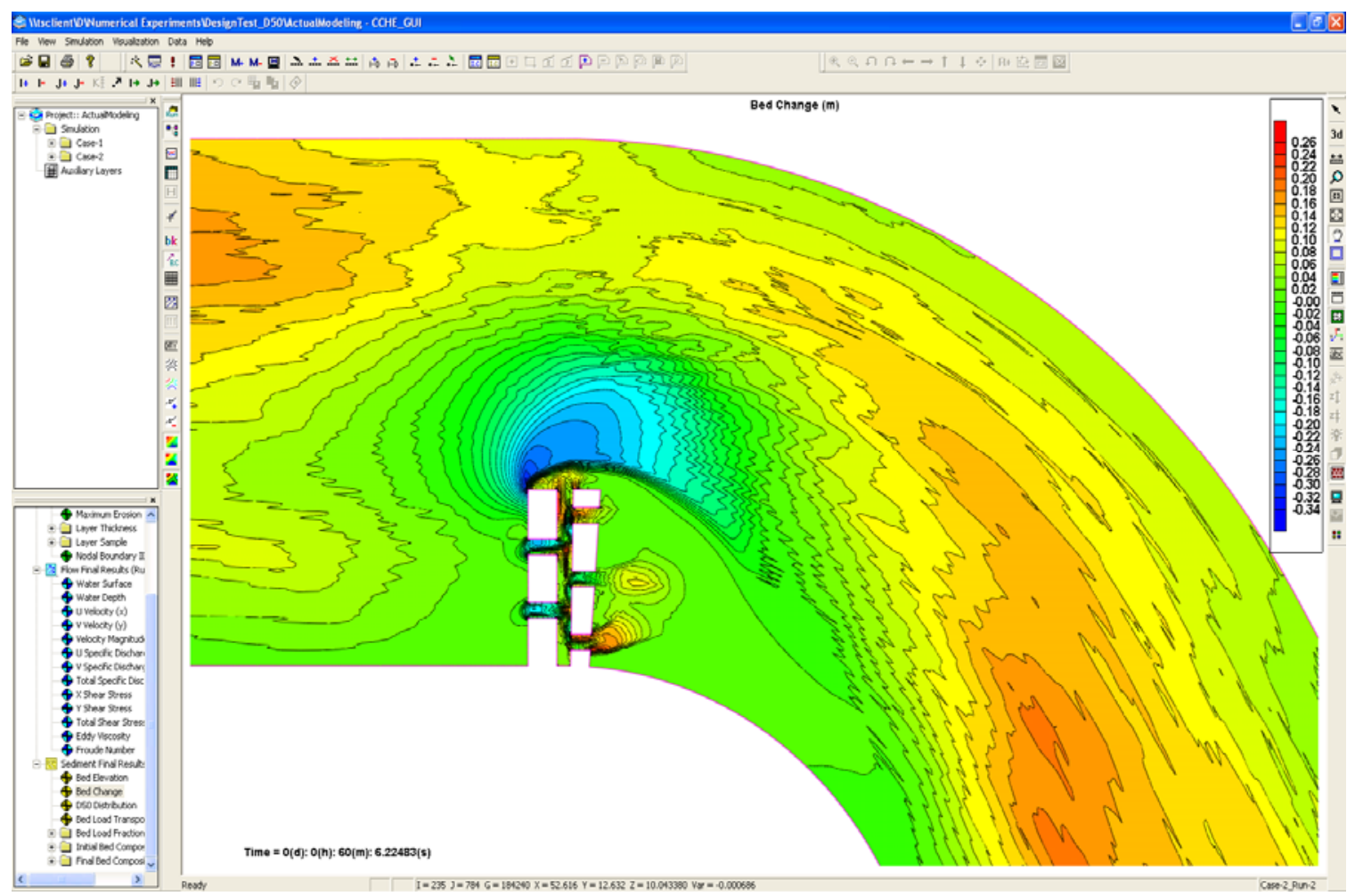

Figure T-175: Bed change for doubling the size of bed material scenario at meander \#5 after 1-hr simulation.

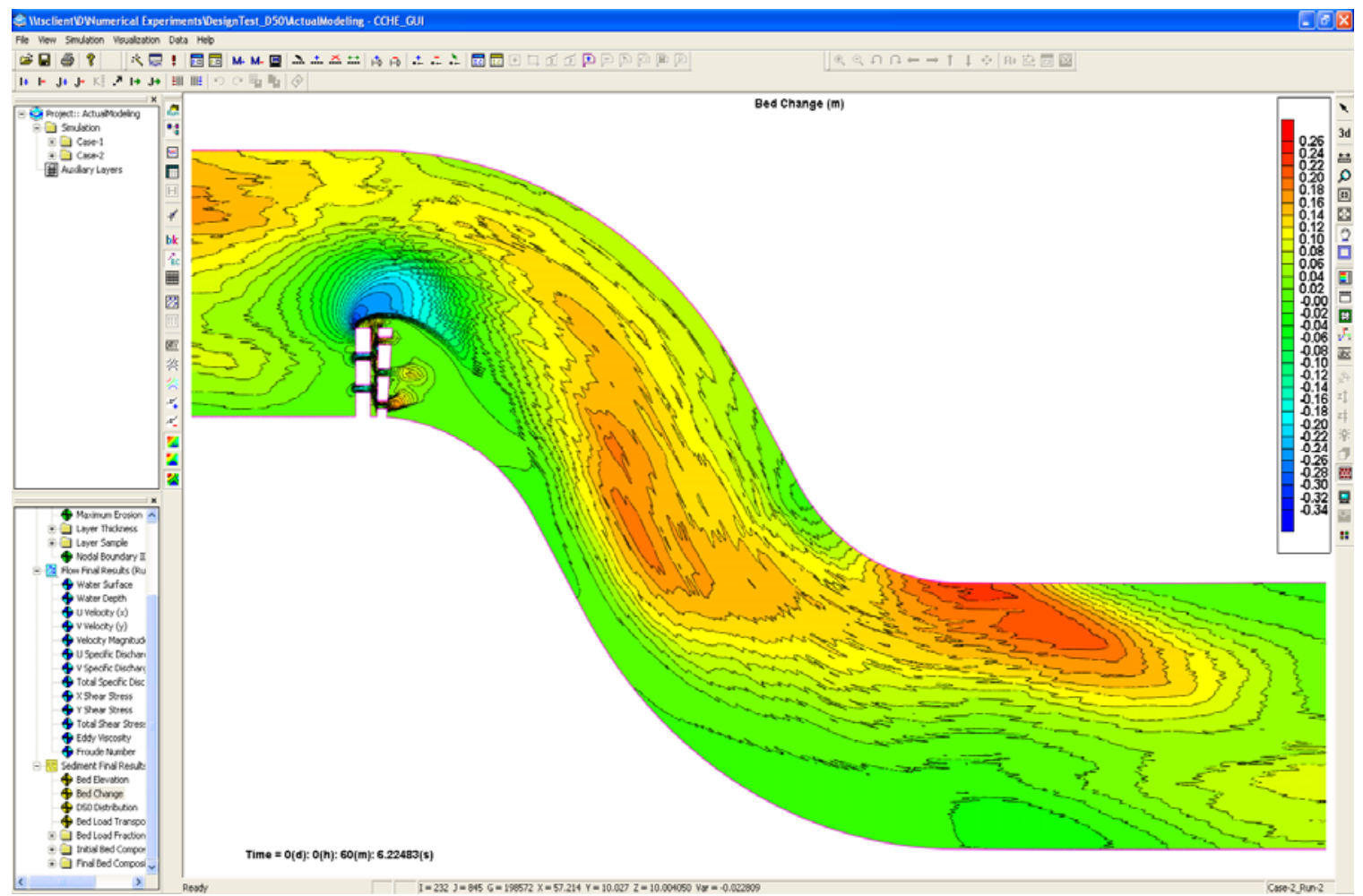

Figure T-176: Bed change for doubling the size of bed material scenario between meanders \#5 and \#6 after 1-hr simulation. 


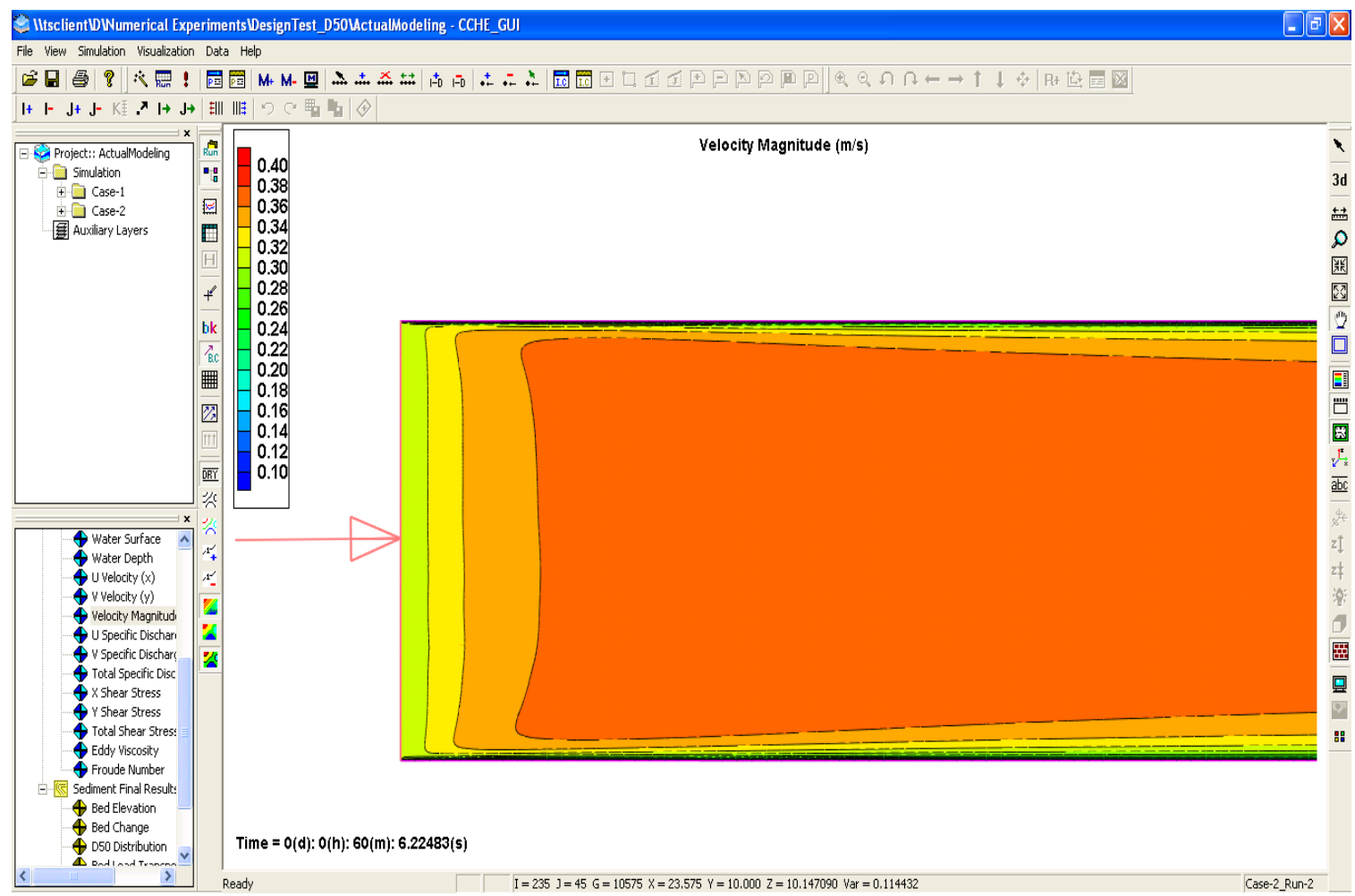

Figure T-177: Velocity magnitude for doubling the size of bed material scenario at upstream boundary after $1-\mathrm{hr}$ simulation.

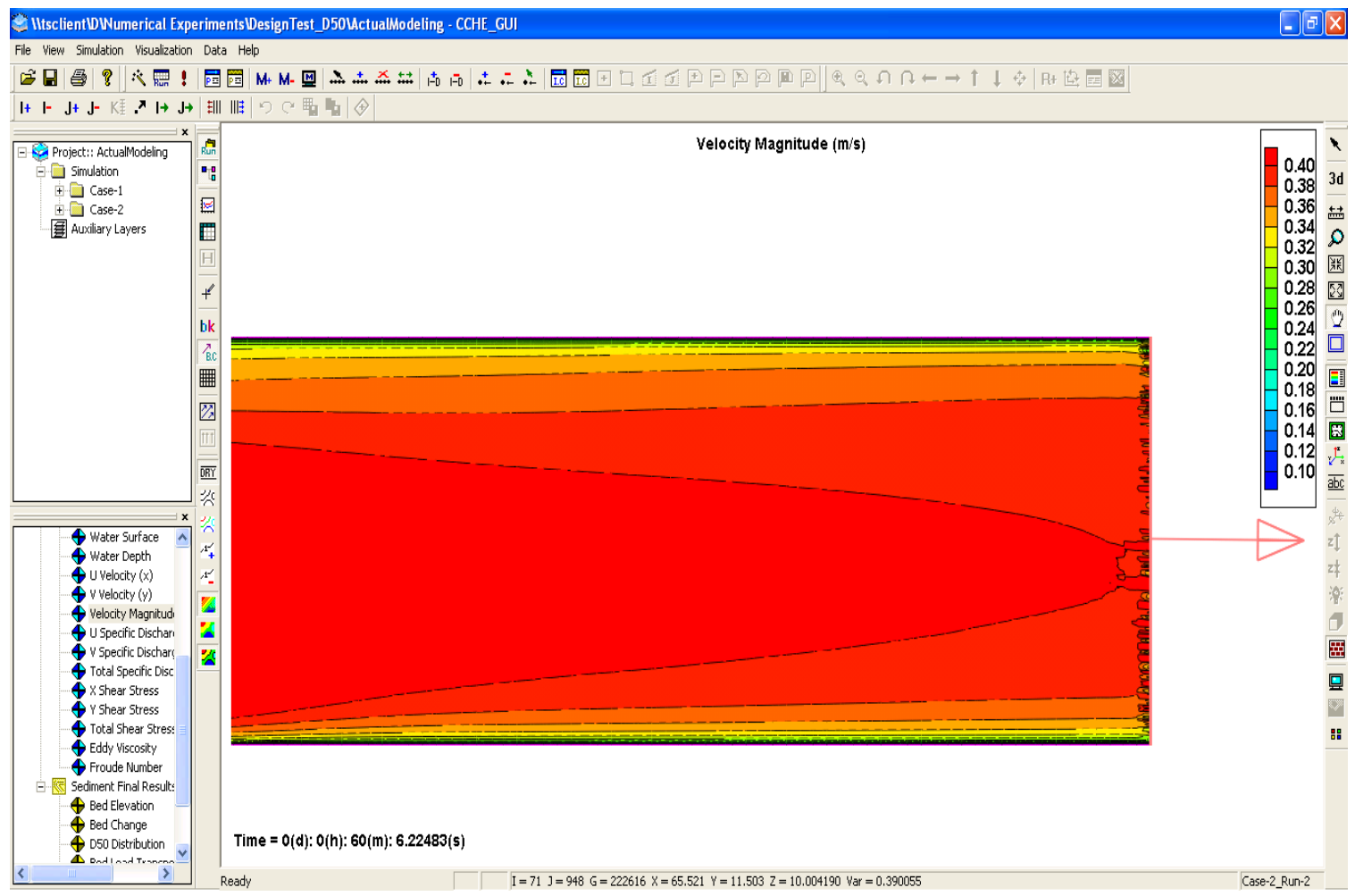

Figure T-178: Velocity magnitude for doubling the size of bed material scenario at downstream boundary after 1 -hr simulation. 


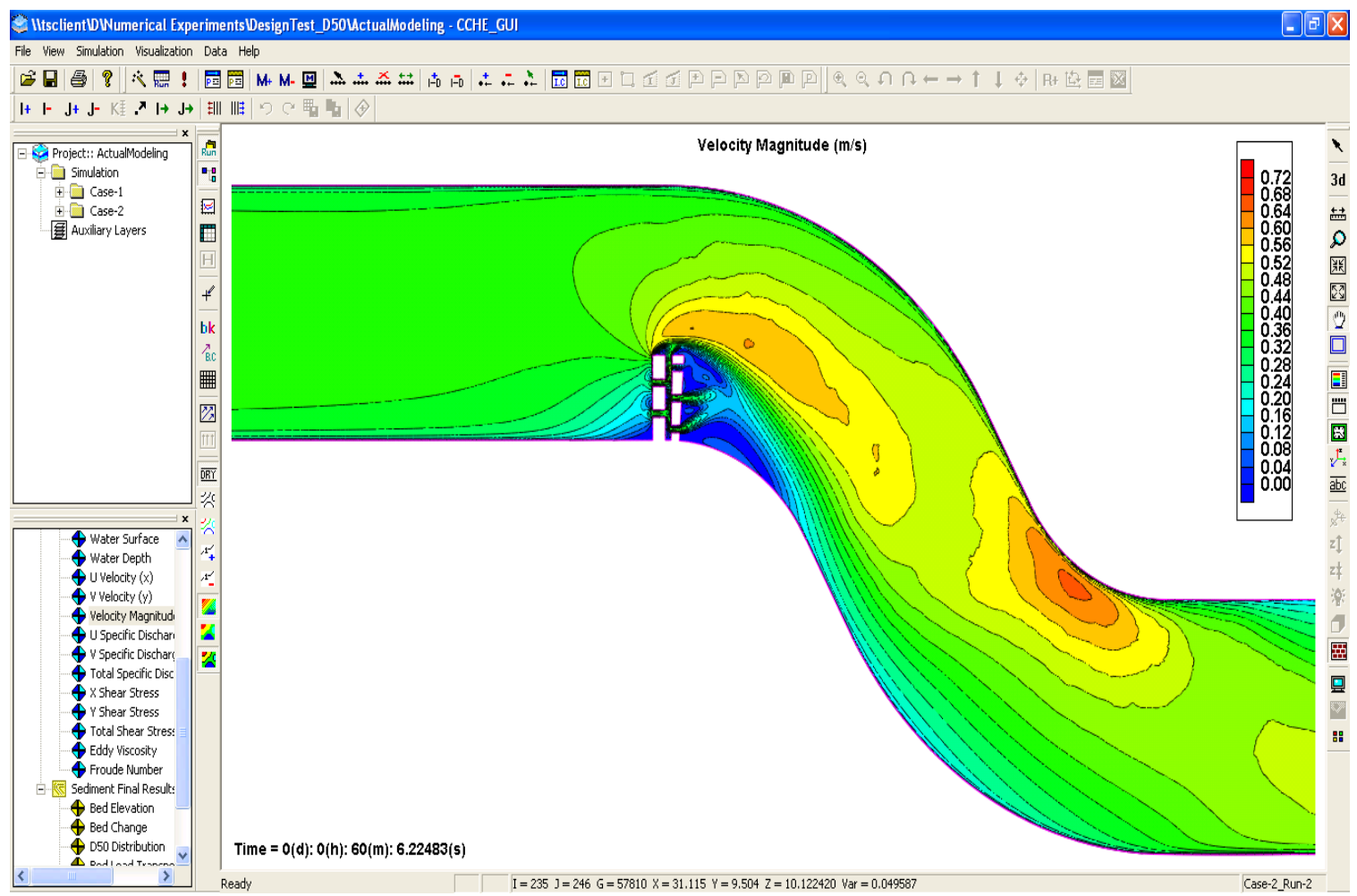

Figure T-179: Velocity magnitude for doubling the size of bed material scenario between meanders \#1 and \#2 after 1-hr simulation.

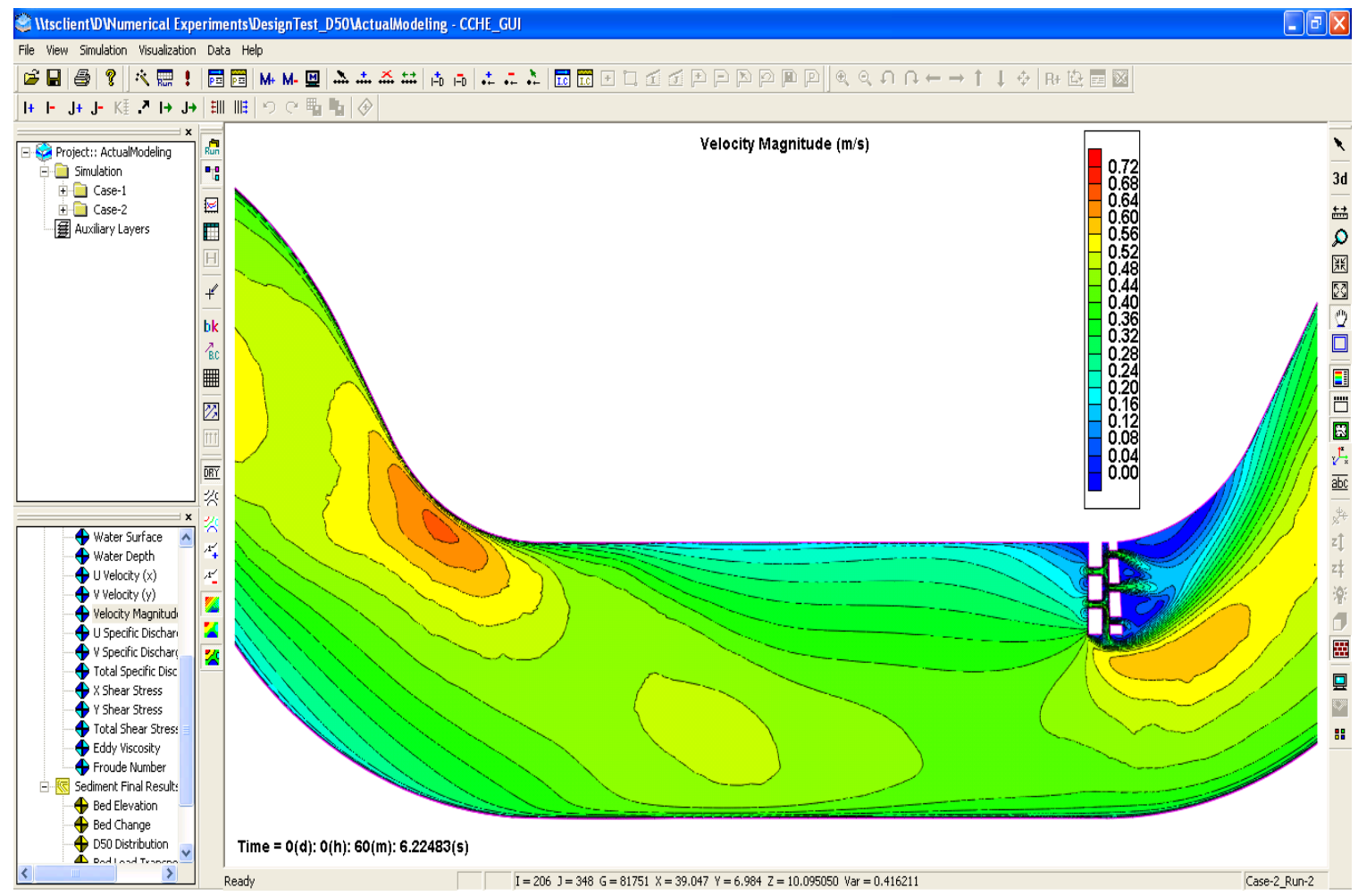

Figure T-180: Velocity magnitude for doubling the size of bed material scenario between meanders \#2 and \#3 after 1-hr simulation. 


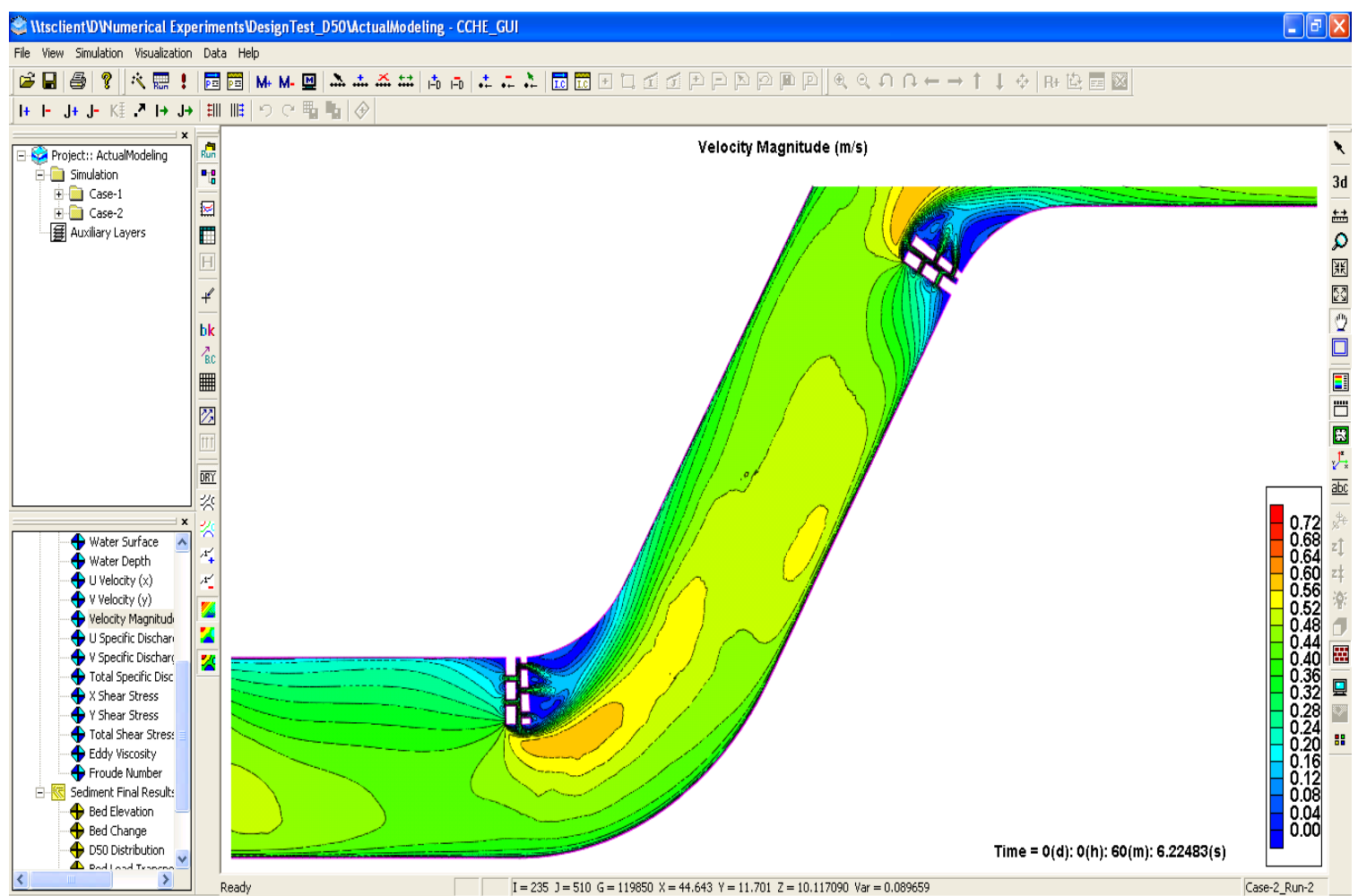

Figure T-181: Velocity magnitude for doubling the size of bed material scenario between meanders \#3 and \#4 after 1-hr simulation.

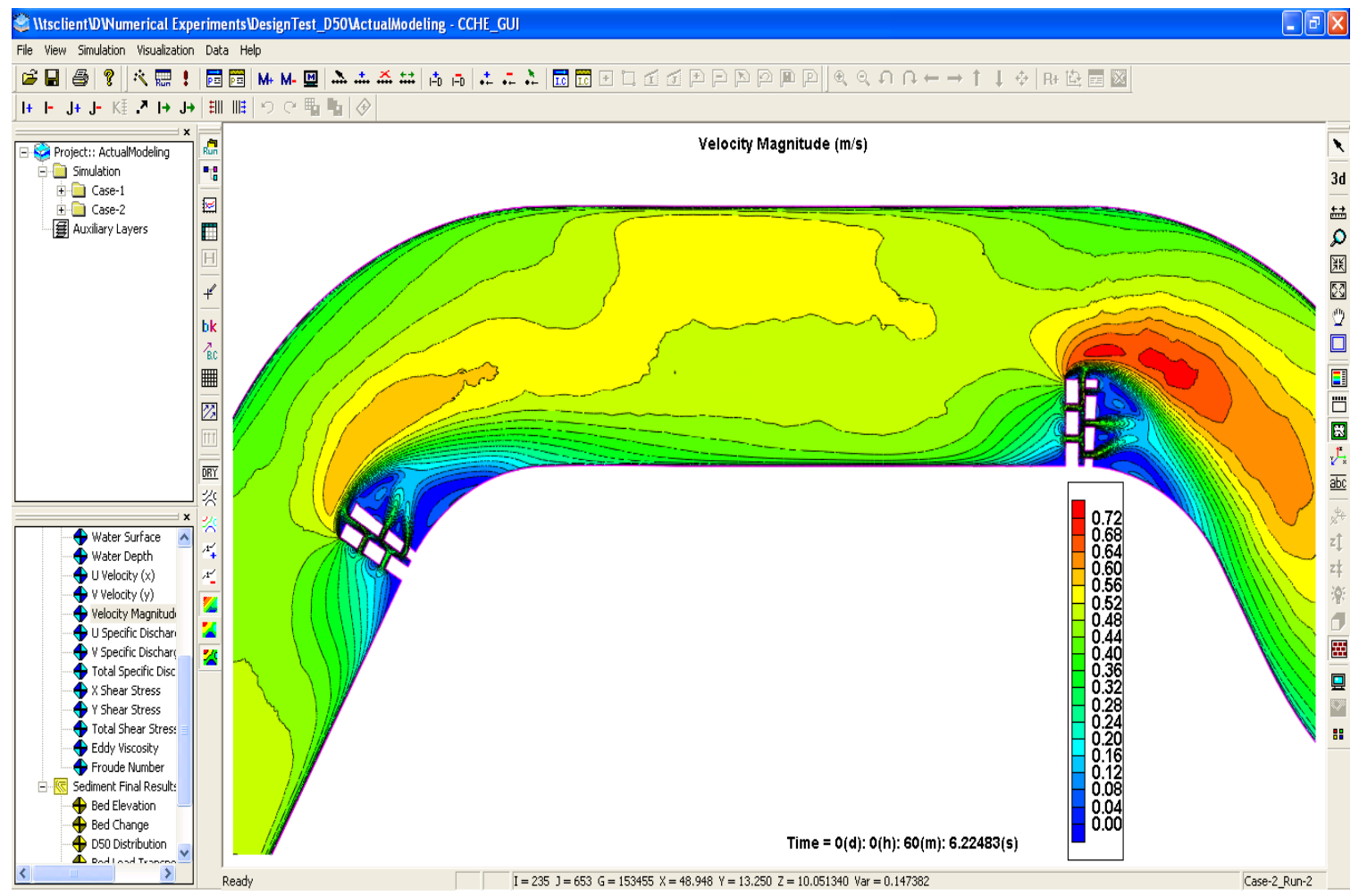

Figure T-182: Velocity magnitude for doubling the size of bed material scenario between meanders \#4 and \#5 after 1-hr simulation. 


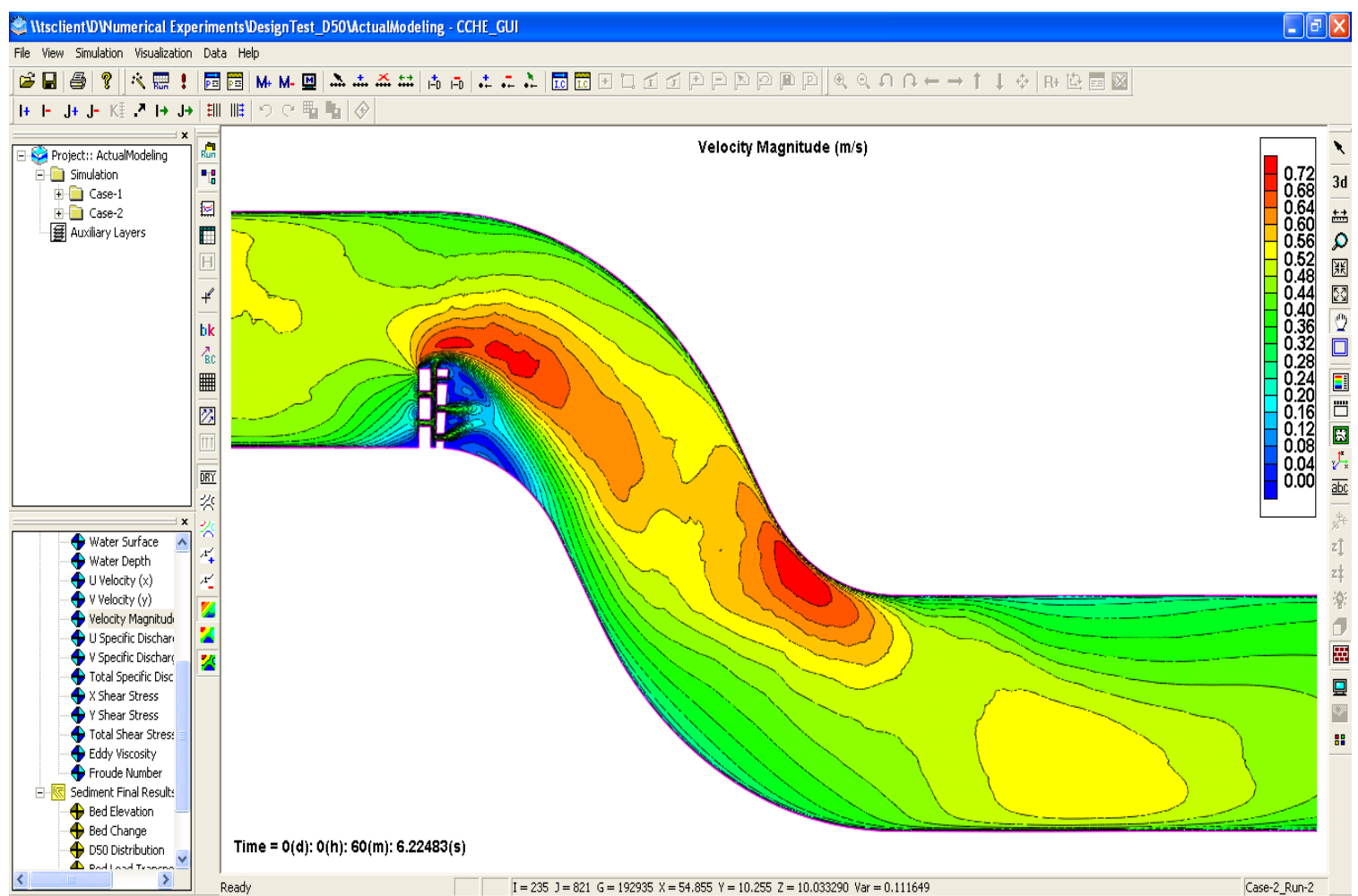

Figure T-183: Velocity magnitude for doubling the size of bed material scenario between meanders \#5 and \#6 after 1-hr simulation.

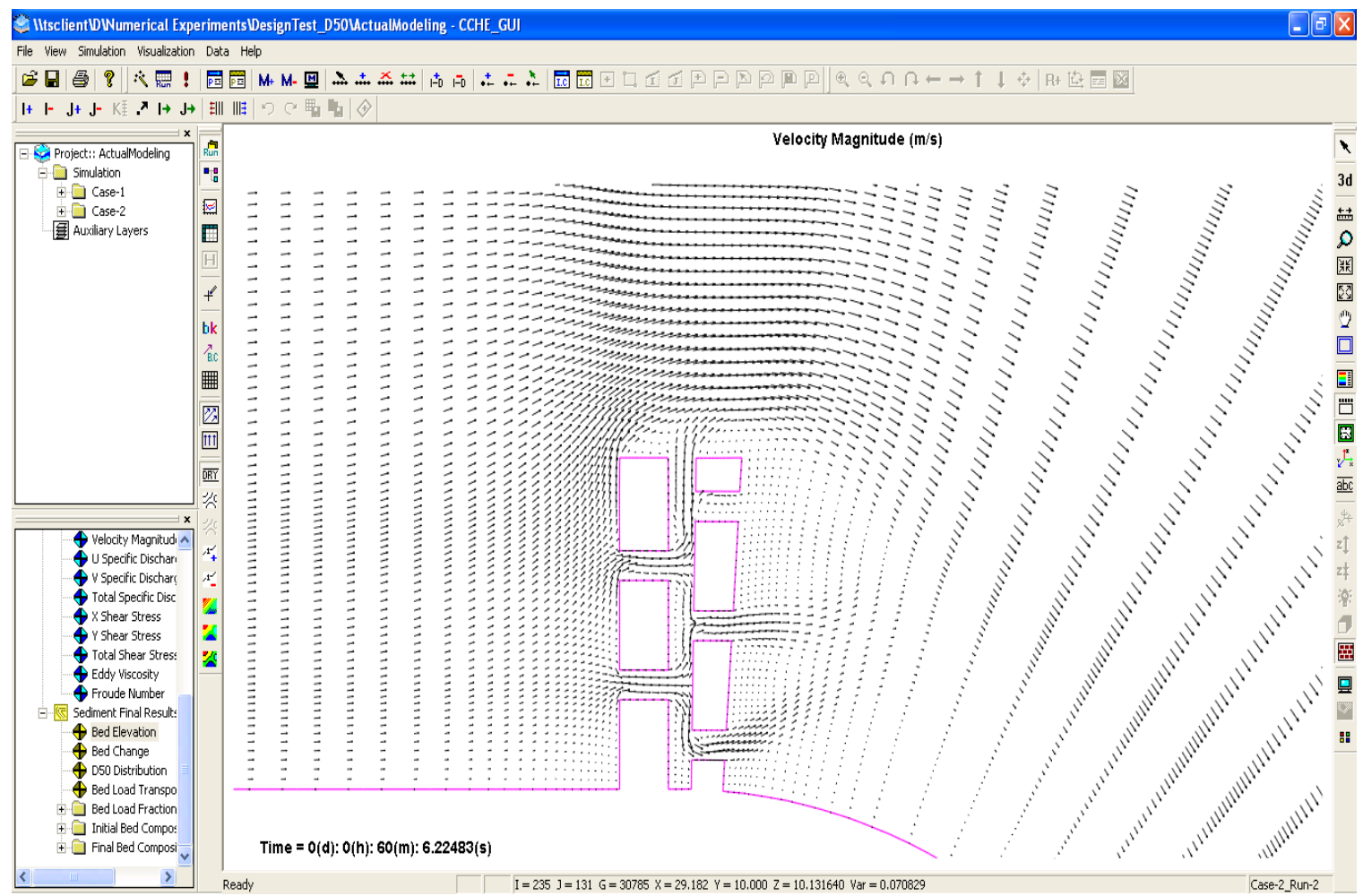

Figure T-184: Velocity direction for doubling the size of bed material scenario at meander \#1 after 1-hr simulation. 


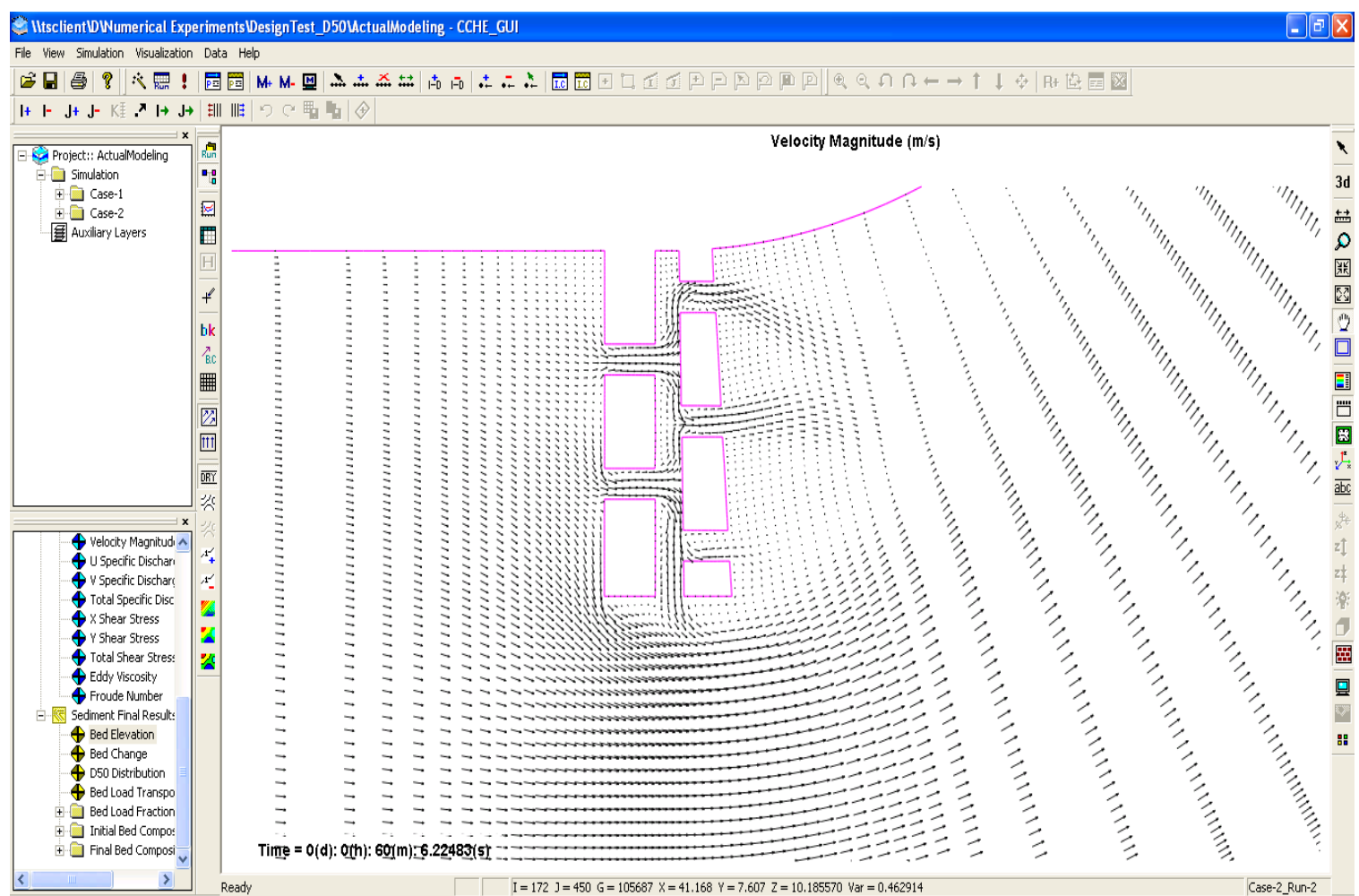

Figure T-185: Velocity direction for doubling the size of bed material scenario at meander \#3 after 1-hr simulation.

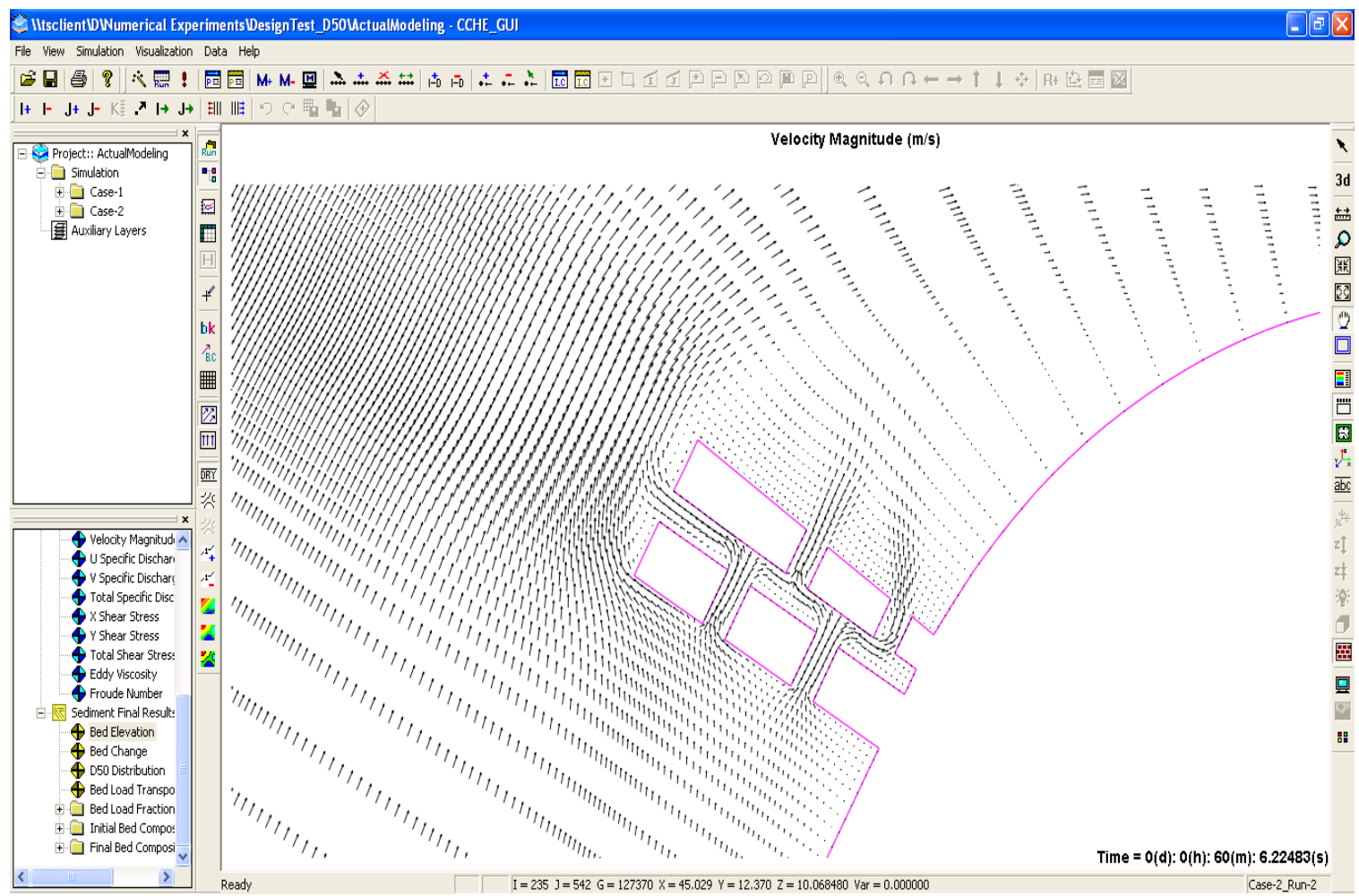

Figure T-186: Velocity direction for doubling the size of bed material scenario at meander \#4 after 1-hr simulation. 


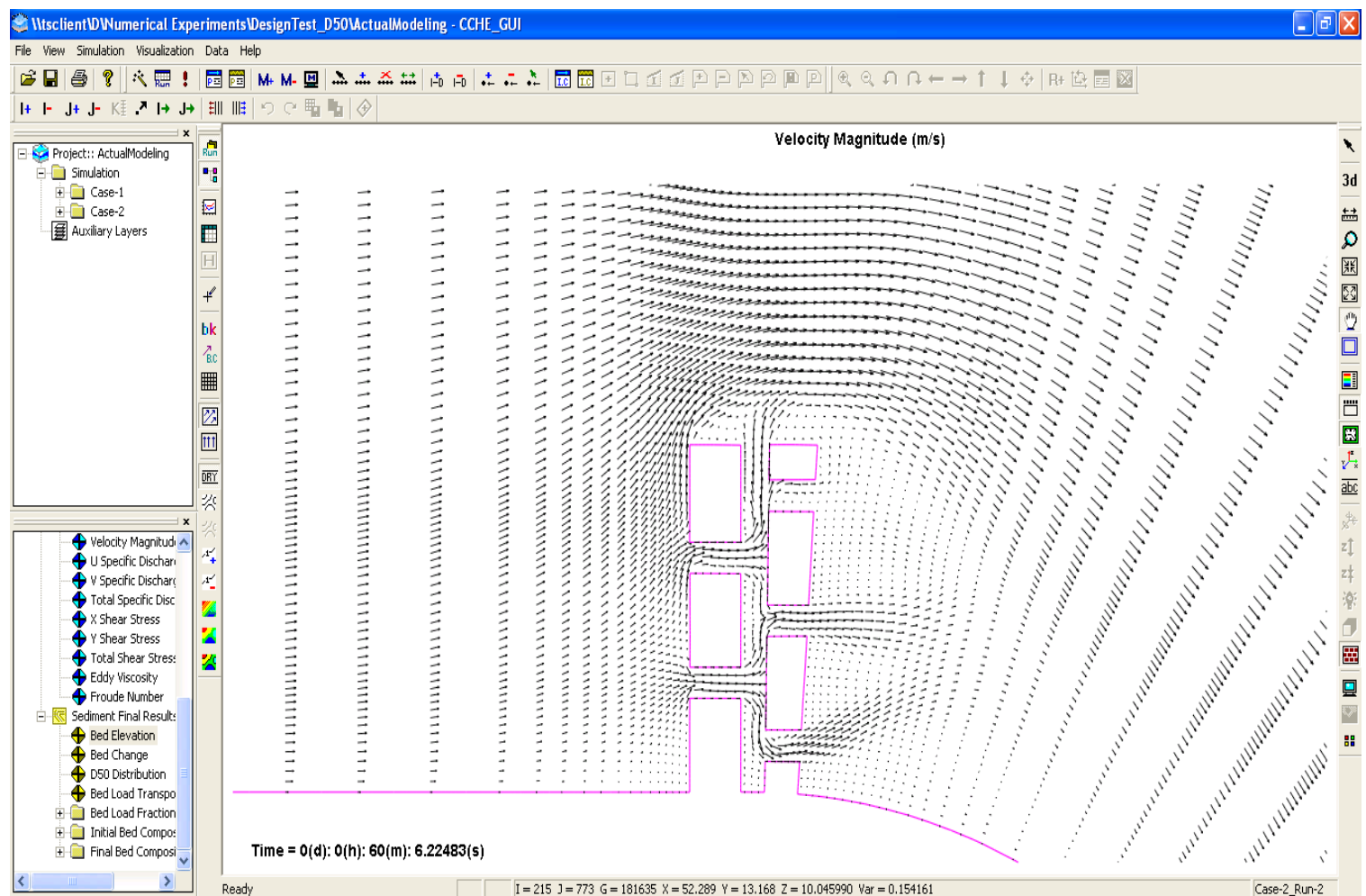

Figure T-187: Velocity direction for doubling the size of bed material scenario at meander \#5 after 1-hr simulation. 


\title{
APPENDIX U
}

\author{
Numerical Results
}

\section{(with Incoming Sediment)}




\section{Dry Weather Condition}

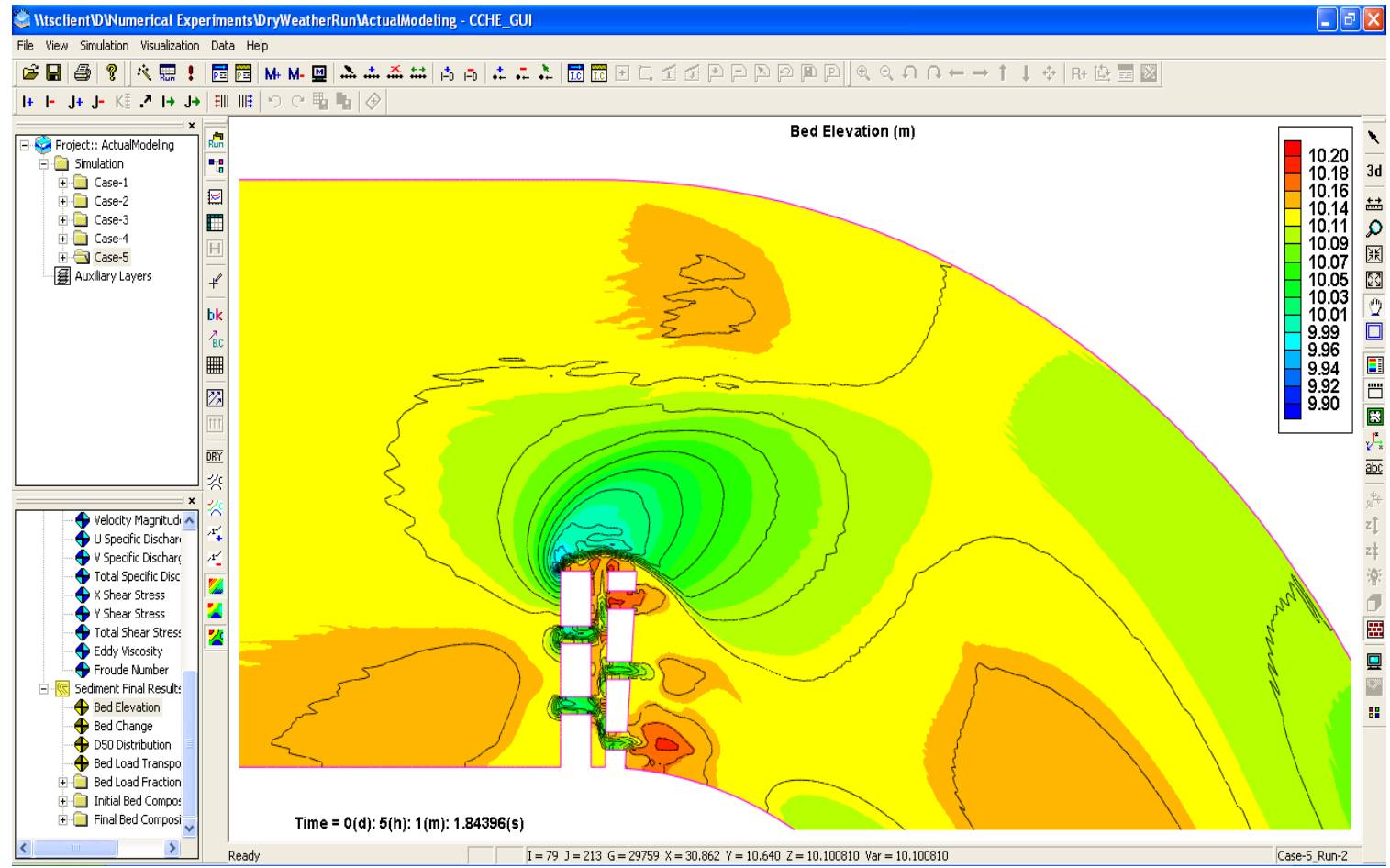

Figure U-1: Bed elevation for dry weather condition (with incoming sediment) at meander \#1 after 5-hr simulation.

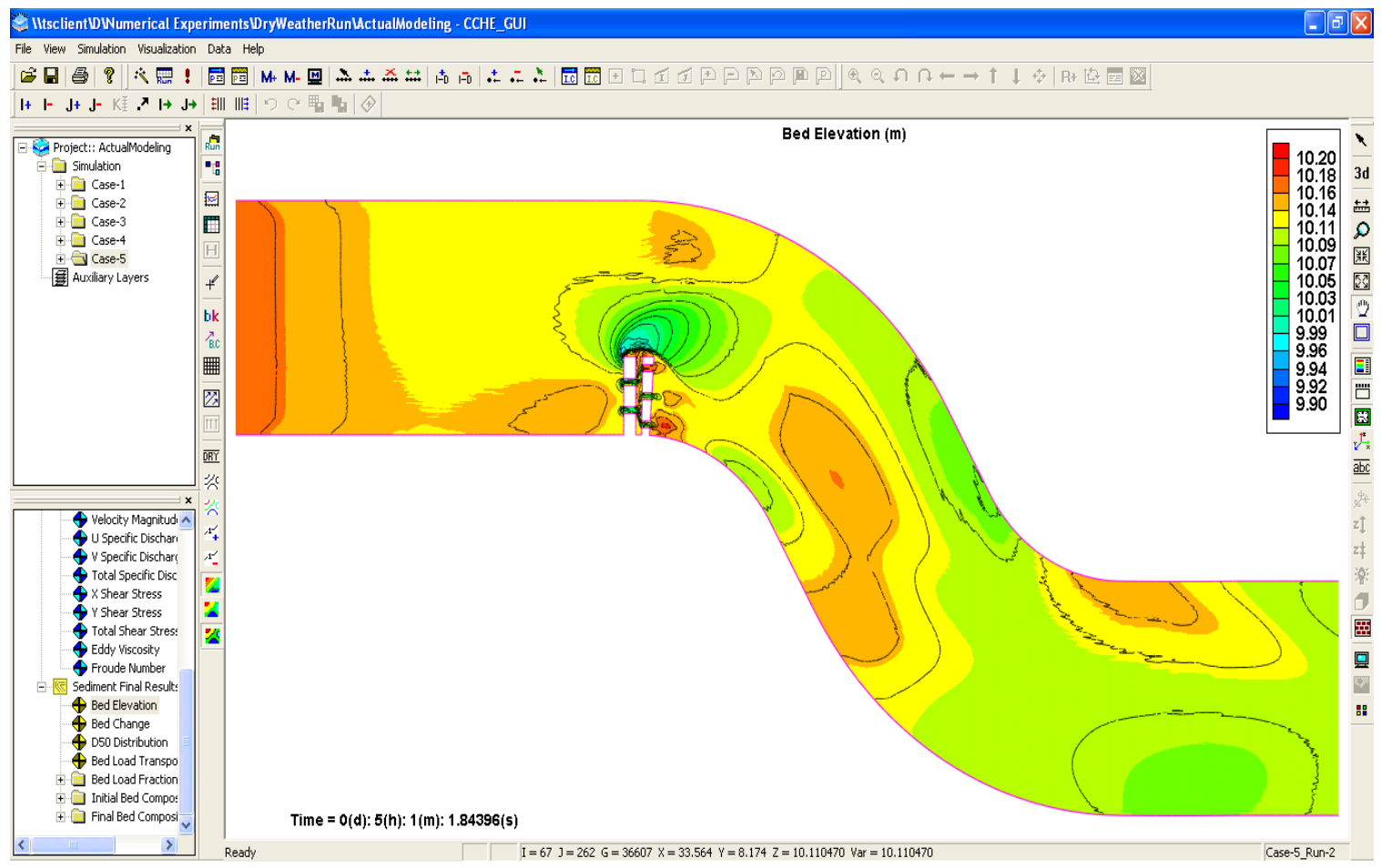

Figure U-2: Bed elevation for dry weather condition (with incoming sediment) between meanders \#1 and \#2 after 5-hr simulation. 


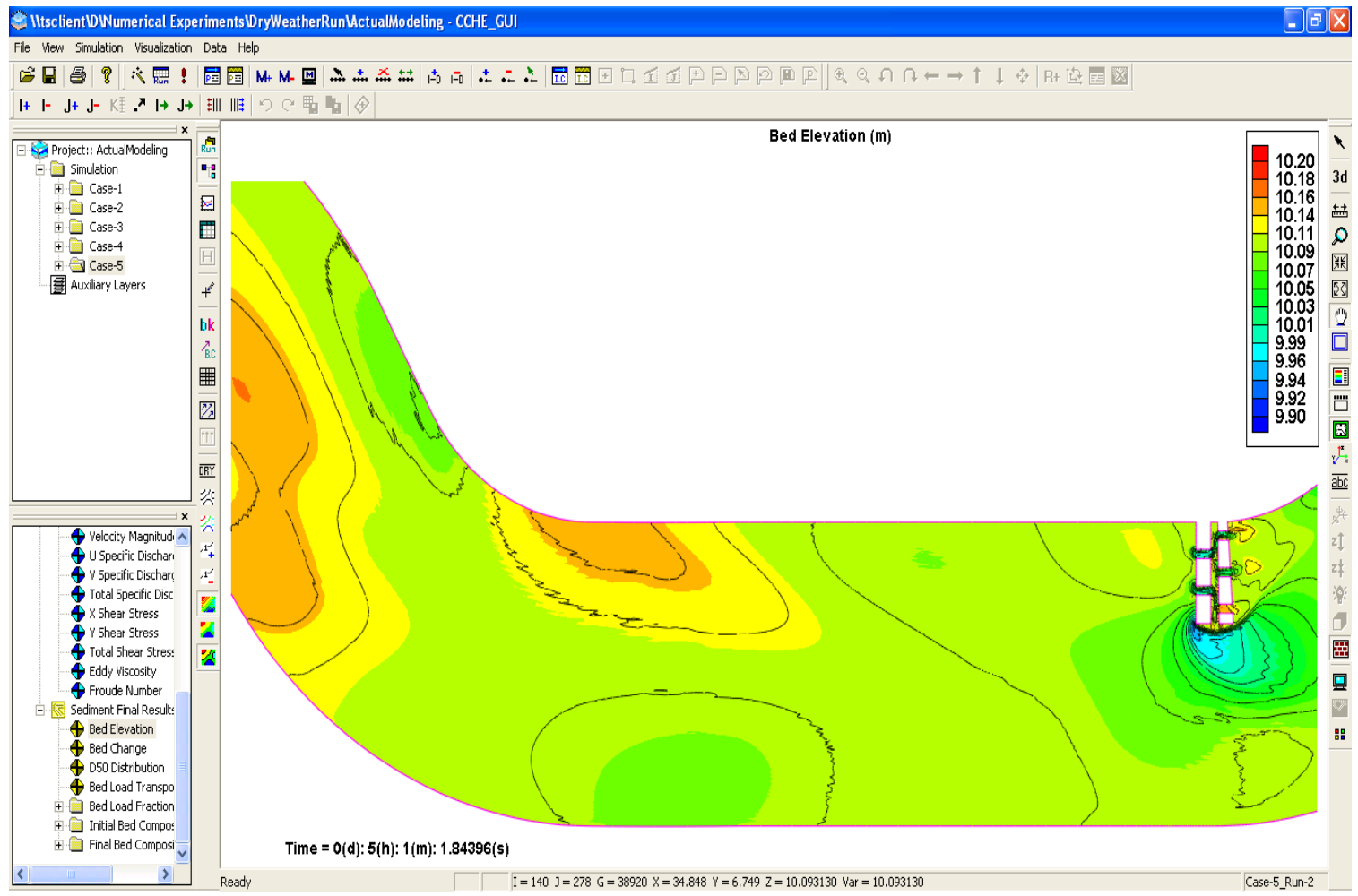

Figure U-3: Bed elevation for dry weather condition (with incoming sediment) between meanders \#2 and \#3 after 5-hr simulation.

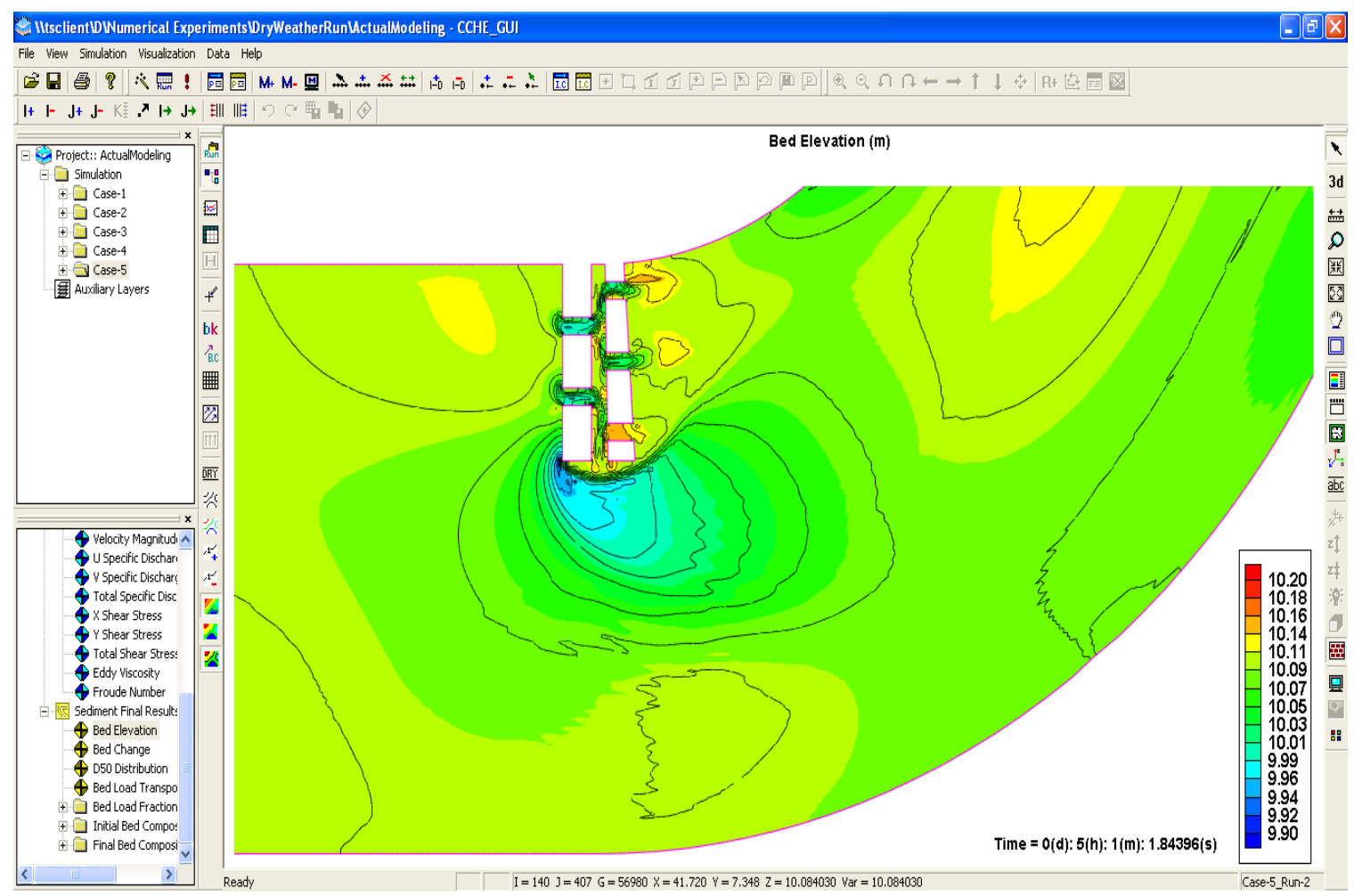

Figure U-4: Bed elevation for dry weather condition (with incoming sediment) at meander \#3 after 5-hr simulation. 


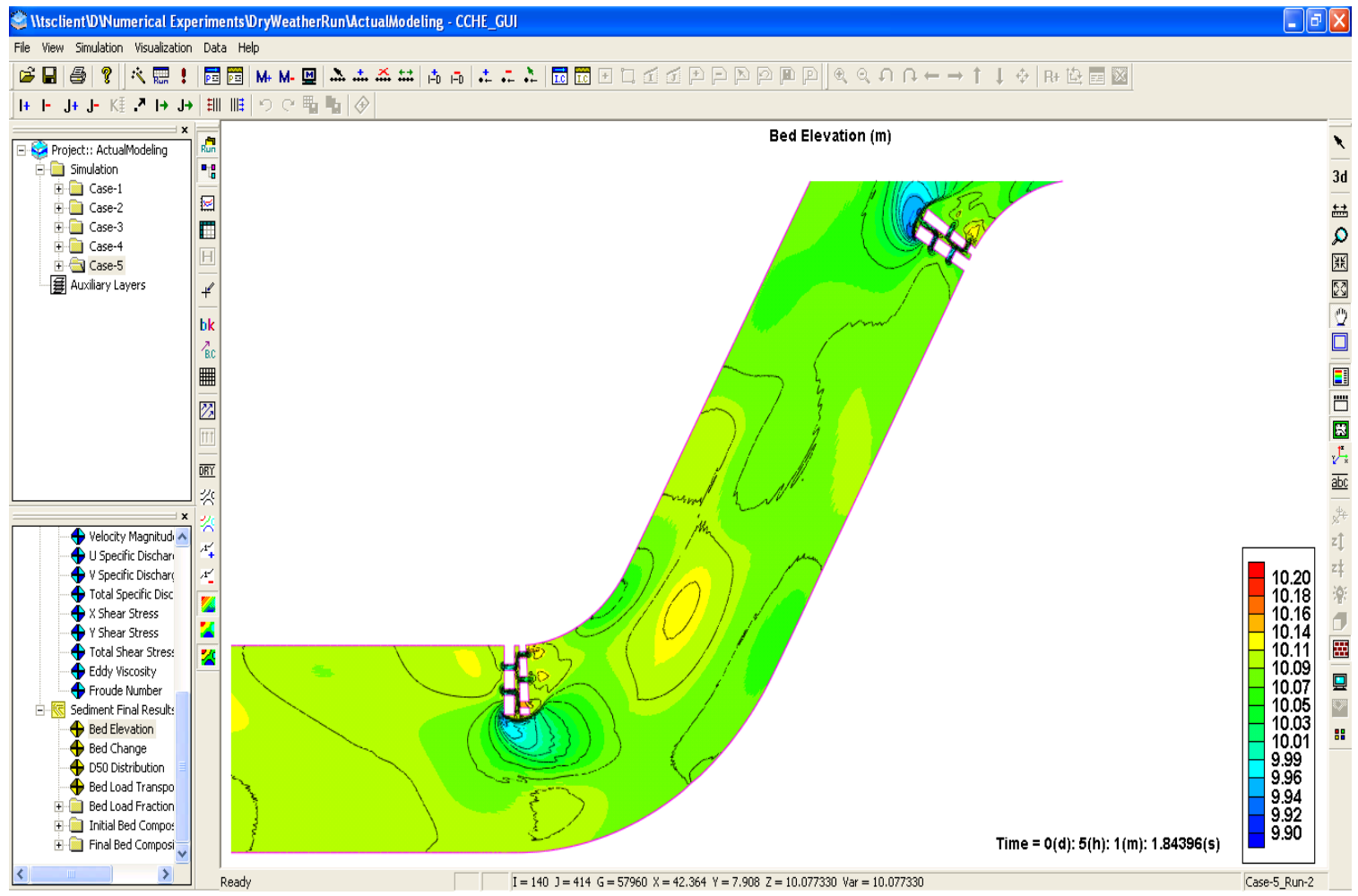

Figure U-5: Bed elevation for dry weather condition (with incoming sediment) between meanders \#3 and \#4 after 5-hr simulation.

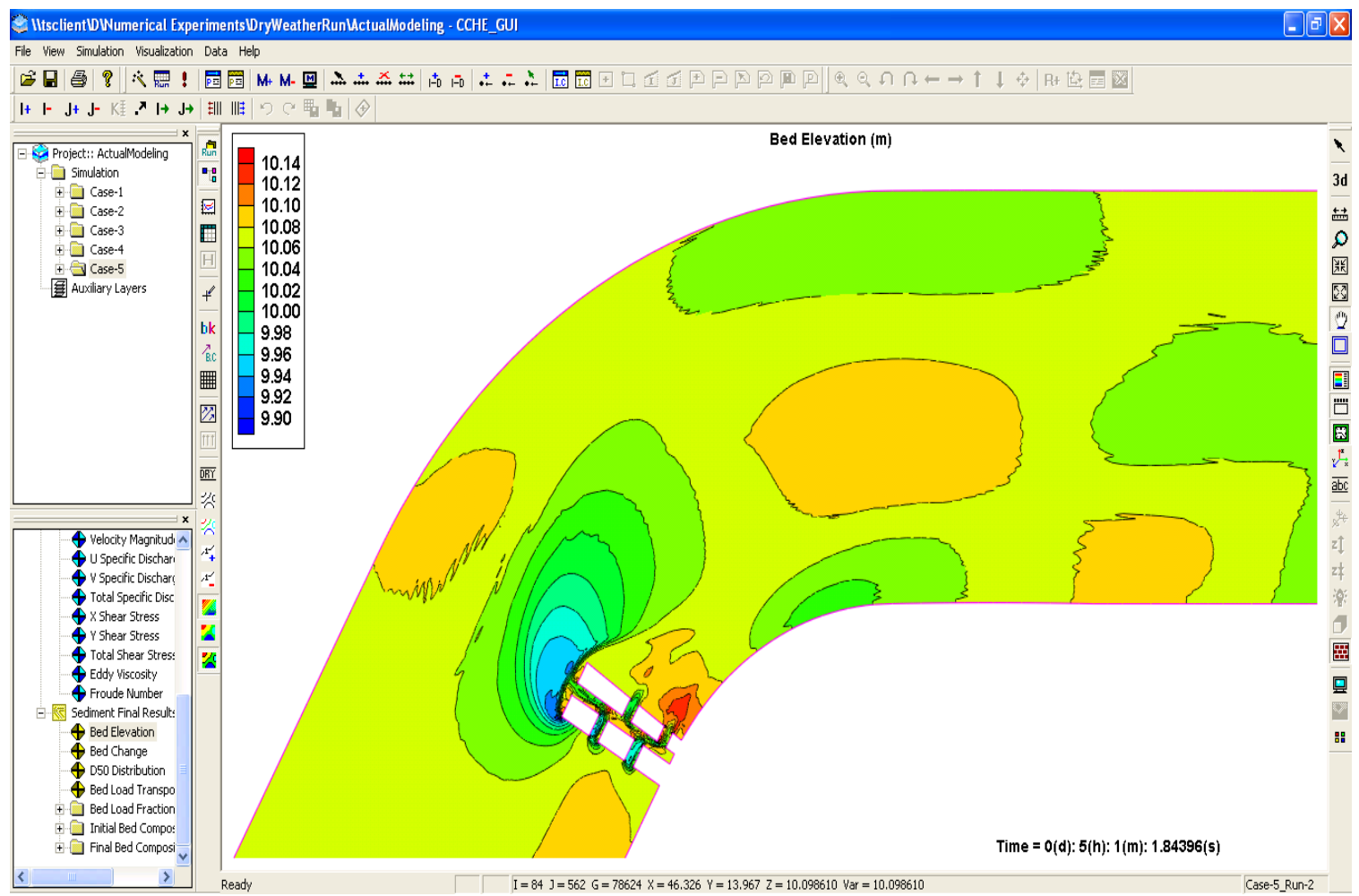

Figure U-6: Bed elevation for dry weather condition (with incoming sediment) at meander \#4 after 5-hr simulation. 


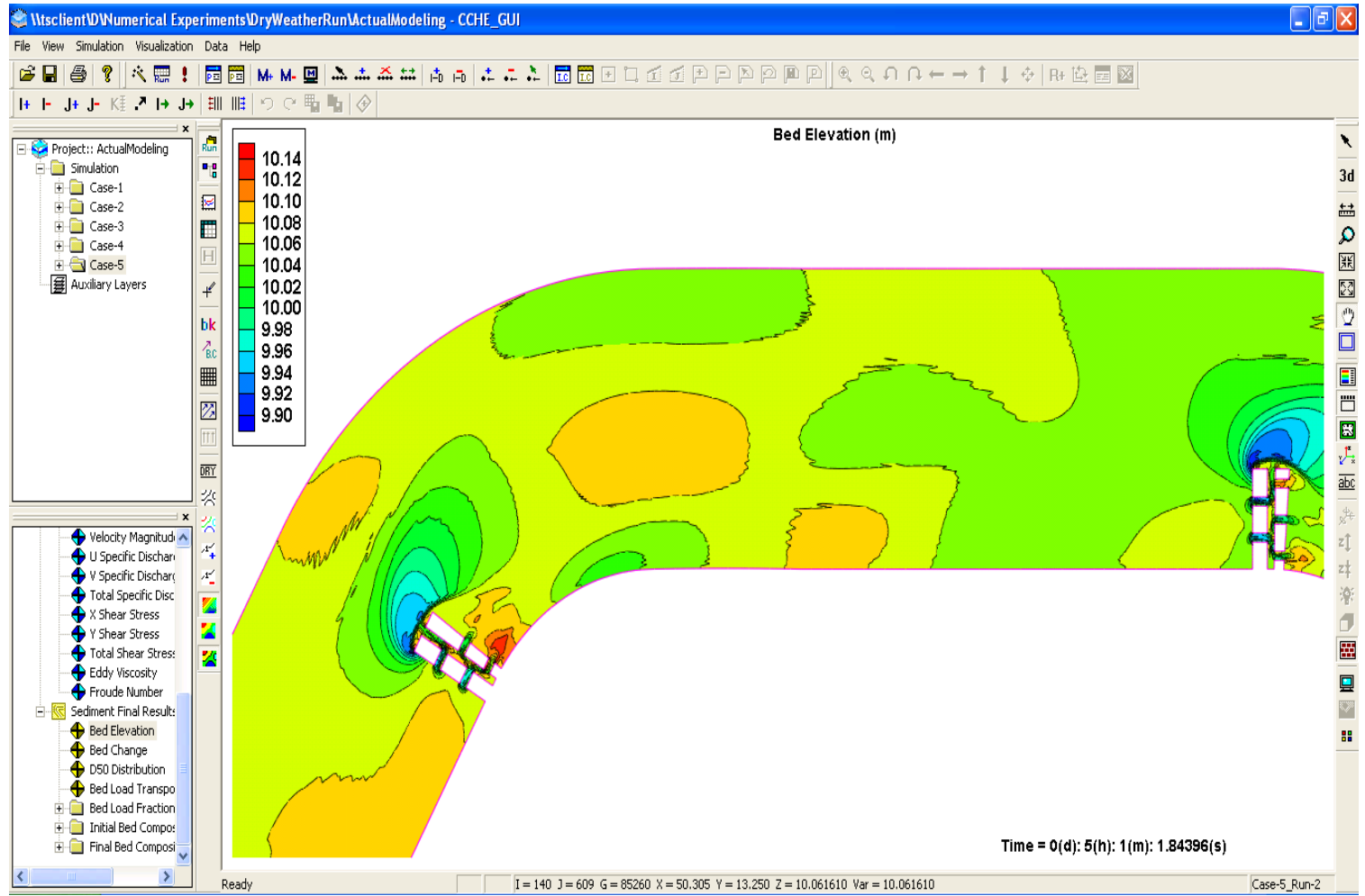

Figure U-7: Bed elevation for dry weather condition (with incoming sediment) between meanders \#4 and \#5 after 5-hr simulation.

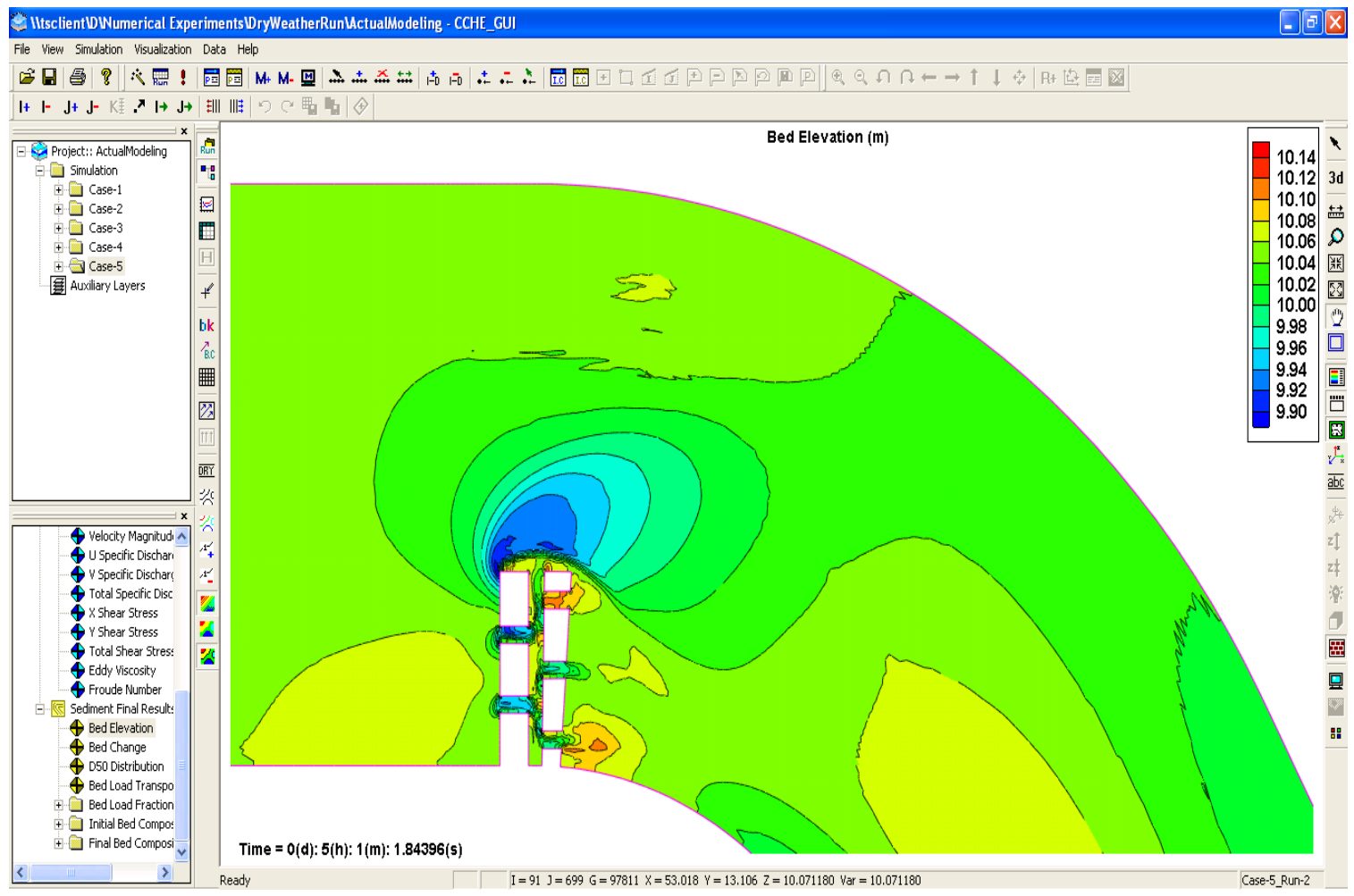

Figure U-8: Bed elevation for dry weather condition (with incoming sediment) at meander \#5 after 5 -hr simulation. 


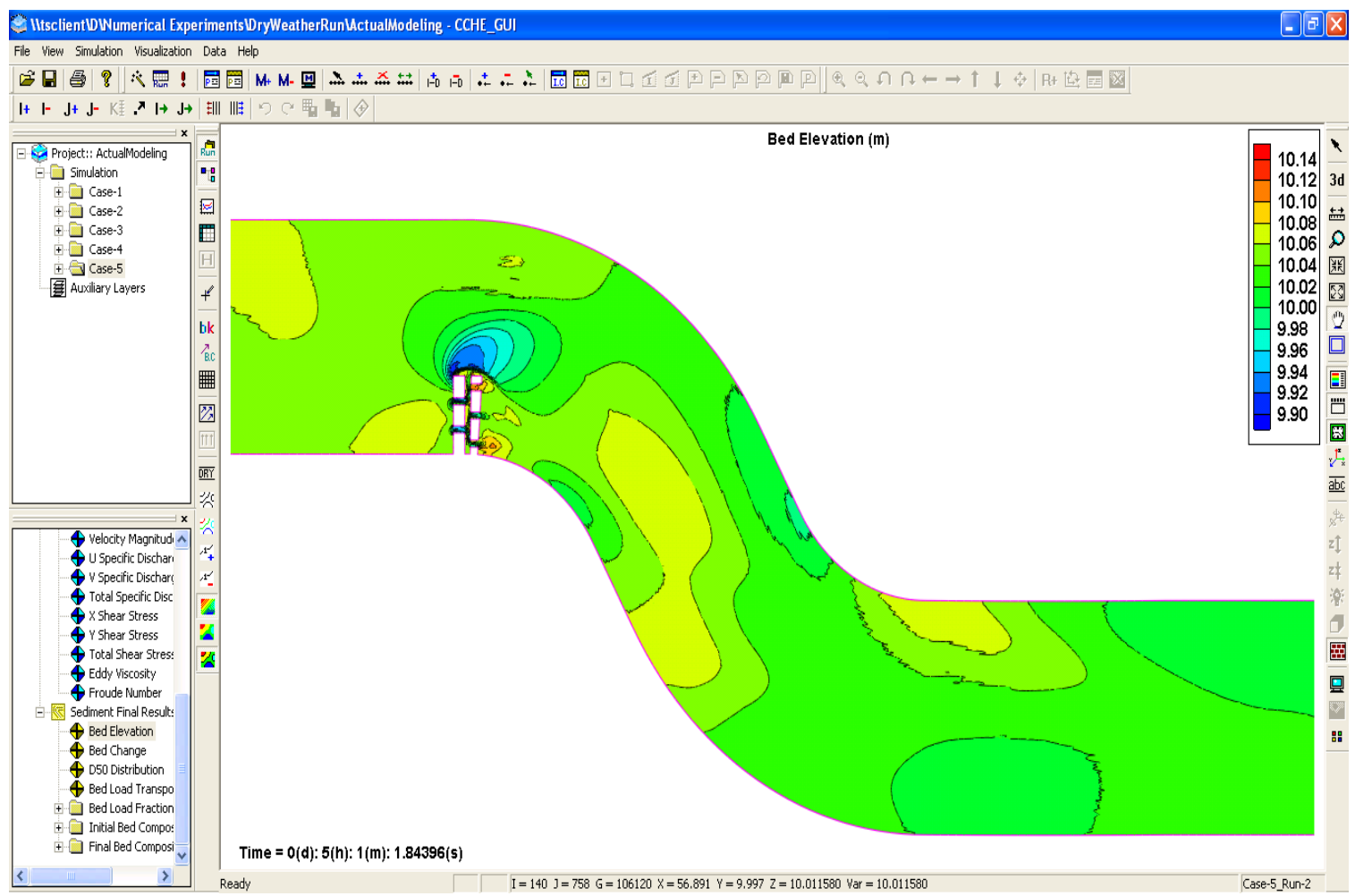

Figure U-9: Bed elevation for dry weather condition (with incoming sediment) between meanders \#5 and \#6 after 5-hr simulation.

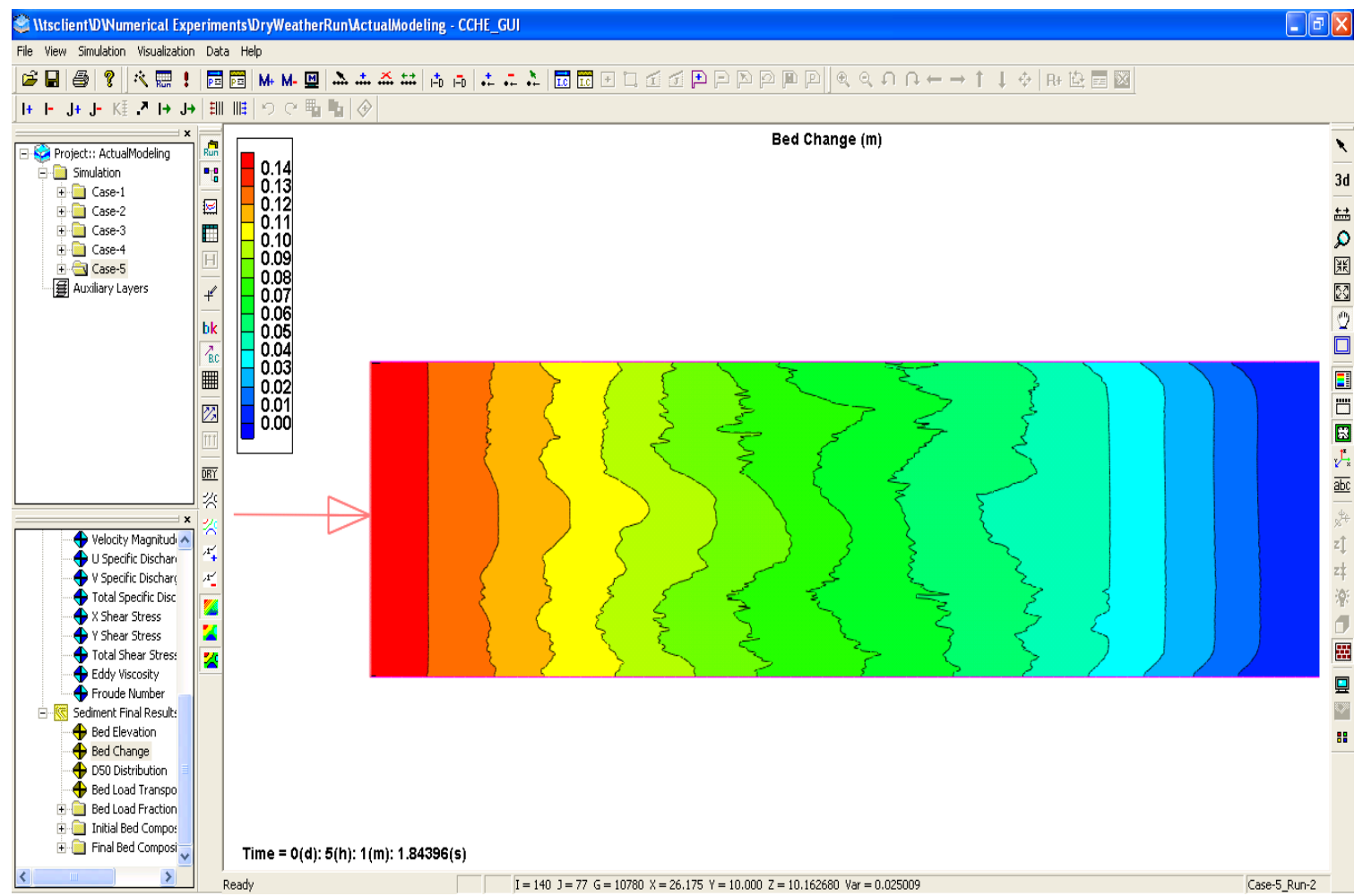

Figure U-10: Bed change for dry weather condition (with incoming sediment) at upstream boundary after 5 -hr simulation. 


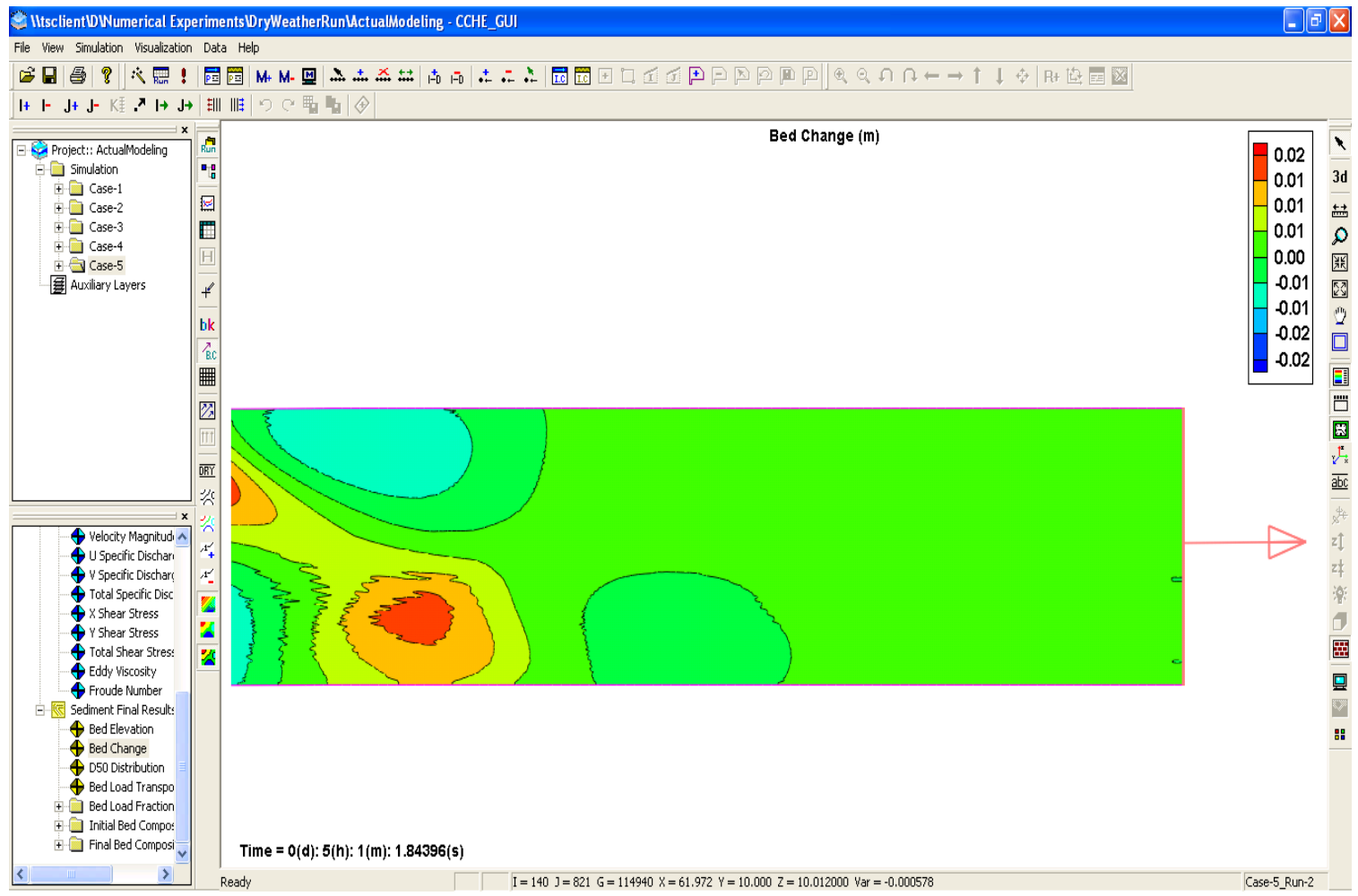

Figure U-11: Bed change for dry weather condition (with incoming sediment) at downstream boundary after 5-hr simulation.

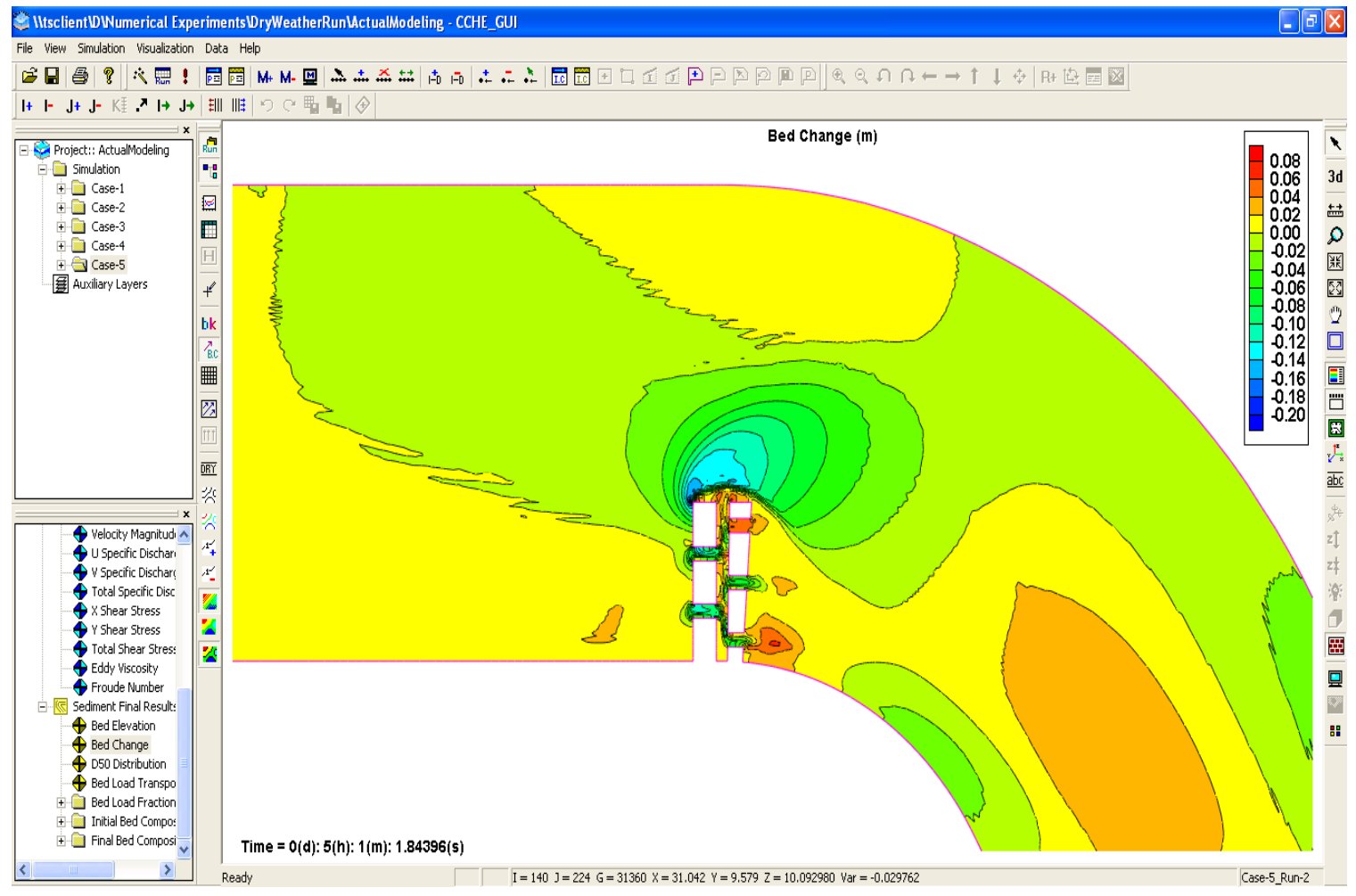

Figure U-12: Bed change for dry weather condition (with incoming sediment) at meander \#1 after 5-hr simulation. 


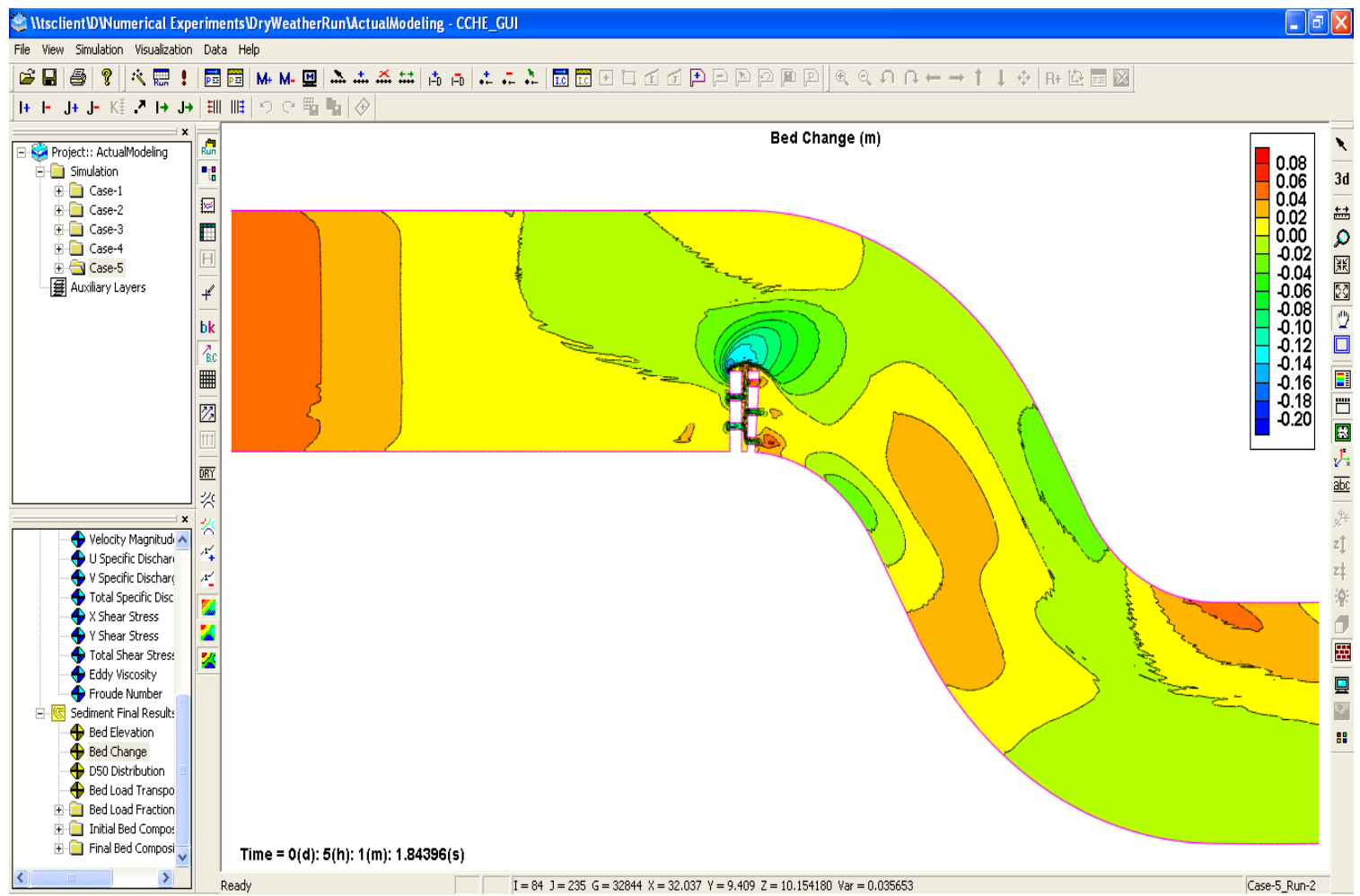

Figure U-13: Bed change for dry weather condition (with incoming sediment) between meanders \#1 and \#2 after 5-hr simulation.

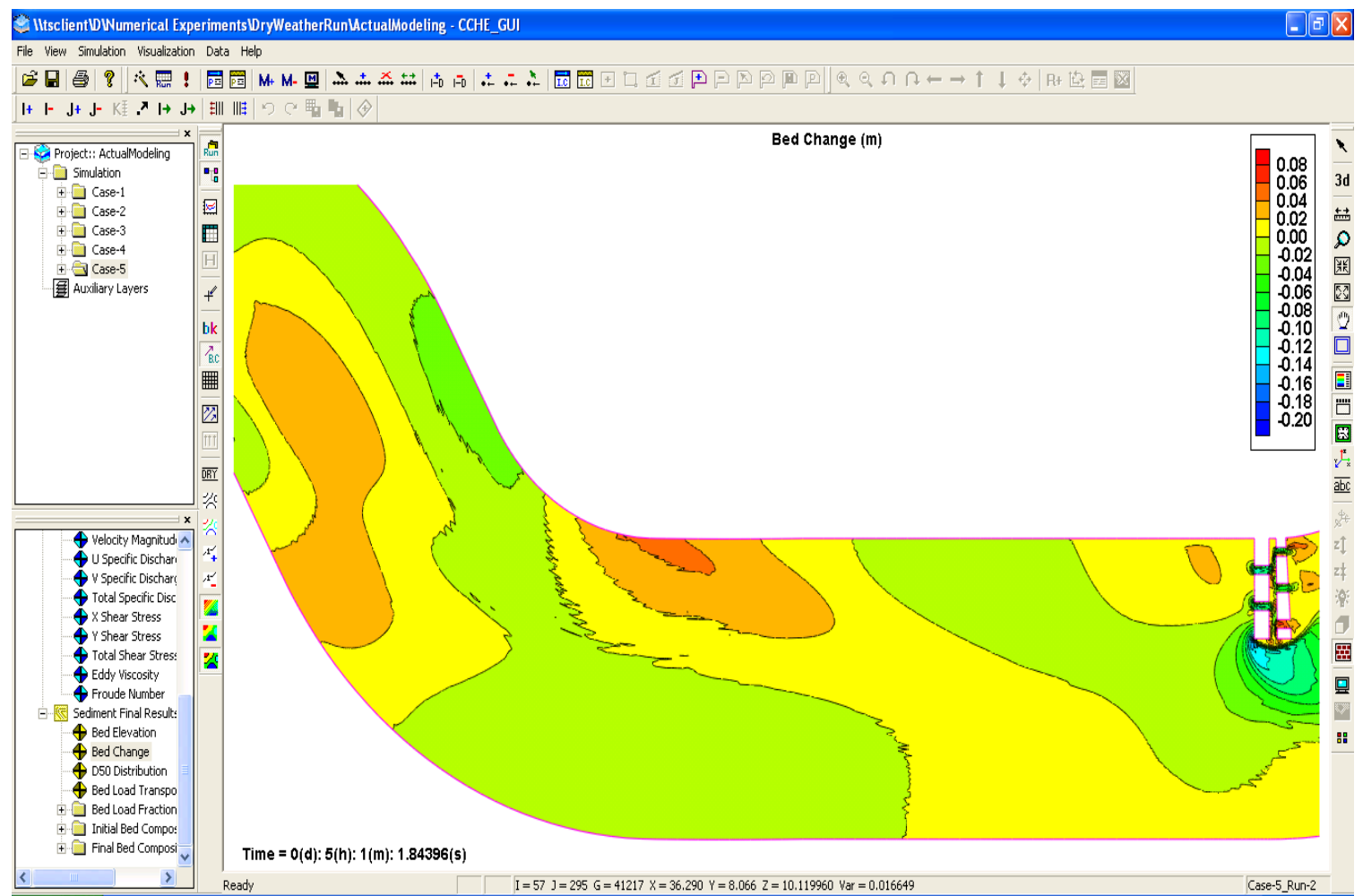

Figure U-14: Bed change for dry weather condition (with incoming sediment) between meanders \#2 and \#3 after 5-hr simulation. 


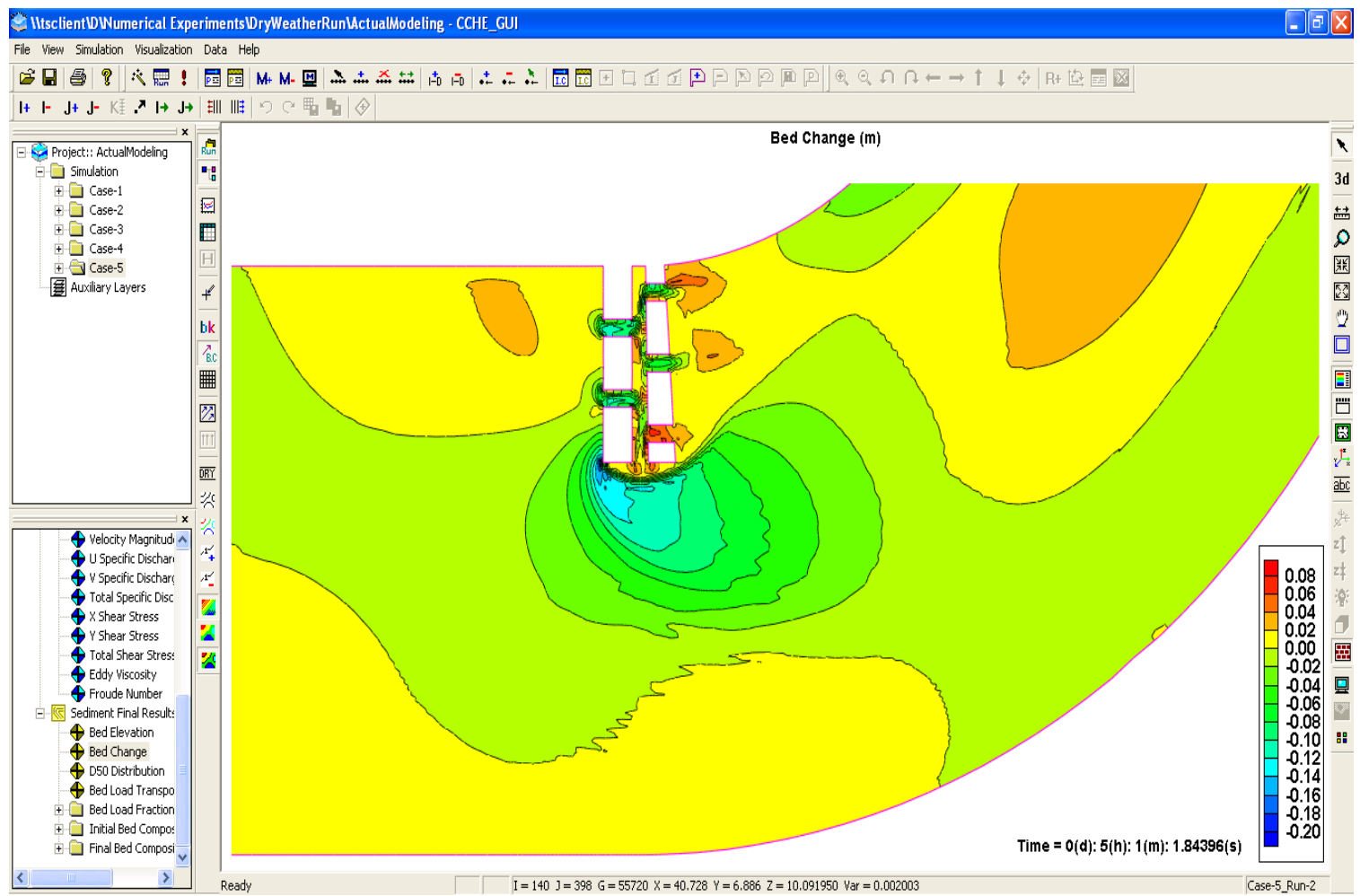

Figure U-15: Bed change for dry weather condition (with incoming sediment) at meander \#3 after 5-hr simulation.

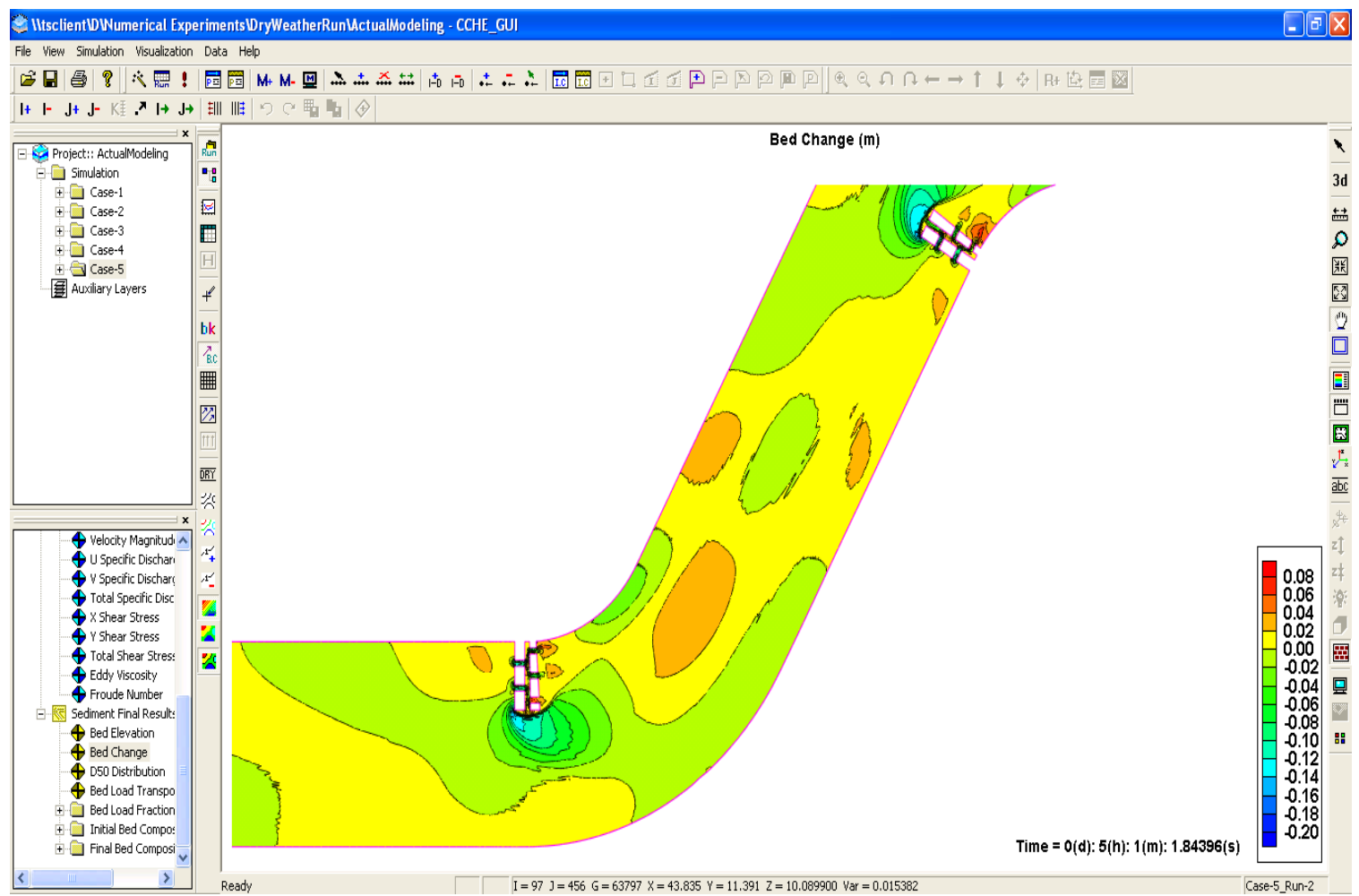

Figure U-16: Bed change for dry weather condition (with incoming sediment) between meanders \#3 and \#4 after 5-hr simulation. 


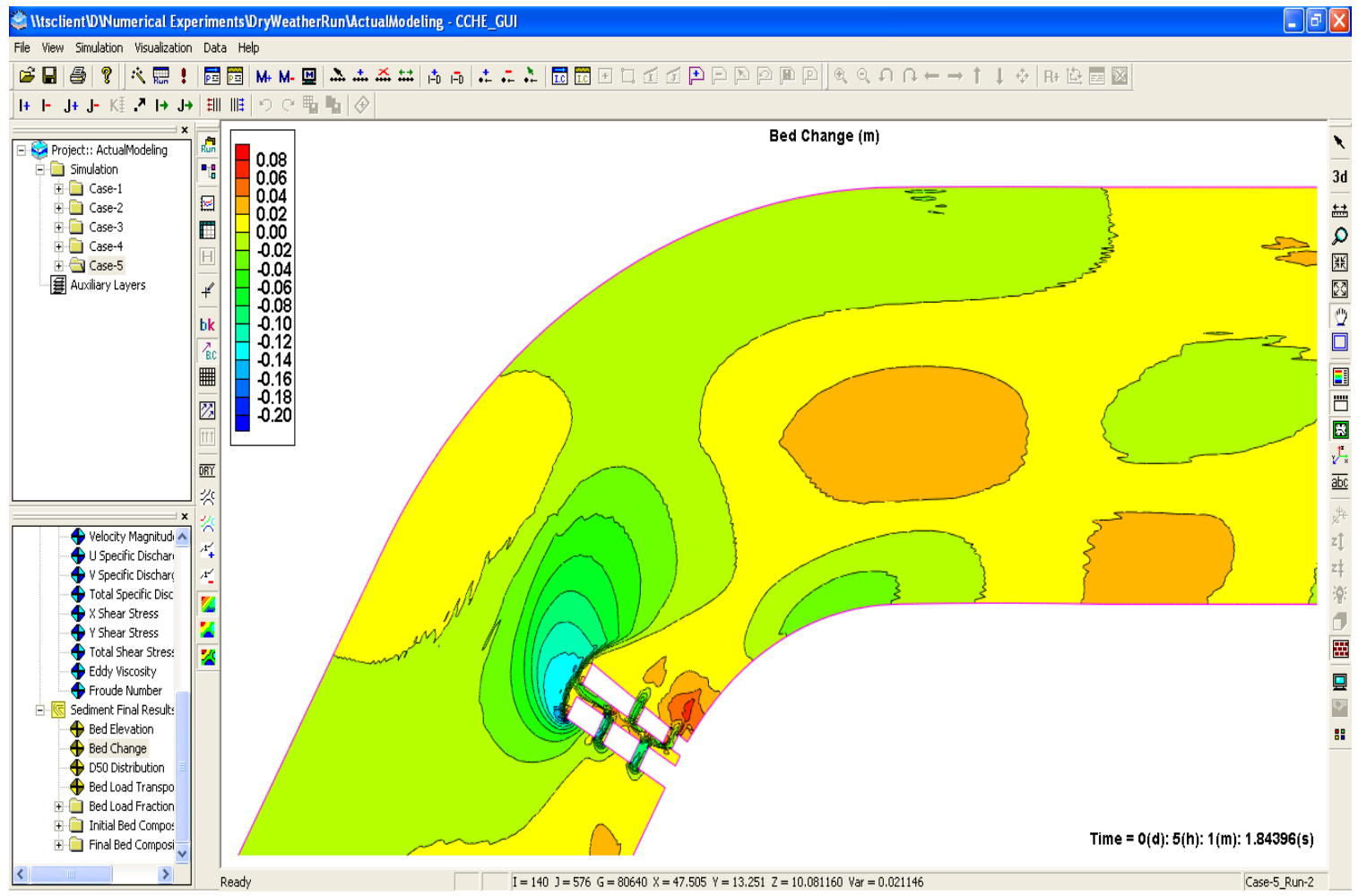

Figure U-17: Bed change for dry weather condition (with incoming sediment) at meander \#4 after 5-hr simulation.

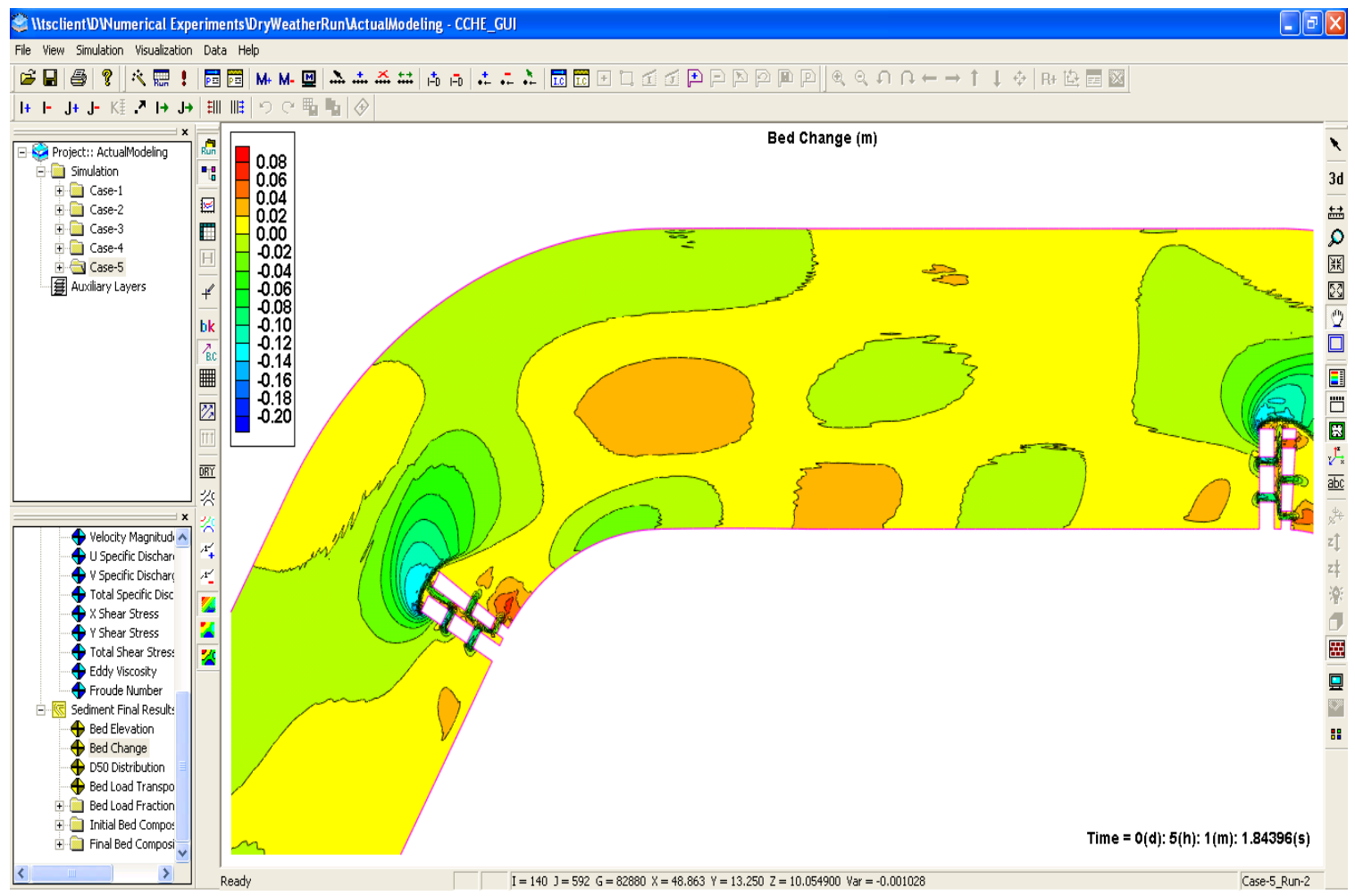

Figure U-18: Bed change for dry weather condition (with incoming sediment) between meanders \#4 and \#5 after 5 -hr simulation. 


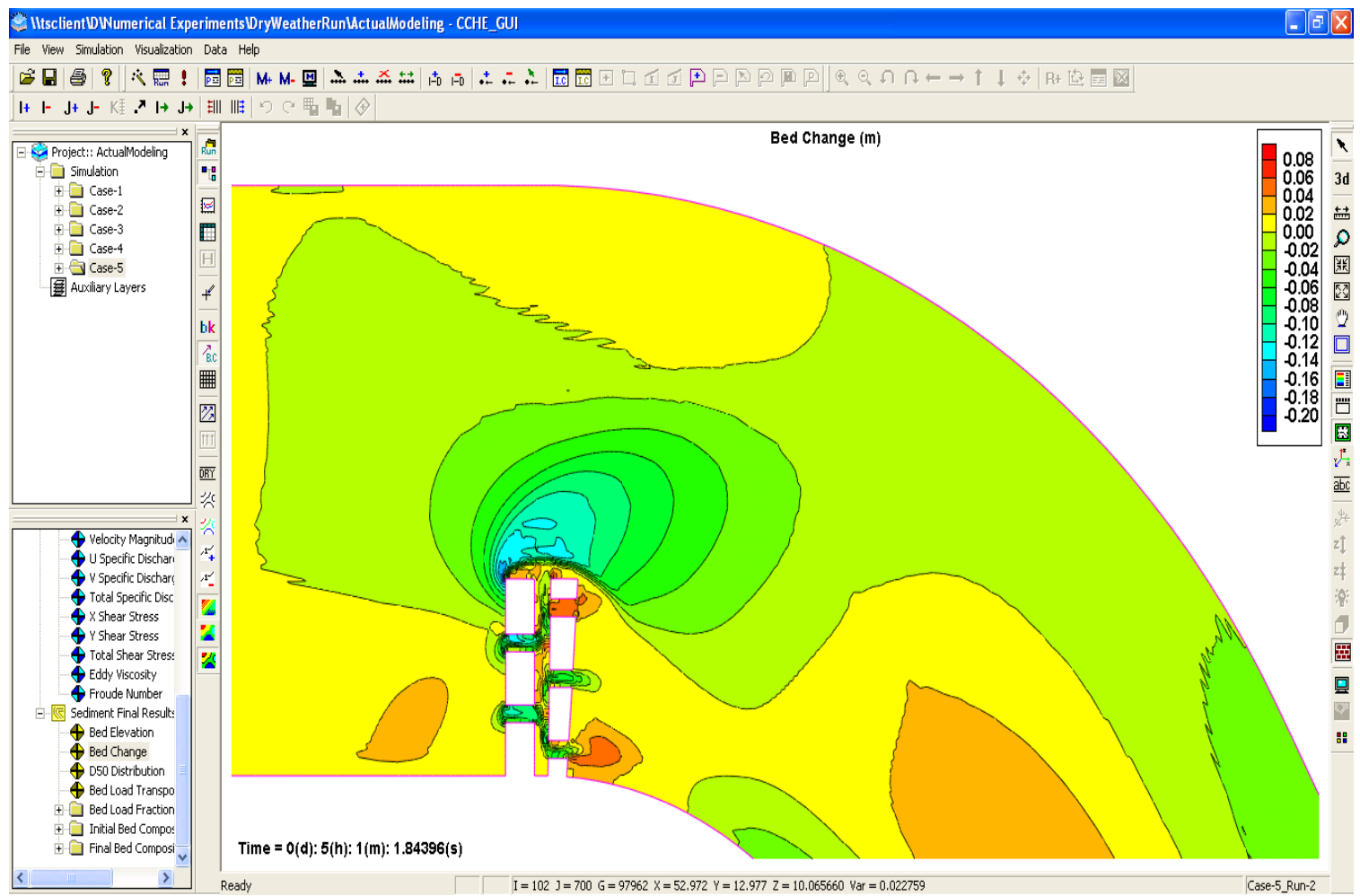

Figure U-19: Bed change for dry weather condition (with incoming sediment) between meander \#5 after 5-hr simulation.

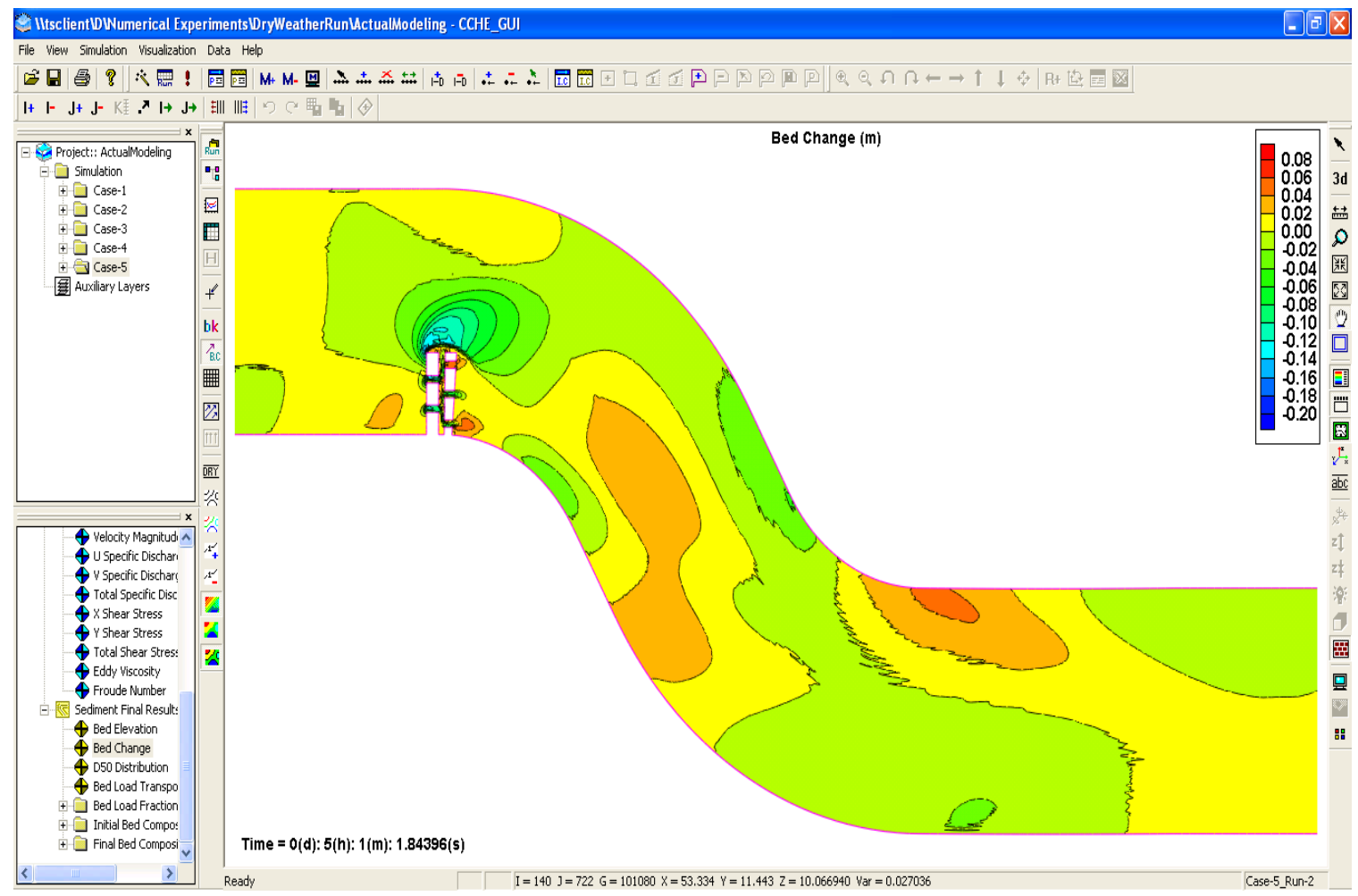

Figure U-20: Bed change for dry weather condition (with incoming sediment) between meanders \#5 and \#6 after 5-hr simulation. 


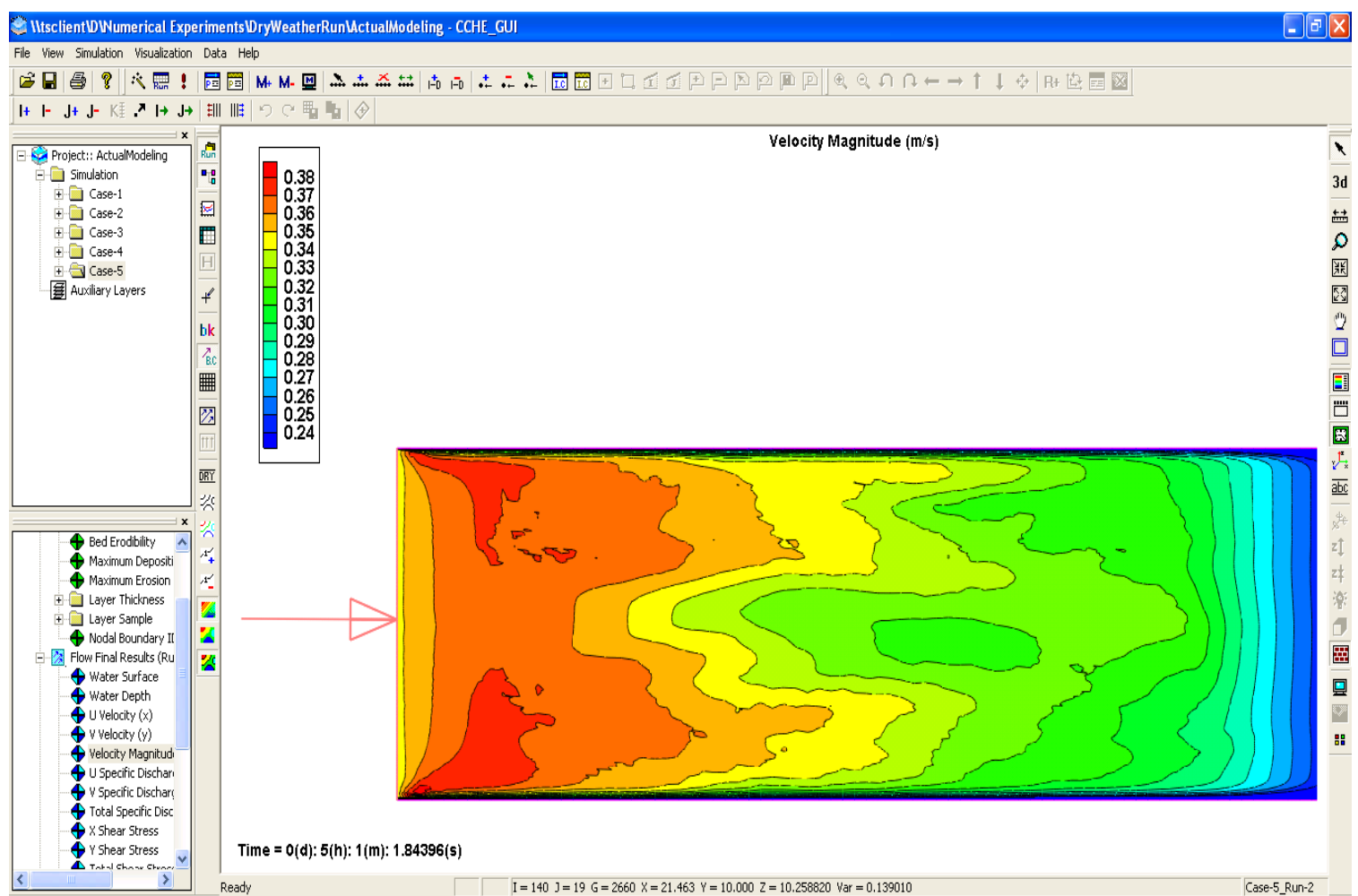

Figure U-21: Velocity magnitude for dry weather condition (with incoming sediment) at upstream boundary after 5-hr simulation.

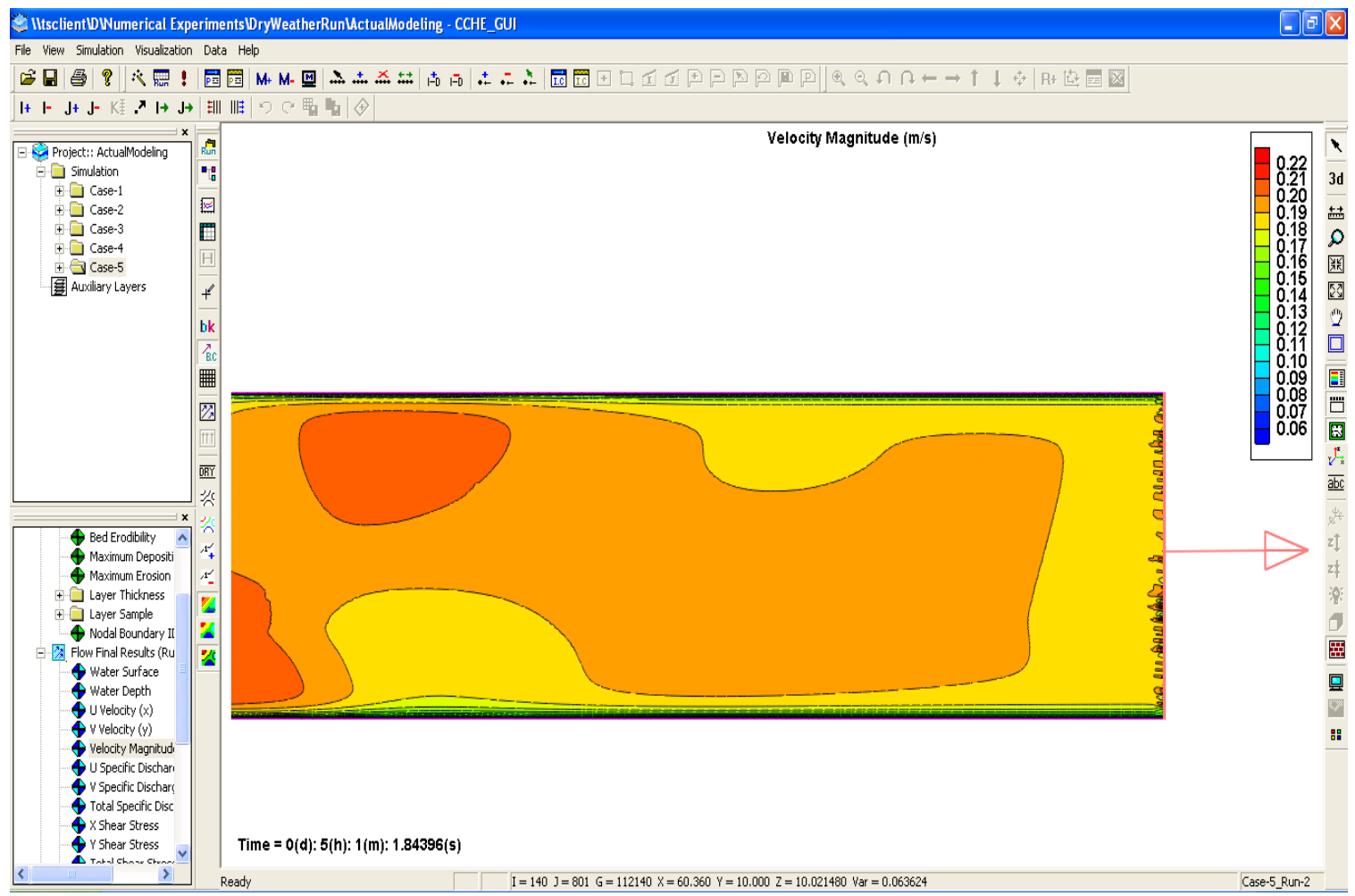

Figure U-22: Velocity magnitude for dry weather condition (with incoming sediment) at downstream boundary after 5 -hr simulation. 


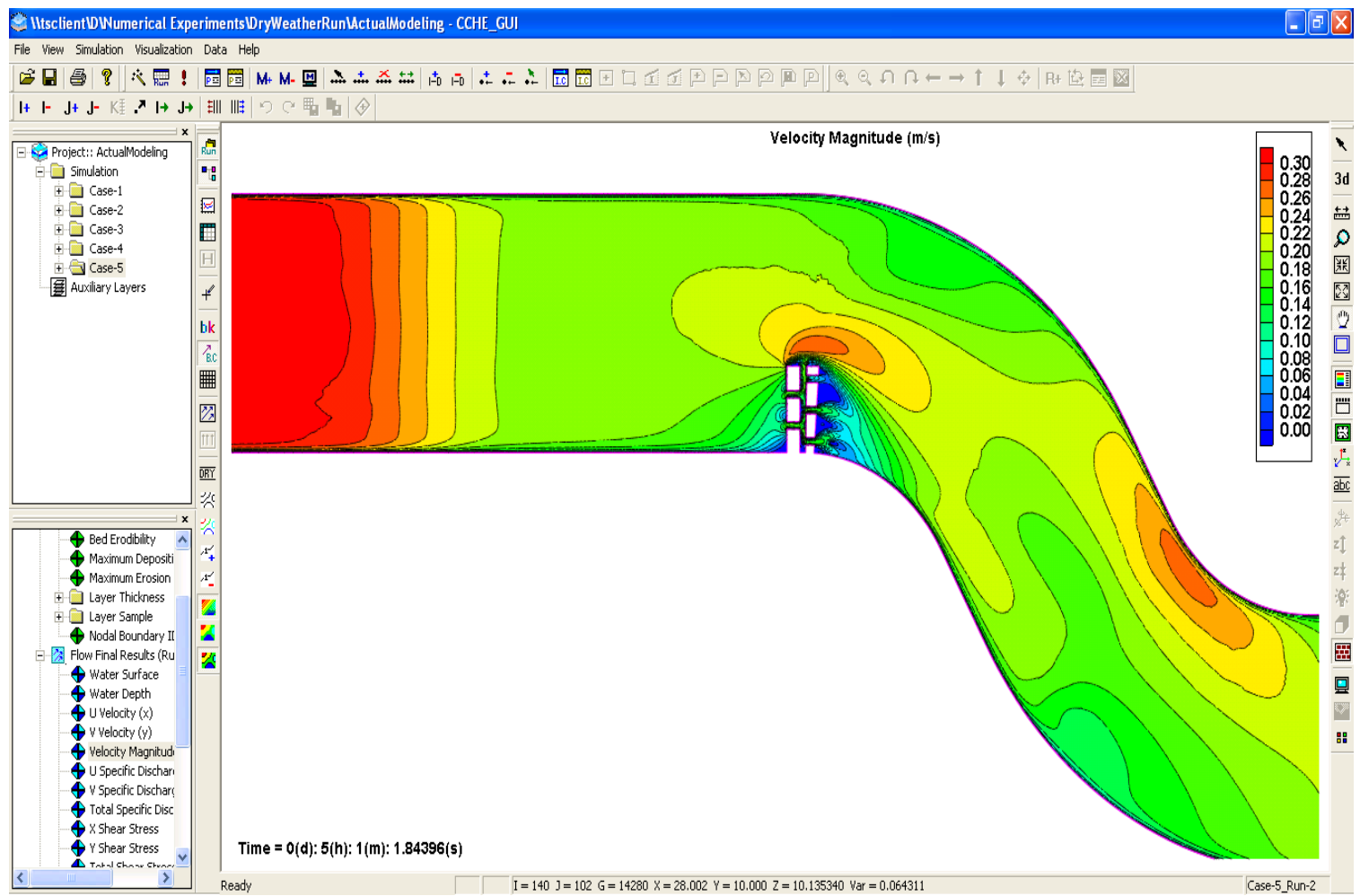

Figure U-23: Velocity magnitude for dry weather condition (with incoming sediment) between meanders \#1 and \#2 after 5-hr simulation.

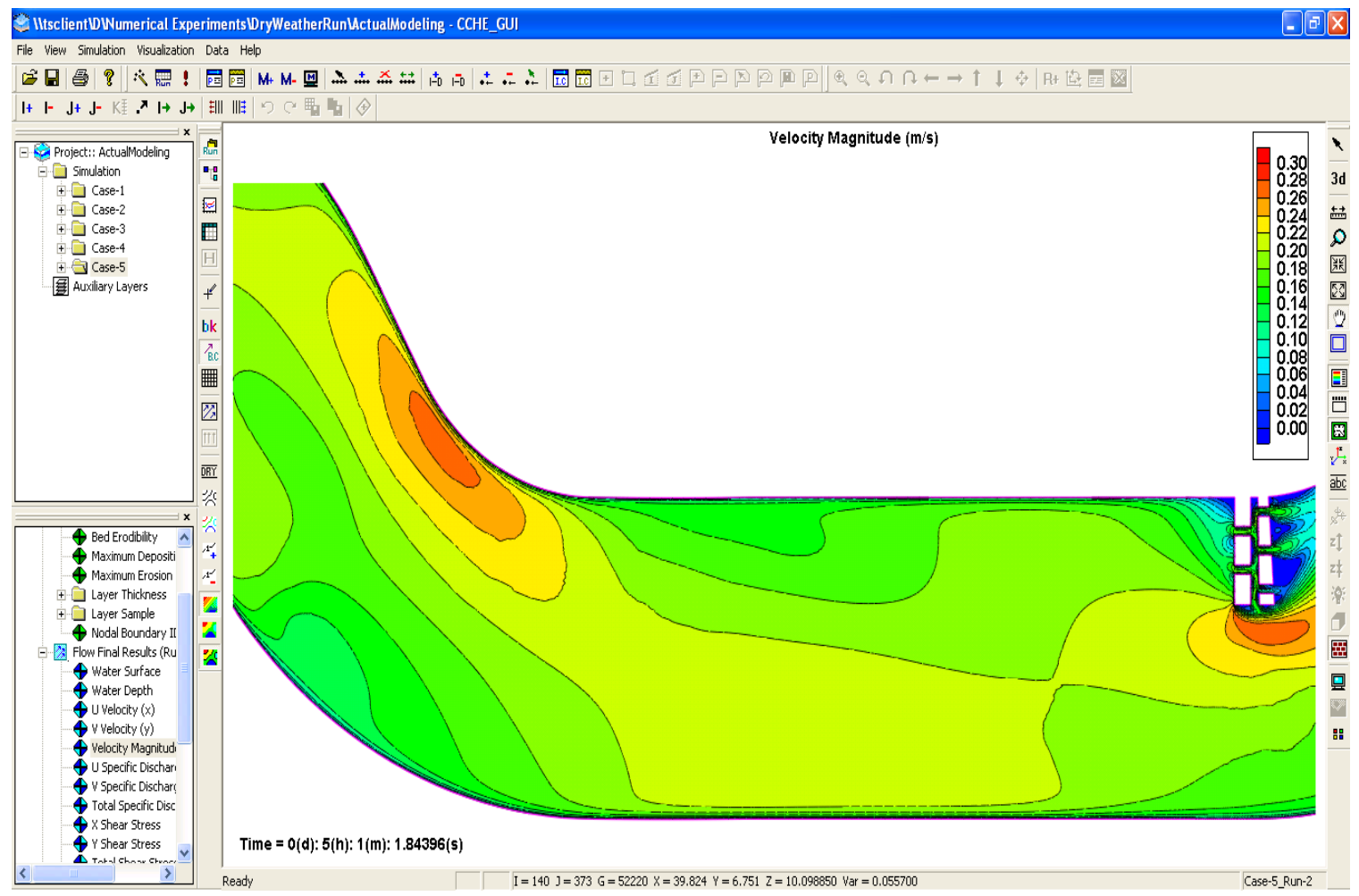

Figure U-24: Velocity magnitude for dry weather condition (with incoming sediment) between meanders \#2 and \#3 after 5-hr simulation. 


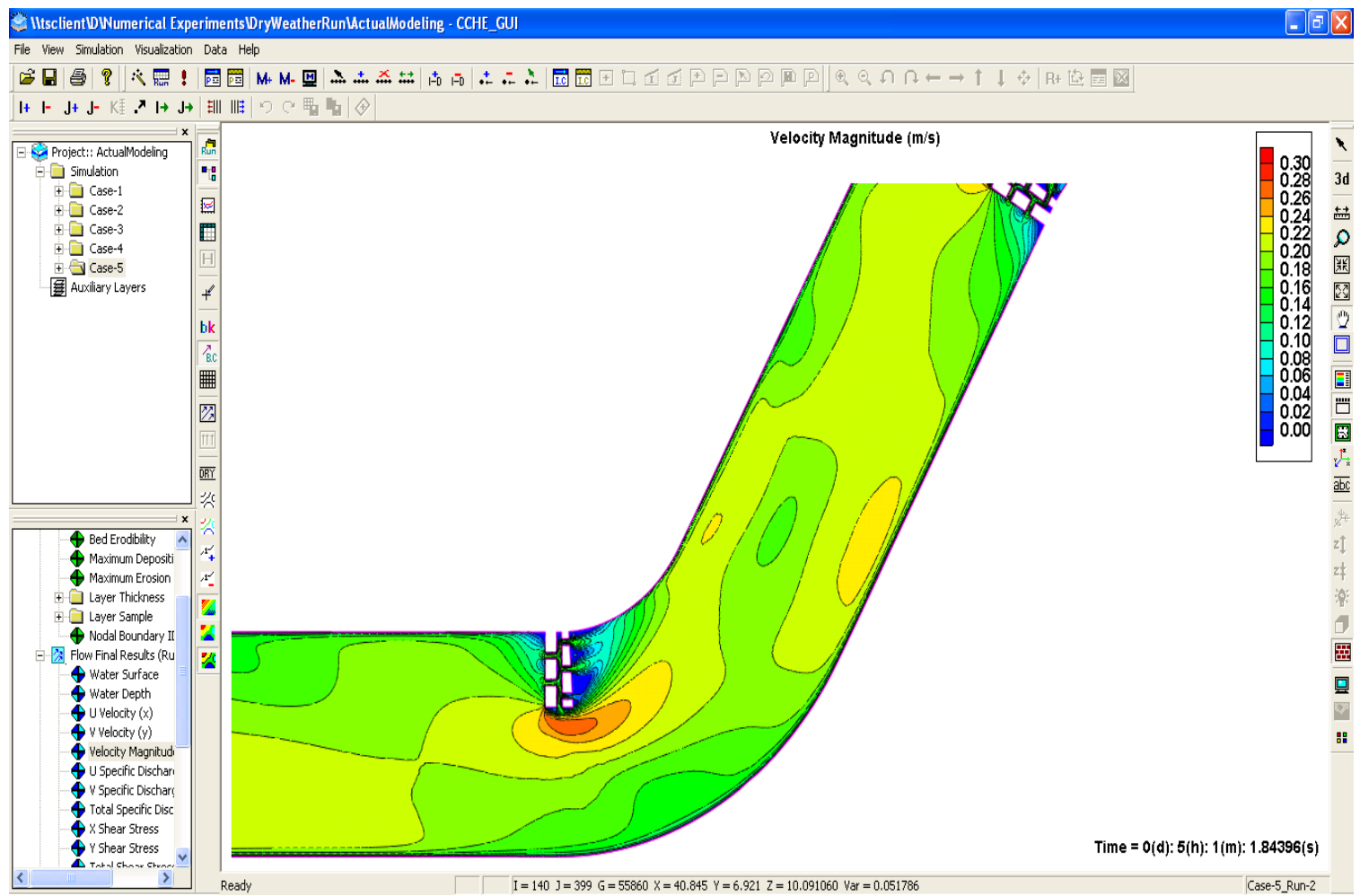

Figure U-25: Velocity magnitude for dry weather condition (with incoming sediment) between meanders \#3 and \#4 after 5-hr simulation.

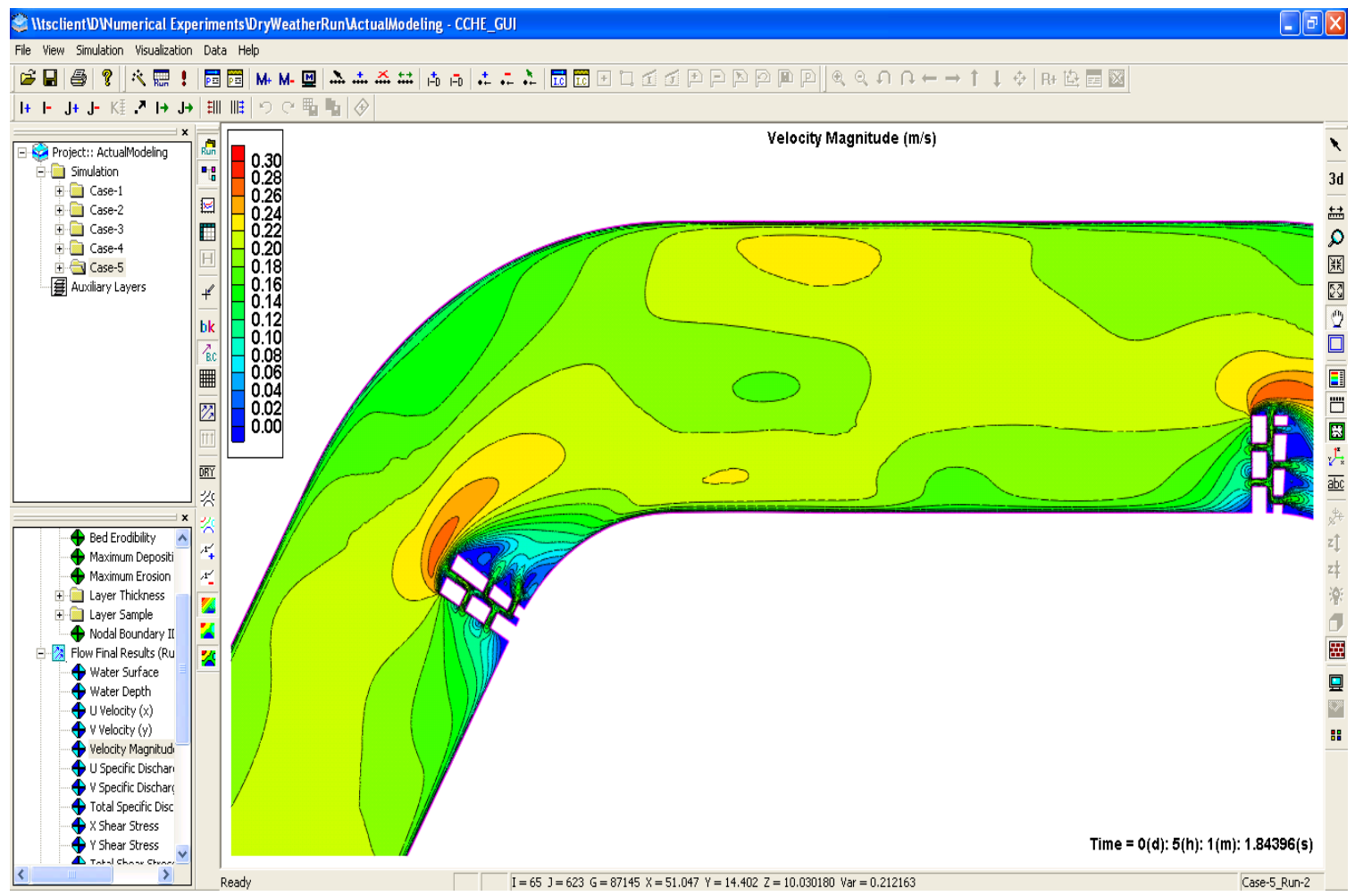

Figure U-26: Velocity magnitude for dry weather condition (with incoming sediment) between meanders \#4 and \#5 after 5-hr simulation. 


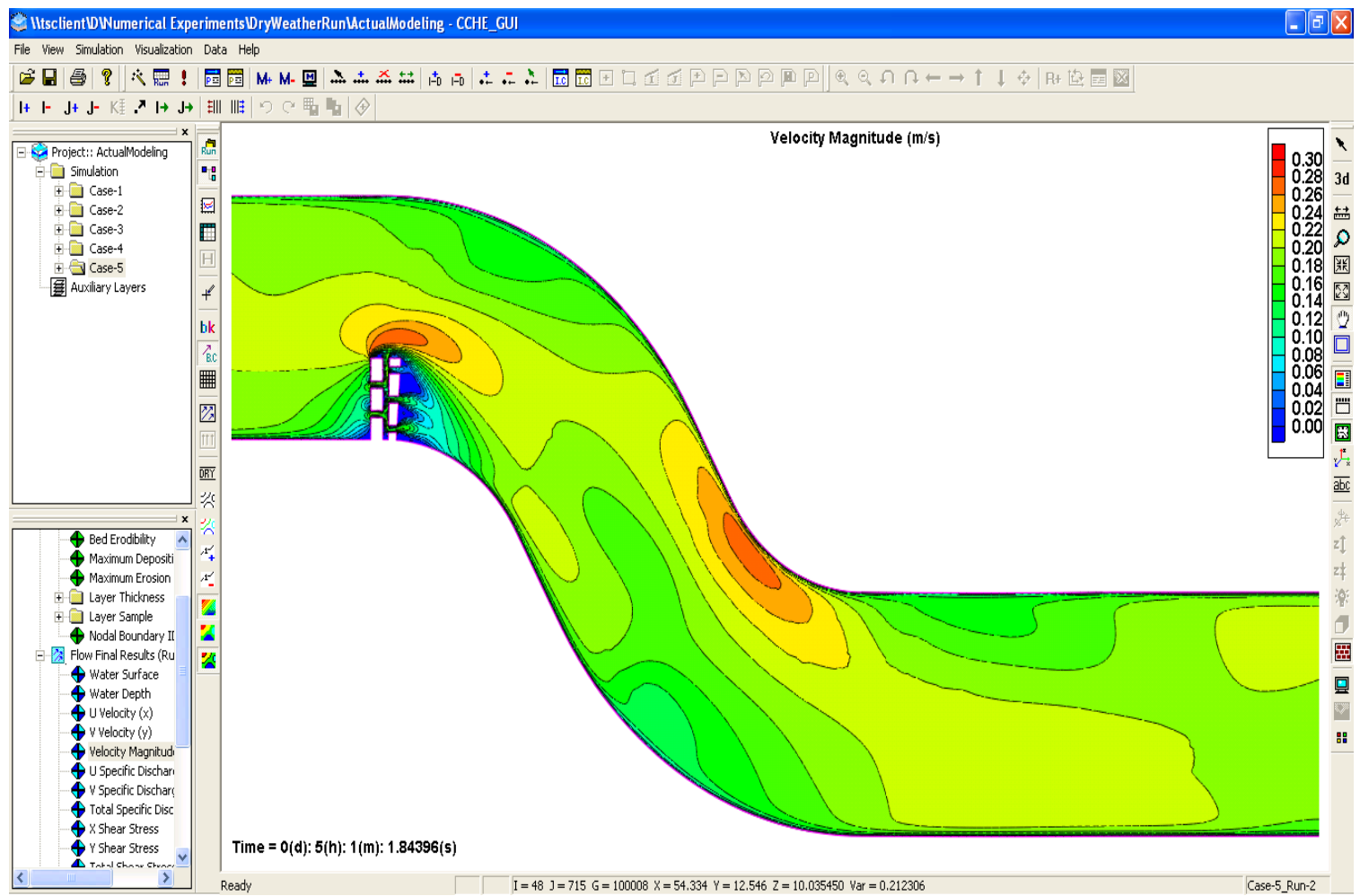

Figure U-27: Velocity magnitude for dry weather condition (with incoming sediment) between meanders \#5 and \#6 after 5-hr simulation.

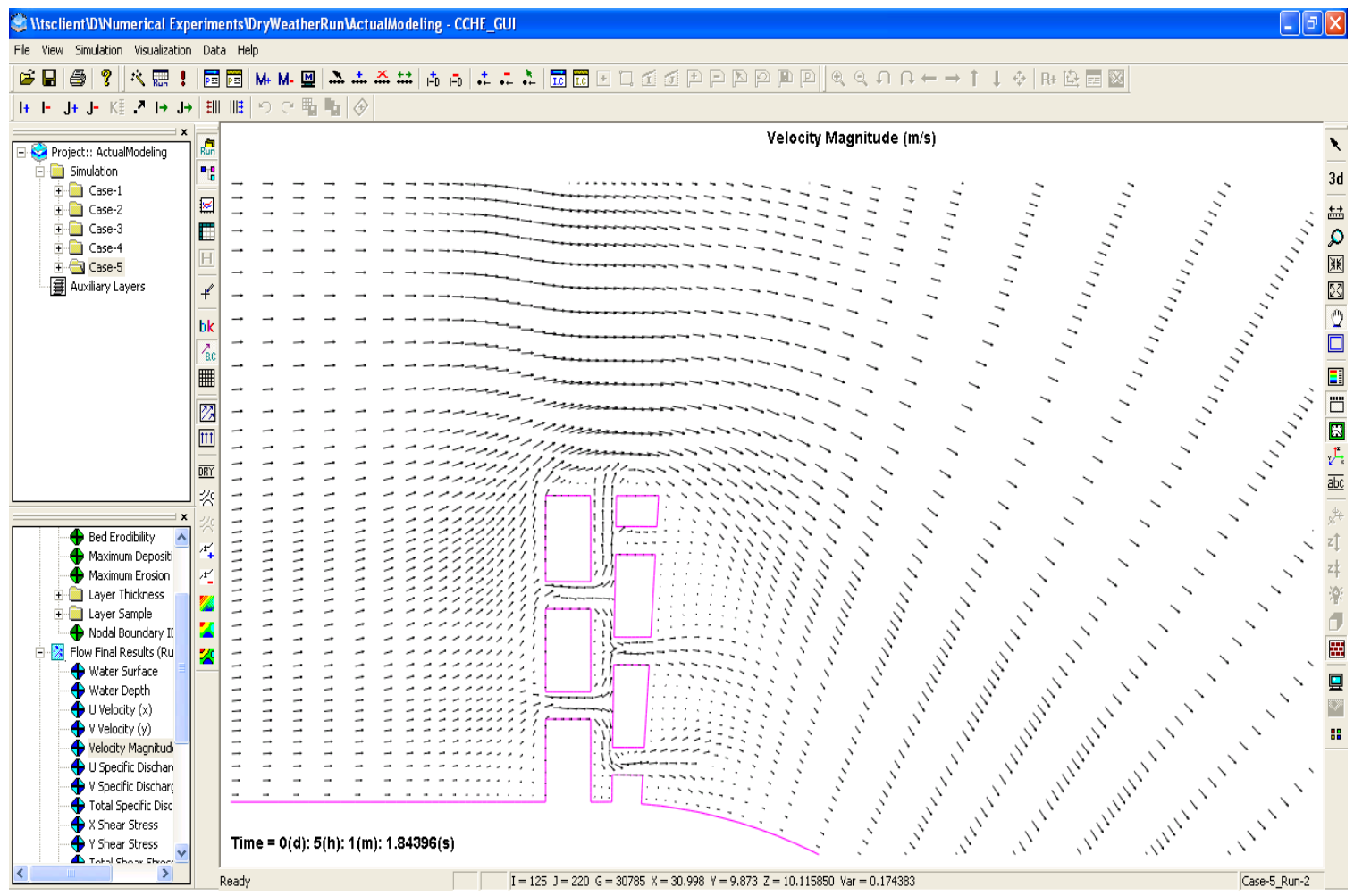

Figure U-28: Velocity direction for dry weather condition (with incoming sediment) at meanders \#1 after 5-hr simulation. 


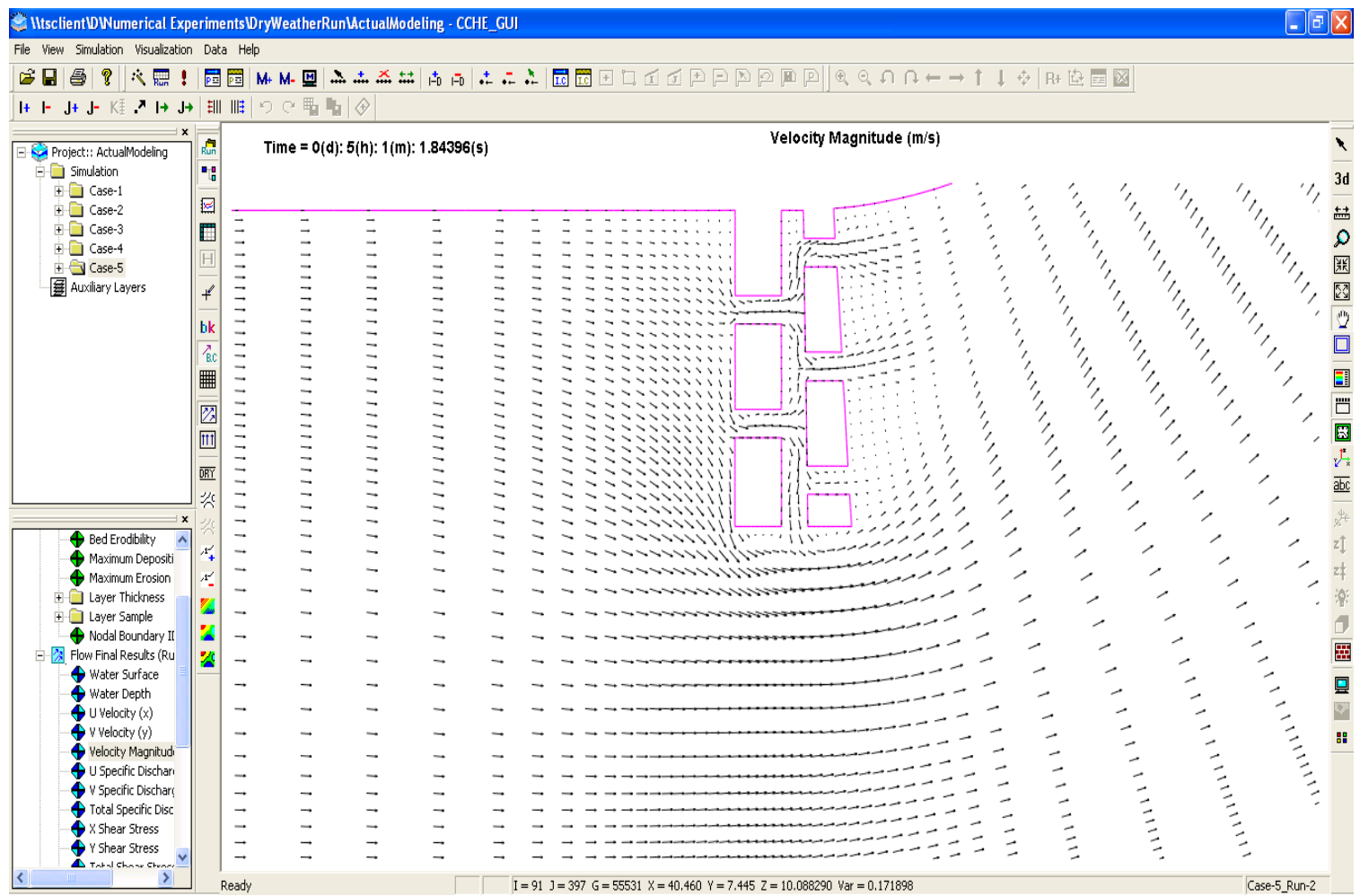

Figure U-29: Velocity direction for dry weather condition (with incoming sediment) at meanders \#3 after 5-hr simulation.

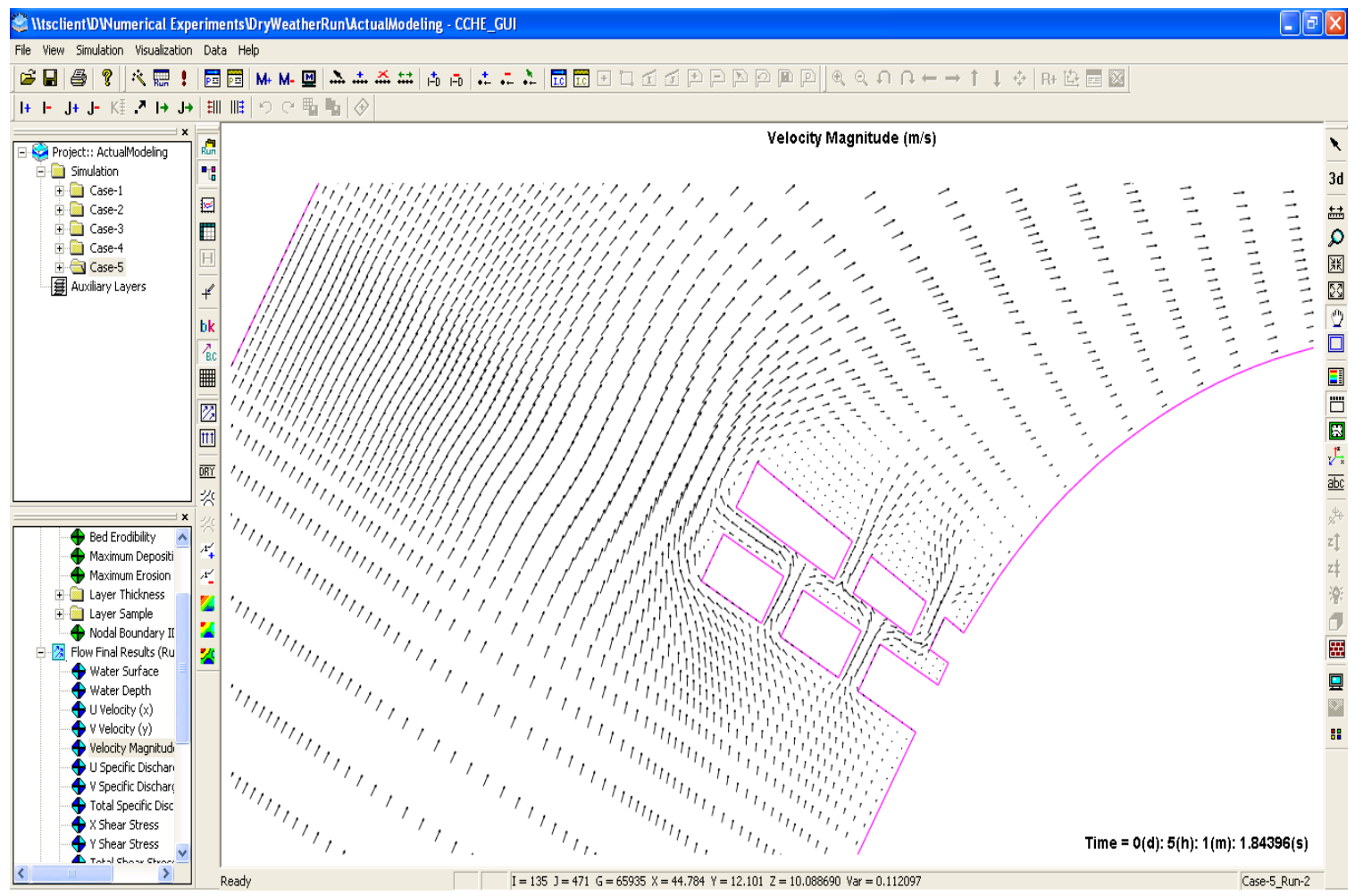

Figure U-30: Velocity direction for dry weather condition (with incoming sediment) at meanders \#4 after 5-hr simulation. 


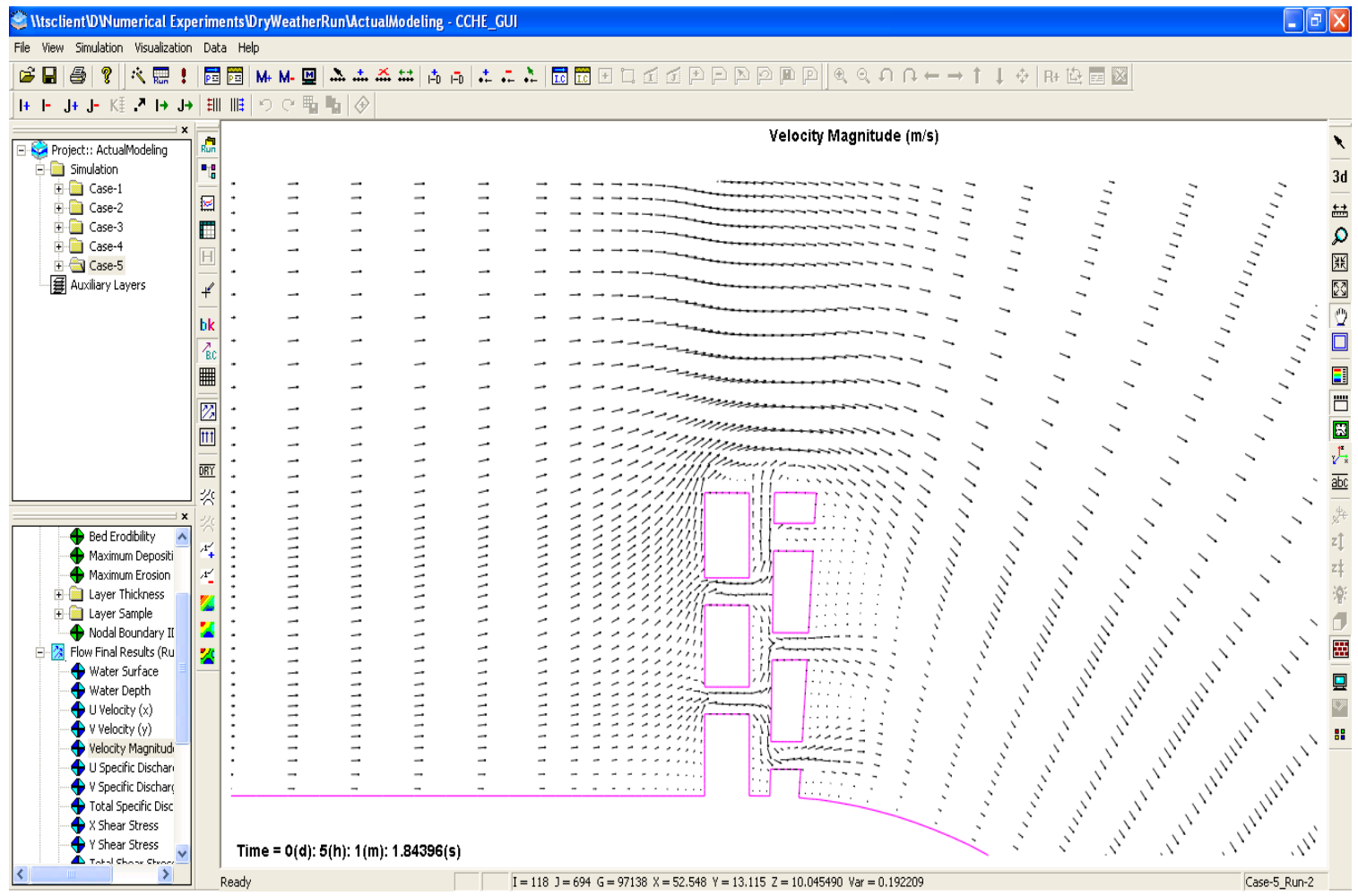

Figure U-31: Velocity direction for dry weather condition (with incoming sediment) at meanders \#5 after 5-hr simulation. 


\section{$5 \mathrm{~cm}$ Below Bankfull of LFC}

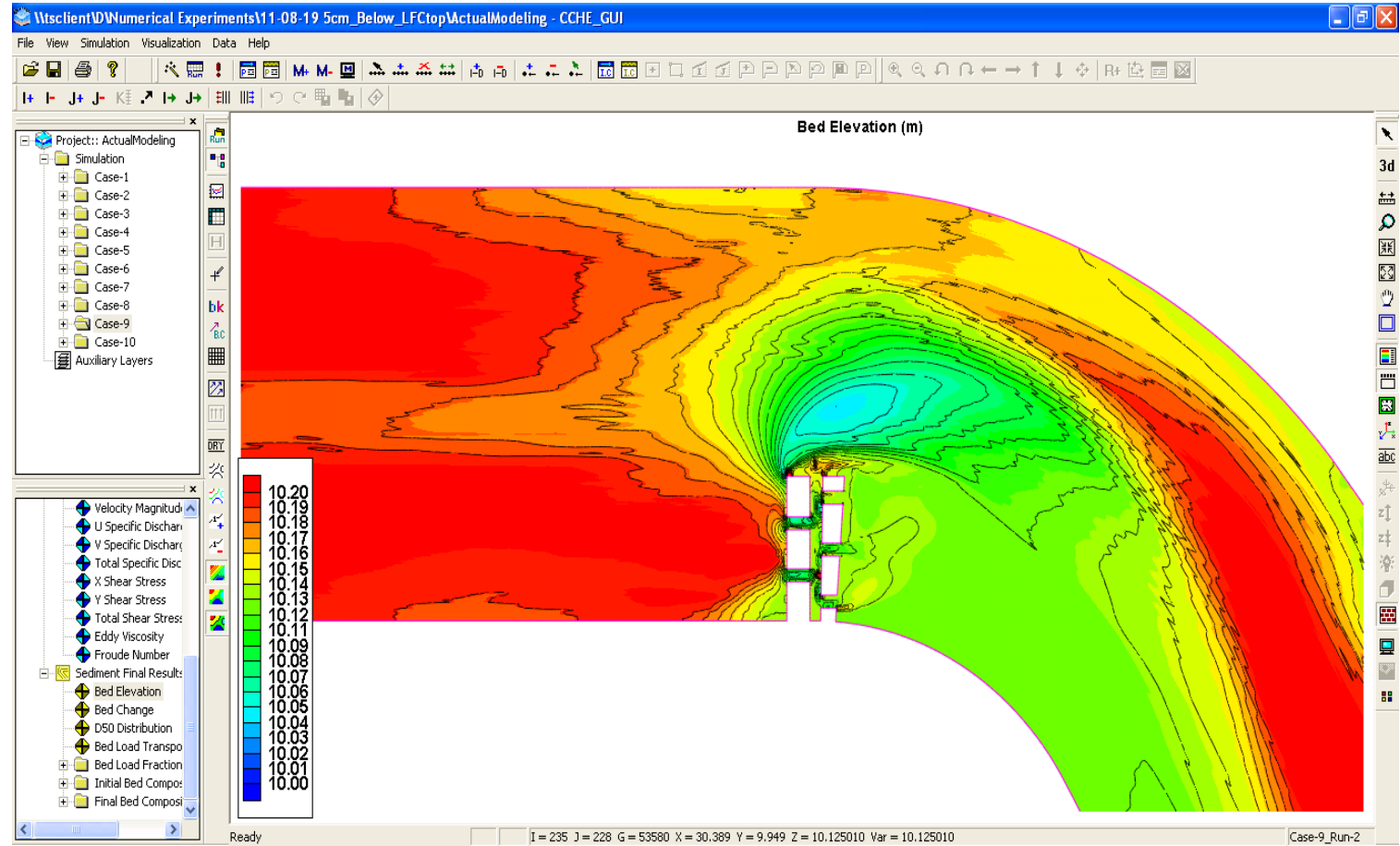

Figure U-32: Bed elevation when water depth of LFC $=40 \mathrm{~cm}$ at meander \#1 (with incoming sediment) after 1-hr flow simulation.

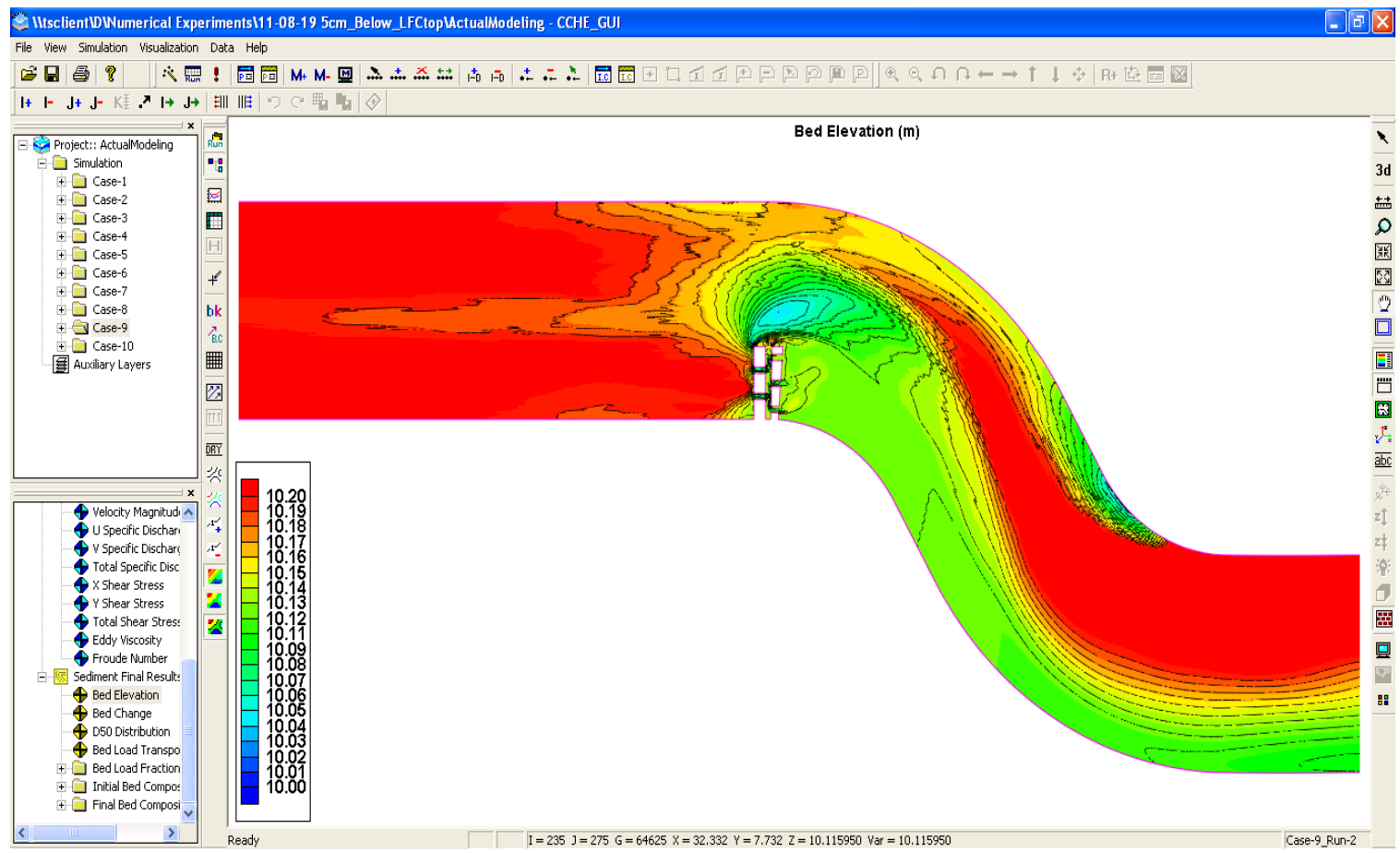

Figure U-33: Bed elevation when water depth of LFC $=40 \mathrm{~cm}$ between meanders \#1 and \#2 (with incoming sediment) after 1-hr flow simulation. 


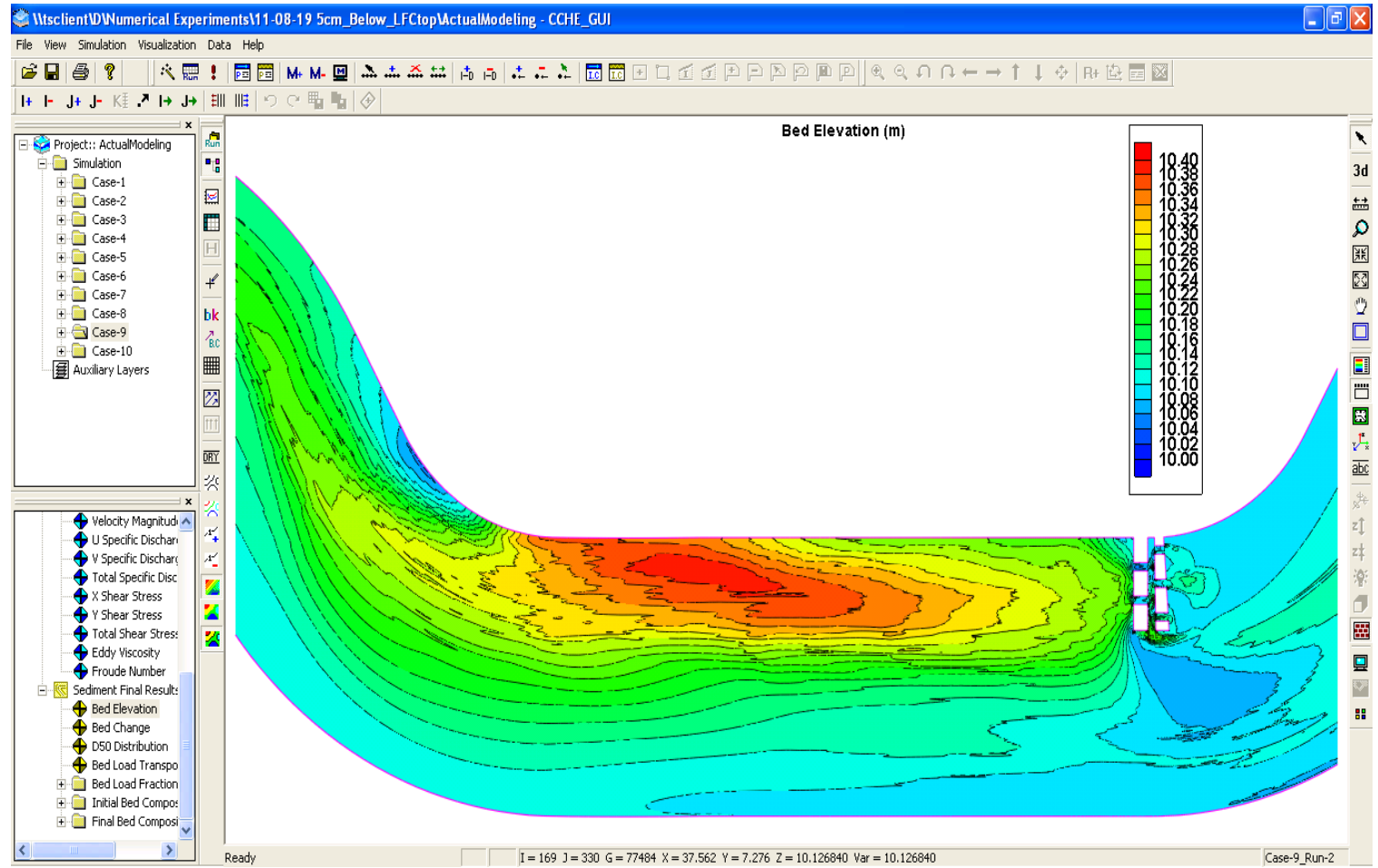

Figure U-34: Bed elevation when water depth of LFC $=40 \mathrm{~cm}$ between meanders \#2 and \#3 (with incoming sediment) after 1-hr flow simulation.

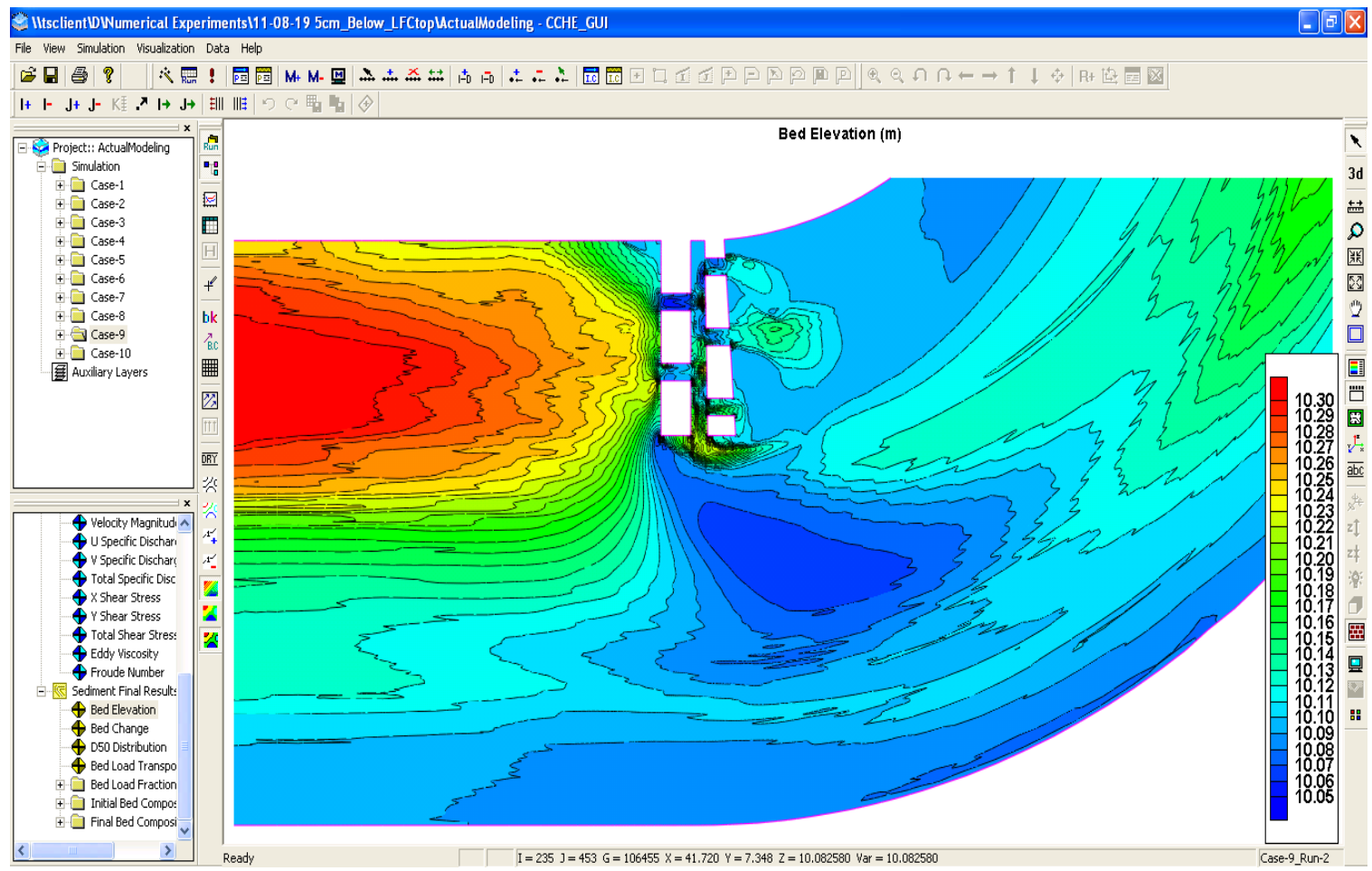

Figure U-35: Bed elevation when water depth of LFC $=40 \mathrm{~cm}$ at meander \#3 (with incoming sediment) after 1-hr flow simulation. 


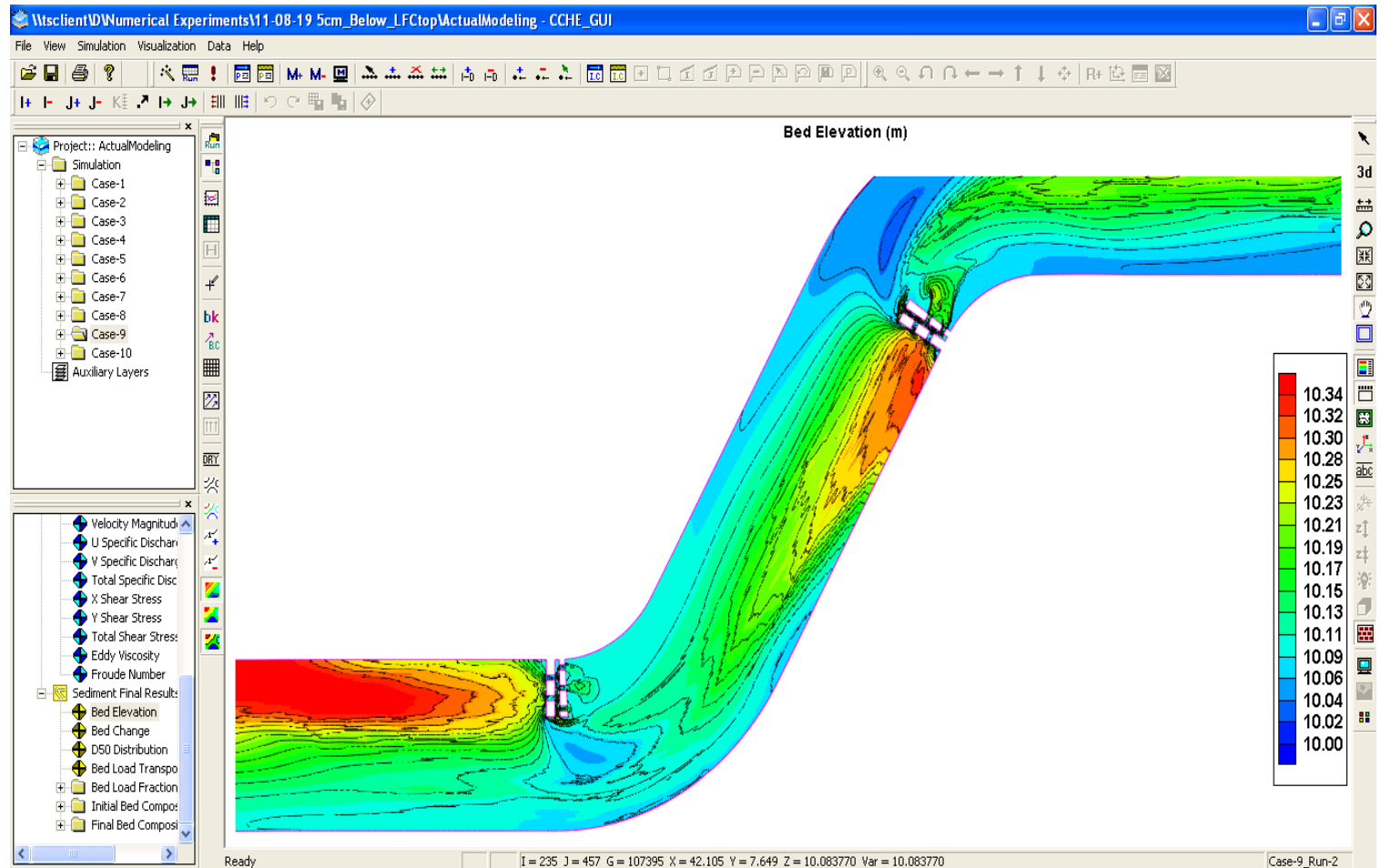

Figure U-36: Bed elevation when water depth of LFC $=40 \mathrm{~cm}$ between meanders \#3 and \#4 (with incoming sediment) after 1-hr flow simulation.

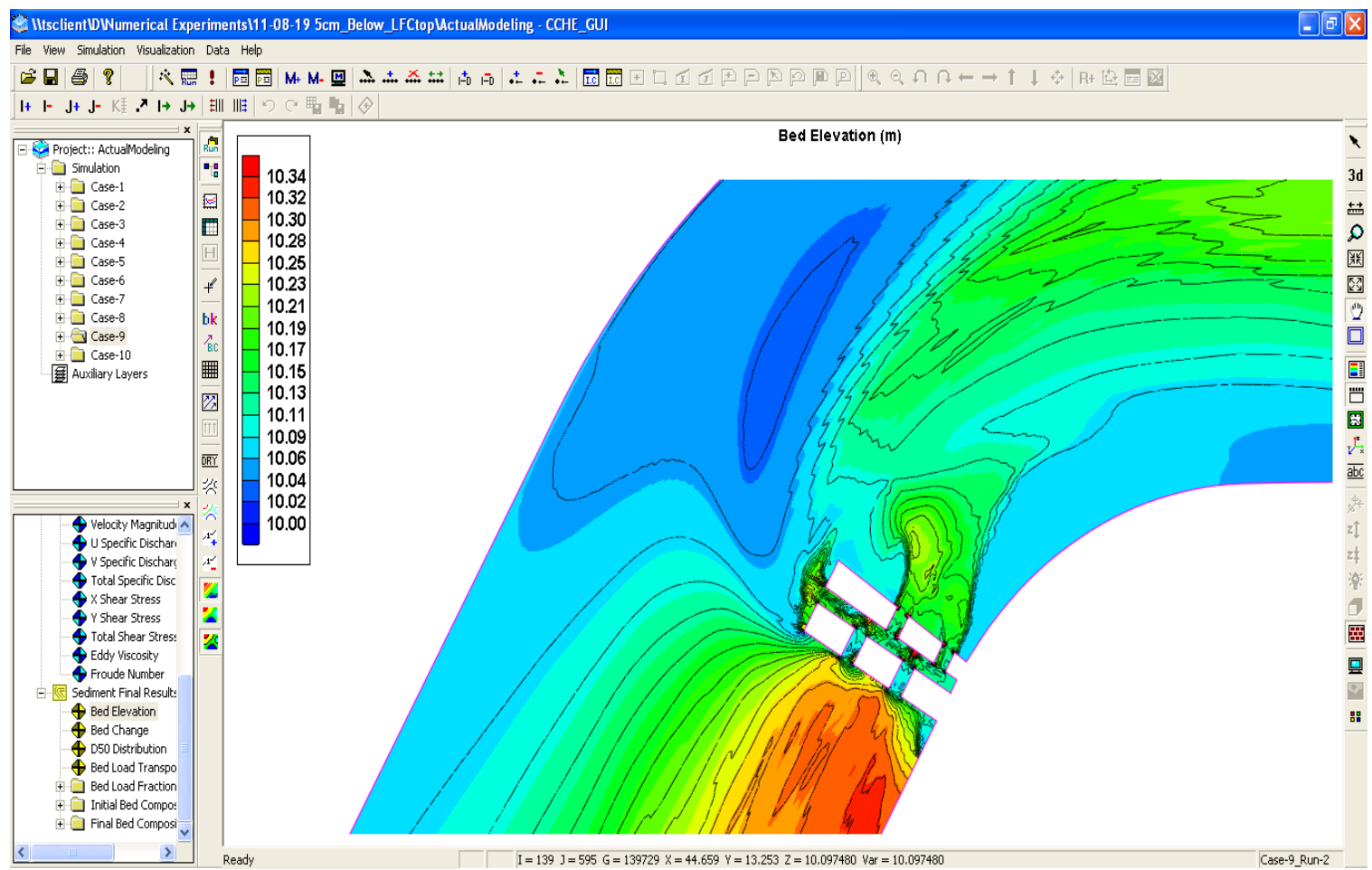

Figure U-37: Bed elevation when water depth of LFC $=40 \mathrm{~cm}$ at meander \#4 (with incoming sediment) after 1-hr flow simulation. 


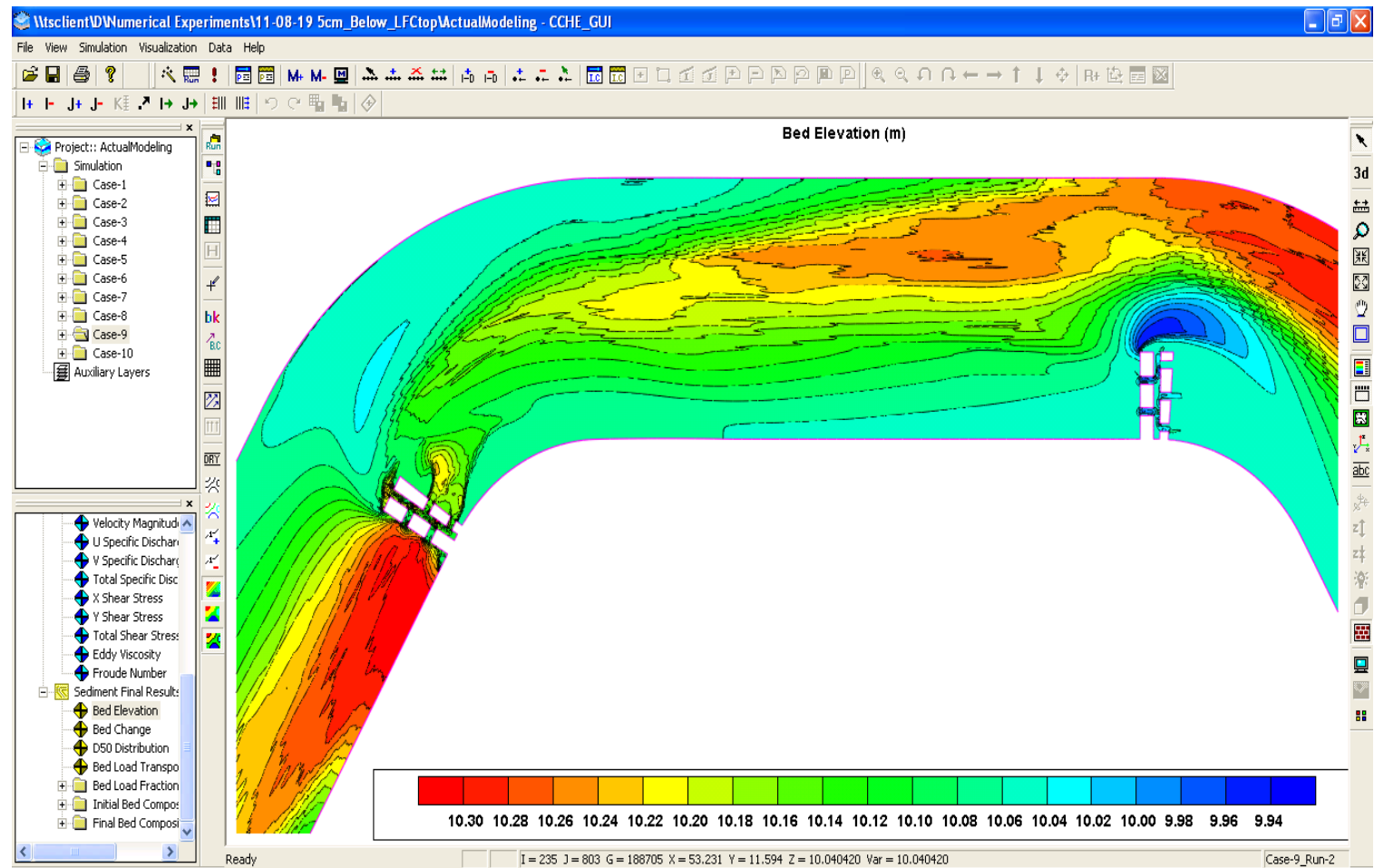

Figure U-38: Bed elevation when water depth of LFC $=40 \mathrm{~cm}$ between meanders \#4 and \#5 (with incoming sediment) after 1-hr flow simulation.

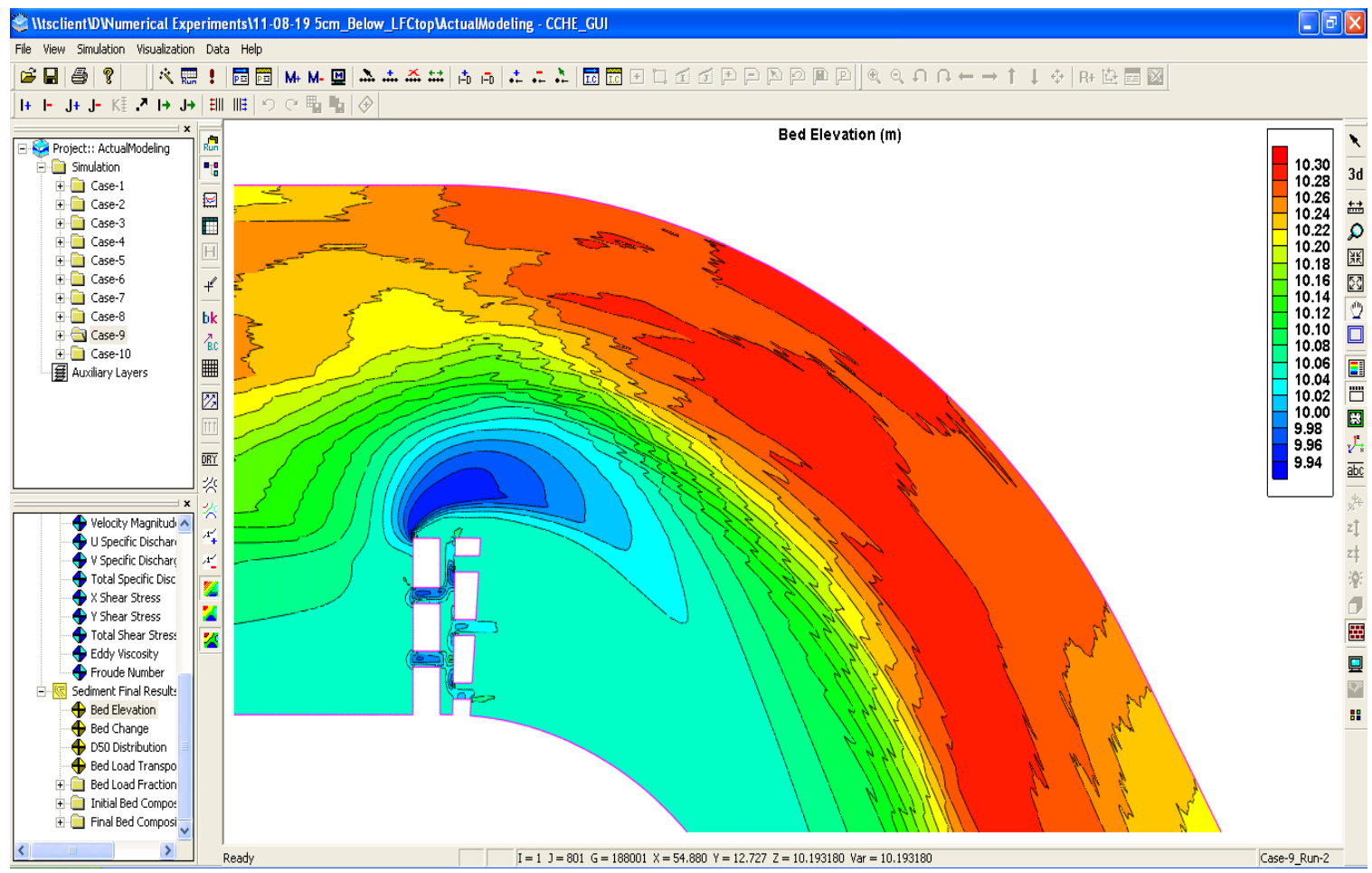

Figure U-39: Bed elevation when water depth of LFC $=40 \mathrm{~cm}$ at meander \#5 (with incoming sediment) after 1-hr flow simulation. 


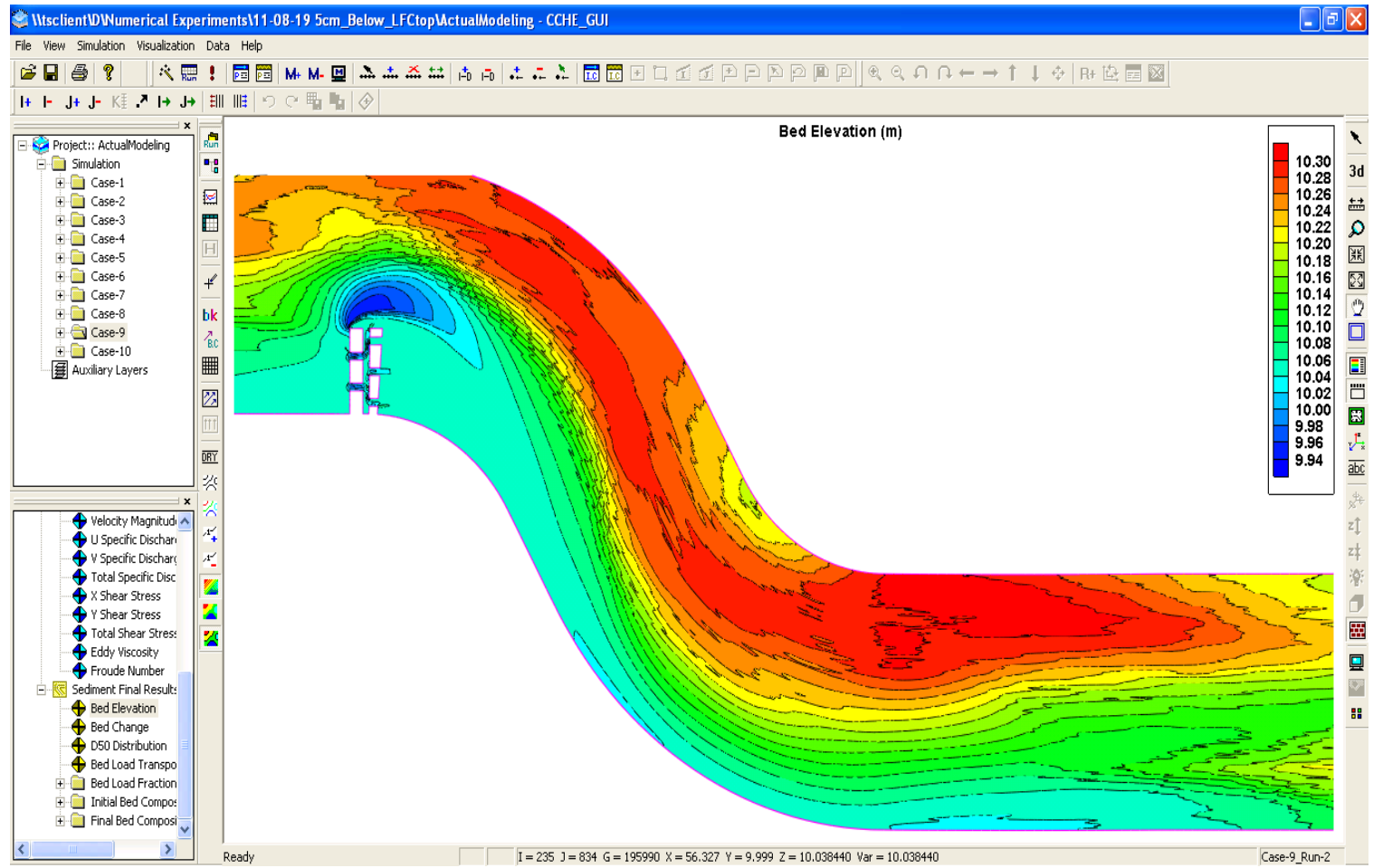

Figure U-40: Bed elevation when water depth of LFC $=40 \mathrm{~cm}$ between meanders \#5 and \#6 (with incoming sediment) after 1-hr flow simulation.

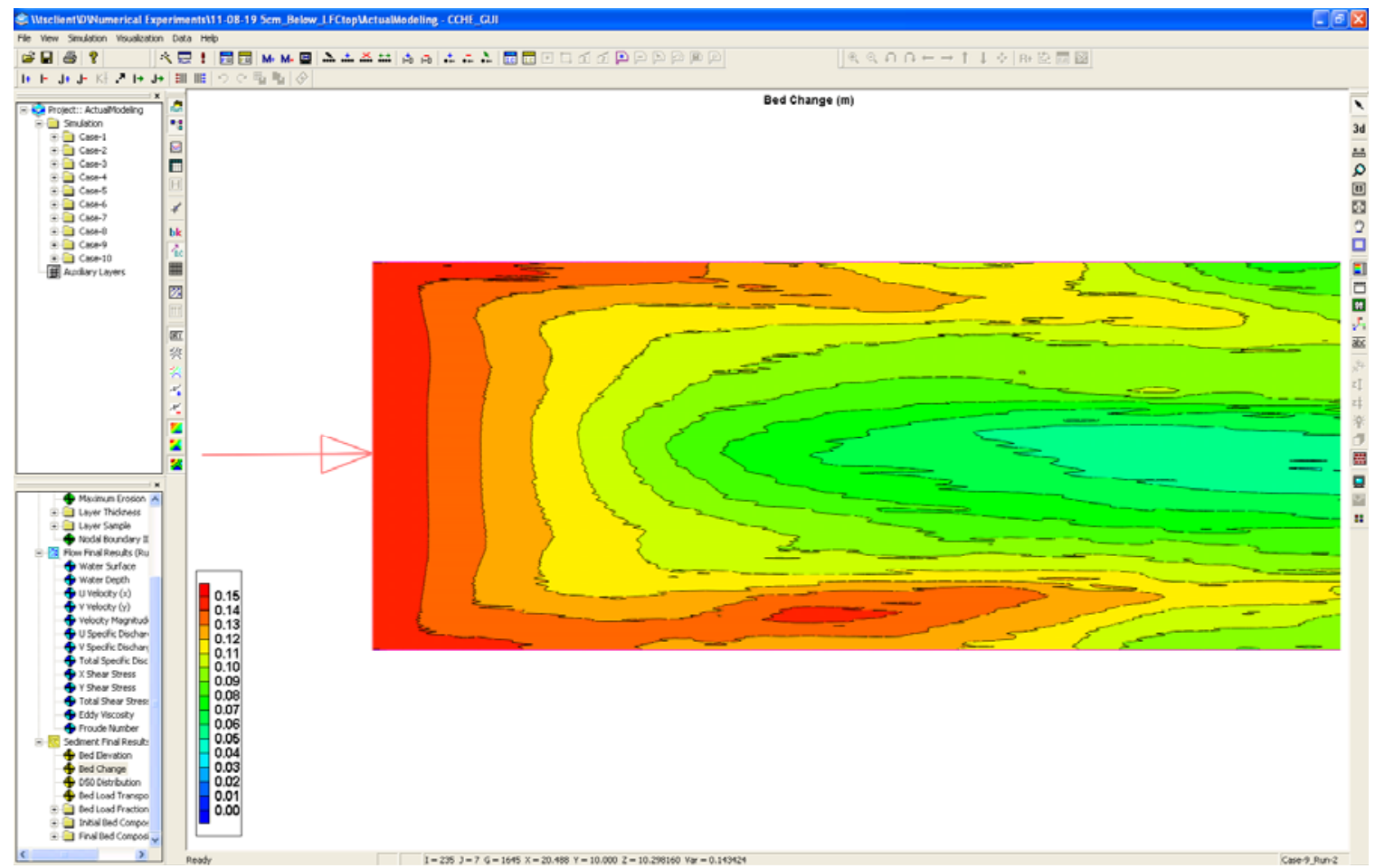

Figure U-41: Bed change when water depth of LFC $=40 \mathrm{~cm}$ (with incoming sediment) at upstream boundary after 1 -hr flow simulation. 


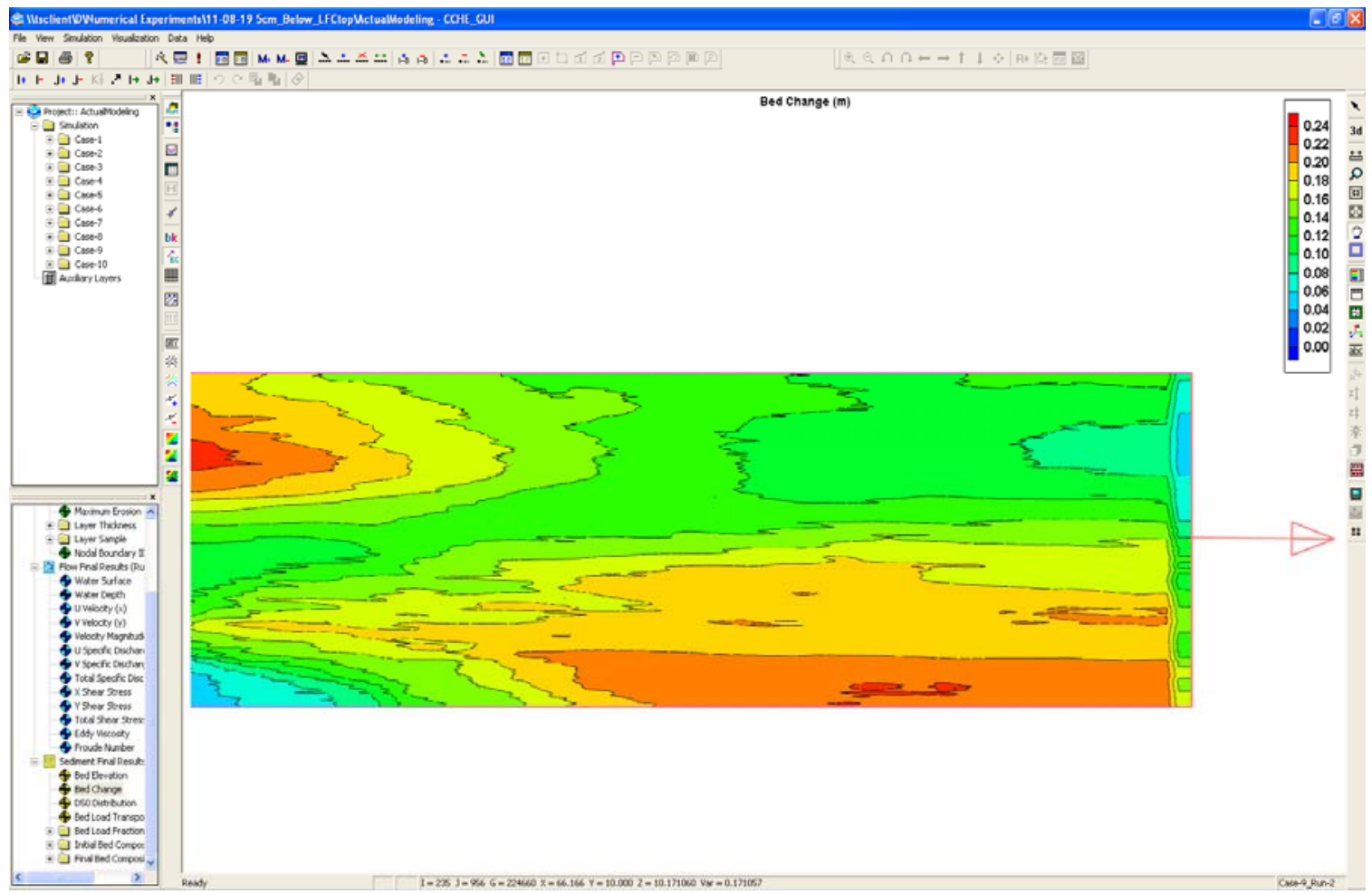

Figure U-42: Bed change when water depth of LFC $=40 \mathrm{~cm}$ (with incoming sediment) at downstream boundary after 1 -hr flow simulation.

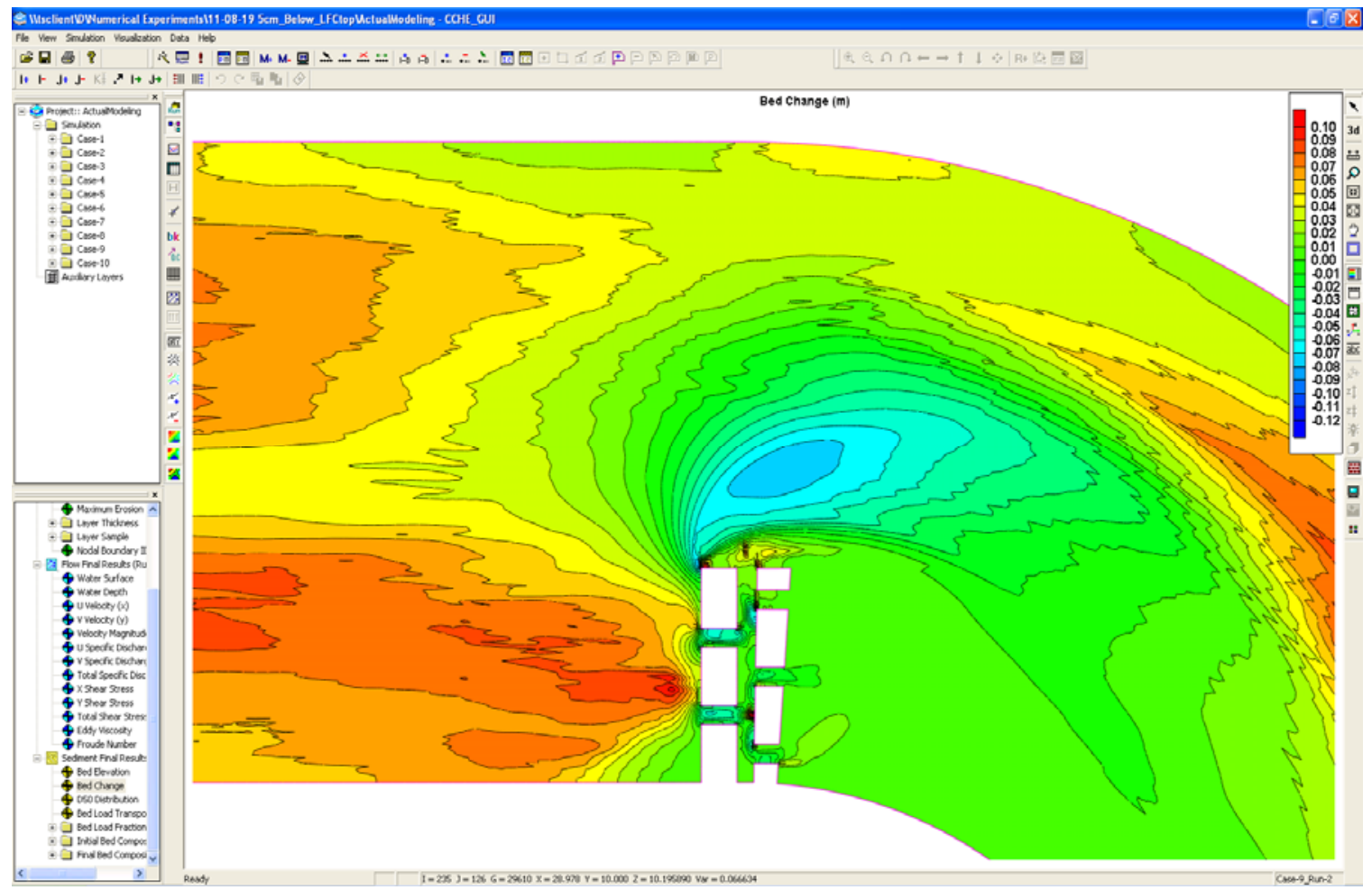

Figure U-43: Bed change when water depth of LFC $=40 \mathrm{~cm}$ (with incoming sediment) at meander \#1 after 1-hr flow simulation. 


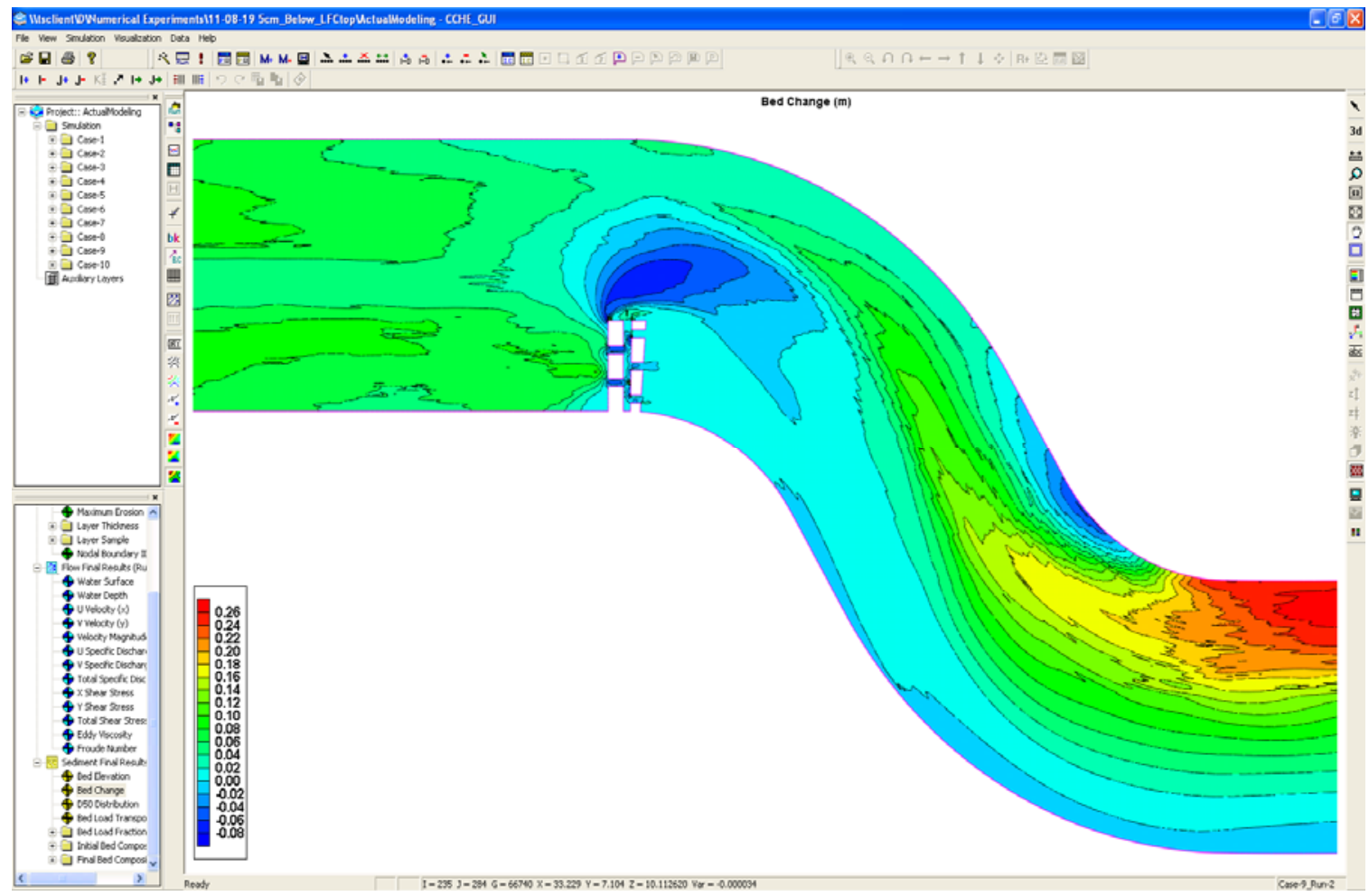

Figure U-44: Bed change when water depth of LFC $=40 \mathrm{~cm}$ (with incoming sediment) between meanders \#1 and \#2 after 1-hr flow simulation.

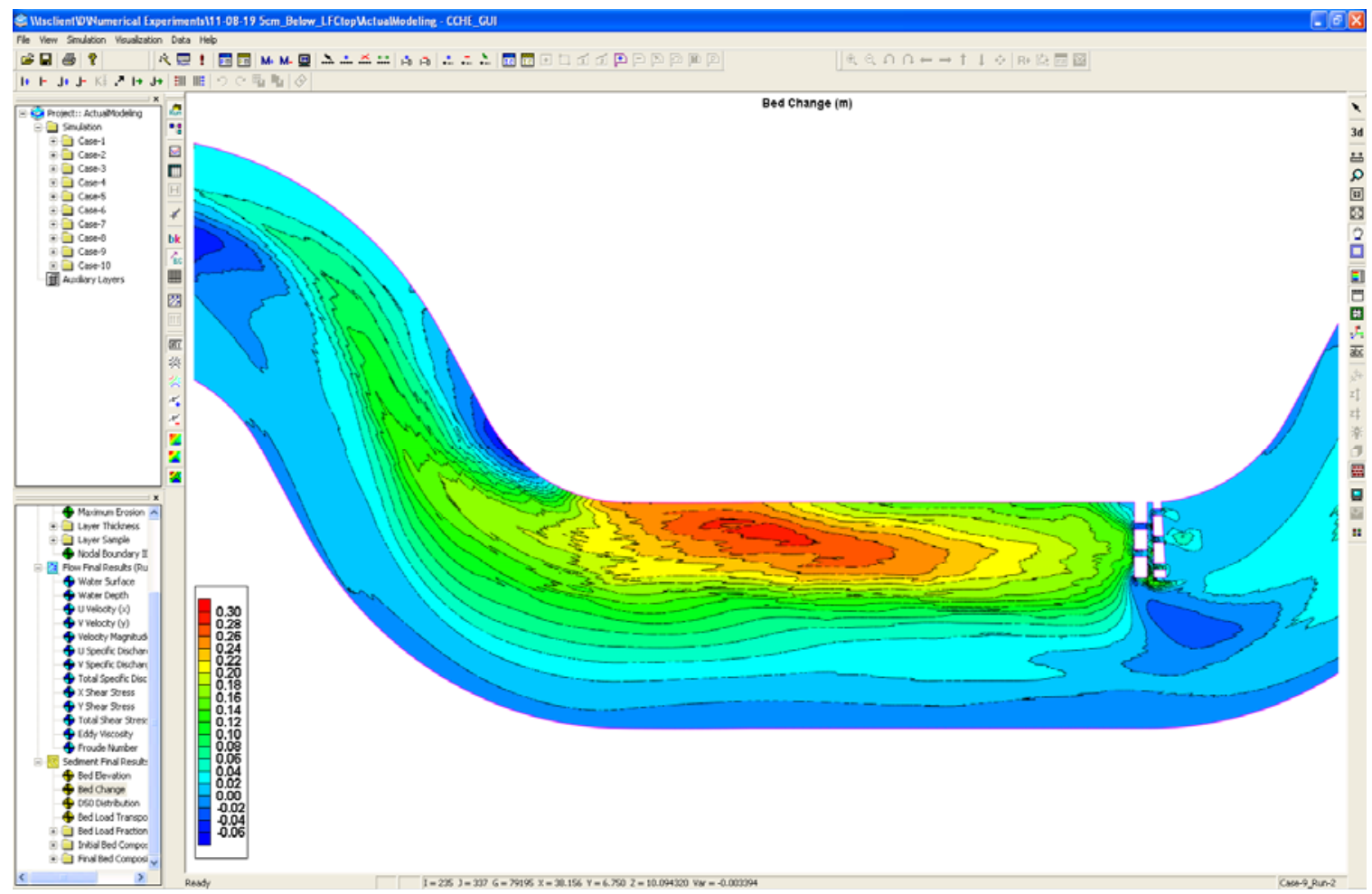

Figure U-45: Bed change when water depth of LFC $=40 \mathrm{~cm}$ (with incoming sediment) between meanders \#2 and \#3 after 1-hr flow simulation. 


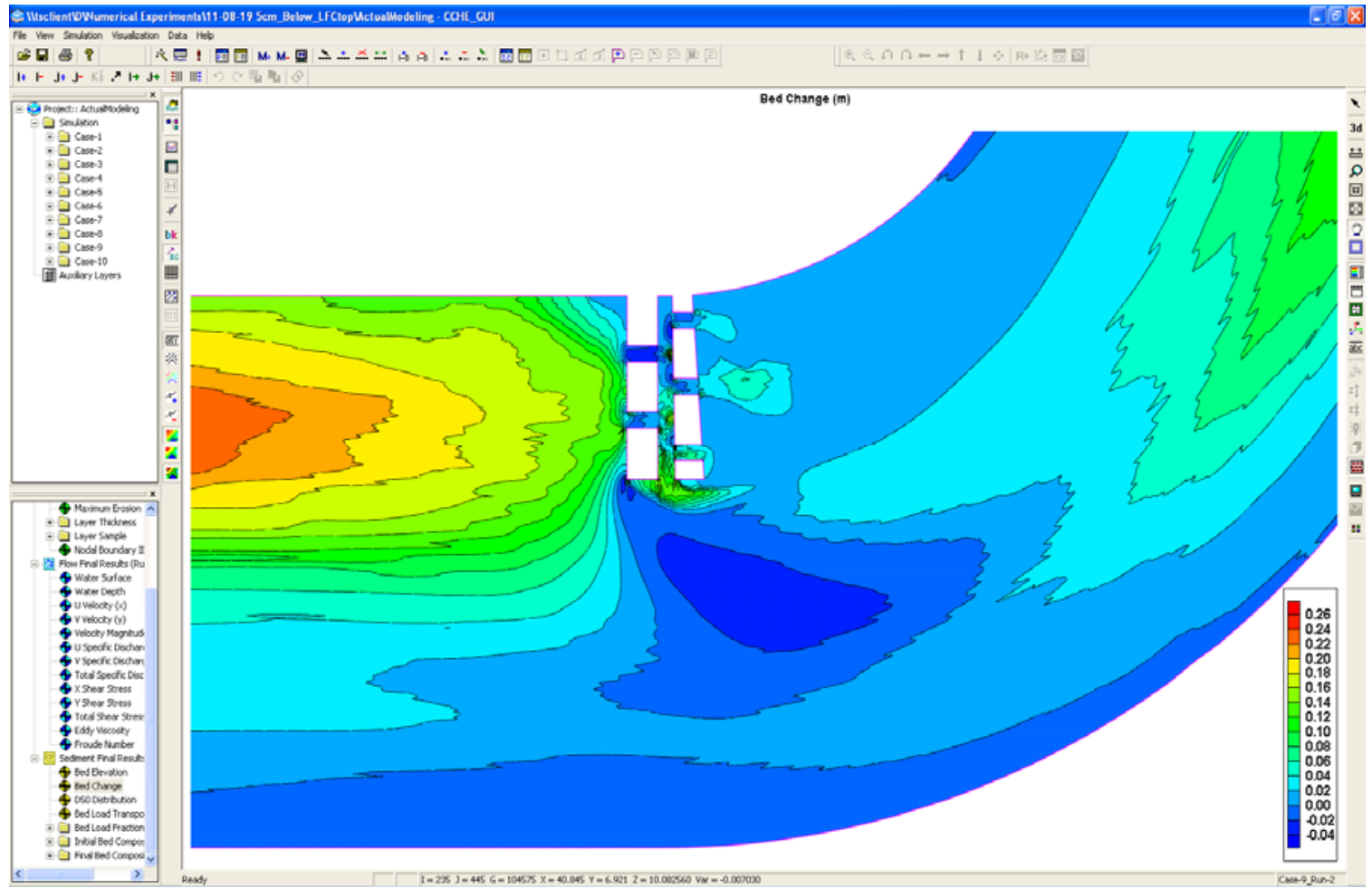

Figure U-46: Bed change when water depth of LFC $=40 \mathrm{~cm}$ (with incoming sediment) at meander \#3 after 1-hr flow simulation.

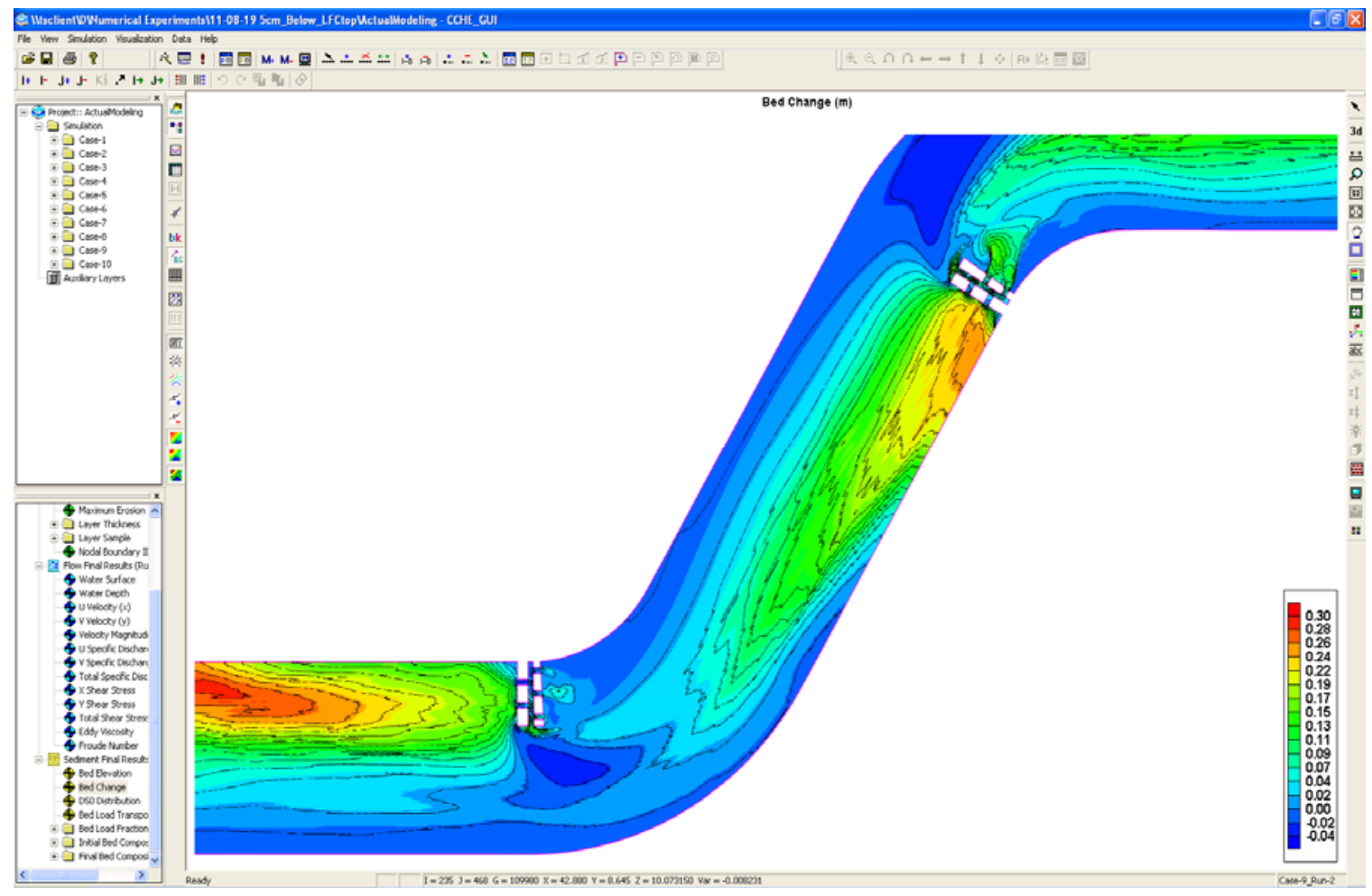

Figure U-47: Bed change when water depth of LFC $=40 \mathrm{~cm}$ (with incoming sediment) between meanders \#3 and \#4 after 1-hr flow simulation. 


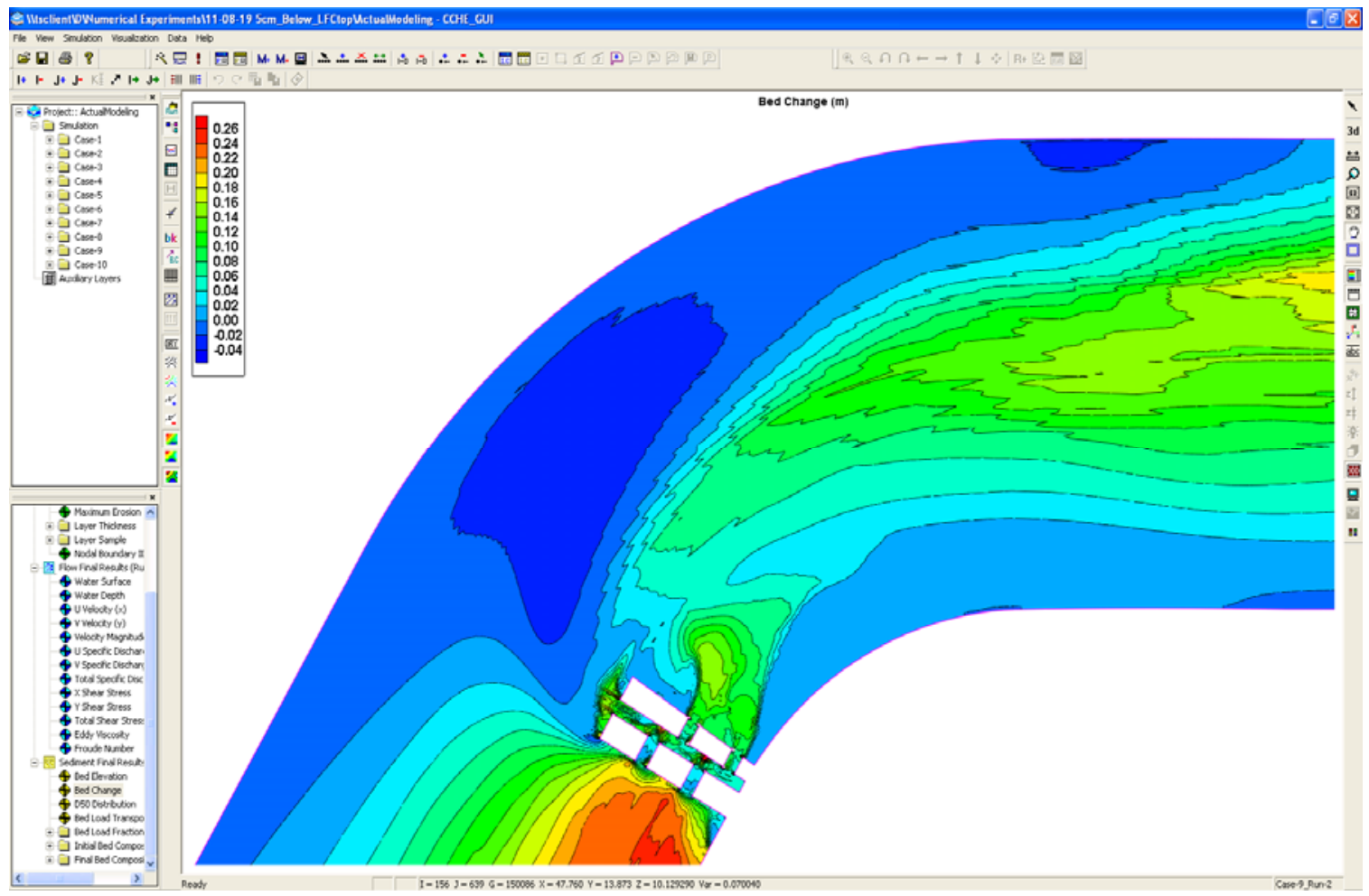

Figure U-48: Bed change when water depth of LFC $=40 \mathrm{~cm}$ (with incoming sediment) at meander \#4 after 1-hr flow simulation.

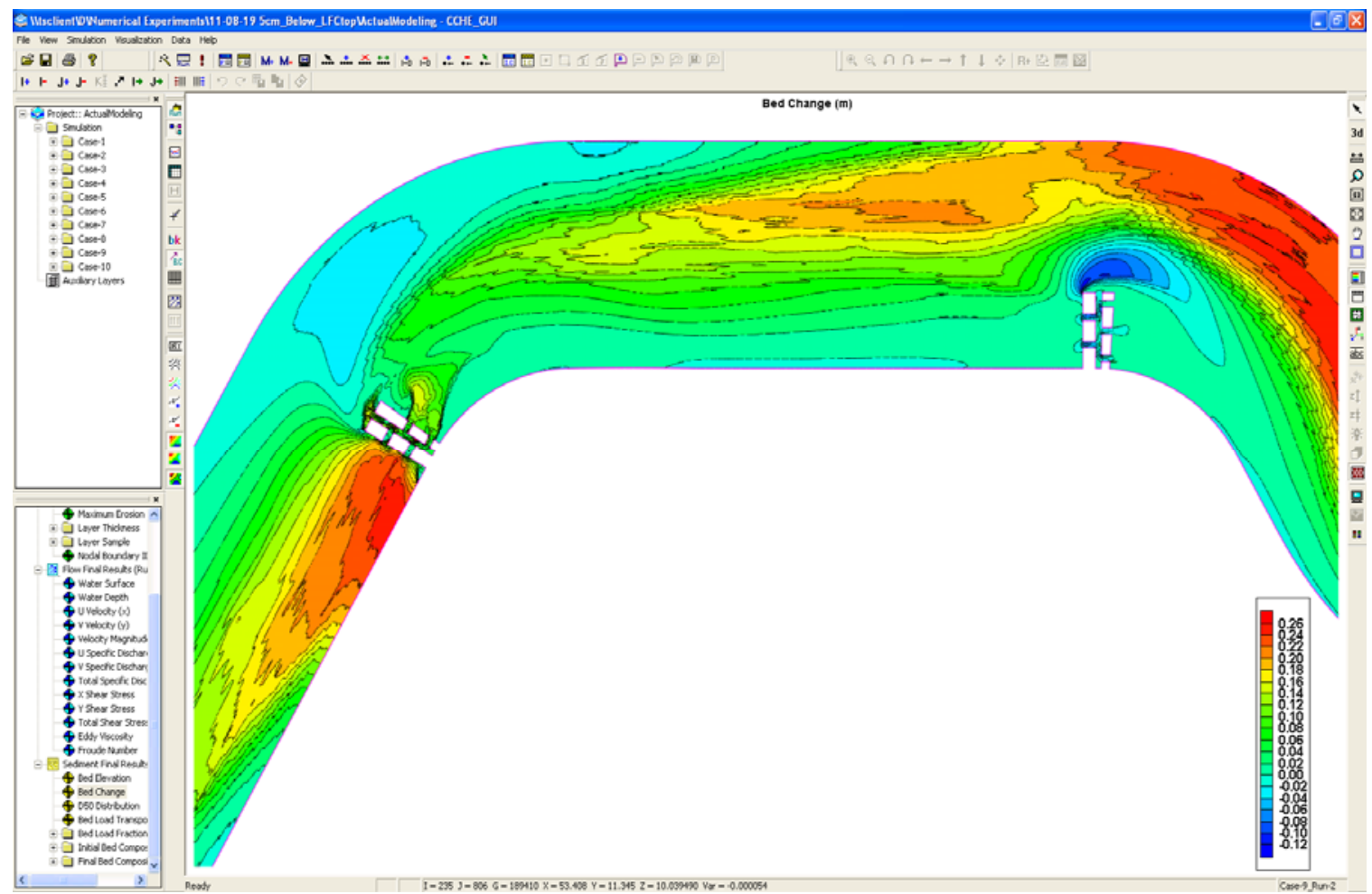

Figure U-49: Bed change when water depth of LFC $=40 \mathrm{~cm}$ (with incoming sediment) between meanders \#4 and \#5 after 1-hr flow simulation. 


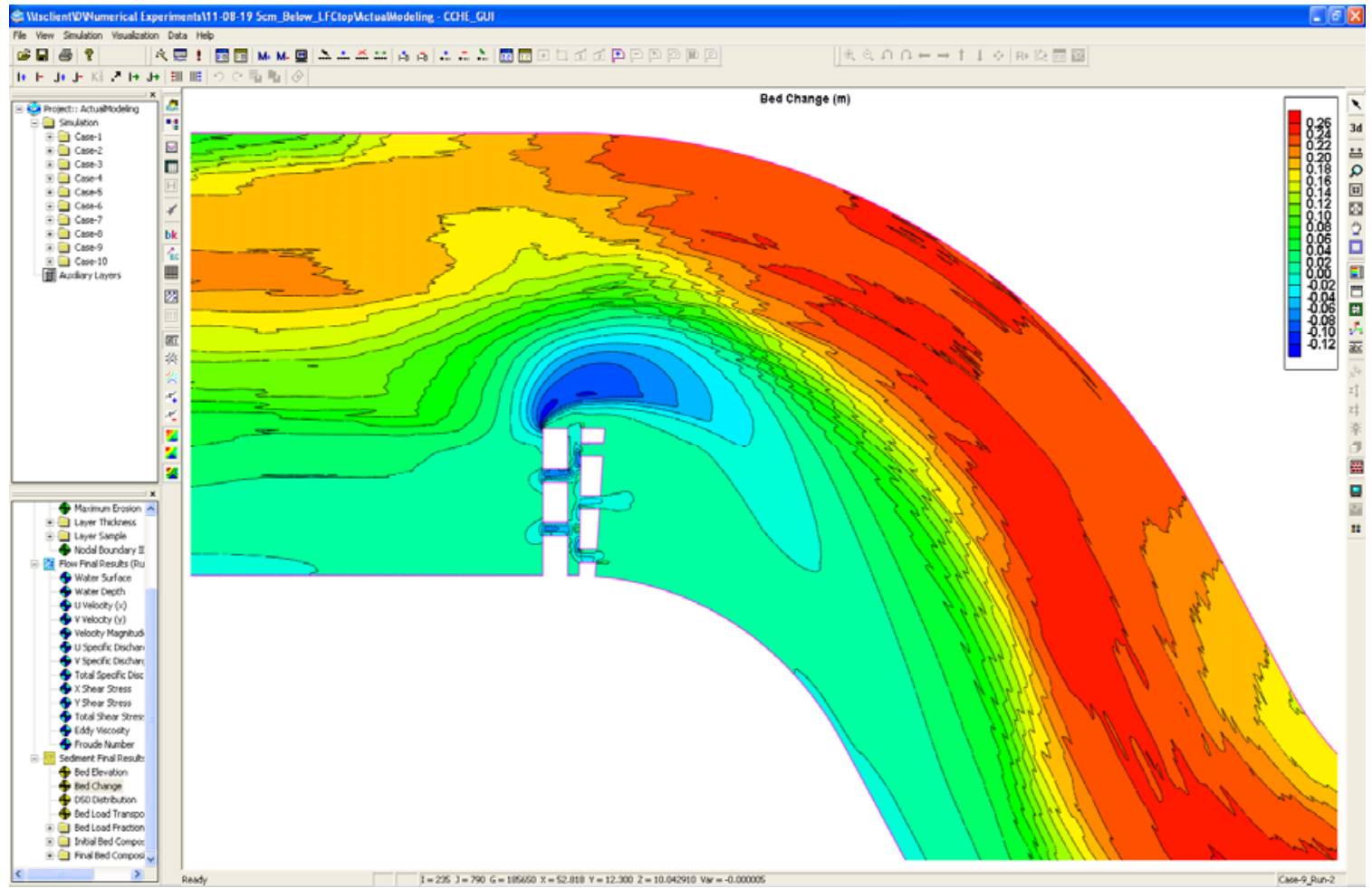

Figure U-50: Bed change when water depth of LFC $=40 \mathrm{~cm}$ (with incoming sediment) at meander \#5 after 1-hr flow simulation.

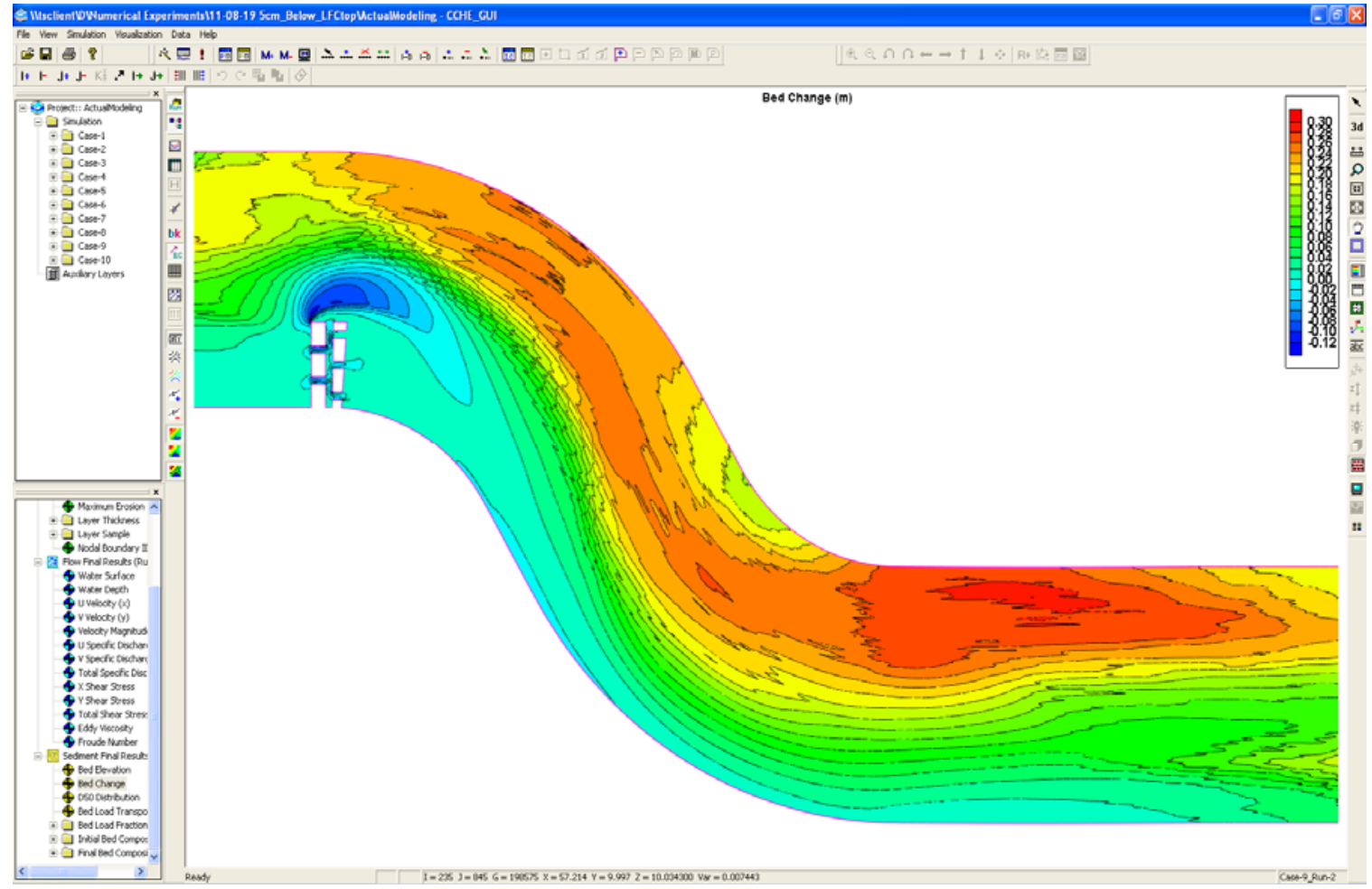

Figure U-51: Bed change when water depth of LFC $=40 \mathrm{~cm}$ (with incoming sediment) between meanders \#5 and \#6 after 1-hr flow simulation. 


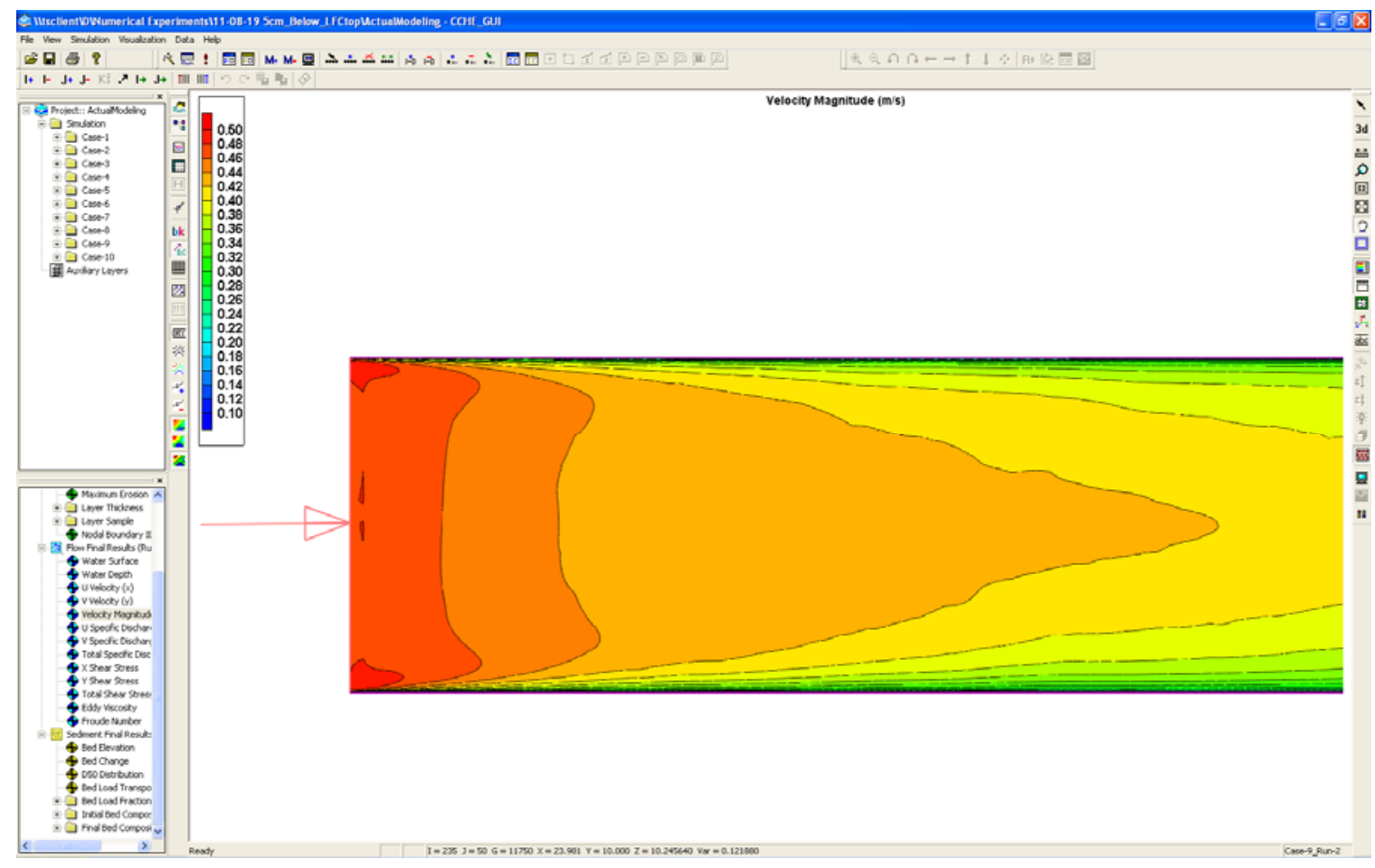

Figure U-52: Velocity magnitude when water depth of LFC $=40 \mathrm{~cm}$ (with incoming sediment) at upstream boundary after 1-hr flow simulation.

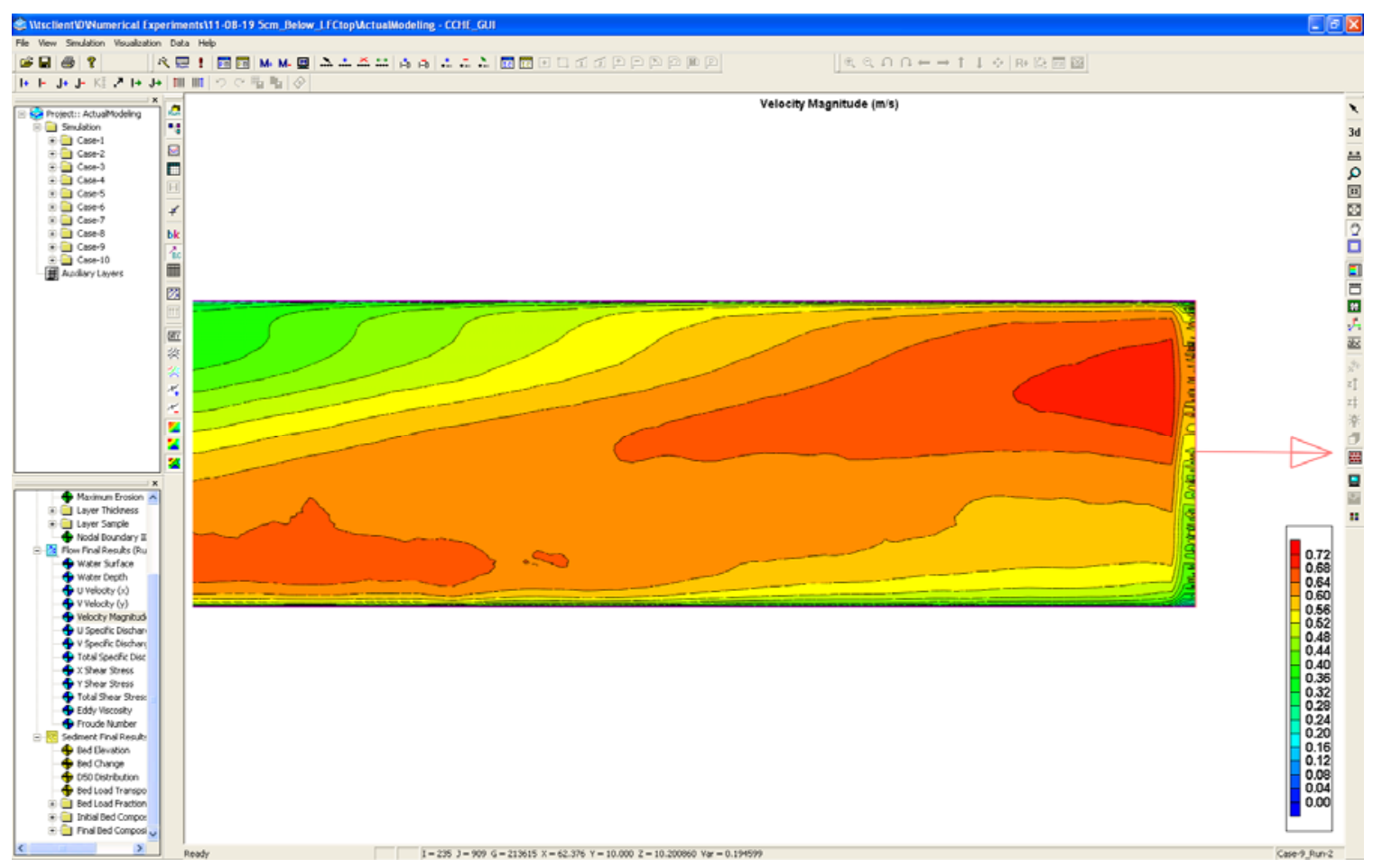

Figure U-53: Velocity magnitude when water depth of LFC $=40 \mathrm{~cm}$ (with incoming sediment) at downstream boundary after 1-hr flow simulation. 


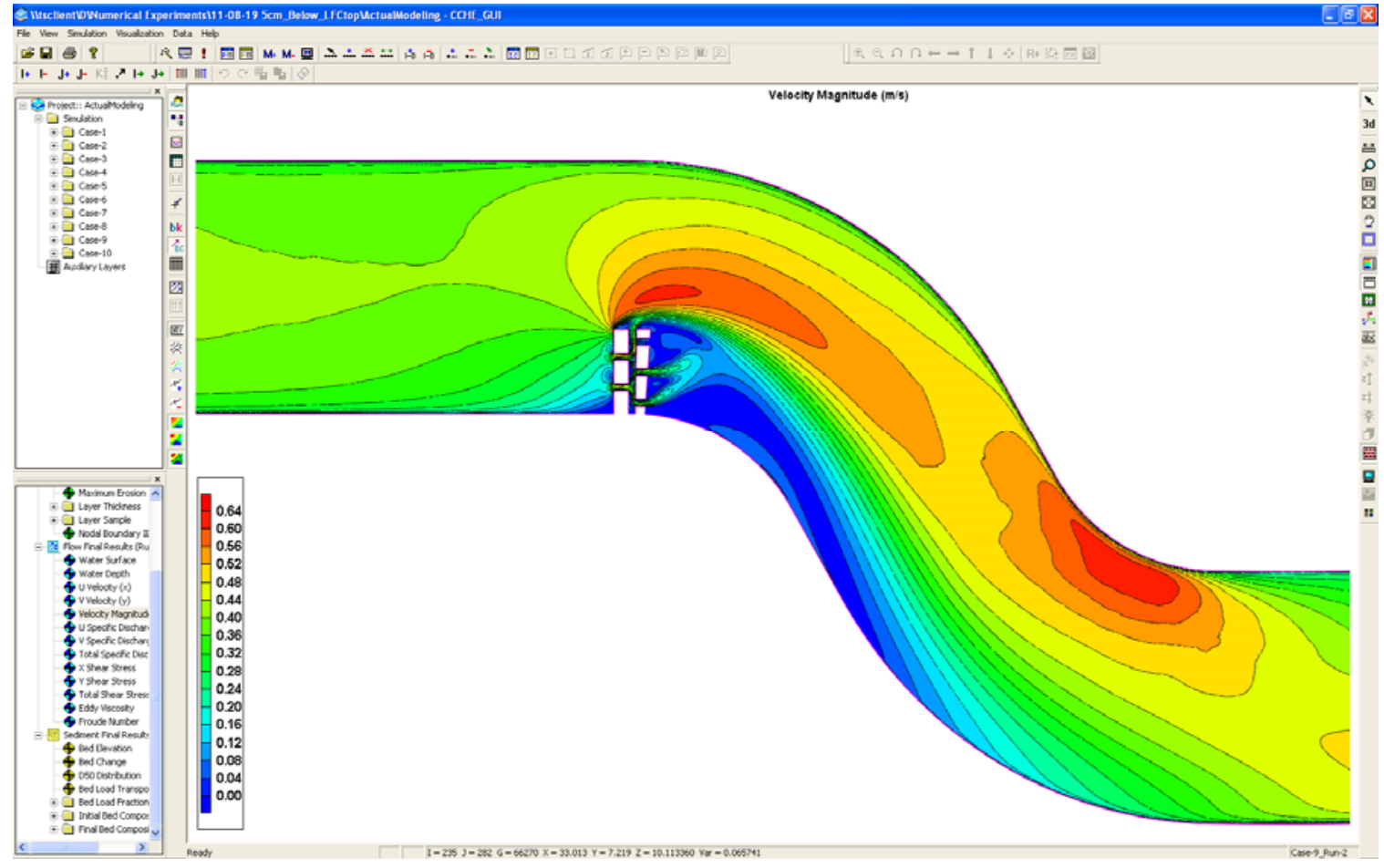

Figure U-54: Velocity magnitude when water depth of LFC $=40 \mathrm{~cm}$ (with incoming sediment) between meanders \#1 and \#2 after 1-hr flow simulation.

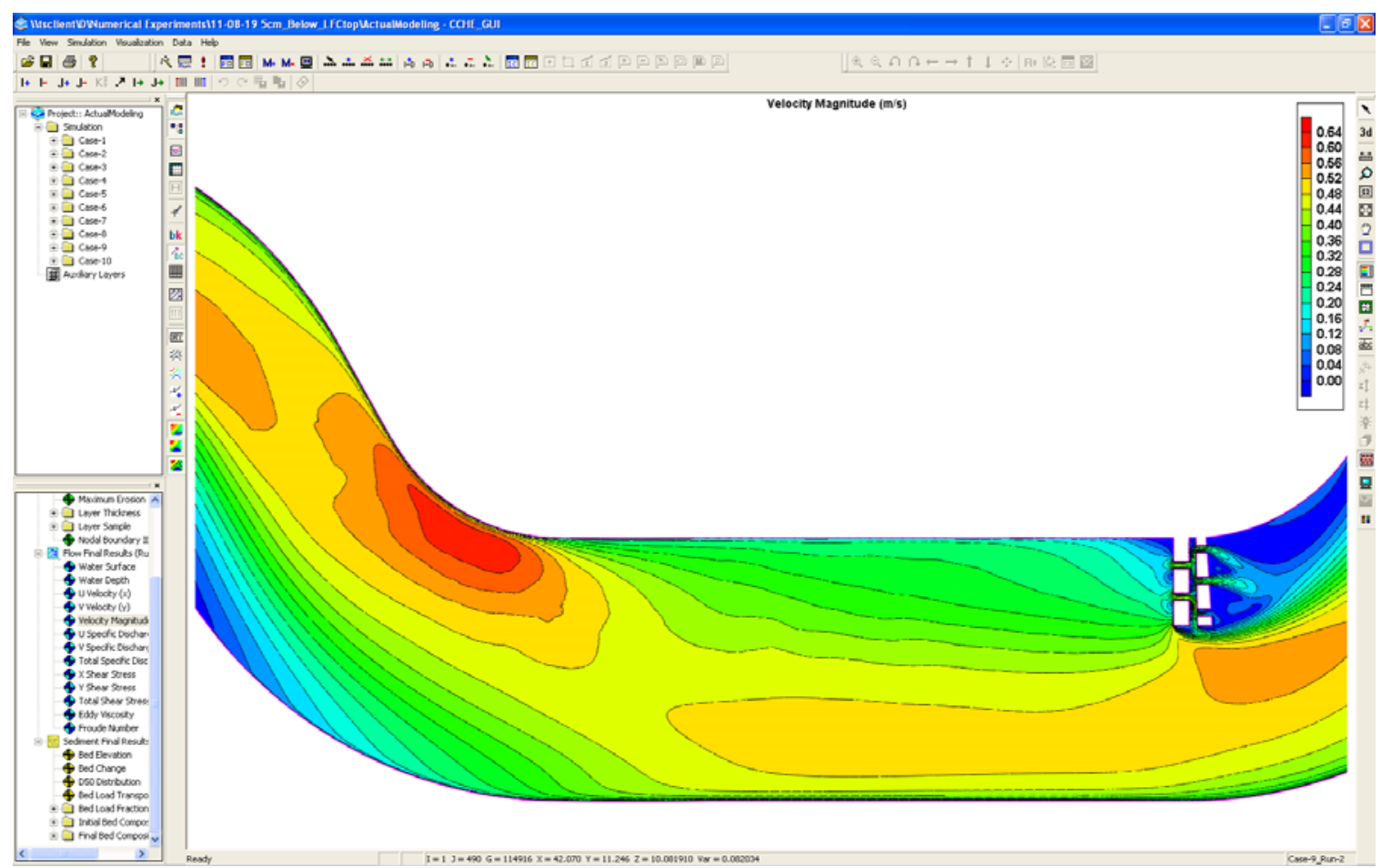

Figure U-55: Velocity magnitude when water depth of LFC $=40 \mathrm{~cm}$ (with incoming sediment) between meanders \#2 and \#3 after 1-hr flow simulation. 


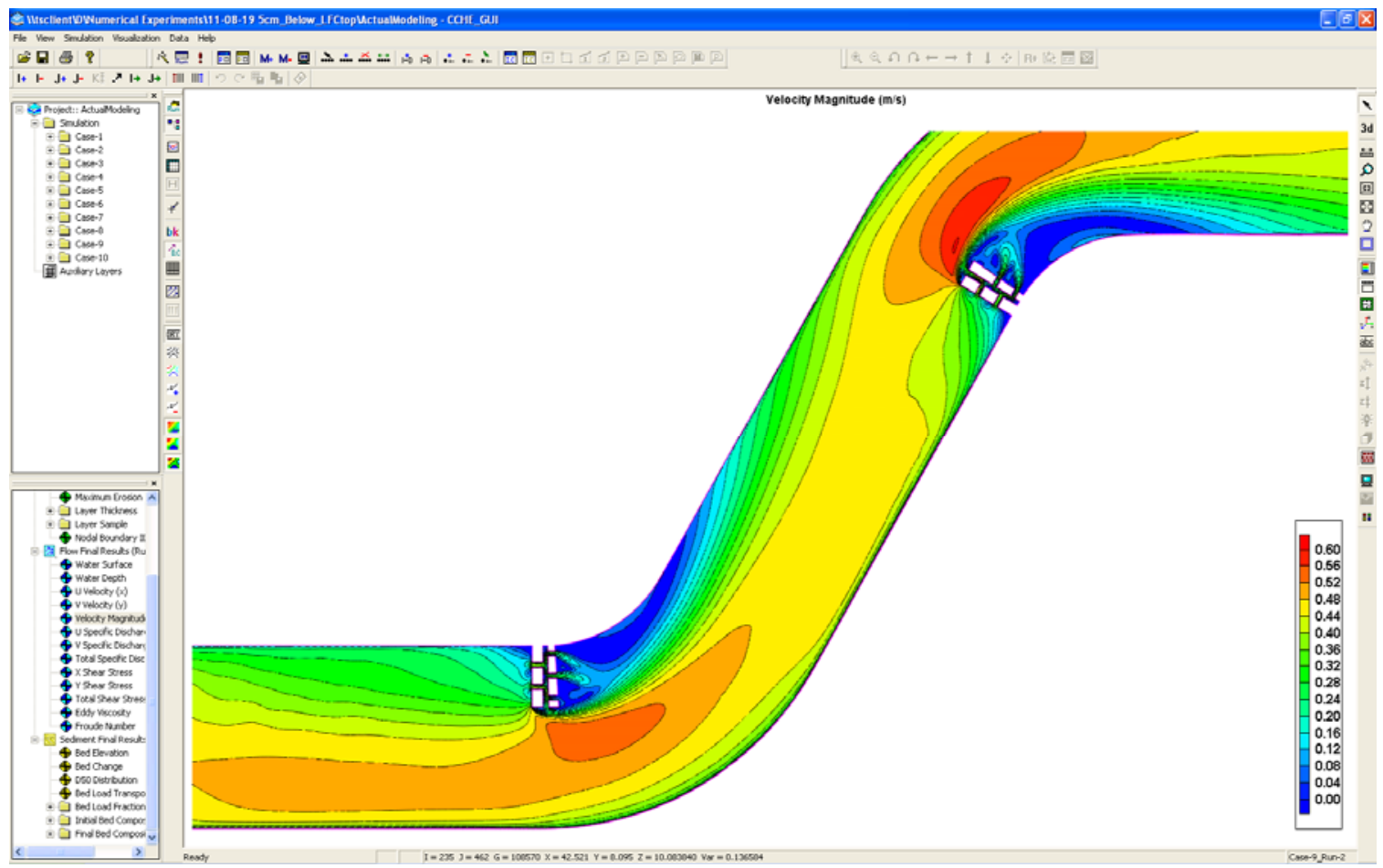

Figure U-56: Velocity magnitude when water depth of LFC $=40 \mathrm{~cm}$ (with incoming sediment) between meanders \#3 and \#4 after 1-hr flow simulation.

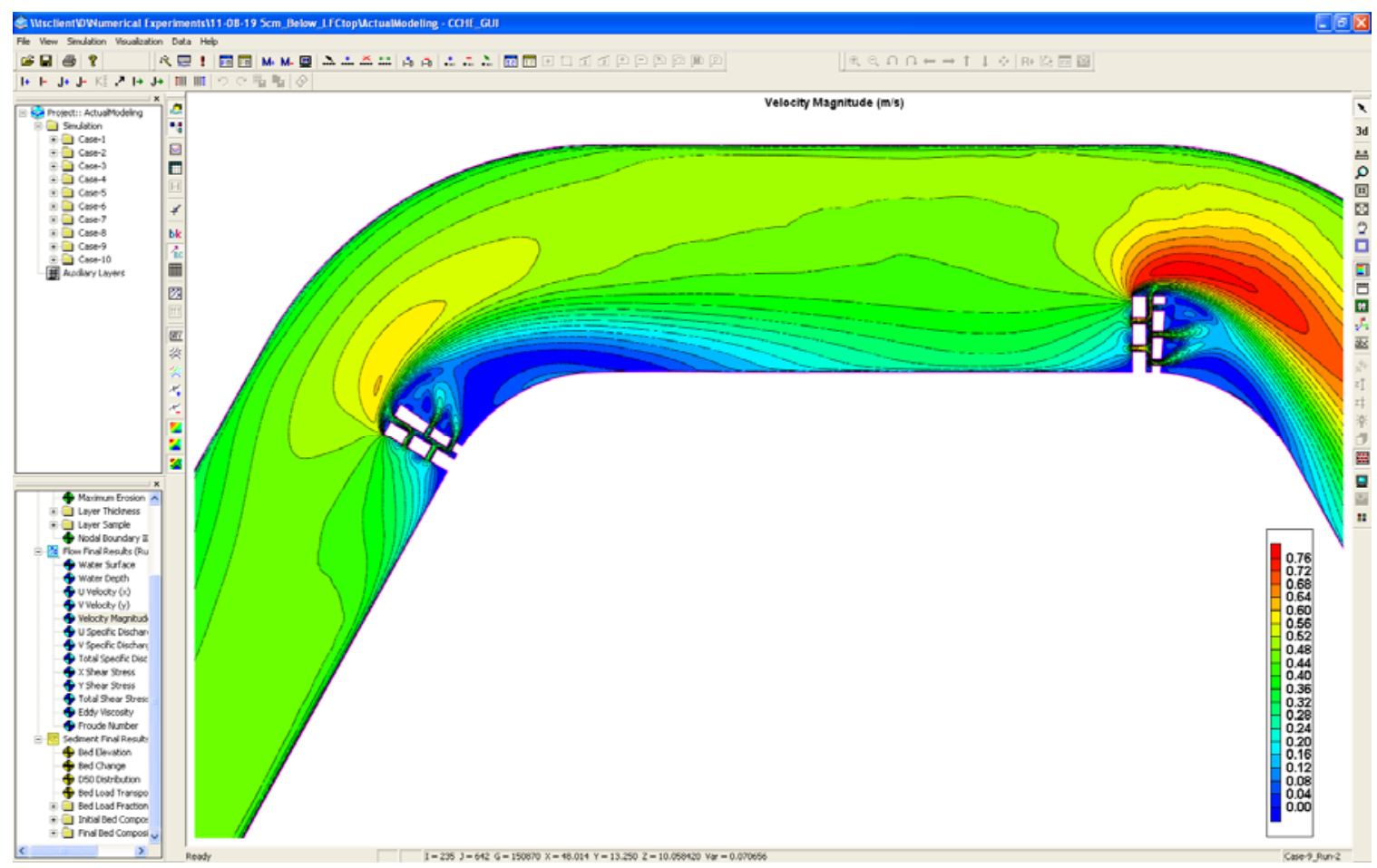

Figure U-57: Velocity magnitude when water depth of LFC $=40 \mathrm{~cm}$ (with incoming sediment) between meanders \#4 and \#5 after 1-hr flow simulation. 


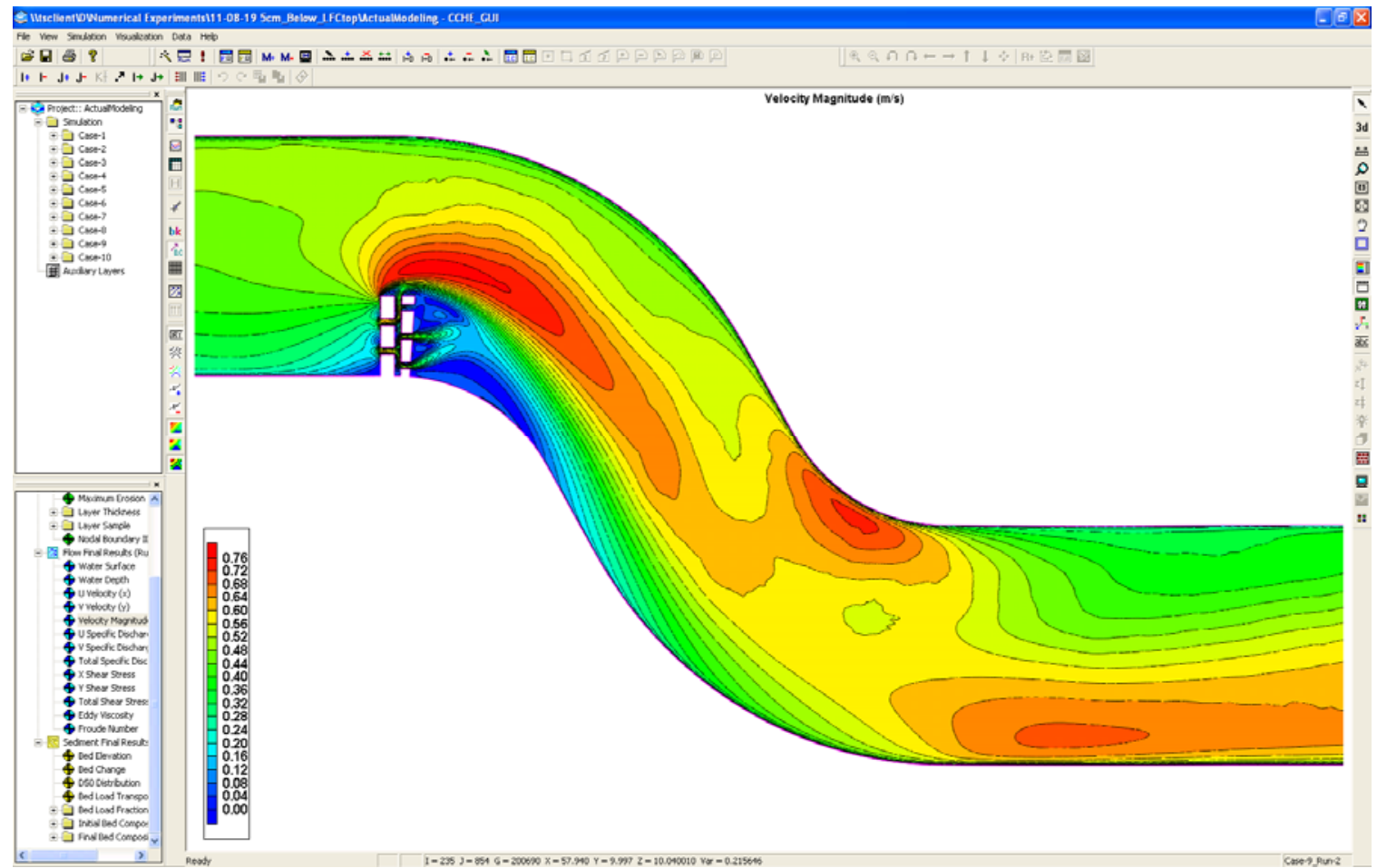

Figure U-58: Velocity magnitude when water depth of LFC $=40 \mathrm{~cm}$ (with incoming sediment) between meanders \#5 and \#6 after 1-hr flow simulation.

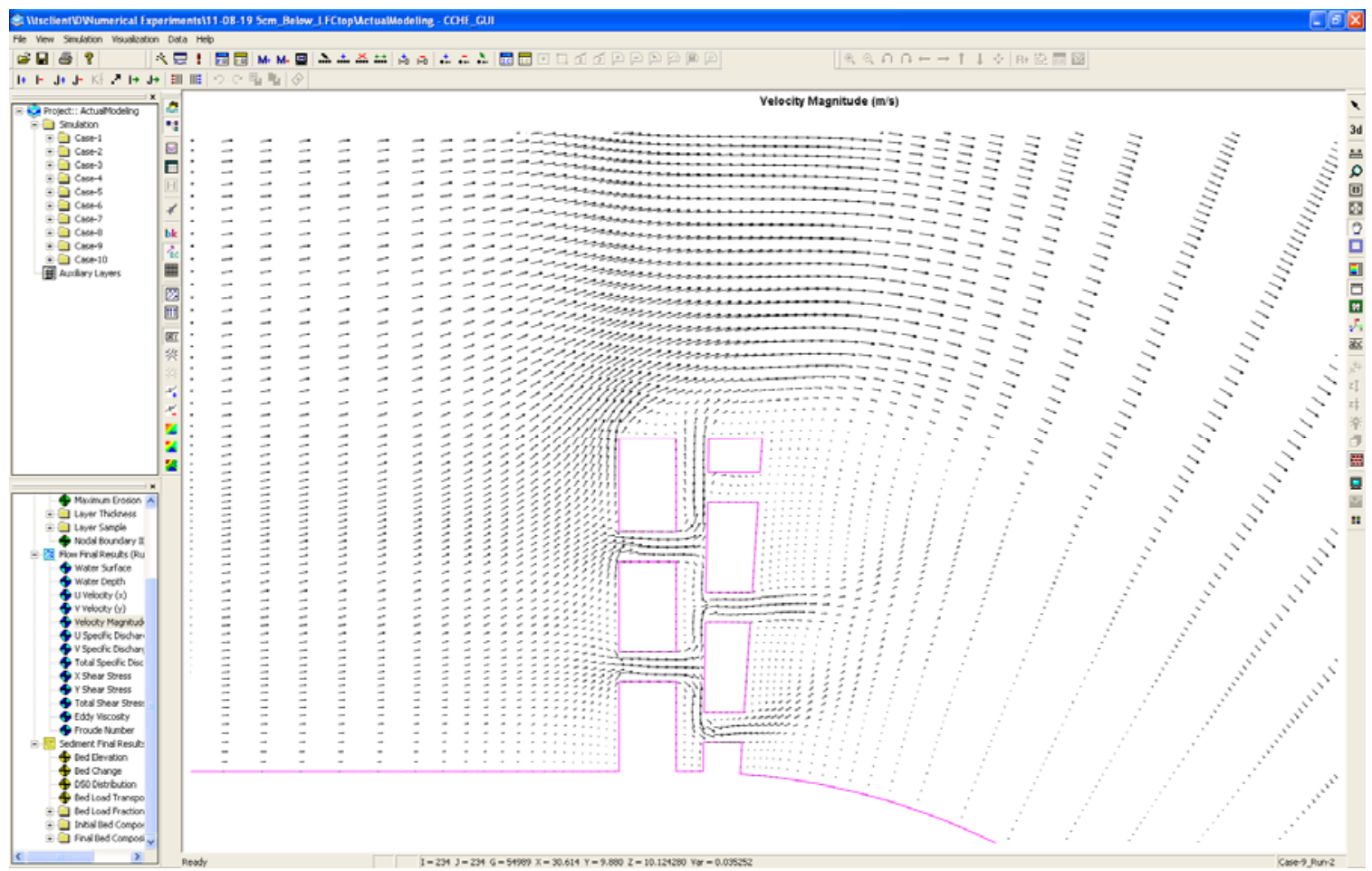

Figure U-59: Velocity direction when water depth of LFC $=40 \mathrm{~cm}$ (with incoming sediment) at meander \#1 after 1-hr flow simulation. 


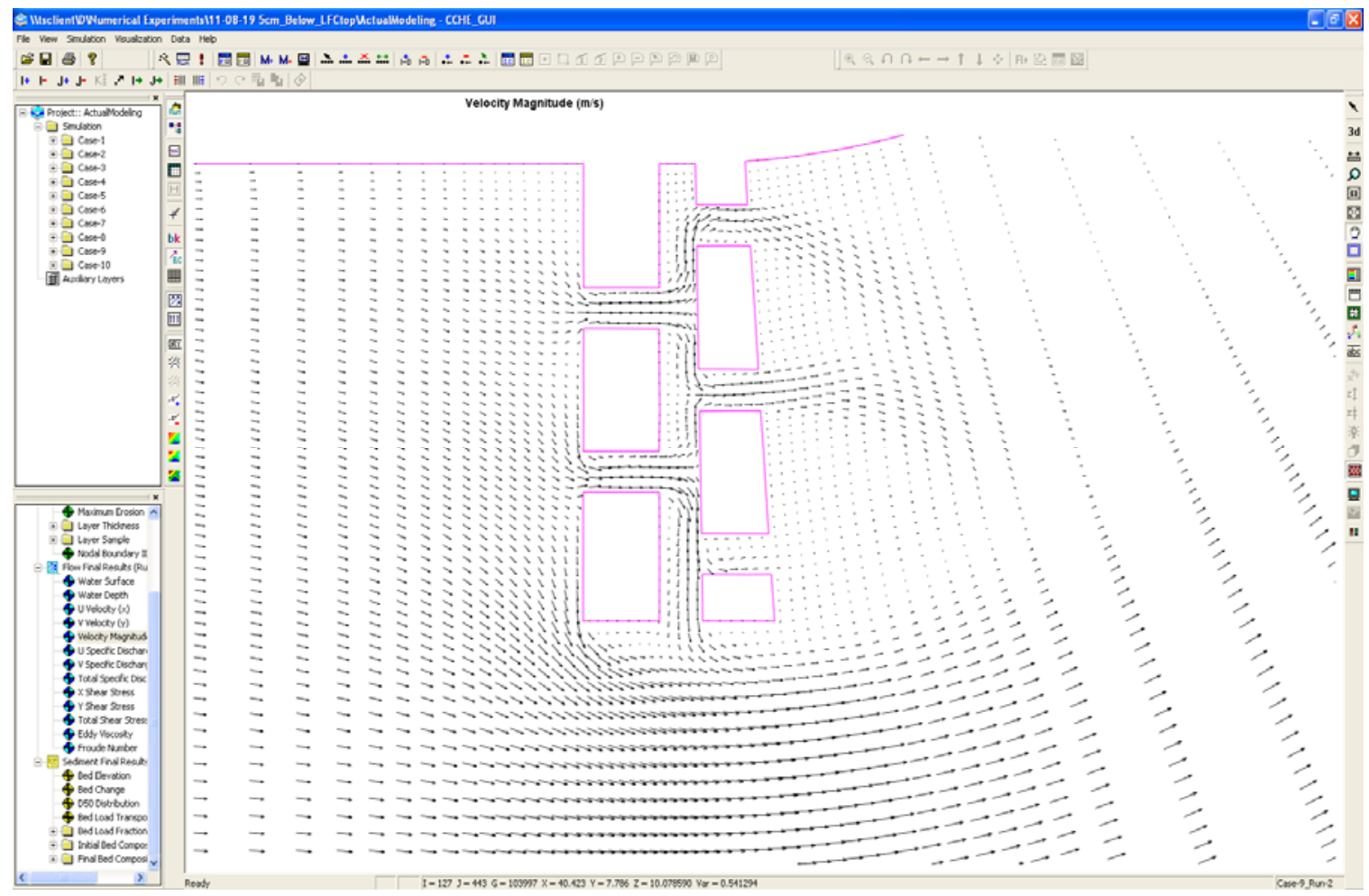

Figure U-60: Velocity direction when water depth of LFC $=40 \mathrm{~cm}$ (with incoming sediment) at meander \#3 after 1-hr flow simulation.

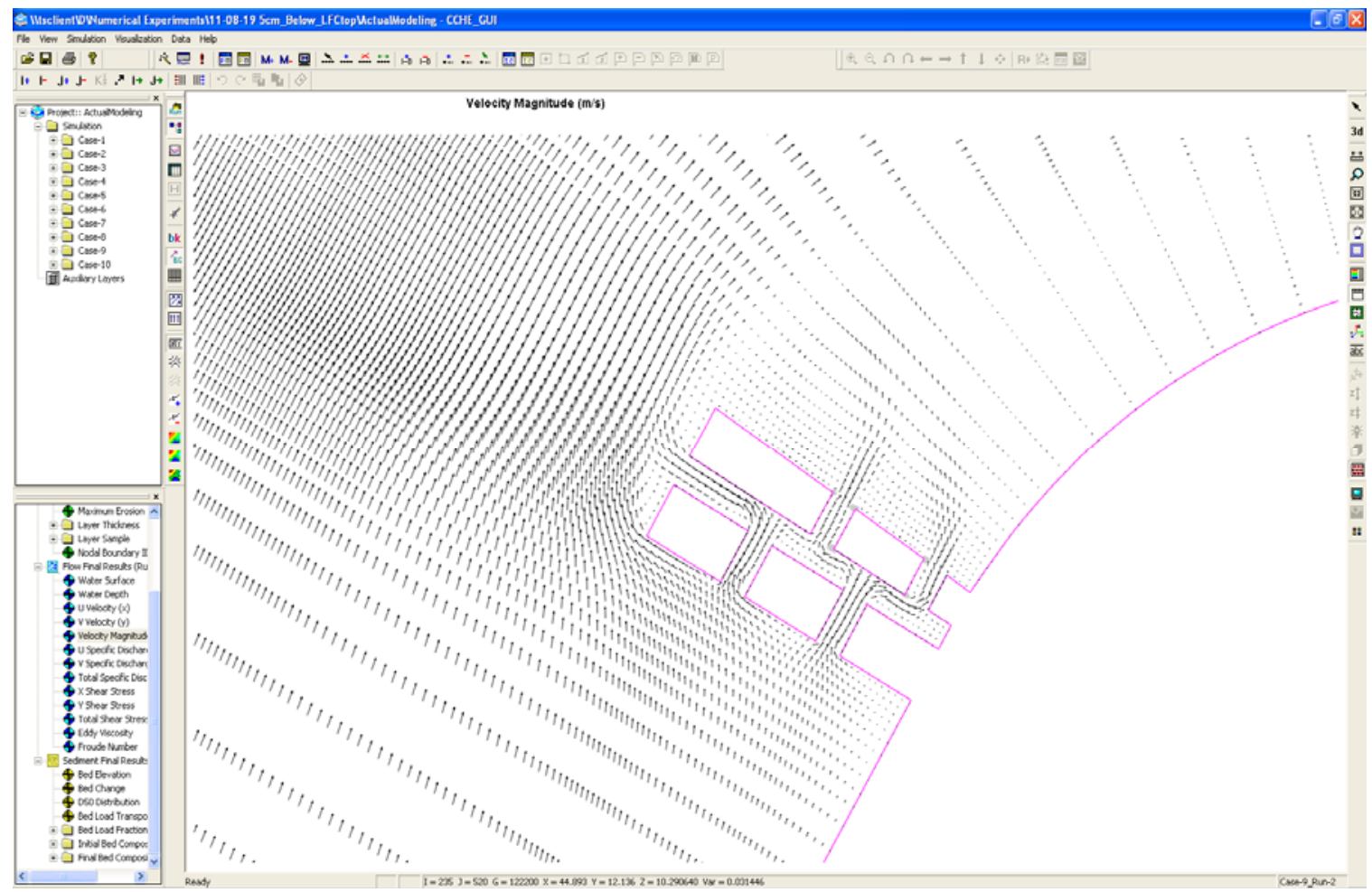

Figure U-61: Velocity direction when water depth of LFC $=40 \mathrm{~cm}$ (with incoming sediment) at meander \#4 after 1-hr flow simulation. 


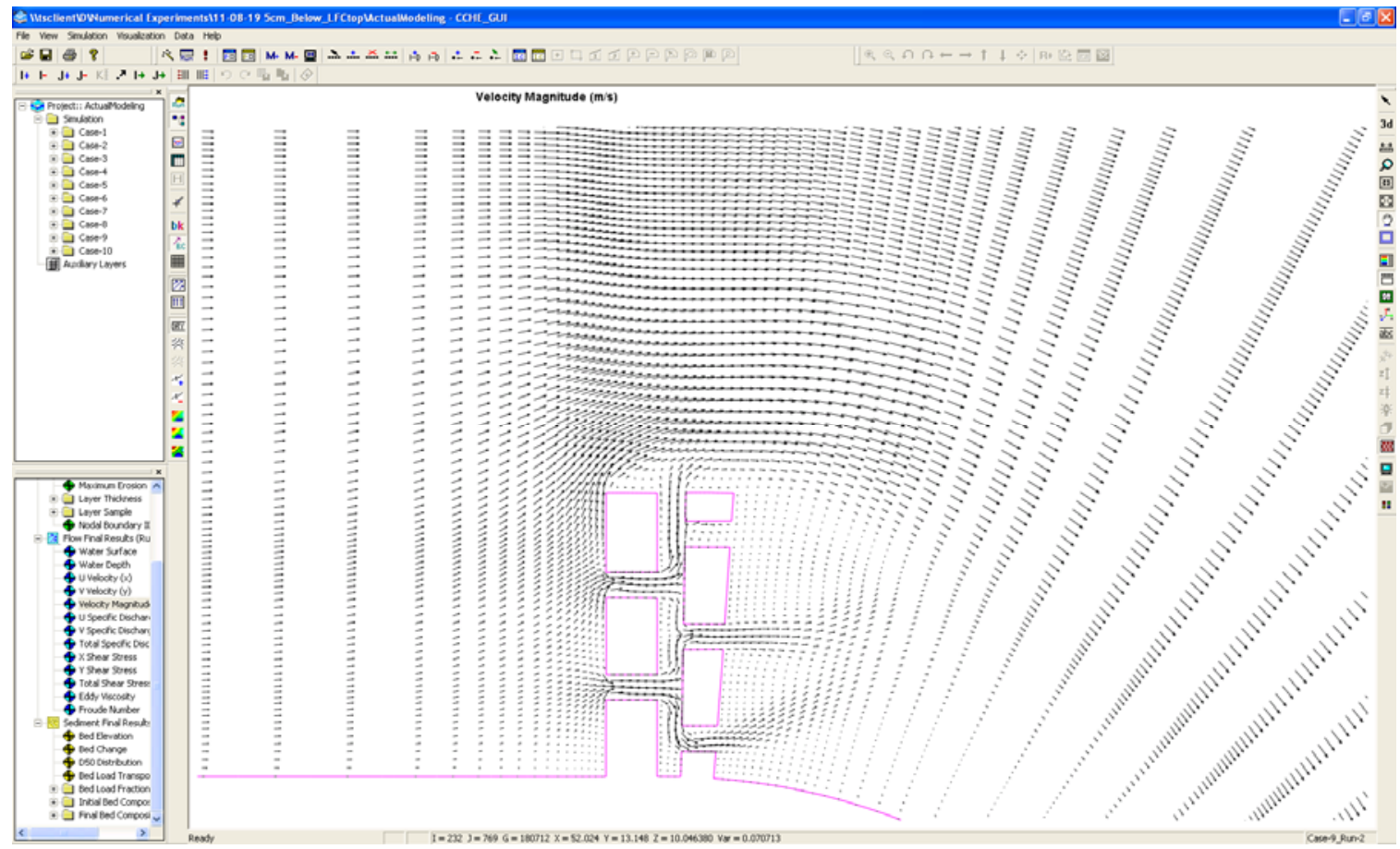

Figure U-62: Velocity direction when water depth of LFC $=40 \mathrm{~cm}$ (with incoming sediment) at meander \#5 after 1-hr flow simulation. 


\section{APPENDIX V}

\section{Abutment Scour Depth Estimation at}

\section{Water Depth $=40 \mathrm{~cm}$ of Low-Flow Channel}




\section{Maryland SHA Abutment Scour Methodology}

Note: Only "Live-Bed Abutment Scour" approach will be used for the scour depth estimation with different $D_{50}$ inputs at $5 \mathrm{~cm}$ below bankfull of LFC condition (Section 5.4) since it is the best estimation towards the physical experiments results.

\section{1) Original $D_{50}$ at the pilot site:}

$$
\begin{aligned}
D_{50} & =0.000281 \mathrm{~m} \\
y_{1} & =0.40 \mathrm{~m} \\
q_{1} & =0.3138 \mathrm{~m}^{3} / \mathrm{sec} \div 2 \mathrm{~m} \quad \text { where } Q \text { is calculated by Manning's equation } \\
& =0.1569 \mathrm{~m}^{3} / \mathrm{sec} / \mathrm{m} \\
q_{2} & =0.3138 \mathrm{~m}^{3} / \mathrm{sec} \div(2 \mathrm{~m}-0.667 \mathrm{~m}) \\
& =0.2354 \mathrm{~m}^{3} / \mathrm{sec} / \mathrm{m} \\
k_{v} & =0.8\left(q_{1} / q_{2}\right)^{1.5}+1 \\
& =0.8(0.1569 / 0.2354)^{1.5}+1 \\
& =1.435 \\
\tau_{c} & =\text { critical shear stress of soil using Shields diagram (Appendix } \mathrm{Q}) \\
& =0.1546 \mathrm{~N} / \mathrm{m}^{2} \\
\tau_{1} & =\text { shear stress at approach section (Appendix } \mathrm{Q}) \\
& =\gamma R S \\
& =\left(9806 \mathrm{~N} / \mathrm{m}^{3}\right)(0.2857 \mathrm{~m})(0.002943) \\
& =8.245 \mathrm{~N} / \mathrm{m}^{2} \\
K_{2} & =0.11\left(\tau_{c} / \tau_{1}+0.4\right)^{2.2}+0.623 \\
& =(0.11)(0.1546 / 8.245+0.4)^{2.2}+0.623 \\
& =0.6392
\end{aligned}
$$

Determine Variables Involved for Exp \#B7:

$$
\begin{aligned}
V_{1} & =0.39 \mathrm{~m} / \mathrm{sec} \quad \text { from numerical results } \\
F r & =V_{1} /\left(g y_{1}\right)^{0.5} \\
& =0.39 /\left(9.806^{*} 0.40\right)^{0.5} \\
& =0.1969 \\
k_{f} & =0.35+3.2 F r \\
& =0.35+(3.2)(0.1969) \\
& =0.9801
\end{aligned}
$$

Maximum Scour Depth Prediction for Exp \#B7:

$$
\begin{aligned}
y_{2 a} & =k_{f} y_{1}\left[\left(k_{v} q_{2}\right) / q_{1}\right]^{K_{2}} \\
& =(0.9801)(0.40)\left[\left(1.435^{\star} 0.2354\right) / 0.1569\right]^{0.6392} \\
& =0.6400 \mathrm{~m}
\end{aligned}
$$


Depth of scour hole $=y_{2 a}-y=0.6400-0.40=\underline{\underline{0.24 m}}$

\section{2) Doubling $D_{50}$}

$$
\begin{aligned}
D_{50} & =0.0005620 \mathrm{~m} \\
y_{1} & =0.40 \mathrm{~m} \\
q_{1} & =0.3138 \mathrm{~m}^{3} / \mathrm{sec} \div 2 \mathrm{~m} \quad \text { where } Q \text { is calculated by Manning's equation } \\
& =0.1569 \mathrm{~m}^{3} / \mathrm{sec} / \mathrm{m} \\
q_{2} & =0.3138 \mathrm{~m}^{3} / \mathrm{sec} \div(2 \mathrm{~m}-0.667 \mathrm{~m}) \\
& =0.2354 \mathrm{~m}^{3} / \mathrm{sec} / \mathrm{m} \\
k_{v} & =0.8\left(q_{1} / q_{2}\right)^{1.5}+1 \\
& =0.8(0.1569 / 0.2354)^{1.5}+1 \\
& =1.435 \\
\tau_{c} & =\text { critical shear stress of soil using Shields diagram (Appendix Q) } \\
& =0.3637 \mathrm{~N} / \mathrm{m}^{2} \\
\tau_{1} & =\text { shear stress at approach section } \\
& =\gamma R S \\
& =\left(9806 \mathrm{~N} / \mathrm{m}^{3}\right)(0.2857 \mathrm{~m})(0.002943) \\
& =8.245 \mathrm{~N} / \mathrm{m}^{2} \\
K_{2} & =0.11\left(\tau_{c} / \tau_{1}+0.4\right)^{2.2}+0.623 \\
& =(0.11)(0.3637 / 8.245+0.4)^{2.2}+0.623 \\
& =0.6414
\end{aligned}
$$

Determine Variables Involved for Exp \#B7:

$$
\begin{aligned}
V_{1} & =0.32 \mathrm{~m} / \mathrm{sec} \quad \text { from numerical results } \\
F r & =V_{1} /\left(g y_{1}\right)^{0.5} \\
& =0.32 /\left(9.806^{*} 0.4\right)^{0.5} \\
& =0.1616 \\
k_{f} & =0.35+3.2 F r \\
& =0.35+(3.2)(0.1616) \\
& =0.8670
\end{aligned}
$$

$$
\begin{aligned}
& \text { Maximum Scour Depth Prediction for Exp \#B7: } \\
& \begin{aligned}
y_{2 a} & =k_{f} y_{1}\left[\left(k_{v} q_{2}\right) / q_{1}\right]^{K_{2}} \\
& =(0.8670)(0.40)\left[\left(1.435^{\star} 0.2354\right) / 0.1569\right]^{0.6414} \\
& =0.5671 \mathrm{~m}
\end{aligned}
\end{aligned}
$$

Depth of scour hole $=y_{2 a}-y=0.5671-0.40=\underline{\underline{0.1671 m}}$ 


\section{APPENDIX $\mathbf{W}$}

Numerical Software Review 


\section{SUTRENCH-2D}

The SUTRENCH-2D program is a finite-volume hydrodynamic and sediment transport model developed by van Rijn and Tan (1985) for simulating sediment transport and associated bed level change under conditions of combined quasisteady currents and wind-induced waves over a sediment bed. The model solves the general advection-diffusion equations by incorporating a lag coefficient to account for the settling of sediments (Papanicolaou et al., 2008). It is based on the mass balance of suspended sediments in the vertical plane, yielding

$$
\frac{\partial(b c)}{\partial t}+\frac{\partial}{\partial x}(b u c)+\frac{\partial}{\partial z}\left[b\left(w-w_{s}\right) c\right]-\frac{\partial}{\partial z}\left(\varepsilon_{s} b \frac{\partial c}{\partial z}\right)=0
$$

where $c=$ local concentration; $u=$ local horizontal flow velocity; $w=$ local vertical flow velocity; $w_{s}=$ fall velocity; $\varepsilon_{s}=$ sediment-mixing coefficient; $t=$ time; $x=$ horizontal coordinate; $z=$ vertical coordinate; and $b=$ stream-tube width. The time-dependent term $\partial(\mathrm{bc}) / \partial \mathrm{t}$ and the horizontal diffusive transport are negligibly small with respect to the other terms, as shown by Kerssens et al. (1979) and van Rijn (1986). The water surface is a rigid lid and the water movement is described by a logarithmic flow-velocity profile:

$$
u(z)=\frac{u_{*}}{\kappa} \ln \frac{z}{z_{o}}
$$

where $u(z)=$ local flow velocity; $u_{*}=$ bed-shear velocity (van Rijn, 1986, 1990); $\rho$ $=$ density of water; $z_{o}=0.033 k_{s}=$ zero-velocity level; $k_{s}=$ equivalent roughness. The diffusion coefficient of the sediment is schematized by a parabolic-linear vertical distribution: 


$$
\varepsilon_{s}=\varepsilon_{s, m}\left[1-\left(1-\frac{2 z}{h}\right)^{2}\right] \quad \text { with } \quad \varepsilon_{s, m}=0.25 \kappa u_{\star} h
$$

where $\kappa=$ Von Karman constant and $h=$ flow depth. The bed boundary condition is modelled by prescribing the bed concentration at a small height $(z=a=$ reference level) above the mean bed level. In that case, the bed concentration, $c_{a}$, may be represented by its equilibrium value, $c_{a, e}$, assuming that there is an instantaneous adjustment to equilibrium conditions close to the bed. The reference level is applied at half the bed-form height (van Rijn et al., 1990).

The equilibrium bed concentration, $c_{a, e}$, is prescribed by a known function that relates the bed concentration to local near-bed hydraulic and sediment parameters (van Rijn, 1984, 1984a, 1989) as follows:

$$
c_{a, e}=0.015 \frac{D_{50}}{a} \frac{T^{1.5}}{D_{*}^{0.3}}
$$

where $D_{50}=$ median grain diameter; $T=$ bed-shear stress parameter; and $D_{*}=$ particle-size parameter. The parameters $T$ and $D *$ are expressed as:

$$
T=\frac{u_{*}^{\prime 2}-u_{* c r}^{2}}{u_{* r}^{2}}
$$

where $u_{*}^{\prime}=\left(\bar{u} g^{0.5} / C^{\prime}\right)=$ bed-shear velocity related to grains; $\bar{u}=$ depth-mean flow velocity; $C^{\prime}=18 \log \left(12 h / 3 D_{90}\right)=$ Chézy coefficient related to grains; $D_{90}=$ $90 \%$ particle diameter of bed material; and $u_{*_{c r}}=$ critical bed-shear velocity; and 


$$
D_{*}=D_{50}\left[\frac{(s-1) g}{v^{2}}\right]^{1 / 3}
$$

where $s$ = specific density; $g=$ acceleration of gravity; and $v=$ kinematic viscosity coefficient (van Rijn et al., 1990).

Total sediment transport, $q_{t}$, is computed as:

$$
q_{t}=q_{s}+q_{b} \quad \text { with } \quad q_{s}=\int_{a}^{h} u c d z
$$

where $q_{s}=$ suspended-sediment transport. The bed-load transport rate, $q_{b}$, is represented by Van Rijn $(1984,1989)$ :

$$
q_{b}=0.053[(s-1) g]^{0.5} D_{50}^{1.5} T^{2.1} D_{*}^{0.3}
$$

\section{$\underline{\text { TABS-2 }}$}

The TABS-2 program is a group of finite-element based on two-dimensional, depth-averaged, hydrodynamic and sediment transport computer codes developed by the USACE Waterways Experimental Station (Thomas and McAnally, 1985) that currently operates by using the SMS v9.0 windows interface. These codes are applicable to rivers, reservoirs, and estuaries. The main components of TAB-2 are the hydrodynamic component, RMA2; the sediment transport component, SED2D (formally STUDH); and the water quality component, RMA4 (Papanicolaou et al., 2008). It computes water surface elevation and horizontal velocity components for subcritical, free-surface flow in two-dimensional flow fields. It also computes a finite element solution of the 
Reynolds form of the Navier-Stokes equations for turbulent flows. Friction can be calculated according to the Manning or the Chézy equation, and eddy viscosity coefficients are used to define turbulence characteristics (Brigham Young University, 2000).

\section{MOBED2}

MOBED2 is a finite-difference hydrodynamic and sediment transport model used in a curvilinear coordinate system, which implies transformation of the governing equations in the real coordinates $X-Y$ of the physical plane into the computational $\xi-\eta$ plane. The software is developed by Spasojevic and Holly (1990) and can simulate water flow, sediment transport, and bed evolution in natural waterways such as reservoirs, estuaries, and coastal environments where depth averaging is appropriate (Papanicolaou et al., 2008). The MOBED2 code comprises a numerical procedure for simulation of two-dimensional (plan view) unsteady interaction of hydrodynamics and sediment movement. The basic governing equations for the flow are the momentum equations (Equations [2.6] and [2.7]) and the continuity equation (Equation [2.5]). The basic sediment equations are the mass conservation equations for the channel bed (Equations [W.9] and [W.10]) and the two-dimensional advection-diffusion equation for suspended-sediment transport (Equation [W.11]). These equations are for any number of distinct sediment size classes.

$$
\rho_{s}\left(1-p_{b}\right) \frac{\partial\left(\beta_{k s} h_{a}\right)}{\partial t}+\frac{\partial q_{b x k s}}{\partial x}+\frac{\partial q_{b y k s}}{\partial y}+E_{k s}-D_{k s}-F_{k s}=0
$$




$$
\rho_{s}\left(1-p_{b}\right) \frac{\partial z_{b}}{\partial t}+\sum_{k s=1}^{K S}\left(\frac{\partial q_{b x k s}}{\partial x}+\frac{\partial q_{b y k s}}{\partial y}+E_{k s}-D_{k s}\right)=0
$$

where $\rho_{s}=$ density of sediment

$p_{b}=$ porosity of the bed material

$\beta_{k s}=$ active-layer fraction of the size class $k s$

$h_{a}=$ active-layer thickness

$q_{b k s}=$ bed-load flux for the size class $k s$

$E_{k s}=$ upward sediment entrainment flux for the size class $k s$

$D_{k s}=$ downward sediment deposition flux for the

$F_{k s}=$ active-layer floor source

$z_{b}=$ bed-surface elevation and is the bed-subsurface control volume ceiling

$$
\begin{aligned}
\frac{\partial\left(h \tilde{c}_{k s}\right)}{\partial t} & +\frac{\partial}{\partial x}\left(\tilde{u} h \tilde{c}_{k s}\right)+\frac{\partial}{\partial y}\left(\tilde{v} h \tilde{c}_{k s}\right) \\
= & \frac{\partial}{\partial x}\left(\widetilde{\varepsilon}_{s} h \frac{\partial \tilde{c}_{k s}}{\partial x}\right)+\frac{\partial}{\partial y}\left(\widetilde{\varepsilon}_{s} h \frac{\partial \widetilde{c}_{k s}}{\partial y}\right)+E_{k s}-D_{k s}
\end{aligned}
$$

where $\tilde{c}_{k s}=$ depth-averaged dimensional (volumetric) concentration of the size class $k s$ particles

$\widetilde{\varepsilon}_{s}=$ horizontal plane mass-diffusivity coefficient, usually only including the eddy diffusivity and neglecting the dispersion due to depth averaging

$\tilde{u}, \tilde{v}=$ depth-averaged water velocity components

The tensor forms of the governing water and sediment equations in an orthogonal curvilinear system are used, permitting ready representation of the boundaries of natural watercourses. The entire code and associated numerical techniques are structured to avoid use of any particular empirical relation until very late in the derivations. Therefore, the overall structure of the computation is independent of particular empirical expressions used to evaluate auxiliary 
relations, and thus they can be exchanged rather easily. The hydrodynamic (depth-averaged Reynolds) equations are solved numerically using a splitoperator procedure. The resulting system of linear algebraic equations is solved by the alternative direction implicit method. The sediment equations, including bed load for each size class and bed evolution, are solved simultaneously for each computational point using the Newton-Raphson method. Sediment mixtures are represented through a suitable number of discrete size classes. The global set of sediment equations for all size classes, taken as a whole and solved simultaneously, are described the behavior of a mixture, including natural phenomena such as differential settling, armoring, and hydraulic sorting. Additionally, sediment particles can move either in suspension or as bed load, depending on local flow conditions. Bed-load and suspended-sediment transport, as well as mechanisms defining exchange between the two, are incorporated into the code (Garcia, 2008).

\section{FAST2D}

FAST2D is a finite-volume hydrodynamic and sediment model with boundaryfitted grids in a curvilinear coordinate system to simulate sediment transport and morphodynamic problems in alluvial channels (Papanicolaou et al., 2008). In this model, the flow field is calculated by solving the Reynolds-averaged NavierStokes equations with $k-\varepsilon$ turbulence model. The bed-load transport is simulated with a non-equilibrium model, for which the concept based on the stochastic bedload description of Einstein is applied. By this concept, the rate of sediment 
exchange between bed and flow is assumed proportional to the difference between the actual instantaneous sediment load and the equilibrium sediment load. This is related to the non-equilibrium adaptation length which characterizes the distance for sediment to adjust from a non-equilibrium state to an equilibrium state (Minh Duc et al., 1998).

\section{MIKE 21}

MIKE21 is a finite-difference model developed by the Danish Hydraulic Institute for simulating transport and fate of dissolved and suspended loads discharged or accidentally spilled in lakes, estuaries, coastal areas, or in the open sea. The system consists of four main model groups (modules): the hydrodynamic and wave models, the sediment process model, and the environmental hydrodynamic model groups. The hydrodynamic and wave models are relevant to the types of physical processes considered in flood-plain mapping. The sediment process models are used to simulate shoreline change and sand transport, whereas the environmental hydrodynamic models are used to examine water quality issues (Papanicolaou et al., 2008; DHI, 2007, 2007a).

The general version of the MIKE 21 is based on a rectilinear computational grid. In river application, however, an accurate resolution of the boundaries is required which necessitates for the use of unstructured or curvilinear grids. The unstructured grid in MIKE21 program is based on an orthogonal curvilinear grid and is created with a graphical based grid generator, which solves a set of elliptic 
partial differential equations. The advantage of using an orthogonal grid is that the finite difference equations describing the two-dimensional flow become substantially simpler than if a general non-orthogonal curvilinear grid was applied. The numerical scheme becomes more accurate with an orthogonal grid and that the computational speed of the engine improves (DHI 2004, 2007, 2007a).

The hydrodynamic model solves the full dynamic and vertically integrated equations of continuity and conservation of momentum, the Saint Venant equations, in two directions. The following effects can be included in the equations when used for river application:

- flow acceleration

- convective and cross-momentum

- pressure gradients (i.e. water surface slopes)

- bed shear stress

- momentum dispersion through the Smagorinsky formulation

- flow curvature and helical flow

The sediment transport models developed by Engelund and Fredsoe (1976) and van Rijn (1984) which distinguish between bed and suspended load form the basis for the sediment transport description. However, the specification of the sediment transport formulas is very flexible. Specially developed sediment transport formulas (i.e. instance field measurements) can be specified separately for bed load and suspended load respectively. With this flexible sediment transport formulation, it is also possible to select formulas like Engelund-Hansen, Smart-Jaeggi, and Meyer-Peter. If the suspended sediment transport is negligible 
compared to the bed load transport, the suspended sediment model can be switched off (DHI 2004, 2007, 2007a).

\section{GSTARS 2.1}

GSTARS program is a series of Generalized Stream Tube computer models for Alluvial River Simulation developed by the U.S. Bureau of Reclamation for steady and quasi-steady flows. It was developed by Molinas and Yang (1985) for mainframe computers to simulate the flow conditions in a semi-two-dimensional manner and the change of channel geometry in a semi-three-dimensional manner based on the stream tube concept. The program consists of four major parts. The first part is the use of both the energy and the momentum equations for the backwater computations. This feature allows the program to compute the water surface profiles through combinations of subcritical and supercritical flows. It also can handle irregular cross sections regardless of whether single channel or multiple channels separated by small islands or sand bars. The second part is the use of the stream tube concept which is used in the sediment routing computations. Hydraulic parameters and sediment routing are computed for each stream tube in order to provide a transversal variation in the cross section in a semi-two-dimensional manner. Although no sediment or flow can be transported across the boundary of a stream tube, the position and width of a stream tube can change after each time step of computation. The scour and deposition computed in each stream tube give the variation of channel geometry in the vertical or lateral direction. The water surface profiles are computed first. The 
channel is then divided into a selected number of stream tubes with the following characteristics: 1) the total discharge carried by the channel is distributed equally among the stream tubes; 2) stream tubes are bounded by channel boundaries and by imaginary vertical walls; 3 ) the discharge along a stream tube is constant; and 4) there is no exchange of water or sediments through stream tube boundaries (Yang and Simões, 2000).

Bed sorting and armoring in each stream tube follows the method proposed by Bennett and Nordin (1977) and the rate of sediment transport can be computed using any of the following methods:

- DuBoys' 1879 method

- Meyer-Peter and Müller's 1948 method

- Laursen's 1958 method

- Toffaleti's 1969 method

- Engelund and Hansen's 1972 method

- Ackers and White's 1973 method

- Revised Ackers and White's 1990 method

- Yang's 1973, 1979 sand and 1984 gravel transport methods

- Parker's 1990 method

- Yang's 1996 modified formula

- Krone's 1962 and Ariathurai and Krone's 1976 methods for cohesive sediment transport

The third part is the use of the theory of minimum energy dissipation rate in its simplified version of minimum total stream power to compute channel width and depth adjustments. The use of this theory allows the channel width to be treated as an unknown variable. Whether a channel width or depth is adjusted 
at a given cross section and at a given time step depends on which condition results in less total stream power. The fourth part is the inclusion of a channel bank side stability criteria based on the angle of repose of bank materials and sediment continuity (Yang and Simões, 2000).

GSTARS 2.1 program does have the following limitations from a theoretical point of view (Yang and Simões, 2000):

- GSTARS 2.1 is a quasi-steady flow model. Water discharge hydrographs are approximated by bursts of constant discharges. Thus, is should not be applied to rapid, varied, unsteady flow conditions.

- GSTARS 2.1 is a semi-two-dimensional model for flow simulation and a semi-three-dimensional model for simulation of channel geometry change. It should not be applied to situations where a truly two-dimensional or truly three-dimensional model is needed for detailed simulation of local conditions.

- GSTARS 2.1 is based on the stream tube concept. The phenomena of secondary current, diffusion, and super elevation are ignored.

- Many of the methods and concepts used in GSTARS 2.1 are simplified approximations of real phenomena. Those approximations and their limits of validity are embedded in the model. 


\section{Delft 2D}

Delft 2D program is a finite-difference hydrodynamic and sediment transport model simulating waves and currents (Walstra et al., 1998). The model couples the hydrodynamics with computed bottom morphological changes in a timedependent way. The model can simulate bed load and suspended load transport by using either a local equilibrium or a non-equilibrium (i.e. the lag effects between flow and sediment) approach. The model can also show the effects of wave motion on transport magnitude and direction (Papanicolaou et al., 2008). 


\section{REFERENCES}

Ackers, P. And Charlton, F.G. 1970. "Meander Geometry Arising from Varying Flows." Journal of Hydrology, 11: 230-252.

Ackers, P. And White, W.R. 1973. "Sediment Transport: A New Approach and Analysis." Journal of Hydraulics Division, ASCE, 99(11): 2041-2060.

Akcelik, V., Jaramaz, B. And Ghattas, O. 2001. "Nearly Orthogonal TwoDimensional Grid Generation with Aspect Ratio Control." Journal of Computational Physics, 171: 805-821.

Alberta Transportation. 2009. Fish Habitat Manual. Alberta Transportation, Aquatic Resources, AL, Canada.

Andrews, E.D. 1980. "Effective and Bankfull Discharges of Streams in the Yampa River Basin, Colorado and Wyoming." Journal of Hydrology, 46: 311-330.

Arcement, G.J. and Schneider, V.R. 1984. Guide for Selecting Manning's $n$ Roughness Coefficient for Natural Channels and Flood Plains. United States Federal Highway Administration Publication Number: TS-84-204

Arminini, A. and di Dilvio, G. 1988. "A One-Dimensional Model for the Transport of a Sediment Mixture in Non-Equilibrium Conditions." Journal of Hydraulic Research, 26(3).

Atkins, J.B. and Pearman, J.L. 1994. Low-Flow and Flow-Duration Characteristics of Alabama Streams. USGS Water-Resources Investigations Report 93-4186. USGS.

BSI Group. 1990. Methods of Test for Soils for Civil Engineering Purposes Classification Tests. BS 1377-2:1990.

Bell, S.G. and Sutherland, A.J. 1983. "Non-Equilibrium Bed-Load Transport by Steady Flows." Journal of Hydraulic Engineering, 109(3): 353-367.

Biedenharn, D.S., Copeland, R.R., Thorne, C.R., Soar, P.J., Hey, R.D. and Watson, C.C. 2000. Effective Discharge Calculation: A Practical Guide. USACE, Engineer Research and Development Center, Coastal and Hydrualics Laborator, Technical Report \#: ERDC/CHL TR-00-15, USACE, Vicksburg, MS, USA.

Biron, P.M., Robson, C., Lapointe, M.F. and Gaskin, S.J. 2005. "ThreeDimensional Flow Dynamics Around Deflectors." River Research and Applications, 21: 961-975. 
Biron, P.M., Robson, C., Lapointe, M.F. and Gaskin, S.J. 2004. "Deflector Designs for Fish Habitat Restoration." Environmental Management, 33(1): 25-35.

Blench, T. 1952. "Regime Theory for Self-Formed Sediment Bearing Channels." Transactions of the American Society of Civil Engineers, 117: 383-400.

Bockelmann, B.N., Fenrich, E.K., Lin, B. And Falconer, R.A. 2004. "Development of an Ecohydraulics Model for Stream and River Restoration." Ecological Engineering, 22: 227-235.

Bray, D.I. 1975. "Representative Discharges for Gravel-Bed Rivers in Alberta, Canada." Journal of Hydrology, 27: 143-153.

Brett, J.R. and Glass, N.R. 1973. "Metabolic Rates and Critical Swimming Speeds of Sockeye Salmon (Oncorhynchus Nerka) in Relation to Size and Temperature." Journal of Fisheries Research Board of Canada, 30: 379387.

Brice, J.C. and Blodgett, J.C. 1978. Countermeasures for Hydraulic Problems at Bridges. Vol. 1 and 2, FHWA/RD-78-162\&163. U.S. FHWA, U.S. DoT, Washington, D.C., U.S.A.

Brigham Young University. 2000. Surface Water Modeling System (SMS) 7.0 User's Manual. Open-Channel Flow and Sedimentation. Environmental Modelling Research Laboratory, Brigham Young University.

Brookes, A. 1987. "Restoring the Sinuosity of Artificially Straightened Stream Channels." Environmental Geology Water Science, 10(1): 33-41.

Brown, S.A. 1985. Design of Spur-Type Streambank Stabilization Structures. Report \#: FHWA/RD-84/101. U.S. FHWA, Office of Engineering \& Highway Operations R\&D Structures Division, VA, U.S.A.

Burns, R. 2002. Manual of River Restoration Techniques. Retrieved June 10, 2007, from River Restoration Centre.

<http://www.therrc.co.uk/manual.php>

Butler, P.J. and Day, N. 1993. "The Relationship Between Intracellular pH and Swimming Performance of Brown Trout Exposed to Neutral and Sublethal pH." The Journal of Experimental Biology, 176: 271-284.

Chang, F. M., Simons, D. B. and Richardson, E. V. 1967. "Total Bed-Material Discharge in Alluvial Channels." Proceedings of the 12th Congress of the IAHR, Fort Collins, Colorado, U.S.A.

Chang, F.F.M. 1973. A Statistical Summary of the Cause and Cost of Bridge Failures. U.S. FHWA, U.S. DoT, Washington, D.C., U.S.A. 
Chow, V. T. 1959. Open channel hydraulics. McGraw-Hill, New York. USA.

Copeland, R.R. and McComas, D.N. 2001. Hydraulic Design of Stream Restoration Projects. Report \#: ERDC/CHL TR-01-28. U.S. Army Corps of Engineers, Washington D.C., U.S.A.

Copeland, R.R. 1983. Bank Protection Techniques Using Spur Dikes. USACE, Engineer Waterways Experiment Station Hydraulics Laboratory, HL-83-1, Vicksburg, MI, USA.

Davis, S.R. 1984. Case Histories of Scour Problems at Bridges. Transportation Research Record 950, Second Bridge Engineering Conference, Vol. 2, Transportation Research Board, Washington, D.C., U.S.A.

DFO. 1995. Freshwater Intake End-of-Pipe Fish Screen Guideline. Catalogue No. Fs 23-270. DFO, Communications Directorate, Ottawa, ON, Canada.

Danish Hydraulic Institute (DHI). 2007. MIKE 21 \& MIKE 3 Flow Model FM Transport Module Short Description. Danish Hydraulic Institute, Hørsholm, Denmark.

Danish Hydraulic Institute (DHI). 2007a. MIKE 21 \& MIKE 3 Flow Model FM Sand Transport Module Short Description. Danish Hydraulic Institute, Hørsholm, Denmark.

Danish Hydraulic Institute (DHI). 2004. MIKE 21C River Morphology: A Short Description. Danish Hydraulic Institute, Hørsholm, Denmark.

Doll, B.A., Grabow, G.L., Hall, K.R., Halley, J., Harman, W.A., Jennings, G.D. and Wise, D.E. 2003. Stream Restoration: A Natural Channel Design Handbook. NC Stream Restoration Institute, NC State University, NC, USA.

Du Boys, M.P. 1879. "Etudes du regime du Rhone et de l'action exercee par les eaux sur un lit a fond de graviers indefiniment affouillable." Annales des Ponts et Chaussees: 5 (18), 141- 195.

Duan, J.G. 2009. "Mean Flow and Turbulence around a Laboratory Spur Dike." Journal of Hydraulic Engineering, 135(10):803-811.

Duan, J.G., and Nanda, S.K. 2006. "Two-Dimensional Depth-Averaged Model Simulation of Suspended Sediment Concentration Distribution in a Groyne Field." Journal of Hydrology, 327(3-4): 426-437. 
Duan, J.G., Wang, S.S., and Jia, Y. 2001. "The Applications of the Enhanced CCHE2D Model to Study the Alluvial Channel Migration Process." Journal of Hydraulic Research, 39(5): 469-480.

Dunne, T. And Leopold, L.B. 1978. Water in Environmental Planning. W.H. Freeman Co., San Francisco, CA, USA.

Dury, G.H. 1973. "Magnitude-Frequency Analysis and Channel Morphology." In Fluvial Geomorphology, ed. Morisaua, M.: 91-121. Allen \& Unwin.

Einstein, H.A. 1950. The Bed Load Function for Sediment Transportation in Open Channel Flows." Technical Bulletin No. 1026, Soil Conservation Service, United States Department of Agriculture, Washington D.C., U.S.A.

Engelund, F. And Hansen, E. 1967. A Monograph on Sediment Transport in Alluvial Streams. Danish Technical Press.: Teknisk Vorlag, Copenhagen, Denmark.

Fang, H.W. 2000. Three-Dimensional Calculations of Flow and Bed-Load Transport in the Elbe River. Report NO. 763, Institute for Hydromechanics, University of Karlsruhe, Germany.

Federal Interagency Stream Restoration Working Group (FISRWG). 1998. Stream Corridor Restoration: Principles, Processes, and Practices. USDA, Natural Resources Conservation Service, Part 653 of National Engineering Handbook.

Fennessey, N.M., and R.M. Vogel. 1990. "Regional Flow Duration Curves for Ungaged Sites in Massachusetts." Journal of Water Resources Planning and Management, ASCE 116 (4): 530-549.

Froehlich, D.C. 1996. "Contraction Scour at Bridges: Analytic Model for CoarseBed Channels." Proceedings of the North American Water and Environment Congress, ASCE, Anaheim, CA, USA.

Froehlich, D.C. 1989. "Local Scour at Bridge Abutments." Proceedings of the National Conference on Hydraulic Engineering, New Orleans, LA, ASCE, pp.13-18.

Garbrecht, J., Kuhnle, R. And Alonso, C. 1995. "A Sediment Transport Capacity Formulation for Application to Large Channel Networks." Journal of Soil and Water Conservation, 50(5): 527-529.

Garcia, M.H. 2008. Sedimentation Engineering, American Society of Civil Engineers Manuals and Reports on Engineering Practice No. 110, Reston, Virginia, U.S.A. 
Garde, R.J., Subramanya, K., and Nambudripad, K.D. 1961. "Study of Scour Around Spur-Dikes." Journal of the Hydraulics Division, 86(HY6): 23-37.

Gee, D.M. 1995. HEC-6: Reservoir Sediment Control Applications. Technical Paper TP-148. US Army Corps of Engineers, Institute for Water Resources, Hydrologic Engineering Centre (HEC): Davis, CA, USA.

Hammer, C. 1995. "Fatigue and Exercise Tests with Fish." Comparative Biochemistry and Physiology_Part A: Molecular \& Integrative Physiology, 122: 1-20.

Harrington, G.D. 2003. Urban Stream Restoration Projects. Retrieved on August 20, 2007. <http://www.harrington-hoyle.com/urbanstream.htm>

Henderson, F.M. 1966. Open Channel Flow. MacMillan Company, New York, U.S.A.

Hey, R.D. and Thorne, C.R. 1975. "Secondary Flows in River Channels." Area: 7(3): 191-195.

Hong Kong Department of Justice (HK DOJ). 1997. Technical Memorandum Standards for Effluents Discharged into Drainage and Sewerage Systems, Inland and Coastal Waters. Hong Kong Legislation: Water Pollution Control Ordinance, Cap 358 section 21. Retrieved Feb 28, 2011 from <http://www.legislation.gov.hk/blis_ind.nsf/da97f6a8ed4002074825648200 06b580/37d3065d5d23c8d78825648a005d23b2?OpenDocument>

Hong Kong Drainage Services Department (HK DSD). 2006. Flow Monitoring Report. Contract No. LD 39/2006/1.

Hong Kong Observatory. 2007. Rainstorm Warning System. The Government of the Hong Kong Special Administrative Region, Hong Kong. Retrieved June 15, 2009 from

<http://www.hko.gov.hk/wservice/warning/rainstor.htm>

Horton, R.E. 1945. "Erosional Development of Streams and their Drainage Basins: Hydrophysical Approach to Quantitative Morphology." Geological Society of American Bulletin, 56: 275-370.

Hughes, S.A. 1993. Physical Models and Laboratory Techniques in Coastal Engineering. Advanced Series on Ocean Engineering, Vol. 7, World Scientific Publishing Co., River Edge, NJ, U.S.A.

Hutchison, N.E. 1975. WATSTORE User's Guide: National Water Data Storage and Retrieval System. USGS Open-File Report 75-426. USGS. 
Inglis, C.C. 1949. The Behavior and Control of Rivers and Canals. U.S. Army Corps of Engineers, Waterways Experiment Station, Vicksburg, Mississippi, U.S.A.

Jia, Y., and Wang, S.S. 1999. "Numerical Model for Channel Flow and Morphological Change Studies." Journal of Hydraulic Engineering, 125(9): 924-933.

Kalinske, A.A. 1947. "Movement of Sediment as Bed Load in Rivers." Transactions - American Geophysical Union, 28(4): 615-620.

Katopodis, C. 1992. Introduction to Fishway Design. Ch 6. Freshwater Institute. Winnipeg, Manitoba, Canada.

Kerssens, P.J.M., Prins, A., and van Rjin, L.C. 1979. "Model for Suspended Sediment Transport." Journal of Hydraulic Division, ASCE, 5: 461-476.

Kieffer, J.D. 2000. "Limits to Exhaustive Exercise in Fish." Comparative Biochemistry and Physiology_Part A: Molecular \& Integrative Physiology, 126: $161-179$.

Knighton, D. 1984. Fluvial Forms and Process. Edward Arnold, London, UK.

Kuhnle, R.A., Alonso, C.V. and Shields Jr., F.D. 2002. "Local Scour Associated with Angled Spur Dikes." Journal of Hydraulic Engineering ASCE, 128:1087-1093.

Kuhnle, R.A., Alonso, C.V. and Shields Jr., F.D. 1999. "Geometry of Scour Holes Associated with 90 Degrees Spur Dikes. Journal of Hydraulic Engineering ASCE, 125: 972-978.

Kolok, A.S. 1991. "Photoperiod Alters the Critical Swimming Speed of Juvenile Largemouth Bass, Micropterus Salmoides, Acclimated to Cold Water." Copeia, 4: 1085-1090.

Kothyari, U. C. and Ranga Raju, K. G. 2001. "Scour Around Spur Dikes and Bridge Abutments." Journal of Hydraulic Research 39: 367-374.

Laursen, E.M. 1980. Predicting Scour at Bridge Piers and Abutments. General Report No. 3, Arizona Department of Transportation, Phoenix, AZ, USA.

Leopard, L.B. 1994. A View of the River. Harvard University Press, Cambridge, MA, USA.

Liu, H.K., Chang, F.M., and Skinner, M.M. 1961. Effect of Bridge Constriction on Scour and Backwater. Department of Civil Engineering, Colorado State University, Fort Collins, CO, USA. 
Lumb, A.M., Kittle, J.L. and Flynn, K.M. 1990. Users Manual for ANNIE: A Computer Program for Interactive Hydrologic Analyses and Data Management. USGS Water Resources Investigations Report 89-4080. USGS, Reston, VA, USA.

Madej, M.A. 1982. Sediment Transport and Channel Changes in an Aggrading Stream in the Puget Lowland, Washington. U.S. Forest Service General Technical Report PNW-141. U.S. Department of Agriculture, Forest Service.

McKenzie, D.J., Martínez, R., Morales, A., Acosta, J., Morales, R., Taylor, E.W., Steffensen, J.F. and Estrada, M.P. 2003. "Effects of Growth Hormone Transgenesis on Metabolic Rate, Exercise Performance and Hypoxia Tolerance in Tilapia Hybrids." Journal of Fish Biology, 63: 398-409.

Melville, B.W. 1992, "Local Scour at Bridge Abutments." Journal of Hydraulic Engineering, American Society of Civil Engineers, Hydraulic Division, 118(4).

Meyer-Peter, E., Favre, H. and Einstein, A. 1934. "Neuere Versuchsresultate uber den Geschiebetrieb." Schweiz Bauzeitung, 103(13).

Meyer-Peter, E. and Mueller, R. 1948. "Formulas for Bed-Load Transport." Proceedings 3rd Conference IAHR, Stockholm, Sweden, 39-64.

Minh Duc, B., Wenka, T. and Rodi, W. 1998. "Depth-average numerical modeling of flow and sediment transport in the Elbe River." Proceedings of 3rd International Conference on Hydroscience and Engineering, Brandenburg University of Technology, Cottbus, Germany.

Montgomery, D.R. and Buffington, J.M. 1993. Channel Classification, Prediction of Channel Response and Assessment of Channel Condition. Report TFW-SH10-93-002. Department of Geological Sciences and Quaternary Research Center, University of Washington, Seattle, USA.

Müller, U.K., Stamhuis, E.J. and Videler, J.J. 2000. "Hydrodynamics of Unsteady Fish Swimming and the Effects of Body Size: Comparing the Flow Fields of Fish Larvae and Adults." The Journal of Experimental Biology, 203: 193-206.

Ness, R. and Joy, D.M. 2002. "Performance of Natural Channel Designs in Southwestern Ontario." Canadian Water Resources Journal, 27(3); 293315.

Newbury, R.W. and Gaboury, M.N. 1993. Stream Analysis and Fish Habitat Design: A Field Manual. 
Nixon, M. 1959. "A Study of Bankfull Discharges of Rivers in England and Wales." Proceedings of the Institution of Civil Engineers, 12: 157-175.

Onishi, Y. and Wise, S.E. 1982. User's Manual for the Instream SedimentContaminant Transport Model SERATRA. EPA 600/3-82-055. Pacific Northwest Laboratory, Battelle-Northwest, Richland, Washington, USA, 99532.

Onishi, Y. and Wise, S.E. 1982a. Mathematical Model, SERATRA, for SedimentContaminant Transport in Rivers and its Application to Pesticide Transport in Four Mile and Wolf Creeks in lowa. EPA 600/3-82-045. Pacific Northwest Laboratory, Battelle-Northwest, Richland, Washington, USA, 99532.

Ontario Ministry of Transportation (MTO). 2006. Environmental Guide for Fish and Fish Habitat. MTO, Provincial and Environmental Planning Office, St. Catharines, Ontario, Canada.

Ontario Ministry of Transportation (MTO). 1997. Drainage Management Manual Part 3, Drainage and Hydrology Section, Transportation Engineering Branch, Quality and Standards Division. Ministry of Transportation, Toronto, Ontario, Canada.

Papanicolaou, A.N., Elhakeem, M., Krallis, G., Prakash, S., and Edinger, J. 2008. "Sediment Transport Modeling Review-Current and Future Developments." Journal of Hydraulic Engineering, 134(1): 1-14.

Phillips, B.C. and Sutherland, A.J. 1989. "Spatial Lag Effects in Bed-Load Sediment Transport." Journal of Hydraulic Research, IAHR, 27(1): 115133.

Pickup, G. And Warner, R.F. 1976. "Effects of Hydrologic Regime on the Magnitude and Frequency of Dominant Discharge." Journal of Hydrology, 29: 51-75.

Ponce, V.M. 1989. Engineering Hydrology: Principles and Practices. PrenticeHall, Englewood Cliffs, New Jersey, USA.

Prof. Dudgeon, D. (January 27, 2008). Reply email to Celia Fan. Subject: Questions about Yuen Long Nullah.

Prof. Wai, O. 2008. Personal Interview from Prof. Wai.

Proffit, G.T. and Sutherland, A.J. 1983. "Transport of Nonuniform Sediment." Journal of Hydraulic Research, 21(1): 33-43. 
Rahuel, J.L., Holly, F.M., Chollet, J.P., Belleudy, P.J. and Yang, G. 1989. "Modelling of Riverbed Evolution for Bedload Sediment Mixtures." Journal of Hydraulic Engineering, ASCE, 115(11): 1521-1542.

Randall, D. and Brauner, C. 1991. "Effects of Environmental Factors on Exercise in Fish." The Journal of Experimental Biology, 160: 113-126.

Reidy, S.P., Kerr, S.R. and Nelson, J.A. 2000. "Aerobic and Anaerobic Swimming Performance of Individual Atlantic Cod." The Journal of Experimental Biology, 203: 347-357.

Richards, K.S. 1982. Rivers: Form and Process in Alluvial Channels. Methuen, London, UK.

Richardson, E.V. and Davis, S.R. 2001. Evaluating Scour at Bridges (4 ${ }^{\text {th }}$ Edition). US FHWA Publication \#: FHWA NHI 01-001, Hydraulic Engineering Circular No. 18. National Highway Institute, VA, USA.

Richardson, E.V. and Richardson, J.R. 1992. "Discussion of Melville, B.W. (1992), Local Scour at Bridge Abutments." ASCE, Journal of Hydraulics Division, September.

Rosgen, D.L. 2006. Cross-vane, W-weir, and J-hook Vane Structures (updated 2006): Description, Design and Application for Stream Stabilization and River Restoration, Wildland Hydrology Inc., CO, USA.

Rosgen, D.L. 2006a. "River Restoration Using a Geomorphic Approach for Natural Channel Design." Proceedings of the $8^{\text {th }}$ Federal Interagency Sedimentation Conference ( $8^{\text {th }}$ FISC), April 2-6, Reno, NV, U.S.A.

Rosgen, D.L. 2001. "The Cross-Vane, W-Weir and J-Hook Vane Structures...Their Description, Design and Application for Stream Stabilization and River Restoration." ASCE Conference, Reno, NV.

Rosgen, D.L. 1998. "The Reference Reach-A Blueprint for Natural Channel Design." Proceedings of the Wetlands and Restoration Conference, ASCE, March 1998, Denver, CO, USA.

Rosgen, D.L. 1996. Applied River Morphology. Pagosa Springs, Colorado: Wildland Hydrology Books.

Rosgen, D.L. 1994. "A Classification of Natural Rivers.” Catena, 22:169-199.

Rottner, J. 1959. "A Formula for Bed Load Transportation." La Houille Blanche, 14 (3): 285-307.

Ryskin, G. and Leal, L.G. 1983. "Orthogonal Mapping." Journal of Computational Physics, 50: 71-100. 
Schoklitsch, A. 1934. "Geschiebetrieb und die Geschiebefracht." Wasser Kraft and Wasser Wirtschaft. Jgg. 39, Heft 4.

Shiono, K., Spooner, J., Chan, T., Rameshwaran, P. and Chandler, J. 2008. "Flow Characteristics in Meandering Channels with Non-Mobile and Mobile Beds for Overbank Flow." Journal of Hydraulic Research, 46(1): 113-132.

Schumm, S.A. 1960. The Shape of Alluvial Channels in Relation to Sediment Type. USGS Professional Paper 352-B. USGS.

Schumm, S.A. 1977. The Fluvial System. John Wiley and Sons, New York, USA.

Schumm, S.A., Harvey, M.D. and Watson, C.C. 1984. Incised Channels: Morphology, Dynamics and Control. Water Resources Publications, Littleton, CO, USA.

Searcy, J.K. 1959. Manual of Hydrology (Part 2): Low-Flow Techniques. USGS Supply Paper W 1542-A.

Seoul Metropolitian Facilities Management Corporation (SMFM). 2009. Official Website of Cheonggyecheon. Retrieved on September 15, 2009.

< http://english.sisul.or.kr/grobal/cheonggye/eng/WebContent/index.html>

Shields, I.A. 1936. "Application of Similarity Principles and Turbulence Research to Bed-Load Movement." A translation of "Anwendung der Ähnlichkeitsmechanik und Turbulenzforschung auf die Geschiebebewegung." Mitteilungen der Preussischen Versuchanstalt für Wasser und Schiffbau, Berlin, No. 26. by W.P. Ott and J.C. van Vchelin, U.S. Soil Conservation Service Cooperative Laboratory, California Institute of Technology, Pasadena, California, U.S.A.

Shin, J.H. 2004. "Dream and Hope of Korea, Cheonggyecheon Restoration." Magazine of Korean Water Resources Association, 37(1).

Simons, D.B. and Sentürk, F. 1976. Sediment Transport Technology. Water Resources Publications, USA.

Sloff, C. J., Jagers, H.R.A., Kitamura, Y. and Kitamura, P. 2001. 2D Morphodynamic Modelling with Graded Sediment. Proceedings on the $2^{\text {nd }}$ IAHR Symposium on River, Coastal and Estuarine Morphodynamics: Obihiro, Japan. Sept 10-14, 2001.

Smith, D.L. 2008. Reconnaissance Study of Fish Passage Impacts Resulting from Structures in the MRGO, IHNC and GIWV-Letter Report. Technical Report: ERDC/EL TR-08-X. USACE, New Orleans District, Hurricane Protection Office. 
Soar, P.J.; Thorne, C.R. 2001. Channel Restoration Design for Meandering Rivers. Report \#: ERDC/CHL CR-01-1, U.S. Army Corps of Engineers, Coastal \& Hydraulics Laboratory, Washington, D.C., U.S.A.

Spasojevic, M., and Holly, F. M. 1990. MOBED2: Numerical simulation of twodimensional mobile-bed processes. Technical Report No. 344, lowa Institute of Hydraulic Research, University of lowa, lowa City, lowa.

Strahler, A.N. 1957. "Quantitative Analysis of Watershed Geomorphology." Amercian Geophysical Union Transactions, 38:913-920.

Straub, L.G. 1935. Missouri River Report. Howe Document 238, U.S. Corps of Engineers, United States Department of the Army to 73rd United States Congress, 2nd Session.

Sturm, T.W. 1999. Abutment Scour Studies for Compound Channels. U.S. Department of Transportation, Federal Highway Administration, September.

Sutherland, B. R. Shallow Water Approximation. Retrieved June 10, 2009 from notes of personal webpage, Department of Earth and Atmospheric Sciences, University of Alberta, Edmonton, Canada. Website: <http://www.math.ualberta.ca/ bruce/glossary.html>

Telis, P.A. 1991. Low-Flow and Flow-Duration Characteristics of Mississippi Streams. USGS Water-Resources Investigations Report 90-4087.

Thomas, W. A, and McAnally, W.H. 1985. User's Manual for the Generalized Computer Program System Open-Channel Flow and SedimentationTABS-2. Instruction Rep. HL-85-1, Waterways Experiment Station, U.S. Army Corps of Engineers, Vicksburg, MI, USA.

Thompson, D.M. 2002. "Channel-bed Scour with High versus Low Deflectors." Journal of Hydraulic Engineering ASCE, 128: 1-4.

Thompson, D.M. 2002a. "Geometric Adjustment of Pools to Changes in Slope and Discharge: A Flume Experiment." Geomorphology, 46(3-4): 257-265.

Thompson, J.F., Warsi, Z.U.A., and Mastin, C.W. 1985. Numerical Grid Generation: Foundation and Application. North-Holland: New York.

Thuc, T. 1991. Two-Dimensional Morphological Computations near Hydraulic Structures. Doctoral Dissertation. Asian Institute of Technology, Bangkok, Thailand. 
USDA. 2001. Stream Corridor Restoration: Principles, Processes, and Practices. The Federal Interagency Stream Restoration Working Group. GOP Item No. 0120-A; SuDocs No. A 57.6/2:EN3/pt.653.

van Rijn, L.C. 1990. Principles of Fluid Flow and Surface Waves in Rivers, Estuaries, Seas and Oceans. Aqua Publications, Amsterdam, The Netherlands.

Van Rijn, L.C., van Rossum, H. and Termes, P. 1990. "Field Verification of 2-D and 3-D Suspended-Sediment Models". Journal of Hydraulic Engineering, ASCE, 116(10): 1270-1288.

van Rijn, L.C. 1989. Handbook of Sediment Transport by Currents and Waves. Delft Hydraulics, Delft, The Netherlands.

van Rijn, L.C. 1987. Mathematical Modelling of Morphological Processes in the Case of Suspended Sediment Transport. Delft Hydraulics Communication No. 382, Delft Hydraulics, Delft, The Netherlands.

van Rijn, L.C. 1986. "Mathematical Modelling of Suspended Sediment in NonUniform Flow." Journal of Hydraulic Engineering, ASCE, 112(6): 433-455.

van Rijn, L.C. and Tan, G.L. 1985. Sutrench Model: Two-Dimensional Vertical Mathematical Model for Sedimentation in Dredged Channels and Trenches by Currents and Waves. Rijskwaterstaat Communications, No. 41.

van Rijn, L.C. 1984. "Sediment Transport, Part I: Bed-Load Transport." Journal of Hydraulic Engineering, ASCE, 110(10): 1431-1456.

van Rijn, L.C. 1984a. "Sediment Transport. Part II: Suspended Load Transport." Journal of Hydraulic Engineering, ASCE, 110(11): 1613-1641.

van Rijn, L.C. 1984b. "Sediment Transport Part III: Bed Forms and Alluvial Roughness." Journal of Hydraulic Engineering, ASCE, 110(12): 17331754.

Vannote, R.L., Minshall, G.W., Cummins, K.W., Sedell, J.R. and Cushing, C.E. 1980. "The River Continuum Concept." Canadian Journal of Fisheries and Aquatic Sciences, 37(1): 130-137.20(7): 649-660.

Videler, J.J. 1993. Fish Swimming. Chapman \& Hall, London, UK.

Vogel, S. 1994. Life in Moving Fluids: The Physical Biology of Flow. 2nd Edition. Princeton University Press, Princeton, USA. 
Vogel, R.M. and Kroll, C.N. 1989. "Low-Flow Frequency Analysis Using Probability-Plot Correlation Coefficients." Journal of Water Resources Planning and Management, ASCE, 115(3): 338-357.

Walstra, D.J., van Rijn, L.C. and Aarninkhof, S.G. 1998. "Sand Transport at the Lower Shoreface of the Dutch Coast." Technical Rep. Z2378, Delft Institute of Hydraulics, The Netherlands.

Wang, Z.Y. 1999. "Experimental Study on Scour Rate and River Bed Inertia." Journal of Hydraulic Research, IAHR, 37(1): 17-37.

Webb, P.W. 1975. Hydrodynamics and Energetics of Fish Propulsion. Bulletin of the Fisheries Research Board of Canada, 190: 1-159.

Wellington, N.W. 1978. A Sediment-Routing Model for Alluvial Streams. M.Eng. Sci. Dissertation, University of Melbourne, Australia.

Wharton,G. 1995. "The Channel-Geometry Methods: Guidelines \& Applications." Earth Surface Processes and Landforms, 20(7):649-660.

Wilcox, D.C. 1998. Turbulence Modeling for CFD. Second edition. Anaheim: DCW Industries.

Williams, G.W. 1978. "Bankfull Discharge of Rivers." Water Resources Research, $14: 1141-1154$.

Wolman, M.G. 1955. The Natural Channel of Brandywine Creek, Pennsylvania. USGS Professional Paper \# 271.

Wolman, M.G. and Leopold, L.B. 1957. River Flood Plains: Some Observations on Their Formation. USGS Professional Paper \#282C.

Wolman, M.G. and Miller, J.P. 1960. "Magnitude and Frequency of Forces in Geomorphic Process." Journal of Geology, 68: 54-74.

Woodyer, K.D. 1968. "Bankfull Frequency in Rivers." Journal of Hydrology, 6: $114-142$.

Wu, W. 1991. The Study and Application of 1-D, Horizontal 2-D and Their Nesting Mathematical Models for Sediment Transport. Ph.D. Dissertation, Wuhan University of Hydraulic and Electric Engineering, China.

Wu, W., Shields, F. D., Bennett, S. J., and Wang, S. S. 2005. "A depth averaged 2-D model for flow, sediment transport and bed topography in curved channels with riparian vegetation." Water Resource Research: 41, 15. 
Wu, W., Rodi, W. and Wenka, T. 2000. "3D Numerical Modeling of Flow and Sediment Transport in Open Channels." Journal of Hydraulic Engineering, ASCE, 126(1): 4-15.

Wu, W. and Vieira, D.A. 2000a. One-Dimensional Channel Network Model CCHE1D 2.0 (Technical Manual). Technical Report \#. NCCHE-TR-2000-1, National Center for Computational Hydroscience and Engineering, The University of Mississippi.

Wu, W., Wang, S.S.Y. and Jia, Y. 2000b. "Nonuniform Sediment Transport in Alluvial Rivers." Journal of Hydraulic Research, IAHR, 38(6):427-434.

Wu, W. and Li, Y. 1992. "Óne- and Two-Dimensional Nesting Model for River Flow and Sedimentation." Processings of $5^{\text {th }}$ International Symposium on River Sedimentation, Karlsruhe, Germany.

Yang, C. T., and Simões, F. J. 2000. Users' Manual for GSTARS 2.1 (Generalized stream tube model for alluvial river simulation version 2.1), Technical Service Center, U.S. Bureau of Reclamation, Denver.

Yang, C.T. 1996. Sediment Transport: Theory and Practice. McGraw-Hill Companies, Inc. U.S.A.

Yang, C.T. 1984. "Unit Stream Power Equation for Gravel." Proc. Am.Soc.Civ.Engrs., J.Hydaul.Div.110(HY12):1783-1797.

Yang, C.T. and Song, C.S. 1979. "Theory of Minimum Rate of Energy Dissipation." Proc.Am.Soc.Civ.Engrs., J.Hydraul.Div., 105(HY7): 769-784.

Yang, C.T. 1971. "Potential Energy and Stream Morphology." Water Resources Research, 7(2): 311-322.

Zalants, M.G. 1991. Low-Flow Frequency and Flow Duration of Selected South Carolina Streams Through 1987. USGS Water-Resources Investigations Report 91-4170. USGS.

Zhang, R.J. and Xie, J.H. 1993. Sedimentation Research in China, Systematic Selections. China Water and Power Press, Beijing, China.

Zhang, Y. 2006. CCHE2D-GUI Graphical User Interface for the CCHE2D Model User's Manual (Version 2.2). The National Center for Computational Hydroscience and Engineering Technical Report: NCCHE-TR-2005-03, University of Mississippi, MS, USA.

Zhang, Y. and Jia, Y. 2009. CCHE-MESH: 2D Structured Mesh Generator User's Manual - Version 3.x. The National Center for Computational Hydroscience and Engineering Technical Report: NCCHE-TR-2009-01, University of Mississippi, MS, USA. 
Zhang, Y. and Jia, Y. 2009a. CCHE-MESH 2D Structured Mesh Generator Version 3.x Quick Start Guide. The National Center for Computational Hydroscience and Engineering Technical Report: NCCHE-TR-2009-02, University of Mississippi, MS, USA.

Zhang, Y., Jia, Y. and Wang, S.S.Y. 2006. "Structured Mesh Generation with Smoothness Controls". International Journal for Numerical Methods in Fluids, 51: 1255-1276.

Zhang, Y.X., Jia, Y.F. and Wang, S.S.Y. 2004. "2D Nearly Orthogonal Mesh Generation." International Journal for Numerical Methods in Fluids, 46: 685-707. 